\title{
derigh Lien!'
}

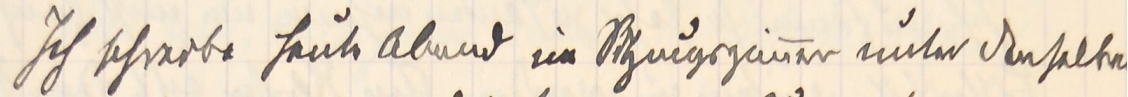

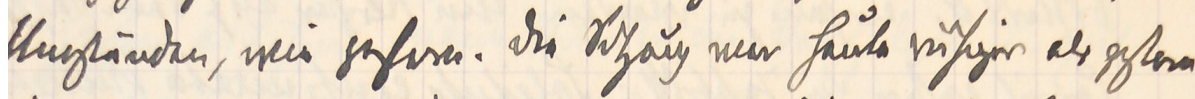

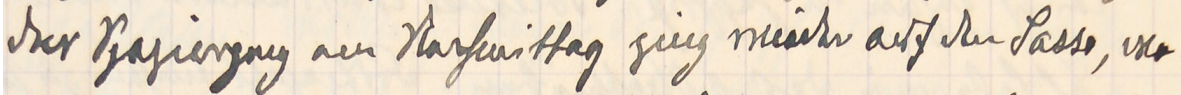

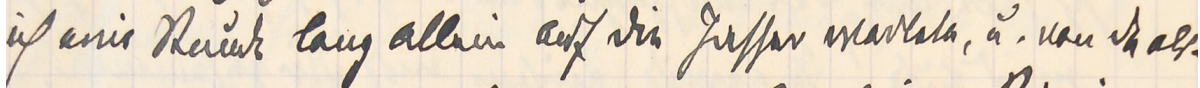

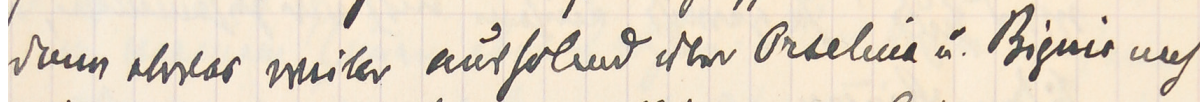

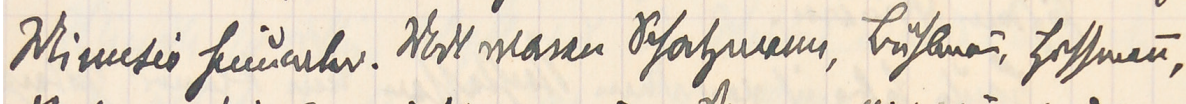

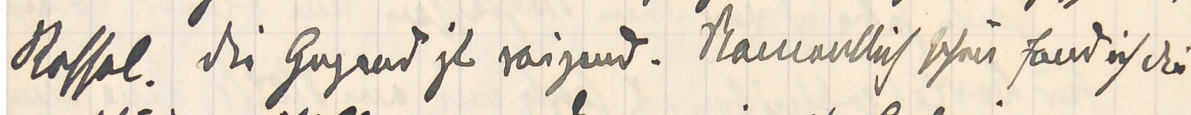

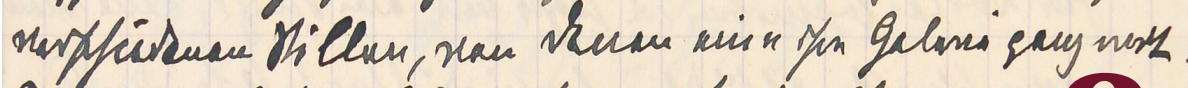

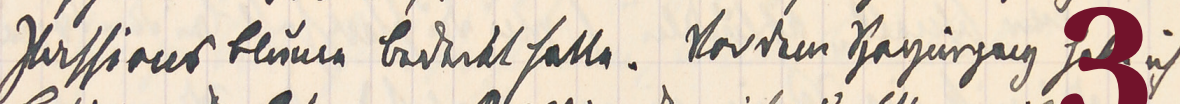

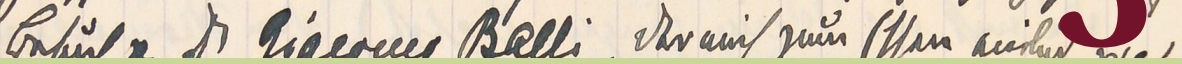

\section{Eugen Huber}

\section{Briefe an die tote Frau}

Band 3: 1912

Briefe 1-255

Herausgegeben von Sibylle Hofer unter Mitarbeit von Emanuel Schädler transkribiert von David Pfammatter 
Eugen Huber

Briefe an die tote Frau

Band 3: 1912 


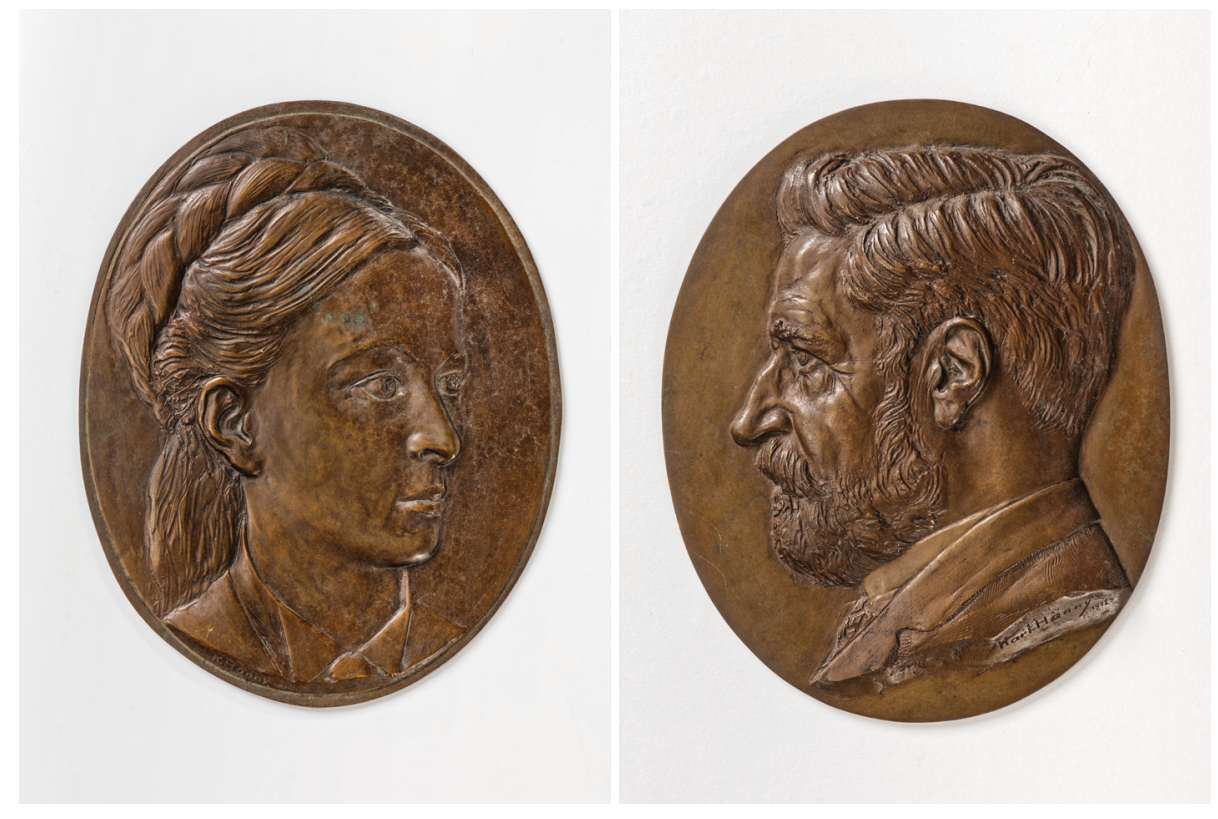

Bronceporträts von Lina und Eugen Huber:

Eugen Huber gab das Porträt von Lina im Jahre 1911 in Auftrag. Er schrieb dazu in den Briefen: «Nach dem Nachtessen kam Hänny [und] brachte das neue Medaillon mit Deinem lieben, so gut getroffenen Bilde.» Ein Jahr später liess Huber sein Porträt herstellen und schrieb dazu: «Am Morgen war Hänny eine halbe Stunde da u. begann mit dem Relief, das ein Seitenstück zu dem Deinigen werden soll, zur Erinnerung für unser Getrauen.» 


\section{Eugen Huber}

\section{Briefe an die tote Frau}

Band 3: 1912

Briefe 1-255

Herausgegeben von Sibylle Hofer

unter Mitarbeit von Emanuel Schädler

transkribiert von David Pfammatter 
Diese Publikation wurde ermöglicht dank Beiträgen der Moser-Nef-Stiftung.

Quelle: Schweizerisches Bundesarchiv J1.109-01\#1000 / 1276\#3*, Az. 1.A, Tagebuch in Briefform, 28. 4. 1910 - 3. 12. 1917

Diese Publikation steht unter der Creative-Lizenz CC BY-NC-SA 4.0

(Namensnennung - Nicht-kommerziell - Weitergabe unter gleichen Bedingungen) https: //creativecommons.org / licenses / by-nc-sa / 4.0 / legalcode.de

\section{(c) (i) $\$($ ) \\ BY NC SA}

Die Onlineversion dieser Publikation ist auf der Plattform BOP Serials

dauerhaft frei zugänglich.

doi: https: //doi.org / 10.21260 / EHB. 1912

Universität Bern

Bern Open Publishing 2020

www.unibe.ch / ub / bop

Umschlagabbildung: Eugen Huber: Brief vom 1. Januar 1911,

Schweizerisches Bundesarchiv

Frontispiz: Bronzeporträts von Lina und Eugen Huber, hergestellt von Karl Hänny (Nachlass Eugen Huber, aufbewahrt im Institut für Rechtsgeschichte der Universität Bern). Foto: Iris Krebs.

Gestaltung: Urs Bernet, Die Büchermacher GmbH, Zürich

ISBN Band 3: 978-3-03917-006-7 (PDF) 


\section{Inhalt}

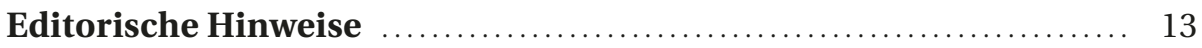

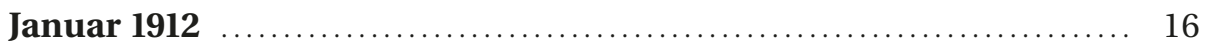

1912: Januar Nr. 1 . ............................................. 16

1912: Januar Nr. 2 . ............................................ 19

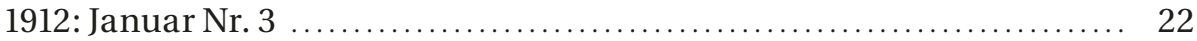

1912: Januar Nr. 4 ............................................... 26

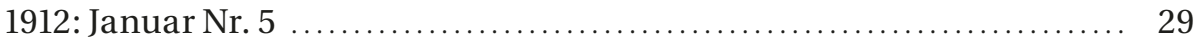

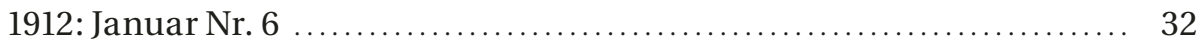

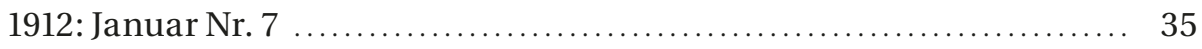

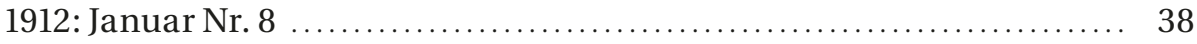

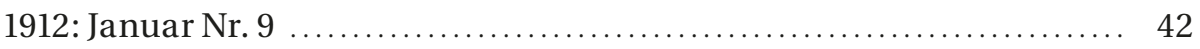

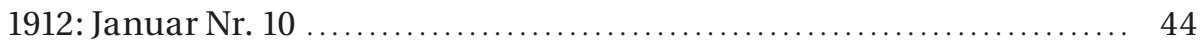

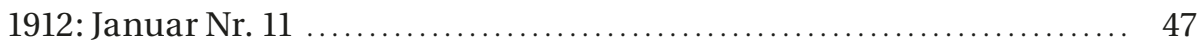

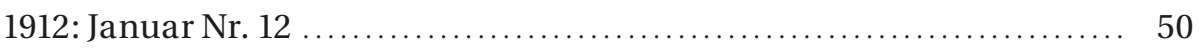

1912: Januar Nr. 13 ............................................. 52

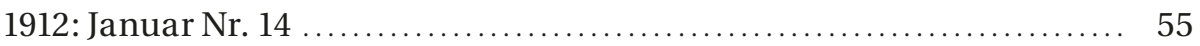

1912: Januar Nr. 15 . ............................................. 58

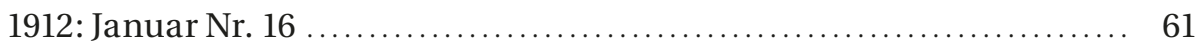

1912: Januar Nr. 17 ................................................. 64

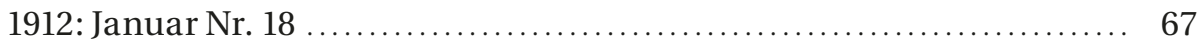

1912: Januar Nr. 19 .............................................. 70

1912: Januar Nr. 20 ............................................... 73

1912: Januar Nr. 21 ............................................... 76

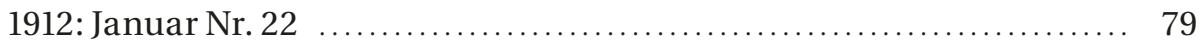

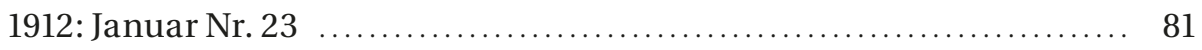

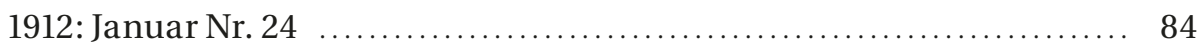

1912: Januar Nr. 25 .............................................. 87

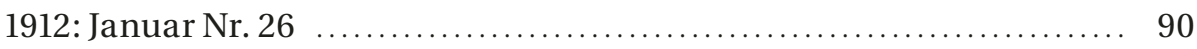




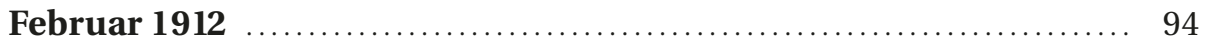

1912: Februar Nr. 27 ....................................... 94

1912: Februar Nr. 28 ............................................. 97

1912: Februar Nr. 29 ......................................... 100

1912: Februar Nr. 30 ............................................ 103

1912: Februar Nr. 31 ............................................... 105

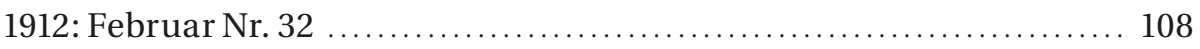

1912: Februar Nr. 33 ............................................ 111

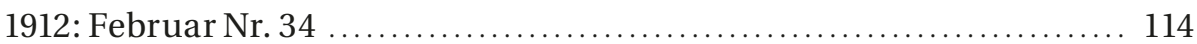

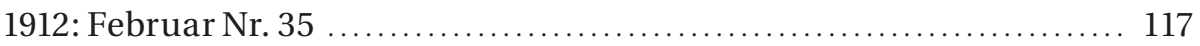

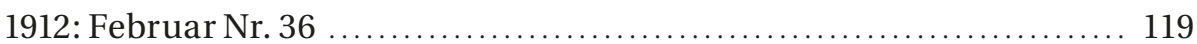

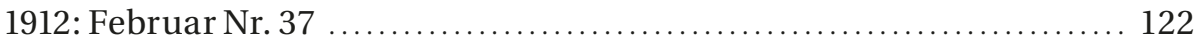

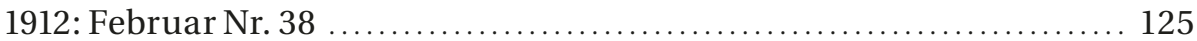

1912: Februar Nr. 39 ............................................. 127

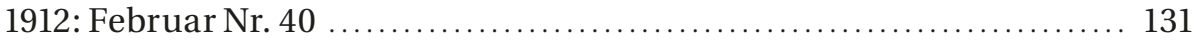

1912: Februar Nr. 41 .......................................... 134

1912: Februar Nr. 42 ............................................... 136

1912: Februar Nr. 43 ........................................... 139

1912: Februar Nr. 44 .............................................. 142

1912: Februar Nr. 45 ................................................ 144

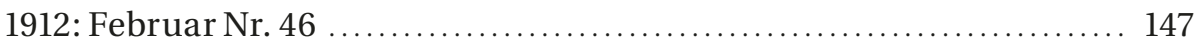

1912: Februar Nr. 47 .......................................... 150

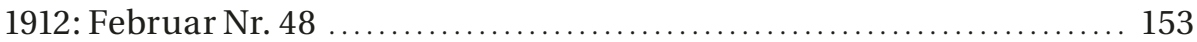

1912: Februar Nr. 49 _........................................... 156

1912: Februar Nr. 50 .............................................. 159

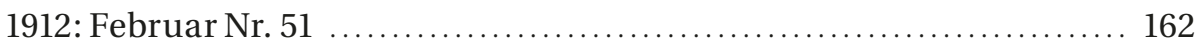

1912: März Nr. 52 ................................................... 164

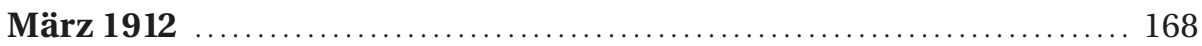

1912: März Nr. 53 ................................................. 168

1912: März Nr. 54 ................................................. 171

1912: März Nr. 55 _................................................. 174

1912: März Nr. 56 _............................................. 177

1912: März Nr. 57 ........................................... 180

1912: März Nr. 58 .............................................. 182

1912: März Nr. 59 _................................................. 185

1912: März Nr. 60 ............................................. 188

1912: März Nr. 61 ................................................ 191 
1912: März Nr. 62

1912: März Nr. 63

1912: März Nr. 64

199

1912: März Nr. 65

202

1912: März Nr. 66

205

1912: März Nr. 67

208

1912: März Nr. 68

211

1912: März Nr. 69

214

1912: März Nr. 70

216

1912: März Nr. 71

219

1912: März Nr. 72

221

1912: März Nr. 73

224

1912: März Nr. 74

227

1912: März Nr. 75

229

1912: März Nr. 76

232

April 1912

236

1912: April Nr. 77

236

1912: April Nr. 78

238

1912: April Nr. 79

241

1912: April Nr. 80 243

1912: April Nr. 81 248

1912: April Nr. 82 251

1912: April Nr. 83 254

1912: April Nr. 84 256

1912: April Nr. 85 259

1912: April Nr. 86 262

1912: April Nr. 87 265

1912: April Nr. 88 268

1912: April Nr. 89 271

1912: April Nr. 90 274

1912: April Nr. 91 277

1912: April Nr. 92 279

1912: April Nr. 93 282

1912: April Nr. 94 285

1912: April Nr. 95 288

1912: April Nr. 96 291

1912: April Nr. 97

294 
1912: April Nr. 98 297

1912:April Nr. 99 300

1912: April Nr. 100 303

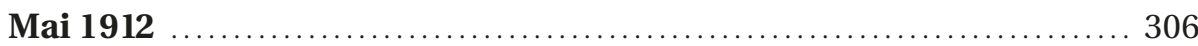

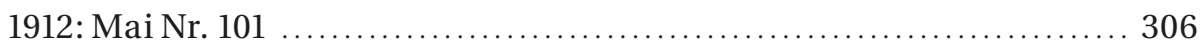

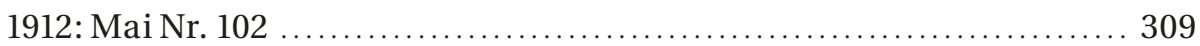

1912: Mai Nr. 103 .................................................... 311

1912: Mai Nr. 104 ...................................................... 314

1912: Mai Nr. 105 ............................................. 317

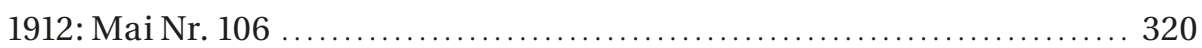

1912: Mai Nr. 107 ............................................ 323

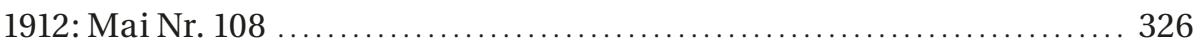

1912: Mai Nr. 109 ........................................... 330

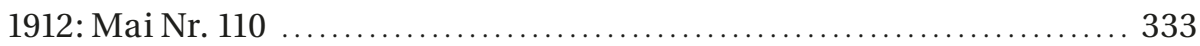

1912: Mai Nr. 111 ............................................... 336

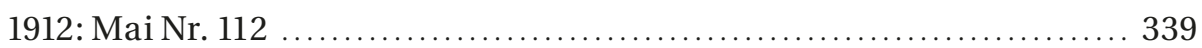

1912: Mai Nr. 113 ................................................. 342

1912: Mai Nr. 114 ..................................................... 345

1912: Mai Nr. 115 ................................................ 347

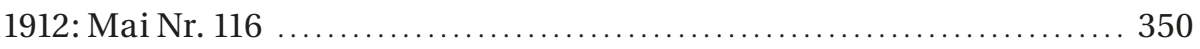

1912: Mai Nr. 117 ................................................. 353

1912: Mai Nr. 118 ............................................. 357

1912: Mai Nr. 119 ................................................. 360

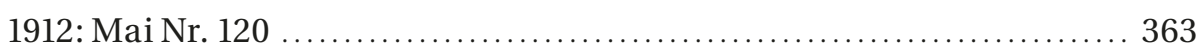

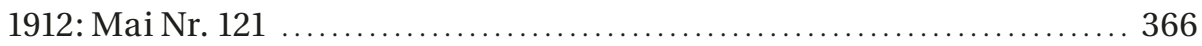

1912: Mai Nr. 122 ................................................... 368

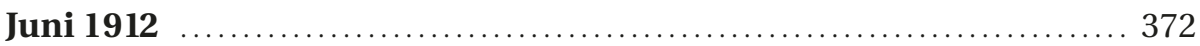

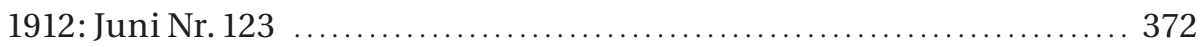

1912: Juni Nr. 124 .............................................. 375

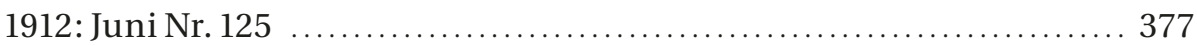

1912: Juni Nr. 126 ............................................. 381

1912: Juni Nr. 127 .............................................. 383

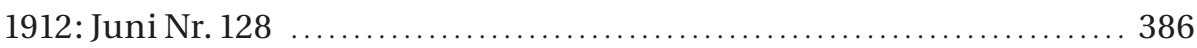

1912: Juni Nr. 129 .............................................. 389

1912: Juni Nr. 130 ............................................. 393

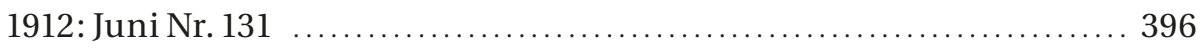

1912: Juni Nr. 132 ............................................. 400 
1912: Juni Nr. 133 403

1912: Juni Nr. 134 406

1912: Juni Nr. 135 409

1912: Juni Nr. 136 413

1912: Juni Nr. 137 416

1912: Juni Nr. 138 419

1912: Juni Nr. 139 423

1912: Juni Nr. 140 427

1912: Juni Nr. 141 431

1912: Juni Nr. 142 434

1912: Juni Nr. 143 437

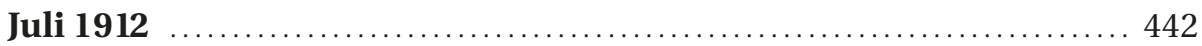

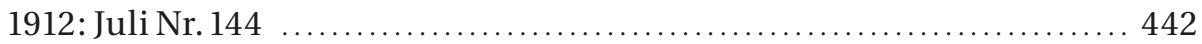

1912: Juli Nr. 145 ........................................... 445

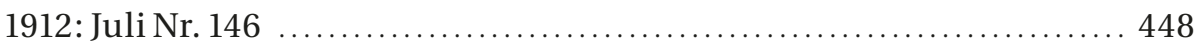

1912: Juli Nr. 147 ................................................ 450

1912: Juli Nr. 148 .................................................. 454

1912: Juli Nr. 149 ................................................ 457

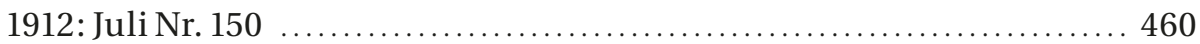

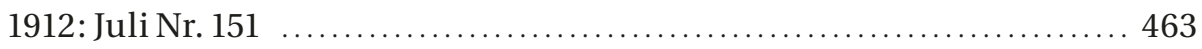

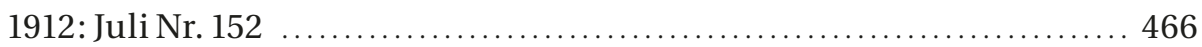

1912: Juli Nr. 153 ........................................... 469

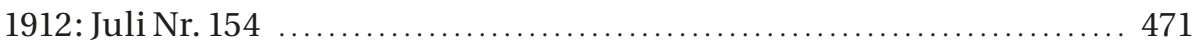

1912: Juli Nr. 155 ................................................. 474

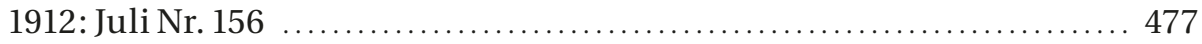

1912: Juli Nr. 157 ............................................... 480

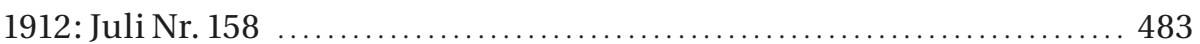

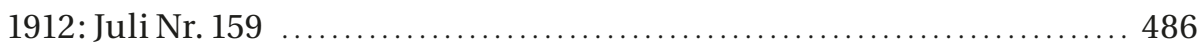

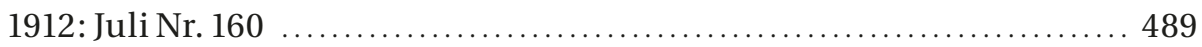

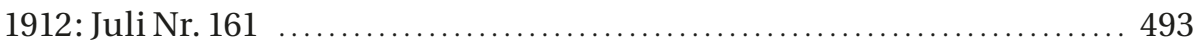

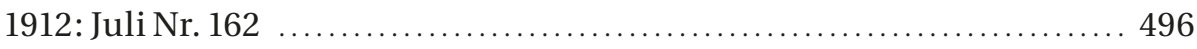

1912: Juli Nr. 163 ................................................. 499

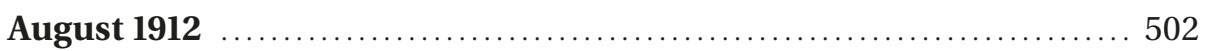

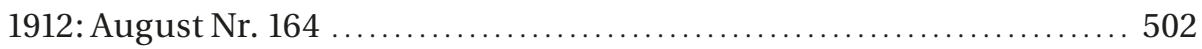

1912: August Nr. 165 ............................................. 505

1912: August Nr. 166 ...................................... 509

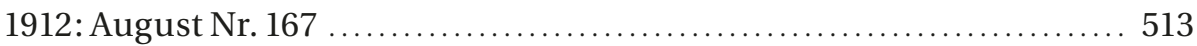


1912: August Nr. 168 ........................................... 516

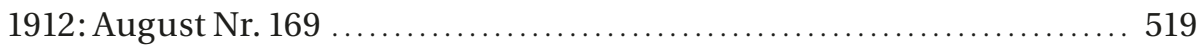

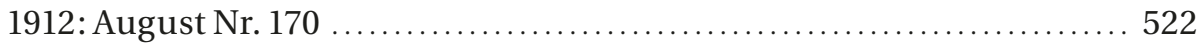

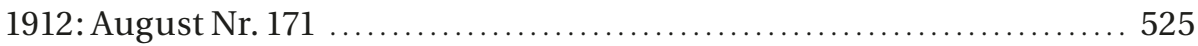

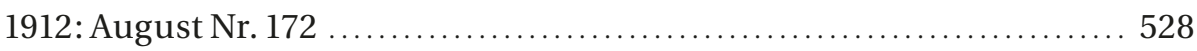

1912: August Nr. 173 ........................................... 531

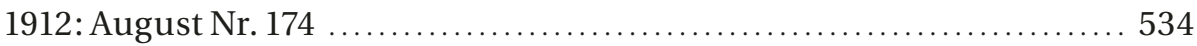

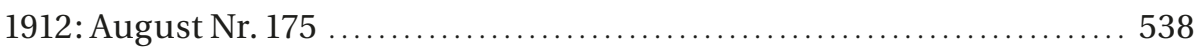

1912: August Nr. 176 ........................................... 541

1912: August Nr. 177 ............................................. 545

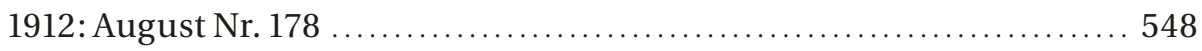

1912: August Nr. 179 ........................................... 550

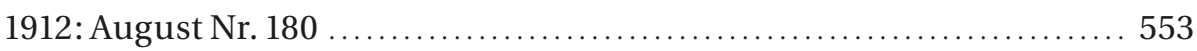

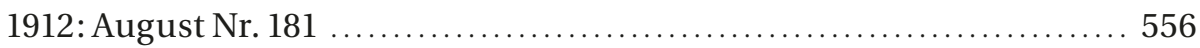

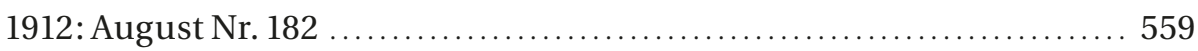

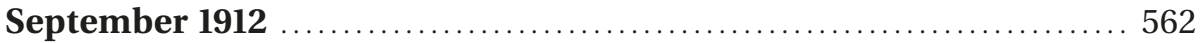

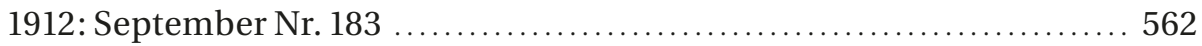

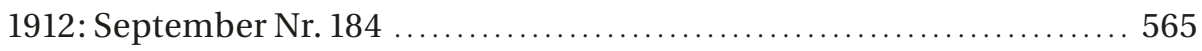

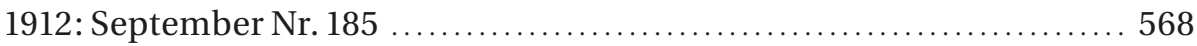

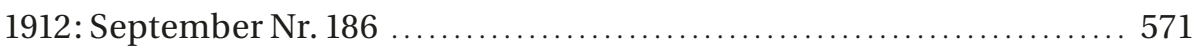

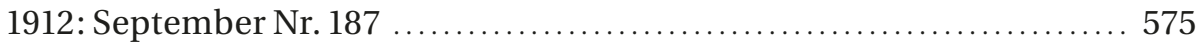

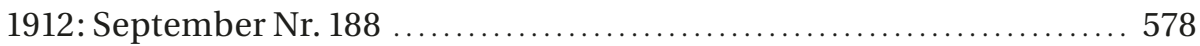

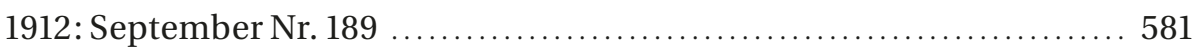

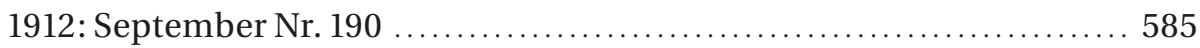

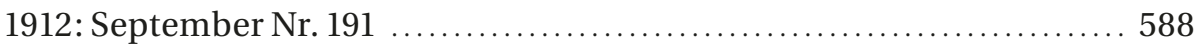

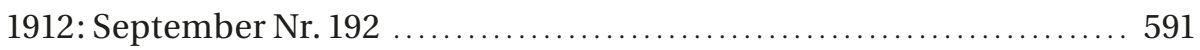

1912: September Nr. 193 _...................................... 594

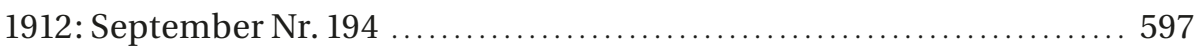

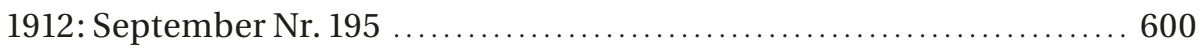

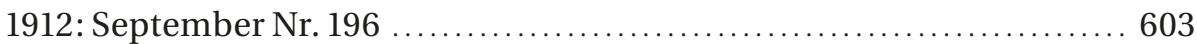

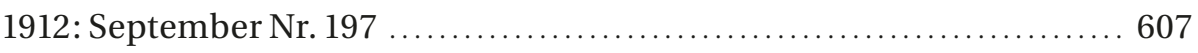

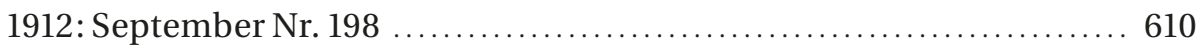

1912: September Nr. 199 _.......................................... 613

1912: September Nr. 200 ...................................... 616

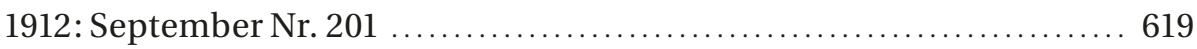

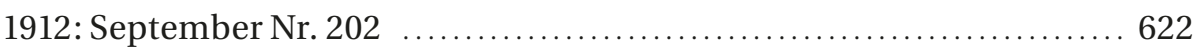




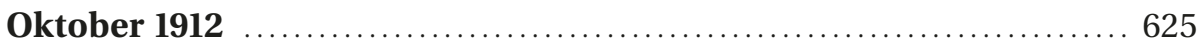

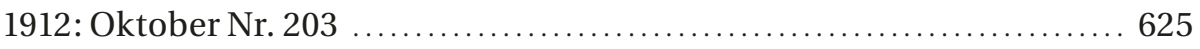

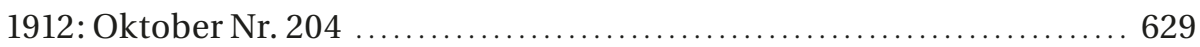

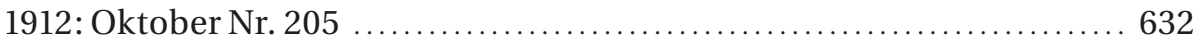

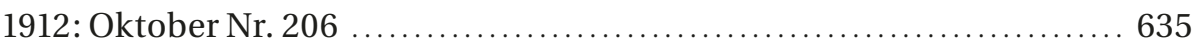

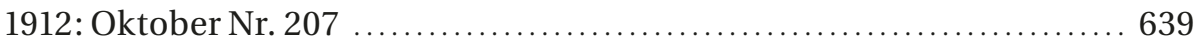

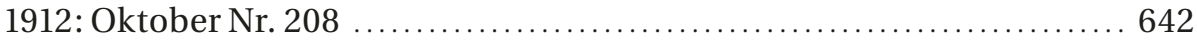

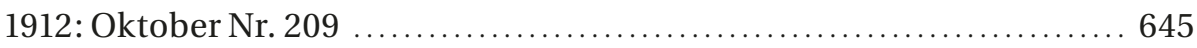

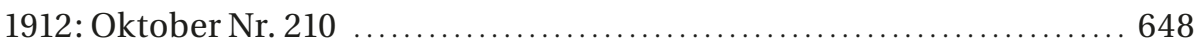

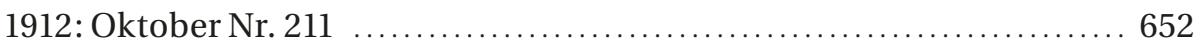

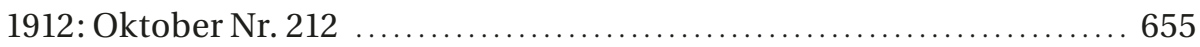

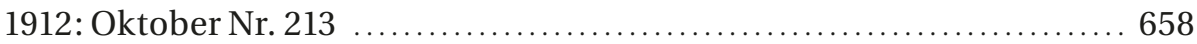

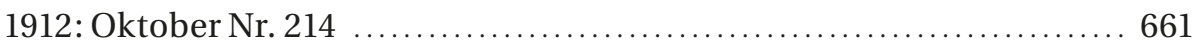

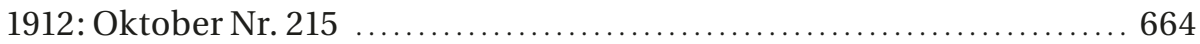

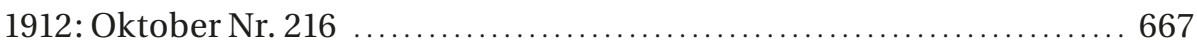

1912: Oktober Nr. 217 .......................................... 670

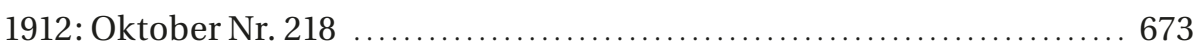

1912: Oktober Nr. 219 ............................................. 676

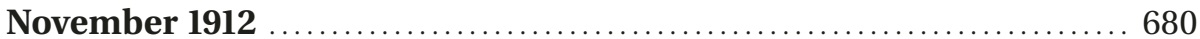

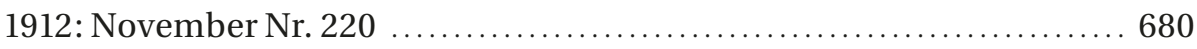

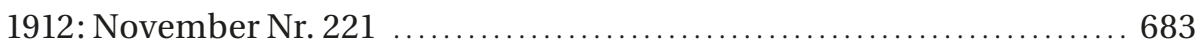

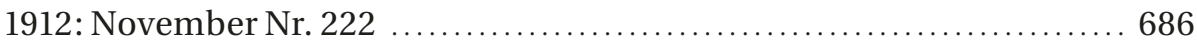

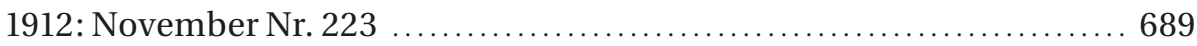

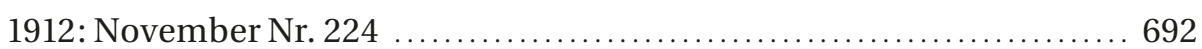

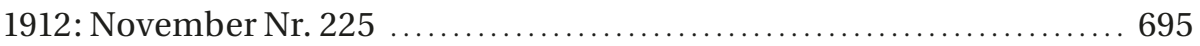

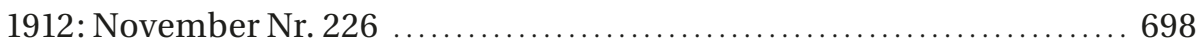

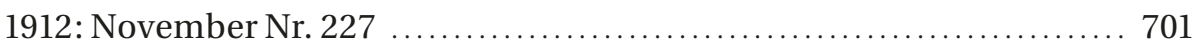

1912: November Nr. 228 ............................................. 704

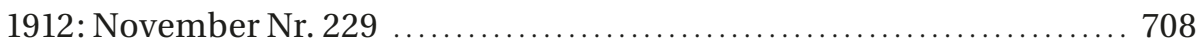

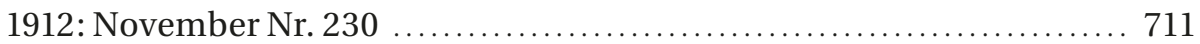

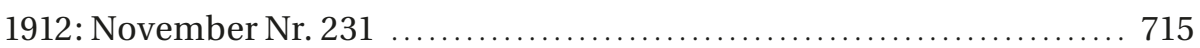

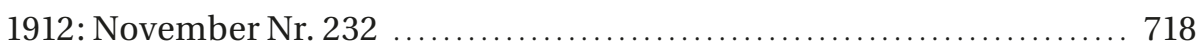

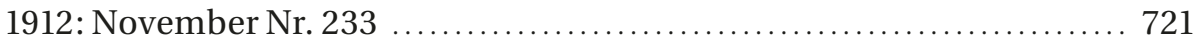

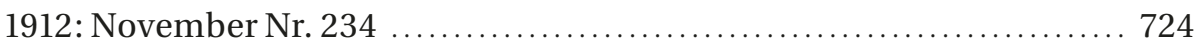

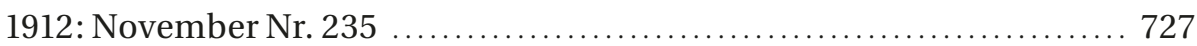

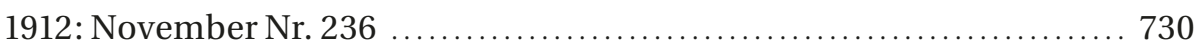

1912: November Nr. 237 ........................................ 733 
Dezember 1912 737

1912: Dezember Nr. 238 ......................................... 737

1912: Dezember Nr. 239 _......................................... 740

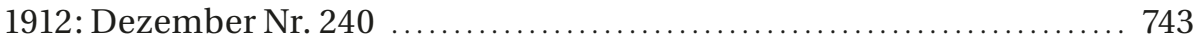

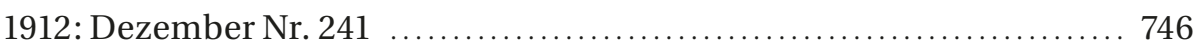

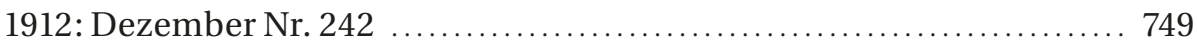

1912: Dezember Nr. 243 _....................................... 752

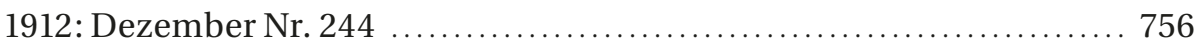

1912: Dezember Nr. 245 ........................................ 759

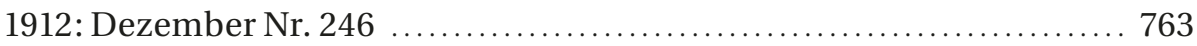

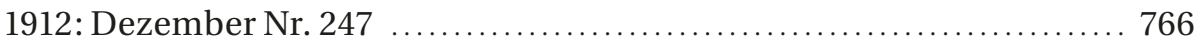

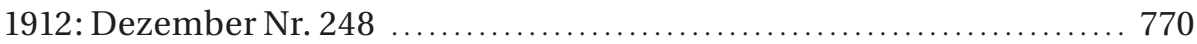

1912: Dezember Nr. 249 ......................................... 774

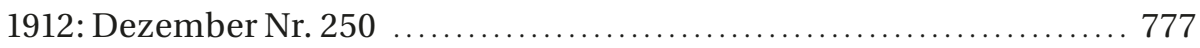

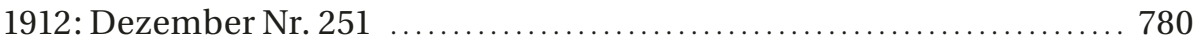

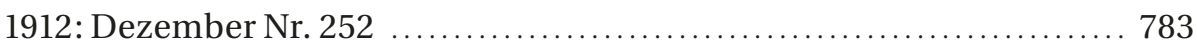

1912: Dezember Nr. 253 _........................................ 786

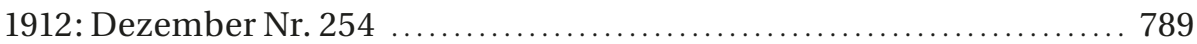

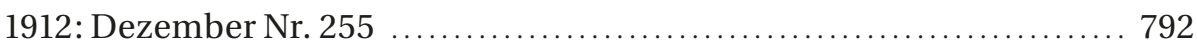




\section{Editorische Hinweise}

Es sei betont, dass es sich nicht um eine kritische Edition mit inhaltlichen Anmerkungen handelt, sondern um eine blosse Transkription der Texte. Deren Publikation soll weitere Forschungen erleichtern, sei es aus dem Bereich der (Rechts-)Geschichte oder auch anderen Forschungsbereichen. Deshalb wurde für die Publikation die digitale Form gewählt.

Die Briefe werden zeichen-, zeilen- und seitengetreu wiedergegeben. Entsprechend werden auch durchgestrichene oder unterstrichene Textstellen einbezogen. Es wird darauf verzichtet, Schreibfehler und Ähnliches durch Bemerkungen besonders zu kennzeichnen. Der Text enthält jeweils nur Kommentare und Hinweise im Hinblick auf die Gestaltung des Textes:

$/=\quad=$ Seitenumbruch innerhalb eines Briefes

$[\langle$ Text $\rangle$ ? $]=$ nicht eindeutige Stellen

[?] = unlesbare Stellen

$\ulcorner\ldots\urcorner=$ Ergänzungen Hubers ausserhalb der jeweiligen Zeile (etwa am Rand), wobei die Notiz zuunterst auf der jeweiligen Briefseite wiedergegeben wird

Vorwort zur Edition der Eugen-Huber-Briefe s. Band 1, 1910, S. 12: https: //dx.doi.org / 10.21260 / EHB. 1910 
L.J. Tamiar 1912.

Hrim hiaghs Goy!

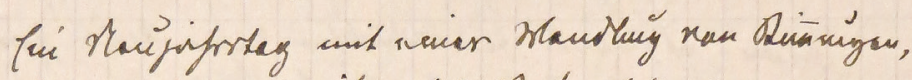

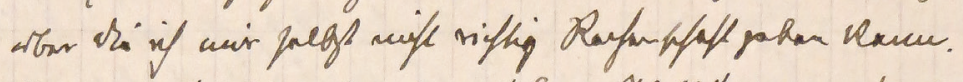

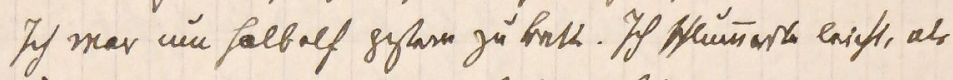

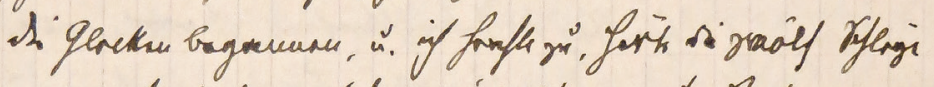

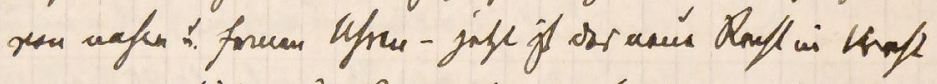

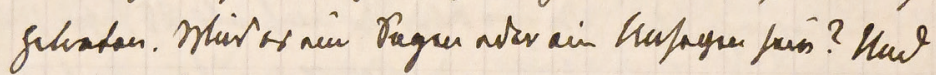

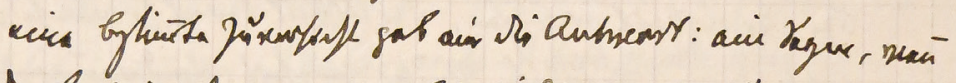

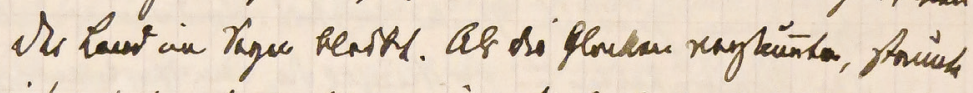

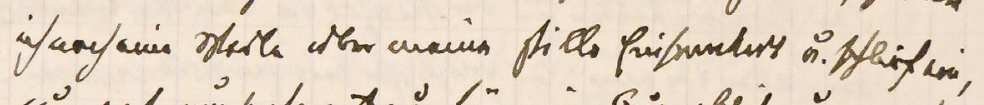

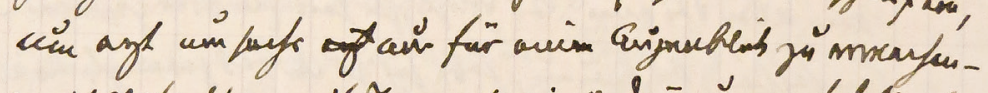

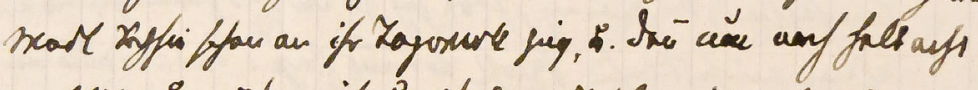

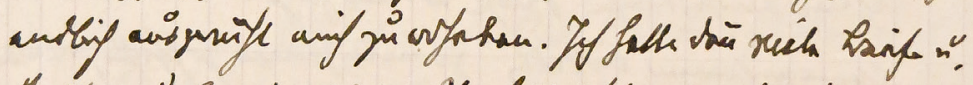

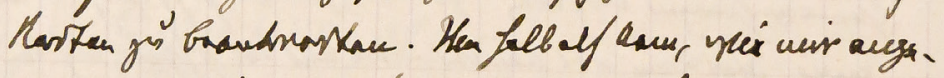

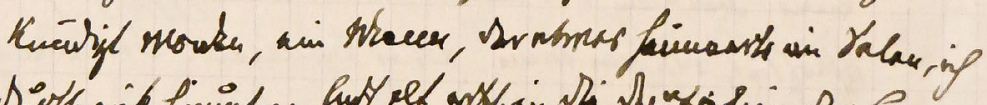

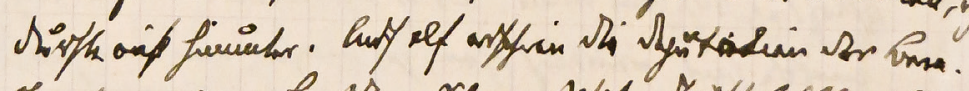

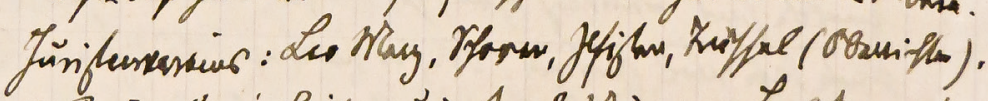

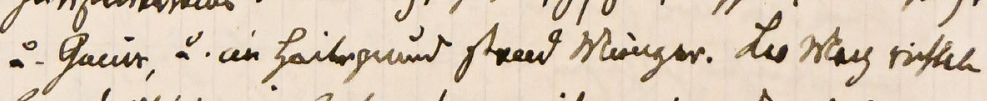

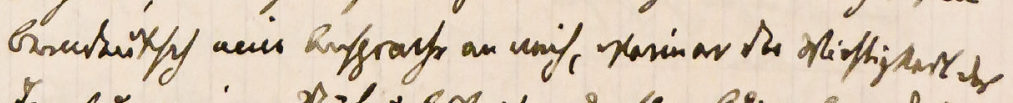

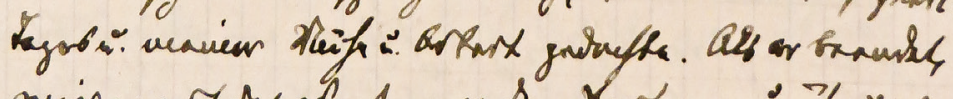

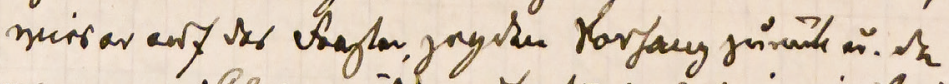

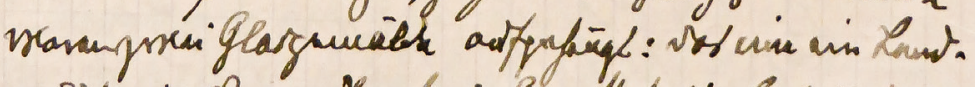

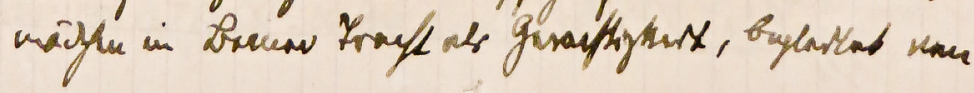

1912: Januar Nr. 1 


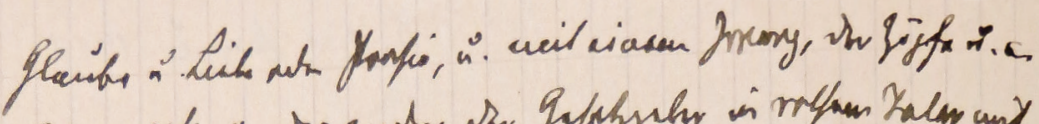

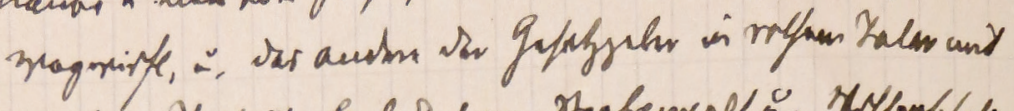

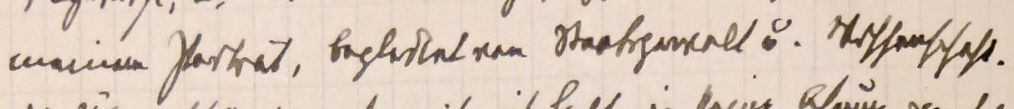

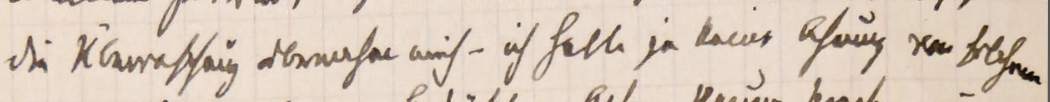

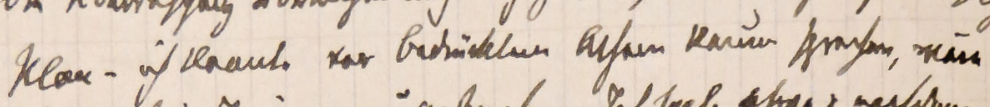

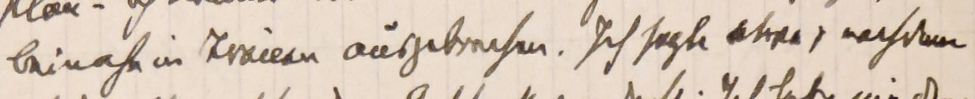

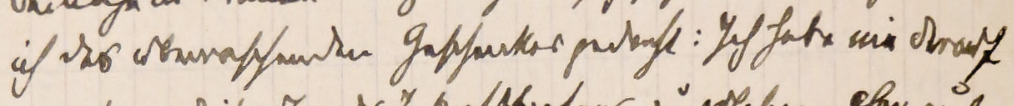

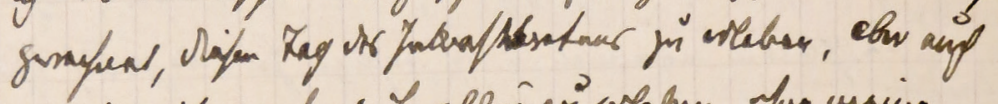

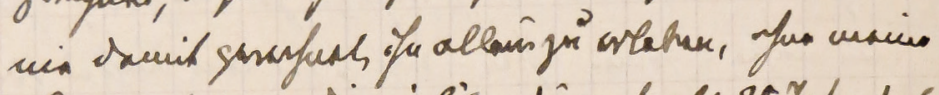

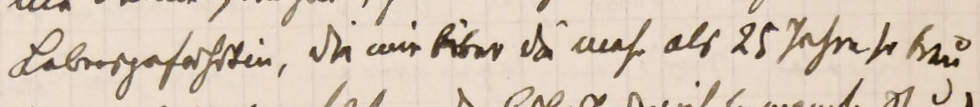

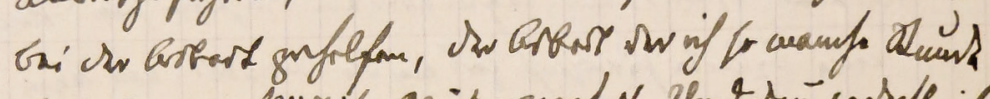

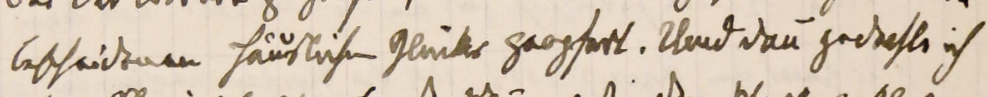

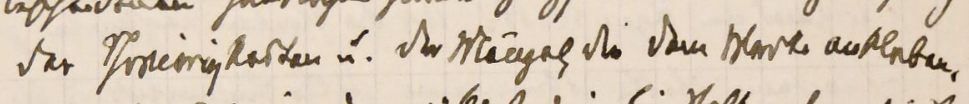

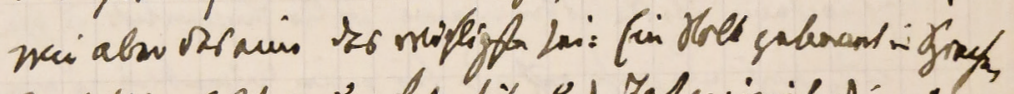

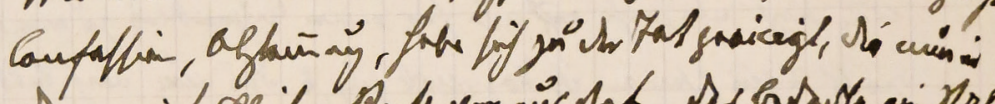

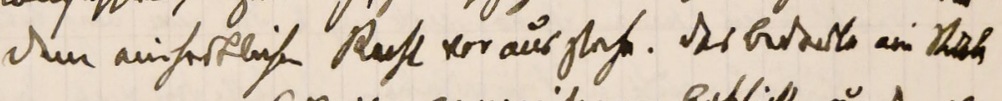

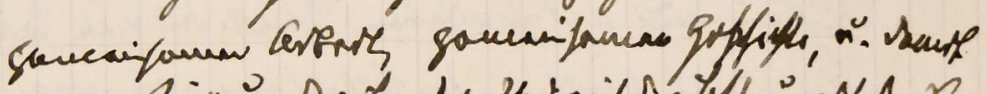

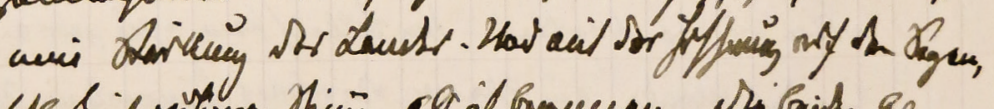

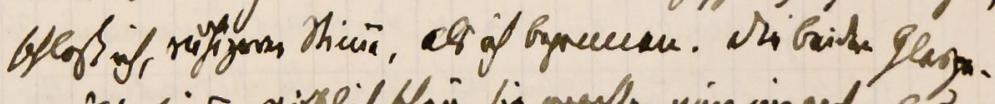

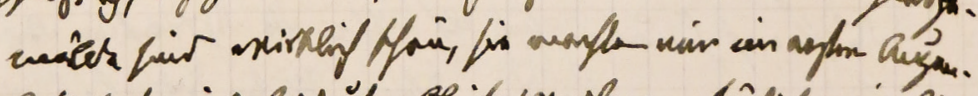

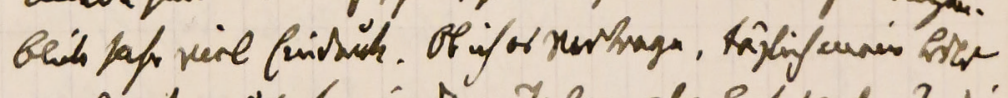

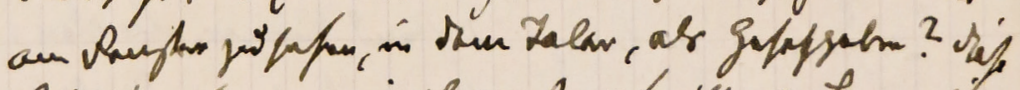

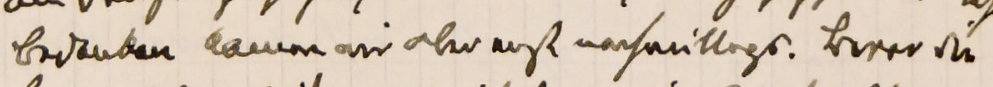

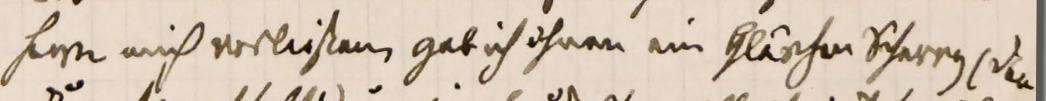

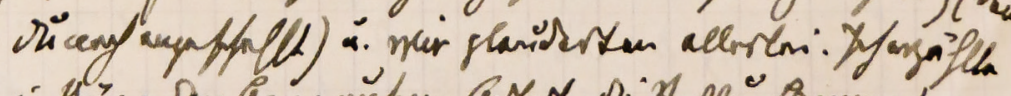

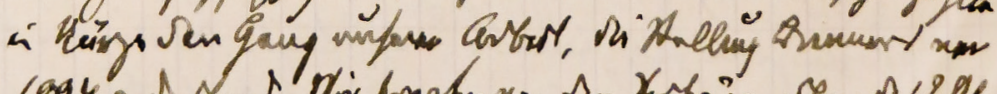

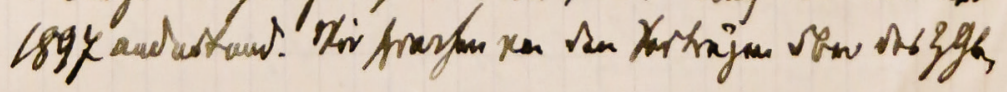




\section{Briefe an die tote Frau}

\section{Januar 1912}

\section{2: Januar Nr. 1}

B. d. 1. Januar 1912.

Mein liebstes Herz!

Ein Neujahrstag mit einer Wandlung von Stimmungen, über die ich mir selbst nicht richtig Rechenschaft geben kann. Ich war um halb elf gestern zu Bett. Ich schlummerte leicht, als die Glocken begannen, u. ich horchte zu, hörte die zwölf Schläge von nahen $\mathrm{u}$. fernen Uhren - jetzt ist das neue Recht in Kraft getreten. Wird es ein Segen oder ein Unsegen sein? Und eine bestimmte Zuversicht gab mir die Antwort: ein Segen, wenn das Land im Segen bleibt. Als die Glocken verstummten, staunte ich noch eine Weile über meine stille Einsamkeit u. schlief ein, um erst um sechs auf nur für einen Augenblick zu erwachen weil Sophie schon an ihr Tageswerk ging, u. dann um nach halb acht endlich ausgeruht mich zu erheben. Ich hatte dann viele Briefe $u$. Karten zu beantworten. Um halb elf kam, wie mir angekündigt worden, ein Mann, der etwas hämmerte im Salon, ich durfte nicht hinunter. Auf halb elf erschien die Deputation des Bern. Juristenvereins: Leo Merz, Schorer, Pfister, Trüssel (Oberrichter), u. Gmür, u. im Hintergrund stand Münger. Leo Merz richtete berndeutsch eine Ansprache an mich, worin er der Wichtigkeit des Tages u. meiner Mühe u. Arbeit gedachte. Als er beendet, wies er auf das Fenster, zog den Vorhang zurück u. da waren zwei Glasgemälde aufgehängt: Das eine ein Landmädchen in Berner Tracht als Gerechtigkeit, begleitet von 
Glaube u. Liebe oder Poesie, u. mit einem Zwerg, der Züpfe u. a. wegwirft, u. das andere der Gesetzgeber in rothem Talar mit meinem Porträt, begleitet von Staatsgewalt $u$. Wissenschaft. Die Überraschung übernahm mich - ich hatte ja keine Ahnung von solchem Plan - ich konnte vor bedrücktem Athem kaum sprechen, wäre beinahe in Tränen ausgebrochen. Ich sagte etwa, nachdem ich des überraschenden Geschenkes gedacht: Ich habe nie darauf gerechnet, diesen Tag des Inkrafttretens zu erleben, aber auch nie damit gerechnet, ihn allein zu erleben, ohne meine Lebensgefährtin, die mir über die mehr als 25 Jahre so treu bei der Arbeit geholfen, der Arbeit der ich so manche Stunde bescheidenen häuslichen Glücks geopfert. Und dann gedachte ich der Schwierigkeiten u. der Mängel, die dem Werke ankleben, wie aber das eine das wichtigste sei: Ein Volk getrennt in Sprache, Confession, Abstammung, habe sich zu der Tat geeinigt, die nun in dem einheitlichen Recht vor uns stehe. Das bedeute ein Stück gemeinsamer Arbeit, gemeinsamer Geschichte, u. damit eine Stärkung des Landes. Und mit der Hoffnung auf den Segen, schloss ich, ruhigerer Stimme, als ich begonnen. Die beiden Glasgemälde sind wirklich schön, sie machten mir im ersten Augenblick sehr viel Eindruck. Ob ich es vertrage, täglich mein Bild am Fenster zu sehen, in dem Talar, als Gesetzgeber? Diese Bedenken kamen mir aber erst nachmittags. Bevor die Herrn mich verliessen, gab ich ihnen ein Gläschen Scherry (den Du noch angeschafft) $u$. wir plauderten allerlei. Ich erzählte in Kürze den Gang unserer Arbeit, die Stellung Brenners vor 1897 andeutend. Wir sprachen von den Vorträgen über das ZGB,

ich erzählte von der originellen Art, wie ein Referent (Cauvoisin) die Güterstände erklärt, indem er eine junge Frau zu sich rief, ihr erst eine Hand gab (Güterverbindung), dann beide (Gütergemeinschaft), u. endlich ihr den Rücken kehrte (Gütertrennung). Ich erwähnte auch, unter der Maske eines Ausspruchs, den ein Bauer mir getan, dass der lieber von der Röhre trinke (Gesetz) als aus dem Trog (Commentar). Ich sprach vielleicht unbesonnen, aber ich war in angeregter Stimmung. 
Marieli kam von Zeit zu Zeit u. schenkte ein. Zum Empfang hatte ich Niemand bei mir haben wollen, als im Geiste Dich, u. das war der Grund meines inneren Schmerzes, der mich kaum zum Worte kommen liess. Als die Herren weggingen, stand ich unter dem Eindruck, der Anlass sei gelungen. Nachher machte ich mir wieder über dies u. das Bedenken, wie das ja meine Dir bekannte Art ist.

Während der kleinen Feier wollten Rossels kommen, er u. sie, u. mussten leider abgewiesen werden. Nachmittags erschienen die Teklenburgs, die den gleichen Eindruck machten, wie andere mal. Den Nachmittag hatte ich wieder Briefe u. Karten zu schreiben, u. es gab Anlass, sich an August Gyr zu erinnern. Er sandte Briefe an mich u. an Anna, die ich uneröffnet zurückadressierte. Sein Vater meldete, dass er gestern seinem Sohn den Brief an Marieli u. meinen Brief zugestellt, mit einer energischen Mahnung an ihn wegen dieser in sinnloser Wut erhobenen Verleumdung. Warten wir nun ab, was weiter geschieht. Immerhin hat dieses Erinnert werden an die schreckliche Geschichte mir nicht wohl getan. Wer weiss, was noch daraus entsteht. Ich erhielt viele liebe Grüsse, von den nächsten am wenigsten, wie das so der Fall zu sein pflegt. Offiziell ist sonst gar nichts ge-

kommen, als eben die Gabe der Berner Juristen.

Ich las den Tag über etwa in meinem Lieblingsbuch, Walter Scott, u. fühlte mich wie befreit von den Zweifeln, die mich sonst, während des Nachmittags über mich selber beschlichen, wenn ich in diese Romantik mich verlieren konnte. Und dabei dachte ich an die Stunden, die Du in Basel an meinem Bett verbrachtest, indem Du mir dieselben Geschichten mit Deiner lieben Stimme vorgelesen. Das ist nun alles, alles ja vorüber.

Ich werde diese Woche noch nicht viel arbeiten. Ich fühle das Bedürfnis, mich noch etwas zu ergehen, ich weiss nicht wo u. wie. Ich will den Segen in der Ausdehnung der Zeit, u. nicht in ihrem allzu raschen Verbrauch versuchen.

Und nun zum ersten Mal in dem neuen Jahr - Schluss u. Gruss. Bleibe bei mir, wie ich bei Dir als

Dein ewiggetreuer Eugen 


\section{2: Januar Nr. 2}

[1]

B. d. 2. Januar 1912.

Liebstes Herz!

Ich hatte heute noch eine Anzahl Briefe u. Karten zu schreiben. Am Morgen war Hänny eine halbe Stunde da u. begann mit dem Relief, das ein Seitenstück zu dem Deinigen werden soll, - zur Erinnerung für unser Getrauen. Dann war Walter B. da, um mich in einer Rechtssache zu consultieren. Ich mag ihm wieder wohler, obgleich ich in der Beurteilung seines Charakters die veränderte Fassung beibehalten muss. Dies namentlich auf Grund eines Ausspruchs, den er bei dem Sylvester Abendbesuch tat, da er mir mitteilte, er habe Stammlers Buch jetzt zu Ende gelesen, $u$. empfinde Neid auf den Autor eines solchen Gedankengefüges - eine Empfindung, die ganz charakteristisch ist. Ich könnte sie niemals haben, Neid war u. ist mir etwas Unbekanntes. Dann war Frida Weber da, ich sah sie nicht. Am Nachmittag machte Hanna Müller-Schnurrenberger Besuch, sie weinte beim Eintritt, weil sie Dich nicht mehr da finde, lud mich auf nächsten Sonntag zu Müllers ein. Aber ich habe abgesagt, weil ich mir den Tag doch für einen allfälligen Auszug irgendwohin frei halten möchte. Weiter war ich bei Rossel, um mich dafür zu entschuldigen, weil seine Frau u. er gestern bei dem Neujahrsbesuch abgewiesen mussten wegen Anwesenheit

der Berner Deputation. Rossel war von der alten Freundlichkeit, sagte sogar, wie sehr ihn die Ehrung, die mir zuteil geworden, freue, u. - bat mich, doch ja mit BRat Müller zu sprechen, dass er u. nicht Comtesse Müllers Morels Nachfolger werde. Endlich sah ich Guhl, der in Amtssachen kam u. mit mir conferierte, ohne des Jahreswechsels oder der gestrigen Ehrung 
mit einem Worte zu gedenken. Es sitzt ihm etwas nicht recht, was, weiss ich nicht, werde aber schon noch einmal davon überrascht werden. Das macht mir alles nun viel weniger, als früher. Die Anerkennung durch die Berner Juristen tut mir wohl, namentlich weil die N. Z. Z. so gar nichts andres, als den schnöden Artikel Martis gebracht hat. Dass Welti jetzt, entgegen früheren Äusserungen von ihm, nichts geschrieben hat, ist auch auf Gründe zurückzuführen, die ich nicht, oder noch nicht kenne.

Marieli ist heute unwohl, war es schon gestern, sie klagt über Übelkeit im Magen. Es ist wahrscheinlich, dass die Gemütsbewegung infolge des infamen Briefes von August Gyrs jetzt erst sich bei ihr geltend macht. Ich entdeckte schon mehrfach $u$. sehe es jetzt immer deutlicher, dass Marieli im Innern nicht so kalt ist, wie es den Anschein hat. Ja, sie muss einen tiefen Grund haben. Die ganze unglaubliche Angelegenheit mit Paul klärt sich mir mehr u. mehr ab, der Verlauf, den ich stückweise beobachten konnte, wird mir nach u. nach vollends deutlich. Ich vereinige die Anzeichen in einem immer bestimmter werdenden Bilde, $\mathrm{u}$. das ist folgendes: Marieli stand schon bei der ersten Anfrage von Paul,

unter dem Eindruck, den einzelnen Äusserungen in dem von ihr ja gelesenen Brief Pauls, auf sie machten, in einem schweren Conflict: Sie weiss, dass sie nur ein angenommenes Kind ist, sie empfindet das als einen «Hauptmangel»- wie sie es in einem ihr entschlüpften Ausdruck schon auf dem Gotthard sagte. Sie sah dann, wie sehr August $u$. auch ich eine Verbindung ihrer Beider gerne gesehen hätten. Ihr Verstand - $u$. der ist nicht klein - sagte ihr, dass eine solche Verbindung den Mangel ganz heilen würde. Sie empfand es sogar als eine Pflicht, sich diesem innern Zwang, aus Dankbarkeit $u$. wegen der angenommenen Angehörigkeit zu unserer Familie zu fügen. Diese Gedanken wurde sie nach der ersten Absage gegenüber Paul nicht los, sie wälzte sie in ihrem verschlossenen Herzen hin u. her, bis sie unter dem Gewicht vielleicht von Nebenumständen, ich weiss es nicht, plötzlich zu dem Entschlusse kam, das Opfer zu wagen, u. so schrieb sie den Brief 
vom 14. November. Anfangs schien es zu gehen, das Opfer konnte sich lohnen. Aber dann, bei dem Besuch in Zürich kam es wieder über sie mit Elementargewalt. Sie kehrte zurück mit dem Entschluss, ihr Wort zu halten, aber auf der Hochzeitsreise zu verschwinden. Aus den Einzelheiten konnte ich entnehmen, wie wenig würdig Paul dieses Opfers sei, u. ich entschloss mich, einzugreifen $\mathrm{u}$. der Sache - unter Berufung auf Marielis geschwächte Gesundheit - ein Ende zu machen. So tat ich den Schritt, mit August zu reden, u ihm, mit seiner Zustimmung den Verlobungsring, u. zugleich den Ring, den Paul schon von der Bovet letztes Frühjahr zurückerhalten, u. den er dann

schnöder Weise als ein neues Geschenk Marieli übergeben hatte, zurückzugeben. Das ist der wahre, tragische Verlauf, den hoffentlich eine nahe Zukunft vollständig heilen, oder aus dem wenigstens nicht grösseres Unheil erwachsen wird. Es wäre zu traurig gewesen, wenn Marieli sich infolge der Annahme in unser Haus zu einer Verbindung hätte verpflichtet betrachten müssen, die ihr Herz niemals bestätigt hat. Gerade weil es nicht Berechnung, sondern Pflichtgefühl, Verlassensein war, was sie zu dem Opfer treiben wollte, konnte ich dies nicht zugeben. Wenn ich ihr befohlen hätte, bei der Verlobung zu bleiben, sie hätte es getan u. gehalten. Aber Schmach über mich, wenn ich so etwas mit meinem guten Namen getan hätte! Wie ich an Vater Gyr schrieb: Marieli geht aus der Verwicklung innerlich ganz u. gar gerechtfertigt hervor. Sie hat dabei nur edle Eigenschaften gezeigt. Sie ist mir infolge dieser Ereignisse viel viel lieber geworden.

Möge es so bleiben!

So beginnt das Jahr mit schweren Betrachtungen. Je mehr man sich geistig vertieft, um so schwerer werden die Herzenssachen. Ich bin jetzt viel aufmerksamer als früher auf alle solche Erscheinungen. Die Welt beginnt mir klarer zu werden, indem ich dem aufkeimenden Pessimismus abschwöre u. anstelle des heiteren Optimismus eine tiefere Erfassung der Gegensätze von Gut u. Böse treten lassen möchte. 
Ich werde darüber vielleicht später mehr schreiben.

Für heute, mein Lieb, gute, gute Nacht!

Ich bin Dein ewig getreuer

Eugen

1912: Januar Nr. 3

[1]

B. d. 3. Jan. 1912.

Liebstes Herz!

Augsut Gyr Vater hat mir auf Neujahr geantwortet, dass er den Brief an seinen Sohn mit Ermahnung zurückgeschickt habe. Heute erhalte ich vom Sohn die Antwort mit Zeilen folgenden Wortlauts:

Leipzig, 1. Jan. 12.

«Lieber Onkel!

«Dein geehrtes Schreiben hat mir mein lb. Papa mitgeteilt.

«Du kannst sicher sein, dass die hässliche Kunde mich zu schmerzlich erschüttert hat, als ieh dass ich es über mich gebracht hätte, es meinen Eltern oder sonst jemand weiter zu erzählen.«Auch versichere ich Dir, dass ich alle Mitteilung von Konrad erhalten habe; weder Paul noch seine Eltern haben das kleinste Wörtchen fallen lassen, obgleich ich öfters bei ihnen war; Paul wenigstens nicht mir gegenüber.

«Was hätte ich anders tun u. lassen können als die verklagte Partei von den Beschuldigungen in Kenntnis zu setzen u. sie um deren Berichtigung zu bitten? Hätte ich, vor so einem Verdacht bedeutet, Euch besuchen u. gekünstelt freundlich tun können, solange sich die Nachricht nicht als gemeine Ver- 
leumdung herausgestellt hatte.«Ich habe den Konrad von dem Vorgegangenen unter-

richtet. Er muss dazu Stellung nehmen. Kann er's nicht,

so trifft aller Verachtung ihn. Und ich hoffe dies sehnsüchtig.

Dann werde ich Marie, meine stets geschätzte Freundin, auf den Knieen um Verzeihung bitten $u$. alle Schmach tragen, die ich ihr zugefügt.

«Du sprichst, dass ich an dem Leid, das ich Euch angetan habe, ebenso schwer trage. Wenn mir die Freundschaft gleichgültig wäre, so hätte mich die verleumderische Darstellung auch kälter gelassen.«In der sehnsüchtigen Erwartung der Entpuppung des schändlichen Verleumders grüsst Dich, lieber Onkel, herzlich Dein «dankb. Neffe «August Gyr».

Ich sandte diese Zeilen sofort ebenfalls an den Vater August Gyr mit folgenden Begleitzeilen:

«Bern, d. 3. Jan. 1912.«Lieber Vetter!

«Ich danke Dir herzlich für Deine Mitteilung vom 1. ds. Zu meinem Bedauern muss ich aber nochmals auf die traurige Geschichte zu sprechen kommen, indem ich mich verpflichtet fühle, Dir auch den Brief mitzuteilen zuzustellen, den ich heute von August erhalten habe «Er befriedigt mich in keiner Weise, u. wird auch Dich nicht befriedigen. Bedenklich erscheint mir namentlich das Hinweggleiten über den ersten schrecklichen Brief u. den $\ulcorner. . .7$ Brief an Lüdemanns auf den zwei ersten Seiten des jetzigen Briefes Schreibens. August scheint sich Г...7 nicht bewusst derden zu sein, dass er

「ebenso schrecklichen

$\ulcorner$ der Schwere seines Vergehens $\urcorner$ 
bedenkt nicht, dass auf Grund Г...7 Wortlauts, Г...

der genannten zwei Briefe, Г...7 gerichtlich

zu Gefängnis verurteilt wurde könnte, wenn er nicht als

unzurechnungsfähig zu bezeichnen würde war.

«Ich schreibe u. schicke die Beilage Dir selbstverständlich wie-

derum ganz confidentiell.»

«Nochmals herzlichst dankend verbleibe ich mit

vielen Grüssen an Dich u. die liebe Frau Liese

«Dein getreuer Vetter

«Eugen Huber».

Nun bleibt abzuwarten, was in der Sache weiter geschieht.

Heute Vormittag war wieder Hänny wegen des Reliefs

bei mir. Nachher ging ich mit Marieli auf den Friedhof u. hatte

mit ihm eine Unterhaltung, die mir u. wohl auch ihr, wohltat.

Am Nachmittag machte ich BRat Müller den ersten Besuch auf dem Departement. Mir fiel - vielleicht im Gegensatz zu Hoffmann auf, wie viel mehr Müller gesprochen hat, als ich es jetzt bereits gewohnt war, immerhin nicht so viel wie Brenner, aber doch schon als älterer Mann. In dem Gespräch ersah ich, dass Müller nicht gerade ein Freund der internationalen Aufgaben der Schweiz ist, u. ich vernahm, dass Frankreich die Wahl von Comtesse gern sehen würde. Also gerade das Gegenteil von dem, was Rossel vorausgesetzt $u$. worüber er mir heute noch einen Brief geschrieben hat, um mich zu animieren. Ich habe auch zu Müller für Rossel gesprochen. Er meinte aber, die Wahl von Comtesse sei sicher, wenn er sich bewerbe. - Endlich um halb neun musste ich noch Guhl empfangen zur Besprechung bis gegen zehn Uhr. Das will kein Ende nehmen.

Ich habe in diesen Ferien eine gewisse Sinnesänderung durch-

$\lceil$ seines $\rceil$

「wie der 7

「schon manchen $\rceil$ 
gemacht, die wesentlich darin besteht, dass ich meine Aufgabe anders erfasse oder auffasse $u$. jeden Gedanken an Preisgeben meiner Stellung von mir weise. Hängt das mit der Lektüre Euckens zusammen? O wie froh wäre ich, zu diesem Standpunkt noch gekommen zu sein, als Du bei mir warst. Du hattest diese grössere Vollkommenheit, Einheit der Seele, erreicht, u. Du vermisstest dasselbe bei mir, wenn auch meine äussern Erfolge Dich darüber wegsehen liessen. Ich wollte ich könnte die Zeit noch einmal erleben mit Dir. Aber so ist es nun mein Schicksal zu spät zu dieser Einsicht gekommen zu sein. Der Zusammenhang mit Dir macht mir allein wohl auch jetzt diese Läuterung möglich. Halte mich fest, ich will bei Dir sein.

Ich las die Tage wieder einmal zwischendurch einen Roman von Scott, Talismann, bin gestern fertig geworden, - die Romantik hat es mir angetan. Freilich die Mängel wurden mir auch bewusst, mehr als vor dreissig Jahren, da Du mir dieselbe Geschichte am Bett vorgelesen hast. Ach, das war eine liebe Zeit, ich denke wie die letzten Tage, auch jetzt wieder mit tiefer Wehmut daran.

Heute begann ich dann auch Hausers Dissertation über Erbengemeindesschaft zu lesen. Sie ist furchtbar schlecht geschrieben im Styl.

Morgen erscheint Siegwart wieder. Also bald wieder

der alte Trott. Spute dich, Kronos!

Mit innigem Gruss

Dein allzeit treuer

Eugen 
B. d. 4. / 5. Jan. 1912.

Liebstes Herz!

Nachdem ich mit Guhl am Vormittag wieder verhandelt, u. dann Hänny gesessen hatte, ging ich zu Frau Vogel, wo auch Jakob auf deren Ersuchen erschien. Sie war recht herzlich. Mein Anliegen aber konnte ich nur mühsam anbringen, $u$. dabei machte ich bald die Entdeckung, dass Frau Vogel ihre Schwägerin nicht als geeignet betrachte zur Aufnahme ins Haus, wie wir es geplant. Aber wir werden noch Bericht erhalten. Zum Mittagessen kam unerwartet Albert Heim, der aber schon auf halb zwei wieder wegging. Trotz der Kürze der Zeit konnte ich aber doch ein herzliches Wesen entgegennehmen, das mich wohltat. Zu gleicher Zeit kam auch ein lieber Brief von Marie Heim. Abends erhielt ich einen eben solchen von Kleiner, nachdem schon am Morgen eine Torte von der Frau mit Brief u. Danksagung Mayrikls eingelaufen.

Beide Lebenszeichen haben mir wohl getan. Ich hatte schon befürchtet, dass diese beiden Freunde über mich erzürnt seien, u. wusste doch nicht recht, weshalb. Am Nachmittag war ich dann auch bei Rossel, um ihm zu sagen, dass nach Müllers Ansicht $u$. Mitteilung die Wahl von Comtesse die Staaten nicht vor den Kopf stossen würde, ja dass umgekehrt Frankreich sich davon sehr befriedigt zeigen werde. Er meinte, das sei schon möglich, wenn

Fallieres Besuch. Das wischte ihm so heraus. Im ganzen bekam ich heute den Eindruck, dass Rossel den Versuch, Comtesse entgegenzutreten, aufgebe, namentlich infolge eines Zusammentreffens noch gestern Abend, nachdem er mir geschrieben. Bessier soll auf Comtesse wütend sein.

Sonst hatte ich meine liebe Not mit der Dissertation Hauser. 
Sie ist konfus u. fürchterlich schlecht deutsch. Es ist ein Schellenwerk, derartiges corrigieren zu müssen.

Heute erhielt ich die erste Anfrage um ein Gutachten i. S. ZGB., von

Borella als Anwalt. Soll ich nun solche Aufträge annehmen

oder ablehnen? Tu ich ersteres, so kann ich doch nicht Honorar

verlangen, $u$. werde jedenfalls in meinen andern Arbeiten

stark gestört. Tu ich letzteres, so muss ich zusehen, wie unter

Umständen Irrtümer sich verbreiten, die ich mit einem

einzigen Wort aufklären könnte. Rossel, dem ich das Dilemma

vortrug, riet mir zu letzterem, u. es stimmt ja auch mit mei-

nem bisherigen Verhalten überein. Ich werde wohl zu

dieser Lösung gelangen.

Sonst bedrückte mich den ganzen Tag die Geschichte mit den

Zürcher Neffen. Herr Gott ist das ein Undank. Ich mag nicht daran denken. Die Nacht war ich entschlossen, August, wenn er nicht beigebe, vor dem Leipziger Universitätsrichter zu verklagen. Was werde ich tun? Doch heute nichts mehr davon. Ich bin müde u. mich brennen die Ohren u. Augen, es ist ein versteckter Schnupfen, der im Kopf rumort. Es wird bis morgen besser sein.

D. 5. Januar.

Nach einer wirklichen Schlafnacht bin ich heute munter an die Arbeit gegangen, aber doch nicht weit gekommen. Die Dissertation Hausers war so mühsam zu vorkorrigieren, dass ich ungebührlich viel Zeit dafür brauchte, $u$. ich bin noch nicht fertig damit. Am Morgen war Hänny wieder da, das Medaillon rückt vorwärts. Nachher hatte ich mit Guhl eine längere Besprechung. Am Nachmittag kam die Edith Hilty u. machte Besuch. Sie logiert zur Zeit in der Pension Herter. Ich vernahm, dass Rappards seit einigen Wochen in der Viktoria logieren. Frau Moser, die gleichzeitig zu Anna kam, sah ich nicht. Um fünf Uhr machte ich Hebbels einen Besuch. Sie waren sehr traurig gestimmt u. Frau Hebbel in jener Dir bekannten Verfassung, wo sie alles Schreckliche sich vorstellt u. über alles in scharfen Ausdrücken herfällt. Nach dem Nachtessen kam Walter Burckhardt ein Stündchen, um mich daran zu erinnern, dass morgen Kommissionssitzung i. S. Wasserrecht stattfinde. 
Ich hatte es fast vergessen. Bei dem Anlass konnte ich ihm sagen, wie sehr mich sein Neid auf Stammler beschäftigt habe. Er merkte schon, was mir dabei am Herzen lag. Er gehört eben zu denen, die nur das sehen, was andere ihm voraus haben, $u$. der neidisch wird, sobald er findet, sie verdienen dieses Voraus nicht, u. er ist dabei natürlich bald geneigt, das so zu finden.

Gerührt hat mich ein Brief von Base Gyr, die klagend mich bittet, doch ja ihrem Sohn zu verzeihen. Ich werde ihr darauf liebevoll zu antworten haben.

Siegwart arbeitet weiter an der Ordnung der Bücher u. Akten. Ich hätte eine schreckliche Unordnung, wenn er nicht derart hülfe. Aber der eigentliche Zweck der Sekretariatsdienste kommt dabei gar nicht zur Geltung. Ich finde einfach die Zeit nicht, an dem Buch zu arbeiten. Die ganzen Ferien sind jetzt an diesen Dingen von Correspondenzen, Anfragen, Dissertationen drauf gegangen. Nur die Lektüre von Euckens Buch ist ein freilich grosser Extragewinn. Wie soll es aber

dabei schliesslich herauskommen? Wie kann ich meinen Pflichten in dieser Richtung entsprechen? Ich sehe keinen Ausweg, aber die Zeit wird lehren.

Heute war auch Mutzner bei mir, den Walter Burckhardt auf meine Empfehlung hin als Nachfolger von Frischs in Basel genannt hat. Ob mit Erfolg? Mutzner kam, um mir zu sagen, dass er die Arbeit für Brauns Annalen, um die ich angegangen wurde, übernehmen wolle. Ich werde morgen darüber Antwort geben.

Die Scheiben des Juristenvereins wirbeln wohl in manchem Kopf Staub auf. Hebbels haben nett davon gesprochen. Walter Burckhardt zeigte auch hierin seine Grundstimmung, dass er mich fragte, ob ich eigentlich es sein soll, der da dargestellt werde als Gesetzgeber. Es sei so etwas Ähnlichkeit. Ich musste lachen, aber wohl hat mir die Bemerkung jedenfalls wiederum nicht getan.

Allein, was sind alle diese Dinge! Die Hauptsache ist jener Rückzug des Lebens auf das innerste Bewusstsein, ohne Hass, ohne Neid, ohne Opfer u. nur gegeben in dem Gewinn seiner selbst. Dies zu behalten, dieses Bewusstsein, das lehre mich, mein Lieb, mit jedem Tag aufs neue! 
Ich werde morgen wohl nun doch in die Kommissionssitzung gehen. Ich treffe dann zwar Zollinger, den Arzt, nicht, der sich auf zwei Uhr angekündigt hat. Aber was schadet es!

Ruhe, zur Ruhe! Der Dich bedrückte, schläfst Du schon, Schmerz? Was Dich beglückte - sage, was war's doch, mein Herz? Diese Verse, die Du mir an einem der letzten gesunden Abende vorsagtest, gehen mir jeden Abend durch den Sinn, sie bedeuten Ruhe u. Ergebung.

Ewig Dein

\section{Eugen}

\section{2: Januar Nr. 5}

B. den 6. Jan. 1912.

Mein liebstes Herz!

Über Nacht entschloss ich mich, die heutige Sitzung der Wasserrechtskommission nicht mit zu machen und sandte Will meine Entschuldigung. Es war gut, dass ich es tat, denn ich hatte gleich mit Guhl wichtige mit der Post angekommene Geschäfte zu erledigen, die andernfalls hätten bis Montag warten müssen. Es waren zugleich verdriessliche Dinge, Anstände mit Baselstadt, mit St. Gallen u. schliesslich auch mit dem Bundesgericht, dem gegenüber der Bundesrat, gegen Müller, aber auf Antrag Hoffmanns, scheints gestern doch in der Angelegenheit des Eigentumsvorbehaltes den Rückzug beschlossen hat. Dann schrieb ich vor sechs Uhr Morgens an ein Gutachten für Notar Hirt, das mir Siegwart am Morgen gleich abschreiben konnte. Von zwei bis vier war Dr. Zollinger aus Goppenstein bei uns. Er erwies sich wieder als der herzlose Gescheite, der von Dir kein Wort hatte, sondern nur von seiner Weiterbildung, u. der Marieli nicht mit einem Wort nachfragte, obgleich ich durchaus nicht den Eindruck hatte, als wäre er von der Geschichte mit Paul unterrichtet. Marieli hatte Besorgnis, es würde von Paul gesprochen, u. ging daher über die Zeit zu Frau Burckhardt, die 
krank im Bett liegt, u. zu Susanne Rossel. Es wäre aber gar nicht nötig gewesen. Ich erinnerte mich, wie es Dich berührte, als Zollinger von der Krankheit seiner Mutter als einem interessanten Fall gesprochen, ohne eine Miene über ihren Tod zu verziehen. Also war er auch heute. Den Nachmittag brachte ich die Dissertation Hauser zu Ende, u. übersandte sie ihm mit meinem ablehnenden Bericht, aber einigen freundlichen Zusätzen. Ich glaubte dann den Abend ganz mit Dir zusammen sein zu können. Aber die Post brachte eine erbrechtliche Anfrage aus St. Gallen, die ich bis zum vorigen Augenblick noch gleich beantwortete. So ist es wieder später geworden u. die Woche schliesst in Hast, während es draussen stürmt $u$. regnet. Von Vater Gyr erhielt ich aus München einen Jammerbrief ähnlich wie gestern von der Mutter. Es war doch etwas hart von mir, dass ich die beiden Briefe nach Zürich sandte. Aber ich konnte nicht anders. Das Zusammensein mit Zollinger vergegenwärtigte mir sehr im Gemüt, wie misslich es jetzt um unser Verhältnis zu den Zürcher Verwandten bestellt ist. Fürwahr es ist eine schlimme Sache, u. es wird, namentlich seit der Verschlimmerung durch Augusts Eingreifen immer bedenklicher. Es ist ärger als wenn ein Todesfall eingetreten wäre. Der Tod vereinigt, das Leben trennt, das ist nur allzu wahr. Aber ich muss es nun tragen. Was will ich nun mit den beiden Ferientagen noch anfangen? Die Dissertation lesen, die

noch der Erledigung harrt, oder den Bericht betr. die Anfrage der Schweiz. Kreditanstalt an das Departement aufsetzen? Oder kann ich noch einige Freiheit mir gönnen? Ich weiss noch nicht, wozu ich mich entschliesse, $u$. vielleicht bringt die Post einen Bericht, der mir alles, was ich planieren könnte, über den Haufen wirft. Warten wir ab.

Die Frl. Frey, die Du bei Obersts kennen gelernt, ist gestorben. So viel ich weiss für die Familie ein harter Verlust. Sonst habe ich von Briefen nur noch zu erwähnen, dass Frau 
Cragnola herzlich schrieb, u. dass von Stammler eine freundliche Neujahrsgratulation eintraf. Soll ich, da der Gedanke von einem Aufenthalt bei Weltis in St. Hilario auch zu nichten geworden zu sein scheint, an Frau Cragnola schreiben? Marieli würde am liebsten mit mir eine Frühjahrsreise machen. Allein ich wage es nicht, nach den gemachten Erfahrungen. Es ist nicht das, was ihr jetzt not tut. Also was bleibt? Auch darüber würde ich gerne noch vor dem Wiederbeginn der Kollegien ins Klare kommen. Aber es wird nicht möglich sein.

Der Zustand des dämmernden Bewusstseins kommt mir gerade jetzt wieder deutlicher zur Empfindung - ein Altwerden, das uns nur noch einen Teil des Lebens lässt. Die Leidenschaften, die allmählich verschwinden, werden nicht ausgefüllt von um so intensiverer geistiger Tätigkeit, sondern sie lassen ein Nichts zurück, das uns bis zu einem gewissen Grad in einen Dämmerzustand versetzt. Wäre nicht das Bisschen Erfolg mit der grösseren Harmonie, die darüber Platz greift, ich weiss nicht, wie das zu tragen wäre. Aber ich will mich tapfer halten, und

arbeiten so gut ich kann. Vielleicht kommt dabei doch noch etwas Gutes heraus. Es ist merkwürdig, wie es mich berührt, dass jetzt mit dem neuen Jahrgang von Hiltys Jahrbuch meine bewährte Lehre, die Du noch mit erlebt hast, veröffentlicht $u$. in der Presse besprochen wird. Der Zwischenraum von damals u. jetzt schrumpft dabei noch besonders in sein Nichts zusammen.

Doch lassen wir das, u. - zur Ruhe. Die Geister spielen in mir den Zapfenstreich. Es war ein langer Tag - gute Nacht! Dein allzeit treuer

Eugen 
B. d. 7. Jan. 1912.

Liebstes Herz!

Es ist gekommen, wie ich befürchtete. Die Post brachte mir am Morgen eine Anfrage, die ich gleich beantwortete, die mir aber dabei den ganzen Vormittag in Anspruch nahm. Am Nachmittag kam ich nur wenig zum Lesen - in Lienerts Hochmutnärrchen, das mir viel Eindruck machte-, dann ich hatte Besuch von Rossel, der nun einsieht, dass er mit Comtesse nicht concurrieren kann u. jetzt auf die Bundesrichterstelle aspiriert $u$. dafür meine guten Dienste in Anspruch nehmen möchte, die ich ihm auch von Herzen gern gewähren werde, - von Dr. Steiger, der mir entwickelte, wie notwendig seine Beförderung zum Extraordinariat sei, wenn aus der Handels- $u$. Verwaltungsabteilung unserer Fakultät etwas werden soll, womit er übrigens bei der Zerfahrenheit der Ziele bei den Beteiligten viel Recht hat. Vor allem aber hatte ich eine grosse Überraschung: Um zwei Uhr meldete mir Sophie ein Frl. Röthlisberger an, u. als ich in den Salon hinunter kam, stand Anneli vor mir, aus Malleray, Marielis Schwester, ein blühendes, prächtiges Mädchen, das wieder einmal, bescheiden u. durchaus erlaubter Weise, nach Marieli fragen wollte, ohne dass es die Schwester zu sehen begehrte. Ich nahm sie ins Studierzimmer,

um ungestört mit ihr sprechen zu können, u. vernahm:

Mit den Halbgeschwistern Rosa in Zürich u. Hermann in Biel, habe sie gar keine Verbindung mehr. Lina ist an Kehlkopfschwindsucht nach halbjähriger Krankheit gestorben. Anneli zog von der Stiefmutter, die es katholisch erzog, weg nach der Firmelung u. wurde Fabrikarbeiterin, wie es jetzt noch ist: Aufseherin mit 4 1⁄2 Fr. Taglohn bei Sandoz in Tavannes. Am 
selben Ort arbeitet der 23 jährige Arnold als Fabrikarbeiter, d. h. Uhrenmacher, u. nahebei, in Bevillard, ist der 27 jährige Fritz, der verheiratet sei u. ein allerliebstes Kindchen von einem Jahr habe. Die drei Geschwister stehen sehr gut zusammen, leben sehr zurückgezogen, in Frieden, aber auch sehr einsam. Anneli ist bei Bauersleuten für $50 \mathrm{Fr}$. einlogiert, u. muss abends jeweils noch im Gewerbe mithelfen, oft bis 11 Uhr. Aber sie sieht gut aus, u. namentlich, sie hat etwas ungemein liebes $u$. sanftes. Sie steht damit in grossem Gegensatz zu Marieli. Es hat mir geradezu wohl getan, diese lieben Augen, dieses sanfte Wesen zu sehen. Daneben scheint sie tüchtig zu sein. Sie wünschte eine Photographie von Marieli zu sehen, - ich gab ihr eine mit u. als Geschenk einen Louisdor, wofür sie fast kindlich dankte. Ich gab dann ihr die Adresse von Frau Bösiger, obgleich sie nicht so recht zu ihr gehen wollte, - sie trifft mit

einem Schulkameraden, der in hier nun Landjungenrekrut ist, um fünf Uhr zusammen u. wird um 6 nach Tavannes zurückgefahren sein. - Was ist jetzt das für eine Schicksalsfügung? Ich erinnere mich, wie ich mit Dir s. Z. die Schritte für Lina besprochen, die dann so kläglich scheiterten, wobei wir im Auge hatten, dass Marieli doch nicht so ganz allein gelassen werden dürfe. Und jetzt ist das Verhältnis zu Zürich zerrüttet. Sie ist allein. Zeigt sich da mit einem mal eine Hülfe? Was kann ich tun? Wie soll ich helfen? Das muss ich jetzt überlegen, u. was ich dann tue, soll rasch geschehen. Vielleicht trägt das zur Heilung der Wunden bei, die jetzt geschlagen worden sind, u. die so sehr schmerzen. Ich war ganz elend, als heute wiederum von August Gyr kein Wort der Reue eintraf! Da gibt es doch schliesslich keinen andern Weg, als Bruch mit dem Geld, u. Herz, Herz, Herz vor allem $u$. von Grund aus! Ich wiederhole, dass ich ganz unter dem Eindruck der lieblichen Person stehe. Die muss ein braves gutes Herz sein. Und etwas Liebe würde Marieli so gut tun! 
Ich werde mir die Sache weiter überlegen. Daran reiht sich weiter der Gedanke, dass sich, wenn Rossel wegzieht, vielleicht für Motta eine Wohnung zu seinem Hause finden liesse. Dann hätte ich auch da eine Nachbarschaft, mit der sich

[4]

wie ich hoffen würde, ein wohltuendes Verhältnis begründen liesse. Also auch da ein Sonnenstrahl. Wenn es mir auch im Grunde leid tun wird, Rossel als Nachbar zu verlieren. Er war in den letzten Wochen so herzlich, wie je in früheren Tagen.

So schliesst der Tag, an dem ich innerlich viel gelitten, mit einem harmonischeren Gefühl. Die Welt des Herzens kann doch nicht unter gehen! Wenn man es nur zu fassen weiss, so wird immer wieder etwas Gutes herauskommen. $O$ wie gern würde ich jetzt mit Dir über diese Dinge sprechen. Aber es muss mir die Gnade genügen, Dich mir gegenwärtig zu wissen $u$. auf dem Fundament Deiner Liebe aufzubauen!

Beim Fortgehen sagte Anneli mehrmals, ob ich jetzt nicht böse sei, dass es gekommen, aber es sei so allein ich habe das verneint, vielleicht zu wenig bestimmt, weil ich eben in grosser Bestürzung war. Die versöhnlichen Gedanken kamen mir erst, als die Schwester Marielis fort war. Jetzt aber beherrschen sie mich.

Und nun Gute, gute Nacht! Möge mir Deine Liebe den richtigen Weg zeigen, den ich suche!

Dein ewig getreuer

Eugen 


\section{2: Januar Nr. 7}

[1]

B. d. 8. Jan. 1912.

Mein liebstes Herz!

Heute hatte ich noch einen verhältnismässig ruhigen, letzten Frei-Tag. Ich hatte mir die letzte Nacht in einer wachen Stunde überlegt, wieso es doch gekommen, dass wir gegen Deinen in den letzten Jahren wiederholt geäusserten Wunsch - nicht dazu gekommen sind, miteinander andere Andacht zu geniessen als beim Natur- oder Kunstgenuss $u$. beim Vorlesen interessanter Bücher. Wieso brachten wir es nicht dazu, jene Stimmung zu pflegen, die ich jetzt je länger je mehr in mich aufnehme, die ich täglich bei den an Dich gerichteten Briefen empfinde. Die Antwort ist keine einfache. Wir waren, das ist jedenfalls ein wichtiger Grund, von Anfang unseres $\mathrm{Zu}$ sammenseins auf die Schaffung eines unseren Bedürfnissen entsprechenden Heims gerichtet, u. gingen auf in diesem Streben. Wir hatten so vieles gemeinsam an unserer äusseren Ausbildung nachzuholen $u$. richteten Jahre lang unser Streben nach dieser Seite. Du warst fremd in den Gesellschaftskreisen, in die Du Dich ja mit wunderbarem Geschick einzuleben verstanden, womit Du aber auch wieder auf Jahre ganz in Anspruch genommen warst. Für mich kam dazu mein Charakterzug, dass ich einen Plan haben muss, an dem ich mit Hingebung arbeite, in dem ich aufgehe, wenn ich nicht in ein nichtschaffendes Tändeln verfallen will. Und das Schicksal stellte mir denn auch Aufgaben genug, die mich ein halbes Menschenalter lang so sehr in Athem hielten, dass ich an nichts anderes zusammenhängendes zu denken vermochte. Ich spürte daneben wohl dann u. wann eine Leere, die in mir den Wunsch zeitigte, mich zurückzuziehen, mit 
oft für einige Stunden genährten ganz abenteuerlichen Plänen, denen Du glücklicherweise mit Erfolg Dich jeweils entgegenstemmtest. Ich wäre gewiss noch zu einem andern Fundament auch mit Dir durchgedrungen, wenn dann nicht das Schicksal es anders gewendet hätte, so dass ich jetzt allein zu diesem Neuen gelange, an dem Du so einigen Anteil genommen hättest. Ich muss mich jetzt dabei beruhigen, wenigstens in Gedanken mit Dir diese neue Welt zu schaffen. Die kurze Zeit, die mir noch hiezu beschieden sein mag, soll mich auf meinem Posten finden. Dir aber kann ich nur ein inniges Verzeichnis zurufen, dass ich nicht mit Dir zu dieser Andacht vorgerückt bin. Es wäre schön gewesen, während jetzt sich manches Bittere in diese Empfindung mischen muss, die mir in der Gemeinschaft mit Dir wenigstens nicht voll zum Bewusstsein zu kommen vermochte!

Gestern Abend vor dem Gute Nacht, da Anna schon hinauf gegangen war, kam ich noch mit Marieli, unter dem Eindruck des Besuches seiner Schwester, auf seine fatale Eigenschaft der Wortkargheit zu sprechen u. ermahnte es, doch bitte ja etwas gütiger u. lieber zu werden. Es antwortete unter Thränen, dass es in der steten Gemeinschaft mit Anna, mit der es über nichts reden könne - u. das ist wahr--, sich so einsam fühle, $u$. heute legte es die folgenden Worte, die es gestern Abend noch auf seinem Zimmer geschrieben habe, auf meinen Tisch: «O liebster, bester Vater, glaub es mir, Ganz unbegrenzt ist mein Vertraun zu Dir! In Dir halt' ich umfangen meine Welt, Von Dir aus strömt der Lebensquell, der mich erhält. Doch Worte find ich nie für mein Empfinden, Gequält muss ich den Andrang der Gefühle tragen,

Muss, was mein Sein erschüttert, einsam klagen, der schweigenden Natur, den Sternen, Wolken, Winden!» Und diese Worte sind ächt. Als August Gyrs Verleumdung sie so tief traf, da sagte sie erst nur - er ist verrückt. Als wir aber dann darüber sprachen, brach sie mit einem mal in ein 
wildes Schluchzen aus u. rief: O wie gut, dass Mama das nicht noch erleben musste».

Von August Gyr ist auch heute noch nichts eingetroffen. Ich überlegte, ob ich seinem Vater einen Schiedsmann vorschlagen soll, etwa Emil Gwalter, der die schwere Schmach, die Marieli zu so grässlichem Unrecht, angetan worden, mit seinem Spruch beseitigen könnte. Aber heute Abend bin ich wieder zweifelhaft. Ich will jedenfalls diese Woche noch nichts darüber beschliessen. Auch heute beschäftigte mich diese Sache zuerst in peinlichen Gefühlen. Gegen Abend wurde ich ruhiger $u$. befinde mich noch in dieser Verfassung. Ich bin heute früh aufgestanden $u$. habe bis zehn Uhr das Gutachten über die Anfragen der Kreditanstalt an das Departement geschrieben. Nachher war Guhl längere Zeit in Amtssachen bei mir. Am Nachmittag las ich als letzte Ferienlektüre Lienerts «Hochmutnärrchen» fertig, mit gemischten Gefühlen. Dann besuchte ich Frau v. Rappard im Sanatorium. Es geht ihrer Tochter ganz schlecht. Die Schwester, die mich hinauf führte, meinte, es wäre ihr zu wünschen, dass sie bald sterben könnte. Sie habe ja doch keine Freude mehr am Leben. Der Krampf in den Gliedern scheint sich jetzt auf die Athemorgane ausgedehnt zu haben, $u$. sie leidet furchtbar. Ihre Mutter empfing mich sehr gefasst u. sprach mit mir über die deutsche Politik u. die [?] in Europa u. Südamerika.

Ich bewunderte mit gemischten Gefühlen diesen Gleichmut der alten, hinfälligen Dame. Aber sie war sehr herzlich zu mir. - Dann machte ich wieder einmal Besuch bei Emil Welti, dem ich das Geld für das Rechtswörterbuch zu überbringen hatte. Ich traf auch die Dame u. unterhielt mich ein Stündchen ganz gut mit ihnen. Es geht ihr nach dritter Kur in Karlsbad bedeutend besser.

Von Albert Heim erhielt ich heute die versprochene Abschrift der Adresse, die von den Fakultätskollegen an ihn mit Unterschrift aller gerichtet wurde u. die Kleiner verfasst hat. Sie ist ein Meisterstück des - Tadels über den Rücktritt verbunden mit Glücks- u. Segenswünschen. Mich hätte so was nicht gefreut. Ich wäre aber auch nicht so zurückgetreten, wie er 
es tat. Davon hast Du mich noch zurückgehalten, als Du bei mir warst, $u$. wird mich künftig meine gewonnene Grundstimmung zurück halten.

Und so komme ich zum Schluss wieder auf den Anfang zurück. Lass mich festhalten an dieser Lebensquelle. Bleibe mein Segen, wie Du es allezeit gewesen bist!

Dein ewig getreuer

Eugen

\section{2: Januar Nr. 8}

B. den 9. Jan. 1912.

Liebstes Herz!

Heute haben die Vorlesungen wieder begonnen. Bei scheusslichem Regen u. Schneeflotsch mit zerbrochenem Schirm stieg ich hinauf u. traf im Gang der Universität Bieri mit einer Vase voll Rosen. Ich fragte ahnungslos, für wen das sei, erhielt aber keine Antwort. Im Professorenzimmer teilte ich das Marti mit, u. da sagte der, das werde für mich bestimmt sein. Ich lachte, hatte aber doch noch Zeit, mir in drei Minuten zu überlegen, was ich sagen sollte, wenn dem so wäre. Und richtig, wie ich ins Auditorium kam, begrüsste mich ein anhaltendes studentisches Getrampel. Ich dankte für die Überraschung, Rosen auf den Weg des Zivilrechts gestreut u. erste Stunde über ZGB. als geltendes Recht. Wenn ich nur eine Ahnung gehabt hätte, so würde ich die denkwürdige Stunde anders eingeleitet haben. Ach, u. die Geschichte mit Aug. Gyr hatte mir die letzten Tage allen Mut u. Schwung geraubt. Eine kurze Hinweisung auf die Arbeit der heranwachsenden Juristen $u$. ihre Aufgabe schloss meine Ansprache, die nochmals mit Getrampel beantwortet wurde. Am Nachmittag war Hoffmann in der Politik, was mich freute. Bei der Rückkehr lag endlich eine Antwort von A. G. da, eine correcte Entschuldigung. Aber mit dem Beifügen, dass ihm der 
Vater das diktiert habe. Ich will nichtsdestoweniger mich dabei beruhigen. Ich schrieb dann an Base Anna einen Brief, den ich Dir wirklich mitteilen will.

«M. l. B.! Dein lieber Brief hat mich sehr bewegt. Ich würde die Angelegenheit ja vollständig ignoriert haben, wenn nur meine

Ehre angegriffen gewesen wäre. Aber es handelte sich um den guten Ruf eines jungen Mädchens, um einen Angriff auf das gute Kind, nicht nur direkt, sondern durch Zuschrift an dritte, an die Eltern eines Collegen. Das durfte ich nicht auf ihr haften lassen. Es fiel mir nicht ein, gerichtlich vorzugehen, aber August musste dessen bewusst werden, was er getan hat. Und ich hielt mich auch für verpflichtet, Euch, seinen lieben Eltern davon Kenntnis zu geben u. Euch um Eure Hülfe zu ersuchen. Nun habe ich soeben eine Abbitte von August erhalten. Von meinem Neffen, den ich wohl kenne, schreibt er nichts mehr. Die Abbitte ist vollständig u. vorbehaltslos. Sie genügt mir, obgleich August beigefügt, sein lieber Vater habe sie ihm diktiert. Ich beruhige mich bei der förmlichen Erledigung. Aber wir haben alle schwere Stunden erlebt!

«Nur für Dich, liebe Base, u. für Deinen verehrten lieben Mann füge ich jetzt noch bei, dass Lüdemanns bei aller Entrüstung die Anklage gegen Marieli ganz auf den Briefsteller selbst zurückfallen liessen, u. dass der Verkehr zwischen ihrer Tochter u. meiner in der Folge nicht gelitten hat, sondern inniger geworden ist. Über die Verlobungsangelegenheit selbst kann ich Dich mit wenigen Worten hinreichend aufklären. Paul - früher schon von Marieli eher geflohen machte sich im August förmlich durch mich an sie. Sie lehnte aber die Bewerbung entschieden ab. In den folgenden Monaten konnte sie wahrnehmen, wie sehr mein lieber Bruder an dem Plan hing, ich sprach auch hie u. da davon, dass Paul sich doch zu einem tüchtigen Fachmann heranbilden dürfte. Auch die Verlobung mit Frl. Bovet, die er zwei Monate vor der Hochzeit gebrochen, dürfe man ihm nicht zu sehr anrechnen, man kenne ihn noch nicht u. s. w. Es war u. blieb eine gedrückte Stimmung, nicht ohne meine Schuld. Und dann überraschte mich Marieli im November eines Morgens mit der Nachricht, dass sie Paul geschrieben $u$. ihm eröffnet habe, dass sie sich anders besonnen. Ich erschrak fast u. doch freute es mich. Marieli erklärte, sie finde, dass sie ihm mit der Abweisung Unrecht getan, dass es bräver von ihm sei, wenn sie sich dem Wunsch Onkel Augusts, den sie sehr verehrte, füge, zumal es doch auch 
mein Wunsch sei. Sie wolle ein gutes Kind sein u. ihr Glück in dem unseren suchen. Paul kam u. es schien auch bei diesem ersten Besuch alle Aussicht

auf einen guten Fortgang des Verhältnisses gegeben zu sein. Dann drängte Paul darauf, dass die Hochzeit nächstes Frühjahr stattfinden müsse. Marieli wurde dringendst

auf Sonntag den 26. Nov. nach Zürich gerufen u. gleich darauf schon auf, Freitag, damit

die Möbel - die s. Z. für den Haushalt mit der Bovet bestimmt waren von ihr ange-

nommen wurden. Sie ging - u. kam am Sonntag mit dem Verlobungsring, aber ganz gebrochen zurück. Erst am Montag entdeckte sie mir, dass sie unter allerlei Eindrücken schwer gelitten. Aber es werde schon gehen, sie bleibe dabei, sie halte ihr Wort. Zugleich aber bekam sie einen Anfall von Herzklopfen, den sie schon in ihrer Seminarzeit infolge Überanstrengung gehabt. Ich liess den Hausarzt, Dr. Dumont, rufen. Dieser konstatierte eine bedenkliche Herzschwäche u. eine Dämpfung auf ihrer rechten Lunge. Am folgenden Tag untersuchte er das Mädchen nochmals, die Sache war nicht besser. Er erklärte mir, dass eine Verlobung u. nahe Heirat für Marieli lebensgefährlich sein müsste. Ich bat ihn, mir darüber zu schreiben. Er tat es, u. nun war ich entschlossen. Ich verabredete mit meinem 1. Bruder eine Zusammenkunft in Olten, teilte ihm den Sachverhalt mit u. er ging, wenn auch schweren Herzens, freundlich darauf ein u. nahm den Ring aus meiner Hand zurück. Paul liess die ganze Zeit nichts von sich hören. Das erste, was ich dann wieder in der Sache vernahm, war der Brief eures Sohnes. «Noch muss ich anfügen, wie es sich mit dem Besuch des«Studentenballes» von dem Konrad zu Eurem August gesprochen, verhielt. Die Sache ist sehr unschuldig. Am Donnerstag vor jener Fahrt nach Zürich fand ein Tanzkränzchen statt, ohne Ballherr, sondern in freier Vereinigung, wobei Marieli schon Wochen vorher ihre Zusage gegeben $u$. sich mit der Tochter von Prof. Röthlisberger verabredet hatte. Ich selbst riet ihr, es noch mitzumachen, da doch die Verlobung noch nicht erfolgt sei u. eine Absage auffallen würde. Mit dieser Freundin, deren Bruder u. einem andern stillen, bescheidenen Professorssohn ging sie hin $\mathrm{u}$. alle vier kehrten auch wieder als die ersten zurück. Freilich musste sie dann gleich folgenden Tags schon unerwartet nach Zürich fahren. Aber als die schlimmste Seite an der ganzen Verleumdung, dass man Marieli dieses Zusammentreffen zu einem ehrenrührigen Vorwurf stempeln wollte! 
«Du weisst nun, liebe Base, alles wesentliche. Behalte es für Dich. Marieli würde sicher ihr Wort gehalten haben, $u$. wenn sie darüber zu Grunde gegangen wäre. Aber ich, ich durfte das nicht geschehen lassen. Und ich fühle mich vor mir

selber gerechtfertigt.«Ich danke Dir u. Vetter August aus tiefstem Herzen für die treue Art, in der Ihr mir beigestanden. Wolle Gott, dass die unglückliche Begebenheit damit beendigt $\mathrm{u}$. begraben sei!

«In treuer Anhänglichkeit Dein Vetter E. H.

«P. S. Ich danke auch noch besonders dem lieben Vetter für die gütigen Zeilen aus München. Ich würde ihm noch direkt schreiben, wenn es nicht besser wäre, denke ich

von der ganzen Sache nicht mehr zu reden.»

Hoffentlich habe ich mit diesem Brief nicht fehl gegriffen. Ich schrieb ihn aus einem innern Drang heraus!

Nun muss ich auch noch Ida, die von der Verleumdungsgeschichte sicher nichts weiss, wenigstens über die Verlobung u. ihren Rückgang ungefähr denselben Aufschluss geben. Dann ist hoffentlich die Sache erledigt. Mich hat sie tiefer aufgewühlt, als ich es mir zugestand. -

Und nun auch Schluss für diesen Tag. Der morgige bringt mir wahrscheinlich eine Unterredung mit Frau Bösiger.

Ich bin Dein getreuer

Eugen

Marieli hat die Rosen der Studenten heute Abend nach

Hause gebracht. Die grosse schöne Vase ist mit bei dem Geschenk!

Wie soll ich mich ohne Dich bedanken? 


\section{2: Januar Nr. 9}

[1]

B. d. 10. Januar 1912.

Mein liebstes Herz!

Ich war heute ein Objekt verschiedener Vorfälle, die mich in eine ziemlich gleichgültige Stimmung versetzt haben: Es geht drunter u. drüber. Also ruhig dabei. Es kommt ja doch alles wieder anders. Diesen Charakter des Tages, an dem ich viele Briefe zu schreiben hatte, entsprechend, will ich Dir nun die Dinge der Reihe nach aufzählen.

Mina Beetschen aus Thun war bei Marieli zu Besuch, über Nacht, Marieli daher wenig sichtbar. Von den von ihr heimgetragenen weissen Rosen berichtete sie heute, dass auch die Vase zum Geschenk gehöre. Wer die Gabe gespendet hat, konnte mir der Pedell nicht sagen.

Von August Gyr kam ein Expressbrief, worin er seinen «Hochverehrten Onkel» nun reuig u. ohne auch nicht indirekten Vorbehalt (wie gestern) um Verzeihung bat. Von Konrad wieder kein Wort.

Guhl ist als Chef des Grundbuchamtes gewählt. Er war hier u. hat allerlei vorgebracht, was zeigt, wie viel Nachlässigkeit in der Bundeskanzlei herrscht. Und Werner Kaiser muss zu wenig streng eingeschritten sein.

Ein Notar, Gegensller, konsultierte mich über die erste Gemeindeschaft, die in Bern gegründet werden will, u. die ist falsch.

Die N. Z. Z. brachte die Nachricht, dass das Justizdepartement

in der Frage des Eigentümervorbehaltes sich so u. so geäussert. Abend stand, das Bundesgericht habe sich gegenteilig erklärt. Und der Bundesrat bereitet einen Beschluss vor, der sich dem B.Ger. anschliesst. 
Dr. Siegwart weiss bald nicht mehr, was er zu tun hat, indem ich keine Zeit finde, ihm Arbeit vorzubereiten.

Endlich die Hauptsache: Ich bat Frau Bösiger zu mir. Sie erzählte mir von dem Besuch des Anneli Röthlisberger. Ich teilte ihr den guten Eindruck mit, den das Mädchen auf mich gemacht, u. sagte ihr, ich hätte an verschiedene Pläne gedacht: Sie einen Beruf lernen zu lassen. Dazu fand Frau Bösiger Anneli als zu alt. Oder sie in unser Haus aufzunehmen. Diesfalls warnte mich Frau Bösiger sehr anständig vor dem «Anhang», u. ich hegte Zweifel über das gute Verhältnis der beiden Schwestern, die doch in verschiedener Stellung im Hause stünden. Oder den drei Geschwistern zu einer Position zu verhelfen. Aber sie seien ja so zufrieden. Lasse man doch, wie sie sind, meinte Frau Bösiger. Und so wird es nun wohl wirklich das Gescheiteste sein! - Aber Frau Bösiger sprach ernstlich davon, ich sollte Marieli nun doch endlich von dem Sachverhalt unterrichten. Die verschlossene Stimmung rühre wohl davon her, dass sich Marieli in einer ihm nicht aufgeklärten Lage befinde. Und sie hat vielleicht recht. Nun ja, ich lege eine Illusion um die andere ab. Möge auch diese fallen. Ich suche ja schon lange nach einer Gelegenheit mit Marieli zu reden. Aber die Geschichte mit Paul, von der ich doch Frau Bösiger nichts sagen konnte, hat mir wieder

alles verschoben. Geduld, Geduld! Ich muss mich nun eben darein finden, dass Du mir nicht mehr zur Seite stehst. Aber Du wirst mir doch helfen, damit die Sache zu einem guten Ende kommt. Der stete Umgang mit der einzigen Tante Anna ist natürlich nicht förderlich.

Frau BRat Müller hat heute persönlich mich u. Marieli auf den 21. zum Essen eingeladen. Sie sagte zu Anna, sie werde nicht mehr kommen wollen, u. Anna hat das bestätigt, aber weiss Gott unter Zaudern. So war sie ja immer, u. ich kann mir denken, wie das auf Marieli, wenn auch unbewusst, drückt. Nicht vergessen darf ich noch anzufügen, dass Stooss mir einen warmen Glückwunsch zum 1. Jan. schrieb mit einem sehr gedrückten Vergleich auf seine Stellung bezogen. Er hat ja Recht. Wir sind eben in verschränkte Stellung geraten. Mir wäre 
wohler in seinem Amt, u. ihm in meiner Stellung. Aber gerade er hat ja diese Situation herbeigeführt, über die ich ihm schon 1898 bei Anlass der Berufung nach Wien ganz in diesem Sinne geschrieben.

Anfügen will ich auch noch, dass das andauernd nasskalte Wetter mich etwas rheumatisch gemacht hat. Ich wurde von dem Gang zur Universität u. bis zur Rückkehr heute sehr müde. Und doch hatte ich gerade in diesen Tagen mich nicht überarbeitet. So siehst Du, in welcher Verfassung ich heute gestanden habe: Wenig Freude, aber auch kein tiefes Leid. Sondern Resignation in dem Stand der Umtriebe, in dem ich mich nun einmal befinde, u. deren ich nicht Herr werden kann. Ich sehe keine Möglichkeit

[4]

darüber hinaus zu kommen, als mit der Zeit, mit der Zeit, die vielleicht gar bald in mir abbricht!

Doch vorwärts! Halte zu mir, einzig treue Seele, wie ich verbleibe

Dein Eugen

1912: Januar Nr. 10

B. den 11. Jan. 1912.

Mein liebstes Herz!

Mein Unwohlsein hat heute angedauert, ich las mühsam meine drei Stunden. Daneben konnte ich nur einige Briefe erledigen $u$. die nötigen Präparationen für die Bücheranschaffungen der Bibliothek beginnen, die nächste Woche beschlossen werden sollen. Um halb zwölf erhielt ich einen unerwarteten Besuch: Münger mit seinem Freund Otto von Greyerz kamen, der Künstler wollte seinem Freund die Scheiben zeigen. Das Zusammentreffen mit 
Otto von G. rief in mir natürlich allerlei Erinnerungen wach. Wenn damals Greyerz (1905) auf eine andere Fährte gekommen wäre - die geschichtliche Pointe der Berta Regina entdeckt hätte, wie würde das mein Leben umgestaltet haben. Und für Dich wärs auch eine grosse Freude gewesen, denn Du hingst an dem Werk, ich fühlte es wohl. Dafür kamen dann ja die andern Erfolge. Ich muss damit zufrieden sein. - Heute bin ich übrigens noch, abgesehen davon, dass ich mich unwohl fühle, aus zwei besondern Gründen niedergeschlagen. Das Durchblättern der Litteratur des Jahres zeigt mir auch diesmal wieder, wie ich zu nichts mehr komme, wie mein Gedächtnis den gewaltigen Stoff nicht mehr umspannen kann. Ich könnte aus Mutlosigkeit alles auf die Seite werfen, wenn ich diese riesige Produktion überblicke u. mich nirgends mehr recht zu Hause fühle. Es ist

zu viel für mich, u. ob ich an Walter B. u. an Thormann die rechte Unterstützung diesmal eher als früher finden werde, ist doch sehr zweifelhaft. Es fehlt auch an der fachmännischen Leitung durch v. Mülinen. Er ist in Bezug auf die Bücheranschaffungen fast eine Null, er ist nur Verwaltungsbeamter. Daneben von gutem Willen u. gefällig. Wenn ich aber denke, wie an der ehemaligen Hochschulbibliothek Hermann u. sein letzter Nachfolger jeweils vorgearbeitet hatten, so überkommt mich gerade darob die Mutlosigkeit: Ich habe die Zeit nicht, die Lücke auszufüllen, u. so bleibt die Sache eben ohne die so nötige richtige Leitung, was mir leid tut. - Das zweite, was mich heute beschäftigte, war, dass Marieli wieder in die alte Unart verfiel, nichts ass, auch Abends nicht, u. stumm war. Das wurde herbeigeführt, oder doch gefördert durch einen Streit mit Sophie, in dem diese entschieden Unrecht hatte, Marieli aber sich nicht recht benahm. Ich hatte bestimmt, dass Marieli jetzt jede Woche einen Tag kochen müsse, u. sie hatte mit Sophie ausgemacht, dass dies jeweils am Donnerstag geschehen soll. Vor acht Tagen war sie verhindert, besorgte dann am Sonntag die Küche, u. heute wieder. Sophie sah es ungern u. protestierte dagegen, dass die Küchenfenster nicht vollständig 
geöffnet werden. Marieli u. Anna wollten es machen, wie es s. Z. unter Kathri geschehen sei. Und so kam es zu einer Szene, bei der Marieli schwieg u. nur bemerkte, Sophie

soll mit mir reden. Das tat nun Sophie nicht, u. Marieli erwartete, dass ich sie zur Rede stellen solle. Aber das tat dann ich nicht. Und darob wurde es innerlich ergrimmt. Gestern Abend hatte es in Roseggers die beiden Hänse vorzulesen begonnen, mit Freude. Ich nahm an, es sperbere auf die Gelegenheit heute fortfahren zu können. Aber es schien es ganz zu übersehen. Ich werde es aber heute Abend noch daran erinnern. Das ist eben der alte Fehler Marielis, streng, hart, ohne Liebe im Äusseren, daneben voll innerer Bewegung, gerecht $u$. gescheit. - Es tut mir leid, dass nach Bewältigung der Affaire mit August Gyr heute gleich wieder etwas Neues passieren musste. Aber ich kann es nicht ändern. Mit Mägdegeschichten hast Du mich soviel als nur möglich verschont, $u$. ich werde mich nicht in ein neues Fahrwasser treiben lassen. Lieber gebe ich den Haushalt auf.

Doch will ich nicht Kleinigkeiten aufbauschen. Ich wollte hier nur darüber schreiben, um die Eindrücke los zu werden. Und ich fühle auch wirklich schon die Beruhigung, die ich erhofft. Mag auch alles u. alles mangelhaft sein. Die Hauptsache liegt ja ganz anderswo. Und die will ich festhalten. Gute Nacht, meine beste, liebste Seele! Ich will ja gerne aushalten u. alles hinnehmen. Stehe nur Du im Geiste zur Seite!

Dein ewig getreuer

Eugen 


\section{2: Januar Nr. 11}

[1]

B. d. 12. Januar 1912.

Mein einziges Lieb!

Es ist bald acht Uhr. Ich hatte, mangels einer andern freien Stunde des Tages Dr. Nauer aus Zürich, der mich absolut sprechen wollte, auf sieben gebeten. Er kommt nicht, u. so beginne ich noch vor seinem Eintreffen diese Zeilen an Dich. Heute war es wieder wie in einem Taubenschlag bei mir, u. auf morgen habe ich vier Consultationen etc. der Reihe nach ansetzen müssen. Dazu drei Anfragen, die schriftlich beantwortet sein wollen, u. eine Dissertation auf Lager!

Ich werde schon hier durch den Besuch von Nauer unterbrochen, der ein Stündchen geblieben ist. Ich vernahm allerlei Neues von ihm, er hat nun den ganzen Verlag Orell Füssli unter sich u. scheint ein sehr rüstiger Mann zu sein. Ich hatte Freude an seiner kräftigen Art, die er aus seinen Studentenjahren sich erhalten hat. Es erscheint bei ihm demnächst ein Buch von Tuor, das dieser selber mir heute mit einer freundlichen Karte angekündigt hat. Er macht mir auch Mitteilungen über den Verlag, die Fusion des [?] u. der Monatsblicke für [?] u. [?] etc. etc. Auch will er eine Serie populärer Schriften herausgeben, zu der ich ihm den einen $u$. andern jungen Mann nennen sollte. Vielleicht ergibt sich etwas für Dr. Siegwart daraus. Er schied mit freundlichem Dank. Am Nachmittag war Hänny wieder da u. hat drauf los modelliert. Das Relief soll morgen fertig werden. Nachher

[2]

war ich auf der Bibliothek u. da kam zufällig auch Frau Dr. Bühler-Flückiger, die sehr nett u. gescheit auftrat. Wie merkwürdig doch die Schicksale. Bühler hat im Leben voll Libertinage gehabt, bis er dann als über Fünfziger dieses reiche Fräulein, die selbst nicht mehr jung geheiratet hat, u. jetzt entwickelt sich 
diese in der Ehe zu einer ganz famosen Frau, die jedenfalls an den neuesten Entwicklungsphasen ihres Mannes einen grossen Anteil hat. Die Moral ist von eigener Gestaltungsgabe. Man muss es anerkennen, dass gar oft Persönlichkeiten bis zu einem gewissen Alter sich gerade bei stark entwickeltem Tätigkeitstrieb sich auf unmoralischen Pfaden bewegen, u. schliesslich doch darüber hinauskommen $u$. besonders Tüchtiges leisten - was ich freilich von Bühler auch nicht mehr gerade erwarte. Aber er ist doch eine grosstrabende, imponierende Natur. Während Andre von jungen Jahren an sich an die Moral anklammern u. sich nicht darüber hinaus zu einer wirklichen Tüchtigkeit zu entwickeln vermögen.

Als ich aus der Bibliothek nach Hause kam, waren Frl. Siegwart, Alfreds Schwester, u. die Sängerin Marietta Amstad in der Stube. Die letztere hatte in Zürich mit einer Frl. Alioth ein Konzert gegeben mit gutem Erfolg $u$. war auf der Durchreise nach Genf, wo sie heute singt. Sie war sehr bereit auch uns ein paar Lieder $u$. Arien zu singen $u$. ich freute mich über ihren glockenreinen Sopran u. die prächtigen Coloraturen. Sie denkt daran auf die Bühne zu gehen, u. lässt sich zu diesem Zweck von einer ital. Sängerin in Turin

ausbilden. Sie war schon letztes Jahr einige Monate dort u. reist jetzt wiederum hin, um bis zum April zu bleiben. Am Nachmittag kam Gerichtspräsident Raaflaub, um mich in einer wichtigen Frage zu consultieren. Zugleich wollte der Doktorand Hans Hauser mit mir über seine verunglückte Dissertation sprechen. Während ich im Praktikum war, kam endlich Frau Vogel u. brachte Bericht, dass Frau Welty demnächst schreiben werde, Marieli könne die paar Monate zu ihnen kommen, es werde ihm und Lineli gut tun. Also das Gegenteil von dem, was ich erwartet hatte. Aber es ist auch nicht sicher, ob wirklich Frau Welty uns das genannte schreiben wird. Merkwürdigerweise fiel Marieli sofort wieder ab u. meinte, es würde doch lieber hier bleiben. Es würde gerne im Frühjahr mit mir reisen u. doch, wenn ich das vorschlüge, wäre es gewiss damit wieder nicht zufrieden u. würde wohl meine Reise wieder in ähnlicher Weise mit 
stummem Trübsein füllen, wie voriges Jahr bei der Fahrt nach England. Das Mädchen bereitet sich innerlich ein schweres Schicksal. Merkwürdigerweise hat August Gyr jetzt noch die Sammlung von Leipziger Ansichtskarten geschickt, von denen er schrieb, er hätte sie aus Zorn über Marielies Treiben verbrannt. Wir werden nicht darauf antworten. Von Walter B. vernahm ich, Marieli bestätigte es bei einem Besuch, dass es seiner Frau gar nicht gut gehe. Sie habe starke Unterleibsschmerzen. Heute Abend sollen Deucher u. der Dr. Burckhard in Basel sie untersuchen. Am Ende gibt es hier doch noch einen Abschluss, das wäre merkwürdig. Walter B. schien heute im Dozentenzimmer viel besorgter zu sein, als

dies bishin zu Tage getreten ist. Aber es wird auch wieder vorüber gehen.

Nun muss ich noch verschiedene Amtssachen erledigen, habe auch Rossel versprochen an Spahn zu schreiben wegen seiner Candidatur fürs Bundesgericht. Marieli ist in den akademischen Vortrag von Mague gegangen, wohl indem sie froh war, heute wieder nicht vorlesen zu müssen. Und doch tut sie das nicht ungern. Sie hat nur kein Feuer dafür. Und nun schliesse ich ab, will bald zu Bett. Es ging mir zwar heute viel besser, ich hatte Müdigkeit u. rheumatisches Empfinden in der letzten Nacht ganz weggeschlafen. Will aber doch auf zehn zu Bett!

Gute, gute Nacht! Ich bleibe wie immerdar Dein getreuer Eugen 
B. den 13. Jan. 1912.

Meine liebste Lina!

Heute war, wie ich vorausgesehen, Sturm bei mir, u.

die Inanspruchnahme wurde noch verschärft durch meine Erlebnisse.

Am Morgen kam Hänny zu mir u. brachte das Medaillon

fertig. Ich glaube es wird sehr ähnlich, wenn auch der Ausdruck

weder mich noch den Künstler ganz befriedigt. Noch während H.

bei mir war, kam der Candidat Hauser u. wollte über seine

verunglückte Dissertation allerlei weitern Aufschluss, ohne un-

bescheiden zu werden, aber doch in diesem Moment lästig, namentlich

da er seine Fehler nicht so leicht einsah, auch wenn sie handgreiflich

waren. Kaum war er fort, so traf auf halb elf der Rechtskonsulant

der Nationalbank ein, der ich ein Gutachten über compte jointe

erstellen soll. Dann konnte ich noch mit der Lektüre der

neuen Auflage der Dissertation Kuhns beginnen, musste aber

nach dem Essen zunächst die Abrechnung der Kreditanstalt prüfen, was mir ziemlich umständlich wurde u. allzu viel an August

erinnerte. Ich schrieb dann ein kleines Gutachten für Luz in

Lutzenberg. Nachher kam Guhl in wichtigen Fragen u. blieb über

eine Stunde. Rechne die Post dazu, so siehst Du, dass der Tag gefüllt

war. Nun aber das Innere.

Am Morgen las ich der Zeitung, dass Klara v. Rappard im

Sanatorium gestorben sei, u. vor zwölf kam Frl. Hilty im Auf-

trag der Mutter, es mir zu melden. Sie fordert mich auf am

Montag 2 Uhr der Kremation beizuwohnen. Ich liess durch

[2]

Marieli einen Kranz besorgen mit einer Karte, auf die ich schrieb: ... nimmt innigsten Anteil an Ihrem schweren Leid. Das Andenken an eine edle Persönlichkeit breitet über den herbsten Schmerz eine versöhnende Beruhigung: Das Gute u. Schöne ist ewig!» Morgen will ich der Mutter condolieren u. 
Montags werde ich der Beisetzung anwohnen. - Dann brachte die Post von Frau Welty in Seon, worin sie nun richtig Marieli auffordert, bei ihnen eine längere Zeit in St. Hilario zu verweilen. Noch letzte Woche würde Marieli das, wie ich glaube, mit Freude angenommen haben, Heute blieb sie stumm u. meinte nur, es ziehe sie gar nicht nach Italien, sie habe eine wahre Sehnsucht nach Deutschland. Ich machte sie auf diesen Wechsel aufmerksam, worauf sie entgegnete, sie wisse schon, dass sie wankelmütig sei. Aber sie wolle gewiss das tun, was ich für vernünftig halte. So bin ich wieder am Ende mit meinem Plan. Ich weiss nicht, was ich machen soll! Von Paolina Crugnola habe ich noch keinen Bericht. - Die gleiche Post brachte noch einen andern Brief, ein Schreiben von Fritz Röthlisberger aus Bevillard, worin er für die gute Aufnahme der Schwester Anneli dankt u. die Hoffnung ausdrückt, auch bald seine Schwester kennen zu lernen. Also richtig, der Anhang, von dem Frau Bösiger sprach, wäre da! Ich weiss auch da nicht, was ich machen soll. Ich komme mit Marieli nicht aus den Aufregungen heraus. Am besten werde ich mir Zeit lassen, aber in nicht zu ferner Zeit muss ich mich eben doch entscheiden. Und das alles in einer Zeit, wo ich alle Hände voll mit anderm zu tun habe! Manchmal über-

steigt diese Last die Kraft meines Herzens u. ich möchte allem entfliehen. Aber ich kann nicht. Nun, geschehe, was wolle, ich will mich halten, solang ich es vermag!

Unangenehm berührt hat mich, dass die Carten der Müngerschen Scheiben bei Frencke ausgestellt werden sollen. Also muss ich doch noch erleben, was ich vermeiden wollte. Und mein Spässchen vom Neujahrstag mit dem Trinken ab der Röhre u. nicht aus dem Trog bringt heute das Intelligenzblatt in einer Umbildung, die das wesentliche nicht wiedergibt. Ich erzählte die Sache den ComitéHerren mit Bezug auf Gesetz u. Kommentar. Und jetzt wird es mit Gesetzesverfasser u. Fürsprech-Notar in Verbindung gesetzt. Endlich muss ich als etwas Unangenehmes anfügen, dass Frau Schory träge u. unartig wird, u. dass Sophie seit dem Kochen von letztem Donnerstag mit Marieli unverschämt $\mathrm{u}$. sonst unartig geworden ist. Und auch damit soll ich mich jetzt befassen, während Du so 
sorglich alle diese Mühen von mir fern gehalten hast!

Ich würde noch vor Kurzem aus diesem Allem den Schluss ge-

zogen haben: Fort, weg von Allem, - aber jetzt vermag ich nicht mehr so zu denken. Ich muss aushalten, gehe es wie es wolle!

Frau Prof. Burckhardt hat nach dem Befund der beiden Ärzte, von denen ich gestern schrieb, eine schwere Ischias, u. vielleicht eine Herzaffektion. Bleibt nun abzuwarten, wie sich die Dinge entwickeln. Walter dauert mich jetzt. Ich will nun noch einiges in Kuhns Dissertation lesen u. nachher will Marieli mit Roseggers beiden [?] fortfahren. Das Surchabis-Essen der Helveter, zu dem ich auf heute Abend eingeladen war, schwänze ich. Ich kann, ich kann nicht, so sehr es

mir wohltäte, wieder einmal in froher Gesellschaft zu sein. Allein, das ist nun eben doch vorüber, ich bin u. bleibe allein. Damit schliesse ich auch diese Woche. Die Zeit fliesst rasch, es muss doch bald ein Ende haben!

Dein ewig getreuer

Eugen

\section{2: Januar Nr. 13}

Bern, den 14. Jan. 1912.

Mein liebstes Herz!

Ich habe heute die Dinge ruhiger genommen als gestern.

Den Vormittag schrieb ich einige Briefe u. hatte Besuche: Von

Deringer, dem Oberstammer, der mir einen sehr guten

Eindruck machte. Ein netter 23jähriger Bankbeamter, der sehr dankbar schien, dass er zu mir kommen durfte. Und dann Walter B. Das Leiden der Frau Prof. ist Ischias. Hervorgerufen durch einen Druck von Exudaten auf den 
Hüftnerv, eine ausserordentlich schmerzhafte Sache, die aber schwindet, sobald die Geschwulst abnimmt. Er war sehr niedergeschlagen, aber nicht mehr ängstlich. Am Nachmittag las ich etwas in Kuhns Dissertation, hatte Besuch von Prof. Barths, die sehr lieb waren. Ich konnte auch mit Marieli plaudern, kam mit ihm ins Reine, dass ich nochmals an Frau Welti schreibe, um zu erfahren, ob ihr die Einladung wirklich ernst ist, vielleicht auch dass inzwischen von Frau Crugnola etwas berichtet wird. Ich wollte auch mit Marieli Guhls besuchen, die aber ausgegangen waren. Von den Berner Notaren erhielt ich eine Danks- $u$. Vernehmungsdepesche, die mich freute. Sophie war unwirsch. Ich dachte einen Moment daran, mit ihr zu brechen u. wieder auf die Schwester in

Malleray zu rekurrieren. Aber ich will den Bruch ihr überlassen. In meinem Alter nimmt man die Sachen anders. Ich habe auch Marieli überzeugt, dass Geduld hier einzig helfen könne. Was würde nach her kommen? Da gilt der Spruch vor allem, in solchen Kleinigkeiten: Lieber die bekannten Übel tragen, als zu unbekannten fliehen. Marieli hat heute wieder von Abbühl zu sprechen begonnen u. mir gestanden, dass sie erst seit dem Missverständnis betr. Ihr Billet tiefer an ihn denke. Ja, es kommt jetzt eben allmählich erst überhaupt eine grössere Tiefe über sie. So muss man nun abwarten. Sie war im Zweifel, ob sie den Helveter Ball mitmachen, oder gerade um ihm zu entgehen nach Italien fahren soll, u. zwar entstand dieser Zweifel nicht aus den Eindrücken der Geschichte mit Paul, sondern merkwürdigerweise wegen Abbühls. Ich riet ihr unter diesen Umständen doch eher noch mit zu machen. Es wird sich aber weisen, was zu geschehen hat, wenn einmal entschieden ist, ob Marieli irgendwo in Italien eine Unterkunft finden kann für zwei bis drei Monate. An die Geschwister in Mallerey dachte ich heute wieder namentlich unter dem Eindruck der Vereinsamung gegen- 
über meiner Familie. Da wird nun Marieli, wenn

ich tot bin, gar keinen Anschluss mehr haben. Was dann?

Soll sie so einsam durchs Leben, falls sie keinen Mann findet? Soll ihr nicht in ihrer angestammten Familie ein Ersatz zu finden sein? Die drei Geschwister im Jura scheinen nette, bescheidene Leutchen zu sein. Sie gehören, wie mir Frau Bösiger sagte, zu den Temperenzlern, u. nach dem Brief von Fritz sind sie auch fromm. Das ist doch alles ein guter Boden, u. möglich wäre es gewiss, durch eine Anknüpfung für Marieli Ersatz zu schaffen. Aber ich muss mir gestehen, dass die Sache nicht eilt, dass ich mit Ruhe den Dingen die weitere Entwicklung überlassen kann. Nur wird es jetzt doch bei nächster Gelegenheit geboten sein, Marieli von der Sache etwas zu sagen.

Ich hoffe eine ruhigere Woche vor mir zu haben. Zwar muss ich morgen Nachmittag an die Beerdigung von Klara Rappard, Kremation. Ich machte heute vor zwölf ihrer Mutter einen Condolenzbesuch im Sanatorium. Sie war sehr gebrochen, sagte aber, wie gut es sei, dass ihr liebes, so hilfsbedürftig gewordenes Kind sie, die Mutter, nicht überlebt habe. Was hätte sie anfangen sollen! Sie, die Mutter, habe nun doch bloss noch einige Jahre vor sich, die sie auch in der grossen ihr gewordenen Einsamkeit, durchbringen werde. Sie sprach schön von Klara. Vor zwanzig Jahren habe sie beim Tod des Vaters den ersten Nervenanfall gehabt.

Dann sei vor zehn Jahren das Übel schwerer geworden, ja wir fanden sie ja im Jahr 1899 in einem betrübenden Zustand. Sie sei immer so ernst gewesen, habe seit dem Tod des Vaters nie mehr gelacht. Sie habe über alle, alle immer nur lieb gesprochen, nie sich lieblos ausgedrückt, nie gehasst, u. niemals geklagt. Auch in der letzten Krankheit sei sie rührend geduldig gewesen. Sie starb, indem ihre Mutter sie wegen eines Anfalls von Athemnot sitzend 
im Bette hielt. Sie neigte mit einem mal das Haupt u. war tot.

Ich will nun hinunter, u. Marieli soll noch etwas vorlesen . Gestern Abend wurde ich mit der im Sommer oder Frühjahr begonnenen Nacht Lektüre, vor dem Nieder liegen zum Schlaf, fertig, mit der ganzen Bibel. Das hat mir mächtig wohl getan. Ich verstehe jetzt eine andere Welt, wie sie in andern Köpfen u. Herzen lebt, ganz anders als vordem u. bin froh u. dankbar darüber.

Gute Nacht! O wärst Du bei mir - gute Nacht!

Dein getreuer

Eugen

\section{2: Januar Nr. 14}

[1]

B. d. 15. Jan. 1912.

Mein einziges Lieb!

Heute also wurde Clara v. Rappard bestattet. Ich war nachträglich noch gebeten worden, mit hinaus zu fahren. Aber ich zog es vor, allein zu gehen $u$. bin auch so wieder zurückgekehrt, trotz freundlicher Aufforderung in dem Wagen Platz zu nehmen. Ich wollte allein sein. Auf dem Kirchhof war ich wohl eine halbe Stunde zu früh u. ging hin u. her durch die Reihen der Gräber, bei düsterem Grau des Himmels. Ich sah verschiedene bekannte Namen. Es war ein Wandeln in wechselnden Erinnerungen, aus denen ich ersehen konnte, wie lange wir doch schon in Bern wohnen. Der Trauerwagen, der mit nur wenig Kränzen behangen war, unter denen der von Marieli bestellte u. ausgewählte einer der schönsten darstellte, war von zwei Wagen begleitet. Vor dem Krematorium warteten mit mir drei Männer u. drei Frauen. Dazu kamen aus den Wagen Prof. Mentha u. mit Frau v. Rappard sechs Damen. Leo Weber war nicht da, ebenso nicht Frl. Hilty. Es war also ein ganz kleines Trauergeleite. Die Orgel des Krematoriums spielte den Schubertschen 
Trauermarsch beim Einführen des Sarges, die Versenkung desselben begleitete ein Choral, u. nachher folgte ein mir nicht bekanntes Orgelstück, für das das Harmonium viel zu dünn klang. Gesprochen wurde nichts. Ich konnte Mentha grüssen, auch beim Hinausgehen ein Wort mit ihm wechseln. Seiner

Frau drückte ich nur im Vorbeigehen die Hand. Frau v. Rappard dankte mir herzlich für meine Teilnahme. Gesprochen wurde gar nicht, auch kein Gebet gehalten, ebenso wenig war das in der Viktoria geschehen. So schied also eine der edelsten Frauengestalten, die uns beiden im Leben begegnet. Wie mächtig waren Du u. ich von ihr bei dem Besuch am Rugen von dieser edlen Persönlichkeit ergriffen, wie leuchteten ihre grossen, tiefblauen Augen uns nach, als wir sie in ihrem Künstlerheim besuchten. Ihre Gedanken - u. zum Ausdruck solcher diente ihr die Malerei - wollten uns nicht mehr verlassen. Und sie sind uns teuer geblieben, auch wenn wir die krank $u$. kränker werdende Künstlerin nur noch zweimal gesehen haben. Sie war älter als wir damals es glaubten, sie erreichte ein Alter von 54 Jahren, zählte also, als wir sie kennen lernten, schon 42 Jahre. Nun ist sie mit Dir vereinigt! Der Kunstverein hatte einen Kranz mit grosser Schleife gestiftet. Das einzige was an die Bedeutung der Toten erinnerte. Sie war eben schon für die Mitwelt nahezu verschollen. Wenige haben sie gekannt. Die Künstler Berns erschienen nicht zur Feier. Wer die zwei Herrn neben Mentha waren, die sich eingefunden, weiss ich nicht. Davinet traf ich gestern in der Viktoria, er hat also doch persönlich condoliert. Gibt wirklich erst der Mann der Frau Bedeutung für die Welt? Fast könnte man es glauben, wenn man der heutigen Kremation beigewohnt hat.

Vor Tisch war Fehlmann von der Hypothekarkasse mit ein 
paar schwierigen Fragen bei mir. Abends Guhl. Sonst konnte ich etwas in Kuhns Dissertation lesen u. hatte mich auf schwierige Fragen der Vorlesungen auf morgen zu präparieren.

Marieli war gestern $u$. heute sehr lieb. Fängt es am Ende doch an in ihrem Herzen zu dämmern? Eignet sie sich mehr Freundlichkeit u. Lieblichkeit an? Ich wäre überglücklich in dem, wenn das geschehen würde. Denn ich habe unter der Herzenshärte gelitten u. sie hat mich manchmal an mir selbst irre gemacht. Wir könnten so gut zusammen leben, wenn wir lieb miteinander sein wollten. Die natürliche Gescheitheit kommt ihr zu statten. Sie merkt am Ende doch, worauf es ankommt, u. wenn sie sich einen andern Ton aneignet, so wirkt das auf das Innere zurück, denn sie ist wahrhaftig.

Sophie teilte Anna mit, dass sie gestern bei Rubins im Kornhauskeller gewesen. Die Tante ist schon seit einiger Zeit von dem Posten als Lingère zurückgetreten, u. es sei dem Vetter bis jetzt nicht gelungen, einen rechten Ersatz zu finden. Sollte das eine Überleitung bedeuten für den Wechsel im Platz für Sophie, so würde ich sie nicht zurückhalten. So sehr ich mit ihr in Betreff der Heizung u. der Küche versehen bin. Es fehlt ihr eben eine Hauptsache, die Liebe zum Hause, die innere Anhänglichkeit, u. keine Vergünstigung, wie sie solche ja reichlich bei mir erfährt, kann ihr das abgewinnen. Oder fehlt es auch da am Ausdruck des Innern? Spielt auch da das unwirsche, hochfahrende Wesen, wie es so vielen Bernern eigen ist, eine verhängnisvolle Rolle? Ich muss es abwarten. Im Sprechzimmer waren Rossel u. Thormann

wieder sehr unartig mit mir. Vielleicht, bei Rossel wenigstens, weil bei Franke die Müngerschen Carten ausgestellt sind. Ich schwankte, ob ich Franke bitten soll, die Ausstellung zu unterlassen. Aber ich durfte das doch nicht, schon aus Rücksicht auf den Künstler. Wollte Gott, dass meine innere Stimmung sich besserte $u$. ich mich versöhnen könnte mit all dem Ungemach, das mich umringt. Ich wäre Dir, nur Dir dafür dankbar! 
Gute Nacht, mein liebstes Herz! Halte mich fest, so wird mir wohl ums Herz! Ich bleibe

Dein ewig getreuer

Eugen

\section{2: Januar Nr. 15}

[1]

B. den 16. Jan. 1912.

Mein liebstes Herz!

Ich habe letzte Nacht unruhig geschlafen, mit einem merkwürdigen Traum beschäftigt, indem ich Flöte spielte u. die mir Zuhorchenden durch den vollen Ton der tiefen Töne entzückte. Halb wach war mir die Melodie ganz deutlich in Erinnerung, eine originelle Weise, nach den Klappengriffen in F-Dur, aber am Morgen wusste ich nichts mehr davon. Die erste Vorlesungsstunde war ich wie verharzt, wozu eine verstockte Nase beitrug. In der zweiten war in [sic!] freier. Die Gesetzgebungspolitik führte mich heute zu meiner Auffassung des Strafrechts als Rechtsmacht zur Verwirklichung des Ausgleichs, u. es schien mir, die Hörer waren befriedigt. An der Dissertation Kuhn konnte ich nichts lesen, weil die hie für bestimmte Stunde Notar Butikofer von der NationalKantonalbank zu mir kam, u. ich Abends das Gutachten für die Basellandschaftliche Kantonalbank schreiben musste. Marieli ist mit Frl. Siegwart, die noch einige Zeit zu Besuch bei ihrer Tante weilt, ins Konzert.

Ich erhielt heute zwei liebe Briefe, einen von Stooss, der mir von seiner Einsamkeit schreibt, in die er durch die Herzkrankheit seiner Frau versetzt ist, u. einen von Ida, die sehr herzlich von unsern freundschaftlichen Beziehungen spricht u. über Marieli u. seine Angelegenheit ein paar trostliche Worte gefunden hat. Sie meint, Pauls Benehmen 
sei beinahe als Schwachsinn zu bezeichnen, dieser Mangel an Takt u. sittlichem Gefühl, wie er mit den Möbeln u. dem Brillantring der Bovet $u$. deren Schenkungen die «zweite Braut» zu Tage getreten. Es ist möglich, dass dieser Ausdruck das richtige trifft $u$. die ganze Abneigung Marielis sich daraus erklärt. Ida hofft, dass wir einen regen Verkehr weiter betätigen werden. Das wäre auch meine Hoffnung. Gestern fragte mich die Glätterin Haldimann, das gute Geschöpf, ob Anna auch schon ein Gespenst gesehen. Als Anna dies lächelnd verneinte, sie glaube nicht an solche Sachen, entgegnete Jgfr Haldimann, vor längerer Zeit sei ihr Nachts beim Nachhausegehen an der Matte eines begegnet, habe sie gestreift $u$. ihr etwas zugemurmelt, $u$. darauf habe sie die halbe Nacht wach gelegen $u$. kein Wort sprechen können. Als sie später dem Abwart Schenk davon erzählt, habe dieser entgegnet, das sei in der Matte nichts seltenes. Oft wenn er am Morgen früh fünf Uhr an die Arbeit gehe, sehe er solche Gespenster. Sie sitzen meist um den Brunnen herum u. schöpfen Wasser! Ich war ganz perplex, aus nächster Nähe diesem Gespensterglauben zu begegnen. Ich sage mir ja auch, es seien mehr Dinge zwischen Himmel u. Erde, als wir mit unseren Sinnen zu erfassen vermögen. Aber Gespenster? Die Passanten anstossen u. anmurmeln, die herumsitzen $u$. Wasser schöpfen? Ja, was sollen dann diese Kobolde? Sie haben ja keinen vernünftigen Zweck. Sie bedeuten nichts, auch wenn sie Wahrheit wären. Wie kann

die Phantasie eines vernünftigen Menschen sie sich ausdenken? Eben da sieht man wieder, wie weit wir im Grunde mit unserer Schulweisheit gekommen sind. Der Glaube ist weg $u$. dafür spukt Aberglaube, man weiss nicht wo. Heute um zehn Uhr traf ich vor der Post den Journalisten Bovet, der auf mich zukam u. mir erklärte, eben sei es dem Bundesrat offizielle mitgeteilt worden, dass der deutsche Kaiser im September ein paar Tage in die Schweiz kommen u. die Manöver 
in der Ostschweiz besuchen wolle. Der «Bund» hat alsdann die Nachricht Abends bestätigt. Ich hoffe, dass daraus für uns keine Schwierigkeiten entstehen werden. Ich traue den Welschen nicht, wir müssen dessen gegenwärtig sein, dass sie einen Höllenspektakel anheben, u. daraus könnte dann für die Schweiz eine höchst ungemütliche Situation erwachsen. Es ist nur zu hoffen, dass die Erinnerung an den vorjährigen Besuch Fallières ihnen ein diskretes Schweigen auferlegt. Für die Schweiz wird eine gute Freundschaft mit dem Reich ja die allerbesten Folgen haben. Die Geschichte rollt unablässig weiter. Wir entrinnen ihr nicht.

Sonst war ich diesen Tag wieder nicht ganz wohl. Ich verspürte ganz leise Magenbeschwerden u. in der linken Wade eine Spannung. Ich habe vielleicht die letzten Tage wieder allzu anhaltend arbeiten müssen. Das vertrage ich eben doch nicht mehr so gut, wie früher, wenngleich die regelmässige Lebensweise mir soviel Kraft belässt, dass ich jetzt leistungsfähiger bin als in dem letzten Winter, den wir zusammen

waren. Die neue Rechtslage klärt sich nun doch allmählich ab u. wir kommen damit zu einer grösseren Ruhe im Innern unser selbst als sowohl als in dem ruhelosen Verkehr mit aller Welt.

Gute Nacht, mein Lieb! Wie haben wir so kindlich miteinander die schönen Jahre zurückgelegt! Das muss doch ein Segen bleiben. Es wäre ja nicht recht, wenn es anders käme.

Ich bin Dein ewig getreuer

Eugen 
B. den 17. / 18. Jan. 1912.

Liebstes Herz!

Ich kann Dir heute nur wenige Zeilen schreiben. Ich war schon vom Morgen an sehr müde, wie gehemmt in den Gedanken. Meine Vorlesung muss sich mühsam angehört haben. Ich hatte dann wieder einzelne Anfragen zu erledigen, las etwas in Kuhns Dissertation, hatte Sitzung der jur. Bücheranschaffungskommission, bei der Walter Burckhardt ganz merkwürdige Vorschläge machte, die ich nur zum geringsten Teil annehmen konnte. Thormann war praktischer. Sonst war Burckhardt lieb, seiner Frau geht es wieder besser. Endlich hat Büchler nach halb neun noch telephonisch um eine kurze Audienz gebeten in dringender Angelegenheit. Ich erwarte ihn jetzt jeden Augenblick. Was muss ich nur machen, wenn es so fortgeht?

Hier hat Büchler mich unterbrochen. Er steckt in einer schwierigen Hauskauf-Affaire, über die er mich konsultieren wollte. Ich konnte ihm meinen Rat geben. Eben jetzt, zehn Uhr, ist er gegangen.

Ich berate ihn gerne aus alter Bekanntschaft.

Marieli ist heute Abend im Studentinnenverein, wo Lili

Zgraggen einen Vortrag hält. Ich hatte heute von Frau Crugnola eine Karte erhalten, wonach sie Marieli vielleicht demnächst eine Familie nennen wird zum Aufenthalt in Italien. Das gute Kind erschrak darüber. Aber ich habe gute Hoffnung, es wird sich zeigen.

Nun sollte ich heute Abend noch mit Sophie sprechen, da Marieli doch morgen nach meiner Anordnung ihren Kochtag haben wird. Ich werde Dir morgen davon schreiben. Für heute muss ich abbrechen, um auf den morgigen strengen Tag 
noch meine Nachtruhe zu haben. Gute, gute Nacht!

Den 18. Jan. 1912.

Ich habe also gestern Abend noch mit Sophie gesprochen u. es stellte sich heraus, dass das bitter notwendig war. Die arme Person mit dem zerrissenen Herzen hatte sich in den Kopf gesetzt, Anna u. Marieli «werchen ihr z'Leid» u. wollen sie von mir forthaben. Mit der Küche sei es nur so ein Anlass gewesen. Ich wurde darüber erzürnt, sprach ihr aber ruhig zu u. sie ging unwirsch davon. Heute aber war sie recht. Anna u. Marieli, das nun wieder gekocht hat, bestätigten das. Also ist doch zu hoffen, dass wieder eine Zeitlang Ruhe im Hause sei. Ich war heute sehr müde. Die Nacht über hatte ich unruhig geschlafen. Am Morgen war die Müdigkeit gleich wohl weg. Dafür aber spürte ich eine gewisse Aufgeregtheit. Ich las besser als gestern. Auch das Nachmittagkolleg geriet mir, wie ich hoffe, ordentlich. Aber sonst war ich zur Arbeit unfähig. Ich las nur einige Seiten in Kuhns Arbeit, wurde noch einmal von Büchler consultiert, sonst war es mir dumpf im Kopf u. Herz.

Heute ist nun auch der angekündigte Brief von Frau Crugnola eingetroffen. Sie offeriert Marieli zu ihrer Tochter zu kommen, für Februar bis April. Und zwar ohne Pensionspreis. Dafür müsste Marieli den beiden Knaben Deutschunterricht geben. Mir leuchtet der Plan sehr ein, wenn auch Marieli erst etwa am 20. Febr. nach Mailand reisen könnte. Marieli war etwas ängstlich, neigt sich nun aber auch eher dazu, die Offerte mit jener

Verschiebung anzunehmen. Ich werde mich morgen oder übermorgen darüber entscheiden müssen.

Marieli kam gestern Abend aus dem Studentinnenverein (dem sie nicht angehört) ziemlich munter nach Hause. Der Vortrag Lilys über Widemanns «Heilige» hatte sie interessiert. Aber sie will doch nicht beitreten. Sie sprach von Skifahren, allein 
auch dies habe ich ihr ziemlich ausreden können. Es liegt nicht in meiner Idee von Weiblichkeit. Marieli kann sich anderswie die nötige Bewegung verschaffen. Heute besuchte es die Turnlehrerin Sandholm, die herzkrank im Spital liegt. Sie hat sich in einem ruhelosen Eifer, den Marieli oft angestaunt hatte, über$\tan u$. scheint jetzt sehr gefährlich krank zu sein. Das war für mich doch eine gute Eigenschaft, dass ich in meinen jüngern Jahren bei aller Arbeit nie nervös, sondern nur faul u. unbrauchbar geworden bin. Und diese Eigenschaft ist mir wahrhaftig geblieben. Ich musste das gestern denken, wie ich so schrecklich unbrauchbar geworden war. Das kam sicherlich von der Ermüdung. Schade nur, dass die Aufregung des gestrigen Abends mir dann doch etwas zugesetzt haben muss. Ich spüre das am Zucken meines Armes, der sonst treu reagiert u. keine solche Sprünge macht. Ich hoffe diese paar Tage ruhiger zu werden. Eine grössere Arbeit ist nicht in Sicht. Vielleicht besuche ich morgen Vormittag Hänny. Er will nun doch demnächst nach Paris reisen u. dort seinen Künstleraufenthalt machen. Im übrigen will ich ruhen. Auf heute Abend habe ich eine Einladung zu Frau v. Wyss abgesagt. Leider muss ich aber auf Sonntag Mittag mit Marieli

zu Bundesrat Müllers. Immerhin kann ich dort vielleicht einiges erfahren oder erleben. Über den angekündigten Kaiser-Besuch, Rossels Bundesrichter-Kandidatur u. s. w.

Jetzt schliesse ich, um die Rechnung zu machen, u. nachher soll Marieli noch etwas in Rosegger vorlesen. Arbeiten will ich nicht mehr heute Abend $u$. hoffentlich stört mich auch niemand mehr.

Bleibe bei mir, meine einzige treue Seele! Ich will ja ewig bei Dir sein, in Deinem Geist der Liebe u. der Dankbarkeit.

Dein Eugen 
Bern, den 19. / 20. Jan. 1912.

\section{Liebstes Herz!}

Ich hatte gestern Abend noch lange gerechnet, da das Titelverzeichnis der Kreditanstalt eingelaufen war. Marieli hatte vorgelesen, war aber so müde, dass es die Worte fast nicht fand. Ich schlief unruhig $u$. hatte den ganzen Tag Kopfweh. Ich war bei Haenny, der mein Relief fertig in Gyps erstellt hat, u. das nun auch gegossen werden soll. Es ist mir nicht sympathisch. Aber es mag gut sein, wenn ich wirklich so bin. Ich sandte Haenny vorläufig 200 Fr., da er am Montag nach Paris verreisen will. Am Morgen war ich auch noch auf der Bibliothek, wurde aber etwas schnöd empfangen, da Wäber-Lindt eben auch anwesend war. Das Praktikum verlief ordentlich. Aber, war ich schon vorher in gedrückter Stimmung, weil alles so schnöd ist u. mich mein Kopfweh plagte, so wurde ich beim Nachtessen vollends geärgert, da Marieli mir sagte, ich müsse jetzt doch der Frau Crugnola schreiben, u. dabei auch nicht eine Spur von Lust zeigte, nach Mailand zu gehen! Also, wenn es nicht will, so sei abgesagt. Aber das ist jetzt der letzte Versuch, den ich jetzt für seine Weiterbildung gemacht habe. Gehe es seine eigenen Wege! Aber freilich bleibe ich ja doch an das Verhältnis gekettet, ich mag das wenden, wie ich will!

Rossel hatte am Mittwoch gesagt, er müsse auf Donnerstag u. Freitag zu einer Nationalratskommission nach St. Gallen, u. er erschien dann auch gestern $u$. heute nicht im Sprechzimmer. In der Zeitung las ich dann aber,dass die Namen der anwesenden Mitglieder, u. er war nicht darunter. Vielleicht hat man ihn nur vergessen, vielleicht ist da wieder 
ein Müsterchen welscher Art. Es wird sich aufklären, geht mich aber ja nichts an.

Ich bin heute auch nicht eine Stunde dazugekommen, in Kuhns Dissertation zu lesen. Drei Anfragen haben mir die freie Zeit wieder weggenommen, $u$. andere liegen noch unerledigt auf dem Tisch. Ich werde morgen daran gehen müssen. Das wäre alles leichter, wenn ich es nur zu Hause gemütlicher hätte. Aber jetzt ist der Sturm vorüber u. die Stimmung zu Marieli droht wieder die alte zu werden. Was mich dabei plagt, das ist, dass es dann nachträglich etwa bemerkt, dass es wegen mir nicht fort gegangen. So hätte ich ja ganz gerne gehabt, dass es nach Deutschland gehe, u. ich habe ja darüber mehrfach correspondiert. Allein es zeigte die gleiche Unlust, wie jetzt wieder. Und doch bemerkte es neulich, es sei nicht nach Deutschland, weil es gedacht habe, mir sei es lieber, wenn es da bleibe. Nun ja, ich werde auch das schlucken. Ich warte jetzt bis morgen, dann, wenn Marieli nicht von sich aus zusagt, lehne ich auch

der Frau Crugnola gegenüber ab - ich muss mich dabei wieder in unappetitlicher Weise wenden u. drehen u. nehme mir dann bestimmt vor, nichts mehr für Marieli in solchen Beziehungen zu tun. So will ich noch abwarten. Kommt vielleicht noch über Nacht ein besserer Gedanke. Etwas ist jetzt wieder in Ordnung, das Verhältnis mit Sophie, aber auch nicht dank Marieli, sondern weil ich mit Sophie gesprochen u. die Missverständnisse aufgeklärt habe. Marieli kann einfach nicht sprechen, d. h. es will nicht, es ist hart $u$. unbeweglich u. meint dann doch, es habe ein Herz voll Empfindung. Doch muss ich daran mich gewöhnen. Das sind eben die Folgen, die Folgen - es wäre nicht recht, wenn es mir noch gut ginge, nachdem Du von mir geschieden bist! In diesen Gedanken schliesse ich heute. Es ist mir wieder unsagbar schwer. Und ich sehe keine Hülfe, anders als Du würdest mir beistehen! 
Ich verbleibe mit einem innigen Gute Nacht.

Dein ewig getreuer

\section{Eugen}

Den 20. Jan.

Ich will auf dem gleichen Blatt noch anfügen, dass Marieli mir heute früh sofort u. aus eignem Antrieb gesagt hat, sie sei entschlossen, nach Mailand zu gehen. Das hat mich gefreut u. meine Stimmung, wie sie in letzter Zeit bestanden hat, wieder befestigt. Sie hatte dann ferner heute die Freude, vom Präses der Helveter eingeladen zu werden zum nächsten Tanzkränzchen. Das tut ihr mächtig wohl. An Frau Crugnola habe

[4]

ich vormittags die Zusage abgesandt $u$. hoffe, dass die Verschiebung der Hinreise auf den 20. Febr. kein Hindernis bilden wird.

Sonst war der Tag wieder sehr angefüllt. Hännys Relief liess ich durch Marieli holen. Es befriedigt weder Marie, noch Anna, noch Siegwart. Es wird also nicht gegossen werden, ich behalte zunächst den Gypsabguss. Dann hatte ich Briefe zu schreiben, Anfragen zu beantworten, Consultationen, Verhandlung mit Guhl, mit Mutzner, eine Arbeit Siegwarts zu lesen, Diskussionsabend des Juristenverein, wo ich aber diesmal das Wort nicht ergriff. Mit der Tagesarbeit bin ich noch nicht fertig, hoffe aber doch, dass Marieli noch ein halbes Stündchen wird vorlesen können.

Ich schliesse den Tag ruhiger, als den gestrigen. Die Nacht über hatte ich mir wieder die schwärzesten Gedanken gemacht. Aber es muss mit meinem Gemüt gewiss doch wieder besser kommen. Mit Reg. R. Scheurer habe ich heute eine Art Friede geschlossen. Wir gaben uns beim Abschied, indem wir zufällig zusammenstiessen, treuherzig die Hand. Wie viel wohler ist es mir dabei!

Doch nun wieder an die Arbeit! Ich setze den zweiten Gut Nacht Gruss auf dieses Blatt u. bin auf immerdar

Dein getreuer

Eugen 


\section{2: Januar Nr. 18}

[1]

B. d. 21. Jan. 1912.

\section{Liebstes Herz!}

Den heutigen Sonntag Vormittag benutzte ich, um so viel als möglich die Dissertation Kuhn weiter zu lesen, mit dem ich gestern verabredet habe, dass er am Mittwoch Abend sie bei mir abholen könne. Zwischenhindurch erhielt ich Besuch von Dürrenmatt, der sehr herzlich war, u. während er sich noch bei mir befand, kam der Fürsprecher Otto Häberli aus Solothurn, um sich nach seiner Arbeit zu erkundigen. Er machte mir einen viel weniger düstern Eindruck. Wills Gott hilft ihm der schliesslich nun doch mit dem Doktortitel abschliessende Erfolg zur Hebung seiner Gemütsdepression. Er sprach viel ruhiger u. gefasster. Ich hoffe, dass dies sich noch mehr bessern werde. Dann wäre in diesem Fall die Prognose Kräpelins richtig gewesen, ein eigentümlicher Fall der Psychose, der Zwangsvorstellung. Ich kann mir diesen Zustand sehr gut denken, ich fühle ja, wie gewiss jeder, der sich etwas vornimmt, sehr wohl, was ein gehegter Plan für eine Gewalt auszuüben vermag. Wie manchmal schon habe ich wochen- ja monatelang unter einem Ziel gestanden, das ich unbedingt verwirklicht wissen wollte, u. dann konnte, erst nach Monaten manchmal, die Ruhe nur mühsam dadurch wieder gewonnen werden, dass das nicht erreichte Ziel allmählich verblasste u. von neuen Gedanken verdeckt oder verdrängt wurde. Wenn nun einer strebenden Seele diese Fähigkeit des Vergessens benommen wird, dann haben wir den krankhaften Zustand, der uns jeden

Tag schwerer zu tragen sein muss u. schliesslich alle gesunden Kräfte lahm zu legen vermag. Was Häberli jetzt mit seinem Examen erreicht, das steht ja in keinem Verhältnis zu der Aufwendung von Zeit u. Kraft, das ihn der Plan gekostet hat. Aber der einzige Weg der Heilung war eben doch schliesslich der Erfolg. 
Ich erinnere mich, dass Kleiner seinerzeit, als er Privatdozent an der Universität u. am Polytechnikum war, sich unter ähnlichem Gemütsdruck befand. Die Kräfte wollten wie die Fähigkeiten nicht ausreichen zur Dozentur. Kappeler überging ihn nochmals bei der Beförderung. Endlich kam das Extraordinariat u. damit die Erlösung. Aber etwas von der Stimmung aus jener Zeit muss ihm geblieben sein, wie z. B. die Beurteilung Albert Heims, der damals ganz im Gegensatz zu ihm unter Kappelers Beistand eine so glänzend rasche Carriere machte, die er ja auch wohl verdiente. Seine Schwächen hat Kleiner niemals eingesehen, dann aber mit seinen Kräften nach anderer Richtung die Stellung so auszufüllen verstanden, dass er seit Jahren der Vertrauensmann der Fakultät u. der Regierung werden konnte, der er immer noch ist u. zeitlebens bleiben wird. Wie nahe berühren sich hier Psychose u. Genie: Wer das Ziel so unablässig verfolgt u. sich durch keine schlimmen Erfahrungen davon ablenken lässt, der wird plötzlich dazu gelangen, wenn er nicht untergeht. Was wäre wohl aus mir geworden, wenn ich mit solcher Kraft u. Ausdauer meine jugendlichen schriftstellerischen Pläne verfolgt hätte? Aber mein Wesen war dafür zu vielseitig, darunter habe ich mir mein Glück u. Ungemach gebildet, u. stehe an einem Ziel, das ich ja begünstigen muss, wenn es mich auch unter den jetzigen Umständen

nicht zu erfüllen vermag. Heute sagten mir Müller u. Bühlmann, ich sei einer der glücklichsten Menschen, $u$. ich sagte nicht nein, dachte mir aber, ich weiss es besser.

Heute auf den Mittag ging ich zum ersten Mal - ich musste nach den gegebenen Verhältnissen dem Chef des Departements zusagen zu einem Mittagessen, zum ersten Mal seit Deinem Hinschied nach 94 Wochen. Marieli war mit eingeladen. BR Müllers hatten den Sohn Fritz u. die Tochter Margrit bei sich, geladen waren: Bühlmanns, Hoffmanns mit Tochter u. Armin Müller u. Frau, mit uns 13 Personen. Es war ganz interessant, wir sassen von nach halb ein bis halb sechs am Tisch, sprachen namentlich viel von dem Kaiserbesuch, wobei man mancherlei erfuhr, was mir von Wert war. Von den Vorlesungen sprach Hoffmann einmal ganz kurz, ohne besondere Anerkennung. Ich habe es ja auch weder gesucht noch erwartet. Das ging schnell 
dahin, mit Essen, Trinken u. Rauchen. Aber ich glaube, es hat mir nicht geschadet. Marieli hatte Freude.

Heute Abend werde ich nun kaum mehr viel weiter arbeiten, nachdem ich das Kolleg präpariert, für morgen. Marieli soll in Rosegger noch einiges vorlesen $u$. tut es gerne. Ich fühle nun deutlich, wie sich das Leben für mich weiter gestaltet. Ich werde in Zurückgezogenheit u. Einsamkeit weiter leben, solange es sein muss, habe ich dabei noch einigen Erfolg, um so besser. Eine Freude daran werde ich, ohne Dich, im landläufigen Sinne ja nicht gewinnen können. Aber es ist doch besser als ohne Ziel sich arbeitslos ableben. Es muss jetzt weiter gehen, komme was da wolle. Die paar Wochen, noch sechs sind's, werde ich wohl gesundheitlich noch aushalten. Dann kommen die Ferien, die ich irgendwie zum Ausspannen zu verwenden gedenke. Mit meiner Arbeit muss es

es [sic!] so gehen, wie es ohne Überanstrengung gehen kann. Also weiter, immer weiter.

In meiner Abwesenheit war Kronecker nachmittags da u. auf seinen Wunsch zeigte ihm Anna die Müngerschen Scheiben. Dann wollte Burckhardt den obligaten Besuch machen. Sonst war Stille im Land. Einen g'spässigen Brief erhielt ich heute vor Mittag von Frau Pulver, der Tochter Baumbergers, deren jüngster Sohn vor kurzem sein Examen gemacht hat u. nun im Beruf auswärts weilt. Sie klagt über Einsamkeit u. möchte gerne Vormundschaftsstellen erlangen. Aber wie kann ich ihr dazu verhelfen? Es gibt doch recht merkwürdige Lebenspläne.

Doch nun sei auch dieser Tag geschlossen. Das Wetter ist nach kühlem Morgen wieder recht warm geworden. Man kann den Winter nicht verstehen. Mir wurde warm beim Weg zu u. von Müllers. - Nun will ich anfügen, dass ich Hoffmann mitteilte, dass Rossel bei der Wahl in das Bundesgericht sein Haus verkaufen möchte, sei es dass er oder Motta darauf reflektieren würden.

Nun aber Schluss u. gute, gute Nacht!

Ich bin Dein ewig getreuer

Eugen 
[1]

B. den 22 / 3. Jan. 1912.

Mein liebstes Herz!

Marieli war heute sehr unwohl, es hat sich gestern an dem Essen bei Müllers den Magen verdorben, wer weiss womit. Waren es Schwämme, oder der Wein (den es ja sonst nie kostet), oder das fünfstündige Sitzen in der Rauchstube an der Türe, wer weiss es. Es ist ein armes Kind, dass es gleich so in Extremen dafür gebüsst wird, wenn es einmal etwas aussergewöhnliches mitmacht. Hoffentlich wird ihm bis Freitag, dem Tanzabend, wieder besser. Ich hatte heute einen normalen Tag. Nach dem etwas flauen Morgenkolleg hatte ich nachzulesen, sprach dann mit Ryser u. Münger über die Scheiben, die jetzt definitiv angebracht werden sollen. Am Nachmittag konnte ich die Dissertation fertig lesen (Kuhn) u. hatte Amtliches zu erledigen. Dann war der gescheite Notar Senn ein Stündchen bei mir, u. nachher kam Guhl mit den Amtssachen. Sonst las ich noch die Jugendbiographie von Fritz v. Wyss fertig, die mich in ihren ersten Partieen mächtig ansprach. Nachher wird es ein Leben, das mich fremder angemutet $u$. das mir auch wieder zeigt, wie behütet solche [sic!] eine Jugend sich dahin zieht im Vergleich zu dem was in unseren Ständen zu kämpfen ist. Und doch war ich selbst weit besser gestellt, wenigstens äusserlich, als die

grosse Masse. Ich bin gespannt auf die Fortsetzung, die in dem nächstjährigen Zürcher Taschenbuch erscheinen soll. Ich weiss nicht, darf ich dieses erste Heft behalten. Es ging so sonderbar zu bei dessen Überreichung, aber vielleicht ist das nur dem Ungeschick des jungen Fritz v. Wyss zuzuschreiben. Wenn nun die amtlichen Sachen etwas spärlicher einlaufen sollten, so komme ich am Ende doch noch zu etwas Arbeit 
am Buche. Ich will sehen. Sonst gestaltet sich mir die Sache nun so, dass ich mich entschliesse, möglichst bald nach Semesterschluss in die Ferien zu reisen. Darüber werde ich bald im klaren sein. Ich fühle mich eben doch recht bald müde, da ich abends im Bett stets bis über halb elf noch in den Worten Chr. lese u. nachschlage, u. in der Nacht oft eine Stunde oder mehr wach bin, komme ich eben doch obgleich ich erst um halb sieben aufstehe, nicht zu einer ganz genügenden Nachtruhe, u. das will nachgeholt sein. Noch weiss ich nicht, wie ich mich einrichte. Kommt Zeit, kommt Rat.

Und nun will ich noch in Stube hinunter. Marieli wird trotz seines Unwohlseins noch etwas vorlesen im Rosegger. Und es wird ihm u. mir dann doch wohl tun, bälder zu Bett zu kommen.

Den 23. Jan.

Ich hoffte, heute Abend ausführlicher schreiben zu können. Da telephoniert sich Guhl auf halbneun an, ich weiss nicht, in welcher pressanten Angelegenheit $\mathrm{u}$. so bleibt mir nur eine kleine Pause nach der Kollegpräparation, um dir wenigstens einen Gruss senden

zu können. Ich habe heute viel an Dich gedacht, es wurde mir Deine Liebe durch gar vielerlei besonders in Erinnerung gerufen. So war heute Marieli immer noch unwohl. Wärst Du da, so würdest Du schon ein Mittel wissen. Uns gegenüber ist Marieli entschieden renitent u. hat vielleicht auch recht, namentlich im Verhältnis zu Anna. Ich sprach mit dieser beim Café - Marieli war in die Lateinstunde gegangen u. war Anna wieder einmal vom alten Schlag. Das was Du früher so oft «ihr böser Gang» genannt hast, zeigte sich wieder. Sie machte verschiedene unartige Bemerkungen über Marieli u. es stellte sich namentlich heraus, dass sie sich über das seit der letzten Auseinandersetzung besser gewordene Verhältnis zwischen Marieli u. Sophie fast nicht beruhigen kann. Hätte ich je denken müssen, in solcher Hausgemeinschaft meinen Lebensabend zubringen zu müssen! Ich mag nicht davon reden.

Marieli erzählte, dass Frau Haag krank sei u. vorgestern einen Anfall von Herzschwäche gehabt habe, dem aber durch KampferEinspritzung begegnet worden. Da hat's geholfen. «Ihre Wahl ver- 
teilt die Gaben, ohne Billikeit [sic!] des Glücks - u. was uns widerstrebt, hockt da u. lebt.» Doch ich will mich nicht in Bitterkeit vergessen.

Heute habe ich mit Siegwart die Kollegsteine für den nächsten Winter besprochen. Er riet mir ab, den viersemestrigen Kurs für das Zivilrecht einzuführen, da doch viele Studenten von Freiburg u. vom Ausland her für einen Kolleg zu zwei Semestern nach Bern kommen, was bei einem doppelt längeren Kurs auf Schwierigkeiten stossen könnte. Lasse ich vorderhand den Plan fallen, so habe ich dann nur die Wahl, nächsten Winter neben den acht Stunden Zivilrecht u. zwei Stunden Übungen noch drei

Stunden Rechtsgeschichte anzukündigen. Denn für die Rechtsphilosophie würde ich nach dem diessemestrigen Kolleg kaum einen rechten Besuch zusammenkriegen. Nun, ich habe noch Zeit, darüber weiter nachzudenken. Der Tag war warm, rheumatischen Beschwerden günstig. Anna beklagte sich gleich mir. Wenn doch nur Schnee käme! Heute im Dekanatszimmer, wie Rossel, Gmür, Thormann u. ich bei einander waren, fuhren die beiden erstern über die Freimaurer her. Ich entgegnete, man könnte meinen, keiner von uns gehöre dazu, u. Rossel bemerkte: Vielleicht Thormann? Worauf dieser entgegnete: Vielleicht ja, vielleicht nein. Dies erklärt mir nun auch die Bekanntschaft Euckens mit den Eltern Thormann, die mir s. Z. aufgefallen war.

Und nun kommt Guhl. Also Schluss! Gute, gute Nacht! Ich bin allzeit Dein getreuer Eugen 
B. den 24. Jan. 1912.

\section{Liebstes Herz!}

Heute bin endlich wieder einmal dazu gekommen, am Buch zu arbeiten. Ich sass «wie eine Zange» (wie Du zu sagen pflegtest) dabei, von halbzwei bis sechs Uhr, ohne dass ich unterbrochen wurde, u. erledigte ein gutes Stück des längsten Paragraphen über die Einführungsgesetze. Die Vorarbeiten Siegwarts erwiesen sich als recht brauchbar. Es machte auf mich einen eigentümlichen, fast möchte ich sagen anheimelnden Eindruck, dergestalt wieder einmal an der Arbeit sitzen zu können. Einige Zeit verlor ich durch das Suchen nach einer Drucksache, die ich wirklich nicht finden konnte, obgleich ich in grösster Eile alle Schubfächer absuchte. Eine andere Störung drohte mir, als Dr. Cramer telephonisch um eine Audienz ersuchte, die ich ihm abschlug. Die Post las ich erst nach dem Nachtessen, ich wollte nicht unterbrechen. Nach sechs Uhr kam der Fürsprecher Kuhn, dessen Dissertation ich die Tage gelesen, zu mir. Ich konnte ihm besten Bericht geben. Leider wird morgen u. wohl auch übermorgen gar nichts für das Buch abfallen. Ich hoffe aber am Samstag fortfahren zu können. Von Maler Münger erhielt ich sieben gute Abzüge der Porträt-Skizze, die ich auf Wunsch Trüssels mit einer

Widmung an die Vorstandsmitglieder des B. J. V. versandte. Am Vormittag haben Frau Dr. Jauch u. Frl Siegwart Besuch gemacht.

Die Hauptsorge war heute das andauernde Unwohlsein Marielis. Es sagt, es vertrage gar keine Speise, oft auch wirklich fast gar nichts u. kommt sehr herunter. Es soll aber nächsten Freitag ein Helveter-Tanzkränzchen mitmachen, 
wobei ihm die nachfolgende Café-Visite Sorge macht. Natürlich. Mit Anna ist bei solchem Anlass nichts anzufangen, u. ich kann doch nicht Ballmutter spielen. Es kommt da wegen unserer unbefriedigenden Verhältnisse alles so ungeschickt heraus. Und wenn Du da wärst, wie nett würden sich da diese Dinge gestaltet haben! Ich bin in Sorge um das Kind. Weiss Gott, welche physische oder psychische Dinge dieser Appetitlosigkeit zu Grunde liegen. Marieli spricht in letzter Zeit oft von Abbühl. Ja, warum hat es ihn nicht festgehalten? Auch da hat ihm eben die Mutter gefehlt. Und dann immer noch die drohenden Nachrichten u. Beziehungen betr. Malleray. Man möchte manchmal davon laufen. Anna ist fortgesetzt unartig. Man hat wieder an ihr das alte «Gifthäfeli» von ehedem. So wie Du bei Deinem letzten Kranksein sie von Dir gewiesen, so steht sie wieder herzlos u. ungeschlacht da u. zeigt nichts als Missgunst. Kann sein, dass das Mitgehen Marielis zu Müllers an alle dem

wieder schuld ist. Wie oft haben wir das erfahren, dass gerade solche Anlässe sie völlig den Kompass verlieren machen. Nun hoffe ich, dass sich das doch wieder verlieren wird. Inzwischen wird dann wohl auch Bericht aus Mailand kommen, $u$. in vier Wochen wäre dann ja Marieli schon in der Fremde. Heute, am 24. Januar, hörte ich beim Weg nach der Universität in Gubsers Garten die erste Amsel singen. Den ganzen Winter hatten wir bis jetzt keinen Schnee, der länger liegen blieb, als einige Stunden. Das ist nun der früheste Vogelgesang, den ich in meinem Leben gehört. Bis dahin war es der 27. Januar, an den ich mich aus dem Jahr 1882 erinnere, da wir zusammen gegen die Schützenmatte in Basel einen Abendspaziergang machten $\mathrm{u}$. uns freuten an den ersten Amselliedchen. O glückliche Zeit!

Die Arbeit hat mich nicht müde gemacht. Fast möchte ich sagen, leider, denn ich fühle mich etwas aufgeregt. Das kann sich aber aus den andern begleitenden Umständen erklären. 
Ich werde es nun schon noch aushalten, denke ich, bis die Ferien kommen, u. dann will ich wieder einmal reisen.

In Sorge bin ich wegen der Anfrage von Frau Pulver in

Betreff der Vormundschaftsübernahmen. Ich ersuchte am Montag Abend Notar Senn, der bei mir war, sie zu empfehlen, bei den Behörden, wenn sie, die ich ja nicht näher kenne, empfehlens wert sei. Er versprach mir, sofort darüber zu schreiben, $u$. bis heute ist nichts von ihm gekommen. Ich besorge, dass er sich nun

allzu intensiv nach ihr erkundigen wird, $u$. wenn sie dann etwas davon vernähme, wäre das doch für mich eine fatale Geschichte. Ich kann freilich den Ton ihres Briefes nicht recht verstehen. So habe ich grosse u. kleine Sorgen. Ich bin eigentlich froh über jeden Tag, der vorüber ist. Man lebt eben doch nicht mehr mit der alten Geschlossenheit nur seinen Plänen. Es kreist zu vierlei um mich herum. Aber, ich will stand halten. Es kommt ja dann auch wieder besser, wieder ganz, ganz gut. Man muss nur Geduld haben u. warten.

Gute Nacht, liebe, liebe Seele! Ich bin Dein ewig getreuer

Eugen.

In Zürich ist Augusts alter Freund Schellenberg, mit der schönen Villa am Sonnenberg, gestorben, siebzig Jahre alt. Das wird August leid tun, u. ach Gott, ich kann jetzt nicht mehr so unmittelbar froh an den Bruder denken! 
B. d.25. Jan. 1912.

Mein liebstes Herz!

Ich war heute den ganzen Tag in einer traurigen

Stimmung, das mag schon äusserlich dadurch hervorgerufen worden sein, dass die für die Zeit unzukömmliche Wärme (am Schatten $6^{\circ} \mathrm{R}$ ) sich unbehaglich empfinden liess.

Dann kamen wieder allerlei gescheite $u$. weniger gescheite Anfragen. Ich hatte Briefe zu schreiben, drei Stunden Kolleg zu halten u. dazu war die Gesetzgebungspolitik wieder miserabel besucht. Es ist bald, als würde ich nur für Hoffmann - der regelmässig da sitzt - $\mathrm{u}$. Werner Kaiser reden. Vor allem aber beschäftigte mich Marieli. Ich hatte mit ihr gestern Abend noch ein Gespräch, in dem ich ihr klar zu machen suchte, dass die Aloepillen ihr den Magen verdorben haben werden. Sie nimmt jetzt bald anderthalb Jahre jeden Tag zwei bis drei u. verliert darüber schliesslich ganz den Appetit. Zum Glück musste sie dann heute mit einer Dissertation zu Frau Sophie Burckhardt, u. zufällig gab ihr diese betreffend die Pillen u. ihre Wirkung denselben Bescheid. Ich ermahnte sie, die mechanischen Hülfsmittel anzuwenden, die Du ganz gewiss schon längst bei ihr durch gesetzt hättest. Nach verschiedenen vorübergehenden Übelkeiten scheint nun aber doch heute Abend der Zustand wieder besser zu werden. Es wäre höchste Zeit. Ich hatte

bereits daran gedacht, einen Arzt zu rufen. Aber wen? Dumont scheint da wieder ganz zu versagen. Marieli sprach ihm von seinem Zustand schon vor Monaten, u. er meinte, das werde sich schon machen, sie soll nur die Pillen nehmen. Natürlich würde auch er anders gesprochen haben, wenn er an die lange Zeit des Gebrauchs u. die Steigerung der Pillenzahl 
gedacht hätte. Aber da haben wir es, das ist ja die Art, die Dir von Anfang an bei Dumont kein Vertrauen aufkommen liess. Er übersieht nicht den ganzen Fall u. zeigt keine Entschlossenheit in seinen Ratschlägen. So ist auch das Lenica, das er das letzte mal Marilei empfahl, nicht genommen worden, weil Marieli mit seinem durch die Mittel angegriffenen Magen sich recht eigentlich nicht daran wagte. Sollte ich nun einen andern Arzt rufen? Dazu hätte Marieli keine Lust u. ich kein Vertrauen, u. es ist gut, dass für einmal nun doch der Fall ohne ärztliches Dazwischentun sich zu erledigen scheint. Ich setze nun einige Hoffnung auf die Frau Burckhardt, so unangenehm es mir ist, sie in der Sache mit Marieli noch näher liiert zu wissen. Am Ende versteht sie doch etwas von der Sache u. ist energisch genug, um Marieli ihre Ratschläge aufzudrängen. Helfe was helfen mag! Guhl war Abends wieder da in Geschäftssachen. Er ist guter Stimmung, geht mit Freude hinter sein Amt. Er wird jetzt mehr konsultiert als ich, wie das sein Amt mit sich

bringt, $\mathrm{u}$. wie das nun auch mir zur willkommenen Entlastung dienen kann. Ich wusste nicht, was ich zu tun haben würde, wenn ich auch noch seine Consultationen zu erledigen hätte. Und in wichtigen Fragen consultiert er mich immer. Freilich bin ich auch sicher, dass er sich als der wahre Kenner des neuen Rechtes aufspielt. Allein das kann ich vertragen. Ich darf auch da mich mehr u. mehr auf den Altenteil versetzen. Es ist doch eigentlich mit Guhl recht eigentümlich gegangen. Als ich ihn vor vier Jahren zur Habilitation einlud, da schwebte mir vor, er werde einmal einen Teil meines Vorlesungspensums übernehmen $u$. mich so entlasten. Dann kamen die Widerstände, die Blumenstein u. namentlich Gmür meinem Plan entgegen setzten, mit seinen Widerwärtigkeiten u. Perfidieen, die Du zum Teil ja noch mit mir erlebt hast. Die Macht der Verhältnisse ist dann stärker gewesen, als meine Pläne. Und jetzt muss ich froh sein, dass es so gekommen. An alle diese Arbeit der 
Einführung mit den vielen Anfragen u. Controversen hatte ich ja gar nicht denken können. Es erwies sich als viel zweckmässiger, mit der Ausarbeitung des Buches noch etwas zuzuwarten, u. dafür konnte ich um so strammer am vollen Vorlesungspensum festhalten. Guhl als Kollege neben mir wäre bei dieser Situation für mich leicht eine Verlegenheit geworden, zumal ich nicht sicher bin - nach einzelnen Anzeichen - ob er nicht mein Rivale hätte werden

wollen. Seine Jugend, sein eigener Verkehr mit den Studenten hätten meine Autorität leicht aufgewogen. Damit rechnete ich ja auch von Anfang an, dachte eben nur, ich sei dann halt nur noch ein halber Professor. Jetzt - ist alles anders. Er hat sein Amt mit ausserordentlich verdienstlichem Wirkungskreis, er nimmt mir einen Hauptteil der Arbeit ab mit den Einführungsfragen, $u$. ich bleibe beim vollen Lehrpensum u. lasse, wo ich ich [sic!] nicht selbst gelegentlich daran arbeiten kann, meinem Dr. Siegwart das Opus fördern, so gut er es nach meiner Anleitung vermag. So wird aus den Dingen etwas ganz anderes, als man gedacht, u. es ist gut, oder besser. Guhl habe ich sehr gern. Seine Jugend entschuldigt alles. Ich arbeite mit Freuden mit ihm zusammen. Und Siegwart - wie muss ich froh sein über ihn. Er arbeitet, was ich nur erwarten kann.

Und nun noch in die Stube hinunter zum Rosegger.

Gute, gute Nacht!

Dein ewig getreuer

Eugen 
B. d. 26. Jan. 1912.

Mein liebstes Herz!

Ich bin nun doch wieder in eine ruhigere Stimmung gekommen u. sehe die Dinge gelassener an. Es wird sich wohl so gestalten, dass ich eben im Kolleglesen meinen «Altenteil» erblicke, davon nichts ablasse, sondern dabei bleibe, solange ich kann, u. das andere als Nebensache betrachte. Das hat nicht nur das Gute, dass ich mich nicht mehr über die Unmöglichkeit, intensiver nebenbei arbeiten zu können, unglücklich fühle u. durch zu grosse Anstrengung, namentlich während der Ferien, aufreibe, sondern es lautet mir wie ein Vermächtnis, dass ich damit gerade das tue, was Du mir bei meinen Kollegentlastungsgedanken vor zwei oder mehr Jahren auf das Bestimmteste angeraten hast. Es war mir ja auch, nachdem Du mir entrissen worden, in erster Linie wieder möglich, mich an den Vorlesungen wieder aufzurichten. Und wenn ich auch den kargen Besuch der Gesetzgebungspolitik schmerzlich empfinde, so war ich doch heute wieder so freudig in dem gut besuchten Praktikum, dass mir das eine das andere wettschlagen darf. Es ist ein Genuss, mit den jungen Kerls so zusammen zu arbeiten, wenn so an die sechzig, siebzig gespannt aufhorchen u. der Fall

mit ihnen in scharfen Conversationen durchgenommen, zerschnitten, gewendet, zerstückelt u. wieder zusammengesetzt wird. Dann steht der Bau am Schluss der Besprechung wieder einheitlich da, wie am Anfang, nur mit dem Unterschied, dass er nun von rechtlichen Erwägungen durchleuchtet sich dem Verständnis ganz anders eröffnet hat, als das beim ersten Anblick möglich zu sein schien. So will ich in solchen Erfahrungen 
Mut fassen u. davon nicht lassen. Das wird mir, wenn ich die Ferien zur Erholung brauche, noch auf Jahre hinaus möglich sein, wenn kein Unfall oder Gift mich hinwegrafft. Ich würde auch das gelassen hinnehmen, weil es mich ja nur um so schneller ans Ziel brächte. Inzwischen arbeitet man an dem, was man kann u. mag. Heute hat Marieli Helveter Tanzkränzchen. Hodler holte es eben ab, derselbe, der Anfangs des Semesters 1909 / 10 bei Dir Besuch machte u. Dir so sehr gefiel. Er war da u. ich begrüsste ihn mit Vergnügen. Er muss ein talentierter Bursche sein, zum zweiten Mal Präses, freilich weiss man nie, wie gerade solche Naturen sich später im Leben machen werden. Marieli war heute wohler, wenn auch noch nicht ganz hergestellt. Frau Sophie Burckhardt liess mir durch ihren Mann sagen, dass sie sich gerne seiner Gesundheit annehmen werde. Ich sprach schon gestern zu dir davon, welche Hoffnung ich hierauf setzen

würde. Ich weiss nicht, ob sie sich realisieren wird. Die Mitteilung Guhls, dass Büttikofer über die Frage, in der er mich consultierte, auch nachträglich bei ihm gewesen sei, veranlasste mich, Büttikofer nochmals zu mir zu bitten. Ich wollte damit in keiner Weise demonstrieren gegen Guhl, dachte nicht einmal hieran, merkte dann aber, dass Büttikofer es in etwas so auffasste, u. das ist mir auch recht. Der Landrat habe ihm Auftrag gegeben, noch Guhl zu befragen. Das ist ja eine kleine Pointe, wie ich jetzt nachträglich einsehe. Hätte ich das früher so betrachtet, so würde ich vielleicht Büttikofer nicht nochmals zu mir gebeten haben. Nun ja, es hat ihm u. mir nicht geschadet.

Bei v. Mülinen vernahm ich heute, dass der schlimme Finger, den er vor zehn Tagen beim Kegeln gequetscht, rhönthgenisiert worden, $\mathrm{u}$. dabei habe sich ein kleiner Bruch im Knochen des vordersten Gliedes des rechten Zeigefingers herausgestellt. Das erinnerte mich an Deinen gebrochenen kleinen Zehen vom Sommer 1880. Wie das wieder liebe Bilder in mir wach rief! Wir haben doch ein reiches Leben miteinander 
gehabt. Und es wäre noch reicher gewesen, wenn wir auf einer höheren Stufe ethisch u. ökonomisch gleich hätten beginnen können. So ging gar viel Kraft verloren, bis man nur einigermassen über das Schlimmste hinaus war. Freilich wäre dann vielleicht, wenn das nicht gewesen wäre, etwas anderes gekommen. Genug, dass schiesslich das Ziel von uns

[4]

erreicht werden konnte. Du hast es abgeschlossen im letzten Ziel, das ich selbst nun in der Gedankengemeinschaft mit Dir auch noch zu erreichen mir vorgenommen habe. Hilf mir dabei, meine beste, einzig liebe Seele!

Heute hat Münger mit dem Glasschneider Feckner aus Freiburg die Windstangen an den beiden Glasbildern angemacht. Sie hängen nun etwas höher u. sehen besser aus. Allein ich muss vielleicht noch etwas Dekoratives dazutun. Es kommt mir jetzt etwas mager vor. Nun gehe ich heute gern frühe zu Bett. Möge Marieli am Morgen gesund zurückgekehrt sein. Ich will schlafen, denn ich bin sehr, sehr müde.

Dein ewig getreuer

Eugen

\section{2: Januar Nr. 23}

[1]

B. d. 27. Jan. 1912 .

Liebstes Herz!

Es war heute ein so unruhiger Tag, dass mir die innere Fassung, die ich gestern errungen zu haben glaubte, u. der ich in meinem gestrigen Brief Ausdruck gegeben habe, beinahe vollständig wieder verloren gegangen ist. 
Ich fühle wieder ein Elend, das ich nicht beschreiben kann. Alles drängt auf mich ein, ich fühle mich neuerdings der Situation nicht gewachsen. Die Morgenpost brachte mir einige Anfragen zum ZGB., die ich prompt beantwortete. Dazwischen wollte Hellmüller telephonisch eine Consultation, die ich glücklicherweise sofort erteilen konnte. Dann kam Guhl in wichtigen Sachen. Nach dem Essen kam Hemmeler, brachte u. holte Bücher. Darauf hatte ich Hafner von der Nationalbank von halb drei bis nach vier Uhr bei mir. Darauf Briefe u. jetzt schreibe ich an Dich, noch vor dem Nachtessen, um im Austausch der Gefühle mit Dir wieder ruhiger zu werden. Was mich noch speziell plagt, das ist, dass von Senn die Antwort betr. Frau Pulver nicht kommt, u. dass Zeerleder mir für das Bild, das ich ihm als Mitglied des Vorstandes des B. J. V. doch senden musste, gar nicht gedankt hat, obgleich ich einen Brief beilegte, in dem ich mich für die Zusendung

[2]

quasi entschuldigte. Scheurer hat doch freundlich geantwortet, die beiden waren es, die am Neujahrsmorgen mit dem übrigen Vorstand nicht gekommen sind, ohne ihr Ausbleiben zu entschuldigen. Jetzt wird sich bei Zeerleder die ganze Rancüne zeigen, die er von jeher gegen mich an den Tag gelegt hat. Und ich vermag doch nichts dafür, dass er vor 27 Jahren in Basel bei mir den damals von ihm planierten Doktor nicht gemacht hat! Lichtblick von heute war ein Brief von der Tochter Crugnolas, Rita Montani, u. ihrem Mann, die Marieli herzlichst willkommen heissen.

Aber nun muss ich doch das Gutachten für die Nationalbank schreiben, $u$. kann doch fast nicht. Es ist ein Jammer, ich breche unter der Last zusammen. Ich werde mir darüber immer klarer, dass mein $\mathrm{Ge}$ mütszustand krankhaft ist. Infolge von andauernder 
Überarbeitung u. von Anlage breitet sich immer mehr die Melancholie über mich aus. Es ist zu viel. Ich hoffte, dass ich diese Stimmung überwunden hätte, aber meine Freude war zu früh. Ich hätte noch etwas mehr arbeiten sollen, in meiner guten Zeit, um mit Dir Hand in Hand das Leben verlassen zu können. Jetzt muss ich allen Jammer allein auf mich nehmen. Oder ich breche am Ende doch alles u. jedes ab u. geh in die Welt hinaus in einen verborgenen Winkel, wo ich den unnützen

Rest des Tages in verschlossener Ruhe zu Ende führen kann. Es ist merkwürdig, dass mir in neuerer Zeit häufig der Traum u. die Wirklichkeit durcheinander kommen. Das ist doch auch ein Zeichen eines krankhaften Seelenzustandes, $u$. die Arbeit, die Arbeit, ich weiss nicht, wie ich sie erledigen soll. Alles drängt u. ich fühle nur die Last u. keine Freude. Und doch wird mir schon wieder wohler, da ich Dir das schreiben kann. Sonst habe ich ja niemanden zum traulichen Verkehr. Marieli bleibt stumm u. wortkarg. Es hat von dem gestrigen Tanzkränzchen, von dem es um 4 Uhr zurückgekehrt ist, kaum ein Dutzend Worte erzählt, u. die gingen dahin, dass sein Begleiter, Hodler, doch wirklich stark «rauche», d. h., wie wir es jeweils von Heims sagten, sich selbst rühme, u. dass sein Begleiter vom 23. Nov. v. J., der Röthlisberger, viel sympathischer sei. Nun ja, vielleicht vernehme ich nach dem Abendessen noch etwas mehr, auch wird bei dem Vorlesen, wo wir heute Roseggers beide Hanse zu Ende kriegen werden, noch das eine u. andere abfallen. Wenn Marieli nun auf den 20. Febr. nach Mailand geht, so könnte ich die Ferien zu einer längeren Reise benutzen. Das ist vielleicht auch das Gescheiteste, was ich tun kann, um wieder munterer zu werden. Ich schreibe später noch einige Zeilen. Hoffentlich bringt die Abendpost nicht neue Arbeit u. Unruhe!

Zum Schluss: Die Post hat nichts gebracht als die Zeitung, 
u. in dieser steht nichts wichtiges. Also keine neue Arbeit. Nur wurde die Dissertation Roggmanns abgegeben, die nicht umfangreich ist u. nicht eilt. Ich werde sie nächste Woche lesen. Damit Schluss, Schluss der Woche, wieder eine weniger. Marieli hat bei Tisch nun doch das eine u. andre vom gestrigen Abend erzählt. Ich bin befriedigt. Ich denke die Tage oft, wenn nur August nicht krank wird u. stirbt. Das wäre in diesem Zeitpunkt sehr, sehr bedrückend. Es wäre fast nicht auszuhalten. Wir sollten noch eine andere Versorgung Pauls u. dann unter uns die Aussöhnung erleben. Nur mit Sophie, Deiner Peinigerin, bleibe ich fertig, wie seit bald zwei Jahren.

Gute, gute Nacht! Ich bin

Dein ewig getreuer

Eugen

\section{2: Januar Nr. 24}

[1]

B. den 28. Jan. 1912.

Mein liebstes Herz!

Heute schien der Winter kommen zu wollen. Es war am Morgen kalt $\left(3^{\circ}\right) \mathrm{u}$. gegen Mittag fing es an zu fisern, als wollte ein Schneefall beginnen. Aber am Nachmittag war alles wieder vorüber, wenn auch der Himmel trüb geblieben ist u. die Sonne nicht durchzudringen vermochte. Ich schrieb am Morgen einige kleine Briefe, u. a. konnte ich Frau Pulver endlich Nachricht geben, in dem Senn mir empfahl, ihr zu sagen, sie soll sich an ihre Zunft (Zimmerleuten) wenden. Damit wird das sonderbare Gesuch hoffentlich erledigt sein. Ich präparierte darauf noch vor Tisch das Kolleg für morgen, $u$. las den ersten Akt Hamlet, seit langem wieder einmal. Am Nachmittag nahm ich etwas 
englische Lektüre vor, dann machte Rossel den versprochenen Besuch, ohne dass er etwas zu fragen hatte, nur aus Freundlichkeit. Auf drei kamen Dr. Siegwart, seine Tante u. seine Schwester $u$. blieben bis nach halb sechs, es waren gemütliche Plauderstündchen. Zwischenhinein wollte Prof Steck zu mir kommen, offenbar um sich die Scheiben anzusehen. Die hangen nun besser. Nur stören die leeren Scheiben mehr als vorher. Ich brachte oberhalb u. unterhalb der bunten Scheiben heute Morgen kleine Vorhängle an, u. so geht es jetzt

besser, ist aber nur ein Provisorium. Ich habe immerhin in den letzten Tagen wieder mehr den Eindruck gehabt, die Scheiben könnten mir mit der Zeit unerträglich werden. Kann sein, dass das verletzende Schweigen Zeerleders mich in diesem Sinne beeinflusst. Es wird sich zeigen, welche Stimmung schliesslich hervorbricht. Bedankt haben sich für das Müngersche Bild: Leo Merz, Schorer, Gmür, Trüssel u. Scheurer. Neben Z. steht noch aus Pfister. - Nach Siegwarts Fortgang kam Walter Burckhardt, wurde aber gleich telephonisch wieder nach Hause gerufen, wahrscheinlich wegen der geistesgestörten Magd, die sie zur Zeit haben. Er liess mir einen Artikel des Berner Tagblatts da, das aus den Zürcher Nachrichten einen sehr unartigen Artikel gegen das Polit. Jahrbuch reproduziert hat, nachdem es selbst, wie ich Dir neulich mitteilte, mit einem sehr scharfen Artikel von sich aus vorangegangen war. Walter B. hat mit dem Buch viel Ärger. Es war ja auch kaum anders zu erwarten, denn Hilty hatte eben doch sich durch seine keiner Partei ganz angehörende Persönlichkeit, seinen Schwung u. seine tatsächlich anerkannte Autorität eine Gemeinde gebildet, die bei aller Anfechtbarkeit der Leistungen des Herausgebers treu zu ihm stand u. einen Grundstock bildete, der das Jahrbuch aufrecht hielt. Jetzt kann diese «Gemeinde» in dem Jahrbuch nicht mehr das finden, was früher, u. die Folge davon wird ein Abbröckeln der alten Freunde sein, ohne dass eine entsprechende Anzahl neuer gewonnen ist. Diese Umwandlung 
muss Verdriesslichkeiten mit sich bringen, die Walter B. manche schwierige Stunde bereiten. Ob er dennoch aushalten wird? Seiner Frau geht es seit gestern wieder nicht gut. Er sprach von Exudaten.

Heute bemerkte ich zu Rossel, es komme mir immer mehr das Leben vor, wie auf Distanz sich abspielend, das werde so eine Altersempfindung sein. Er meinte, das sei schon möglich. Es wird aber wirklich so sein. Dazu kommt mein intensiveres Bewusstsein auf das was sein sollte, der Ausblick u. Rückblick unter anderen Gesichtspunkten, als ich sie in den Studentenjahren mir aus Mangel an anderer Pflege angeeignet. Ich war doch mehrfach hart daran, nebenaus zu geraten, u. nur ein fester Plan, eine Aufgabe hat mich dann allemal wieder auf die Bahn gebracht. In den letzten Jahren des Gymnasiums das Drama, in dem 5. u. 6. Semester die Dissertation, ein junger Beruf, die Liebe zu Dir, später die Professur, das Werk, das deutsche Amt, die Codification. So, der Reihe nach. Und jetzt baue ich wieder ab. Du bist mir entrissen, das Werk in zweiter Auflage interessiert mich nicht, die Professur wird zur Routine - es hört eines nach dem andern auf. Wird mich die Schriftstellerei in philosophias noch etwas über Wasser halten. Von Missraten kann ja nun freilich nicht mehr die Rede sein, nur vom Aushalten, vom Abbauen, von Reife u. Frucht. Und das will ich nun abwarten, mit soviel Ruhe als möglich. Ich will meine Ferien haben, ich will träumen können, ich will meine Seele davor bewahren, in einem öden Ding unter zu gehen. Von

Aufgaben kann ja nun eigentlich nicht mehr die Rede sein, nicht einmal mehr von Ernte, nur von «Sucheln», wie es der Weinlese folgt $u$. wie ich es als Knabe auch betrieben habe.

Jetzt will Marieli aus der Ebner-Eschenbach etwas beginnen. Denn die beiden Hanse haben wir gestern fertig vorgelesen. Schade, gegen den Schluss liefert Rossegger nur noch ein «Gschichtli». 
Doch genug für heute. Bleib bei mir, liebe Seele, ich will im Denken nicht müde werden!

Dein ewig getreuer

Eugen

1912: Januar Nr. 25

[1]

B. d. 29. Jan. 1912.

Liebstes Herz!

Heute war kalte Bise, der Spaziergang auf der grossen

Schanze vor Beginn des Morgenkollegs liess mich die Kälte eisig empfinden, aber es war ein heiterer Himmel $u$. ich ging mit frischem Kopf an die Arbeit, war auch im Sprechen lebhaft, vielleicht nur zu sehr. Nach Hause zurückgekehrt, fand ich keine besondere Arbeit. Ich hatte für das Praktikum Fälle zu präparieren - was ich gestern ganz vergessen -, u. erledigte nebenbei, nach dem Essen, die Empfangnahme u. Neuhingabe von Büchern für den Buchbinder u. die Neuplanierung der Scheiben Müngers. Sie hangen jetzt besser, als Münger es angeordnet, diskreter u. doch gut beleuchtet, weil ich das Doppelfenster hinter ihnen im Erker des Salons entfernen liess. Was später zu machen ist, wollen wir wieder sehen. Zunächst werden jetzt für die Regale die beiden farbigen Gestalten mit einem leichten Tüllvorhang bedeckt sein, man kann ihn zurückschlagen, wenn man die Sache näher besehen oder sehen lassen will. Am spätern Nachmittag ging ich noch zu Guhl, der heute sein Grundbuchbüreau bezogen hat. Ich grüsste die Herren: Röthlisberger, Leiniger, Baltensperger. - Robert wird als Kanzlist nächsten Mittwoch antreten. Guhl schien in sehr gehobener Stimmung. Er wird sich seines Amtes mit Würde u. Geschick annehmen, dessen 
vertraue ich mich des Bestimmtesten. Er arbeitet jetzt nicht mehr zu Hause, sondern auf dem Büreau, u. scheint darüber vorwiegend froh zu sein. In den letzten Tagen bemerkte er einmal zu mir, der Lärm der beiden herzigen Kleinen habe ihn doch oft gestört. Es mag auch noch anders gewesen sein. Als gestern Rossel so freundlich zu mir kam, erwartete ich, er werde etwas von mir haben wollen. Das war dann auch der Fall, aber die Freundlichkeit klärte sich heute doch auf: Die Zeitungen der welschen Schweiz bringen jetzt nämlich die Nachricht: Rossel habe sich bereit erklärt, eine Wahl in das Bundesgericht anzunehmen, was bei dem hervorragenden Anteil, den Rossel an der Ausarbeitung des C. C. S. genommen, sehr zu begrüssen sei. Und die Bereitwilligkeit, die Professur mit dem Richteramt zu vertauschen, sei um so mehr anzuerkennen, als Rossel neulich eine ihm angebotene Stelle als Chef des internationalen Amts für geistiges Eigentum abgelehnt habe, um der Wissenschaft u. dem Lehrstuhl treu zu bleiben. So soll es, wie Frau George Marieli mitteilte, in den Lausanner Zeitungen gestanden haben. Ist das nicht ein Meisterstück von Schauspiel? Rossel weiss, dass ich den Sachverhalt, der ja gerade der umgekehrte war, kenne, u. er hat allen Anlass mich zum Schweigen zu veranlassen. Natürlich werde ich auch schweigen. - Aber meine Gedanken über dieses Erlebnis sich zu machen, das ist mir schon erlaubt. Rossel wird mir dadurch nicht ehrenwerter. Herr Gott, wie kann man an solchen Un-

wahrheiten wohl leben! Es wird jetzt schon so kommen, dass Rossel sich als Retter des ZGB, in das BG. wählen lässt. Nachdem erst mit so unverborgener Abneigung von der Wahl ins BG. gesprochen $u$. nur mit Widerstreben den Gedanken näher getreten ist an den Wechsel, der ja erst dann ihm möglich schien, als alle Versuche mit dem internationalen Amt gescheitert waren! Eine prächtige Komödie! Als ich heute in die Universität kam, sagte mir Bieri, er habe eben zwei für 
Bern schwere Nachrichten in der Zeitung gelesen: Die Zuckerfabrik in Aarberg sei abgebrannt, u. Rossel wolle die Universität verlassen. Der Pedell hatte den Rektor Rossel sehr geschätzt, während Rossel den Schlag wie Bieri in seinem Innersten verlacht. So sind eben unsere Leute. Sie glauben den Welschen alles, wenn die uns den richtigen Ton mit ihnen zu verkehren treffen, u. umgekehrt ist ihnen die offene, etwas hochfahrende Art der deutschen Kollegen vom Grunde des Herzens aus verhasst. Man kann lernen aus solchen Beobachtungen, u. lernt niemals aus. Ich konnte am heutigen Tag wieder nicht viel arbeiten. Die Zeit zerrinnt mir unter den Händen bei allerlei Vielgeschäftigkeit. Die Nacht habe ich bei längerem Wachsein wieder Pläne gemacht, aber wann lassen sie sich ausführen? Ich vertraue auf die Zukunft. Nur vorwärts, es wird schon wieder besser kommen. Gestern sagte ich leider zu Rossel, die Stelle im BG. sei doch eine sehr schöne, sie würde mir unter Umständen in jüngeren Jahren auch gefallen haben. Aber meine Aufgaben - das sagte ich nicht zu ihm - haben mich daran verhindert. Wie vieles habe ich

dieser Aufgabe zum Opfer gebracht. Und dass mir dafür einiger Dank mehr wird, als andern, die keine Opfer brachten, das wollen diese andern mir nicht gelten lassen. Doch nochmals vorwärts, das sind ja alles Nebendinge.

Gute, gute Nacht! Ich bin Dein ewig getreuer

Eugen 
[1]

B. den 30. / 31. Jan. 1912.

Liebstes Herz!

Ich schreibe während der Examenssitzung diese Zeilen, ohne in Sammlung mich zu befinden, die ich gern haben möchte, wenn ich mit Dir plaudere. Ich weiss nicht weshalb, fühle ich mich diese Tage in einer innern Aufregung, die vielleicht nur von der ungewohnten Bise u. dem Sonnenschein herrührt, die über den Mittag in den Zimmern eine wenig gemütliche Wärme verbreitet. Daneben haben andere Momente meine Gemütsverfassung beeinflusst. Von Frau Welti ist eine Zusage eingelaufen, wonach Marieli nach Nervi kommen könnte. Ich habe sofort abgeschrieben, da der Plan mit Mailand nun feststeht. Aber es war nicht angenehm, die Freundlichkeit, die wir doch provoziert hatten, abzulehnen. In der Sache denke ich, dass Marieli bei Frau Rita Montani mehr gewinnen wird, als in dem bäurischen Haushalt in der feinen, zum Lebensstandard so wenig passenden Villa in St. Ilario.

Dann bemerkte ich, dass heute in der Vormittagsvorlesung Hodler immer gelächelt hat, also offenbar auch eine Stimmung, die mir nicht glücklich zu sein scheint. Dazu immer wieder die drückende Aussicht, dass es mit der Arbeit am Buch nicht gut vorwärts gehen wird. Nun, ich hoffe auf Besserung. - Unter den heutigen Kandidaten ist der

Helveter Schmid, der Leibbursche Abbühls. Er hat bei mir gut bestanden, ein gescheiter junger Mann. Mir tat es leid, durch ihn an die Affaire mit Abbühl erinnert zu werden, bei der Marieli nicht ohne meine Mitschuld ein gewisses Unrecht begangen hat. Das letzte Jahr war für es doch recht peinlich. Es weiss selbst nicht, was es sich alles durch 
die Schwankungen in seinen Neigungen verdorben hat. Übrigens hat es heute wieder Magenstörungen gehabt, u. dabei Veranlassung genommen, die anerbotene Hülfe in den Ratschlägen der Frau Sophie Burckhardt in Anspruch zu nehmen. Diese hat ihm dann auch diese Ratschläge erteilt. Was ich dabei vernahm ist, dass jedenfalls Marieli künftig das Fleischessen bleiben lassen wird. Ob es dann wirklich das andere positive tut, was ihm angeraten, nämlich ein Morgenessen von Grahambrot, Butter, Honig etc. u. abwechselnd Reis zu nehmen, das bleibt abzuwarten. Ich hoffe es inständig. Doch nun muss ich heute schon abbrechen, das Examen schreitet weiter. Wocher, der zweite Kandidat wird wahrscheinlich durchfallen. - Gute, gute Nacht!

Den 31. Januar.

Wocher ist gestern doch noch, mit Ach $\mathrm{u}$. Krach, rite als Licentiat durchgekommen. Heute besuchte er mich, ganz niedergedrückt, von dem Gedanken geplagt, dass er zum Doktor das Examen noch einmal machen müsste. Er brach bei mir in Tränen aus. Der gute Kerl hat sich offenbar überarbeitet, ist nervös geworden. Ich suchte ihn zu beruhigen $u$. er ging ziemlich getröstet weg. - Heute machte mir zu

meiner Überraschung - ich hatte vorher nichts davon verspürt - das Kolleglesen in der Stunde mit einem Mal Mühe, sodass ich gegen $10 \mathrm{Uhr}$ in der zweiten Stunde fast nicht mehr sprechen konnte: Ich war stark heiser. Das hat sich dann gesteigert über den Mittag u. ist erst gegen Abend wieder besser geworden. Ich hatte einen ruhigen Nachmittag, musste nur Wocher, u. einen Studenten, der nicht lange blieb, empfangen, konnte also meine Stimme schonen. So hoffe ich, dass bis morgen die Sache im wesentlichen vorüber sein wird, sodass ich nicht werde aussetzen müssen. Ich hoffe das namentlich deshalb, weil ich keine Befangenheit im Kopf, kein Fieber verspüre, wenn es mich auch ab u. zu kalt durchrieselt. Jedenfalls hat die Bise mit dem vielen Staub, der jetzt in den Strassen wirbelt, mich infiziert. Durch diesen Zwischenfall hat sich auch noch eine andere Angelegenheit erledigt. Ich musste Guhl vor Tisch in Amtssachen zu mir kommen 
lassen, u. dabei - nach vorausgehender telephonischer Ankündigungmachte mir Guhl die Mitteilung, dass BRat Müller ihm telephoniert habe, Direktor Schulthess von der Kreditanstalt habe sich ebenfalls telephonisch angemeldet zu der vom Departement angebotenen Conferenz wegen der Anleihenstitel, u. Müller habe ihn an das Grundbuchamt gewiesen. Guhl habe gleich entgegnet, die Behandlung der Frage sei durch mich erfolgt, es sei daher zweckmässig, wenn ich an der Conferenz teilnehme, womit Müller einverstanden. Nun konnte ich aber wegen der starken Heiserkeit, wenn ich nicht riskieren wollte, morgen gar nicht Kolleg lesen können, heute unmöglich die Besprechung abhalten. Also überliess ich Guhl die Erledigung. Einerseits hätte es mich sehr gefreut, mit Schulthess in der Sache zu sprechen, ja ich hatte mich darauf gefreut. Anderseits aber liegt die Sache nun doch so, dass

Guhl Chef des Grundbuchamtes ist, der auf Jahre hinaus diese Sachen in seiner Hand behalten wird. Es ist daher besser, wenn er solche Verhandlungen nun ebenfalls in seine Hand nimmt. Ich habe auch das Vertrauen in ihn, dass er die Sache recht machen wird. So konnte ich mich damit begnügen, ihn noch auf die Hauptpunkte hinzuweisen u. ihn auf die Schwierigkeiten u. deren Lösung hinzuweisen. Er will mir nachher von dem Ergebnis der Besprechung Mitteilung machen. So entwickelt sich auch hierin für mich immer deutlicher die Stellung des «Altenteils». Die Jungen streben vorwärts, sie haben das Recht dazu, u. wir müssen froh sein, wenn Junge da sind, um die von uns begründeten Aufgaben in richtiger Lösung weiter zu führen.

Als ich heut Nachmittag so still in meiner Stube sass u. mit der Dissertation Bruggmanns begann - von der ich fast eine Hälfte erledigt - da wurde mir so überaus deutlich, wie das Ziel des Lebens sich darstellt. Du bist mir vorangegangen, wie in vielem Früheren so auch hier in dem Schlusse, u. ich weiss, dass u. wie ich nachfolge. Sei Du nur mein guter Führer. Ich werde meine Pflicht noch tun, soweit ich es kann u. vermag, u. dann Gott befohlen!

Frau Rossel hat mich $\mathrm{u}$. Marieli gestern auf Sonntag zum Mittagessen eingeladen, mit Gmürs. Ich sagte zu aus nachbar- 
licher Rücksicht. Heute kam Rossel nach Tisch u. trug mir den Wunsch vor, anstatt am Sonntag am Montag zum Essen zu kommen, da Gmür Sonntags in die Berge wolle. Das war mir so recht, wie das andere. Ich machte also keine Einwendung. Heute setzt Marieli seine Kur, wie sie Frau Burckhardt empfohlen, ins Werk. Zum Café war Frau Dr. Tecklenburg da. Er ist munter. Und nun für heute Schluss!

Dein

Eugen

[Zusatz]

Monsieur le Directeur des Archives

Nationales

Berne

Suisse 


\title{
Februar 1912
}

\author{
1912: Februar Nr. 27
}

B. den 1. Febr. 1912.

\section{Liebstes Herz!}

Gestern Nachmittag u. am Abend war ich so heiser $u$. in den Gedanken gehemmt, dass ich befürchtete, heute aussetzen zu müssen, was fataler Weise wieder auf den Donnerstag getroffen hätte u. mich in den Augen Burckhardts wohl wieder in Verdacht hätte setzen müssen. Ich ging gleich nach acht Uhr zu Bett, las noch wie immer in den «Werken» Chamberlains u. stellte die Zitate zusammen bis neun Uhr. Dann muss ich sofort fest geschlafen haben, denn ich hörte nichts mehr von Marieli, das doch um halbzehn von dem Vortrag der Frl. Emmerling ganz vergnügt nach Hause gekehrt sein soll. Die Nachtruhe tat mir wohl. Heute war auch die Bise bereits wieder vorüber, u. ich las die zwei Morgenstunden u. das Nachmittagskolleg wenn auch etwas mühsam, doch ohne Unfall durch $u$. habe also den Angriff wieder einmal überwunden. $\mathrm{Zu}$ weiterer Arbeit bin ich nicht gekommen. Ich hatte vor Tisch Siegwart die Hammond Maschine zu erklären, die Guhl, weil er sie, auf dem Bureau, jetzt nicht mehr braucht, zurückgebracht hat. Von 6 bis 7 Uhr war Guhl da. Die Besprechung mit Direktor Schulthess, von 4-5 Uhr gestern, soll, wie er mir mitteilte, zu dessen Befriedigung ausgefallen sein. Das Abend kolleg war wieder einmal schlecht besucht. Auch Hoffmann fehlte, was ich wohl begreife. Infolge davon habe ich mir sofort wieder Gedanken gemacht, ob ich am Ende doch 
nicht besser täte, mich vom nächsten Winter an auf die privatrechtlichen Vorlesungen zu beschränken $u$. Rechtsphilosophie samt Rechtsgeschichte fahren zu lassen. Das ist eine ganz üble Eigenschaft, die mich da wieder plagt. Vor wenigen Tagen glaubte ich ganz sicher in mir den Plan gegründet zu haben, nun eben wacker, mit $12 \mathrm{u}$. 13 Stunden, drauflos zu lesen u. das Schreiben zurückzusetzen. Und jetzt plagen mich wieder Bedenken. Und ich habe so gar niemand, mit dem ich darüber sprechen könnte. Auch bei Walter B fühle ich mich nicht mehr sicher, ob er mir nicht einen Rat geben würde, der seinem Neidgefühl, aber nicht meinen Interessen entspräche. Freilich habe ich noch Monate Zeit, mir die Sache zu überlegen. Aber, aber! Wenn dann der Moment kommt, sollte ich einen gefestigten Plan haben, u. darüber bin ich immer noch nicht mit mir einig.

Beim Verlassen der Universität traf ich Frl. Reineck, redete sie an u. sie begann über Marieli mit mir zu sprechen. Sie fragte, ob es unter dem Druck des Vorgefallenen mit Paul sehr leide. Ich musste dies verneinen. Sie meinte, ob es denn auch so sicher sei, dass es mit Paul nichts werde. Marieli habe ihr aus Zürich s. Z. geschrieben, dass ich gestrahlt habe vor Freude über der Verbindung. Ich versicherte sie, dass Marieli fest entschlossen sei u. ich nicht minder. Der Plan sei mir immer bedenklich vorgekommen $u$. Marieli habe mich mit jener Ankündigung seiner Verlobung fast erschreckend überrascht. Davon wusste sie gar nichts. Sie fragte auch, ob Marieli

in den Studentinnenverein eintreten werde, was ich mit der Mitteilung beantwortete, dass es demnächst für zwei Monate nach Mailand gehen werde. Sie bemerkte nebenbei, es würde Marieli so gut tun, sich mit andern mehr auf Diskussionen einzulassen u. zu reiben. Aber ich hatte darauf nicht mehr zu antworten. Wirklich würde ich es nicht begrüssen, wenn Marieli diesem Kreise in engerer Art beiträte. Sie ist dafür noch zu sehr in der Richtung empfänglich, dass sie am Ende mir noch ganz in 
materialistischem Sinne entfremdet $u$. in das gelehrte Altjungferntum hinüber geführt würde. Da hoffe ich doch immer noch eher, dass sie einen Mann findet, der ihr dann den mangelnden Halt gibt. Aber es ist ja möglich, dass ich die Dinge in meinem Alter u. in meiner Abgeschiedenheit falsch beurteile, die Zeit wird lehren!

Von Augusts u. von Gyrs vernehme ich nichts mehr. Was das bedeutet, weiss ich nicht. Es können noch allerlei Überraschungen zu Tage treten. Von Fritz Zeerleder habe ich keine Antwort auf die Sendung des Bildes erhalten, allerdings auch von Pfister nicht. Aber bei Zeerleder muss ich dies doch als eine Unhöflichkeit empfinden, die mir verletzt. Ich mache mir ja aus dem Manne nicht viel. Er hat von Anfang meines Hierseins an sich mir gegenüber, trotz aller Avancen, die ich gemacht, unstät u. unzuverlässig bewiesen. Als Secretär der Commission hat er meine Voten immer nur so ebenhin protokolliert u. mir auch gar zu wenig Beachtung geschenkt. So wird das nun eben aus demselben Geist entspringen, was ich jetzt an ihm

erfahren habe. Es ist gut, dass Andere sich anders zu mir verhalten, sonst könnte ich wohl wieder an Bern verzweifeln. Doch ich bin heute doch nicht in der gedrückten Stimmung, um Klage erheben zu wollen. Das alles ist eben der Lauf der Welt. Marieli will heute in der Ebner-Eschenbach noch etwas weiter vorlesen. Also gehe ich jetzt hinunter u. dann zur Ruh! Gute, gute Nacht!

Allezeit Dein

Eugen. 
B. d. 2. Febr. 1912.

Mein liebstes Herz!

Heute fiel der erste Schnee des Winters, der liegen blieb u. die ganze Gegend in weiss gehüllt hat. Das Zwielicht in den Stuben war heimelig. Ich war heiter bei der Arbeit, las die Dissertation Bruggmann fertig-er muss noch etliches umarbeiten -, schrieb ein kleines Gutachten, präparierte u. hielt mein Praktikum, das gut besucht war, u. jetzt sitze ich bei der Lanze u. schreibe an Dich.

Marieli war vom Morgen an wieder unpässlich. Der Druck im Magen hat sich wieder eingestellt. Es gibt dem Porridge schuld u. isst fast nichts. Die Kur mit der sauren Milch, die ihm Frau Burckhardt anempfohlen, ist aufgegeben. Ich liess dann eine Flasche Eisen-China-Wein kommen, von der es vor dem Nachtessen einen Löffel genommen, um sich gleich wieder über Beschwerden im Magen zu beklagen. Die Constipation hat wieder begonnen. Jetzt ist es mit Susanne Rossel in den akademischen Vortrag von Frl. Tumarkin gegangen «Was ist uns heute Kant.» Vorgelesen wird heute nicht. Ich will sehen, ob es etwas über den Vortrag zu erzählen weiss.

Natürlich ist es keine Gesellschaft für Marie, nur immer um die so alte $u$. nicht besser gewordene «Tante» zu sein. Bei dieser hat die Erinnerung an Dich lange nachgewirkt. Jetzt ist sie nachgerade wieder wie früher. Was hattest Du eine Mühe mit ihrem bösen

[2]

Wesen. Wie viel, viel Geduld brauchte es, dass Du es durchsetztest, sie die ganzen langen Jahre bei uns zu haben. Jetzt bin ich allein mit mir, u. sie weiss ja manches zu verrichten, was recht ist. Aber das Gemüt, die Frische, das kann man in ihrem Alter ja gewiss jetzt weniger zu recht verlangen, als früher. So ist es 
nun mit mir beschlossen $\mathrm{u}$. ich muss ja froh sein, dass es nicht schlimmer ist.

Mit meiner Heiserkeit ging es jetzt ordentlich. Am Morgen

fühlte ich mich sehr gehemmt. Der Schneefall hat mir dann Erleichterung gebracht. Die Luft war auf dem Weg zur Universität herrlich, $u$. ich vermochte auch die zwei Stunden in den Übungen auszuhalten mit der Stimme. Jetzt folgen, wie ich hoffe, zwei ruhige Tage, u. dann noch vier Wochen Semester u. auch dieser Schritt ist vorüber. In unserem Beruf ist ja jedes Semester nur ein Schritt, u. in der Erinnerung schrumpft dann der ganze Gang durch die Wissenschaft in ein kurzes Abschreiten der Front zusammen, wobei Kollegen u. Commilitonen die Linie bilden.

Soll ich mich weiter plagen mit Gedanken an die Zukunft? Ich denke nicht. Ich will nun schematisch mich davon fern halten u. einfach mal für mal tun, was ich kann u. mag. Mit dem Altenteil hat es schon seine Richtigkeit. Aber es ist nicht nötig, denselben sich absichtlich abzugrenzen. Die Grenzen ergeben sich von selbst aus dem Stande des Alters. Siegwart berichtete heute recht fröhlich von seinen Versuchen mit der Schreibmaschine. Er habe schon mit dem Schreiben begonnen $u$. freue sich über die Maschine. Ich dachte mir doch, dass

er daran Freude haben werde. Bei der Rückgabe der «Hammond» durch Guhl wurden mir die Umstände lebhaft in das Gedächtnis gerufen, unter denen er s. Z. die Maschine von mir bekommen hat. Und ich merkte aus einigen Worten, die er fallen liess, dass es ihm ebenso ergangen ist. Wie merkwürdig haben sich die Dinge gefügt. Ich war s. Z. erstaunt, dass er eine Stelle als Kanzlist im Departement des Innern angenommen u. drei Jahre bekleidet hatte, ohne dass er mich besuchte, obgleich er mir doch als Doktorand sehr nahe gekommen war u. die Anregung zur Habilitation von mir empfangen hatte. Wie ich dann im Winter 1907 / 8 nach einer Erleichterung in den Vorlesungen suchte, erinnerte ich mich seiner, suchte ihn auf u. machte ihm nochmals den Vorschlag. Er ging mit Eifer darauf ein. Es bot sich die Combination mit der Aushülfe betr. die Kontrolle der Einf.gesetze u. die Hülfe im OR. 
Er las für mich Handelsrecht. Es schien alles gut zu gehen, bis Gmür merkte, dass hier für ihn eine Konkurrenz entstehen könnte. In jenem Sommer 1908 verkehrte ich freundschaftlich mit ihm, er war oft stundenlang bei der Zigarre bei mir u. er sah wie sehr ich seiner Mithülfe bei dem künftigen Buche bedürfen werde. Die ersten Zweifel erwachten in mir, als er so merkwürdig den Allüren Ingen. Leuteneggers zustimmte u. nicht verstand, wie so dieser nicht genügen konnte. Wie grosse Hoffnungen hatte ich auf diesen gesetzt - die Enttäuschung war für mich hart u. Guhl war eher geneigt, ihn gegenüber dem Departement Recht zu geben. Dann ereignete sich im Frühjahr 1909 jene Nachlässigkeit, da Guhl den Auftrag, den ich ihm vor der Abreise nach Portofino erteilte, einfach liegen liess. Darauf

die weitern Geschichten mit Gmür, u. im Winter 1909 / 10 von Guhl eine Reihe von Bemerkungen, wonach mein Kolleg nach Aussage verschiedener Studenten nicht mehr auf der Höhe gewesen wäre. Ich merkte schon, was dahinter lag. Aber inzwischen wurden Guhls Arbeiten für das Departement so wichtig, dass ich seine Hülfe dringend nötig hatte, $u$. er nahm meine Anleitungen willig auf u. führte sie prächtig durch. In dieser Richtung verselbständigte er sich dann weiter, indess ich wieder meine Vorlesungen ganz in die Hand nahm. Was Du voraus gesehen, ist bei mir eingetreten. Gerade mit Dir hätte ich das alles erleben sollen. Es wäre in Deinem Geiste gewesen. Die Maschine gab ich ihm im Juni 1909, wie schon die amtlichen Arbeiten dringender wurden. Wie er sie zurückgibt, ist die Entwicklung, die damals begonnen, abgeschlossen. Ich suche daraus zu lehren, was ich kann. Heute erhielt ich von Dr. Hans Gwalter zwei Kärtchen, mit seinem Namen eines u. das andere mit «Finken Toming», einem skandinavischen Namen. Ich gratulierte herzlich zu seiner Verlobung. 
Damit schliesse ich für heute. Es ist so beruhigend, mit Dir über alles, alles zu sprechen. Ich habe ja sonst niemanden. Mit den Erinnerungen bin ich so allein. Wie war es schön, wie wäre es schön, gemeinsam in ihnen zu leben!

Immer u. immer Dein Eugen

\section{2: Februar Nr. 29}

B. d. 3. Febr. 1912.

Mein liebstes Herz!

Ich habe mir heute einen Ruhetag gegönnt. Ich habe nur das Unaufschiebbare getan: Mit Guhl verhandelt, Volmar empfangen, Langhard über seine Adoptionspläne aufgeklärt, Bruggmann mit Instruktionen die Dissertation zurückgegeben, das kleine Gutachten für die Volksbank geschrieben. Sonst las ich gemütlich die Post u. vertiefte mich in Coopers Englisch, um wieder einmal in dieser eigenen Romantik zu schwelgen. Ich hätte schon ein paar Stunden erübrigen können, um am Buche weiter zu arbeiten, aber ich hatte auch gar keinen Zug dafür. Das gehört doch auch zu meinem «Altenteil», dass ich ein wenig Zeit für meine Liebhabereien gewinnen kann. Marieli sprach heute von der Lust, die es hätte Ski zulaufen u. richtig am Nachmittag telephonierte schon Frl. Reineck, ob es morgen zu einer Tour mitkommen wolle. Es eilte zu ihr u. blieb zwei Stunden weg. Bei der Rückkehr war die Lust bereits Bedenken gewichen. Es hat eben doch diese Woche die ernsten Magenstörungen gehabt, die auch heute noch nicht gehoben waren - es lässt sich dem Übel nicht beikommen-, dazu machte es sich doch Gedanken, wie das aufgenommen würde, wenn es mit dem Akademischen 
Alpenklub - denn um den Ausflug dieses Vereins auf Falkenfluh handelte es sich, - als Anfängerin mitginge neben seiner Beteiligung an den Helveter Anlässen. So siegten dann gesunde Überlegungen $u$. es telephonierte ab. Es soll morgen einen richtigen Ruhetag haben. Gewiss ist es so besser. Auch Du würdest es so gefunden haben. Von Frau Sophie Burckhardt vernahm Marieli gestern, dass Walter B. mit Leo Weber ziemlich intim verkehre. Das hat mich überrascht, da er über diesen immer in sehr abschätzigem Tone redet. Allein es entspricht dem Bilde, das ich nachgerade von dem guten jungen Freund mir machen muss. Auch von Zusammenkommen mit der Frl. Tumarkin erzählte Frau Sophie, u. dass davon die Rede gewesen sei, wie ich ihr den Besuch meiner Rechtsphilosophie nicht gestattet habe. Freilich hätte Walter B. ihr gesagt, er würde es ihr auch nicht gestattet haben. Mein Misstrauen gegen sie kennt er allerdings nicht. Es rührt von jener Geschichte mit Sidlers Testament her, da sie u. Frl. Sommer noch ein paar Tage vor dem Tod dem kranken Mann noch eine Vergabung für jede von 5000 Fr. abschwatzten. Drum wollte ich ja auch letztes Jahr nicht auf die Bitte der Sommer Zeuge beim Testament der Frau Sidler sein.

Balli war heute bei mir. Er hat meinen Wink befolgt $u$. bei Lohner sich zur Übernahme der Rosselschen Professur bereit erklärt. Lohner sei erst sehr perplex gewesen, dann aber scheine ihm die Sache eingeleuchtet zu haben. Jedenfalls ist jetzt die

Anregung gemacht. Wir wollen abwarten, was weiter geschieht.

Wie ich sehe, war der Tag sonst ruhig, ein schöner Wintertag, den ich gerne innerhalb der vier Wände für mich genoss. Morgen werde ich Briefe schreiben u.dann zur Urne gehen müssen. Volmer meint, es sei eine Übersättigung mit Gesetzen im Volk vorhanden. Das sei der schlimmste Feind der Versicherungsvorlage, u. er liess durchblicken, dass das Land am neuen Zivilrecht noch lange 
$\mathrm{zu}$ verdauen haben werde. Nun es ist $\mathrm{u}$. bleibt, das ist die Hauptsache. Wie so einige ruhige Stunden wohltun können. Auch meine Stimme hat sich gebessert. Ich werde den Rest des Semesters, die vier Wochen, schon noch aushalten. Und inzwischen reist ja Marieli nach Mailand.

Wir wollen heute Abend noch etwas vorlesen in der Ebner. Das gehört jetzt auch zu den Ruhepausen. Gestern konnten wir nicht, weil Marieli den Vortrag der Frl. Tumarkin besuchte. Es wusste aber von seinem Inhalt gar nichts zu sagen, weil es die längste Zeit geschlafen habe. Das ist ein sprechendes Zeichen von seinem Zustand. Auch Frl. Reineck sagte ihm heute, dass sie den Schlaf nicht habe überwinden können. Der Vortrag wird übrigens in den Zeitungen gerühmt. Jedenfalls war darin Kant gebührend gewürdigt, so weit das in solchem Falle erwartet werden konnte.

Und nun also auf morgen! Wenn ich ein Schlafrecht vor mir habe, trotz Mondschein u. Schneeglanz, so will ich es Dir danken. Wie wird mir alles so ruhig, sobald ich nur

mit Dir zusammen sein kann! Kopfweh fürchte ich für morgen nicht. Es wollte sich heute melden, ging dann aber ziemlich unmerklich in ein paar Stunden vorüber.

Also dann, gute, gute Nacht - zum Tagesschluss!

Ich bin immerdar

Dein getreuer

Eugen 
B. d. 4. Febr. 1912.

Mein liebstes Herz!

Also heute ist die grosse Abstimmung über das Versicherungsgesetz. Seit den Äusserungen Volmars betrachte ich die Sache etwas unter dem Gesichtspunkt, als ob in dem Sieg oder in der Niederlage des Gesetzes die Missstimmung oder die Genugtuung über das Neue Recht zum Ausdruck kommen würde. Diese Art der Betrachtung wurde mir heute noch erhöht durch die Circulare, die mir Notar Hirt zugesandt hat, u. in denen die Schwierigkeiten in der Handhabung des Neuen Hypothekarrechtes dargelegt sind. Das gibt mir soviel zu denken. Es besteht so viel böser Wille ringsum, dass ich immer wieder an jenen «Hannibal» erinnert werde, der mir bei der schönen Feier in Laupen zufällig neben der Ehrenmitgliedschaft der Concordia auf den Weg mitgegeben wurde. In einigen Stunden wird das Ergebnis bekannt sein. Ich würde im Falle des Sieges mit in die Parteiversammlung gehen, wenn ich nur nicht so traurig wäre.

Am Abstimmungslokal an der Schosshalde kam diesmal ziemlich viel Volk. Ich wurde im Lokal begrüsst von mich kennenden mir Unbekannten. Marieli begleitete mich den kalten Wintermorgen mit dem tiefen frisch gefallenen Schnee. Ich sprach ihr von dem Bilde der

Vollkommenheit, das wir in Gott verehren u. an dem unser Bewusstsein unser Verhalten misst. Wir gingen bis zum Muristalden. Dann wandte sie sich links, um Frau Mutzner den Rosegger zurück zu bringen, $u$. ich machte den längst schuldigen Besuch bei Frau Rappard in der Pension Hodler. Es war letzter Termin, denn in einigen Tagen wird sie Bern verlassen. Ich wurde sehr herzlich aufgenommen. Ich 
traf dort auch Frl. Hilty und Frau Mentha. Beide waren offensichtlich erfreut mich zu sehen $u$. ich meinerseits freute mich über den feinen Ton, der in der Gesellschaft herrschte. Ich blieb eine halbe Stunde. Marieli kehrte fast gleichzeitig mit mir zurück.

Sie leidet heute wieder unter dem Druck im Magen, ist müde u. unlustig. Sie friert, isst nichts u. schläft schlecht. Alle Mittel sind nutzlos, u. was Du auf sie einwirken hättest können, das ist nun nicht da u. wird auch trotz aller meiner Ermahnungen nicht beachtet. Wem nicht zu raten, dem ist nicht zu helfen. Endlich hat Marieli heute die zwei immer wieder verschobenen Briefe geschrieben, an Frau Montani u. an Lini Welty. Sie brachte sie mir zum Lesen mit der Bemerkung, sie sei froh, dass sie sie geschrieben habe. Viel Freude an dem Kommenden spricht nicht aus ihnen. Aber es geht doch vorwärts. Wenn nur die Gesundheit stand hält! Ich wollte mit Marieli weiter

[3]

plaudern über das am Morgen begonnene Thema. Aber es war nicht zu haben.

Hier hat mich der Besuch von Walter B. u. Frau Sophie unterbrochen. Sie hat damit den ersten Ausgang nach der fast fünfwöchentlichen schweren Krankheit gemacht. Ich benutzte den Anlass, vor Marieli einmal mein belastetes Gemüt zu befreien $u$. nach einer endlich energischen Hilfe zu rufen gegen das schlaffe, so unselige, nervöse Dahinschleppen des armen Kindes. Hoffentlich hilft es was. Aber es ist ein Jammer, dass Du nicht da bist. Es will alles nicht recht fassen. Sage ich: Tu jetzt das, so bejaht Marieli, aber nicht mehr, erst wenn ich ins Bett gehe! Will ich auf 3 Uhr, so will sie auf fünf. Heisse ich sie etwa, so erwacht sie gleichsam aus einem Dusel u. möchte am liebsten gleich nein sagen, aber sie besinnt sich doch $u$. tut es, aber eben - aber! Es geschieht nicht mit Herz! Und ich bin mir das seit Jahrzehnten so anders gewohnt gewesen! Manchmal möchte ich davonspringen! Und alles Hauswesen Preis geben, sie sollen sehen, wie sie es ohne mich treiben. - Aber der Beruf hält mich fest, fester als je. 
Nun, hoffen wir das Beste, ich will ja Vertrauen haben, ich will mich fügen. Es muss gehen, aber es ist alles so schwer. Nun werden es heute 96 Wochen, seit Du mich verlassen hast. Ach, das hätte nicht geschehen sollen! Mein Leben ist ja zu innig mit dem Deinen verknüpft gewesen. Ich kann es unter der Einsamkeit nur noch als Beruf weiterführen, u.

[4]

auch das wird mir streitig gemacht!

O Solon, Solon, Solon! Ich wollte, ich hätte Dein Beispiel befolgt $\mathrm{u}$. wäre nach Abschluss der Gesetzgebung davon gegangen! Was soll ich jetzt mit der bittern Missgunst eines Wieland, eines Meili, eines Zeerleders mich herumschlagen? Und es sind noch so viele Andere! Die Zeitschr. f. Schw. R. brachte einen etwas vernünftigeren Artikel über Egger, von Wieland, aber mit einem Compliment gegenüber dem insolenten Althehrs-Artikel Meilis in der N. Z. Z., das mich ganz irr gemacht hat. Sind das meine Mitarbeiter?

Doch genug, ich schliesse. Halte Du nur zu mir, dann wird es schon gehen, solange es noch gehen muss!

Dein ewig Dir verbundener

\section{Eugen}

\section{2: Februar Nr. 31}

[1]

B. d. 5. Februar 1912.

Mein liebstes Herz!

Amtliche Sachen sind heute mit der Post nicht angekommen, ich fühlte mich förmlich befreit, dass ich nicht wieder hinsitzen u. für das Amt arbeiten musste. Dagegen erhielt ich einen Brief von Milliot, der mir mitteilt, dass der Student Metry in seiner Dissertation über die Walliser Wasserfuhren die Einleitung aus einem Aufsatz von Rauchenstein in der Schweiz. 
Statist. Zeitschr. abgeschrieben habe. Ich liess den Vormittag den betr. Band durch Siegwart von der Landesbibliothek holen u. habe mit Siegwart die Sache controliert. Zum Glück für Metri beschränkt sich nun die Abschrift auf die fast wörtliche Wiedergabe einiger Sätze, u. ich werde noch nachsehen, morgen, ob nicht auch diese aus Blotnizki, den er citiert hat, gemeinsam mit Rauchenstein von ihm herübergenommen worden sind. Überdies hat Metri Rauchenstein zwar im Literaturverzeichnis nicht aufgeführt, aber an zwei Stellen der Einleitung zitiert, sodass ich hoffe, der Vorwurf kann abgelehnt werden. Ich hätte Mühe, eine unredliche Handlung von Metri zu glauben. Er ist sehr tüchtig u. seine Arbeit hat ein recht bedeutendes Verdienst. Milliot aber zeigt sich da wieder als ein ziemlich oberflächlicher $u$. insolenter Vielwisser. Hätte er zuerst genau nachgesehen, so würde er den Vorwurf gewiss nicht erhoben haben. Er wiegt doch gar zu schwer, um nur so nebenbei angebracht werden zu dürfen.

Marieli blieb heute im Bett. Seine zunehmende Schwäche machte ein gründliches Ausruhen nötig, u. es soll auch morgen noch die Ruhe wahren. Frau Sophie Burckhardt war am Nachmittag eine Stunde bei ihr u. sehr nett mit ihr. Es soll nun eine gewisse Methode durchgeführt werden, um den Druck auf den Magen, der stets nach dem doch so überaus spärlichen Essen eintritt, zu beseitigen u. die andauernde Constipation zu heben. Hoffen wir das beste.

Zum Mittagessen bei Rossels ging ich allein ohne Marieli. Ich sass zwischen Frau Rossel u. Gertrud. Ausser Rossels u. den Kindern Gertrud, Susanne, Helene u. André waren da Bassirs u. Gmürs, sowie die Witwe des Bruders von Rossel, die Basler Jüdin Bloch, die Du wohl auch gekannt hast. Im Anfang war es ganz nett, auch Frau Gmür war freundlich. Allein schon gegen Schluss des Essens u. dann nachher, als wir bei der Zigarre in Rossels Studierstube sassen, wurde es mir bald öde u. ich bekam das Gefühl, ich passe nicht hieher. Es ist sonderbar, man kann keine Rechte Unterhaltung führen. Man bewegt sich in Reminiszenzen von dies $u$. das u. streift das eine $u$. andere, aber eine Gleichartigkeit 
u. rücksichtslose Offenheit, ein misstrauensloses sich Geben tritt nicht ein. Und ich war froh, als ich um 4 Uhr wieder zu Hause war. Wir sprachen auch von Rossels Wahl in das Bundesgericht. Aber es kam nichts Neues zu Tage. Merkwürdig ist, dass nun doch Morel auf den 1. Februar die Direktorstelle quittiert, u. dass zu gleicher Zeit der Bund einen energischen Artikel für Röthlisberger bringt. Also doch am Ende die Perspektive

die ich von Anfang an im Auge hatte, u. die vielleicht auch Rossel kannte, aber mir nicht zugeben wollte. Zugleich deutet der Bund an, was auch schon Rossel als eine Möglichkeit genannt hatte, dass nämlich das Amt geteilt werden könnte. Nur wären dann eben die beiden Candidaten nicht Comtesse u. Rossel, sondern Comtesse u. Röthlisberger. Auch da wollen wir die Dinge abwarten.

Es war auch heute ein rechter Wintertag, Schnee, kalt, 6-8, u. trüb. Der Amselgesang, den ich letzte Woche in den Anfängen einmal gehört, ist verstummt. So werden wir wohl noch einen rechten, wenn auch späten Winter erhalten, u. es ist ja gut so, wenn es einen auch hart ankommt, in der Morgenfrühe in die Kälte hinaus zu gehen, wo man bald des Semesters müde ist. Im Morgentramm sitzen nun wieder die Schulmädchen, deren Schule um 8 Uhr beginnt. So nett die Szenen manchmal sind, so habe ich doch einen freieren Wagen lieber. Ich sass heute länger an Marielis Bett, u. ich dachte daran, wie $\mathrm{Du}$ - fast auf die Woche stimmt es - sechs Tage bei ihr gesessen u. sie zum Essen $u$. Ruhen mit Deiner Liebe genötigt hast, bis sie endlich wieder zu Kräften gekommen war. Jetzt ist Anna um sie, Frau Burckhardt dazu, ach, welch ein Gegensatz, so ohne lieben Blick u. ohne tieferes seelisches Empfinden. Es schien mir auch, dass Marieli den Vergleich anstellte, über den man ja nicht wegkommt, wenn man ihn in sich aufgenommen hat. Von Arbeit neben dem genannten war heute wieder nicht die Rede. Ich mache auch gar keinen Versuch mehr in der Richtung, ich lasse es jetzt kommen, wie es will, u. lese, lese, um 
mir den Altenteil zu sichern. Warten wir ab, wie es weiter geht.

Gute Nacht, meine liebe, liebe Seele! Ich bin bei Dir allezeit als Dein getreuer

Eugen

1912: Februar Nr. 32

[1]

B. d. 6. / 7. Februar 1912.

Liebstes Herz!

Ich habe heute wieder ein dreifaches Examen u. das wird mich mit anschliessenden Fakultätsberatungen bis in den spätern Abend hinein occupieren. Ich beginne den heutigen Brief noch zu Hause, in der Hoffnung, ihn dann während der Examenssitzung fortsetzen zu können.

Marieli liegt auch heute noch zu Bett. Sie klagt über einen lästigen, andauernden Druck im Magen $u$. ich habe mich infolge dessen entschlossen, die ihr sympathische junge Medizinerin Frl. Hoff zu consultieren. Erst war dann noch Frau Sophie Burckhardt da u. begann auch etwas bedenklich zu werden. Nun ist aber um halb zwölf Frl. Hoff da gewesen, u. ihr Befund lautet dahin, dass das alles von der Constipation herkomme u. dass es gar keine Mittel gebe, die Beschwerden zu heben, als im Essen u. Verdauung vernünftig zu leben. Sie gab Marieli Verhaltungsmassregeln u. ich hoffe, sie werden befolgt. Von einer Klimaänderung, mit dem Aufenthalt in Mailand, erwartet sie nur eine gute Wirkung. Diese junge, fast ängstliche Dame hat mir einen vertrauenerweckenden Eindruck gemacht. Sie will Marieli weiter beobachten. Morgen soll es wieder aufstehen u. eine Karlsbader-Salz-Kur beginnen. Es wäre ein Grosses Glück, wenn nun damit wirklich eine dauernde Besserung erreicht werden könnte! 
Die Angelegenheit mit Metry habe ich weiter verfolgt, die Nachforschungen waren aber dem Candidaten nicht günstig. Ich habe ihn jetzt telegraphisch hergerufen $u$. will hoffen, er kann

sich rechtfertigen. Tatsächlich hat er eben doch einige Seiten der Einleitung aus Rauchenstein wörtlich abgeschrieben, ohne die Quelle direkt anzugeben. Er täte mir furchtbar leid, wenn er sich nicht zu rechtfertigen vermöchte! Ich konnte während der Sitzung nicht mit dem Schreiben fortfahren, da ich von drei Kandidaten zwei im Zivilrecht je 20 Minuten zu sehen hatte. Elser u. Schwendener erhielten m. c. l., der Ungar Nagel rite, die Bern. Fürsprecher Kuhn S. c. l. u. Otto Häberli m. c. 1. Die Promotion Häberlis war mir eine grosse Freude. Der Promovierte wartete noch nach der Sitzung auf mich $u$. richtete mir Grüsse von seiner Mutter u. seiner Schwester aus. Möchte der endliche Erfolg seine Gemütsdepression vollständig heben! Er ist ein so braver u. tüchtiger Mann! Und nun, zurückgekehrt, schliesse ich für heute ab. Morgen hoffentlich nichts Schlimmes!

Den 7. Febr. 1912.

Heute um halb acht hat mich Marieli zur Hochschule begleitet, um den ihr von Frl. Hopf empfohlenen Spaziergang vor dem Morgenessen zu machen. Es war ihm anfangs noch nicht recht wohl. Nach der Rückkehr soll es ordentlich gegessen haben. Wir trafen beim Sanatorium den jungen Dr. Dumont an. Ich fragte ihn, ob er den Vater vertrete, u. erst aus seiner Antwort vernahm ich, dass dem wirklich so sei, indem Dumont Vater an einer schmerzhaften Vehnenentzündung seit 14 Tagen schon darniederliege. So hätten wir ihn also für Marieli gar nicht haben können u. die Hülfe der Frl. Hopf war um so mehr richtig. Auf zwei Uhr erwartete ich Metry. Gleich nach 1 Uhr kam aber schon Rossel, um mich nochmals zu ersuchen, an Hoffmann 
zu schreiben, dass er trotz der Kandidatur für das Bundesgericht die Direktorstelle gerne annehmen würde. Ich tat das gerne u. habe Hoffmann gleich ein paar orientierende u. meine Hochschätzung der Rosselschen Kandidatur bezeugenden Worte geschrieben. Es wird aber kaum viel abtragen. Die ganze Sache scheint in eine fatale Intrigue Comtesses oder noch anderer hinauszulaufen. Mitmachen möchte ich da nicht.

Metry kam alsdann. Er bekannte sofort, dass er Rauchenstein bewusst abgeschrieben, ohne wegen der Unbedeutendheit der Sache etwas Böses darin zu finden. Ich ersuchte ihn, da ich von der Wahrheit dieser Mitteilung überzeugt war, mir darüber zu schreiben, u. ich versprach auch, in der Fakultät den Standpunkt zu vertreten. Hätte mir Metry nicht wieder den guten Eindruck gemacht, so würde ich ihm, wie ich es die Nacht überdacht hatte, aufgefordert haben, seine Anmeldung zum Examen zurück zu ziehen. Die Arbeit hätte man dann in der Zeitschr. f. Schweiz. R. veröffentlichen können. Jetzt aber will ich sehen, was für ihn zu tun ist.

Ich las dann, auf Veranlassung von einer Bemerkung Stecks etwas in "Geld u. Geist», um den Konflikt, der auf der Berner ehl. Güterrecht darin aufgebaut ist, wieder einmal mir klar zu vergegenwärtigen. Um fünf Uhr aber kam Frau BR. Brenner, um mich in einigen Fragen zu consultieren. Aber ich vernahm nichts rechtes. Ich hörte, dass sie von Ernst nicht ganz rücksichtsvoll behandelt werde, während ihr Schwiegersohn viel lieber mit ihr sei. Sie wollte wissen, ob sie das von ihr eingebrachte Silberzeug für sich behalten dürfe, ob sie berechtigt sei, die

Privatkorrespondenz ihres Mannes für sich zu behalten u. nach Gutfinden zu zerstören. Ob ihr nicht die nicht berufliche Bibliothek überlassen werden müsse. Sie weinte $u$. war gutmütig, haltlos, eben ganz wie sie immer auch von ihrem Manne dargestellt $u$. behandelt worden ist: eine gute Gesinnung bei sehr wenig Verstand. Sie wusste nach her wohl selbst nicht mehr, was ich ihr geantwortet. Die Hauptsache war für sie, mit mir 
über die Angelegenheiten gesprochen zu haben. Sie wusste auch, vor Aufregung, mit Brille u. Zwicker gar nicht umzugehen, kramte in ihrem Handtäschchen nach einem Notizbüchlein u. fand in dem abgerissenen Heftchen gar nicht, was sie finden wollte. Sie tut mir leid, aber es mag ihr wohlgetan haben, in einer inneren Bekümmernis mit mir gesprochen zu haben. Ich anerbot mich natürlich zu weitern Ratschlägen, wenn ich ihr dienen könne.

Und so ist es wieder Abend geworden. Noch schrieb ich im Laufe des Tages zwei kleine Gutachten, eines, an Bühlmann, habe ich abgeschickt. Das andere, an Schär, muss ich noch ins Reine schreiben. Sonst gab es auch heute wieder keine besondere Arbeit. Allein das war ja gegen Ende des Semesters die letzten Wochen von jeher so, man kann nicht mehr. Die Kälte ist schon wieder gebrochen. Der Schnee schmilzt. Ich aber schliesse den Tag, indem ich hinuntergehe. Marieli will noch mit Hesses «Gertrud» vorzulesen beginnen.

Bleibe bei mir, liebe, liebe Seele! Ich bin auf immerdar Deingetreuer

Eugen

\section{2: Februar Nr. 33}

B. den 8. Febr. 1912.

Mein liebstes Herz!

Es hat mich gefreut, dass die beiden jungen Doktoren Schwendener gestern, Elser heute zu mir kamen u. mir dankten, für das was sie bei mir gelernt. Ich war beide Male durch andern Besuch verhindert, sie länger bei mir zu haben, gestern war eben Metry da u. heute Oser. Aber die wenigen Worte, die ich mit ihnen im kleinen Kabinet wechseln konnte, taten mir wohl. 
Oser hatte sich angekündigt $\mathrm{u}$. war sehr freundschaftlich. Ich merkte nichts, bis er von den Wahlen ins Bundesgericht zu sprechen begann, u. eigentlich auch da dachte ich an nichts, denn die Candidatur Rossels war ein so selbstverständliches Gesprächsthema. Erst nachträglich fiel es mir dann ein, dass Oser früher wohl an diese Wahl für sich gedacht, u. dass es passend gewesen wäre, wenn ich ihm gesagt hätte, wie sehr es mich freuen würde, wenn er vorgeschlagen würde. Stattdessen meinte ich, es seien genug Freiburger im Gericht, u. dachte nur an einen Welschen u. nicht an Oser. Vielleicht kann ich es noch gut machen.

Siegwart musste mir heute die Stellen in Metrys Dissertation blau antreichen, die dem Aufsatz Rauchensteins entnommen sind, $u$. roth diejenigen aus Blotnizks: Leider fällt das Ergebnis dabei für Metry nicht günstig

aus, u. ich fürchte, es wird doch noch zum Rückzug vom Examen kommen. Das tut mir furchtbar leid, denn die Arbeit ist im übrigen vortrefflich. Die eine Unbesonnenheit u. Unehrlichkeit, die dem unbedachten jungen Mann begegnet, zerstört eine grosse Hoffnung, wenn es so weit kommen sollte!

Sonst verwendete ich den Tag für die Kollegien u. allerlei kleinere Lektüre. Auch ein kleines Gutachten habe ich im Gedanken entworfen. Morgen vormittags will ich dies u. andres erledigen. Dann werde ich, statt auf die Bibliothek zu gehen, wo v. Mülinen abwesend ist, wie er mir heute sagte, Kronauer besuchen, der im Salem sich aufhält, nachdem vor zwei Wochen eine Operation in einem Auge vorgenommen worden. Frau BR. Brenner sprach mir schon gestern davon. Heute traf ich Kronauers Tochter auf der Brücke, die mit einem Kulturingenieur verheiratet jetzt in Malleray wohnt. Es scheint eine schlimme Geschichte zu sein. Auch das andere Auge werde noch operiert werden müssen, u. Kronauer sei sehr mutlos. Namentlich plage es ihn, dass er jetzt die Vorarbeiten für die Strafrechtskommission nicht besorgen könne. Es ist eigentüm- 
lich, wie diese Strafrechtsarbeiten von einem bösen Geist verfolgt werden. Oder ist es von gutem, wenn Zürcher den Nebenbuhler Kronauer nicht mehr um sich hat? Wird er mit Hafter auskommen? Nun, es wird ja vielleicht mit

[3]

Kronauer inzwischen doch wieder besser.

Ich fühle mich mit dem Wärmerwerden wieder viel stärker verschnupft $u$. sehe dem Ende des Semesters gerne entgegen. Zwar plagt mich weniger Müdigkeit als sonst. Körperlich fühle ich mich trotz des Schnupfens munter. Aber die Gedanken wollen nicht kommen. Ich bin leer gepumpt. Das spürte ich heute in der Abendvorlesung, da ich altbekanntes vortrug u. auch nicht ein einziges neues Ideechen einzumischen verstand.

Nach Rossels Mitteilungen macht sich die Sache nun so, dass Morel von Forrer die Abdankung wieder zurückerhalten haben soll. Er soll warten, bis Comtesse den Bericht über die eidgen. Verwaltungsreform beendigt habe. Also kommt es dann wirklich darauf hinaus, dass zunächst alles beim alten bleibt, $u$. Rossel eben doch auf eine Wendung zu seinen Gunsten nicht hoffen kann. Im Grunde wäre es mir doch recht lieb gewesen, wenn er hier bliebe. Frau George sagte heute dagegen zu Marieli, sie sei froh, wenn Rossels wegziehen, sie habe einen gar zu ungünstigen Eindruck von Susanne. Marieli hat gestern u. heute Karlsbadersalz getrunken, ohne jeden Erfolg, trotzdem sie heute sogar die doppelte Dose nahm. Den Morgenspaziergang machte sie heute in freundlicher Stimmung mit mir. Vielleicht wird es auf morgen besser. Oh könntest Du im Geiste ihr beistehen! Aber auf meine noch so gut gemeinte Suggestion versagt sie vollständig.

Wir haben im Hause nun sonst seit längeren Tagen eine

friedliche Stimmung. Sophie ist andauernd voll guten Willens u. Marieli u. Anna kommen mit ihr u. unter sich gut aus.

Du bist im Geiste unter ihnen, u. ich vertraue darauf, dass es so bleiben werde. Reich uns die Hand, ich will Dich festhalten. 
Sieh, wenn ich auch die letzten Zeilen von Dir weniger als sonst geschrieben habe, Du bist u. bleibst mir jeden Tag das erste u. das letzte.

Gute, gute Nacht, nimm diesen Gruss zum Tagesschluss von Deinem ewig getreuen

Eugen

\section{2: Februar Nr. 34}

B. d. 9. Febr. 1912.

Mein liebstes Herz!

Es war heute ein mühsamer Tag. Nach dumpfem Schlaf erwachte ich mit starkem Stockschnupfen u. Halsweh, u. wie ich an meine Geschäfte gegangen $u$. das Gutachten von gestern für Schär abgeschrieben, brachte mir die Post nichts erfreuliches, umgekehrt einen neuen Aufsatz von Rabel, dem Advocatus Diaboli unseres Gesetzbuches, mit einer neuen Auflage von verworrenen Spitzfindigkeiten, Missverständnissen u. geistlosen rabulistischen Auslegungen. Ich blätterte einiges heraus $u$. fühlte mich ganz gedrückt. Dazu machten mir ein paar Anfragen Mühe. Guhl kommt auch noch u. wollte einigen Aufschluss haben, den ich mühsam erteilte. Wenn dann auch am Nachmittag der Schnupfen leichter wurde u. das Halsweh ganz verging, so war ich doch im Praktikum nicht gewandt, nicht bei der Sache u. war über meine ganze Juristerei etwas im innern Kampf. Der Italiener Zerdetti brachte eine Ansicht vor, über die einige lachten, u. obgleich ich ihm in der Antwort entgegenkam, stand eine Weile nachher der schlanke, schöne aber eigentümlich beschränkte junge Mann auf $u$. verliess das Lokal mitten in der Übung stillschweigend. Ob er sonst fortgehen musste, oder ob es wirklich der 
Ärger war, der ihn vertrieb, weiss ich noch nicht. Ich vermute letzteres. Und vielleicht ist es so gut, denn er hat sich mit Walter B. auch schon wegen der Unzugänglichkeit für jede Belehrung überworfen $u$. hatte sich an mich herangemacht, um unter meiner Führung doch noch an die Examensziele zu kommen. Wenn er nun auch von mir genug hat, so ist das natürlich bedauerlich, aber für mich am Ende eher eine Befreiung als eine Belastung Ja, ich musste mir heute sagen, wohin komme ich mit meiner Juristerei! Wenn ich nicht so fest auf meinem jetzt einmal gefassten Entschluss beharrte, bei meiner jetzigen Arbeit zu bleiben $u$. treu alles auszuhalten, so würde ich heute wieder an allerlei Nebenpläne gedacht haben. So aber hielt ich es aus u. werde es aushalten, sie mögen mit mir machen, was sie wollen. Interessant ist es mir, mich zu erinnern, wie Brenner s. Z. mehrfach die Basler Kritik an dem ZGB. wesentlich auf Rabel, der damals noch in dort war, schalt, u. meinte, diese Kritiken des Professors werden meinem Rufe nichts anzutun vermögen. Ich nahm es damals für ein Abladen von den Basler Schultern, sehe jetzt aber, dass etwas daran wahr gewesen sein muss. Ich muss nun sehen, was alles weiter über mich herfällt.

Von Bühlmann erhielt ich als Antwort auf mein kleines Gutachten ein liebes Billet, worin er anfrägt, ob wir vielleicht in den Ferien uns irgendwo treffen könnten.

Ich hatte bei Müllers meiner Nachbarin Frau Bühlmann eine unbestimmte Andeutung gemacht in diesem Sinne. Dann fragte mich Schmid von Wien an, ob ich nicht der Jur. Gesellschaft in dort Ende März einen Vortrag halten wolle, unter Anerbietung aller Gastfreundschaft. Mein erster Gedanke war gegenüber beiden Anregungen die Ablehnung. Jetzt wenigstens bin ich zu müde u. zu gedankenleer, um an solche Pläne denken zu können. Aber ich will es mir doch überlegen. 
Am Vormittag machte ich Besuch bei Kronauer, dessen Tochter Frau Schwatzmann, mir, wie ich gestern geschrieben, von dessen Augenoperation erzählte. Er war sehr herzlich. Sein Leiden war der Anfang des grünen Stars, an dem seine beiden Augen operiert werden müssen. Er klagte über Langeweile, war aber sonst munter $\mathrm{u}$. leidet keine Schmerzen. Ich werde ihn wieder besuchen.

Marieli ward heute etwas freier. Es begab sich am Nachmittag zu Frl. Hoff u. brachte den Bericht heim, dass es mit dem Magen gut stehe, dass aber die rechte Lunge von Katarrh angegriffen sei. Es soll jetzt jeden Vormittag um 9 Uhr die Temperatur messen. Also würde die grösste Gefahr doch wieder von dieser Seite her drohen. Das war ja unsere alte Befürchtung. Ich will aber auch da nichts zum voraus klagen, sondern bei der Hoffnung bleiben.

Marieli liest jetzt Hesses Gertrud vor. Was wir gestern Abend davon vernommen, hat uns ausserordentlich wohl getan. Daneben habe ich etwas in Gotthelfs Geld u. Geist

gelesen, um mir den güterrechtlichen Konflikt wieder zu vergegenwärtigen, auf den mich College Steck, wie ich neulich sagte, hingewiesen. Ich hatte die Sache fast vergessen. Auch da kann ich ersehen, wie wenig ich innerlich Jurist bin, sonst würde mir das ja schon von früher her die Hauptsache gewesen sein.

Nun aber auch für heute wieder Schluss. Bleib bei mir u. halte mich aufrecht, solange es noch sein muss!

Dein ewig Dir verbundener Eugen 
B. den 10. Februar 1912.

\section{Liebstes Herz!}

Heute war ich den Vormittag in heitrer Stimmung bei der Nach holung aller kleiner Auskünfte u. Antworten die sich aufgehäuft hatten. Die gute Stimmung wurde noch erhöht dadurch, dass Marieli sich am Morgen recht wohl fühlte. Ich schrieb etwa neun Briefe. Wie ich dann aber zum Essen kam, hatte Marieli schon wieder zu klagen, so dass ich ganz aus der Stimmung gerissen wurde. Da, um zwei Uhr, telephoniert es u. Marieli bringt mir den Bericht hinauf, Frau Hebbel habe eben mitgeteilt, Herr Oberst sei seit gestern totkrank. Ich eilte hin u. traf die Frau ganz niedergeworfen. Meinen Freund konnte ich noch sehen. Er lag schon im Todeskampf, hatte kein rechtes Bewusstsein mehr, erkannte mich kaum, wie ich ihn so sah, ging mir ein Grausen durch die Brust. Wie elend nun dieses Ende, wie schwer, nach so viel blühenden Tagen. O Gott, wie viel leichter, plötzlich wegberufen zu werden! Ich konnte meine Gedanken erst sammeln als ich wieder zu Hause war. Frau Oberst hätte uns früher berichten sollen, dass ihr Mann krank sei. Aber sie sagte, es sei nicht so schlimm gegangen, eine Herzbeutelentzündung. Erst seit gestern wurde die Sache so bedenklich, wie es jetzt aussieht, wobei offenbar die Ärzte,

Dumont u. sein Ersatzmann Strohlui, nun selber keine Hoffnung mehr haben. Doch kann sich sein Todeskampf noch lange lange hinziehen. Wenngleich es mir war, er könnte sterben, wie ich neben dem Krankenlager sass. Der Frau bloss sagte ich etwas von Hoffnung, aber sie schüttelte den Kopf. Marieli geht gerade jetzt noch einmal hin, um zu erfahren, wie der Befund der Ärzte von heute Abend gewesen sei. 
Marieli hatte heute die beiden Kranzfreundinnen bei sich u. es war ein Photograph bestellt, ein Neuenschwander, der sie zusammen aufnehmen sollte. Ich glaubte, das sei der angehende Künstler N., u. anerbot mich ebenfalls wieder einmal zum Photographieren. Wie ich von Hebbel zurückkam, wurden dann richtig in meinem Studierzimmer zwei Bilder abgeknipst. Aber ich vernahm auch, dass der Künstler nur simpler Photograph u. nicht identisch sei mit dem Vermeinten. Nun, deshalb können die Bilder doch geraten sein. Wir wollen sehen. Etwas von der Aufregung, in die mich der unmittelbar vorhergehende Krankenbesuch versetzte, kann darauf schon bemerkbar sein.

Auf vier Uhr ging ich dann in die Jur. Versammlung, wo Guhl seinen Vortrag über Pflichtteilsrecht hielt. Bühlmann war auch da u. griff in die Diskussion ein. Ich selbst schloss mich dann an. Der Vortrag war hübsch, aber es

ist an Guhl eben doch etwas merkwürdig Kaltes, wenn er spricht. Übrigens konnte ich ihm dankbar sein, dass er gegenüber allen Angriffen u. Missdeutungen das Gesetz als ein so klares u. einfaches hingestellt u. erwiesen hat. Das wird in den weiteren Aufklärungen wohltun. Da zeigt sich halt dann doch der überlegene Verstand, wenn bei aller Compliziertheit der Fälle einfach gedacht wird. Eben kommt Marieli von Hebbels zurück. Mein schneller Besuch habe Frau Oberst sehr sehr gefreut. Der arme liebe Kranke aber, der mich als ich bei ihm sass, kaum zu erkennen schien, habe nach meinem Fortgehen immer von mir gesprochen. «O der Huber, der Huber, nur nicht der Meili», habe er gebrochen gerufen $u$. von Berlin phantasiert $u$. hochdeutsch gesprochen. Ich hatte bei dem kurzen Besuch ein leises Wort gesagt, um sein Bewusstsein anzuregen, indem ich sagte: Lieber Freund, denkst Du noch an unser Zusammensein in Berlin? Und das hat dann nachgewirkt. Es ist rührend, es ist ein Abschied - ach so schwer! Die zwei Ärzte haben heute Abend gefunden, die Operation, Serumentzug, sei 
nicht mehr zu machen. Der Kranke sei zu schwach. Heute Abend soll noch Schönenberger aus St. Gallen kommen, der mir morgen Bericht geben werde. Und ach der Kampf kann noch lange dauern!

Noch muss ich anfügen, dass ich gestern die Verweisungen zu Chamberlains Worten, meine Andacht in den letzten Wochen,

[4]

ja vor dem Einschlafen, bis aufs letzte fertig gebracht habe.

Es haben sich mir einige wunderbare Resultate ergeben, über die ich Dir gelegentlich schreiben werde. In der letzten Nacht kam mir zwischen Schlaf u. Wachsein der Gedanke, ich könnte in Wien einen Vortrag halten über die modernen Schriftgelehrten, nach der Art Rabelais. Sie verdienten das wunderbare «Schlangen u. Ottergezücht!»

Doch nun will ich noch zum Vorlesen Marielis hinunter

u. dann auch dieser Tag wieder zu Ende!

Gute, gute Nacht!

Dein ewig Dir verbundener

Eugen

1912: Februar Nr. 36

[1]

B. d. 11. Febr. 1912.

Liebstes Herz!

Gestern Abend sagte Frau Hebbel zu Marieli, sie werde heute Morgen telephonieren, oder Schönenberger werde zu mir kommen. Ich wartete deshalb trotz aller ängstlichen Spannung, bis ich dann gegen Mittag bei Dumont durch Marieli anklingeln liess u. vernahm, dass sich der Zustand verschlimmert habe. Am Nachmittag kam richtig, als ich nun eben selbst zu Hebbels gehen wollte, Schönenberger. Er berichtete, sein Onkel habe eine sehr unruhige Nacht ge- 
habt, in Delirien gesungen u. aufstehen wollen. Jetzt gehe es etwas besser, d. h. der Kranke sei ruhiger, das könne aber auch ein Zeichen zunehmender Schwäche sein. Noch während Sch. da war, klingelte das Telephon u. die Magd Hebbels berichtete, Herr Schönenberger möchte doch schnell kommen. Auf Marielis Frage, was es gegeben habe, antwortete sie, sie wissen es eben nicht, es sei nur anders. Sch. eilte davon, u. den versprochenen Telephonbericht habe ich nicht erhalten. Das deutet wohl darauf, dass die richtige Agonie begonnen hat. Schönenberger berichtete, Strehlin habe noch eine Rippenresection machen wollen, aber es scheine, dass Dumont das als eine nutzlose Plagerei beurteilt habe. So sei die Operation unterblieben. Alle Hoffnung sei noch nicht verloren, aber alle

Anzeichen, Delirium, Durchfall etc. etc. deuten auf das Schlimmste. Aber man wisse nicht, wie lange es noch gehen könne. Das Herz sei eben nicht mehr in Ordnung, wie schon der Anfall vom letzten November gezeigt. Es sei ein allgemeiner Kräftezerfall vorhanden, dessen Symtome schon lange bemerkbar gewesen. So erwarte ich nun weitern Bericht. Ich schwankte, ob ich nochmals hingehen solle, habe es dann aber für besser gefunden, das bleiben zu lassen. Ich würde wohl in ein Bild hineingegriffen haben, das ich nicht stören darf. Schon die Befürchtung der Störung widerriet meine Zudringlichkeit. Hülfe kann man ja nicht leisten.

Am Vormittag war Burckhardt bei mir. Ich legte ihm den Fall Metry vor. Er war geneigt, die Sache nicht als schwer zu betrachten. Er schätzt sie als eine Unvorsichtigkeit. Ich aber will abwarten, was Metrys versprochener Brief mir mitteilt. Er bleibt länger aus, als ich erwartet hatte. Mit Burckhardt sprach ich zum ersten Mal auch über die Gleichnisse Jesus zu der sozialen Ordnung, u. ich fand ihn recht beschlagen. Aber die eigentlichen Probleme hat er auch noch nicht überdacht. Interessant war mir, dass Burckhardt dabei, unter Anknüpfung an einige Gutachten Kaisers 
meinte, dieser habe nicht den rechten Überblick, es fehle ihm der philosophische Geist. Das ist nun, sowie ich Kaiser kenne, nicht der Fall. Dagegen mag es richtig sein, dass

es für Lobend, auf den er auch zu sprechen kam, zutrifft. Lobend ist ganz semitischer Dialektiker, ein Virtuos. Ich teilte bei dem Anlass Burckhardt mein Urteil über den gestrigen Vortrag Guhls mit. Auch der ist ganz Dialektiker. Aber er hat den Zug zum Einfachen, u. das wird ihn über andere erheben. Merkwürdig ist, dass Guhl in seiner Entwicklung oder Abwicklung auch gar keine Historische Ader zeigte, die doch gerade in seinem Thema so prächtig hätte mitspielen können. Man muss die Talente eben nehmen wie sie sind.

Den Nachmittag besuchten mich Dr. Stämpfli u. seine junge Frau. Sie waren sehr freundlich. Der Zweck des Besuches aber war, mich für ein Unternehmen zu gewinnen, das [?] [?] scheints aufgebracht hat, nämlich nach französischen u. deutschen Vorbildern eine Ausgabe der Praxis herzustellen, die auf losen Blättern erscheinen, in systematisch geordneten Mappen des ZGB u. BKG. eingereiht werden könnte. Die Idee ist gut, wenn unser Land gross genug ist, um für das Unternehmen Absatz zu sichern. Die Litteratur würde mitverarbeitet. [?] hätte dabei wohl die Hauptarbeit zu leisten. Vorläufig habe Stämpfli mit BR. Müller darüber gesprochen $u$. werde morgen bei Kaiser mit [?] eine Besprechung haben.

Anna ist nach Lyssach gefahren. Marieli hat mir eine Stunde vorgelesen in Hesses Gertud. Was wir lasen, war sehr packend, u. so wohltuend rein. Marieli ist von der bevorstehenden Reise nach Mailand gar nicht erbaut, es

teilte mir mit, Frau Sophie Burckhardt habe, wie es sie heute besuchte, gesagt, es sollte statt nach Mailand zu reisen, ein paar Monate bei ihnen wohnen, sie würde es zur nötigen Ruhe u. zum Essen anhalten. Zudem hüstelt Marieli wieder 
ein wenig. So zeigt sich hier wieder wie überall das Fehlen der nötigen Lebensenergie. Nichts macht Freude, nichts weckt inneren Trieb. Das Ende wird mir immer deutlicher. Anna kommt jetzt eben nach Hause. Sollte auch ein Bericht von Hebbels Befinden eintreffen, so würde ich ihn diesen Zeilen noch anfügen. Andernfalls schliesse ich in inniger Liebe $u$. treuer Anhänglichkeit an mein Alles, was Du mir bist!

Dein

Eugen

Noch zwei Nachrichten:

Schönenberger telephonierte am spätern Abend, sein Onkel liege in tiefer Bewusstlosigkeit. Es werde zu Ende gehn.

Anna brachte von Lyssach, sie habe Bigler nicht getroffen, nur seine Frau, u. diese habe ihr mitgeteilt, heute sei ihr Mann von zwei Polizisten verhört worden, als des Mordes der alten Jungfern Rats u. Nägeli in Pfäffikon verdächtig. Er sei an jenem Tag in Lyssach gewesen, aber er könne es nicht beweisen. Und er sei gar jähzornig. Herr Gott, wäre das für Anna eine Geschichte!

\section{2: Februar Nr. 37}

B. d. 12./ 13. Febr. 1912.

Liebstes Herz!

Ich lag heute den ganzen Tag im Nest, von einem widerwärtigen Husten geplagt, der mich gestern Abend plötzlich ergriff. Schneller Puls, Kopfweh, ganz nach früheren Mustern u. ich liess das Kolleg absagen. In der sicheren Hoffnung, dass ich morgen wieder werde lesen können. Aber diese Aussicht wird mir heute Abend unsicher. Ich muss mich wohl für einige Tage ergeben. Jetzt bin ich zum Nachtessen aufgestanden. Gestern Abend gegen Neun telephonierte Schönenberger zum zweiten Mal: Sein Onkel sei tot. Ich liess heute einen Kranz 
hintragen u. Marieli musste mich bei Frau Oberst entschuldigen. Sie soll gefasst gewesen sein.

Ich habe im Bett über einen Nekrolog für Hebbel nachgedacht, aber ich habe zu wenig Daten. - Sonst dachte ich noch an den Wiener Vortrag, ob ich ihn übernehmen soll oder nicht. Zuerst kam mir die Entscheidung für plausibler vor. Dann aber waren wieder andere Zwischengedanken. Ich fühlte namentlich nicht den Enthusiasmus, in ein grosses Problem bahnbrechend eingreifen zu wollen. Dazu bin ich doch wohl

zu alt. Ich muss jedenfalls in diesen Tagen antworten.

Damit höre ich auf. Es ist nicht recht nicht wohl, auch nicht im Magen. Also sei begnügt mit diesen wenigen Zeilen.

Dein immerdar Dir folgender alter Eugen

Den 13. Febr. 1912.

Ich habe mich entschlossen, nach einer fast hustenlosen Nacht heute wieder ins Kolleg zu gehen u. es ist mir zwar etwas zittrig geworden, aber es ging. Ich konnte Vor- $\mathrm{u}$. Nachmittag lesen u. sitze jetzt im Examen. Strebel wird eben von Gmür geprüft, den andern, Marin, kenne ich nicht. Hoffmann sass im Kolleg. Ich kam durch, wenn auch mühsam. Frau Hoffmann hatte Marieli u. mich auf Samstag eingeladen. Ich habe mich auf meinen verschleppten Katarrh berufen, der mir verbietet, Abends auszugehen. Ihr Mann hat nun selbst hören können, wie sich diese Entschuldigung zur Realität verhält, u. er wird ihr die Tatsache bestätigen.

Sonst bin ich heute leer $\mathrm{u}$. haltlos gewesen. Jede kleinste Gedankenarbeit machte mir Mühe u. ich fand fast keine Gedanken. So bei der Präparation der Nachmittagsstunde. Erst in derselben wurde ich wärmer u. damit dann auch wieder wärmer u. tiefer. Aber etwas des Improvisierens blieb dann doch noch fühlbar. Ich muss das eben mitmachen als Folge 
des Unwohlseins u. der Semestermüdigkeit.

Da ich im Hals einen Schmerz verspüre, habe ich mein Examen möglichst bald abgewandelt $u$. bin nach Hause gegangen, um den müden verschnupften Kopf ins Bett zu legen. Es wird sich zeigen, was weiter geschieht. Den Nachmittag hatte ich beim Sprechen sehr mit dem Katarrh zu kämpfen.

Gmür ist jetzt immer sehr recht mit mir. Ich legte ihm heute den Fall Metry vor u. er teilt meine u. Burckhards Auffassung. Burckhardt sagte ich heute Abend, ich hätte ihm verheimlichen wollen, dass ich gestern kein Kolleg gehalten. Aber dann hätten die Nachfragen Meilis u. Thormanns von heute früh mich verraten. Es ist möglich, dass er mich verstanden hat. Sein Schafspelz ist doch sehr interessant, man darf ihm schon zu merken geben, dass man erkennt, welchen Pelz er eigentlich auf dem Leibe hat.

Sonst nichts neues. Der Tod Hebbels verfolgt mich. Ich muss immer daran denken. Dass ich bei der Beerdigung hinter den condolierenden Militärfreunden zurücktrete, ist ganz natürlich, entspricht ganz dem Verhältnis, das zwischen mir u. ihm bei seinen Lebzeiten bestanden hat.

Die Vorlesung von Donnerstag habe ich nun aber doch ausgesetzt, um der Kremation dabei zu sein. Reden werde ich nicht. Ob andere? Damit schliesse ich u. geh jetzt früh zu Bett. Marieli will mit Frl. Reineck das Ab. Konzert besuchen. Die Ruhe wird mir gut tun.

Mit innigem Gruss

Dein ewig treuer

Eugen 
BR. Forrer soll sich mit einer Tochter Landi Confiseurs verlobt haben. Das wäre ächt. Kanntest Du sie, die Schwester des Prof. Bärgi?

\section{2: Februar Nr. 38}

B. den 14. Febr. 1912.

Mein liebstes Herz!

Ein schwerer Tag, nicht wegen des fortdauernden schmerzenden Halses u. der Heiserkeit, die ich im Kolleg fast nicht überwinden konnte, sondern aus andern Gründen.

Zunächst einmal schrieb ich v. Schmid ab wegen des Vortrages in Wien, nicht gern, aber unter dem Druck der ungünstigen Verhältnisse.

Sodann war ich bei Frau Hebbel, die furchtbar verbittert war. So z. B. teilte sie mir mit, die Instruktionsoffiziere hätten zum Begräbnis kommen wollen. Sie habe aber erklärt, das wäre ein Hohn auf Ottos Gedächtnis, u. so werde das unterbleiben. Finanziell stehen sie nicht schlimm, Frau Oberst wird etwa den Zins von 150000 Fr. zu geniessen haben. Das ist freilich nicht mehr als für ihre Lebensgewohnheit gerade notwendig. Heute war der junge Lüscher da, dessen Vater am Schlag als 49 plötzlich gestorben. Ein prächtiger junger Mann. Das war Herz. Ich wurde mir dessen um so mehr bewusst, als ich heute ein drittes in mir erwogen, ein sonderbarer Vorfall mit Marieli.

Schon heute beim Gang nach der Universität sagte es mir, es habe Stechen auf der Lunge. Als mich das wunderte, 
erklärte es, das schon seit einigen Tagen, seit Montag, zu spüren. Und es meinte, es gehe heute zu Frl. Hoff. Ich meinte, dann könne es am Ende nicht an den Ball, besser wäre gewesen, ihn überhaupt bleiben zu lassen. Es aber meinte, der Dr. Hoff werde es von dem Ball nur im Notfall etwas sagen, denn sie liebe die Farbenstudenten nicht. Nach Tisch ging es zu Frl. Hoff, ich hatte den Langweiler Dr. Cramer (jetzt in Basel) in Audienz. Der war lange fort, Marieli war ein Weilchen zurück, da kam es endlich herauf u. brachte etwas ängstlich aber sanft den Bericht vor: Frl. Hoff habe gesagt, am besten wäre für es eine richtige Kur, es sollte in die Berge anstatt nach Mailand. Frl. Hoff werde mir darüber schreiben. Und der Ball, wandte ich ein. Ja, da habe es nicht gefragt, weil es, solange es bei Frl. Hoff gewesen angenommen, der falle jetzt natürlich auch weg. Also jetzt nicht mehr? Nein, nicht gerade. Das sah mir nun ganz aus wie ein abgekartetes Spiel. Zuerst wollte Marie nicht nach Nervi, dann als das sich zerschellte, nicht nach Mailand, dann als es hätte auf Anfang Februar dahin gehen sollen, wollte es nicht den Helveter Ball preis geben, dann hing es sich an die Revanche, u. gab sie nur ungern auf. Dazwischen meinte es immer, wenn

es nur Ski laufen dürfte, $u$. jetzt sollten alle die Hoffnungen sich dadurch realisieren lassen, dass es erst den Ball nicht macht, dann am Dienstag nicht nach Mailand reist, dann dafür die Revanche mit macht, darauf zur Prophylaxis in die Berge geht. Prächtig, prächtig, u. ich kann überall wieder abschreiben, u. bin der Narr im Spiel, das war mir nun sehr genug, über u. über. Ich bat Marieli, sofort wieder zu Frl. Hoff zu gehen u. ihr das vom Ball auch zu sagen, es ging $u$. brachte zurück, natürlich unterbleibe auch dieser am besten. Ferner erinnerte ich Marieli daran, dass Dumont letztes 
Jahr entschieden von einer Winterkur in den Bergen abgeraten, obgleich ihr Zustand auf den Lungen damals bedenklicher war als jetzt.

Morgen will Frl. Hoff zu mir kommen. Ich werde ihren Bericht entgegen nehmen, u. dann mit Dumont conferieren. Ich will nicht der Spielball in diesen Trotzkopflaunen sein. Was recht ist, soll geschehen, weiter nicht. Lieber breche ich mit Marieli ab. Es dürfte übrigens nicht mehr lange gehen, so bricht sie selbst mit mir. Die Unterwürfigkeit bei Konflikten hat schon bedeutend nach gelassen. Sie wird mir demnächst einmal entgegentreten u. dann - kann ich nicht dafür bürgen,

[4]

dass es zum Konflikt kommt. Doch will ich jetzt nicht zu schwarz malen. Es fehlt die Liebe, Du fehlst! Das hat das Kind bemeistert. Jetzt Gnad ihm Gott! Doch Schluss, es ist eine traurige Epistel. In der Bibliothekssitzung, der ich beiwohnte, hatten wir ganz nette Erlebnisse. Ich war gerne dabei. Es war ein kleiner Lichtblick in diesem düsteren Tag. Gute, gute Nacht! Ich bin Dein ewig getreuer Eugen

1912: Februar Nr. 39

[1]

B. den 15. Febr. 1912.

Mein liebstes Herz!

Ich stehe unter dem Eindruck von zwei heutigen Erlebnissen, der Beseitigung der Befürchtungen, die mich gestern so sehr alternierten, u. des Begräbnisses Hebbels.

Frl. Hoff kam um halb zwölf. Ich dankte ihr für den guten 
Erfolg, den ihre Ratschläge mit Marielis Constipation gehabt haben, u. liess mir dann den Plan einer Kur wegen der Lunge entwickeln. Sie schlug einen Aufenthalt von etwa zwei Monaten in St. Moritz vor, wo Marieli jetzt noch recht Sport betreiben könnte, u. meinte, eventuell würde ihm eine etwa drei monatliche Tuberkulin Kur wohltun. Ich trat darauf ein $u$. wollte vor allem wissen, ob eine momentane Gefahr vorhanden sei, was sie bestritt. Denn eine wirkliche [?] liege nicht vor, nur ein schwacher Lungenkatarrh, den man eben erfahrungsgemäss als tuberkulos gefährlich beobachten müsse. Ich wies sodann darauf hin, dass Marieli den morgigen Ball doch nur unter Berufung auf Erkrankung ablehnen könne, u. dies würde einen grossen Eindruck auf seinen Bekanntenkreis ausüben, so gross, dass ich mich frage, ob wirklich genügend Grund vorhanden sei, diesen Nachteil auf sich zu laden. Da gab sie leicht bei u. meinte, wenn es sich recht in Acht nehme, so könnte es den Ball am Ende wagen. Und

jetzt ging ich auf Mailand über, setzte ihr auseinander, dass das eben nicht nur eine improvisierte Geschichte sei, dass die Stelle, in die Marieli jetzt eintrete, für sie seit drei Monaten offen gehalten, dass die Familie Montani in Verlegenheit versetzt würde, dass man da wiederum sich auf Krankheit berufen müsste, u. das falle mir hier noch schwerer als dort. Da meinte sie, Marieli habe ihr gesagt, der Aufenthalt in Mailand liesse sich verschieben. Aber, wenn es so sei, so könnte man auch umgekehrt verfahren: Marieli könnte jetzt nach Mailand, u. nachher, im Sommer, einen längern Höhenaufenthalt machen. Da waren wir nun mit einem Schlag an dem gewünschten Ziel, u. so wurde dann festgestellt: Ball u. Mailand, beides mit strengster Mahnung zur Vorsicht, bleiben festgelegt. Nach der Rückkehr kann eine Tuberkulinkur in Frage kommen, u. dann im Sommer der Berg. Marieli nahm das ganze fröhlich auf. Die Frl. Hoff schien erst etwas verlegen, aber gescheit, wie sie ist, 
nahm sie den rechten Faden, den ich ihr in die Hand spielte, sofort auf. Es war offenbar etwas Einverständnis bei der Sache, in wie weit für Marieli voll bewusst, weiss ich nicht $u$. will es auch nicht untersuchen. Ich sollte dazu gebracht werden, dem Wunsch Marielis nach Wintersport zu gewähren, u. wie man nun gesehen hat, es geht nicht, so ist die Sache mit Marieli nicht halb so gefährlich. Ich hoffe,

dass sich das jetzt so weiter gestalten lässt. Marieli ist den Abend jetzt wirklich fröhlich, u. es hat Anna versichert, dass es gerne nach Mailand gehe.

Und nun die Kremation. Dass ich nicht klug daraus wurde, ob Frau Oberst mich lieber bei sich u. ihren Verwandten gehabt habe, oder nicht, weiss ich nicht zu sagen, anders als gestern. Ich mochte mich nicht vordrängen $u$. so gingen wir drei direkt zum Friedhof. Nach langem Warten an der Frühlingssonne kamen die Wagen. Anwesend waren die Gesellschaft «Amistad» der St. Galler Freunde, mit denen Hebbel noch letztes Jahr die Reise in Süddeutschland gemacht, eine Abordnung der St. Galler Regierung offiziös. Eine Deputation des St. Gallischen Artillerievereins in Uniform mit Fanion. Eine ebensolche des schweiz. Unteroffiziervereins mit der Vereinsfahne. Etliche Offiziere in Uniform, darunter der Waffenchef Hebbels Nachfolger Schmidt, den sich gerade Frau Hebbel verboten hatte. Dann etliche höhere Militärs in Zivil, wie Wildbolz, Isler, Koller, Lohner, Stämpfli, Pfister etc. Das Krematorium füllte sich. Pfarrer Haller hielt das Leichengebet, indem er als Text die Stelle des 1. Korrinther Br. über die Liebe vorlas (13), aber ohne in der trockenen inhaltslosen Rede darauf irgendwie abzustellen. Dann trat Schmidt auf u. hielt ein sehr schöne, warme Rede mit hoher Anerkennung im Auftrag des Departements. (Anna beobachtete, dass es Frau Hebbel während derselben ein paar Mal schüttelte - in innerem Grimm, den sie auch in diesem Augenblick nicht vermeiden konnte?) dann 
trat noch der ehemalige Regimentsadjutant Huber von St. Gallen auf u. begann im Namen St. Gallens u. der intimeren Freunde zu reden. Er sagte, er widme dem Sarg eine weisse Blume - eine rote Blume - eine blaue Blume - $u$. wusste dann jeweils nicht mehr, welche Deutung den Blumen zu geben war, $u$. konnte sich auch aus dem beschriebenen Blättchen, das er hervorzog, nicht mehr zurecht finden. Aber es war gut gemeint. Es musste ja ein St. Galler sein. Ich war auch hier wieder, wie immer, Hebbels verborgener Freund. - Beim Hinausgehen konnte ich Schönenberger u. a. die Hand drücken. Frau Hebbel war unzugänglich. Dagegen traf Marieli zufällig Martha Gemperle u. es wird morgen mit seinem Bruder Albert uns besuchen. - Ich will Frau Hebbel beistehen, wie ich nur kann. Aber sie hat einen schweren Stand, das ist sicher. Lohner, dem ich vor dem Ausgang die Hand gab, meinte, St. Gallen sei da stark vertreten gewesen. Die Redner sprachen von der Ostmark des Landes. Organisiert war die Feier nicht gut, ein Mittelding von offiziell u. intim. Aber es war ja auch niemand da, Frau Hebbel zu beraten. Hätte sie sich beraten lassen?

Ich habe heute Abend neuerdings Halsweh, aber sonst fühle ich mich wohler. Wir wollen sehen, ob es den Semesterschluss noch standhält, das bisschen unverbrauchte Energie. Und nun soll Marieli noch etwas vorlesen $u$. ich schliesse für heute - mit innigem Dank für Deine Hülfe, Deinen Segen! Halte zu uns, bleib bei Deinem getreuen

Eugen 
B. den 16. Febr. 1912.

Mein liebstes Herz!

Ich bin alleine zu Hause. Marieli wurde um 8 Uhr von dem [?], Morgenthaler, 1. Sem. Helv., abgeholt. Es trägt das umgeänderte Kleid, das Du ihr s. Z. für Lina Gewalters Hochzeit bestellt hast. Frau Sophie Burckhardt u. Susanne Rossel kamen noch, um sie im Balstat zu sehen. Marieli ging fröhlich. Sie war in dem einfachen eleganten Kleid eine flotte Erscheinung. Ihre rauhen Arme - sie sagte selbst, sie habe eine Gänsehaut - zeigten mir den Abstand der Art zu Dir u. Deinesgleichen. Auch war sie in den Bewegungen wenig fein, in der Miene leicht hochmütig. Man erkennt eben nicht sich selber in ihr. Aber sie ist recht $u$. wie immer gescheit. Der Besuch von Martha Gemperle u. ihrem Bruder, der ihr gestern versprochen worden, ist ausgeblieben. Die Aufklärung wird morgen denk ich erfolgen. Anna ist mit Frl. Baumgartner zum Zuschauen gegangen. Sie werden wohl erst nach Mitternacht zurück sein. Marieli erwarte ich erst am Morgen.

Das Praktikum war heute lückenhaft besucht, aber interessant. Die Helveter fehlten bis auf zwei. Im Dekanatszimmer traf ich Rossel. Für den ist jetzt das fait accompli geschaffen: Der BR. hat heute Comtesse zum Nachfolger

Morels gewählt. Rossel wusste, dass drei Mitglieder Comtesse hätten bestimmen wollen, in der Behörde zu bleiben. Er habe aber mit grosser Bestimmtheit darauf beharrt, er sei wohl wirklich krank, habe auch in der Sache gehandelt, wie ein kranker Mann. Am Vormittag erledigte ich verschiedene Briefe etc. $u$. machte dann im Salem Besuch bei Kronauer, dessen 
zweites Auge nun auch operiert ist, u. der am Montag wird entlassen werden. Bevor er in den Salon kam, wo ich auf ihn wartete, erschien seine Tochter Frau Schwatzmann (?), die im Gespräch mir mitteilte, dass sich ihr Vater mit seiner Schwester ganz überworfen. Sie meinte, vor acht Tagen habe ihr Vater sehr schlecht ausgesehen, was ich bestätigen musste. Als er dann im Salon erschien, machte sie mir ein erschrecktes Zeichen, $u$. wirklich, der gute alte Papa im Schlafrock kam so unsicher u. hinfällig herein, dass es war, als stünde er unter den Folgen eines Schlaganfalles oder dgl. Im Gespräch wurde er dann wieder normaler. Er dankte mir sehr für den zweiten Besuch. Nächste Woche wolle er nach Zürich u. mit Ernsts Sohn Eugen, Notar in Oberstrass, reden u. ihn vor Spekulationen warnen. Auch nach Embrach werde er gehen zu Ernst, der seit einiger Zeit in grossem Kummer u. an der Gesundheit angegriffen sei. Ich verliess Salem, das ich

bis jetzt immer nur mit eigentümlichen Krankenbesuchen aufsuchte. Seinerzeit war es mir so Angst gewesen, ich werde Dich einmal dort haben müssen. Ähnlich wie ja auch Frau Baltzer in der Viktoria war u. starb. Das ist nun uns, Dir u. mir, erspart geblieben.

Guhl war vor Tisch da, ziemlich aufgeregt. Wenn er nur nicht zu viel schwatzt $u$. sich in Unannehmlichkeiten stürzt. Heute wusste er, dass richtig BR. Jäger Hoffmann irregeführt u. unter der Vorgabe, er sei mit dem Departement einverstanden, zu dem Schritt der Anfrage beim BGericht i. V. des Eigentumsvorbehaltes verleitet, während er dann als Referent gerade in gegenteiligem Sinn gewirkt habe. Das sind schöne Geschichten. Hoffmann sei darüber aufs Höchste erzürnt. Aber man weiss ja nicht, was an der Sache ist, u. ich lege ihr gar nicht die Bedeutung bei, die Guhl bei seinen Mitteilungen voraussetzt. Er zeigte mir heute eine goldene Uhr, die er von den Aarg. Notaren erhalten.

Ähnlich ist die Geschichte, die er mir gleichfalls heute erzählte, bei der Kaiser sich um mein Gutachten drücken wolle. Rothplatz 
habe verlangt, dass eine Gewerkschaft sich eintragen lasse, während sie als Verein mit nicht wirtschaftlich-gewerblichem Zweck von der Eintragung befreit zu sein behaupte. Nun hätte ich mich in meinen Vorträgen in letzterem Sinne aus gesprochen. Kaiser wolle daher nicht mich consultieren, sondern Walter Burckhardt. Guhl u. Mutzner hätten dem widerraten,

u. vielleicht werden jetzt Walter B. u. ich angefragt. Nun muss ich sagen, dass dies ein eigentümliches Vorgehen bedeutet. Ich habe in den Kommissionen u. Referaten ausdrücklich die Gewerkschaften als Verein $u$. nicht als Genossenschaften bezeichnet, u. es täte mir leid, wenn diesen das Leben saurer gemacht würde, ähnlich etwa wie in Deutschland, da sollte ich aber doch im Departement ein Wort mitzusprechen haben. Warten wir ab, was wahres an der Sache ist. Geht's schief, so ist es wiederum kein Anlass unglücklich zu sein. Von Hänny erhielt ich aus Paris einen düstern Brief, den ich sogleich beantwortete. Gedanken hat mir heute auch die Phantasie bereitet, die ich die Nacht halb wach in mir herumtrug, nämlich unser Haus als ein Jur. Seminar zu stiften. Nun ja, was kann nicht noch werden, wenn ich einige Jahre bei guten Kräften weiter lebe. Es kann ja aber auch schon morgen vorbei sein. Mit Augusts freilich wird der Bruch wohl ein dauernder sein. Ich finde es schnöde, dass auf die so schreckliche Verleumdungsgeschichte hinunter jetzt Wochen lang alles einfach stumm bleibt.

Und jetzt will ich die einsame Stunde schliessen $u$. mich zur Ruhe begeben. Ich bin sehr, sehr müde. Nimm diesen Gruss zum Tagesschluss von

Deinem allzeit getreuen

Eugen 
[1]

B. den 17. Febr. 1912.

Mein liebstes Herz!

Heute habe ich Dir von einem Tag zu berichten, an dem sich mancherlei wie am Schnürchen abwickelte. Ich stand zeitig auf, erledigte die Post, begab mich zu BR. Müller, um mit ihm über die Frage, die ich gestern angeführt, zu sprechen, traf ihn gerade noch zeitig genug, bevor er verreisen wollte. Nach meiner Rückkehr besuchten uns Martha Gemperle u. ihr Bruder Albert, der Instruktionsoffizier am St. Gotthard ist. Kaum waren sie fort, so kam wie bestellt Guhl mit einigen Fragen. Am Nachmittag consultierte mich Notar Härdi fast zwei Stunden, dann schrieb ich Stammler einen siebenseitigen Geburtstagsbrief. Darauf hatte ich gerade noch Zeit, Frau Hebbel den versprochenen Besuch zu machen $u$. endlich mit der Abendpost kam das angekündigte Gesuch des Departements betr. Begutachtung der gestrigen Frage, zu der sich auch Walter B. äussern soll. Und jetzt ist es Abend, ich schreibe noch an Dich u. gehe zu Bett. Bei dem Besuch fand ich Frau Hebbel gefasst. Was

[2]

mich dabei besonders bewegte, dass ich aus ihren Mitteilungen einiges von Hebbel vernahm, das mir bisher ganz unbekannt war: Wie er für seine Untergebenen sorgte, auch mit Geldmitteln, u. wie er auf die Aspiranten einen so grossen versittlichenden u. charakterstärkenden Einfluss ausgeübt. Frau Hebbel erzählte mir von Geldsammlungen, die er veranstaltet, von Vormundschaften, die er besorgt. Ja, das waren 
Züge, die seinen Einfluss markieren, die aber auch dem Verständnis seiner Gegner so fern lagen, dass das alles nicht mehr galt, sobald seine glänzenden Eigenschaften mit dem Altwerden sich verminderten. Da haben wir die Erklärung. Seine Gegner sind wohl alle solche, die für diese Seite des Amtes unempfindlich waren, seelenlose Draufgänger, denen man eben nicht hätte nachgeben sollen. Und gerade wegen seiner moralischen Eigenschaften war er dann diesen Leuten nicht mehr verständlich. Es hat sich gewissermassen an ihm gerächt, dass er so viel mit den «Vornehmen» verkehrte, da gerade diese ihn fallen liessen, als er nicht mehr der alte glänzende Soldat war. Er aber hat seine gute Seite bis an den Schluss seines Lebens beibehalten. Er dachte sozial, er

hat auch aus diesem Grunde unserer Verbindung ein Verständnis entgegengebracht, wie kein anderer meiner damaligen Freunde. Diese Seite seines Wesens macht mir jetzt seine Erinnerung besonders lieb u. wert. Ich hoffe, seiner Frau einigen Beistand leisten zu können. Merkwürdig hat diese berührt, dass er sie einfach beim St. Gallischen Recht beliess. Er hätte, nachdem was ich ihm sagte, doch ganz anders handeln können. Aber er fand, seine Frau habe im Falle seines Todes genug um zu leben, $u$. mochte seinen Verwandten nichts entziehen. Frau Oberst sagte mir, dass die Knechtenhofers doch sehr ihrer Unterstützung bedürfen. Da zeigt sich wieder der Gegensatz der ostschweizerischen u. der bernischen Familienauffassung! Marieli kam vom Ball nach Hause, wie ich aufstand. Es rief vor der Türe ein Gutentag. Aber meinen Rat, nun etwas abzuliegen befolgte es nicht $u$. dachte sogar daran, den Katerbummel nach Worb heute Nachmittag mitzumachen. Es liess sich aber leicht bestimmen, das bleiben zu lassen, $u$. war dann nach Tisch $u$. nach der Lateinstunde, die es besuchte, sehr sehr müde u. un- 
wohl. Hoffentlich wird es bis morgen wieder besser.

Das Fest hat ihm Freude gemacht. Hätte es sich den Vormittag

noch gelegt, so würden die Strapazzen wohl auch leichter vorüber gegangen sein. Nun, wir wollen abwarten. Es versteht mit seinen Kräften nicht zu haushalten. Es begleitete mich bis zum Zeitgloggen, als ich zu Frau Hebbel ging, u. sagte mir, dass eben doch keiner von allen soviel Eindruck auf es gemacht habe, wie Abbühl. Das Gefühl bleibt ihm, u. es hat sich das verscherzt durch eine mir unverständliche Unsicherheit der Empfindung. Was hätte es sich alles erspart, was gewonnen, wenn es mir auf dem Gotthard, wie ich eigentlich erwartete, gesagt hätte: Abbühl u. kein anderer.

Da sprach eben doch die Härte seines Wesens mit, u. nun büsst es dafür.

Es war heute ein rechter Frühlingstag. Wenn mir nur nicht die Ferien über dafür bitter kalt bekommen! Warten wir es ab.

Gute Nacht, mit innigem Gruss zum Schluss!

Ich bin bei Dir in Treu u. Liebe

Dein

Eugen

\section{2: Februar Nr. 42}

[1]

B. d. 18. / 19. Febr. 1912.

Mein liebstes Herz!

Nur ein paar Worte, um wenigstens nicht in

Gedanken ein Moment bei einander zu sein. Ich hatte heute von früh an Kopfweh, Brechreiz, Husten, u. es steigerte sich so, dass ich um 11 Uhr zu Bett ging, freilich dann nach vier 
wieder aufstand, indem ich auf morgen noch das Kolleg zu präparieren hatte $u$. überdies den letzten Sonntag vor Marielis Abreise noch mit ihm wenigstens etwas zusammen sein wollte. Es war aber ein schwerer Tag, ich konnte nur staunen $u$. husten. Gott bessere es für morgen. Die Sache tat mir um so mehr leid, als Fritsche den angekündigten Besuch machte, von 10 bis 11 Uhr. Er wollte mich consultieren, in der Frage, ob er seine Gerichtsschreiberstelle in Horgen verlassen $u$. sich doch noch der Wissenschaft widmen solle. Aber ich konnte ihm keinen Rat erteilen, heute weniger denn je. Die Stelle behagt ihm an sich. Nur hat er eine unausgesetzt verantwortliche Arbeitsleistung in dem Laiengericht, die fast nicht zu sagen sei $u$. jedenfalls keine wissenschaftliche Arbeit zulasse. Und das bekümmert ihn. Ich verwies ihn auf die spätere Carriere als Oberrichter. Mit seinem Adjunkte Willy v. Wyss ist er sehr zufrieden.

Den andern, Specker, hat er zu meiner Überraschung als einen praktisch fast nicht brauchbaren Theoretiker bezeichnet. Es war heute wieder schöner Frühlingstag. Ich lag im Dusel herum. Marieli war bewegter als ich erwartet. - Letzte Nacht muss ich übrigens gut geschlafen haben, denn es brannte um halb vier bei der Eisenbahnbrücke ein Haus nieder u. ich merkte nichts davon.

Doch Schluss für heute. Ich muss schlafen. Gute, gute Nacht! Den 19. Febr. 1912.

Ich hatte gestern so viel gelegen $\mathrm{u}$. geschlafen, dass ich mich heute, als ich um vier Uhr ohne Kopfweh erwachte, ganz ausgeruht fühlte u. aufstand, um die Akten in der Sache des Locomotivheizerverbandes im Bett zu lesen. Um halb sechs war ich fertig u. schlief dann wieder bis halb sieben. Das Kolleg verlief gut. Nachher war ich genügend vorbereitet, um den Entwurf des «Gutachtens» gleich vor Tisch noch an Siegwart zum stenogr. Diktat geben zu können. Den Nachmittag waren Studenten da. Ich suchte Materialien zu den Protokollen für das Gutachten zusammen. Ferner hatte ich eine Anfrage von Frau v. Rappard wegen der Erbschaftssteuer zu 
beantworten $\mathrm{u}$. mich vorher zu dem Zweck in der mir nicht vertrauten Materie zu orientieren. Freude machte mir ein schönes Bild von Klara v. R., das sie ohne Anfrage beilegte, u. das ich in m. Zimmer aufhängen will neben den andern kleinen Photographien. Endlich kam noch Neuenschwander $u$. brachte die ersten Abzüge der beiden Aufnahmen,

die er am Samstag vor acht Tagen im Studierzimmer von mir gemacht. Das stehende Bild ist sehr gelungen. Das sitzende etwas weniger.

So ist der Tag zum Abend gekommen. Es war eine grosse Aufregung im Hinblick auf die nahe Abreise Marielis. Dieses scheint dem Studenten Morgenthaler eine Karte geschickt zu haben mit der Absage vom «Katerbummel», die ihn nicht freute. Denn Blanche Röthlisberger kam heute Abend zu Marieli, um zu fragen, was es gegeben, freilich auch um zugleich zu erzählen, wie der Spaziergang verlaufen sei. Auch da zeigte sich wieder die ganze ungeschickte Art Marielis. Hätte es am Samstag früh dem Morgenthaler gleich gesagt, es könne den Bummel nicht mitmachen, so wäre alles in Ordnung gewesen. Aber sein Charakter! Morgenthaler kam dann heute Abend auch noch um Marieli zu besuchen, es war abwesend. Sophie benachrichtigte mich nicht, u. so ging er unverrichteter Dinge wieder weg. Marieli eilt herum, um Kommissionen zu machen. $\mathrm{Zu}$ Abschiedsbesuchen ist sie heute nur bei Frau Sophie Burckhardt gekommen.

Soeben ist noch Guhl eingetroffen in Amtssachen, um den unruhigen Nachmittag abzuschliessen. Ich muss mich nun noch auf das Morgenkolleg präparieren u. die Rechnung für Marieli abschliessen. O wie froh, wenn es wieder etwas ruhiger wird! Im Bundesgericht scheint jetzt, nach den Mitteilungen Guhls, ein wirklich ungemütlicher Geist sich allmählich festzusetzen. Der böse «Jäger», wie er in den Gespenstergeschichten spukt, waltet hier in seinem neurasthenischen Zustand des 
Amtes, dass man bald Besorgnis haben könnte. Aber nur zu. Auch das wird ein Ende nehmen. Ich darf es mich nicht anfechten lassen.

Gute Nacht, meine liebe, liebe Seele! Hab Dank für

Deinen Beistand! Ich bin immerdar

Dein getreuer

Eugen

1912: Februar Nr. 43

[1]

B. d. 20. Februar 1912.

Mein liebstes Herz!

Marieli war heute in einer grossen Aufregung mit

Packen u. Abschiednehmen. Aber beim Nachtessen war

alles erledigt $u$. die Spannung auf das Neue hat jetzt

doch so zugenommen, dass die freudigen Gefühle überwiegen.

Das ist mir lieb, denn ich erwarte so weit eher von seinem

Mailänder Aufenthalt eine gute Wirkung, dass es mehr aus

sich heraus kommt, die «verdrückten» Gefühle verliert

u. für den einmal nötigen Umgang verträglicher u.

erträglicher wird. Am Ende ist es nur ein bisschen zu viel

Stolz, was ihm ein oft zu unangenehmes Cachet gibt,

u. da es im Innern doch guter Natur ist, so sollte diese weniger angenehme Seite so gut corrigiert werden können, wie das mit seiner Wirbelverschiebung der Fall war. Hilf ihm, liebe Seele, mit Deiner Geduld u. Liebe. Möchte es etwas davon dauernd in sich aufnehmen. Ich war heute, bei kaltem Regen, wieder ziemlich von Husten geplagt. Im Kolleg ging es mir recht, nur spürte ich die innere Aufregung, die wohl von etwas Fieber her$\mathrm{kam}$. Von Fritsche erhielt ich einen sehr lieben DankeBrief, der mich über den in meinem miserabeln Zustand 
am letzten Sonntag missglückten Besuch einigermassen beruhigt hat.

Über das Gutachten, das ich betr. den Loc. Heizerverein abstatten soll, habe ich zu Walter B., der ja auch beauftragt ist, nicht zu sprechen begonnen. Ich liess ihm den Vortritt u. so fing er dann heute im Dozentenzimmer auch wirklich davon an, indem er zugleich sagte, Kaiser habe ihm gesagt, wir könnten das Gutachten auch gemeinsam abgeben. Das lehnte ich natürlich ab. Wenn ich einen Mitbegutachter einmal haben soll, so soll er doch die Sache gerade für sich machen. Ich bin mit meiner Arbeit der Hauptsache nach fertig. Freude habe ich an diesem Vorgehen natürlich nicht. Unter Hoffmann wäre das schwerlich vorgekommen, u. Müller versteht eben noch nichts von der Sache. Kann auch sein, dass sie mich gerne wegbrächten von dem Nebenamt im Departement. Aber da ich mich nun einmal zu dessen Annahme noch unter Hoffmanns Regiment entschlossen habe, so muss ich daran festhalten, so gut ich es vermag. Als Marieli heute mit mir ins Dekanatszimmer kam, musste sie lachen über die Art wie Hut u. Überrock Walter Bs am Ständer hingen. Sieh doch, meinte es, ganz der Duckmäuser, wie er ist! Und wirklich man glaubte den Mann am Hacken hängen zu sehen. Im Professorenzimmer war heute Lüdemann sehr freundlich mit mir. Seine Frau ist aus Berlin zurückgekehrt. Seine Tochter hätte Marieli schon lange gerne besucht, aber sie sei mit der Haushaltung bis zur Rückkehr der Mutter allzusehr beschäftigt gewesen. Ich glaubte ihm das u. es war mir recht,

diesen Ausdruck ungetrübter Stimmung von ihm zu erhalten.

Mit den Arbeiten bin ich heute auch nicht weiter gekommen. Laufend Briefe, eine Consultation des Wohnungsagenten Gustav v. Wattenwyl u. ein Studentenbesuch von v. Planta-Zuoz nahmen mir alle Zeit neben den Kollegien in Anspruch. Das geht jetzt so weiter, bis das 
Semester zu Ende ist. Ich begehre es auch nicht anders. Von Rossels Georges vernimmt man nur Gleichgültiges, woraus ich schliesse, dass es ihm leider nicht besser geht. Dazu kommt nun ein starker Husten Susannes, von dem sie Marieli gestern erzählte. Das wäre doch ein grosses Leid, wenn Rossel derart seine ihm liebsten Kinder verlieren sollte. Susanne hat Marieli erzählt, als es neulich so gehustet, habe sein Vater gesagt, es müsse aus der Lehramtsschule austreten. Rossels Wahl ist jetzt sicher, in vier Wochen ist er Bundesrichter. Das mag ihn für anderes entschädigen. Für Röthlisberger hat die Wahl Comtesse durch die Zeitungspolemik eine recht unangenehme Wendung bekommen. Gegen den «Bund» meinte ein welsches Blatt, R. habe den Bund ersucht, seine Candidatur nicht zu bringen $u$. der Bund habe einen Brief Rs geradezu abzudrucken verweigert. Nun kommt heute der «Bund» u. erklärt, R. habe ihm gar keinen solchen Brief geschickt. Was natürlich an sich gegenüber R. sehr ungeschickt. Aber so wird bei uns alles ins Groteske gezogen. Gott bewahre mich vor Berner Ärzten, Berner Uhrenmachern u. Berner Zeitungspolemiken. Ich will ja mit aller

Monopolfestigkeit meiner selbst $u$. anderer mich abfinden, wenn in nur vor Solchem verschont bleibe!

Ich will nun noch eine Weile unten mit Marieli zusammensitzen. Morgen ist es in Mailand.

Damit Schluss für heute, meine liebe Seele - wie gerne schreibe ich jeden Tag dieses von Dir tausendfältig gesprochene Wort!

Immerdar Dein getreuer

Eugen 
[1]

B. den 21. Febr. 1912.

Mein liebstes Herz!

Heute ist Marieli verreist, mit ängstlicher, fast trotziger Miene u. mit sonderbar gemischtem Ausdruck. Ich weckte es um fünf. Nach sechs war alles fertig. Ich fuhr an den Bahnhof mit ihr, löste das Billet u. sass zu ihr in den Wagen. Zu einem rechten Gespräch kam es nicht mehr, sie war wieder ganz in ihre Stummheit versunken. Wir sassen noch beieinander, da kam Groffina in das Coupé mit einer jungen Dame, seiner Tochter, u. es stellte sich heraus, dass diese nach Chiasso reiste. Also waren die bei einander, wie verabredet, $u$. ich hoffe nur, dass die Begleitung Marieli mehr gefreut als geärgert hat. Mir machte die feine Tessinerin einen sehr guten Eindruck. Sie schien so weich, so seelenvoll. Zweimal stürzten ihr die Tränen über die Wangen. Ach, es ist so schön, ein weiches Gemüt zu sehen. Und ich habe so gar keinen Umgang mehr mit solchen. Alles ist hart $\mathrm{u}$. rauh oder roh, ich mag in Berührung kommen, wo ich will. Oder lauernd berechnet, wie es mir bei den sanfteren Kollegen vorkommt. Bis morgen Mittag kann frühstens der erste Bericht Marielis da sein, ich bin aufs äusserte gespannt,

wie er lauten wird. Anna sagte heute Abend, es komme ihr furchtbar einsam vor, als wäre jemand gestorben. Und ich mache mir halb u. halb Gedanken, dass ich mich durch die vielen Störungen in der Liebe zu dem Kinde eben doch habe beeinflussen lassen. Aber man kann doch nicht anders, als etwas an der Strenge festhalten, wenn es so wetterwendisch zu geht. Dass ich Marieli doch liebe, das spüre ich gerade aus diesen Gedanken heraus am deutlichsten. 
Diese Tage, oder vielmehr in der Nacht, überlegte ich mir auch wieder einmal, ob ich am Ende nicht doch das gute Anneli herrufen könnte, gerade jetzt, da Marieli fort ist. Freilich hat Frau Bösiger manches Bedenken geltend gemacht, aber, aber, wäre es nicht doch besser den guten Gedanken Folge zu geben? Heute wurde Karl Hess beerdigt. Es war im Münster eine würdige Trauerfeier. Erst ein Orgelspiel von Locher, dann eine wunderschöne Mottete von der Liedertafel gesungen, darauf eine wirklich gute Rede von Thalung, weiter den Choral «Wenn ich einmal soll scheiden», vom Münsterchor rein vorgetragen. Dann Rede Stecks im Namen der Universität, mässig, u. nach einem Gebet Schluss mit Orgelvortrag. Aufs Grab ging ich nicht mit, teils wegen meiner andauernden Erkältung, teils weil ich das

Gutachten für das Departement fertig machen wollte, das dann auch Siegwart nach sechs Uhr zum Abschreiben abholen konnte.

Es war ein milder Tag heute, für Marieli ein guter Reisetag, aber für mich etwas gedrückt. Ich machte mir auch über meine fachlichen Leistungen Vorwürfe, weiss nicht weshalb. Es wird doch nicht Altersdepression sein! Nein, es ist Semestermüdigkeit, u. dazu immer der Katarrh, u. jetzt auch gar keine Lust, keine Freude, an eine Ferienreise zu denken. Die neuesten Erlebnisse mit Marieli, mit Hebbel, haben mir offenbar zugesetzt. Aber ich hoffe, ein paar Ferientage werden mich wieder aufbringen. Zum ersten Mal kam jetzt aus einem Geschäft eine Rechnung über Bezüge, die Du im Oktober-November 1909 gemacht habest, von Friedländer. Und bei dem haben wir inzwischen so manches bezogen $u$. bezahlt. Ich kann Dich nicht mehr fragen, Deine Notizen geben wohl über Zahlungen an F. Aufschluss, aber in den andern Posten, als den jetzt verlangten. Ich will nichts Unrechtes, aber ist es nicht einfach ein Judenstreich? Jedenfalls zahle ich jetzt noch nicht, sondern verlange Ausweis, u. dann kann ich immer noch sehen, 
was das Rechte sei. Das Nachsuchen hat mir wieder einmal

Gelegenheit gegeben, Dein Notizbüchlein zu durchblättern.

[4]

Wie viel Mühe u. Sorge - ich mag es nicht bedenken!

Die Zigarrenspitze, die ich um Neujahr vergeblich suchte, lag

diese Tage plötzlich wieder in dem alten Pultfach. Und niemand

will etwas davon wissen. Lügt denn wirklich Sophie? Das

wäre ein schlimmes Symtom, das zur Vorsicht mahnen würde.

Doch nun auch heute wieder Schluss. Ich bin in weher

Stimmung Dein armer, aber treuer Kamerad,

Dein

Eugen

\section{2: Februar Nr. 45}

[1]

B. d. 22./ 23. Febr. 1912.

Mein liebstes Herz!

Wer ist daran schuld, dass ich heute mich so niedergedrückt fühle? Ich las am Morgen die zwei Stunden mit Freude. Am Nachmittag hatte ich eine Frage in der Gesetzgebungspolitik zu behandeln, die mich sehr interessiert, auch war der Besuch etwas besser. Dennoch die elende Stimmung, die sich steigerte, ohne dass ich weiss weshalb. Es wäre denn, dass mir eben wieder das Bewusstsein stärker geworden von der Vereinsamung, in der ich mich befinde. Frl. Reineck klopfte nach der Stunde an der Türe des Dozentenzimmers u. kam herein, während Rossel da war. Sie wollte testieren u. beide, sie $u$. ich vergassen das über ihrer zweiten Frage, ob ich im Studentinnenverein nächstes Semester einen Vortrag halten wollte. Ich lehnte in der Form unbestimmt ab, indes ich sachlich ganz gewiss das nicht übernehmen kann, schon 
nicht weil ich wohl weiss, wie wenig Dich eine solche Geschichte von mir freuen würde. Aber der Vorfall hat ja mit der Gemütsstimmung nichts zu tun, er trug höchstens nicht dazu bei, sie zu bessern. Auch der erste Bericht von Marieli, ein kleines, gerade nach der Ankunft in Mailand geschriebenes Briefchen, kann

nicht die Ursache sein. Der Bericht macht Meldung von glücklicher Reise u. Ankunft u. herzlicher Aufnahme. Und wenn er auch von beginnendem Heimweh spricht, so ist das noch kein Grund für mich zur Traurigkeit. Vielmehr liegt dieser wohl, neben der Ermüdung im ganzen, darin, dass ich keinen Plan vor mir habe. Was soll ich mit den Ferien beginnen? Ich hatte allerlei Ideen, u. sie sind wieder verschwunden. Soll ich arbeiten? Oder an den Genfersee, nach Mailand? Ich weiss es nicht, habe weder zu diesem noch zu jenem Lust, $u$. die einzige Gelegenheit, mich nützlich zu betätigen auf einer Reise, der Vortrag in Wien, habe ich abgelehnt. Nun ja, ich muss mich mit alledem abfinden. Vielleicht wird's besser, wenn ich etwas ausgeruht bin, die Heiserkeit u. der Husten plagen mich immer noch.

Sonst hatte ich heute verschiedene Besuche. Frey-Godet war bei mir, um mich über juristische Litteratur zu consultieren. Auch schrieb ich einige Briefchen. Aber die Hauptzeit nahmen die Kollegien weg. Und es war so warm, so schwül. Morgen schreibe ich weiter. Vielleicht bin ich dann munterer.

Den 23. Febr.

Heute war ich wieder einmal bei Walter B. Ich ging am Morgen zuerst zu Werner Kaiser, gab ihm mein Gutachten über die Lokomotivheizer ab, traf auch zufällig gerade Rothplatz bei 
ihm u. konnte in freundlicher Ruhe über die Sache kurz mit ihnen sprechen, in der Hoffnung u. wie mir schien begründeter Hoffnung, damit die Spannung zu beseitigen, die Rothplatz mit seiner Voreingenommenheit gegen mich, die wahrscheinlich Guhl verschuldet hat, u. Kaiser mit seiner Unentschlossenheit hatten entstehen lassen. Kaiser war gutgestimmt, da die N. Z. Z. ihn heute Morgen als Kandidaten für das Bundesgericht vorgeschlagen hat. Er sagte mir auch, wie Hoffmann u. er sich über meine gestrige Vorlesung gefreut hätten. Zugleich vernahm ich, dass Hoffmann zur Schlussvorlesung nicht kommen könne, da er die ganze nächste Woche in Geschützproben in Bülach weilen müsse. Ich ging dann zur Bibliothek, besprach mich dort mit Mülinen über die Anschaffung amerikanischer Bücher, die ich ihm angetragen, $u$. begab mich, da es sich um Staatsrecht handelte, zu Walter B., mit dem ich eine Stunde gemütlich plauderte. Die Spannung muss auch hier überwunden werden, es geht so nicht weiter, also habe ich den Anfang gemacht. Den Nachmittag hatte ich Studentenbesuche, u. a. Altherr aus Speicher, der auf der Mensur einen bösen Baggenhieb erhalten hat, der ihm noch einiges zu leiden geben wird. Das Praktikum war belebt. Nach demselben kam Zardelli u. entschuldigte sich, dass er vor zwei Wochen während der Stunde hinausgegangen, er hätte wegen einer Besprechung weggehen müssen. Ich hatte damals den Eindruck, der Ärger habe ihn weggetrieben. Um so besser, wenn dem nun anders ist. - Sonst bin ich heute, nachdem mir am Morgen wieder das Kopfweh gedroht, in einer gemischten Stimmung. Ich fühle in der gesteigerten Müdigkeit Mangel an Halt. Ich bin so recht

der Spielball wechselnder Eindrücke. Von Marieli kam eine Karte an Anna, worin sie einige Postkarten für die Buben, mit dem Kindlifresser, Bärengraben, Hirschpark verlangte. Anna hat solche gleich besorgt, $u$. die Sache sollte jetzt schon auf der Fahrt nach Mailand sein.

Briefe, Briefe, ich habe noch viele zu schreiben $u$. werde fast nicht fertig. Und inzwischen hat Siegwart bald wieder keine 
Arbeit, u. ich kann am Buch nicht weiter arbeiten. Ich

könnte mich vielleicht zwingen, aber ich fühle, es käme nichts

Gutes heraus. Ich muss nun eben immer $u$. immer wieder mit dem Alter rechnen. Das ist nun mein Rest.

Verlasse nur Du mich nicht, trotz allem. Schliesslich kommt dann

doch noch ein erträgliches Ende. Heute las ich zufällig Erinne-

rungen an Justinus Kerner. Sein Stickeln hat mich ganz

u. gar an Dich gemahnt. Wären wir beide auf der Stufe

ins Leben getreten, wie jene Beiden, wir würden zu-

sammen die gleiche Höhe erreicht haben. So brauchten wir

Jahre u. Jahre nur für den Anfang. Aber am Ende ging es auch so. Wir taten was wir konnten.

Ich will nun auch noch ein paar Korrespondenzen erledigen, u. dann zur Ruhe! Ich lechze danach.

Nimm mich auf, wie ich bin, ich bleibe Dein treuer

Eugen

\section{2: Februar Nr. 46}

[1]

B. d. 24. Febr. 1912.

Mein liebstes Herz!

Ich bin auch heute aus meiner Betrübnis nicht herausgekommen. Den Vormittag ging ich aus, um die Nummer der «Times» irgendwo zu finden, in der ein Leitartikel über das ZGB. gestanden haben soll, über den u. aus dem der «Bund» eine freundliche u. die N. Z. Z. eine hämische telegraphische Notiz gebracht hatten. Ich war am Bahnhof, am Kiosk auf dem Bärenplatz, im Lesezimmer des Bundeshauses, auf der Museumsgesellschaft, auf der Bahngesellschaft. Nirgends waren die «Times» zu finden. Schliesslich zurückgekehrt gab ich Siegwart Auftrag, die Nummer in London für mich zu bestellen. Es war sehr warm, schon in der Früh über $8^{\circ}$ R., ich ging ohne Überzieher, geriet aber doch in starken Schweiss. Ich begab mich auf dieser Fahrt auch noch auf die Hochschule, um 
daselbst Gmür zu treffen, mit dem ich über die Fortsetzung der Zettelsammlung für das deutsche Rechtswörterbuch zu sprechen hatte. Dabei bekam ich einen starken Hustenanfall, der mich auch zu Hause vor Tisch plagte, als Guhl in Amtssachen zu mir kam. Ich glaubte, nicht in die Versammlung des Juristenvereins gehen zu können. Doch konnte ich dann nach Tisch fast eine Stunde fest schlafen u. nachher war mir wohler, sodass ich auf Pfistern ging u. es war gut. Der Vortrag von Wyss, dem Dir bekannten Hypothekarkassenverwalter,

[2]

versuchte eine unmögliche Interpretation durch zu setzen, der erst Guhl u. dann ich entgegentraten. Ausserdem war Bühlmann da, der mich in einer wichtigen Sache consultierte, u. er begleitete mich nachher, immer noch diskutierend, über die Brücke. Da kam mir eine erlösende Idee, die er dankbar annahm. Die Versammlung war gedrückt, namentlich wegen eines Conflictes, den Wyss scheints mit den Notaren hat. Umgekehrt versicherte mich Bühlmann, dass die Bauern im Verkehr mit seiner Kasse sich über das neue Recht ausserordentlich befriedigt zeigen. O es wird noch manche Kämpfe geben, bis das Neue begriffen $u$. richtig angewendet wird. Guhl erzählte mir, dass Schulthess nochmals in einer neuen Sache in grosser Aufregung bei ihm gewesen u. dann aber mit einer kurzen Aufklärung vollständig beruhigt worden sei. Und so geht es Tag für Tag. Vorwärts!

Was mich besonders beschäftigte, war ein erster Brief Marielis, worin es ohne jede Freude von seinen ersten Eindrücken in Mailand spricht. So wird mir klar, dass das Kind die Mailänder Zeit am Ende, weil sie seinem Wollen nicht entspricht, ganz so zubringen wird, wie s. Z. den Aufenthalt in England: ohne Freude u. ohne Gewinn. Das wäre schlimm! Ich hoffe ja freilich auf eine Besserung, aber die Sache tut mir doch weh, u. ich habe ihm sofort eine Antwort geschickt, ohne Vorwürfe, aber in einem Ton, aus dem es das Echo 
auf seinen Brief schon herauslesen wird. Aber so kann es ja nicht weiter gehen. Ich spüre immer deutlicher, wie die Liebe zu Marieli bei mir abnimmt, u. wenn es selber schliesslich in diese Stimmung verfallen sollte, was dann? Ich weiss keinen Ausweg. Ich beschwöre Deinen guten Geist, mir zu helfen. Es darf doch nicht alles in die Brüche gehen, es muss eine Wendung zum Guten kommen! Als ich heute Vormittag nach Hause zurückkehrte, traf ich Frau Gmür u. ihren Bruder, der morgen für ein Jahr nach Amerika verreist. Sie waren recht herzlich. Am Nachmittag traf dann Frau Gmür Anna an u. sagte ihr, sie hätte von ihrem Mann vernommen, dass ich immer noch unwohl sei, u. mache sich Vorwürfe, dass sie mich am Morgen auf der Strasse zu sprechen veranlasst. Ja, geschadet hat mir das nicht. Ein paar freundliche Worte tun wohl an jeder Zugluft.

Das warme Wetter - sogar ein leichter warmer Regen fiel heute Nachmittag - schafft einen ausserordentlich frühen Frühling. Und wenn dann Rückschläge kommen? Warten wir das ab u. seien wir auch da nicht mutlos. Ich weiss immer noch nicht, wie ich die Ferien verbringen soll. Unter anderem würde ich gerne Hermine Abegg sprechen, um sie betr. Marieli aufzuklären. Ich schickte ihr die Heliographien der Glasscheiben u. fragte sie an, ob sie vielleicht irgendwo einen Frühlingsaufenthalt machen wolle, ich würde sie dann für einige Tage besuchen. Ferner denke ich an einen Besuch

bei Richard Schröders, wenn sie wieder nach Baden gehen. Anderes wird sich zeigen. $\mathrm{O}$ wie froh bin ich, wenn die Zeit eilt. Es ist so schwer, recht zu handeln!

Gute, gute Nacht! Vielleicht wird der Schlaf mich wieder in bessere Stimmung bringen! 
Noch will ich anfügen, dass ich heute vom jungen Dumont erfuhr, dass sein Vater einen Rückfall, mit einer Embolie, gehabt. Jetzt gehe es aber entschieden besser. Der Junge war aber wenig freundlich. Er ist jetzt auch in grossem Sturm. Anderes erzähle ich ein nächstes Mal. Jetzt Tagesschluss!

In treuer Liebe immerdar!

Dein

Eugen

\section{2: Februar Nr. 47}

B. d. 25. Februar 1912.

Mein liebe, gute Lina!

Heute Nacht werden die 99 Wochen verstrichen sein, dass Du mir entrissen worden bist, $\mathrm{u}$. ich bin heute besonders an diese schwerste, folgenschwerste Stunde meines Lebens erinnert worden, da Dr. Victor Schläpfer bei mir war. Er ass mit Anna u. mir zu Mittag u. nachher befragte ich ihn, ob die Cocain-Anwendung Deinen Herzschlag herbeigeführt haben könnte. Er nannte mir - aus eigener peinlicher Erfahrung - die Symptome der Cocainvergiftung: Vergrösserung der Pupille u. gesteigertes Durstgefühl. Beides fehlte nach meiner u. Annas Erinnerung in Deinen letzten Stunden. Er vermutet, dass eine nervöse Störung die lethale Wendung herbeigeführt haben müsse, indem die Nervenentzündung wohl hieraus zu erklären sei, wenn sie auch durch Druck oder Erkältung dann zum Ausbruch der Gürtelrose geführt haben könne. Also bleibt das Rätsel ungelöst. Ich muss mich nur an den Trost halten, den er anführte, dass Du durch diesen raschen Ausgang wohl von schwereren Herzleiden bewahrt worden seist, die sonst bei den vorhandenen Anzeichen gedroht haben möchten. Wie Du ja selbst so oft es befürchtet hattest. Ja, das ist ein Trost, aber keine Beruhigung für mich. Ich habe Dich eben doch viel zu früh ver- 
loren. Was wäre mir das Leben schön geworden, wenn ich nach Überwindung Deiner Krankheit, in die Stimmung der Beschaulichkeit hätte einkehren können, die mit Dir zusammen

wir so innig genossen hätten, während wir jetzt getrennt sind u. mir in meiner Einsamkeit die Beschaulichkeit zur herzbrechenden Wehmut werden muss! Das hilft nun ja alles nichts, zu klagen. Ich muss stille stehen u. warten, wie es auch noch werden mag. - Schläpfer war recht. Er sieht immer noch schlecht aus u. kann nur mit grösster Behutsamkeit sich in einiger Leistungsfähigkeit erhalten. In Basel gefällt es ihm nicht, er will daselbst nur wenige Monate bleiben u. gedenkt nachher nach Zürich zurück zu kehren, um sich dort zu habilitieren $u$. nebenbei der Privatpraxis zu widmen. Er gedachte Deiner mit Liebe, es gebe, sagte er, so wenig Menschen, bei denen man den Eindruck bekäme, sie meinen es gut mit einem, u. bei Dir habe er diesen Eindruck gehabt. Er sprach auch von seiner Schwester mit schmerzlichem Andenken. - Er kam um 12 Uhr. Ich hatte bei Dätwyler ein kleines Mittagessen durch Anna bestellt. Und Anna deckte den Tisch ordentlich. Sophie servierte. Aber es störte mich schon, dass Anna ohne mich zu fragen für sich Deinen Platz einnahm u. mich an ihren wies, während Schläpfer oben sass. Ich hatte mir gedacht, ich behalte meinen Platz, Anna den ihren u. der Gast setzt sich mir zur Rechten. Dann suchte Anna mit Unterhaltung die Hauswirtin zu spielen u. war sehr selbstbewusst. Die Tücke des Geschicks blieben aber nicht aus: Anna liess beim Einschenken des Bordeaux die Flasche fallen, sodass die Hälfte des Tisches rot übergossen wurde, natürlich in der Richtung des Gastes. Und sie wusste darauf sich gar nicht zu helfen. Zerbrochen war nichts, aber

erst auf mein Geheiss wurde eine Serviette über den Schaden gelegt, u. die Schwette am Boden blieb unbeachtet. Merkwürdigerweise machte sich Anna aber aus der Sache gar nichts, 
während mir deutlich vor Augen trat, dass ich eben mit ihr schlechterdings keine Gäste haben kann. - Nach Tisch sassen Schläpfer u. ich auf der Verandah beim schwarzen Kaffee. Wir sprachen über seine Erlebnisse u. über allerlei Krankheiten. Er ist gewiss ein gescheiter u. braver Mensch. Doch trug dies alles nicht zu meiner Aufmunterung bei. Ich wurde nur immer von neuem des Gegensatzes zu früher bewusst. Vorwürfe habe ich ihr nicht mit einem Wort gemacht $u$. werde das auch bleiben lassen. Das Erlebnis entspricht ja ganz dem, was ich erwartet hatte. Den frühren Vormittag habe ich die verschobenen Correspondenzen, soweit möglich, nachgeholt. Kaum war ich fertig, so kam Walter B., mit dem ich wieder einmal ein vernünftiges rechtsphilosophisches Gespräch abhalten konnte. Wir waren nicht zu Ende, so rief ihn seine Frau telephonisch heim, sie wollen ja einen Besuch machen. Und als er fort war, kam Frieda Weber, sehr recht u. gemütlich, u. während sie noch da war, meldeten sich Maler Jakob Welti u. seine Frau. Sie sind seit zwei Wochen wieder da. Er habe viel zu arbeiten, möchte so gerne ganz nach Bern übersiedeln. Andere Besuche habe er noch nicht gemacht. Während des Besuchs verfiel er aber momentweise wieder in ein eigentümliches Sinnen, bei dem er bleich u. gebeugt dasass u. kein Wort sprach, als würde ihn ein Kummer drücken, ganz so wie Marieli es von seinem letzten Besuch im Herbst erzählt hatte. Ich weiss nicht, was

das gewesen ist. Ob doch noch etwas in ihm nagt, oder ob seine Gesundheit gestört sein mag? Weltis gingen, dann auch Frieda u. es blieb Schläpfer, der inzwischen auch eingetroffen war. Nach Schläpfers Weggang u. meiner Rückkehr vom Bahnhof las ich wieder einmal in Nepos Geschichte Hannibals. Der Ausgang ist mir jedesmal ein Schmerz. Rom war schon damals schrecklich.

Und nun sei der Tag geschlossen. Es geht mir seit gestern Abend bedeutend besser. Es ist als ob mir das Glas Wein, das ich gestern in Pfistern getrunken, den Husten weggespült habe. Um so besser. Ich gehe gerne in besserm Befinden in die Ferien hinein. 
Gute Nacht, meine einzige Seele! Halte trotz allem

zu mir. Es muss ja auch einmal wieder besser werden.

Dein ewig treuer

Eugen

\section{2: Februar Nr. 48}

[1]

B. d. 26. Febr. 1912.

Mein liebstes Herz!

Als ich heute wieder einmal mit dem Tram zum Bahnhof gefahren war u. auf die Grosse Schanze hinauf gepilgert hin $u$. her schlenderte, kam zu meiner Überraschung schon vor acht Uhr Marli daher, in ernster Stimmung. Und was er mir mitteilte, war auch ein Ernstes: Barth ist gestern Abend halb sechs Uhr gestorben! Ich hatte ihn noch am Mittwoch gesehen. Am Donnerstag musste er wegen eines Abzesses am Halse zu Hause bleiben. Am Freitag trat Erisipel auf, die [Fi?] steigerten sich, Delirium trat ein, es war von Samstag Abend an wachsende Gefahr, u. dann der unerwartete Tod! Der Mann tut mir furchtbar leid. Ich hatte ihn gern. Er war ein Basler in etwas anderem Sinn als sie es gewöhnlich sind: Keine Spur von Schmähsucht, sondern ernstes, [?] Wesen. Weiter Blick für soziale Aufgaben zeichneten ihn aus. War er auch in seinen confessionellen Ansichten zur Orthodoxie geneigt, so übte er doch eine herzliche Toleranz. Ich sprach gerne mit ihm über religiöse Fragen. Es war auch lieb von ihm, dass er mich seit Deinem Hinschied mehrmals an Sonntag Nachmittagen besuchte. Ich hoffte, ihm, wenn ich wieder einmal geselliger leben würde, näher zu kommen. Und nun ist er vorangegangen. Er war ein Jahrgänger 
Brenners, dem gegenüber er allerdings unter den Einfluss der Basler Stimmung von früher her ganz u. gar nicht gerecht wurde. Und nun sind sie beide vereinigt, mit relativ jungem Tod, beide aufgezehrt durch jahrelange Arbeit über alles Mass der vorhandenen Kräfte, bei Brenner mit beeinflusst durch ein politisches Gesellschaftswesen, bei Barth unter der Mitwirkung leidenschaftlicher Kämpfe in engen Kreisen, denen er früher mit etwas zu viel Eifer gedient haben mag. Ich sandte einen Kranz u. schrieb an Frau Professor einen warmen Brief, wie ich es empfand. Später will ich sie besuchen.

Die Nachricht zitterte den ganzen Tag in mir nach. Am Morgen hatte ich noch mit Guhl zu verhandeln. Am Nachmittag verfasste ich ein kleines Gutachten für Hellmüller u. schrieb einige Briefe. Vor dem Nachtessen kam Gmür, mit dem ich über die Weiterführung der Wörterbuchs-Zettel zu verhandeln hatte. Die Abendpost brachte einen Brief von Teichmann, der sehr angekränkelt von seinem zerfahrenen Zustand, von dem man mir berichtete, eine Nachricht enthielt, die mir leid tut. Der «Times» Artikel von dem die Zeitungen telegraphische Ankündigung brachten, soll nämlich nach Teichmann eher abfällig als anerkennend sein. Und T. fragt mich, ob er antworten soll, oder ich es tun wolle. Zuerst muss ich den Artikel selbst lesen, ich erwarte ihn in einigen Tagen. Dann will ich sehen, was zu machen. Jedenfalls schreibe ich selbst

nichts. Und es wird wohl überhaupt besser sein, wenn man in jener Zeitung nicht antwortet. Der Artikel sei nicht gezeichnet, schreibt Teichmann. Wer aber mag dahinter stecken? Etwa Carlin, oder Meili? Ich weiss es nicht. Man hat Feinde überall. Es ist gut, wenn man sie nicht kennt.

So ist der Tag vorüber gegangen mit Windeseile. Es war auch heute wieder Frühlingswärme. Der Katarrh hat mich nicht mehr geplagt. Das Glas Wein von der Samstag-Versammlung 
her hat Wunder gewirkt. Ich trete wirklich die Ferien gerne in besserer Verfassung an als ich sie die letzte Zeit in mir fühlte.

Wenn man so sieht, wie Bekannte um Bekannte dahinsterben, im gleichen Alter oder noch jünger als man selbst ist, so wird man geneigt, den Rest als Geschenk zu betrachten, dem man Ehre erweisen muss. Aushalten, in den Geleisen, wie Du, meine liebe Seele, so warm u. schön mir empfohlen. Du warst die stärkere u. die normalere Natur als ich es bin. Du hast Dein Leben richtiger orientiert als ich, u. doch hast Du Dich darin zu früh aufgezehrt. Ja darin lag vielleicht gerade das Ziel Deiner Lebensweisheit. Jetzt erst habe ich ja begonnen, das zu erfassen. Ich will es machen wie Du: wirken solange es Tag ist u. dann auf eine rasche Erlösung hoffen! Die Ferien nahen. Ich wollte das Hauptkolleg am Mittwoch schliessen. Jetzt wird wegen Barths Beerdigung am Mittwoch nicht gelesen. Ich kann also erst am Donnerstag fertig machen, wenn Gmür mich richtig berichtet hat. Nun

es ist auch da noch Zeit. Und dann die Ferien? Das Haushalten mit den Kräften empfiehlt mir, sie doch zu einer Reise zu benutzen. Aber wann, wie, wohin - alles ist mir noch unklar. Balli war heut nach Tisch bei mir. Er geht ins Tessin. Er sagte aber nichts davon, dass ich ihn besuchen soll. Ich werde es doch tun, wenn ich nach Locarno kommen sollte.

Teichmanns Brief soll mich nicht unruhig machen. Ich bin viel gelassener in solchen Dingen als früher. Ich habe meine Erfahrung gemacht. Aber es ist doch auch das wieder ein Moment, das mir zeigt, dass etwas Wechsel gut tun wird. Warten wir weitere Nachrichten ab.

Zum Schluss mein Herzensgruss! Ich bin, meine liebe, gute Seele, immerdar

Dein getreuer

Eugen 
[1]

B. d.27. Febr. 1912.

Mein liebstes Herz!

Ich komme von den letzten Vorlesungen über Gesetzgebungspolitik, u. zwar, wie ich jetzt entschlossen bin, von der letzten, die ich überhaupt über diesen Gegenstand je lesen werde. Der Besuch war heute ordentlich, wegen des Abtestierens. Hoffmann fehlte, weil er in Kommissionssitzungen abwesend ist. Kaiser sah ich nicht, er war wohl auch nicht da. Es ist merkwürdig, dass dieses Semester der Gegenstand so wenig Teilnahme gefunden. Es war wieder, wie es vor Jahren mit der Vorlesung über die Grundlagen des Rechts gewesen. Zwischen hinein waren einige Jahre gut. Jetzt habe ich aber gesehen, dass ich auf diesem Boden in einem Missverhältnis mich befinde zu der Arbeit, die mich die Sache kostet, u. dem Anklang, den sie bei den Studenten findet. Also schliessen wir diesen, ich kann wohl sagen, Lebensabschnitt, denn für mich war es ein Stück meines Lebens. Wenn ich mich weiter mit den Problemen beschäftige, so wird es, abgesehen von den Vorlesungen über Rechtsphilosophie, die ich mir für den Winter 1913 / 14 vorbehalte, wenn ich dann noch lese, nur noch zum Zweck der Ausarbeitung eines Buches geschehen. Heute erhielt ich vom Departement den Artikel der Times A new civil code of Switzerland zur Einsicht zugestellt. Die Londoner Gesandschaft hat ihn übersandt. Es ist

aber ein sehr trauriges Machwerk, das in einem kurzen ersten Teil darauf hinweist, dass für England doch auch eine Rechtsvereinheitlichung möglich sein sollte, wenn es für die Schweiz bei ihren schwierigen Verhältnissen möglich gewesen sei, u. in dem noch kürzern zweiten Teil wird mit ein paar 
Phrasen über Art. 1 geschimpft u. Art. 2 auch heran gezogen, mit einem Unverstand, der mich kalt lässt. Aus dem Umstand, dass die Gesandtschaft den Artikel übersandte, u. dass die Depeschen an die Schweizer Blätter gingen, sowie wohl offenbar ein Nicht-Engländer den Artikel verfasst hat, da ein Engländer mit Notwendigkeit auf die Parallele der englischen Rechtsprechung verfallen sein müsste, schliesse ich, dass der Artikel wohl aus den Kreisen gerade der Gesandtschaft hervorgegangen sein muss, vielleicht, nach seinem hochmütigen Ton, von Carlin selbst herrührt. Wohl bekomms. Schaden tuts nichts. Es zeigt mir nur in neuem Licht, wo meine Feinde sind, nämlich überall da, wo der Neid u. Hochmut das Regiment führen. Die Sache ist damit für mich abgetan. Nur muss ich morgen allerdings noch über die Sache an Teichmann schreiben.

Morgen kann ich nicht lesen. Wegen der Beerdigung Barths fallen alle Vormittags-Collegien aus. So werde ich also das Zivilrecht am Donnerstag schliessen u. die

Übungen am Freitag. Damit ist dann auch dieser Abschnitt erledigt.

Heute Mittag überraschte mich ein Briefchen aus Bern (nach Zürich adressiert) von August, worin er frägt, ob er morgen um halb eins zu mir kommen könne. Er sehe eigentlich doch keinen Grund ein für eine Feindschaft zwischen uns. Ich bat ihn sofort, mit Entschuldigung wegen der morgigen Abhaltung durch Barths Trauerfeier, heute zum Nachtessen zu kommen, u. erwarte ihn jeden Augenblick. Ich will Dir dann nachher über dieses Wiedersehen einige Zeilen beifügen.

Sonst war der heutige Tag durch einige Besuche in Anspruch genommen, dissertierende Studenten $u$. Tecklenburg, der mir mitteilte, dass er nur bis Herbst 1913 seine Eigenschaft als deutscher Rechtsanwalt beibehalten könne, u. daher bis zu diesem Termin wissen möchte, welche Chancen er in Bern habe. Also die alte, drollige Geschichte. Ich 
liess ihn reden. Versprechen konnte ich ihm nichts, u. ihn auf das Unanständige, Jüdische in diesem Handeln aufmerksam zu machen, fühlte ich mich auch nicht berufen. Er wird ziemlich enttäuscht gewesen sein.

Dann traf ich Frau Staub, die mich auf der Strasse anredete, u. mich bat, doch ja Frau Heim bei ihrem Besuch nächste Woche einmal bei ihnen essen zu lassen. Ich wusste aber gar nichts von einem Besuch u. vernahm erst jetzt, Frau Heim sei seit sechs Wochen krank

u. abgeschwächt in Goldiwil u. jetzt habe sie geschrieben, es gehe ihr etwas besser $u$. sie werde nach Bern kommen. Von alledem berichtet man direkt mir nichts. Hier kam August. Er war recht, wir hatten eine kleine Auseinandersetzung. Von Bedeutung war mir nur, dass er offenbar von der Geschichte Konrad-August Gyr kein Wort weiss - ich sagte ihm jetzt auch nichts. Im Ganzen hatten Anna u. ich den Eindruck, er wolle es doch nicht ganz verderben mit mir, aus einleuchtenden Gründen. Er übernachtet heute noch im Bären u. verreist morgen 1.40. - Nun, es ist doch äusserlich wieder eingefädelt.

Die Abendpost brachte einen lieben Brief von Frau Rita Montani. Sie scheint Marieli gern zu haben $u$. schreibt recht nett über ihre Pläne.

Und nun ist es fast spät geworden, $u$. ich will zur Ruhe. Der Husten ist wieder gekommen. Hoffentlich ist er morgen wieder vorüber. Gute, gute Nacht!

Dein immer dir verbundener Eugen 
B. d. 28. Febr. 1912.

Mein liebstes Herz!

Der gestrige Besuch Augusts hat heute noch bei mir nachgeklungen, aber in nicht ganz befriedigendem Tone. Beim Morgenessen sagten Anna u. ich gleichzeitig, das Billet Augusts, worin er fragte, ob er kommen dürfe, habe uns mehr gefreut als seine Gegenwart. In seinem Benehmen empfanden wir den Ausdruck des Bemühens, den Bruch zu vermeiden ohne Eintritt wirklich herzlicher Gesinnung, nur zum Zweck, am Ende einen andern Schaden mit der Beibehaltung der Beziehungen abwenden zu können. Namentlich die Frage, ob Paul mir wieder schreiben dürfe, u. ähnliches machten mich aufmerksam. Ich habe ja freilich seit der Geschichte mit August Gyr reichlich überlegt, ob ich nicht unser ganzes gemeinsames Vermögen mit Vorbehalt der Rente für Marieli dem Bunde zum Zweck der Errichtung eines jur. Seminars für die jur. Facultät in Bern überlassen soll. Die Änderung gegenüber dem, was wir gemeinsam aufgesetzt vor zehn Jahren, würde darin bestehen, dass ich von der Verwendung des Hauses als Wohnung eines Bundesratsmitgliedes u. damit von dem Hauszins als Mittel des Instituts absehen u. dieses Mittel dafür dadurch herstellen würde, dass Konrad u. Paul nichts erhalten. Sie haben ja sonst genug. Ich werde das noch manchmal überlegen. Aber die Ida wird mit jeder Woche bestimmter.

Heute traf ich zum ersten mal Motta. Er begann vom Hause Rossels zu sprechen. Es ist möglich, dass er es erwirbt. Ich habe ihm sehr dazu geraten. Er war auf dem Weg zu Comtesse, in dessen Wohnung der Bundesrat um $8 \mathrm{Uhr}$ Sitzung hielt. Comtesse ist nämlich an Gelbsucht erkrankt. Ob 
in Folge der Angriffe, die gegen ihn gerichtet wurden? Ich sah vor dem Bundeshaus dann auch Müller, Hoffmann u. Deucher. Sie sprachen von der Erkrankung nicht unbedenklich. Mit Müller konnte ich über den «Times» Artikel sprechen. Er fand meine Vermutung der Autorschaft Calins nicht unplausibel. Das würde, meinte er, seiner Gamin-Natur ganz gleich sehen.

Ich war dann auch bei Kaiser, mit dem ich allerhand verhandelte. Er war recht zuvorkommend. Nachher spazierte ich mit Mutzner ein Stündchen. Guhl hatte ihr mir von ihm gesprochen, als sei er sehr verbittert, weil Kaiser ihn zurücksetze, u. er mit Müller in gar kein direktes Verhältnis komme. Mutzner bestätigte das mit Beispielen von Kaiser u. fügte an, dass Kaiser auch Guhl in den Rücken schiesse. Aber ich überzeugte ihn, dass dies doch nur Kleinigkeiten seien, dass er sich dadurch nicht verbittern lassen dürfe, dass er seine wissenschaftlichen Pläne festhalten müsse u. s. w. Mutzner ging sehr nett darauf ein. Er sagte auch, seine Frau, in Trauer über den Tod ihrer Tante, Frau Epars, habe die Sache schwer genommen,

aber sie seien doch mit einander zu der Überzeugung gelangt, dass es wirklich, ganz wie ich es meine, besser sei, wenn er in hier aushalte. Seine Stellung habe sich freilich mit dem Weggang Hoffmanns sehr verschlimmert. Aber er soll doch bedenken, dass das auch wieder besser werden kann.

Heute wurde also Barth begraben. Pfarrer Rickli hat in der Nydeckkirche eine sehr schöne Ansprache gehalten. Marti sprach für die Universität, correct, aber nicht sehr warm. Darauf folgte Hadorn als Sprecher der Geistlichkeit. Dann der Dichter v. Tavel, der im Namen des evangel. Vereins, der neuen Mädchenschule etc. ganz schön gesprochen hat, u. endlich ein Student Lindenmayer, der etwas stecken blieb. Die Orgel spielte, der Kirchenchor sang zwei Choräle. Zwei Dinge sind mir dann aufgefallen: Auch hier wieder der Kult der Zofingia. Die ganze Hälfte des vordern Mittelschiffs war für sie reserviert. Die Fahnen umstanden den Sarg, Füchse hielten eine 
Art Ehrenwache. Ich begreife diesen Geist nicht. Dann zweitens war für die Begleitung des Sarges zum Friedhof gar nichts geordnet, soweit nicht die nächsten Richtungsgenossen in Frage kamen. Professoren hat man nirgends eingereiht $u$.

Folge davon war denn auch, dass von uns offenbar nur wenige hinausgingen. Ich selbst hatte die Absicht, den Sarg zu begleiten. Als ich aber sah, dass ich in ganz u. ausschliesslich orthodox-conservativer Begleitung, ohne einen Facultätsgenossen mit gehen musste, da entschloss ich mich anders u. trat mit Graf den Heimweg an. Dieser war übrigens

sehr freundlich, meinte auch, es gehe ihm wieder ausgezeichnet, aber dabei kam er beim Weg über die Kornhausbrücke in ein Keuchen, das mir deutlich zeigte, wie es sich objektiv mit dem Mann verhält. Ich kam unerwartet nach Hause u. traf Anna in meinem Studierzimmer. Also die alte «Nauserin». Es hat mich weder gewundert noch betrübt. Die Post brachte mir einen netten Brief Rümelins, der mir von seinem Plan nach Cap d'Antibes zu fahren erzählt. Und ganz unerwartet einen Brief Marielis, der in viel herzlicherem Ton gehalten war als der letzte. Wie es mit seiner Gesundheit steht, ist freilich nicht klar daraus ersichtlich. Ich werde mit der Antwort gleichwohl bis Samstag warten. - Sonst konnte ich heute noch einige Briefe u. namentlich den Nachtrag zum Gutachten über Metrys Arbeit endlich reduzieren. Auch an Teichmann habe ich geschrieben.

Es war ein warmer Frühlingstag. Alles etwas Frühling. Kommt wirklich kein Rückschlag? Damit schliesse ich. Bleibe bei mir! Graf hat auf dem Heimweg so schön gesagt, welch ideales Verhältnis ich gehabt zu Dir, u. das muss wahr sein u. nachwirken.

Dein allzeit getreuer

Eugen 
B. d. 29. Febr. 1912.

Mein liebstes Herz!

Von Marieli hat Anna heute eine fröhliche Karte erhalten, u. von anderer Seite, Guhl u. a. höre ich ebenfalls, dass es Karten geschickt habe. Es scheint also doch, dass die erste gedrückte Stimmung verschwunden ist, dann kann ich am Ende doch noch hoffen, der Aufenthalt in Mailand werde für es gute Früchte tragen. Wills Gott! Heute habe ich - knapp mit der Zeit reichend - das Zivilrechtskolleg geschlossen. Nun morgen noch das Praktikum, u. dann ist das Semester zu Ende. Ich hatte heute mehrere Studentenbesuche. Auch Guhl kam mit einigen Fragen. Die Müdigkeit des Semesterschlusses bekämpfte ich dadurch, dass ich eine Abhandlung von Fraenkel gegen Stammlers «soziales Ideal» las u. für Fries, dessen Rechtsphilosophie auf Kantscher Grundlage ich noch gar nicht kannte. Die Abhandlung stammt aus Göttingen. Es ist merkwürdig, dass von daher Stammler u. mir die Kritik erwachsen soll, mir von Rabel, Stammler von diesem Fraenkel. Freilich ist der Untergrund der beiden sehr verschieden. Darin sind sie aber wieder einig, dass sie neben sehr scharfen Worten in den Grundzügen einige Anerkennung aussprechen. Man muss sich aus alledem

nichts machen. Da passt der Refrain des Predigers, alles ist eitel. Ich sagte gestern, dass ich die Bundesräte auf dem Weg zu Comtesse angetroffen, der erkrankt ist, u. dass ich nur Müller schnell sagen konnte, ich habe Carlin als Verfasser des Times-Artikels in Verdacht. Und er sprach von dem «Gamin» Carlin. Ich wusste nicht, u. erfuhr erst 
heute, dass sich meine Bemerkung sonderbar gerade dem Geschäfte anfügte, für das die Sitzung bei Comtesse abgehalten wurde. Nämlich die Wahl des Nachfolgers von Graffina stand in Frage u. gewählt wurde der ehemalige Gesandte in London, Bourcart, der s. Z. 1902 von Carlin in so unschöner Weise aus London verdrängt wurde. Es ist ein Akt später Gerechtigkeit, dass der Bundesrat diesen Mann wieder zu Ehren gezogen hat. Carlin hätte schon bei der Art, wie er gegen Barier in Rom 1895 vorging, verdient, mit einem Tritt aus der Bundesbeamtung hinaus befördert zu werden. Der Flegel wird aber schon noch einmal seinen Lohn endgültig bekommen, wenn ich es noch erlebe.

Seit gestern Abend war mir wieder weniger wohl als den Tag vorher. Vielleicht habe ich mich mittags in der NydeckKirche neuerdings erkältet. Ich spüre auch Schmerzen in der Nierengegend, vielleicht nur rheumatisch. Ich hoffe doch

gesund die Ferien antreten zu können. Was bei meinen Reiseplänen herauskommt, weiss ich noch nicht. Wenn ich nicht das Gefühl hätte, eine rechte Fahrt täte mir wohl, ich bliebe am liebsten gleich bei der Arbeit. Rümelin schlägt mir Cap Antibes vor. Hermine Abegg schreibt, ich soll nach Zürich kommen. Von Schröder habe ich noch keine Antwort. Ist er krank? Ich werde nun, bevor ich Entschlüsse fasse, noch einige Tage abwarten, habe ja auch noch einige ganz dringende Arbeit zu verrichten.

Anna ist merkwürdig viel frischer, seit Marieli verreist ist. Es scheint, dass die grössere Verantwortlichkeit ihr gut tut, wenn auch noch so sehr ihre Leistungen stückwerkig bleiben. Ja, ja, es muss eben gehen, u. die Erinnerung an Dich tut ihr offensichtlich gut. Das ist ja auch das Beste, was ich von ihr erwarten darf. Von Sophie muss ich doch auch wieder einmal ein Wort beifügen $u$. das ist, dass sie entschieden am Haus mehr Interesse nimmt als früher. Sie verkehrt auch weniger mehr mit ihrem Anhang von früher her, was nur gut tut. Und sie nimmt allmählich in ihr Herz das Be- 
wusstsein auf, dass man es mit ihr gut meine. Das ist am Ende die Hauptquelle eines besseren Geistes. Die Verbitterung wird umso mehr weichen, je bestimmter sie in das Gefühl der Dankbarkeit eintritt. Und dazu hat sie jetzt Anlass genug, da sie mit der Versorgung ihres älteren Jungen

zufrieden sein kann, u. auch den kleinen Karle ganz gut herangedeihen sieht. Seine krummen Beinchen, die er von Berlin her gebracht hat, sind jetzt nahezu gerade gewachsen. Könnte man doch alle Kummer so gerade wachsen sehen! Damit sage ich Dir gute Nacht, mein Lieb, u. bin wie immerdar

Dein getreuer

Eugen

\section{2: März Nr. 52}

B. d. 1. März 1912.

Mein liebstes Herz!

Es ging mir heute in Abwicklung der Geschäfte u. Vorsätze gut. Am Morgen ein paar Briefe, dann eine Nachfrage auf der Staats Kanzlei für Heusler, die gleich Erfolg hatte, darauf Besuch bei Frau Hebbel, bei der ich ihren Neffen Georg traf, weiter Condolenzvisite bei Frau Prof. Barth, zu der die beiden jüngern Söhne kamen. Nach Tisch mehrere Studenten- u. Candidatenbesuche, letztes, recht ordentlich besuchtes Praktikum. Und in einer halben Stunde will noch Dr. Langhard kommen u. mir die Adoptionsurkunde betr. Lisly u. Lydia zeigen. Also alles am Schnürchen $u$. ich muss namentlich für den guten Semesterschluss dankbar sein. Und doch ist Unruhe über mich gekommen. Warum? Mit Recht? Ich weiss es nicht: 
Die Geschichten mit Werner Kaiser - Mutzner - Guhl, - Müller befriedigen mich nicht $u$. ich musste mich fragen, ob es nicht am Ende doch gescheiter gewesen wäre, die Verbindung mit dem Departement flattern zu lassen. Nun ja, das ist ein altes Bedenken. Dann aber war Frau Hebbel heute so sonderbar, ich hätte gerne ein vertrautes Wort über ihre Verhältnisse mit ihr gesprochen. Aber sie rief gleich ihren Neffen u. im Gespräch war sie innerlich grimmig. Ich befürchte zwei Dinge. Sie sagte mir ja, ihr Mann habe ihr gesagt, für sie sei gesorgt,

er habe alles mit mir besprochen. Und nachträglich zeigte es sich, dass er sie recht wenig günstig gestellt $u$. seine Verwandten offenbar vor den ihrigen bevorzugt hat. Aber dafür kann ich ja nichts. Ich hatte ihn bei seinem Besuch vor Neujahr ausdrücklich darauf hingewiesen, dass er seine Frau besser stellen möge. Allein er entgegnete, ohne Zahlen zu nennen, sie sei sorglos gestellt, es sei ihm lieber, wenn das Vermögen soweit möglich bei den Hebbels bleibe. Ich glaubte auch wirklich, dass er ein grösseres Vermögen hinterlassen werde, als es jetzt der Fall ist. Wenn sie mir alles gesagt hat, so würde sie an Zinsen zwischen 5 - 6000 Fr. beziehen. Dazu eine Pension aus der Instruktorenskasse. Das ist ja freilich nicht unbedeutend. Es könnte aber mehr sein. Immerhin will sie wo möglich ihre Wohnung beibehalten. Das zweite war, dass sie mir mitteilte, ihre Nichte in Mailand, Frau Ritner-Haag, habe ihr von dem Besuch Marielis geschrieben, u. dass es ihr gesagt habe, es habe immer Heimweh, auch wenn es mit dem Papa Reisen mache. Und das bekam einen so spitzen Klang. Ich werde Marieli warnen müssen, auf dessen morgigen Brief ich gespannt bin. So plagt man sich immer mit etwas. Kuentins Brief freut mich auch nicht. Ich hatte ihm einen so herzlichen langen Brief geschrieben, u. er antwortete so geschäftsmässig ohne für den Brief auch nur zu danken, geschweige auf dessen Inhalt einzutreten. Und von Schröder habe ich überhaupt keine Antwort. 
Mir gehen die letzten Todesfälle oft durch den Sinn. Hätte ich mit Barth in ein innigeres Verhältnis kommen können? Heute hatte ich von der Witwe einen bessern Eindruck als an dem Begräbnistag. Sie war wirklich betrübt $u$. hatte nichts Gemachtes an sich. - Hebbels Begräbnis kommt mir nachträglich wie eine Szene aus Gottfried Keller vor. Die sieben Aufrechten, Biedermeier aus der Zeit der Regeneration, des so naiven selbstbewussten Kleinbürgertums. Und das Fähnlein hat so wohl dazu gepasst. Würtemberger hat eine Fahne daraus gemacht. Hier sah ich das Fähnlein, wie es hinter dem Sarg daher ging, begleitet von den Abgesandten des StadtSt. Gallischen Artillerievereins, den Unteroffizieren in Uniform, die den Geist der speziell gepflegten Spezialwaffen von damals so drastisch repräsentierten. Die Aufrechten, alte naive gute Männer, in dem Verein der Stadtschule von ehemals unter dem Namen der Amistad vereinigt, woraus sie den Namen Amistand gemacht haben. Und es war so naive Trauer. Ja, das war ja die schöne Zeit, wo man bei uns glaubte, das Bürgertum der kleinen Leute sei die Welt. Und Hebbel war ein Angehöriger dieses Kreises nach der guten u. nach der schlimmen Seite hin. Wer wird der nächste sein, dem ich zum Grabe das Geleite gebe? Von Auer vernahm ich, dass er, der am gleichen Tag mit Barth verschied, an Rheumatismen gestorben sei, die sich auf den Kopf gezogen u. den Schlaganfall verursacht hätten. Das ist die Krankheit, die mir 
früher gedroht hat. Jetzt hoffe ich davon befreit zu sein. Die idealen Gedanken erhalten gesund. Das muss ich mir jeden Tag sagen.

Und jetzt kommt in einem Augenblick noch Langhard. Ich sehe ihn gerne noch. Wie es mit ihm gegangen, will ich Dir morgen berichten.

Gute Nacht, mein Lieb, hab immer lieb

Deinen allzeit getreuen

Eugen 


\section{März 1912}

\section{2: März Nr. 53}

[1]

B. d. 2. März 1912.

Liebstes Herz!

Heute Abend beginnen die Ferien. Am

Vormittag hatte ich noch Examen: drei Licentiaten:

Gerhard Ziegler, Sproll u. v. Schumacher kamen

m. c. l. durch. Nach her brachte ich die Sache Metry vor

u. fand die Zustimmung der Facultät. Und zum Schluss

stellte uns Spektabilität Gmür den neuen Prof.

Weyermann vor, der mehr als eine halbe Stunde

auf das Ende unserer Beratungen gewartet hatte.

Er brachte mir Grüsse von Alfred Schulze u. von

Diehl. Der junge Mann gefiel mir.

Am Nachmittag schrieb ich an Marieli, das einen

ganz freien Brief geschickt, $u$. nachher ging ich zu

Müller, um ihm zu sagen, dass ich für mein

«Gutachten» kein Honorar verlangen könne, wenn

das Departement nicht das System mir gegenüber

ändere u. die fixe Besoldung aufheben wolle.

Ich bekam durchaus den Eindruck, das sei bei Müller

nicht der Fall u. er versicherte mich, dass auch

Kaiser nicht so denke. Ich will das zu meiner Be- 
ruhigung nun auch annehmen. Die Zeit reichte hin, um dann auch Hoffmann einen Besuch zu machen, der mich warmherzig empfing.

Nun aber die Hauptsache - das letztgenannte ist zwar auch wichtig, u. ich muss ja erst noch sehen, ob ich mit den heutigen Schritten wirklich eine Klärung herbeigeführt habe -: In der letzten Nacht halb drei wurde ich durch einen Fall geweckt, es war mir, es sei ein Sessel umgestürzt. Bald darauf tröpfelte etwas, u. ich hörte ein Stöhnen. Ich stand auf, rief im Corridor hinauf, was es gebe. Ich glaubte, es sei dem Kleinen etwas begegnet. Sophie antwortete, es ist nichts. Anna kam im Hemd hervor u. ging hinauf. Es stellte sich heraus, dass Sophie an starker Übelkeit gelitten, aufgestanden war um Kaffee zu machen, dass sie ohnmächtig wurde u. zu Boden fiel. Sie warf einen Kessel mit Wasser um, das an der Decke meines Schlafzimmers Spuren erheblichen Umfangs eingezeichnet. Ich musste nur sagen, Gottlob, dass es nicht die Lampe war. Gegen vier Uhr war wieder alles ruhig. Aber die Sache ging mir sehr zu Herzen. Anna dauerte mich, wie wenn ich nun auch nicht zu Hause

gewesen wäre u. etwa Feuer statt Wasser aufgetreten! Ich durfte nicht daran denken! Ich stand wieder auf, schrieb eine Karte an Anneli Röthlisberger, u. ich sandte sie heute früh ab. Ich will das Kind morgen noch einmal sehen! Wenn es mir wieder den guten Eindruck macht wie am 7. Januar, so nehme ich es trotz Abratens der Frau Bösiger zu mir. In der Hoffnung, dass das auch für Marieli ein Segen sei. Es geht nicht mit der alten Anna, sie kann nicht mehr, u. Sophie ist eben doch körperlich u. geistig nicht ganz zuverlässig, obgleich sie seit längerem den besten Willen hat. So suche ich nach einer Hülfe. Ich bleibe nun ja doch in Bern u. in 
unserem Hause. Konntest Du darin sterben, so werde ich es auch können. Für Marieli aber wäre die

Schwester ein grosser Gewinn, wenn sie gut mit einander auskommen. Darüber muss ich mir noch eine feste Ansicht bilden. Fällt sie günstig aus, so will ich den Schritt wagen! Ich denke dabei namentlich an Dich, wie Du mit Marielis verstorbener Schwester Lina einen ähnlichen Plan nicht nur gebilligt, sondern mit Eifer verfolgt, 1899, bis dann alles in die Brüche ging. Vielleicht ist jetzt das Schicksal der Sache günstiger. Aber

es wird ein schwerer Entschluss sein, wenn es dazu kommt, u. die Wirkung auf Marieli ist ja ganz unsicher. Ich kann nur das beste hoffen! So werde ich also morgen, wenn Anneli kommt, weiter ein Stück Schicksal spielen müssen. Ich kann eben aus meiner enthusiastischen Natur nicht heraus. Ich machte mir heute Abend schon wieder Gedanken, ob ich mich Müller gegenüber zu offen ausgesprochen. Ich werde dieselben Zweifel auch mit dem Plane betr. Anneli nachträglich empfinden. Hilf mir das rechte bedenken, sei bei mir in der schweren Sache, mit der ich meine Ferien beginne! Ich drücke Dir im Geiste die Hand. An Deiner Güte u. Liebe will ich mich aufrichten u. das Rechte suchen. Auf dem, sursum corda! Es wird schon ein gutes Ziel sich erringen lassen!

In unendlicher Liebe

Dein getreuer Eugen 


\section{2: März Nr. 54}

[1]

B. d. 3. März 1912.

Mein liebstes Herz!

Anneli Röthlisberger ist also heute um zwei Uhr zu

uns gekommen. Es kam mich stiller vor, als das letzte

Mal u. zeigte eine grössere Ähnlichkeit mit Marieli, als ich das mir gedacht hatte. Aber ich hatte doch einen so guten

Eindruck von ihr, es trat so bescheiden u. anständig auf u. zeigte sich so lieb, dass ich mich, unter Zustimmung von Anna, entschloss u. ihm angeboten habe, mit Marieli zusammen bei uns zu wohnen, vorausgesetzt, dass Marieli sich dazu bekenne u. nicht etwa über diese Wendung unglücklich werden sollte. Anneli war sichtlich gerührt u. bewegt. Es schien sehr ängstlich zu werden, aber die Freude leuchtete ihm aus seinen lieben, guten Augen. Denn diese Augen machten mir wieder den gleichen Eindruck, wie das erste Mal, da ich das Mädchen sah. Damit ist nun auch entschieden, dass ich mit Marieli über die ganze Sache sprechen muss. Ich hoffe, dass die Mitgabe, indem es zugleich eine liebe Schwester gewinnt, ihm die Aufklärung weniger eingreifend gestalten werde. Wie ich das nun mache, weiss ich nicht. Ich handle impulsiv, wie seiner Zeit mit Sophie, u. überhaupt bei allen wichtigen Entscheidungen in meinem Leben. Mein Herz gehört eben doch diesen armen, braven Leuten aus dem Volk $u$. nicht den Grossen. Um so mehr bin

ich der Hoffnung, dass alles gut kommen werde. Hätte ich andere noch darüber befragt, etwa Walter B. oder jemand sonst, ich weiss, sie würden mir abgeraten haben, wie ja auch Frau Bösiger selbst zu diesen Abratenden gehört hat. Aber meine innere Stimme hat mich alle diese Ratschläge gering einschätzen lassen. Es musste jetzt so sein, weil 
eine andere Entscheidung mich nachher in innere Vorwürfe gestürzt hätte. Mag jetzt daraus werden, was da will. Wir werden schon zum rechten sehen können. Marieli hat eben doch an die feinern Damen der sog. Gesellschaft keinen Anschluss. Ich kann das in dem Verhalten zu Mariechen Rümelin, zu der Elisabeth Hoffmann beobachten. Martha Gemperle bildet eine Ausnahme, die ich mir aus der grossen Gutmütigkeit der Martha erkläre. Marieli würde sich eher noch den studierenden Damen gesteigerter geistiger Potenz anschliessen, wie Frl. Reineck. Allein auch damit finde ich für Marieli keinen sehr glücklichen Weg eingeschlagen. Ich wäre glücklich, wenn es in Anneli nun eine hingebende treue schwesterliche Freundin u. Begleiterin durchs Leben erhalten würde. Es wird im Hause nicht mehr so einsam sein, wie dies eben ohne Dich tatsächlich nun sich herausgestaltet hat. Das sind die Hoffnungen, die ich mit dem Schritt verknüpfe, u. dabei wird auch Marielis Gesundheit, wie ich bestimmt hoffe, gewinnen. Ich sagte Anneli, das noch mit uns zu Nacht gegessen hat, dass ich heute von ihm noch keine bindende Erklärung annehme.

Es soll zuerst mit seinem Bruder Fritz, an dem es sehr hängt, reden. Vielleicht hat dieser Bedenken. Ich würde das auch wohl begreifen, denn die Wandlung wird für Anneli sehr gross sein. Aus dem grossen Umtrieb in der Uhrenfabrik kommt es in die Stelle unseres Hauses. Freilich meinte es schnell, das werde bald überwunden sein. Aber es soll mir darüber noch schreiben, u. dann will ich sehen, wie u. wann ich mit Marieli darüber spreche. Zuerst dachte ich, Anneli könnte gleich kommen, damit während meiner Ferien-Abwesenheit Anna nicht allein wäre. Aber Anna schien mir das doch nicht zu wünschen, u. mit Rücksicht auf Marieli wird es auch sonst besser sein, wenn ich zuerst mit diesem spreche u. es heimkehren lasse. Dann würde Anneli etwa auf Anfang Mai zu uns kommen. 
Habe ich nun in Deinem Sinne gehandelt, liebe Seele? Ich hatte Dich die ganze Zeit vor Augen, als sässest Du leibhaftig neben mir u. nähmst Teil an unserer Besprechung. Ich weiss wie Du die Sache vor 13 Jahren mit Lina beurteiltest. Schon damals sahst Du voraus, dass Marieli an den Söhnen Augusts keine Freunde u. keine Freude haben werde. Und es war Dein, wie mein Wunsch, Marieli in seiner eigenen Verwandtschaft einen Anschluss zu suchen, der es vor späterer Vereinsamung schützt. War es in etwas egoistisch, dass wir das Kind zu uns nahmen, so ist diese Anknüpfung nun der Versuch einer Korrektur. Wie ich es nie u. nimmer ertragen hätte, dass Marieli den Familienplänen Augusts u. Pauls

geopfert würde, so gebe ich ihm nun diesen Ersatz. Das weitere sei Gott befohlen!

Am heutigen Vormittag habe ich die Lebensbeschreibung Natrat. Bählers gelesen. Der Mann wurde mir dadurch in seiner ganzen sympathischen Erscheinung bestätigt, obgleich der Herausgeber des Büchleins, sein Sohn, nicht gerade geschickt ist. Zudem bekam ich einen eigenen Einblick in die ganze ländliche Berner Familienart. Es sind wackere Leute, das zeigt sich Schritt für Schritt, u. sie haben sehr viel Geduld. Gestern vergass ich Dir anzufügen, was Langhard am Freitag Abend von mir wollte: Er zeigte mir die Adoptionsurkunde für Lisly u. Lydia.

Ich habe vom heutigen Tag einen solchen Eindruck, dass ich an eine Ferienreise gar nicht mehr denken mag. Es wäre mir jetzt am liebsten gleich alles ins Blei zu bringen. Aber lassen wir die Tage sich folgen. Sophie geht es jetzt wieder besser.

Heute vor 104 Wochen war ich zum letzten Mal mit Dir in Gesundheit zusammen. Da kehrtest Du krank nach Hause. Weshalb habe ich doch gleich am Bahnhof zu Marieli gesagt, oder gefragt, du habest Gürtelrose? Gibt es doch solche Seherzustände? Ich wusste ja gar nichts von der 
Art der Erkrankung. Und wie denke ich vom heutigen

Tag? Ich hoffe, ich bete, ich flehe!

Nimm im Geiste innigsten Kuss von Deinem

getreuen

Eugen

1912: März Nr. 55

[1]

B. d. 4. März 1912.

Mein liebstes Herz!

Als ich heute früh aufwachte, war mein erster Eindruck der einer innern Befriedigung über die gestern gefassten Entschlüsse. Möge es so bleiben.

Den ersten Ferientag verwendete ich dazu, das längst schuldige Gutachten für die Nationalbank zu entwerfen. Ich werde es morgen Siegwart diktieren. Sonst hatte ich viel Unruhe, obgleich, glücklicherweise die Post keine neuen Aufträge gebracht hat. Wie froh war ich, heute Abend nicht in die Nationalratssitzung gehen zu müssen. Um elf Uhr machte ich den schon für letzte Woche versprochenen Besuch im Atelier Weltis. Ich traf es gut. Er war eben auf der Treppe im Arbeitsmantel, er wollte zum Briefkasten u. ging mit mir zurück. Er zeigte mir das in den letzten zwei Wochen gemalte, fast fertige Bild einer Frau Dr. R. [Häuselmann?], einer Witwe, es scheint, dass ihm die lebensgrosse sitzende Figur sehr gut geraten ist. Daneben hatte er ein fertiges [Brugger?] Bildnis eines Geschäftsmannes in Muri, das er morgen abliefern will, auch dieses gefiel mir. Endlich zeigte er mir noch einige Skizzen, u. die Photographie der jungen Tochter des Stadtrats Nägeli, ein Bildchen, das mir sehr viel Eindruck machte. Er war sehr nett. Seine Frau kam von einem Ausgang noch zurück, solange ich dort war. Es sind beides herzensgute Menschen, aber er machte mir wieder den Eindruck eines sehr empfindlichen Gemüts. 
Mein Temperament wird sich ihm gegenüber gar leicht verfehlen können. Ich erinnerte mich ihm gegenüber in der letzten Zeit etwa an das Erlebnis mit dem Posthalter Zellweger in Trogen, der mit einemmal mir ganz entsetzlich feind wurde, ohne dass ich eine Ahnung von der Ursache hatte. Erst Frau Präsident Sturzenegger klärte mich dann auf darüber, ich hatte als Kronengesellschaftsvorsitzender in einer Comitteesitzung eine Bemerkung darüber gemacht, dass es unkorrekt sei, wenn Comitteemitglieder einer andern Gesellschaft (Hirschen) von den durch uns vorbereiteten Veranstaltungen für den «Kläusler» Mitteilung machten, und das traf eben den gutherzigen, aber so arg empfindlichen Posthalter. Er hat es mir niemals mehr verziehen.

Am Nachmittag kam Werner Kaiser zu mir wegen der Notiz im Departementsbericht wegen meiner Uebernahme der Revisionsvorarbeiten für den Rest des OR. Er war recht, Müller hatte ihn geschickt, mich noch zu befragen. Es wird nun wohl eine Notiz erscheinen, aber nicht mit der Anfügung, die Kaiser vorgeschlagen, nachdem diese Arbeit erst auf den Abschluss des Strafrechts fertig gestellt werden soll. Freilich kann ja von Seiten Kaisers nicht guter Wille vorliegen, indem er wohl gerne selber diese Arbeit besorgt hätte. Ich habe s. Z. mit ihm darüber gesprochen, bevor ich den Auftrag angenommen u. damals sprach er sich entschieden in dem Sinne aus, dass selbstverständlich ich diesen Auftrag

erhalten werde u. annehmen müsse. Dann kam Gottlieb Huber, zu einem freundlichen Ferienbesuch, wobei er mich aber wegen eines Anstandes mit einem Appenzeller Zettelschuldner consultieren wollte. Ich musste dem Schuldner Recht geben. Aber die Sache erinnerte mich wieder lebhaft daran, wie bei uns die Collegen nur zu einem kommen, wenn sie etwas haben wollen. - Endlich erschien der glückliche Licentiat 
Ziegler aus Schaffhausen, um Abschied zu nehmen. Ich habe den jungen Mann lieb gehabt, obgleich ich ihm ja in dieser Zeit gar keine Freundlichkeiten erweisen konnte. Im Winter 1908 / 9 u. 1909 / 10, da waren wir mit den Studenten sehr gesellig. August Gyr u. Paul gaben dazu den Anlass. Aber wie gering ist das Ergebnis unserer Freundlichkeit gewesen. August u. Paul sind abgefallen. Die damaligen Helden, wie Heft, Hans Trub, sitzen noch da u. leisten nichts. Ich habe ja auch früher darüber geschrieben, wie leid es mir jedesmal tut, wenn ich an die Mühe denke, die Du mit den jungen Leuten Dir gegeben hast. Und es war einer der ersten Fälle, wo Du die Geselligkeit als Mühe empfandest. Ich nahm es nicht richtig auf. Bei Dir aber war es auch nicht der Gedanke an die Nutzlosigkeit u. Gemütsverschwendung, was Dich zu dem innern Widerspruch brachte, sondern es war Deine mir ach unbekannte Ermüdung, der Aufbrauch Deiner Kräfte.

Die Nacht dachte ich viel an unser liebes Anneli. Mag sein, dass der Besuch des andern Anneli mich hierauf gebracht

hat. Wie waren wir beide so wenig auf die Elternschaft eingerichtet, innerlich u. äusserlich! Es fehlte jede Grundlage in einer schützenden Familie, Anna, die bei uns war, wirkte ja eher im gegenteiligen Sinne. Jetzt ist alles vorüber. Ich dachte auch an jenen gescheiten Idioten, der in Bern einmal an uns vorbeiging u. sagte: «Du häst e schöns Fraueli, heb em Sorg!» Und auch dies habe ich zu wenig beherzigt, sonst wärst Du noch bei mir. Oder wir wären beide miteinander aus der Welt gegangen.

Heute bemerkte mir jemand, es habe einer einen andern gefragt, wie alt ich wohl sein möge, u. die Antwort sei gewesen: «O der ist schon alt, der kann 55 Jahre haben». Eia, da haben wir ein combinierts Urteil. Alt u. doch nicht so alt, wie sie glauben, oder vielmehr nach Jahren viel älter! 
Wir haben die Tage häufig prächtige Abendbeleuchtung, so auch heute, während es gestern Nachmittag, wie beim ersten Besuch Annelis, regnete. Niemand kommt, mir zu sagen, sieh doch, wie schön sind die Berge! Und ohne Dich sagen sie mir auch so ganz anderes, als dies früher der Fall war. Mit den Ferienplänen wird es sich jetzt dann abklären. Schröder schreibt, er sei vom 11. ds. bis 4. April in Baden, u. ich will ihn, wohl gleich anfangs, besuchen. Zunächst noch Arbeit.

Und damit Schluss für heute. Ich umarme dich im Geiste u. bleibe

\section{Dein getreuer}

\section{Eugen}

\section{2: März Nr. 56}

B. d. 5. März 1912.

Meine einzige Liebe!

Wenn es alle Tage so ruhig wäre, wie heute, so würde es mir am wohlsten tun, die Ferien über zu Hause zu bleiben. Höchstens etwa den Besuch bei Richard Schröder in Baden würde ich machen u. Marieli in Mailand abholen. Und sonst zu Hause bleiben, Ordnung schaffen, am Buch schreiben, mit aller Musse, ohne jede Hast, u damit auch zu meiner Erholung. Nur der Tessiner Student Padroni war da, ein netter, schon alt aussehender Chiassoner, der mir viele Schmeicheleien sagte, in gutherzigem Ton. Ich konnte bis halbzehn Siegwart das Gutachten für die Nationalbank diktieren, schrieb vier Briefe u. begann dann in Hausers zweiter Ausfertigung der Dissertation zu lesen. War ich über diese im ersten Drittel ungehalten, so besserte sich meine Stimmung im Fortgang u. ich brachte es bis über die Hälfte. In dem ersten Drittel aber allerdings feierte mein kritischer Bleistift wieder Orgien. Es ist unglaublich, wie ungeschickt $u$. 
unlogisch der Verfasser hier wiederum geschrieben hat. Es ist, als könnte er die deutsche Sprache nicht besser als ein Fremder in blossen Schulkenntnissen, u. doch hat er die Aarauer Matura. Hoffentlich fährt die bessere Seite fort anzudauern bis zum Schluss. Dann will ich damit schliesslich zufrieden sein. Aber wie einsam ist es daneben mit Anna allein zusammen.

Der Tag, überdies voll Regen $\mathrm{u}$. Wind, verfloss in einer unglaublichen Stille. Und die regierte nicht nur äusserlich, sondern auch innerlich. Ich habe mit Anna trotz des langen Zusammenlebens so wenige Erinnerungen, worüber ich mit ihr als gemeinsam Erlebten sprechen könnte. Und das wenige nimmt bei ihr eben, wie Du wohl weisst, gar keine Gestalt an. Wie ganz ganz anders war das früher. Ich dachte das heute besonders bei der Stille bei verschiedenen Dingen. Die Clivia in der Verandah fängt an zu blühen. Seit 1901, unserem silbernen Hochzeitstag kam sie immer auf diese Zeit, Du sprachst mit mir darüber $u$. wir freuten uns wie Kinder. Und in den ersten Märztagen, da fragte ich Dich allemal im Scherz: Wie heisst es denn bei Schoffel «es war am ersten Märze», oder, «am zweiten, dritten, fünften», u. Du entgegnetest: Nein Lieber «es war am zwölften Märze». Alle alle diese Dinge klingen mir in Ohr u. Herz wieder, aber sie kommen nicht mehr, u. niemand hält mir diese Erinnerungen aufrecht. Da spürt man das Altwerden u. Einsamsein. Bei mir ist diese Vereinsamung nun gerade in der Zeit eingetreten, da man nach dem natürlichen Lauf der Dinge lieber zurück - als vorwärts schaut. Ich sollte jetzt tüchtig in die Zukunft greifen, aber ich vermag es nicht mehr, u. die Vergangenheit ist mir nichts als eine lange lange Wehmut.

Sehr gefreut hat es mich, dass beide Ratspräsidenten in ihren Eröffnungsreden gestern des Inkrafttretens des Zivilrechts

[3]

warm gedachten $u$. dabei - wie das besonders im Ständerat von Calonder geschah - meine Verdienste betonten $u$. nochmals 
Dank aussprachen. Wenn ich jetzt so still zu Hause sitze während der Bundesversammlung, könnte mir ja schon hin u. wieder der Gedanke kommen, eigentlich gehörte ich jetzt ins Rathaus. Allein mächtig wird dieser Gedanke in mir entschieden nicht. Dann einmal tut mir die einsame Ruhe - wenn ich sie nur haben kann - so wohl, u. anderseits stand ich ja immer unter dem Eindruck, dass ich kein gutes Mitglied der Bundesversammlung sei. Ich war auf die Geschäfte im Allgemeinen viel zu wenig präpariert, ich nahm an den Beratungen viel zu wenig innern Anteil, ich fühlte mich viel zu sehr von besondern Auffassungen beherrscht, die mir zu den herrschenden Politikern eigentlich in Gegensatz hätten bringen sollen, denen ich aber doch nicht Ausdruck geben mochte, um nicht noch mehr Zeit u. Stimmung dieser Aufgabe opfern zu müssen. Gerade jetzt würde es mir wieder ganz so ergehen, wie so viele male früher. Ich begreife es nicht, dass die Deutschschweizer jetzt in der freisinnigen Partei einen dritten Welschen wählen wollen, nur aus Besorgnis, dass andernfalls die Neuenburger, Genfer, Waadtländer aufbegehren würden, u. nicht etwa deshalb, weil die Welschen einen besonders geeigneten Kandidaten hätten. Und sie bedenken nicht, dass sie mit dieser Verwelschung die Anteilnahme der deutschen Schweiz an dem Bundeswesen allmählich abschwächen u. ins Gegenteil verkehren. Die deutsche Schweiz gibt ihrem Ärger nicht lärmenden Ausdruck, wie das von Seiten unserer welschen Brüder geschieht. Da wird nicht

gleich gedroht, dann machen wir nicht mehr mit. Aber das Unbillige wird umso tiefer empfunden $u$. wirkt umso länger nach. Wir wollen doch nicht von einer Minderheit regiert werden, wir wollen doch deutsch bleiben. Nun, die Wahl hat noch nicht stattgefunden. Vielleicht kommt es noch besser.

Ich schliesse den ruhigen Tag mit einem innigen Gruss u.

Kuss. Halte fest zu mir, wie ich Dir immerdar verbleiben werde

\section{Dein getreuer}


[1]

B. d. 6. März 1912.

Mein liebstes Herz!

Der heutige Tag war nicht so ruhig, wie der gestrige.

Pressante Briefe, unter andern einer an Oser wegen

seiner nun auftauchenden Candidatur für das Bundesgericht, eine amtliche Anfrage etc. beschäftigten mich. Dazu kamen am Nachmittag ein langer herzlicher Besuch von A. Welti, zwei Studentenconsultationen in Dissertationssachen $u$. in Berufsangelegenheiten, ein Besuch Walter Bs. Immerhin konnte ich die erste Niederschrift des Gutachtens für die Nationalbank durch Siegwart zur Reinschrift bereit machen u. die Dissertation Hausers zu Ende lesen. Sie gab mir in dem letzten Drittel wieder zu vielen Ausstellungen Anlass, so dass ich dem Verfasser nicht gerade einen für ihn freudigen Brief schreiben musste. Ich bin nun gespannt, was er antworten wird.

Sehr erfreut hat mich ein Brief Marielis. Er ist flott geschrieben $u$. es spricht sehr viel Verständnis für seine jetzigen Gelegenheiten daraus. Auch von Frau Rita schreibt es nun sehr nett, u. mit Montani selbst scheint es gut auszukommen. Es erkennt nun doch mehr u. mehr, dass es in Mailand sehr viel lernen u. vom Leben erkennen $u$. erfahren kann $u$. das wird auf seine

ganze Ausbildung von grossem, wie ich hoffe, günstigem Einfluss sein. Als gutes Zeichen nehme ich es auch, dass es mir einige Zeilen über seinen Herzenskummer betr. Abbühl angefügt hat. Ich werde ihm darüber einige Worte schreiben. Wenn wirklich jetzt die Neigung erst erwacht ist, so muss man freilich das gute Kind dafür bemitleiden, dass 
es nicht an dem jungen Mann letzten Sommer festgehalten hat. Wie vieles wäre ihm erspart geblieben! Aber ich bin nicht sicher, ob es sich nicht auch jetzt wieder bei ihm um blosse Gefühlsgährungen handelt, die noch nicht zur Abklärung gekommen sind.

Zum Lesen von irgend etwas Schönem bin ich heute nicht gekommen. Im übrigen waren gestern $u$. heute von jenen Dir an mir so wohl bekannten Ferientagen, wo ich keinen Schritt vors Haus setze. Das tut so wohl, derart in den vier Wänden zu bleiben $u$. alles an sich herankommen zu lassen, ohne sich ausgeben zu müssen. Freilich die Besuche haben mich ja zum Sprechen genügsam veranlasst. Mit Welti kam ich vom ersten ins hundertste. Eigentlich Neues habe ich nicht vernommen, was ich Dir zu berichten hätte.

In der letzten Nacht hatte ich wieder einmal jenen schon mehrmals wiedergekehrten Traum, in welchem ich in einem grossen Saal ganz zu ungewohnter Stunde Colleg lese. Und dabei sind dann immer allerlei Überraschungen betreffend die Hörer u. den Gegenstand des Vortrages. Ich

spreche da über allerlei mir fremde Gebiete u. empfinde Angst, ob ich es auch recht mache. Dies mal kam dann ein Kolleg an fremder Universität dazwischen, wobei ich mir sagte, jene Extrastunden hätten mir nicht etwa nur geträumt, sondern sie seien von mir wirklich mit Erfolg gehalten worden. Ich las im Buch mit grossen Einschreibelisten u. etwas wie ein Gefühl, ich hätte dem verstorbenen Onken Concurrenz gemacht. Wie ich aufgewacht zu sein glaubte, sagte ich mir, diesmal sei es aber kein Traum gewesen. Dann war es mir, es sei doch richtig, dass Kobolde uns umschweben, die unsichtbar uns allerlei Schabernack spielen. Mit dem Schreibtischschlüssel, der gestern plötzlich seinen Dienst versagte, sei es auch so gewesen. Ein Baumwöllchen aus meiner Tasche hatte sich merkwürdigerweise in das enge Kanönchen des Schlüssels versteckt u verhinderte den Gebrauch des Schlüssels. Das habe einer der Kobolde gemacht. Solche Phantasien verfolgten mich die Nacht an einem fort, ohne dass sie 
mich ängstigten oder sonst plagten. Es schien mir, es müsse eben so sein. Merkwürdige Zustände!

Von Anneli habe ich noch keinen Bericht. Es fährt fort, mir als ein besonders liebes Geschöpf im Gedächtnis zu stehen, $u$. ich werde immer mehr gespannt auf seine Antwort. Möge sie richtig ausfallen $u$. dann mit Marieli sich ein gutes Fundament künftiger Tage schaffen lassen. Ich habe so sehr den guten Willen dazu, aber es ist so schwer das Rechte zu erkennen u. zu verwirklichen. - Anna scheint dem Plan jetzt ganz gewogen zu

[4]

sein. Sophie u. ihr Kleiner sind wieder normal. Der Kleine hat sich ein Stück seines Stirnhaares geschnitten. Er sieht drollig aus. Marieli findet übrigens, er sei gesitteter als der ältere der Montani Knaben.

Und jetzt auch Schluss von diesem Tag! Gute, gute Nacht.

Dein allzeit treuer

Eugen

1912: März Nr. 58

[1]

B. d. 7. März 1912.

Meine einzige Liebe!

Heute hatte ich wieder Besuche. Den Vormittag brachte mir Siegwart die Abschrift des Gutachtens - ach, wie hast Du Dich hingegeben für solche Abschriften, die ich jetzt von fremder Hand besorgen lassen muss. - Dann kam Guhl mit einigen Fragen. Vorher aber schrieb ich einige kurze Antworten auf Anfragen $u$. fertigte einen Bericht für das Departement aus. Ich glaubte auch, heute mit den Arbeiten beginnen zu können u. las einen Paragraphen, den Siegwart nach meinem Schema vor einigen Wochen schon ausgefertigt, $u$. den ich recht annehmbar gefunden, 
mir zu grosser Beruhigung. Am Nachmittag wollte ich fortfahren in dieser Arbeit. Da, um 2 Uhr kam Sophie u. sagte, eine Frau Dr. Heim sei im Salon, u. es war Marie, die von Goldiwyl um 1 Uhr hierhergekommen u. vorher noch schnell ein Pflegekind besucht hatte, das sie in Bern untergebracht. Ich war bei ihrem ersten Anblick ganz erschrocken. Sie kam mir ganz ausserordentlich gealtert u. hinfällig vor. Nachher belebten sich ihre Züge. Sie war herzlich, aber ganz in ihrem Wesen. Ich vernahm, wie es Albert gehe, wie seit langem er $u$. Arnold miteinander in einem anhaltenden Zerwürfnis gelebt. Wie Albert es schon so schwer getragen, als Helene, anstatt bei ihm

zu bleiben, in das Schwesternhaus eingetreten, was Du s. Z. auch so unnatürlich gefunden hast. Daneben wieder ein Rühmen von Arnold u. Helene u. eine wenig verhehlte Ablehnung Alberts selbst, der jetzt fast ebensoviel zu tun habe, wie vorher $u$. sich über seinen Nachfolger ärgere, der so gar nicht nach Alberts Sinn die Aufgaben, die jetzt gestellt seien, an die Hand nehme. Aber die Entlassung aus dem Professorat sei aber doch notwendig gewesen, vertraute Schüler Alberts haben es gesagt, dass er in kurzer Zeit wohl in einem Lehramt nicht mehr genügt hätte. Es scheine ihr, sagte Marie, dass Albert etwas von der Melancholie in sich habe, an der Sophie leide. Und sie selber treibt sich an ihren Aufgaben empor mit einem Eifer, der ihre Kräfte anspornt, auch wenn sie nach allem Anschein zusammen zu fallen drohen. Also das alte Bild: Kolossale Zusammenfassung des Willens, Übertreibung der Ziele, Überschätzung des eigenen u. der Freunde Könnens. In diesem sind gewiss Albert u. Marie lebenslang einig. Aber, wie die alte Mutter Heine bei ihrer Verlobung mir sagte, sie schaffen sich nicht wechselseitig Ruhe u. Stärkung, sondern sie treiben sich an u. reiben sich auf in eitler Willensbetätigung, ohne die Tiefe, die eigentlich dem Bau als Fundament dienen sollte. Nun ja, was kann man dagegen sagen, 
wenn das doch bis in ihr jetziges Alter angehalten hat! Nur, waren sie dabei am Ende wirklich glücklicher in der Be-

tätigung $u$. in ihrem inneren Empfinden? Das kann ich nicht finden $u$. konnte es auch heute nicht wahrnehmen. Albert soll mich anfangs nächster Woche, meinte Marie, besuchen. Das würde mich freuen. Ich begleitete dann Marie, die nicht länger bleiben wollte, zu Frau Staub, die jetzt mit ihrem Mann in der Pension Stamm, oben am Schänzli, wohnt, indem sie ihren eigenen Haushalt, weil alle Kinder weggezogen, aufgegeben haben. Frau Staub war aber nicht zu Hause u. so fuhr ich mit Marie noch an die Luisenstrasse, wo sie bei einer Bekannten, die sie in Goldiwyl kennen gelernt, Besuch versprochen, nämlich bei Frau von Arx-Bolert, die vor neun Jahren bei mir als Handelsschülerin Kolleg gehört. Um vier Uhr waren wir dort. Ich verabschiedete mich, ohne ins Haus hineinzugehen. Marie wollte um 5.40 von dort nach Hause, so dass ich sie nicht mehr sehen konnte. - Wie ich zurückkam, war Zürcher eben herangekommen. Er schien mir auch nicht munter. Es geht ihm mit dem Schlafen nicht gut. Es scheint sein Herz macht ihm Sorge. Er erwartet aber auf das Frühjahr Besuch aus Berlin, von Thea u. der kleinen Enkelin. Er verspricht sich davon viel Stärkung, wie auch Marie meinte, wenn im Herbst Arnold $u$. Helene wieder zu Hause sein werden, so würde bei ihnen auch der Friede u. die Ruhe wieder einkehren. - Kaum war Zürcher fort, so kamen Frau Oberst Hebbel u. Frau Gemperle. Sie war diesmal wieder in besserer Stimmung u. erzählte mir, dass sie von Marieli ein sehr liebes Briefchen bekommen, auf das sie

bald antworten werde. Sie hatte offenbar gar keine Ahnung, wie mich ihr Benehmen bei meinem letzten Besuch betrübt hatte.

Sie [sic!] ist der Tag vorüber gegangen. Ich fühle mich heute müde. Ich spüre doch, dass ein Ausspannen nötig wird. Warten 
wir ab, welche Berichte von Rümelin, u. welche von

Anneli einlaufen. Ich sage schon «Anneli», als wäre das

liebe Geschöpf für mein Haus, für unser Haus, sicher gewonnen.

Welche Überraschungen werden von da her noch zu erwarten

sein?

Gute, gute Nacht! Bleib immerdar bei

Deinem getreuen

Eugen

\section{2: März Nr. 59}

[1]

B. d. 8. März 1912.

Mein liebstes Herz!

Ich war heute in einer unbestimmten Unruhe, hatte wieder mehr Husten u. fühlte mich müde. Anna meinte, ich habe mich gestern, als ich Marie ohne Überrock an die Luisenstrasse begleitete (freilich hin u. her im Tramm) erkältet. Ich weiss es nicht. Heute Abend fühle ich mich schon wieder besser, aber die Unruhe ist geblieben. Ich schreibe sie allerlei Gedanken u. Eindrücken zu. Am Vormittag brachte ich das Gutachten für die Nationalbank Hr. Hafner, dem Sohn des Bundesrichters, für den Du mit Recht so grosse Sympathie gehabt hast. Er ist Rechtskonsulent der Bank. Dann war ich bei Mülinen, recht nett. Auf der Strasse traf ich Gaston v. Muralt, unsern vornehmen Nachbar von der Alpenstrasse, dessen Sohn neulich gestorben, u. condolierte ihm. Da vernahm ich, dass auch dieser, der Jüngste, der in Dresden studierte $u$. vor dem Ingenieurexamen stand, durch einen Unglücksfall das Leben verloren. Der mittlere stürzte vor einigen Jahren am Blüemlisalphorn ab. Und zwar erzählte mir der Vater, der lebensfreudige Candidat der mit Freude dem Examen entgegengesehen, sei mit einigen Kameraden bei einem Arbeitertumult 
mit der Browningpistole in der Tasche Abends aus gewesen. Auf seinem Zimmer aber sei, aus unbekannten

Gründen, als er allein gewesen, die Pistole losgegangen, die Kugel habe von der Achsel her die Lunge, den Magen die Eingeweide durchbohrt. Dennoch habe man mit einer Operation ihn wieder in einen erträglichen Zustand gebracht u. sie hätten der Heilung hoffnungsvoll entgegen gesehen. Da sei aber nach acht Tagen eine Peritonitis dazu getreten, der der arme Leidende erlegen. Man könnte solches nicht ertragen, fügte er bei, wenn man nicht wüsste, dass was geschehen, ihm u. ihnen allen nur zum besten diene. Das ist grosse Resignation, $\mathrm{u}$. der Vater trug diese dann auch wirklich auf seinem Gesicht. - Die Mittagspost brachte eine Karte von Kleiner, worin er sich auf morgen zum Mittagessen ankündigt, in etwas patzigem Ton, aber es ist ja nicht bös gemeint. Und dann kam die Antwort von Anneli Röthlisberger, französisch, u. mit der Zusage, dass es zu uns kommen wolle. Nun ist es geschehen, was ich in einem Impuls mir ausgedacht, der mir wieder Vielerlei Schweres bringen kann. Aber, aber ich hoffe, ich hoffe! Was mir am Herzen liegt, das ist vornehmlich doch, für Marieli eine andere Atmosphäre zu schaffen. Es soll lieber werden, u. darauf rechne ich nun, wenn es in dem täglichen Umgang mit einem wirklich lieblichen Wesen als seiner Schwester kommt. Ist das in Deinem Geist? Gewiss, liebe Seele, ich weiss es, es wird gut kommen. Du wirst in Deinem Geist der Liebe u.

Dankbarkeit Marieli leiten, dass es zur Schwester in ein gutes Verhältnis kommt. Möge das auch für sie ein Segen sein. Es muss doch wieder irgendwo Wurzeln fassen, $u$. so sei nun das Beste in unserer Hoffnung! Es muss gehen, $u$. 
ist jetzt doppelt notwendig, nachdem mit den Söhnen Augusts ja doch keine Beziehung mehr möglich sein wird.

Nach Tisch war Rossel bei mir, der jetzt definitiv als Kandidat für das Bundesgericht aufgestellt ist. Er war so freundlich als nur möglich. Ich weiss noch nicht, was ich davon halten soll. Kann sein, dass es nur deshalb ist, weil er mich, wie er sagte, bei schwierigen Fragen etwa consultieren möchte. Das wäre mir ja ganz recht. Aber eine sehr traurige Nachricht vernahm ich dann von ihm: Soleilles ist gestorben! Und das muss ich von ihm vernehmen, u. er hat es in dem Genfer Journal u. in der Gazette de Lausanne gelesen. Er meinte, schon vor sechs Tagen. Dann aber sandte er mir nachher die beiden Blätter, sie datieren vom Mittwoch. Also kann vielleicht doch noch eine Anzeige aus Paris für mich eintreffen. Der Verlust tut mir leid. Ich hatte durch Soleilles eine so schöne Beziehung zu den französischen Juristen. Nun ist auch sie dahin, u. eine andere wird sich nicht mehr anknüpfen lassen. Bei der Mitteilung Rossels fiel es mir auf, wie ein Schatten von Schadenfreude über sein Gesicht lief, als er sah, dass ich von Soleilles Tod noch gar keine Nachricht hatte. Oder habe ich mich getäuscht?

Ich bleibe ein unverbesserlicher Optimist in allen meinen

Plänen, die ich mit so grosser Freude anpacke, um dann immer wieder zu sehen, nachträglich zu sehen, wie schwer die Ausführung ist. Klar man muss doch einmal etwas an die Hand nehmen, sonst ist das Leben doppelt leer. Und ich besonders werde ganz untüchtig, wenn nicht ein enthusiastisches Gemüt mich vorwärts treibt. Also vorwärts auch jetzt. Hoffen wir, hoffen wir, es wird doch alles noch erträglich werden! Und Du, liebe Seele, hilfst mir dabei! Ich las heute ein wenig englisch. Ich ordnete alte Akten. Morgen will ich mit Siegwart das fortsetzen. Er ist ein guter Mensch, u. ich hoffe er bleibt mir noch 
lange erhalten. Heute nickte er mir freudig zu, als ich

ihm von dieser Hoffnung ein Wörtchen fallen liess:

Und jetzt mein Gruss u. Kuss.

Ich bleibe

Dein getreuer

Eugen

1912: März Nr. 60

[1]

B. d. 9. März 1912.

Meine liebste Lina!

Heute habe ich bis halb elf Uhr mit Siegwart die Akten der Zivilrechtsberatungen neu geordnet $u$. dabei bin ich auf manches gestossen, was alte Erinnerungen wach rufen musste. Damit aber warst immer Du, du zu allernächst verknüpft. Es wurde mir wieder gegenwärtig, wie Du mich für die Kommissionssitzungen auszurüsten pflegtest. Mir wurde erwogen, was ich unternehmen soll, wie alles hübsch geordnet u. eingepackt, wie halfst Du mir die Bücher u. Akten einzuwickeln u. in die Kiste zu verpacken. Wie manches traute Wort, wie mancher Scherz, wie auch dann u. wann ein kleiner Ärger!, u. an alles das dachte ich heute mit treuer Erinnerung u. es wurde mir weh im Gedanken, dass Du mir nicht heute halfst, diese Sachen neu zu ordnen. Ich sagte auch Siegwart, wenn Du noch bei mir wärst, würdest Du hinter mir stehen u. alles hübsch vom Staub reinigen. Jetzt liegt halt alles so da, niemand hat den Eifer, die Zeit, den Sinn dafür, in solchen kleinen Sachen Ordnung zu schaffen. Ob ich in Anneli hierin ein Hülfe bekomme? Hie u. da denke ich, ja, dann kommen wieder Zweifel. Der heutige Brief Marielis war wieder viel kälter als die letzten. Es hat für u. über Montanis kein herzliches Wort. Dagegen von der Frau Rittener weiss es manches zu sagen. Es ist halt 
mit ihm immer so: was man gern hätte an ihm, das geschieht nicht oder gegen die Neigung, $u$ das andere tritt hervor, wie zum Trotz. Doch ist vielleicht der nächste Brief wieder besser.

Um 12 Uhr kam Kleiner. Er blieb bis nach 3 Uhr u. ich hatte Freude an ihm. Er ist entzückt von seinem jetzigen Physikkollegen dem Holländer Debye, den sie aber wahrscheinlich bald wieder verlieren. Von den Seinigen berichtete er nur Gutes, aber gar nichts von Lislys Verlobung, die er im Herbst auf Weihnachten vorausgesagt hatte. Er verreist heute Abend wieder nach Zürich.

Nachher hatte ich den Candidaten Hauser bei mir, der aus sich selbst den Weg der nochmaligen Umbesserung seiner Dissertation wählte, was mich freute. Hoffentlich bekommt sie jetzt dann endlich annehmbare Gestalt u. Inhalt. Ferner war Direktor Winkler ein Stündchen da, u. er meinte, ich soll nächstens zu ihnen kommen, mit Hoffmanns. Ich sagte nicht ab, werde aber nicht gehen. Er wusste viel von allerlei Anlässen u. Festen zu erzählen, er ist ein Schwerenöter.

Endlich besuchte mich Nationalrat Eisenring, um mich in einer Rechtsfrage zu consultieren. So ist der Tag zur Neige gekommen ohne eine Stunde stiller Beschaulichkeit. Jetzt muss ich zu Hoffmanns, wo ich gern hingehe. Wie es war will ich dir morgen berichten. Denn es wird wohl gegen Mitternacht gehen, wenn ich den weiten Weg zu Hause

zurückgekehrt u. morgen erwarte ich Reichel. Kleiner wollte für morgen nicht bleiben, weil Alfred seinen 22sten Geburtstag feiert. Da konnte ich nichts dagegen sagen.

Wichtige Nachrichten sind keine gekommen. An Soleilles muss ich immer denken. Es tut mir so leid, von den Seinen nicht unter die Freunde gerechnet worden zu sein, denen eine spezielle Anzeige gewidmet wurde. Ich habe ihn wirklich verehrt $u$. lieb gehabt $u$. freute mich über diese freundschaftliche u. wissenschaftliche Beziehung. Aber so geht es: man ist der 
Einschätzung auch bei den Nächsten niemals sicher. Man weiss nie, was auf dem Grunde ruht!

Doch nun muss ich abbrechen $u$. mich für Hoffmanns rüsten. Vielleicht ist von dort noch etwas zu berichten. Sonst für heute gute, gute Nacht!

\section{Dein getreuer}

Eugen

Ich war alleine bei Hoffmanns. Es war ein herzlicher Abend. Hoffmann hat zwar nicht viele Geheimnisse ausgegraben, aber ich hatte doch wieder einmal Fühlung mit ihm. Frau Hoffmann war wieder eine feine Frau u. das Spiel mit ihrer geigenden Tochter war recht stimmungsvoll. Sonst wäre ich auch nicht so lange geblieben, bis über elf Uhr. Auf dem Heimweg begleiteten mich allerlei Gedanken. Wie anders wäre es! Und wie wird es werden! Ich konnte bei dem Gang durch das Gryfenhübeli u. die Marienstrasse mir alle die Erlebnisse vorstellen, die uns dort zusammen bedrückt u. beglückt. Die Gegend ist freilich anders, ist fremder geworden.

Ich musste die Häuser mir weg denken u. grüne Matten an ihre Stelle setzen, wenn ich daran dachte, wie ich die ersten Sommer nach dem Abendkolleg durch die englischen Anlagen nach Hause schlenderte u. auf dem Bänklein nächst der Birshalde ausruhte, $u$. wie Du mich dann von der Terrasse aus erspähtest u. herunter kamst, so dass wir Hand in Hand der «Burg» zuwandern konnten. Und wir waren so einig, so glücklich. Aber ich will mit ungetrübter Freude erinnern an das Glück, das doch mein eigen war $u$. mir in dem Gedanken eigen bleibt. Das kann mir kein Schicksal rauben! Nun ist zwölf vorbei, ich geh zur Ruh, nochmals gute, gute Nacht! 
B. d. 10. März 1912.

Mein liebstes Herz!

Ich stand heute unter dem Eindruck des gestrigen Tages mit seiner Aufregung $u$. fühlte mich am Morgen, ja in der Nacht schon, nicht wohl. Meine Nerven waren sensibel, ich hatte Unlust etwas zu tun. So verstrich der Morgen mit Zeitung lesen u. im Garten spazieren. Walter B. war eine Stunde da u. wir plauderten über Rechtsphilosophisches. In der Nacht hatte ich einen Aufsatz überdacht, den ich für das Jahrbuch schreiben könnte, über soziale Gesinnung, u. das ging mir, wie ja früher schon hie $u$. da, durch den Kopf, aber es kam nichts dabei heraus. Nach Tisch schlief ich fest ein. Vor zwei aber kamen die beiden Richter Reichel, der Bundesrichter u. der Oberrichter. Zuerst tranken wir auf der Verandah den schwarzen Kaffee. Dann gings an die Kantate, die mir ja A. Reichel heute vorzuspielen kam. Ich schlug das Harmonium vor, u. der Oberrichter brachte es auch recht nett fertig, das Tongedicht vom Blatt zu spielen. Alex sang dazu. Einige Partien fand ich sehr hübsch. Nachher sassen wir in der Stube bei einem Glas Wein, Chablis, u. die Cantate wurde vom Componisten selbst nochmals auf dem Piano gespielt. Auch da fand ich einzelnes recht hübsch, wie den Chor der [Pilgrims?]

u. der Rezitative «So war es einst.» Ich bin froh, das Stück nun auch zu kennen $u$. kann mir gut vorstellen, wie es gewirkt hat in Luzern. Und von Alex war es freundlich, dass er mir die Composition derart vorgeführt hat. Wir plauderten dann noch viel, woraus ich nur einiges hervorheben will. Einmal corrigierte Alex seinen Brief betr. die Collision meiner Ferien mit seiner Abwesenheit von Lausanne u. forderte 
mich auf, ihn diesen Monat noch zu besuchen. Am 22. April hat seine Tochter Hochzeit. Dann nannte er als die sechs Richter, die gegen den Antrag Jägers in Betr. des Eigentumsvorbehaltes dem Departement zustimmten: Weiss, Stooss, Schurter, Kirchhofer, Ursprung u. Ostertag. Er selbst war bei Jäger, wusste aber nichts von dessen Intrigue gegenüber Hoffmann. Weiter vernahm ich, dass der Urgrossvater Reichel seinen Geschlechtsnamen geändert. Darum haben sie unter den Reichels in Sachsen gar keine Verwandte. So erzählte der Oberrichter, während Alex nichts hievon wissen wollte u. die Mitteilung offenbar ungern hörte. Das spricht ganz deutlich für den jüdischen Ursprung. Übrigens war auch die Heirat mit einer hohen Adeligen erwähnt, deren Ehe nachträglich nicht habe nachgewiesen werden können, weil die Akten in Ossa bei Danzig verbrannt seien. Aus Anlass der Strafrechtskommission erinnerte mich der Oberrichter an einen Conflikt mit Stooss, den ich faktisch ganz vergessen hatte. Er meinte,

die Entlassung Stooss aus der Kommission sei eine verspätete Rache des Schicksals. Wofür? Ja, Stooss habe mich doch im ersten Jahr meines Hierseins im Juristenverein so unschön angegriffen. Ach, das hatte ich jetzt die langen Jahre absolut nie mehr in die Erinnerung bekommen. Aber es ist richtig, u. hat mir s. Z. sehr weh getan. Es kamen dann aber die Jahre des Erfolges. Sei es so oder anders gewesen. Stooss dauert mich, dass er Zürcher weichen muss. - Aufgefallen ist mir, dass beide Reichel absolut kein Wort der Sympathie u. Anerkennung hatten. Ihre Gegenwart war genug, u. das ist ja auch recht. Alex scheint mit Favey gut zu stehen, den ich gerade am wenigsten schätze. Jäger soll sich wieder in einem Sanatorium befinden. Was da so mit erzählt wurde, lässt mich in keiner Weise bedauern, nicht in das Gericht mich versetzt zu haben. Es ist besser hier u. man kann mehr wirken. Wie das aber mit Antipathien u. Sympathien durchgreift, das zeigt auch der fernere Umstand, dass Reichel von Rabel gut gesprochen, er kennt aber seine neuen Publicationen gar nicht. Überhaupt scheint Reichel wenig 
zu lesen. Er träumt, musiziert, u. findet, er sei in der Beurteilung einzelner Fälle doch ein ganz potenter Kerl. Nun, der Sonntag Nachmittag brachte mir doch allerlei Gutes. Es ist mehr das Fremdartige, was mich fern hällt u. innerlich beeinflusst im Verkehr mit Reichel. Sonst kann ich ja nur sagen, dass sie mir wert sind, wie sie es verdienen.

[4]

Und nun wird heute die 101. Woche verstrichen sein seit Deinem Hingehen! So kurz, u. doch so lang! Und wie lange wird es dauern, bis sich alle die verworrenen Pfade auch bei mir in das eine grosse Thor zusammen finden, durch das ich Dich wieder erreiche! Vorwärts also! Ich mag heute nicht mehr weiter denken. Ich geh jetzt dann gleich zur Ruhe. Meine Gedanken umfassen Dich, ich halte Dich fest in schmerzlicher Hingabe an das was war $u$. was immer noch sein könnte! Aber alles was ist, geschieht aus Notwendigkeit. In diesem Tempel müssen wir leben.

Dein allzeit treuer

Eugen

1912: März Nr. 62

[1]

B. d. 11. März 1912.

Mein liebstes Herz!

Obgleich ich die letzte Nacht recht ausgeschlafen, geriet ich gleich am Morgen in eine wenig erfreuliche Stimmung, deren ich mich selbst schäme. Die Vormittagsbeschäftigung, Ordnen der Akten aus der Beratungszeit, steigerte meine Aufregung schon aus körperlichen Gründen, ich bin mich an derartige Hantierungen so wenig gewöhnt. Siegwart hatte anderes zu ordnen. Nun, der Grund der Missstimmung war, dass in den Morgenzeitungen stand, der Bericht des Justiz- 
departements besage, Prof. Huber habe sich vom Bundesrat bestimmen lassen, die Ausarbeitung des Revisionstextes des OR. mit Botschaft zu übernehmen. Das ist so ungeschickt gesagt. Kaiser hat es redigiert. Er ist doch nicht ein Intrigant? Und Müller hat unterschrieben. Es ist eine dumme Wendung, die mir die Sache von vorneherein vergellt. Ich habe ja lange geschwankt, ob ich die Arbeit übernehmen soll, gerade weil ich schwankte, ob nicht Kaiser darauf spitze. Der versicherte mich freilich auf direkte u. indirekte Anfragen hin, mehrfach, dass selbstverständlich ich diese Arbeit übernehmen müsse. Hat er im innersten Herzen am Ende doch einen andern Gedanken $u$. Wunsch gehabt? Nun, es ist jetzt so. Dann sandte mir Altherr mit der Post eine Nummer des von ihm redigierten Schweizerbauern, der ich entnahm, dass die Tagwacht

darüber gehöhnt habe, dass der Nationalratspräsident wieder einmal, in seiner Eröffnungsrede, den «Zivilrechts Huber» verhimmelt habe. Die «Zür. Post» soll darauf derb geantwortet haben. Gewicht messe ich den Schreibereien der Tagwacht nicht bei. Aber die Begleiterscheinung ist nicht unerfreulich. Dazu ist die Nachwirkung des kalt höflichen Benehmens der beiden Reichel von gestern mir noch im Gefühl gelegen. Ferner beunruhigte mich das Ausbleiben einer Nachricht von Rümelin. Ein Briefchen von Marieli an Anna, worin es meint, es wäre doch auch schön gewesen, mit Lini am Strand von Nervi zu spazieren, trug zur Erheiterung auch nicht bei. Kurz, ich war in einer wenig erfreulichen Verfassung. - Ich machte am Nachmittag meine Rechnung, nicht ohne die Folgen der innern Unruhe am Zahlenhandhaben zu verspüren. Eine Consultation von Frau Barth, durch Peter ausgeführt, u. damit zusammenhängend der Besuch von Notar Greyerz, der sich die Scheiben ansehen wollte, besserten meinen Zustand etwas. Endlich gegen Abend brachte ich es noch fertig, zwei geschäftliche Sachen mit längeren Schreiben an das Departement zu erledigen. Zwischen hindurch schlief ich eine halbe Stunde, vor lauter Ärger. Jetzt ist es Abend u. Bettzeit geworden. Ich bin froh, dass dieser Tag zu Ende ist. 
Ich könnte nicht sagen, dass mich heute ein einziger besserer Gedanke erfrischt hätte. Ich fühlte mich leer. Ist dies das Zeichen, dass ich ausspannen muss? So geht es doch nicht weiter. Aber

wohin soll ich? Mit Kleiner ist nichts verabredet. Nach Mailand zu Marieli würde ich wohl gerne gehen, wenn es in seinen Briefen etwas mehr Freude an dem dortigen Aufenthalt zeigte. So aber habe ich den Eindruck, mein Besuch würde leicht das wenige verderben, was es von dort noch einheimsen kann. Mit Rümelin in die Ferne reisen? Sein langes Schweigen zeigt mir, dass mein Eindruck von seinem Briefe richtig empfunden war. Es ist der ähnliche Conflict, ein kleiner, wie s. Z. mit Leipzig: Er hat sich bereits mit andern, gesellschaftliche ihm nahestehender Bekannter verabredet, mochte $u$. mag mir aber das nicht schreiben, u. so habe ich ihm am Ende nur eine Verlegenheit bereitet. Nun, schliesslich greife ich einfach zum Wanderstab, u. reise davon, so weit mich die Bahn tragen will, bis zu unterst in den italienischen Stiefel. Wenn das nur nicht so eigentümlich aussähe! Oder ich bleibe u. - verkümmere. Kann sein eine Nachricht in den nächsten Tagen bringt mich noch auf eine bessere Strasse. Mit dem, was notwendig gemacht sein musste, bin ich jetzt fertig. Also könnte ich gehen. Jedenfalls besuche ich diese Woche noch Schröder in Baden. In solchen Stimmungslagen $\mathrm{u}$. Tagesstimmungen soll sich der Halt bewähren, den eine gefestigte Lebensauffassung zu verschaffen hat. Und indem ich hieran denke, finde ich auch einen Trost u. meine Ruhe. Ich will schlafen, u. wohl auch werde ich schlafen. Es geht schon besser über alle die Unebenheiten des Weges hinweg, wenn man geruht hat $\mathrm{u}$. wieder auf bestimmte Ziele sich sammelt. Ohne solche bin ich ja von jeher ver-

loren gewesen, weniger wert als das geringste Schreiberlein. Also!

Im Grunde liegt dann eben - neben dem Verkehr mit der alten Anna - in der Sehnsucht der letzte Quell meiner 
Ungeschlossenheit. Ach ja, es wird mir schliesslich alles fehl gehen, das kann schon sein, $\mathrm{u}$. ich muss erst noch dazu sagen, dass es so ganz recht ist. Denn weshalb, wozu soll es mir gut gehen, wenn Du nicht mehr bei mir bist?

Gute, gute Nacht! Ich schliesse mit innigem Kuss, als Dein alter, alter Eugen

\section{2: März Nr. 63}

[1]

B. d.12. / 3. März 1912.

Meine liebste Lina!

Heute war viel Ungemach in der Luft. Und gegenteils bei Anderm Erfolg u. Freude. Das ist der Welt Lauf u. stört mich nicht. Rossel ist zum Bundesrichter gewählt, als erster mit 193 Stimmen von 217. Hauser erhielt 183, Oser 179. Rossel wollte noch Vormittags mich besuchen u. mir das sagen. Ich war abwesend. Nach Tisch gratulierte ich seiner Frau, die lachte u. helle Tränen weinte im gleichen Augenblick. Aber ich konnte freudig gratulieren u. schliesslich ist auch für Rossel die Wendung eine glückliche. Ich schrieb auch an Oser ein Gratulationskärtchen. Ich konnte dem «Bund» einen Dienst erweisen, indem ich auf telephonische Anfrage den Lebenslauf u. die Verdienste des neugewählten Richters angab. Sie standen dann im Nachm. Bund, neben den Angaben über die andern Neugewählten, u. waren eine Nummer herzlicher als diese. Ich wollte Hänny besuchen, er war in Twann mit Frau u. Kind. Ich ging zu Münger, traf ihn aber auch nicht. Dann war ich bei Walter B., den ich traf. Auch seine Frau erschien, u. sagte, sie habe von Marie eine Karte bekommen. Darauf habe ich ihr dann doch geschrieben, das sei nichts, es 
müsse ganz anders aus sich herausgehen. Unter dem gleichen Eindruck stehe ja auch ich, namentlich nach Maries Brief an Anna. Das ist kein Benehmen. Frau Burckhardt meinte dann zwar beruhigend, sie sei als jung auch so gewesen. Allein das ist für mich gerade das allerschlimmste Prognostikon. Ist es Hochmut von Marieli? Oh ich hoffe so sehr, dass ihm die Tage in Mailand zur Befreiung dienen mögen! Bis jetzt, nach drei Wochen, ist diese noch nicht erfolgt, $u$. ich fürchte, es nützt wiederum alles nichts. Jedenfalls gehe ich jetzt, so lange es so steht, nicht nach Mailand. Ich bleibe gerne zu Hause. Warten wir die weitern Briefe ab.

Meine bittere Stimmung liess etwas nach, als ich am Abend in meinem Sokrates-Buche las. Dann kam Dürrenmatt mit Geschäftssachen. Zugleich Rossel, mit dem ich separat ein halbes Stündchen plauderte, indess Anna bei D. verblieb. Jetzt ist es spät geworden, $u$. ich schliesse, um morgen, ich hoffe in besserer Verfassung, fortzufahren.

Den 13. März.

Ich bin heute früh aufgestanden, habe an Massigli geschrieben, ihn um Auskunft betr. Soleilles bittend, sodann an Winkler, um ihm zu sagen, dass ich keine Geselligkeit mitmache, u. dann noch an Raaflaub, dem mir so sympathischen

Gerichtspräsidenten, der wegen seiner Freisprechung eines «Gesundbeters» von den Medizinern hart angegriffen worden ist. Dann kam ich endlich dazu am Buch etwas weiter zu arbeiten. Auf 12 Uhr war Guhl bei mir, in allerlei Nöten, aber sehr magistral. Am Nachmittag las ich etwas in dem Socratesbuch, was mich sehr interessiert, war dann bei Werner Kaiser, um ihm von Reichels Besuch zu erzählen. Kaiser glaubt zu wissen, dass die sechs Bundesrichter waren: Weiss, Kirchofer, Schurter, Honegger, Ursprung u. Stooss. Zugleich sagte ich ihm, wie mich die Fassung des Berichts betr. meiner Beauftragung 
zur Revision des Rests des OR. beunruhigt habe. Es war ihm leid, ich war recht mit ihm. Ich ging dann auch zu Mutzner u. entschuldigte mich wegen des Fehlens in seinem Vortrag. Ich hatte ihn ob Kleiners Besuch ganz vergessen, es sind eben Ferien.

In meiner Abwesenheit war Walter B. da, um zu sagen, dass Marieli seiner Frau einen 12 seitigen Brief geschrieben mit allerlei Betrachtungen über den Galerien. Damit wollte nun offenbar Marieli sich gegenüber dem Vorwurf, es gehe nicht genug aus sich heraus, revangieren. Es tut damit aber nur wieder zu viel. Ich selbst erhielt von ihm ebenfalls einen Brief, u. zwar einen solchen, der mir gefallen hat. Mit einem mal ist da auch von Frl. Graffina die Rede, über die es sich von der Reise her bis jetzt zu meinem Ärger total ausgeschwiegen hatte. Aber an eine Umkehr glaube ich doch noch nicht.

Von Rümelin erhielt ich eine Karte, freundlich gehalten, mit der Anzeige, dass sie am Freitag bis Genf fahren, u. Samstag Abend weiter nach Antibes. Die Angabe der Züge zeigte mir deutlich, dass sie über Bern kämen. Ich telegraphierte daher sofort, sie möchten den Halt in Bern statt in Genf machen. Am Nachmittag kam die Antwort: Unmöglich aus Gesundheitsrücksichten, Brief folgt. Nun ja, ich hoffe, sie wenigstens auf der Durchreise zu sehen. Der Plan, selbst nach Antibes mitzugehen, ist mir augenblicklich ganz entschwunden.

Nun bin ich merkwürdig leer u. müde. Also zur

Ruhe. Ich kann u. mag nicht mehr denken.

Nimm innigsten Gruss u. Kuss von

Deinem allgetreuen

Eugen 
B. d. 14. / 5. März 1912.

Mein liebstes Herz!

Ich wollte heute Abend in meinem üblichen

Einsamstrott die Zeitungen lesen, noch etwas Wissenschaftliches vornehmen $\mathrm{u}$. dann zum Tagesschluss an Dich schreiben, wieder in nicht optimistischer Stimmung. Da kam Walter B. u. hatte mir von Lausanne viel zu erzählen. Er meinte, Rossel sei nicht zu beneiden, es sei nicht schön dort zu wohnen, u. er habe es der Frau gestern angedeutet. Und während er noch so plauderte, erschien Haenny, brachte uns seine Pariser Zeichnungen $u$. Radierungen, $u$. war sehr gemütlich, auch in sehr erlaubtem Mass selbstbewusster, so dass ich meine Freude an ihm hatte. Walter B. ging halb zehn Uhr. Haenny blieb bis elf, so dass ich jetzt die Zeitungen auf morgen verschiebe $u$. nur noch rasch die Zeilen an Dich hinwerfe, um Dich doch nicht ohne Gruss zu lassen. Sie haben mich von meinen Befürchtungen u. Zweifeln etwas abgelenkt. Ein Rabe sass heute Abend auf der Lärche u. ging nicht fort, als ich hart unter dem Baum trat. Erst als ich am Stamme schüttelte, flog er davon stumm. Ich weiss, wie Du das

Gekrächz von Raben als schlimmes Zeichen scheuetest. Hier war ich also froh, den stummen Vogel vertrieben zu haben.

Und nun fallen mir die Augen zu. Morgen ein Weiteres. Gute, gute, Nacht! Liebe, liebe Seele! 
Ich hatte gestern Vormittag am Buch gearbeitet u. konnte heute fortfahren, was mir Freude machte. Ich war noch bei Mülinen, hatte Guhl bei mir. Sonst aber bedrückte mich ein dumpfer Kopf, der wahrscheinlich von der Frühlingssonne herkommt, an der ich gestern Nachmittag eine Stunde gesessen habe. Eben war dann Brustlein bei mir, um mich in einer interessanten Rechtssache zu beraten. Und auf vier Uhr geh ich zum Bahnhof, um die vorbeifahrenden Rümelins zu begrüssen. Es klärt sich ab, weshalb er nicht in Bern Halt macht. Nicht nur ist die Reise mit dem Unterbruch in Genf für Frau Rümelin leichter zu machen, sondern sie werden dort mit Baues zusammen sein, dem jungen Dozenten aus Tübingen. Ich gedenke mit Rümelin nach Freiburg $\mathrm{zu}$ fahren, begleitender Weise, $\mathrm{u}$. dort alsdann Oser zu grüssen. Auf beide Begegnungen bin ich gespannt. Brustlein wünschte meine Unterschrift unter die Heliogravuren der Widmungsschreiben. Ich konnte nicht abschlagen u. schrieb: Zur Erinnerung an den 1. Jan. 1912 u. meine Unterschrift. Der Mann hat mich wieder sympathisch berührt, wie in alten Tagen. Es ist etwas

in ihm, was mir ihn vertraut macht, ich mag noch so viel Ungünstiges von ihm vernehmen.

Ich schreibe nach der Rückkehr aus Freiburg noch einige Zeilen, jetzt will ich mich aufmachen zur Bahn.

Noch eines will ich, um es nicht zu vergessen, anfügen. Ich hatte gestern Nachmittag den kleinen, contrakten Photographen Neuenschwander, den bleichen Jungen bei mir u. liess noch zwei sitzende Aufnahmen machen. Es wird sich zeigen, wie sie ausgefallen sind.

Ich war also auf den Vieruhrzug am Bahnhof. Rümelins winkten mir von ferne, ich stieg in den Wagen, u. ich machte es, wie einmal mit Dir, als Du nach Basel fuhrst: Ich «vergass» auszusteigen. Rümelin war ganz perplex, aber er merkte 
es gleich u. beide waren dann über meine Begleitung sehr erfreut $u$. wir hatten ein herzliches halbes Stündchen. Sie haben nach Antibes nichts mit Andern verabredet. Also könnte ich jetzt sehr wohl zu ihnen dorthin fahren. Aber ich weiss nicht, ob ich es tun soll.

In Freiburg schlenderte ich gegen Osers hinaus u. traf Fritz Speiser, mit dem ich recht nett plaudern konnte. Er meinte, es würde ein Germanist an Osers Stelle berufen u. Tuor u. jener sich teilen in die Aufgabe. Ob das aber geschieht? Ich traf bei Osers den kleinen Wolf im Garten. Er erkannte mich gleich, ich ihn erst nicht. Ich überraschte Oser am Beantworten der Gratulationen. Beide sind glücklich. Ich fing mit ihm über die Nachfolgerschaft zu sprechen an $u$. da zeigte er mir einen Brief, den er eben an mich geschrieben, worin er mich

frägt, ob ich Siegwart empfehlen würde. Nun hatte ich mit diesem vorgestern bereits von der Möglichkeit gesprochen, nannte ihn auch Oser, bevor er mir den Brief gezeigt. Die Nomination schlug ein. Siegwart soll morgen Nachmittag hinüber. Ich würde ihn sehr, sehr ungern verlieren, aber am Ende wäre es so doch besser. Für ihn, was man ermessen kann, ein Glücksfall. Was ich dann anfangen würde, das überlege ich lieber noch gar nicht. So schliesst dieser Tag mit einer sehr wichtigen Perspektive. Gut, was kommen mag! Ich lege meinen müden Kopf zu Bett, es war mir heute den ganzen Tag unwohl.

Gute, gute Nacht! Meine liebe Seele!

Immerdar Dein treuer Eugen.

Albert Heim war in meiner Abwesenheit da, in einem Sturm der Geschäfter. Vielleicht kommt er morgen noch einmal vorbei. Wäre mir lieb!

Noch eins: im Wagen begrüsste mich der [?]

Dutwyler aus Zürich, der bekannte von der Griesalp, u. fragte, wie es dir gehe. Ich war im Aussteigen u. vermochte kaum, 
Antwort zu geben. Nachher beim Einsteigen, sah ich ihn nochmals. Nachher nicht mehr. Eine wehmütige Erinnerung!

\section{2: März Nr. 65}

B. d. 16. März 1912.

Meine liebste Lina!

Die zweite Ferienwoche geht heute zu Ende u. ich stehe vor einer doppelten Ratlosigkeit, die mich schwer bedrücken könnte, wenn ich mich nicht an einigen Gedanken aufzurichten vermöchte, die mich gerade innerlich beschäftigen. Die erste Ratlosigkeit ist durch den Brief veranlasst, den ich heute von Marieli empfangen habe u. der mir deutlich zeigt, dass das gute Kind seinen Mailänder Aufenthalt leider immer noch nicht in der Weise benutzt, innerlich benutzt, wie ich es gerne sehen würde u. gehofft habe. Gegenüber den Montanis, die ihm offenbar sehr lieb begegnen, hat es nur kritische Bemerkungen, zurückhaltend zwar, aber um so verräterischer in Bezug auf die innere Stimmung. Von der Frau Rittener dagegen spricht es in freudiger Hingebung $u$. alles concentriert sich auf den Tag, den es wiederum in dieser Woche dort zugebracht. Dass ihm doch Frau Hebbel diese Adresse geben musste! Und wie dumm von dieser Frau R., dass sie das gute Kind nicht seiner Aufgabe lässt u. es so eigennützig an sich zieht. Ich weiss mir aber nicht zu helfen, anders als ich gehe aus lauter Verdruss schliesslich gar nicht nach Mailand. Und das ist dann wiederum nicht Recht gegenüber Montanis u. Frau Crugnola. Es ist ein Jammer.

Die zweite Ratlosigkeit besteht gegenüber Siegwart, 
der nun wohl Osers Nachfolger wird. Ich habe ihn gern gehabt u. er hat mir gute Dienste geleistet. Ich dachte daran, ihn ganz an meine Aufgabe zu fesseln u. ihn zum Erben gewissermassen meines geistigen Vemächtnisses zu machen. Ich war sehr vertraut zu ihm u. habe ihm Vieles mitgeteilt, was er gegen mich ausbeuten könnte. Wird er nun treu genug sein, mich nicht zu verraten? Hat er den Charakter seines Grossvaters? Da kann ich nun nichts mehr machen, als abzuwarten $u$. das Vertrauen fortzusetzen. Am Ende sollte doch der gute Kern, den ich sicherlich an ihm gefunden habe, mich vor irgendwelcher Untreue beschützen. Eine andere Frage ist die, wie ich es mit dem Ersatz halten soll. Siegwart war mir ja in einer Beziehung nie ganz entsprechend, nämlich in Betreff seiner Zugehörigkeit zum Ultramontanismus. Es gab Perioden - ich habe dir früher darüber geschrieben - wo ich aus diesem Grunde schwere Bedenken gegen seine Anstellung empfunden habe. Erst im Laufe dieses Winters habe ich diese eigentlich vollständig überwunden. Eine Hülfe aus dem eigenen Lager wäre mir lieber. Aber wo finde ich sie? Das ist eine schwere Frage, die mich wieder in alle die Unsicherheit zurück wirft, die ich noch im letzten Halbjahr unseres Zusammenseins mit Dir durchgemacht habe. Ich will aber darüber noch nicht weiter schreiben, auch nicht weiter denken, bis die Sache selbst entschieden ist. - Dieser unerwartete Fall

erheischt nun sehr meine Gegenwart. Es ist gut, war ich nicht verreist, u. es wird auch gut sein, wenn ich jetzt noch bis zur Entscheidung da bleibe. Freilich hatte ich heute das Gefühl, ich sollte doch etwas aus dem Einerlei heraus. Anna fühlt sich sehr bedrückt. Sie meinte kürzlich, sie fühle so ganz, wie sie mir nicht das sein könne, was ich haben sollte, kein Verkehr bei Tisch u. in den Arbeitspausen. Sie hat ja auch recht damit. Aber anderseits trage ich auch Bedenken, sie mit Sophie allein im Hause zu 
lassen. Sie wird mit jeder Woche gebrechlicher.

Und nun dazu noch die Aussicht auf den Eintritt Annelis in unsere Familie! Wo ich bei dem Charakter Marielis so gar nicht voraus sagen kann, wie es werden wird! Nun ja, ich muss die Dinge nun kommen lassen, wie es mein Schicksal will. Ich kann nur sagen, dass ich in allen den jüngsten Entschliessungen einfach nach Pflicht u. Gewissen zu handeln glaubte. War ich ungeschickt, so muss ich daran heben, da gibt es kein Entrinnen mehr. Sie werden mir das Leben verbittern, aber mich von dem, was ich als gut erkannt, nicht abbringen können. Also mutig vorwärts!

Ich will Dir versprechen, den Kopf nicht hängen zu lassen. Es ist jetzt offenbar eine Periode des Untendurchgehens für mich gekommen. Warten wir ab, wie u. wann es auch wieder besser werden wird.

Eines hat mich heute betrübt: Ernst Brenner kam, mir

mitzuteilen, dass er seine Anmeldung zum Examen zurückgezogen habe. Und das sagt er mir als Tatsache, während er Forrer darüber beraten $u$. von diesem eine Antwort erhalten hat, wie sie aber Forrer aus Mangel an Erfahrung in solchen Candidatennöten nicht besser erteilen konnte. Ich würde Brenner eine andere Antwort erteilt haben. Aber vielleicht hat er gerade in Voraussicht dessen mich nicht zum Voraus um Rat gefragt. Die Mutter tut mir leid. Heute habe ich Frau Soleilles einen längeren Condolationsbrief geschickt. Wenn ich an diesen Verlust denke, wird es mir weh ums Herz!

Und nun nochmals: mutig vorwärts! Mag es auch schlimm kommen, über das Ärgste bin ich ja weg u. das Ende ist bald erreicht!

Nimm Gruss u. Kuss von Deinem ewig getreuen Eugen 
Bern, den 17. März 1912.

Meine liebste Lina!

Ich schreibe diese Zeilen auf einem Papier, das in besonderem Sinne in mir die Erinnerung an Dich wachruft. Als ich nämlich heute Nachmittag wieder einmal die Bilder aus dem Kasten hervorholte, die wir in Italien, auf unsern Reisen uns angeschafft, die grossen Mappen, von Florenz, von Venedig, von Speyer, von unsrer silbernen Hochzeit, da stiess ich auf einige vergessene Pakete Mimeographenpapier, das Du noch angeschafft, als Du im Herbst 1909 einwilligtest, die Mimeographenarbeit nicht mehr selber zu machen, so dass der Rest des Papiers bis jetzt unbenutzt liegen blieb. Ich will es nun für meine Schreibmaschinenbriefe etc. brauchen. - Die Erinnerung ist köstlich u. ist schmerzlich. Denn einerseits hast Du mir ja immer gesagt, welche Freude, welchen Stolz Du darein setzest, diese Arbeit, die recht mühsam $u$. beschwerlich war, für mich zu machen, und ich scheute eigentlich, Dir dieses Amt wegzunehmen, in der Besorgnis, Dich damit zu kränken. Ich hätte es doch schon lange Zeit früher tun sollen, weil ich hätte sehen sollen, dass es Dich körperlich zu sehr anstrengte. Es ist das einer der Punkte, wo ich mir Vorwürfe machen muss, Dir bei aller guten Meinung nicht genug Sorge getragen zu haben. Andererseits aber, als Du dann doch einwilligtest, die

Mimeographenarbeit abzugeben, da geschah das unter dem Eindruck des unglücklichen Wortes von August Gyr, der Dir die viele Liebe u. Gastfreundschaft, die er bei uns genossen, dadurch vergalt, dass er über die Abzüge wegen ihrer alten «th» u. a. Bemerkungen machte, es seien so u. so viel Schreibfehler darin. Da hattest Du genug, u. mit Recht. Es war ein Vorspiel der Herzlosigkeit, womit der dann 
zwei Jahre später Marieli verleumdet hat. Mit ihm u.

Augusts Söhnen hatten wir schon damals Erfahrung genug gesammelt, um Anlass zum Bruch zu haben, den ich dann allein vollzogen habe $u$. den ich nicht mehr gehoben wünsche. Es ist zu viel Bitterkeit, es ist zu viel ungerechter Mamon auf jener Seite ins Spiel getreten. Also lassen wir diese Sippschaft. Wir haben um geringeren Anlasses willen Deine Nichte auch aufgeben müssen.

Wäre jener Vorfall nicht eingetreten, so würdest $\mathrm{Du}$ wohl dieses Papier zu den weiter fortgeführten Abzügen verwendet haben u. es läge, mit Rechtsfällen bedruckt schon lange in der Hand eines Praktikumsteilnehmers. So dient es mir nun, um die Erinnerung aufzufrischen $u$. Dir von ganzer Seele wieder einmal zu danken für allen diesen lieb erfüllten Eifer, der Dich erfüllt hat! Das wird mich mein Leben lang begleiten, es wird die einsamen Tage mir wach erhalten, die ich noch in dumpfer Pflichterfüllung vollenden muss!

Walter B. war heute wieder bei mir u. erzählte mir, dass Albert Heim am Freitag bei ihm zu Nacht gegessen. Es war eine merkwürdige Begegnung. Als Albert mich nicht getroffen u. durch den botanischen Garten nach der Stadt zurück wollte, traf ihn Walter B, grüsste ihn u. teilte ihm mit, es sei s. Z. noch ein Stein, den Albert sich am Gotthard ausgelesen, in Walters Rucksack liegen geblieben, ob er ihn ihm zurückschicken solle. Albert sagte, er nehme ihn gleich mit, ging mit Walter zurück u. wie er in dessen Wohnung war, blieb er zum einfachen Abendkakao, bis gegen acht Uhr, wo er zu andern Verabredungen eilen musste. Die Begebenheit ist typisch für Albert. Er war, wie er zu Anna kam, so pressiert, dass er nicht einmal das Haus betrat, sondern gleich wieder davon stürmte. Dagegen sobald es etwas zu gelten gab, da fand er zwei Stunden Zeit zum plaudern. Am folgenden Morgen natürlich war er dann wieder so gehetzt, dass er nicht nochmals zu mir hinaus kommen konnte. Und bei Marie ist es nicht anders, das zeigte ihr neuester Besuch. Es ist auch bei ihrer Ge- 
mütsart nicht anders denkbar, als dass sie unter dem Eindruck leiden, dass ich in gleichem Alter mein Amt weiter versehe, während er zurückgetreten ist. Und mit Arnold ist es auch eine Sache. Sie halten ihn instinktiv von mir ferne. Und wenn er doch einmal kommt nach seiner Rückkehr, werde ich vielleicht Zeuge einer grossen Abwendung. Walter B.

fand, Albert sei nicht schlimmer dran, als im Sommer, d. h. recht frisch. Er habe nur geklagt über Ischias-Schmerzen, die er im Winter eine Zeitlang gehabt. Es war mir von Wert, diesen Eindruck von Albert auf Walter kennen zu lernen.

Ich denke wieder milder über Marieli, seit ich ihm geschrieben. Und das Benehmen Annas, die mich in meinem Unbehagen getreulich schürt $u$. unterstützt, mahnt mich zur Vorsicht. Wie oft hast Du es gesagt: Anna hat ein böses Herz, es ist ihr nicht wohl, wenn Friede besteht, u. das war gemeint, niemals mit Hinsicht auf das Verhältnis zwischen uns. Da kam Anna nie, auch nicht ein einziges Mal dazu, sich einzumischen, sondern in unseren Beziehungen zu den Verwandten u. Freunden, u. namentlich in Deiner Stellung zur Dienstmagd. Doch Du hast ihr das alles mit Liebe vergolten, u. sie spricht jetzt auch niemals anders von Dir als in Liebe, sie ahnt wenigstens, was sie Dir zu verdanken hat, $u$. dies sei auch mir genug.

Ich habe heute Teichmanns Sohn erwartet, dem ich geschrieben, er soll Sonntags zu mir kommen. Allein es scheint - ich schreibe diese Zeilen am spätern Nachmittag - ich warte vergebens.

Und nun lese ich in Socrates weiter. Es tut wohl! Eine Dissertation, von Jost, habe ich heute Morgen begonnen. Ich hoffe, sie macht mir nicht zu viel Arbeit.

Innigst Gruss u. Kuss von Deinem allzeit treuen Eugen

Jetzt sind es 102 Wochen seit deinem letzten Gruss in meinem Studierzimmer. 
B. d. 18. / 9. März 1912.

Mein liebstes Herz!

Heute schreibe ich Dir nur noch ein paar Zeilen. Ich komme von Baden zurück, wo ich Schröder u. seine Frau im «Ochsen» besucht habe. Ich fuhr mit dem Nachmittagszug hinunter, verfehlte dann Schröders, die am Bahnhof mich in Empfang nehmen wollten, aus ihrer Schuld, traf sie dann aber bald darauf im Gasthof u. plauderte fröhlich von vier bis halb sieben Uhr mit den alten gemütlichen Leuten, selber alt genug, um sie zu verstehen $u$. auch den richtigen Ton zu finden. Sie scheinen sehr kränklich zu sein, namentlich er, aber geistig war er so frisch als je. Ich nahm die Gelegenheit wahr, ihm von Frensdorf zu sagen, wie er im Herbst 1908 wegen meiner Entwurfsarbeit neben den Kollegien den Toast auf mich gehalten, den Du ja auch gehört hast, während er 1911 mich im Tone des Vorwurfs fragte, ob ich die Collegien neben der gesetzgeberischen Arbeit bei behalten. Schröder sagte sofort, das sei auf Rechnung des Arterienverkalkung zu setzen. Frensdorf sei überhaupt sehr stumm u. unumgänglich gewesen letzten Herbst. Und als Pendant erzählte er, dass er mit Karlowa an dem Begräbnis eines Kollegen gewesen. Acht Tage später habe er mit Karlowa dessen Frau begegnet, u. da habe Karlowa diese gefragt, wie geht es Ihrem Mann? Er habe ihn an sich gerissen u. ihm Vorstellungen gemacht. Es sei aber auch eines der ersten Symptome seiner Krankheit gewesen. - Der Besuch scheint Schröders gefreut zu haben, u. ich habe mein Wort eingelöst. Damit muss ich zufrieden sein. Neues, was ich Dir berichten könnte, habe ich

nicht erfahren. - Am Vormittag erstattete mir Siegwart Bericht von seinem Samstag-Nachmittag-Besuch in Freiburg. Oser habe ihn an der Bahn erwartet u. ihm gleich gesagt, die Sache stehe 
nicht so günstig, wie er zu mir bemerkt habe, indem Tuor noch schwanke, ob er nicht doch das ZGB, übernehmen soll. Siegwart wurde mit dem Dekan Lisker, mit Lampert u. Tuor bekannt. Das war alles. Ob etwas weiteres ansteht, ist jetzt ganz ungewiss. Um so besser, dass ich noch nicht mir die Ersatzfrage zu Herzen gehen liess. Siegwart war sehr nett übrigens.

Diesen Vormittag schrieb ich dann auch an Frau Crugnola, um Gewissheit zu erlangen, wie es mit Marieli stehe, u. um ihr zu sagen, dass ich nicht nach Mailand komme, weil ich es so im Interesse Marielis für besser halte.

Um 111/2 Uhr brachten mir der Präsident des Schweiz. Notariatsvereins Borlet u. der alt Prof. Berger eine silberne Schale, als Dank für meine Hilfe in den Notariatsfragen der Einführung, u. als Aussteuerstück für meine Tochter. Sie waren sehr herzlich. Leider konnte ich sie nicht bewirten. Ich war ja nicht sicher, was Anna angestellt hätte.

Und jetzt fallen mir die Augen zu, also zur Ruh, zur Ruh. Morgen schreibe ich weiter!

Den 19. März 1912.

Leider war ich heute bereits wieder in trauriger Verfassung $\mathrm{u}$. Stimmung. Verursacht wurde das durch einen Brief Marielis, der gestern schon eingetroffen, eine Antwort auf meine «Vorwürfe», die zwar anerkennt, es habe nicht recht gehandelt, auch in den Ausdrücken freundlich gehalten ist, aber eben doch sich zu entschuldigen sucht. Es sind

eben die Grundstimmungen, die hier im Stiche lassen. Wegen der Mitteilung, dass die Nachricht die ihm Susanne gemacht, betr. ein Studentenständchen, das ihm gebracht worden sei, erfunden sein müsse, antwortet es, Susanne habe das nicht erfunden, sondern Sophie habe es Rossels Magd gesagt $\mathrm{u}$. diese der Susanne. Ich stellte gestern schon Sophie zur Rede $u$. heute wieder $u$. sie versichert mich, dass sie kein Wort von so etwas gesprochen. Darauf ging ich zu Rossel, der mich gestern besuchen wollte, heute aber nach Davos verreist ist, u. fragte dann noch Susanne, die mir auf meinen Vorhalt, sie habe wohl einen Spass machen wollen, erklärte, nein, Sophie habe es ihrer Magd gesagt u. dies auch gleich durch diese bestätigen liess. Die unbedeutende Sache hat mich sehr geärgert. Dass ich mich mit solchen Dingen abgeben 
muss, es ist ein Jammer! - Ich antwortete Marieli noch nicht, ich will einen ruhigeren Brief von ihm abwarten.

Den Vormittag gab ich Siegwart den Rat, nochmals nach Freiburg zu gehen. Ob er nun heute gegangen, werde ich morgen erfahren. Veranlasst ward ich dazu durch eine Mitteilung Osers, die viel weniger optimistisch lautete, als seine mündlichen Aussagen.

Sonst las ich in der Dissertation Jost, die im ersten Viertel unbrauchbar ist u. mir sehr viel Mühe bereitet. Dann beschäftigte mich schon gestern $u$. heute den ganzen Nachmittag die eine Anfrage Bühlmanns, über die ich vor Mittag mit Guhl conferierte, nachdem ich meine Ansicht gebildet. Ferner hatte ich eine Conferenz mit einem Notar der Waisenkommission in interessanter Sache. - Endlich kam der junge Teichmann, ein prächtiger junger Mensch, nicht das Kind, bei dessen Taufe wir s. Z. waren (1886), das ist gestorben, sondern der zweite Sohn, 1889 geboren. Er hatte meine Aufforderung auf Sonntag wegen Wohnungswechsel erst heute erhalten. Sein Eindruck auf mich war gut. Er erzählte mir von den sehr schweren Zeiten, die er durchgemacht, u. von den Krankheiten des Vaters,

der am ganzen Körper mit Ausschlag behaftet, lange Monate im Spital lag, dann wegen Nervenstörungen in eine Privatheilanstalt schlimmster Sorte in Zihlschlacht u. nachher ins Irrenhaus Basel kam. Jetzt aber ist er zu Hause u. seine Tochter pflege ihn rührend. Sie sei, sagte der Bruder, überhaupt eine liebe Martha. Ich dachte dabei an das Urteil der Welt. Die Fehlbaren sind immer wieder mit unter den Besten, wenn es Liebe u. Hingebung gibt.

So ist der Tag schwer verstrichen. Von Maurheim erhielt ich die Tagebücher Arnolds, die ich jetzt gelegentlich lesen will. Aber es ist mir so schwer in allem. In der Bahn sass mir eine Zeitlang gestern ein Mann gegenüber, der seinem Nachbar, als freier Schweizer erzählte, wie er ein Kind Pflegeeltern übergeben, dass er es aber schon wieder holen werde. Und dabei [?] er von seinem Militärdienst u. wie er seinen Vorgesetzten gezeigt habe, er sei «ein freier Schweizer». Beim Verlassen des Wagens aber entschuldigte er sich bei mir, dass er mich durch sein vieles Reden gestört habe. Zwischen Olten u. Brugg habe ich schon mehrfach solch aufgeregten Leuten im Wagen begegnet. 
Wenn ich nun nicht nach Italien reise, überlege ich, ob ich die Angelegenheit mit Anneli dem Marieli schriftlich vorlegen soll. Das hätte auch etwas für sich. Allein - soll ich? O könnte ich Dich fragen! Aber dann wäre eben alles anders $u$. die Lage gar nicht so zerfahren geworden, wie sie jetzt zu werden droht!

Doch, indem ich Dir schreibe, wird mir schon wieder wohler. Es wird doch noch alles gut werden. Darauf vertraue ich, u. Du hilfst mir, gelt, liebe gute Seele!

Gute Nacht, der Tag ist vorüber! Dein ewig treuer

Eugen

1912: März Nr. 68

[1]

Bern, den 20. März 1912.

Mein liebstes Herz!

In einem tiefen Schlaf von heute auf gestern hat es mir merkwürdige Sachen geträumt. An einem ähnlichen Rebberg, wie am Stammheimer Kirchweg, kam mir ein Zug Helveter entgegen, ich stiess zufällig an einen beschärpten Mann, der burschikos mich zur Rede stellte. Dann kam eine Musik, es wurde getanzt, u. ich hatte die Empfindung, das sei gut, damit es nicht weitern Spektakel gebe. Offenbar hatte das Helveterständchen nachgewirkt, mit dem nach Susannes Aussage Marieli beglückt werden sein sollte. Das hat sich jetzt übrigens abgeklärt. Sophie soll einmal gesagt haben, man höre bei uns etwa Abends so schön singen (sie meinte den Gesang von drüben, dem wir ja auch vielfach gelauscht), u. daraus hat dann, als Rossels Magd dies Susanne mitteilte, diese die gerügte Botschaft gemacht. Es ist eine welsche Kinderei, nichts anderes.

Am Vormittag arbeitete ich die Dissertation Josts weiter, bis zur Hälfte. Sie ist unbrauchbar, ich muss aber die zweite Hälfte doch noch lesen, vielleicht ist sie besser.

Dann war Walter B. bei mir u. teilte mit, dass er am Sonntag 
bei Brenner gewesen u. diesem dringend empfohlen hätte, das Examen zu unternehmen. Frau BRat sei dabei gewesen. Aber gefrommt habe es doch nichts: Brenner stehe nicht auf der Liste.

So wird jetzt als Folge des Todes des Vaters der auf eigene Füsse gestellte Sohn sich in jenen Bahnen bewegen, die dem Vater immer als Gefahr vor Augen standen: Entschlussschwäche, Verfall in den Zustand des Grossvaters Sturzenegger. Das sind sonderbare Erlebnisse. Das Examen, meint Burckhardt, wird Brenner im Herbst oder später weniger machen als jetzt. Das ist Schicksal, u. doch tut es mir leid um den jungen Mann.

Am Nachmittag hatte ich einige Briefe zu schreiben, las dann mit grosser Freude Platons Protagoras fertig, hatte auch Guhl ein Stündchen in Amtssachen da. Schon gestern Abend erhielt ich weiter die Tagebücher von Arnold Heim, in deren erstem ich gestern $u$. heute etwas gelesen habe. Es ist eine mitreissende Lektüre, aber durchaus nicht schriftstellerisch. Auch fällt mir bis jetzt auf, dass er von Munti häufig schreibt, vom Vater aber gar nie. Wir wollen sehen, wies weiter geht.

Im übrigen stand mir die Geschichte mir Marieli immer noch vor Augen. Es ist heute ein Brief von ihm eingetroffen. Korrekt freundlich, an einigen Stellen etwas gemacht, aber wieder nicht eigentlich lieb. Sollte es dieses Tones wirklich nicht fähig sein? Ich glaube das nicht, sondern nehme an, man darf ihm keinen Tadel aussprechen, ohne dass es die Sache bös nimmt. Doch will ich noch nicht weiter

urteilen. Man kann ja alles noch erleben, was an dem Charakter liegt oder nicht liegt. Wegen des Planes mit Anneli neige ich mich heute entschiedener zu dem Entschlusse, Marieli zu schreiben, komme was wolle. Doch will ich auch darüber noch einige Überlegung verstreichen lassen. 
In der letzten Nacht dachte ich auch wieder bestimmter über den Plan nach, den schon einmal erwähnten Aufsatz über soziale Gesinnung zu schreiben u. ihn Walter B. für das polit. Jahrbuch zu geben. Ich machte die Einleitung u. die Disposition in Gedanken fast fertig u. hoffte, heute zum Niederschreiben zu kommen. Allein es war wegen der andern Arbeit keine Musse dazu. Vielleicht kommts morgen besser. Socrates freut mich, $u$. ich begreife jetzt seine Auffassung der Erkenntnis in der Identität mit dem Willen viel besser. Da das Gute ihm das im höchsten Sinn Vernünftige, Zweckmässige für den Menschen bedeutet, so vermag er aus dessen Erkenntnis auch den guten Willen abzuleiten. Aber Erkenntnis bedeutet dann eben hier etwas anderes als bei Kant. Und nun haben wir schon wieder Tag u. Nachtgleiche! Die Zeit fliegt. Wie werde ich froh sein, wenn sich die Schwierigkeiten mit Marieli wieder geglättet haben! Ich hätte ja meine Vorstellungen mir sparen können. Aber ich stand unter dem Eindruck, dass eben doch eine Wandlung der Seele

bei ihm versucht werden müsse. Hilf mir, dies zum Guten zu lenken. Es muss am Ende doch ein Weg sich öffnen in das verschlossene Herz!

Und nun gute, gute Nacht! Ich bin immerdar Dein getreuer

Eugen 
[1]

B. d. 21. März 1912.

Mein liebstes Herz!

Wieder ein Tag vorbei! Schon wieder Tag u. Nacht-Gleiche, es geht ja wunderbar rasch. Und ich befestige mich in dem Gedanken, die Ferien zu Hause zu bleiben. Eine Karte von Rümelin, die heute von Cap d'Antibes eingetroffen, macht mich nicht schwanken. Ich habe das Gefühl, ich würde mich in dort oder anderswo sehr verlassen fühlen, trotz Freundschaft. Und die Beschwerlichkeit mit dem schwachen Arm an fremder Tafel lässt mich auch nicht gerade die unbekannte Welt aufsuchen. Doch will ich noch sehen, welche Nachricht ich von Marieli bekomme. Es ist mir manchmal so bange um den Gang der Dinge in dort. Denn hinter dem harten Wesen Marielis verbirgt sich ein leidenschaftliches Temperament. Was habe ich davon zu befürchten? Nun, ich musste ihm meine Ermahnung schicken $\mathrm{u}$. auf seine Antwort, in der es meine Ermahnungen als Vorwürfe behandelte u. z. Teil zurückwies, konnte ich nicht wieder sofort antworten. In solchen Sachen lässt man sich auf eine Diskussion nicht ein. Aber was geschieht inzwischen? Die Annäherung Annelis kam zur unrechten Zeit - oder vielleicht gerade zur rechten. Ich will Vertrauen haben! Die Dissertation Josts hat mich heute wieder mühsame Stunden gekostet. Was soll ich da machen! Ich verliere meine Zeit an eine Korrektur, wie sie z. Teil von einem

Primarlehrer gemacht werden sollte, wenn z. B. wiederholt geschrieben steht: «Es ist einen grossen Unterschied» u. solche Dinge rücken alle Augenblicke auf, von der Verwirrung, die der Candiat in Segessers anschaulicher Darstellung angerichtet hat, nicht zu sprechen. Hoffentlich bringe ich das Ding diese Woche noch zu Ende. 
Heute rief mich Lohner zu sich, wegen der Nachfolgerschaft Rossels. Nach mehrfachem Hin u. Her empfahl ich ihm, Balli vorläufig mit der Übernahme eines Teils der Sommervorlesungen Rossels zu beauftragen, es werde sich dann zeigen, ob der Besuch der Jurassischen Studenten sich Balli anpasse, ob nicht von anderer Seite Opposition erfolge, u. namentlich würde damit die Professur für ital. Kollegien befestigt. Er schien sich dieser Lösung anschliessen zu wollen. Bei dem Anlass sprach ich auch für Chérra, den wir eventuell herkriegen könnten. Ferner befragte mich Lohner über die Gehaltsaufbesserungen, $\mathrm{u}$. ich äusserte mich dahin, dass schon lange mir als der geeignetste Plan der vorgekommen sei, den Professoren ein fixes Minimum zuzuweisen, 7 - 8000 Fr., in der Meinung, dass sie durchschnittlich mit Gehalt $u$. Kollegiengeld auf diesen Betrag kommen sollen. Die Zeit zur Kürzung der Kollegiengelder scheint jetzt auch schlecht gewählt. So erzählte mir Lohner, Strasser habe im Winter 1907 / 811700 Fr. bezogen, netto, u. 1910 / 11 nur noch 4 600, dies in Folge des bekannten Exodus der Russen. Es scheint, dass auf die

Handelsabteilung grosse Hoffnungen gesetzt werden. Das bleibt nun abzuwarten.

Heute Nachmittag war dann Bühlmann in der Rechtsfrage bei mir, über die ich ihm seit Montag schon zwei Briefe geschrieben. Ich konnte ihm dann eine Lösung geben, die ihn sehr befriedigte. Er war sehr herzlich.

Nebendurch habe ich in Arnold Heims Tagebuch gelesen. Ich bewundere die Energie, womit er alle die Aufzeichnungen Tag für Tag vorgenommen, trotz aller Urwaldstrapazzen. Ja, es bedarf des jugendlichen Unternehmungsgeistes, um eine solche Arbeit als ein Glück zu empfinden, dem man die ruhige Laufbahn in der Heimat opfert. Sehr originell oder gescheit kommt mir Arnold in den Büchern nicht vor. Aber von rastlosem Eifer $u$. vieler guter Bildung. Was er da aufgezeichnet hat, ist wertvoll, als Momentaufnahme. Es sind prächtige Erlebnisse darin erzählt. 
Zu einer Niederschrift über die «soziale Gesinnung» bin ich wieder nicht gekommen. Wenn Josts Dissertation erledigt ist, könnte ich wohl daran denken, aber da meldet sich schon Siegwart u. hat die Ordnung der Entwurfsakten erledigt, so dass ich auch da zu neuer Arbeit gezwungen werde. Was soll ich da machen? Ruhig bleiben, Vertrauen haben. Wenn ich auch recht wehmütig dasitze, sobald ich wieder an Dich schreibe, tritt die Besinnung auf das wesentliche ein u. es wird mir im Herzen wohler. Wie eigen kann die Trauer, das Leid sich umsetzen.

[4]

Indem ich mich darin vertiefe, bekommen die Dinge eine andre Perspektive u. ich fühle mich gestärkt u. gehoben.

Gute Nacht, liebe, liebe Seele!

Dein ewig treuer

\section{Eugen}

\section{2: März Nr. 70}

[1]

Bern, den 22. / 3. März 1912.

Mein liebstes Herz!

Heute habe ich zwei erlösende Dinge erlebt: ich habe die Dissertation Jost fertig gelesen u. zur Verbesserung zurückgesandt, u. ich habe von Marieli einen Brief erhalten, der mich gefreut hat. Darauf habe ich ihm ausführlich geantwortet. Ich war hiezu um so mehr veranlasst, als Frau Crugnola mir auf meine Anfrage geschrieben hat, ihre Kinder hätten Marieli sehr gern, aber es sei wirklich wortkarg. Rita glaube, es werde von einem geheimen Kummer bedrückt. Dann sollte es doch offen mit ihr reden, so könne man ihm helfen. Das hat mich gefreut.

Ich war auf dem Amt, mit Geschäftssachen, die ich zu erledigen hatte. Da sagte mir Kaiser, er werde bestürmt, eine 
Kandidatur in die Solothurner Regierung anzunehmen. Ich riet ihm ab. Er wird sich aber demnächst entscheiden. Im Gang traf ich Müller u. Hoffmann. Mit letzterem ging ich noch aufs Bureau u. vernahm, dass Rossel sein Haus an Zurbrügg verkauft, für 85000 , u. dass Motta sich etwas reuig gezeigt habe, nicht für 80000 zugegriffen zu haben. Sonst schrieb ich heute einen langen Brief an M. u. war in Gedanken damit beschäftigt, die Ferien weiter auszugestalten. Darüber will ich morgen auch Rümelin

schreiben $u$. für heute diese Zeilen abbrechen, um in Arnolds Tagebüchern noch etwas weiter zu kommen.

Den 23. März

Heute habe ich endlich fertig gebracht, mit dem Aufsatz, über soziale Gesinnung zu beginnen, $\mathrm{u}$. habe sieben Seiten Maschinenschrift (etwa 8 1 12 des Jahrb.) geschrieben. Ich will nun auch sehen, dass ich die Tage noch fortfahren kann $u$. zum Abschluss im Rohentwurf gelange. Die Sache interessiert mich, aber die erste Niederschrift sollte bis in einer Woche vollendet sein, d. h. vor meiner nun auf den 30 . geplanten Abreise nach Lugano. Sonst gibts wieder nichts draus.

Ich hatte daneben mit [Hiober?] wegen der Sommerausrüstung zu verhandeln $u$. Flückiger brachte mir die korrigierte Rechnung, in der er 9 Fr. als unrichtig gebucht anerkannte. Er will mir später einen Vorschlag machen betr. Übernahme der Gartenarbeit um eine [Bausch?]summe. Dann kam Guhl in Amtssachen, heute etwas zerfahren, u. zugleich Rossel. Dieser sagte, er habe George recht gut getroffen. Der Arzt meine aber, es wäre zu empfehlen, dass er den ganzen Sommer noch in Davos bleibe, was nun auch geschehen wird. Dann aber könne er voraussichtlich als geheilt entlassen werden. Vom 
Hausverkauf ist Rossel erfreut. Die alte Frau Zurbrügg hat auf Rossels erste Angebote von 90000 gleich stehenden Fusses 85000 geboten $\mathrm{u}$. so wurde der Handel schon letzten Samstag abgeschlossen. Über seine eigene Nachfolgerschaft, namentlich die Frage, ob der Lehrstuhl überhaupt wieder zu besetzen sei, ist Rossel immer noch schwankend. Er wird heute Nachmittag mit Lohner darüber gesprochen haben. Wahrscheinlich kommt es zu der von mir angeregten provisorischen Lösung, dass Balli für nächsten Sommer einen Teil der von Rossel angekündigten Vorlesungen übernimmt, in der Hoffnung auf eine definitive Regelung in diesem Sinne. In Arnolds Tagebuch konnte ich heute nicht viel lesen. Er wird aber merkbar mit jeder Woche wilder $u$. verbitterter. In den ersten Monaten ist er noch ganz der zarte Kulturmensch. Jetzt kommts allmählich anders, u. das ist auch nicht zu verwundern. Es ist unglaublich, was der junge Mann durchzu machen hatte. Wie schade, dass Du das nicht mit mir geniessen kannst, es würde auch Dir grossen Eindruck machen. Aber was schreibe ich! Wir bleiben ja in der Gemeinschaft, ich weiss es wohl, $u$. ich setze uns beide fort, so gut es geht, bis u. so lange es gehen kann. Ich schliesse heute die dritte Ferienwoche in einer Verfassung, in der eigentlich erst der heutige Tag mich müde gemacht hat. Aber es wird schon besser sein,

wenn ich zwischen Palmsonntag u. Ostern etwas ausruhe. Mit Siegwart bin ich dann allerdings in Verlegenheit. Aber es wird auch gehen!

Nun lese ich noch ein Stündchen Tagebücher u. dann zu Bett! Gute, gute Nacht von Deinem alten treuen Eugen 


\section{2: März Nr. 71}

[1]

B. d. 24. März 1912.

Mein liebstes Herz!

Ich hatte heute den ganzen Tag ein drückendes

Gefühl, wie von einem nahenden Unglück. Ich konnte es auch mit Arbeit nicht überwinden. Zwar machte es mir Freude an der «sozialen Gesinnung» zu schreiben u. ich bin auch bis auf neun Seiten gekommen, mit gestern zusammen 17. Aber das Gefühl wollte nicht weg. Am Vormittag kam Walter B., mit dem ich länger als eine Stunde plauderte, wobei ich anlässlich Wieland von der Schmähsucht der Basler etwas bemerken konnte. Er nahm es hin, aber vielleicht hat es ihn doch gewurmt. Es kam mir eben alles wieder in den Sinn, was ich von den Baslern erlebt habe. Und doch musste ich anfügen, wie sehr ich anderseits für das Empfangene dankbar sei. - Am Nachmittag kam ganz unerwartet Hans Gwalter mit seiner Braut, [?] Toming aus Bergen. Sie hält sich einige Zeit in Lausanne auf. Die nicht mehr sehr junge Dame machte mir einen sehr guten Eindruck, sie scheint wacker, besonnen, ist im Gesicht nicht lieblich, aber hat einen offenen Blick u. trägt eine stolze Gestalt. Er war sehr recht. Von Marieli u. Paul wusste er offenbar nichts. Dagegen wusste er anderseits mir von August Gyr zu erzählen, er habe ihm so eigen-

tümliche Briefe geschrieben, in denen er über seinen [Va?], über Sohm, über Binding losgegangen u. unter andrem geschrieben habe, er habe sich mit Sohm gezankt, $u$. der habe erklärt, er werde bei ihm nie das Examen machen können. August scheine ihm geistig krank geworden zu sein. Also doch! Das würde vieles erklären, wenn auch Konrad nicht entschuldigen. Mit 
diesem bleibe ich beim alten. Hans Gwalter fuhr nach Zürich zurück, seine Braut nach Lausanne.

Heute habe ich dann in Arnolds Tagebuch ein grosses Stück weiter gelesen $u$. bin bald fertig. Die Auf-

zeichnungen sind immer interessant. Aber die Art des Erzählens, die Ausbrüche starker Missstimmung u. mangelnder innerer Fassung machen die Lektüre weniger erquicklich, als sie in den ersten Heften war. Zu Anfang des Aufenthalts in den Tropen überwog selbstverständlich das Neue. Mit naiver Art ging Arnold in all die Pracht hinein, u. jede Unannehmlichkeit wurde aufgewogen durch die Reize der Romantik. Er hat dann allerdings schwer durchgemacht. Es ist schauderhaft, mit welchen Qualen er zu ringen hatte. Aber da kehrt sich das Gemüt mit einemmal um zu einer Erbitterung, die z. Tl. sich gegen seinen «Dätte» richtet. [Munli?] ist alles. Er beklagt nebenbei an einer Stelle seine mangelhafte allgemeine

Ausbildung, u. er gibt dann unbewusst wirklich Proben davon, wenn er findet, holländisch sei viel schöner als deutsch, oder die Russen stehen weit über den Deutschen $u$. Schweizern etc etc. Das schrieb er natürlich in Augenblicksstimmungen. Aber auch so sollten derartige Entgleisungen nicht vorkommen. Stellenweise scheint er sich stark anlügen haben zu lassen. Er urteilt naiv, aber er hat in der wirklich ungeheuer strapazziösen Zeit seines Sumatra-Urwald-Lebens doch viel, viel gelernt, $u$. ich sehe voraus, dass er mit der Rückkehr in normalere Verhältnisse sich prächtig erstarkt zeigen wird.

Nun heute noch eine Woche bis zum Abend, wo sich Dein Hinschied zum zweiten Mal verjährt. Es ist eigentümlich, wie gerade diese Ferien, wie ich sie die drei Wochen verbracht habe, mich an diejenigen des vorletzten Jahres erinnern, da ich nun so drauflos maschinenschreibe, wird die Parallele um so voller. Wird es mit Marieli etwas geben? Nach seinem Bericht sollte es heute bei Frl. Graffina in Mendrisio gewesen sein. Von Frau Rittener 
hat es nichts mehr geschrieben. Gewiss war es schmerzlich für Marieli, dass ich den Umgang mit Ritteners, an denen es ein so grosses Wohlgefallen hatte, missbilligte. Aber wie sollte ich ihm das nicht merken lassen? Ich bin überzeugt, dass das ganze Verhältnis zu Rita Crugnola ein anderes wäre

oder geworden wäre, wenn diese Beziehung nicht dazwischen hätte treten müssen. Ich kenne ja den Antagonismus der Italiener zu den Deutschschweizern in Mailand. Nun, vielleicht kommt es doch besser!

Und jetzt gehe ich zur Ruhe, ich bin müde. Gute Nacht, liebe, liebe Seele!

Ich bleibe Dein alter

Eugen

\section{2: März Nr. 72}

$$
\text { B. d. 25. / 6. März } 1912 .
$$

Mein liebstes Herz!

Heute habe ich wieder mein Pensum an der sozialen Gesinnung geschrieben $u$. ging dann zu Werner Kaiser, um ihm u. uns Glück zu wünschen. Er hatte mir mit Karte mitgeteilt, dass er die Kandidatur in die Solothurner Regierung abgelehnt habe, obgleich ihm zugleich ein Sitz im Ständerat versprochen worden sei. Schöpfer hat sich nun doch bewegen lassen, in den Riss zu treten. Dann sprach ich bei Müller vor, mit dem ich allerlei zu plaudern hatte, namentlich auch wegen der Gesamtausgabe der Einführungsgesetze. Ich hatte Freude an ihm, wie er die Parallele entwickelte, von der freien Handhabung des Zivilrechts, u. der freien Truppenführung u. der freien Verwaltungspflege. Es gibt wirklich eine solche Gesamtströmung. Ich will das im Auge behalten. Dann fiel mir ein, ich 
könnte noch dem Bundespräsidenten Forrer für die Wiederwahl ins Haager Gericht einen Besuch abstatten. Ich tat es u. traf ihn wieder in der ganzen eigenen Art, mit einer Reihe schlotteriger, unzusammenhängender, aber oft geistreicher Bemerkungen. Zu Zürcher habe er gesagt, er wünsche ihm jetzt eines, dass er die Schaffung des Strafrechts erleben möge, wie sein Freund Huber. Abah!

Am Nachmittag kam Dürrenmatt zu mir, in grosser Not, wegen der Stempelsteuer-Geschichte betr. die Versicherungsquittungen.

[2]

Ich glaube, er hat recht, wenn er sich wehrt. Aber ihm ein Gutachten zu machen, wie er mich bat, das lehnte ich doch auf einer mir so fremden Materie ab. Allein als er mir dann ausrechnete, dass für jede einzelne «Quittung» die Strafe gegen $30 \mathrm{Fr}$. betragen könnte, $u$. dass über tausend ausgegeben seien, da wurde auch mir schwül, u. ich stellte ihm doch eine kurze Erklärung aus zu seinen Gunsten, die er morgen vor dem Polizeirichter Raaflaub benutzen kann. Er schied sehr getröstet, aber es wird ihm doch nicht viel helfen, d. h. er würd auch ohne das freigesprochen, wenn die Sache nicht gar zu fiscalisch angepackt wird. Wir wollen sehen.

Heute habe ich das siebente $u$. letzte bei mir liegende Tagebuch Arnolds fertig gelesen. Die jüngeren sind nicht nur weniger interessant, sondern in einem kleinlichen, verbissenen Ton gehalten, der mir leid tat. Arnold hat sich danach mit der Gesellschaft ganz überworfen, ist misstrauisch geworden, nervös, schwärmt für seinen Freund Ernst Gans, der doch in den Angaben auch nicht besonders klug auftritt. Es fehlt ihm das Weltmännische. Nun ja, ich werde wohl auch die Fortsetzungen erhalten $u$. ihn im Herbst selbst sehen. Ausserordentlich viel hat er gelitten $u$. gestritten in dieser Zeit, das ist hoch anzuerkennen.

Ich will jetzt noch an Marie u. an ihn ein paar Zeilen schreiben u. schliesse für heute, um hoffentlich morgen von Marieli einiges anfügen zu können. 
Ich bin heute halb neun ganz verschwitzt nach Hause gekommen, wie von einer Sommertour. Ich war nämlich in Grosshöchstetten bei Bühlmanns, unangemeldet um 3 Uhr angekommen u. bis $7 \mathrm{Uhr}$ geblieben. Sie waren herzlich, namentlich Frau Bühlmann wurde mit jeder halben Stunde wärmer. Der kleine Erik war herzig. Mit Bühlmann machte ich einen Spaziergang etwa eine Stunde weit auf dem «Bühl», wo er einen Bauplatz erworben hat u. schon seit zehn Jahren Bausteine u. Sand aufgehäuft sind. Es sollte ein Sommersitz werden, aber die Pläne änderten u. das Projekt blieb unausgeführt. Der Weg war sehr schön, aber bei heller Sonne u. Föhn ausserordentlich warm, so dass wir beide ganz nass wurden. Er wechselte vor dem Nachtessen die Kleider, ich blieb bis vorhin in dem nassen, schlampigen Col. Aber das Spaziergängchen hat mir wohl getan. Und namentlich bin ich froh, Bühlmanns, wegen meiner verschiedenen Kosagen piquiert, nun, wie ich hoffe, wieder versöhnt zu haben. Ich vernahm allerlei, auch eine Bemerkung von Guhl in einem Schreiben an Bühlmann, die auf einem kleinen Abweg hindeutet $\mathrm{u}$. mich wieder einmal an der Offenheit Guhls stutzig machen könnte. Aber, was erlebte Leonardo an seinen Schülern! Man darf nicht misstrauisch werden.

Heute hat mich dann auch noch ein anderer Schüler beschäftigt, nämlich Siegwart. Ich erhielt von Pesthon einen

Brief, worin er mich um Aufschluss über diesen ersucht $u$. beifügt, die Entscheidung liege nun ganz in meinen Händen. Ich habe diese Anfrage $u$. auch meine sofortige Antwort, eine warme Empfehlung Siegwarts, diesem wörtlich mitgeteilt. Ob es nun sicher sein wird, dass er die Stelle bekommt. Wie ich von der Sache denke, habe ich Dir neulich niedergeschrieben. Am Vormittag schrieb ich den dritten Abschnitt der «sozialen 
Gesinnung». Vielleicht krieg ich den ersten Entwurf doch noch fertig vor der Reise nach Lugano.

Und nun, müde bin ich, geh zur Ruh - gute, gute

Nacht! Ich bin immerdar Dein alter, treuer

Eugen

\section{2: März Nr. 73}

B. d. 27. / 8. März 1912.

Mein liebstes Herz!

Heute bin ich, bei der sömmerlichen Temperatur, die wir jetzt haben, um $6 \mathrm{Uhr}$ aufgestanden $\mathrm{u}$. habe gemaschinelt, bis ich um 1/2 12 Uhr den Aufsatz über die soziale Gesinnung fertig entworfen hatte. Dann waren noch einige Kleinigkeiten zu erledigen. Am Nachmittag aber hatte ich Besuchstournée. Erst kam Walter B. zum Plaudern, darauf Gmür, der mir erzählte, dass er einen Bauernhof oberhalb Signau kaufen wolle, für die Ferien der Kinder u. die Frau, u. dass er mit der Vermögensverwaltung sehr viel zu tun habe u. gar nicht recht zum Arbeiten komme. Burckhardt blieb bis drei, Gmür bis nach vier Uhr. Kaum hatte ich dann begonnen, die Manuskripte zu durchlesen, kam der Rektor Marti, mit dem ich eine sehr rege Unterhaltung führte, u. dazu Guhl, den ich in Amtssachen bei mir haben musste. Es stellt sich nun heraus, dass Guhl seine Bemerkung über das ZGB. anzufügen meinte zur Entschuldigung Bühlmanns selber, u. es ist sonst eine unbedeutende Geschichte, sodass ich davon nicht weiter sprechen will.

Am Mittag kam ein Brief Marielis, recht, ich kann nicht klagen. Es schreibt jetzt gar nicht mehr von Ritteners. Heute wird es nach Induno übergesiedelt sein, worauf es sich 
offenbar gefreut hat. Es wäre jetzt alles in Ordnung, wenn nur Rümelin schreiben würde. So weiss ich immer noch nicht, wann ich nach Lugano reisen soll, ja das ob wird mir unter den Umständen manchmal wieder zweifelhaft. Mit dem Plan, nach Lugano zu fahren, ist es auch entschieden, dass ich Marieli von seinem Schwesterchen nicht brieflich, sondern mündlich Mitteilung machen werde. Und es wird so auch besser sein. Allein es ist mir etwas bange auf den Moment. Von Interesse ist es mir zu hören, dass Marieli überall hin in freudigem Ton von dem Aufenthalt in Mailand geschrieben hat. Hoffentlich wird diese Stimmung der Wahrheit entsprechen. Nun will ich noch etwas an dem M'skript weiter corrigieren, u. dann zeitig zu Bett. Heute war es wie gestern warm, wie sonst nur im Maien. Ich konnte mit meinen Besuchen auf der Terrasse sitzen, als hätten wir schon Sommerszeit. Marieli schreibt auch, in Mailand sei es schon recht warm. Morgen will ich einige Besuche machen, aber wegen der Wärme lieber am Vormittag.

Der Druck mit «Ahnung» ist vorüber. Dagegen klagt Anna. Seit ich mit Marieli wieder besser zufrieden, ist es als ob sie etwas drückte, die alte Geschichte!

Doch genug für heute. Bleib bei mir, liebe Seele!

Den 28. März.

Heute habe ich am Vormittag das Mskript der «sozialen Gesinnung» corrigiert u. es dann Walter B. gebracht, mit der

Bitte, mir zu sagen, ob er es für das Jahrbuch brauchen könne. Sagt er ja, so werde ich es im Laufe des Sommersemesters noch durchnehmen u. feilen u. ergänzen. Sagt er nein, oder zaudert er, so überlasse ich es der Schachtel «Rechtsphilosophie». Am Nachmittag holte ich eine Reihe von Correspondenzen nach. Auch konnte ich endlich nach Lugano schreiben, indem mir Rümelin mit Karte mitteilte, dass er am Dienstag dort eintreffen 
werde. Ich habe an Hotel d'Europe geschrieben, mich wundert, wie die Antwort ausfallen wird. Beschäftigt hat mich sodann die Mitteilung Bühlmanns, der mir beide Briefe Guhls zusandte, von dem ich Dir schon geschrieben. Ich conferierte nochmals darüber mit Guhl u. habe eine Antwort aufgesetzt, die ich morgen an Bühlmann expedieren will. Um 5 Uhr kam Fany Langhard, allein, um mich zu grüssen. Sie blieb auf meine Einladung zum Nachtessen $u$. war ein sehr munteres Landmädchen, das mir Freude gemacht hat.

So ist der Tag vorüber gegangen, ich weiss nicht wie. Etwas beschäftigte mich dabei noch in eigner Art. Ich erinnerte mich, dass Fitting mir geschrieben, im April habe Brünneck ein Jubiläum, welches wusste ich nicht mehr. Ich hatte die Tag in Erinnerung, dass ich mir vorgenommen, ihm zu gratulieren, $u$. das gestrige Gespräch mit Marti frischte diesen Gedanken auf. Wie ich nun aber heute früh $u$. Mittags in Frühlingsbriefen nachschlagen wollte, fand ich - rein Nichts von einer derartigen Mitteilung. Was ist mir nun da durcheinander gekommen? Oder habe ich geträumt? Ich suchte lange - Du weisst, wie hartnäckig ich da sein kann - aber vergebens. Das Rätsel bleibt ungelöst.

Kann sein, dass im Gespräch in Jena so etwas gesagt wurde. Kann aber auch sein, dass es sich wirklich um einen Traum handelt. Aber dann wird mir fast bange. Wie will ich weiter wissenschaftlich arbeiten, wenn mir solches begegnet? Bin ich wirklich so alt? Ich denke dabei an den Vorfall, den ich mit Kleiner bei seinem letzten Besuch hatte, da er sich entschuldigte, mir für die Übersendung der Neujahrs Heliogravuren nicht gedankt zu haben. Und er hatte mir darüber ein so liebes Briefchen geschrieben! Ja, ja, wir werden alt. Seis drum, es kommt jeder an die Reihe! Jetzt ist es spät geworden u. ich gehe zur Ruhe. Es war heute wieder ein sehr warmer Tag. Die Gärtner haben den Garten hübsch in Ordnung gemacht. Geheizt haben wir schon heute nicht mehr! 
Gute Nacht, liebste Seele! Gestern hättest Du mir in

der frühen Morgenstunde wieder einmal sagen können: Nicht Trömmelen, Schlafen, lieber Eugen! Ich ertappte mich an einem langen Marsch, den ich auf die Bettstelle klöpfelte, u. dann schlief ich wieder bis fast sieben Uhr.

Nochmals, zur Ruh, zur Ruh! Dein ewig getreuer Eugen

\section{2: März Nr. 74}

B. d. 29. März 1912.

Mein liebstes Herz!

Ich stehe unter dem Eindruck einer Todesanzeige: Fritz Müller, der Dir wohlbekannte Sohn v. Bundesrat Müller, ist gestern an einer akuten Gelenkentzündung mit Herzschlag gestorben. Ich habe den jungen Mann sehr lieb gehabt. Für die Eltern, mit denen er enger als die andern Kinder verbunden war, ist es ein schwerer Schlag. Ich sandte einen Kranz u. ein Condolenzschreiben. Morgen Nachmittag ist Kremation, die vierte, der ich in diesem Halbjahr beiwohnen werde.

Von Morgen an hatte ich heute Kopfweh u. Übelkeit. Ich schrieb den langen Brief an Bühlmann ab, sonst aber war ich, abgehoben von der Condolation u. einigen andern, kleinen Correspondenzen, zu keiner Arbeit fähig. Inzwischen sollte ich Siegwart neue Arbeit rüsten. Aber es ist so ungewiss, ob er nicht in der allernächsten Zeit seine ganze Kraft dem neuen, schönen Amt wird zuwenden müssen, dass wir heute verabredeten, er soll mit Ende dieses Monats bei mir provisorisch austreten. Wird er Professor, so wird der Austritt sofort definitiv. Zerschlägt sich die Sache, so bleibt er, wie wenn kein Unterbruch stattgefunden hätte, bei mir. Es tut mir leid, dass es jetzt so rasch sich entscheidet, aber es ist so besser. Natürlich drückt dies dann auch auf die Fertigstellung 
des ersten Bandes. Allein da kann ich mich aber immer wieder nicht von einem Missbehagen gegen den Verleger frei machen. Ich sprach davon offen zu Walter B. der mich Nachmittags besuchte, u. er zeigte Verständnis. Er kennt die zwei Hauptmomente, die mich an Lichtenhahn stutzig gemacht haben. Hat er doch im Departement dabei teilweise mitgewirkt. Ich sprach ihm auch von dem neuen Erlebnis mit Guhl, u. er schien es ernster aufzufassen, als ich dies zu tun entschlossen bin. Guhl ist noch jung $u$. hat doch gewiss eine gute Gesinnung. Also warten wir zum mindesten weiteres ab. Im übrigen kam Walter B. zu mir, um mir zu sagen, dass er die «soziale Gesinnung» gerne in das Jahrbuch aufnehmen werde. Er sprach sehr nett davon, wenn auch in seiner Art, trockenbrödlerisch. Ich lasse nun den Entwurf längere Wochen liegen, um ihn dann gegen Mitte des Jahres, wenn nichts anderes dazwischen kommt, fertig zu machen.

Heute hatte Anna den 75. Geburtstag. Ich gab ihr Geld u. sie kaufte sich davon eine Kleinigkeit, ein Paar seidene feine Handschuhe. Marieli sandte einige Arbeiten u. ein sehr nettes Briefchen aus Induno, wo es ihm gut gefällt. Von Frau Moser kamen Blumen aus ihrem Garten. Karle überreichte ein Veilchensträusschen, das Sophie selbst hinter dem Hause gepflückt hatte. Anna war heute

munterer als sonst. Sie beginnt das neue Altenjahr ruhiger, als ich es in den letzten Tagen geglaubt hatte.

Dann war am Vormittag Rossel bei mir. Er bedauert sehr, mit Soldati u. Jäger in der gleichen Kammer zu sitzen. In Lausanne hat er für 35000 eine Villa gemietet, hinter dem Penitentiaire, mit grossem Garten, aber kleinen Zimmern. Es ist ihm doch etwa bange vor dem neuen Leben, u. er gibt den Gedanken nicht auf, doch wenigstens der Nachfolger Comtesses werden zu können. 
Gegen Abend ist mir wohler geworden. Aber ich habe Schlafsucht $u$. werde jetzt dann gleich zu Bette gehen. Was mag es sein, was mich derart in den letzten Wochen fast periodisch plagt? Ich werde doch nicht in meinen alten Tagen noch Migräne bekommen? Am Ende ist es doch Semestermüdigkeit u. die beabsichtigte Ausspannung der nächsten Woche wird mir dann gut tun.

Es ist ja alle Wahrscheinlichkeit vorhanden, dass ich Siegwart jetzt wirklich morgen den letzten Tag bei mir haben werde. Das tut mir leid, denn ich bin jetzt wieder in das Ungewisse versetzt. Wie will ich mich einrichten? Und wenn jetzt Anneli wirklich zu uns kommt, wie kann ich etwa auf Marielis Hülfe rechnen? Es drängt mich jetzt doch mit dem lieben Kind über alles das zu sprechen. Ich erwarte noch Anzeige vom Hotel d'Europe, u. werde mich dann einrichten, dass ich mit Marieli in dort oder in Induno nochmals

zusammensein kann. Bin ich dann zurück, so habe ich noch etwa zwei Wochen bis zum Semesterbeginn. Das reicht hin, um das noch Nötige vorzubereiten.

Und nun tue ich, wie ich gesagt, u. lege den müden Kopf bald zu Bett. Gute, gute Nacht! Bleibe bei

Deinem immerdar treuen

Eugen

1912: März Nr. 75

[1]

B. d. 30. März 1912.

Mein liebstes Herz!

Heute Nachmittag wurde Fritz Müller im Krematorium beigesetzt. Absolut jede Kirchlichkeit vermieden, u. eine Feierlichkeit eigener Art. Es waren drei Kutschen, 
der Totenwagen u. ein Blumenwagen. Auf dem Friedhof versammelten sich die Helvetia in Farben u. mit Fahne, u. dazu eine stattliche Zahl von Althelvetern. Vom Bundesrat waren Forrer $\mathrm{u}$. Hoffmann erschienen, dazu Oberst Emil Frey. Ich sah viele Bekannte. Vor dem Sarg sprach Raaflaub, er war so bewegt, dass er schwer sprechen konnte. Nach ihm hielt Stud. Hodler eine schöne Ansprache. Beide betonten das Helvetertum. Die Feier war davon durchzogen. Ja, da konnte man sehen, welchen Halt die Angehörigen einer solchen Verbindung haben. Die Helvetia ersetzte auch jede religiöse Anspielung. Sie war alles. Frau Bundesrat nickte mir aus dem Wagen zu. Sie schien sehr gefasst. Bei Hodlers Rede brach sie aber in Tränen aus, sodass Margrit sie umklammerte. Der Vater war stumm, unbewegt. Ich weiss, wie tief es ihm geht. So sucht eine jede Richtung sich etwas herzustellen, was ihnen bei solch schweren Lebensmomenten für Schmerz u. Trauer Ausdruck gibt. Aber es ist kaum möglich, auch nur ein Teil der Stimmung wieder zu schaffen, die in altüberlieferten

Formen uns gegeben ist. Ich sprach auf dem Heimweg mit Hoffmann, den ich vielleicht morgen noch sehe. Dann mit Oberst Frey, der darüber klagte, dass er an Schwindel leide. Ferner mit Raaflaub u. mit dem jungen Walter. Von den Trauernden konnte ich keines begrüssen. Raaflaub war der Leibbursch Fritz Müllers gewesen. Die Freundschaft war denn auch das schönste was in des erstern Rede zum Ausdruck kam.

Heute hat Siegwart mir noch mancherlei geordnet. Ich habe ihn frei gegeben. Er sollte, wie wir verabredeten, auf alle Eventualität hin jetzt nicht für mich, sondern für die Professur arbeiten. Da erschien er um 2 Uhr mit Oser: er ist von Pylsen als Professor vorgeschlagen, also gewählt. Er war strahlend. Das verdanke ich Ihnen, sagte er, ich will hoffen, dass er auch später sich dessen erinnert. Bei mir hat er viel gelernt. Und ich hab ihn gern gehabt. Ich musste denken, wie doch das Schicksal Gegensätze schafft: Am gleichen 
Tag, wo ich zum Begräbnis Fritz Müllers gehe, in diese typische Helveter Feier, nehme ich an der Freude Teil, die der Enkel Siegwart Müllers darüber empfindet, dass er in Freiburg dank meiner Empfehlung Professor geworden. Und doch bin ich auf festem Grund $\mathrm{u}$. konnte beides mit guten Gründen verteidigen. Ich war da u. dort mich selbst. Aber ich habe eben eine andere Richtung als sie alle. Und das macht mir das Leben so schwer.

Heute hatte ich dann noch Guhl bei mir, in einigen nicht

unwichtigen Fragen. Ich überlegte, ob ich Mutzner auf morgen zu mir bitten soll. Aber ich unterliess es. Ich kann das immer noch tun, wenn ich zurück bin. Aber irgendwie muss ich es ihm doch sagen, dass Guhls Dozententum kein Hindernis sein soll für seine Habilitation.

Und sonst war wieder der Tag mit Briefen $u$. einigen Consultationen gefüllt. Ich komme zu nichts rechtem, trotz unausgesetzter Tätigkeit. Arbeiten wir weiter, es muss ja einmal ein Ende nehmen.

Morgen bin ich noch da, verreise erst Montags. Was mich in dieser Voraussicht plagt, das ist der Gedanke, wie Marieli den Vorschlag betr. Anneli aufnehmen wird. Ich flehe Dich im Geiste an, hilf mir zum Guten! Es wird ja schliesslich sich schon ein Weg finden lassen. Aber er wird sehr schwer sein. Marielis Brief von heute hat mich in verschiedenen Beziehungen gefreut. Namentlich was es vom Besuch bei der Frau Mina erzählt, der es von Frau Bühlmann empfohlen worden, war sehr hübsch gesagt. Ach, es wird, wie es selbst schreibt, schliesslich doch zu einem lebendigeren Degagement gelangen.

Es war heute wieder ein prächtiger Tag, aber kälter als letzthin, was mir gut getan hat. Die vierte Ferienwoche ist jetzt vorüber. Was bringt die Fünfte? Wer weiss es! Man hat so viel Unerwartetes, in der letzten Zeit ganz besonders. Fassung, Fassung, u. Vertrauen! Es muss ja gehen, trotz allem Feindlichen, was jeden umgibt. Schliesslich, wenn alles bricht, 
soll doch der Mut nicht gebrochen sein. Eines las ich noch heute, freilich nur kursorisch, Platons Symposion. Aber ich war davon nicht erbaut, auch wenn Socrates aus diesem Sumpf hervorragt als weiser Mann. Da tritt nun eben doch das zu Tage, was die christliche Kultur von der griechischen unterscheidet $u$. trennt.

Und jetzt auch diese Woche-Schluss!

Mit innigem Kuss bin ich Dein altgetreuer

Eugen

1912: März Nr. 76

[1]

B. d. 31. März 1912.

Mein einziges Herz!

Heute vor 104 Wochen sass ich um dieselbe Zeit am selben Platz u. las die Schrift von Gerland über den englischen Richter, bis halbzehn Uhr. Dann schlich ich in das Schlafzimmer, wo Du zu ruhen schienst in sanftem Schlaf, von Schmerzen frei, - u. dann zweieinhalb Stunden später begann jene Not, die uns für das Leben getrennt hat. Ich stellte mir immer wieder vor, was ich anders hätte machen sollen. Aber es ist geschehen, u. es war ja auch alles in meiner Auffassung begründet. Hätte ich anders gehandelt, $\mathrm{u}$. so würde die Katastrophe auf andere Weise herbeigekommen sein. Ich kann jetzt nicht so ruhig über die Sache denken, wie vielleicht vor einem Vierteljahr, heute wenigstens nicht, infolge der Verjährung, u. dann weil mich augenblicklich anderes in quälender Weise beschäftigt, worüber Du mir raten solltest u. nicht kannst. Und doch, wenn ich an Dich denke, so empfinde ich, Du kannst es, denn Dein Wesen lebt in mir weiter.

Ich ging heute zu Hoffmann, der sich sichtlich freute, dass ich kam. Den Besuch benutzte ich, um mit ihm über die persön- 
lichen Differenzen im Justizdepartement zu sprechen, die ich aufs höchste beklage. Vielleicht kann er auch etwa etwas helfen, namentlich wenn er Müller in der Abwesenheit zu vertreten hat. Bei dem Anlass meinte er dann, Guhl

habe «Höhenrauch» bekommen u. ich soll mich in Acht nehmen. Ich konnte bestätigen, dass ich selbst schon mehrfach stutzig geworden. Die Mahnung sei mir also nicht unerwartet, $u$. ich werde sie auch beherzigen. Mutzner schätzt Hoffmann als einen sehr graden, tüchtigen Mann, den er nicht der Ränke fähig erachtete, die er Guhl zutraut. Er wollte Gmür dafür etwas rehabilitieren bei mir, als ich ihm aber die Geschichte mit den Kollegienheften anzeigte, war er betroffen, $u$. ist nun besser unterrichtet. Von Hoffmann ging ich auf Umwegen - indem ich Müller noch zu sehen hoffte, zu Werner Kaiser. Er u. seine Frau empfingen mich herzlich. Das ist gewiss kein Intriguant! Bei seinem Abendbesuch sprach ich Walter B. von den Reibungen im Departement, u. er will sich Mutzners etwas annehmen, damit er nicht ganz unter den Einfluss Guhls gerät. Diese Dinge rufen mir des deutlichsten Deinen Rat in Erinnerung: Trau weder Gmür noch Guhl, behalte Dein Amt ganz u. ungeteilt, solang Du kannst, u. wenn Dus nicht mehr kannst, so zieh Dich vollständig zurück. Dieser, Dein Gedanke ist mir jetzt bestätigt. Es ist merkwürdig, wie Du Personen u. Verhältnisse so gut durchschautest, indes ich von meinen Wünschen befangen war! Und nun das zweite: In vier, fünf Tagen werde ich mit Marieli über sein u. mein Schicksal, u. über Annelis Zukunft gesprochen haben. Wie wird das kommen! Wird es stutzig, unglücklich, oder ist es für sein Herz eine Freude? Kann ich die volle Aufklärung versüssen durch den Gewinn 
einer Schwester? Ich habe mir die Sache nun so geplant: Am Dienstag fahre ich nach Induno. Es ist dann zwar Ritas Geburtstag, aber umso besser. Ich will ihr etwas mitbringen, u. nach einigem Planieren hat Anna die Silbermesserchen vorgeschlagen, die Du s. Z. bei Hofer gegen die Bismarckbüste eingetauscht. Sie wurden von Dir nie mehr gebraucht, u. sie haben auch für mich einen problematischen Erinnerungswert. Dann will ich an diesem Dienstag mit Marieli verabreden, dass es am Donnerstag, dem Kalendertag Deines Hinschiedes, d. 4. April, nach Lugano kommt. Ich will dann allein sein mit ihm u. Gelegenheit finden, die Lage zu besprechen. Aber es wird mir sehr bange auf diese Stunde. Es war doch eine rechte Unbesonnenheit, mit Anneli zu sprechen, bevor ich der Gesinnung Marielis sicher war. Allein auch da muss ich sagen, was ich damals tat, tat ich aus guten Gründen. Hätte ich es nicht getan, so würden vielleicht andere Schwierigkeiten entstanden sein!

So stehen diese zwei Schwierigkeiten vor mir. Die erste mag sich hinziehen, die zweite wird so oder anders in Bälde gehoben sein.

Heute Abend war Winkler ein Stündchen bei mir, in einer Rechtssache, daneben aber gescheit wie immer. Dann besuchte uns Frau Jauch, die Angst hat, ob Siegwart dem Amte gewachsen sei. Zwar wäre er immer ein hervorragender Schüler gewesen, aber die Aufgabe laste ihm schwer auf dem Herzen. Ich konnte ihr antworten, dass ich dies als besonders

günstiges Zeichen dafür betrachte, dass ihm die Aufgabe gelingen werde. Sie dankte mir herzlich für die Unterstützung, die ich ihrem Neffen zuteil werden gelassen.

So ist der Tag, schwerblütig, vorübergegangen. Ich dachte nach, ich las, in der [Di?] u. i. a., meine Gedanken blieben auf Dich concentriert. Dir lebe ich, ohne Dich lebe ich nicht. Was ich wurde, verdanke ich Dir, denn im Ziel auf Dich wurde ich für das Leben tüchtig. Du hast mich unbewusst 
geleitet. Wo ich davon abirrte, wars ein Quelle vom Ungemach. Du wirst mich auch noch bis ans Ende führen!

In den Zeitungen las ich, dass Kägi sich hat pensionieren lassen, der erste, der Albert nachgefolgt. Wenn ich nicht Dich vor Augen gehabt hätte, wäre ich nicht vielleicht jetzt in der gleichen Verfassung wie jene?

Und nun in dieser Nacht - bleibe bei mir, wie ich bei Dir! Es muss zum besten werden. Wir können vereint des Herzens Frieden finden!

Gute, gute Nacht, meine gute, liebe Seele, mein Leitstern in des Lebens Dunkelheit! Ich bin

Dein ewig getreuer

\section{Eugen}




\section{April 1912}

\section{2: April Nr. 77}

[1]

Lugano, Villa Tivoli, Europe

den 1. April 1912.

Mein liebstes Herz!

So habe ich also die Reise angetreten $u$. bin schon in meinem Einerzimmer in Lugano. Die neue Dependence zum Europe liegt ähnlich wie das Belvedere s. Z. zum Parc Hotel, wo wir 1893 zusammen so reiche zwei Wochen verlebt haben. Auch am See, Wellenschlag, Blick ins Weite. Aber ich habe nur die Erinnerung an die Freude, diese selbst ist verschwunden.

Zum Reisen war es ein Regentag, aber bis Luzern las ich wiedereinmal in le mie prigioni von Silvio Pelico, und hatte grosse Freude. Ich konnte mir ganz gut vorstellen, weshalb diese Lektüre als ich 1875 nach Zürich zurückgekehrt war u. sie mir der Zufall u. die Herzensgüte Robert [F?] in die Hände spielte, so grossen Eindruck gemacht hat. Er wiederholte sich heute. Es ist ein tiefes Buch.

Bei dem Regenwetter hätte es eigentlich wenig Sinn gehabt, von Luzern bis Flüelen das Schiff zu benutzen. Aber ich hatte Albert nach [?] geschrieben, dass ich vorbeifahren werde, u. richtig, war er schon in Weggis am Ufer u. fuhr dann mit mir 
bis Brunnen. Ich fand ihn erst sehr deprimiert. Allsgemach taute er auf, u. wir hatten ein fruchtbares Plauderstündchen zusammen. Mit Arnold kann er sich immer noch nicht aussöhnen, ich redete zum besten.

Beim Einsteigen in Luzern kam auf dem Dampfschiff Dr. Scheiber auf mich zu. Er war auf der Fahrt nach Rigikulm, mit seinem Personal. Ist es nicht merkwürdig, dass ich ihn wieder auf dieser Fahrt treffen musste? Schon einmal begegnete er uns beiden mit seinem Tross in Vitznau, u. ein andermal in Luzern. Wir freuten uns über das wiederholte Zusammentreffen. Er sah gesund aus, aber im Blick recht gealtert. Es kam mir anfangs sogar vor, er sei zu sehr friedlich im Ausdruck. Er ist ein Jahr jünger als ich, was will man! Er hatte zwei Söhne eine Schwiegertochter u. vier kleine Enkel bei sich. Es war ein trautes Geplauder mit ihm bis Vitznau, wo er ausstieg.

Die Fahrt über den Gotthard in den überfüllten Wagen war weniger schön. Ich traf im gleichen Coupé Frau Prof. Theophil Studer u. ihren Mann. Wir kamen aber nicht nebeneinander zu sitzen $u$. ich trachtete auch nicht

nach einer Anknüpfung. Ich bin jetzt genug mit meinen Angelegenheiten beschäftigt.

Morgen werde ich also nach Varese fahren. Einen Gegenbrief von Frau Crugnola war nicht im Hotel. Wie werde ich es antreffen? Was wird geschehen? Ich werde es in Bälde wissen.

Eben jetzt stürmt es arg. Gut, auch wenn es bis morgen anhält. Aber dann wäre etwas besseres Wetter schon wünschenswert. Du hast zwar immer für die Karwoche rauhes Wetter gewünscht $u$. vorausgesagt. Kann sein, dass es kommt. Wenn Rümelin eintrifft, werden wir uns schon zu helfen wissen. Heute früh bin ich noch hingesessen $u$. habe das neue eigenhändige Testament aufgesetzt $u$. dann Siegwart 
zur Aufbewahrung übergeben. Das wesentlich Neue daran ist, dass unser Haus Seminar werden soll, $u$ dass Augusts nichts erhalten. Ich habe dieses kurz motiviert: Sie haben genug, mehr wäre ungesund, wie Beispiele zeigen. Es kostete mich keine Mühe, das so zu redigieren. Kehre ich gesund von der Reise zurück, so kann ich dann

[4]

immer noch modifizieren.

Nun spüre ich aber, ich bin müde. Also Schluss für heute.

Sei im Geiste innigst umarmt von

Deinem getreuen

Eugen

\section{2: April Nr. 78}

[1]

Lugano, Tivoli-Europe

d. 2. April 1912.

Mein liebstes Herz!

Heute habe ich das Schwere unternommen u. zum ersten Mal mit Marieli über seine Verhältnisse gesprochen.

Es geschah hinter Induno auf einem Felsabsatz u. verlief merkwürdig. Marieli bekannte mir, nach einigem Stocken darüber, als sie Pauls Brief gelesen, offen, sie habe ihn gelesen u. ferner sie habe seit der Secundarschule gewusst, dass sie nicht unser Kind sei. Nicht dass ihr das immer vorgeschwebt, aber zuerst habe es sie sehr aufgeregt, nachher sei sie nur momentan davon beeinflusst gewesen. Im Verhältnis zu Paul sei das für ihren Bruch die Hauptveranlassung gewesen, dass er gesagt habe oder doch angedeutet, sie müsse froh sein, dass sie ihn bekomme. Und da hatte sie auch ganz recht, dies in bestimmter Art abzulehnen. Meine Mitteilungen fielen also auf einen wohl vorbereiteten Boden u. ich kann in dieser Hinsicht über den 
Gang unserer Beziehung u. fam. Erfolg zufrieden sein. Sie versicherte auch beim Abschied, dass sie nur umso inniger mit mir verbunden sei. Was nun aber der Plan mit Anneli anbelangt, so hat Marieli die Sache durchaus mit im ersten Schuss eingeleuchtet. Sie wird mir darüber aber übermorgen, wo sie

nach Lugano kommt, Bericht geben. Sie hatte Bedenken über die Stellung der Schwester, ob sie nicht sich als Aschenbrödel vorkommen werde, $u$. ferner meinte sie, es würde dadurch allgemein bekannt, dass sie nicht unsere leibliche Tochter sei, während es jetzt viele nicht wissen, z. B. auch nicht Frl. Reineck. Namentlich frappierte mich dann aber die Mitteilung, dass im Dezember 1910, als ich im Nationalrat abwesend war, eines Tages zwei Knaben der Rosa, die damals bei uns war, einen Brief mit Marielis Adresse übergaben u. in diesem Brief habe ihr Anna Röthlisberger geschrieben, sie müsse im Auftrage ihres Vaters ihr mitteilen, dass sie, Marie, noch eine Schwester, die Schreiberin, u. zwei Brüder habe. Der Brief sei recht gehalten gewesen, als Adresse zur Antwort sei ein Hotel im Jura angegeben gewesen. Dieser Brief habe sie sehr aufgeregt. Sie habe ihn sofort zerrissen $u$. sich entschlossen, mir nichts zu sagen. Das war nun gewiss temperamentvoll gehandelt, aber nicht klug. Mich aber machte die Mitteilung stutzig in meinem Urteil über Anneli. Zwar ist es mir, als hätte sie mir gesagt, sie habe einmal an Marieli geschrieben. Dagegen war jedenfalls von ihrem Hoteldienst nicht die Rede. Steckt da etwas dahinter? Ich muss mir die Sache neuerdings überlegen. Und wenn man solche Pläne zu überlegen beginnt, so geschehen sie nicht. Ich will damit nicht sagen, dass der Plan ganz dahin

gefallen sei. Ich habe Marieli ersucht, nächsten Donnerstag nach Lugano zu kommen, übermorgen, u. mir dann zu sagen, was sie darüber denkt. Jedenfalls aber ist bei der Gemütsverfassung Marielis die Sache nicht mehr so einfach, wie ich sie mir 
vorgestellt habe. Ich will mir selber noch klarer werden! Heute hatten wir den ganzen Tag schwere Bise, wie ich sie in Lugano nie erlebt habe. Ich spazierte am Quai, wo die Wogen über die Mauer spritzten, dann fuhr ich halb neun nach Porto u. Induno. Marieli holte mich am Bahnhof ab. Bei Frau Crugnola wurde ich sehr freundlich aufgenommen u. auch Montanis waren sehr nett. Das Geschenk freute die junge Frau. Die beiden Knaben waren recht nett, ich hatte das vergessen, ihnen etwas zu bringen, was ja deshalb den Eindruck meines Besuches bei ihnen sehr beeinträchtigt hat. Nach dem Essen war ich auf dem Friedhof mit Marieli u. besuchte das Familiengrab der Crugnola u. Ghiringohelli. Wie Marieli es schrieb, kam es mir auch vor, einfach, aber auch nicht mit Geschmack aufgebaut. Ich blieb bis halb fünf. Marieli begleitete mich noch bis Porto. Die Bise war auf dem Schiff bei der Rückkehr geradezu wohltuend.

Und nun mitten in diese innere Unruhe kommen Rümelins

heute Nacht 11 1⁄2 Uhr. Ich werde wohl an die Bahn müssen, wenn es mir nicht zu kalt wird. Ich würde lieber zu Bett gehen.

So will ich diesen Tag nun schliessen. Er zieht äusserlich ein Facit, das innerlich offenbar schon geschehen war. Also, drauf denn, wir ändern doch nichts mehr an dem was geschehen ist.

Gute, gute Nacht! Jetzt sollte ich halt mit Dir reden können, u. das ist nicht mehr möglich, so dass ich ratlos stehe u. abwarte, was kommen muss! Nochmals, liebe Seele, gute, gute Nacht! Dein ewig treuer Eugen 


\section{2: April Nr. 79}

[1]

Lugano, Tivoli, [?]

d. 3. April 1912.

Liebstes Herz!

Der heutige Tag war mit Erinnerungen angefüllt an Dich u. mit Gedanken an Marieli. Ich schrieb in diesen letztern befangen einen Brief an Abbühl, werde ihn aber nicht ohne Marielis Zustimmung abgehen lassen. Darin schlage ich ihm vor, mein Secretär für die halbe Zeit zu werden, wenn es ihm passt. Dann verabredete ich mit Marieli die morgige Zusammenkunft in Morcote, damit ich zunächst eine Weile mit ihm allein sein kann. Rümelin musste ich von den näheren Umständen der Geschichte mit Paul erzählen. Er fand die Sache auch sehr gravierend taktlos. Ins Einzelne bin ich nicht eingetreten. - Als ich am Vormittag mit Rümelin über Castagnola hinausspazierte, kamen mir alle die frohen Stunden in den Sinn, die wir dort erlebt. Und am Nachmittag, bei einem Besuch in Gandrea steigerten sich die Eindrücke. Ich sollte nicht da sein, u. doch wieder ist es so schön, alles dessen zu gedenken, gerade an dem Tage, da Dein Hinschied sich zum zweiten Male jährt! Was werde ich morgen mit Marieli erleben? Es macht mir bange, u. doch sehe ich, dass wir nur Gutes wollten. Bleiben wir im Vertrauen, dass es auch gut werden werde! Briefe erhalte ich natürlich jetzt fast gar nicht. Wer wollte

mir schreiben? Die schöne Zeit ist auch da vorüber, da ich jeden Tag von Dir Bericht u. liebe Worte erhielt. Es geht jetzt alles, alles anders.

Es war heute ein Glanztag, aber sehr starke Bise u. kalt u. staubig. Wenn die Bise nicht aufhörte, so lange wir hier sind, werde ich einen ähnlichen Eindruck bekommen, wie 
vom Wind auf dem St. Gotthard. Aber die Sonne ist lieblicher. An den Gotthard erinnerte es mich auch, dass ich heute den Maler Bresta antraf. Merkwürdig gealtert. Er sagte auch, dass er unter einer Influenza leide, lud mich aber ein, ihn einmal in Licco zu besuchen. Das werde ich wohl tun müssen, ebenso wie ich auch Bertoni u. Bargorghi geschwind grüssen sollte.

Ich habe vor Tisch bis hierher geschrieben, blieb dann bis Rümelin aufbrach, zehn Uhr, in dem Hall. So war die Umgebung keineswegs der Stimmung der Stunde entsprechend. Ich habe das ja voraussehen müssen, als ich mich entschloss, auf diese Erinnerungswoche nach Lugano zu reisen. Morgen werde ich mit Marie vielleicht auch wenig Stimmung gewinnen. Ihr Verhalten hat mir übrigens den Plan mit Anneli in weitere Ferne gerückt. Was beginnt sich mit dem Ablauf des zweiten Trauerjahres alles zu zerschlagen. Ich erkenne das immer deutlicher u. zwar in der Richtung, dass Du mit Deinen Anschauungen überall recht bekommst.

Du hattest in letzter Stunde gegen die Aufnahme Marielis schwere Bedenken, die ich erst zerstreuen musste. Dass jetzt soviel Kummer daraus erwächst, das zeigt, wie Recht Du hattest. Du warst gegen die Verbindung Maries mit Paul, als Du sahst, dass sie ihn nicht mochte u. er nur aus Geldgier u. Bequemlichkeitssucht sie haben möchte. Und dass Marie davon abwich, nicht ohne meine Schuld, brachte den grossen Kummer über uns. Du warntest mich vor Gmür u. Guhl, u. ich hatte hohe Zeit das einzusehen, $u$. wenn ich zu etwas gutem komme in meinem Beruf, so war es aus dieser Einsicht u. wird aus ihr kommen. Ich spüre tief innerlich, wie schwer ich im Unrecht war, Dir in diesen u. andern Dingen die Leitung anzuvertrauen, $\mathrm{u}$. wenn ich das bekenne, so mag dies für den heutigen Abend der tiefste Ausdruck meiner Trauer um Dich bedeuten! Und zugleich des Dankes, den ich Dir spende, wie man dem Tag für das Licht dankt, wenn die Sonne untergegangen ist. 
Nun ja, Wirken so lange es Tag ist, oder solange es noch dämmert wenigstens. Die Dämmerung, in der ich mich stehen fühle, geht der vollen Nacht entgegen, es ist keine Morgendämmerung. Und doch fühle ich Perspektiven sich mir eröffnen, von denen ich am hellen Tag wenig geahnt habe. So ist die Nacht dann doch dem Herzen wieder lichter Tag, u. dass es so kommen möge, dafür weisest Du mir den Weg

u. leitest mich mit Deiner lieben Hand!

Hilf mir auch morgen das Rechte zu finden, hilf Marieli in seinem unerfahrenen Herzen. Lass uns in Liebe $u$. Dankbarkeit verbunden sein, das ist der einzige Trost, den ich empfinde $u$. für das schwere gedrückte Herz annehmen kann. Wie wird es im nächsten Jahre sein? Innigst grüsse ich Dich heute, Du gute treue Seele, u. bin auf ewig

Dein getreuer

\section{Eugen}

\section{2: April Nr. 80}

Lugano, Tivoli Zm. 111

d. 4. April 1912.

Mein liebstes Herz!

Wie eigentümlich ist dieser Erinnerungstag vorübergegangen. Hoffnung u. Angst folgten sich in einer Reihe. Ich hatte eine ruhige Nacht, trotz starken Nordsturmes, u. fuhr um halbneun nach Morcote ab. Auf dem Schiff erst sah ich, dass das Schiff, das ich Marieli bezeichnete in Morcote nicht hält, so dass Marieli dort mit mir nicht zusammen treffen konnte. Richtig war es auch an der Landungsstelle nicht zu sehen $u$. so fuhr ich weiter nach Porto. Aber auch da war Marieli auf dem ihm angegebenen, noch im Hafen 
haltenden Schiff nicht zu finden, u. mich überkam eine grosse Angst, die mich veranlasste, gleich nach Induno weiter zu fahren. Auch dort war Marieli nicht am Bahnhof. Ich eilte also zu Frau Crugnola hinunter, traf diese mit der Dir aus Taramo bekannten Magd Maria, u. als diese mir sagten, Marieli sei um 9 Uhr regelrecht verreist, fuhr ich gleich zurück nach Porto, ging aufs Schiff, in der Meinung, nun günstigsten Falles Marieli in Lugano zu treffen. Und da stand sie nun in Morcote am Landungssteg u. kam zu mir auf das Schiff. Die Sache erklärte sich so, Marieli hatte in Porto vernommen, dass das ihr angewiesene Schiff gar nicht im Morcote halte, u. nahm schnell entschlossen eine Barke,

die sie auf neun zehn Uhr nach Morcote brachte, während ich selbst dort schon vor halb zehn vorüber gefahren. So sass sie in der Barke, indess ich auf dem Schiff an ihr vorbei fuhr. Mir war es sehr, sehr Angst, es möchte etwas mit ihr begegnet sein, u. ich fühlte mich glücklich, sie nun wieder bei mir zu haben. Auf der Fahrt nach Lugano konnte ich dann die zwei so wichtigen Fragen, die ich mit ihr zu überlegen hatte, besprechen.

Zunächst den Vorschlag an Abbühl, mein Secretär zu werden. Sie leuchtete auf, als ich ihn nannte, meinte aber doch, es werde sich zeigen, wie die Sachen sich gestalten. Insofern also auch da nicht eine kritiklose Hingebung. Der Brief wurde von ihr in den Briefkasten in Lugano geworfen u. wird am Samstag bei Abbühl sein, warten wir das weitere ab. Dann die Aufnahme Annelis in unsere Familie. Sie, Marie, war hier auf dem Schiff noch so zaudernd, wie vorgestern. Doch brachten wir die Besprechung auf dem Schiff nicht zu Ende. Nach dem Lunch ging ich dann mit Marieli allein auf den S. Salvatore, u. als wir von dort zurück waren u. in den Strassen des Paradiso herum streiften, da kamen nun erst ihre Bedenken Stück für Stück zu Wort. Sie bemerkte erst, ich werde sie am Ende für herzlos halten, wenn sie so rede, aber der entschiedene Ausspruch ging dahin, überwiegend, weil 
überwiegende Gründe sprechen gegen den Plan mit Anneli. Es lässt sich ihr Verhältnis zu Marieli in der Familie gar nicht so fixieren u. abklären, dass ein willkommenes Resultat einigermassen sicher wäre. Also besser, bleiben lassen des bisherigen Zustandes. Diese Auffassung Marielis war jetzt so entschieden, dass ich ihr eine andere Entschliessung gar nicht mehr zumuten konnte. Sie würde sich als degradiert erachtet haben, wenn ich den Schritt doch gewollt hätte. So versprach ich ihr, einen Brief an Anneli aufzusetzen, worin dieser negativen Entscheidung Ausdruck gegeben sei, den werde ich ihr nach Induno senden, u. sie möge ihn dann von dort auf die Post geben. Die Concepte der beiden Briefe, an Abbühl u. an Anneli lege ich hier bei. Sie stehen nicht nur zeitlich in Zusammenhang, sondern auch innerlich. Es ist eine eigne Welt, die sich da in Marieli's Gemütsleben entwickelt u. gezeigt hat. Mir nicht [?], aber, das muss ich sagen, sehr vernünftig, u. am Ende handelt es sich in beiden Fragen um Dinge, die Marieli mehr als mich berühren. Freilich der Sonnenschein, auf den ich gehofft, ist damit für mich nicht geschaffen oder gerettet. Marieli verreiste sechs Uhr. Rümelins waren sehr nett mit ihm u. luden es für längere Wochen auf Tübingen ein. Es wird sich zeigen - den Ostertag soll ich in Induno zubringen. Nach dem Pranzo sassen wir, Rümelins u. ich, noch bis halb zehn zusammen. Um 10 Uhr ging ich dann mit Rümelin

noch zu einem Glas Bier u. hatten ein langes Gespräch über wissenschaftliche Fragen, wobei er mir sagte, im Jahr 1906 hätten Gierke u. er mit Binding in Tarasp über mich einen längeren Disput gehabt, dessen Einzelheiten mir Binding als meinen Gegner zeigten. Von March wusste er zu erzählen, dass er seit dem Tode seiner Frau im Colleg nachlässig geworden sei u. sehr abnehme. Ich musste mir sagen, wie dankbar ich Dir sein wolle, dass Du mich gerade in dieser Richtung umgekehrt zu grösseren Leistungen aufgemuntert. Denn was ich die zwei Jahre getan, war doch nur Dein Werk, dass Du durch Dein Wesen in mir hast werden lassen! 
So endet dieser Tag. Mitternacht ist nahe. Die Post hat mir manch Amtliches gebracht, worüber ich morgen werde schreiben müssen. Jetzt zur Ruhe, in Liebe u. Dankbarkeit, die Du mich gelernt, u. die mir den Rest des Lebens erträglich machen werden!

Gute, gute Nacht! Dein ewig getreuer

\section{Eugen}

Auf dem Salvatore war heute eine selten klare Aussicht. Wie erinnerte ich mich an jenen Tag mir Dir. Der Maschinist war wieder auf der Zwischenstation, u. wieder älter als vor sieben Jahren, aber die gleiche sympathische Erscheinung, wie wir sie vor 19 Jahren in uns aufgenommen haben!

Den 5. April 1912.

\section{Geehrtes Fräulein Röthlisberger!}

Auf Ihre Zeilen konnte ich nicht früher antworten, als

bis ich, wie ich es Ihnen schon mündlich versprach sagte, mit Marieli gesprochen hatte. Das ist nun in diesen Tagen geschehen u. ich kann muss Ihnen als das Ergebnis der Besprechung mitteilen, dass sich der Plan, den ich Ihnen vorgelegt habe, nicht ausführen lässt. So wie die Sachen jetzt liegen, ist es für besser zu erachten, dass wenn weder Sie u. Ihre Geschwister noch Marieli an dem bisherigen Verhältnis irgend etwas ändern. verharren, was auch Marieli

sich zu nichts anderem zu entschliessen. Ich habe selbstverständlich gute Gründe hat dafür den Entschluss ihr Marieli ganz anheimgestellt Die Wege lhr Lebensweg hat sie nun so anders geführt, als

Der Lebensweg war für sie u. ihre Geschwister nun doch so lange Zeit ganz verschieden, dass es wohl zu begreifen, wenn ihr die von mir geplante Änderung weder für Sie u. Ihre Brüder, noch für Sie Marieli ratsam, ja nun gekehrt als zu gewagt betrachtet wird. verkommt ... 
Es tut mir leid aber Ich sage Ihnen dieses Ergebnis an am, indem besten gerade heraus $u$. danke ich Ihnen zugleich herzlich für Ihre freundliche Gesinnung [?] danke und mich, zugleich mit aufrichtiger Entschuldigung für die Mühe, die ich Ihnen verursacht habe, aufrichtig entschuldige.

Mit freundlichen Grüssen, auch an Ihren Bruder,

Fritz, dessen Brief hiermit

ebenfalls beantwortet ist,

Ihr

$\mathrm{EH}$.

Marieli bedauert dies mit mir aufrichtig. mir die dass der Entschluss anders ausgefallen. Wäre die

Gleichstellung der zwei Schwestern nützlich

[6]

In etwas anderer Fassung

abgesandt den 4. April.

G므OTEL DE L'EUROPE AU LAC

H. BURKARD-SPILLMANN, PROPR. den 3. April 1912.

LUGANO-PARADISO

TELEGR.: EUROPE-LUGANO

GOLF LINKS-ROLLER-SKATING

TENNIS

Lieber Herr Abbühl!

Ich suche eine Hilfe in meiner Arbeit,

einen wissenschaftlichen Secretär, der mir

die Bibliothek in Ordnung hält, Concepte aus-

fertigt etc. etc. Ich brauche diese Hilfe aber nur

für je den halben Tag, die andere Hälfte hat

mein Secretär für sich frei. Als Honorar rechne

ich etwa $40 \mathrm{Fr}$. die Woche, effektiv. 
Nun dachte ich, ob diese Stelle vielleicht Ihnen

für die Zwischenzeit vom ersten zum zweiten

Examen passen würde. Was Sie bei der

Arbeit für mich lernten, könnten Sie die

Nachmittage wohl durch Arbeit auf einem

Notariatsbureau ergänzen.

Überlegen Sie sich meinen Vorschlag $\mathrm{u}$.

wenn sie ihm u. damit mir näher treten

wollen, bitte ich Sie, nach dem Examen,

das Sie nächste Woche, wie ich höre, bestehen

werden, bei mir in Bern vorzusprechen.

Ich bleibe bis nach Ostern vermutlich in

[7]

hier, wo ich in Gesellschaft eines befreundeten

Kollegen einige Ruhetage zubringe.

Es würde mich freuen, sie als jungen Hilfs-

arbeiter zu erhalten, wenn Ihnen mein

vorschlag passt.

Mit freundlichem Gruss

Ihr

Prof EHuber

\section{2: April Nr. 81}

[1]

Lugano, Europe Tivoli 111

d. 5. April 1912.

Mein liebstes Herz!

Ich war heute den ganzen Tag in einer wehmütig befangenen Stimmung, ganz gewiss wegen Anneli. Das gute Mädchen hat mir einen so lieben Eindruck gemacht, u. meine Absicht war so gut gemeint. Und nun muss ich ihren Traum von Glück, dem sie so rührenden Ausdruck gab, als sie bei uns zu 
Nacht ass u. bemerkte, wie würde sich der Vater freuen, wenn er sie an diesem Tische sitzen sähe, nun muss ich also diesen Traum selbst zu zerstören helfen. Ich begreife ja Marieli schon, aber seine Frage, ich soll es doch nicht für herzlos halten, zeigt deutlich, dass die Stimme des Guten in ihr sich erhob, u. sie nur über den Stolz in Kleinigkeiten nicht hinweg kam. Ich hätte ja schon anders auftreten können, aber doch wieder nur unter Verletzung einer andern Pflicht Marieli gegenüber. Wenn sein Herz nicht genügend geweckt war, hatte ich keine Macht mehr. Denn mir den Unfrieden ins Haus zu pflanzen, das hätte doch auch gegenüber Anneli keinen vernünftigen Sinn. Da ist es ihr, ob sie auch nicht weiss, wohler, wo sie ist. Vielleicht komme ich noch dazu, dem guten Kind das einmal zu erklären. Deutlich ist eines, dass die drei Geschwister sich nun mit innerer Entrüstung von Marieli abwenden werden, u. wenn dann einmal die Einsicht bei diesem kommt, so wird es sich in seiner

Freundlosigkeit unglücklich fühlen. Ich hoffe, dass es nicht so kommen wird. Aber eine gewisse Gerechtigkeit macht diesen Ausblick wahrscheinlich. Schon mir gegenüber ist durch dieses Verhalten, das ich wohl von ihr befürchtet, aber nicht erwartet hatte, Marielis Stellung innerlich eine andere geworden. Ohne dass ich dies will, wird dies zum Ausdruck kommen. Ich hatte erwartet, dass das Entgegenkommen, das ich ihr durch das Verhalten zu Abbühl erst erweise, sie weichstimme. Dafür nahm sie das selbst mit einem kritischen Vorbehalt entgegen, man könne dann ja sehen, ob sich Abbühl so halte, dass er uns befriedige. Und die Stimmung in dem andern Plan blieb fort. Gewiss kann ich begreifen, wieso Marieli zu solcher Auffassung kommt, die auch nicht eine Spur von Bezeugung von Dankbarkeit in sich schliesst. Allein es ist aber gerade dies doch ein fremder Zug in ihr, ein meinem Gemüt so fremder Zug, dass Dir viel erspart ist, dies nicht erleben zu müssen. Warten wir jetzt ab, was geschieht. Ich hatte halb die Absicht, Marieli bei seiner Heimreise entgegen zu fahren. Ich werde das in meiner jetzt begründeten Stimmung nicht tun. 
Was mich dann heute weiter in drückender Weise beschäftigte, das war ein Gespräch mit Rümelin über Deutschlands Zukunft. Er sieht die Sache sehr düster an, so sehr wie ich es nach den Aussprüchen, die er noch letzten Herbst getan, niemals für möglich gehalten hätte. Dazu dann so manches

einzelne, wie die autoritative Stellung, die Stutz sich in Bonn geschaffen habe gegenüber Zittelmann, Bergbosen, Zorn. Es scheint, Stutz ist jetzt ganz Regierungstrabant geworden. Eine Prädestination hiefür hatte man ihm freilich schon lange angesehen. Und doch dachte ich die letzten Jahre milder über ihn. Vielleicht habe ich hiermit auch eine richtigere Gesinnung über ihn gehabt $u$. tu besser daran, sie zu behalten. Heute war ein Karfreitag ohne Feststimmung. Am Vormittag schrieb ich etwa sechs Briefe, u. ging zu Kommissionen Rümelins in die Stadt, wobei ich dem Knaben Montani ein deutsches Bilderbuch kaufte als Ostergruss. Am Nachmittag fuhren wir nach Arvellino hinüber, gingen zu Fuss über die Felsen nach Caprino u. waren um 6 Uhr wieder zurück. An beiden Orten tranken wir guten Asti, u. ich erinnerte mich wohl an die schöne Fahrt, die wir in einem Kahn nach den Cantinen hierher gemacht hatten. Wir waren bei jenem Luganer Aufenthalt so frei, so froh. Ich kann nicht sagen auch so fromm, wenn man die Frömmigkeit in landläufigem Sinne von Gutgläubigkeit oder Rechtgläubigkeit auffasst. Das war ja ein Mangel unserer Tage, den wir mit uns geschleppt, um erst in älteren Jahren uns einzeln auf Besseres zu besinnen. Ich kann nur hoffen, dass wir in Folge dessen nicht schwereres verbrochen haben, als uns selbst um eine Pflege gebracht, die ja auch sonst bei der vielen Arbeit u. der Absorption durch die Aufgaben des Tages 
schwierig gewesen wäre. Und was hat eine solche Weiterbildung für einen Wert, wenn sie nicht aus der Seele selbst heraus gearbeitet wird? Mit diesen Gedanken muss ich mich über dieser Mauer unseres Lebens hinweg trösten.

Doch nun sei abgeschlossen. Sei gegrüsst, liebe, gute Seele, bleibe bei mir, wie ich ewig verbleibe Dein getreuer

Eugen

1912: April Nr. 82

Lugano, Tivoli, d. 6. April 1912.

Mein liebstes Herz!

War ich gestern nachdem ich den Klagebrief an Dich geschrieben, war ich sehr gedrückt u. mochte den ganzen Abend mit Rümelins kein Wort sprechen. Ich konnte dann aber die Nacht vor Müdigkeit doch gut schlafen, u. als ich um halbsechs erwachte $u$. der Tag so hell in mein Zimmer drang, fühlte ich Lust gleich hinter Arbeiten, die mich beschäftigten, zu gehen $u$. ich schrieb vor dem Morgenessen das eine u. nachher das andere kleine Gutachten $u$. konnte beide Briefe, an die Volksbanku. an Roulet in den Kasten werfen, als Rümelins zum Frühstück kamen. Wir fuhren dann am Vormittag bei sich immer mehr aufheiternden aber auch mehr Föhnzeichen sich wärmenden Himmel auf Monte Bré. Dass ich dabei die Wege genau verfolgte, die wir vor neunzehn Jahren miteinander machten bis Monte Boglia so gut es nur ging, mir vergegenwärtigte, brauche ich Dir nicht zu beschreiben. Es war eine schöne Stimmung in der Landschaft $u$. ich war fähig mich des mit Dir Genossenen in Dankbarkeit zu erinnern. Am Nachmittag sassen wir herum, bis 
wir mit einem Extraschiff, nachdem Rümelin das ordentliche uns hatte verfehlen lassen, nach San Mamette u. gingen zu Fuss nach Oria. Es war ein wunderschöner Blick u. ich sah auch gerne das Haus Fogazaras. Auf dem Weg

begegneten uns herzige Kinder, von denen ein ganz kleines, das ich zum Spass am nackten Füsschen fassen wollte, in grosse Palaver geriet, so dass es mir ganz leid tat. In Oria tranken wir, wie gestern, Asti, u. ein überfülltes Dampfboot brachte uns zum Nachtessen ins Paradiso zurück. Abends spielte uns das Welt-Mignon in der Halle einige schöne Listz u. Wagner vor. Und zuletzt machte ich noch mit Rümelin einen Quaibummel, es war sömmerlich warm u. alles auf den Füssen.

Was mich nun aber neben diesen zwei schönen Spaziergängen heute vor allem innerlich bewegte, das war der Gedanke an das, was im Tage lag. Heute hat Abbühl meinen Brief erhalten, der vielleicht über Marielis Schicksal entscheidet. Heute wird Marieli meinen ihr übersandten Brief an Anneli zur Post gegeben haben. Und heute erhielt ich von August einen sehr freundlichen Brief, worin er mir mitteilt, dass Paul sich mit Helene Graf, der Tochter des Pfarrers in Aarau, verlobt habe! Diese letzte Nachricht hat mich von einem wahren Alpdruck befreit. Jetzt kann ich doch hoffen, dass das Verhältnis zu August wieder besser werde. Nicht dass ich die Geschichte mit Paul jetzt anders einschätze. Ein Brief von Pauline an Anna, den diese mir heute

zugeschickt, deutet sehr deutlich auf das hin, was ich selbst an August empfinde. Aber es war eben doch ein Fehler, den Marieli im Verhältnis zu Paul begangen, u. das ist nun wettgemacht. Die schnelle Wiederverlobung Pauls, drei Bräute in einem Jahr, spricht ja deutlich genug, um die Stimmung Marielis nicht nur zu erklären, sondern auch zu erklären. So ist also diesem Schritt das Schreckliche, das in 
jener Geschichte lag u. das durch Konrads Verleumdung u. die Verrücktheit August Gyrs in so fürchterlichen Ausdruck gefunden, nunmehr zugedeckt $u$. kann bei uns nichts mehr zurückbleiben. Wie mag Marieli die Nachricht aufnehmen? Sie hätte, wenn auf die Geschichte im Oktober nicht noch diejenige vom November $u$. zu Weihnachten gefolgt wäre, bei ihm wahrscheinlich ein Gefühl der Reue aufkommen lassen. Jetzt kann u. wird sie nur froh sein, dass alles so gekommen. Wenn Marieli nur gegenüber Anneli keine andere Stimmung gehabt hätte! Dann könnte ich mich jetzt des einen $u$. andern wirklich freuen. Derart aber bleibt bei mir ein Etwas zurück, das ich nicht leicht ganz zu bewältigen vermag. Warten wir ab, was der morgige Tag bringt! Heute wollte mich Frida Weber besuchen, die in Lugano sich aufhält. Ich werde ihr nun nächste Woche auch einen Besuch

machen müssen. Sonst treffe ich wenig Bekannte; den Chemiker Rossel, den Reg. Rat. Bütiker, den Dr. Kuoni aus Chur - das ist bis jetzt alles. Aber ich bin dessen froh. Ich kann umso ungestörter mit Rümelins verkehren, die mit mir sehr recht sind u. mir eine wirklich freundschaftliche Gesinnung bezeugen. Und nun ist es elf Uhr. Vor dem Hause spielt eine wandernde Musikanten-Bande allerlei Stücke, u. die abendliche Stimmung ist recht italienisch. Ich schliesse den Tag dankbar ab, der Schmerz vermag sich in Liebe auszuklingen. Und so soll es sein. Gute, gute Nacht!

Dein immerdar treuer, alter

Eugen 


\section{2: April Nr. 83}

[1]

Lugano, Tivoli 111

7. April 1912.

Mein liebstes Herz!

Der Ostertag brachte mir die Verlobungsanzeige

Pauls mit Leny Graf, «Ostern» als Datum, also Ideal, u.

für mich die Befreiung von dem Druck, den mir die Geschichte

doch bereitet hatte. Ich fuhr an dem wunderhellen Morgen

mit Rümelins bis Morcote, wo sie ausstiegen, um den

wunderbar gelegenen Kirchhof zu besuchen, den wir leider

nie miteinander gesehen haben. Mein Weg führte mich

ohne Aufenthalt weiter nach Induno, wo mich Marieli er-

wartete. Auf dem Weg zu Crugnolas teilte ich ihr Pauls

Verlobung mit, sie ward dadurch sehr beruhigt, indem es ihr recht war, dass er zuerst u. so bald wieder verlobt habe. Jetzt erst sei sie frei u. gerechtfertigt. Sie aber teilte mir mit, dass sie den Brief an Anneli abgesandt habe. Sie muss dabei sogleich empfunden haben, dass ich auf eine andere Entscheidung gehofft hatte. Dann im Laufe des Tages fragte sie mich mehrmals nebenher, ob ich sie nun für stolz $u$. herzlos halte. Erst nachdem ich um vier Uhr Crugnolas verlassen, fand sie sich dann in meine Stimmung u. schied von mir einigermassen

beruhigt. Es blitzte dabei auch etwas von wirklicher Liebe u. Milde aus ihrem Auge, dasselbe wie mir bei Anneli so gleich das Herz gewonnen hatte. Könnte dies das Vorzeichen einer Wendung sein, die mir das liebe Kind unendlich näher brächte?

Bei den Montanis beschäftigte ich mich heute namentlich mit den Gastgebern. Erst suchten die Knaben die Ostereier u. die [?frau] brachte ein Kaninchen als Osterhase. Dann war Mittagessen u. nachher unterhielt ich mich lange mit 
Montani über seine Journalistentätigkeit u. seine weitern Pläne, sowie die politsichen Aussichten. Ich besuchte dann die kranke Schwester Crugnolas im obern Stockwerk, Frau Witwe [Coeni?], die mir einen sehr guten Eindruck hinterliess. Endlich wurde noch gespielt u. gesungen, wobei Frau Rita wieder in Arien der Margareta u. der Aida, ihre prächtige italienisch geschulte Stimme zeigte. So ging der Tag vorüber, u. ich verabschiedete mich erst von Crugnolas - Montanis mit herzlichen Einladungen nach Bern, u. von Marieli auf Wiedersehn in Bern. Auf dem Schiff traf ich Fritsche, Nationalrat v. Zürich, der mir viel Interessantes berichtete, namentlich auch, dass Reg. Rat Locher sich mit 63 Jahren eben wieder

mit einer 41 jährigen früheren Lehrerin verheiratet habe, weil er gar so einsam gewesen sei, indem sein Sohn gestorben u. er mit seiner Tochter nicht ausgekommen sei.

Marieli machte mir heute einen bessern Eindruck als je, es ist doch möglich, dass die offenere Stellung, die wir nun zueinander haben, sie günstig beeinflusst. Jedenfalls versicherte sie mich bewegten Herzens auf eine Bemerkung, dass wir doch nur ihr Bestes im Auge gehabt hätten, mit bewegter Stimme, wie ich auch nur einen Augenblick zweifeln könne, dass sie das nicht anerkenne.

Nach Tisch machten sich Frau Rümelin u. er selber an die Gesellschaft Pischek heran, u es blieb mir nur die Wahl entweder auch mitzugehen, oder sie abzulenken. Letzteres wollte ich nicht, u. so machte ich eine Weile mit, um dann bei der ersten Gelegenheit zu verschwinden. Den Anlass dazu gaben mir Prof. Albers, die ich traf, u. in deren Gespräch ich dann die andern verlor $u$. nach Hause auf das Zimmer gehen konnte, um mit Dir allein zu sein, dies war mir gerade in dem Moment lehrreich, weil mir Marieli gesagt hatte, Frau Rümelin habe mir letzten Donnerstag zweimal Du gesagt, ob das nicht ein Anzeichen sein sollte, $u$. ich in der Tat heute Abend überlegt hatte, ob ich ihr das Du 
antragen soll. Es wäre Anlass dazu gewesen, indem Rümelin eine Flasche Sausern bestellte u. wir drei damit anstiessen. Dass ich es dann doch unterlassen habe, war mir jetzt besonders recht, wie ich sah, mit welcher Raschheit sie sich der neuen Situation bei Pischeks u. Anhang anschloss.

Es ist besser, auch da auf die langjährige Erfahrung mehr zu vertrauen, als auf den Augenblickseindruck.

Der Portier übergab mir einen Brief an «Frau Prof. Huber», den ich aus Versehen öffnete, er war von ganz fremder Hand $u$. ich adressierte ihn sofort um. Er wurde mir am Abend nochmals angeboten $u$. ich wies ihn jetzt definitiv zurück. Wenn nur nicht eine Schwätzerei daraus entsteht!

So ist der Tag vorüber, Ostern 1912, ein Tag, der vielleicht auch Abbühl zu denken gegeben hat, der mir in Erinnerung stehen wird, als ein Moment, der mir alle die Schwierigkeiten vergegenwärtigt hat, in denen ich stecke, der aber im ganzen doch eine innere Harmonie aufwies!

Und nun gute Nacht, liebe Seele! Ich bin allzeit Dein treuer alter

Eugen

\section{2: April Nr. 84}

Lugano, Tivoli 111.

8. April 1912.

Mein liebstes Herz!

Seit einigen Tagen finden allabendlich unter meinem im zweiten Stock gelegenen Zimmer Concerte statt, die sich ziemlich lärmend gestalten, bis nach elf Uhr. Gestern sassen der Minister Pischek u. ein Leipziger Rechtsanwalt, Mittelstatt, 
mit Frauen u. Andern da unten in sehr fröhlichem Kreis. Rümelins hatten sich angeschlossen, glücklicherweise ohne dass man mir zumutete mitzumachen. Mein Fenster sei schon dunkel gewesen, als sie fortgegangen, meinte heute Mittag Rümelin, u. als ein Anderer sagte, ich hätte das bessere Teil erwählt, bemerkte die Frau Mittelstatt zu mir, nicht wahr, wer Schlafen einer anziehenden Gesellschaft vorziehe, sei doch ein Barbar, was ich höflich lachend bestätigte.

Heute mussten Rümelins umziehen, ich bleibe in meinem Zimmer, was mir recht ist. Diesen Abend gingen Rümelins ins Reichmann hinüber zu Minister Fleischauer, ich lehnte es natürlich ab, mitzugehen. Heute sitzt nun wieder die ganze Gesellschaft unter meinem Fenster. Fleischauer konnte mir schnell vorgestellt werden. Ich hatte aber wieder keine Veranlassung mitzugehen. Wie vieles wohler tut es mir, bei Dir zu sein. Wie wenig würde es in Deinem Sinn gelegen haben, diese Art der Geselligkeit mitzutun. Frau Rümelin ging übrigens heute auch nicht mit. Es scheint, die begleitenden Frauen gefallen

Lugano, d. 8. April 1912.

ihr nicht, was ich mir bei ihrer etwas weniger [?] Natur auch gut erklären kann. Ich sage etwas, - es ist ein ganz anderes. Sie macht da nur mit aus Politik. Ich habe übrigens Rümelin in Verdacht, dass seine Depesche: Bestelle Zimmer im Europa zu jedem Preis, darauf zurückzuführen sei, dass er in [?] davon vernommen, dass die Minister hier seien. Und ich habe dabei erfahren, dass er halt doch so ist, wie ich immer mir vorgestellt. Er muss seine Ferien dazu benutzen, persönliche Bekanntschaften in jenen Kreisen zu machen. Es wird daher schwer sein, künftig mit ihm etwas zu verabreden. Denn ich kann da nicht machen. Ich würde es eher meiden als aufsuchen in Gesellschaft unserer Bundesräte die Ferien zu zu bringen. Um so weniger mache ich natürlich mit den Schwaben oder Deutschen mit.

Und nun schliesst der Aufenthalt hier bald ab. Rümelins verreisen Mittwochs. Ich wohl auch, wenn auch in einem andern Zug. Denn wenn der Minister mitreist, so muss Rü- 
melin sich zu ihm halten, $u$. überdies ist es immer schwieriger für drei Platz zu finden in den überfüllten Zügen, als für zwei. Ich wollte heute Frida Webers Besuch erwidern, traf sie aber nicht. Was mir auch recht war, denn was soll ich mit einer näheren Bekanntschaft? Ich liess ihr sagen, dass ich vor der Abreise stehe u. sie daher nicht mehr besuchen könne. Erst nachträglich wurde ich inne, dass ihre Pension die der Erzählerin Wyss ist - die hätte ich gerne kennen gelernt. Am Nachmittag wixte ich Rümelins eine

Motor Fahrt nach San Memetto, u. dazu war ich durch eine Stimmung verlasst, in die mich ein Buch versetzte, das mir Rümelin zum Lesen gegeben. Es sind [Versionen in Verse?] von einem jungen Phtisiker Zöpf, von einer wunderbaren Innigkeit. Die ganze Lebensbetrachtung erinnerte mich so ganz an Dich, dass ich erklärte, ich behalte die beiden Büchelchen gleich für mich. Gefühl für Güte, Liebe, Ehrbarkeit, Lebensernst u. Lebensfreude in [?] Bildern entrollen sich hier mit fesselnder Kraft. Eine Reihe von Ausdrücken stammen wie von Dir, es war mir eine unaussprechliche Freude! Die Fahrt nach San Memetto war sehr nett. Der See war etwas bewegt, die Aussicht kühl, die Luft frisch u. rein, während wir am Morgen unter Staub u. wahrhaft sommerlicher Wärme gelitten hatten.

Dann brachte mir die Post ein Billet, wonach er sich bereit erklärt, die Secretärstelle bei mir anzunehmen. Ich sandte es sofort an Marie. Aber was wird nun werden? Es kam dazu dann leider die Anfrage Tuors, ob er mich diese Woche sprechen könne, was ich freilich wegen Abwesenheit ablehnte. Klar wenn das darauf deutete, dass die Berufung Siegwarts noch nicht in Ordnung sei? Das wäre eine schöne Bescherung. Dann hätte ich zwei Secretäre, einen Helveter u. einen Burgunder. Hoffentlich wird mir diese peinliche Auseinandersetzung erspart. Aber wenn einmal eine Sache falsch geht, so wird 
ja so oft das dümmste Wirklichkeit. Ich kann mich freilich darauf berufen, dass Oser u. Siegwart mir gesagt haben, die Ernennung durch den Staatsrat sei nur noch eine Formalität. Ich erhielt dann weiter ein paar Zeilen von Kleiner, worin er mir mitteilt, Lislys Liebster habe jetzt eine Stelle, u. Anna sei mit Oechsli nach Rom gereist.

Ferner bestätigte er, dass Locher sich wieder verheiratet habe. Er, Kleiner, könne jetzt keine Ferien machen. Sonst ist von dem heutigen Tag nicht viel zu sagen. Ich muss mich entscheiden, ob ich jetzt noch Berta u. Bertoni besuchen soll. Wenn ja, so bleibe ich noch ein oder zwei Tage länger als Rümelins. Morgen will ich darüber schlüssig werden.

Und nun Schluss! Der Lärm von unten dauert fort, aber er hat mich nicht gestört, es war ein fernes Anklingen einer fremden Welt, ein Gegensatz zum Verkehr mit Dir, der mich eher gehoben als unsicher gemacht hat.

Gute, gute Nacht! Ich bleibe Dein ewig getreuer Eugen

\section{2: April Nr. 85}

[1]

Lugano, den 9. April 1912.

Mein liebstes Herz!

Geht es, wie ich es mir vorgenommen, so sind das die letzten Zeilen, die ich Dir aus Lugano schreibe. Es war heute früh regnerisch. Wir sassen herum, Fremde, wie [Polentenwelt?] [Müntz?] aus Berlin, [Binz?] aus Leipzig u. Rechtsanwalt Mittelstett kamen herzu, an sich ganz nette Leute, denen ich aber hier kein Interesse abgewinnen konnte. So ging ich dann nach zehn allein in die Stadt, wollte den Maler Berta besuchen, trafihn aber nicht in seinem [?] im [?]. Dann nahm ich einen Wagen, fuhr zum Studio von Bertoni, der mich sehr freund- 
lich empfing, aber trotz der Kürze des Besuches Zeit fand, mitzuteilen, Heusler habe ihm einige Anfragen geschickt, voll Gift gegen das Einführungsgesetz u. das ZGB. Natürlich will er nun sich an Bertoni wenden mit seiner Galle, indem er voraussetzt, der sei dafür, nachdem er nicht Bundesrichter geworden, besonders empfänglich. Ich fuhr dann zu Frau Bertoni nach M. hinaus in die hübsche Villa, die 1907 im Herbst im Bau war, u. wurde sehr nett, herzlich, würdevoll aufgenommen. Es ist eine prächtige Frau, die mir dann auch offen sagte, ihr Mann wäre sehr gerne von Lugano weg, wegen allerlei Geschichten mit dem Schwager,

Gㅁ HOTEL DE L'EUROPE AU LAC H. BURKARD-SPILLMANN, PROPR. LUGANO-PARADISO

TELEGR.: EUROPE-LUGANO GOLF LINKS-ROLLER-SKATING TENNIS und sie wollte auch wissen dass namentlich die Waadtländer gegen ihren Mann aufgetreten seien. Nun ja, ich konnte nur

bestätigen, dass Bertonis Wahl mich sehr gefreut hätte. Sie dankte mir für die Ehre, die ich ihr erwiesen, u. ich fuhr bei strömendem Regen zur Stadt zurück, wo ich dann im Hotel gerade recht zum Lunch eintraf.

Am Nachmittag machten Rümelin u. ich eine Schachpartie, sie war sehr unwirsch, ich weiss nicht weshalb. Nachher setzte sich wieder Binz zu uns u. später verabschiedeten sich Mittelstett u. seine Frau, die mich sehr an Frau Prof. Barth erinnerte: Hübsch, gewandt, in allen Sätteln gerecht, aber dann doch wohl mehr coquette als diese. Rümelin $u$. ich begleiteten Frau Rümelin zur Stadt, wo sie einkaufen wollte. Aber es hatte angefangen so zu regnen u. zu stürmen, dass Rümelin seine Frau allein gehen liess $u$. er $u$. ich mit triefenden Schirmen zurückkehrten. Ich sass dann allein in meinem Zimmer an meinem Fenster u. schaute den Wogen zu, die mächtig anstürmten. Dann aber sah ich plötzlich, wie der alte liebe Boglia einen weissen Kopf bekommen, u. es brach eine herrliche Abendsonne durch, die die Landschaft für zehn Minuten 
wunderbar beleuchtete. Nach dem Pranzo spielte Rümelin mit Minister Pischek eine Parti remis. Dann gabs wieder einen grossen Kreis: Minister Fleischauer, Secretär Mosthof, Prof Lange u. Frau aus Leipzig, ein Commerzienrat aus Stuttgart mit Frau, Prof. v. Mass, Gräcist aus Tübingen, dazu wir vier u. Pischek u. Binz u. Frau. Es wurde allerlei geplaudert $u$. von einigen Flaschenbier getrunken. Ich sprach namentlich mit v. Mass u. Lange; blieb auch bis zum Schluss. Nur die lange stehende Verabschiedungsszene schenkte ich mir u. ging allein auf meine Nr. 111, um an Dich zu schreiben.

Und nun bin ich, nachdem ich heute die Besuche gemacht, entschlossen, morgen um 9 Uhr mit Rümelins zu verreisen. Ich kann ja in den Basler Wagen sitzen u. sie zu Pischek in den Zürcher Wagen. Der Aufenthalt im Ganzen war hier sehr schön, es war aufrichtig, als ich das heute Abend der Frau Burkhardt sagte. Auch dass Rümelin durch mich gestört u. sein Zusammensein mit den ministeriellen Kreisen beeinträchtigt wurde, hat mich nicht geplagt, das sind ja alles Kleinigkeiten. Gern wäre ich aber mit etwas anderem Entscheid über Annelis Schicksal nach Hause gekehrt. Wenn ich an die Scene denke, wie sie so leuchtenden Blicks bei mir

am Theetisch sass u. sagte, der Vater würde sich freuen, wenn er sie da sehe, $u$. nun soll ich glauben, dass die guten Gedanken, die sich für mich damit verbunden, alle zu nichte geworden seien, so tut mir das redlich weh, und doch konnte ich Marieli zu dem Schritt, gegen den sie so viele Vernunftgründe geltend machte, nicht zwischen. Aber es ist eine bittere Beigabe zu dem Verhältnis, dass wie es nun zwischen mir u. Marieli bestehen wird. Doch will ich auch da das beste hoffen, u. niemandem etwas von diesen innern Kämpfen sagen. 
Damit Schluss für Lugano. Wie anders als vor 19 Jahren im Frühling! Man ist alt, man ist einsam geworden.

Gute Nacht, liebste, beste Seele!

Ich bleibe Dein immerdar treuer

Eugen

1912: April Nr. 86

B. d. 10. / 11. April 1912.

Mein liebstes Herz!

Ich habe mich nun in der Nacht entschlossen, gleich am Morgen Lugano zu verlassen. Es war die Nacht sehr stürmisch, am Morgen ging der Nordwind, wie am 2. April. Mit mir haben Rümelins, Pischek u. Prof. Langes das Hotel verlassen. Es war aufrichtig, dass ich Burkhard für den Aufenthalt dankte, gestern Abend sagte ich denselben Dank schon seiner Frau, die heute Morgen nicht mehr sichtbar war. Sie leide an Rheuma. Die Fahrt machte ich allein, im Vorzug, während die andern den Hauptzug benutzten. Das war schon angezeigt, weil die ganze Gesellschaft schwer im selben Wagen des Hauptzuges Unterkunft gefunden, u. Rümelin doch Wert darauf gesetzt hätte, mit dem Minister zu sitzen. Überdies war ich so sicher, den Berner Zug in Olten zu erreichen. Das ist dann auch geschehen u. nach siebenstündiger, wie ein Traum an eine vorüberhuschende Fahrt war ich daheim, - wenn es noch ein Daheim wäre, wie früher. Sophie soll sehr recht gewesen sein. Sie soll bezeigt haben, dass sie Wert darauf setze, in unserem Hause zu dienen. Der Abschied von Rümelins war herzlich, von Seiten der Frau überschwenglich. Aber deshalb nicht unaufrichtig. Es ist ihr Temperament, zu allem etwas Steigung zu fügen, u. in dem Moment, wo sie es tut, fühlt sie auch so. Die Eingänge habe ich zu Hause heute Abend schon ordnen 
können, bin jetzt aber mit einem Mal sehr, sehr müde. Ich muss bei meiner Ankunft wie im Traum gehandelt haben, denn später sah ich das eine $u$. andere einfach verstellt. Ich fühle mich auch nicht wohl, gleichsam schwindlich, was von dem neuerdings auftretenden Katarrh, u. dem Schneefall herrühren kann. Also verschiebe ich weitres auf den morgigen Abend, wo dann wohl auch die Zweifel betr. Siegwart beseitigt sein werden. Innigst Gut Nacht inzwischen!

\section{Den 11. April.}

Den heutigen Tag musste ich mich, neben einigem Aufräumen fast ganz mit der Correctur der englischen Übersetzung meines Abrisses der schweiz. R. Geschichte befassen. Sie traf gestern mit der Abendpost ein $u$. ich las u. verglich heute stundenlang daran. Dabei wurde mir ganz schwer zu Mut, wegen einer Bleistiftnotiz, die auf dem englischen Mskript angebracht $u$. wieder gestrichen war, etwa des Sinnes, es sei von mir Manches unklar gelassen u. er der Übersetzer wolle look up his [?] ... u. da kann ich ein Wort nicht lesen, ... and catch this in the proof. Eine andere Hand, die die Bemerkung gestrichen, hat dazu gefügt: No don't. Und ein letzter Abschnitt ist aus Orellis Rechtsschulen ausgegangen, 7 Seiten! Hätte ich die noch für mich nehmen können, so würde ich ja freilich Manches aus-

führlicher u. damit deutlicher gesagt haben. So erlebe ich also auch hier wieder statt Dank, einen Ärger. Es geht mir nun einmal so im Leben. Am Nachmittag war ich bei Mutzner - Müller, Kaiser u. Käslin sind an der Conferenz in Luzern - u. Mutzner sprach sich wieder dahin aus, dass Kaiser ihn plage. Ich suchte ihm dies auszureden $u$. ermunterte ihn, sich zu habilitieren. Er ist ein gescheiter, prächtiger Kopf. Übermütig freilich, wo 
er sich überlegen muss. Aber daneben ohne jede Intrigue u. von innerstem Eifer erfüllt. Nachher war Guhl noch bei mir, mit einigen Nachrichten, die aber nur Amtliches betrafen.

Wegen Siegwart, der heute ein halbes Stündchen bei mir war, gerate ich jetzt doch fast in Unruhe. Was sollte ich machen, wenn er am Ende doch nicht gewählt würde, u. ich hätte Abbühl schon angefragt? Ich kann doch nicht zwei Secretärs brauchen? Dürfte ich Siegwart gehen lassen? Doch ich will mich darüber noch nicht plagen, wenn es eintritt, kann ich dann immer noch sehen, was zu machen ist.

Diese Geschichten, dazu die traurige Ordnung, die im Hause herrscht, wo der Corridor überstellt u. auf die Telephonklingel niemand Bescheid gibt, bereiteten mir heute eine Niedergeschlagenheit, die mich den Tod

mehr als sonst herbei sehnen liess. Es ist eben doch nichts mehr mit mir. Die Nachrichten über den Tod der Frau Coradi-Stahl mahnten mir in einem Ausspruch, den sie getan haben soll, an Dich: Wenn ich nicht mehr arbeiten kann, will ich lieber sterben. Das ist ihr zuteil geworden, u. auch Dir! Mir aber, was wird mir begegnen?

Ich muss mich neuerdings in das Leben gewöhnen, ich fühle mich so grenzenlos einsam, untüchtig, $u$. verlassen von aller Welt.

Doch weshalb Dir darüber schreiben? Du wirst mir ja helfen, wo Hülfe möglich ist, u. inzwischen halte ich es aus, wies kommen wird.

Gute, gute Nacht von Deinem alten, treuen Eugen 


\section{2: April Nr. 87}

[1]

B. d. 12. April 1912.

Mein liebstes, bestes Herz!

Heute sind es drei u. dreissig Jahre, seit wir unser herziges gutes Anneli verloren haben. Es ist begründet, dass ich heute mehr als die letzten Jahre an jenen Tag gedacht habe. Was wir uns als Ersatz dachten, $u$. was ich für Dich gewünscht $u$. wir beide als solchen erachtet haben, das hat jetzt eine Wendung bekommen, über deren Ursache u. Bedeutung ich mir selber noch nicht klar bin. Ich habe den damaligen Verlust nicht so tief erfasst, wie es hätte sein sollen. Eigene Kinder zu haben, das war mir nicht als ein so entscheidendes Ideal vorgekommen, vermutlich weil ich von jungen Jahren an immer nur die Klage meiner lieben Mutter über ihre Kinder, die Schwestern Pauline u. Emma, die so ganz ihre eigenen Wege gegangen sind, u. über die gezwungene Wohltätigkeit Augusts u. vieles andere zu hören bekam. Ich sagte mir: eigene Kinder sind, nach den Worten der Mutter, oft ein Unglück, ein «Fluch», u. so erschien mir der Besitz an solchen ein Geschick, das gut oder böse sein könne. Aber der innigen Zusammenhänge, die trotz allem mit der Abstammung gegeben sind, wurde ich mir nicht bewusst. Als wir dann vierzehn Jahre später Marieli aufnahmen $u$. nach Ablauf eines weitern Jahres in volle Pflege erhielten, da dachte ich mir, das Verhältnis werde ein so inniges sein, wie wenn das Kind uns entstammte, u. auch Du hattest diese Hoffnung, die Dich über die Erfahrungen mit Deinen Schwestern hinweg setzte. Jetzt aber

zeigt sich eben doch ein Bruch in den innigsten Gefühlen. Du hättest ihn noch miterleben können, würdest Du auf die Anzeichen geachtet haben, die schon während der Schuljahre bei Marieli zu Tage traten. Es erzählte mir, dass es, 
als es in der Secundarschule zum ersten Mal bestimmt gewusst, es sei nicht unser Kind, mehrere Abende uns nicht mehr recht gute Nacht gewünscht u. geküsst habe, u. nachträglich fiel es mir auch ein, dass Du einmal in tiefem Schmerz mir bemerkt hast, Marieli sei ganz anders, es wisse am Ende von dem ganzen Verhältnis. Das muss damals gewesen sein. Auch das Betragen vor dem Examen, als es nach Dumonts Consultation sich am Montag früh als unwohl erklärte $u$. von Dir zu Hause behalten wurde, klärte mir Marieli dahin auf, dass es weil es keinen Geburtsschein habe bringen können, der ihnen an dem Morgen in der Schule abverlangt worden wäre, sich krank gestellt habe, um nicht in die Schule gehen zu müssen. Und so war Dein unendlicher Liebesdienst, dass Du tagelang neben dem Kinde sassest $u$. seiner wartetest, eine Komödie, die es Dir u. uns spielte. Daneben war es ja wohl von Marieli anerkannt, dass es von Dir mit aller Liebe gepflegt worden, u. es bekannte selber, dass mehrfach Bekannte sagten, es sehe Dir so ähnlich. Der Umgang mir Dir schuf die Ähnlichkeit, wie dies ja vorkommen soll. Aber das Gemüt blieb doch verschieden. Und ob es jetzt noch besser werden kann, das werde ich zu erleben haben. Du bist am Tag nach jenem Abschluss, der Dir mit Marielis Rückkehr vom bestandenen Examen das Herz zu innerst bewegte, von uns gegangen. Das war für Dich ein geheiligter

Abschluss. Für mich bleibt nun die Nachlese. Es ist möglich, dass der Eintritt von Abbühl bei mir die Gesinnung wieder bessert. Aber es ist nicht sicher. Mir schnitt es ins Herz, dass Marieli, sobald ich ihm von meinem Schritte zu seiner, Marielis, Seelenberuhigung sprach, sofort den Vorbehalt machte, man werde ja nun sehen, was er sei u. was aus ihm werde. So spricht doch die Liebe nicht? Und doch hatte Marieli von Abbühl beim ersten Besuch in Induno in einem Ton gesprochen, als ob das Lebensglück für es an dem Wiederanknüpfen der Beziehungen zu ihm abhange. Es hat mir leidgetan, heute Abbühl nicht gleich mit aller Bestimmtheit engagieren zu können. Allein ich musste ihm sagen, dass die Ernennung Siegwarts noch nicht erfolgt sei, u. dass ich, wenn 
ein ganz u. gar unerwartetes Hindernis dazwischen trete, noch nicht wisse, wie die Sache zu ordnen sei. Er nahm das sehr vernünftig auf u. sagte - was für seine Bravheit spricht - dann trete er natürlich zurück. Aber mir wäre er doch lieber. Ich war heute Abend allein auf dem Friedhof. Auf dem Heimweg traf ich Lüdemann an u. teilte ihm die Verlobung Pauls mit. Er kennt den Pfarrer Graf in Aarau als einen tüchtigen Geistlichen. Auf Glückgüter, meinte er, habe da doch Paul nicht geschaut. Das wird sich zeigen. Er fragte mich auch nach August Gyr, u. ich erzählte ihm, was mir Hans Gwalter gesagt hatte. - Auf dem Wege überlegte ich mir auch, ob ich nicht doch unser Haus abgeben $u$. wegziehen soll. Aber nur einen Augenblick, um sofort wieder die Perspektive auf dasjenige Ziel einzustellen, das Du mir gewiesen. Veranlasst ward ich zu den Zweifeln durch die grosse Unordentlichkeit, die ich bei meiner Rückkehr im Hause angetroffen. Ich darf

gar nicht daran denken, wie das alles sich seit Deinem Hinschied geändert hat: die blanken Böden, die glänzenden Geländer, die staubfreien Möbeln u. s. w. u. s. w. sind eben nicht mehr da. Anna genügt nicht, das wissen wir ja schon lange, Frau Schory ist eine gegen «Reichtum» Anderer Hass erfüllte Seele u. langsame Arbeiterin, Sophie ist nicht auf der Höhe, um an Alles was Not täte, zu denken. Aber wie soll ich mir helfen? Ich hatte den schönen Traum, in Marielis Schwester, die mir so lieb vorkam, eine Hülfe zu finden, u. ich musste die Herzlosigkeit begehen, ihr abzuschreiben, um nicht die Verbindung mit Marieli zu gefährden!

Solche Erfahrungen nagen an mir, ich spüre es. Ich werde vielleicht mich wieder besser darüber weg setzen können, wenn das Semester im Gange ist. Heute bereitete ich die ersten Praktikumsfälle vor. Wie weh war mir, dabei an all die Arbeit zu denken, die Du damit jahrelang verbunden hattest!

Ich musste Halle verlassen, um ganz zu wissen, was die deutsche Professur uns war. Ich musste Dich verlieren, um zu fühlen, wie glücklich wir waren. Ist das ein innerer 
Mangel an mir, oder ist es Menschenlos, wo das gesäte Korn sich aufzehren muss, damit überhaupt neue Frucht emporkeimt?

Ich denke Dein u. danke Dir, meine gute, gute

Seele! Wir bleiben zusammen auf ewig! Dein getreuer

Eugen

\section{2: April Nr. 88}

[1]

B. d. 13. April 1912.

Meine einzige Lina!

Wie ist der heutige Tag vorüber gegangen!

Am Vormittag schrieb u. copierte ich zwei Gutächtchen, an Bühlmann, der in Gunten sein «Handbuch» fertig schreiben will u. dort mehr Ruhe findet, als zu Hause, u. an Brosi, den Sohn des von Dir so geschätzten verstorbenen Nationalrats. Dann kam Siegwartimmer noch ohne Nachricht von Freiburg - u. brachte mir seine Bemerkungen zur englischen Übersetzung des Abrisses der Rechtsgeschichte. Ich konnte vor dem Essen gerade noch den Brief an Wigmorn in Chicago aufsetzen u. Brief u. Pakete für die Post verpacken bis zum etwas späten Mittagessen. Den Nachmittag sass ich an der Sonne im Garten in allerlei Nachdenken versunken, plauderte beim Café in der Stube mit Anna über die Jahre, da wir vor Mutters Tod in Riersbach u. Hottingen zusammen wohnten. Dann entschloss ich mich - nach Erledigung kleinerer Correspondenzen - noch die Anschläge Brière auf die Universität zu bringen, schrieb sie u. eilte hinaus.

Bei Rossels kam mir vom Rabbenthal her ein junger Herr entgegen, ich glaubte, ein Student, der 
fixierte, stellte mich u. sagte, er sei «Arnold». Welcher Arnold? Arnold Röthlisberger! Er wolle sich persönlich erkundigen nach der Ursache des Briefes, den ich seiner Schwester geschrieben. Er ging dann mit mir über die Kornhausbrücke, u. ich teilte ihm mit, dass ich mehrfach mit Marieli über den Plan betr. Anneli gesprochen, u. dass es sich mit sehr bestimmter, vernünftig begründeter Überlegung entschieden ablehnend verhalten habe. Er ging darauf ein, fand es auch begreiflich. Es lasse sich da nichts zwingen, u. schliesslich sagte er, er fahre jetzt sofort zurück. Ich bemerkte dann, es soll jetzt alles im Alten bleiben. Wenn etwas sich änderte, würde ich seiner Schwester schreiben. Vorauszusehen sei das aber nicht, u. so verabschiedeten wir uns beim Zeitglocken. Der Eindruck, den ich von dem jungen Mann, der blauäugig, aber stark brünet ist, war: grosse Gewandtheit, ein Zug ins Welsche, eine Strebsamkeit, nicht weit entfernt von Aufspielerei. Ich musste mir sagen, das wäre wieder eine andere Note gewesen als Anneli. Am Ende hat Marieli doch recht mit seiner Entscheidung, mag sie auch noch so sehr von eigenen Interessen begründet gewesen sein. Ich habe einen solchen Besuch, oder doch einen Brief, noch erwartet. Ich konnte die Sache jetzt auf der Strasse abmachen,

u. wenn ich die Entscheidung auf Marieli ablud, so ist dies ja der Wahrheit entsprechend, u. war ja jedermann verständlich, dass ich in dieser Frage auf Marieli keinen Druck ausüben konnte. Ich teilte auch Arnold mit, dass Anneli bereits vor anderthalb Jahren an Marieli geschrieben, $u$. dass dieses niemandem etwas davon gesagt u. den Brief ignoriert u. vernichtet habe. Auch klärte es sich auf, dass Anneli damals als Adresse einen Gasthof in Malleray angegeben $u$. die Geschwister wohnten damals 
im blauen Kreuz daselbst, Anneli war nicht angestellt, sondern arbeitete bereits in der Fabrik. Wenn das so ist, wie Arnold stückweise sagte. Von jenem Brief schien er nichts wissen zu wollen.

Wenn ich jetzt unter diesem Eindruck die Sache betrachte, so kann ich wohl sagen, Marieli hat sich an die ihm durch uns geschaffene Lage mehr eingesponnen, als ich es geahnt hatte. Sie lehnt ihre Verwandtschaft ab, u. damit sollte doch gegeben sein, dass sie sich um so mehr mit der unsrigen verbindet. Wäre nicht die Katastrophe mit Paul gewesen, so würde sich dies alles prächtig machen. Warten wir das weitere ab.

Von Marieli erhielt ich heute einen kurzen, aber rechten Brief. Er hat sich mit dem gestrigen von mir gekreuzt. Die Montanis kehren am Montag nach Mailand zurück, u. in acht Tagen ist Marieli wieder da. Es hat Frau Crugnola recht lieb bekommen u. das freut

mich. Vielleicht wird es später wieder bei ihr für längere Zeit zu Gast sein.

Den Abend erhielt ich von Max Huber ein längeres Exposé über die Völkerrechtsakademie, die in Den Haag geplant wird. Ich will es morgen lesen. Auch erwähne ich noch, dass Marie Heim mich anfragte, ob sie jetzt die Fortsetzung von Arnolds Tagebüchern schicken soll. Ich bejahte es. Zugleich kam die Todesanzeige von Sophie Heim, der Stiefschwester Alberts, einer eigenen Person, die von der Stiefmutter ignoriert ein einsames Leben geführt hat u. nun im Alter von 77 Jahren in Wil gestorben ist, ohne Krankheit, am Schlag. Schrieb ich Dir auch, dass Emma Blatter, jetzt Frau Kuster, mich kürzlich um mein Bild ersucht hat? Ihr Mann hat jetzt ein kleines Heimatli mit Rindern, Geissen etc. bei Teufen in Bubenrüti! Wie merkwürdig würfelt das Schicksal unsere Bekannten durcheinander! Das Leben ist ein Schachspiel, für jeden eine besondere Partie, für keinen identisch mit andern. Wer Bildung u. Familie hat, der 
kommt zur richtigen «Eröffnung», aber das Spiel selbst ist damit noch lange nicht durchgeführt. Da hat jeder sein Eigenes zu geben!

Gute, gute Nacht! Nimm diesen Kuss zum Tagesschluss! Es war heute ein wunderbar klarer Tag.

In ewiger Treue bin ich

Dein geplagter, alter

Eugen

\section{2: April Nr. 89}

B. d. 14. April 1912.

Meine einzige Liebe!

Heute sind es schon 106 Wochen seit jenem letzten kurzen Besuch in meinem Zimmer, von dem mir der Gummibaum mit dem «lieben jungen Blättchen» täglich spricht. Die letzte Ferienwoche ist angetreten, von den Ferien, die so vieles Unerwartetes gezeitigt haben: Das Geheimnisvolle im Verhältnis zu Marieli ist beseitigt. Der Plan, ihm eine liebe, treue Schwester zu verschaffen, ist begraben, eine neue Phase ist in den Beziehungen zwischen mir $u$. Marie eingetreten, bei der ich wohl manchmal Deine Hülfe vermissen werde. Das Secretariat Siegwarts ist zu Ende es wird doch wohl ganz sicher zu Ende gehn - u. der Versuch mit Abbühl ist eingeleitet. Pauls Verlobung hat die Erinnerung an das schreckliche Erlebnis in erträgliche Ferne gerückt. Arbeit ist getan u. nicht getan, meine Einsamkeit ist dieselbe wie seither, aber in meiner Empfindung verschärft. Ich lebe verschlossener denn je, denn es geht nicht mehr nach Wunsch u. Ziel, sondern nur noch in bereits gelegten Geleisen nach dem was hinter mir liegt.

Aufgefallen ist mir, wie in diesen Tagen, da ich mit Anna allein zusammen war, die alte Zeit, die Zeit, bevor wir einander angehörten, wieder in der Erinnerung auf- 
gelebt ist. Ich nähere mich der Distanz, aus der das Zusammensein mit Dir, die siebenundreissig Jahre, wie eine in den Lebenslauf eingeschobene Einheit sich dem Gemüt u. Herz kundbar machen. Ich fühlte mich unendlich gehoben,

[2]

als ich Dich errungen hatte, u. diese Gehobenheit hat, bei allem Verwirrten, Verlassenen, Irrenden u. Zweifelnden, die ganze Zeit angedauert. Wie bin ich Dir dafür dankbar. Jetzt fühle ich, in meiner heutigen Umgebung, wie diese Gehobenheit allmählich wieder in sich zusammen sinkt. Ich werde wieder, was ich früher war, wenn nicht gebessert u. geläutert, durch das erfahrene Glück. Und was ich als dieses Glück mir festzuhalten hoffen will, das ist erst noch dasjenige, was uns in unserem inneren Verkehr nicht recht zum Bewusstsein gekommen war, obgleich Du in den letzten Jahren manchmal genug danach verlangtest, $u$. mir das Verständnis dafür nur in nebelhaften Umrissen aufdämmerte. Wir hatten zusammen zu wenig Ruhe, wir litten darunter, indes das Leben uns immer wieder neue Kämpfe zumutete. Deine Vollendung wirkt nun in einem Abglanz in mir nach. Aber der Schmerz u. die Traurigkeit vermag das nicht zu überwinden.

Ich habe am Vormittag einige Briefe geschrieben u. die Berichte gelesen, die Max Huber mir zugeschickt. Dann ging ich zu Hoffmann auf das Rathaus u. hatte eine vertraute, liebe Stunde mit ihm. Ich wollte sodann Müllers besuchen, fand aber niemand zu Hause. Ich vernahm später, dass sie heute bei ihrem Sohn in Basel weilen. Am Nachmittag kam Kronauer zu mir, um mich über seine Vorschläge betr. die Todesstrafe zu consultieren, über die diese Woche in der Expertenkommission beraten werden soll. Bei dem Anlass blieb Kronauer drei Stunden u. erzählte mir von 
vielerlei Dingen. Am meisten frappierte mich, was er von Lochers Wiederverheiratung sagte. Vor acht Tagen hat mir auf dem Dampfschiff Fritsche mitgeteilt, die Heirat, mit einer sehr tüchtigen ehemaligen Lehrerin, sei ein Glück für Locher. Er habe so einsam gelebt. Seine Tochter sei von ihm weg nach London, er habe sich mit einer Haushälterin geholfen, mit der er, der aus Gesundheitsrücksichten Abends nie ausgehe, kein vernünftiges Wort habe sprechen können. Kronauers Bericht lautete nun ganz anders. Die zweite Frau sei im Büreau Lochers angestellt gewesen. Locher habe mit ihr ein Verhältnis unterhalten, über das sich die Mitangestellten lustig machten, z. B. indem sie die Billete, die die Liebenden sich zugeschickt u. dann zerrissen, aus dem Papierkorb genommen $u$. wieder zusammengesetzt hätten. Die Tochter sei wegen dieses Verhältnisses nach London. Das Fräulein habe den Regierungsrat dran gekriegt, der seine Kollegen weder vor noch nach der Hochzeit von seinem Schritt Kenntnis gegeben. Ja, ja, das sei aber immer das Zeichen der senilen [...?] meinte Kronauer, wenn eine solche Heirat stattfinde.

Ich sage eher: es beweist, dass das erste eheliche Verhältnis nicht das richtige war, sei es aus diesem oder aus jenem Grunde. Denn wer das Andenken hochhält, kann es nicht derart selbst zerstören. Mir tut Locher leid, es ist eine harte Sache, sich derart vor den edler denkenden bloss zu stellen.

Während Kronauer da war, kam Wiedemann, um

einen Abschiedsbesuch zu machen. Er kommt als Inspektor der orientalischen Bahnen nach Konstantinopel. Was er erzählte, zeigte mir wieder die Romantik, die in dem jungen Mann steckt. Er tat mir neben dem sehr gealterten, in seinen Starbrillen ungemein hinfällig aussehenden Oskar Kronauer ganz wohl. 
Mit Anna habe ich wieder viel von dem Früheren besprochen. Sie meint übrigens, es tue ihr so wohl, wenn sie jetzt noch nach ihren Kräften Haushalten könne. Ist jetzt dann Marieli wieder da, so werden wir ja sehen, ob wir im alten Trott fortfahren können, oder ob ich mich doch nach weitern Hülfen umsehen muss.

Damit Schluss für heute. Der Tag war wiederum hell u. frisch. Freilich die Magnolia mit ihren halboffenen Blüten hat sehr gelitten.

Liebe, gute Seele, nimm einen Kuss u. gute Nacht! Ich bleibe immerdar

Dein getreuer

\section{Eugen}

\section{2: April Nr. 90}

B. d. 15. April 1912.

Mein liebstes Herz!

Die zerrissene Stimmung hat heute bei mir angedauert, ich weiss nicht weshalb. Am Morgen machte ich Ordnung in den alten Nationalrats-Akten. Siegwart kam, immer noch ohne Nachricht, was meine Stimmung nicht verbesserte. Darauf ging ich zu Schatzmann, um ihm über die Litteratur des ZGB. den erbetenen Aufschluss zu geben, u. ich benutzte den Anlass, um ihn zu fragen, ob ich nicht die Publikationen erhalten könnte, die den Nationalratsmitgliedern zugestellt werden, wie ich sie von der Berner Staatskanzlei seit bald zwanzig Jahren erhalte, u. dass Schatzmann mir dies abschlug, als unmöglich abschlagen musste, soweit ich nicht bestimmte Begehren im einzelnen Fall namhaft machen würde, machte wiederum meine Stimmung nicht besser. Am Nachmittag ordnete ich andere Papiere, aus Mangel an Stimmung für etwas besseres. Dazwischen las ich den Trinkspruch von Börlins, gehalten beim Aktionäressen der N. Z. Z., das sein Abschieds- 
essen war, - den mir Hoffmann zustellte, u. der wirklich recht nett zu lesen war, las auch etwas in Erkmanns

Rekrut u. in Zöpfs «Es muss ein Himmel sein», u. schrieb etliche Briefe, unter anderem auch eine Antwort auf die Sendung eines Brasilianers aus Rio, der sich gegen den

bekannten «Times» Artikel gewendet hat. Alles, alles half mir nicht zu besserer Stimmung. Aber jetzt weiss ich doch, indem ich dieses schreibe, woher dieser Unmut kommt. Es ist der Mangel an einem mich packenden Ziel in der Arbeit, die Unlust mich hinter das «Buch» zu machen, wie sie mir durch die andauernden Plackereien Häuslers u. anderer eingeflösst worden ist, das Scheitern der Pläne betr. Anneli, so sehr ich sehe, wie gewagt dessen Aufnahme in unser Haus gewesen wäre, die Schwierigkeiten betreffend Siegwart, das Misstrauen gegen viele meiner Nächsten, unter anderem auch den viel zu freundlichen Guhl, u. s. w. u. s. w. Wie tief diese Stimmung in mir wühlte, erkannte ich zu meinem Schrecken daraus, dass mich die Nachricht von der Erkrankung Reichels, der in Luzern letzten Freitag von einer Bronchialaffektion so heftig ergriffen worden sein soll, dass seine Frau hergerufen wurde u. der Arzt die Reise nach Hause untersagte - gar nicht schmerzlich ergriff, sondern nur als etwas Notwendiges von mir entgegengenommen wurde. Du hast es mir selbst einmal gesagt, ich sei in solchen Momenten ein armes, verlassenes Geschöpf, u. dass dem so war, das fühlte ich jetzt ohne Dich doppelt schwer. Aber es wird doch wieder anders kommen. Ich werde die Arbeit wieder aufnehmen, mit Freude, wenn nur endlich wieder einmal etwas von Anerkennung an mich herantritt.

Pierre Baguin war heute ein Stündchen bei mir. Er hat seine Stellung bei der «Zürich» verlassen, ist Knall u. Fall aus Barcelona zurückgekehrt. Er erzählte mir von der Art, mit der das Geschäft in dieser Gesellschaft betrieben werde, von 
der Härte, ja Gefühlsrohheit des Direktors Meier, wie niemals ein Wort der Anerkennung über seine Lippen komme, wie alles sich in Geld u. wiederum in Geld auflöse. Es spricht für den jungen Mann, dass er das nicht ausgehalten hat. Die drei Monate in Barcelona waren für ihn eine harte Schule der Einsamkeit. Jetzt sucht er eine andere Stelle, vielleicht erhält er sie beim «Unfall» Winterthur. Ich wünsche ihm alles Gute!

Heute habe ich wieder erfahren, wie sehr in dem ausschliesslichen Verkehr mit Anna, die alte Zeit wieder in der Erinnerung auftaucht. Sie erzählte mir heute, was ich bis jetzt gar nicht wusste, dass unser Vater einmal wochenlang darauf gedrängt habe, das Tischgebet bei uns Kindern einzuführen. Die Mutter habe aber sich, schliesslich erfolgreich, dessen erwehrt, u. die Mutter sei zu ihren freigeistigen Ansichten durch die Familie Brägger gekommen, oder [vielmehr] Bretscher, bei der sie als junges Mädchen zwei Jahre lang den Schneiderinnenberuf erlernte. Auch bei einer Familie Meier habe sie viel verkehrt, die ganz in diesem Fahrwasser gesegelt, deren Tochter später Frau Pfarrer Walder in Barken geworden. Bretscher sei ein arger Spötter gewesen, ein Bauer aus der Nähe von Fällanden, der in Teurungsjahren Kornwucher getrieben,

dann aber den rechten Moment verpasst habe zum Verkauf u. schliesslich um Hab u. Gut gekommen sei. Solche Erinnerungen tauchen jetzt auf, sie ersetzen mir ein klein wenig die Erinnerungen, die wir mit einander austauschen könnten. Ach, wir beide haben von unseren Jugendjahren so wenig gemeinsam verkehren $u$. sich uns gegenseitig erschliessen können! War doch die Gegenwart von Anfang an für uns allzu gefüllt $u$. bewegt!

Die Erzählungen Zöpfs mahnen mich Schritt für Schritt an Dich, das ist eine Poesie, die Dir wohlgetan hätte. Auch hat sie gar viel von dem Kindesgemüt der Susanna Spyri. Aber wie wenige verstehen das! Dass Frau Rümelin sich davon tief ergriffen fühlt, macht sie mir lieber, als wir es eigentlich ihr gegenüber beide früher für möglich gehalten hätten. 
Kommt es morgen für mich besser? Ich weiss es nicht. Es fehlen in meinem jetzigen Leben so viele Faktoren, um ein richtiges Ergebnis als möglich oder wahrscheinlich erscheinen zu lassen!

Gute Nacht, liebe, liebe Seele! Auf Deine Hülfe vertraue ich $\mathrm{u}$. bleibe für immerdar

Dein getreuer

Eugen

\section{2: April Nr. 91}

B. d. 16. April 1912.

Mein liebstes Herz!

Auch heute habe ich den ersten halben Tag mit Ordnen der Correspondenzen betr. ZGB. u. OR. von 1908 / 11, u. d. Nationalratsakten verbracht. Die andere Hälfte las ich die zwei weitern Hefte von Arnolds Tagebüchern (VIII u. IX), die mir Marie Heim gestern zugesandt hat. Es war etwas Sonne, aber ich ging nicht aus. Es soll auf der Brücke eine giftige Bise geblasen haben. Gesehen habe ich einen Candidaten, der mich wegen einer Dissertation consultierte, u. Guhl, der mir Amtliches vorlegte. Sonst war der Tag still u. ich für mich. Siegwart kam nicht. Doch noch zwei Sachen nicht zu vergessen: der 21 jährige Photograph Neuenschwander brachte mir die Bilder, die er in meiner Studierstube aufgenommen, in neuer Ausfertigung, $\mathrm{u}$. ich bestellte von zweien, die mir gefielen, je 10 Stück. Ferner kam Nationalrat Suter, um mich wegen der Erbschaftssteuer zu beraten, u. blieb fast bis ein Uhr. Seine Frau ist gestorben, im März, 59 Jahre alt. Er sagte, es sei eine gute, kluge Frau gewesen. Sonst zeigte er wenig Trauer, bis er unter der Haustüre bemerkte: Ich bin jetzt in der gleichen 
Lage, wie sie. Der Mann hatte immer ein so volles Zutrauen zu mir gezeigt. Aber er ist für mich für sein Alter sehr geschwätzig. Seine natürliche Klugheit macht ihn aber trotzdem interessant.

Beim Aufräumen stiess ich gestern auf den Mimeographen u. die Metallschreibfläche, die schon vor etlichen Jahren von Dir bis zur Unbrauchbarkeit zum Schreiben mit dem Stahlgriffel gebraucht worden war. Es zeigen sich an den Rändern der glattgeschriebenen, d. h. -gedrückten Mittelstelle noch deutlich Deine Schriftzüge. Ich schraubte die Platte los, u. jetzt ist sie mir ein liebes, wehmütiges Andenken, das mich Tag für Tag an Deine Mithülfe erinnern wird. Was hast Du da alles Liebes gedacht $u$. in unermüdlicher Arbeit für mich getan, bis diese Platte glatt geworden! Das versinnbildlicht mir nun, wie Du mir in Allem so lieb u. treu zur Seite gestanden. Es ist ein Denkmal, ein Denkzeichen Deiner Hingebung u. unerschütterlichen Pflichttreue. Ich bin so froh, jeden Tag daran gemahnt zu werden!

Siegwart hat offenbar noch keinen Bericht bekommen. Er war gestern bei Guhl, um Grundbuchmaterial zu erhalten, $u$. hat diesem gesagt, er trete bei mir aus $u$. werde Professor in Freiburg. Also hat er doch selbst die bestimmte Zuversicht. Als Guhl ihm bemerkt, das werde mir nicht recht sein, habe er geantwortet, oh, ich habe

schon Ersatz. Ich sagte Guhl, dass die Sache noch nicht entschieden sei. Und da rückte er mit dem Vorschlag heraus, ich soll doch Mutzner nehmen. In der Tat hatte ich an diesen erst auch gedacht, vielleicht habe ich Dir das geschrieben, u. zwar mit verschiedenen Combinationen. Aber ich sagte mir, das würde schlechterdings nicht möglich sein. Dies bemerkte ich dann auch Guhl: Ich hätte diese Secretärdienste niemals Mutzner anbieten dürfen. Dazu ist er zu alt, durch seine Familie zu sehr gebunden, $\mathrm{u}$. zu bedeutend. Nur ein 
junger Anfänger darf sich in eine so unselbständige, halbe Stellung wagen. Ich würde Mutzner jederzeit abraten, einen solchen Schritt zu tun. Dies schien dann auch Guhl zu begreifen, wenigstens sagte er es. Nebenbei mag er sich auch dabei gedacht haben, ich hätte über seine Stellung zu mir ebenso gedacht, u. das ist auch ganz richtig.

Mutzners Zerwürfnis mit Werner Kaiser braucht auch durchaus nicht so akut zu bleiben, wie es jetzt ist. Es wird sich, wenn Mutzner mit Geduld sich wappnet, gewiss wieder bessern. Ich habe von ihm eine sehr gute Meinung. Er ist auch gutmütig. Aber wenn er sein Temperament etwas zu bemeistern lernt, so kann das für seine $\mathrm{Zu}$ kunft, mag sie sich so oder anders entwickeln, nur von Gutem sein. Ich hoffe innigst, dass er den richtigen Weg finden werde. Es wäre jammerschade, wenn er durch Dinge, die doch nur von secundärer Bedeutung sind, sich

verleiten liesse zu Schritten, die für ihn viel viel ungünstiger wären. Mein Secretär kann er aber ganz gewiss nicht werden. Im übrigen warte ich jetzt auf die Entscheidung mit Siegwart u. mit Abbühl.

Genug für heute. Nimm innigen Gruss u. Kuss von Deinem allzeit getreuen

Eugen

1912: April Nr. 92

[1]

B. d. 17. April 1912.

Meine liebe, gute Lina!

Heute habe ich vor u. nach dem Morgenessen die Notizen in meiner Schachtel für Rechtsphilosophie wieder einmal herausgenommen, durchblättert u. dasjenige, was mir zur 
Ausfeilung der «sozialen Gesinnung» dienen kann bei Seite gelegt. Nachher aber bestand meine ganze Tagesarbeit darin, die zwei letzten, mir übersandten Tagebücher Arnolds durchzulesen. Bei allem Hochinteressanten, was sie bieten, $u$. bei aller Bewunderung, die man der Energie zollen muss, mit der Arnold diese Blätter in so consequenter, ausführlicher Weise durchgeführt hat, bleibt mir doch ein schmerzlicher Eindruck, Arnold kommt auf der ganzen Reise nie zur Ruhe, ärgert sich über viel zu viel, ist mit seinem Urteil viel zu schnell in Gutem u. Bösen. Über seine Beziehungen zu den Eltern macht er sich oft, ja leider in gewissem Sinn motivierte Vorwürfe. Ja er schreibt sogar an einer Stelle, dass ihn die Schuld treffe, dass zu Hause alles aus Rand u. Band sei, wozu die Mutter mit Bleistift freilich die Notiz angebracht hat, so schlimm sei es dann doch nicht. Albert hat an einigen Stellen in geologischen Dingen Correcturen angebracht, die ich ihm auch geschenkt hätte in Anbetracht der Laien, denen diese Blätter zu lesen gegeben wurden. Ich bin nun gespannt

auf die Berichte aus Amerika. Sehr nett war eine Herzensepisode aus Nizza, wo sich Arnold in ein herziges Japaner Zimmermädchen offenbar bis über die Ohren verliebt u. ihr zum Abschied - alles in Ehren - einen weissen Halspelz gekauft hat, worüber der Japaner Wirt erstaunt gewesen sein mag - denn die Fremden im allgemeinen sind sonst dort nicht so gefühlsfrei u. gefühlsvoll.

Am Nachmittag kam Siegwart, wieder ohne Bericht. Er will morgen nach Freiburg hinüber zu Oser, u. mir dann am Abend noch Bericht geben. Ich würde so gerne nun wissen, wie ich es mit Abbühl halten kann. Das Gespräch mit Guhl ist mir übrigens gestern Abend noch $\mathrm{u}$. heute Morgen recht nachgeklungen. Ich überlegte, ob ich am Ende nicht doch die Arbeit der zweiten Auflage auf ihn übertragen soll u. stellte mir das als recht praktikabel vor. Aber ich bin mit meinen derartigen Einfällen recht kritisch geworden. Es fehlt mir eben die Controle u. Korrektur, die 
ich jeweils von Dir empfangen habe. Beispiele, wie die Erlebnisse mit Balli u. mit Anneli - so verschiedenartig sie sind, müssen mich vorsichtig machen gegen mich selbst. Freilich mag darunter dann auch manch Gutes zu kurz kommen. Jedenfalls will ich in erster Linie nun abwarten, wie sich Mutzner selbst zu seinen mir u. Guhl gegenüber geäusserten Gedanken von Rücktritt aus dem Amt definitiv verhält, ferner wie sich die Sache mit

Siegwart u. daran anschliessend mit Abbühl verhält. Dann erst wird es sich zeigen, ob ich mit Mutzner etwas combinieren kann oder soll.

Die Abendpost brachte mir einen Brief von Anneli, worin sie mir Aufschluss gibt, wieso sie dazu gekommen sei, vor bald zwei Jahren an Marieli direkt zu schreiben, wobei ein Telephonangestellter den Brief vermittelt habe, $u$. weshalb sie mir davon nichts gesagt, als sie hier war. Sie habe, weil keine Antwort gekommen, geglaubt, der Brief sei gar nicht bestellt worden. Mein Zweifel, ob sie mir am Ende nicht doch etwas davon gesprochen, was ich nur wieder vergessen hätte (so was ist mir schon in jüngeren Tagen gelegentlich in wichtigen Sachen passiert $u$. läge mir bei meinem Alter jetzt noch näher), war also unbegründet, u. die Geschwister fassen nun offenbar dieses Moment als dasjenige auf, woran mein Plan im wesentlichen zum Scheitern gekommen sei. Es ist das auch möglich, bei Marieli u. bei mir. Im übrigen spricht sie die Hoffnung aus, später doch noch mit Marieli in Beziehung zu treten. Das ist ein Punkt, über den ich jetzt die Entscheidung ganz Marieli überlassen will u. muss. Du würdest es auch so halten. - Was Du mir raten würdest, wenn der peinliche Conflict zwischen Siegwart u. Abbühl eintreten sollte? Darüber bin ich noch ganz im Unklaren. Heute habe ich Siegwart darauf hingewiesen, dass er nach diesen Erlebnissen den Plan fast notwendig 
unter allen Umständen, wäre es auch nur als Privatdozent, zur Durchführung bringen sollte. Sein Dienst als Secretär bei mir sei seiner jetzt nicht mehr würdig. Und es ist ja auch tatsächlich so.

Die Sonnenfinsternis, die wir heute von 12 bis $2 \frac{1}{2} \mathrm{Uhr}$ hatten, erinnerte mich an die fröhliche Stimmung, in der wir vor etwa acht Jahren ein ähnliches Ereignis mit allen Andern betrachteten. Es war heute weniger fröhlich. Und eben jetzt fällt mir der Polterabend bei Moulins ein - sechsunddreissig Jahre sind seitdem verschwunden, $u$. alles u. alles ist wie ein Traum!

Ich schliesse für heute $u$. bin in treuer Liebe

Dein guter alter Kamerad Dein Eugen

\section{2: April Nr. 93}

[1]

B. den 18. April 1912.

Mein liebstes, bestes Herz!

Heute vor sechsunddreissig Jahren! Ich habe den Tag in meiner Erinnerung wiederholt: Die Morgenfahrt mit Zürcher u. Mr. Moulin, die Trauung im Standesamt, von der zurückkehrend Du von Mr. Moulin so traulich als Madame Huber begrüsst wurdest. Die Fahrt zur Kirche, der freundliche Geistliche, der uns die französische Hausbibel überreichte. Das Mittagessen im Hotel de Rattie mit Moulins, Eltern u. beiden Knaben, Nella Magor u. Zürcher. Und wie ich diese Zeilen zu schreiben beginne, stehe ich mit Dir auf dem Bahnhof von Gentet, um nach Lausanne zu fahren. Heute ist draussen Sonnenschein, damals begann es zu regnen. Wie wanderten wir dann miteinander unter einem Schirm zu Fuss in der Nacht 
nach dem Beau Rivage hinunter, so fröhlich, so innig beglückt, dass durch alle Not $u$. Wirrsale hindurch wir zu diesem Ziel gelangt waren. Wir dachten damals, fünfundzwanzig Jahre wäre schon ein gutes Geschenk, das uns das Schicksal in Lebensgemeinschaft gönnen würde. Und vor elf Jahren waren wir auch dankbar dafür, aber wir stellten den Anspruch schon höher u. dachten, wir würden wohl zu vierzig oder fünfzig Jahren kommen. Und nun sind schon zwei Jahre vorüber, dass Du mich verlassen hast. Wir können nicht mehr gemeinsam uns jenes Tages erinnern, ich bin allein. Die Clivia, die uns zur silbernen Hochzeit geschenkt wurde, hat jedes Jahr auf diesen Tag ihre rote Blume

leuchten lassen. Am ersten Hochzeitstag, den ich einsam feiern musste, $u$. in Gent verbrachte, auf der Fahrt mit Marieli nach Den Haag, war sie noch pünktlich, letztes Jahr neigte sie sich schon zum Abblühen, u. heute steht sie schon seit einigen Tagen kahl, nachdem sie allerdings vorher zwei Blüten lange Tage hindurch getragen. Sie gedeiht noch, aber sie hat die Zeiten verwechselt. Sie nahm Deinen Todestag für unseren Erinnerungstag.

Ich las heute früh, etwas unwohl, meine alten Notizen über die «soziale Gesinnung». Nachher schrieb ich an Marie Heim, der ich Arnolds Tagebücher zurückschickte, u. Rümelins. Darauf machte ich Hänny einen Besuch u. fand ihn $u$. seine gute Frau recht traulich. Er zeigte mir wieder allerlei u. kam nach dem Essen, um das Relief, das er um Neujahr von mir gemacht, nochmals zu controlieren. Es wird jetzt sehr gut hoffe ich. Hänny blieb dann auch zum Café. Ich spielte ihm allerlei, Wagner u. Chopin, auf dem Aeolion u. er war sehr dankbar u. freudig. Ich hab ihn gern. Es hat mich auch gefreut, dass er auf meine Bemerkungen zu dem Reliefpendant, das er zu dem Deinigen von mir angefertigt hat, so verständnisvoll eingetreten ist. Er wird es übermorgen fertig machen, in einer Art, die mich vielmehr befriedigt $u$. meinem Charakter mehr entspricht. In jener 
ersten Auffassung wollte er mich, wie er sagte, fassen, wie ich aussehe, wenn ich über einen guten Witz lache oder doch mich freue. Da nun doch dies aber doch nicht meine Grundstimmung ist, in der ich in Bronce abgehelget zu werden bestimmt bin, so ist es mir wirklich lieber, wenn das nun

geändert u. eine ernstere Wiedergabe gewonnen wird. Während Haenny bei mir war, wollte Im Hof von Schaffhausen mich besuchen. Er kam dann soeben wieder $\mathrm{u}$. hat mir herzlich gedankt für alles, was ich seinem Sohn getan. Damit wäre nun auch für diese Geschichte, die mich so oft geplagt hat, ein wenigstens einigermassen befriedigender $\mathrm{Ab}$ schluss gefunden.

Und nun erfahre ich soeben noch etwas Erfreuliches: Siegwart war heute in Freiburg, wollte während Im Hof bei mir, mit mir sprechen, wird nach dem Abendessen nochmals vorsprechen. Vorläufig sagte er zu Anna, sie soll mir mitteilen, dass alles in Ordnung sei. Gottlob und Dank! Nun ist die Angelegenheit auch mit Abbühl ins Reine zu bringen. Der gefürchtete Conflikt ist gehoben. Ich kann mir nun auch noch freier überlegen, ob ich Mutzner für mein Buch heranziehen will.

Es ist mir lieb u. besonders wert, dass diese drei Sachen, von denen ich da erzähle, gerade auf unsern Hochzeitstag zur Abklärung gekommen sind. Wie habe ich mich die letzten Tage, ja Wochen gedrückt gefühlt. Und jetzt ziehen unsichtbare Hände die Fäden auseinander u. es entwirrt sich die krause Verschlingung. Ich hoffe, mit dieser Auffassung nicht wieder einer Täuschung zu unterliegen. Es kann ja manches auch so sich wieder verwickeln und unklar werden, aber ich beginne doch das Semester mit frohem Mut, u. das ist mir viel wert. Ich erschrak die letzten Tage vor mir selber, als ich entdeckte, dass ich auf den Beginn der Vorlesungen mich dieses mal gar nicht freue. 
Ich glaube aber, es wird jetzt besser, u. diesen Umschwung verdanke ich unserem Hochzeitstag.

Wir haben den Tag immer still gefeiert. Wir waren ja nie laut in unseren Freundschaftsbezeugungen. Feire ich ihn heute still u. dazu einsam, so will ich doch an der Hoffnung festhalten, die mich mit Dir verbindet, so gut ich es nur mit aller Herzenskraft vermag. Oh bleibe bei mir, hilf mir in allen Schwierigkeiten! Hast Du mir während unserer Lebensgemeinschaft Liebe $u$. Dankbarkeit von Anfang bis zum Ende in einem Reichtum erwiesen, den ich mangels eigner innerer Gestaltung u. umfangen von äussern Momenten nicht zu vergelten vermochte, so ist jetzt die Zeit gekommen, da ich meine Schuld an Liebe u. Dankbarkeit Dir noch abzutragen vermag. Darauf hoffe ich mit meiner ganzen Seele u. mit meinem ganzen Gemüt!

Nimm im Geiste innigsten Kuss u. Umarmung! Ich bleibe

Dein ewig getreuer

\section{Eugen}

1912: April Nr. 94

B. d. 19./ 20. April 1912.

Mein liebstes Herz!

Heute habe ich meine Briefschulden nachgeholt - bis auf Ida - u. ein vierseitiges Gutachten für Landammann Dähler geschrieben $u$. abgeschrieben. Auch war der junge Hans Hoffmann, der Sohn des Bundesrats bei mir u. wollte meine Ratschläge für das erste Semester. Also war der Tag schon gefüllt, wenn ich auch nicht unter dem Eindruck fruchtbarer Arbeit gestanden habe. 
Aber nun ist meine Stimmung weit mehr unter dem Eindruck von etwas anderem. Ich überlegte die halbe Nacht, ob ich nicht Mutzner eine Gelegenheit zur Erlangung der von ihm so heiss ersehnten wissenschaftlichen Stellung schaffen könnte, unter Förderung meiner Buchpläne. Und ich rechnete aus: Ich könnte ihm, von den 45000 Fr., die mir das Buch brutto eintragen soll, unter Abzug der mutmasslichen $10 \mathrm{Fr}$. Autorkosten per Bogen 42000 Fr., hievon ein Drittel offerieren, also 14000 Fr. oder per Bogen 44 Fr., u. dies auf vier Jahre verteilt würde ihm eine Einnahme von 3500 Fr. per Jahr verschaffen. Er würde sich habilitieren u. aus den Kollegiengeldern u. Gutachten doch auch etwa $2000 \mathrm{Fr}$. einnehmen, also soviel wie er jetzt hat. So rechnete ich u. ging am Vormittag zu ihm,

um ihm hievon zu sprechen. Er nahm es sehr freudig auf, will sich die Sache überlegen. Aber mir kommen die allerschwersten Bedenken. Das Risico! Wie wenn dann innerhalb der vier Jahre sich keine Professur eröffnete, oder wenn sonst widrige Zufälle dazwischen träten? Oder wenn er die Arbeit gar nicht so schnell bewältigen könnte? Und ist das überhaupt das Richtige? Ich weiss es nicht, ich bin nur fürchterlich ängstlich geworden $u$. habe kein rechtes Vertrauen zum Plan. Muss ich nicht mit meinen Feinden rechnen? Könnten sie nicht mein Buch gleich beim ersten Anfang schlecht machen, sodass ich nachher innerlich gar keinen Willen mehr verspürte, es fortzusetzen? Und soll wissenschaftlich überhaupt auf solche Weise gerechnet $u$. gearbeitet werden? Hat Mutzner wirklich diesen idealistischen Zug zur wissenschaftlichen Arbeit? Welch ein Unterschied in der Stellung, die damit Mutzner geschaffen würde, gegenüber der Position, die gleich zu Anfang für Guhl gewonnen wurde! Und doch ist Mutzner der begabtere u. namentlich wissenschaftlich besser veranlagte $u$. weit aus weniger berechnete, unter den Beiden! Jetzt habe ich 
Mutzner meine Karten offen hingelegt. Was kann daraus für mich entstehen! Das sind die Folgen davon, wenn man so einsam wie ich lebt u. seine Pläne ausheckt! Es ist jetzt doch wieder von mir ein Streich, wie bei

[3]

Balli, ich fürchte, in eine Sache mich eingelassen zu haben, die mir schwere Sorgen bereiten kann. O Gott hätte ich doch das Buch nicht auf dem Nacken! Ich weiss ja nicht, wie ich es bei meiner jetzigen Gemütsbeschaffenheit zu Ende bringen kann!

Von Siegwarts Ernennung noch keine Mitteilung. Ich traf heute Redaktor Welti, der mir mitteilte, dass sein Bruder, der Maler, krank geworden sei: Magenstörungen. Ich mag heute nicht weiter schreiben, ich bin niedergedrückt. Es ahnt mir, als ob recht viel Widrigkeit in der Luft liege. Ich bin aber nicht mehr der alte!

Den 20. April.

Heute halb neun Uhr soll also Marieli heimkehren. Möge seine Rückkunft gesegnet sein. Seine Freunde haben Blumen geschickt, Sophie einen Willkomms-Kranz gewunden. Ich selber freue mich auf eine Zukunft, der ich in anderer Beziehung so schwer bedrückt entgegensehe. Siegwart brachte mir heute den Bericht, dass er gewählt sei. Ich hatte noch eine freundliche halbe Stunde Gedankenaustausch mit ihm. Aber daneben plagt mich die Anerbietung, die ich gestern, freilich unverbindlich, gestern Mutzner gemacht habe. Es erscheint mir jetzt alles anders. Ich nahm die Sache so zu Herzen, dass ich im Begriff war, Lichtenhahn zu schreiben, die Ausarbeitung des Buches nach meinen Anordnungen solle überhaupt an Mutzner übertragen werden. Als ich aber die bereits für den ersten Band verarbeiteten Manuskripte am Vormittag durchging, neu ordnete, u. sah, dass daraus zwei Bände von je etwa 30 Bogen 
gemacht werden können, überfiel mich eine innere Lust, dies nun doch selbst zu machen. Aber wie dann meine andern Aufgaben? Wie mit Mutzner mich auseinandersetzen? Darüber kam ich den ganzen Tag nicht zur Ruhe. - Am Nachmittag war Haenny wieder drei Stunden da u. hat nahezu zwei streng gearbeitet. Aber das Ergebnis befriedigt mich nicht, es tritt wieder weit mehr der hämische Zug hervor, der mich an der ersten Probe so anwiderte. Ich werde mir unter solcher Maske selber zum Abscheu. Und ich kann ihm nicht sagen, woran der Fehler liegt, ich kann nur sagen, dass ich nicht so bin.

Ich gehe jetzt auf die Bahn, um Marieli abzuholen. Hoffentlich hat er Anschluss in Lausanne u. kommt zur rechten Zeit. Vor Schlafengehen will ich diesen Zeilen noch einige Worte beifügen.

Marieli ist recht lieb heimgekommen. Gott Lob u. Dank! Möge es gesund bleiben!

Mit innigem Kuss Dein alter treuer Eugen

\section{2: April Nr. 95}

B. d. 21. / 2. April 1912.

Mein liebstes Herz!

Heute war ich als am Sonntag in einer Sprechkette von halbzehn bis halbneun: Erst Walter B., dann unter der Haustüre Dr. Fick aus Küsnacht, darauf nach dem Mittagessen Egger, den ich am Bahnhof abholte u. Abends zur Bahn geleitete. Die drei Besuche waren mir lieb u. wert, ich bin froh, sie gehabt zu haben. Aber zum Brief schreiben kam ich nicht $u$. jetzt bin ich müde u. gehe gern zu Bett. Marieli war heute recht munter, sonst aber von dem gestrigen Abendessen her nicht disponiert. Schädelis, die Besuch machten, hat es allein empfangen. 
Die Unterhaltung mit Egger machte mir den Eindruck, als ob ihm das Rektorat sehr gelegen komme, um vorwärts zu kommen, ohne sich zur Zeit allzu viel in die wissenschaftliche Kleinarbeit vergraben zu müssen. Er war sehr nett u. dankbar. Interessant war es mir die Spannung zu beobachten, die in Zürich latent unter den Fakultätskollegen besteht. Von Zürcher erzählte Egger, dass er doch wirklich oft an Schlaflosigkeit leide u. in den Sitzungen unmotiviert heftig werde, sobald er ermüdet sei. - Fritz machte mir den Eindruck eines müden, fast misstrauisch gewordenen Mannes. Walter B. war wie immer, Trockenbrödler auch nach der schönsten Weise. Er sprach namentlich vom Louvre, u. verfiel hier auf die Bewunderung der Venus von Milo, die ich ja

auch teile, für die wir also nicht noch besonders zu bereden hatten. Alle drei Collegen waren lieb u. gut u. ich freue mich dessen u. geh jetzt, müde, wirklich müde zu Bett.

Den 22. April.

Der heutige Tag war unruhiger $u$. mühsamer als der gestrige, ein sonderbarer Ferienschluss oder Semesteranfang, wie man's nimmt.

Ich begann damit, dass ich das blaue feine Glas auf dem Waschtisch zerbrach. Hoffentlich war ich geschickter mit dem Abschluss des Briefes an Ida, den ich gestern nicht mehr beendigen konnte. Darauf nahm ich die Collegienhefte für morgen hervor, wurde aber gleich gestört, erst durch die Consultation eines hiesigen Kaufmannes Weiss, der wissen wollte, was sein Sohn, der Fürsprecher werden will, zuerst zu hören habe. Der Junge war mit u. machte mir einen guten Eindruck. Darauf kam Rossel, der vierzehn Tage in Mentone bei Bassires gewesen war. Er war mit Muskelschmerzen in einem Fuss verreist. Es geht ihm aber wieder besser. Dass gestern in Neuenburg Mentha gegenüber dem Socialisten Graber bei den Nationalratswahlen unterlegen, gab ihm viel zu schaffen. Von Balli meinte er, nach dem Brief, den dieser 
ihm geschrieben, beherrsche er die französische Sprache nicht genügend, um seine Vorlesungen zu übernehmen, ein Bescheid, der mir leid tut. Darauf kam Abbühl, mit dem ich nun abgemacht habe für Eintritt mit Dienstag den 30. April. Abbühl

[3]

musste mir einiges aus seinem Leben erzählen, $u$. ich vernahm zu meinem Erstaunen, dass er nach anderthalb Jahren aus dem Seminar Muristalden ausgetreten $u$. dann anderthalb Jahre im Schiffsdienst als Secretär zwischen England u. Nord- u. Südamerika herum gefahren. Also romantisch. Nun wird es sich zeigen, ob etwas ist an ihm oder ob er nach der gefehlten Seite neigt. Dann kam Guhl mit einigen Anfragen. Am Nachmittag hatte ich Haenny eine halbe Stunde bei mir, der mein Relief recht hübsch fertig gemacht hat. Ich gab ihm auch die Mimeographenplatte mit, mit der Bitte auf der Rückseite etwas zu gravieren, das für den Fall passe, etwa die Diana mit dem Büffel, nebst Decorationen. Und er ging freudig darauf an. Sofort nachher kam Mutzner u. brachte mir den Bericht, dass er meine Offerte annehme. Also bin ich nun gebunden! Ich wand mich etwas unter der Antwort, aber ich konnte mich nicht mehr entwinden. Jetzt muss es sein. Also vorwärts, entstehe daraus, was da wolle. Es wird mir auch wieder von Nutzen sein! Endlich konnte ich an die Kollegienpräparation gehen, las alsdann noch den Bericht von Guhl betr. die Grundbuchabreden mit den Kantonen zur geplanten Besprechung. Und dann kam der junge Teichmann u. brachte mir zwei Mappen Bilder seines Prinzipals Henn, die mich sehr interessierten. Seinem Vater gehe es jetzt wieder recht gut. Die Schwester aber sei schwer angegriffen. Man wisse keinen Tag ob sie nicht

an Herzschwäche sterbe. Er will nun für seinen Vater Jadason consultieren. Ich erzähle Dir diese Sache nur so zur Andeutung. Rechne dazu, dass Marieli seit gestern recht angegriffen ist $u$. wieder 
nicht recht weiss, was sie will, so magst Du ermessen, wie dieser Semesterbeginn mich in eine innere Unruhe versetzt. Nun, morgen, wenn die Vorlesungen begonnen, wird schon gleich mehr Ruhe eintreten. Ich bin ängstlich auf diesen Anfang, wie immer.

Gute, gute Nacht! In solchen Momenten sollte ich mit Dir reden, Deine lieben Worte vernehmen können. Es wird so alles doppelt schwer!

Innigst Dein allzeit treuer

Eugen

1912: April Nr. 96

B. d. 23. / 4. April 1912.

Mein liebstes Herz!

Ich begann den heutigen Tag mit einer elenden Stimmung, die dadurch hervorgerufen wurde, dass Marieli sich bei meinem Morgenessen als an Halslweh leidend meldete u. tatsächlich heiser war. Sie liess durchblicken, dass sie krank sein könnte u. ich dachte sofort daran, sie ohne Aufschub ins Engadin zu schicken, wenn es doch nicht anders sein dürfe. Also wiederum Unruhe u. nichts als Unruhe, u. dabei von Marielis Seite der Geist der Härte, den ich durch den Aufenthalt in Genf gedämpft glaubte, das Bestreben, jetzt in verstärktem Mass Kollegien besuchen zu wollen, während sie anderseits sich krank fühlt, u. noch anderseits dem Haus eine ruhige, behagliche Hilfe so bitter Not täte! Diese Stimmung, die gewiss nicht in ihrem ganzen Umfang berechtigt war, dauerte an $\mathrm{u}$. auch der starke Besuch in meinen beiden ersten Vorlesungen, wo um $7 \mathrm{u}$. um 8 Uhr die Hörer in Nr. 42 fast nicht Platz fanden, vermochte sie nicht zu bessern. Nach Hause zurückgekehrt schrieb ich acht Briefe u. Karten, Antworten auf Sendungen, was mich bis gegen Mittag beschäftigte. Und blieb immer noch 
in der Stimmung. Nach Tisch war Hieber da, dann ein Student, $u$. nachher arbeitete ich an den Kollegien für morgen $u$. später, bis Mutzner von halb fünf sechs bis sieben mich in einer

Rekurssache consultierte. Jetzt, nach dem Nachtessen, bei der Lampe wird es mir freier. Ich muss es als eine grosse Gnade auffassen, in meinem Alter noch derart in den Vorlesungen Erfolg zu haben, u. darf das, was sich mir dazwischenstellt, nicht mir über den Kopf wachsen lassen. Am Ende ist es bei Marieli nun auch nichts anderes als der Wechsel des Klimas, was sie etwas angegriffen hat. Sie will morgen Dumont consultieren. Heute hat sie bei Türler Besuch gemacht, bei dem sie Urkundenlehre hören soll, nach Haags Anraten. Und Türler hat ihr aufgegeben, auch gleich die Übungen mitzumachen. Dafür fällt das Kolleg bei Schulthess, Latein, Stilübungen, weg. Mit den Privatstunden, die sie im Latein erhält u. gibt, u. der projektierten Klavierstunden bei Reding, würde sie in der Woche 20 Stunden haben. Ist sie gesund, so sollte das möglich sein. Ist sie angegriffen, so fällt ja überhaupt alles weg. Lieber wäre mir freilich gewesen, sie hätte ihre Ruhe in der intensiveren Teilnahme am Haushalt gesucht $u$. gefunden. Ich werde Dir morgen über den Bericht Dumonts Bericht geben können. Für heute will ich hier abbrechen.

Den 24. April.

Marieli war heute vor Tisch bei Dumont. Er schien es nicht gerne zu haben, dass sie ihm von den Mitteln sprach, die Marieli Rümelin mit Erfolg gegen die Constipation verwendet hat, aber das Gute hatte doch die Anmerkung, dass Dumont sich nun dieser Angelegenheit speziell angenommen.

Aus ihrer Heiserkeit $\mathrm{u}$. den einigen stechenden Hustenreizen machte er nach vorgenommener Untersuchung gar nichts. Er riet ihr auch davon ab, jetzt in die Ferien zu gehen. Sie soll im 
Sommer in die Höhe. - So wäre also dieser Schrecken wieder einmal überwunden. Hoffentlich für längere Zeit!

Heute las ich wieder in Nr. 31, nicht ungern, wenn es so weiter geht. Die gute Frequenz hat mich heute mehr gefreut als gestern.

Rossel besuchte mich, um mich über die ersten Zivilrechtsakten zu consultieren, $u$. ich konnte ihn vor einem Irrtum bewahren, der mir sehr peinlich gewesen wäre.

Neben allerlei Nebenarbeit begann ich heute die Dissertation zu lesen, die mir Hans Trub aus Enneda brachte, u. Gottlob und Dank scheint sie recht zu sein. Der Besuch erinnerte mich an die Tage, wo Trub mit der andern um Paul u. August gesammelten Corona bei uns verkehrten. Ich dachte an die Mühe, die Dir die Abende bereiteten, u. stelle mir vor, dass auch meine Mühe damit verbunden war. Denn die jungen Herrn haben sich wenig bewährt. Jedenfalls sind sie nicht, was ich erhofft, ideal gerichtete Herzen, sondern entweder wenig bedeutend, oder Glücksritter. Wir müssen uns das so vorstellen, wenn sie Jahrelang derart auf der akademischen Strasse liegen $u$. keine Spur von Dankbarkeit dafür zeigen, was man ihnen in Liebe geboten hat oder doch zu bieten versuchte.

Guhl war heute nach dem Nachtessen bei mir, auch er hat

kein gut besuchtes Kolleg. Von Mutzner sagte er mir, dass er heute bei ihm gewesen u. erklärt habe, er sei jetzt entschlossen seine Demission zu nehmen u. sich zu habilitieren.

Und nun gute, gute Nacht! Bleibe bei Deinem ewig getreuen

Eugen

Ich habe Zeit gefunden, heute zwischendurch auch einiges in Zöpfs «Es muss ein Himmel sein» zu lesen. Immer die selbe Innigkeit u. Liebe u. poetische Verklärung für alles, was ihm begegnet $u$. wovon seine Feder spricht! Überall die gleiche Erinnerung an Dich! Das ist es, was mir das Buch so lieb macht. Wie muss ich Rümelins danken, dass sie mich 
mit diesem kindlichen Gemüt, mit dieser tiefen Frömmigkeit bekannt gemacht haben!

Von Neuenschwander habe ich heute die 10 stehenden $u$. die 10 sitzenden Photographien erhalten. Sie sind recht. Guhl hat gleich eine stehende ausgewählt, eine Erinnerung, wie er sagte, an den «Professor».

\section{2: April Nr. 97}

B. d.25. April 1912.

Mein liebstes, bestes Herz!

Marieli ging gestern nach dem Nachtessen noch zu Architekt Baumgarts hinauf, um zu fragen, wie es der Tochter Leni gehe, die am Generoso vor zwei Wochen verunglückt ist $\mathrm{u}$. im Lindenhof immer noch in Gefahr schwer darnieder liegt. Ich hatte mir vorgenommen, bald zu Bett zu gehen, weil ich die letzten Nächte nicht ganz genug geschlafen hatte. Und nun kam Marieli ganz gegen seine Absicht erst gegen halb zehn Uhr zurück u. zwar deshalb so spät, weil ihm Frau Baumgart den ganzen Unfall in alle Einzelheiten, mitsamt der Reise der Eltern u. der Heimfahrt erzählt hatte. Und Marieli berichtete die traurige Geschichte wieder, so dass es bis zum Schlafen gehen spät wurde. Da ich überdies daraufhin sehr unruhig schlief u. doch früh auf musste, war ich heute den ganzen Tag ermüdet, holte zwei mal mit je einem Viertelstündchen auf der Chaise longue nach, war aber schwer zur Arbeit zu bringen. Dennoch ging es mir in dem stark besuchten Kolleg gut. Ich glaube, ich bringe es in diesem Semester auf gegen hundert Hörer, wenn es so fort geht. Das steigert natürlich auch die Verpflichtung zur Präparation. Ich habe heute erst etwas an der «rechten Gesinnung» gearbeitet, dann in Trubs Dissertation weiter gelesen, zum Glück wieder befriedigt. Sonst 
ging meine Zeit auf in den Arbeiten am Kolleg, wozu noch ein paar Candidaten mit Dissertationen u. ein lieber Besuch Siegwarts gekommen sind. Es hat mich eigentümlich berührt, dass dieser mir erzählte, er habe immer noch keine Anzeige seiner Wahl, die freilich in einzelnen Zeitungen - nicht in denen, die ich lese, gestanden hat.

Marieli hat jetzt einen starken Schnupfen bekommen, fühlt sich aber sonst wohler als vorher. Hoffentlich entwickelt sich daraus nicht der übliche Husten, sondern geht es jetzt doch einem gleichmässigeren Befinden $u$. Empfinden entgegen . Es war die Tage wieder munterer. Wie es über Susanne u. andere urteilt, macht mir immer Freude. Heute Abend soll es, von Richter gebeten, noch ein Weilchen zu Baltzers hinüber. Hoffentlich verfolgen die nicht eine besondere Absicht mit der ganz ungewohnten Aufforderung zum Besuch.

Marieli brachte gestern Abend auch die Nachricht, neben dem Zimmer Helene Baumgarts liege der Oberst Weber, dem man wegen Zuckerkrankheit den Fuss habe abnehmen müssen. Ist das der Genie Oberst, Alters- $u$. Schulgenosse Albert Heims? Das wäre hart zu denken, er ist ein braver, sympathischer, hochverdienter Mann. Dann las ich von Alt Nationalrat Bösch, dass er vor einigen Tagen in Cham auf dem Bahnhof am Herzschlag gestorben sei. Auch ein Altersgenosse, den ich im Rate sehr wohl mochte. Wenn

ich an solche Schicksale denke, erkenne ich erst, wie besonders begünstigt ich doch bin, dass ich in meinem Alter noch so viel Erfolg in den Vorlesungen einheimse. Und das mahnt zur Dankbarkeit u. Zufriedenheit. Aber freilich eine Freude, tief innerlich, kann darüber doch nicht aufkommen, denn Du fehlst mir, Du solltest Dich mitfreuen können! Und ich begreife gar nicht, wie ich im letzten Jahr unseres Zusammenseins den Gedanken ernsthaft erwägen konnte, ganz oder zum Teil 
zu resignieren. Es muss jene Stimmung von der Ermüdung hergekommen sein, die mir selber unbewusst die lange anhaltende, aufregende Arbeit über mich gebracht hatte. Du hattest damals, das muss ich immer wieder denken, die bessere Einsicht. Aushalten, war Dein Rat. Und jetzt halte ich aus, ohne Dich, u. es wäre so schön gewesen, wenn wir das alles noch lebensfrisch miteinander hätten aufnehmen können!

Es sind diese Tage rechte Frühlingsstimmungen im Lande, wenn auch immer noch geheizt werden muss. Und im Hause soll Friedensstimmung walten. Anna tut was sie kann, Sophie ist anhaltend viel besser als jemals. Ihr Gesicht bekommt einen ganz andern Ausdruck. Sie hat auch das zerrissene, gellende Auflachen nicht mehr. Sie wird friedlicher u. ihr Gemüt wird gesunder u. ruhiger. Möchte doch diese Stimmung anhalten, möchte auch Marieli in diesen Frieden hineintreten u. damit die innere Verfassung erlangen, die auch die körperliche Erstarkung u. Gesundung herbeiführen muss! Ich wäre so dankbar, wenn unser Haus uns allen den inneren Frieden verschaffen könnte,

der dem Andenken an Dich, liebste Seele, so ganz entsprechen würde. Hilf mit, mein Herz, u. Alles ist gewonnen.

Nun gehe ich heute aber sicher bald zu Bett, u. will daher diese Zeilen schliessen. Gut Nacht, mein treues Herz, bleibe bei Deinem alten Kameraden

Deinem Dir ewig verbundenen Eugen 


\section{2: April Nr. 98}

[1]

B. d. 26. / 7. April 1912.

Mein liebstes Herz!

Die erste Kollegwoche ist vorüber. Ich bin aber heute Abend so erhitzt, dass ich Dir nur wenig werde schreiben können. Ich weiss nicht ist es das Wärmer werden der Luft, oder ist es wirkliche Ermüdung, die mich erfasst hat. Jedenfalls muss es besser kommen, sonst würde es mir schwer fallen, das Semester auszuhalten. Ich erinnere mich freilich, dass ich in früheren Jahren auch etwa gleich zu Anfang des Sommersemesters diese Müdigkeit empfunden habe. Man sagte dann, das sei eben der Frühling. Nun wollen wir abwarten.

Die Vorlesungen sind fortgesetzt gut besucht. Dagegen fand ich im Praktikum weniger Teilnehmer als ich nach der starken Frequenz der Vorlesung über das OR. erwartet hatte, nur etwa 60 , die aber auf 70 bis 80 anwachsen können. Ich selbst habe die erste Übung etwas schematisch abgewickelt, ich befand mich im Verlauf derselben in einer Art von Dusel, worin ich monoton, wenn auch geläufig drauf zu redete. Am Vormittag besuchte ich wieder einmal v. Mülinen, der mir von seinem ersten, achttägigen Aufenthalt in Paris mit Begeisterung sprach. Er wusste allerlei Neues zu berichten, was mich an unsere zwei Pariserfahrten erinnerte. Steck erzählte mich [sic!] heute im Professorenzimmer, Reg. Rat Lohner habe ihm von den Strafrechtsverhandlungen in Luzern er-

zählt, es gehe lahm u. wenig erfreulich vorwärts. Man werde sehen müssen, was dann aus dem Entwurf, nach welchem z. B. der Mord künftig nur noch ein Vergehen $u$. kein Verbrechen sein solle, machen werde. Es fehle eben ein überragender Geist, der das Ganze, wie beim Zivilrecht, leite. 
Von Prof. Teichmann erhielt ich die Anzeige, dass er morgen Jadasson consultieren $u$. mich dann gerne besuchen werde, etwa halb sechs Uhr. Ich schwankte, ob ich ihn zum Nachtessen einladen soll, tat es dann aber nicht. Ich bin darauf eben doch gar nicht mehr eingerichtet $u$. bin dazu noch so müde, dass es mich eine grosse Überwindung kostete, da etwas geselliger mitzumachen. Doch wollen wir sehen, wie die Stimmung morgen ist.

Arbeiten konnte ich neben drei vier Kollegstunden u. den Besuchen heute gar nichts. Vielleicht wird es morgen besser. Für heute schliesse ich ab u. gehe früh zu Bett.

Den 27. April.

Heute bin ich dazu gekommen, an der «rechten Gesinnung» zu arbeiten $u$. habe die Dissertation Trub bis über die Hälfte durch genommen. Am Nachmittag las ich in dem 12. Heft von Arnolds Tagebuch, das ich früh durch die Post erhalten. Und dann kam Guhl, der über den Vertrag Siegmunds bei den Landwirten berichtete - es muss ein ganz Siegmundsches Rede-

werk gewesen sein, was er da losgelassen $u$. leider soll es gedruckt werden, mit allen seinen Anödungen u. Missverständnissen. Dann kam Burckhardt u. berichtete mir, der Basler Professor von Frisch, der nach Gorowitz geht, habe eine Brochüre zum Abschied geschrieben u. Häusler gewidmet, worin er die Redaktion unserer - Bundesverfassung in eckliger Weise herunter mache. Endlich kam als dritte Basler Reminiszenz Teichmann, der angekündigte, der ganz kahl u. sehr alt geworden, aber in der Unterhaltung noch grosse Frische erwies. Auch er erzählte mir von Basel recht Unerfreuliches. Ich hätte ihn zum Abendessen behalten, wenn ich mich besser auf meine Geister hätte verlassen können. Aber bei dem umständlichen Teichmann durfte ich nichts riskieren. So begleitete ich ihn dann zum «Althoff», wo sein Sohn u. seine Tochter, die ihn von Basel begleitete, ihn erwarten sollten. Wir spazierten fast eine Stunde in feinem Sprühregen. Endlich kamen die zwei. Der Sohn sah 
heute, auf der Strasse, schon eher wie ein Tunichtgut aus. Die Tochter war zart, schon ältlich, aber man sah ihr das nicht an, was die bösen Basler Mäuler von ihr erzählten. Es wird auch nicht wahr sein. Teichmann berichtete mir von seinen biographischen Arbeiten, wo er immer noch in alle Details orientiert zu sein scheint. Von seiner Consultation bei [?] meinte er, er sollte danach wieder eine mehrmonatliche Spitalkur machen. Allein dazu könne er sich wirklich nicht entschliessen. Seine Tochter fügte freilich bei, das werde man noch überlegen müssen.

Teichmann ass mit den Kindern im «Althoff» u. reist noch heute heim. Ich kann über die «Basler» nachdenken u. empfinde ein rechtes Elend darüber. Welch eine kleinliche, giftige Lieblosigkeit steckt in dem allem, aktiv u. passiv, u. wie stellt sich Häusler als deren eigentlicher Brennpunkt dar! Es tut weh zu denken, dass unter solchem Geist sich unser Zusammenhang mit der deutschen Kultur über Basel gestalten soll. Da werden wir schon zu nichts Besserem mehr gelangen. Wenn man diese Früchte der «Frömmigkeit» wahrnimmt, begreift man den Groll, der weite Kreise erfasst hat.

Doch ich will mich nicht darin verlieren. Gleichwohl, trotz alledem: Dankbarkeit u. Liebe, lass Du sie mich festhalten, sie bedeuten die Überwindung des Lebens, mag es auch noch so öde sein!

Gute, gute Nacht, mein einziges Herz! Ich bleibe immerdar

Dein getreuer

Eugen 


\section{2: April Nr. 99}

[1]

B. d. 28. April 1912.

Mein liebstes Herz!

Ich bin heute wieder in die gedrückte Stimmung verfallen, in der ich alles schwarz sehe. Möglich, dass die drei Basler von gestern auf mich gewirkt haben. Dazu kam in der Nacht wieder ein «Samstags Brand», wie sie in Bern für Sonntag früh oder spät so typisch u. so häufig sind, u. ferner das Bedenkliche, was in den Zeitungen von Splügen u. Greina steht (die viel gerühmte Verteidigung der Greinalinie stammt, wie ich heute erfahren, von Innerhauser, wenn das Hebbel erlebt hätte!) u. ein unüberwindliches Unbehagen zu Hause, sodass alles mich in die schwerere Gemütsverfassung hineingestossen hat! Es ist nicht recht von mir. Der Erfolg mit dem Kolleg in diesem Semester sollte mich ja über alles das hinweg heben.

Nun ist freilich mit diesem Erfolg auch wieder ein Erlebnis dazwischen getreten, das mich fast komisch berührt hat. Am Dienstag Abend kam Walter B. zu mir, gegen neun Uhr, in verzweifelter Stimmung, da sein Kolleg so schlecht begonnen habe. Seine Frau erzählte nachträglich Marieli, dass er entsetzlich gejammert u. aus Hilflosigkeit noch so spät zu mir gekommen sei. Dafür hatte er dann am Freitag, 6 - 8 Uhr zu seiner Überraschung im eidgen. Verwaltungsrecht so viel Leute, dass auch er in Nr. 31

[2]

übergesiedelt ist. Das wäre schön u. gut. Aber nun kommt die Kehrseite, von der mir gestern schon Guhl u. heute Walter B. selber gesprochen haben. Es stellt sich nämlich heraus, dass Walter B. die Bundeskanzlei ersucht hat, die Beamten auf diese Vorlesung aufmerksam zu machen, was mit einem Circular Davids 
des Vizekanzlers an alle Beamten ausgeführt worden ist. Als Blumenstein davon Kenntnis erhalten, habe er dasselbe verlangt, $u$. es sei dann auch ein zweites Circular erlassen worden, indem gesagt war: Man teile der Kanzlei mit, dass auch Prof. Blumenstein über Verwaltungsrecht lese. Und nun noch das Beste: Die Beamten sollen beabsichtigen, den Bundesrat zu ersuchen, die Collegiengelder für sie zu bezahlen! Als Walter B. hievon erfuhr, wurde er sehr betreten. Das sehe aus, wie eine offizielle Subsidie an ihn, er könne das nicht dulden, er müsse das Kolleg gratis lesen u. s. w. Ich suchte ihn zu beruhigen $u$. weiss nun nicht, was weiter geschehen wird. In etwas hat Walter B. mit seinen Bedenken schon recht. Aber er hätte eben den ersten Schritt in der Sache nicht tun sollen.

Heute Nachmittag, als ich am Kollegpräparieren sass, kam Dürrenmatt, der mir erst recht unwillkommen war, da ich vermutete, er werde wieder ein rechtliches Anliegen haben. Aber es war nicht so. Sein Sohn war mit der Philadelphia

nach Oberriet gegangen, seine Frau heute Mittag für einige Tage zu den Verwandten nach Aarwangen gefahren, u. seine Einsamkeit veranlasste ihn dann, ein Stündchen zu mir zu kommen. Das freute mich. Im Geschäft haben sie jetzt viel zu tun. Walter u. Schobert arbeiten jetzt gut in einander, jener auf dem technischen, dieser im Reclamegebiet, $u$. so scheint nun doch eine bessere Zeit für den alten Dürrenmatt anzubrechen. Es würde mich freuen. Wenn nur nicht ein Todesfall, oder der Steuerprozess, in dem er steht, den jungen Trieb wieder knickt. Das wäre der Ruin für die Familie.

Am Vormittag konnte ich einige Zeit ungestört an der «sozialen Gesinnung» arbeiten, was mir Freude machte. Und die zwei Kolleglesen Tage haben mich recht ausgeruht. Ich fühle mich zwar immer wieder etwas müde, aber es ist eine ruhigere, behaglichere Müdigkeit, als wie ich sie während der Woche empfunden habe. Könnte ich doch diese beschaulich- 
elegische Ruhe, dieses Fertigsein mit Wunsch u. Befürchtung mir ganz aneignen. Was sollen mich dann die bösartigen Dinge eines Andreas Hausler u. seiner Trabanten oder Brand gross angehen? Sie können mich ja wohl plagen, aber mich nicht vernichten, sie können mich verfolgen, aber nicht aus der Welt schaffen. Und kann ich es anders verlangen, als dass auch mir der Schmerz des Unrechts bereitet wird? Wem

wurde er erspart! Man muss ja dankbar bleiben, wenn dazwischen allerlei Gutes einfliesst $u$. einem zuteil wird, u. daran habe ich kein Mangel. Es ist nur nicht das, was ich wohl möchte, in allen Dingen. Ich las heute früh auch Arnolds $12^{\text {tes }}$ Tagebuch fertig. So schmerzvoll u. unerfreulich, wie Marias Karte es ankündigte, ist es doch nicht. Aber ich bekomme stark den Eindruck, den ich schon aus den früheren hatte: Arnolds Energie ist stärker als sein Geist. Und das kritische Element wirft allzu oft Blasen. Dennoch Respekt vor der energischen Hand, mit der er sich bei allem Missgeschick durchhilft. Und wenn er sich selbst anklagt, so sind seine Worte rührend.

Jetzt Schluss! Ich will die Woche mit einem längeren Schlaf beginnen. Hoffentlich weckt mich nicht wieder ein Feuerlärm.

Innigst Gruss u. Kuss, liebe Seele, von

Deinem allzeit getreuen

Eugen 


\section{2: April Nr. 100}

[1]

B. d. 29. / 30. April 1912.

\section{Liebstes Herz!}

Heute, nachdem ich meine zwei Stunden im grossen Auditorium gelesen, sagte Steck zu mir, der alte Nippold habe s. Z. (er war damals noch nicht fünfzig) gesagt, wenn er zwei Stunden hintereinander gelesen, sei er fertig $u$. den ganzen Tag nicht mehr fähig zu arbeiten. Und Hilty habe aus dem gleichen Grunde nicht mehr zwei Stunden nacheinander abgehalten. Die zweite werde immer schlechter. Ich kann meinerseits das letztere nicht sagen. Oft ist die erste besser, ebenso oft aber komme ich durch die erste recht in die Stimmung u. dann wird die zweite besser. Was nun aber die Gesamtanstrengung anbelangt, so ist es ja zu Zeiten wohl der Fall, dass die zwei Stunden mich hart an die Grenze der Leistungsfähigkeit bringen. Aber ich muss daneben noch so vielerlei arbeiten, dass ich mich nicht darum kümmern darf. Gewiss fühle ich mich am wohlsten, wenn ich nach den zwei Stunden den Tag über nichts Strenges mehr zu arbeiten habe $u$. anmutende Allotria treiben darf. Aber das geht nicht, meistens nicht, u. Gottlob dass ich es anders noch kann. Auch da sehe ich wieder, wie dankbar ich dafür sein muss, dass ich diese Arbeit noch zu wältigen vermag, u. wie dankbar Dir, dass Du mir vor drei Jahren so entschieden

zugesprochen hast in vollem Amte zu bleiben. Kaegi ist jetzt pensioniert. Sein Sohn hat mir gestern Besuch gemacht u. war sehr nett. Heute Morgen war er in einer oder in beiden Vorlesungen, ich sah ihn im OR. Brenner, den ich heute antraf sagte, es gehe ihm wieder besser. Hoffentlich bleibt er nun auf der Bahn u. macht das Examen. Seine Mutter hält sich in Luzern auf. 
Heute habe ich Trubs Dissertation fertig gelesen. Sie ist sauber gearbeitet, aber nicht sehr gescheit. Ich schwankte noch, ob ich ihn zu einer Umarbeitung anhalten will. Am Nachmittag wollte ich, nachdem Siegwart mir einen freundlichen Besuch gemacht, zu BRat Müller, der mich aber am Telephon ersuchte, erst morgen zu kommen, da er zuviel Arbeit habe. Inzwischen traf Marieli Frau BRat Müller auf der Strasse, u. zwar in hellem Kleid u. hell auf. Ich habe das von ihr erwartet. Sie gehört zu denen, die das innere Leben absichtlich verwahrlosen lassen u. glauben, damit einem höheren Prinzip, der Wahrheit zu dienen. Aber Sympathie pflanzt das bei mir nicht, wenngleich auch Frau v. Rappard in diese Kathegorie gehören wird.

Sonst arbeitete ich wieder ein paar Stunden an der sozialen Gesinnung. Ich bin nun nachgerade selbst begierig zu sehen, was daraus wird.

[3]

Den 30. April 1912.

Gestern Abend kam Haenny mit seiner Frau noch spät hieher, - ich hatte eben obige Zeilen abgeschlossen -, u. brachte die Mimeographenplatte - Stahlplatte, die von Dir glatt geschrieben, zurück, mit einer herzigen Ätzung: In der Mitte der Büffel mit Diana, die er in Paris gezeichnet, u. links u. rechts Dein u. mein Monogramm, neben dem Büffel ein Schildchen mit den Zahlen 1895 - 1909. Ganz so hatte ich es ihm angegeben $u$. es ist prächtig gelungen, so dass ich sehr erfreut, ja gerührt war. Welch liebes Andenken an Deine treue Mithülfe ist mir damit nun gegeben! Haennys blieben bis gegen $10 \mathrm{Uhr}$. Marieli aber brachte Bericht, dass Helene Baumgart sich ganz schlecht befinde $u$. wohl rettungslos verloren sei. Ich schlief unter alle dem die Nacht sehr schlecht. (Das Bett war verhurschet) u. stand am Morgen missmutig auf. Erst am Nachmittag, nachdem ich wieder an der «Gesinnung" gearbeitet, ging es besser u. daran waren zwei Dinge schuld, die nun hoffentlich zu meiner Entlastung sich gestalten. 
Das erste ist: Balli sieht ein, dass ich für ihn betr. Rossels Nachfolge getan, was ich konnte. Er war bei mir u. sehr herzlich.

Und Müller, bei dem ich Nachmittags war, teilte mir mit, dass Mutzner die Entlassung genommen, u. dass er ihn halten möchte! Das hat mich um so mehr gefreut, als es mich von Müller überraschte. Ich redete ihm zuerst mündlich u. dann

mit einem Briefchen. Glücklicherweise stiess ich gerade dazwischen auf Mutzner selbst, der mit den Bedingungen, von denen Müller mir schon gesprochen, sehr einverstanden war $u$. also nun wahrscheinlich bleibt. Gottlob, dass ich dann diese Verantwortung los bin! Was hat mich diese Geschichte geplagt!

Möchte nun auch noch die Beschwerde sich gut erledigen, die ich dagegen erheben muss, dass Herberts wieder in Nr. 31 anfängt, die Wandtafel dauernd in Beschlag zu legen.

Es ist die Geschichte des letzten Jahres, der ich über den Winter in Nr. 42 entronnen war, u. die jetzt wieder kommt.

Doch hierüber ein andermal!

Innigst liebe Seele,

Dein alt getreuer

Eugen 


\section{Mai 1912}

\section{2: Mai Nr. 101}

B. d. 1. Mai 1912.

Liebstes Herz!

Kühl, frostig, draussen, u. im Innern nicht viel besser.

Es hat mich heute früh beschäftigt, dass ich mit Herberts mich über die Wandtafel des Auditoriums 31 streiten soll. Ich kann solche Anmassungen, solche Übergriffe schlechterdings nicht verstehen. Schulthess anerbot sich, mit H. zu reden u. die Sache, ganz in meinem Sinn, zu erledigen. Interessant war es mir zu beachten, wie der Rektor, Prof Marti, sich verhielt, als Schulthess sich an ihn wandte u. sagte: Ich kann wohl auch sagen, dass der Rektor ganz diese Auffassung teilt. Marti brachte nicht über sich, das zu bejahen, obgleich er vorher, unmittelbar vorher, uns zugestimmt hatte. Am Ende muss ich dann eben doch mir selbst helfen u. die Tafel für meine Vorlesung selbst reine machen. Wenn nur Nr. 31 nicht der Hörsaal der philos. Facultät wäre! Heute ist Abbühl bei mir eingetreten, schlicht $u$. recht, ich will sehen, was er leistet. Angefangen hat er damit, einiges anders zu machen, als ich ihm gestern sagte, also hat er nicht gut aufgepasst. Aber sonst wars recht. Es ist möglich, dass es ein Mann «ohne Ohren» ist, der eben aus sich selber die Sachen macht. Aber daraus kann ja auch wieder etwas gutes werden.

Am Nachmittag hatte ich Hans Trub fast zwei Stunden bei mir u. gab ihm Anleitung zur Umarbeitung des 
letzten Teiles seiner Dissertation. Er war sehr betreten, hat aber doch am Schluss wirklich gedankt.

Von Teichmann erhielt ich ohne Begleitbrief die Auskunft über ein franz. Gesetz, das ich Samstags im Gespräch erwähnt u. ein altes Zürich-Bildchen u. zwar merkwürdiger Weise mit dem Berner Poststempel zugesandt. Hat es sein Sohn zur Post gegeben, oder hat Teichmann hier nun doch die von Jadassohn empfohlene Kur begonnen? Ich schrieb sofort dem Sohn um Auskunft, die ich noch heute erwarte.

Ob auch Mutzner noch heute mir von der Unterredung mit Müller berichten wird? Dass ich diesem noch im Sinne der Beibehaltung Mutzners geschrieben, war doch nicht etwa eine Dummheit?

Marieli war heute früh sehr unwohl, dann aber ging es seinen Geschäften nach u. will lieb sein. Man kann ihm wenig helfen. Es legt sich alles selbst zurecht $u$. führt es aus nach seinem Kopf. Gut, wenn es recht herauskommt! Um sechs Uhr ist richtig Mutzner zu mir gekommen $u$. hat mir die Nachricht gebracht, dass BRat Müller mit ihm gesprochen $u$. ihm die Zusagen gemacht habe, über die ich an Müller geschrieben u. mit Mutzner gestern auf dem Abendspaziergang gesprochen habe: Teilung der Arbeit nach Materien u. Urlaub zur Vollendung des Kommentars u. zur Habilitation für drei Monate! Auch Käslin u. Kaiser,

letzterer scheints nicht ohne eine peinliche Auseinandersetzung mit Mutzner, erklären sich einverstanden, u. sollte die Sache in Ordnung sein. Ich bin darüber froh, denn wer weiss, wie es mit Mutzner gegangen wäre, Verpflichtungen ihm gegenüber habe ich jetzt nicht mehr. Aber er bleibt mir ein lieber junger Freund, zu dem ich alles Vertrauen habe.

Walter Burckhardt kam, während ich diese Zeilen schreibe, auch herauf u brachte mir die Häusler gewidmete Brochüre von v. Frisch, worin dieser gegen das Bundestaatsrecht der Schweiz los- 
zieht $u$. eine sehr giftige Bemerkung gegen das ZGB, auf Grund der Kritik Rabels einflicht. Was soll ich gegen diese Feindschaft sagen? Ich weiss doch, dass ich nicht mit derselben Kritik antworten kann u. mag. Nur bin ich natürlich wieder der Narr im Spiel, indem ich diesem Herrn meine Verehrung bezeuge (à la Häusler) u. dann von ihm dafür doch schlecht behandelt werde. Walter B. kam mit äusserster Freundlichkeit, mir das Büchlein zu bringen. Ich dachte gleich, da sei etwas Schiefes im Gange, u. richtig, er wird darin gelobt, u. das ZGB. herunter gemacht. O Welt, wie bist du so ungerecht! Und doch wird der Ausgleich kommen. Es braucht nur Zeit, Zeit, viel Zeit u. viel Geduld!

Nun erwarte ich noch den jungen Teichmann, der sich auf gegen $9 \mathrm{Uhr}$ angekündigt hat, $\mathrm{u}$. nachher will ich bald zu Bett. Ich hatte doch wieder einen strengen Tag trotz aller Abwechslung, die er geboten hat. Es ist so schwer, sich aufrecht zu erhalten, wenn alles drunter $u$. drüber geht. Doch

will ich nicht klagen. Ich bin ja noch arbeitsfähig u. will sehen, was ich noch zustande bringen kann.

Mir macht Haennys Büffel mit der feinen Diana stündlich Freude. Man muss doch noch an etwas sich freuen, u. in der Verknüpfung mit den alten Erinnerungen liegt meine [sic!] noch meine einzige $u$. letzte Freude!

Gute, gute Nacht! Ich bleibe immerdar, wie ich es bin u. war, Dein treuer Kamerad,

Dein

Eugen 
B. d. 2. / 3. Mai 1912.

Mein liebstes Herz!

Nachdem gestern um 9 Uhr noch der Sohn Teichmanns bei mir gewesen, konnte ich auf 10 Uhr zu Bett, hatte aber eine recht unruhige Nacht, teils wohl wegen des hellen Mondscheins, der mich ja schon früher hie u. da wach gehalten hat, teils wegen der Mitteilungen Burckhardt u. der ganzen Misere unserer kleinlichen Verhältnisse, die sie mir wieder so lebhaft vor Augen geführt hat. Ich war matt den Vormittag $u$. nachdem ich die Vorlesungen ohne Schwung erledigt, ging ich hinter die Dissertation Hauser, in dritter Auflage eingereicht, um zu meinem Leidwesen zu entdecken, dass sie nicht viel besser geworden ist. Nun kann ich wieder hinsitzen u. sie lesen, nochmals lesen, mit dem Frohndienst, Reihe an Reihe der dümmsten Satzfehler corrigieren zu müssen. Wie jammerschade um meine Zeit! Am Nachmittag kam dann Siegwart einen Augenblick zu mir, in heller Freude. Er hat heute Morgen sein erstes Colleg gehalten u. es sei gut gegangen, mit etwa zwanzig Hörern. Das macht mir Freude. Übrigens bin ich auch mit Abbühl zufrieden. Ich habe Vertrauen, dass es mit ihm recht heraus kommen wird.

Nach Siegwart kam Lauch, den ich Mutzner als seinen Stellvertretenden Volontär empfohlen. Lauch war aber nicht

entschlossen, ob er die Stelle annehmen wolle. Er hat bereits in Genf etwas in Aussicht. Er sprach mit mir mehr über seiner Dissertation u. von einem ihn beschäftigenden Rechtsfall. Endlich kam Guhl für fast zwei Stunden, dem ich eine Anzahl der an mich gelangten Anfragen vorlegte, um ihm meine Auffassung zur Kontrolle zu stellen. Er war recht. Von Mutzners 
Wandlung wusste er schon. Über Walter B wusste er, dass die Beamten seinen Vortrag gern gehört hätten. Er bestätigte dabei, dass Walter B, wie Marieli jeweils sagt, ein arger Spötter sei. Ja, das wissen wir schon, es hat jeder dieser Sanften seine böse Seite. So erzählte Teichmann gestern Abend, seine Schwester habe ihm mitgeteilt, der Vater sei bei der Consultation mit [Judassohn?] geradezu grob geworden. Kannst Du Dir Teichmann grob denken! - Das Pamphlet von Prof. v. Frisch hat Guhl wie mich entrüstet. Er will Leemann schreiben. Ich gab ihm als möglichen Schluss einer dem [?] entsprechenden Besprechung in der Juristenzeitung den Satz, der mir heute Nacht eingefallen ist an: «Ob wohl der«Altmeister in Basel diesen Gestank als Weihrauch annehmen wird?» Ich habe auch heute Abend noch viel Arbeit, Kollegpräparation u. anderes. Ich will also nur noch eines erwähnen; Herberts hat auf Anfrage von Schulthess sofort zugestanden, dass ich Anspruch auf die reine Tafel habe u. ich fand dann

auch heute bereits im Auditorium die Tafel rein gewischt. Damit genug für heute, u. nicht genug. Als ich heute [?] Zürcher Idyll herauslas aus dem Bücherschrank, da kam mir die ganze schwere meiner Einsamkeit aufs Gemüt. Ich hatte über das Büchlein mit Teichmann gesprochen $u$. sandte es ihm heute zu als Andenken.

Den 3. Mai 1912.

Die Mitteilung Mutzners, dass die Helveter den TagwachtRedaktor wegen der Verleumdung von Fritz Müller durchgeprügelt hätten, erweist sich als unrichtig. Es ist fast schade. In solchen Fällen verspüre ich einen mächtigen Drang nach Selbsthülfe. Da könnte ich nicht mehr besonnen sein. Mutzner kam heute nach Tisch wieder zu mir u. machte mir Mitteilung, Lauch sei bei ihm gewesen, habe aber so unverschämt gefordert u. gesprochen, dass er auf ihn verzichte. Was mag in Lauch gefahren sein? Es ist ein Sportsfreund Panschouds, u. hat diesen consultiert. Das wird also Panchoudscher Geist sein, der da zu Tage getreten ist. Aber wenn Lauch sich so leicht von einem Grobian beeinflussen lässt, so ist 
er nichts Besseres. Da haben wir den Freund der Frl. Reineck, das sind halt alles andere Leute. Und leider gehört Marieli auch ein bisschen zu ihnen. Es kann auch potzig werden, das habe ich heute Abend mir wieder vor Augen halten müssen, bei einem Anlass, der übrigens gar nicht wert ist, erwähnt zu werden. Sonst musste ich heute an der Dissertation Hauser weiter lesen, es ist schrecklich. Ich kam nicht weit, weil Rossel am

Vormittag ein Stündchen zu mir kam u. mir Bericht brachte von dem Rechtsfall, über den ich ihn vor zwei Wochen Consultation gegeben. Meine Auffassung ist durchgedrungen, nach langem Kampf. Ich bin froh darüber.

Aus Lausanne kommt auch die Nachricht, dass Tschumi am Schlag gestorben. Welch liebliche Erinnerungen an BeauRivage sind mir da aufgetaucht. Wie waren wir in Freude u. Hoffnungssonne. Nun ja, es nimmt ja alles ein Ende, u. man muss noch darüber froh sein. Mit innigstem Kuss bin ich immerdar in treuer Liebe

Dein

Eugen

1912: Mai Nr. 103

[1]

B. den 4. Mai 1912.

Mein liebstes Herz!

Ein Tag voll constanter, nicht heftiger, aber ergiebiger Arbeit. Samstagsarbeit! In bin keinen Moment zu einer beschaulichen Betrachtung, zur Sammlung auf auch nur eine Frage gekommen, die mich im tiefsten Grunde an einem fort beschäftigen. Ich ging gleich nach dem Morgenessen hinter die Dissertation Hauser, an der ich gestern spät noch eine Stunde 
gelesen. Um 9 Uhr war ich fertig u. kam, nach Schwankungen, nun doch zum Ergebnis, die Dissertation trotz der crassen Flüchtigkeit, womit die neu geschriebene Einleitung abgefasst ist, zu dem Ergebnis, dass ich ihre Annahme empfehle, wenn auch mit dem mindesten Grad. In diesem Sinne schrieb ich dann gleich das Gutachten u. um Mittag trug Marieli das Schmerzenskind zu Walter Burckhardt. Es ist ein Jammer mit solchen Leuten. Könnten wir sie doch samt u. sonders absägen. Aber was wir ohne wirkliche Not verwerfen, das nutzen nur unsere Konkurrenten aus, so dass die Kleinheit unserer Verhältnisse uns zwingt, auch klein zu sein! Nach dem Gutachten diktierte ich Abbühl zwei kleinere u. ein grösseres Gutachten, die einige Tage schon bei mir gelegen hatten, u. so wurde es Mittag, bis ich die Post

des Vormittags lesen konnte. Am Nachmittag hatte ich noch einiges Amtliche zu erledigen $u$. begann dann mit der Lektüre der neuen Redaktion der Dissertation Bruggmanns, die zum Glück gut geraten zu sein scheint. Ich werde sie wohl morgen oder übermorgen fertig bringen.

Gegen sechs kam Abbühl, der die zwei kleinern Gutachten mit Maschinenschrift auszufertigen hatte. Zugleich brachte er Bericht, dass der frisch patentierte Fürsprecher Schürch, ein ehemaliger Singstudent, sich gerne um die Stellvertretung Mutzners bewerben würde. Diese Stellvertretung gibt nun mehr Mühe, als ich erwartet hatte. Lauch hat sich offenbar gegenüber Mutzner sehr ungeschickt benommen, grosse Honorarforderung (das ganze monatliche Honorar Mutzners, $400 \mathrm{Fr}$.) verlangt, so dass er nun ausscheidet. Pater schrieb ab, weil er unwohl sei u. der Erholung bedürfe. Kaiser nannte nun, wie mir Mutzner telephonierte, den Solothurner Hugo Meier, den ich auch wohl empfehlen könnte, u. der genannte Schürch wird nun wohl heute Nachmittag zu Mutzner gegangen sein. So kommt dann schliesslich vielleicht doch noch ein gutes Resultat heraus. Frl. Reineck war heute zum Thee bei Marieli, u. war sehr erstaunt, dass Lauch nicht zugegriffen. Ich finde auch, dass 
er einen Fehler gemacht, u. es mag schon sein, dass die jüngsten Erfolge, wie Frl. Reineck meinte, den jungen Mann vielleicht

zu anspruchsvoll gemacht haben, so dass es nur noch der Dummheit eines Panschoud bedurfte, um ihn die Situation ganz und gar verkommen zu lassen.

Gestern erfuhr ich, dass nur etwa 25 Handelsschüler sich bei unserer Fakultät angemeldet haben. Wenn auch einige davon bei mir das OR. hören werden, so kann der starke Besuch dieser Vorlesung doch nicht daher kommen, dass die neue Abteilung der Fakultät eröffnet worden ist. Sondern es wird dies darauf zurück zu führen sein, dass ich OR seit vier Semestern nicht gelesen habe. Das vergegenwärtigte mir die Tatsache, dass bei dem so oft überlegten Viersemester-Betrieb meine Vorlesungen doch viel stärker besucht wären, in späteren Semestern noch mehr, wenn Guhl dann nicht, wie beim OR. letzten Sommer, in der Zwischenzeit lesen würde. Und ich kam wieder auf den Plan zurück, der mir gestatten würde, die Materie etwas weniger gedrängt zu lesen: 1 . Semester: Allgem. Teil u. Personenrecht: 5 Stden, 2. S. Familien- u. Erbrecht (Sommer) 8 Stden, 3. S. Sachenrecht: 5 St., u. 4. S. OR. 7 - 8 Stden. Das wäre eine Einteilung, die mir jeweils im Winter an den Nachmittagsstunden alternativ Re geschichte $u$. R philosophie gestatten würde. Ich fragte Abbühl, wie sich wohl die Studenten zu dem Kurs von vier Semestern verhalten würden, u. er meinte, er würde entschieden dem Jahreskurs vorgezogen, denn das ganze Zivilrecht in einem einzigen Jahr sei entschieden zu viel auf einmal. Er mag Recht haben. Ich fragte ihn

dann auch, ob wohl für den nächsten Winter eher ein Bedürfnis für Rechtsgeschichte oder für R.philosophie vorhanden wäre, u. er entschied sich für erstere, will aber noch etwas nachfragen.

So klärt sich jetzt die Frage allmählich ab, u. ich komme am Ende doch dazu, schon im nächsten Winter mit dem 
Viersemesterkurs zu beginnen. Wenn ich dabei nur nicht eine Dummheit mache!

Und jetzt Schluss, ich trinke noch meinen Abendschoppen Limonade von Marieli angemacht, die mir, weil nicht süss, sehr wohl bekommt, u. dann zu Bett. Müdigkeit spüre ich zwar jetzt nicht viel, wohl nur, weil ich von der Arbeit zu sehr angeregt bin. Zudem ist es, nachdem wir die letzten Tage wieder heizen mussten, heute recht frühlingswarm.

Der Helene Baumgart geht es jetzt nach sehr kritischen Tagen viel besser. Sie scheint nun doch gerettet zu sein, was ich freudig begrüsse, auch wenn mir die Leute ferner stehen.

Gute, gute Nacht, meine liebe Seele! Halte fest

Deinen allzeit getreuen

Eugen

\section{2: Mai Nr. 104}

B. d. 5. Mai 1912.

Meine liebe, gute Lina!

Wie komme ich den Abend wieder zu Dir, um ein Weilchen mit Dir zu plaudern, wie ehemals. Es war heute ein Maientag mit leichtem Gewitter Mittags u. Regen den ganzen Nachmittag. Und ich blieb zu Hause, erledigte die geordnete Correspondenz, namentlich die Danksagungen für Bucher, die mir zugesandt worden, $u$. die Dissertation Bruggmann, die ich ohne Bedenken annehmen kann. Sonst sass ich wohl auch wenig heraus, las in der [Di?] einige Seiten, präparierte die schwierigen Kapitel, über die ich morgen Vorlesung habe. Marie war auf dem Friedhof $u$. zeigte sich offensichtlich bestrebt, recht zu sein. Mehr will ich ja nicht. $\mathrm{Zu}$ Besuch kam Walter B., der von dem Pamphlet v. Frischs zu sprechen begann, worauf ich aber gar nicht einging, sondern 
nur bemerkte, es sei vielleicht ganz gut, dass diese blöden Angriffe gegen das schweiz. Recht im allgemeinen aufgetreten, daraus werde mancher um so mehr die Nichtigkeit der Angriffe Rabels erkennen. Er fand dafür dann das richtige Wort, es fehle eben diesen Leuten die Liebe zur Schweiz, was gewiss auch in Betreff des Bundesrechts bei Häusler zutrifft. Ich fragte dann auch Walter B., was

er von den Gedanken betr. die neue Kollegordnung halte, u. er ging sofort mit Verständnis darauf an u. sie scheinen ihm praktisch zu sein. Er bemerkte aber auch, dann hätte ich noch mehr Leute. Und das hat mich dann wieder stutzig gemacht, so dass ich heute Abend wieder eher dazu neige, bei der alten Ordnung zu bleiben. Wir wollen sehen.

Dann kam auch Guhl her, der für zwei Wochen in einen Schiesskurs nach Wallenstatt einberufen ist. Wie erledigten einiges Amtliche u. sprachen dann von Mutzner. Er hält den Bruch zwischen Mutzner u. Kaiser für irreparabel. Er sagte auch, die Fama meine, ich habe Mutzner das eingerichtet, während ich Dir wohl geschrieben habe, dass der Urlaubsgedanke von Müller (wahrscheinlich Hoffmann) ausgegangen $u$. von mir dann nur aufgegriffen worden ist, um mich aus der Situation zu ziehen, aus der Zwangslage betr. mein Buch, in die mich die Demission Mutzners, nach dem was voran gegangen, versetzt hätte. Ich hoffe, es kommt nun alles gut heraus. Wir sind aber noch nicht über den Berg.

Zu der Kollegfrage werde ich schliesslich die Stellung einnehmen müssen, von der ich früher oft gesprochen: Es kommt darauf an, ob ich meine Haupttätigkeit auf die Vorlesungen oder auf das Buch verlegen will u. stelle ich die Frage so, so werde ich zur Zeit sicher mit besserem Grunde das erstere wählen als das letztere. Bleibe ich 
dabei, so wird es mir doch auferlegt sein, nun noch einige Zeit bei dem Jahrespensum des ganzen Zivilrechts zu bleiben. Ich kann mir ja wohl noch für einige Zeit sonst helfen. Inzwischen wird es sich zeigen, welche Dienste mir Abbühl leistet. Vielleicht geht es ganz gut. Bin ich so regelmässig an der Arbeit, wie nun seit letztem Herbst fast ohne Unterbruch, so sollte doch schliesslich etwas Rechtes dabei heraus schauen. Und halte ich diese konstante Arbeit auf die Dauer nicht aus u. werde krank, so weiss ich dann auch, woran ich bin u. habe mich für eine gute Sache aufgezehrt. Also frisch u. mutig drauf los! Es ist fast Schade für die Zeit, die ich wieder für andere Überlegungen geopfert habe. Der entsetzliche Hauser mit seiner quälenden Arbeit ist Schuld daran.

Sonst bin ich heute, wie gesagt, zu andern Überlegungen nicht gekommen. Ich sehe nach dem Gespräch mit Walter B. nur wieder deutlicher, dass ich daran festhalten muss, die Liebe zum ZGB. zu nähren u. den jungen Adepten den Geist zu befestigen, der ihm gewogen bleibt. Dann kommt ja schliesslich alles zum Besten. Sind mir für diese Aufgabe noch Jahre gegeben, so wird es im Ergebnis ziemlich gleichgültig sein, wie ich mich äusserlich darüber einrichte. Hauptsache bleibt dann nur die unablässige Arbeit an dieser Aufgabe, $\mathrm{u}$. die soll so oder anders von mir getan werden. Also keine Gedanken darüber, sondern froh u. munter vorwärts. Es ist mir, Du stimmest mir mit deutlicher Stimme bei in diesem Gedanken. Es stimmt

dann, was Du immer als Richtschnur befolgt u. das Schönste ist ja dabei, wenn man bis an das Ende leistungsfähig bleibt. Ich will es Dir nach machen, damit wir auch hierin uns als eines Herzens u. einer Seele erweisen!

Ich grüsse Dich innigst, u. dankbar aus tiefster Seele für Deine Hülfe! Ich bleibe auf ewig

Dein treuer 
B. d. 6. Mai 1912.

Mein liebstes Herz!

Heute habe ich, ausgeruht u. mit frischen Mut meine zwei Stunden Morgenkolleg gelesen. Zurückgekehrt waren eine Reihe amtlicher Geschäfte für das Departement zu erledigen. Am Nachmittag las ich die schon lange der Erledigung harrenden Examensarbeiten, soweit das notwendig ist, «kritisch» durch $\mathrm{u}$. hatte dann wieder amtliche Arbeit u. namentlich Kollegpräparation, da ich mich in beiden Vorlesungen bei ziemlich schwierigen Materien befinde. Dazwischen erhielt ich verschiedene Besuche. Pierre Boguin kam u. meldete mir, dass er weder in Winterthur eine Stelle erhalten, noch nach einem Amte in den nun neu zu schaffenden eidgen. Versicherungsbehörde in Luzern in Aussicht nehme, sondern ein Büreau für Consultaion in Versicherungsfragen in Bern eröffnen werde. Er gedenke dann auch noch das bernische Fürsprecher-Examen abzulegen, er werde rasch eine sehr umfangreiche Tätigkeit entfalten können. Er war, wie immer, sehr bestimmt, selbstbewusst, aber nicht etwa unangenehm. Es ist möglich, dass er hiermit nun in seiner ganz u. gar individualistischen $u$. romanischen Geistesart zusagende Tätigkeit ergriffen hat. Wünschen wir ihm alles Glück.

Dann kam der frisch patentierte Fürsprech Weyss, der in Langenthal bereits bei Fürsprech Grieb eine Anstellung hat, um zu erfahren, ob die Stelle im Departement für Mutzner nicht ihm mehr eintragen würde. Natürlich ist dies nicht der Fall u. so zog er mit negativem Bescheid ab. Ferner kam der aus demselben Examen hervor- 
gegangene frisch gebackene Fürsprech Alexander, um sich nach einem Dissertationsthema zu erkundigen. Er wählte das Dotalsystem, will nun noch nach Genf, um sich in der Sprache zu vervollkommnen. Weiter meldete sich Stocker aus Luzern, der morgen ins Examen kommt, u. darauf kam Hugo Meier aus Olten, der auf Veranlassung Kaisers nun die Stellvertretung Mutzners übernommen hat. Diese Wahl ist entschieden glücklich. Meier ist sicher nach Charakter u. Talent ein vortrefflicher Mann, u., was mir besonders gefällt, er hat nicht nach der Besoldung gefragt. Der also ist auf dem richtigen Weg geblieben, der sich für einen Anfänger schickt. Überdies wird es gut sein, dass Kaiser ihn gefunden u. zum Amte bewogen hat. Das wird zur Versöhnung Kaisers mit Mutzner beitragen.

Um vier Uhr brachte mir, diesmal wie verabredet, Abbühl zwei Ausfertigungen u. blieb eine Weile. Der junge Mann hat mir heute sehr gefallen. Er gab mir Bescheid, wieso er nach anderthalb Jahren das MuristaldenSeminar, trotz guter Schulerfolge verlassen habe. Es sei

gar nichts vorgefallen, auch nicht etwa in Betreff Conflikt mit den religiösen Auffassungen, die dort die Herrschaft führen. Er habe eben einfach keine Neigung für den Lehrerberuf empfunden u. sich zum Notariat hingezogen gefühlt. Mit seiner Familie sei er darob entzweit geworden $u$. deshalb dann nach England in die Fremde gegangen. Nach weitern anderthalb Jahren habe er dann aber doch die Zustimmung des Notars für die Notariatsstudien erhalten u. sei 1909 auf den Herbst an die Universität gekommen. In die Helvetia sei er eingetreten, weil sein Onkel, Notar Abbühl ebenfalls dem Verein angehört habe, ebenso wie eine Anzahl anderer ihrer näher Bekannten in Erlenbach $u$. Umgebung. Und jetzt werde er von Lehrer Schenker auf die Maturität vorbereitet, die er übers Jahr abzulegen hoffe. Der junge Mann hat Eigensinn, das ist deutlich, aber auch eigenen Sinn. Ich werde ihn aufmerksam weiter verfolgen. 
Heute traf er Marieli, als er um vier von mir weg ging, u. lud es zur «Maifahrt» ein. Also geht das nun den Weg, den ich mir klar gemacht, u. den zu eröffnen ich Marieli schuldig zu sein glaubte, nachdem es mit Paul u. mit August Gyr gar so schweres durchgemacht hat. Ich habe auch den Eindruck, dass es ihm wirklich mit der Gesundheit seit einigen Tagen besser geht. Es ist jetzt manches abgeklärt, was es gedrückt hat. Die freiere Stimmung wird dazu beitragen, dass es im Ganzen lebhafter u. offener wird. O wie wäre ich glücklich, wenn hier eine Wendung zum Bessern eintreten wollte!

Heute war es im Lindenhof, um Helene Baumgart zu besuchen, der es jetzt entschieden besser geht, sie darf als gerettet betrachtet werden.

Leid tut es mir, dass ich über alledem zu keiner Fortsetzung an der «sozialen Gesinnung» gelange. Ich muss mich immer auf die Zukunft vertrösten $u$. dabei geht Tag um Tag, Woche für Woche vorüber, ich weiss nicht wie. Und immer kommt das Ziel näher. Doch, das ist gut, nicht wahr, das ist es, was wir ersehnen! Nun gute Nacht, liebe Seele. Hilf mir Standzu halten trotz aller Widerwärtigkeiten. In treuer Liebe bin ich ja allezeit

\section{Dein}


[1]

B. d. 7. / 8. Mai 1912.

Liebste Lina!

Heute findet das erste Examen dieses Semesters statt, gleich ein Dreier-Examen u. da ich spät zum Nachtessen kommen werde $u$. dann mich noch auf die Kollegien zu präparieren habe, so schreibe ich vor der Sitzung ein paar Zeilen an Dich.

Bruggmann kam heute nach Tisch $u$. holte seine Dissertation, glücklich, erfreut u. dankbar. Er ist ein lieber Bursche. Dann erschien Siegwart wieder u. teilte mir mit, dass er heute gegen 30 Hörer gehabt habe. Auch sei er bei dem Dekan Lidker (einem Holländer, Rechtsphilosoph) gewesen, der ihn erst sehr kalt empfangen habe, dann aber aufgetaut sei. Er versprach, mitzuhelfen, dass sich die Spannung in der Fakultät gegen Siegwart so bald als möglich ausgleichen werde. Wirklich kann man Siegwart auch nicht wohl einen Vorwurf machen. Er wusste nichts von der Differenz mit der Kommission, bis er die Zusage an Python gegeben, so wenig wie ich. Wenn jemand sich gegen die Fakultät vergangen hat, so ist es Oser, der dann auch die Verbindung mir ihr abgebrochen hat u. das Erbrecht nicht mehr liest. Siegwart hat dafür angekündigt, dass er im Winter den Ausfall nachholen werde. Sonst hatte ich wieder eine Reihe von amtlichen Geschäften zu besorgen. Die Zeit geht mit diesen kleinen Geschichten im Fluge davon, u. ich komme zu nichts Zusammenhängendem.

$[2]$

War das früher anders? Und hat nur meine Arbeitskraft $u$. mein Eifer in der Ausnützung der Zeit nachgelassen? Ich glaube das nicht. Es ist jetzt eben viel mehr Zersplitterung für mich da als früher. Allerdings liebe ich die Beschaulichkeit u. wünsche jeden Tag wenigstens ein Stündchen für mich zu reservieren. Aber früher 
habe ich ja oft ganze Tage geruht $u$. bin doch zu grossen Arbeiten gekommen. Da sieht man doch, dass die Änderung an den Verhältnissen liegt, mit dem Älterwerden hat sich eben eine Unsumme von Kleinigkeiten mir angeheftet, u. das ist es, was mich nicht mehr recht zu Athem kommen lässt. Die grosse Korrespondenz, die vielerlei Anfragen: Kurz, es ist jetzt so, u. ich muss mich damit wohl oder übel abfinden.

Heute in der Fakultät werde ich mit Einigen verschiedenes besprechen müssen, mit Thormann Kohlers Anfrage betr. die Habilitation eines Privatdozenten für Strafrecht, dazu dann mit Walter B. die Kollegienanordnung, wobei ich jetzt den Standpunkt einnehme, Alles beim Alten zu belassen. Ich gehe nun, vielleicht vor Schlafengehen ein paar Worte noch. Wie geht es wohl den Kandidaten? Es sind Müller (Thurgau), Bolter (Biel) u. Stocker (Luzern).

Es ist heute sehr warm, die Hitze fängt schon an, mir lästig zu werden. -

Bolter u. Stocker haben mit Ach u. Krach rite licenciiert, Müller magna cum laude doktoriert. Ich sah Thormann, der von den Verhandlungen in Luzern sehr nett sprach, u. wegen der Habilitationsfrage Kohlers (betr. Contin) mir eine neutrale Antwort überlässt. Wegermann u. Lohner sind wegen des Dr. oec. nach Berlin gefahren. In der Luft lag

[3]

ein Konflikt zwischen Reichenberg u. Wegermann, die Sache wurde verschoben. - Anna hatte inzwischen Besuch von Frau Dr. Jauch u. Frau Julia Weber. Was mag sie wieder alles geschwatzt haben! Es ist mir jedes mal ein Stich ins Herz, wenn ich heimkomme u. statt von Dir von ihr empfangen werde! Hätte ich das früher gedacht! O wie leichtsinnig habe ich in das Glück hinein gelebt! Doch nun zu Bett, zur Ruh! Es wird ja doch nicht besser so. 
Den 8. Mai.

Ich glaubte Dir heute Abend mit heiterm Gemüt schreiben zu können. Der Tag hatte recht begonnen, ich las mein Pensum, ich schrieb an Kohler, fertigte das Gutachten für die Dissertation Bruggmanns aus, empfing Besuch von Borter, der sich artig bedankte, eine Sitzung der Bibliothekskommission war ganz interessant. Namentlich aber war Marieli munter in der Küche u. besuchte dann am Nachmittag die erste Stunde bei Reding. Mit Anna allein beim Kaffee sprachen wir davon, dass es nun doch Marieli wirklich besser gehe, es plaudere mehr, esse ganz ordentlich u. sehe zufriedener aus. Leider, leider war das beim Abendessen alles wieder anders. Es nahm ein paar Salatblättchen, um zum Schein etwas auf dem Teller zu haben, trank ein halbes Tässchen leeren Thee, u. schwieg dazu. Was mag die Ursache sein? Wer weiss es! Vielleicht, weil es gerne heute Abend in den Studentinnenverein gehen würde, oder so was, u. mich doch nicht zu fragen wagt, obgleich ich ihm das ja nicht verbieten möchte. Und Anna sass daneben, mit dem "geschwollenen Kopf», den wir ja beide als Jahrzehnte langer Erfahrung bestens kennen. Die Anna, der die zwei gestrigen Besuche so ins Gemüt gestiegen sind, dass sie sich als Repräsentantin des Hauses fühlt! Es tut mir in der Seele weh, dass ich von der Schwester immer noch

denken muss, wie ich es immer auffasste $u$. wie Du es hundertmal gesagt $u$. die lange, lange Zeit trotz aller Ungemach ertragen hast: Sie hat u. behält ein böses Herz, das sofort stockt $u$. hoppert, sobald sie sich in ihrer Meinung verletzt oder gehoben fühlt. O die Liebe! Sie ist fort aus meinem Hause u. ich kann das nicht ändern. Ich kann es nur bejammern, wenn ich nicht dazu doch noch getrieben werde, das eigne Heim aufzugeben. - Aber sagte ich mir heute im Laufe des Tages nicht, ich habe so viel Anlass dankbar zu sein? Ich weiss es wohl. Auch dass Du meine Lebensgefährtin gewesen, ist ja ein Grund der aller tiefsten Dankbarkeit! Aber die Gegenwart ist so wenig erfreulich, mit den beiden Hausgeistern, die nicht eine Spur der Liebe zeigen, wie ich sie mir die langen Jahre zum Lebenselement geschenkt worden war! 
Ich präparierte sonst heute Colleg $\mathrm{u}$. hatte einiges zu lesen. Es war den ganzen Tag schwül, wie im Sommer.

Und nun also gute Nacht. Der Tag ist zu Ende, sagen wir ein wenig glücklich, weil es ein Glück ist, dass jeder Tag vorüber geht.

Ich sollte Dir doch einmal schreiben, wie ich jetzt Paulus verstehe, verstehen gelernt habe, glaube zu verstehen. Es tut so wohl, am Abend noch sich in diese Elemente zu versenken. Wenn wir es nur miteinander könnten! Doch nicht nur bist Du bei mir, sondern Du bist die Ursache, dass ich diese Wahrheit mir näher gebracht habe.

Und nun nochmals gute, gute Nacht! Dein allzeit treuer Eugen

1912: Mai Nr. 107

B. d. 9. / 10. Mai 1912.

Mein liebstes Herz!

Ich glaubte heute Abend noch ein ruhiges Stündchen für Dich zu haben, nachdem ich den Tag über seit dem Morgenkolleg an der «sozialen Gesinnung» gearbeitet $u$. sie für den Druck fertig gestellt hatte. Da kam nach halb acht Walter B. u. brachte mir eine sein Fach beschlagende Bemerkung zur Dissertaion Bruggmanns, die mich weiter nicht beschäftigte, obgleich der Besuch mir die wenig Zeit wegnahm, die ich frei glaubte. Überdies hat der Besuch, der mir sonst lieb $\mathrm{u}$. wert war, meine Stimmung nicht verbessert, die aus einem andern Grunde heute sehr gedrückt war: Die N. Z.Z. brachte aus Lausanne einen Bericht, über den Fall, in dem mich Rossel consultiert hatte, u. zwar mit einem ganz unbegründeten Vorwurf gegen die Redaktionskommission des ZGB. Wir sollen etwas nicht beachtet haben, während es sich doch nur um eine 
mangelhafte Kenntnis des Gesetzes bei einzelnen Richtern handelt! Sollen wir das nun wirklich derart über uns ergehen lassen? Es ist eine schlimme Sache, die mich, wenn sie fort- $u$. andauert entweder aufreiben oder vertreiben wird. Du hast auch da im Grunde wieder recht: Das sind alles Folgen des Entschlusses,

den ich s. Z. fasste, als ich nach Bern zog. Nun muss ich den Trank bis zur Hefe leeren! Doch will ich nicht verzweifeln, sondern mich wehren, so gut ich kann. Aber es ist in älteren Tagen so schwer!

Gute Nacht, meine liebe Seele! Morgen werde ich wieder ruhiger sein.

Eine Freude von gestern Abend spät muss ich noch anfügen: Ich las noch vor Schlafengehen die Dissertation, die ein Jos. Jost aus Luzern über das Bauhandwerkerprivileg eingesandt: Sie ist so ganz u. gar nicht Dissertation, dass ich sie ohne Kritik einfach zurückschicken konnte. Er soll sie am Ende als Zeitungsartikel publizieren.

Doch nun, es ist spät u. morgen ein strenger Tag, also zur Ruh, zur Ruh!

\section{Den 10. Mai}

Dass ich den unfreundlichen Angriff auf das ZGB. u. die Redaktionskommission - $u$. als solchen Angriff muss ich die Notiz in der N. Z.Z. heute noch auffassen - rasch überwunden habe, magst Du am besten aus folgendem ersehen: Der «Bund» brachte heute Morgen einen Artikel, wohl von dem neuen Redaktor Schürch, den ich als Gifttopf u. -kopf schon in seinen Studentenjahren kennen lernte (übrigens ein Schützling Gmürs), worin gegen die Dienstvertragsbestimmungen des neuen OR. grob losgegangen worden $u$. zwar in ganz u. gar unbegründeter, auf fatalster Rechtsunkenntnis u. verwirrung berührender Weise. Und das hat mich nicht nur kalt gelassen, sondern mich sogar getröstet. 
Denn es war mir ein Zeichen der Nichtigkeit dieser Tendenz das ZGB. nachträglich schlecht zu machen. Wie wäre ich glücklich, wenn ich mich dauernd über solche Dinge zu erheben vermöchte, in der schönen Paulinischen Gedankenfolge: Trübsal, Geduld, Erfahrung u. Hoffnung! Ja, ich hoffe wieder, gerade aus diesen betrübenden Angriffen heraus, denn das sind ja - Wespen, die gerade an den besten Früchten nagen. Also - nicht mutlos, trotz alles Ungemaches! Es muss besser werden!

Auf einen Brief von Kohler habe ich, in Erinnerung an die Absage vom letztem Winter wegen des Congresses in Bern, freundlich geantwortet. Von Kohler kam heute Abend schon eine Antwort, die mir leider zeigt, dass ich einen zu freundlichen Ton angeschlagen. Wieder aus Erfahrung, die mir nichts Schmerzliches hinterlässt. Ich muss nur immer denken: Verdiene ich diese oder jene Enttäuschung oder Kränkung nicht jetzt, so habe ich sie für anderes verdient. Also nicht muksen, nicht sich auflehnen, sondern geduldig Alles hinnehmen u. der Zukunft vertrauen. In Kolleg u. Praktikum hatte ich heute eine Freude. Möchte doch der Besuch auch weiterhin so gut bleiben, wie er jetzt es ist. Das würde ja über Alles hinwegheben. Heute besuchte mich Otto Häberli, der so mühsam die letzten Jahre den Doktor seiner gemütlichen Depression abgerungen hat. Ich glaubte, er wolle etwas von mir, aber das war nicht der Fall. Ich war recht zu ihm u. er

war stumm aber dankbar. Er hat noch keine Stellung. Ich hoffe, er wird sie mit der Zeit wieder ganz erholen. Jetzt arbeitet er gelegentlich für diese u. jene Auftraggeber.

Walter B. war heute im Sprechzimmer etwas aufgeregt. Ich weiss nicht was ihn bewegt hat. Vielleicht ist es die Reaktion gegen eine zu sehr gesteigerte 
Stimmung, die sich bei ihm die letzte Zeit bemerkbar gemacht hatte.

Heute sah ich auch Kanzler Ringier wieder einmal.

Er wollte wegen einer Testamentsfrage zu mir kommen. Es passte mir besser, auf dem Weg zur Universität bei ihm vorzusprechen. Er ist der alte. Diese Zeilen schreibe ich um halb neun auf der Terrasse, also ganz wie schon zur Sommerzeit. So geht der Lauf rasch voran. In elf Wochen haben wir bereits wieder Ferien.

Und nun gute Nacht, es wird dunkel. Ich bin in dankbarer Hingebung Dein alter, treuer

Eugen.

Anna war heute wieder einmal bei Frau Moser. Sie kam recht zurück. Aber Gott weiss, was sie dort gesprochen hat. Das muss ich jetzt halt immer als Risico tragen. Ich kanns nicht ändern. Nochmals Dein

Eugen

\section{2: Mai Nr. 108}

B. d. 11. / 2. Mai 1912.

Liebstes Herz!

Sommerliche, drückende Wärme, kein Drang zur Arbeit, sondern ein stetes sich Vorstellen, wie es sein sollte, kein rechtes Vertrauen in meine Umgebung, die mich unter der alten Schwester Führung mit gar so viel Kleinigkeiten plagt, dazu die Nachwirkung der Angelegenheiten, die ich in der Anregung der gestrigen Kollegarbeit überwunden glaubte, das alles hat mich heute fast arbeitsunfähig gemacht $u$. mir seit langem einen der schwersten Tage bereitet. Marieli wurde 
von Frau Bühlmann mit Telephon nach Grosshöchstetten gerufen, ich lehnte, weil ich zu arbeiten beabsichtigte ab. Um vier Uhr wollte Frau Bühlmann mich nochmals aufs Abendessen haben, ich mochte mich nicht entschliessen bei der gegenwärtigen Verfassung. So ist der Druck geblieben. Ich lehne alle Freundlichkeiten ab, weil ich nicht daran glaube. Von Frau Kronecker erhielt ich einen Abdruck von Reisebriefen zugesandt, ich las sie schnell u. sandte sie mit einem freundl. Billet zurück. Kohler schrieb, ich hätte ihm so überaus freundlich geantwortet, ich schreib ihm sofort, das sei in der Freude darüber geschehen, dass er die Congress-Absage vom letzten Dezember mir nicht nachgetragen (was auch stimmt), damit er nicht etwa glaube, das sei wegen seiner in Aussicht gestellten günstigen

Besprechung des ZGB. - Dann war Mutzner bei mir, ferner kam Teichmann Sohn nach dem Nachtessen ein halbes Stündchen. Aber trotz alledem vermochte ich der Depression nicht Herr zu werden. Sie kann einmal in ein bitteres Leid umschlagen. Ich fühle mich eben in der Welt, die ich jetzt habe, nicht wohl, u. kann es nicht ändern. Oder wäre es besser, wenn ich Bern verliesse u. mich in irgend einen weltverborgenen Winkel verkröche? Das darf ich nicht! Möge doch die tiefere Erfahrung mich vor solchem Leid bewahren! Aber sieh, indem ich dies schreibe, wird mir schon wohler!

Marieli wird in wenig Augenblicken von der Bahn zurück kehren. Ich tue besser nicht weiter zu schreiben. Nur eines füge ich noch an, dass ich am Nachmittag eine Stunde bei Siegwart war. Er war etwas verlegen, als ich ihn fragte, ob er den unglücklichen kleinen Candidaten Jost gesprochen? Das hatte er mir verheimlicht. Aber solche Dinge passieren ja oft ohne böse Absicht. 
Es war heute ein sehr warmer Tag, bis über $20 \mathrm{R}^{\circ}$ mit fast brennendem Wind, $\mathrm{u}$. so blieb man gern zu Hause, um stillen Sonntag zu feiern. Walter B. war ein Stündchen bei mir. Nach dem Essen kam Balli, der sehr zutraulich geworden ist. Sonst arbeitete ich etwas an den Kollegien, schrieb an den Conlin, den Kohler uns als Privatdozent empfiehlt u. der mir die Akten betr. die Demission, was

seinen Standpunkt wenigstens zustellte, in ziemlich ablehnender Art. Ich habe zu diesen in der Schweiz sich zankenden Reichsdeutschen keine grosse Neigung. Im übrigen dauerte meine Stimmung von gestern, in Resignation übersetzt, fort. Auch die bangen Gedanken an unsere Zukunft, da wir in der Schweiz doch auch gar keinen guten Willen untereinander an den Tag legen, wollten mich, namentlich nach dem Gespräch mit Balli, das zum Teil den Tessin betrifft, nicht verlassen. Die Italiener sorgen für die Herstellung einer Volkspsyche, $u$. vielleicht werden sie damit grosse Dinge leisten. Aber uns zum Schaden. Ob wir an Deutschland einen Halt haben werden, ist ja bei den jetzigen [Zeitl?] gar so unbestimmt. Ziele, Ziele, die fehlen Deutschland, uns aber noch viel mehr. Ich gab mich etwas mit einer Schachaufgabe ab, die ich endlich löste. Dann schaute ich in Bädeker nach, wo ich etwa im Sommer ein paar Ferienwochen verbringen könnte. Ich blieb ein wenig am Weissenstein hängen, weiss aber wirklich nicht, ob dies am Ende nicht ganz dumm wäre. Sind nicht vorzugsweise Basler dort?

Es ist mir jetzt bekannt, was Walter B. am Freitag etwas beschäftigt hat: Die Kommission zur Beratung eines neuen Urheberrechtes war veröffentlicht worden, u. er nicht dabei, während er doch in erster Linie, jedenfalls vor Reichel $u$. andern, darin hätte Platz haben sollen. So sei ihm, sagte er heute, früher auch gesagt worden, er werde in die Kommission berufen - hat Müller nicht an ihn gedacht, oder war er andern unbequem? Das sind so Erlebnisse, die ich ja auch erfahren habe. Man 
muss sich damit abfinden. Als Kommissionsmitglied leistet zwar Walter B. seinem Temperament entsprechend, nicht

sehr viel, immer aber noch mehr als ein Reichel, der in den Sitzungen grösstenteils schläft, mit offenen Augen u. manchmal sogar mit geschlossenen.

Die beschaulichen Stunden des heutigen Tages haben mir wohl getan. Ich konnte aus der Conlin-Affaire ersehen, was es auf sich hat, gewaltsam mit seinem Schicksal umzuspringen. Es gibt doch nichts Besseres, als in einer nützlichen Tätigkeit auszuharren, solange man die Kräfte dazu hat. Ich erinnere mich, dass ich in jungen Jahren mir gar nichts anderes dachte u. z. B. die Lebensweise des alten Lienbach gar nicht verstehen konnte. Ich weiss ja, wie sehr dies Dein Standpunkt gewesen ist. Lasse ich diese Gedanken ganz über mich herrschen, so wird mir dann vielleicht auch ein Ende zu Teil, wie Dir - ohne Siechtum, in der nicht gebrochenen Kraft. Das muss ich jetzt abwarten, mich in Geduld üben. Ich weiss ja, dass was noch kommt, kein schöner Abschnitt meines Lebens sein wird.

Von Zürcher erhielt ich die Nachricht von dem Tode der kleinen Enkelin, dem einjährigen Töchterchen der Thea. Die guten Leute tun mir leid.

Es schien, während ich diese Zeilen - wieder auf der Terrasse - schrieb, ein Gewitter geben zu wollen. Nun ist es dunkel geworden u. die Wolken verziehen sich wieder. Wollte Gott, die Woche würde mir einige innere Freude bringen. Ich hätte es so sehr nötig! Innigst küsst Dich, meine liebe Seele, Dein treuer, einsamer Eugen 
[1]

B. d. 13. / 4. Mai 1912.

Liebstes Herz!

Es war heute wiederum ein merkwürdig heisser Tag, um 6 Uhr schon $17^{\circ} \mathrm{C}$. u. den ganzen Tag glänzende Sonne mit warmem Wind. Ich war froh, den Morgen meine Stunden abwickeln zu können, die gut besucht waren. Nachher fand ich zu Hause zufällig gleich drei oder vier wichtige Anfragen, zu denen dann Mutzner noch eine weitere fügte, als er am Nachmittag in der Sache des «Bund»-Artikels zu mir kam u. mir eine Antwort, die er verfasst, vorlegte, die mir recht sein kann, obgleich ich sie jetzt nicht mehr begehre. Es wird sich jetzt zeigen, was der «Bund» damit macht. Sonst kam ich noch dazu die Hälfte der «sozialen Gesinnung» corrigierend zu durchlesen u. einen kleinen amtlichen Bericht zu schreiben, und damit ist der Tag wieder vorüber.

Marieli war heute Nachmittag bei Frau Tecklenburg u. brachte zum zweiten Mal die Nachricht, Frau T. habe ihr gesagt, sie würde so wohl zu dem Bruder ihres Mannes passen, der Pastor in einem Dorf im Taunus ist. Diesmal fügte sie bei, der Bruder werde nächstens herkommen u. dann werde Frau T. sie einladen, u. Spaziergänge veranstalten, damit sie sich kennen lernten. Und Marieli wollte nichts davon wissen, als ich sagte, sie werde doch abgelehnt u. abgewunken haben. Das könne es dann immer noch, wenn die Einladung komme. Was ist nun das für ein Zeichen, da in denselben Tagen die Bekanntschaft mit 
Abbühl auf Marielis Wunsch so intensiv erneuert hat? Ist das wieder naiv, kindisch? Ich weiss es nicht. «Frau Pastor im Taunus!» rief es aus, u. ich glaube, sie lehnt den Gedanken wirklich nicht ganz ab. Nun ja, die Wege, die es wandelt, sind nun einmal eigenartig, also lassen wir der Welt den Lauf!

Die erhaltenen Anfragen haben mich im ersten Moment bestürzt. Nachher sah ich, dass das alles eben notwendig mit der Einführung des neuen Rechtes verbunden ist, u. dass sich gerade in der Gestaltungsfähigkeit der neuen Regeln deren Vorzug enthüllt. Also bleibe ich bei der wieder befestigten Ruhe $u$. arbeite weiter. Morgen haben wir um 8 Uhr eine Fakultätssitzung i. S. der Handelsabteilung u. Rossels Nachfolge. Es kann länger dauern, sodass ich Dir nicht viel werde schreiben können, wenn ich am Mittwoch zur Zeit u. frisch wieder an der Arbeit sein will. Noch eines:

Heute traf ich Frau Bösiger auf der Strasse. Sie war sehr recht. Von Soncoboz weiss sie nichts. Also habe ich ihr auch nichts weiter mitzuteilen.

Und damit gute Nacht für heute! Ich bin mit einem mal, müde, sehr müde!

Den 14. Mai.

Die Hitze dauert an, wir haben so warm, wie in dem vorigen heissen Sommer erst im Juli. Doch hat mich dieser Zustand noch nicht angegriffen. Ich habe gut geschlafen $u$. war im Kolleg glaube ich munter. Nach den Vorlesungen diktierte ich zwei kleine Gutachten, die mir Abbühl morgen aus-

fertigt. Am Nachmittag konnte ich einige Seiten der sozialen Gesinnung durchsehen u. hatte dann Kolleg zu präparieren. Zwei Studenten kamen: Der Frauenfelder Schmid, der in Dissertationsnöten steckt, u. ein Aargauer Nationalratskandidat, der 
wissen wollte, ob er wohl mein Praktikum besuchen könne. Ein netter Bursche, naiv, Landkind, der mich (wie auch schon früher einmal einer) beim Fortgehen fragte, was er schuldig sei.

Heute erhielt ich die Anzeige des Todes von Nationalrat Suter, der mich noch vor wenigen Wochen wegen seines Testamentes consultierte. Er hat, wie ich Dir damals schrieb, im März seine Frau verloren. Es steht, dass er nach kurzer, schwerer Krankheit gestorben, also wohl ähnlich wie Hebbel, in dessen Alter er auch gestanden. Der hat nun seine Frau nicht mehr lange überleben müssen! Ich hatte immer den Eindruck von einem sehr gealterten Wesen an ihm trotz seiner robusten Constitution. Er sprach nicht zusammenhängend, aber er war so gut, in dem was er sagte. Ein rechter Mann aus dem Volk, wohlwollend gegen alle Welt, u. dabei doch recht überlegt, ja mit einer guten Dosis Bauernschlauheit ausgerüstet. Mir begegnete er immer sehr freundlich $u$. anerkennend. Ich war sein Berater schon vor Jahren in Familienstreitigkeiten mit seinen Verwandten. Dem Gesetzbuch hat er immer die Stange gehalten u. sich dabei auch in Volksversammlungen als zuverlässig erwiesen. Wie er das letzte mal fortging, kam noch unter der Türe ein Wort über den Verlust seiner Frau über seine Lippen, ich habe Dir damals geschrieben. Jetzt klingt es mir nach als eine Äusserung von Todesahnung. Er hat jetzt Ruhe. Auch daran erinnere ich mich, wie er sagte,

Leute seiner Art werden, wenn es ihnen gut gehe, vom Neid verfolgt. Wenn man auf der Höhe stehe, wie ich, werde davon nicht die Rede sein. Worauf ich ihm entgegnete, man erlebe allerlei, aber wer arbeite, dürfe sich dies nicht anfechten lassen. Ich glaube schon, dass er in einem grossen Neidsumpf gesteckt hat, mit seiner selbstgeschaffenen Welt von Erfolg u. den Schwächen, die ihm das Alter allmählich angeheftet hatte. Geht es mir anders?

Die Widerwärtigkeiten im Tessin mit dem Giornale d'Italia beschäftigen mich immer noch, $u$. machen mich traurig. Ich muss immer an den «Hannibal» denken, von dem ich Dir schon oft gesprochen, den Hannibal, mit dem ich 
s. Z. den ersten u. wichtigsten Sieg vor Volkskreisen mit dem ZGB. davon getragen.

Wir haben heute um acht die angekündigte Fakultätssitzung, die wohl lange dauern wird, so dass ich nachher nicht mehr schreiben, sondern schleunigst zu Bett gehen werde. Also schliesse ich jetzt diese Zeilen, mit einem innigen treuen Gut Nacht!

Dein alter Kamerad

Dein

Eugen

1912: Mai Nr. 110

[1]

B. d. 15. Mai 1912.

Liebstes Herz!

Nach einer gekürzten Ruhe habe ich heute einen Tag verbracht ohne richtige Arbeit. Sobald ich Abends nicht zur rechten Zeit zum Schlafe komme, so spüre ich das den folgenden Tag, oder ich wehre mich wenigstens nicht mehr dagegen, mich gehen zu lassen. So schrieb ich heute dann nur einige Briefe $u$. kleine Gutachten. Dann hatte ich Besuch von Balli, der auf nächstes Semester «Rechtsphilosophie» ankündigen will, ferner von Lauch, der mir mitteilte, dass er Freitags nach Genf verreise u. als Dissertationsthema den Erbvertrag gewählt habe, von der Affaire mit dem Departement war kein Wort mehr die Rede. Und endlich von Tuor, der mir über den Conflict der Facultät mit Pylsen u. mit Oser Aufschluss gab, wobei ich nichts Neues vernahm, dagegen merken konnte, dass die Missstimmung über Osers Benehmen bei Tuor ziemlich tief sitzt. Von Siegwart berichtete er, dass die Studenten sich über seine Vorlesungen sehr befriedigt gezeigt hätten. Von Oser meinte er, dass er nie von Herzen Professor gewesen sei. Dann las ich verschiedenes u. brauchte auch einige Zeit, eine 
Aufgabe mathematischen Problems im «Schweizerdorf» $\mathrm{zu}$ lösen, wie ich sie ja, wie Du weisst, so gerne vornehme, wie etwa die Schachaufgaben. Heute früh war es noch sehr warm. Den Nachmittag bedeckte sich der Himmel u. jetzt bei

[2]

angebrochener Nacht beginnt es wohl doch zu regnen. Das Barometer ist gefallen u. es geht ein kühlerer Wind. Das wird gut tun. Denn wirklich wäre es fast zu viel gewesen, wenn wir jetzt schon andauernde Sommerwärme erhalten hätten. Die Tage haben mich mehr mitgenommen, als ich es spürte. Ich merke es allemal am ehesten meiner Schrift an.

In den Zeitungen standen in diesen Tagen mehrere Todesanzeigen von Bekannten, die gerade mein Alter erreicht haben. Ich sehe jedes mal darauf u. mache mir darüber Gedanken. Ich fürchte den Tod nicht. Aber ich fühle dann doch, dass ich eigentlich noch einige Zeit sollte arbeiten können, um das viele Angefangene einigermassen fertig bringen zu können. Doch komme es wie es wolle, ich bin auf alles gefasst.

Gestern Abend hatten wir Facultätssitzung von $8 \mathrm{Uhr}$ bis gegen elf. Zuerst gab ein Habilitationsgesuch Glücksmanns viel zu reden. Wir haben es, weil eine Dissertation nicht vorlag, mit Mehr abgewiesen, ohne auf die weitere Qualification einzutreten. Dann folgte die Beratung einer Abmachung Lohners mit dem preussischen Unterrichtsministerium betr. die Anerkennung des Doktors, den Deutsche an unserer Handelswissenschaftlichen Abteilung machen. Hier griff ich gegenüber langatmigen Voten v. Milliet, Blumenstein etc. mit ein paar kurzen Sätzen ein u. blieb Sieger. Endlich kam die Nachfolge für Rossel zur Sprache. Neben einem 
Pariser jungen Juristen hat sich Oberrichter Folletête gemeldet, u. ich muss das Gutachten machen, ohne über diesen irgendwelche Materialien zu besitzen. Rossel wird mir da wohl aushelfen müssen. - Nach der Sitzung gingen die jungen Collegen noch zu einem Glas Bier. Ich verzichtete, weil ich doch nicht gar zu spät zur Ruhe kommen wollte.

Und morgen ist wieder Auffahrtstag. Wir haben ihn immer still zusammen daheim begangen. So wird es auch morgen der Fall sein. Du sollst bei mir sein den ganzen Tag, u. ich freue mich heute schon darauf. Ich bin ja entschlossen, mich nun in meiner Stellung solange es immer geht zu behaupten $u$. weiter zu arbeiten. Aber mit Musse. Solche Tage, wie heute, $u$. wie auch morgen sein soll, wenn nichts Störendes dazwischen kommt, lassen den inneren Menschen wieder aufleben. Man gewinnt Ausblicke, die sonst bei der andauernden Arbeit nicht gewonnen werden könnten. Es ist wie bei einer Bergbesteigung: Wer immer noch vorwärts hastet, der gelangt gar nicht zum Genuss. Und wie sehr muss ich mir vorwerfen, unter solchem Druck, der ja freilich nicht immer freiwillig übernommen war, jene Ausblicke versäumt zu haben. Wäre ich als anderer innerer Mensch an diese Aufgaben gelangt, wie Manches würde sich leichter bewältigt haben. Allein wir sind nun einmal dazu da, uns nach unserer Anlage abzuleben, und man muss ja froh sein, wenn die Ergebnisse dabei nicht gar zu schlimm ausgefallen sind. Also bleibe ich dankbar für das was ich Gutes empfangen $u$. lasse das Üble als ein Notwendiges

neben herlaufen, indem ich bedenke, dass es auch gar manchmal Gutes gewirkt hat, u. nie in der Summe alles Geschehenden unverdient war!

Anna ist seit einigen Tagen unwohl, Sophie klagt auch. Marieli geht es dagegen ordentlich. Es kam heute aus der zweiten Redingstunde recht munter zurück. 
Und jetzt Schluss für heute, u. ich hoffe auf eine Schlafnacht. Ach Gott, ich nehme mit allem vorlieb, wenn nur die Zeit vorübergeht, ohne dass Schuld u. Reue Einzug halten können. Man darf sich mit dem Älterwerden besonders davor hüten, denn Fehltritte sind in höheren Jahren weniger gut auszugleichen als in jüngeren. Mein Leben ist jetzt eine sich immer mehr befestigende Regelmässigkeit. Darauf baue ich auch einzig noch meine Hoffnung.

Gute, gute Nacht, meine einzige, liebe Seele! Ich bleibe immerdar

Dein getreuer

Eugen

\section{2: Mai Nr. 111}

B. d. 16. Mai 1912.

Mein liebstes Herz!

Der heutige Himmelfahrtstag hatte wirklich nicht die Beschaulichkeit, die ich gestern erhofft, aber deren Beeinträchtigung ich auch befürchtet hatte. Es kamen mit der Post Anfragen u. Gutachten, u. wenn ich auch nur eines sofort erledigte, so beschäftigten mich doch die andern. Ich schrieb einige Briefe, las etwas englisch, präparierte die Kollegien u. brachte die Durchsicht der sozialen Gesinnung zu Ende. Dazwischen hindurch hatte ich Besuch von Walter Im Hof, der mir viele Grüsse von Paul brachte, mit dem er in derselben Pension zusammen ist (Dornbirer). Am Nachmittag kam Marieli einen Augenblick zu mir ins Zimmer, um mir das Heft mit abgeschriebenen Gedichten, das ihr Frau Tecklenburg zum Lesen mit gegeben, zu zeigen, u. dabei fragte es mich, was es wohl machen müsse, wenn Frau T. es einlade, um es mit dem Pfarrer, dem Bruder ihres Mannes, der aus Waldorf für einige Ferienzeit hieher kommen soll, bekannt zu machen. Ich konnte mich nicht enthalten, ihm die Gegenfrage zu stellen, wie es denn in seinen Gefühlen zu Abbühl stehe, da es doch mir so schwere Nöten in dieser 
Beziehung geklagt $u$. mich dadurch veranlasst habe, Abbühl als Secretär zu nehmen. Die Antwort war, es würde sich gewiss für Abbühl entscheiden. Allein es sei gar nicht sicher, dass dieser sich so entschliessen werde. Also eine tiefe, grosse Liebe

liegt offenbar beidseitig nicht vor. Um so mehr heisst es für mich abzuwarten. Abbühl leistet mir noch lange nicht, was Siegwart. Aber es kann ja besser werden, u. Zeit gewinnen ist hier das einzig ratsame.

Diese Unterhaltung mit Marie wurde etwas besänftigt, durch den Eindruck, den ich von ihm hatte, dass es eben doch seit einiger Zeit etwas mehr Seele in den Augen hat. Sein Blick ist manchmal derselbe wie er mir an seiner Schwester Anneli so sehr gefallen hat. Das wird doch wohl von der grösseren Ruhe herkommen, die es in seinem Innern trägt, u. gibt mir Hoffnung, dass es doch noch besser komme mit seinem Gemüt. Zwar hat sich bei dem geringsten Fragezeichen von meiner Seite der Blick sofort wieder geändert, doch nur für eine Weile. Also Hoffnung! Es ist merkwürdig, wie mich die beiden Töchter der Vers. Primrose, von denen ich heute in Goldsmith gelesen, an die beiden Schwestern, Marieli u. Anneli, erinnerten. Und die Mutter hat einige wesentliche Züge von Dir. Das verklärte Wesen dieses Haushaltes hätten wir auch haben können, wenn ich der Vicar gewesen wäre. Allein da dies nicht zugetroffen, so ist alles anders geworden $u$. bin ich jetzt so allein auf der Welt. Diese Einsamkeit kommt an solchen Tagen wie heute besonders zum Bewusstsein. Anna wird wieder mit jedem Tag stumpfer, hat auch zur Zeit einen erheblichen Katarrh. Marieli geht ganz in den Nebensachen auf, womit es seine Zeit belastet, und sonst habe

ich ja niemand, suche auch niemand, ja ich scheue mich förmlich, anderswo Besuch zu machen. Denn man erlebt es hier so selten, dass man den Leuten willkommen ist, $\mathrm{u}$. ich habe keine Lust mehr an solchem Umgang. 
Was mich heute dann des weitern namentlich beschäftigte, das war ein Artikel des Winkel-Korrespondenten in der N. Z.Z., der direkt für Frankreich gegen Deutschland hetzt. Also haben wir jetzt richtig diese Wandlung in der N. Z. Z., sie ist Reichsfeindlich geworden. Das ist sehr dumm, u. mir peinlich. Ich vertrage solche Unnatürlichkeiten nicht mehr, u. werde, wenn das so fortgeht, auf dieses Blatt verzichten. Mit dem Dürrenmatt-Blättchen steht es in dieser Beziehung etwas besser, als früher. Der schnöde Deutschhasser (Pilichody?) lässt schon lange nichts mehr von sich hören. Mag sein, dass auch das Zürcher Blatt wieder mehr zur Besinnung kommt. Es ist ja richtig, dass die Salbadereien oder Schüleraufsätze Bärlins mir auch nicht mehr behagen wollten. Und es würde der kurzsichtigen Naivetät der leitenden Kreise der N. Z. Z. ganz entsprechen, wenn sie geglaubt hätten, mit mehr Schärfe u. Originalität würde in dieser Beziehung das Blatt auf eine für die Leser genussreichere Stufe gehoben. Allein dabei bedachten sie wohl nicht genug, welchen Wandel sie vollzogen. Sie fanden, dass sich das Publikum über die schalen deutschfreundlichen Ausführungen Bärlins ärgerte $u$. bezogen den Ärger auf die Deutschfreund-

lichkeit statt auf die Schalheit. Sie werden wohl bald zu merken bekommen, dass sie sich den unrichtigen Zahn haben ziehen lassen.

So dachte ich heute über dies u. das nach u. der Tag ging vorüber. Ich bin froh über jeden der vorüber gegangen.

Gute, gute Nacht! Bleib bei mir, hilf mir, ich bin Dein allzeit getreuer Eugen 
B. d. 17. / 8. Mai 1912.

Mein liebstes Herz!

Die Antwort Mutzners auf den giftigen Artikel im «Bund», den unzweifelhaft der neue Redaktor Schürch, den ich aus seiner Studentenzeit als bornierten Rechthaber kennen gelernt habe, ist heute erschienen, natürlich begleitet von einigen Bemerkungen der «Redaktion», die wiederum so verkehrt als möglich sind, u. neuerdings eine scharfe Antwort verdienen würden. Allein ich kenne ja dieses Gelichter. Die schmutzige Seele, die in dem Kerl wohnt, muss sich selbst überlassen bleiben. Auch da wird die Korrektur schon noch herein brechen. Wer alt genug wird, mag es erleben. Damit hoffe ich diese Gelegenheit als abgetan betrachten zu können $u$. werde ohne Not nicht mehr darauf zurückkommen.

Heute war es recht kühl. Ich war ordentlich munter u. habe neben den vier Kollegstunden das Gutachten über das Pflichtteilsrecht an Abbühl diktiert, das vom Departement auf eine Anfrage Bordys verlangt worden ist. Zugleich habe ich dasjenige über Übergang von Nutzen u. Gefahr, das Scheurer wünscht, mir zurecht gelegt u. will es morgen niederschreiben oder diktieren.

Die Tage habe ich, auf Veranlassung eines Plans von Marieli u. Leni Arn, die aus England zurückgekehrt ist, den Vicar of Wackfield wieder einmal vorgenommen $u$. lese darin mit grosser Freude

zwischendurch ein paar Seiten, wie ich Dir gestern schon geschreiben. Ich will mir damit das Englisch etwas auffrischen, denn ich denke mit einemmal daran, vielleicht in den Ferien doch nach England zu gehen. Jedenfalls 
dient das Buch auch zur seelischen Erfrischung. Dieser Vicar ist ja ein Mann, der uns über manches belehrt, u. die ganze Stimmung des Buches ist so lieblich $u$. treuherzig. Es tut gut, neben all der unvermeidlichen Misere, in der selbstgewählten Einsamkeit, die ich mit Dir teile, auf solchen Inseln des Gemütes dann u. wann von der rauhen, kalten Fahrt etwas auszuruhen.

Ich fühle mich etwas matt, vielleicht von dem Wetterumschlag her u. will sehen, dass ich schlafen kann. Warten wir nun ab, was die Tage wieder bringen werden. Morgen kommt wohl Guhl zurück u. am Samstag hoffe ich ihn zu sehen.

Und nun genug für heute, liebe gute Seele. Vielleicht habe ich morgen mehreres zu berichten.

D. 18. Mai.

Heute war ich zeitig an der Arbeit u. habe das Gutachten für Scheurer, acht Folio-Seiten, gleich ins Reine niedergeschrieben. Abbühl musste es nicht abschreiben, ich sandte es um zehn an die Adresse mit der Bitte, mir einen Abzug zu schicken. Ich bin froh diese Aufgabe erledigt zu haben. Es war eine schwere, aber dann nach der Lösung doch leicht scheinende Frage. Abbühl brachte mir sodann seine Niederschriften zu den gestrigen Gutachtelchen, leider

weder sauber noch correct, so dass ich etwas stutzig wurde über seine Qualität. Ich hoffe das nur seiner Jugend $u$. mangelnden Bildung zuschreiben zu müssen, so dass es sich dann mit jeder Woche bessern würde. Aber wenn das nicht einträte, wäre er schliesslich doch nicht mein Mann. - Am Nachmittag kam Siegwart wieder ein Stündchen zu mir, glückstrahlend. Es geht ihm recht gut u. namentlich scheint er bereits seine Collegen für sich gewonnen zu haben, so dass selbst Tuor von dem geplanten Protest gegen die Wahl absehen dürfte. Das wäre ein grosser Gewinn für Siegwart. Ich hoffe auf eine solche Lösung. Oser freilich kommt dabei immer noch nicht gut weg. - Ich ging dann zu Rossel, traf aber nur seine Frau, die lachend erzählte, es gefalle ihm in Lausanne 
recht gut u. sie gehe jetzt auch gerne dahin. Endlich machte ich Frau Oberst Hebbel wieder einmal einen Besuch, traf sie aber wieder in grosser Verbitterung, da in einem Circular der Kanzlei des Militärdepartements gesagt gewesen sei, sie befinde sich nicht in guten Verhältnissen, dies zur Motivierung einer Pension für die Instruktors-Witwe. Ich suchte ihr die Stimmung etwas auszureden. Sie schien von meinem Besuch erfreut zu sein.

Bei der Abendzeitung erschien plötzlich Albert Heim, nur für ein halbes Stündchen, u. die ganze Zeit bewunderte er die Alpen, die in der Abendbeleuchtung sehr hell waren, $u$. machte Notizen für eine Publikation, die Farben in der Natur! Wir standen fast die ganze Zeit auf des Daches Zinne u. konnten wenig miteinander plaudern. Von Arnold haben sie gute Berichte. Marie geht es immer gleich u. Sophie nicht gut. Er will in einigen Wochen einmal bei uns übernachten.

So ist der Tag zu Ende gegangen, im ganzen Ruhetag, etwas Kopfweh, an dem ich jetzt dann u. wann leide, u. im übrigen Resignation. Froh sein, dass es nicht schlimmer ist, das ist ja auch ein Standpunkt, u. Dankbarkeit u. Liebe in Deinem Sinn pflegen, das ist jetzt meine ganze Weisheit.

Marieli war im Kränzchen bei Müngers.

Und nun sei auch diese Woche geschlossen. Ich lese noch etwas in Vicar u. will dann schlafen, um nächste Woche wieder rüstig zu sein. Ich spüre es meiner Schrift an, dass ich etwas aufgeregt bin. Ich vertrage das Dozieren nicht mehr so gut. Es kommt wohl vom Herzen.

Gute Nacht, gute Nacht! Ich bin Dein ewig getreuer 
[1]

B. d. 19. Mai 1912.

Mein liebstes Herz!

Heute war wieder ein stiller, u. doch bewegter Sonntag. Nach der Morgenpost kam Rossel u. brachte mir einige Angaben über Folletête, der nun sein Nachfolger in hier werden wird. Was er angibt, reicht ganz wohl aus, dass ihn die Fakultät mit gutem Gewissen vorschlagen kann, wenn es auch ganz unsicher ist, ob er als Professor etwas leisten wird. Il louche, sagte Rossel, hoffen wir, nach zwei guten Richtungen. Dann kam Walter B., der mir erzählte, zu welchen Conferenzen im Wetterwesen er einberufen werde. Neben Max Huber als Referenten wird er im Juli in St. Gallen an einer Versammlung das Correferat halten. Er war nett, nur fiel mir auf, dass er meine Mitteilung, ich habe jetzt den Aufsatz über die soziale Gesinnung fertig gestellt, kalt aufnahm, wie ja freilich auch einfach seine Natur sein mag. Und erkundigte er sich so merkwürdig, ob nicht wieder Grösseres oder Kleineres über das Zivilrecht erschienen sei. Ich erblickte in der Äusserung, wie sie fiel, eine Art von Freude darüber, wenn Angriffe erfolgen. Auch da ist es aber gewiss nur seine Natur, der Zug oder Einschlag von Missgunst, der in ihm steckt, was zu solchen Worten geführt hat. Es ist ja überaus freundlich, dass er jeden Sonntag mich besucht. Er will es recht, das verstehe ich wohl, u. über sich selber hinaus kann keiner. Endlich kam Guhl, aus den zwei Wochen Militärdienst gebräunt u. etwas

$[2]$

gemagert zurück. Ich konnte mit ihm gleich einiges Amtliches verhandeln $u$. hatte den Eindruck, dass er mit grossem Eifer hinter die Arbeit gehe. Dabei denkt er aber auch an Mutzner, dessen Habilitation ihm offenbar sehr wenig gefällt. Er muss es jetzt eben auch haben. Kann sein, dass zu 
gleicher Zeit sich nun doch auch Conlin sich für Germanistik habilitiert. Gmür soll so etwas zu Rossel gesagt haben. Ich selbst weiss noch nichts bestimmtes. Nebenbei erzählte Guhl, dass Lohner den Privatdozenten Hediger so merkwürdig abgewimmelt habe: In der bekannten Manier vom Anbieten in unannehmbarer Form. Überhaupt habe sich Lohner in der Sache sonderbar benommen. Müri, den er, Guhl, auf der Bahn getroffen, habe gesagt, es sei nichts mit ihm, er sei ein Blonder, $\mathrm{u}$. Isler habe zugestimmt. Ach das sind ja wieder die Mitteilungen à la Guhl, die ich jetzt einige Wochen ganz entbehrt hatte.

Am Nachmittag präparierte ich für die Kollegien u. las dann wieder, wie schon am Morgen zwischen hindurch, im Vicar. Dann kam Frida Weber, gross u. schwer, u. hatte mit Marieli u. mir ein Plauderstündchen, wobei wir wenig zu sagen brauchten. Aber sie war recht u. gut gesinnt. Ich bin froh, dass nun offenbar Hans Weber doch fortdauernd recht zu mir denkt.

Heute ging Marieli auf 8 Uhr in eine italienische Morgenpredigt in der Trinitate Kirche, auf die Frau Dr. Jauch Anna aufmerksam gemacht hatte. Sie kam erfreut zurück u. erzählte, dass sie Siegwart u. Frau Jauch dort getroffen u. neben ihnen gesessen habe. Die beiden begleiteten sie

bis vor unser Gartentor u. Frau Jauch lud Marieli nicht nur zu sich in hier herzlich ein, sondern sie forderte es auch auf, nach Altdorf zu kommen u. dort Ferien zu machen. Und Marieli denkt ernsthaft hieran, nachdem sich der Plan der Freundin Beetschen mit der Alphütte, da diese von Verwandten in Anspruch genommen wird, zerschlagen hat. Auch da muss ich mich wieder fragen, woher dann in Mailand das Verlangen mit Abbühl wieder zusammen zu kommen, wenn jetzt gleich wieder Pastor Tecklenburg u. Professor Siegwart solchen Eindruck machen können? Übrigens hat sich Marieli wieder erkältet u. hustet neuerdings. Es ist eben andauernd schwach, isst $\mathrm{u}$. schläft zu wenig $\mathrm{u}$. wird gleich von jedem Lufthauch krank. Und zu Dumont hat es auch nicht eine Spur von Zutrauen. Es nimmt 
seine Arznei nicht mehr, sondern trinkt Bittersalz, u. bringt es weder mit dem einen noch zu mit dem andern zu bessern Resultaten.

Ich will aber nicht mehr in diese Klagen mich hineinverlieren. Im Herzen war Marieli die letzten Wochen entschieden besser in Stimmung. Wenn ich zwischen Abbühl u. Siegwart zu wählen hätte, weiss ich nicht, was zu tun wäre. Abbühl erscheint mir nach den ersten drei Wochen, die er jetzt bei mir ist, nicht so reell, wie ich erwartet. Allein das kann sich noch machen. Und Siegwart ist jetzt eben am Anfang einer prächtigen Laufbahn u. wird wohl darauf bleiben. Aber seine ultramontane Umgebung wäre schwer zu tragen. Freilich sind ja herzensgute Menschen dabei. Also lassen wir der Sache den Lauf. Es lässt sich da wenig davon oder dazu tun,

wenigstens mir würde das schwer fallen. Hilf Du mit Deiner Güte Marieli. Ich fürchte nur, dass es auch Dir gegenüber nicht die klare Stimmung hat, die ich ihm wünschen möchte. $\mathrm{Zu}$ mir zeigt sich das bei verschiedenen Gelegenheiten. Das sind Beobachtungen u. Erfahrungen.

Ich habe diese Zeilen wieder auf der Terrasse geschrieben, beim Abendglockenklang u. Amselgesang. Es war ein lieblicher Sonntag.

Nimm innigsten Kuss von Deinem immerdar getreuen

Eugen 
B. d. 20. Mai 1912.

Mein liebstes Herz!

Heute war ich von exemplarischer Ungeschicklichkeit, alles was ich in die Hände nahm, wurde verschüttet oder sonst übel behandelt. Als ich von der Vorlesung nach Hause kam, entdeckte ich, dass meine rechte Hand bis zur weissen Handmanchette, diese inbegriffen, über u. über mit Tinte beklext war. Ich meinte zuerst, die Füllfeder des Studenten, mit der ich am Schluss der Vorlesung die Testate geschrieben hatte, habe das verschuldet $u$. ich habe es eben erst jetzt bemerkt. Aber bei näherer Nachschau entdeckte ich, dass die Westentasche, in der ich meinen langen Füllfederhalter trug (der kurze ist zur Reparatur bei Kaiser), ganz nass war, u. bei noch näherer Untersuchung fand sich ein Durchschlag bis zum Hemd. Der Füllfederhalter war, aus welchem Grunde weiss ich nicht, aufgegangen $u$. bei jeder Bewegung traten aus den Fugen der Feder, des Gewindes, ein paar Tropfen Tinte, was beim Nachhause gehen schon einen kleinen Schaden ausmachen konnte. Mit gutem Humor machte ich mich, so gut es ging, reine, kleidete mich um. u. jetzt hält die Feder wieder dicht. - Dazu kamen dann kleinere Ungeschicklichkeiten. Und wahrscheinlich ist es eine Folge dieser, dass ich gegen Abend in die Stimmung geriet, es sei nicht mit mir, namentlich nichts mit meiner Jurisprudenz. Ich arbeitete

dann gleichwohl, indem ich einzelne Partien der «sozialen Gesinnung» nochmals durchlas u. Kolleg präparierte. Sonst unterhielt ich mich den Tag über zwischendurch mit dem «Vicar», u. dann war von 4 1/2 bis 6 1⁄2 Uhr Frau Haenny bei Marieli, mit ihrem sechsjährigen Kurt, der ein lieber prächtiger Bub ist. 
In meiner Stimmung lag mir auch ein gestriger Ausspruch Marielis auf dem Herzen. Es verglich nämlich die Glasscheiben Müngers mit Bühlmanns Bild u. mit den meinigen $u$. meinte, der Maler habe das Charakteristische gerade verkehrt. Bühlmann sei behaglich breit $u$. ich hager, mit gerissenen Zügen, fanatisch dargestellt, wenn man tadeln wolle. Ist dies das Urteil meiner Nächsten, so hat die Scheibe wenig Wert mehr für mich. Aber es stimmt mit Marielis Charakter, dass es für diese gespannte, gehobene Stimmung die der Maler wiedergibt, gar keinen Sinn hat. Heute sprach ich wieder einmal von Colliers, u. es meinte, ob ich wieder hingehen wolle, da ich so oft auf sie zu reden komme. Ich sagte, ja, es sei doch kein rechter Plan, u. so allein sei es eine weite Reise. Darauf wurde Marieli sehr geneigt u. sagte, das kränke sie jedesmal, wenn ich daran erinnere, wie sie dort gewesen sei. Es tue ihr ja leid, dass das so gewesen. Ich entgegnete nichts, bin aber überzeugt, dass eine Reise mit Marieli nicht besser würde, als das letzte Mal. Übrigens hustet es auch heute noch, ist matt u. schläfrig u. schläft doch nicht. Es ist ein Jammer.

Frau Haenny kam mit der Violine, sie kann aber nicht viel.

Beim Abendessen machte Marieli darauf aufmerksam, dass sie mit Lisely Kleiner im Reden u. wohl auch in der Schärfe des Wesens viel Ähnlichkeit habe. Es trifft zu, wie denn überhaupt Marieli gut beobachtet.

Heute war es gerade recht warm, um sich des Frühlings zu erfreuen. Es wäre alles recht, wenn nur Du mir nicht fehltest. Anna u. Marie reden selten mehr von Dir, u. ich behalte Dich für mich. Das mache ich mit mir selber ab.

Sophie hat den Wunsch zu Anna u. Marieli geäussert, sie möchte für zwei Wochen in die Ferien gelassen werden. Das wird sich machen lassen, wenn Marieli Ferien hat. Aber wie soll ich die Ferien sonst einrichten? Dass ich mit Anna nicht versorgt sein würde, wenn sie allein wäre, das weiss ich zum voraus. Und so kann ich mit Marieli eine grössere Reise nicht machen, während doch das gute Kind auch seine Erholung 
haben sollte. Am Ende bleibe ich eben zu Hause, es täte mir auch gut, indem ich abwechselnd die Hausgenossen in ihre Ferien entliesse. Hätte ich fremde Haushaltshülfe, so könnte ich befehlen, so aber bin ich gebunden. Aber es wird auch wieder zu etwas gut sein.

Ich habe noch immer mit dem Buch nicht weiter gefahren, bin aber heute mit Abbühl zufriedener gewesen. Er wird aber auch noch etwas lernen müssen. Ist er guten Willens, so wird alles recht, $\mathrm{u}$. das muss ich nun abwarten.

Spute dich, Kronos! Wie froh bin ich für jeden Tag, der vorbei ist. Nicht dass ich jetzt mich unglücklich fühlte. Ich war im Gegenteil heute trotz der innern Zweifel heiter u. gelassen. Es gibt auf das Alter zweierlei Ausgestaltungen: Verbissene Polterer

u. gutmütige Tscholi. Ich will am Ende doch nach dem letztern ausschlagen. Man ist wohler dabei.

Und jetzt Schluss! Noch Zeitung, Cigarre u. zur Ruh! Dein ewig treuer

Eugen

1912: Mai Nr. 115

[1]

B. d. 21. Mai 1912.

Mein liebstes Herz!

Heute habe ich meine «soziale Gesinnung» Walter B. zum Abdruck in meinem Jahrbuch überbracht. Wir plauderten über dessen Herausgabe. Er meinte, er habe vielleicht doch einen Fehler gemacht, diese Publication zu übernehmen. Er sei mit dem Jahresbericht Aug. Weltis nicht überall einverstanden, werde zu einzelnem (z. B. wegen der Verwaltungsreform) Stellung nehmen müssen, Welti werde es ungern haben, wenn er seinen Ausführungen eine widersprechende An- 
merkung anfüge, u. doch könne er gegebenen Falles nicht anders. Dann gebe das Beschaffen von Abhandlungen viele Schreibereien u. er selber müsse jetzt noch einen Aufsatz etwas allgemeineren Inhaltes verfassen, etwa über die Neutralität der Schweiz. Denn was er bis jetzt geschrieben für diesen Jahrgang, über Budgetrecht, sei zu unpersönlich, zu farblos. Ich knüpfte gerade an diesem letzten Punkt an, indem ich darauf hinwies, welch schöne Aufgabe dem Jahrbuch gestellt sei, wenn es zu einer Art Führerschaft für die wohlgesinnten, echt schweizerischen Elemente werde, u. wie schön es sei, derart mit der Persönlichkeit Jahr für Jahr auf die Zeitgenossen Einfluss auszuüben. Gerade dafür aber hat Walter B anscheinend wenig Sinn, oder er stellt sich das so ganz anders vor $\mathrm{u}$. kommt vor lauter Trockenbrödlerlei zu keiner rechten Stimmung für die Sache. Immerhin wird er noch dieses u. das nächste Jahr die Herausgabe behalten, vielleicht dann auch länger. Ich sprach davon, dass ich ihm für den nächstjährigen Band vielleicht wieder etwas schreiben

werde, u. dachte dabei für mich an die «Rechtsmacht» oder «Wissenschaft u. Gesetzgebung». Aber ich will keine allzu grossen Pläne machen. Das Arbeiten wird mir ja vielleicht inzwischen ganz verleidet.

Guhl war heute in Amtssachen bei mir. Daneben weiss er immer etwas zu erzählen $u$. teilte mir heute mit, in den Kreisen der Bundesbeamten habe die Beurlaubung u. Habilitation Mutzners grossen Unwillen hervorgerufen. Das hatte sich ja auch bereits in der Bemerkung Schatzmanns oder Davids gezeigt, von der mir Mutzner selbst erzählte. Guhl sagte, Hofer, der schrecklich unbedeutende Zivilstandsmensch im Departement, hätte bemerkt, er werde jetzt dann auch Urlaub nehmen u. sich habilitieren. Er sollte es probieren! Und auch Rothplatz vom Handelsregisteramt sei unglücklich. Von Kaiser sprach Guhl heute ganz nett, er meinte, Rothplatz u. Hofer seien ihm nur deshalb über den Kopf gewachsen, weil Müller im Delacasa jeden Abend beim Bier mit ihnen, wenigstens mit Rothplatz zusammenkomme u. wenn dann Kaiser eine von den Anträgen dieser abweichende Ansicht 
geäussert, habe Müller bemerkt, er sei schon orientiert. Dann habe eben Kaiser einfach angefangen, die Anträge dieses ohne Opposition vorzulegen. Auf meine Entgegnung, dann habe also Hoffmann die Begünstigung Mutzners wohl durchgesetzt, meinte Guhl, ja, oder Müller betrachte eben doch sein jetziges Departement als eine Art Ruheposten $u$. habe eingesehen, dass er dazu tüchtiger Beamter bedürfe, wie Mutzner einer sei. Aus den hiermit gezeichneten Verhältnissen würde es sich dann auch erklären, weshalb Rothplatz, Krebs (dessen ganz minderwertiger Arbeit, Brenners unbegreiflicher BaslerGünstling) u. Hofer mit Hoffamnn sogar nicht zufrieden waren.

Krebs soll einmal zu Kaiser gesagt haben, Hoffmann verstehe vom Handelsregister einen «Dreck». Es wird sich jetzt ja etwas abklären. Merkwürdig ist es mir bei der Sache doch gegangen. Hätte ich nicht in jener Stimmung über mein Buch mit Mutzner angebunden, so hätte er den jetzigen Vorteil niemals erhalten. Und dass er nun doch nicht mit mir sich enger verknüpft $u$. im Amte bleibt, betrachte ich jetzt als eine Erlösung aus einem Zwang, der mir schrecklich geworden wäre. Also ist doch am Ende die Unbedachtheit zu einem guten Ende gekommen u. Mutzners Bleiben wird auch für mich nur vom Guten sein.

Heute Nachmittag las ich im Vicar, präparierte Kolleg, u. hatte dazwischen Besuch von einem jungen Doktor aus Kopenhagen, Dr. Wissing (Ussing), der einen Monat hier bleiben u. sich im schweiz. Privatrecht orientieren will. Der junge Mann machte mir einen recht guten Eindruck. Was mir nun freilich dabei leid tut, ist, dass ich dem Fremden keine Gastfreundschaft werde erweisen können. Ich bringe es nicht über mich. Versuche habe ich ja gemacht. Aber sie sind nicht gut ausgefallen. Mit der alten Anna geht es nicht - mit der jungen wäre es freilich auch niemals gegangen, das weisst $\mathrm{Du}-\mathrm{u}$. Anna beiseite schieben, geht auch nicht. Also lasse ich es eben bleiben, so leid es mir auch tut u. so sehr es mir schaden kann. Es ist nur darin eben ein grosser Widerspruch gegen ein solches Verhalten, dass ich ein so grosses, für Gäste einge- 
richtetes Haus habe. Allein wer weiss, wie es ist, wird mir in meinem Entschlusse doch recht geben, u. die andern geht es nichts an.

Ich schreibe diese Zeilen auf der Terrasse bei prickelndem

[4]

Regen. Es ist nicht kalt, aber doch nicht mehr die drückende Föhnluft, die wir gestern wiederum hatten. Ich bin müde u. gehe gern zu Bett. Wenn nur Marieli auch recht schlafen könnte. Es strengt sich an, recht zu tun. Vielleicht kommt doch noch ein Herzenston dazu.

Gute Nacht, meine liebe gute Seele!

Dein allzeit getreuer

Eugen

1912: Mai Nr. 116

[1]

B. d.22. Mai 1912.

Mein liebstes Herz!

Soeben war der Verleger Lichtenhahn aus Basel bei mir. Er ist Mitglied der Kommission, die unter Müllers Leitung den Entwurf eines neuen Urheberrechtsgesetzes vorberät. Ich erhielt von ihm ein Briefchen, worin er anfrägt, ob er mich einmal besuchen dürfe. Ich telephonierte ihm sofort ins National, er soll gleich heute kommen, u. so ist er erschienen $\mathrm{u}$. ich konnte die Unterredung mit ihm abhalten, an die ich schon oft gedacht, die ich aber in meinem wachsenden Ingrimm gegen die Basler immer wieder verschoben habe. Er kam sehr freundlich u. ging à la Basler. Aber ich bin doch mit dem Ergebnis der Besprechung nicht unzufrieden. Es ist nun abgemacht, dass er mir im Laufe der nächsten Wochen, wenn er nach Basel zurückgekehrt sein wird, mir einen Brief schreiben wird. Darin wird 
er mir zunächst sagen, er überlasse es mir ganz den Zeitpunkt des Beginns mit dem Druck zu bestimmen u. wolle durchaus keinen Druck auf mich ausüben. Sodann wird er mir vorschlagen, das Format zu vergrössern u. den Band auf etwa 800 Seiten anwachsen zu lassen, was mir bei entsprechender Erhöhung des Bogenhonorars auch recht ist. Damit habe ich nun wieder Luft bekommen, kann abwarten, wie sich die Dinge mit meinen sonstigen Arbeiten gestalten $u$. sehe ruhiger in die Zukunft. Das wichtigste für mich ist,

dass ich den Eindruck bekommen habe, Lichtenhahn setzt doch Wert darauf, dass ich das Buch bei ihm verlegen lasse, $u$. er will auch bemüht sein, dass ich es gerne schreibe. Also werde ich wieder mit mehr Eifer an die Sache denken $u$. die Arbeit rüstiger fördern, als die letzten Monate.

Interessant war für mich zu vernehmen, dass Lichtenhahn zuerst von v. Frisch die neueste Publikation angetragen erhalten $u$. dass er sie abgelehnt hat, weil sie Pamphletcharakter habe. Er erzählte auch, dass Nauer ihm gesagt, er habe das Mskrt. angenommen. Ich sprach mein Bedauern aus, dass dieses Schundbüchlein Heusler gewidmet sei, der könne das doch nicht vorher gekannt haben, worauf er die Achseln zuckte u. meinte, Heusler sei unglaublich scharf u. unzugänglich geworden. Es müsse schon eine senile Erscheinung darin erblickt werden. Ich sprach nochmals aus, wie ich Heusler verehre $u$. wie leid mit das tue, solches zu vernehmen. Von Wieland sagte L., dass er sehr stark durch Heusler beeinflusst sei, dass er im ganzen auch wenig umgänglich sei u. z. B. es schon abgelehnt habe, später die Ztschr. f. schw. R, zu übernehmen. Ich hatte den Eindruck, dass hienach also Wieland wirklich mit Heusler in der Schimpferei Hand in Hand gehe, nur hat er noch nicht Heuslers Autorität u. wird sie auch nie erringen. Übrigens meinte Lichtenhahn, die Urteile über Heusler werden auch in Basel immer bitterer, viele sagen, es sei bald nicht mehr zum aushalten. 
Das war unser Gespräch. Unmittelbar vor dem Besuch las ich in der Jur. Ztg. die Schrift von Frischs rezensiert von Leemann, sehr gut. Kurz abgefertigt. Auch da wird der

Pamphletcharakter des Büchleins hervorgehoben. Nun ja, es ist ja recht, wenn das erkannt wird. Aber noch besser wäre es gewesen, wenn das gar nicht vorgekommen wäre!

Duplizität der Fälle: Letzte Woche erhielt ich eines Tages eine Anfrage von meinem alten Stammheimer Schulfreund Nägeli $\mathrm{u}$. am folgenden Tag eine solche von dem alten Stammheimer Nachbar Kronauer, beides Notare. Gestern fragte mich der Däne Dr. Ussing, ob er mein Oblig. r. besuchen dürfe. Heute vor acht stand ein Berliner Rechtsanwalt u. alter Herr im Corridor, stellte sich als Martens, wenn ich recht verstand, vor u. fragte, ob er mein OR. besuchen dürfe. Er befindet sich für einige Zeit in der Klinik Dubois in der Favorita. Dieser zweite sass dann auch im Kolleg von 8 - 9 Uhr, dagegen sah ich den Dänen allerdings nicht.

Ich las auch heute wieder etwas im Vicar. Vor Tisch hatte ich ein kleines Gutachten für Borlet zu schreiben. Sonst ging der Tag schlecht $u$. recht vorüber. Marieli hatte die dritte Stunde bei Reding. Es sollte viel üben darauf, aber ich bekämpfe es so gut als möglich. Es hat ja sonst viel zu wenig Kraft, um zu tun, was es sollte, nichteinmal zum Schlafen. Oder vielmehr, das ist gerade die Quelle seiner Schwäche u. nun fing es an, Abends von $8-10$ zu üben. Natürlich hat das dem Schlaf vollends Abbruch getan. Ich hoffe aber Meister zu werden.

Nun ja, vorwärts, vorwärts! Mir ist der Schlaf jetzt wieder recht treu. Ich bin in der Nacht selten länger als ein Viertelstündchen wach u. fühle mich am Morgen ausgeruht. Ich bin auch nicht so heftig an der Arbeit u. gerade das macht mir die Arbeit möglich, solange 
sie mir überhaupt noch möglich sein wird.

Heute war Prof. Marti nicht in der Universität. Es wurde befürchtet, es sei seinem Sohn nicht gut gegangen, der seit einigen Tagen an hohem Fieber darnieder liegt. Marti hat mir gegenüber die Sache so unbedeutend als möglich hingestellt. Weshalb, glaube ich zu wissen. Steck meinte, der Sohn sei totkrank. Aber vernommen habe ich noch nichts über den weitern Gang der Krankheit.

Innigst, innigst, meine Seele, grüsse ich Dich u. verbleibe

Dein allzeit treuer Eugen

1912: Mai Nr. 117

B. d. 23. Mai 1912.

Mein liebstes Herz!

Heute erhielt ich mit der Morgenpost die erschütternde Nachricht vom Tode der Frau Oser! Sie starb vorgestern früh, ein Uhr, nach einer kurzen schweren Krankheit im Alter von 42 Jahren. Ich weiss noch nichts näheres, aber der Fall hat mich in eine aufregende Gedankenwelt versetzt. Oser muss das erleben, in dem Augenblick, da er am Ziel seiner Bestrebungen angelangt $u$. im Begriff ist als Bundesrichter nach Lausanne zu übersiedeln! Man hat vor Jahren einmal uns gesagt, Oser lebe mit seiner Frau nicht mehr in Frieden, sie seien uneins u. er behandle sie nicht schön. Mag sein, dass allerlei Differenzen in der Familie, da die Knaben noch klein waren, bestanden haben, u. zwar gewiss, wenn es so ist, nicht ohne Schuld seinerseits. Denn er ist ein schwieriger Charakter mit viel unnötiger Schärfe u. einer Neigung zu Taktlosig- 
keiten. Mag das so oder anders gewesen sein, in der Zeit der letzten Jahre hatte ich immer den Eindruck, ihr gutes Herz, ihre nachsichtige, duldende Frömmigkeit hat gesiegt. Schon wie sie uns Besuch machten, in den letzten Jahren vor Deinem Hinschied, bekamen wir beide die Auffassung, es sei eine Aussöhnung eingetreten. Ich vergesse nie den dankbaren Blick, den Frau Oser Dir u. mir zuwarf, als Du ihr die paar Sächelchen übergabst, darunter eine geweihte Kerze, die wir aus Loretto für sie mitgebracht hatten. Und wie ich im November letzthin dort war,

sowie auch bei dem kurzen Besuch von Mitte März, da ich sie zum letzten Mal gesehen haben sollte, schien mir mit den beiden lieben Knaben eine neue Liebe auch unter den Eltern emporgewachsen zu sein. Die armen Kinder, wie wird ihnen diese liebe gute Mutter fehlen! Der Vater ist rauh mit ihnen. Der Jüngste, Wolf, schien in seiner zarten Art besonders mit der Mutter verwachsen zu sein. Sie redete so lieb mit ihm; u. er erwiederte immer bescheiden u. folgsam. Nun hat er diese Sorge nicht mehr über sich. Das Leben wird ihn rauher anfassen. - Der Haushalt der Frau Oser machte Dir früher keinen besonders guten Eindruck, weil die Wohnung nicht sauber u. manches nachlässig gehalten war. Man findet dies ja häufig in katholischen Familien. Doch war auch das in den letzten Jahren besser geworden. Und nun ist alles zu Ende! Ich denke mir für Oser die Lage ähnlich, wie wenn du mir schon in Basel entrissen worden wärst $u$. ich allein hätte nach Halle ziehen müssen. Ob Oser selbst in seinem Jammern so arg mit seiner Frau verbunden war, weiss ich freilich nicht, das wird sich jetzt zeigen. Natürlich hatte ihre bescheidene Begabung auch nicht das innige Band unter ihnen in der Arbeit u. in dem ganzen, gesamten Leben begründen können, wie es uns zusammen verbunden hat. 
Der Tag war sonst heute ein rechter Besuchstag, Regenwetter $u$. Wind dazu. Vor Tisch kam Guhl mit einigen Fragen, sehr recht. Um zwei erschien Weger vom Schauensee, der sich angekündigt hatte, u. zwar

extra hergereist, nur um mir Besuch zu machen. Ich begriff das anfänglich nicht. Dann aber im Gespräch zeigte es sich, dass er in seinem wissenschaftlichen Ruf verletzt durch die Nichtwahl als Obergerichtspräsident offenbar durch einen Besuch bei mir sich beruhigen wollte. Er sprach sehr anerkennend von dem Gesetzbuch, wusste über Walter, Nat.rat, Zelger u. Sigrist, alles meine alten Schüler, allerlei zu erzählen, wie ich selbst auch einiges ihm mitteilen konnte. Er wünschte, dass ich doch Walter gelegentlich (wenn er demnächst als Nationalrat nach Bern kommt) sagen möchte, Weger sei doch kein Pamphletist, wie er sich geäussert haben soll, u. das will ich gerne besorgen. Nun waren mir einige Müsterchen von Stoossers Hochmut gegen Gretener, aber das sind jetzt alte Geschichten! Es wurde vier Uhr bis Weger von Schauensee mich verliess. Er schien etwas getröstet zu sein. Merkwürdig berührt hat mich seine Mitteilung, dass seine Gegner die Abwesenheit Wegers - er musste wegen eines Armbruchs in den Sitzungen einige Zeit fehlen - benutzt hätten, um nach dem Entlassungsgesuch Häfligers ihn, Weger, obgleich er Vizepräsident gewesen, stillschweigend übergangen u. den zwanzig Jahre jüngeren Müller zu dem Amte gewählt hätten. Darin glaubte Weger eine Intrigue zu erblicken, bei der eben auch Walter mitgewirkt habe.

W. v. Sch. war noch nicht fort, so kam Nat. rat Grand u. consultierte mich in einer Rechtssache. Und dieser war noch bei mir, als der Stud. Jost erschien, der Verfasser 
der schauderhaften Dissertation u. der unglückliche Begleiter Helen Baumgarts. Er will die Dissertation umarbeiten. Von dem Unfall am Generoso hat er nur ein Neues mir erzählt: Er sei mit ihr, wenige Hundert Meter vom Hotel entfernt gewesen $\mathrm{u}$. auf ein etwa $20 \mathrm{~m}$ breites Schneecouloir etwa $5 \mathrm{~m}$ vorgeschritten, als der Absturz erfolgte. Aber er habe nicht "gedurft» über die Absturzstelle zurück zu schreiten, sondern sei über das Schneeband u. den Fussweg talwärts geeilt, bis er nach etwa einer halben Stunde einen Mann angetroffen, der dann nach einem anderen gerufen. Und dann seien sie auf die Suche der Abgestürzten gegangen. Diese offene Erzählung besserte meinen Eindruck von dem jungen Mann.

Und nun Schluss für heute. Ich präpariere noch das Kolleg u. lese etwas. Dann Schlafnacht. Der Rechtsanwalt Munk (so heisst er) aus Berlin war heute nicht im Kolleg. Gute, gute Nacht! Dein ewig treuer Eugen

Ich sandte Oser mit einem Condolenzbrief eine $\mathrm{Ab}$ schrift der Verse Rückerts «Ein Apfel fällt vom Stamm in seines Gärtners Hand.» - im Andenken auch an Wasserrab. 
B. d. 24. / 5. Mai 1912.

Liebstes Herz!

Walter B. ging heute auf 8 Uhr nach Freiburg zur Beerdigung von Frau Oser. Er erzählte, die Buben u. Oser selbst seien gefasst gewesen. Aber die ganz katholisch ceremonielle Weise habe es nicht ermöglicht ein Wort mit Oser zu sprechen, abgesehen von Gruss u. Üblichem. Marieli meinte, wahrscheinlich werde Oser jetzt noch hässiger. Ich befürchte es auch, er wird wohl seine Buben in ein Institut schicken.

Heute war der Berliner, Markus heisst er, im Kolleg, nachher holte ich die Hauptrate der Kollegiengelder, die grösste Summe, die ich je bezogen, 5751 Fr. in einem Semester u. nur als Hauptbetrag. Jenny meinte, ich habe nun alle andern ausgestochen. Kein Professor habe in diesem Semester ein höheres Kollegiengeld. Ich spürte daraus, wie Vorwurf oder Missgunst, machte mir aber nichts daraus. Ich ging zur Bank, dann auf die Bibliothek, wo ich v. Mülinen endlich wieder einmal traf. Am Nachmittag, wie ich eben ins Praktikum wollte, kam der Pariser Ramadier, der sich für Rossels Nachfolge angemeldet hat. Schade, der Mann gefiel mir, aber die Anmeldung Folletêtes lässt sich ja nicht übergehen, was ich Ramadier auch andeuten musste.

Sonst war der Tag ruhig. Meyer v. Sch. schrieb mir über die gestrige Unterredung noch eine Dankkarte wahrhaft rührend. Was mag der Grund sein? Innere Zweifel, die ich

ihm abschwäche? Wenn nicht noch irgend ein Zweck hervortritt, so freut es mich, dass die Freundlichkeit sich wirklich aus eigenem Bedürfnis erklärt. 
Marieli war endlich heute bei Frau Guhl u. kam mit einem herzlichen Eindruck von Frau u. Kindern zurück. Es freut mich, wenn es der guten Frau etwas sein kann.

Und nun bin ich müde, sehr müde. Ich werde die Pfingsttage wohl am liebsten ruhig zu Hause bleiben, etwas Arbeit dabei u. sonst Ruhe. Die tut mir gut. Es kann sein, dass auch etwas Schnupfen im Anzug ist, u. dass ich daraus die Müdigkeit verspüre. Oder es ist das Ende der Woche, die mit dem grossen Auditorium doch sehr anstrengt. Also lasse ich für heute das Schreiben bleiben, in der Hoffnung, dass es morgen besser gehen werde.*

Den 25. Mai.

Heute, dem Vorabend vor Pfingsten, hatten wir den ganzen Tag Regen u. kalt. Man war gern zu Hause.

Ich musste Fürsprech Sassler eine Consultation geben, der mich über ein Gutachten interpellierte, das ich vor etwa vier Jahren seiner Gegenpartei, deren Anwalt Brüstlein, in einer Stellvertretungssache erteilt. Ich konnte meine damals vertretene Meinung aufrecht erhalten, wies aber eine Honorierung für diese sonderbare Inanspruchnahme entschieden zurück. - Dann präparierte ich neue Praktikumsfälle, wobei mir Deine Schriftzüge durch die Hände gingen $u$. mich an all das Schöne der früheren Zeit *Beim Gang auf die Universität traf ich Lohner, der mir aus freien Stücken erklärte, er werde jetzt Guhl befördern.

erinnerten. Sonst las ich gemächlich Zeitungen u. las im

Vicar, machte mich auch an Schachprobleme, u. so ist der Tag

still vorüber gegangen, ein Ruhetag. Ich hatte ihn nötig.

Von Lisly Kleiner ist die Verlobungsanzeige, mit dem

jungen Kaiser aus Burgdorf eingelaufen, der wie es

scheint in Bözingen angestellt ist. Auch das eine Erinnerung.

Jene vier Monate waren doch recht sonderbar. Es ist gut, dass sie nun einen Zusatz finden, der über Manches dauernd hinweg hebt. 
Ich denke heute endlich auch daran, wie ich eine Zeit lang es mir zur Pflicht mache, über Pfingsten einen Ausflug mit dem ganzen Haus zu machen: Die Fahrt nach dem Eismeer, mit Auguste, war die erste solche Gelegenheit. Dann war ich zweimal durch Sitzungen der Psychiatergesellschaft gerade über Pfingsten in Anspruch genommen. Aber darauf folgten der Ausflug nach der Taubenschlucht u. Magglingen, die Tour nach Beatenberg u. Amisbühl, der Ausflug nach Kiental u. nach den Pochten-Fällen mit der Heimkehr über Aeschi, das einzige Mal, wo wir über Nacht auswärts blieben. Dann der schöne Weg über Mürren u. Stechelberg, darauf die Fahrt von Zweisimmen nach Bulle, letzter beide mit Kathri, u. zuletzt noch ein Jahr vor Beginn meiner Einsamkeit der Besuch von Solothurn u. der Einsiedelei. Es waren schöne Tage, so mitten aus dem Semester heraus, u. wir haben

immer mit Liebe daran gedacht. Ich glaube halb u. halb diesmal wieder etwas ähnliches zu unternehmen, etwa auf den Weissenstein zu fahren. Aber ich bringe mich nicht zu dieser Fortsetzung, die mich ja doch nur an die Einsamkeit erinnern müsste, in der ich lebe. Jetzt scheint schon das Wetter alle solche Gedanken nieder zu schlagen, was mir um Marieli willen recht ist. Freilich wie viele legitime Freude wird durch diesen Regen zerstört.

Sophie hätte jedenfalls nicht mitgekonnt. Wegen ihres Buben, der übrigens ein ganz munteres frisches Bürschchen wird $u$. viel gesunder aussieht als früher. Eben jetzt, bevor er zu Bett muss, singt er, in ganz richtigen Melodien, einige Liedchen. Sophie wünscht den Sommer Ferien. Es ist etwas anmassend, sie hat es auch mir nicht zu sagen gewagt. Soll ich ja sagen? Ich weiss es noch nicht.

Am Montag ist Ausflug der Männer Helvetia. Ich werde nicht hingehen. Ich kann nicht, u. das Verhältnis zu Abbühl ist mir noch zu wenig abgeklärt. 
Damit schliesse ich den Ruhetag. Vorwärts, damit die Zeit vorüber geht. Ich las heute in Goldschmith, wenn auch der Umgang mit Menschen dem Unglücklichen verloren gehe, so bleiben ihm doch die Bücher, um das Leben wenigstens erträglich zu machen. Und mir, mir ist vor allem die Erinnerung geblieben!

In innigster Liebe

Dein allzeit treuer

Eugen

1912: Mai Nr. 119

[1]

B. d.26. Mai 1912.

Mein liebstes Herz!

Es war eine stille Pfingsten, die ich heute in meinen vier Wänden verbracht habe. Walter B. kam am Vormittag zu einer Plauderstunde u. ich war recht erfreut. Wir konnten manches besprechen, was uns beide interessierte. Vorher schrieb ich ein kleines Gutachten für das Departement, das ich mir über Nacht zurecht gelegt hatte, $u$. beantwortete eine Einladung von Thormann auf nächsten Freitag Abend, u. zwar ablehnend. Ich hatte den richtigen Grund dazu in dem Umstand, dass ich Abends überhaupt nicht mehr in Gesellschaft gehe (mein Alter gibt mir das Recht dazu, mich hierauf zu berufen), überdies aber fand ich es auch merkwürdig, dass Thormann mich eingeladen hat, ohne mich vorher einmal mit seiner Frau zu besuchen. Ich kenne sie gar nicht. Dann las ich den ganzen Tag im Vicar. Das Buch, das ich bis jetzt nie ganz gelesen, fesselt mich sehr. Es ist mit Recht berühmt. Ich finde darin eine in vielen Beziehungen auffallende Parallele zu Manzonis Promessi Sposi, u. zwar nicht wegen des Frauenraubes, sondern in der Schilderung von Zuständen, über die wir nun 
doch Herr geworden sind. Unsere Ungerechtigkeiten haben einen anderen Charakter als die hier gezeichneten. Es ist doch besser geworden mit dem demokratischen

Geist. Die soziale Gesinnung ist stärker, der Egoismus kleidet oder verkleidet sich in anderen Formen. Sehr bewegt hat mich die Zeitungsmeldung, wonach Olivetti, der [A?] Bertonis, wegen des früher erwähnten Artikels in der Luganeser Zeitung Giornale d'Italia nun richtig vom Bundesrat aus der Schweiz gewiesen worden ist. Nicht dass ich diese Ausweisung nicht für gerechtfertigt halten würde. Allein es ist der erste Fall, wo die öffentliche Gewalt wegen der Gefahr für die nationale Einheit der Schweiz derart einschreiten muss. Das ist ein Symptom u. zwar beängstigend. Das kann sich in Genf, oder im Tessin wiederholen $u$. dann werden wir Mühe haben, diesen Gewalten zu wehren. Der Tag war sehr still. Über Tisch brachte Marieli das Gespräch auf die Ferien u. hätte gern erfahren, welche Pläne ich habe. Ja, ich glaubte vor einigen Wochen, welche zu haben, aber jetzt sind sie mir wieder ganz entschwunden. Ich mag nicht allein an einen eigentlichen Kurort gehen, ich mag auch Marieli nicht an einen solchen mitnehmen $u$. Anna mit Sophie längere Zeit allein lassen. Marieli allein in die Berge schicken u. eine Reise ans Meer, an die Nordsee, in die Bretagne, nach England reisen, das darf ich dem Kinde gegenüber nicht wagen, u. es dazu

mitnehmen, widerstreitet seinen innersten Wünschen. Es wird mir immer deutlicher, dass ich mich mit meinem Haushalt in einer fatalen Lage befinde. Was will ich machen mit der alten Schwester, die ja ihr möglichstes tut, trotz Anfällen von böser Gesinnung, die Du ja reichlich kennen gelernt hast. Die Sorge um mich, um das Haus, 
um den Tisch nimmt immer mehr ab, u. es keine Einsicht dafür vorhanden. Ich kann es nur spüren. Solange Anna da ist, wird es nicht besser. Neben Marieli kann ich nicht noch eine Hülfe ins Haus nehmen, u. Marieli hat so wenig Sinn für das Wohlsein, weder seiner selbst noch des Hauses. Nun ja, es ist mir heute nur wieder mehr zum Bewusstsein gekommen, weil ich den ganzen Tag zu Hause war. Ich will mich ja darein schicken u. werde nicht oft mehr darüber schreiben. Auch Kleinigkeiten kleinster Art, wie die Ferien Sophies, hätte ich nicht nochmals erwähnen sollen. Es ist wirklich nicht der Mühe wert. Ich muss jeweils nur meine Gedanken auf wirkliches äusseres Ungemach richten, auf Krankheit, Lähmung u. dgl., auf die abnehmende Arbeitskraft $u$. was sonst in meinem Alter zu fürchten ist, so darf ich es ja niemandem sagen, dass mein Gemüt nicht heiter. Denn von alle dem bin ich ja bis jetzt verschont geblieben, habe umgekehrt in diesem Semester in den Kollegien den höchsten äussern Erfolg

meiner doch schon recht langen Dozentenlaufbahn. Also dann, munter, grad auf, u. auch mit Marieli wird es schon besser werden. Ich vertraue darauf. Die Ferien aber bleibe ich vielleicht zunächst ganz zu Hause, um dann eher im September mir noch eine Reise ins Ausland zu gönnen. Doch sei auch dieses noch kein Plan, man weiss ja gar nicht, ob man es erlebt. Pfingsten, der Tag war ohne Regen, aber mit bewölktem Himmel u. kühl. Wir wären zu Hause geblieben, wenn Du noch bei mir wärest. Und morgen werde ich auch nicht zu den Helvetern gehen. Es würde mir schwerlich gut bekommen.

Gute Nacht, meine einzige Liebe, an die ich mich noch halten kann! Ich bleibe mit innigem Kuss

Dein in Ewigkeit!

Eugen 
B. d. 27. / 8. Mai 1912.

Mein liebstes Herz!

Heute um acht überraschte mich Abbühl in vollem [?] mit seinem Besuch. Er wollte sehen, ob ich doch den Pfingstausflug der Männer Helvetia mitmache. Es war nämlich ein heiterer Morgen. Allein ich war schon am Zeitschriftenordnen $u$. hatte mir die Arbeit sonst zurecht gelegt, so dass ich versagte. Ich habe dann auch den ganzen Tag an der Dissertation Zehnders gelesen, die nicht übel ausgefallen ist, aber solchen Umfang hat, dass ich noch einige Tage darauf werde verwenden müssen. Diese Dissertationen sind mir eine grosse Plage. Aber ich habe ja meine guthonorierte Stellung dafür. - Zu Besuch kam niemand als Frau Ringier, die mich auf Donnerstag in acht Tagen zum Mittagessen mit Bühlmann einlud. Ich konnte nicht nein sagen, aber die Sache ist mir lästig. Bei dem Besuch, wie immer von Frau Ringier ein Neues, erfuhr ich, dass Frau BRat Welti, 85 Jahre alt gestorben ist. Frau Dr. Welti soll eben auf der Heimreise aus Karlsbad sich befinden, wo sie keine gute Kur gemacht habe.

Sonst war ich also im ganzen, nicht schönen, aber freundlichen Tag, Pfingstmontag, zu Hause, sehr zum Schmerz von Marieli, das dann allein noch etwas spazieren ging. Es soll ein grosses Trubel in den Strassen $u$. Wegen gewesen sein. Alles hatte ja frei, $u$. bedurfte nach den letzten kalten

Regentagen besonders der frischen Luft. Mir kam die Ruhe sehr gelegen, um die Rückstände nachzuarbeiten. Ich befinde mich übrigens auch sonst ganz u. gar nicht in der Stimmung, unter die Leute zu gehen. Ich muss fast fürchten, das werde krankhaft bei mir. Ich spüre allerlei Groll u. 
Spott aus dem was gesagt wird, auch wenn ich mir sagen muss, es ist nicht so. Allein das hatte ich ja von jeher so. Es fehlt mir jetzt nur die süsse Gelegenheit, mit einem verständigen Herzen darüber zu sprechen, wie ich das bei Dir so herzlich gewöhnt war. Anna versteht nichts u. könnte einen, wenn man auf sie etwas gäbe, furchtbar hineinreiten. Marieli ist zu jung, so sehr es das Talent hat, Personen in ihren psychischen Eigenschaften zu erfassen.

Heute habe ich den Vicar fertig gelesen. Der Schluss ist ganz u. gar nicht auf der Höhe Manzonis. Was hier von Theatercoup, Zufall u. Unwahrscheinlichkeit geleistet wird, ist grossartig. Der Autor spürt es auch selber u. will sich entschuldigen. Er drängt aber zum Abschluss, u. in sofern auch seine wenig befriedigende Manier ihn zu finden ergreifend, als er alles von weither auf eine solche Schlussenthüllung vorbereitet hat. Es war eben auch eine Zeit, die anders gefühlt $u$. gedacht hat.

Damit schliesse ich diese Pfingstzeilen $u$. bin wie immerdar Dein getreuer

Eugen

Den 28. Mai.

Marieli war heute, schon gestern Abend vor Schlafengehen, überreizt, es schläft nicht, isst nicht, u. wenn es isst, riskiert es gleich wieder Verdauungsstörungen. Die Klavierstunden bedrücken es, u. doch will es sie nicht aufgeben, aber dann doch wieder die Stunde von morgen aussetzen. Ich hatte ihm so sehr abgeraten, diese weitere Bürde mit Stunden bei Reding auf sich zu nehmen. Ich weiss nicht, was aus allem dem noch wird. Und doch ging es heute auf vier zu Besuch zu Frl. Reineck, wenngleich es beim Fortgehen sagte, es fühle sich unendlich müde, u. nach dem Nachtessen will es zu Flora Reber, obschon ich ihm beide Besuche widerraten habe. Ich muss mich in die Weiterentwicklung fügen. 
Von Abbühl veranlasst, sandten mir etwa 30 Helveter einen Gruss von Diesbach. Das ist recht, wenn ich nur mit den Arbeiten Abbühls zufriedener wäre. Ich habe seine Auszüge jetzt durchgangen. Einige haben kindliche Fehler, andere sind ganz unübersichtlich. Ist es wirklich nur seine Jugend, die ihn verhindert besseres zu leisten? Und wenn es Untüchtigkeit sein sollte, wie würde ich mich mit ihm ablösen können? Ich dachte, ihm bei Antritt seines Militärdienstes zu sagen, er werde nach seiner Rückkehr, vom November an, besser die ganze Zeit der Vorbereitung für das Maturitätsexamen widmen, aber ich hoffe, es komme doch nicht zu dieser Auflösung. Ich könnte glauben, dass die Beobachtung, dass ich nicht so zufrieden sei, auf Marieli eingewirkt. Allein das kann es nicht sein, weil die gleichen Störungen schon vorhanden waren, als ich meine volle Zufriedenheit äusserte. Es bestreitet auch entschieden,

dass meine gelegentlichen geäusserten Zweifel auf es von Einfluss gewesen sein könnten, was ja mit dem, was ich betr. dem Bruder Tecklenburgs u. Siegwart früher geschrieben, ganz übereinstimmt. Aber das alles ist so mühsam, neben der alten, untüchtigen Anna!

In solcher Stimmung habe ich heute früh Frau Ringier nachträglich doch abgeschrieben. Ich kann u. mag nicht in Gesellschaft gehen.

Den ganzen Vormittag las ich in der mässigen Dissertation Zehnders weiter $\mathrm{u}$. bin nun über die Mitte gekommen, sie ist annehmbar. Dann war Hafner i. S. Gutachten Nationalbank bei mir. Am Nachm. las ich etwas Rechtsphilosophisches u. präparierte mich für morgen, wieder auf der Terrasse. Es ist wärmer geworden.

Die Abendpost brachte mir ein Geschenk der Standeskommission von Appenzell IRH., das Dir Freude gemacht hätte: ein Kissen mit feinster Handstickerei. Was soll ich damit anfangen? Es gehört in mein Trophäen-Schränklein. 
Endlich bemerke ich noch, dass Marieli von Frl. Reineck spät, aber heiterer zurückgekehrt ist. Ich harre jeden Tag der Wendung zum bessern. Ich bin doch nicht so ungrad, dass ich etwas Gutes nicht erkennen u. liebhaben könnte? Hilf mir!

Doch nun noch Abendpost u. dann zur Ruh!

Ich bin immerdar als treuer Kamerad

Dein

Eugen

\section{2: Mai Nr. 121}

B. d.29.Mai 1912 .

Mein liebstes Herz!

Die Frequenz unserer Fakultät ist wirklich sehr gestiegen. Also kommt meine Steigerung in den Collegien von daher. Wir haben jetzt, vorläufig gezählt, etwas über 500 , u. wenn auch etliche davon noch werden gestrichen werden müssen, so bleiben doch genug, um den Sprung zu verdeutlichen, den wir in den zwanzig Jahren gemacht haben, wo ich das Semester mit 102 immatrikulierten Juristen antrat. Hätten wir auch die Ausländer, die Exoten, wie vor sechs Jahren, hätte man diese nicht verdrängt $u$. nach Zürich u. Genf getrieben, was ja übrigens wohl begründet war, so würden noch etwa fünfzig mehr sein. Wir sind jetzt die stärkste Fakultät an der Hochschule. Das ist natürlich sehr schmeichelhaft, u. man sollte sich darüber freuen. Aber es will mir nicht recht gelingen. Kleiner hat in seinem letzten Brief geschrieben, es begleite all sein Tun beständig ein Unterton der Gedrücktheit. Ist das eine Alterserscheinung? Freilich ist ja bei mir Grund zu dieser Gedrücktheit Genüge vorhanden. Ich mag nicht wiederholen, was ich meine. Es ist ja doch immer die alte Klage, dass es zu Hause nicht recht klappen will. Der Abstand zu früher ist eben für mich zu gross um so leicht getragen werden zu 
können. Die Absage haben mir übrigens Ringiers nicht übel genommen. Sie waren ganz recht mit mir, als ich sie heute bei der Kremation von Frau Bundesrat Welti traf. - Die Feierlichkeit war sehr einfach. Hadorn spracht die Abdankung, süsslich, aber im Inhalt recht. Man begegnete vielen Bekannten. Ich konnte Emil Welti die Hand drücken. Frau Emil Welti sah schlecht aus. Frau BRat Welti wurde 85 Jahre alt, sie war zwei Jahre jünger als ihr Mann, u. hat ihn um 13 Jahre überlebt. Sie war seit 53 verheiratet, also 46 Jahre. Von den Kindern sagte der Bericht nichts, wohl um nicht der schweren Geschichten mit der Tochter Mathilde irgend gedenken zu müssen.

Sonst war der Tag heute wieder einer von denen, wo mannigfaltige Arbeit einläuft, die mich lange in Atem halten u. mir eine Beschäftigung mit Grösserem ganz unmöglich machen wird. Am Morgen nach dem Kolleg war Burckhardt bei mir, der von dem Vortrag in Erstfelden her gedrückt zu sein schien. Doch hat der «Bund» heute Abend dann einen sehr netten Bericht gebracht, der ihn wohl trösten wird. Es hat so was zutrauliches zu sehen, wie Walter B. allemal, wenn es ihm schwer ist, zu mir kommt, das ist trotz allem doch die gute Anlage zur Freundschaft. Dann war

Guhl da, in wichtigen Amtssachen, die uns bis gegen ein Uhr beschäftigten. Den Nachmittag konnte ich neben dem Leichenbegängnis nur noch Kolleg präparieren u. etwas an einer Einfrage arbeiten, die zum Rechtswörterbuch ergangen ist. Und nun haben wir wieder Abend. Mit Abbühl habe ich heute in einigen kurzen Sätzen gesprochen: Er dürfe niemals mehr etwas schreiben, was nicht für ihn einen Sinn habe, das sei Schülerarbeit u. zwar schlechte, u. seiner nicht würdig. Er nahm es aber recht auf u. schien durchaus die rechte Auffassung zu haben. 
Das würde mich freuen, denn die Empfänglichkeit für Tadel ist das beste Zeichen von Verstand.

Walter B. sagte mir heute, er hätte in Erstfelden einen Einblick getan in die ultramontane Herrschaft, was man ihm da erzählt habe! Wie eine Lehrschwester, als ein Sittenvergehen an einem Mädchen vorgefallen, die Schülerinnen ermahnt habe, nie von einem Mann sich nebenaus locken zu lassen, mit dem Zusatz: und nie einen Protestanten zu heiraten, u. dgl. Aber Walter ist sehr vorsichtig, u. er will ja nichts unternehmen, was Kultur kämpferisch aussehen würde.

Ich spüre doch recht angenehm die paar Tage Ruhe. Wenn nur nicht wieder gleich viel Nebenarbeit eingelaufen wäre! Nun ja, man arbeitet daran, was man mag,

u. dabei ist jedenfalls eines ja sicher gewonnen: Die Zeit geht vorüber u. zwar in Mühe u. Arbeit. Gute Nacht, mein einziger Schatz! Ich bin immerdar Dein treuer Eugen

1912: Mai Nr. 122 B. d. 30. / 1. Mai 1912.

Mein liebstes Herz!

Ich beschloss heute, die Musik, die mir Teichmann zugestellt u. Reichels Cantate zurückzusenden. Marieli spielt beides ja doch nicht, u. was soll ich mich weiter ärgern, sie herum liegen zu sehen? Marieli hat ohne Protest beides zur Post getragen.

Und dann arbeitete ich an Aufzuräumendem. Eine Abschrift, die Abbühl machen musste, war wieder flüchtig. Es scheint eben doch, dass er sich zum Secretär nicht recht eignet, weil er sich wohl 
zu hoch denkt. Sollte dies sich wirklich erweisen, so wäre ich bald entschlossen. Ich habe noch bis Ende Juli Zeit darüber Erfahrungen zu sammeln.

An der Dissertation konnte ich wenig arbeiten, nur ein Kapitel weiter lesen, es ist nicht besser als die früheren.

Ich schrieb mehrere Briefe, erledigte auch die Drucksachen des Rechtswörterbuches, was mir ziemlich Zeit weggenommen.

Dann hatte ich Besuch von Siegwart, der sehr nett war, darauf von Guhl, dessen Frau mit den zwei herzigen Kleinen beim Kaffee da war, u. endlich kam nach dem Nachtessen noch der junge Teichmann. Obschon er etwas ungelegen kam, ergriff ich doch die Gelegenheit, ihm von Ausdauer zu sprechen, eine Erwähnung, die vielleicht nicht unnütz u. nutzlos ist.

So ging der Tag rasch vorüber, u. die schnelle Arbeit

verbesserte meine Stimmung, sodass ich jetzt wieder gelassener bin. Alles kann ich nicht gerade machen. Also vorwärts in dem, was man ist u. kann.

Morgen ist Ausflug der Helveter u. Marieli mit Abbühl zusammen. Es wird sich aber, nach dem was ich ihm sagte, in Acht nehmen.

Die Rekruten schlagen den Zapfenstreich, u. ich will auch meinerseits schliessen. Was werde ich Dir morgen zu berichten haben?

\section{Den 31. Mai.}

Ich glaubte heute recht munter zu sein, $\mathrm{u}$. habe im Morgenkolleg mit fast zu grossem Eifer vorgetragen. In der Pause kam der Berliner Marcus (wie es scheint, Vorsitzender einer Handelsgerichtsabteilung) zu mir im Corridor u. machte mir einige Elogen, fragte mich, weshalb ich nicht diese Vorträge publiziere etc. Nach der Vorlesung war ich bei Mülinen zum üblichen Besuch, auch angeregter als sonst. Auf dem Heimweg traf ich noch Abbühl, dem ich seinen ersten Lohn auf den Tisch 
gelegt hatte. Er bedankte sich u. meinte, er hätte das

Geld für seine Anfängerleistungen eigentlich nicht verdient, worauf ich nichts bemerkte. Dann schrieb ich Briefe, wir assen früher, weil Marieli auf 12 3/4 zur Maifahrt der Helveter von Abbühl abgeholt werden sollte. Dann aber warteten wir, bis $1 \frac{1}{4} \mathrm{Uhr}, \mathrm{u}$. inzwischen ging ich im

[3]

Zimmer auf u. ab u. Marieli stand da in weissem Kleid u. grossem Hut. Der rote Fleck am Parquet der Stube, von Annas Weinmaleur herrührend, dem seit drei Monaten niemand recht auf den Leib rückt, ärgerte mich mit jedem Schritt mehr, u. als endlich Abbühl kam, war ich froh, die beiden jungen Leute nur aus den Augen zu haben. Kaum war ich dann auf dem Zimmer u. allein, so zerbrach ich etwas, u. dann klingelte Frida Weber, ich möchte doch zu ihrem Vater kommen, er hätte mir etwas wichtiges zu sagen. Ich lehnte wegen des Praktikums zuerst ab, wie ich dann aber mit der Präparation fertig war, so litt es mich doch nicht, u. ich eilte nach drei Uhr an die Bundesgasse. Weber war sehr reduziert, zu sagen hatte er mir gar nichts, es war nur das Verlangen gewesen, mich wieder einmal zu sehen. Ich blieb bis gegen vier Uhr, hielt dann ein gut besuchtes $u$. sehr angeregtes Praktikum u. eilte nach Hause, wo ich um Einlass klingeln musste. Die Post brachte mir darauf vier Anfragen, die ich sofort beantwortete, $u$. jetzt ist es dunkel geworden u. der Tag vorüber. Marieli wird nun in dieser Stunde auf der Fahrt von Laupen nach Oberried sein, ich weiss nicht, weshalb, aber ich sah sie diesmal am wenigsten gern in der Sache. Kann sein, dass meine Bedenken betr. Abbühl mich in etwas andere Stimmung versetzt haben.

Ich war trotz der Aufregung heute innerlich müde. Walter B. den ich traf, sagte dasselbe, u. ebenso Reichsberg. Und doch 
stehen uns noch acht Wochen strengen Dienstes bevor.

Ich schicke mich drein, aber fühle mich leer dabei. Was wird Marieli morgen zu berichten haben? Launisch ist es gar nicht, aber verschlossen kann es sein. Morgen will es bei Frau Dr. Jauch u. Siegwarts einen Besuch machen. Claire Siegwart ist da.

Und nun will ich weiter gar nichts schreiben, sondern zur Ruhe gehen. Die wachsende Ungemütlichkeit in unserem Hause kann ich nicht bannen, ich kann sie nur verschlafen u. schliesse am besten die Augen.

Halte Du fest zu mir, sei meine Hülfe, meine Hoffnung, die Liebe kann alles!

Innigst bin ich immerdar

Dein alter treuer

Eugen 


\section{Juni 1912}

\section{2: Juni Nr. 123}

B. den 1. Juni 1912.

Meine einzige Liebe!

Ich habe heute es sehr nötig, an Dir einen Halt zu suchen, denn ich war den ganzen Tag in sehr schwerer Stimmung. Es hielte mir schwer, einen Grund für diese Schwere anzugeben, als eben die ganze Umgebung, an der ich immer u. immer neu dich vermisse. Anna wird von den vielen Widerwärtigkeiten mürrisch, Sophie hat nicht immer den richtigen Willen, u. Marie ist noch so jung, so unerfahren. Mir tut nur wohl, zu sehen, dass sie Verstand, sehr viel Verstand hat, u. daraus lässt sich doch einige Hoffnung ziehen. Ihre Seele ist eben anders gerichtet, als ich gewohnt bin u. mir lieb wäre. Allein am Ende kann auch hierbei etwas Gutes herauskommen. Ich bin denn auch den Abend gefasster als über den Tag. Es wird mit Deiner Hülfe doch endlich besser werden.

Ich war eben aufgestanden, als Marie von der Maifahrt heimkam, in Anbetracht der durchtanzten Nacht merkwürdig frisch. Es erzählte, dass es viel mit Hodler zusammen gewesen sei, der prachtvoll Klavier gespielt habe. Von Abbühl scheint es weniger Eindruck bekommen zu haben. Jedenfalls hat eine Annäherung nicht stattgefunden, u. das ist mir jetzt die Hauptsache, denn meine Zweifel in 
die Tüchtigkeit Abbühls sind ziemlich lebhaft geworden, er ist doch gar zu flüchtig u. zu selbstvertrauend. Siegwart war ungleich tüchtiger. Auch scheint es mir, dass Abbühl Secretärdienste nicht gerne besorgt, $u$. das wäre für mich aber doch die hauptsächlichste Entlastung. - Ich las dann am Morgen in Zehnders Dissertation weiter, die mich je länger je weniger befriedigt, sodass ich sie wohl zur Verbesserung zurückgeben muss. Nachher folgte ein kurzes Gutachten für das Departement $u$. am Nachmittag nach einiger Lektüre in Zöpf u. in Erkmann, wieder die Dissertation, mit der ich jetzt fast fertig bin.

Marieli wollte nicht zur Ruhe, es will die Nacht über den Schlaf nachholen. Es ging in die Stadt, machte Besuch bei Frau Jauch u. kam wieder mit dem Bescheid, dass sie uns Montag besuchen wollen. Siegwart, den es bei seinem zweiten Gang dorthin gesprochen, machte ihm einen viel mächtigeren Eindruck als Abbühl. Aber das sind vorüberhuschende Eindrücke. Etwas beunruhigt wurde Marieli durch einen Brief Augusts, der nächsten Freitag bei uns essen will. Marie meint, sie werde dann in keinem Fall hier sein, u. sie hat recht. Ich ging den ganzen Tag nicht aus, weil ich die unsinnige Blumenattaque vermeiden wollte, die heute wieder einmal geritten wurde. Wir beide waren

stets Gegner der Wohltätigkeits-Bazards, u. nun spielen die Leute den gleichen, uns widerwärtigen Geist mit den Blumentagen auf die Strasse! Ich kann mir nicht helfen, aber dieses Juhei bei der Wohltätigkeit geht mir so ganz u. gar gegen das Gemüt, dass ich davor eigentlich zurückschrecke. Was verbinden sich für unlautere Dinge mit der Zudringlichkeit der jungen Mädchen, wie wird der ernste Geist durch dieses Treiben nieder gedrückt, wie muss der Arbeiter es empfinden, wenn er derart geschröpft wird! Aber das ist nun die Signatur unserer Zeit, alles soll Spiel und Zeitver- 
treib sein, die Schule, das Studium u. auch die Guttat. Die sogenannten Bessern, the betters, fassen ihre Pflicht nicht mit Ernst an u. mit der Erweckung der Gefühle der Opferwilligkeit, sondern mit Juhei u. Lustigsein. Aber das hält ja nicht an, das wird zu schweren Zeiten führen.

Heute habe ich wieder ein halbes Dutzend Anfragen bekommen, u. zwar recht schwierige Fragen. Es häuft sich wieder, man sieht neuerdings kein Ende ab, zu zusammenhängender Arbeit zu gelangen. Ich muss mich fügen. Wenn ich nur nicht die Gemütsstörungen hätte, die mich in meiner Einsamkeit so schwer verdüstern. Ich ärgere mich über Kleines u. Grosses. Es ist so Vieles jetzt unordentlich, was Du im Hause in Glanz u. Schimmer gehalten hattest, und ich kanns nicht ändern. Platz für eine tüchtige Haushälterin habe ich neben Anna schon äusserlich

nicht, u. Marie hat keinen Sinn für das Haus. Also-Geduld Geduld, u. dankbar bleiben dafür, dass es mir in den Vorlesungen gut geht. So habe ich doch noch eine Art von Nützlichkeit in meinem Dasein festgehalten, was ja so manchem in meinem Alter versagt geblieben ist. Ich will, wenn die Düsterkeit mich überfällt, immer an Dich u. dies einzige mir gebliebene Gute denken.

Und nun gute, gute Nacht! Bleibe bei mir, wie ich bei Dir als Dein ewig getreuer

Eugen 
B. d. 2. Juni 1912.

Mein liebstes Herz!

Heute hat Hermine Abegg mich mit ihrem Besuch überrascht. Sie kam, um mit dem Direktor der Grünau über die Ferien der drei Buben v. Hans Abegg zu verhandeln, war mit ihrer Freundin Frau Ziegler hergefahren, im Bären logiert, u. heute dann nach Wabern, nachher zu uns gefahren, konnte etwa eine Stunde hier bleiben u. ist dann heute Abend wieder zurückgekehrt. Ich nahm die Gelegenheit wahr, ihr über die Angelegenheit Paul-Marieli einige Aufklärung zu geben, was sie recht aufnahm. Sie wollte mir auch von Sophie etwas erzählen, was ihr Konrads Marie geklagt. Allein dann trat Marieli ein u. die Sache blieb unerledigt. Sie will bald wiederkommen, was mir recht wäre, wegen Marielis. Sie fand unser Haus sehr schön u. heimelig. Sie war beweglicher als wie ich sie vor einem Jahr gesehen.

Als Hermine einrückte, war Walter B. bei mir. Es wurde mir eine Frau Bock aus Zürich gemeldet, wie sich dann herausstellte, dass es Marieli Hermine war, verabschiedete ich ihn. Unter der Thüre sagte er mir noch, Marieli habe ihnen aus Oberried eine Karte geschickt, worin es auf die telephonische Anfrage, die Donnerstag Abends Frau Burckhardt an es richtete, ob es eine Französisch-Stunde in der Secundar-

[2]

schule am Freitag Nachmittag übernehmen könne, angespielt u. angefügt habe «Rache ist süss». Marieli hatte davon nichts gesagt, wenigstens mir nicht. Der Spass war hüben u. drüben massiv. Walter B. hatte mir am Freitag davon zu sprechen begonnen u. gesagt, sie hätten sehen wollen, ob 
Marieli ein Vergnügen der Schulstunde opfern würde. Ich erklärte ihm schon damals, dass M. wirklich nicht mehr hätte absagen können. Dagegen bemerkte ich heute dann Marieli doch, dass es die «Rache» auch spasseshalber nicht hätte anrufen sollen.

Am Nachmittag erhielt ich Besuch von Herr u. Frau Hauser aus Neapel. Ihr Neffe, Coflisch, Sohn der Schwester der Frau Hauser, studiert jetzt hier. Sie sprachen mit grosser Wärme von dem Aufenthalt vor vier Jahren, von unserem Besuch in Rivolta u. von Dir, sodass mich der Besuch sehr freute. Sie luden mich u. dann auch Marieli, das sich übrigens nicht zeigte, zu einem Besuch in Neapel ein.

Nachher kam Frl. Reineck zu Marieli. Ich war ein Weilchen bei den beiden im Gartenhäuschen, u. dabei brachte Frl. Reineck das Gespräch auf die Scheidung, die im ZGB. viel zu streng geordert sei. Ich entwickelte ihr dann die sozialen Gründe, die zur Festhaltung an dem Lebensband der Ehe zwingen, u. ich glaube, die Überlegungen haben ihr einigen Eindruck gemacht. Aber interessant ist es, wie da auch Frl.

Reineck von der individualistischen Auffassung der Ehe als Vertrag sich ganz beherrscht zeigte. Die Leute denken nicht nach. Sie vertiefen sich nicht!

Endlich habe ich die Dissertation von Zehnder fertig gelesen. Das Resultat ist, dass ich die Arbeit ihm zurückgeben muss. Sie ist zu flüchtig gearbeitet, wenn auch fleissig, u. dazu kommt da u. dort ein dummer naiver Zug der Kritik des Gesetzes dazwischen, den ich keinesfalls passieren lassen darf.

Walter B. erzählte mir, mit innerem Triumph, dass er gestern mit Will nach Kalnach gefahren u. die dortigen Werke besucht habe. Der «Bund«redaktor Schürch sei auch dabei gewesen. Diesen schilderte er nicht unzutreffend: Nicht gebildet in seinem Benehmen u. etwas aufdringlich in den Bemerkungen u. grob im Wesen. Man wird ihn schon noch kennen lernen. Der «Bund» hat für die innere Politik unter dieser Hand bereits einen ewig kläffenden Ton 
angenommen. Wenn der andauert, werde ich das

Blatt nicht mehr halten.

Der Sonntag ist vorübergegangen, ohne viel Sammlung zu

bringen. Umgekehrt war Zerstreuung seine Signatur. Aber am Ende hat das auch wieder gut getan. Am Morgen war ausgemachtes Regenwetter. Es wäre heimelig gewesen. Aber es kam doch nicht die rechte Stimmung auf. Um zwei Uhr heiterte es auf u. begann Sonnenschein. Ich ging kaum in den Garten. Die Stunden folgten sich wie ich geschrieben,

kaum dass ich nach Tisch noch einige Seiten in der Débacle lesen konnte.

Und jetzt noch acht Wochen, strenge Wochen, u. dann sind die Ferien wieder da. Allein was ich mit diesen anfangen werde, das ist mir je länger je weniger klar.

Ich schliesse mit einem innigen Gut-Nacht-Kuss! Es muss ja doch ein Ende nehmen, also vorwärts!

In innigstem Zusammensein

Dein ewig getreuer

\section{Eugen}

1912: Juni Nr. 125

[1]

B. d. 3. / 4. Juni 1912.

Mein liebstes Herz!

Es drängt sich auf heute u. diese Tage soviel Arbeit zusammen, dass ich Dir jetzt schon am Nachmittag diese wenigen Zeilen schreiben muss. Nach dem Nachtessen kommt Guhl zu mir, um wichtige Fragen zu besprechen. Es kann lange gehen, bis wir fertig sind $\mathrm{u}$. morgen früh ist die gewohnte Vorlesung. Vor dem Nachtessen werden Siegwart $u$. seine Schwester $u$. Tante etwa zwei Stunden bei uns sein. Ich musste sie bei Gelegenheit der Anwesenheit der 
Schwester Claire einmal bei uns haben, u. es bot sich keine andere Zeit als heute Nachmittag vor ihrer Rückreise. Heute war ich im Colleg befangen, aber es ging. Nachher war ich auf dem Rathaus, traf aber nur den Registraten Bühlmann, der mir die gewünschten Auskünfte erteilen konnte. Und dann schrieb ich Hans Weber über das Opus, das er für die Unions-Zeitung verfasst u. mir zur Prüfung eingesandt hatte. Es ist ganz gescheit gedacht, aber nicht wissenschaftlich ausgeführt, mit Gemeinplätzen, die den früheren Redaktor u. Politiker wiederspiegeln. Als summarischen Zeitungsartikel liest es sich ganz nett $\mathrm{u}$. ich habe ihm nicht abgeraten, es in dem Organ erscheinen zu lassen. Ich konnte aber mich doch nicht enthalten, ihm zu bemerken, dass er eine tiefergehende Arbeit in Aussicht nehmen u. das hier entworfene als Material für später reservieren könnte; was er jetzt tun wird, wollen wir abwarten.

Ich beginne etwas ruhiger in die Zukunft zu blicken, auch betr. Marie. Man muss die Sachen etwas sich selbst überlassen. Wenn nur keine hässlichen Zwischenfälle mehr kommen. Abbühl war heute eifrig, hat mir von selbst einen Registraturplan vorgelegt, um alle Daten zu den einzelnen Artikeln zusammen zu stellen. Dämmert es am Ende doch noch in dem träumenden Kopf? Das wäre ein grosser Gewinn. Inzwischen Arbeit u. Hoffnung, u. damit den Rest des Lebens vorwärts getrieben!

Morgen haben wir von 3 - 7 Uhr Examen u. dann erst noch Fakultätstraktanden. So werde ich auch morgen Abend schwer zum Schreiben kommen. Es geht jetzt alles auf diese Tage zusammen, u. es könnte mir fast bange machen, wie die acht Wochen Semester noch auszuhalten seien. Aber es muss gehen. Heute beginnt auch die Bundesversammlung. Vermutlich bringt das auch wieder allerlei Störungen. Ich kann mir gar nicht denken, wie ich es machen würde, wenn ich noch im Rate sässe. Jedenfalls würden die Vorlesungen darunter leiden, von den andern Arbeiten ganz zu schweigen. 
Also begreife die Kürze, zu der ich jetzt gedrängt bin.

Die Stimmung ist besser. Die sich häufenden Unannehmlichkeiten der letzten Zeit sind innerlich verarbeitet. Wenn nicht gleich wieder neue kommen, so sollte es auszuhalten sein. Eben haben mich zwei Kandidaten von morgen besucht, dabei der prächtige Bruggmann mit dem ruhigen gescheiten Philosophenkopf. Es interessierte mich zu vernehmen, dass die hiesige Zofingia einen Abstinenten abgewiesen habe, der nun in Basel aufgenommen sei. Dort im Verein

grossen Krach, der in diesen Tagen mit der Spitze gegen Bruggmann u. seine Freunde zum Austrag kommen soll. Doch nichts mehr davon. Siegwarts kommen jeden Augenblick. Ich schreibe morgen weiter.

Den 4. Juni.

Der Besuch Siegwarts u. s. Schwester u. Tante verlief gestern recht nett, von halbfünf bis halbsieben sassen wir am Cafétisch u. waren in solcher Unterhaltung begriffen, dass alle überrascht schienen, wie es sechs Uhr schlug. Besondere Anknüpfungen fanden bei dem Besuche nicht statt. Auch über meine Ferien hat sich nichts abgeklärt. Nach dem Nachtessen war Guhl bis gegen zehn Uhr bei mir in wichtigen Amtssachen. Das Wichtigste aber war etwas Nichtamtliches. Leemann, der gestern den ganzen Tag bei Guhl teilte diesem nämlich mit, es ärgere ihn sehr, dass das Gerücht gehe, er sei nicht nur bei der Wahl des BG-secretärs durchgefallen, sondern auch bei der Ernennung des Grundbuchchefs, wo er sich doch gar nicht beworben. Und das Gerücht komme daher, dass Kaiser sich nach Leemann vor dieser Wahl erkundigt habe bei Staatsanwalt Schnabel, Oberrichter Hauser u. Ständerat Usteri. Aus welchem Grund mag das geschehen sein? Ich kann es nicht glauben, dass Kaiser gegen Guhl intrigiert habe, er musste auf Ersuchen anderer die Informationen eingezogen haben. Aber von wem? Hoffmann, der sich ja allerdings über Guhl etwas absprechend geäussert hat, oder sonst jemand? Es täte mir leid, wenn Kaiser sich derart als Intrigant entpuppen würde! Ich werde darüber aber schon Aufschluss erhalten $u$. ich hoffe solchen, der Kaiser ganz entlastet. 
Heute habe ich wieder etwas mühsam Kolleg gehalten, bin nach Hause geeilt $u$. vor Tisch hatte ich drei der pendenten Begutachtungen Abbühl diktiert, der sich sehr zusammennahm. Zwischen hindurch war Dr. Volmer bei mir, der mir über die Besserung

der Aussichten des Baugläubigerprivilegs sehr guten Bericht brachte. Ich war recht erfreut. So gewinnt man Anhänger für eine gute Sache, mag man auch gar nicht daran gedacht haben.

Und nun um zwei Uhr kam Kaiser mich in Güterrechtssachen in Müllers Auftrag etwas zu fragen. Ich benutzte gleich die Gelegenheit, ihn zu fragen, ob er bei Hauser etc. Informationen eingezogen. Und Kaiser verneinte dies des bestimmtesten. Also eine Schwätzerei. Ich werde das Guhl gerne mitteilen. Hoffentlich wird damit ein Samen der Zwietracht von vorneherein zerstört. Denn dass Kaiser sich verleugnet hätte, das glaube ich niemals.

Von den vier Kandidaten, die wir von 3 bis $7 \mathrm{zu}$ prüfen hatten, Helbling, Bruggmann, Schüppli u. Meienberg, ist der letzte um $3 \mathrm{Uhr}$ nicht erschienen. Gmürs Aufgebot hat uns also nur Zeit gekostet u. nützt nicht viel. Die Ergebnisse der Prüfungen will ich morgen anfügen. Ich werde spät nach Hause kommen u. will dann möglichst bald zur Ruhe.

$\mathrm{Zu}$ Hause schreibe ich noch die paar Worte. Bruggmann hat leider das Examen nur rite bestanden. Er war bei Blumenstein $u$. Reichesberg durchgefallen. Das tut mir leid. Schüppli hat auch nur rite. Helbling für dessen Durchfallen ich stimmte, ebenso. Die Fakultätssitzung war wie immer. Aber ich habe im ganzen doch von ihnen einen sympathischeren Eindruck als früher, zur Zeit Onkens u. Hiltys. Nachfolger Rossels wird Oberrichter Folletête werden. Als zweiten Vorschlag nennen wir den Pariser Ramadier auf meinen Antrag.

Nun Schluss, mit innigem Gefühl der Dankbarkeit, wenn es mir besser gehen wird in meiner Stimmung! Hilf, Du hilfst ja, indem Du alles machst! Dein allzeit treuer

Eugen 
B. d. 5. Juni 1912.

Mein liebstes Herz!

Heute hatte ich die vier Helveter bei mir zum Café, wie es die Sitte ist, die vier mit denen Marieli seit letztem November die verschiedenen Vergnügungen des Vereins mitgemacht: Röthlisberger, den seine Schwester Blanche begleitete, Hodler, Morgenthaler u. Abbühl. Sie kamen um zwei u. blieben bis halb sechs, bei Café, Kirsch u. Chablis. Die Unterhaltung war immer sehr nett, es entstanden nie Langweilepausen. Ich habe mitgemacht, ohne dass ich sagen könnte, dass ich mit dem Herz dabei war. Ich bin froh, diese Pflicht erledigt $u$. Marieli eine Freude gemacht zu haben, Hodler hat die Unterhaltung eigentlich geleitet, soweit ich nicht etwa die Direktiven zu geben versuchte. Er ist ein sehr gewandter, gescheiter u. entschlossener Mensch, dem ich aber nicht viel Tiefe oder Originalität anspürte. Er wird aber sicher seinen guten Weg machen, wenn er Ehrgeiz behält, um etwas zu leisten. Röthlisberger, mit dem zurückgehaltenen Feuer der romanischen Rasse seiner Mutter, war erst sehr stumm. Nach u. nach aber wurde auch er lebhaft, $u$. hat mit seiner klugen Beobachtung manches Gute eingeflochten in die Unterhaltung. Morgenthaler, der zweisemestrige Fuchs, war stumm, hat aber

was er etwa anbrachte, mit bescheidenem Anstand angemerkt. Am wenigsten konnte ich Abbühl begreifen, der ein ziemlich verdutztes Gesicht machte u. mit gutmütigem Lächeln da sass, als wäre er anderswo. Ich weiss nicht, mir schien, er sei nicht auf der Höhe, aber es kann ja auch nur Verlegenheit gewesen sein. Meine Leute sagten nachher, er hätte so nach Carbol gerochen. Mein versteckter Schnupfen 
hinderte mich daran, solches wahrzunehmen. Blanche war recht nett, sprach nicht viel, war bescheiden u. klug. Das Mädchen machte mir einen günstigeren Eindruck als je zuvor. Aber im Ganzen musste ich mir doch sagen, das alles ist nicht meine Welt, u. ich weiss nicht, ob es nicht am Ende auch für Marieli nicht die rechten Wege sind. Nun, wir befinden uns einmal auf dieser Bahn u. müssen vorwärts. Nachdem die Verleumdungen Konrads u. der Hassausbruch August Gyrs die Brücke mit Zürich auf immer abgebrochen, handelt es sich darum, aus dem Verbliebenen sich so günstig als möglich herauszuziehen. Also sei jetzt kein weiterer Entschluss gefasst, als auszuhalten. Es erschreckte mich freilich heute wieder, als Abbühl die Abschriften der Diktate, die ich ihm gestern mitgegeben, nicht ohne ganz dumme Fehler herbrachte. Wenn es so fortgeht, so ist ja freilich mit ihm nicht viel anzufangen. Aber ich bin sicher, dass er auch

von Marieli dann nicht angenommen wird. Und das würde leicht wiederum schwere Konflikte erzeugen. Ich habe heute vor Tisch einige Briefe erledigt, darunter die Antwort an Massiglis auf seine zwei Mitteilungen betr. Soleilles u. betr. Ramadier. Abends präparierte ich Kolleg u. war dabei fast ängstlich, weil mir so vieles unvollkommen vorkam. Und jetzt ist der Tag wieder vorüber. Die Tage reihen sich aneinander $u$. ich gelange zu keiner rechten Arbeit. Es ist immer dieselbe Klage.

Die Geschichte mit Frau Prof. Burckhardt, betr. die «süsse Rache», von der ihr Marieli in seiner Ungeschicklichkeit schrieb, gab mich wegen einiger kleinen Bemerkungen Walter Bs. gestern $u$. heute noch zu denken. Ich habe schon bemerkt, dass Frau Burckhardt merkwürdig rasch von ihren Sympathien in Antipathieen umschlägt. Es wäre denkbar, dass sie nun wegen des kleinen Vorfalls auch Marieli gegenüber zu einem andern Verhalten gelänge. So sehr ich es an sich begrüssen würde, wenn Marieli weniger mit dieser sonderbaren, taktlosen Frau verkehrte, so sehr würde es mir doch leid tun, wenn von ihrer Seite wegen des kleinen Anlasses 
nun gegen Marieli eine andere Stimmung Platz griffe.

Wir hätten da wieder ein Beispiel, wie man schliesslich, sobald man sich mit Leuten geringeren Charakters einlässt, im Ergebnis geprellt ist. Es könnte dies dann für Marieli eine

Lehre sein, wenn es für solche zugänglich ist. Es begab sich aber noch zu Siegwarts, da Claire morgen verreist. Was wird es von da nach Hause bringen?

Es ist dunkel geworden $u$. ich bin müde. Also Gute Nacht, mein einziger Schatz! Ich fühlte mich gestern etwas fiebrig. Heute ging es schon besser, u. auf morgen hoffe ich es ganz wegzuschlafen! Gute, gute Nacht!

Dein auf immerdar!

Eugen

\section{2: Juni Nr. 127}

B. d. 6. Juni 1912.

Liebe, gute Lina!

Bei warmem Gewitterregen sitze ich auf der Terrasse u. schreibe diese Zeilen mit dem Gefühl einer innigen Vereinigung mit Dir. Sieh, das hilft mir am Ende über die schweren Gemütsverstimmungen weg, an denen ich seit langem unter den mich umgebenden Verhältnissen gelitten habe, die Du ja auch schon gekannt u. bekämpft hast. Mit Marieli komme ich jetzt dann gewiss in ein besseres Verhältnis. Ich beginne mir seine guten Seiten mehr als die andern vorzustellen, u. es reift eben auch allmählich zu einer tieferen Erfahrung heran. Es hat namentlich einen grossen Verstand für die Beobachtung u. das Sprachentalent wird ihm auch mehr Freude machen, wenn es endlich einmal anfängt zu lesen, wenn die Litteratur beginnt es zu interessieren. Das muss jetzt noch 
abgewartet werden. Merkwürdig hält es sich nun zum Klavierspiel. Anfangs, wie die Stunden bei Reding begannen, wollte es fast verzappeln mit Üben. Jetzt übt es wenig u. denkt doch nicht daran, die Stunden aufzugeben. Was es mit Reding darüber gesprochen haben mag, kann ich nur vermuten. Denn in dieser Beziehung bleibt für gewisse Dinge immer noch das alte Übel der Verschlossenheit, der Wortkargheit, die es sonst in letzter Zeit tapfer bekämpft hat. Als die Nachricht kam, dass August morgen bei uns zu Mittag essen werde, erklärte es sofort, da wolle es fort u. mit Frl. Reineck im «Daheim» zu Mittag essen. Heute aber erklärte es aus sich heraus, dass es wohl doch besser sei, wenn es bleibe. Und das finde ich auch: Wenn August kommen will, so soll er uns finden, wie wir sind, so wird

sich die Sache am richtigsten gestalten. Ob August dabei auf das Verleumdungsverbrechen Konrads zu sprechen kommen wird? Ich denke kaum. Aber wenn es geschieht, so werde ich ihm schon sagen müssen, was ich davon denke.

Abbühl war heute als aktiver Helveter beim Fechten. Er sagte gestern, dass er um elf doch noch zu mir kommen werde. Nach zehn Uhr aber klingelte man mich ans Telephon, u. da war es Abbühl, der mir mitteilte, er würde gerne erst auf Mittag u. dann nachmittags kommen. Ich entliess ihn für den ganzen Tag u. zwar nicht ungern. So konnte ich, nachdem ich am Morgen eine Reihe von amtlichen Sachen mit Guhl erledigt, um 2 Uhr an die Kritik des Kreisschreibens des Finanzdepartements betr. die Hypothekarbank gehen u. für das Justizdepartement den Bericht ausarbeiten, den ich dann gleich mit der Maschine ausfertigte. Das machte mir mehr Freude, als wenn ich Abbühl diktiert u. ihm die Ausfertigung überlassen hätte. Er hat so wenig Sinn, solche Sachen ordentlich zu machen, dass mir die geringere Mühe durch den nachfolgenden Ärger mehr als aufgewogen wird. Marieli denkt über ihn jetzt auch etwas anders. Aber natürlich bleibt doch die fatale Situation, dass Marieli wegen Abbühl von mir in die jetzige Stellung versetzt worden ist. Seine Berichte lauteten so vertrauenserweckend. Vielleicht ja kommt 
es noch besser, $u$. arbeitet sich der junge Mann zu einer tüchtigen Leistungsfähigkeit durch. Aber der erste Monat war nicht viel versprechend. Eines muss ich ihm lassen, er scheint sehr gutmütig zu sein. Ist ihm am Ende «der Knopf noch nicht aufgegangen», trotz seiner Helveter Allüren? Das wäre ja auch noch möglich. Also auch hier-abwarten!

Und während des Wartens freudig u. dankbar bleiben! Das ist eine grosse Kunst. In Zöpfs Büchlein lese ich fast jeden Mittag auf der Chaise longue im Schlafzimmer ein paar Seiten. Sie wirken wie ein Rezept. Zöpf hat etwas vom Seelenarzt. Ich habe jetzt noch sehr viel unerledigte Arbeit auf Lager. Alles amtliches oder halbamtliches. Es wird mich noch manchen Tag beschäftigen, $u$. wenn inzwischen Neues einläuft, so könnte ich am Ende zu mir ganz ungewohnten Verspätungen gelangen. Im Kolleg darf ich nicht müde werden, sonst ist meine beste Freude dahin.

Ich treffe in diesem Semester häufig Kollege Schulthess, der mir Freude macht. Kürzlich erzählte er von einem Appenzeller Barbier, der mit einem schlecht geschliffenen Messer einen Engländer rasierte, u. als diesem die Tränen über die Backen liefen, bemerkte «Hast Heimweh?». Ich musste so lachen, dass ich, gerade vor der Auditoriums Thüre war das gesagt, mich fast nicht fürs Katheder schnell genug fassen konnte. Ich treffe jetzt Finsler wieder häufiger an u. zwar bei der Post. Heute kam er mir freudig entgegen $u$. erzählte, er gehe immer mit so grossem Animus in die jetzige vierte Klasse. Das sei eine ganz seltene Erscheinung, wie er mit diesen Leuten verfahren könne. Also die alte Erscheinung: ein paar tüchtige, wenn sie prävalieren, reissen die ganze Sache heraus. Umgekehrt können ein paar Taugenichtse den ganzen Jahrgang verderben. Das habe ich ja im Kolleg u. Praktikum auch so.

Guhl schien heute sehr froh über den Bericht, den ich ihm von Kaiser geben konnte, meinte aber doch, Kaiser habe vielleicht nur eine schriftliche Anfrage abgestritten $u$. mündlich sich doch erkundigt. Allein so diplomatisch hat sich Kaiser wirklich nicht ausgedrückt. Übrigens traf ich heute Nationalrat Sträuli, 
der mir bestätigte, dass man in Zürich gesagt habe, Leemann sei auch in der Grundbuchbewerbung durchgefallen. Ich teilte Sträuli mit, dass er sich gar nie darum beworben.

Wie froh bin ich, dass ich für heute bei Ringier abgesagt. Und dass ich Montag Abends nicht bei Rossel sein muss, ist mir ebenso lieb, wenngleich Frau Rossel die Absage nicht so gnädig aufgenommen hat, wie Herr u. Frau Ringier.

Und nun noch Kollegpräparation u. dann zur Ruhe! Gute, gute Nacht sagt Dir, liebe Seele, Dein allzeit treuer Eugen

1912: Juni Nr. 128

B. d. 7. / 8. Juni 1912.

Meine liebe, gute Lina!

Heute also war August bei uns. Er kam nach Erledigung der Revision der Gasgesellschaft um halb eins. Marieli war geblieben u. kam in den Salon, um ihn zu begrüssen, ganz recht, ohne Misston. Über Tisch war August munter, wenn auch natürlich gegenüber Marieli wortkarg. Nach dem Essen sass ich mit ihm in der Verandah, u. da brachte ich das Gespräch auf Pauls Braut, nachdem er schon vorher einige reservierte Andeutungen gemacht hatte. Sie sei, sagte er, ein ganz nettes Mädchen, aber ohne jedes Vermögen. Der Vater, Pfarrer Graf, sei einmal bei Augusts gewesen, von halb drei bis fünf Uhr, auch er sei ganz recht gewesen, aber näher seien sie sich nicht gekommen, ausser dass sie einmal zum Mittagessen in Aarau gewesen. Leni Graf sei dann auch mit Paul u. August im April acht Tage in Weesen gewesen. Paul habe sie an einem Hausball der Pension Dornbirrer kennen gelernt, u. die Verlobung sei dann früher als beabsichtigt erfolgt, weil Leni Graf die Absicht gehabt habe, in England eine Stelle 
anzunehmen. Jetzt besuche sie den Haushaltungskurs der Mine Gerolts in Holligen. Es seien bei Grafs viele Kinder, u. Leni das jüngste. Ein Bruder von ihr hat hier doktoriert, es ist der kleine bucklige gescheite Graf, Schützling Forrers, an den ich mich sehr wohl erinnere. Sein Examen stammt etwa von 1902. August trank dann noch den drei Uhr-Kaffee u. begleitete mich zur Hochschule. Auf dem Weg bemerkte er nochmals, die Braut sei vermögenslos. Von Konrads u. auch von Sophie sprach er kein Wort.

Also blieb die Geschichte mit August Gyr gänzlich unberührt. Das ist mir nicht recht, es wäre mir lieb gewesen, wenn August, der jetzt doch jedenfalls davon Kenntnis hat, eine Abbitte angebracht hätte. Ich selbst konnte nicht davon anfangen. Marieli ging auf drei Uhr zur Universität. August kehrte von der Begleitung zur Schanze nicht mehr nach dem Rabbenthal zurück, sondern ist offenbar um 5 Uhr verreist. Es ist ein weher Anblick, zu sehen, wie ihn das Geld drückt, das der Braut fehlt, während er mir heute sagen konnte, er werde seinen zwei Buben etwa eine halbe Million hinterlassen. Da sieht man, wo der Segen liegt. Heute früh war es wie Herbstnebel. Mittags Sonnenschein. Nachmittags $u$. bis jetzt Regen u. eine feuchte, warme Luft. Das Praktikum war recht nett. Den Vormittag, nach Kolleg u. Besuch der Bibliothek, musste ich zur Kollegpräparation verwenden.

Ich bin froh, dass der Besuch August vorüber ist. Ich begreife seine Überwindung zu mir zu kommen, denn eine solche ist es offenbar. Aber ich sage mir, durch den Besuch wird zu leicht der alte Groll wieder wachgerufen. Es ist noch zu wenig Zeit verflossen, noch zu wenig an der Sachlage verändert. Deshalb bemerkte ich auch, als August mich fragte, ob Paul mich mit seiner Braut einmal besuchen dürfe, es sei wohl besser, wenn der Besuch erst nach der Hochzeit stattfinde. Wann diese abgehalten werde, wusste August nicht zu sagen, vielleicht gegen Weihnachten, meinte er. Ich stehe wieder ganz unter dem Eindruck, dass Konrad u. August Gyr die Sache dahin gebracht haben, wo sie jetzt ist. Hoffen wir, uns allen zum Segen, dann wird durch das Böse wieder einmal Gutes geschaffen worden sein. 
Den 8. Juni.

Eben ist gegen Mitternacht Haenny fortgegangen, der nach dem Nachtessen zu mir kam u. mir von seiner Reise mit Dr. Steger durch Corsica sehr vieles u. lebhaft zu erzählen wusste. Wie manches kam mir dabei von unsern Reisen in den Sinn. Und ich musste immer denken, wie wir doch alt geworden waren, bis wir die erste längere Reise machen konnten zusammen. Das waren schmale Jahre, bis es dann besser kam, u. dann ergreift mich, wie der Geldmangel vorüber war, der Zeitmangel, u. zu den schönen Freuden der öftern Reisen sind wir wenig gekommen. Doch die Erinnerung an das wenige war uns beiden ja immer um so lieber u. treuer. Daran halte ich mich auch jetzt u. im übrigen hört alles einmal auf. Haenny hat viel gesehen u. erlebt, er hat sich auch recht erholt, u. er erzählt gerne, er gibt sich gerne bei aller Bescheidenheit, er ist Künstler. Den heutigen Tag habe ich viel gearbeitet. Ich stand zeitig auf, schrieb ein Gutachten, bevor Abbühl kam, diktierte ihm zwei, die er dann zu Hause schreiben musste $u$. Nachmittags brachte, leider wieder nicht korrekt gearbeitet, - dann setzte ich einen sechsseitigen Bericht auf u. schrieb ihn bis Mittag ins Reine. Endlich am Nachmittag schrieb ich ein fünftes Gutachten, sodass ich jetzt alle Resten bis auf eines erledigt habe u. sehr, sehr froh bin darüber. Ich brachte die Gutachten für das Departement Kaiser selbst. Müller war in Mezières abwesend, der ganze Bundesrat sei hingegangen, hiess es. Kaiser war kälter, vielleicht viel beschäftigt, vielleicht nachträglich etwas piquert von meiner Frage vom letzten Montag. Um so besser, falls doch etwas dahinter ist. Ich ging dann auch am Nachmittag geschwind bei Rossel vorbei, um mich für meine Absage für Montag Abend

noch besonders zu entschuldigen. Er schien meine Antwort zu begreifen. Frau Rossel war schwieriger. Gestern habe ich dann auch eine Einladung zu Lüdemanns auf morgen Abend abgesagt. Und mir ist so wohl dabei! 
Morgen sollte ich einen ruhigen Tag erhalten, wenn nicht Unerwartetes kommt. Etwa Kollegpräparation u. dann kann die Woche wieder ins Rollen kommen. Es ist spät, ich schliesse. Gute, gute Nacht, liebste Seele, ich bleibe bei Dir u. bin auf immerdar Dein guter Kamerad! Dein Eugen

\section{2: Juni Nr. 129}

B. d. 9. / 10. Juni 1912.

Mein liebstes Herz!

Regensonntag, stiller Tag, diesmal wirklich still. Nur Walter B. machte Vormittags seinen gewohnten gemütlichen Besuch - er hatte diesmal über Kaiser u. Hoffmann, resp. Müller zu klagen, wegen der Nichtaufnahme in die Autorrechtskommission u. am Nachmittag kam Frau Onken, die jetzt bleibend in Bern wohnen will. Sie redete viel, aber die Stille des Tages konnte das doch nicht beeinträchtigen. Bei Marieli war Ella Dähler, die jetzt mit dem Patent als Schweizerische Turnlehrerin nach zweijährigem Kurs aus Stockholm zurückgekehrt ist $u$. bereits eine Anstellung erhalten hat. Sie ist ein feines Mädchen. Frau Onken erzählte von der letzten Lebenszeit ihres Mannes, es war ein bedenklicher Zustand. Wir wissen wohl, wie wir sind, aber nicht wie wir werden können. Marieli hat nachmittags weder Café mit uns genommen, da der Thee für es u. Ella [?] ging, noch das Abendessen da es zu Lüdemanns geht, wo ich abgesagt habe, aus den bekannten Gründen. Auf acht Uhr war es in der katholischen Kirche, um die ital. Predigt wieder einmal zu hören, u. traf Siegwarts. Ich fragte heute Anna, ob sie an Marielis Stelle Siegwart heiraten würde, wenn er fragte. Sie meinte, ganz sicher, es sei doch ein flotter Bursche. Ich muss mir sagen, meine Antwort wäre dieselbe, namentlich wenn ich seine Disziplin u. Tüchtigkeit mit Abbühls bis jetzt so unbefriedigenden Leistungen vergleiche. 
Den Tag über las ich dies u. das, studierte in der Dir ja bekannten Hartnäckigkeit an einer Schachaufgabe herum, ohne bis jetzt die Lösung gefunden zu haben - ein Vierzüger -, u. präparierte Collegien. Ich musste mir wieder einmal einen Quasi-Ruhetag gönnen. Denn die letzten Tage waren zu arbeitsvoll.

Der Garten wird dieses Frühjahr merkwürdig voll, u. die Deckung gegen Dicks Neugierde ist bald vollständig, reicht wenigstens schon über das Küchenfenster. Du hättest Freude daran gehabt, wenn Du noch den Erfolg Deiner letzten Anlageänderung mit leiblichen Augen Dir angesehen. Ich selbst war heute, wie ich Walter B. hinaus begleitete, ganz überrascht. Ich will auch ein wenig Freude daran haben. Jedenfalls ist mir das Haus trotz der mangelhaften Führung wieder lieber als eine Zeit lang der Fall war. Ich gelobe mir überhaupt, jeden Tag, mich wieder mehr zusammenzunehmen. Man muss ja doch sich durchschlagen, solange es hält, also mutig! Wenn ich es nur mit den Kollegien aushalte, dann ist alles andere eher zu tragen. Aber manchmal habe ich den Eindruck, es gehe nicht, wie es sollte, obgleich ich mich recht vorbereite. Ich leide aber darunter, dass mir zu wenig Zeit zur Verfügung steht, sodass ich wenig Beispiele bringen kann. Die Sache wird abstrakter als früher. Oder ich habe, weil mir die Materie gewohnter geworden ist, einen andern Eindruck als früher. In zwei Wochen werde ich Kochers Fest mit machen. Er hat mich u. Marieli bereits zum Gartenfest nach dem Bankett in seine Villa eingeladen. Aber soll ich über acht Tage zu den Concordianern gehen, die ihr Stiftungsfest haben? Ich denke ja, bin aber noch nicht sicher. Meine besten Bekannten vom Dorfe leben nicht mehr. Ich werde mich einsam fühlen. 
Den 10. Juni.

Ich glaubte nach den Vorlesungen, die mir heute besonders Freude machten,

einen gemütsruhigen $\mathrm{u}$. behaglichen Tag vor mir zu haben. Vor Tisch erledigte ich allerlei Briefe u. legte mir die Arbeit für Nachmittag zurecht. Dann begann ich um 2 Uhr auch gemächlich mit dieser. Aber bald kam der Däne Ussing u. blieb bis gegen vier Uhr, u. nachher ging ich an die Kollegpräparation $u$. traf so viele Schwierigkeiten, dass ich bis zum Abendessen fast nicht fertig wurde. So flog der Tag dahin, u. es ist Abend geworden, ohne die erhoffte Behaglichkeit. Die ist mir nun einmal nicht beschieden, u. da ich sie, solange ich sie mit Dir vereint hätte geniessen können, auch nicht hatte, so ist es ja ganz recht, dass es so ist. Froh bin ich, heute nicht zu Rossels gehen zu müssen. Das hätte mir jetzt vollends alles verdorben.

In Ussing habe ich heute einen lieben Menschen u. einen feinen Kopf kennen gelernt, der mir grosse Freude machte. Er sass scheint's die ganze Zeit im OR., nur an verschiedenen Plätzen, u. er passte so tüchtig auf, dass er mir heute einige Fragen vorlegen konnte, die mich wirklich auf Lücken in meiner Darstellung aufmerksam machten. Er bleibt nur noch ein paar Tage u. will dann nach München zurück, u. von dort nach Paris. Ich sprach ihm aufrichtig den Wunsch aus, ihn ein anderes mal in der Schweiz wiederzusehen.

Im Kolleg habe ich einige alte Knaben, unter anderen den Dr. Teindurg, der sich, wohl um das neue Recht kennen zu lernen, nochmals immatrikulieren liess. Er fehlte die letzten Tage, offenbar, weil er, wie ich den Zeitungen entnahm, gestern einen Vortrag in einer Versammlung gehalten hat. Heute war er wieder da. Dagegen ist Marcus seit einigen Tagen ausgeblieben. Ob es ihm in den Nerven schlechter geht, oder ob er verreist ist? Ich mache mir manchmal bei den Besuchsschwankungen Gedanken, wie ein Anfänger. Das ist meine alte Schwäche, die Du ja auch gekannt hast. Übrigens bin ich wirklich heiterer u. gelassener u. will mich bemühen, so zu bleiben. Ob das damit zusammenhängt, dass Marieli wirklich netter u. freundlicher geworden ist? Heute 
war es schnell bei Frau Dr. Jauch u. kam ganz fröhlich zurück. Am Mittwoch kommt Siegwarts verheiratete Schwester u. soll dann mit Bruder $u$. Tante bei uns den Nachmittagskaffee nehmen. Ich will nicht weiter schreiben, nur noch anfügen, dass Marieli von dem gestrigen Nachtessen bei Lüdemanns sehr erfreut $u$. nicht spät nach Hause kam. So macht sich das allmählich. Möchte es immer besser werden!

Gmürs gehen für den August auf den Weissenstein. Damit ist jetzt entschieden, dass ich nicht gehe. Aber was ich anderes mit den Ferien anfange, darüber befragt mich zwar Marieli fast jeden Tag, u. ich weiss es nicht. Heute meinte es, ich soll doch nur etwas sagen, damit es sich in Gedanken freuen könne, wenn auch nachher gar nichts daraus werde. Und ich entgegnete, dann könne ich ja sagen, dass wir auf den Montblanc wollen.

Ich schreibe auf der Terrasse. Es donnert u. einige Tropfen fallen. Aber es ist ein rechter Sommerabend. Ich will zeitig zu Bett u. mich nochmals darüber freuen, dass ich nicht an Rossels engem Tisch sitze u. mit Leuten schwatzen muss, die mir ja in der Mehrzahl doch nichts bieten könnten. Lieber morgen wieder eine rechte Vorlesung. Und nun gute, gute Nacht! Wenn es noch so sommerabendlich hell ist, so sagt man das Wort freilich mit anderem Grund, als im Winter. Aber auch die kurze Nacht kann wohltuende Ruhe bringen. Und sie Dir zu wünschen, bedeutet ja für mich ein Gebet um Ruh u. Frieden!

Also gute, gute Nacht von Deinem alten Kameraden, Deinem allzeit treuen Eugen 
B. d. 11. Juni 1912.

Mein liebstes Herz!

Ich bin heute in meinen Vorlesungen so wenig

weit gekommen, dass ich unter den Eindruck geriet, viel zu viel Detail gegeben zu haben, was mich bedrückte. Nach dem Kolleg kam Gmür ins Professorenzimmer, frisch, ausgeruht, u. erzählte, dass es bei Rossels sehr nett gewesen sei gestern Abend. Neben ihm seien Burckhardt, Bühlmann, CalameCollin, Folletête u. andre dagewesen. Man sei bis 12 geblieben. Namentlich sei Bühlmann ausserordentlich frisch gewesen. Ich spürte eine Art Pointe heraus u. liess mich nicht darauf ein. Es war unter allen Umständen so viel besser, dass ich zu Hause blieb. Wieder zurückgekehrt, überraschte mich die Mitteilung, dass jemand sich auf 10 Uhr zu einer Consultation telephonisch angekündigt habe. Das war mir in dem Zustand des Ruhebedürfnisses sehr wenig angenehm. Es kam dann aber Borella zu einem sehr netten Plauderstündchen u. überbrachte mir 60 Fr. als Honorar für ein kleines Gutachten, das ich ihm i. S. [?] im Frühjahr geschrieben hatte. Die Post brachte mir dafür eine andere, unentgeltliche Arbeit, wieder eine Anfrage von Notar Hirt, die ich nach Borellas Besuch noch vor Tisch beantwortete u. Abbühl zum Abschreiben mitgab. Hoffentlich erledigt er die Sache diesmal tadellos. An Anweisungen meinerseits hat es nicht gefehlt. Den Nachmittag machte ich mich an den Nachtrag zum Gutachten für die Nationalbank. Die Frage war schwierig u. hatte mich die letzte Zeit in der Nacht verfolgt. Es gelang mir, 
die Ausführungen vor fünf Uhr zu Ende zu bringen. Abbühl soll sie morgen ins Reine schreiben.

Zu Marieli, das in wachsendem Sturme lebt, kam heute Helene Baumgart in den Garten, begleitet von seiner kleinen Schwester. Ich begrüsste die Patientin u. war erstaunt über ihr gutes Aussehen. Der eine Fuss u. das andre Knie sind noch im Verband. Die Narbe an der Stirne sieht viel weniger schlimm aus, als ich vermutete. Das Fräulein hat schöne blaue Augen, die aber nicht viel mehr aus hausbackenen Verstand ausdrücken. Von ihrem Unfall erzählte sie in trockener Weise, ohne viel Gemüt in die Sache zu legen. Frau Baumgart hat vor Überanstrengung in der letzten Zeit einen Ohnmachtsanfall gehabt, ist gestürzt, hat sich verletzt u. liegt im Bett. Morgen könne sie aber wieder aufstehen.

Marieli ist im Sturm, sagte ich. Morgen nachmittags kommen Frau Dr. Jauch, die junge Apothekersfrau Schmid, eine Schwester Siegwarts mit ihrem Kindchen u. Siegwart. Donnerstag soll der Schulausflug nach der Griesalp stattfinden, wenn wenigstens das Wetter es erlaubt, u. Abends $8 \mathrm{Uhr}$ ist die Enge der Helveter-Revanche-Ball, sodass Marieli vom Bahnhof direkt hinaus zu fahren gedenkt. Und am Samstag will es mit Olga Reber u. einer Klassenfreundin dieser, sowie den Schwestern Beetschen aus Thun über den Jaunpass, um von Bulle am Abend wieder hier zu sein. Es ist ja recht, wenn es Leben entwickelt, das wird ihm auch gesundheitlich gut tun. Ich lasse ihm daher den Willen, mag es sehen, wie weit es reicht!

Ich wollte heute im Laufe des Tages wieder in Trübsinn geraten, habe mich aber kräftig gewehrt. Die Kollegien halten mich aufrecht. Ich habe fortgesetzt Freude daran. Ich bemerke auch, wie sich die tägliche gute Präparation bewährt. Das System prägt sich mir ganz anders ein, $u$. ich sehe voraus, dass sich die Mühe, die ich mir heute gebe, im nächsten Jahreskurs lohnen wird. 
Also vorwärts in dem angetretenen Trott! Mögen sie mir auch da u. dort übel wollen: Wir leiden allenthalben Trübsal, u. verzagen aber wir ängsten uns nicht, wie es ist uns bange, aber wir verzagen nicht, wir leiden Verfolgung, aber wir sind nicht verlassen, wir werden unterdrückt, aber wir kommen nicht um. So etwa heisst es in den Worten, die mir aus der Stimmung heraus gesprochen sind, die ich empfinde, wenn ich aus allem Trübsinn mich aufraffe u. Freude u. Dankbarkeit pflegen will. Ich erinnere mich, dass ich vor vielen Jahren, als wir einmal nach Muri hinaus den Abendspaziergang machten, zu der Zeit, da Stooss so unartig war u. Ruffy im Departement ein mir feindliches Regiment führte, das auch Leo Weber allzu wenig milderte, dass ich da zu Dir sagte: Sie sollen mich plagen $u$. verfolgen. Umbringen können sie mich doch nicht. So war es schon damals, u. wenn nun auch die hinter mir liegenden Erfolge dem ganzen Ausklingen eine besondre Färbung geben, sodass ich das einst mit dem jetzt nicht vergleichen darf, $u$. wenn ich auch Dich nicht mehr seitlich um mich habe, mit der lieben Stimme, die kein andrer Laut mir je auf der Welt zu ersetzen vermag, so will ich doch so tapfer sein, wie damals u. aushalten. Am Ende kann man auch aus den einsamen, grauen

Herbsttagen eine Freude ziehen, die der Erinnerung an Dich würdig ist. Nur Geduld, nur Aushalten u. sich üben im Warten! Ich schreibe diese Zeilen wieder auf der Terrasse, beim abnehmenden Dämmerlicht. Es ist wieder die Zeit der Ruhe gekommen. Gute Nacht, mein Lieb, gute Nacht! Dein immerdar treuer Eugen 
[1]

B. d. 12./ 13. Juni 1912.

Mein liebstes Herz!

Nur ein paar Zeilen, denn bis vor dem Nachtessen war Besuch da u. auf gleich hat sich der Nachbar Dr. Dick angemeldet, um mich in einer Erbsache zu consultieren.

Im Kolleg ging es heute besser. Im Sprechzimmer war Gmür sehr niedergeschlagen $u$. klagte, er komme zu keiner rechten Arbeit $u$. müsse jetzt nach den Ferien mit Frau u. Kindern auf den Weissenstein. Die Stimmung, die aus ihm sprach, schien ächt zu sein, u. es wäre kein schlimmes Zeichen, wenn er dann u. wann sich darüber Gedanken machte, dass er auch so gar keine Produktivität entwickelt. Im Korridor traf ich Ussing, mit dem ich ein paar Worte wechselte, u. der mir in der Art, wie er hier auftrat, sehr gefiel. Er erkundigte sich auch nach dem Grundbuch $u$. will meinen früheren Rat doch noch befolgen $u$. es besuchen. Zu Hause angekommen traf ich die Abschrift des vorgestrigen Gutachtens, die Abbühl zwar nicht sauber, aber doch ohne erhebliche Fehler gemacht hatte. Auf elf brachte er dann die Abschrift des gestrigen, $u$. die war wieder mit etwa sieben sinnentstellender Fehlern orniert, die mich an dem guten Willen oder an der Begabung stutzig machen mussten. Ich stellte ihn freundlich, aber bestimmt zur Rede u. sandte ihn nach Hause, damit er es nochmals u. richtig schreibe. Ob er das Gewicht einer solchen Abfuhr empfindet? Es ist nicht einmal sicher. Denn was Marieli von ihm sagt, wird zutreffen: Er ist nicht eingebildet, aber er erkennt nicht die Schwierigkeiten dessen, was er unternimmt, u. 
stellt sich alles zu leicht $u$. einfach vor. Das ist aber gerade eine sehr fatale Eigenschaft. Sollte er wirklich nicht zu meinem Secretär taugen, so müsste ich sehen, wie ich ihn auf den Herbst verabschieden kann. Warten wir das ab, ich habe Dich früher ja auch schon darüber geschrieben u. muss die Sache so gut als möglich zu schlichten suchen. Auch mit Marie ist die Sache nicht so einfach. Du wirst mir auch noch helfen, liebe Seele, denn in Deinem Geist soll alles getan sein.

Nach Tisch hatte ich Kollegarbeit. Dann kamen nach drei Uhr Frau Dr. Jauch, Frau Schmid-Siegwart mit ihrer zweijährigen Gabriela u. Dr. Siegwart. Sie blieben bis gegen sechs Uhr, es war ein netter Besuch. Diese ältere Schwester Siegwarts ist nicht so lieb in ihrem Wesen, wie die jüngere, Claire, aber auch eine sympathische Erscheinung. Als die kleine Gabriela Anna Grandmaman nannte, fuhr es ihr heraus: Jetzt sagt es ihr schon Gr. m! - Nach Siegwarts kam Max Huber zu einem Plauderstündchen, er ging zum Nachtessen zu Walter B., hatte Besprechungen hier. Er machte mir einen vortrefflichen Eindruck. Namentlich was er einerseits von Frisch, der mit einem bekannten Diebesgruss sich verabschiedet habe, u. von Häusler sagte, u. seine anerkennenden Bemerkungen über Hilty, waren sehr fein. Vielleicht ein andermal näheres darüber. Ich erwarte nun jeden $\mathrm{Au}$ genblick Dr. Dick u. will dann später weiter schreiben. Marieli hat von selbst den Plan nun doch aufgegeben, morgen - die Schulreise mit Frl. Reineck soll stattfinden den Tag über nach Griesalp zu gehen u. 9 1⁄2 Uhr Abend zurückzusein, um sofort nach der inneren Enge zur Helveter Revanche zu gehen. Ich machte ihm gestern eine Bemerkung, die auf das Unziemende hinwies, wenn es erst um halb elf in die

Ballgesellschaft käme. Es ist nun einmal das Zusammentreffen der zwei Anlässe erfolgt. Da gab es nur zu wählen, nicht zu cumulieren. Und Marieli konnte nicht wohl anders, als der älteren Abrede den Vorzug geben. Hätte es auch darin meinen 
Rat befolgt, Frl. Reineck bei Zeiten zu sagen, dass es am Donnerstag verhindert sei, so würde die Sache sich wahrscheinlich schon haben richten lassen. Nun morgen regnet es vielleicht. Das ist der Trost, den sich Marieli bereitet. Jetzt kommt Dr. Dick!

Den 13. Juni 1912.

Ich hatte Dr. Dick gestern bis gegen 10 bei mir, er entwarf ein eigenhändiges Testament für sich $u$. seine Frau u. war dabei gerade so sympathisch, wie ich es mir vorgestellt hatte. Er hat in seinem Auftreten sehr viel Ähnlichkeit mit Bühlmann, mit dem er auch in aller Freundschaft zu stehen scheint. Nur ist gewiss Bühlmann der tüchtigere Mann. Was er jetzt weiter macht, weiss ich nicht. Er will mir noch Mitteilung machen.

Und heute hat es nun richtig von sieben an an einem fort geregnet. Die Schulkinder von Frl. Reineck waren um fünf am Bahnhof. Obgleich es da noch nicht regnete, hatte Frl. Reineck den Mut, die Kinder wieder heim zu schicken. Marieli hat also da nichts versäumt. Es erzählte, bei der Gelegenheit, seine erste Lungenaffektion habe es sich bei der Schulreise über den Oberalppass zugezogen, wo sie bei strömendem Regen auf Braaks von Tschamutt nach Dissentis fuhren. Eben wird es von Abbühl zur Revanche abgeholt. Es hat ihn nicht mehr gern, er kommt ihm jetzt ungeschickt u. grob vor. So wechseln noch die Stimmungen in diesem trotzigen, unerfahrenen Herzen! Die Nacht war ich eine Zeit lang wach u. da kamen mir übermächtig die Gedanken an eine Verbindung zwischen Siegwart u. Marieli, u. über alle Bedenken hinweg stellte ich mir vor, das würde ein grosses Glück für beide u. für mich sein. Heute schaue ich die Sache wieder nüchterner an. Die Bedenken, mit der Verschiedenheit der Konfession u. den so ganz u. gar uns unbekannten Verwandten, erscheinen mir jetzt wieder bedenklicher, $u$. ich vermute, dass auch Siegwart, wenngleich er sich auch schon

Pläne gemacht haben mag, schliesslich vor der Sache zurückschreckt. Also keine Träumereien, u. lassen wir der jungen Welt ihren Lauf!

Ich kam heute wieder einmal dazu, etwas zu lesen, Hecks Rede über die Rechtsgewinnung zu Königs Geburtstag in Tübingen gehalten, eine mir nicht sehr sympathische, aber ganz gescheite Ausführung, die sich freilich in merkwürdige Kleinlichkeiten der verwandten Literatur verliert. Dann schrieb ich Briefe, präparierte Kolleg, hatte Guhl bei mir u. gab dem Fürsprech 
Illi aus Triengen eine Consultation, die recht herzlich verlief, da er sich als dankbarer Schüler von ehemals erwies.

Abbühl war beim Abholen Marielis etwas verlegen, ich empfing ihn freundlich $u$. beide gingen zufrieden dem Tanzvergnügen zu, im Taxameter. Am Morgen werde ich Marie vor dem Kolleg wohl wiedersehen. Abbühl habe ich auf morgen frei gegeben.

Zürcher hat sich noch nicht sehen lassen, während der zwei Wochen der B'versammlg, obgleich er jetzt ganz in der Nähe wohnt, da Meisters an die Schanzenbergstrasse gezogen sind. Trifft es wohl zu, dass er sehr niedergeschlagen ist, wie Kleiner geschrieben? Ich sandte ihm heute ein Billet, vielleicht reagiert er darauf.

Im ganzen kann ich wohl sagen, dass ich mich in diesem Semester weniger müde fühle als voriges Jahr. Vielleicht ist die Freude daran schuld, die ich an dem gutbesuchten Kolleg empfinde. Vielleicht auch kommt die Ermüdung noch. Kleiner wird am Samstag Abend zu mir kommen. Ich hoffe, er bleibt über Nacht, obgleich er davon geschrieben, dass er mit dem letzten Zug zurückfahren wolle. Am Samstag muss ich das Fest der Concordia mitmachen. Kleiners Besuch gestattet mir, mich bälder zu verabschieden.

Im übrigen will ich die Regennacht benutzen, um wiedereinmal um 9 zu Bett zu gehen, u. schliesse hier. Gute Nacht, meine einzige, liebe Seele. Ich verbleibe immerdar

Dein getreuer

Eugen.

Blumenstein hat Walter B. gesagt, er werde von Frisch abführen. Jetzt steht aber in seiner Zeitschrift ein wenig passendes Artikelchen, das sogar mit einer Empfehlung des Pamphlets schliesst. O kleine Welt! 
[1]

B. d. 14 Juni 1912.

Meine liebe, gute Lina!

Nach den gestrigen, ununterbrochenen Regengüssen, die an vielen Orten Überschwemmungen herbei geführt haben $u$. auch die Aare über ihre Ufer treten liessen, folgte heute ein regenloser, windiger Tag, der mich sehr müde gemacht hat. Immerhin habe ich mein Pensum schlecht u. recht abgewickelt, die Morgenstunden u. das Nachmittagspraktikum. Vormittags war ich auf der Bibliothek $u$. habe die Biographische Skizze über Hilty von Schellenberger in Bettelheims Sammlung deutscher Biographien nachgelesen, ich fand sie auf der Stadtbibliothek, nachdem sie Abbühl gestern auf der Landesbibliothek vergeblich gesucht hatte. Er brachte mir dafür Hiltys Biographie von Auer, in der Meinung, das gehe für das andre. Ich gab sie ihm zurück $u$. dazu bemerkte ich, er könne das Büchlein wieder hinbringen, oder auch es lesen, es schade ihm nichts, wenn er zwischendurch etwas lese. Abends sagte er dann zu Marieli, er habe auf mein Geheiss den Nachmittag eine Hilty-Biographie lesen müssen. Marieli erzählte auch, dass er ein paar mal so einfältig geredet, z. B. wenn von einem «Brunner» die Rede gewesen sei, gemeint, das sei wohl der Bruder des Studenten «Brunner», den er kenne, während er jenen «Brunner» gar nicht kannte. Und von mir habe er gesagt, ich sei ein «Huber» von Altstetten bei Zürich, es werde wohl nicht auch Huber von Altstätten im St. Gallen geben. Und weiter, sein Commilitone Bühler werde jetzt Major,

$[2]$

u. Kommandant eines Bataillons (der 23 jährige!) u. er, der noch die Aspirantenschule machen muss, sein Adjutant, u. der Bruder der Ella Beetschen in Thun, Polytechniker, 
sei Kommandant einer Batterie geworden. Das alles nur als Geschwätz auf Grund von Namensgleichheit. Es scheint, dass Marieli sich klug zurück gehalten. Er wollte am Morgen (5 Uhr) im Auto allein mit ihr zurück. Sie hielt aber darauf, dass alle drei Rabbenthalerinnen miteinander, begleitet von ihren drei Ballherren, zurück ging, sodass sie ein Alleinsein mit ihm gleich sich vermieden hat. Der Gesamteindruck für Marieli war, der Revanche-Ball sei sehr nett gewesen, aber Abbühl seie wirklich nicht intelligent. Es ist nur schade, dass sie das erst jetzt gemerkt hat, wo es mir schwer werden wird, ihn mit guter Manier wieder abzustossen. Es wird mich eventuell teuer zu stehn kommen.

Zürcher kam gestern nicht, weil die Partei ihren Ausflug hatte. Es hätte mich gefreut, wenn ich dazu eingeladen worden wäre. Aber es scheint nun wirklich, dass man mich als ausgeschieden betrachten $\mathrm{u}$. behandeln will, ganz der Antwort entsprechend, die mir Schatzmann auf meine früher gestellte Frage gegeben hat. Ich schrieb Dir s. Z. darüber. Das kann mir auch recht sein. Ich bin meiner selbst um so sicherer.

Walter B. teilte ich heute mit, wie Blumenstein seinen Ausspruch betr. die Kennzeichnung des Pamphlets von v. Frisch gehalten habe. Er war erstaunt u. fand, das sei ganz dem Wesen Blumensteins entsprechend. Er fand aber kein Wort der Missbilligung, weil der eben selbst

für das Unanständige in Frischs Benehmen keinen richtigen Fühler hat. Das stimmt ja mit alten Beobachtungen $u$. gibt mir nicht mehr viel zu denken. Ich will u. muss darüber hinaus sein.

Marieli traf heute Siegwart beim Gang zur Universität. Am Nachmittag kam Frau Schmid u. bat es zu ihnen. Es war dann auch dort bis Abends, machte Spaziergang mit dem ganzen Trupp u. kam vergnügt nach Hause. Ich sagte Dir gestern, ich will der Sache den Lauf lassen. Und ich meine, Du seiest damit auch einverstanden. 
Bist Du es nicht? Wäre Dir der Katholizismus ein Bedenken oder ein Hinderniss? Nach dem, was wir oft zusammen gesprochen, glaube ich das nicht. Aber es ist ja vielleicht überhaupt nichts an der Sache. Den Katerbummel nach Muri hat Marieli gestern sofort abgelehnt, weil die Aussicht auf Siegwarts Einladung vorbestanden. Das war auch gescheit. Ich hoffe, diese Gescheitheit werde etwas von der mangelnden Herzlichkeit u. Innigkeit ersetzen.

Schellenbergers Biographie hat mich entrüstet, es spricht soviel Hass u. Hohn daraus, u. wenn er auch den Mann nicht unrichtig kritisiert, so hat er doch viel zu wenig Tiefe, um seine guten Seiten zu verstehen. Ich sprach darüber mit v. Mülinen u. klagte ihm mein Leid, dass überall soviel Neid u. Verkleinerungssucht unter den Schweizern herrsche. Es entwickelte sich daraus wieder einmal ein recht herzliches Gespräch, das wir früher ja häufig an den Freitag-Morgen miteinander geführt haben. Ich war heute wieder den ganzen Tag in jenem

Gefühl des Träumens, vielleicht mit bedingt durch einen anrückenden Schnupfen. Es ist ganz merkwürdig, wie in dieser Verfassung die Wirklichkeit entrückt wird u. dem Traume ähnelt. Es ist manchmal schwer, den Traum von der Wirklichkeit zu scheiden.

Sehr gefreut hat es mich, dass Ussing sich bei mir heute nach der Vorlesung im Corridor sehr dankbar u. herzlich verabschiedet hat. Der junge Mann hat mir bei den wenigen Begegnungen, die ich mit ihm hatte, wohlgetan.

Jetzt wird es dunkel. Ich will die Lampe nicht mehr anstecken, sondern breche hier ab.

Hilf mir mit Deiner Güte u. Menschenkenntnis. Lasse Marieli den rechten Weg finden! So muss ja alles sich zum Guten wenden!

Gute, gute Nacht, von Deinem ewig getreuen Eugen 
B. d. 15. / 16. Juni 1912.

Mein liebstes Herz!

Heute habe ich das Fest der Concordia mitgemacht, von 10 bis fünf Uhr, u. nachher war Kleiner bei mir, an dessen ruhiger besonnenen Art ich wieder einmal eine rechte Freude hatte. Ich begleitete ihn auf den letzten Zug, er wollte nicht über Nacht bleiben.

Die fünfzigjährige Gründungsfeier war ausgezeichnet durch die Rede, die der einzig überlebende Gründer, RR. Scheurer Vater, gehalten hat. Die «Erinnerungen» an die Gründungserlebnisse waren für Zeit u. Leute sehr interessant. Beim Bankett in der inneren Enge sass ich ihm zur Seite u. konnte noch manches vernehmen. Bei dem Anlass bemerkte ich auch, dass Scheurer mir nicht, wie ich befürchtete, nicht wohl will, sondern die Verhältnisse objektiv beurteilt. Im Ganzen habe ich an dem Wiedersehen mit manchen alten Bekannten $u$. Hörern Freude gehabt. Marti, als Rektor, sprach ein paar Worte, Gmür als Dekan war vom Rektor mitabgeordnet, hat aber, wenigstens solang ich dort war, das Wort nicht ergriffen. Auch mit dem Amtsrichter Siebenthal sprach ich ein paar Worte. Ich war recht guter Stimmung, wurde aber beim Essen bald müde u. war froh, wegen Kleiners Besuch gegen fünf weggehen zu müssen. Die Müdigkeit wirkt jetzt noch. Es ist die alte Erscheinung, dass man während der andauernden Arbeit der Müdigkeit nicht bewusst wird. Sobald man dann aber einen Tag faulenzt, wie heute ich,

so wird sie spürbar. Ich halte mich auch für berechtigt, ihr nachzugeben u. sage Dir gute, gute Nacht! Wie mag es Abbühl bei dem Säbelduell gegangen sein, an dem er als Secundant zu funktionieren hatte? Er schilderte 
mir heute den ganzen Hergang: Den Bandagen, Secundanten, Schlappern, Pronotanten, oder wie sie heissen. Die Romantik war mir fast zu stark. Doch nochmals gute, gute Nacht!

Den 16. Juni.

Den heutigen Sonntag, den ich lieber zu Hause verbrachte, als an die Professorenconferenz nach Olten zu gehen, hatte ich zwei liebe Besuche: Leo Merz consultierte mich wegen der an ihn gelangten Anfrage, das Präsidium für das neugeschaffene Berner Handelsgericht zu übernehmen. Er legte mir allerlei Gründe dar, die mich schliesslich dazu brachten, ihn ganz auf seine innere Neigung zu verweisen. Alle Rücksichten auf Geld u. s. w. sind ja für ihn bedeutungsschwach. Er kann, wenn er auch nur 10000 Fr. Besoldung einnimmt (u. das wäre bei der Combination der Präsidentenstelle mit der eines Mitgliedes des Direktoriums der Hypothekarkasse der Fall) u. 15 - 16000 Fr. im Jahr braucht, immer noch von den Zinsen zurücklegen. Also da ist keine entschiedene Not. Nur die Rücksicht auf seinen immer noch kranken Bruder, den er, falls er das B'Gericht verlassen muss, gerne in sein Büreau aufnehmen würde, wäre etwa geeignet, aus ökonomischer Rücksichtnahme ihn so oder anders zu bestimmen. Allein die Gefahr ist noch sehr fern u. tritt hoffentlich gar nicht ein, sodass Leo wirklich frei handeln kann. Da soll er nun doch sich so entscheiden, wie es

im Innersten ihm wohltut, u. das bedeutet wirklich für ihn Annahme der Richterstelle. Ich bin nun gespannt, wie er sich entscheiden wird. Bis zum September muss die Frage geregelt werden. - Der zweite Besuch waren Dürrenmatts. Sie zeigten sich sehr anhänglich, ich hatte Freude an beiden, den gutmütigen Menschen, wenn auch die «Gruben», von denen ich Dir früher einmal schrieb, mir beim Anschauen der guten Frau nicht recht aus dem Sinn kommen wollten. Ihr Walter ist heute mit einigen jungen Leuten auf die [Schweb?] gegangen. Hoffentlich kehrt er heil mit ihnen zurück.

Anna ist heute nach Kalnach gegangen $u$. in dem Moment, wo ich dies schreibe, nicht zurück. Marieli kam heute zwischen zwei 
Stühle zu sitzen $u$. war darob den ganzen Tag unlustig $u$. verdriesslich. Bei gutem Wetter $-u$. so wurde es schliesslich heute - wollte sie die Tour über den Jaunpass machen. Da erhielt es gestern Nachmittag auf Anfrage telephonisch Bescheid, dass die Mina Betschen wegen Erkältung nicht gehen könne. Vorher aber hatte Marieli bei Frau Dr. Jauch abgesagt, die einen Ausflug auf den Gurten geplant hatte. Nun ja, das sind keine schlimmen Erfahrungen. Schlimmer ist, dass Marieli wieder die ganze Woche nie geübt $u$. daher die Stunde für Dienstag notgedrungen abgesagt hat. Ich nahm dies zum Anlass, Marie zu sagen, dass es überhaupt weit mehr die Zeit zusammennehmen $u$. weniger «staunen» sollte. Ich kenne ja aus meinen jüngeren Jahren diesen Zustand sehr wohl. Aber es hätte mir auch gut getan, frühzeitiger davon befreit zu werden. Marielis körperlicher Zustand ist ja besser, als vor einigen Monaten, es ist kräftiger geworden. Allein das sollte sich noch ganz anders zeigen. Ich bin immer noch im Ungewissen, was ich mit ihr

in den Ferien - die in sechs Wochen da sind - machen soll.

Nach Christiania? Sie mitnehmen, auf Geratewohl, dass alles wieder ungemütlich herauskommt? Und Anna so lange wieder mit Sophie allein lassen? Oder Marieli die Einladung zu Siegwarts in Altdorf annehmen lassen? Darüber u. über anderes schwanke ich noch immer hin u. her. Aber es muss sich bald abklären u. wirst mir bei der Entscheidung zur Seite stehen. Auf Marieli selbst kann ich mich leider, wie ich jetzt mehrfach erfahren, nicht verlassen.

Ich muss heute etwas fiebrig sein, du merkst es an den Schriftzügen. Sonst aber fühle ich mich wohl u. gehe morgen gerne wieder zur Vorlesung.

Adieu für heute! Ich bin in alter Liebe immerdar

Dein getreuer

Eugen 
[1]

B. d. 17. Juni 1912.

Mein liebstes Herz!

Gestern Abend halb neun telephonierte es $\mathrm{u}$. fragte Albert Heim vom Bahnhof her an, ob er zu uns kommen könne. Natürlich sagte Marieli von sich aus sofort zu. Das Gästezimmer wurde schnell hergerichtet. Vor neun war er da. Er hatte am Samstag dieselbe Kommissionssitzung wie Kleiner, war dann nach Goldiwil gefahren, wo Marie seit zehn Tagen wieder sich aufhält, da sie neuerdings sehr an ihrem Krampfhusten gelitten habe. Sonntags besuchte Albert seinen Freund, den Geologen Forel in Morges, u. von da kehrte er nach Bern zurück. Kleiner hätte mir sagen sollen, dass Albert am Sonntag wahrscheinlich komme. Obgleich wir von Albert u. Marie sprachen, hat er vergessen, das auszurichten. Albert war am Sonntag Abend sehr angeregt. Wir blieben bis gegen elf Uhr zusammen. Dann hatte ich kurzen Schlaf. Auf heute verabredeten wir, uns nach neun Uhr beim Postgebäude zu treffen, da Albert mir das Relief von Simon, das Berner Oberland, zeigen wollte, das eben jetzt zusammen gepackt $u$. an das Polytechnikum transportiert werden soll. Marieli u. Albert erwarteten mich nach Neun, Marieli in ihrer scharfen Art etwas ungeduldig, da ich erst zehn Minuten nach neun aus dem Universitätsgebäude heraus kam. Das Relief war in den Kellergewölben aufgestellt u. machte mir einen grossen Eindruck. Es umfasst eine Fläche von 6 zu 5 Metern, reicht vom Wildstrubel bis über das Wetterhorn. Haslital soll noch angefügt werden. Simon war sehr angeregt $u$. hat mir allerlei besondres

erklärt, unter anderem auch, dass ein Ausschnitt, betr. die Jungfrau, von der Jungfraubahn dem Kaiser im Anschluss an seinen Besuch überreicht werden soll. Um halb elf war ich zu 
Hause, u. auch Albert kam zum Mittagessen. Nachher wollte er auf 2.14 verreisen, blieb dann aber bis halb vier $u$.

dem verdanke ich, dass wir noch ein recht intimes Plauderstündchen im Garten haben konnten. Endlich erfuhr ich etwas näheres von dem Conflict mit Arnold. Es scheint eben doch, dass dieser ganz wesentlich vom Geldfieber erfasst war $u$. bei den geringsten Schwierigkeiten der wissenschaftlichen Arbeit nicht mehr viel Geschmack abgewinnen konnte. Er hat ja auch mit seiner Hetze u. seiner nervösen Erkrankung sich diese Arbeit ganz besonders schwer gemacht. Auch der Bruch mit der Geita Haushausen, den deren Vater durch Verleumdungen über Arnold herbeigeführt haben soll, ist unter diesen Gesichtspunkten zu betrachten. Arnold wolle nun im Herbst nach Hause kommen, aber was er dann anfange, sei noch gar nicht gewiss, am wenigsten wohl bei ihm selbst. Wahrscheinlich gedenke er dann als freier Geologe diesen $u$. jenen Unternehmungen zu dienen. Ob er wieder sich habilitieren werde? Ganz unsicher u. nicht wahrscheinlich. - Albert klagte gestern $u$. heute über seinen Nachfolger, der sein Amt nun so ganz anders betreibe, als er. Die ganze Schule von Geologen, die er herangebildet, sei in Frage gezogen. Ich konnte mich nicht enthalten, ihm darauf zu sagen, dass er eben das Amt nicht hätte verlassen sollen, u. er widersprach mir diesmal nicht. So erfüllt sich das Schicksal, vielleicht noch schneller, als ich geahnt. Albert sah zeitweise sehr müde u. überanstrengt,

bleich u. bekümmert aus, so dass er mich dauerte $u$. ich mich wirklich herzlich mit ihm verbunden fühlte.

Mit Abbühl hatte ich heute die Fortsetzung des Gesprächs über die Mensuren. Testant heisst derjenige, der das Protokoll aufnimmt, nicht Portonotant, wie ich gestern schrieb. Er teilte mir auch mit, dass er in der zweiten Hälfte Juli nochmals werde schlagen müssen, was mir nicht recht gefallen wollte. Ich sehe schon, dass Abbühl ganz u. gar in diesen Kreisen $u$. ihren Interessen aufgeht, $u$. dass er so wenig leistet, mag sich aus dieser Atmosphäre ebenso gut wie aus seiner mangelhaften Begabung erklären. Nun ja, die Suppe ist jetzt eingebrockt u. muss gegessen werden. 
Ob mir Marieli mit Siegwarts eine zweite einbrockt? Es wollte heute beim Abendessen durchaus wissen, wie ich nun über die Ferien verfügen werde. Und da konnte ich aber nichts anderes sagen, als dass ich mich jetzt nicht entscheiden könne, u. dass es selber den richtigen Weg im Verhältnis zu Siegwarts finden müsse. Die Gedanken hieran könnten mir ja wahrhaftig wieder viel zu schaffen geben. Aber es darf nicht sein, ich darf mich nicht die diese Gemütsdepression verlieren. Hoffnung muss stehen bleiben, $\mathrm{u}$. ich will mir erneut alles vorstellen, was mir zum Troste gereichen kann, um nicht neuerdings in Trübsal zu verfallen. Es ist nun eben u. bleibt eine schwere Zeit. Elemente, die mir widerstreben, tauchen auf u. gewinnen die Oberhand. Aber es schadet nichts, ich will aushalten $\mathrm{u}$. im Gemüt aufrecht bleiben, komme was da wolle!

Am Nachmittag kam Frida Weber schon wieder zu Besuch, u. Anna war einfältig genug mich herunter zu rufen. Sie, Frida, war übrigens sehr recht $u$. wir haben eine halbe Stunde gemütlich geplaudert. Sonst war auch noch die Studentin Hedwig Höhn bei mir, die ich noch nicht recht klassifizieren kann.

Dagegen war Zürcher nicht, wie er in Aussicht gestellt hatte, am Telephon.

Es war heute ein etwas windiger, kühler Sommertag. Das fiebrige Gefühl in den Fingern hat angedauert. Es wird sich nun aber wohl ausschlafen lassen.

Gute, gute Nacht, mein einziges Lieb! Ich bin

Dein ewig getreuer

Eugen 
B. d. 18. Juni 1912.

Meine liebe, gute Seele!

Ich hatte gestern Abend, als ich zu Bett gehen wollte, noch eine grosse Aufregung. Marieli hatte gesagt, es müsse noch zu Siegwarts, um zu fragen, ob sie auf heute oder morgen etwas vorhaben. Es ging vor acht, $u$. als ich um halbzehn in die Stube herunterkam, war es noch nicht zurück. Ich wartete bis zehn Uhr, u. ging in Kittel u. Pantoffeln auf die Strasse, zu sehen, ob es nicht komme. Ich ging bis unter das Schänzli, wo aber bei der schönen Sommernacht so viele Leute herumstanden, um das Konzert zu hören, dass ich es nicht über mich brachte, in meinem Zustand weiter zu gehen, sondern umkehrte, u. Anna ersuchte, bis zu Siegwarts vorzudringen, um zu sehen, ob Licht dort sei, oder sonst etwas zu erfahren. Ich stellte mir alles Schreckliche vor, Tramwagenunglück u. anderes u. irrte in Aufregung in den Zimmern u. im Garten herum. Ich spürte, wie mein Herz klopfte, u. dachte, wie ich mich zu verhalten habe, wenn Marieli länger ausbleibe. Zorn u. Zuneigung wechselten in mir. Ich erinnerte mich auch daran, wie ich einmal in Basel, als Du um 1 Uhr Mittags von einem Ausgang nicht zurückwarst, in Aufregung geriet. Es war nicht nur das höhere Alter, das mich jetzt schwankend empfinden liess. Da endlich um halb elf höre ich unten Stimmen. Von Frau Jauch u. Dr. Siegwart begleitet, kam Marieli zum Gartentor. Lachend wurde Abschied genommen u. in der Stube, in die ich Marieli aus dem dunkeln Garten nachfolgte Anna kam etwas später auch zurück - erhielt ich den Aufschluss: M. hatte Frau Jauch u. Siegwart mit Ständerat Wirz angetroffen, wie sie aus der Haustüre traten. Sie wollten mit M. zurückkehren, was M. mit Recht ablehnte. Dafür wurde es gebeten, mit ihnen zu kommen. Es ging langsam zum Bubenberg. Dann lud Wirz die drei ein, in den Casino-Garten zu kommen. Er ass dort zu Nacht 
u. Marieli erhielt eine Glace, $u$. war sehr vergnügt. Unter unserem Gartentor habe Siegwart noch bemerkt, wenn ich bös werde wegen des Spätkommens, so wolle er Marieli morgen für mich einen Zettel schreiben. Nun ja, ich war bald beruhigt, die Angst war natürlich gleich weg, aber das Herz wollte sich nicht so bald beschwichtigen lassen. Ich hatte so Schreckliches gedacht, dass ich fast nicht einschlafen konnte, bald wieder erwachte, $u$. aus den leichten Zahnschmerzen, die ich zu spüren begann u. mich heute noch etwas plagen, merkte ich, dass ich mich überdies erkältet hatte. Nach der unruhigen Nacht war ich heute im Kolleg reduziert. Die Studenten merkten auch wohl, dass ich nicht wohl war.

Vor Tisch u. heute Abend präparierte ich am Colleg. Von halb drei aber bis halb fünf war Emil Zürcher bei mir, der so herzlich war, als möglich. Er sprach nicht viel von dem Tod der kleinen Klara, aber ich merkte schon, dass er die Sache, namentlich Theas wegen, nicht überwunden hat. Er erzählte, am Ostertag habe er die ganze Familie bei einander gehabt, u. sie seien glücklich gewesen. Auch Karl sei aus dem Militärdienst gekommen, er sei jetzt kräftiger geworden, als Emil u. sei mit viel Witz ausgerüstet. Auf einem Spaziergang sei z. B. Ernst Hoffmann voraus gegangen $u$. der Vater Zürcher habe Karl gesagt, er soll ihn doch zurückholen. Da sei Karl dem etwas kleineren Schwager nachgegangen $u$. habe ihm auf die Achsel geklopft mit den Worten: «Büebli, wem ghörst?» So was hätte auch der Vater Zürcher etwa angebracht.

Wir sprachen von allerlei, aus dem Berufsleben, namentlich aber von der Gesundheit, wobei mir Zürcher mitteilte, er leide eben doch etwas an Fettherz, könne oft nicht einschlafen $u$. habe Zwicke u. Stiche in der Herzgegend. Aber seit Frühjahr gehe es ihm wieder bedeutend besser. Ich meinte, das sei wohl ein Zeichen, dass die Nervosität daran Schuld, er aber sagte, nein, der Winter 
sei immer für ihn die schlimmere Zeit gewesen. Letztes Frühjahr habe er einmal mehrere Nächte hinter einander nicht schlafen können, sodass ihm Dr. Seitz Digalon verschrieben, wovon er aber nur wenig genommen habe. Jetzt müsse er noch im Sommer die Fortsetzung der Erläuterungen zum Strafrechtsentwurf schreiben, was ihn beängstige. Ich hatte den Eindruck, dass sein Sohn Emil da in die Lücke treten könnte.

Nun aber noch das Merkwürdigste. Ich fragte ihn noch nach den Kollegen, wobei er namentlich bei Reichel stehen blieb u. erzählte, dieser schreibe zu viel u. zu windig. Er habe ihm nämlich ein Manuskript zurückgegeben mit dem Rat, das nicht zu veröffentlichen. Zuletzt fragte ich auch nach Meili, u. da bemerkte er, ja der sei bös daran: Letzten Sonntag habe ihm Meilis Haushälterin telephoniert, er soll noch zum Kassationsgerichtspräsidenten herunter kommen. Und wie er bei Meili erschienen, habe ihm dieser gesagt, er könne das Gericht in der Sitzung des folgenden Tages, also gestern, nicht präsidieren. Zürcher als Vizepräsident müsse das übernehmen. Er, Meili, sei nämlich plötzlich auf einem Auge völlig erblindet. Der Arzt meine, da sei nicht mehr zu helfen. Es sei eine Gefässverstopfung - nicht NetzhautAblösung. Und Meili habe gesagt, das sei wohl der Anfang vom Ende. Dabei haben sie beide mit Galgenhumor vom Tode gesprochen. Aufgefallen sei ihm dabei, dass Meili bemerkt habe, es sei für ihn doch ein schönes Leben gewesen. Niemals hätte er, Zürcher, geglaubt, dass dies das Gesamtfazit für Meili über sein Leben sein könnte, nachdem er auf so schreckliche Weise seine Frau u. auf noch schrecklichere seinen einzigen Sohn verloren. Ich stehe auch unter diesem Eindruck. Aber das Selbsturteil stimmt sehr mit Meilis ganzem selbstzufriedenen, oberflächlichen Wesen. Übrigens ist der Fall wohl doch nicht so schlimm, es hat schon mancher ein Auge durch Apoplexia verloren $u$. noch lange gelebt. Meine Pläne betr. Christiania könnten nun, wenn Meili, wie jetzt doch wahrscheinlich, nicht hinreist, bestimmter werden.

Morgen wird Marieli endlich die längst geplante Schulreise 
mit Frl. Reineck nach der Griesalp abwickeln. Auch diesmal nicht ohne Collisionen. Es hat Reding die Stunde abgesagt, die er als Ersatz für die auf heute wegen Mangels an Präparation abgesagte, vorgeschlagen, es hat eine Einladung der Frau Gmür in ein Concert von heute Abend ausgeschlagen, es hat der kleinen Lüdemann die auf morgen verabredete Zusammenkunft zum vierhändig spielen verschoben, u. hat der in Aussicht stehenden Einladung zu Frau Jauch auf morgen abgeschrieben. Übrigens zeigt das auch, in welchem Getriebe die Kleine eigentlich steht. Da kann ja aus dem Studium nichts herauskommen. Allein gesundheitlich bekommt ihr das entschieden besser, als das Studium.

Die Zahnschmerzen haben sich heute Abend gesteigert. Ich bin etwas geschwollen. Wenn nur nichts schlimmeres kommt!

Ich schliesse einen Tag, den ich mehr als sonst wie im Traum verbracht. Es war ein Fieber in mir die letzten Tage spürbar. Heute hat es wohl den Höhepunkt wieder überschritten, u. ich hoffe wieder in ruhigere Verfassung zu kommen. Aber die Sammlung, was wird aus meiner Sammlung für das, was ich noch tun sollte? Ich habe heute einen Brief von Rümelin erhalten, der aus einer ähnlichen zerfahrenen Verfassung heraus geschrieben zu sein scheint. Das tägliche Berufsleben zehrt uns auf. Aber es mit Ruhe zwangsweise vertauschen? Das kann $u$. will ich jetzt nicht mehr denken, $u$. ich weiss mich darin mit Dir einig!

Gute Nacht, mein liebstes Herz! Ich bin auf immerdar Dein getreuer Eugen 
B. den 19. Juli [sic!] 1912.

Mein liebstes Herz!

Das schöne Wetter scheint gekommen zu sein, Marieli hat heute einen prächtigen Tag zum Schulausflug nach der Griesalp. Die bessere Witterung hat mein Zahnweh rasch verjagt. Aber es war heute doch ein unruhiger, bekümmerter Tag. Ich wachte zeitig auf $u$. klopfte an Marielis Türe, um 3 1/2 Uhr. Dann wollte ich aber weiter schlafen $\mathrm{u}$. fand auch nach $4 \mathrm{Uhr}$ den Schlaf wieder, bis um 4 11/4 Uhr ein Geschall an der Alarmklingel losging, worauf ich schlaflos bis zur Zeit meines Aufstehens (gegen 5 플 Uhr) liegen blieb, aber mich nicht ausgeruht fühlte. Anna hatte den Streich begangen, indem sie zwecklos aufstand u., während Marieli noch auf seinem Zimmer sich fertig machte, hinunter ging, ohne die Klingel abzustellen, u. die Haustüre öffnete. Eine Kleinigkeit, die mich aber etwas gestört hat. Im Kolleg war ich munter. Nachher hatte ich eine Antwort an Berlot zu schreiben u. andere Briefe. Am Nachmittag war Zehnder, aus Wien u. Graz zurück, bei mir u. ich nahm mit ihm meine Bemerkungen zur Dissertation durch. Er war während der Besprechung oftmals verletzt, verabschiedete sich aber mit höflichem Dank. Dann begegnete das zweite von heute, was mich nun wirklich erzürnte. Ich klingelte, wie gewöhnlich beim Fortgehen eines Studenten, damit die Türe ihm geöffnet $u$. wieder geschlossen werde, ging in mein Cabinet u. wollte etwa zehn Minuten später zum Telephon, als ich Zehnder noch im Corridor traf, der sich entschuldigte, er könne die Haustüre nicht öffnen, d. h. in seiner Höflichkeit wollte er nicht aus eigenen Stücken öffnen, da ja niemand, wie er sagte, wieder geschlossen hätte. Es stellte sich heraus, dass Sophie auf ihrem Zimmer oben

war, sie behauptete, meine Klingel nicht gehört zu haben, $\mathrm{u}$. Anna war in der Stube u. hatte auch nichts gehört. Beide wussten, 
dass Jemand bei mir war, der jeden Augenblick weggehen konnte. Wahrscheinlich hat die eine im Trutz, die andere aus Trägheit sich auf die andere verlassen $u$. so passierte die Unregelmässigkeit, die mich gerade wegen des höflichen, fast schleichenden Photographensohnes sehr betrübte. So ist es nun eben mit meinem Haushalt. Ich wiederhole immer u. immer wieder, nie hätte ich gedacht, mit Anna Haushalten zu müssen. Das war mir ja von jeher bekannt, wie wenig sie zu einer solchen Leistung taugt. Welche Mühe hattest Du nur die langen Jahre über, sie einigermassen an unsere, an Deine Hausordnung zu gewöhnen! Sophie ist zu wenig interessiert $\mathrm{u}$. zu eigenwillig, obgleich ja vieles bei ihr besser geworden ist, $\mathrm{u}$. Marieli ist zu jung $\mathrm{u}$. hat überhaupt gar keinen Sinn für den Haushalt. Diese Arbeitsrichtung hätte es erst in diesen Jahren noch unter Deiner Leitung lernen sollen, $\mathrm{u}$. das ist nun eben nicht geschehen! Ich war im Moment von dem Vorfall, so unbedeutend er ist, sehr betrübt u. erregt. Hat er mir doch meine häuslichen Verhältnisse grell beleuchtet, u. da kommt dann gleich der Jammer über mich. - Ich ging dann an Kollegpräparation $u$. hatte dabei auch einige Schwierigkeiten zu überwinden. Doch ist es mir jetzt wieder wohler $u$. ich bin ruhig geworden. Das sind ja alles Kleinigkeiten, die für die Zeit, wo es noch gilt, zu tragen sein werden. In Albert Weltis Nachruf steht, dass er beim Tode seiner Frau einen Leichenzug gezeichnet mit der Aufschrift: «Glück u. Unglück - beides trag in Ruh!«Alles geht vorüber, Und auch Du!» In der Zeitung las ich, dass Josephine v. Grebel plötzlich gestorben sei. Ich habe an Anna v. Grebel sofort ein herzliches Beileid-

Kärtchen geschrieben. Die Nachricht hat mir jene Tage ins Gedächtnis gerufen, da Josephine u. Anna v. Grebel im Sommer 1879 bei uns im Landammann Haus unsere Ferienpensionäre waren. Es sollte die Gelegenheit unseren Finanzen etwas aufhelfen, u. Du hast es bei dem niedrigen Pensionspreis von vier Franken pro Tag auch verstanden, wohl zu haushalten. Die kleine Elise Hehl, das Confirmations Schülerchen, war Dein Dienstmädchen, Anna sass an der Strickmaschine im Parterre, u. ich auf dem Bureau im Rathaus. Wir suchten auch nach einer Ablenkung nach dem Tod des lieben Anneli u. Du verrichtetest absichtlich strenge Arbeit, um über Deine Stimmungen hin- 
weg zu kommen. Wir machten auch einige Ausflüge mit Grebels, einen im Zweispänner nach Appenzell u. auf die Ebenalp, von Weidbad zu Fuss. Auf der Rückfahrt stieg ich in Bühler mit Anna von Grebel aus, während Du mit Josephine über Gais weiterfuhrst. Ich ging mit ihr über die Weissegg direkt nach Trogen. Im Herzen hattest Du die Pensionäre gern, Du verstandest ja auch die Sache trefflich zu führen. Aber ich erinnere mich doch noch an einen Ausbruch des Schmerzes, in der Zeit wie die Grebels bei uns waren, wo Du verzweifelt jammertest, dass Du zu solcher Arbeit geraten seiest, es war Annelis Tod, der Dir auf dem Gemüte lag. Nachher hast Du den Vorfall ganz vergessen. Es kamen ja andere Jahre. Und als ich einmal darüber mit Dir sprechen wollte, da merkte ich wohl, dass es nicht nur Selbstbeherrschung war, die dich anleitete, nicht darauf einzutreten, sondern ein wirkliches, völliges Vergessen. Du warst niemals so gerne in Trogen wie ich. Die späteren Schicksale haben eine Ausgleichung gebracht.

Gestern gegen neun Uhr kam Walter B. noch eine Weile zu mir.

Er hatte etwas Wissenschaftliches zu fragen u. blieb eine Weile. Es machte mir Freude u. ich schloss den Tag mit frohem Herzen. Ich

will es heute trotz des Vorgefallenen nicht anders halten. Danken wir für das was wir haben. Was fehlt ist, ja doch nur eine Lücke, die das Schicksal ausfüllen u. verebnen wird, wenn es mich mit Dir vereint.

Wenn jetzt warme Tage kommen, so wird mir das zu schaffen geben. Aber es geht ja nicht mehr lange. Von morgen an werden die Tage schon wieder kürzer.

Gute, gute Nacht, meine liebe Seele! Allezeit

Dein getreuer

Eugen 
[1]

B. den 20. Juni 1912.

Mein liebstes Herz!

Heute habe ich die versprochene Mitteilung von dem

Verleger Lichtenhahn erhalten, worin er mir bestätigt, dass wir übereingekommen seien, mit dem Druck des ersten Bandes erst zu beginnen, wenn sämtliche Einführungsarbeiten erledigt seien $u$. zudem die Vorbereitung des zweiten Bandes soweit gefördert scheine, um den ununterbrochenen Weiterdruck zu sichern. Das gibt mir vor der Hand wieder etwas Spielraum, aber zur eigentlichen Verbesserung der Lage reicht es nicht hin. Denn zur Zeit beschäftigen mich täglich immer noch so viele $u$. wichtige Anfragen, dass ich an eine Arbeit am Buche gar nicht denken kann. Wird das so bald besser? Ich muss es hoffen $u$. inzwischen darauf vertrauen, dass ja jede Stunde meiner Vorlesungen mich auch in Bezug auf das Buch fördert. Letztes Aushülfsmittel würde es dann immer noch sein, geradezu das Kollegienheft zum Buche auszuarbeiten u. dem Professorat daraufhin oder währenddem Lebewohl zu sagen. Allein ich befinde mich jetzt gar nicht in der Stimmung, das zu tun, ich meine nur, ich könnte durch die Umstände dazu gezwungen werden. - Zugleich mit dem Brief über unsere Abmachungen hat Lichtenhahn mir auch Vorschläge gemacht über die von ihm in Aussicht gestellte Vergrösserung des Formates für das Buch. Er legte mir zwei Probeseiten bei, die eine in Borgis, bei der mein Honorar von 140 auf ca. 190 Fr. per Bogen steigen würde, $u$. die andere in Garmond mit Erhöhung auf 175. Allein beide gefallen mir nicht, weil 
die grossen 47 zeiligen Seiten zu eng gedruckt erscheinen u. das Ganze sehr wenig übersichtlich werden liessen. Da bleibe ich am Ende doch lieber bei dem Format der ersten Auflage. Um das Urteil mir abzuklären habe ich heute Nachmittag die ganzen Vorarbeiten für den ersten Band nochmals oder wieder einmal durchblättert $u$. den Umfang der einzelnen Paragraphen genauer abgeschätzt. Ich glaube nun, es doch zu wege zu bringen, dass ohne erhebliche Kürzungen der ganze Band, Allgemeiner Teil $u$. Personenrecht umfassend, auf etwa 740 Seiten, mit dem geplanten Register 770 / 80 kommen würde, also nicht mehr als der erste $u$. vierte Band der ersten Auflage umfassten. Ist dies der Fall, dann bleiben wir doch lieber bei der früheren Abrede. Ich musste mir gleich sagen, wenn Du die beiden Probeseiten sähest, so würdest Du gleichfalls weder die eine noch die andere wählen, sondern beim alten bleiben. Ich werde mir nun die Sache noch einige Tage durch den Kopf gehen lassen u. dann, wenn nicht besondere Umstände mich andern Sinnes werden lassen, Lichtenhahn in besagter Weise antworten.

Wie ich die Manuskripte der Paragraphen des ersten Bandes durchging, bekam ich wieder die rechte Vorstellung, wie viel mir Siegwart gearbeitet hat. Überall hat er mit Verständnis nach meinen Anweisungen Zusammenstellungen gemacht $u$. Ergänzungen angebracht. Es ist gar nicht daran zu denken, dass Abbühl, auch mit den Jahren, je dazu kommen wird, Gleichwertiges zu leisten. Er hat zu wenig Zug zur Wissenschaft $u$. wird den nie sich aneignen. Ich bin daher in einer wirklich ungeschickten Lage. Fortschicken kann

ich ihn nicht, wenigstens nicht ohne einen kleinen Skandal, der mir für den gutmütigen Naturburschen leid täte. Und doch versperrt er mir den Platz für etwas Besseres, von dem weggeworfenen Geld nicht zu reden, denn das rechtfertigt sich am Ende im Sinne der Unterstützung für einen strebsamen Com- 
militonen. Da hat mir die Rücksicht auf Marieli u. seine Stimmung eine grosse Verlegenheit eingebrockt. Wäre der Plan mit seiner Schwester Anneli besser geglückt! Eigentlich meinte ich beides, $u$. dann hat Marieli das eine, vielleicht das bessere, abgelehnt, u. mit dem andern sitze ich in der Tinte. Doch will ich auch da nicht verzagen. Es kommt vielleicht doch noch besser. Auf morgen habe ich Abbühl noch einmal ein kleines Gutachten zur Reinschrift mitgegeben. Wenn das besser gelingt, als seine früheren Leistungen, so will ich wieder Hoffnung schöpfen.

Gestern Abend schrieb ich noch, weil Marieli von der Schulreise erst gegen zehn zurück sein konnte, den Entwurf zu dem genannten kleinen Gutachten, das ich dann heute vor Tisch fertig stellte. Dann kam auch Guhl wieder einmal mit verschieden interessanten Fragen. Von der Schulfahrt auf die Griesalp war Marieli gestern Abend recht vergnügt zurückgekehrt, die Abwechslung hat ihm gut getan. Heute war es mit Frau Jauch etc. auf dem Schänzli. Ich lasse es nun so gewähren.

Von Marti stand in der Zeitung, dass er aus Gesundheitsrücksichten seine Entlassung aus dem Kassationsgericht genommen. Das bestätigt die Mitteilungen Zürchers. Ich halte mich trotz der inneren u. äusseren Mühe, die mir die Anfragen bereiten, aufrecht. Ich will in den alten

Trübsinn sobald nicht wieder verfallen. Hoffe auch, dass wenn mir das gelingt, darin nicht ein Anzeichen von Altersschwäche gefunden werden müsse. Ich wollte nur, dass wir zusammen uns nach solcher ruhigeren beschaulicher Stimmung hätten erfreuen können. Du hast mich gerade da verlassen, wo die Umkehr sich in mir abzuklären begann. Das gehört zu den bitteren Erfahrungen in meinem Leben, u. es lässt sich nur innerlich bessern, in der äusseren Gestalt ist das Glück u. bleibt es gebrochen!

Anna ist sehr unmutig. Ich weiss nicht warum. Martha Gämperle hat sich verlobt u. sie erhielt keine Anzeige. Die jungen Leute sollen in Bern zu wohnen kommen. 
Heute Abend ist Fackelzug für Kocher. Der alte Langhans soll gesagt haben, er habe abgelehnt. Er stellt sich also mit Kocher auf gleiche Linie. Nun ja, jedem das Seine, oder etwas mehr, nur nicht weniger!

Jetzt wird es auf der Terrasse dunkel u. ich muss noch Kolleg präparieren. Also Schluss für heute, ich will wieder einmal vor zehn zu Bett.

Mit innigstem Gruss u. Kuss immerdar Dein

Eugen

\section{2: Juni Nr. 138}

B. den 21. / 22. Juni 1912.

Mein liebstes Herz!

Ich fühlte mich heute von Anfang des Tages an unwohl.

Es war, was Lüscher vor länger als vier Jahren einmal eine «Stauung» genannt hat, wobei ich Wärme in Wangen u. Augen verspürte. Und in der Herzgegend war ein latenter schwacher Schmerz, der aber, wie übrigens schon in den letzten Wochen einige Male, den Sitz wechselte und sich so als Rheumatismus kennzeichnete. Dazu kam, dass um sieben Uhr das Auditorium nur halb beisammen war, was mich sehr bestürzte, bis ich dann die Erklärung darin fand, dass die Farbenstudenten von Kocher nach dem gestrigen Fackelzug im Casino-Garten einen Commers gemixt erhielten, der bis halbsechs diesen Morgen gedauert haben soll. Da waren die Morgenkollegien natürlich verpfuscht. Übrigens eine ächt Kochersche Rücksichtslosigkeit. Sie bildet einen prägnanten Gegensatz zum Verhalten von Sahli, der als ihm vor mehr als Jahresfrist auch ein Fackelzug gebracht wurde, nicht einen einzigen Studenten dafür regalierte, was ihm sehr übel genommen wurde. Interessant sind beide Verhalten. Ich könnte als drittes mein Vorgehen anfügen, das darin bestanden hat, einfach den Fackelzug nicht anzunehmen. 
Ich hatte auf der Bibliothek zu tun. Nach meiner Rückkehr war Abbühl da. Er hat trotz der Commersgelegenheit die Abschrift erledigt, ohne wichtige Fehler, aber freilich nicht sauber. Nach dem Essen schlief ich wieder einmal fest. Nachher Collegpräparation. Der Café brachte mich dann in Schweiss u. darauf wurde mir leichter, sodass ich die Übungen ohne Störungen abhalten konnte. Die Farbenstudenten fehlten

auch hier fast alle. Aber es war doch eine ganz anregende Diskussion.

Kleiner schrieb mir, dass er heute vielleicht zu mir komme, nämlich wenn er, aus einer Kommissionssitzung, nicht um fünf verreisen könne. Er erschien nicht, u. das war mir schon recht, denn ich war u. bin eben doch sehr müde u. wäre nicht gerne nochmals zum Bahnhof gegangen. Dafür kommt Frl. Reineck zu Marieli, die mir aus Griesalp eine einfältige Karte geschickt hat. Ich muss sie schnell grüssen, will aber gewiss zeitig zu Bett.

Der Haushalt lässt wieder sehr viel zu wünschen übrig. Sophie hat kein Herz bei der Sache, die alten Stimmungen kommen immer wieder. Nun ja, man muss es tragen, auch das zweifelhafte Geköch. Marieli hat auch nicht eine Ader für das Hauswesen, u. Anna kennen wir ja. Aber ich will nicht wieder in Trübsinn verfallen, sondern mich in der Stimmung erhalten, die ich mir mühsam errungen habe. Die Gärtner haben den Garten gemacht, das wäre recht, aber der Sohn Flückiger - der Vater ist vor einigen Wochen gestorben - hat die Sache doch nicht recht in der Hand, das sieht man aus seinem wechselnden Personal. Das war mit Anderem eine Beobachtung, die mich vordem oft auf den Gedanken brachte, das Haus zu verkaufen. Jetzt bin ich auch über dieses hinweg. Trotz allem Unbehagen, das mich hier so oft umfängt, ist es halt doch die bessere Einsicht, wenn ich aushalte, still u. unentwegt. Das ist mein Teil, u. dabei will u. soll ich bleiben, solange ich kann. Der längste Tag! Schon wieder ist er da, u. die Nächte werden wieder länger. Man muss zusehen, seine Zeit zu benutzen, 
$\mathrm{u}$. ich leiste so wenig, $\mathrm{u}$. bringe es nie zu einer Ruhe mit

Würde. Das ist nicht unseres Volkes, unseres Schlages, wir

müssen arbeiten, sonst gelten wir nichts. Also nochmals: aushalten, stillhalten, Maul halten möchte ich fast sagen. Das zu viele Reflektieren ist auch nicht von gutem. Morgen ist das Kocherfest. Ich will Dir dann auch ein paar Sätze darüber schreiben!

Den 22. Juni.

Der heutige Tag war ganz von der Kocherfeier in Anspruch genommen. Um 91/4 musste ich aufbrechen. Vor zehn sammelten sich die Teilnehmer in der Universität, wo ich manchen Bekannten seit langem wieder einmal sah. Die Ansprachen in der Aula dauerten von zehn bis ein Uhr. Daran schloss sich das Bankett von 1/1/4 bis etwa $5 \frac{1}{2}$ Uhr, ich ging vor fünf weg, um auf $5 \frac{3}{4} 4$ in der neuen Villa Kocher der Garden Party mit Marieli beizuwohnen. Von dort war ich zu Fuss um 83/4 zu Hause. Die Garden Party gab Gelegenheit, viele Bekannte zu grüssen. Wir waren zu meist mit Martis, Rektor u. Frau u. ihrer Tochter Esther zusammen. Ich lernte auch einige andere kennen. Am Essen war ich ziemlich weit vom Honoratiorentisch, in der Mitte, hatte aber zu Nachbarn links Sauerbruch von Zürich, u. Prof. Kuhn von Amsterdam. Der letztere hat dann in dem Park Kochers mit Marieli viel geplaudert. Er war ganz erstaunt, als er in mir den Professor des ZGB., von dem er viel gehört, entdeckte. Sauerbruch kannte mich nicht, aber er erzählte mir, als er hörte, ich sei Jurist, von Hitzig, u. das Neue, was ich von ihm vernahm, war, dass er seit dessen Tod allerlei vernommen über dessen Art u. Leben, was den schlimmen Ausgang erklärlicher mache. Übrigens habe Hitzig so dringend die sofortige Operation gewünscht, dass er erklärt habe, er reise sofort nach Leipzig, wenn S. die Operation nicht mache. Auch hätte er sich geweigert, erst sich etwas Ferien zu machen etc. etc. Ich ersah daraus, dass die Sache Sauerbruch sehr nahe gegangen sein muss. - Bei Kochers sah ich auch Garé wieder einmal, den ich s. Z. in Basel kennen gelernt. Natürlich haben die Mediziner überall prävaliert. 
Im Ganzen habe ich den Eindruck gehabt, die Feier schliesst in günstigster Weise die Rechnung des Kocherschen Lebens. Eine Arbeitskraft u. - Summe ausserordentlicher Grösse hat ihn zu den Ehren u. dem Reichtum gebracht, die er hier nun in voller Reife darstellen konnte. Und damit die Note des Gemeinsinnes nicht fehle, hat er sich dazu entschlossen, im Einverständnis mit seiner Frau eine Stiftung von 200000 Fr. zu machen für eine biologisches Institut, das etwa 1934 eröffnet werden soll, wenn mit Zinsen bis dahin auf $1 \frac{2}{2}$ Million angewachsen. Schon von 1915 aber sollen alle drei Jahre $3000 \mathrm{Fr}$. an ein bedeutendes Werk, wie Hiltys Glück, oder Hubers Zivilgesetzbuch entrichtet werden, so heisst es in der heute verlesenen Stiftungsurkunde, also an ein Werk irgend einer Fakultät. Ich habe ihm gedankt für das anerkennende Wort. - Er ist in seiner Antwort als gläubiger Mann aufgetreten, gewandt, scharf, u. sehr bewegt. Er war um Mittag älter als am Abend. - Trotz diesem sympathischen Eindruck von der ganzen Feier ist mir doch das Gefühl nicht ganz geschwunden, dass das in unsere Verhältnisse nicht recht passt. Die Schweizer Gäste haben sich auch ganz anders benommen als die ausländischen, man spürte ihnen an, dass für sie diese Note von Lob u. Anerkennung etwas ganz ungewohntes u. fremdes war. Einzelne fehlten, wie Dumont, ganz, andere kamen nur an die Aula-Feier, wie Lüscher. Sahli war ganz dabei, was mich für ihn freute. Es wurde von Kocher selbst ein Ausspruch Billroths zitiert: Solche Jubiläen seien Begräbnisfeiern bei lebendigem Leib. Es ist sicher, dass bei unserem Wesen in solchen Dingen derjenige, der sich weigert, in den Augen der meisten besser tut, als der annimmt. Aber eineweg, für mich war die Feier schön u. belebend. Du hättest auch Deine Freude daran gehabt, liebe Seele!

Und nun müde zu Bett! Gute, gute Nacht! Immerdar Dein alter, treuer

Eugen 
B. d. 23. Juni 1912 .

Mein liebstes Herz!

Ich benutzte die Pause zwischen der stillen Pause nach Tisch u. dem Eintreffen der «Siegwarts», die heute nochmals, von der Abreise der Frau Schmid, den Nachmittag bei uns zubringen wird, um diese Zeilen zu beginnen. Der Nachgeschmack von den gestrigen Festlichkeiten ist gut, aber nicht so, dass ich es wünschen würde, einmal so gefeiert zu werden. Es ist eben doch etwas fremdes in diesen Veranstaltungen, fremd für mich, für uns. Wir sind zu eng, zu klein für derartiges. Wenn gestern einer der Redner betonte, dass Bern seinen grossen Haller verkannt habe, so befindet es sich in einem doppelten Irrtum. Einerseits gibt es bei uns u. gab es schon zu Hallers Zeiten einzelne genug, fähig, das Grosse zu erkennen, aber sie wollten es nicht zeigen, um sich nicht kleiner zu machen. Und anderseits, wenn wir gestern Kocher feierten, so war das für die grosse Menge doch nicht die Erkenntnis der Grösse, sondern ein Mitmachen, zum Zweck der Selbstbespiegelung. Ich konnte das gestern Abend in Kochers Garten gar vielen anmerken. Und man kann es ihnen auch gar nicht übel nehmen. Habe ich richtig gehandelt, dass ich Kocher nur kurz begrüsste, indem ich voraussetzte, er sei nun ganz von Näherstehenden umringt? Und doch traf ich ihn allein mit seiner Frau u. wusste nichts rechtes zu sagen, da ich ihm gegenüberstand. Es fehlt die Perspektive. Der Grosse ist entweder allein, oder er muss sich mit den Kleinen begnügen, u. ich vermute, dass Kocher manchen unter seinen grossen $\mathrm{Ge}-$ nossen vermisst hat. Bern ist abgelegen $u$. kann dies mit einem Festtag nicht wett machen. Das reicht ja gar nicht aus. Als ich nach Hause kam, fand ich ein Paket aus Baltimore, das 
die Probeabzüge des ganzen ZGB. in englischer Übersetzung enthielt, mit der Bitte, es zu durchgehen u. mit meinen Bemerkungen zurück zu schicken. Wenn ich das machen soll, so ist es eine Arbeit mehrerer Wochen. Wie soll ich das leisten, ohne fremde Hülfe? Und wer hilft mir? Im November 1909 hatte ich die ersten paar Dutzend Artikel à Maschinenschrift erhalten. Ich las sie damals durch. Guhl u. seine Frau halfen, u. ich konnte einzelne Bemerkungen einsenden $u$. anerbot mich, in dieser Weise fortzufahren, u. jetzt kommt, nachdem ich vergeblich gewartet, das Ganze auf einmal. Ich weiss noch nicht, wie ich mir helfen soll! Ein kurzer Überblick von heute Vormittag hat mir grosse Bedenken erweckt.

Sonst arbeitete ich heute Vormittag an dem Kollegienheft, ich muss gestehen, ohne grosse Lust. Es wird mir Alles so überdrüssig, wenn ich immer nur den dialektischen Kämpfen gegenüberstehe u. nicht weiss, wie das enden soll. Das ist doch nicht Recht, nicht Gerechtigkeit, das löst sich - ich arbeitete an der Miete - in lauter Wortgekläff auf. Dann war Kaiser bei mir, der mich im Auftrag Müllers über eine Antwort consultieren wollte, die unsere Vertreter an der Haager Wechselkonferenz haben wollten. Wir waren bald fertig. Müller soll zu Kaiser gesagt haben, ich sei nicht am Bankett gewesen, während man Kaiser, als er gestern Nachmittag zu mir wollte, den Bescheid gab, ich sei im Casino. Es ist wahr, ich habe es auch vermisst, Müller mit keinem Wort grüssen zu können, aber wir sassen so weit auseinander, u. er war in solcher Umgebung, dass ich mich scheute, mich vorzudrängen. Weshalb hat man mich da hinunter gesetzt zu den Leuten, denen die Offiziellen ferne standen? Mir war ja freilich wohl dabei. Ich wünschte 
nichts anderes als bei einem Sauerbruch $u$. andern zu sein, denen ich freundliches Beisammensein können anspürte. Aber dann verschwindet man in der Menge u. Müller konnte nur sagen, er habe mich nicht gesehen, aber nicht, ich sei nicht da gewesen. Doch ich ertappe mich wieder in pessimistischen Gedankengängen. Das darf nicht sein, ich muss ausharren, es gibt nichts anderes, nichts besseres für mich.

Übrigens hat Kocher sich selbst in bescheidenster Weise ausgesprochen. Er führte an, dass er zuerst ganz abgelehnt habe, eine solche Feier anzunehmen, u. als er endlich dem wiederholten Drängen seiner Freunde nachgegeben, habe er das in dem Gedanken getan, dass es ein Anlass gewesen sei, diesen u. allen zu danken für das was er in der arbeitsreichen Laufbahn empfangen. Auch dass er meiner u. Hiltys Erwähnung getan, deutet auf das Bestreben, die Stellung, die er einnimmt, in eine allgemeine Perspektive zu setzen. Sehr hübsch führte er aus, wie Keiner alles allein mache, $u$. wie oft dasjenige, was einem zum Verdienst angerechnet werde, der Arbeit der andern entsprungen sei.

Einen kleinen Unfall muss ich auch noch nachtragen: Als der Burgerratspräsident Liedl die riesige Adresse des Rats verlas, wusste er mit dem umfangreichen Deckel nichts anzufangen, er schob ihn unbehülflich auf dem Rednerpult hin u. her, bis er richtig die links vom Redner stehende Blumenvase hinunterstiess, auf die Kniee eines der gedrängt zunächst stehenden Professors oder Gasts u. von da auf den Boden, wo sie mit dumpfem Schlag in Scherben ging. Es wurde aber niemand gestört. Marti hatte die Geistesgegenwart, die Vase rechts zu Boden zu stellen. Marieli hat mich wieder nach den Ferien gefragt. Und ich bin so unglücklich immer noch nichts antworten zu können. Es hängt nun eigentlich alles davon ab, ob ich nach Christiania gehen soll. Und wenn ich mich entschliesse, ob ich Marieli mitnehmen soll $u$. 
darf. Es sagte mir heute, Frl. Reineck gehe für drei Wochen auf die Forclas u. habe gefragt, ob es mitkomme. Das wäre ein Ausweg. Mit dem Besuch bei Siegwarts wird es mir immer bedenklicher. Das muss sich jetzt übrigens bald abklären. In fünf Wochen haben wir Ferien.

Es ist heute ein sehr warmer, sonniger Sommer-Sonntag. Wie wird da alles ausgerückt sein. Mir ist es wohl zu Hause, bei meinen Gedanken, in meiner Einsamkeit. Ich kann mich aber auch darin eigentlich nicht beklagen. Heute Nachmittag kamen Siegwarts (Frau Dr. Jauch, Frau Schmid mit der kleinen Gabriela, Dr. S.) zu uns, wir tranken im Garten Kaffee. Nachher war ich bei mit Siegwart auf m. Zimmer u. dann erschien Wegemann mit seiner Frau, zum Antrittsbesuch. Ich hatte von beiden einen sehr guten Eindruck. Schon vorher kam Walter B., den ich mit Siegwart eine Weile, um Wegemanns zu empfangen, allein lassen musste. Und nach dem Nachtessen kam Rossel zu einem kurzen Besuch, dem ich mitteilen konnte, dass ein Passus in einem in der Schweiz. J. Z. abgedruckten Vortrag über eine Stelle in der Botschaft von 1905 mich sehr befremdet $u$. an der Noblesse Ostertags stutzig gemacht habe. Ich bin ja wehrlos gegen solche Perfidieen, aber ich kann doch nicht gehalten sein, sie anzuerkennen. Es betrifft die ersten Artikel des Einführungstitels.

Doch nun ist es auch an diesem langen Sommertag Nacht geworden u. ich gehe zur Ruhe. Es bedarf allen Mutes um in einer Welt von Missgunst sich aufrecht zu erhalten $u$. heiter zu bleiben. Aber ich will es ja tun, mit Deiner Hülfe. Die Erlösung wird so oder anders nicht ausbleiben.

Gute, gute Nacht, meine liebe Seele! Ich bin u. bleibe immerdar Dein getreuer Eugen 
B. d. 24. / 25. Juni 1912.

Mein liebstes Herz!

Ich scheue mich fast, Dir zu sagen, in welch böser Stimmung ich heute Vormittag gewesen bin. Ich hatte zwar trotz Donner $u$. Regen ordentlich geschlafen $u$. auch dass Marie noch um elf den Hund, der um neun Sophie drausgelaufen war, hereinholte, u. dass um drei Uhr Karle aus dem Bett fiel u. jämmerlich nach der Mutter rief, die nichts hörte, hatte mich nicht gestört. Aber auf dem Weg zum Kolleg kam mir all das Widerwärtige in den Sinn, das ich von den Baslern erfahren. Das gestrige Gespräch mit Rossel, die satte Unbedeutendheit, die er wieder einmal ausgebreitet hatte, waren mir die Veranlassung gewesen, an all all das erfahrene «Gute» zu denken, $u$. jetzt kam es mir mit Macht in den Sinn. Ich dozierte mich sogar fast in einen Grimm hinein u. sagte mir, es ist leichter, dass ein Kamel durch eine Nadelöhre schlüpft, als dass ein Basler den Himmel gewinnt. Das Auftreten Ostertags kam mir jetzt so vor, als sei er am Ende, u. nicht Jäger, der böse Geist in dem schlimmen Beschluss des B. Ger. gegenüber dem Departement gewesen. Wenn ich das annehme, so wird mir vieles erklärlicher, aber es tut mir leid, dass ich dann Ostertag eben auch zu den perfiden, selbstgerechten Baslern zählen muss. Ich werde nur froh sein, das jetzt noch entdeckt zu haben, bevor mir das Vertrauen, dass ich in Erinnerung an Lienhard in ihn gesetzt hatte, noch grössern Schaden bringen konnte. In solchem Grimm kam ich nach Hause, $u$. wie dann Abbühl ohne Entschuldigung erst nach zehn Uhr kam, war ich gestimmt, ihn merken zu lassen, dass es mir nicht gefalle. Ich übergab ihm die ersten hundert Artikel der englischen Übersetzung zum revidieren, es ihm überlassend, dies hier zu machen 
oder zu Hause. Er zog letzteres vor u. ich liess ihn gerne gehen. Ich hatte sogar den Eindruck, es könnte sich eine Auflösung ohne Zwist, beidseitig vorbereiten. Das wäre mir sehr recht, wenns nicht besser kommt.

Am Nachmittag wurde mir besser. Erst kam der unglückliche Steiner aus Solothurn, der eine Dissertation beginnen will, dem ich aber wohl merklich abwinkte. Darauf machte Frau Hebbel einen Besuch, die über Marthas Verlobung sehr glücklich ist. Ich konnte sie aber nur einen Augenblick sehen, denn gleich kam Justizdirektor Glaser u. unterholte mit mir fast zwei Stunden über das Testament der Frau des Bankiers Wüst, worüber ich ihm schon schriftlich Auskunft gegeben.

Inzwischen präparierte ich Colleg vor u. nachher u. zwar wieder mit grösserer innerer Befriedigung als die letzten Tage. Freilich müde fühle ich mir gerade jetzt erheblich. Auch zeigt mir meine Schrift, dass ich offenbar wieder etwas fiebrig bin. Allein ich bin es zufrieden, wenn ich nur nicht in der bösen Stimmung befangen bleibe, von der ich diesen Morgen beherrscht war. Es kreuzen oder combinieren sich da offenbar jeweils psychische u. physische Verfassung. Aber ich sollte ihrer doch mit der Zeit Herr werden.

Heute war Marieli zum Café bei Frau Brenner u. Annie. Es berichtet, dass erstere merkwürdig fröhlich gewesen sei. Ja, das sind eben die Wechselstimmungen mit ihrer Melancholie. Brenner hat mir ja manches davon erzählt. Ich will meine Müdigkeit heute bald aufs Kopfkissen legen. Das wird ihr gut tun, u. dringende Arbeit habe ich eben nicht. Es lässt sich alles morgen machen $u$. ich denke manchmal wirklich mir selber zum Erstaunen «Morgen, morgen, nur nicht heute, wenn mich diese steten kleinen Zänkereien, für die ich arbeiten muss, bis an den Hals hinauf anfüllen. 
Den 25. Juni.

Da Frau Schmid den auf heute angekündigten Besuch nicht machte, hatten wir Besorgnis, die kleine Gabriela, die Sonntags so fiebrig aussah, sei krank geworden, $\mathrm{u}$. ich sandte daher nach dem Essen Anna zur Nachfrage an die Wittenbachstrasse. Sie brachte aber guten Bericht. Morgen wollen Frau Schmid u. ihr hergereister Mann, ein Sohn des Bundesrichters, uns zum Abschied noch einen Besuch machen. Die ganze Verwandtschaft Siegwarts ist ausserordentlich freundlich zu uns. Ich frage mich an einem fort, ob das wirklich Marieli gilt. Und wenn dem so wäre, bedeutete es ein Glück für das Kind? Ich bezweifle keinen Augenblick, dass M. zurzeit bei der Alternative zwischen Siegwart u. Abbühl den erstern vorziehen würde. Es hat vor Abbühl keinen rechten Respekt mehr, hat ihn auch offenbar hochmütig behandelt. Sicher ist auch Siegwart der gescheitere u. feinere. Aber die Nebenumstände, sogar die Confessionsgegensätze, vermag Marieli noch nicht in ihrem ganzen Gewicht einzuschätzen. Immerhin, ich selbst würde zurzeit ebenso entscheiden. Und was kann alles noch begegnen, bis die Entscheidung, sei es das Verfliegen aller dieser Pläne eintreten mag! - Die Collection der ersten etwa 30 Artikel der englischen Übersetzung hat Abbühl heute Vormittag, wie mir schien, nicht ungeschickt erledigt. Er war wenigstens, als er um $12 \mathrm{Uhr}$ kam, ganz zuversichtlich. Freilich will das noch nicht viel sagen, er hat aber diese innere Überzeugung auch in anderem gehabt, u. dann war seine Leistung doch untüchtig. Also warten wir, ob in dieser Arbeit am Ende doch etwas liegt, was ihn mir durch seine Leistungen lieber machen könnte.

Von Andreas Häusler empfing ich einen Brief, worin er mir mitteilt, dass ihm Lichtenhahn die Fusion der Ztschr. f. Schw. R. mit der Schw. Zschr. f. St. r. anzeige, u. er will, mit freundlichen Worten, aber offenbar in grossem Ärger, meine Ansicht wissen. Er würde alsdann offenbar von der Redaktion zurücktreten. Es kommt 
mir wunderbar vor, dass er an mich gelangt. Ich erblicke darin wieder ein Zeichen seiner Naivität, die ihn gar nicht erkennen lässt, wie unfein, grob, verletzend er durch sein Auftreten er sich gehen lässt. Ich werde die dargebotene Hand nicht zurückstossen. Aber ich muss vorerst noch mit W. Burckhardt darüber sprechen. So viel steht fest, dass ich die Redaktion in dieser oder jener Gestalt bei Hs. Weggang nicht übernehmen werde.

Sonst las ich heute allerlei, schrieb zwei kleinere Gutachten, u. die Eindrücke der Kocherfeier verfolgen mich immer wieder. Ich sagte heute zu Marti u. andern: so habe man doch einmal bei uns etwas gelten lassen. Und dieser Gedanke erwärmt mich, u. das uns Fremde, das ich in der Feier erblickte u. erblicke, bekommt immer mehr eine sympathische Gestalt. O könnten wir uns doch aus unserer Kleinheit empor schwingen! Wie viel Lebensfreude u. Lebensenergie wäre damit gewonnen!

Marieli war heute nach seinem Colleg bei Frau Guhl u. den Kindern im Dählhölzli u. kam recht erfrischt nach Hause. Inzwischen hatte ich Besuch von Liseli Langhard, das nächste Woche in eine Pension nach Morges verreist. Das Mädchen ist in dem Alter, wo sie nicht mehr so frisch u. natürlich sind, wie Kinder, ohne etwas anders zu werden. Immerhin hatte ich Freude.

Und nun werden die Pläne mit den Ferien doch allmählich bestimmter. Der Plan der Reise nach Christiania befestigt sich. Ob ich dann aber vorher noch ein paar Tage in die Berge soll? In die Nähe von Altdorf? Vielleicht doch. Mag daraus entstehen, was da will. Inzwischen habe ich noch reichlich Arbeitszeit vor mir. Also drauf u. dran!

Es ist merkwürdig, wie sich meine Stimmung leichter wieder glättet, seit ich mit Dir in Deinem Grunde mich fester verankert. Wäre mir das früher beschieden gewesen! Aber hätte ich dann dasselbe geleistet, wie mit meiner von Dir so oft genannten «geduldigen Ungeduld»? Aber das ist jetzt alles vorüber!

Mit innigstem Gruss u. Kuss

Dein allzeit getreuer

Eugen 
B. d. 26./ 27. Juni 1912.

Mein liebstes Herz!

Da ich gestern Abend aus einem mir unbekannten Grunde u. mir ganz ungewohnt nicht sofort einschlafen konnte $u$. bis gegen Mitternacht wach blieb, fühlte ich mich heute nicht recht ausgeruht. Im Kolleg ging es so, allein es ist eine eigene Sache seit längerem mit mir: In solchen Zuständen kommt wie eine geistige Dämmerung über mich u. ich behalte keine Eindrücke. Das Denken ist mir ebenfalls schwerer, was ich gestern Nachmittags so sehr verspürte, dass es mir fast bange wurde, es zeigen sich Alterserscheinungen. Und doch wenn ich vergleiche: wie oft verstrudelte ich mich im Colleg, was mir jetzt doch selten begegnet, wie oft verstand ich Sachen nicht, die eben doch für den Augenblick bewältigt sein wollten, $u$. jetzt bin ich ganz anders $u$. ausdauernder in diesen logischen Übungen drin. Es ist eher eine Übersättigung, was mich jetzt etwa hinunter drückt. Und diese Übersättigung kommt von einer Ermüdung hier, die mich manchmal eine Abneigung empfinden lässt, irgend den geringsten Paragraphen aufzuschlagen. So empfand ich es gestern, u. doch muss ich jetzt noch nahezu fünf volle Wochen aushalten.

Nach dem Kolleg präparierte ich weiter im OR. u. hatte dann Besuch von Frau Schmid u. ihrem Mann, dem Sohn des Bundesrichters, Apotheker, u. mit der kleinen Gabriela, die sich verabschiedeten. Marieli wurde wiederum herzlich nach Altdorf eingeladen $u$. wird nun wohl hingehen, entstehe daraus, was da wolle. - Ich ging dann zu Walter B., um mit ihm

zu besprechen, was ich Häusler antworten soll. Trafich ihn nicht, so kam er dann um drei zu mir u. nachher schrieb ich Häusler einen offen gehaltenen Brief, worin ich ihm sagte, wie wenig Interesse ich an der Zeitschriftenfrage nehme, aus dem 
Mangel an Zeit, der mir wegen der vielen Schwierigkeiten, denen ich begegne, noch empfindlicher werde.

Bei Marieli war Gertrud Lüdemann, ein munteres, gewecktes Fräulein. Sie spielten vierhändig.

So ging der Tag vorüber. Jetzt spüre ich mich aber wieder fiebrig $\mathrm{u}$. müde $\mathrm{u}$. will abbrechen, um bald zu Bett zu kommen. Trage meine Sorgen mit. Sie kommen immer wieder, aber ich will sie überwinden!

Den 27. Juni.

Ich war heute den ganzen Tag sehr müde in den Augen u. in den Gliedern, dazu heiser u. im Kopf gehemmt. Danach habe ich mich im Kolleg zur Frische gezwungen u. den Vormittag nach dem Kolleg noch einiges gearbeitet, aufgeräumt. Am Nachmittag kam ein Landwirt, der sich auch für Rechtssachen interessiert u. mein Sachenrecht hört, zu mir, um mich zu fragen, ob er gekauften Wald stöckweise wieder verkaufen dürfe, oder ob er Holz verkaufen könnte, trotz der Schutzwaldabstimmungen, ob Lengnau, wo die vom Naturschutz geretteten Riesentannen nun in staatlichem Forst stehen. Ich konnte ihm keinen Rat gehen [sic!], die Mitteilungen haben mich aber interessiert. Er hat für 1/4 Million Land gekauft mit zwei Brüdern $u$. will nun sehen, wie sie damit ihren Gewinn machen. Sie heissen Zürcher. - Dann kam Frau Prof. v. Wyss u. holte ihre 5 Fr., blieb dabei etwa eine Stunde, wobei ich wieder einmal vernahm, wie es ihr u. Fritz geht. Wie es scheint, ist jetzt besser mit ihm auszukommen.

Sonst ging mir der Nachmittag darauf hin, dass ich in Bädekers Schweden u. Norwegen die Fahrten mir ansah, die mit der Reise nach Christiania verbunden werden könnten. Am Ende nehme ich jetzt doch Marieli mit. So wie es sich in der letzten Zeit gegeben hat, darf ich es wohl wagen.

Rechne dazu etliche Kollegarbeit, so ist das wieder der ganze Tag. Ich fühle mich, wie gesagt, unwohl, gehemmt u. will daher bald zu Bett gehen. Weil ich jetzt aber daran denke, muss ich Dir doch noch von einem Vorfall erzählen, den ich doch Dir schon vor Tagen berichten wollte. Ein Zuger Anwalt, Rossel meinte, es sei der 
junge Rüttimann gewesen, hat einem hessischen Gericht, das von dem Zuger Obergericht eine Auskunft über Zuger Recht erbat, geschrieben, das Gericht könne die Auskunft nicht geben, es sei aus Laien zusammengesetzt, die aus politischen Rücksichten gewählt u. dazu noch nicht lange im Amt seien. Dafür wurde er vom Obergericht in eine Busse verfällt, gegen die er staatsrechtlichen Rekurs ergriff, womit er auch durchdrang. Da die fatal taktlose Handlung nicht in anwaltlicher Handlung begangen worden sei. Im übrigen haben wir da wieder einmal ein Zeichen, wohin diese frechen jungen Juristen bei uns steuern. Rüttimann war ein Spezialschüler von Gmür, mir hat er immer einen ungünstigen Eindruck gemacht, u. ich bestätige bei mir selbst gerne, dass ich ihn, wie es sich da zeigt, richtig beurteilt habe. Wir werden es bei der Schaffung einer eidgen. Gerichtsorganisation erleben, dass man das Laienelement aus den Gerichten hinaus höhnen will. Damit verlieren wir dann wieder ein Stück unserer gesunden Eigenart, wenn es dazu kommt. Vielleicht aber kehrt inzwischen in dem deutschen Gerichtswesen ein volkstümlicherer Geist ein. Wir vertragen unsererseits schon noch etwas mehr Fachwissenschaft. Aber die Grundlage sollte doch

volkstümlich bleiben. Ich vertraue darauf, dass diese Richtung über alle Gegenströmungen schliesslich doch den Sieg erringen wird. Meine fiebrigen Finger wollen nicht weiter, also breche ich hier ab. Gute, gute Nacht von

Deinem alten treuen

Eugen 
[1]

B. d.28. Juni 1912.

Meine liebe, gute Lina!

Das Verhältnis zu Deiner Schwester setzt sich ohne Veränderung fort, u. es hat für mich etwas Rührendes, jedes Vierteljahr einen Brief von ihr zu erhalten, worin sie mit Dank für die Sendung Deiner in trauernder Liebe gedenkt. Die alten Leutchen sind unendlich dankbar, dass sie durch Dich die Unterstützung fort $\mathrm{u}$. fort erhalten, die ihnen einigermassen zu leben ermöglicht. Wie Emma im Winter kränker war als gewöhnlich, schrieb sie mir, ob ich nach ihrem Tode ihrem Mann doch noch weiter zur Seite stehen würde, u. als ich das natürlich bejahte, war sie sehr glücklich, ohne zu verhehlen, dass sie nicht recht wüsste, wie dann die Dinge sich überhaupt gestalteten. Das wird sich zeigen. Inzwischen ist es mir eine innere Genugtuung, noch etwas in Deinem Namen zu tun, wenn ich mich auch wohl erinnere, dass diese Pflicht Dir selber als eine Unbilligkeit vorkam, so dass Du oft darüber geklagt hast. Doch, was will man! Wenn es den einen Familiengliedern gut geht $\mathrm{u}$. andern schlecht, so gehört man doch zusammen, mag auch noch so sehr diese Verschiedenheit des Schicksals in den Vorzügen oder Mängeln der Personen begründet sein. Also nimmt man es hin, wie anderes, das einen trifft. Emma Blatter, die jetzt mit ihrem Mann auf Bubenrüti bei Teufen ein Heimetli bewohnt, habe ich zwar auf ihr Ansuchen, ihr meine Photographie zu schicken, gar nicht geantwortet. Dort liegt der Fall anders. Ich erinnere mich zu sehr an die Warnung, die oft von Deiner älteren Schwester $u$. ihrer Tochter mir ausgesprochen hast, um es nicht vermeiden zu müssen, ihr irgendwie wieder näher zu treten. Doch auch da weiss man nicht, was das Schicksal noch bringt.

Ich war heute geistig müde, schon vom Kolleg her, u. als Guhl eine Stunde vor Tisch bei mir war, hatte ich Mühe, mir die Fragen, 
die er stellte, in Gedanken zurecht zu legen. Er sammelt jeweils eine ganze Reihe von natürlich meist schwierigen Fällen, die ihm die Praxis, sein Amt an die Hand gibt. Allein oft werde ich mir doch der Verfassung bewusst, aus der heraus ich in Basel s. Z. in den ersten Jahren nur allgemeinen Teil des OR gelesen $u$. die einzelnen Vorträge andern überlassen habe. Mich interessieren die speculativen, construktiven Entwicklungen in dem Sinne innerlich nicht, dass ich ihnen eben einen grössern Wert nicht beimessen kann. Und wenn ich auch lange Jahre, vom Doziererfolg angeregt, mich doch mit ihnen intensiv beschäftigt habe, so stellt sich jetzt wieder allmählich die alte Stimmung ein, namentlich wenn ich müde bin. Aber ich muss noch aushalten, muss gleichwohl diese Arbeiten bewältigen, es geht ja nicht anders. Nur wäre das schliesslich ein Faktor, der wenn er anwachsen sollte, mich in den nie ganz verschwindenden Rücktrittsgedanken bestärken könnte. Wir haben jetzt bei frischer Morgentemperatur warme Sommertage, die aber für Erkältungen gefährlich sind. Sophies Kleiner wurde heute als unwohl aus der Schule geschickt, u. ich sagte Sophie, sie soll mit ihm zu Dumont. Berichtet hat sie mir darüber noch nichts. Marieli klagt über starke Kopfschmerzen. Ich selbst bin heute besser dran als gestern, aber auch nicht recht wohl. Mich plagen meine nicht erfüllten Pflichten u. dazu eben jenes Gefühl, dass mir die Gedanken schwer werden. Auch jenes bei mir untrügliche Zeichen der Ermüdung, das sich Versprechen im Kolleg, ist in den letzten Tagen einige mal aufgetreten. Nun, morgen $u$. übermorgen habe ich frei, u. will auch wirklich etwas ausruhen, wenn nichts dazwischen kommt, was mich hindert. Allerdings findet morgen Abend das Abschiedsbankett statt, das die Facultät Rossel gibt, u. werde ich schon sprechen müssen. Ich habe mir noch nicht überlegt, was ich sagen soll. Seine Selbstzufriedenheit in der neuen Stellung hätte mich fast in Bedenken bringen können, ob ich nicht am Ende doch recht unklug gehandelt 
habe, als ich mich entschloss, nicht Bundesrichter zu werden, sondern Professor zu bleiben. Doch gingen diese Gedanken rasch vorüber, u. ich sehe neuerdings ein, dass es für mich nichts besseres gibt als lebenslang auf meinem Posten zu bleiben u. zwar fröhlich u. mit Freuden. Denn das ist nun mein Teil.

Durch Anna habe ich nun erfahren, dass Karle nach Aussage Dumonts die Windpocken habe, dass er einige Tage im Bett gehalten werden müsse u. dass Sophie nächsten Montag nochmals mit ihm in die Sprechstunde kommen soll. Sophie ging ganz widerwillig hin, äusserte sich aber nach der Rückkehr doch sehr dankbar dafür, dass man sie zu dem Gang gedrängt hat. So ist sie eben, das unbändige, halbwilde Wesen. Wenn sie doch nur in unserem Hause dauernd in eine andere Verfassung gebracht werden könnte! Das würde so wohltätig auf sie u. uns einwirken. Ich wurde bei dem Anlass an die Zeit ihres frühern Aufenthaltes in unserem Hause auch dadurch heute stärker erinnert, dass Elisa Bösiger an Marieli aus Lugano einen Magnolienstrauss einsandte zu Deiner Erinnerung, mit einem dankbaren Kärtchen, das mich freute. Wie sonderbar ist es doch uns mit Elisa gegangen. Wäre sie geblieben, so würdest Du den vielen Ärger mit Kathri nicht gehabt haben, aber freilich auch nicht der tüchtigen Leistungen dieser teilhaft geworden sein. Weshalb musste Elisa fort? Wir wussten keinen Grund, als die zu grosse Vertraulichkeit, die sie sich allmählich angeeignet hatte, u. die namentlich Dir gegenüber eine wachsende Antipathie erzeugte. Es geht halt so im Leben. Schattenseiten sind überall $u$. die Sonne wird schliesslich nicht mehr geachtet, nur der Schatten. Mir war es recht, dass endlich der Wechsel erfolgte. Die Beziehungen zu Frau Bösiger liessen Dir den Weggang Elisas nachgerade noch wünschenswerter erscheinen.

Ich kam heute aus dem Praktikum ganz erschöpft nach Hause, während ich mich in den Stunden selbst, bei mässigem Besuch, 
noch ganz aufrecht erhalten hatte. Noch vier Wochen habe ich jetzt vor mir.

In diesen Zeilen wurde ich unterbrochen durch den unerwarteten lieben Besuch von Bundesrat Hoffmann u. seiner Frau. Ich hatte Marieli gebeten, in diesen Tagen bei ihnen vorbei zu gehen, um sie zu fragen, ob sie nicht an einem Abend zu uns in den Garten kommen wollten. Dass sie jetzt von selbst gekommen, ist mir besonders lieb. Es waren einige sehr herzerfrischende Plauderstündchen, die wir derart zusammen haben konnten. Die Frau hat mir wieder einen herzensguten Eindruck gemacht. So ist man also doch nicht so ganz allein! Gute Nacht nun, mein einziger Schatz! Ich gehe munterer zu Bett, als seit langem. Gibt es trotz Wein u. Zigarren eine Schlafnacht, weil das Gemüt etwas bekommen hat? Ich hoffe es, denn ich hätte es nötig.

In ewiger Liebe

Dein

\section{Eugen}

\section{2: Juni Nr. 143}

B. d. 29. / 30. Juni 1912.

Mein liebstes Herz!

Ich schreibe Dir Abend vor dem Abschiedsbankett für Rossel, da ich von demselben doch wohl erst nach Mitternacht zurück sein werde. Ob ich bei der Gelegenheit reden muss? Gmür als Dekan hat nichts gesagt. Bei Hilty allerdings haben wir alle ein paar Worte gesprochen. Aber das war eben Jubiläum. Jetzt hält man es wohl eher wie bei Gretener, wo nur der Dekan redete u. der Scheidende. Übrigens habe ich s. Z. auch bei Hilty nichts vorbereitet gehabt $\mathrm{u}$. dann doch wenigstens das zweite Mal (Doktorjubiläum) eine Ansprache gehalten, für die mir der Sohn 
Hilitys Jahre nachher noch einmal im Namen der Familie die Dankbarkeit bezeugte. Also lasse ich es darauf ankommen. Ich bin übrigens gerade jetzt auf Rossel nicht besonders zu sprechen. Marieli wusste wieder allerlei deutschfeindliche Unverschämtheiten von Susanne zu berichten. Auch etwas Falschheit kam bei Frau Georges - ich hatte das ja immer befürchtet - zu Tage, indem sie, die bei Marieli über Susanne u. Rossels nicht genug schimpfen konnte u. sagte, wie sie froh sei, dass jetzt Susanne fortkomme, sie gerade nun Susanne u. Andri in Pension nimmt für das halbe u. das ganze Jahr, wo sie nach Rossels Wegzug der Schulen halber noch in Bern bleiben müssen.

Ich wurde, wie ich Dir gestern schrieb, durch den Besuch Hoffmanns gestern in eine dankbare Stimmung versetzt. Heute wäre sie mir fast wieder gestört worden durch eine Bemerkung Marielis, die in mir etwas Bitterkeit ausgelöst hat. Marieli meinte nämlich, der deutsche Kaiser würde wohl bei seinem bevorstehenden Besuch in der Schweiz wünschen, mich zu sehen, $u$. ich werde wohl zum Bankett

[2]

eingeladen werden. Es habe das immer so gedacht $u$. würde das für recht finden. Darauf belehrte ich die Unerfahrenheit, dass so etwas bei uns nicht vorkomme, wo einer den andern zu verkleinern strebe, $u$. dass namentlich unter der Präsidentschaft von Forrer niemals davon die Rede sein könnte. Wir seien alle gleich $u$. jeder habe sich selbst zu ehren u. nicht nötig von andern geehrt zu werden, im Gegenteil: Herunter mit dem Respekt! Diese Gedanken spannen wir dann weiter u. ich war, wie gesagt, im Begriff, daran meine Heiterkeit zu verlieren, würde ich nicht zeitig eingelenkt haben. Jetzt stehe ich der Frage wieder in der nötigen Distanz gegenüber. Wir müssen uns nun einmal bescheiden zu sein wie wir sind.

Ich konnte heute nicht recht arbeiten, hatte mir auch vorgenommen, den Tag zur Ruhe zu benutzen. Ich bereitete für das Praktikum einige Fälle vor. Dann brachte Abbühl wieder ein Stück der Revision der engl. Übersetzung des ZGB., die sehr oberflächlich u. unschön gearbeitet ist. Dazwischen las ich die Reiserouten, die ich bei einer Fahrt nach Christiania etwa wählen könnte, u. das versäumte mich bis zum 
Mittag. Ich werde aber noch oftmals auf u. ab sinnen, bevor ich mich wirklich zur Reise entschliesse. Man hat so gar keinen Nachgenuss in hier, indem man mit Niemand darüber reden kann, ohne Neid zu erwecken oder des Blagierens beschuldigt zu werden. Du hast das ja auch erfahren. So muss man auch in dieser Beziehung den Genuss u. die Förderung in sich selbst suchen.

Auf andere darf man sich bei uns nicht beziehen, sonst erlebt man böse Geschichten.

In Wirklichkeit sind das ja auch Nebendinge. Wenn wir alle Brüder sind, so muss man ja zugestehen, dass es eine Parteilichkeit

der Eltern ist, wenn sie das eine Kind reisen u. sich vergnügen lassen, während die andern arbeiten müssen. Von dem Standpunkte aus angesehen, sollte man eben überhaupt nicht sich vergnügen. Doch muss ich zu meiner Rechtfertigung sagen, dass ich die Reise nach Christiania wirklich nicht aus Vergnügungssucht geplant habe, sondern im Gedanken, dass ich damit etwas tue, was man von mir verlangen darf. Wo kommen wir hin in der Schweiz, wenn wir Juristen uns stetsfort absondern? Sollen wir den Unbedeutendsten oder Frechsten die freie Bahn zugestehen, sich als Vertreter der Schweiz zu gerieren? Man muss wirklich darauf halten, etwas dabei zu sein, mag auch Walter Burckhardt in griesgrämiger Art darüber spotten oder höhnen in seinem Innern. Gleichwohl bin ich zur Reise noch keineswegs entschlossen. Die Combination mit Marielis Plänen macht die Sache nur noch schwieriger.

Der Ruhetag hat mir heute wohl getan. Wie hielt ich es doch früher? Ich arbeitete zwei Tage intensiv $u$. den dritten ruhte ich aus $u$. legte mir die Arbeit für die zwei folgenden zurecht. So in Basel u. in Halle u. zu Anfang auch noch in hier. So schrieb ich die vier Bände. Dann wurde mir der Plan durch die andauernde Zwangslage unmöglich gemacht, $u$. ich besinne mich vom Gryfenhübeli her selten auf Tage der geplanten Musse. Und doch sind sie so erfrischend. Ich will mir den heutigen Tag unter diesem Gesichtspunkt rechtfertigen. Übrigens wäre auch sonst 
heute mit der Arbeit nicht viel anzufangen gewesen: ich habe wieder einmal meine Heiserkeit u. die fiebrigen Empfindungen mit leichten rheumatischen Gefühlen, u. da ist es auch angezeigt, sich der Ruhe zu ergeben. Ich merke diese Stimmungen doch am sichersten meinen Fingern an: Wenn die die Feder krampfhaft u. heiss fühlen, so ist es nicht gut, dann lassen wir alles ruhen, was nicht

sein muss. So ist es denn auch gerade jetzt $-\mathrm{u}$. ich breche ab.

$$
\text { D. 30. Juni. }
$$

Ich bin halb zwei vom Ratskeller zurückgekommen. Das Bankett war wie erwartet. Anwesend waren ausser Rossel alle, auch Folletête, mit Ausnahme von Markeise, Wegemann, Geiser u. Sieber, also 16. Gmür gab eine ganz nette Charakterisierung Rossels. Dieser antwortete u. sagte diesmal, dass er die Interpret. d. ZGB für Hauptarbeit halte, u. das meine Werk. Ich sprach darauf von s. Poesie, mit Toast auf Frau Rossel. Ferner redeten Folletête, zweimal, Milliet, Steiger, u. in fremden Sprachen Balli, Lifschitz (hebr.), Reifesberg (russ.), Röthlisberger (span.), dann Milliet nochmals, Tecklenburg. So ging die Zeit rasch vorüber. Ich holte Rossel zu Hause ab, wir kamen in Gewitterregen. Er hatte mit Recht sich darüber aufgehalten, dass der Dekan ihm nur Bietkarte durch Pedell geschickt. Von Abholen vollends nichts. Gmür machte auch aus dem Bankett im dritten Drittel einen Commers. Es fehlt ihm Lebensart in solch feineren Gelegenheiten. Rossel hat sie schon, empfindet den Unterschied. Gmür sprach vom Wiederholen solcher Anlässe. Ich kam mir fremd vor u. zwar steigend. Aber da ist nun nichts zu wollen. Heute ging ich vor dem Nachtessen geschwind zu Rossel hinüber, wir kamen darauf zu sprechen, wie er in Lausanne nun einen freundschaftlichen Kollegenkreis um sich habe, der hier ja niemals, auch nicht für ihn vorhanden war. Natürlich hätte ich eine solche Atmosphäre der hiesigen vorgezogen. Aber es ist jetzt so, $u$. ich habe die Versuche es zu ändern längst aufgegeben.

Am Vormittag hatte ich Besuch von Prof. Hoffmann. Er machte mir einen freundlichen Eindruck. Sonst war ich mit Kollegarbeit, mit Dicks Testament u. andern Briefen etc. beschäftigt. Dazwischen las ich im Krieg von 1870 / 1, der uns jetzt so fern liegt, wie in meiner Jugendzeit die napoleonischen Feldzüge u. Schlachten. 
Ich gehe heute zeitig zu Bett, habe freilich über Tag einmal fast eine Stunde geschlafen, muss aber doch noch nachholen.

Also gute, gute Nacht! Heute sind es hundert siebenzehn Wochen, seit

ich einsam geworden bin - gute, gute Nacht!

Immerdar Dein alter, Dein treuer

Eugen 


\section{Juli 1912}

\section{2: Juli Nr. 144}

B. d. 1./2. Juli 1912.

Mein liebstes Herz!

Ich bin heute weniger wohl als gestern. Die Heiserkeit fängt an mich zu plagen. Auch das Fiebergefühl wird lästiger, u. ich sollte eben doch die vier Wochen noch aushalten. Also vorwärts! Heute Nachmittag, nachdem Rennefahrt wegen seines Aktienpublikationsprojektes eine Stunde bei mir gewesen, $\mathrm{u}$. ich die Post erledigt von Mittag, war mir so wenig um das Weiterarbeiten, dass ich den Gang zu Mutzner u. auf Guhls Büreau, den ich schon lange vorhatte, unternahm. Mutzner traf ich nicht, er ist scheints entgegen seinem mir mitgeteilten Plan noch länger auf dem Büreau u. beginnt seinen Urlaub einen Monat später. Guhl stellte ich zur Rede, was ihn am Samstag so geärgert, dass er sich so sonderbar verhalten. Er meinte erst, nichts, dann aber erzählte er mir erst von einem familiären Grund, ein Nachbarmädchen, das oft zu seinen Kindern komme, liege, wie er eben damals vernommen, todkrank darnieder, dann meinte er, ein Ärger auf dem Büreau, da Röthlisberger die Prozente einer Zürchersubvention falsch berechnet, $u$. deshalb von dem Bundesrat habe reklamiert werden müssen, habe ihn damals eben beeinflusst. Ich fand, weder das eine noch das andre sei ernsthaft. Vielmehr habe ich mich einer Andeutung von Mutzner erinnert, dass Guhl vielleicht doch noch zur Praxis übergehe. Gestern war er bei Salm in Brugg. Es ist 
nicht ausgeschlossen, dass er an der Wissenschaft genug bekommt $\mathrm{u}$. sich knall u. fall für eine praktische Stellung entscheidet.

Doch müssen wir das noch abwarten. Es kann auch wieder vorüber gehen. Der Ausgang hat mir gut getan. Nur bin ich jetzt wieder auf frische Arbeit angewiesen, indem von Werner Martin eine grosse $u$. schwierige Dissertation eingelaufen. Und ich würde so gerne ausruhen, oder meiner Hauptsache leben. Es ist ein Jammer.

Auf dem Heimweg begleitete mich Guhl, u. über die Kirchenfeldbrücke begegneten wir verschiedenen Bekannten, die aber nur Guhl sahen. Die Welt ist dort drüben doch bewegter als hier, hier kann man einsamer sein oder auch Sonderling werden.

Ich würde so gerne in diesen Zeilen an Dich allerlei besprechen, was mich allgemeines bewegt, in Zusammenhang über Tage $\mathrm{u}$. Wochen, aber ich bin allemal Abends nicht mehr concentriert genug. Es nimmt ja alles ab bei mir, unter dem Druck der vielen Neider $u$. Feinde um so rascher! Und doch sollen sie mich nicht niederdrücken. Ich muss dieser jungen Welt notgedrungen noch etwas den Platz sperren. - Abbühl war heute sehr munter, hat merkwürdig viele Artikel gebracht, während er doch heute nicht länger als zwei Stunden an der Arbeit gesessen haben kann. Wäre Marielis Vermutung richtig, dass er sich die Arbeit durch jemand anders machen lässt?

Ich will heute sofort zu Bett, das wird meinem Hals gut tun. Morgen habe ich Examen, vielleicht tue ich besser, auch an diesem zu fehlen. Das werde ich morgen sehen. Jedenfalls für heute Schluss, lieber inniger Schlusspunkt!

Den, 2. Juli.

Ich bin zwar in den Vorlesungen am Morgen ordentlich munter 
gewesen, allein gleich nachher verschärfte sich die Heiserkeit wieder. Nach dem Essen war Mutzner bei mir, den ich gestern nicht getroffen. Er will Mitte Juli seinen Urlaub antreten, u. nachher kam ein sympathischer Student, Guiré, mit einer Empfehlung von Töndury, St. Gallen. Aber jetzt fühle ich mich in der Stimme so prekär, dass ich mich entschlossen habe, die heutige Fakultätssitzung nicht mitzumachen, ich habe diese Möglichkeit schon heute Gmür als Dekan genannt u. jetzt an Bieri telephoniert.

Ich bin ziemlich gedrückt, namentlich da auch Marieli gestern wieder Magenstörungen hatte, so dass ich an meinem Plan der Christianiareise stutzig wurde. Am Ende gehe ich besser weder selbst hin, noch lasse ich mich, wenn ich gehe, von ihr begleiten. Es bekommt uns beiden so besser. Wenigstens jetzt denke ich so, indess es mich in den Eingeweiden brennt u. im Halse kratzt. Morgen schon ist es vielleicht besser.

Der Kampf mit dem Unverstand will kein Ende nehmen. Hügli hat wieder etwas im «Bund» wegen der Übung im Dienstvertrag. Es ist ein Jammer mit diesen Leuten. Ich büsse hart dafür, mit patriotischem Eifer die wissenschaftliche Stellung in Deutschland verlassen haben. Aber die Busse, der schon Du still aus dem Weg gegangen, dauert ja nicht mehr lange. Also tragen wir sie.

Marieli war sehr unglücklich, als ich ihm heute sagte, wir gehen wohl besser nicht nach Christiania. Aber ich kann nicht helfen. Mit Abbühl habe ich heute ein vertrauteres Wort gesprochen $u$. ihn darauf vorbereitet, dass es wohl für ihn besser wäre, vom August an nicht mehr bei mir Secretär zu sein, sondern sich ganz der Vorbereitung für die Matura

zu widmen, wenn er vom Militärdienst (Ende Oktober) zurück sein wird. Ich bin nun gespannt, was er tut, wie dies Wort bei ihm verfängt.

Innigst Dein alter, müder

Eugen 
B. d. 3. / 4. Juli 1912.

Mein liebstes Herz!

Um den Tag nicht zu schliessen, ohne eine Zeile an mein Liebes, bin ich geschwind aufgestanden u. schreibe nur schnell diesen Gruss! Ich war heute im Kolleg. Nachher kam Walter B. zu mir u. es ging ordentlich. Aber nach dem Essen fühlte ich mich wieder elend, heiser, rheumatisch $u$. ging vor vier zu Bett.

Ein russischer Professor, Gordon, wollte mich besuchen, ich liess ihn abweisen. Marieli war bei Langhards Lisely, das nächstens in die Pension verreist, $u$. nachher im Musikexamen, wo eben Hanneli Michel spielte, scheints sehr aufgeregt, aber sehr schön u. schwierig. Dann erhielt ich heute die zweite Collegiengeldrate mit 700 Fr. also zum erstenmal eine Gesamtsumme von 6400 Fr.!

Doch ich schreibe morgen weiter. Hoffentlich vergeht die Heiserkeit u. auch die Beschwerde im Unterleib, die mich etwas plagt. Hat nichts zu bedeuten!

Gute, gute Nacht, meine liebe, einzige Lina! Ich sehe jeden Tag neu, was Du mir warst. Wie ist jetzt doch alles anders. Etwas Liebe spürte ich heute den zwei Briefen an, die Marieli von Claire Siegwart u. zugleich von Frau Schmid-Siegwart erhalten. Ja, es wäre schön, mit liebendem Leben wieder in engere Berührung zu kommen. Aber ich weiss nicht, was ich von Marieli halten soll. Abbühl scheint ihm entschwunden, hat es für anderes ein offenes Herz? Warten wir ab u. 
die Hoffnung lässt nicht zu Schanden werden!

Den 4. Juli.

Ich fühle mich heute, nachdem ich am Morgen ziemlich frisch meine zwei Stunden gelesen, am Nachmittag wieder nicht wohl u. will gleich jetzt dann, gegen vier, wenn keine Abhaltung kommt, wieder zu Bett. Die Hauptursache meines gestörten Befindens ist sicher die Kälte. Dann wird mir die Bettwärme wieder gut tun. Ich habe heute Strümpfe angezogen statt Socken. Ich weiss, Du hättest mich schon längst zu dieser $u$. jener Vorsichtsmassregel angehalten. Die Douchen beim Aufstehen dürfte ich gewiss nicht mehr nehmen. Und ich würde sie so gerne noch durch setzen, bis die Ferien kommen. Überhaupt die drei Wochen sollte ich noch aushalten! - Anna hat bei Morgenkaffee gesagt, es sei ihr in der Nacht eingefallen, sie hätte mir, da ich im Bett lag, doch auf den Morgen noch die Kleider richten sollen - ach ich werde so vieles entbehren müssen!, u. dabei fing sie an zu weinen. Ich rechne ihr dies hoch an, ich sehe, wie ernst es ihr damit ist. Sie hat doch einen bessern Willen als früher, das ist kein Zweifel, u. ich will mit ihr nachsichtiger sein.

Gestern Abend kam Jennys Abrechnung. Zu meinem grossen Erstaunen sind 123 Hörer im Sachenrecht, u. wenn ich im Obligationenrecht den Dän u. den Berliner zurechne, in dieser Vorlesung 150, in den Übungen allerdings nur 83. Hätte ich mir für Bern je einen solchen Erfolg

träumen lassen! Wenn der grosse Hörsaal mit 120 Plätzen für mich eingerichtet worden wäre, so würde er auch zu klein gewesen sein in diesem Semester. Ich weiss ja wohl, dass das nur eine vorübergehende Steigerung ist. Aber ich habe nun doch diesen Erfolg gehabt u. will mich dessen freuen. Es wird mir unter dem Gewicht dieser Erlebnisse deutlicher als noch im Frühling vor Augen geführt, dass ich nun hierin noch den Rest meines Wirkens zu erblicken habe. Was soll ich 
noch Internationales suchen? Ich bin zu alt dafür, ich kann ein Neues nicht mehr anfangen. Also Schuster bleib bei deinem Leisten. Diejenigen, die mir die Teilnahme an den Haager Conferenzen wegintrigiert haben (Walter B. ist der Hauptheld der Schwerenöter), haben mir in Wirklichkeit eine Wohltat erwiesen. Denn ohne jenes, würde mir jetzt der Kollegerfolg dieses Semesters nicht zuteil geworden sein. Ob man nun wohl in nächster Zeit die Kollegiengelder kürzen wird? Es wäre für mich eine Störung in der bescheidenen Freude am Erfolg. Und ich sammle die Gelder ja doch nur für gemeinliche Zwecke. Doch jetzt kein solcher Ausblick. Was erlebt, ist erlebt, das kann mir niemand nehmen!

Abbühl kommt nun doch nicht zum fechten. Der einsichtige Farbenbruder, Mediziner, hat es durchgesetzt, dass Abbühl so kurz vor dem Militärdienst das Risico der Abfuhr nicht riskieren dürfe. Er erzählte mir das mit merkwürdiger Naivität, mit offensichtlichem Bedauern. Daneben gutmütig. Die Revision der englischen Übersetzung macht er recht, aber Marieli

behauptet, dass er das gewiss durch einen andern besorgen lasse. Ob ich wohl von Siegwart eine Fortsetzung u. Sorge für meinen «Nachlass» erwarten dürfte? O hilf mir, Liebe, u. richte alles zum Besten!

Ich bin nicht mehr müde, aber matt, fiebrig, rheumatisch. Um mich aufrecht zu halten, nehme ich mich für die zwei Morgenkollegstunden zusammen. Es muss sich noch aushalten.

In inniger Liebe mit treuestem Gruss u. Kuss

Dein getreuer

Eugen 
[1]

B. d. 5. / 6. Juli 1912.

Mein liebstes Herz!

Mit Mühe gegen die Heiserkeit ankämpfend habe ich heute gegen meine vier Kollegstunden abgehalten, war auch bei Mülinen auf der Bibliothek, ohne diesmal etwas Freundliches davon zu haben. Von 11 - 12 Uhr war Siegwart bei mir. Nach zwei Uhr, in Marielis Abwesenheit, kam Martha Gemperle, mit der ich auch etwas plaudern musste. Endlich nach dem Nachtessen wollte noch der junge Teichmann mich besuchen. Aber da hatte ich Weisung gegeben, jedermann abzuweisen, weil ich mit Unwohlsein schon zu Bett gegangen, u. so blieb mir dieser Besuch erspart. Ich bin müde u. nicht wohler als gestern. Hoffentlich wird es über die beiden Ruhetage, Samstag u. Sonntag, besser. - Was mich heute innerlich beschäftigte, war der Gegensatz zwischen Siegwart, u. Abbühl, der mich gerade zwischen dem Gespräch mit Siegwart im kleinen Cabinet sprach. Welchen würde ich für Marieli vorziehen? Heute war ich, weiss der Himmel, unsicher. Das sind Stimmungen. Siegwart war gescheit, freundlich, er tat mir wohl. Abbühl hatte wieder seine naive Frische. Dieser steht, gewiss für die Zukunft, meinen Traditionen näher. Jener bietet mir eine Welt eigner Art, eignen Werks, der unmittelbar gehoben werden kann. Nun, ich habe nicht zu wählen, ich

$[2]$

muss die Sachen sich entwickeln lassen. Und doch weiss ich, dass was ich tue u. sage von grossem Einfluss sein wird.

Dazwischen zieht sich der unverdiente Erfolg mit den Collegien dieses Semesters immer durch das Gemüt. Wie mag das gekommen sein, wie wird es im nächsten Semester sein? Wenn ich nur nicht krank u. elend werde. Soll ich leben, so 
sollte ich auch arbeiten. Wird mir das Schicksal das am Ende versagen?

Wenn jetzt das Wetter besser wird, so kann es noch drei heisse Wochen absetzen. Aber die nahen Ferien werden mich aufrecht erhalten. Solche Nähe hilft merkwürdig. Ist es nicht dasselbe, was ich empfinde, wenn ich mir denke, dass meine Einsamkeit ja auch nicht mehr lange dauern wird!

Gestern Abend als ich im Bette lag, wollte Langhard mich besuchen $u$. blieb eine Stunde bei Anna. Nach dem Nachtessen kamen Walter B. u. seine Frau, die für die Studenteneinladung Besteck bei uns entlehnt. Was gesprochen worden, vernahm ich spärlich. Ich war froh, meine Stimme schonen zu können.

Marieli ist heute Abend mit Frau Dr. Jauch in ein Musikschulkonzert gegangen. Es scheint sich ihr recht anzuschliessen, die Ereignisse gehen ihren Gang.

Für heute, wenn ich vor es dunkel wird, im Bett sein will, muss ich schliessen. Ich bin die Tage so unfähig, etwas zu denken. Ich muss immer wieder vergleichen $u$. fühle mich

matt. Aber habe ich nicht mit den Kollegien wenigstens für jeden Tag etwas geleistet. Das muss mich trösten!

Den 6. Juli.

Ich bleibe heute wegen meiner Heiserkeit u. Schmerzen im Unterleib im Bett u. stehe nur geschwind auf, um Dir diesen Gruss zu senden!

Ich schlafe u. lese im Bett u. habe den Eindruck, das tue mir gut. Jedenfalls muss ich nicht reden. Eine in Aussicht genommene Consultation ist abgesagt. Über Mittag hat es gewittert. Es wurde ganz finster $u$. hat in Strömen geregnet. Das ist der Anfang der Schulferien. Der Morgen begann heute früh warm u. heiter. In meinem Studierzimmer hat es durch die Fensterritzen geregnet.

Marieli ist den ganzen Tag fast abwesend, hat mir aber freundlich das Essen aufs Zimmer gebracht. Es hat eine Einladung 
von Beetschen zu gemeinsamen Ferien in der Lenk, wie diese hingeht, erhalten u. war weiss Gott, einen Augenblick schwankend, ob es nicht statt zu Siegwarts in die Lenk gehen soll. Ich redete nicht drein. Sein Schluss war: erst ein paar Tage in die Lenk $u$. nach her, zur verabredeten Zeit nach Altdorf. Das ist mir auch recht.

Ich bin mit der Arbeit nicht so gehetzt, dass ich nicht heute mir die Ruhe u. Bettwärme gönnen dürfte. Ich kann um so mehr hoffen, die drei Wochen ungestört zu Ende zu lesen.

Es stürmt u. regnet furchtbar! Ich breche ab, ich bin

[4]

mit dem innigsten Gruss

Dein allzeit treuer

Eugen

\section{2: Juli Nr. 147}

B. d. 7. / 8. Juli 1912.

Mein liebstes Herz!

Heute bin ich wieder ordnungsmässig auf den Beinen gewesen. Walter B. kam nicht zum Sonntagsbesuch, er war an einer Comitésitzung in Solothurn. Dafür war Dürrenmatt da, der mir klagte, dass er seinen Steuerprozess in Delsberg führen müsse. Ferner kam Jean Rossel u. redete mit mir über die Einreichung seiner Dissertation. Andere Besuche hatte ich nicht, konnte also füglich «das Maul halten». Aber die Heiserkeit wollte doch nicht vorübergehen. Ich spüre sie etwas weniger, aber immer noch so, dass der gestrige Ruhetag mir nicht die Erleichterung gebracht hat, die ich von ihm erhoffte.

Sonst schrieb ich heute an Welharill, Philadelphia, wegen der englischen Übersetzung, ziemlich scharf. Ich will sehen, 
was er darauf antwortet. Dann hatte ich mit dem

morgigen Kolleg viel zu tun, u. im übrigen las ich in

Houssayes Jona. Das Buch ist im Geiste u. in der Methode des

Verfassers von Watterloo geschrieben. Aber es wird, was

ich bis jetzt gelesen, entstellt durch den Herausgeber Medelin, - Houssaye ist vor der Vollendung gestorben -, der die ganze Darstellung auf die Ermutigung der Franzosen zur Revanche zugeschnitten zu haben scheint. Es ist merkwürdig, wie da der Ton der Darstellung sofort wechselt. Ich würde ein

solches Buch nicht gekauft haben, wenn mich der Name Houssayes dazu verleitet hätte. Doch will ich mein Urteil noch zurückhalten bis ich das ganze gelesen.

Gestern im Bett las ich noch das Tagebuch Arnolds Nr. XIII, ganz fertig, u. sandte es heute an Marie zurück. In einem besondern Couvert musste ich ihr auch über einen Brief Arnolds schreiben, den sie mir übermittelt $u$. über den sich Albert scheints furchtbar entrüstet hat. Es ist auch zu sagen, dass Arnold aus dem Brief nicht in sympathischer Gestalt ersteht. Aber ich habe soviel als möglich zu beruhigen versucht. Es tut einem so leid, nun über dem Wesen Arnolds den guten Albert in solchen Kummer u. Zorn gestürzt zu sehen. Gewiss reut ihn die Preisgabe der Kollegien je länger je mehr, u. auch das hat Arnold in ihm zur Reife gebracht, es war kein guter Samen.

Ich erwartete heute Papa Rossel bei mir, u. ich hätte ihm gerne meine Beschwerde wegen einer Korrespondenz in der N. Z. Z. angebracht, die anlässlich eines Falles über einen Artikel des ZGB, etwas ganz schiefes u. gehässiges gebracht hat. Nun, es ist vielleicht besser, Rossel sei heute nicht gekommen $\mathrm{u}$. ich spreche mit ihm gar nicht darüber. Er war ja in diesen Dingen nie zuverlässig. Inzwischen kann ich mir die Sache zurecht legen u. vielleicht an Honnegger schreiben, in dessen Kammer der betr. Fall wohl behandelt worden ist. 
Es war heute trübe u. trostlos. Ich fühle wohl auch wieder das kühle Wetter. Wenn ich freier bin, will ich Dir ausführlicher schreiben. Heute habe ich wieder etwas Fieber in den Fingern, ich brauche es nicht zu sagen, es ist sichtbar.

Den 8. Juli.

Leider ist die Heiserkeit, die ich am Morgen beim Aufstehen nur noch schwach spürte, nach den zwei Vorlesungen wieder gekommen. Nach dem Essen war Tuor bei mir, der mir sein Buch über das «Neue Recht» überbrachte. Es war nett von ihm. Auch sonst war, was er von Siegwart etc. sagte, nur Gutes. Wie sein Buch beschaffen, wollen wir sehen. Gegen Abend ging ich ins Rathaus, traf Meyerstrasse, Hänny, Forrer, Käslin, Mutzner, Motta, Raaflaub (in Uniform), also viele, von denen ich vieles vernahm. Kaiser dagegen war in die Ferien verschwunden $u$. Müller zwar von Basel zurück, aber schon vom Büreau gegangen.

Ich schrieb heute Bundesrichter Honegger, wegen der hämischen Bemerkung des Lausanner Korrespondenten der N. Z. Z., um doch das wenige zu tun, um diesen wiederholten Nadelstichen ein Ende zu bereiten. Wie er es aufnimmt, u. ob er diskret ist, das bleibt abzuwarten. Hoffentlich steckt nicht Rossel hinter der ganzen Sache, wenigstens kam er gestern Abend trotz Abrede nicht vorbei u. heute Morgen stand er an der Tramhütte als ich über die Brücke kam, drehte sich aber so zu den Plakaten, dass er mich nicht sehen konnte.

Am Nachmittag präparierte ich Kolleg u. schrieb ein Gutachten für Borlet. Der ist mit seinen Ansprüchen unerschöpflich. Es ist von mir auch abgeschrieben gleich zur Post

gegangen. Vom Secretär habe ich an Abbühl ja wirklich keine rechte Hülfe. Ich werde aber sehen, dass er zu einer seiner entsprechenderen Stellung gelangt: Er soll ausschliesslich MaturaKandidat sein nach dem Militärdienst. Es ist so besser. 
Mit Marieli hatte ich wieder eine Auseinandersetzung. Es will nun um alles mit der Reineck ein paar Tage auf der Forclaz sein, u. das gerade gefällt mir nicht. [Reineckise?] scheint verlobt, mit dem jungen Lauch, der erst das Examen gemacht hat. Mehr als sieben Jahre Unterschied! Und dazu ist sie oft [?], u. sie will mit Marie in einem Zimmer hausen! Das gefällt mir nicht, es ist nicht fein, u. ich habe Marieli abgeraten. Aber ich weiss nicht, es verdreht sich alles gegenüber der Kleinen. Ich will sehen, was sie tut. Meinen Wunsch kennt sie nun.

Heute fragte mich Marieli auch, sie sollte nächsten Samstag das Kränzchen bei uns abhalten u. es falle auf den 13. Jli. Was sie nur machen soll? Natürlich sagte ich ihr, sie soll sich doch um den Geburtstag nicht scheren. Ihre Frage war mir schon genug. Mangel an Herz! Oder Jugend? Sollte nicht Siegwart sich schwer täuschen? Doch er ist klug. Er wird sich die Sache schon zu recht legen.

Und nun hoffe ich doch, dass die Heiserkeit noch vor Ende der Woche vorüber gehe. Es sollte sein, ich muss wieder freier werden!

Noch eins: Dr. Emil Gmür, den die alte Steiger jeweils das Bischuli nannte, ist gestorben. Regierungsrat seit einem Jahr. 31 Jahre alt. Ich habe seiner Frau innig condoliert.

Nun Schluss, mit Gruss u. Kuss bin ich Dein allzeit treuer

Eugen 
[1]

B. d. 9. Juli 1912.

Meine liebe, gute Seele!

Heute war meine Heiserkeit etwas besser, dafür mein ganzer Zustand fiebriger. Ich las fast den ganzen Tag an Martins Dissertation, die gut ist. Ich bin über die Mitte gekommen. Dann hatte ich Guhl wieder einmal bei mir. Er war recht, nimmt aber richtig nun wohl definitiv die Direktor-Miene an. Man spürt weniger Herzliches als früher. Das Sprunghafte im Erzählen hat sich vermehrt. Er wird damit zu einem Detaillisten, freilich zu einem guten. Es fehlt an Ganzheit u. Tiefe. Von Mutzner spricht er stets ausweichend, wohl weil er in ihm einen Concurrenten vermutet. Dafür hat er sich mit Blumenstein ganz unnütz angefreundet. Was dahintersteckt, wer weiss es! Auf Blumenstein habe ich ein Auge, mehr als eine Zeitlang wieder. Er könnte elend feindselig handeln, wenn seine Interessen in Frage stehen. Ich muss mir bei solchen Gedanken immer nur sagen, wie gut, dass ich noch lesen kann. Hoffentlich spielen mir Hals u. Fieber nicht doch in Bälde noch einen schlimmen Streich! Gestern spürte ich plötzlich in der rechten Wade einen Stich u. Druck, bei einer Bewegung im Aufstehen vom Arbeitsstuhl. Ich dachte an Venengeschichten. Es war aber nicht als eine sonderbare Muskelstreckung, die schon Abends ganz verschwunden war u. mich keinen Moment am Gehen hinderte.

Marieli war nun, mit schwerer Überwindung, doch so klug, den Plan, für fünf Tage vor Altdorf zur Braut Reineck nach Forclaz zu gehen, fahren zu lassen. Ich gab freilich meine Missbilligung 
des Planes deutlich zu verstehen. Will es mit Mine Beetschen noch für einige Tage in die Lenk, so habe ich nichts dagegen.

Wichtig war für mich auch, dass heute die Anstellung Abbühls sich abgeklärt hat. Ich sagte ihm schon letzte Woche einmal u. dann gestern, dass es wohl besser wäre, wenn er ganz auf die Matura losarbeiten u. sich nicht zersplittern würde. Er soll darüber mit seinem Matura-Lehrer, Schenker, sprechen. Dieser Schenker ist ein alter Schüler von mir, der das erste juristische Examen bestanden, dann aber aus Freude an den Sprachen sich ganz der Philologie hingegeben hat. Vor etwa sechs Jahren dachte er, um seinen Vater zu befriedigen, daran, bei mir eine Dissertation zu schreiben, wurde dann krank, nahm eine Stelle in Zürich als Sprachlehrer an $u$. hat seither in Bern sich mit Stunden in allen Sprachen unabhängig vom Vater durchgebracht, will jetzt aber noch das Gymnasiallehrer-Examen machen. Diesen Schenker liess ich nun durch Abbühl zu mir bitten. Er kam vor zwei Uhr. Nach kurzem Gespräch teilte er mir mit, dass er Abbühl für begabt u. fleissig halte. Die Helvetia nehme ihn aber etwas stark in Anspruch u. der halbe Tag bei mir passe nicht recht zur Präparation auf die Matura. Wenn Abbühl auf nächstes Frühjahr oder dem Sommer das Examen machen wolle, so sei es seiner Ansicht nach notwendig, dass er sich ausschliesslich dieser Aufgabe widme, sobald er aus dem Militär zurück sei, also von Ende Oktober ab. Damit ist nun die Sache entschieden. Ich entlasse Abbühl Ende nächster Woche, in Frieden, aber ohne Verabredung für später. Ich glaube, ihm selber ist wirklich

wohler so. Er hat doch selbst merken müssen, dass seine Leistungen mich nicht befriedigten, $\mathrm{u}$. ich komme mit einem Vierteljahr, 480 Fr., aus dem Experiment heraus. Die Sache hätte natürlich einen ganz andern Charakter bekommen, wenn sich das Verhältnis zu Marieli anders gestaltete. Allein es hat von dem Moment an, da er täglich bei mir erschien, keinen rechten Respekt mehr vor ihm gehabt. Er gab sich wenig bedeutend $\mathrm{u}$. wurde so eingeschätzt. Nach dem was mir Marieli harmlos er- 
zählte, muss es Abbühl geradezu kalt behandelt u. verletzt haben. Nicht nur wich es jedem Alleinsein aus, sondern bei den Damentouren engagierte es niemals ihn, obgleich der gute Ton verlangt, dass die Dame in erster Linie ihren Begleiter auswählt. Als ich heute Marieli von der bevorstehenden Lösung sprach, äusserte es lebhaft seine Befriedigung. Ich aber muss sagen, auch dieser mein Streich ist noch glimpflich abgelaufen, geradeso wie das mit Mutzner gerichtet werden konnte. Und merkwürdig ist, dass ich bei diesen Loswicklungen trotz aller Einsicht aus einer fatalen Lage, in die ich mich enthusiastisch verpallogiert, herausgezogen zu haben, doch über die Ergebnisse nicht unfroh bin. Die Stellung zu Mutzner ist mir jetzt viel klarer als vorher, auch die Stellung zu meinem Buche hat sich dabei abgeklärt. Und betr. Abbühl habe ich doch den guten Willen betätigt, Marieli zur Erfüllung eines Herzenstraumes zu helfen. Wäre nichts geschehen, so würde der Gedanke an jene Möglichkeit Marieli zeitlebens vielleicht verfolgt haben. Jetzt hat es gesehen, dass die Sache nicht recht passt, u. da es ja wesentlich verstandesmässig handelt, so ist die Sache damit

ohne dass man sich Vorwürfe machen muss, erledigt.

Die Gärtner waren schon wieder da heute, u. die Rechnung Flückigers für das letzte halbe Jahr ist unverschämt. Ich war heute Mittag nahe daran, Flückiger zu künden. Jetzt bin ich wieder ruhiger. Was will man mit dem Wechsel! Es geht ja alles nicht mehr lange!

Der Tag war ruhig, u. nicht ohne Bedeutung. Verschaffe mir eine ruhsame Nacht, damit ich morgen wieder frisch an der Arbeit bin.

Gute, gute Nacht! Von Deinem allzeit getreuen Eugen 
[1]

B. d. 10. Juli 1912.

Mein liebstes Herz!

Ich konnte heute in Martins Dissertation nicht soweit

vorrücken, als ich gehofft. Ich schrieb e. Bericht für das Departement, dann kamen Studenten zu mir u. mit Abbühl hatte ich eine längere Unterredung. Bei Marieli war den ganzen Tag die naturfrische Mina Beetschen. Anna hatte den Nachmittag Besuch von Frau Dr. Jauch. In den Vorlesungen ging es mir ordentlich. Die Heiserkeit hat jetzt doch etwas nachgelassen.

Mit Abbühl sprach ich über das Ergebnis der Besprechung mit Schenker. Er schien sehr froh zu sein, dass er sich von dem Secretariat losmachen u. ausschliesslich auf die Matura hinarbeiten soll. Mir ist, ich wiederhole es, eine schwere Sorge abgenommen. Vermutlich nehme ich zunächst niemand. Siegwart anerbot sich, mir etwa zu helfen, vielleicht könnte bei dem freundschaftlichen Verhältnis, das sich anzubahnen scheint, diese Hilfe mir gerade genügen. Marieli hat von Frau Schmid, d. h. Gabi, eine sehr nette Bonbonniere erhalten, als Gegengabe für die Photographien, die es ihr sandte. - Was mir dann weiter Abbühl mitteilte, hat mich sehr bewegt. Die hiesigen Helveter sind von den Frankonen in Darmstadt so beschimpft worden, nach vorangehenden Rempeleien, dass die Helveter sechs oder neun Säbelduelle Line-Line fordern. Das sind Gänge, die um gesunde Glieder, oft sogar das Leben gehen, u. Abbühl soll einer der ersten, oder der erste sein. Kaum hat er noch Ende der letzten Woche sich gefreut, dass er wegen seines Militärdienstes nun von

der Verpflichtung zu einer nochmaligen Mensur in diesem Sommer befreit worden sei. Freilich eher eine Vernunftsfreude als eine Herzensfreude wie mir schien, - und jetzt soll der doch noch vor dem Dienst die viel schwerere Sache auf sich nehmen. Er nannte als 
Schläger der Helveter: sich selbst, Weniger, Schürler, Schwab, Hürzeler, Weger, $u$. vielleicht noch andere. Geschlagen soll in Darmstadt werden u. zwar nach derselben Art, die unsern Schlägern weniger bekannt ist. Dafür glaubt Abbühl, dass ihre Leute stärker seien, als die dortigen. Allein das ist mir nicht sicher, u. im Säbelduell kommt viel auf die Kraft an. Vielleicht wird der blutige Gang auf Anfang des Wintersemesters verschoben. Doch sicher ist es nicht. Es ist eine ganz schlimme Geschichte. Da Line, d. h. ohne die üblichen Schutzbandagen gefochten wird, mit Ausnahme von ganz wenigen Lederschutzriemen, kann ein Arm abgehackt, der Schädel eingeschlagen werden, man weiss es nicht. Abbühl wird dabei einer der mutigsten, aber auch der exponiertesten sein. Denn er verachtet Parade $u$. trachtet nur dem andern was beizubringen. Und doch kann ich in der Sache nichts tun, als zu sehen, was geht, solange nicht Dinge geschehen, die über die Ehre hinausreichen. Die Frankonen haben geschrieben, die Berner Helveter seien elende Typen, Auskneifer etc. Darüber nun natürlich blutige Revange!

Den Nachmittag waren drei Candidaten bei mir. Der Frauenfelder Schmid, der Bündner Caflisch, der eine Dissertation sucht, später wird er Mitinhaber des grossen Restaurants in Neapel, u. Nietlisbach, der das Examen gar nicht gemacht hat, wie mir Walter B. berichtet hatte, sondern irrtümlich von Gmür zitiert worden war. Gmür macht jetzt viele solche Böcke,

er scheint in einer grossen Unruhe, die drei Kandidaten waren typisch: Der verbummelte Corpsstudent, der sich zusammenrafft, der in Geld schwimmende Fabrikanten- oder Rentierssohn, der sich sorgsam auf seine künftige Stellung besinnt $u$. arbeiten will, $u$. der Sohn des Burgers u. Beamten vom Lande, sogar Nationalratssohn, der schüchtern, brav, seine Wege geht u. nun den Abschluss erreicht hat. Ich hoffe es werden alle drei zu guten Ergebnissen gelangen. Sie machen mir guten Eindruck.

Wenn ich mich nicht täusche, so steht es jetzt wirklich wieder besser mit meinem Hals. Trotz feuchter Luft, warmem Regen fühle ich mich wohler, habe die Schmerzen in den Eingeweiden verloren, bin weder rheumatisch noch fiebrig. Geraucht habe ich die ganzen Tage nicht mehr u. das bekommt mir so wohl, dass ich 
schon daran gedacht habe, das Laster ganz aufzugeben. Aber Du hattest Dich doch damit so lieb befreundet, dass Du sogar der Anlass gewesen bist, aus dem ich nach 21 Jahren wieder damit begann. Von Ruchet las man, dass er wegen Krankheit seine Entlassung als Bundesrat genommen. Die Ersatzwahl wird schon am 12. Juli stattfinden. Den haben sie nun zur Demission gebracht, Deucher nicht. Ruchet wird so wenig als Deucher lange mehr leben. Ruchet folgt mit seinem reichen Herzen seiner Frau. Er hatte unter dem Verlust, vom November 1909, viel gelitten. Er vertraute es selbst mir einmal an. Nun gehört er zu denen, die nicht mehr lange allein sein müssten. Er scheidet in meinen Augen als edler Mensch, der das Gute gewollt hat, wenn er auch oft recht ungeschickt war es zu erreichen!

Gestern Abend kam Walter B. noch zu mir, ziemlich spät.

Seine Frau ist mit ihrem Brüderchen Fredi für einige Zeit nach Trub gegangen. Walter B. erzählte mir von allerlei neuem, sodass er für die Leipziger Illustrierte einen Aufsatz über die Beziehungen der Schweiz zu Deutschland schreiben soll, der in einer «Kaiser» Nummer des Blattes im Herbst erscheinen soll.

Und nun gute, gute Nacht! Ich bleibe immerdar

Dein treuer

Eugen 
B. d. 11. / 2. Juli 1912.

Mein liebstes Herz!

Heute auf der Universität vernahm ich, dass BRat Deucher gestern Abend gestorben ist. Man hatte es ihm noch nahe legen wollen, doch seine Entlassung jetzt auch zu nehmen, wie Ruchet. Nun hat er sie genommen. Er war schon lange ein gebrochener Mann u. hat an seinem Amt zu zähe festgehalten, da er nicht mehr im Stande war, es auszufüllen. Aber ein guter Patriot $u$. ein feuriges Temperament, dies ist er bis an sein Ende geblieben. Die Trauer ist allgemein. Mich wundert, ob sie nun Schulthess wählen werden. An den Sohn Paul, den Mediziner, schrieb ich soeben die Zeilen: «Empfangen Sie mit Ihrem verehrten Herrn Bruder $u$. allen Ihrigen den herzlichsten Ausdruck meiner Teilnahme an dem schweren Leid, das sie betroffen. Wo das ganze Land so aufrichtig mittrauert, da verschwindet der Einzelne. Es ist mir aber ein tiefes Bedürfnis, es Ihnen doch auch persönlich auszusprechen, wie sehr ich mich Ihrem hochverdienten Vater verbunden gefühlt habe. Mit welcher Freude habe ich seinerzeit mitgeholfen, als unsere Fakultät ihm den Ehrendoktor verlieh! Wie war ich ihm dankbar, da er im Rat mir wiederholt mit ermunternden Worten in schwierigen Lagen zugesprochen hat! Er durfte ein reiches Leben voll u. ganz ausgestalten, für diesen Segen werden auch Sie mit den Ihrigen bei allem schweren Leid im Gefühl der Dankbarkeit u. innigen Trostes empfinden! Seine Werke folgen ihm nach! In tiefer Mittrauer bin ich Ihr ganz erg.» - Was ich da schrieb, kommt mir wirklich vom Herzen. Ich habe mich einige Male über seine Unzulänglichkeit in den letzten Jahren schmerzlich geärgert. Aber der 
Mann im Ganzen hat doch einen guten Posten gestanden. Wir haben nicht viele von solchem Feuereifer.

Heute habe ich schon wieder ein Gutachten für Borlet schreiben müssen, das mich bis vier Uhr beschäftigte. Vor Tisch war Guhl da, länger habe ich auch mit Abbühl über die Duell-Affäre gesprochen. Nun las ich bis sieben Uhr die Dissertation Martins fertig. Sie macht mir einen guten Eindruck. Sie ist gescheit u. fleissig. Heute war Marieli bei Frl. Hoff, um sie zu zahlen u. sich wieder einmal untersuchen zu lassen. Der Bericht war, die Lunge sei immer noch etwas afficiert, nicht weniger als im Frühjahr. Marieli soll nicht reisen, sondern eine Höhenkur machen. Nun verzichtet es gerne auf die Lenk, nachdem es nicht mit der Reineck gehen «darf». Aber den Besuch in Altdorf will es doch machen, u. denkt dann nachher mit mir auf dem Klausen ein paar Wochen auszuruhen. Die Hoff empfiehlt, nicht Touren zu machen, sondern viel, jeden Tag mindestens vier Stunden, zu liegen. Sie möchte gerne die Lunge auch rönthgenisieren lassen. Das sind Übertreibungen. Ich finde aber wirklich auch, dass Marieli mehr Ruhe haben sollte. Aber es ist zu eigenwillig. Wem nicht zu raten, dem ist nicht zu helfen. Jetzt eben ist die Reineck nochmals gekommen, um mich zu fragen, ob ich nicht Marieli auf die Forclaz lassen wolle. Ich werde mich reservieren, $u$. möglichst bald zu Bett gehen. Ich bin überdies noch nicht auf morgen präpariert.

Den 12. Juli.

Der sehr warme Sommertag hat die Herren Commilitonen sehr müde gemacht. Sie waren unlustig an der Arbeit, besuchten auch das Praktikum schwach. Die Zofinger waren am Centralfest. 
Früher haben die Studenten solche Centralfeste in die Ferien verlegt oder doch am Sonntag abgehalten. Jetzt feiern sie unbedenklich an Kollegtagen.

Morgen wird Deucher beerdigt. Marti als Rektor hat mit dem Zugsordner Leupold verhandelt u. merkwürdiger Weise dabei gewünscht, dass die Abordnung der Universität (Rektor u. Dekan) an der Spitze der Farbendelegierten mit ihren Fahnen eingereiht werde. Und da diese vor dem Sarg marschieren, sollen die Professoren an die Spitze des Zuges kommen. Das ist von Seiten einer kantonalen Anstalt merkwürdig u. es wundert mich, ob es ausgeführt wird. Neben der Delegation ist für uns Professoren kein rechter Platz mehr, u. so bleiben wir, Walter B. u. ich, obgleich gerade wir zwei daran dachten, die Feier mitzumachen, weg. Ich denke es ist so richtig. Ich muss ohne dies morgen Abend den Helveter Kommers mit Marti mit machen.

Abbühl war heute wieder merkwürdig zerfahren, behauptete, Calander sei Oberst u. sei als General in Aussicht genommen u. dgl. Es ist ein merkwürdiger Mensch, von einer überwältigenden Dummheit. Aber wie solche Naturen manchmal mit ihrem Eifer doch Carriere machen, das habe ich ja an Fritz von Calker gesehen, den ich s. Z. nicht höher einschätzte. Immerhin keine Zusammenstellung. Calker entstammt einer ganz andern Grundlage. Die wenig freie Zeit neben dem Üblichen verwandte ich zu Kollegpräparation. Auch war Rossel bei mir, der mir wieder von dem vergnügten Leben als Bundesrichter erzählte. Nächste Woche machen alle wie eine Schule ein Tagesreischen. Und sonst soll der Verkehr ein sehr gemütlicher sein. Ich habe mir immer gedacht, dass diese Klagen von Arbeitsnot übertrieben seien. Jetzt vollends haben sie ein gutes Dabeisein. Und doch darf es mich nicht reuen,

[4]

in Bern geblieben zu sein. Der Erfolg dieses Semesters allein hat die Entscheidung nachträglich gerechtfertigt. Und ich würde nicht an allem Freude haben, an dem Rossel Freude hat. 
Nun aber werde ich müde u. schliesse. Es kommt das Semesterende, man spürt es schon.

Zum Tagesschluss innigen Gruss! Ich bleibe immerdar

Dein getreuer

Eugen

\section{2: Juli Nr. 151}

[1]

B. d. 13. Juli 1912.

Meine liebste, beste Seele!

In der Nacht auf den heutigen Geburtstag war ich längere Zeit wach, u. überlegte, ob ich nicht morgen nach Klausenpasshöhe fahren soll, hin u. zurück, mit Marieli, um mir die Ferienangelegenheit anzusehen. Nach dem alten Kursbuch, das ich im Pult hatte, wäre es gegangen. Die geltenden Fahrzeiten aber erwiesen es dann als unmöglich, an einem Tag die Tour zu machen, u. so fiel die Sache weg.

In der Nacht träumte mir, an einer festlichen Gelegenheit habe Marieli von L'Ammann Wirz oder seiner Umgebung zwei StaatsKleider erhalten. Auf mein Erstaunen wurde mir verlegen bemerkt, sie hätten gedacht, es müsste ja ohnedies bald ein Hochzeitskleid geschenkt werden, $u$. ich fasste bewegt die Hand einer Dame, als die der mir unbekannten Frau Siegwart, Mutter Alfreds, u. drückte sie an mein Herz. Na, sowas, sagte ich gleich dabei, u. fort war der Zauber.

Siegwart kam heute gegen drei u. blieb über fünf Uhr. Er gratulierte mir freundlichst. Er war herzlich, bewegt, ich sprach mit ihm über Pläne $u$. anderes, ich hatte Freude an ihm. Marieli war den ganzen Nachmittag mit seinem Kranz im Dählhölzli. Marieli soll sich wieder geärgert haben über das Benehmen Susannes, während es doch mitgemacht $u$. angesichts der Badenden hart an dem Ufer der Aare seinen The trank. Ich bin darüber innerlich erbost, weiss nicht was zu machen, aber der Geburtstag eignet sich nicht zu einer Beschwerde. Am Morgen gratulierte mir Anna mit einer neuen Käsglocke 
u. einem Hortenzienstöcklein, u. Marieli mit einer HolzbrandKleinigkeit, Aschenbecherchen u. Streichholzschächtelchen. Dann kam der kleine Karle u. brachte mir ein Geranium, sauber, nett, lieb. - Zur Feier Deucher ging ich gemäss Abrede mit Walter B. nicht. Marieli, war zuerst im Bad u. dann auf der Strasse, mit der kleinen Lüdemann. Es kam erst ein Uhr nach Hause u. verschwand vor zwei Uhr wieder zu dem schon erwähnten Kranz. Auf acht Uhr wollen die beiden, Marieli u. Lüdemanns, nochmals in die Stadt. Ich soll ja auch gehen, zum Kommers der Helveter, dem 80jähr. Stiftungsfest. Ich habe mit Rektor Marti mich verabredet. Abbühl anerbot sich, mich abzuholen. Ich konnte mit der Abrede ablehnen. Abbühl kam mir heute wieder so einfach vor. Ich entliess ihn elf Uhr, nachdem er nach acht gekommen. Ich bin froh, wenn er nicht mehr kommt. Er sagt mir nichts.

Von Stammler erhielt ich einen Brief, mit frohen Nachrichten über die ganze Stellung. Er strotzt wieder vor Glück. Von den Kollegen oder andern Verhältnissen habe ich nichts vernommen. Dagegen schreibt er von sechs Praxisarbeiten, die eingegangen. Er wird mir darüber noch berichten. Eine gemeinsame Beratung scheint er gar nicht in Aussicht zu nehmen. Daneben habe ich heute noch die Rechtswörterbuchsachen, die pendent waren, erledigt, ferner Briefe geschrieben $u$. die Studenten- oder Kandidatenbesuche gehabt, zum Teil während Siegwart da war. Dabei auch Prof. Töndury von St. Gallen, den ich nach seiner $u$. Tuors Meinung hätte bei Pylhon empfehlen sollen, was ich natürlich ablehnte, solange ich nicht gefragt werde. Es ist naiv, so auf mich zu spekulieren, u. dies empfand Töndury

offenbar nachträglich, sodass sein Besuch ein Entschuldigungsbesuch war. So ist der dritte Geburtstag vorüber gegangen. - Nur von August erhielt ich noch eine Ansichtskarte mit Glückwunsch. - Der dritte ohne Dich. «Freude u. Kummer, fühl ich, zerrann.» Das ist meine Stimmung. Es freut mich manches nicht, aber es muss gehen. Ich will dafür dankbar sein, dass es nicht schlimmer ist. 
Ich schliesse die Zeilen nicht vor Schlafengehen, da ich noch an den Helveterkommers gehen muss. Ich dachte mir im Frühling die Annäherung an diesen Kreis freilich anders. Jetzt hat die Anbendelung mit Abbühl der Sache eher Schaden gebracht. Wie konnte ich nur auf Marieli so fest vertrauen! Aus Mitleid mit seinen Stimmungen! Etwas Besondres wird wohl den Abend nicht vorfallen. So lassen wir die Sache vorübergehen. Was zu sagen ist, werde ich morgen anfügen. Wertvoll war für mich der Einblick in das Helveterwesen durch die Seele eines Abbühl. Er ist naiv, er ist treu, er ist beschränkt, aber er kann mit Fleiss sich vorwärts bringen. Also warten wir ab. Seine ganze Art zeigt eine sonderbare Doppeltheit. Er ist so kindlich u. urteilt daneben über alles mit Wichtigkeit auf die urteilsloseste Art. Ich kann mit ihm nichts besprechen. Übrigens mit Gmür ist es oft dasselbe. Bei Teichmann ist es mir ebenfalls aufgefallen, nur wird es bei diesem durch eminentes Wissen gemildert.

Es fehlt nach meinem Empfinden bei solchen Köpfen etwas, wahrscheinlich die Ordnung, das systematische Denken. Und daraus ergibt sich dann der Mangel an Urteil, der mir so peinlich auffällt. Das Gedächtnis ersetzt dann bis zu einem gewissen Grad das mangelnde Urteil, oberflächlich genug. So sind eben viele, die es noch dazu zu etwas bringen, wenn sie mit ihrem Blenden Glück haben. Sonst arme

Menschen, die nirgends recht brauchbar sind.

Mit Marieli hatte ich noch, bevor es zum Helveter Umzug ging, eine kleine Auseinandersetzung, bei der ich ihm verständlich zu machen suchte, dass sein guter Ruf unter der Kameradschaft mit Susanne leiden könnte, u. dass es gewagt gewesen für sie die Kranzdamen, sich ans Ufer der Aare in die Nähe der Badenden zu setzen. Aber wo die Empfindung für so etwas fehlt, kann man sie mit keinen Vorstellungen ersetzen. Ich spüre nur, dass mir Marieli wieder mehr u. mehr fremd wird. Das ist der Lohn für unser Experiment.

Doch nun weg mit den trüben Gedanken. Der Geburtstag soll mich doch erfreuen, komme was wolle! Seid dankbar, wie oft sagtest Du es, $u$. ich will dankbar sein.

Innigst Dein ewig treuer

\section{Eugen}


B. d. 14. Juli 1912.

Mein liebstes Herz!

Der heutige Tag kam mir sehr warm vor u. ich war sehr schlaff, wohl von gestern her. Ich war um 1 Uhr in meinem Schlafzimmer u. habe auch bis sieben gut geruht. Aber der Lärm u. die Hitze in dem Kommerslokal haben eben doch auf mich so eingewirkt, dass ich heute es den Tag über verspürte, ohne irgend unwohl zu sein. Es kam Niemand her, u. ich ging auch nicht aus. Es war mir zu heiss, um die schuldigen Besuche bei Hoff- $u$. Weyermann zu machen. Ich hätte dann am Nachmittag zu Kocher gehen können, der aufAnfrage Martis sich anerbot, diejenigen, die es begehrten, in seiner Villa die Adressen auf sein Fest vorzuzeigen. Aber auch dafür war es mir zu heiss. Ich sah voraus, dass ich mit ganz verschwitztem Kragen dastehen oder sitzen müsste, unter Leuten, die ich fast nicht kenne. Mit Marti u. Tobler wäre ich ja schon gerne gegangen. Aber so wie die Sache nun war, tat ich doch wohl besser daran, zu Hause zu bleiben. Den Nachmittag hat es sich übrigens sehr getrübt, u. vielleicht bricht auf den Abend noch ein Gewitter aus. Der gestrige Kommers war sehr besucht, gewiss 150 Rothmützen. Ich erhielt auch Band u. Mütze, das Band nahm ich nach Hause, die Mütze habe ich ein paar Momente auf dem Kopf gehabt, wie s. Z. die Mütze der Concordia in Laupen. Der Vorsitzende, Theologe von Känel, wollte mich zum Sprechen bewegen. Zwar hatte er in seiner Hauptansprache nichts von meiner Gegenwart gesagt, aber Marti meinte dann, Professoren seien unter der Helvetia wenige, aber einer sei da als Ehrenmitglied, der zehn aufwiege. Und im späteren Abend ergriff der

Präses das Wort, um mich speziell zu grüssen. Auch ein ehemaliger Schüler, Dürst, bat mich geradezu zu sprechen. Aber ich tat es doch nicht, teils wegen meiner Heiserkeit, die es mir, wenn es auch viel besser geht, unsicher erscheinen liess, in dem grossen Lärm durchzudringen. 
Dann weil ich ganz u. gar nicht mochte. Abbühl verdarb mir die Sache ein wenig, indem er sich an meine Seite setzte u. nicht von mir wich. Ich hätte nicht gewusst was sagen, u. indess ich wartete, ergriff dann ein alter Herr, Dähler nein Billo glaube ich, das Wort, der 40 Jahre im Ausland war u. sich in einer heftigen Anklage über die Änderung erging, die inzwischen in den politischen Dingen der Schweiz Platz gegriffen. 「...า Er sprach von den zwei schändlichen Tagen in Zürich (Generalstreik), von Lumpenfreuden etc. Ich sah einen Conflict voraus. Denn Zgraggen war da u. hörte an der Tür zu. Aber dann ging er ohne Antwort. Ich aber wollte darauf um so weniger das Wort ergreifen. Etwas Neutrales hätte nicht mehr gepasst u. zu einer Entgegnung oder Ergänzung fühlte ich mich nicht in der Lage u. die Kommerssituation ganz u. gar nicht geeignet. - Ich sah viele Bekannte, Ruprecht sass längere Zeit neben mir. S. Willemer, Abbühls Schutzpatron kam auch u. blieb einige Zeit. Schopfer aus Lausanne grüsste, viele andere, der junge Ursprung, der junge Decoppet desgleichen etc. Es war rasch $12 \mathrm{Uhr}$ bei dem turbulenten Schwarm, der den Saal in steigendem Mass erfüllte. Im Grunde wird mein Schweigen aber wohl schliesslich darauf zurückzuführen sein, dass ich ganz u. gar die Stimmung für den Kommers verlor, als die Nachricht kam, Ruchet sei gestorben! Ich dachte daran, wie er im Sommer 1910 zu mir gesagt hat, nicht wahr, man versteht den Selbstmord des römischen Litteraten, wenn

「Ist das m. alter Bekannter Billos aus Zürich?ך

man eine liebe Frau verliert (in den Zeitungen war eben damals von einem solchen Vorfall die Rede gewesen), u. ferner, wie er, als das Gerücht ging, er wolle sich wieder verheiraten, erklärt haben soll. Wenn man eine so liebe Frau gehabt hat, wie ich, so heiratet man nicht wieder. Ich sagte mir, jetzt hat Ruchet die Wartezeit überstanden u. es kam ein so wehmütig, resigniertes Gefühl über mich, dass ich an nichts anderes mehr dachte $u$. mich ganz in diese Gedankenu. Gefühlsrichtung verlor. Ich ging auch gerne weg. Sonst wäre ich vielleicht länger geblieben u. doch noch zum Worte gekommen. Aber es war u. ist so besser. Der gute Ruchet. Ein so braver Mann, der in reichem innern Leben sich in einer stilleren Stellung so wohl hätte 
fühlen können, u. jetzt sich dem Amte geopfert hat, bis es genug war. Und ohne viel Dank zu ernten. Aber er hätte eben nicht nur fühlen sollen, dass ihm eine ruhigere Beschäftigung am Genfersee besser zusage, er hätte auch demgemäss sich entschliessen dürfen. Aber der Waadtländer Radicale liess sich von seinen Freunden bestimmen, u. jetzt ist ja alles ausgeglichen!

BRat Müller war richtig gestern nicht bei der Beerdigung Deuchers. Wie sonderbar! Nun wird er auch Ruchet die Ehre nicht erweisen, u. dafür ungestörte Ferien haben. Oder ist er unwohl? Oder ist es der Einfluss seiner Frau?

Ich habe heute einen Aufsatz von Bekker gelesen, den ich mit der Post erhalten. Dann schlief ich zwischendurch eine halbe Stunde auf der Chaise longue, von der erwähnten Mattigkeit überwältigt. Ich schrieb weiter einige Briefchen, präparierte Kolleg, u. las in Houssayes 1814. Es ist weit mehr französisch einseitig als Watterloo aber lange nicht so plump, wie Jona, das ich letzte Woche gelesen.

Ich werde zwischenhindurch an dem 1814 weiter lesen. Leider ist gestern eine Dissertation gekommen, die mir von den letzten Tagen wieder etliche rauben wird. Wenn sich nur diese Crux abschütteln liesse! Aber es geht nicht, ich muss aushalten.

Indes ich diese Zeilen geschrieben, ist es richtig dunkel geworden u. donnert in der Ferne. Hoffentlich wird die Nachtruhe nicht gestört, ich hätte sie nötig.

Gestern verlor ich am Kommers meinen neuen silbernen Zahnstecker. Marie ging heute ins Des Alpes, man hat ihn nicht gefunden. Vielleicht bringt ihn Abbühl mir morgen.

Und nun Schluss, mein liebes Herz - ach, ich bin so ganz bei Dir, dass ich gar nicht an Anderes denken mag.

Dein treuer, stetsfort getreuer Kamerad, Dein

Eugen 
B. d. 15. Juli 1912.

Mein liebstes, bestes Herz!

Der Tag war warm, erst jetzt bei Beginn der Dämmerung wird es kühler. Ich hatte am Vormittag länger als eine Stunde Weyermann bei mir, der aus den Examensfächern gerne das «Obligationenrecht» entfernt hätte. Ich kam ihm entgegen, weiss aber nicht, was Gmür dazu sagen wird. Jedenfalls ist Walter B.s Idee, das Oblig. r. mit der Encyglopädie zu verbinden, nicht gangbar. Ich werde eben auf die deutschen Candidaten, die uns Weyermann verspricht, verzichten müssen. Daneben habe ich mit W. ein interessantes Gespräch begonnen, das ich gelegentlich fortsetzen möchte. Ich vernahm auch, dass er ein eigenes Automobil selbst lenkt u. dass er gestern mit Thormann u. den Frauen im Auto einen Ausflug nach Grindelwald gemacht hat. Das ist interessant. Die Frau Weyermann machte mir ganz den Eindruck einer feudalen. Es ist möglich, dass Thormann hier doch Verkehr pflegt, während er es ja sonst nicht tut. Auch bringt das Freimaurertum die beiden vielleicht zusammen.

Dann war Mutzner eine Stunde bei mir nach sechs. Er hat heute die drei Monate Urlaub angetreten. Ich habe ihn sehr animiert, nun mutig auf die Habilitation loszuarbeiten. Über Guhl sprach er sich skeptisch aus u. meinte,

je nach Stimmung rede er bald günstig bald ungünstig von dem Plan, den Mutzner verfolge. Er mag recht haben. Von Abbühl erwartete ich, dass er mir heute den Zahnstecker bringen werde. Statt dessen vernahm ich gleich, dass er daran gar nicht mehr gedacht $u$. nicht weiter nachgeschaut habe. Wogegen er sagte, sie seien über den Präses von Känel sehr böse ge- 
wesen, dass er in seiner Begrüssungsrede von meiner Gegenwart kein Wort gesagt. Ich musste ihm wahrheitsgemäss sagen, dass mir das auch nicht einen Augenblick aufgefallen sei, was er dann wieder sehr sonderbar fand.

Kurz ich hatte an Abbühl wieder keine rechte Freude. Es wundert mich, was Dr. Willemer andeuten wollte, als er sagte, es sollte manches an Abbühl anders sein, u. dass er meinte, seine Mutter sei eine sehr treffliche Frau, während der Vater nichts bedeute, u. dass er als ich bemerkte, Abbühl spreche aber von der Mutter gar nicht $u$. eher vom Vater, fand, das sei kein gutes Zeichen. Nun, mit dieser Woche geht ja der ganze Zauber mit dem Secretär glücklich zu Ende.

Wegen der Leichenfeier für Ruchet wird morgen nicht gelesen, so dass ich den ganzen Tag frei habe, etwas unbequem am Schluss des Semesters, aber es wird gehen. Auch die Fakultätssitzung ist verschoben. Heute konnte ich mit der Dissertation von Hugo Meier beginnen, die ich mit

Freuden bis jetzt wenigstens als eine brauchbare Arbeit gefunden habe. Und dann las ich zwischendurch etwas in Houssayes 1814. So flott wie Waterloo ist es nicht, aber der gute Eindruck von diesem wird wenigstens nicht weiter verdorben.

Endlich hatte ich Besuch von Lisly Kleiner u. ihrem Bräutigam. Die Kleine kam bescheiden, er ist ein gutmütiger, junger Mensch, vielleicht so eine Art Bösiger, nur natürlich gebildet. Sie werden am 30. Juli Hochzeit halten u. Lisly hat Marieli dazu eingeladen, das eben nicht da war. Eine kirchliche Feier wird wie bei Hedy nicht stattfinden, sondern nur ein Abendempfang im Tiefenbrunnen. Doch wird Marieli wohl besser nicht hingehen. Wo sollte es absteigen, da es nicht zu Augusts kann, u. vollends die dummen Geschichten mit Konrad u. August Gyr. Man braucht nur an diese Ereignisse zurück zu denken, um ganz erbost zu werden $u$. zu empfinden, dass Marieli sich jetzt nicht nach Zürich begeben u. nicht der Unannehmlichkeit eines Rencontres aussetzen kann. So wird Marieli wohl morgen abschreiben. Ge- 
wiss ist es auch besser, wenn wir den Aufenthalt auf dem Klausen nicht noch um eine halbe Woche weiter hinausschieben. Lisly u. ihr Bräutigam gingen schnell weiter, zur Bahn. Es war für mich ein sonderbarer Eindruck, die alternde Kleine mit dem jungen naiven, fast knabenhaften aber ruhig phlegmatischen Berner dahin schreiten zu sehen. Nun, das

wird sich vielleicht gerade zu gutem Glück zusammenfinden. Die Tage sind schon kürzer geworden. Es ist noch nicht halb neun u. doch kann ich fast nicht mehr ohne Licht schreiben. Wie eilt die Zeit! Und morgen tritt Ruchet seine letzte Reise an, die ihn mit seiner Geliebten wieder vereinigt hat. Pferd u. Ziegen von seiner Frau her hat er scheints nach deren Tod noch behalten auch in dem neuen Logis an der Schwarztorstrasse. Er kam zu keinem rechten Leben mehr, nachdem er sie verloren.

Und nun zum Schluss - innigsten Gruss von

Deinem allzeit treuen

Eugen

\section{2: Juli Nr. 154}

[1]

B. d. 16. / 7. Juli 1912.

Mein liebstes Herz!

Heute hatte ich einen stillen Tag zu Hause, der mir wohlbekam. Wegen der Beerdigung Ruchets wurde nicht gelesen. Ich ruhte mich aus - es war wieder so heiss den ganzen Tag - las die Disseretation Hugo Meiers, soweit sie eingereicht ist, fertig - es fehlt an Verarbeitung - $u$. hatte etliche Briefe u. amtliche Sachen zu erledigen. Abbühl arbeitete bei mir, er brachte bessern Bescheid, sodass er vor dem Militärdienst jedenfalls nicht zu fechten braucht. Zwischendurch las ich in Houssayes 1814, das mich mächtig interessiert. 
Die Beerdigung Ruchets habe ich nicht mitgemacht, obgleich mich Marti diesmal direkt aufforderte, an der Delegation teilzu-

nehmen. Ich blieb doch lieber zu Hause. Zwar nicht weil ich mir gesagt hätte, wenn ich nicht die Feierlichkeit Deucher mitgemacht, so werde ich die Ruchets auch nicht besuchen. Mir stand Ruchet doch näher, u. es war ein Contact mit ihm da, der mich herzlichen Anteil empfinden liess. Aber war es nötig, dies äusserlich zu markieren? Das ist nicht meine Meinung gewesen. Erfreut hat es mich, dass in den Reden von Wild (Natr.) u. von Calander die innige Beziehung von Ruchet zu seiner Frau u. der Schmerz um ihren Verlust als Ursache seines Hinfalls hervorgehoben wurde. Namentlich Calander hat schöne, wahre Worte dafür gefunden, die ich ihm nicht vergessen werde. Der silberne Zahnstecker, der neue, den ich beim Kommers auf dem Tisch liegen liess, ist nicht mehr gefunden worden. Ich habe bereits Ersatz. Eine Erinnerung knüpft sich nicht an das Stück. Merkwürdig ist es aber doch,

dass bei einem solchen Anlass in geschlossener Gesellschaft so etwas verloren gehen kann. Abbühl hat sich gar nicht dafür interessiert. Ich erwarte auch Guhl in Amtssachen u. nachher wirds Zeit sein zu Bett. Ich bin so müde, trotz des Ruhetages.

Den 17. Juli.

Es war heute drückend schwül, gegen Abend kam eine [sic!] kleiner Regen mit heftigem Wind, der die Fenster nicht zu öffnen gestattete. Ich war seit der Heimkehr aus dem Morgenkolleg in einem andauernden gelinden Schweiss u. zu jeder Arbeit unlustig. So begann ich nur in Georg Steiners Dissertation zu lesen, die bis jetzt mässig ist, u. als am Nachmittag Frau Guhl mit ihren beiden lieben Kindern kam, verweilte ich etwas bei ihnen. Sonst schrieb ich ein paar Briefchen, präparierte Kolleg u. liess mich von Houssayes Schilderung der Leiden Frankreichs von 1814 sehr in Anspruch nehmen. Der Tag ging riesig rasch vorüber. Erlebt habe ich nichts, als dass ich stutzig geworden bin, ob ich mit dem Klausen eine gute Wahl getroffen, denn auf die Anfrage vom Samstag habe ich bis heute Abend noch keine Antwort erhalten. Das kann 
auf eine schlechte Führung des Hotels deuten, wir wollen sehen. Marieli hat der Beetschen für die Lenk abgeschrieben. Was ich mache, wenn es sich mit dem Klausen zerschlägt, weiss ich wirklich noch nicht, obgleich Marie auch schon wieder alle Augenblicke frägt, wohin wir dann gehen.

Marie war heute Vormittag mit Frau Dr. Jauch auf dem Dentenberg, sah vor dem Abmarsch Siegwart u. kam

munter zurück. Dann aber beobachtete ich, dass Marie von ihrer Rückkehr beim Lavoir im Gang stand, als Abbühl das Haus verliess, u. dass er angelegentlich mit ihm plauderte. Darauf erfuhr ich dann auch, dass Marie beim Weg zu Frau Jauch schon Abbühl am Morgen angetroffen hatte. Mir war aufgefallen, dass Abbühl diesen Morgen munterer war, ferner erinnerte ich mich, dass Marie gestern ins Cabinet wollte, während ich gerade bei Abbühl sass. Es entschuldigte sich nachher bei mir, dass es gar nicht an Abbühls Anwesenheit gedacht habe, obgleich es mich doch eher im grossen Zimmer gesucht hätte. Nun ja, es ist möglich, dass die Stimmung sich wieder mehr dem Abbühl zuwendet u. dem Siegwart entfremdet. Ich traue das alles Marieli zu, u. warte ab, um schliesslich mich darnach zu richten. Abbühl bleibt nun blos noch diese Woche bei mir. Es ist vielleicht gut, wenn Marieli da noch eine nicht gerade unfreundliche Stimmung unbewusst zu schaffen hilft.

Heute waren die beiden Ersatzwahlen in den Bundesrat, Decoppet erhielt 173 Stimmen, Schulthess 128. Im Anfang des letzten Jahres zählten die sieben Bundesräte zusammen $80+66$ $+63+64+58+62+54=447$, u. jetzt $66+64+$ $63+56+41+43+47=380$ Jahre! Das ist nun wirklich die Verjüngung, von deren Notwendigkeit man schon so lange gesprochen. Ich glaube, die Zusammensetzung ist jetzt vortrefflich. Müller freilich zählt nicht mehr so viel wie früher, aber die alte Bravheit ist ihm geblieben. Sein Nichterscheinen bei den KollegenBegräbnissen hat er in den Zeitungen durch Eintritt eines Krank- 
heitsfalles in der Familie während des Bergaufenthaltes (in Urigen) entschuldigt. Wer mag krank geworden sein? Mit Forrer kann ich mich immer noch nicht innerlich ausgleichen, das ist eine merkwürdige Sache. Die jungen sind entschieden alle tüchtig, Hoffmann voraus!

Nun Schluss, ich will noch etwas lesen u. dann zu Bett! Innigst Dein allzeit treuer Kamerad Eugen

1912: Juli Nr. 155

B. d. 18./ 9. Juli 1912.

Mein liebstes Herz!

Heute war Regen, Gewitter, dazwischen Sonne, Wind u. dann wieder warm. Ich las mein Kolleg u. zu Hause kam ich etwas vorwärts in der Dissertation Steiners. Die eine ordentliche Schülerarbeit ist. Jean Rossel war da, mit Schittenhelm musste ich über ein neues Paar Schuhe verhandeln, die letzten hat er mir im Jahr 1906 gemacht, u. dazwischen sass u. lag ich herum, las in Houssaye u. liess den Tag an mir vorübergehen in einer Stimmung, die sich verschlechterte als vom Klausen wieder keine Antwort eintraf $u$. mich Marieli drängen wollte, jetzt etwas anderes zu wählen. Ich wies das scharf ab. Ich begreife dieses unstete Wesen nicht. Gestern spazierte sie nach dem Nachtessen mit Frau Dr. Jauch bis 10 Uhr, auch Siegwart kam dazu, u. heute meint sie, dann könne man ja nicht nach Altdorf. Heute Nachmittag war sie mit der Italienerin im Spaziergang u. Confiserie zusammen, jenem Fräulein, das im Winter bei Frau Isenschmid gewohnt, ich habe nicht begriffen, wieso diese wenig Vertrauen erweckende Person den ganzen Nachmittag erhalten musste, während Marie schon längst zu Frau Karl Hänny u. zu Frau Dr. Mutzner hätte gehen sollen. 
Aber ich begreife eben manches nicht $u$. muss mich fügen, da lässt sich nun eben bei mangelnder Seelenharmonie, wie wir sie hatten, nichts machen. - Morgen ist Rektorwahl. Ich wurde schon vor Wochen gelegentlich gefragt, ob ich, da die

Juristen wieder an der Reihe seien, eine Wahl nicht annehme. Ich tue es nicht. Heute nun fragte mich Gmür, indem er sagte, wenn ich irgendwie Lust habe, so werde er in keiner Weise candidieren, $u$. es war ihm ernst damit, das sah ich. Aber ich habe mir immer so zurecht gelegt, dass Gmür jetzt an die Reihe kommen solle. Wenn er vor sechs Jahren übergangen $u$. Rossel statt dessen gewählt wurde, so war sein damaliges Auftreten daran schuld, seine frische Hochzeit, die nahe Erinnerung an die Entlobung mit Hedwig Hauser. Jetzt ist das verrauscht, u. es ist alle Aussicht vorhanden, dass Gmür morgen gewählt wird. Mir wäre der Gedanke jetzt in meiner Einsamkeit das Rektorat führen zu müssen geradezu schrecklich! Gestern nach halb neun war wieder Walter B. ein Stündchen da. Er hatte mancherlei zu klagen, so dass der Departementssekretär Miller ihm mitgeteilt, der Bundesbeamte u. Hörer Burkhardts Fässler habe erzählt, B. habe im Kolleg einige Unrichtigkeiten gesagt. Er sei dann zu Fässler gegangen, der aber nur etwas falsch aufgefasst habe, $u$. anderes mehr.

Ich weiss nicht, ist es die Semestermüdigkeit, aber ich sehe jetzt wieder alles düster an. Wir wollen sehen, ob ich es wieder zu überwinden vermag. Die Dinge mir Marieli bereiten mir immer wieder Kummer. Ich habe so gar nichts an seiner Mitarbeit im Haushalt. Es fehlt die Liebe oder wenigstens der Ausdruck der Liebe. - Doch muss ich eines von Marieli erwähnen, das mich gefreut hat: Es gibt jetzt jeden Abend dem kleinen Karle ein Weilchen Unterricht vor dem Schlafengehn des Kleinen u.er soll bereits einige Buchstaben gelernt haben.

Wenn vom Klausen kein annehmbarer Bericht kommt, so gehe ich am Ende für einige Zeit trotz Albert Heim auf den Rigi. 
Nach einer abominevolen Regennacht war's heute sehr feucht u. doch warm, sodass ich mich recht schläfrig fühlte. Im Sprechzimmer fragte ich Tobler etwas über die Schweizertruppen im Feldzug 1814, worauf er keine Auskunft wusste u. ich den Anstrich bekam, als hätte ich plaguieren wollen. Es ist merkwürdig, dass mir dasselbe mit Tobler mehrfach passiert ist; sobald ich ihn etwas frage, was er nicht weiss, ist er piquiert $u$. dreht die Sache so, dass der ausruft, was ich doch alles lese, wie ich Zeit zu allem finde u. s. w. - Marti habe ich auch schon manchmal befragt. Er aber kommt nicht in diese Stellung. Er weiss auch immer Auskunft. Die Sache liegt wohl daran, dass Marti eben intensiv weiter arbeitet, während Tobler schon seiner Augen wegen seit Jahren auf dem Boden steht, dass er das Colleg hält u. daran genug tut. Marti meinte gestern dasselbe von dem alten Theologen Müller. Es ist auch begreiflich, wenn man schliesslich auf diese Ziele hinaus kommt, namentlich wenn so wenig wissenschaftlicher Umgang vorhanden ist. Doch gibt es an den grössten Centren der Leute genug, die auch dort zu diesem Standpunkt gelangen. Übrigens sollte das ja das allergrösste sein, was man im Beruf erreicht, ein guter Dozent, weiter nichts. Ich denke immer an Heinrich Grob, wie er diese Aufgabe für das Gymnasium verfolgt $\mathrm{u}$. einzig ihr lobend zu einer ausserordentlichen Meisterschaft emporgestiegen ist! Wenn ich nun in meinen alten Tagen noch daran etwas festhalte $u$.

hierin meine Leistungsfähigkeit erschöpfen sollte, so wäre dies doch auch noch zu etwas nütze.

Anna hat heute zu seiner grössten Bestürzung eine Depesche erhalten: Schwester Grita fragt an, ob Schwester Marie bei ihr übernachten könne. Natürlich habe ich ja gesagt. Es ist aber merkwürdig, dass diese Anfrage mit einemmal gestellt wird. Vom Klausen habe ich immer noch keine Nachricht. Warte ich nicht mehr länger, so werde ich in einem andern Höhenort mich festzusetzen suchen, z. B. Schynige Platte. Das wird sich jetzt bald entscheiden müssen. 
Die Studenten sind faul u. das Semester zerbröckelt. Es ist merkwürdig, wie das Pflichtbewusstsein vor dem Sport abnimmt.

Ich will nach der Senatssitzung noch beifügen, wie es mit Gmürs Wahl gegangen ist, u. schliesse in innigstem Gedanken als Dein ewig getreuer

Eugen

Ich komm um 10 aus der Senatssitzung: Gmür ist gewählt. Ich hatte bei absolutem Mehr von 16 Stimmen noch 12, trotz Ablehnung, Lotmar 1, Gmür 18. Jetzt bin ich auf Lebenszeit eliminiert, denn auf Gmür folgen nun alle 6 Jahre die Jungen. Gottlobunddank!

Gute Nacht, mein liebstes Herz! Nochmals

Dein

E.

\section{2: Juli Nr. 156}

B. d. 20. / 1. Juli 1912.

Mein liebstes Herz!

Soeben komme ich bei strömendem Regen vom Tram zurück, wohin ich Egger begleitete, der mich um fünf besuchte u. zum Nachtessen blieb. Seine Herzlichkeit u. Frische haben mich sehr erfreut, es war ein wohltuendes Zusammensein. Am Vormittag habe ich Weyermann den Besuch erwidert $u$. an ihm u. seiner Frau Freude gehabt. Auch da viel Frische $u$. redliches Streben.

Dann habe ich heute Abbühl entlassen, mit vollem Monatslohn, wofür er aber nicht besonders dankte. Er machte mir den Eindruck, er sei so froh von seiner hiesigen Arbeit loszukommen, wie ich ihn loszuwerden. Das ist ja meist gegenseitig. Er wird nach dem Militärdienst eifrig auf die Matura losarbeiten, hat er die gemacht, aufs erste Fürsprecher- 
Examen dann aufs zweite, darauf aufs zweite Notariatsexamen u. endlich auf den Doktor. Das ist noch viel Plan, wenn man nicht besonders begabt ist, sondern nur aus Ehrgeiz drauflos strebt. Und daneben noch forscher Helveter u. Militär sein will! Ich bin gespannt, was aus ihm wird. Aber sein Wesen war mir insofern doch immer etwas fremd, als er gar keine Fühlung mit der tieferen Erfassung der Dinge aufweist. Es ist alles Wille,

nichts Einsicht. Das müsste sich noch ausgleichen. Sonst fürchte ich, wird er schwer zu einem guten Ziel gelangen. Aber ich bin im Grunde doch froh, ihn kennen gelernt zu haben. Ich begreife jetzt manches an andern besser.

Sonst las ich heute im Houssaye u. in Steiners Dissertation weiter. Letztere ist dürftig, muss noch etwas ausgearbeitet werden. Dann war Karl Haenny da von halb zwei bis drei. Er brachte mir den Bronceabguss des Reliefs von mir, der mir sehr gefällt. Er, Haenny, war viel fröhlicher als sonst. Er scheint jetzt wirklich viel Arbeit zu haben.

\section{21. Juli 1912.}

Den heutigen Sonntag war ich schon in rechter Ferienstimmung. Ich mochte an keine rechte Arbeit denken, las wohl etwas in Steiners Dissertation, präparierte die Kollegien, war aber sonst mit anderem beschäftigt. Ich ging zuerst auf halbelf ins Kunstmuseum, um die Rappard-Ausstellung zu sehen. Klara von Rappard tritt da in der ganzen Kraft ihres Könnens auf. Ich dachte daran, eines der Bilder zu kaufen. Aber bei allen die nicht im Privatbesitz stehen, fand ich bereits die Notiz «verk.» also verkauft. Wie ich dann Devinet traf u. ihm das bemerkte, entgegnete er, «verk.» wolle sagen «verkäuflich». Ich war aber schon aus dem Saal u. habe deshalb die Sache nicht weiter verfolgt. Vielleicht schaffe ich aber doch noch etwas an, etwa die "Jungfrau», die wir s. Z. von Gertrud u. Mathilde Salzmann erhalten sollten. Ich sah das Bild, u. sagte mir bei dem Anlass, dass wir damals mit unsern Verwandten doch recht 
unfreundlich verfahren sind. Nun, es ist jetzt ja längst vorüber. Möge Gertrud glücklich geworden sein. Die arme Mathilde geht das alles nichts mehr an. - In der Ausstellung traf ich Thormann mit seiner Schwägerin v. Wyss, u. dann kamen noch Frau v. Büren u. ihre Tochter, Frau Thormann. So sah ich diese zum ersten mal. Thormann stellte sie mir vor. Sie machte mir bessern Eindruck, als ich es nach den Aussagen Marielis erwartet hatte. Vom Kunstmuseum führ ich nach dem Thunplatz u. machte bei Prof. Hoffmann Besuch. Ich traf ihn u. hatte wieder einen guten Eindruck, wie bei seinem Besuch bei mir. Beim Fortgehen stiess ich mit Prof. Dürr zusammen, u. wir erinnerten uns, s. Z. ebenso bei dem Gegenbesuch für Friedrichson zusammengetroffen zu sein. Dürr war sehr nett. Er hat ja nachher mit seiner Frau bei uns Besuch gemacht. Aber sie gefiel uns weniger. Wir haben den Besuch erwidert, aber sie nie eingeladen. Ich war so müde, u. Du hattest nicht mehr die alte Lust an den Einladungen. Von fünf bis sieben waren Siegwart u. seine Tante bei uns. Er war in Freude über das erste, mit Erfolg zurückgelegte Semester. Ich sagte ihnen von der Enttäuschung vom Klausen. Frau Dr. Jauch fand, es sei wohl besser, wenn wir nicht dort hinauf gezogen. Und es wurde verabredet, dass Marieli allein nach Altdorf gehen [sic!] zu den Schwestern Siegwarts. Ich soll die Eltern dann später, im September besuchen. Sonach werde ich also dann nächste Woche zunächst allein auf die Schynige Platte fahren, oder anderswohin. Ich dachte auch daran, den Anlass zu einem Besuch bei Pauline zu benutzen. Ich will sehen, was sich machen lässt.

Mir sind, wie immer, sobald ich etwas ruhe, allerlei Pläne durch den Kopf gefahren. Unter anderm dachte ich, ich könnte auf der Schynige Platte die Schweiz. Rechtsgeschichte zum Druck vorbereiten. Doch werde ich wohl besser daran tun, dann wenigstens die ersten Wochen wirklich auszuruhen.

Ach, wenn man mit Leuten verkehrt, werden sie Herr u. Meister über einen. Nur der einsame gehört sich selber, ist aber dafür auch einsam. 
Gute Nacht, liebste, beste Seele! Mit Dir bin ich ja niemals einsam. Du lebst in mir, solange ich lebe!

Innigst

$$
\text { Dein getr. }
$$

Eugen

1912: Juli Nr. 157

B. d. 22. / 3. Juli 1912.

Mein liebstes Herz!

Ich hatte schon gehofft, dass dieses Semester ruhig ausklingen werde, und nun kommt doch der Semsterschluss-Trubel über mich. Die Dissertation Steiner habe ich heute Nachmittag fertig gelesen $u$. ihm darüber geschrieben. Dann waren Briefe zu erledigen, Studenten kamen, Guhl wollte eine Besprechung, die dann auch wieder bis sieben dauerte. Morgen haben wir von drei bis sieben Examen $u$. nachher noch Fakultätsberatungen, die ziemlich lange dauern können. Dazu wieder neue Briefe u. etliche Examensarbeiten, die ich morgen Vormittags noch werde erledigen müssen, es ist eine gehetzte Sache. Aber item in einigen Tagen ist es vorüber u. kommt hoffentlich willkommene Ruhe.

Heute war es geradezu kalt, in den Bergen hat es bis zu $1400 \mathrm{~m}$ herab geschneit. Wir haben gefroren, wie im Herbst u. ich spürte die Kälte in den Beinen recht unangenehm. Aber auch dies geht ja rasch vorüber. Nur muss ich mir sagen, wozu diese Pläne zu Höhenaufenthalt, wenn es diesen Sommer nicht wärmer wird? Jedenfalls wird nun Marieli Ende dieser Woche einmal nach Altdorf zu Siegwarts reisen. Wann ich selbst dann auf die Schynige Platte (oder anderswohin) fahre, weiss ich noch nicht.

Zwischen hindurch konnte ich heute doch wieder in Houssaye lesen. Es ist merkwürdig, wie packend da das Geschick Napoleons 
geschildert ist. Ich kann mich ganz darin versenken u. die dramatische Gliederung packt mich manchmal mit grosser Gewalt. Schade, dass ich das schöne Werk nicht früher kennen gelernt habe!

Mit Guhl bin ich wieder auf Wielands Kommentar zu sprechen gekommen. Er ist ihm wieder über Unrichtigkeiten geraten. Es ist merkwürdig, wie dieses Urteil nun überhand nimmt. Egger erzählte mir, Julius Frey von der Kreditanstalt habe sich über den Kommentar ebenfalls höchst abfällig ausgesprochen. An Wieland rächt es sich, dass er meine Darlegungen nie ernst genommen, wahrscheinlich die Erläuterungen kaum gelesen, jedenfalls sie nie gebührend gewürdigt hat. So kommt man dann eben als Basler zur Geringschätzung des Eigenen, Schweizerischen, wird Nachbeter des Deutschen u. verfällt in die ärgste Sclaverei, indess man sich den Schein gibt, originell zu arbeiten. Ich hatte gleich den Eindruck bei Wielands Publikation, da hat die untere Mittelmässigkeit was Neues u. Kräftiges überflutet. Und so stellt es sich mehr u. mehr heraus. Wie viel Arbeit bis dieser angeschwemmte Schutt vom grünen fruchtbaren Boden wieder weggeräumt ist! Aber wir werden das schon noch besorgen können.

Marieli war bei Frau Mutzner, die ein «frisches Mädchen» erwartet u. sehr elegisch gewesen sein muss. Mutzner kann nun doch im Lauf der Woche seine Ferien antreten.

Von Redaktor Gisi, den ich antraf, vernahm ich, dass an der Erkrankung in der Familie von BRat Müller in den Ferien doch etwas richtig sei, u. zwar betreffe es Frau Bundesrat. Hat sie wohl wieder einen Ischiasrückfall? Das wäre traurig! Stammler meldet mir heute, dass Gerhard wieder an den Augen leide. Und auf den Geburtstag hatte er mir geschrieben, es gehe ausgezeichnet. Er schreibt auch heute, jene selbstzufriedene Stimmung habe einen schweren Riss bekommen. Das Leben ist Keinem leicht! 
Heute hatte ich eine Anzahl Candidaten in der Sprechstunde u. dazu kam Siegwart, der mir die Litteratur nachtragen will, am Nachmittag u. trank den Café mit mir - Marieli ging ins Colleg u. Anna war nach Aaregg gepilgert. Brachten diese Leute eine gewisse Unruhe über mich, so wurde sie noch gesteigert durch zwei Dinge. Einmal erhielt ich eine Karte von Frau v. Rappard, worin sie mir anerbietet, die Ausstellung ihrer Tochter mit ihr zu besuchen. Ich muss jetzt jedenfalls zu der alten Dame in Pension Hirter gehen $u$. werde am Ende dann doch etwas von der Ausstellung mir anschaffen müssen. Marieli war heute in der Ausstellung u. fand ein Jungfraubild sehr schön. Wir wollen sehen. Sodann schrieb ich gestern an Kaufmann auf den Schynigen Platte u. fragte nach Unterkunft, u. heute kommt ein sehr nettes Briefchen vom Klausen, ohne ein Wort über die Verspätung der Antwort, aber im Ton sehr verlockend. Was soll ich jetzt machen? Eigentlich hatte ich im Sinn, den Klausenwirt wegen der Verspätung zu ignorieren. Allein nun bin ich doch

unschlüssig geworden. Bis eine Antwort von Kaufmann eingelaufen, werde ich mit der Entscheidung besser noch zuwarten. Ein Geratewohl ist ja das eine u. das andre.

Neben dem einigen Amtlichen, was zu erledigen war, habe ich heute das Buch Houssayes zu Ende gelesen, 1814. Es klingt nicht so befriedigend aus. Die höchste Spannung liegt in dem Moment, da Napoleon hinter den Alliierten herstürmt, um ihnen zuvorzukommen, u. dann in dem Abfall Mormonts der ist meisterhaft geschildert.

Das Examen von drei Candidaten wurde von $5-7 \mathrm{Uhr}$ abgehalten. Es ist kein Bekannter, der uns näher gekommen, darunter. Über die Reglementsdebatte will ich morgen berichten. 
Ich schliesse für heute mit innigstem Gruss! Auf die Kälte ist jetzt gleich wieder heute eine Wärmewelle gekommen; wenigstens den Nachmittag hatte ich wieder eine Art Hast im Blut.

Nochmals innigst

Dein ewig treuer

Eugen

\section{2: Juli Nr. 158}

[1]

B. d. 24. Juli 1912.

Mein liebstes Herz!

Das Semester geht zu Ende. Heute hatte ich sehr viele Abtestierungen, morgen schliesse ich beide Vorlesungen. Im ganzen kann ich zufrieden sein. Die Abnahme im Besuch war die normale, durch Militärdienst, Seminaranlässe etc. bedingte. Als mir heute Guhl, der mich in einigen Sachen consultierte, mir sagte, sein Colleg habe auch nicht um einen abgenommen während des ganzen Semesters, gratulierte ich ihm dazu, dass er keine Militärdienstpflichtige gehabt habe, u. darauf corrigierte er sich, doch, einer habe sich abgemeldet.

Bei dem gestrigen Examen kam der Schwyzer Styger zu gut weg, denn er wusste wenig u. bekam doch m. c. l. Gmür hielt ihm sehr die Stange, weil er diesen als Schützling cultiviert hatte. Bruggmann wurde von ihm umgekehrt, weil dieser ihn abgelehnt hatte, schnöd behandelt. Die Menschen sind so. Merkwürdig war auch das Examen von Erker: sehr gut bis auf Lotmar u. Blumenstein, u. die beiden haben das m. c. 1 . verhindert. Burkhardt hätte sich für ihn besser wehren sollen, denn bei ihm macht er die Dissertation. Aber so ist es immer: die billiger $\mathrm{u}$. aufs allgemeine denkenden kommen zu kurz, weil sie stets ausgleichen, während von rücksichtslosen Egoisten der Ausgleich, sobald es bei ihnen nicht gut gegangen ist, abgelehnt wird. Das wird immer so gewesen sein. - Walter B. hätte sich gestern fast sogar das Examen in seiner Encyclopädie ver- 
schandelt, indem Weyermann dasselbe mit dem OR. alternativ stellen wollte. Burkhardt stimmte bereits zu, als ich mich dann doch für ihn wehrte, sodass die Sache unterblieb. Weyermann ist egoistisch, aber ein formaler Deutscher. Mit ihm wird auszukommen sein. Die Freundschaft, die sich mit dem ebenfalls egoistischen Thormann anzubändeln scheint, ruht daneben, wie ich jetzt wirklich bemerken konnte, auf dem Freimaurertum.

Heute war Alfred Siegwart den ganzen Vormittag bei mir u. hat für mich gearbeitet, am Litteraturverzeichnis u. am Katalog. Ich sprach mit ihm recht herzlich. Seine Art gefiel mir. Er will morgen wieder kommen. Guhls Consultation verhinderte eine Abrede.

Von der Schynigen Platte erhielt ich eine gute Antwort. Allein es prävaliert mir nun doch, auf den Klausen zu gehen. Ich wollte Marieli die Wahl überlassen, um die Redensarten, wie sie Fräulein Dr. Hoff gebraucht haben soll (nach Marielis Mitteilung) von mir fern zu halten, nämlich, dass es unvernünftig sei, auf den Klausen zu gehen wegen der Unruhe. Marieli wollte aber nicht. Unter diesen Umständen mache ich es nun am besten so: Marieli geht nach Altdorf, ich auf den Klausen. Wenn es mir nicht ganz gut zu sein scheint, so schreibe ich dann Marieli, es soll nicht auf den Klausen kommen, sondern nach Bern zurückkehren u. von hier auf die Schynige Platte gehen. Dann kann ich ja vom Klausen weg später auch noch ein paar Tage an letztern Ort gehen. So hat Marieli was es will, u. mich kränkt die Sache weniger, als wenn ich Tag für Tag dabei sein muss.

Diese Tage habe ich mehrfach daran denken müssen, wie doch die Dinge sich verschränken können. Die junge Tenger sagte mir, dass sein Vater erkrankt sei u. dass er nun mit Frau Hebbel zu verhandeln habe. Sie sei aber schwer zu behandeln. $\mathrm{Ob}$ er mich etwa consultieren dürfe. Was ich natürlich zusagte, ohne dass bis jetzt etwas geschehen. Frau Hebbel ist dabei gegen mich 
sehr wenig freundlich. Es wird sich erklären. Freund Otto Hebbel consultierte mich Ende Dezember, was er machen soll, am liebsten wäre es ihm, einfach beim St. Galler Recht zu bleiben u. die Frau nicht weiter erben zu lassen. Ich bemerkte ihm, dass er seine Frau besser stelle, sowohl mit Erklärung beim alten bleiben zu wollen, als mit Option fürs Ganze. Er sagte aber, seine Frau sei ganz gut gestellt mit dem St. Gallischen Güterrecht u. dem neuen Erbrecht. Er wollte nicht, dass die Verwandten seiner Frau mehr bekommen. Ich entgegnete ihm nochmals, aber ob dann seine Frau wirklich jeder Sorge enthoben sei, was er kurz bejahte. Ich empfahl ihm die Sache doch noch zu überlegen u. etwa ein Testament, für seine Frau zu machen. Nichts geschah weiter. Erst nach seinem Tod sagte mir seine Frau, er habe von mir zurückgekehrt gesagt, er habe nun alles mit mir besprochen u. es sei ganz für sie gesorget. Und jetzt stehe sie in misslicheren Verhältnissen. Was wollte ich da sagen? Durfte ich ihr bemerken, dass Freund Otto ja gar nicht nach meinem Rat gehandelt habe? Ich sagte es nicht. Mag sie nun denken, wie sie will. Lieber noch soll sie von mir ungünstig denken, als von ihrem verstorbenen Lebensgefährten. Begreiflich ist mir Hebbels Benehmen unter dem Gesichtspunkt eines inneren Grolles gegen die Familie Bekley, den er immer etwas gezeigt, u. der Befangenheit

in den Anschauungen eines engen Familiensinns, denn wenn keine Kinder da sind, die eigene Familie alles ist.

Heute um fünf wollte ich zu Frau Rappard, um ihr zu danken u. zu sehen, wie es sich etwa mit ihrer Erwartung, dass ich ein Bild kaufen würde, verhalte. Ich traf sie nicht, sie war bei Dr. Stooss. So konnte ich ihr durch das Pensionsfräulein Dank u. Gruss bestellen, indem ich bemerkte, dass ich die Ausstellung schon besucht habe u. demnächst verreise. Damit ist nun hoffentlich die Sache in Ordnung. 
Ich erwarte heute vor neun noch den jungen Teichmann. Inzwischen will ich noch Kolleg präparieren, die letzten. Ich habe heute sonst nichts anderes gemacht, als noch ein kleines Gutachten für einen Landwirt.

Innigsten Gruss - gute Nacht! Ich bin müde. Ewig Dein

Eugen

\section{2: Juli Nr. 159}

B. d. 25. / 6. Juli 1912.

Mein liebstes Herz!

Heute habe ich, noch bei ganz ordentlichem Besuch, die zwei Vorlesungen geschlossen. Nachher brachte Frl. Bieri ein prächtiges Bouquet mit dem Kärtchen «Hedwig Höhn» ins Professorenzimmer, was mir unangenehm war. Was braucht die so etwas zu machen? Eine plumpe Verehrung, oder eine backfischartige Verirrung. Frl. Bieri trug die Blumen, die ich oben liess, nach Tisch ins Rabbenthal. Den Tag über schrieb ich Briefe, in niedergeschlagener Stimmung. Ferner kamen drei Kandidaten. Um fünf hatten wir Examen. Ein ostpreussischer Jude erhielt rite. Der Sohn der Lehrerin von Bergen fiel im Licentiat durch. Er scheint nicht dumm zu sein, hat aber nach seinem Aussehen keinen inneren Halt. Lotmar wurde Dekan, er wünschte es zu werden, sonst wäre Reichenberg an der Reihe gewesen. Gmür hat im Schlusswort seines Dekanats die Collegen ersucht, die von ihm zu präsidierenden Senatssitzungen fleissig zu besuchen. Ich verabschiedete mich von den Herren, diesmal ohne einen Misston, wie letztes Jahr.

Siegwart kam heute gegen die Abrede nicht vorbei. Die kleinste Unregelmässigkeit macht mich immer wieder stutzig. Ich weiss gar nicht, was ich sagen soll. Es ist eben keine Sache, die so selbstverständlich aussieht, wie es mit Paul der Fall gewesen wäre. 
An Lisly hat Marieli als Hochzeitsgeschenk die vier silbernen Salzbüchschen mit Löffelchen in grünem Etui geschickt, die Du noch in Deinem letzten Jahr bei Pochen gekauft, weil sie Dir wohl gefielen. Du hast ja solche Sachen immer gelegentlich angeschafft, um etwa ein Geschenk machen zu können. Auch die Tassen, die Du im Herbst 1909 an Hedwig sandtest, waren so vorhanden. Also geschieht die Gabe ganz in Deinem Sinn auch an Lisly.

Von Frau v. Rappard erhielt ich ein Billet mit herzlichen Abschiedsworten. Sie verreise demnächst für längere Zeit nach England. Von der Ausstellung oder Bilderkauf ist nicht mehr die Rede.

Ich bin bei der steten, feuchten, düppig warmen $u$. dann wieder plötzlich kühlen Luft konstant etwas unwohl. Ob es besser geht auf dem Klausen? Wo ich frieren werde? Ich weiss es nicht, es ist mir auch gleichgültig. Wenn ich nur nicht chronisch zu leiden bekomme. Ich gehe heute früh zu Bett.

Den 26. Juli.

Ich war heute schon besser in Stimmung $u$. habe, als Nachzügler, noch die Übungen abgehalten vor etwa 2 / 3 des Auditoriums, u. zwar mit viel Eifer u. Freude beiderseits. Am Morgen arbeitete ich am Wortverzeichnis für das Wörterbuch, um das Pendente fertig zu machen. Dann war Alfred Siegwart bei mir, sehr sympathisch. Darauf kam Guhl, in Amtssachen, er verreist morgen mit der ganzen Familie für zwei Tage

zum Vater, der am Montag den 75. Geburtstag feiert. Nachmittag hatte ich mich noch für das Praktikum vorzubereiten.

Marieli hatte heute noch eine Hatz, hat aber alles erledigt, was ihm vorschwebte. Am frühen Morgen brannte u. malte es einen Korb für Frau Dr. Jauch. Dann wurde gepackt u. am Nachmittag waren fünf Martis Töchter da, ein nettes 
Gesellschäftchen, das sehr innig war, das ich ihm aber nicht verwehren mochte. Ich begrüsste sie auch einen Augenblick. Jetzt nach dem Essen macht es noch Nachbarsbesuche u. bringt das Körbchen zu Frau Jauch. Ich erwarte noch den jungen Teichmann, wenn er abkommen kann.

Ich schwanke, ob ich auf dem Klausen mir eine bestimmte Arbeit vornehmen soll. Als solche schwebt mir die Rechtsgeschichte vor. Aber es ist wohl besser, wenn ich jetzt nichts beschliesse, sondern nach den Umständen handle. Das Ausspannen wird sich dann von selbst machen. Empfinde ich Lust, so kann ich daraus auch auf Frische für die Arbeit schliessen. Die Hauptsache aber sollen doch die Erholungstage für mich sein. Wie wohltuend war in dieser Beziehung das Lizard u. letztes Jahr der Gotthard. Reiht sich der Klausen dem ebenbürtig an, so will ichs zufrieden sein u. mir den Erfolg nicht mit Arbeitsplänen stören. Ich stelle mir immer deutlicher vor, dass ja doch das Kolleg halten für mich jetzt das einzige Feld zu werden verspricht, auf dem ich etwas noch leisten kann. Also sammle ich die Kräfte in erster Linie für dieses Ziel.

In letzter Zeit hatte ich wieder häufiger Träume von unbegreiflicher Deutlichkeit, u. zwar namentlich in der Empfindung von Persönlichkeiten in ihrem Charakter. Es wäre schwer eine solche Empfindung zu analysieren. In der letzten Nacht schwebte mir

ganz wach auch wieder einmal jene Fälle vor Augen, wo ich die Zukunft sah, ohne sie zu erfassen: Jenes Scheitern des Planes mit meinem ersten Drama, wo ich das Manuskript in das Pult legte $u$. als zweitsemestriger Student zum Regal ging $u$. anfing das Zürcher Printer mit den Pandekten zu vergleichen, indem ich mir sagte, da liegt deine Zukunft, - um das dann so lange wiederum zu vergessen. Denn jenes Auffinden der «Eule», als ich zu Welti ging, um ihm zu sagen, dass ich die Privatdozentur verlassen $u$. ganz zur Redaktion gehen werde. Und endlich jener Einfall, da ich zu Marieli, wie es mich am Bahnhof abholte, sagte, Du habest Gürtelrose, während ich doch gar nichts von der Art Deiner Erkrankung gehört, was mich auf 
diesen Gedanken hätte bringen können. Und auch da verlor sich mir die Angst wieder unter dem Einfluss des so unglücklichen beschwichtigenden Berichts Öris. Wer fähig wäre, so das Zeitliche zu erfassen $u$. danach zu handeln! Aber das sind die Unbegreiflichkeiten, die mir zeigen, wie unendlich compliziert unser Bewusstsein ist. Und man muss hinnehmen, was dann weiter sich daraus ohne Erkenntnis u. ohne sichtbare Consequenz entwickelt! Und nun Semesterschluss, schon der fünfte ohne Dich! Es geht vorwärts, dem Ziele immer näher. Ich will morgen einige Briefe schreiben. Und dann hinaus, hinan. Und dem kommenden Semester entgegen! Als ich gestern mit Gmür, Thormann u. a. aus der Sitzung ging, berechneten sie, wie lange es gehen werde, bis das Dekanat an sie kommen werde. Ich warf ein, das sollen sie nicht so denken, wie manchmal ändere der Tod alle Verhältnisse, worauf sie betroffen schwiegen. Sie denken an dieses letzte Ziel alle eben weniger oft $u$. weniger gerne als ich.

Gruss u. Kuss zum Tagesschluss! Ich bleibe immer dar Dein alter treuer Kamerad, Dein

Eugen

1912: Juli Nr. 160

[1]

D. 27. / 8. Juli 1912.

Mein liebstes Herz!

Der heutige Tag hat mir gleich am Morgen den Ärger gebracht, dass ein W (wohl Winckler) in der N. Z. Z. eine Besprechung des Pamphlets v. Frischs gebracht hat, die bei allem Protest gegen Übertreibung eben doch der Hauptsache nach meint, er habe in vielem Recht. Ganz dem Charakter unseres öffentlichen Geistes bei dieser Art von Leuten entsprechend: Wenn ein Ausländer sie anspuckte, so würden sie noch freundlich lächeln u. sagen, er hat schon Recht. Und zwar nicht etwa aus christlichem Postulat der Feindesliebe, bewahre, 
sondern aus Freude an dem Ärger, den die Sache andern bereitet. Wir sind kein edles Volk.

Um 6.58 ist Marieli abgereist. Ich habe es zum Bahnhof begleitet, wo Frau Jauch u. Siegwart bereits waren. Der Abschied war recht. Hoffentlich bringt auch der Aufenthalt Segen, wäre es auch nur in Gestalt von Abklärung. - Nachher schrieb ich an Rümelin u. an Stammler längere Briefe u. ging auf elf Uhr zu Haenny, der mich sehr munter empfing. Auch seine Frau war trotz des kranken Fusses in der Küche. Der kleine Kurt hat mir wieder mächtig gefallen. Haenny scheint nun wirklich äusserlich $u$. innerlich zu erstarken. Ich habe Freude an ihm. Was er arbeitet, ist merkwürdig aus dem Innern herausgeschafft. Das muss, wenn er gesund bleibt, bei seinem andauernden Fleiss zu guten Resultaten kommen. - Nachmittags waren Studenten da, namentlich lange der Studiosus Fejanoff aus Varna. Er will eine Grundpfandrechtliche Dissertation schreiben. Dann kam Hahnleser, der Aegypter, der vor zwei Jahren mit mir über die Habilitation

in Neuenburg lange verhandelt. Inzwischen ist sein Bruder gestorben u. er war genötigt das Geschäft, einen Baumwollhandel in Alexandrien, zu übernehmen u. das behagt ihm jetzt ganz gut. Er hat mir von den Geschäftsbeziehungen viel erzählt, was mir gefallen hat. Er war mir auch heute wieder trotz seiner steifen Art sehr sympathisch.

Die Zeit reichte dann noch, Lüdemann den versprochenen Besuch abzustatten. Ich trafihn ganz glücklich über seine Augenoperation. Er soll nun im rechten Auge, das vollständig erblindet war, vollständig sehend werden, u. zwar weitsichtig. Schon jetzt freut er sich der intensiven Farben, die er erst jetzt in ihrer Pracht in sich aufnehmen könne. Er habe gar nie gewusst, dass die Welt so schön sei. Und wirkliche Freude sprach aus dem grauen Kopf mit frischem Herzen. Seiner Frau geht es aber leider nicht so gut. - Nach dem Nachtessen kam Blanche Röthlisberger mit Frau Geheimrat Kohler zu mir, um zu fragen, wann ihr Mann mich morgen treffen könne. Er komme um 4 Uhr an. Jetzt wo auch Marieli nicht da ist, darf ich vollends nicht daran denken, ein Nachtessen anzubieten. So bleibt mir nichts 
anderes, als was ich ihr sagte: Kohler soll bestimmen, er komme ermüdet von der Reise an, u. sie versprach dann zu telephonieren. Also! Wie schön wäre das wieder gewesen, wenn noch die alte Zeit mir beschieden wäre! - Endlich kam Walter B. u. blieb bis gegen zehn Uhr. Ich verhehlte ihm nicht den Kummer, den ich heute herum trage. Es ist mir dabei, wie bei diesen Zeilen etwas leichter geworden.

Doch jetzt Tagesschluss. Gutnacht, mein einziges Herz!

Den 28. Juli.

Heute Vormittag wollte ich BR Hoffmann einen FerienAbschiedsbesuch machen, ich vernahm aber am Telephon, dass er den ganzen Tag abwesend sei. Also morgen! Dafür erhielt ich dann, als ich wieder einmal vor der Türe im Garten über einer Schachaufgabe sass, den Besuch von Werner Kaiser, der seine drei Wochen Ferien mit Frau u. Kind auf der Griesalp zugebracht. Was er erzählte, brachte so manches von unserem letzten Ferienaufenthalt mir in Erinnerung. Kaisers waren neben Engländern u. andern Fremden die einzigen Schweizer, $u$. wie wir oben waren, sind die Gäste zur grossen Mehrzahl Schweizer gewesen. So wechseln die Zeiten. Dann kam auch noch Walter B., der den Morgen mit seinem Schwägerlein auf dem Gurten gewesen war. Wir hatten ein nettes Plauderstündchen.

Den Nachmittag las ich einen kleinen Aufsatz von Niemeyer übers Schylock, eine interessante [?] Reminiszenz, aus der hervorgeht, dass der Dichter wirkliche Vorgänge aus Gerichtsurteilen des späteren Mittelalters als Grundlage genommen hat. Was Niemeyer selbst dazu tut, ist wie er immer schreibt, nicht viel. Aber die Gesamtauffassung ist gegenüber [?], Kohler u. Humelin wohl die richtige. So war das Recht. Und ist es nicht immer noch so? Wenn Rabel Meister wäre, so müsste man das annehmen. Und nun erwarte ich jeden Augenblick Kohler mit seiner Frau. Ich lasse jede Bewirtung nun bleiben. Es ist nun einmal so. Ich tue es aber gegen mein Gemüt, ähnlich wie ich auch gegen das Gemüt auf die Anschaffung eines Gemäldes der Klara v. Rappard verzichtet habe. Und doch in beiden u. so vielen ähnlichen Fällen, die mir jetzt begegnen, ist es gerade 
das Gemüt, was mich an anderem Handeln verhindert. Ich will doch nicht mehr gesellig sein, ich will nicht, weil ich es ohne Dich sein müsste. Und dabei plagt mich der Gedanke in diesen Tagen so oft, was wohl die Zukunft mir noch bringen wird?

Ich fühle mich oft unwohl, wo wird es ausbrechen? Gehen wir dem Schicksal entgegen, mag es bringen, was es will. Das Ende ist ja doch die Erlösung.

Heute schrieb ich noch einige Briefe, Absagen von Festlichkeit, die auf nächstes Jahr in hier sollte abgehalten werden (internationale Vereinigung) $u$. anderes, auch ein kleines Gutachten. Anna war auf dem Friedhof. Gestern traf ich dort einen jüngeren Arbeiter mit einem kleinen schwarzgekleideten Mädchen vor einem frischen Grab, in Tränen gebadet. Ich musste mich abwenden, u. hätte doch gerne mit ihm gesprochen.

Gegen sechs Uhr sind richtig Kohler u. seine Frau gekommen u. blieben

eine Stunde. Sie waren von Röthlisberger begleitet. Er sprach mit grosser Anerkennung von meinen Arbeiten, hat von Rabel, vom Kongress, von [?lin] nichts angefangen, sodass wir in den allgemeinsten Dingen verblieben $\mathrm{u}$. uns gut verstanden. Es hat mich wirklich gefreut, dass er, obgleich er erst vier Uhr von der Fahrt aus Berlin her kam, den Weg noch den Abend zu mir gemacht hat. Ich entschuldigte mich, dass ich keine Gastfreundschaft üben könne, da Marieli weg sei, u. so ging er, ohne dass ich fürchten muss, einen verletzten Gast bei mir gehabt zu haben. Ich glaube, Kohler meint es ehrlich mit mir. Röthlisbergers Sohn, der Helveter, hat gestern eine Blinddarmoperation bestanden, es soll alles gut gegangen sein.

Heute Abend hab ich noch mit Anna die Sachen für den Koffer zusammen gelesen. Ich schrieb auch ein paar Zeilen an Marieli. Und so ist der Sonntag wieder vorüber. Es war auch gut, sich in dessen Verlauf wieder einmal vorzustellen, was nicht hätte geschehen sollen. Wenn man das bedenkt, wird man ergebener gegenüber alle dem, was man Unrecht zu erleiden glaubt.

Gute, gute Nacht! Ich bleibe immerdar Dein getreuer Eugen 
B. d. 29. Juli 1912.

Mein liebstes Herz!

Heute war ganz Tag vor der Abreise. Vor dem Frühstück packte Anna mit mir den Koffer fertig u. er wurde von einem telephonisch hergerufenen Dienstmann u. Sophie zur Post gebracht, damit ich ihn morgen sicher auf dem Klausen antreffe. Dann ging ich nach der gewohnten Morgen-ZeitungsLektüre zu Franke u. kaufte die Siegfried-Blätter für den Klausen. Ich sprach dann bei Kaiser vor u. verabschiedete mich, auch bei Käslin, u. sagte BR Hoffmann Adieu, der sehr herzlich war. Darauf noch ein Stündchen bei Wildbolz u. nachher bis zum Mittag studierte ich auf den Karten die möglichen Spaziergänge vom Klausen, wobei ich wirklich freudig mich vorstellte, es könne da oben recht nett werden. Nach Tisch kam Gmür zu mir, um sich über seine Rektoratsrede zu besprechen. Er dachte an «Juristen u. Laien», war aber ganz unklar, in welcher Richtung er diese interessante Frage behandeln würde. Ich nannte ihm «Das Eigentum», ein Thema sehr alt in meinem Sinn, das ich s. Z. schon als meine Basler Rektoratsrede 1888 in Aussicht genommen hatte. Er wird sich zwischen den beiden Vorwürfen entscheiden. Drauf las ich noch allerlei, will auch noch zu Walter B. hinunter, u. dann morgen Adee!

Von Marieli erhielt ich einen sehr netten Brief. Die Ankunft in Altdorf u. der erste Abend waren recht. Es ist doch ein merkwürdiger Vorgang in diesem jungen, unerfahrenen Herzen. In Mailand malte es sich Abbühl als seine Liebe aus u. klagte darüber, dass es seine Liebe verscherzt mit dem

Absage-Briefchen vom letzten Herbst. Dann war es, als ich als meinen Secretär engagierte, ganz glücklich, bis es ihn dann als lange nicht so tüchtig entdeckte, als es sich vorgestellt hatte. Darauf 
mied es ihn geflissentlich, u. dafür wurde das Verhältnis zu Siegwart immer freundlicher. Und jetzt hat es sich offenbar zu der Überzeugung durchgearbeitet, dass Siegwart doch ein ganz andrer Kerl wäre. Wie wird das nun kommen? Ich habe mit Anna über den Fall gesprochen, $u$. wir haben beide gefunden, wenn Siegwart Marieli wirklich zur Frau begehrt, so wäre es ein Glück für Marieli, u. ich glaube auch für Siegwart. Er ist mir lieb, u. ich hätte gewiss einen freundlichen Verkehr mit dem jungen Fachkollegen, den ich gerne meinen Sohn nennen würde. Aber es sind viele Hindernisse zu überwinden. Der Aufenthalt Marielis in Altdorf wird vieles abklären. Warten wir ab, ohne zu bestimmte Hoffnungen. Solche Dinge müssen bei dem Charakter Siegwarts, der mit dem meinigen in vieler Hinsicht übereinstimmt, reif werden. In Kleinigkeiten erinnert mich Siegwart vielfach an mich. Nur ist er viel ruhiger $u$. kritischer, oder es geht sein Impuls weniger stracks auf Ziel, was davon herrühren mag, dass er ganz anders erzogen worden ist als ich, der ich mich selbst heranbilden musste. Gmür hat mir heute in einer Besprechung wieder einmal den alten Eindruck gemacht, als ob er Gedanken in sich trage. Unangenehm aber war mir auch heute, dass er von mir für seine Rede Nachhülfe erwartete. Ich habe sie ihm ja auch insofern geleistet, als ich ihm mein altes Thema zur Verfügung stellte. Aber er sollte doch mehr auf sich selbst ruhen, namentlich nach dem, was mit den Kollegienheften s. Z. zwischen ihm u. mir vorgefallen ist. Er war etwa eine Stunde bei mir. Ende dieser Woche will

er mit Frau u. Kindern auf den Weissenstein, an den ja auch ich zuerst gedacht $u$. auf den ich ihn dadurch, dass ich ihm dies mitteilte, aufmerksam gemacht hatte. Ob er dort arbeiten wird? Er gedenkt nach dem dortigen Aufenthalt noch für eine Woche ins Wallis zu gehen, vielleicht mit Ernst Brenner. Interessant war es mir, wie Kohler gestern auf Gmür zu sprechen kam. Er sagte, er habe vernommen, dass Gmür im Kolleg Witze mache, u. das habe ihn sehr für Gmür eingenommen. Ja, es ist eben eine andere Geistesrichtung. Kohler schimpfte gestern über den preussischen Geist, gerade in der Richtung, worin mir dieser imponiert. Er meinte, die grössere Freiheit 
sei nun ja auch im ZGB. zum Ausdruck gekommen. Aber er verstand das sicherlich anders als ich. Denn ich möchte das ZGB. mit als im Gegensatz stehend zur fachmännischen Entwicklung erblicken, wie sie im preussi-

schen Geist uns entgegentritt. Ich meine, der Fachmann sollte ein anderer sein. Beim Gang durch die Stadt sah ich heute Kohler u. seine Frau von weitem $u$. war im Begriff, auf sie zuzugehen, als sie abbogen. Vielleicht hätte ich besser getan, ihnen nachzugehen. Sie haben mich nicht gesehen.

Von Hoffmann erfuhr ich, dass Müller in unerklärlicher Weise die Leichenbegräbnisse von Ruchet $u$. Deucher gefehlt, u. von Urigen nach Weggis gegangen sei, obgleich er mit seiner Schwester in dort sonst seit einiger Zeit nicht mehr verkehrt habe. Man sage, seine Frau sei erkrankt, aber nicht am Ischias, sondern an Psychose. Kaiser hatte gehört, der Aufenthalt in Urigen habe ihm nicht gefallen, weil man keine Spaziergänge machen könne. Mag sein, dass die steilen Wege, die jedenfalls dort überall gemacht werden müssen, ihm u. seiner Frau nicht behagt haben.

Lisly Kleiner hat sehr herzlich für die silbernen Salzbüchschen gedankt. So scheint da nun jede Spannung gehoben zu sein. Kleiner

schrieb mir, dass er wahrscheinlich auch auf den Klausen kommen werde, aber vom Hochzeitsfest kein Wort.

Ich füge noch einige Zeilen bei, nachdem ich Walter B. meinen Abschiedsbesuch gemacht. Ich fand Burckhardt an seiner Arbeit über die Beziehungen Deutschlands u. der Schweiz in Sorge u. Missmut. Der Artikel soll in der Kaisernummer der Leipziger Illustrierten erscheinen. Ist B. der Mann, so etwas zu schreiben? Hat er Schwung genug u. Phantasie u. politischen Weitblick? Das macht ihm offenbar selber Sorge u. ich hätte ihm gerne angeboten, ihm zu helfen, aber er tat keinen Wink in dieser Richtung. Dazu soll er noch einen allgemeinen Artikel für das Jahrbuch schreiben, u. erst, wenn auch dies getan ist, will er in die Ferien. Und doch sieht er so müde u. abgespannt aus!

Heute Abend kam noch ein Billet von Abbühl an Marie, worin er es zu einem Abendspaziergang auffordert. Ich sende die Einladung nicht nach Altdorf, ich will bei dem $\mathrm{Zu}$ - 
sammentreffen mit Marie darüber reden. Die Sache ist mir sonderbar vorgekommen.

Und nun, es regnet, u. morgen um diese Zeit

bin ich auf der Klausen Höhe. Wie mag es ablaufen?

Gute gute Nacht, meine liebe, einzig liebe Seele!

Ich bleibe auf ewig

Dein getreuer

Eugen

\section{2: Juli Nr. 162}

Klausenpass, d. 30. Juli 1912.

Liebstes Herz!

Jetzt habe ich meinen Plan ausgeführt u. sitze in dem Nebel oben auf dem Klausenpass in merkwürdiger Einsamkeit. Ich hatte die letzte Nacht wenig geschlafen. Denn ich war ziemlich spät zu Bett gekommen u. hatte mich mit der Abendarbeit so erregt, dass ich fast nicht die Ruhe finden konnte. Ich erwachte früh, stand auf, um allerlei zu ordnen, u. pilgerte dann mit Anna zum Bahnhof. Sie war ganz erfreut, wie sie sagte, dass ich sie mitnahm, u. ich nahm also herzlichen Abschied. Auf der Bahn las ich bis Zürich meistens im dritten Houssayeschen 1815. In Zürich sah ich nur zwei Bekannte, den Berner Oberrichter Fröhlich u. den Anwalt Hügli, verpfuschten Angedenkens. Die Fahrt hatte ich aber offenbar mit einigen Gästen zu Lislys Hochzeit gemacht, die in Burgdorf eingestiegen, mit Cylinder. Bis Weesen sass ich einer alten Basler Dame gegenüber, mit der ich aber erst nach dem Umsteigen auf der Fahrt nach Linthal ins Gespräch kam. Sie ging nach Braunwald. Zuerst kam sie merkwürdig massiv vor, nachher wurde es besser. In Zürich hatte ich einen Bouillon genommen, in Linthal konnte ich im Adler schnell Kalbsfleisch mit Apfelmus essen, u. dann in den Wagen. 
Ich war im Wagen nicht allein, indem eine Hamburgerin das Coupé mit mir teilen musste, eine Dame, die sich dann als Kaufmannsfrau, Mutter von zwei Söhnen u. drei Töchtern, im Alter von 8 bis 21 Jahren heraus stellte. Ihr Mann mit dem zweitältesten Sohn war zu Fuss voraus gegangen. Wir holten sie aber auf dem Urner Boden ein, wo sie des Regens wegen im «Tell» halt gemacht. Trotz Regen gingen sie dann wieder vor uns weiter, wir holten sie wieder ein $u$. dann hätten sie gerne die achtplätzige Post mit uns benutzt, aber es war kein Platz. Darauf kehrten sie im Ärger zum «Tell» zurück u. nahmen einen Wagen, der eine Stunde nach uns in Passhöhe ankam. Ich habe mich mit der Dame, die mich an Frau Leutert erinnerte, recht gut unterhalten, sie war mitteilsam u. da sie, nachdem ich zu Nacht gegessen draussen auf ihren Mann wartete, ging ich mit ihr auf u. ab, bis sie kamen. Ich stellte mich unter diesen Umständen flüchtig vor, aber vernahm seinen Namen nicht. Er war früher in Calcutta. Sein ältester Sohn ist auch Kaufmann. Beim Betreten des Hauses begrüsste mich der Wirt, Schillig, recht freundlich. Das Zimmer, das er mir angewiesen, ist gar nicht gross, hat aber Sonnenlage u. Aussicht. Am meisten werde ich den Schrank vermissen, ich muss einen Teil der Effekten eben im Koffer lassen.

Der Morgen war schon bei der Abfahrt von Bern bedeckt. In Wesen begann es zu regnen, hörte dann aber auf, bis gegen den Urnerboden neuer Regen eintrat, der anhielt

bis auf die Passhöhe. Die kurze Fahrt von dort bis zum Hotel, das in «Balm» liegt, war wieder regenfrei. Ich konnte mir doch eine Idee von der Lage verschaffen. Das Hotel scheint schon wesentlich Passanten Herberge zu sein. Aber deswegen kann es mir doch gefallen. Ich will nun sehen, wie es geht. - Ich bin ja mit meinen Plänen sehr geduldig u. wechsle nicht gerne, wenn ich einmal irgendwo sitze. Es ist vielleicht dumm von mir. Einmal weiss ich, dass ich mit dieser 
Ausdauer in unbefriedigender Herberge einen erschrecklichen Lapsus gemacht habe, nämlich 1906 in Mailand. Warum sind wir da nicht, wie Du es wünschtest, ins Cavour umgezogen vom Pozzo? Ich mochte nicht, im Gedanken an die grossen Kosten. Aber was hätte uns das gemacht! Du hast solche Dinge ein paar mal an mir ertragen müssen, die ich jetzt bedaure, so oft ich daran denke.

Wird mir nun die Lage in der frischen Höhe so gut tun, wie ich es erhoffe? Der erste Eindruck ist ein gemischter. Die Wirtsleute machen offenbar alles mit eigenen Kräften, wenigstens müssen junge Buben u. Mädchen mithelfen, u. soviel ich sah, war die Frau, noch jung wie der Wirt, beim Servieren. Das wird sich jetzt alles zeigen. Ich werde ja in jedem Fall eine Woche ausprobieren. Die Frische der hohen Luft hat mich etwas angeregt. Ich glaube aber, wenn das Bett recht ist, kann ich gut schlafen. Wir wollen sehen. Das Zimmer ist zwei

Treppen hoch, aber vielleicht um so ruhiger. Auch das wird sich zeigen. Ach man wird so geduldig, $u$. ich hatte überhaupt nie Dein Talent, in den Hotels das Beste heraus zu verlangen u. zu erhalten.

Jetzt habe ich ausgepackt $u$. geh zu Bett. Gute, gute Nacht, ich bin jetzt wirklich müde. Ich habe trotz der letzten kurzen Nachtruhe den ganzen Tag nie geschlafen, die geschilderten Reiseumstände hinderten mich daran.

Dein allzeit treuer, alter Kamerad

Eugen 
Klausen, d. 31. Juli / 1. Aug. 1912.

Mein liebstes Herz!

Der erste Ferientag hier oben ist vorüber. Es war sonnig u. ich war im Ganzen gut gestimmt. Nur eines hat mich etwas stutzig gemacht: Es ist von Marieli keine Nachricht gekommen. Ich will aber denken, dass nichts Schlimmes dahinter liegt. Vielleicht ist meine Karte verspätet angekommen, oder es hat heute einen Ausflug gemacht, oder sonst eine Abhaltung gehabt. Vertrösten wir uns also auf morgen Nachmittag!

Heute bin ich nach dem Morgenessen eine Stunde gegen Urigen hinunter gestiegen, bei Sonnenschein $u$. schöner Aussicht. Die Landschaft ist nicht so gewaltig wie St. Gotthard, aber die Luft war herrlich. Am Nachmittag sass ich herum, schrieb einige Karten $u$. trank einen Thee, las auch ein paar Kapitel in Houssayes 1815 III. Dann gegen Abend pilgerte ich noch auf die Passhöhe $u$. was mich am meisten beschäftigte war das wechselnde Bild der Durchreisenden, die bald so bald anders ihre Szene auf solcher Naturbühne aufspielen. Bekannte gab es gar nicht darunter, dagegen recht gewöhnliche Leute, die so u. anders mir gefielen, wie z. B. eine schwäbische Familie, Eltern u. Kinder u. eine Glarner Dame mit ihren Ferien Kindern. Interessant war es mir, in dem «Herrn Müller», an einem Vis-à-vis

bei Tisch, den mir der Wirt gestern vorstellte, einen Dr. jur., Rechtsanwalt in Chemnitz sich entpuppen zu sehen, der mir in seiner Art viel Freude machte. Er ist zwar eingefleischter Berufsjurist, der die Teilnahme von Laien in der Rechtspflege einfach nicht kennt $u$. versteht. Aber es scheint ein junger 
braver Fachmann zu sein. Er studierte ein Jahr in Tübingen u. rühmte sehr Max Rümelin.

Die Post brachte mir einen Kartengruss von Rossel, u. ein Briefchen von Anna Röthlisberger, das mir nun gar nicht gefällt. Sie bittet mich um einen Beitrag an ihre Aussteuer, da sie sich verheiraten wolle, u. dabei motiviert sie das Gesuch damit, dass sie in der Aussicht auf den Eintritt in unsere Familie die Aussteuersachen, die sie sich allmählich zusammengespart, zu halben Preisen verkauft habe u. nun mit teurem Gelde frisches anschaffen müsse. Das ist ganz gewiss eine Unwahrheit. Ich komme aber vielleicht doch dazu, ihr zu sagen, dass ich ihr «diesen Ausfall» ersetzen wolle. Zunächst aber will ich mit Marieli darüber reden. Ich muss mit ihm also gleich über zwei unangenehme Anfragen sprechen: Die von Abbühl, die ich vorgestern erwähnte, u. diese neue Geschichte. Die erste hat es sich selbst eingebrockt. Die zweite kommt auf mein Konto. Vielleicht stellt es sich da nun doch heraus, dass die Entscheidung Marielis vom letzten Frühling zwar im Motiv bedenklich, aber in der Sache richtig war!

Den 1. August 1912.

Bundesfeier auf der Klausenpasshöhe: ein volles Haus, Leute, die unangemeldet noch bei Nachteinbruch kamen, eine Schule, Buben u. Mädchen, aus Birwinken, viel Animus, aber keine Leitung. Ein Klavierspieler kam wirklich her, der allerlei konnte, zuerst einige österreichische Märsche - auch den «Honigmond» hörte ich wieder einmal, der uns in Neapel s. Z. so gut gefallen - dann einige Schweizerlieder, bei denen ich mithalf. Zuletzt aber Tanz in der Restauration, das Klavier wurde extra aus dem Speisesaal hinüber geschafft. Die Hauptsache war ein Feuerwerk - Frau Schillig bemerkte mir, als ich meinte, es sei farbig, o nein, ihr Mann habe für schweres Geld Sachen heraufgeschafft. Zur Feier des Tages mixte ich mir - in Andenken an Max Rümelin auf Mürren - u. dem lieben Dr. Müller eine Flasche wirklich guten 
Asti Spumante. Das Feuer auf der Höhe hinter dem Hotel konnte wegen des starken Föhns, der gegen Abend ging, nicht angezündet werden. Es ging wohl anderwärts so, wir sahen talabwärts nur drei Höhenfunken.

Am Morgen hörte ich Murmeltiere pfeifen u. ging mit Müller in die Geröllhalden hinauf, jedoch umsonst. Wir stiegen mit aller Musse den ganzen Vormittag herum. Am Nachmittag ging ich allein auf die Höhe, wo der Funken brennen sollte, las etwas in 1815. Und dann brachte die Post mehrere Sachen, die ich gleich beantwortete, unter anderm auch endlich einen Brief von Marieli mit ganz guten, fröhlichen Nachrichten. Ich stellte es ihm anheim, in Altdorf zu bleiben, solang es wolle,

ohne «unverschämt» zu werden. - Mit Dr. Müller konnte ich heute manches besprechen. Morgen verreist er.

Unten wird, während ich diese Zeilen schreibe, noch gespielt u. getanzt.

Ich bin müde u. schliesse im Gedanken, dass ich trotz des fernen Lärms werde schlafen können. Ich bin immer noch etwas unwohl, ich wollte es wäre bald vorbei.

Nun - ich kann zu keiner rechten Sammlung nicht kommen, nicht einmal auf die Bundesfeier, es ist zu viel Lärm in den Ohren. Also abgebrochen u. zur Ruhe!

Bleibe bei mir, liebste, einzige Seele, wie ich immerdar, auch wenn das Elend über mich kommen sollte, bei Dir bleiben will!

Dein alter getreuer

Eugen 


\section{August 1912}

1912: August Nr. 164

[1]

Klausen, den 2. Aug. 1912.

Mein liebstes Herz!

Trotz Regenwetter, das heute den ganzen Tag angedauert hat, war ich bei guter Stimmung. Von 8 bis 9 spazierte ich mit dem Schirm auf der Terrasse vor dem Hotel auf u. nieder $u$. machte meine Beobachtungen. Zwei Braacks wurden vom Hotel zur netten Fahrt nach Altdorf gerüstet. Sie waren gedeckt, der eine sogar flott eingemacht von allen Seiten. Zwei andere, offenere kamen von Urigen her auf telephonische Bestellung. Im besten der vier wurden eine Anzahl Gäste des Hotels placiert $u$. sie stiegen lachend in ihren verschiedenen Umhüllungen ein. Der zweite gedeckte nahm sechs Schülerinnen auf u. zwei Lehrer oder dgl., die mit zahlreicheren Knaben gestern Abend eingerückt $u$. in Massenquartier Unterkunft gefunden hatten. Die zwei offenen bestiegen die 24 Buben u. zwar so, dass je zwei eine Decke erhielten, die sie sich über die Rücken legten, auf dem Umschlag sitzend u. mit den beiden Enden die Kniee deckend. Ein Lehrer ordnete das ganz geschickt so an, während die Kutscher eine einfachere Anordnung haben wollten. Nur die nackten Waden blieben dem einen $u$. andern ungeschützt $u$. lachten verdriesslich in den Regen hinaus, wie ich den Wagen so von der Seite mir ansah. Der Herr Pfarrer u. zwei Lehrer schlugen den Weg zu Fuss ein. Der erstere erinnerte mich in Gestalt u. Manier an Dr. Straub von Romanshorn, unsern alten Bekannten. 
Ich las hier im 1815, plauderte mit Dr. Georg Müller, auch nach Tisch. Dann aber fand dieser Platz in der Post nach Urigen u. fuhr sich herzlich verabschiedend davon. Ich gab ihm bei dem strömenden Regen das Geleite zum Wagen, mit dem

Schirm. Es regnete so stark, dass die fünf Minuten den Schirm u. die nicht geschützten Zipfel meines Kleides tropfen machten. Ich eilte in die Gaststube zurück, stellte den Schirm in das Garderobegestell, holte mir die Fremdenliste im Vierwaldstätter Fremdenblatt, las darin, ging aufs Zimmer, fuhr in Houssayes Buch fort, nahm dann einen Thee, um die Zeitungen, die von Anna einlangten, zu lesen, unten im Restaurant. Dann wollte ich trotz des Regens noch ein wenig hinaus - u. mein Schirm war weg. Ich suchte, die Frau Wirtin suchte. Da gewesen war seit Abfahrt der Post nur ein schweizerisches Ehepaar, das von der Passhöhe hergekommen, noch gehofft hatte, die Post zu erreichen, schnell etwas nahm u. den Weg nach Urigen fortsetzte. Die Wirtsleute meinten, der Schirm sei von diesen verwechselt worden, ich weiss es nicht; sie gaben sich aber keine weitere Mühe, meinten nur, er werde vielleicht von Urigen aus heute Abend zurück gesandt. Dann müsste ja ein anderer hier stehen geblieben sein, $u$. das stellten sie nicht fest. Ich denke also, das wahrscheinlichere ist, dass er mir gestohlen worden sei, u. das tut mir leid. Es ist der Reiseschirm, das feine, elegante Stück, das Du mir zur letzten Weihnacht, die wir so glücklich zusammen verlebt, geschenkt hast, mit hübschem silberbelegtem Griff, elegantem Stoff, wie Du eben die Sachen haben wolltest. Ich vermisse ihn ungern. Die Sache tut mir leid, u. möglicherweise ist es mir ein Zeichen, dass meines Bleibens hier doch nicht solange sein soll, als ich es vor hatte. Einen Schirm muss ich haben. Soll ich an Anna schreiben, dass sie mir einen ähnlichen (sie kennt ja den verlorenen) kauft u. schickt? Oder verzichte ich auf Ersatz u. lasse mir einen meiner gewöhnlichen Schirme zustellen? Oder geh ich heim, um zur Sache zu sehen u. daheim zu bleiben? Kurz die Sache ist mir nicht recht. Möglich, dass sie sich noch aufklärt, aber ich 
glaube, ich hoffe es nicht. So bin ich dann um eine liebe Erinnerung an Dich ärmer. Es nimmt alles ein Ende, manchmal schneller als man es sich denkt.

Die Post brachte mir ausser den Zeitungen u. eine Studentenanfrage, die ich gleich beantwortete, eine Karte aus Freiburg i. B. Ich habe Dir erzählt, dass ich die Fahrt von Linthal hieher im Coupé mit einer ältern Hamburger Dame machte. Da ich nach dem Nachtessen, indem sie zu mir heraus kam $u$. mich anredete, vor dem Hause auf ihren nachfolgenden Mann mit dem Sohn wartete, hielt ich es für passend, mich vorzustellen, was er mit [?] Bekanntschaft zu machen, erwiederte, ohne seinen Namen zu nennen. Ich wünschte ihnen gute Reise u. ging weg, geärgert von dieser Art. Nun hat die wirklich feine Dame wohl nachträglich auch gefunden, das sei ungehöriges Verhalten gewesen $u$. daher nun von ihrer ersten Haltestelle aus der Kartengruss mit ihrer Unterschrift, die ich aber nicht sicher entziffern kann. Das ist auch gleichgültig. Mich interessiert nur die Art der Gutmachung eines nicht richtigen Verhaltens.

Gestern Abend, nachdem ich an dich geschrieben u. zu Bett gegangen war, dauerte die Tanzmusik unten noch eine Weile fort, störte mich aber nicht, da der Lärm zum zweiten Stockwerk sehr gedämpft herauf drang. Bis $12 \mathrm{Uhr}$ soll die Freude gedauert haben. Sehr sympathisch war, dass gestern alle Couvert mit einem Fähnchen geschmückt waren, roth $\mathrm{u}$. weisses Kreuz, aber auf beiden Seiten «Chamsager Strub» gedruckt. Ein Sinnbild unseres «Guglielm Hotel»! Es frappierte mich gleich, u. hätte es noch mehr, wenn nicht zugleich ein Alpenrosensträusschen daneben gelegen. Heute las ich, dass solche «Fähnchen» auf den 1. August an alle Hotels verschickt worden. Also richtige «Fremdenindustrie» mit Ausbeutung des «Nationalfestes» zu Reclamezwecken. Nun, 
die meisten Leute denken ja gar nicht so weit $\mathrm{u}$. sehen in solchen Dingen gar nichts Böses. Ich schliesse mich ihnen nicht an.

Die Achtuhr-Post hat meinen Schirm nicht gebracht, u. es hat von den Wirtsleuten niemand ein Wort darüber weiter verloren. Ich habe auch geschwiegen. Aber der Aufenthalt in hier hat in meiner Stimmung einen Riss bekommen. Ist es ein Wink von Dir - zu gehen?

Am Abendtisch war ich mit drei Engländern, zwei Herrn u. eine Dame, zusammen. Ich habe englisch mit ihnen gesprochen u. es ging besser als ich es mir gedacht hätte.

Nun Schluss. Ich bin nach dem Nachtessen noch eine Weile unter der Dachtraufe - ohne Schirm - hin u. her gegangen, bis die Abendzigarre geraucht war. Und jetzt zu Bett.

Dir ewig verbunden!

Dein

\section{Eugen}

\section{2: August Nr. 165}

Klausen, d. 3. / 4. Aug. 1912.

Mein liebstes Herz!

Heute habe ich bei Sonnenschein u. Nebeltreiben ein paar hübsche Spaziergänge gemacht, vormittags erst zur Schutzhütte u. dann auf die untere Balmalp, nachmittags über Geisswege nach dem kleinen Höchen u. der Niemerstafelalp, einem unglaublich sumpfigen Grund mit schmutzigen Schweinen. Hinter dem Höchen kam ich in ein ganz einsames Talkesselchen, wo die eine Talseite noch voll stand von blühenden Alpenrosen. Interessant war auch eine Schlucht, ein Riss, an den man dicht heran treten kann u. der sich gähnend bis zur der etwa fünfhundert Meter tiefer liegenden Aeschalp hinzieht. - Am Tisch habe ich fortgefahren mit den Engländern zu sprechen, nachdem mir Frau Schillig von sich aus entschuldigend gesagt hat, sie hätten nicht tele- 
phoniert, weil sie sich sagten, ein redlicher Tausch werde ohnedas gutgemacht werden, $u$. bei einer unredlichen Verwechslung nütze es doch nichts. Ich fand übrigens heute bei Tag in dem Schirmständer einen grauen Reiseschirm, der dem mir von dir geschenkten ähnlich ist. Vielleicht ist es der vertauschte. Ich liess ihn beiseite stellen, in der Meinung, dass ich ihn behalten werde, wenn kein weiterer Bericht kommt u. ihn niemand aus dem Hotel reklamiert. Die Verwechslung ist dann doch sehr wahrscheinlich u. bei dem gestrigen Trübsal im strömenden Regen um so mehr. Wenn ich denke, wie ich im Café de la Sorte vorletzten Winter nach der Rathausvorlesung Dr. Mattis Stock mitnehmen konnte, der doch viel schöner war als der meinige!

Schon am ersten Abend hörte ich bei anbrechender Nacht einen Jodler, der mich an den Frutt-Alpsegen erinnerte, der uns vor 36 Jahren so mächtig überraschte u. ergriff. Seither vernahm ich ihn jeden Abend, wirklich ein Alpsegen. Ich habe nachgefragt, wo er gesungen wird, $u$. will mir die Worte aufschreiben. Als ich heute dort vorbei kam, war der Senn abwesend. Man sagte mir, dass diese Sitte im ganzen Schächental noch heimisch sei.

Vorgestern, als beim Föhn die Nebel so merkwürdig geballt u. geworfen wurde, stand über dem Schächental eine kleine Weile eine weisse Wolke, die die Gestalt eines klassisch-schönen Frauenkopfes annahm, dann aber rasch verzerrt wurde u. verschwand. Hat wohl der Maler Girou auf Deinem Ratsaalbild auch etwas hingemalt, das er derart einmal gesehen? Man kann sich schon denken, dass solche Erscheinungen mächtigen Eindruck machen können. Ich vergesse es nicht, wie seinerzeit in den dürren Frühlingsmonaten des Jahres 1903 in den Zeitungen stand, Bauern im Emmental hätten den Heiland auf einer Wolke sitzend gesehen, $\mathrm{u}$. wie daraus der Glaube an ein Gesicht Gottes abgeleitet wurde. Dass wir solches in den Wolken erblicken, ist ja ein innerer Vorgang u. innere Wahrheit, die ja auch dem Denker u. dem Herz des Schauenden auch äussere Wahrheit wird. Sollte ich nicht bei jenem Frauenkopf an Dich in Deiner Verklärung denken, da Du mich ja überall hin begleitest u. bei mir bist?

Von Marieli habe ich heute Nachmittag keine Berichte erhalten, wie ich es angenommen. Es ist in Altdorf ganz in freundschaftlichem Kreis eingesponnen. Wie es schreibt, schläft es auch jetzt erst wieder nor- 
mal, nachdem es seit Monaten sich den Schlaf in wahrhaft erschreckender Weise durch allerlei Äusseres u. Inneres hat verkürzen lassen. Komme das in Altdorf in Ordnung, so würde schon deshalb der Besuch als ein gesegneter gelten müssen. Ich will dankbar sein dafür!

Zu meiner Überraschung brachte mir die Halbachtuhrpost heute noch etwas: Eine Karte von Walter B., vom 1. August, worin er mir u. a. mitteilt, dass er noch immer «büffle», und einen Brief von Marieli, worin es von seinem fröhlichen Aufenthalt in Altdorf erzählt u. seine Herkunft in hier auf Mittwoch oder Donnerstag ankündigt. Es ist alles recht, wenn es nur mit dem lieben Kind innerlich besser wird. Neben dem fröhlichen Treiben in hier gehe ich gerne $u$. innerlich Anteil nehmend

einher. Die Engländer sind nett mit mir. Und die Tage sind mir bis jetzt ohne einen Augenblick von Leere vorübergegangen. Ich habe nicht einmal zu arbeiten Lust oder auch nur Zeit gefunden.

Im Restaurationssaal spielen sie das Tellerspiel. Ich habe etwas zugeschaut, mich gefreut u. geh jetzt gern zu Bett. Für Dich u. mich war diese Fröhlichkeit nie geschaffen, unsere Jugend ist dafür zu ernst gewesen. Ein alter Herr, Klassen, der gut englisch spricht, macht mit, es war drollig u. doch gemütserheiternd, ihm zuzuschauen.

Heute begleiteten mich beim Morgenspaziergang zwei junge Hunde, von denen drei im Hotel gehalten werden. Sie spielten miteinander u. jagten den Geissen Furcht ein, ich hatte meine Freude daran, denn gefährlich war es weder für die einen noch für die andern.

Den 4. August.

Heute Nacht rückte um halb zwei ein Veloclub ein, ich hörte die Signale u. die Nachtklingel, halb im Schlaf. Sie wurden noch in Massenquartiere untergebracht. Ich schlief sofort wieder u. fand beim Erwachen einen wunderbar hellen Morgen. Ich genoss die Aussicht beim Hotel, mit der Karte in der Hand, pilgerte dann langsam zur Passhöhe u. darüber hinaus. Da begegneten sich zwei Cyclisten u. der eine bat den andern um Öl, u. als das besorgt war, schlug er vor, eine Photographieaufnahme zu machen, bei einer Fahrgruppe, mit initiertem Seil, u. ich wurde ersucht, den Apparat, wenn 
die beiden in Stellung wären, abzudrücken. Ich tat es, u. der Photograph, ein Schreiner in Rapperswil, versprach, mir auch einen Abzug zu schicken. Will sehen, ob daraus etwas wird, ob ich recht abgeknipst habe.

Beim Mittagessen grüsste mich der durchgefallene Rechtscandidat Eglof, der jetzt am Zürcher Bezirksgericht eine Auditorstelle hat. Ich war freundlich mit ihm, vernahm allerlei. Er ass mit mir u. nachher tranken wir den Café, worauf er gegen drei nach Urigen weiter pilgerte.

Gestern hatte ich eine andere Begegnung. Als ich auf der Terrasse meine Cigarre

rauchte, kam ein junger Bursche auf mich zu. Die Kellnerin habe ihm gesagt, ich sei Prof. H. aus Bern u. es freue ihn so, mich persönlich kennen zu lernen, er habe viel von mir gelesen. Er heisse Meier u. sei Polytechniker in Zürich. Ich fragte, ob er Zofinger sei, worauf er: kein Badener. Die Matura habe er in Aarau gemacht. Er sei an der Ingenieur-Abteilung. Er reiste weiter, wonach

mir erst in den Sinn kam, dass er gewiss glaubte, den Gottlieb H. vor sich zu haben. Er hatte die richtige Aargauer Frische.

Noch eines beobachtete ich: Von der Höhe kamen drei Jungen, laut kantierend, ausgelassen, eine dicke Mutter mit fettem, herrschseligem Gesichtsausdruck u. eine kleine [ver?] Dame hinter sich. Die tranken lärmend auf der Terrasse, u. wie ich auf der Höhe drüben war, sah u. hörte ich wieder, wie sie laut grölend abwärts marschierten. Typen des syfisantesten vornehmen Jungen-Ton, der in der Landschaft so wenig passte: Dumm, reich, rücksichtslos, gefühllos. Richtige Ohrfeigengesichter.

Von vier Uhr an sassen heute morgen Velocipedisten u. andere herum, u. einer, mit einer Stimme, die gerade wie die Conrads klang, lärmte u. disponierte so laut u. constant, als ob er das Haus wecken wollte. Anders letzten Freitag Morgen die Thurgauer Schüler, die beim Morgenessen, als man ihnen sagte, sie sollten die Gäste nicht wecken, nur noch lispelnd miteinander gesprochen haben.

Es war hübsch, wie heute Vormittag so zahlreich Familienväter mit Frau u. Kind, oder Gruppen von jungen Leuten mit den höflichsten Gesichtern vorüber zogen, den Gruss freundlich erwidernd. Heute Nachmittag wehte wieder der Wind, sehr stark. Das Publikum war ein anderes. Ich sah jetzt zum ersten mal eine Touristin in Hosen, von einem Mann u. einer jüngeren Tochter begleitet. Schweizerleute, kein erhabener Anblick. Er wurde aber «überholt», als etwas später sehr junge Schweizerinnen etc. in dem 
Hosencostüm einrückten, ein Pensionat? Sah ich solches nicht letztes Jahr auch in Göschenen? Ich weiss es nicht mehr. Man sagte mir später, es sei der St. Galler Damenturnverein gewesen!

Heute Abend sah ich an der Strasse unter dem Hotel etwas eigentümliches: Ein kleiner hoher Wasserfall war vom Föhn so direkt getroffen, dass das Wasser beim Beginn des Falles zurück geworfen u. vom Wind aufwärts gestäubt wurde. Ein ganz merkwürdiger Anblick: Auf der Strasse traf ich ein junges Paar aus Basel, müde, fröhlich, noch dem Urnerboden zustrebend. Ich plauderte mit ihnen in herzlicher Erinnerung.

Und nun gute, gute Nacht! Trotz Trübsal geniesse ich die hohe Freiheit hier mit jedem Tage mehr. Wenn nur die Gesundheit stand hält!

Bleibe bei mir, wie ich bleibe auf immerdar Dein getreuer

Eugen

\section{2: August Nr. 166}

Klausen, den 5. / 6. Aug. 1912.

Mein liebstes Herz!

In der Nacht hatten wir ein paar Donnerschläge u. dann Regen u. Regen. Am Morgen war es kühl, auf den Bergen lag bis auf 2000 Meter herunter Schnee. Ich las am Vormittag die Zeitungen, die gestern angekommen waren u. schrieb dann eine Anzahl Briefe (an Anna, Marie) u. Karten. Dann zog es mich hinaus, aber bei dem kalten Regen war es unlustig, herum zu gehen. Eine Schachaufgabe der N. Z.Z. beschäftigte mich, ich konnte sie aber noch nicht lösen. Am Nachmittag las ich Houssaye bis zum Gang Napoleons auf dem Balerophon, u. schrieb an Kleiner, von dem ich eine liebe Karte erhalten. Dann sprang ich zur Passhöhe hinauf u. zurück. Und so verging der Tag. Mit dem kleinen Engländer zu meiner Linken verabredete ich ein Schach, aber das Spiel war in Altdorf. Nach dem Nachtessen spielte der alte Klassen mit seinem jungen Begleiter (v. h.?) Pfänderspiel mit den kleinen Töchterchen Schilligs. Und so ist die Zeit vorüber gegangen. War der Tag äusserlich monoton, so war er 
doch innerlich für mich ein freudiger Tag, ich weiss nicht warum. Es ist eben doch, als ob die gedrückte Stimmung, unter der ich so oft leide, eine Folge von Ermüdung ist. War das bei mir nicht von jeher, schon in der Kantonsschule so? Ich bin eben doch geistig nicht so stark, dass mich nicht anhaltende Arbeit ermüden würde, u. dann kommt

die Reaktion, wenn nicht in ausgesprochener körperlicher Müdigkeit, so in einer gedrückten Stimmung. Zur Belebung meines Animus trägt jetzt natürlich auch die hohe Bergluft bei. Darum halte ich es hier gerne aus. Ich kann dabei trotz Regen u. Kälte nach meinem Gefühl nur gewinnen. Doch jetzt gute Nacht, ich bin körperlich müde geworden bei der heutigen kühlen Witterung. Mit den Engländern verkehre ich immer freundlicher, ich habe Freude an ihnen. Doch gute Nacht nochmals. Was wird mir Marieli berichten, was wird Kleiner machen, auf meine heutigen Berichte? Beim heutigen Ausgang eignete ich mir den Schirm an, der mit Deinem Geschenk verwechselt worden, womit nun die Sache erledigt sein wird. Aber jetzt zum dritten Male: Gute, gute Nacht!

Den 6. August.

Heute würden wir Deinen 61. Geburtstag feiern, wenn es das Glück gewollt hätte. Ich hatte nicht oft daran gedacht, dass Du vor mir sterben könntest, aber wenn ich es dachte, so verschloss ich die Augen u. das Herz vor einer solchen Zukunft. Nun ist sie Gegenwart, schon länger als zwei Jahre, u. ich trage es, aber in zunehmender Einsamkeit. Ich bin selbst daran Schuld, ich weiss es, aber ich will es nicht anders haben. Also weiter. So wie es gerichtet ist, das Leben dauert ja nicht mehr zu lang.

Heute Vormittag ging ich zum Senn Schuler-Jödler, der allabendlich den Alpsegen spricht u. ersuchte ihn um die Worte. Er erbat sich solche aufzuschreiben $u$. versprach sie mir in einigen Tagen zu senden. Der Mann ist 65 Jahre alt u. als ich ihm sagte, ich sei auch 63, meinte er mit Recht, er sehe doch jünger aus. Einen prächtigen Senn habe ich in Gisler kennen gelernt, der täglich dem Hotel die Milch 
bringt. Ferner interessierte mich die Familie Arnold, deren blondes Mädchen täglich die Post holt.

Mit meinen Engländer, M. v. Nur. Benneth u. Mr. Newland geht es immer besser. Wenn ich noch lange allein mit ihnen bin, repetiere ich mein Englisch. Marieli wird aber bald kommen. Ich schrieb ihm, es soll morgen die Post nehmen, heute aber telephoniert es, es möchte bei schönem Wetter noch einen Ausflug machen. Also wenn es schlecht bleibt, morgen Abend Ankunft, sonst später. Auch recht, mir ist ja wohl allein.

Sonst habe ich diesen Morgen in Houssaye weiter gelesen. Das Buch fesselt mich fortgesetzt. Briefe habe ich keine pressanten. Ich denke aber, es wäre recht, doch einmal an Müller zu schreiben.

Während es am Vormittag aufzuheitern schien, ist am Nachmittag starker Regen gekommen $u$. die Berge sind mit wechselnden Wolken behangen. Auch ist es erheblich kühler geworden. Demnach bietet die Landschaft vielfach wechselnden Reiz. Die Beleuchtung ist eine ganz andre, die Wolken- $u$. Nebelstreifen lassen bald diesen, bald jenen Kopf oder Felsvorsprung ganz anders hervortreten als dies bei unbedeckter Landschaft der Fall ist. So sah ich heute vor dem allgemeinen Steigen des Nebels die Balmwand in einer Grossartigkeit wie niemals vorher. Die nassen Matten scheinen grüner, der Absturz über die Talstufe zum Aeschälpli hinunter aprupter. Sehr schön war gestern in der Dämmerung auch ein Nebelmeer, das das ganze Schächental ausfüllte, mit langen weisslichen Streifen, dann sich aber rasch verteilte $u$. das heimelige Licht von Unterschächen herauf leuchten liess.

Die fünf Kinder des Wirts lerne ich allmählich kennen: Marina, Regina, Erna, Helena, u. dazwischen der elfjährige Emanuel. Dieser erzählte mir, dass der Geolog Dr. Staub jedes Jahr herkomme. Auch diesmal werde er auf Ende August erwartet. Albert Heim scheint mit Schillig näher bekannt zu sein. Frau Schillig, eine Aschwanden, 
wird von den Serviermädchen als sehr arbeitstüchtig, geschätzt. Ihre Mutter, an die siebzig alt, war die Tage auch da. Eines der Mädchen meinte, die Frau Schillig werde nicht so alt wie ihre Mutter, sie arbeite zu viel. Also auch hier «Eine gute Frau wird nicht, oder selten, alt.»

So ende ich diesen Deinen Geburtstag. Trotz allem ist es für mich ein wehmütig frohes Sein hier auf der Höhe, wo ein konstanter Fremdenstrom hin- u. herüber flutet, ohne dass man sich mit einer Zufallsgesellschaft enger beschäftigen muss. Es sind Leute in Ferienstimmung, die vorbeiwandern, also solche die Vergnügen suchen, $u$. insofern ist dieser Anblick weniger vielsagend, als der von vorbeifahrenden Schiffen am Meeresstrand. Aber ich denke nun doch auch an die Arbeit, die zumeist diese Leute hinter sich u. vor sich haben, wenn sie zur Erholung u. Stärkung diese Wanderung unternehmen. Im Ganzen waltet der ernste Ton vor. Ich denke z. B. an die Handwerker u. Angestellten, die da ihre Gebresten abzuschütteln u. ihre Kräfte zu sammeln suchen. Wenn dann der Nebel u. Regen sie umgiebt, ziehen sie dahin, im Gedanken, dass ihnen zwar von der Freude viel genommen, die Erholung u. Kräftigung aber doch gesichert wird.

Und nun, ein neues Jahr in Deiner Zeitenfolge. Wo u. wie wird der nächste 6 . August mich sehen? Wie steht es dann mit Marieli, werde ich von Krankheit verschont bleiben, die Arbeitskraft behalten haben, oder mit Dir wieder vereint sein? Das wollen wir mit ruhigem Gemüte abwarten.

Heute nach dem Nachtessen hat den Engländern Hr. Klassen u. sein junger Begleiter, von Günther, seine Sammlung der Schmetterlinge des Klausenpasses gezeigt. Welche Fülle! Sobald man etwas recht anfasst, wird es zur Wissenschaft.

Jetzt aber gute, gute Nacht! Dein ewig treuer

Eugen 


\section{2: August Nr. 167}

[1]

Klausenpass, d. 7./ 8. Aug. 1912.

Mein liebes gutes Herz!

Es ist heute ein kalter Regentag mit Schnee auf $1900 \mathrm{~m}$. Ich ging am Vormittag, um mich zu erwärmen, etwas herum, las ein grosses Stück in Houssaye - bald bin ich fertig. Am Nachmittag kam, nachdem ich in der geheizten Stube mitten im Lärm der merkwürdigerweise sehr zahlreichen Gäste die Zeitungen gelesen, eine ausgiebige Post, von der ich das dringendste gleich erledigen konnte. Ein Thee, noch einmal ein kurzer Gang trotz Regen, u. nun warte ich auf dem Zimmer auf das Nachtessen u. - auf Marielis Ankunft mit der Abendpost. Es hätte keinen ungünstigeren Reisetag erwischen können. Das arme Kind tut mit wirklich leid, dass es so frieren muss. Wenn es nur keinen Schaden nimmt! Es bekommt ein ganz nettes Zimmer, drei Türen von mir. Hoffentlich kann es sich bald an besserem Wetter erwärmen. - Zugleich kündigt Kleiner an, dass er mit Gritli herreise, vielleicht so dass er mit der gleichen Post ankommt, wie Marie, vielleicht auch erst morgen. Und Wettstein mit seiner Frau werde am Donnerstag oder Freitag auch vorbeikommen. Alfred der Sohn ebenso am Samstag. Es wird also belebter werden, denke ich. Aber es ist mir auch recht, wenn nur das Wetter bald besser wird.

Die Nachrichten von zu Hause, von Anna, sind recht. Wenn es so weiter geht, kann ich getrost weg bleiben. Von Oser habe ich einen

längeren Brief erhalten, worin es über Wissenschaftliches u. seine Stellung im Bundesgericht spricht, aber seine Familie, seine Frau mit keinem Wort erwähnt. Er ist halt anders als ich. 
Auf Morgen sende ich Brunneck in Halle eine Gratulationsdepesche, er feiert sein fünfzigjähriges Doktorjubiläum.

Gestern Abend zeigte uns, den Engländern u. mir, Herr Klassen seine prächtige Sammlung, wie ich Dir schon geschrieben. Ich schreibe nochmals davon, weil ich mich dabei nachträglich über einer Unhöflichkeit ertappt habe. Ich habe ihm nämlich gar nicht gedankt, während die Engländer das nicht vergassen. Ich habe das Versäumte dann heute mit einigen Worten nachgeholt.

Ich sagte schon, es seien ganz unerwartet viele Gäste hier. Wenn Kleiner kommt, muss er in das Nebengebäude. Merkwürdig, dass er sich nie rechtzeitig anmelden kann. Auf dem Gotthard war es letztes Jahr auch so. Das kommt von seiner Unschlüssigkeit her. Er hat Mühe, sich für etwas zu entscheiden. Deshalb trifft er keine Vorbereitungen.

Ich füge noch vor Schlafengehen bei, dass Marieli um halb acht als einziger Passagier mit der Post von Altdorf angekommen ist, ganz durchfroren, aber sonst in guter Stimmung. Zugleich erschien Reitschel aus Tübingen von Linthal her, sodass ich mich in die beiden teilen musste. Nach Tisch wurde getanzt. Marie hat fröhlich mitgetanzt u. Kompliment als gute Tänzerin erhalten. Es ist elf Uhr geworden, ich will daher abbrechen. Von seinen Erlebnissen konnte mir Marieli unter den ge-

gebenen Umständen nicht mehr viel, oder noch nicht viel erzählen. Gute, gute Nacht!

Den 8. Aug. 1912.

Heute konnte ich bis elf mit Prof. Reitschel zusammen sein u. hatte einen recht freundlichen Eindruck von ihm. Es war für mein wissenschaftliches Sein wie eine Erfrischung wieder einmal in der Weise plaudern zu können, wie ich es früher so liebte. Von Wert war es mir, einiges von v. Frisch zu hören, wie er in Heidelberg eine Antrittsrede gehalten, von der Jellinek zu ihm selbst gesagt habe, es sei die schlechteste, die er je gehört, worauf der Frechling geantwortet 
habe, er habe sich auch gar keine Mühe gegeben. Über Rümelin erzählte Reitschel, er habe viel zu viel Arbeit. Von Heck schien er sehr erbaut. Kurz ich vernahm so vieles u. hatte auch die Freude, dass Reitschel meine Sache sehr wohl kannte u. hübsch darüber urteilte, dass es mir eine Freude war. Er ging zu Fuss nach Altdorf, um die Ferien mit seiner Familie in einem Chalet zu verbringen.

Der Tag war auch sonst anders als die bisherigen, weil Marieli da war. Ich machte vor Tisch u. am Nachmittag auf der Strasse Spaziergänge mit ihm, wenn es nicht regnete. Der Tag war kühl u. nass. Von Siegwarts scheint Marieli sehr erbaut zu sein. Es erzählte mir viel Liebes von der ganzen Familie. Und Velo hat es fahren gelernt. Nun soll auch ein Velo her, das wird sich nicht mehr vermeiden lassen. Von Abbühl kam ein Expressbrief an Marie, worin er unter hohen Ausdrücken seinen Besuch auf Samstag Abend ankündigte. Ich habe ihm auf Anraten Maries telegraphiert, dass, «Leider durch Besuch aus Zürich in Anspruch genommen.»

In der Tat erwarten wir ja Kleiners. Und bei schönem Wetter kommen vielleicht auch die Geschwister Siegwarts. Ich begreife auch hier Abbühl nicht.

Nach dem Essen wurden Spieler gemacht, an denen sich Marieli ganz nett beteiligte. Es ging aber lange u. ist jetzt schon elf Uhr. Also Lichterlöschen u. Gute, gute Nacht!

Dein ewig getreuer

Eugen 
[1]

Klausenpass, den 9./10. Aug. 1912.

Mein liebstes Herz!

Heute, bei schönem, hellen Morgenstunden u. nachfolgenden Regen u. Nebel gab es Unvorhergesehenes. Ich wollte nach dem Morgenessen über die Obere Balmalp u. dann gegen den Ruosseralppass. Aber wir kamen bald auflästig nasse Pfade u.

bei der ersten Hütte fiel Marieli, das furchtbar froh u. sich unzweckmässig eingehüllt hatte, in eine böse Pfütze, so dass es von oben bis unten mit Kuhmist beschmutzt war. Also Rückkehr. Es musste die Kleider zum Waschen geben, u. ich las Houssaye fertig. Nach Tisch las ich etwas in Wegemanns Buch, dann warteten wir auf die Post, Marieli unter schrecklichen Leiden unter der Kälte. Da kamen mit der Altdorfer Post wider Erwarten Kleiner u. Grittli. Mit diesen machten wir einen Lauf nach den Kehren, von wo man einen Überblick über den Urnerboden hat, marschierten hin u. zurück also etwa 7 Kilometer, u. das scheint Marieli gutgetan zu haben. Nach dem Nachtessen gab es wieder Spieler. Wir gingen aber bälder hinauf als gestern. Es ist, da ich diese Zeilen schreibe, zehn Uhr. Mich betrübte eine Zeitlang heute wieder der Zustand Marielis. Was ich ihm sagte, beachtete es nicht. Wem nicht zu raten, dem ist nicht zu helfen. Ich rief ihm z. B. zu, es solle längs der Hütte gehen, hätte es das befolgt, so wäre es nicht so schlimm hinein gepatscht. Aber das ist wohl Jugend. - Von Siegwart habe ich bereits Antwort erhalten. Er will mit Claire so bald als möglich herkommen,

$[2]$

um die geplante Tour von hier aus zu machen. Auch von Walter Burckhardt erhielt ich einen lieben Brief. Sonst Amtliches u. Geschäftliches, das mich auch hier nicht ganz ungeschoren lässt.

Es ist kalt auf dem Zimmer. Ich verschiebe alle Beantwortungen auf morgen $u$. will für Dich hier abbrechen. Nur 
eines sei noch angefügt, dass Kleiner sehr lieb gekommen ist u. die Gegend prächtig findet. Wie lange er zu bleiben gedenkt, weiss ich nicht. Ich dachte heute einen Moment daran, ob Marieli nicht besser nach Bern zurückkehren würde. Aber wenn es mit dem Freien besser kommen sollte, so wäre es halt doch ein grosser Gewinn, dass es diesen Höhenaufenthalt machen würde. Also erwarte ich den Einfall u. warte ab. Auch der Besuch von Siegwart kann ja von Einfluss sein auf die Entschliessung.

Zu eigentlicher Concentration komme ich immer noch nicht, es ist eine schlimme Sache. Aber die Ferien sind immer so gewesen: Die ersten paar Wochen gehen wie die Trauer vorüber. Erst allmählich macht sich dann wieder ein Hunger der Vernunft geltend $u$. der leitet von selbst über zu dem Neubeginn der geistigen Arbeit. So sage ich mir das zum Trost u. hoffe auf reichere Tage.

Aber es wird kalt an den Füssen. Ich schliesse für heute. Heute hatte ich eine so grosse Freude, als ich glaubte, das schöne Wetter komme. Vielleicht wird die Freude doch in einigen Tagen reell begründet. - Noch eines muss ich sagen: Heute rückte ein

schwäbisches Ehepaar ein mit fünf prächtigen Töchterchen. Und der Familus des Herrn Klassen heisst von Gulgen, nicht Hünter. Ferner waren die unsympathischen St. Galler Herr u. Frau Keppeler. Ich muss es doch aufschreiben, um es im Sinne zu behalten. Gute, gute Nacht!

Den 10. Aug. 1912.

Der heutige Tag fing vielversprechend an. Die Berge waren hell. Kleiner u. Gritli gingen schon vor dem Morgenessen in die Alpenrosen. Etwa um halb neun machten wir uns bei Sonnenschein auf, alle Viere, u. stiegen aufs Balmer Grätli. Ich kam dabei im obersten Stück etwas von den andern ab u. entdeckte eine Höhle, von der dann aber der Weg ans Ziel sehr glitschig war, auf nassem langem Gras u. sehr steil, einmal kam ich ins Rutschen, konnte mich aber mit dem Stock wieder oberhalb eines ein paar Meter hohen Felsbandes festhalten. Während Marieli noch höher stieg, 
kamen Nebel, wir konnten aber noch bei Sonnenschein heruntersteigen, aber am Nachmittag gleich nach Ankunft der Post begann es zu regnen. Wir sassen dann plaudernd in dem Anbau, schliesslich wurde es kalt, in dem Esszimmer wurde geheizt.

Marieli friert immer. Nur bei der Tour vom Vormittag u. dann bei dem Gang, den es mit Margrit um u. über die «Kleine Höhe» machte, fühlte es warm. Dazu hat es jeden Morgen Nasenbluten, ich weiss nur nicht, wie weit es in einer Stimmung ist, in der es gern mich zu einem ihm convenierenden Entscheid bringen möchte. Das können wir abwarten. Inzwischen wird doch die Höhenluft ihm gut tun.

Zum Lesen oder Schreiben werde ich jetzt weniger kommen, wo Kleiner da ist. Aber es bietet das Zusammensein andere Vorzüge, so dass ich doch recht froh sein muss über das Rendez-vous.

Heute war bei den Nachmittagsposten gar kein solcher Andrang, wie es auf den Samstag erwartet wurde. Das wird auf die Nacht anders geworden sein, denn das ganze Haus ist voll. Marieli wurde sogar veranlasst, das Margritli in sein zweibettiges Zimmer zu nehmen.

Alfred der Sohn ist heute halb neun, nach Gewaltsmarsch in dreieinhalb Stunden von Altdorf nach hieher eingerückt, u. kehrt um vier Uhr morgen Nachmittag nach Linthal-Zürich zurück. Es ist ein flotter Bursche geworden, der mich freut. Wie mir der Vater sagte, sucht er möglichst bald praktische Stellung, weil er eine Liebe habe. Sonst würde der Vater es vorziehen, wenn er sich der akademischen Laufbahn widmete.

Es ist auch heute kalt. Also zu Bett. Ich fror heute Abend sehr, da ich weil Kleiner nicht mitmachen wollte, über den Nachmittag nichts genommen.

Marieli leidet an Kopfschmerzen, ist gereizt, namentlich gegen mich. Es ist alte Geschichte, wie ich sie nun schon mehrfach erlebt habe. Du, liebe Seele, hast mich eben verwöhnt.

Gute, gute Nacht! Ich bleibe bei Dir auf immerdar, Dein getreuer

Eugen 
Klausenpass, den 11./2. Aug. 1912.

Meine liebe, gute Lina!

Nach stürmischer, regnerischer Nacht hatten wir einen kalten, nassen Vormittag. Alfred der Sohn entschloss sich, schon um halb elf nach Linthal weiter zu marschieren, $u$. dem Wunsche des Vaters, offenbar, folgend nahm er trotz des schlechten Wetters Gritli mit. Alle drei wanderten über die Höhe dem Glarnerland zu, der Vater kehrte auf zwölf zurück. Alfred hat mir einen guten Eindruck gemacht. Er wird allem nach ein praktisch sehr tüchtiger Mann. Er hält sich in Zucht, die Art wie z. B. vor seinem Abmarsch noch eine halbe Stunde in dem Nebel $u$. Regen herumging, um Steinröschen $\mathrm{u}$. andere Blumen zu pflücken, die er nach Hause bringen wolle, hat mir sehr gefallen. Dagegen halte ich ihn nicht für einen originellen Menschen, u. er wird schwerlich für die wissenschaftliche Berufbahn passen. Zeigt auch keine Neigung dazu. Vater Kleiner hat auf das gestrige Diktum bei mir unbewusst abgeschwächt, indem er mir sagte, Studula habe Alfred als bedeutend begabt für die Wissenschaft bezeichnet, dann aber auffallender Weise, doch nicht ihn, sondern einen andern, Studierfreund Alfreds, zu seinem Assistenten gewählt, u. doch wäre das der richtige Weg gewesen, mit der akademischen Carriere zu beginnen. Überall dasselbe: Freundliche Worte u. dann in dem entscheidenden Moment nicht die ihnen entsprechende Handlungsweise. Ich habe dies ja auch erlebt.

Den Nachmittag wurde Lotto gespielt, wobei Marieli zum Gaudium seiner selbst u. anderer ein Päärchen Frankfurterli gewann. Ich war mit Kleiner zusammen. Gegen vier machten 
wir drei einen Spaziergang gegen Urigen. Marieli war am Vormittag noch recht verdriesslich, klagte über Kopfschmerzen. Am Nachmittag hat es eine normalere Verfassung gezeigt, wodurch auch meine Stimmung bedeutend gebessert wurde. Kleiner scheint nun die Absicht zu haben, noch diese Woche hier zu bleiben. Hoffentlich wird das Wetter doch noch etwas besser. Das Barometer steht gut - freilich ohne dass das Wetter bis jetzt dem entsprechend besser geworden wäre. Immerhin hatten wir den Nachmittag einige Sonnenblicke. In den Gasträumen wird jeden Tag geheizt.

Am Vormittag schrieb ich bei der Abwesenheit Kleiners einige Briefe, bin aber mit meinen Briefschulden noch lange nicht durch. Das gehört auch zu den Ferien, sich in solchen Pflichten grössere Musse zu gönnen.

Nach dem Nachtessen wurde heute getanzt. Marieli war eifrig dabei, hat sich auch mit aller Reserviertheit recht gut ausgemacht. Kleiner $u$. ich schauten zu.

So vergeht ein Tag um den andern. Heute hat schon die dritte Ferienwoche begonnen. Die Zeit fliegt!

\section{Den 12. August.}

Das schöne Wetter, das der Barometer auf heute angesagt hatte, ist nicht eingetreten. Zwar der Vormittag war noch recht ordentlich, nicht sonnig, aber doch Regen los. Kleiner stand spät auf, sodass ich noch an Röthlisberger um Auskunft über Kohler u. die Kochersche Operation schreiben konnte. Marieli kam unwohl herunter $\mathrm{u}$. beklagte sich über Erbrechen etc. (es hat eines der Würstchen, die es gestern im Lotto gewonnen, vor Schlafengehen gegessen). Wir wanderten alle drei nach Äsch hinunter,

von neun bis Viertel nach zehn. Der Abstieg strapazierte mich ziemlich u. ich schlug vor, statt wieder hinauf zu steigen, die 600 m., nach Unterschächen u. Urigen zu spazieren. Aber Kleiner antwortete mit einem unzufriedenen Gesicht, dass er direkt hinauf 
wolle $u$. so ging es dann von halb elf bis halb eins wieder die Balmwand aufwärts. Die Landschaft ist wunderschön, ich hatte so grosse Freude daran, dass ich die Müdigkeit vergass u. gut oben ankam. Im Gasthof war inzwischen Bericht eingetroffen, dass Siegwart u. seine Schwester Claire auf den Nachmittag heraufkommen u. richtig, sie rückten nach drei Uhr ein, begleitet von einem hübschen Pinscherchen, das ihnen von Büglen her nachgelaufen war. Sie brachten ihre Velos mit. Siegwart hat mir sehr gefallen, auch seine Schwester war lieb. Wir tranken alle fünf den Thee. Es war ein gemütliches Zusammensein. Am Nachmittag grüsste mich ein ehemaliger Student, Staatsanwalt Riggenbach aus Goldau, der als Hauptmann die Unterkunftsgelegenheiten auf der Niederalp inspizieret hatte. Die drei Jungen machten dann noch einen Spaziergang unter einem gossen Regenschirm nach der Klausenpasshöhe u. waren kreuzfidel, trotzdem es um drei zu regnen begonnen hatte u. den ganzen Abend nicht mehr zu regnen aufhörte.-

Beim Nachtessen begrüsste mich auch Dr. Franz Schmid, der eine morgige Alpversammlung zu präsidieren hat.

Der Tag war derart gefüllt, dass ich zu gar nichts anderm gekommen bin, als wie ich es Dir beschrieben. Bei dem Regen war auch nichts weiter anzufangen. Kleiner amüsierte mich $u$. sich mit seinen Tierbeobachtungen. Die beiden jungen Hotelhunde

haben zu den Alpkühen ein zu drolliges Verhältnis. Sie springen immer laut bellend auf sie los, wenn sie ihnen den Schwanz zukehren. Wendet aber die Kuh den Kopf, so fliehen sie schleunigst zurück. Ganz wie es die lauten Leute machen. Sonst schien mir Kleiner eben die Tage hier oben als Ruhetage einfach aufbrauchen zu wollen, ohne sich über die Witterung zu ärgern. Das ist der beste Teil, den wir nehmen können.

Und jetzt in dem kalten Schlafzimmer Schluss! Hoffentlich wird es Marie bald besser. Es muss sich eben etwas zusammennehmen. Es muss mit ihm doch auch zu einer gefestigteren Stimmung kommen. Der Besuch der beiden Siegwarts hat es offenbar sehr erfreut. Also ich rechne auf psychischen Einfluss. Sonst weiss ich nicht, was besser ist für es, hier aushalten, oder nach Hause fahren. 
Die Engländer sind jetzt alle verreist. Herr Klassen mit seinem Neffen von Gülgen will diese Woche noch hier bleiben. Er dirigiert alle Belustigungen. Ich sagte ihm, eine solche «Klassenherrschaft» lasse ich mir gefallen, was er schmunzelnd bestätigte.

Aber wirklich, es ist zu kalt in dem Schlafzimmer. Also Schluss! Gute, gute Nacht!

Dein allzeit treuer

Eugen

\section{2: August Nr. 170}

[1]

Klausenpass, d. 13. / 4. Aug. 1912.

Mein liebstes Herz!

Jetzt bin ich zwei Wochen hier oben $u$. habe an sechs Tagen etwas erhebliche Sonne gehabt. Aber der Aufenthalt tut mir gut. Ich sehe es daran, dass ich mich zu keiner Arbeit aufgelegt fühle. Heute schien ein schöner Tag zu werden. Beide Siegwarts, Marieli u. Kleiner wollten nach dem Urnerboden hinüber, indess ich Briefe zu schreiben hatte. Aber ich war mit diesen kaum fertig, so kehrten sie von der Passhöhe zurück, weil alles voll Nebel liege. Der Wind begann. Die Siegwarts rüsteten sich, um noch vor dem Regen nach Altdorf zu kommen. Sie fuhren nach zehn Uhr ab, um zwölf werden sie unten gewesen sein, u. um diese Zeit regnete es bereits hier oben. Telephonisch berichteten sie uns, dass sie gut angekommen. Den ganzen Tag war dann Regen, bis wir Abends sechs Uhr noch etwas die Moos hinunter spazieren konnten. Der Besuch hat mir einen wehmütigen Eindruck gemacht. Ich habe auch gar keine Anzeichen von einer Annäherung von Siegwart zu Marieli. Für meine Freihaltung dankten sie herzlich. Als ich Siegwart proponierte, in der Zeit meiner Abwesenheit, da er allein in Bern zurück sein wird, bei uns zu logieren $u$. zu essen, sagte er zu, mit dem Bemerken: «Aber ohne weitere Verpflichtung», was ich natürlich eiligst bestätigte, ohne 
zu wissen, was er eigentlich meinte. Marieli war heute recht, lieb

herzlicher als sonst. Welchem Einfluss dies zuzuschreiben, weiss ich nicht,

vielleicht auch der Einsicht, dass das alles ein Traum gewesen sei. Kleiner war sehr stumm, machte mir einige kritische Bemerkungen. Ich las ein Aufsätzchen von Rümelin, zur Rousseaufeier, das sich ausnahm, wie eine Selbstanzeige seiner drei Werke. Von Bühlmann erhielt ich einen sehr freundlichen Brief, worin er mich anfrägt, ob ich mit ihm im Auto die «Kaiser» Manöver besuchen wolle. Aber das tu ich doch nicht.

Es kommt mir heute wieder einmal so Vieles gar traurig vor. Ich hatte gedacht, ich werde an der heute hier abgehaltenen Versammlung der Alpwirtschafter etwas mit hinein kommen. Aber ich traf wohl Dr. Franz Schmid, den ehemaligen Studenten, von dem Du mir das Diktum berichtetest: Meine Augen trugen nicht. - Er war sehr nett. Dann stellte sich mir Ständerat Amstad von Beckenried vor, mit dem ich längere Zeit plauderte. Aber eine gewisse Entfremdung machte sich mir hier überall fühlbar. Und diese geht auf Siegwart zurück. So muss ich nun eben mich im Ungewissen weiter schleppen. Es ist ein Jammer, aber man muss ihn in sich verschliessen. Vielleicht wird's auch wieder besser, oder es geht zeitig vorher zu Ende. Gute Nacht, Liebe! Ich will nicht klagen, ich habe Dich ja immer bei mir!

Den 14. Aug.

Nach Sturm u. Regen in der Nacht lag heute früh Schnee auf der Balm-Alp. Wir sassen den Vormittag zusammen. Die Herren vom Alpen-Wanderkurs verliessen das Hotel um acht. Nur einige alte Herren blieben zurück, unter diesen alt Ständerat Amstad, 
mit dem ich plauderte, u. ein Gerber von Solothurn, einer der verbreiteten, im Jura s. Z. berühmten Wiedertäufer Familie der Gerber. Der redete mich an, er freue sich meine Bekanntschaft zu machen $u$. wir hatten dann fast eine Stunde lang eine rege Conversation, worin er mir seine Stellung des Bauernstandes zur Sozialdemokratie u. seine Auffassung vom Bibelglauben auseinandersetzte. Er erzählte mir, wie er zuerst als Zimmermann sein Brot verdient habe u. wie er dann zu andern Handwerken gekommen u. schliesslich als Bauer sich eine grosse Stellung errungen. Manches was er sagte, war mir nicht neu, aber der Eindruck einer Persönlichkeit wurde für mich immer bestimmter. Das ist eben doch eine häufige Erscheinung, dass der Glaube die Persönlichkeit schafft u. erhält. Ich hatte Freude an dem Mann.

Am Nachmittag konnten wir erst etwas herumsitzen u. auf der Strasse abwärts gehen, wo wir Schafherden begegneten. Marie erklärte mir, dass es ihr ganz wohl sei. Am Abend wanderten wir auf die Passhöhe u. Kleiner u. Marie gingen bis zur Klus hinunter, indess ich oben hin $u$. her spazierte. Kleiner kam auf Grund eines Briefes von Zürich zum Entschluss schon morgen zu verreisen.

Nach dem Nachtessen hatte ich Durst u. Marieli noch mehr. Es klagte darüber $u$. ich bestellte zum Abschiedstrunk ein Asti, um so mehr als Marieli sich über Durst beklagte. Aber leider kreuzte sich damit etwas anderes. Es ist morgen Maria Himmelfahrt, u. die Kinder Schillig zogen zur Messe auf den Urner Boden. Das ältere Fräulein fragte Marie, ob es auch mitwolle. Und ich meinte, das wäre ganz nett. So kam die Abrede zustande, dass Marieli morgen um

halbsieben geweckt werde, um sieben frühstücke, um halb acht abmarschiere, um auf den Mittag zurück zu sein. Und nachher war Marie tief gekränkt, trank fast keinen Asti mit, da es sonst am Morgen nicht so früh aufstehen könne u. sagte, es wäre viel lieber bei mir $u$. Kleiner geblieben. Also wieder ein Rückfall, jenes Etwas, das ich nie erfasse, eine Freudlosigkeit, vor der mir schauert. 
Wenn ich denke, wie Du Dich benommen hättest, wie Du Dich an dem guten Trunk gefreut, wie Du Dich freudig so oder anders entschieden hättest, will mich das Weh fast übermannen. Das alles alles ist verschwunden. Mich umgibt eine Freudlosigkeit, der ich nur bald zu entrinnen hoffen kann.

Gute, gute Nacht! Du verstehst mich. Mir aber wird meine Lage mit jedem neuen Erlebnis um so klarer!

In unwandelbarer Treue

Dein

Eugen

1912: August Nr. 171

[1]

Klausenpass, d. 15. Aug. 1912.

Mein liebstes Herz!

Das kalte Zimmer ist Schuld daran, dass meine Briefe von hier oben kürzer sind, als sie es sein könnten u. sollten. Heute war wieder ein gefüllter Tag. Es begann in der Morgenfrühe, als ich um halb drei durch die Hausklingel geweckt wurde, die so lange anhielt, dass das ganze Haus - mit Ausnahme glücklicherweise von Marieli - geweckt wurde. Der Veloklub von Altdorf rückte an, u. als sie den Knopf der Hausklingel drückten, ging er nicht mehr zurück, bis Hilfe kam. Ich hörte dann den Lärm der Männerstimmen, wie die Gäste in die «Halle» geführt wurden, u. später etwa 3 1/4 Uhr wie etliche ob mir Quartier bezogen. Dann vor sechs Uhr weckte mich die Tagwacht einer Clarinette, mit einem Gefühl, das ich mir selber am besten dadurch klar machte, dass ich ein Moment dachte, ich gehe doch mit Bühlmann zu den Manövern. Um halb sieben stand ich auf, war vor sieben unten, wo eben auch Kleiner eintraf, $u$. ich fand Marieli bereits bei den Kindern Schillig am Frühstück. Es war munter u. ging dann um sieben gerne mit den Gespanen davon zum Urnerboden, zur Messe in der Kapelle, wo Mariä Himmelfahrt gefeiert wurde. - Kleiner u. ich spazierten zur Passhöhe, es war ein 
heller Morgen, wenn auch mit bleicher Sonne. Kleiner hatte die Nacht noch ein Extra-Abenteuer erlebt, um zwölf öffneten der neu angekommene «Professor» der Französischen aus dem Collegium in Altdorf, der der ältesten Tochter Nachhülfsunterricht

[2]

im Französischen erteilen soll, da sie auf den Herbst in die Handelsschule von Ingenbohl eintreten soll, mit dem Küchenchef die Türe von Kleiners Zimmer, die er nicht verschlossen u. vor die er auch die Schuhe zu stellen vergessen hatte. Er fuhr aus einem Traum, wo Einbrecher einsteigen wollten, mit einem Schrei auf «Was gibt’s da!» Natürlich sofort Aufklärung. Kleiner aber verriegelte sein Zimmer u. schlief weiter. Nun wollte er noch seinen Plan ausführen u. auf das Bödnerstöckli steigen, während ich mich dafür zu müde hielt. Er trennte sich von mir unterhalb der Passhöhe u. ich sagte, ich wolle ihm mit den Augen folgen. Natürlich verlor er sich bald hinter den kleinen Anhöhen des Aufstieges. Ich ging ins Hotel, schrieb eine Karte an Albert Heim, las die N. Z. Z. u. ging dann abwärts, wo ich bald Kleiner auf den Felsen des Stöckli angekommen erblickte. Wir winkten uns zu u. ich setzte mich weiter unten auf einen Stein, u. ihn über eine Geröllhalde herabkommen zu sehen, auf der wir am Dienstag einige Alpwirtschaftler herunter steigen sahen. Es war $101 / 4 \mathrm{Uhr}$. Ich wartete $\mathrm{u}$. wartete, bis 11 Uhr. Es kam niemand daher. Ich ging ins Hotel zurück, u. in steigender Angst sagte ich dem Wirt, ich fürchte, es sei ihm etwas begegnet. Er lachte mich aus, meinte aber doch, wenn Kleiner zum Mittagessen nicht da sei, werde er nachsehen lassen. Ich ging dann weiter hin $\mathrm{u}$. her, gegen die Passhöhe. - Kein Kleiner kam. Ich überlegte, was ich seinem Sohn telegraphieren sollte u. s. w. - Da plötzlich erschien mein Freund, vom Hotel her. Er war weiter westlich hinter einem andern Felsen herunter gestiegen, den ich von meinem Standort aus nicht sehen 
konnte, befand sich, ohne von jemandem gesehen zu werden, schon um 10.40 Uhr beim Hotel, hatte mich gesucht, war bis zur Passhöhe gestiegen,

u. so kamen wir dann endlich wieder zusammen. Ich war furchtbar froh, dass er da war. Bald fuhr dann auch der Wagen Schilligs an, der die Kinder vom Urner Boden hergeholt, u. Marieli war ganz vergnügt. Die Feier in der kleinen Kapelle hatte ihm sehr gefallen u. es bereute nicht, den Weg gemacht zu haben.

Nach dem Essen rüstete Kleiner sich zur Abreise. Er mixte uns noch eine Tasse Café. Der Himmel hatte sich inzwischen wieder getrübt. Er fand einen Platz in der Drei-Uhr-Post, u. liess sich in der Banquette das Verdeck schliessen. Der Regen setzte ein $u$. so fuhr er mit einem freundlichen Abschied davon. Es war noch immer so, wenn ich mit ihm zusammen war: er hielt es höchstens neun Tage aus. - diesmal waren es acht.

Mit Marli konnte ich dann noch einen kleinen Abendspaziergang machen. Es war wieder viel Volk im Gasthof. Wir schrieben einiges u. lasen. Herr Klassen u. seine Begleiter machten Spieler. Ich sass dann noch mit Marieli in der Halle, u. bei diesem ersten alleinigen Zusammensein trat es mir näher $u$. wurde offener. Es erzählte mir, dass es an Clair eine Seite geschrieben, worin es ihr das «Du» angetragen, u. dass sie darauf mit grosser Wärme geantwortet. Ich schliesse daraus, dass es wirklich an Siegwart Freude gefasst hat. Und was nun daraus wird, das walte Gott! Ich bin auch jetzt noch zu keiner Arbeit aufgelegt, es muss noch Ferien sein, ich fühle es. Und dass das Wetter nicht besser ist, das

kümmert mich wenig. Die Hauptsache ist die Sammlung der Kräfte u. Gewinnung der richtigen Stimmung. Inzwischen halten wir weiter aus. Wenn nur das Verhältnis zu Marieli ein besseres wird! Und das hoffe ich immer wieder. 
Es wird kälter, ich muss schliessen, die Finger werden steif $u$. das Kerzenlicht flackert trübselig. Also gute, gute Nacht! Hilf uns den rechten Weg beschreiten. Es muss doch alles besser werden. Ich habe heute früh zu Kleiner über unsere Zukunft ziemlich pessimistisch gesprochen. Heute Abend sehe ich wieder mit mehr Zuversicht in die Zukunft. Hilf mir, sage ich nochmals! Verlasse nie Deinen ewig treuen Eugen

\section{2: August Nr. 172}

Klausenpass, d. 16. / 7. Aug. 1912.

Mein liebstes Herz!

Heute hatten wir zwar keinen Sonnenschein, aber auch keinen Regen, u. die Wolken zogen so hoch, dass hie u. da eine Bergspitze sichtbar wurde. Am Vormittag spazierte ich mit Marieli zur Passhöhe, nachher wurden Briefe geschrieben u. sass man herum bis zum Mittag. Nach dem Essen verabschiedeten sich Herr Klassen u. sein Neffe von Gülgen, sie wollen noch einige Tage im Urnerboden zubringen, um wo möglich die Schmetterlingssammlung zu ergänzen. Vielleicht spielt auch noch eine andere Geschichte mit, von der mir Marieli zu erzählen wusste. Die Posthalterin vom Urnerboden, ein hübsches, noch nicht 25jähriges Mädchen, sei nämlich in von Gülgen sterblich verliebt. Schon zweimal sei sie mit der halbacht Uhr Post hieher gefahren, um dann nach einer Viertelstunde gleich wieder zurück zu gehen, mit der Absicht, den Geliebten geschwind zu sehen. Das erste mal sei es ihr gelungen, das zweitemal dagegen habe Herr Schillig einerseits den jungen Herrn durch die Nichte, Seline Menoud, aufhalten lassen $u$. anderseits die Posthalterin eilig in rückfahrend Post bugsiert. Ich weiss nicht, was davon zu halten, aber so wie die Posthalterin mir geschildert wurde, scheint sie ein braves, unerfahrenes Ding zu sein, das von dem jungen «Souteur» schwer hingehalten werden 
wird. Immerhin weiss man ja nicht, wie sehr auch dieser ernsthaft sein kann. Der alte Classen gefiel mir beim Abschied sehr gut. Er

versprach, mich wenn er einmal nach Bern komme, zu besuchen.

Marieli u. ich gingen sodann nach Tisch nach Urigen hinunter, ein prächtiger Weg von anderthalb Stunden. Wir tranken im Posthaus den Café u. kehrten auch sechs Uhr in $2 \frac{1}{1} 4$ nach dem Passhotel zurück. Urigen gefiel mir. Marieli freute sich, in einem Einfang drei Murmeltiere zu sehen $u$. von Unterschächen herauf ein Alphorn zu hören. Selten schön ist der Blick von der Strasse ins Brunnital u. auf Unterschächen hinunter. Aber auch die Aussicht auf Äsch u. die wechselnden Aspekte des Tals sind von entzückender Schönheit. Ich musste immer wieder denken, weshalb bin ich nie mit Dir über den Klausen, um dies zu geniessen mit Dir zusammen. Aber es sprachen so manche Gründe dagegen u. so unterblieb die Tour, die uns sicher grosse Freude gemacht hätte.

Auf dem Rückweg begegnete uns Hr. Schillig, der im Wagen den Portier ins Krankenhaus nach Altdorf führte. Die naive Natur des Jungen, der ein blondes Baiernkind aus Landshut ist, hat mir immer einen guten Eindruck gemacht, er war fast zu täpisch, aber sehr diensteifrig. In der Nacht, wo die Altdorfer Velocipedisten anrückten, muss er sich erkältet haben. Es brach eine heftige Halsentzündung aus, die vielleicht diphteristischen Charakter hat. Das beste war, ihn ins Krankenhaus zu bringen. Übermässig streng war sein Dienst in letzter Zeit nicht, aber der kalten Witterung hat er nicht mit der nötigen Vorsicht begegnet.

Nach dem Nachtessen wurden in der «Halle» wieder Spieler gemacht. Ein Heer, Engländer-Schotten, waren jetzt die leitenden, 
sie sind in hier am Abschluss einer Reise um die Welt.

Marieli erzählte mir heute, dass es am Tag der Rückfahrt der Geschwister Siegwart noch an Clair eine Karte geschickt, worin es ihr das «Du» angeboten. Der Brief Claires acceptierte das mit freundlichen Worten. Aber, ich weiss nicht! Nun, wir wollen sehen, wie die Berichte Siegwarts weiter lauten. Von der Post ist heute nichts gekommen.

Nun jetzt zu Bett, es ist kalt. Gute, gute Nacht!

\section{Den 17. Aug.}

Heute hatten wir wieder einmal einen schönen Tag. Sonnenschein von früh bis spät $u$. dazu steigende Wolken, die wundersame Beleuchtungen schufen. Ich war aber sehr müde. Am Vormittag schrieb ich etwas u. sass dann herum, am Nachmittag gingen Marieli u. ich auf die Kammlialp, am Fuss des Schaerhorngletschers. Die Landschaft ist ausserordentlich schön, hoch alpin. In der kleinen Alphütte trafen wir drei Männer, eine Frau u. sieben allerliebste Kinder, die mir viel Freude machten. Wir tranken den Café u. wanderten langsam wieder dem Passe zu. Hier stiessen wir auf einen Knaben mit Rucksack, der uns sagte, er komme vom Muttensee, sei gestern über den Kistenpass u. wolle heute noch nach Bürgeln, wo er Verwandte habe. - Zwei Sängervereine kamen heute vorbei, einer Männerchor aus Buchs u. Abends ein solcher aus St. Gallen, der zum Abschied ein Lied vortrug. Sonst ist das Haus heute merkwürdiger Weise gar nicht überfüllt, während heute vor acht Tagen trotz schlimmsten Regenwetters alles voll war.

Anna berichtet uns, dass Siegwart also bei uns logieren wird, bis wir zurück sind. Mag es zum Segen sein, so oder anders. Sonst 
sind keine besondern Nachrichten eingetroffen, nur wird es sich jetzt doch so entscheiden, dass ich nicht mit Bühlmann an die Manöver fahren werde. Denn er schreibt mir, dass Oberst Will mit sein würde, u. da hat die Sache für mich ohnedies einen andern Charakter. Warten wir die weitere Antwort ab.

Heute Abend hörte ich mit Marieli wieder einmal den Alpsegen. Nachher waren wieder Spieler im Gange, diesmal ohne Engländer. Merkwürdig, wie die halbwüchsigen Mädchen so anzügliche Reden im Munde führen. Aber es ist naiv.

Und damit sei auch diese, die dritte Ferienwoche abgeschlossen. Gute, gute Nacht! Hilf mir, mag kommen was da will! Dein allzeit treuer

Eugen

\section{2: August Nr. 173}

Klausenpass, den 18. Aug. 1912.

Meine liebe gute Lina!

Auch heute war ein warmer, schöner Tag, bei dem viel Volk vorüberzog. Unter der Masse ein Bekannter: Schätti, der Helveter, mit dem wir vor etwa fünf Jahren einmal bei BR Müller zum Essen zusammen waren. Er kam herzlich zu mir. Von Zürich aus, wo er bei E. Curti als Fürsprech tätig ist, machte er einen Ausflug mit seinem Vater. Die Ferien hatte er mit seiner Frau u. einem 1 1 $2 / 2$ jährigen Kind anderswo verbracht, war aber wegen des schlechten Wetter früher heimgekehrt. Sein Vater erzählte mir das, mit dem Beifügen, dass er zur Besserung der Stimmung des Sohnes ihn aufgefordert habe, mit ihm über den Klausen $u$. ins Tellspiel nach Altdorf zu gehen. Es scheinen beide so brave Leute zu sein. 
Am Morgen spazierte ich später mit Marieli zur Passhöhe u. es ging nach abwärts bis zur zweiten Kehre, während ich auf dem Übergang blieb, wo ein abstinenter Turnverein aus Zürich sich gelagert hatte. Als diese wieder aufbrechen wollte, fehlten noch einige Mann, die nach Alpenrosen u. Edelweiss gegangen waren. Zuletzt sah ich noch einen hoch oben an den Hängen des Märcherstöckli. Der suchte über steile Grasbänder den direkten Abweg zu machen, aber die Bänder endeten in Felsabstürze, u. als ein grosser Stein sich unter seinen Füssen loslöste u. über ein paar Absätze kollerte, glaubte ich schon, es sei der Mann, der gestürzt. Aber der stand noch oben,

fand ein Kamin im Felsen u. kletterte richtig dieses hinunter. Er war ein schlanker, schwarzer Kerl, der dann richtig zuletzt auf die Strasse kam u. mir das Edelweiss zeigte, das er an jenen Hängen gefunden. - Unter diesen Turnern ging einer mit nacktem Oberkörper: Früchte der Abstinenz?

Zugleich mit diesem Verein, der mit Trommelschlag Altdorf zuzog, waren drei Pärchen oben. Das heisst, ein Mann fehlte, er war mit einem 15 jährigen Jungen in die Alpenrosen von der Strasse südwärts abgewichen u. nun wollte er nicht mehr erscheinen. Seine Frau irrte auf u. ab, während die andern dem Gasthof zuzogen. Es war eine ernste blonde Frau, ganz schwarz gekleidet, die immer mehr sich ängstigte, zu weinen begann, «Jakob, Jakob» in die Hänge hinauf rief, aber er erschien nicht. Ich suchte sie zu trösten, es sei dort keine Gefahr, aber Viertelstunde um Viertelstunde verstrich, ohne dass Jakob kam. Endlich, endlich erschienen die Beiden weit oben über dem Weg nach Kammlialp. Der Zurückgekehrte war taktvoll genug, der Frau keine Grobheiten zu machen, aber für diese war jedenfalls die Freude an diesem Ausflug verdorben. Wir sahen dann die drei Pärchen im Schatten eines Bruckwagens beim Gasthof Rast halten. Es scheinen Handwerksleute zu sein.

Am Nachmittag stieg Marieli allein gegen das Stöckli hinan, indess ich las u. rauchte. Die Post brachte dann einen Bericht von Bühlmann, worin er sich freut über meine Zusage, an die Manöver mitzugehen. Es ist damit entschieden, dass ich 
diesen Ausflug mitmachen werde. Dann ein freundliches Billet von Kohler, dem ich durch meine gestrige Gratulation glücklicherweise zuvorgekommen bin. Und neben den Zeitungen noch einen Brief von Kleiner, sehr herzlich, $\mathrm{u}$. leider eine Absage von Albert, er kann nicht herkommen.

Mit diesen Berichten ist nun mein weiterer Ferienplan einigermassen fixiert. Heute zum ersten Mal fühlte ich etwas wie Genüge. Man darf also an die Heimkehr denken. Vielleicht bleibe ich noch die ganze Woche. Aber dann wird es für Marieli u. mich genug sein. Ich komme in hier wirklich zu keiner Arbeit. Bei gutem Wetter ist man der Unruhe des Passgetriebes, bei schlechtem ist es auf dem Zimmer zu kalt. Heute las ich Hecks Abhandlung über Rechtsgewinnung nochmals fertig, u. ich empfand eine Art Moralischen, dass ich über diese Probleme die Litteratur so wenig beherrsche. Ich empfand auch Gewissensbisse, dass ich die Korrekturen nicht erledigt. Aber anderseits musste ich mir sagen, Kleiner hat recht, wenn er in seinem heutigen Brief bemerkt, mein System, ein paar Wochen radical zu faulenzen, imponiere ihm immer mehr. Es sei doch das richtige, sich derart auszuspannen, um nachher wieder in voller Energie zu arbeiten. So will ich also nicht selber mein System bereuen, wenn es von so besonnener Seite, wie Kleiner Anerkennung findet. Und ich bleibe vorläufig ohne Reue.

Heute haben wir wieder ein volles Haus. Aber es ist nicht

lärmig, es sind nette Gäste. Wie das Wetter morgen sein wird, ist ungewiss. Der Föhn scheint wieder kommen zu wollen. 
Gute Nacht, mein Lieb, gute Nacht. Mit Marieli bin ich auch heute recht zufrieden, es hat seinen Gedanken, früher nach Hause zu reisen, doch vernünftig controlliert u. geht mit mir einig. Hilf Du ihm, wie mir!

Dein ewig getreuer

\section{Eugen}

\section{2: August Nr. 174}

Klausenpass, d. 19. / 20. Aug. 1912.

Mein liebstes Herz!

Die vergangene Nacht haben einige Franzosen, die über uns logierten, das ganze Haus in Unruhe versetzt. Sie wollten in der Morgenfrüh auf den Griessstock, liessen um drei den Wecker rasseln, stampften eine Stunde lang in Bergschuhen herum. Als sie endlich um 5 Uhr weg waren, kamen Velozipedisten aus Wassried, die gestern hier angerückt, an die Reihe mit lauten Rufen u. Signalen auf der Strasse, so dass auch der Nachschlaf gestört war. Ich stand zeitig auf, schrieb einige Briefe, hatte dann das Malheur, dass mein Füllfederhalter brach. Ein Versuch ihn zu reparieren, misslang gründlich. Ich bat Anna, mir den andern zu schicken, u. es ärgert mich, dass ich schon wieder eine Reparatur habe. Heute u. morgen werde ich mit Marielis breiter Feder schreiben müssen, wie aus diesen Zeilen schon zu ersehen ist.

Von Morgen bis Abend hatten wir heftigen Föhn. Aber wir waren doch munter. Ich ging mit Marieli den alten Saumpfad zur Passhöhe u. die Strasse zurück. Der Wind war bald warm, bald kalt. Der Plan hat sich jetzt geklärt, dass ich am Montag von hier verreisen werde. Oder wenigstens Marieli geht zu Siegwarts u. ich hole es dort zur Heimreise ab, ein paar Tage später. Wie es am besten zu machen ist, hängt von Siegwarts Verhältnissen ab. Siegwart der Sohn ist jetzt in Bern mein Gast. Aber dennoch mag ich nicht bei seinen Eltern logieren. Was ist hier das beste? Der Brief S.s aus Bern, 
den ich heute erhalten, trägt auch keine Spur von Nähertreten. Es ist möglich, dass Siegwart in diesem Verhältnis einfach fortsetzen will u. sich gar nichts weiter vornimmt. Das wäre mir ja auch recht, aber wenn ich nur Bescheid wüsste. Solche hängenden Sachen reizen mehr als nötig meine Ungeduld.

Von Reitschel erhielt ich eine sehr herzliche Karte aus Reuti. Er schreibt, dass auch er von Rümelin keine Antwort bekomme, u. meint, am Ende sei R. gar nicht in Mürren, infolge irgend eines Hindernisses. Warten wir ab, was weiter erfolgt.

Heute war ich mit einer Schachaufgabe u. mit dem Versuch der Reparatur des Füllfederhalters in jener Dir bekannten dumm ausdauernden Versessenheit so in Anspruch genommen, dass ich mir keine Gedanken machen konnte über das was ich eigentlich tun sollte. Erst jetzt, am Abend, stelle ich mir vor, es wäre an der Zeit, endlich sich wieder auf die Pflichten zu besinnen. Das wird nun so auf u. ab gehen, bis der entscheidende Zug geschieht. Wie war es letztes Jahr? Nach dem Gotthard war ich Morschach, zwei Wochen später in Heidelberg u. dann in Jena $u$. in Stuttgart $u$. Tübingen. Heuer werden solche Reisen nicht geplant. Freilich sollte die Arbeit eigentlich um so mehr sich aufdrängen. Es ist ja wieder ein Jahr später. Aber manchmal beschleicht mich die Sorge, dass überhaupt meine Leistungskraft abgenommen habe. Ich habe ja freilich immer in solcher Weise gelebt, dass ich längere Zeit mich nicht ans Geschirr brachte u. dann mit einem Mal alle überholte. Allein wäre es nicht möglich, dass ersteres geblieben wäre, ohne von letzterem mehr corrigiert zu werden? Die Zufriedenheit mit dem Kolleglesen könnte mir da einen bösen Streich spielen! Ich will solches 
nicht denken, dass ich es aber doch ins Auge fasse, zeigt Dir, wie die Ferienstimmung allmählich zu weichen beginnt. Mit heute hat ja auch schon die vierte Ferienwoche begonnen!

Den 20. Aug.

Heute Nacht war ein ausserordentlich heftiger Sturm. Ich war mit Zahn- oder Gesichtsschmerzen auf der linken Seite eingeschlafen. Als der Sturm mich weckte, waren sie verschwunden, dafür aber bedeutend heftiger auf der rechten Seite aufgetreten. Ich kam auf die Idee, mir die rechte Wange u. Schläfe zu massieren. Anfang steigerten sich die Schmerzen, aber dann als ich gleichwohl fortsetzte, nahmen sie rasch ab, ich schlief wieder ein, u. als ich erwachte, am Morgen waren sie weg. Wie bin ich froh gewesen. Ich dachte an Deine Zahnschmerzen auf dem Rigi. Hätten wir sie damals nicht auch so vertreiben können, anstatt Dich nach Viznau zu dem ungeschickten Zahnarzt gehen zu heissen? Ich stelle mir manchmal vor, ich werde alle die Schmerzen, die Du getragen, auch noch durchmachen müssen, u. dachte in der Nacht, das sei wieder ein Stück des Ausgleiches $u$. ich soll es geduldig tragen. Aber, wie gesagt, diesmal verliessen mich die Schmerzen rasch.

Der heutige Tag war Nebel u. Regen u. Regen u. Nebel. Ich benutzte die Gelegenheit, um nun doch mit der Korrektur zu beginnen. Marieli las mir vor $u$. wir erledigten etwa die Hälfte. Es ging ganz gut. Nachher, in einem regenfreien Moment spazierten wir Strasse abwärts. Da zeigte sich an der fernen Felsenecke - ein Automobil, das sich ausserordentlich rasch heran pustete. Ich vermutete, ein Militärautomobil, da die Strasse von Unterschächen bis Urner Boden für den Autoverkehr gesperrt ist. Ich glaubte auch beim Herannahen Oberst Isler zu erkennen. Aber als sie beim Hotel anhielten, wer stieg aus? Prof. Weyermann 
u. seine Frau u. ein feiner älterer Italiener, Ingenieur aus Mailand, ihr Freund. Sie waren von Weggis hergekommen u. sagten, sie hätten gelesen, der Pass sei den Autos geöffnet. Zufällig war ein Polizist in Civil da, der gleich intervenierte. Die Herren mussten $100 \mathrm{Fr}$. deponieren. Auf telephonische Anfrage beim Polizeidirektor, Nationalrat Furrer, wurde, indem sich Schillig auf meine Bekanntschaft mit den Bussfälligen berief, gestattet, den Weg gleich fortzusetzen. Nach dem Essen taten sie so. Die Frau hat Marieli gefallen. Es war ein fast komisches Intemezzo.

Die Post brachte viele Briefe. Sie u. die Zeitungen nahmen den Nachmittag in Anspruch. Gegen Abend konnten wir im Nebel, aber ohne Regen noch einen stündigen Gang machen, der wohltat. Interessantes Volk ist den Nachmittag zahlreich angekommen. Diesmal überwogen die Süddeutschen, nette, bescheidene Leute.

Frau Schillig ist in Altdorf, eigentlich sollte er nun um so mehr des Geschäftes sich annehmen. Aber er anerbot sich, mit dem Auto nach Urner Boden mitzufahren, damit ihnen keine weitern Schwierigkeiten begegnen. Und zurückkehren will er erst mit der Abendpost.

Auch heute stehe ich wieder unter dem Eindruck: Es wird genug. Kann ich nur noch ein wenig hier oben arbeiten, so ist ja der Aufenthalt schon noch einige Tage wert. Aber nicht mehr lange. Rümelin schreibt, dass ich ihn, u. zwar ihn allein auf den 7. Sept. etwa erwarten könne. Also schliesst sich das eine an das andere bis zur Hälfte der Ferien!

Gute, gute Nacht! Ich will hoffen, dass der Winter um so besser an uns vorüber gehe, $\mathrm{u}$. damit mich trösten.

Innigst bin ich Dein allzeit getreuer Eugen 
Klausenpass, d. 21./2. Aug. 1912.

Mein liebstes Herz!

Die letzte Nacht überfielen mich die Gesichtsschmerzen, die mir schon einige Mal gedroht hatten, mit einer Heftigkeit, dass ich bis gegen fünf Uhr nicht recht schlafen konnte. Alles Massieren, u. auch kalte Überschläge nutzten nichts, ja sie steigerten die Schmerzen, dass vom Ohr bis zu den Schläfen u. zum Kiefer das blosse Berühren mir weh tat. Dabei waren die Zähne beim Beklopfen unempfindlich, so dass die Geschichte also nicht von Zahnschmerzen herkommen konnte. Ich überlegte mir, ob ich nicht sofort heute heimreisen sollte. Beim Erwachen am Morgen war jedoch die Attaque der Hauptsache nach vorüber. Ich spürte über Tag nur ein paar Mal eine Erneuerung der Empfindlichkeit, wenn ich im Nebel spazierte. Hoffentlich lässt mich die Sache heute Nacht in Ruhe.

Der heutige Tag war unfreundlich, Nebel u. Regen, kalt, aber doch dann u. wann ein Moment von Sonnenschein. Die starke Ansammlung von Touristen verlief sich am Vormittag, sodass Marieli u. ich beim Mittagstisch mit dem Collegiumsprofessor Schneider u. einem Altdorfer Spirituosen Händler fast allein waren. Erst gegen Abend sammelte sich wieder einiges Volk u. zwar, wie schon gestern, namentlich Deutsche.

Ich konnte am Vormittag die Korrektur fertig lesen mit Marieli. Dann sah ich noch die Korrekturen Siegwarts nach, u. sandte die Bogen an Wyss. Es ist mir eine Last vom Herzen, dass wenigstens dies jetzt besorgt ist. Am Nachmittag brachte die Post meine Berner Federhalter u. zugleich Birnen u. Trauben, die 
uns gut schmeckten, die wir aber eilig vertilgen müssen, wenn wir am Montag verreisen wollen. Marieli fühlte sich heute Nachmittag, wie schon gestern Abend, im Magen gar nicht wohl. Es war auch infolge dessen nicht gerade gut in der Gesellschaft, aber es nahm sich zusammen.

Von den Korrekturen hat es gar nichts gehabt, wenn es von mir auch eine Erklärung des Ausdrucks Kategorischer Imperativ haben wollte. In dem Gegensatz zwischen Individualismus u. Kollektivismus meinte es auf dem Spaziergang, es sei ganz Individualistin, im Gegensatz zu mir. Das gab u. gibt mir zu denken, umso mehr als das stimmen wird.

Frau Schillig war seit Montag abwesend, was sich darin zeigte, dass die Führung der Wirtschaft sich etwas unbeholfen erwies, u. überdies der Mann etwas viel der lustigen Jassgesellschaft nach ging. Der Liquerhändler soll letzte Nacht ganz betrunken gewesen sein u. um zwei Uhr in den Gängen herumgehend nach seiner Frau (in Altdorf) gerufen haben. Vielleicht ists auch anders. Mit der Rückkehr der Frau Schillig, heute Abend, wurde der Ton wieder besser. Es war nett, wie alle Kinder ihr entgegeneilten, u. der Koch ein Paar Böllerschüsse abbrannte. Sie ist die Seele des Hauses.

Über das Automobil von gestern sei heute noch viel gesprochen worden, hiess es. Die Post habe reklamiert u. es ergeben sich vielleicht noch weitere Folgen. Von dem Begleiter Weyermanns, Castellini, hatte Marieli keinen guten Eindruck. Es meint, er habe Weyermann absichtlich hineingelegt. Merkwürdig war, dass die junge Frau sich wesentlich mit dem ital.

Hausfreund abgab. Sie machte uns eher den Eindruck einer Romanin als einer Deutschen, gefiel uns aber doch wohl.

Von Haenny habe ich heute einen lieben Brief bekommen, mit einem formlosen Gedicht, das merkwürdig krause Gedanken ent- 
wickelt. Haenny ist ein gährendes Element, das sich vielleicht zu einer gewissen Genialität durcharbeitet. Wie hoch ich ihn schätze, weisst Du.

Ich will in dem kalten Zimmer nicht länger aufbleiben. Vielleicht ists morgen besser. Es ist auch im übrigen am heutigen Tage nicht viel passiert.

Den 22. Aug.

Ich ging gestern bei bester Stimmung vor zehn zu Bett u. schlief bis halb fünf. Da erwachte ich u. hatte einen Brummschädel, als ob ich einen Rausch gehabt hätte. Richtiger Kater, Brechreiz, u. wenn ich auch wieder einschlief, wurde es doch nicht besser, den ganzen Vormittag war ich unwohl, höchst ungemütlich. Getrunken hatte ich nichts, es muss von Trauben gewesen sein, die ich vor Schlafengehen gegessen. Marieli war es gestern Abend schon sehr übel gewesen. Heute Vormittag fühlte es sich ganz wohl, aber Nachmittags stellten sich wieder Magenschmerzen ein. Vielleicht sind wir gestern Abend vor sieben auch etwas zu schnell in dem Nebel zur Passhöhe hinauf u. zurück gelaufen.

Heute war es kalt, kein Regen, aber auch keine Sonne. Im ganzen ist es jetzt deutlich für uns beide, dass wir hier lange genug gewesen. Es wird Zeit zur Heimkehr, sonst könnte die Gesundheit dann doch mehr gestört werden, als es sich mit der allgemeinen Blut- u. Nervenstärkung in der Höhenluft verträgt. Zum ersten Mal hier oben fühlte Marieli heute Vormittag etwas Lungenstiche. Hoffentlich geht noch alles gut vorüber.

Ich schrieb heute einige Briefe, namentlich an Rümelin. Sonst plauderte ich viel mit dem Collegiumsprofessor Schnyder, der

mir in seinem Eifer u. seiner beruflichen Tüchtigkeit einen immer bessern Eindruck macht. Angenehm empfindet man heute im Hause auch wieder, dass die Frau wieder da ist.

Es kamen heute wenig Gäste vorbei. Marieli machte bei seinem Vormittagsspaziergang die Bekanntschaft eines Ulmer Arztes Dr. Fischer, der es von der Passhöhe herab begleitete. Am Nachmittag plauderte ich etwas mit einem Berner in meinem Alter, der sich schliesslich als Humbert an der Kantonalbank vorstellte. 
Ich sage, es wird Zeit zu gehen. Alles beginnt herbstlichen Anstrich zu bekommen, mehrere Wochen früher als sonst. Es ist so kalt, die Kühe brüllen oft auf der Weide. Die Freudigkeit des Alpenlebens ist verschwunden. Und doch sind die Ausblicke, die bald so bald anders in den Wolken sich gestalten, oft von wunderbarer Schönheit. So war es beispielsweise mit dem Blick auf die Balmwand u. den Kammlitritt heut Abend, als ich mit Marieli die Strasse abwärts spazierte. Aber es wäre natürlich alles noch viel wirkungsvoller gewesen, wenn wir auch nur einigermassen günstiges Wetter gehabt hätten. Freilich im Tal muss es nicht viel besser gewesen sein, überall.

Ich schreibe diese Zeilen vor dem Nachtessen, denn nachher mag ich nicht länger im kalten Zimmer sitzen $u$. werde, wenn es nichts mehr anzufügen gibt, gleich zu Bette gehen.

Gute, gute Nacht! Ich bin im Treuen immerdar

Dein Eugen

\section{2: August Nr. 176}

Klausenpass, d. 23. / 4. Aug. 1912.

Mein liebstes Herz!

Nach einer ruhsamen Nacht fand ich heute zum zweiten Mal bis auf $1700 \mathrm{~m}$ die ganze Alp mit Schnee bedeckt. Schillig hatte auf heute einen Ausflug mit seiner Familie nach Braunwald festgelegt $u$. Marieli sollte mit, wozu es sich eigentlich schwer entschlossen hätte. Um sechs sollte geklopft werden. Aber natürlich wurde jetzt nicht geklopft, u. Marieli wie ich kamen erst um halbneun zum Frühstück. Die andern Gäste, die sich nicht früh auf den Weg machen wollten, noch später.

Ich schrieb dann den längst geplanten Brief an Ida u. anderes. Dann aber, wie ich mit Marieli in der Gaststube plauderte, setzte sich ein Gast, der gestern mit seiner Frau angekommen war, ans Klavier $u$. begann wunderschön zu spielen. Das war dann ein Anknüpfungspunkt, 
u. es stellte sich heraus, dass es ein Med. Dr. Hoffmann aus Roggwil war, seine Frau eine Zürcherin. Er war erfreut, mich kennen zu lernen, u. wir plauderten über das Recht der Unehelichen u. s. w. Plötzlich fragte er mich dann, ob ich Determinist sei. Das war der Anfang einer lebhaften Auseinandersetzung. Bei der er sich erst als Materialist bekannte, dann aber einlenkte. Es ging bis zum Mittagessen. Nachher waren andere Gäste da. Gegen vier verliessen die Doktorsleute das Haus Urigen wärts. Nach ihrem Weggang kam ein anderes Paar, das nur einen kurzen Imbiss nahm. Aber - oh Duplizität der Fälle! - Der Mann setzte sich auch ans Klavier u. spielte sehr schön, wenn auch lange nicht so fein wie der Doktor.

Sonst ist von dem heutigen Tag nicht viel zu sagen. Marieli ist munter, spaziert auch trotz Schnee u. Nebel, ohne dass es ihm schadet. Ich begnügte mich heute mit einem 5 / 4 stündigen Spaziergang auf der Strasse, wo ich den Senn Joder antraf u. mit ihm über das „[Abc-?]», «zBode [?]», «Zstöss[?]» U. a. sprach. Nach Tisch interessierte mich auch

ein Schäfer, der einen Kaffee trank u. erzählte, dass er jetzt gehe, seine Schafe oben in den Geröllhalden aus dem Schnee zusammen zu suchen. Eine sehr alte, aber noch grad auf marschierende Frau kam auch, die von einem Leichenbegräbnis zum Urner Boden zurückkehrte. Sie meinte, als ich sagte, es sei ein nasser Weg, sie seien es eben gewohnt. Die Leute machen mir hier alle den Eindruck energischen Charakters. Das hat überall Rasse.

Schillig ist manchmal mit seinen Kindern sehr heftig, u. spricht auch von seiner Frau nicht immer nett. Und doch finde ich immer wieder bestätigt, dass sie die Seele des Hauses ist. Schillig meint etwa, er müsse mir gegenüber ein freisinniges Poltern zeigen. Natürlich ist die Wirkung gerade die gegenteilige, als die er im Auge hat.

Heute Abend sind noch einige Herren, Deutsche u. Schweizer, gekommen, mit dem Plan, morgen früh über die Kammlilücke nach dem Maderanertal zu gehen, trotz allem Schnee u. Unwetter. Der Führer Adelrich Arnold von Unterschächen wurde hertelephoniert u. kam auf zehn Uhr. Ich lernte den Mann, von dem hier viel erzählt wird, gerne kennen $u$. habe noch ein paar Worte mit ihm gesprochen. Er machte mir einen vortrefflichen Eindruck, ganz Zuverlässigkeit. Er meinte aber, bei dem Wetter werde jener Plan wohl unausge- 
führt bleiben, es sei wegen der Lawinen zu gefährlich. Nachher sprach er mit den Herren. Was nun ausgemacht wird, werden wir morgen hören. Ich erzählte Dir glaub ich schon von dem andern Führer, der vor zwei Wochen mit einem französischen Ehepaar hier war, Julen aus Zermatt. Ein ganz andrer Typ, der seine Führertätigkeit weit mehr als Geschäft an die Hand zu nehmen schien. Kleiners u. ich sprachen damals mit ihm. Arnold hat eben sein eigenes Heimwesen $u$. eine kleine Wirtschaft, er soll eine sehr tüchtige Frau haben u. mehr als zehn Kinder. Was er als Führer unternimmt, macht er nebenbei u. natürlich mit ganz anderm Geist, als bei jenem, der übrigens auch sehr tüchtig sein mag.

Den 24. Aug.

Heute überraschte uns am Morgen ein glänzender Himmel. Die drei Touristen, die sich gestern bei dem regnerisch-kalten Abend den Führer Adelrich kommen liessen, traten frohgemut um sieben die Tour nach der Kammlilücke an. Die Sonne schien prächtig, bis gegen Abend wieder eine kleine Trübung eintrat, die mir zu sagen scheint, dass es morgen nicht mehr so schön sein werde. Marieli u. ich konnten dann am Morgen doch noch den längst geplanten Gang auf das Bödenerstöckli unternehmen u. der Weg, wie die Aussicht von dieser natürlichen «Schlossruine» hat uns viel Freude gemacht. Den Nachmittag blieben wir zunächst in der Nähe des Hotels. Gäste kamen u. gingen, unter anderen ein Fräulein Schleicher aus Stuttgart, eine alte Dame, die wir als «Wetterhexe» bezeichneten, die das gute Wetter gebracht habe. Ich sprach einige Worte mit ihr, da ich dachte, sie könnte vielleicht Ida oder Frl. Mildenmuth kennen, was aber nicht der Fall war. Dabei sagte sie dann, zu meiner Überraschung selbst, sie bringe überall, wo sie hinkomme, schönes Wetter mit. Mit der drei UhrPost fuhr sie nach Linthal zurück. Die Post brachte den erwarteten Brief von Claire nicht, $u$. wir spazierten dann zusammen ziemlich missmutig auf die Passhöhe. Da wurde uns wieder besser. Auf dem Weg begegneten wir der alten, jedenfalls mehr als siebzig jährigen Frau wieder, die gestern oder vorgestern in Trauer hier passiert u. eine Suppe gegessen hatte. Ich sprach sie an $u$. 
sie sagte, sie komme vom «Gedächtnis» ihres Mannes, der vor dreissig Tagen 86 jährig gestorben. Die Art, wie die Frau davon sprach, war rührend. Ich hatte eine innere Freude an ihrem ernsten, gediegenem Wesen, eine wackere Frau, die noch immer einer grossen Familie vorsteht, aber sich auch nicht mehr gesund fühlt.

Sie sei fast nicht mehr die Klus hinauf gekommen vom Urner Boden. Dabei hat sie aber doch bis nach Hause noch einen Weg von wenigstens fünf Stunden gemacht. Übrigens auch die alte Stuttgarterin hatte hier ihre Gebresten. Sie erzählte den Saaljungfern, diese Nacht habe sie Herzklopfen gehabt, u. da sie gedacht, sie könnte sterben, sei sie aufgestanden $u$. habe Briefe geschrieben, damit man doch wüsste, woher sie sei u. an wen man Bericht geben müsse. Und dabei war sie so fröhlich u. meinte, überall wo sie hinkomme, habe man sie gerne $u$. heisse sie wiederkommen.

Um halb acht kam dann der erwartete Brief Claires, ziemlich kühl, aber recht. Wir reisen also Montags um acht, in einem Einspänner, u. ich kann hoffen, um acht Uhr Abend zu Hause zu sein. Schillig wollte, dass Marieli noch die Tour, die er mit seinen Kindern u. den Menouds auf morgen (trotz Sonntag!) vor hat, mit mache. Er meinte auch, Frau Menoud werde mit ihrer Tochter Seline am Montag mit uns nach Altdorf fahren. Aber ich hätte wünschen müssen, dass doch früh weggefahren werde, $u$. so ist auch dieser Plan glücklicherweise gescheitert.

Nach dem Essen hatten Marieli u. ich noch eine sehr nette Unterhaltung mit dem Collegiumsprofessor Schnyder. Er ist ein sehr gebildeter Philologe, der mir einen recht guten Eindruck gemacht hat. Auf diese Weise ist der sonnenhelle Tag gut abgeschlossen worden.

Wenn nur Marieli nicht wieder zu serbeln beginnt. Aber es ist so schwer, ohne zu raten. Doch davon ein andermal. Hilf mir, mein Herz, in allem Schweren! Ich will ja das rechte, sollte ich dazu ungeschickt sein?

Gute, gute Nacht, meine liebe Seele!

Dein ewig getreuer

Eugen 
Klausenpass, den 25. Aug. 1912.

Mein liebstes Herz!

Der letzte Tag auf der Klausenpasshöhe ist vorüber, das sind die letzten Zeilen, die ich von hier oben aus Abends beim Kerzenstümpchen an Dich schreibe. Der Tag begann mit Regen, sodass der Ausflug der Schilligs nach Braunwald nicht angetreten wurde. Dann aber schon nach acht Uhr kam die Sonne u. es wurde ein heller schöner Bergsommertag. Am Vormittag packten Marieli u. ich unsere Siebensachen. Am Nachmittag warteten wir die Post ab u. freuten uns an den, zwar gar nicht zahlreichen Touristen. Unter diesen waren sieben deutsche junge Leute, wohl Studenten, die allerliebst auftraten, enthusiastisch sangen $u$. sich mit den Mädchen vom Hause anständig amüsierten. Frau Schillig u. Seline Menoud taten das Mögliche, sie fest zu halten. Sie photographierten die Hotelfamilie, zogen aber mit Sang u. Klang weiter nach Unterschächen, wo sie Quartier bestellt hatten. Die Post brachte unerwarteter Weise noch Sendungen aus Bern, darunter eine wichtige Anfrage, die ich heute Abend gleich beantwortet habe. Nach vier Uhr spazierten Marieli u. ich das letzte Mal nach der Passhöhe u. der Weg war so schön, dass wir weiter gingen bis zur Klus, bei wunderbar schöner Aussicht auf den Urner Boden u. auf die Clariden. Gegen halb sieben

waren wir wieder zurück. Marieli, das vorher immer über Kälte geklagt hatte, lief sich dabei warm, u. mir war es eine weihevolle Freude, doch noch einmal diese schöne Gegend in ihrem vollen Glanze sehen zu dürfen. 
Im Ganzen kann ich, wie ich glaube, mit dem Aufenthalt auf dem Klausen zufrieden sein. Und auch Marieli sieht besser aus u. hat die Luft, trotz kleinen Störungen, die bei ihr, wie ja auch bei mir, eingetreten, gut vertragen. Wir fahren morgen vor acht Uhr ab. Ich bin gespannt auf den Besuch bei Siegwarts Eltern u. bei Bundesrichter Schmid. Ob auf das Verhältnis zu Alfred Siegwart angespielt werden wird? Ich bin jetzt der Ansicht, dass eine nähere Beziehung zu Marieli nicht vorliegt $u$. dass es ein Fehler war, auch nur die geringste Annäherung zu gestatten. Aber warten wir das Weitre ab. Mit den Helvetern will Marieli nächsten Winter, so wie jetzt seine Stimmung ist, nicht weiter verkehren, also im Herbst die zu gewärtigende Einladung ablehnen. Aber es können ja noch allerlei Zwischenfälle kommen.

Wenn nur nicht so schlimm, wie letztes Jahr!

Ich bin jetzt 27 Tage hier oben gewesen, $u$. von diesen waren neun ganz oder doch, wie heute, vorzugsweise sonnig. Natürlich hätte mehr Sonne wohl getan. Aber es hat anderseits zur Ruhe beigetragen, dass die Witterung nicht allzu grossen Umtrieb gestattete. Die Lage ist wunderschön u. das Haus gut gehalten. Den Wirt Schillig habe ich erst die letzten Tage kennen gelernt. Er ist sehr regsam,

aber er hat wenig Ernst u. kann schlechte u. gute Witze nicht unterscheiden, beide sich nicht versagen. Was mir an ihm am meisten missfallen hat, das ist, dass er auf seine Frau Bemerkungen macht, die sie verletzen müssen. Und doch verdankt er ihr die gute Führung des Gasthofs. Daneben ist sie oft zu sehr Wirtsfrau, spielt Tänze, damit die jungen Leute sich amüsieren, u. sogar das «Solise» habe ich nochmals aus ihrem Munde gehört.

Interessant waren mir auch die Erzählungen aus dem Stillleben von Altdorf. Was kam da für eine Krähwinkelei zum Vorschein: Namentlich die Schicksale des Collegiums wurden verhandelt, wozu der Sprachlehrer Schnyder, der übrigens heute seine Frau, ein bescheidenes Persönchen, in 
Urigen im Zweispänner abgeholt hat, Veranlassung gab.

Dabei vernahm man auch etwas von dem Mitwirken der

Geistlichkeit. Ja, ja, der stille Frieden dieser abgeschiedenen

Orte hat seine doppelte Seite. Es werden mir einige von den

Geschichten im Gedächtnis bleiben.

Der Eindruck wäre vielleicht noch besser gewesen, wenn

nicht die Tochter der Schwester von Frau Schillig, Seline, sich so gar

auffallend mit den jungen Herrn, die vorbeizogen, eingelassen hätte. In der Coquetterie erinnerte Seline Menoud Marie ganz an Susanne Rossel. Es scheint das also im welschen Blut zu liegen, eine Frucht der Erziehung u. der Anlage. Die Gesellschaft will nun morgen den Ausflug nach Braunwald machen, was uns sehr recht ist, denn so können Marieli u. ich nun allein die Fahrt nach Altdorf machen.

Ich muss nochmals sagen, wie gespannt ich auf den morgigen Tag u. den Empfang in Altdorf bin. Hilf mir, dass ich nichts Dummes mache u. dass ich weder mich in etwas versäume noch mich unnütz ausgebe.

War der Aufenthalt auf dem Gotthard oder der auf dem Klausen schöner, fragte mich heute Marieli. Das wird sich zeigen, wenn man deren Wirkungen miteinander vergleichen kann.

Und jetzt, zum letzten Mal auf dieser Höhe, gute, gute Nacht. Möge ich morgen Abend zu Hause Dir Gutes berichten können. Gute, gute Nacht!

Dein ewig getreuer 
Bern, d. 26. Aug. 1912.

Mein liebstes Herz!

So bin ich wieder eingerückt u. habe durch Siegwart, der mich am Bahnhof abholte, u. durch Anna u. Sophie eine recht gute Heimkehr gehabt. Selbst Möhrli hat mich aufs netteste begrüsst. Zum Aufräumen hatte ich bis zu dem Moment nicht Zeit genommen, das kommt später. Dagegen will ich Dir ein paar Zeilen über den heutigen Tag schreiben.

Wir standen um sechs auf, nach einer Nacht, in der ich vom Sturm-Föhn mehrfach geweckt worden bin.

Die Schilligs machten sich auf nach Braunwald u. konnten um halb acht abfahren. Ich beglich die Rechnung, die sehr vernünftig war, u. verabschiedete mich bei Allen. Ein Viertel vor acht fuhren wir in einem Zweispänner - sie mussten einen grossen Braak unten holen - anstatt des verabredeten Einspänners in einer schnellen, zum Teil von Sturm begleiteten, aber sehr schönen u. regenlosen Fahrt zu Tal. Um 9 3/4 (statt halbzehn) waren wir schon vor Siegwarts Haus, wo wir von Claire, die bald herbeikam begrüsst wurden. Sie empfing Marieli recht, hatte aber natürlich zuerst ein «Sie» für es. Frau Siegwart kam dann bald auch, eine zarte, kluge Frau, von der der Sohn seine besten Eigenschaften zu haben scheint, wie

dann auch die äussere Ähnlichkeit, namentlich im Blick, nicht zu verkennen ist. Eine Freundin der Frau Siegwart, die seit mehreren Wochen zu Besuch ist, Frl. Wohler von Wohlen, in Dresden bei ihrem Bruder, Kaufmann Wohler, stellte sich ebenfalls ein $u$. machte mir einen guten Eindruck. Frau Siegwart gab uns dann den Rat, den Besuch 
bei Bundesrichter Schmid noch vor Tisch zu machen. Erst besuchten wir Frau Marie Schmid u. ihre kleine Gaby. Dann kam Frau Schmid mit mir zu ihrem Schwiegervater, wo ich eine gute Stunde plaudernd verblieb. Über irgendwelche intimen Sachen wurde nicht gesprochen. Bei der Rückkehr zu Siegwarts sass der alte Herr schon am Tisch u. begrüsste mich herzlich. Wir waren dann am Mittagessen alle zusammen in sehr gemütlicher Verfassung, gingen darauf in den Salon hinauf u. die Zeit der Abfahrt war für mich bald gekommen. Bei strömendem Regen begleiteten mich Marieli u. Claire zum Bahnhof. Um acht war ich ohne jede besondere Begegnung zu Bern angekommen.

Das Verhalten der Siegwarts hat mir sehr gefallen. Die Abholung in Bern u. das nachfolgende Gespräch mit Siegwart geben mir ebenfalls einen guten Eindruck. Es scheint mir allerseits gute Gesinnung, aber durchaus nichts Präjudiziertes zu bestehen. Marieli mag nun noch einige Tage in Altdorf bleiben. Ich bin beruhigt, dass in der Sache

nichts beschlossen, aber auch nichts verdorben ist. Mag sich das Schicksal nun weiter erfüllen! Heute hatte ich aber insofern ein bestimmteres Urteil, als ich fand, ganz persönlich genommen würde Marieli an Siegwart jemand finden, wie es sich kaum je freundlicher gestalten könnte. Und ich selbst könnte damit auch zufrieden sein.

Ich bin von der Reise $u$. der Luftveränderung recht abgeschlagen, u. namentlich im Kopf Gedankenleer. Auch auf der Fahrt fiel es mir auf, wie stumpf ich bei allem war $u$. wie ich gar keine Einfälle hatte. In der Nacht hatte es mir sehr deutlich von Kollegen geträumt. Am Tag auf der Fahrt war alles leer. Wahrscheinlich hatte ich letzte Nacht nicht genug geschlafen. Übrigens dürfte es mich nicht wunder nehmen, wie die vier Wochen der Ausschaltung eigentlich geistigen Umgangs mich etwas versiegelt hätten. Letztes Jahr kam ich aber vom Gotthard nicht direkt nach Hause, sondern zu Rümelin auf den Gotthard. Auch hatte ich dort selbst noch den anregenden Verkehr mit Berta, dem Maler. Ich werde 
diese Stumpfheit wohl rasch überwinden. Was mir auf der heutigen Eisenbahnfahrt Eindruck machte, war nur eines: Ich hörte einem Gespräch zu, das ein sehr sympathischer Deutscher mit einem älteren englischen Ehepaar führte, dem ich entnehmen konnte, dass er von einer mehrjährigen Weltumseglung zurückkehre, die er aus Gesundheitsrücksichten unternommen, u. die

Engländer blieben im Plaudern über diese u. jene Länder, [Städt?] u. Weltteile nichts schuldig. Es war Zug in der Sache.

So ist der ersorgete Tag relativ gut vorübergegangen. Ich werde Dir gelegentlich einzelnes weiter davon erzählen. Jetzt muss ich zu Bett, die Augen fallen mir zu.

Ich bin immerdar Dein getreuer Eugen

1912: August Nr. 179

Bern, den 27. Aug. 1912.

Mein liebstes Herz!

Der heutige Tag verstrich mit Ordnungmachen, u. es überkam mich dabei ein so wehmütiges Gefühl, dass ich Abends hinaus u. auf den Friedhof gehen musste, u. ich wäre kaum gefasster zurückgekehrt, wenn ich nicht von Speyr angetroffen $u$. mit diesem lange über Viktor Merz gesprochen hätte. Das führte mich wieder zu einem gerechteren Massstab der Dinge zurück. Ich musste mir bei dem schweren psychopathischen Problem, das mit diesem so hoch gestellten Geist gegeben ist, sagen, dass doch eigentlich alles sich nur darum handelt, leistungskräftig zu sein. Wo dieses fehlt, da hat das Leben seinen Wert verloren. Was soll man leben, wenn man kein Leben mehr hat? Und daran knüpfen 
sich die Gedanken, wie es wohl anders wäre, wenn ich das frühere Leben noch hätte, wie aber eben jung zu bleiben, ein unrationeller Wunsch ist. Und wieder bewahrheitet sich mir die alte Beobachtung, dass der beste Trost über den Verlust des eigenen Glückes der Gedanke an den eigenen Tod ist.

Der Verein christlicher Studenten hat mich angefragt, ob ich nicht in Aarau im Frühling nächsten Jahres einen Vortrag über Ethik u. Politik halten wolle. In derselben Gelegenheit hat Oberst Sprecher u. a. einen Vortrag gehalten. Ich habe abgelehnt $u$. Walter Burckhardt dafür empfohlen.

An u. für sich hätte mich das Thema verlockt. Aber zwei Erwägungen widerrieten mir die Zusage: Einmal die Gewissheit, dass mich diese Arbeit auf lange hinaus in Sicht ganz unverhältnismässig viel Zeit kosten würde, u. sodann die Abneigung gegen das spezifisch-orthodoxe, was jenem Verein anhaftet. Dass die Anfrage von einem Basler ausging, war für mich auch keine Empfehlung. Ich kenne ja diese Lastermäuler.

Siegwart war heute ganz bei der Arbeit. Ich liess ihn machen, ich habe ihn sogar gemieden. Er soll nun arbeiten, wie wenn ich nicht da wäre. Die Sache ist jetzt so, dass ich das Interesse daran verloren habe. Marieli soll in Altdorf bleiben, so lange es will. Kehrt es zeitig zurück, so geschieht es ja ohnedies nur, um das Velofahren zu lernen. Das ist für mich ein eigentlicher Schmerz, dass es von keinen besseren Interessen geleitet wird. Aber da es nun einmal so ist, so lasse ich der Sache den Lauf. Nur soll man dann nicht von mir verlangen, dass ich dazu freundlich stehe. Ich kann auch unfreundlich sein, u. werde dazu vielleicht bälder kommen, als ich jetzt glaube. Die Erinnerung ist eben doch auch jetzt wieder keine angenehme. Es war mir so wohl, die ersten einsamen Tage auf der Höhe. Für die Gesundheit war aber freilich das Heraufkommen Marielis sicher geboten.

Was ich heute erledigt, waren sonst kleine Briefsachen. Ich hatte einiges vorgefunden, was mir Anna hätte schicken sollen. 
Es ist merkwürdig wie sie darüber kein Urteil hat. Sie sollte sich doch sagen, dass das geschickt werden muss, was sofort der Antwort bedarf, wie Verlobungsanzeigen u. dgl. Daneben gibt sie sich ja redlich Mühe, so dass sie jetzt die Haushaltung ohne Marie, aber mit Siegwart u. mir unverdrossen weiterführt, ist aller Anerkennung wert.

Ich habe heute wohl auf Siegwart den Eindruck der Schwere gemacht. Ich fühlte auch, dass ich mich in einer inneren Missstimmung befand, $u$. ich gab mir nicht einmal die Mühe, das zu verbergen. Vielleicht wird es morgen besser. Noch bin ich im Ungewissen, wie ich die Zeit verwenden will in den nächsten Tagen. Soll ich an die Arbeit? Ich mag es nicht. Aber was dann? Nun, es liegen eine Anzahl Zusendungen herum, auf die ich ja antworten muss. Und schon diese Pflichten werden mir unsäglich schwer. Ich denke manchmal, ich sollte eigentlich mich doch lieber ganz zurückziehen, als in einem solchen inneren Widerwillen die nächsten Pflichten zu erledigen.

Ich weiss schon, wo der letzte Grund meiner Stimmung liegt: Im Mangel der Anerkennung, wo ich sie suchte. Aber soll ich mich nicht trösten über die, so mir zu Teil geworden? Und wenn dann wirklich alles missrät, wie z. B. in der Entwicklung meiner Häuslichkeit? Aber es kann ja nicht alles geraten. Sage Du es mir allzeit $u$. Stunde für Stunde, dann werde ich es schon glauben u. mich danach richten.

Doch nun weiter. Ich werde morgen hoffentlich bereits über die Sache anders denken. Ich muss ja Lichtenhahn antworten, der mir endlich wieder einmal eine Abrechnung geschickt, 
u. Liebmann, der für die projektierte Festschrift des Deutschen Juristenjahres 1913 mein Bild haben will.

Und nun bin ich müde, müde, müde. Die Augen wollen versagen $u$. die Gedanken sind leer. Also Schluss, mit der Bitte, meine liebe Seele, dass Du mir helfest die innere Einsamkeit zu überwinden!

Allzeit getreu

Dein

Eugen

1912: August Nr. 180

[1]

B. d. 28 / 9. Aug. 1912 .

Mein liebstes Herz!

Heute habe ich bei Werner Kaiser Besuch gemacht, der mich herzlich empfing, ohne dass ich nähere Fühlung mit ihm bekam. Er erzählte mir, Carlin sei zwei Wochen hier gewesen $u$. habe davon berichtet, wie Wieland zu nichts zu bringen gewesen sei u. über andere ein unverschämtes Maul gehabt habe. Ob das auf mich gegangen, weiss ich nicht, wäre Basler Art. Dann war ich bei BR. Müller, der mir mitteilte, dass seine Frau in Urigen keine Fühlung mit den dortigen Gästen bekommen, die sich als eine ultramontane Gesellschaft erwiesen u. dass Frau BRat deshalb sich deprimiert gefühlt, auch keine ihr passenden Spaziergänge habe machen können, wogegen sie sich im Alpenblick dann in ihrem Element gefunden habe. Er teilte mir auch mit, dass Leo Weber in der Strafrechtskommission nicht mehr mitmachen wolle. Er fühle sich schwach, vertrage länger als drei Stunden keine Sitzungen mehr u. habe oft Schwindel. Die Siebzig zeigt sich also auch hier. 
Am Nachmittag war Walter Burckhardt bei mir. Seine Frau hat wieder Schmerzen im Unterleib. Er war frischer als wie ich ihn verliess, obgleich er keine Ferien gehabt hat. Er sprach sehr nett von seinen Arbeiten. Daneben erledigte ich den Brief an Lichtenhahn, das Gutachten an Eduard Sturzenegger $u$. anderes, ohne jede strengere Arbeit. Ich war heute merkwürdig müde. Mit Siegwart war ich mehr

zusammen als gestern. Er war recht zutraulich. Man bekommt ihn gern, je mehr man ihn kennt.

Und so gehen nun die Ferientage weiter. Wenn ich gesund bleibe, werde ich schon noch einiges erarbeiten können.

Ich habe mit Siegwart zu lange Schach gespielt, das er erst lernt, u. gehe nun gleich zu Bett. Vielleicht weiss ich morgen Mehreres niederzuschreiben.

Den 29. August.

Auch heute fühlte ich mich recht bedrückt, u. das wurde noch durch ein Vorkommnis vermehrt, das mich sehr ärgert. Ich hatte noch auf dem Klausen eine Einladung zur Bibliothekssitzung auf den 28. ds erhalten, u. am Dienstag hatte v. Mülinen telephonisch angefragt, ob ich auch da sei, was bestätigt wurde. Und nun meinte ich gestern, es sei Dienstag, u. heute es sei Mittwoch. Ich verfügte mich also erst heute auf fünf Uhr zur Bibliothek u. gewahrte den Irrtum, als ich Kommissionszimmer nichts gerüstet traf u. niemand fand. Ich musste mir sagen, wieder einmal ein Fall, der dem «Ungeschicktesten» begegnen kann. Ich weiss nur einmal noch, dass es mir in Basel begegnete, eine Justizkommissionssitzung in den Ferien ganz zu vergessen. Hätte ich Dich, liebe Seele, um mich gehabt, so würdest Du gewiss mich an die Sitzung erinnert haben. Aber ich fühle mich so allein, u. so im Sturm, innerlich, manchmal wie verwirrt. Es wird, ich weiss nicht was, daraus.

Heute habe ich allerlei Kleines gearbeitet, u. den Besuch eines jungen Russen Zolnicky gehabt, eines vornehmen 
Juden aus Kiew, der sich mir mit grosser Verehrung nahte u. davon sprach, einmal ein Semester bei mir studieren zu wollen. Ich habe ihm freundlich begegnet.

Statt in der Bibliothekskommission war ich Nachmittags bei Walter Burckhardt. Seine Frau ist wieder ausser Bett, aber nicht recht gesund. Er selber ist nicht zu Ferien fortzubringen $u$. über dieses $u$. jenes verdriesslich. Ich selber weiss nicht, wie ich die Sache beurteilen soll. Sie sprachen mir viel von Maler Welti, der wieder hier sein soll, von der Frau von Redaktor Welti, die wieder nervös gestört sein soll, $\mathrm{u}$. anderem, was mich nur halb interessiert. Mich wundert nur, wie es sich im ganzen weiter entwickeln soll. Ich kann ja, wenn es so fort geht, gar nicht mehr recht arbeiten. Ich bin müde, u. fühle mich gleich fiebrig, u. dabei wollen die kleinen Aufgaben nicht abnehmen. Heute Vormittag war der Amtsvormund Dr. Leuenberger bei mir, mit der Frage des Vorgehens gegen eine verwarloste neunzehnjährige Tochter. Ich freute mich, dass er die Sache so frisch anfasste $u$. glaube ihm einen guten Rat haben geben zu können.

Zum Lesen, abgesehen von den Zeitungen, komme ich nicht. Siegwart nimmt mir doch viel Zeit weg. Er ist lieb mit mir u. ich habe ihn gern. Nur muss er noch etwas freier werden, $u$. da weiss ich nicht recht, was ich von ihm halten soll. Dass er nicht Gegner der Jesuiten ist, habe ich schon gesehen, aber ist er ihnen zugewandt? Gehört er irgendwie zu ihnen? Was ich ihn darüber fragte, hat er

entschieden abgelehnt, $\mathrm{u}$. ich glaube doch nicht, dass er so sehr mit den Jesuiten befreundet wäre, um auch darüber mir etwas vorzumachen. Aber wie es mit Marieli geht, weiss Gott!

Ich wiederhole nochmals, dass ich mich aufgeregt $\mathrm{u}$. Gedankenarm fühle. Das ist schon Alter, aber es muss doch wieder besser kommen, wenn man noch einige Zeit aushalten soll. Hilf, liebe Seele, dass es mir wieder besser wird in Herz u. Kopf!

Innigst bei Dir! Dein immerdar getreuer

Eugen 


\section{2: August Nr. 181}

[1]

B. d. 30. Aug. 1912.

Mein liebstes Herz!

Nachdem es gestern so sonnig warm gewesen $\mathrm{u}$. auch

heute früh noch ein schöner Tag anzubrechen schien, ist gegen

Mittag der Himmel wieder trüb geworden u. seit Nachmittag regnet es ununterbrochen. Vor fünf Wochen habe ich mit den Übungen das Sommersemester abgeschlossen. Der Aufenthalt auf dem Klausen ist dazwischen gelegen, der mir wohlgetan hat, aber eigentlich doch eine Monotonie in der Erinnerung zurücklässt, die mir nicht soviel bietet, wie das bei geschickterer Verwendung der Ferien hätte sein können oder auch bei nur einigermassen besserem Wetter gewesen wäre. Mit der Arbeit bin ich nicht weitergekommen. Ich werde, wenn es so fortgeht, geistig ein Einsiedler, weil ich geistig mich auf wenige Interessen zurückziehe. Nun ja, das ist das Schicksal des Alters, bei dem man, wenn man sich andere Schicksale vergegenwärtigt, froh sein muss, dass nicht, oder wenn nicht Schlimmeres eintritt. Rossel war heute nach Tisch bei mir u. wir kamen auf verschiedene Fälle zu sprechen, anknüpfend an den Tod Colones-Colliet, dem der schliessliche Schlaganfall eine gar schlimme Zukunft abgekürzt haben soll. Berthoud z. B., den ich 1902, wie ich Dir damals schrieb, als so freundlichen Gastwirt in Neuenburg kennen lernte, liege jetzt seit Monaten im Bett, in der Furcht, täglich erneut, am Sterben zu sein. Wir sagten uns, was ist uns beschieden! Dabei freilich ist Rossel um neun Jahre jünger als ich, u. ist ein Mann, dem der Wechsel im Beruf gerade jetzt ausserordentlich wohl getan zu haben scheint. 
Nach drei wöchentlichem Bergaufenthalt kam er eben jetzt von einer nach den Bergferien besuchten achttägigen Jagd im Elsass zurück. Er sieht sehr gut aus u. wird immer dicker.

Heute hat Siegwart seinen Geburtstag. Er ist 27 Jahre alt u. voll Lebenskraft. Weil es Freitag ist, hat Anna kein Fleisch, sondern Käspastetchen u. Fisch serviert. Dabei sprachen wir vom Fasten u. er gab uns, ziemlich geniert, eine gleichsam entschuldigende Erklärung des Fastens. Ich habe ihn dabei sehr katholisch gefunden $u$. konnte dieses Gefühl schwer bemeistern. Uns trennt von dieser Gesinnungsweise eben doch eine ganze Welt. Ob sie sich überbrücken lässt? Am Vormittag arbeitete ich mit ihm zusammen. Er zeigte sich dabei als scharfsinniger Grammatiker. Allein ich benutzte den Anlass doch, um ihn auf die Lücken im bisherigen Bildungsgang hinzuweisen. Er liest zu wenig, er ist noch jung $u$. kann gerade in seiner jetzigen Stellung noch manches, ja alles nachholen, wenn er vom richtigen Geist getrieben wird. Sein gleichmässiger froher Mut kann ihm dabei viel helfen. Er hat eine Gewohnheit, die auch mir in früheren Tagen eigen war: Er pfeift vor sich hin bei der Arbeit, er ist ein rechtes Volkskind. Doch den Enthusiasmus, der mir eigen war, hat er entschieden nicht. Freilich, hätte er ihn, so könnte er auch nicht so gleichmässig sein. Denn enthusiastisch kann man nicht an einemfort sich fühlen.

Ich habe heute verschiedenerlei nachgearbeitet, u. auch gutachtlich Briefe beantwortet $u$. die Rückstände im Rechtswörterbuch nachgearbeitet $u$. an Künssberg eingeschickt. Sonst war der Tag behaglich u. ohne Störung. Doch er ist ja noch nicht vorüber.

Auf acht Uhr soll nun Marieli aus Altdorf zurückkommen. Ich bin gespannt auf seine Auskunft u. will nachher vor Schlafengehen noch einige Zeilen beifügen. Zweifelslos haben die äusseren Vorkommnisse sie u. mich der Familie Siegwart nun doch näher gebracht, u. ich bleibe bei dem Eindruck, dass wenn Siegwart sich noch weiter nähern will, bei mir kein Hindernis vorliegen wird. Aber einerseits bin ich ganz unsicher, ob Siegwart das tun wird, ja 
umgekehrt, ich glaube, er wird es nicht tun. Und anderseits bin ich nicht sicher, ob ich mit der Erleichterung der Annäherung nicht schon zu weit gegangen sei, u. meine jedenfalls nicht weiter gehen zu dürfen. Man muss in solchen Dingen der Welt ihren Lauf lassen. Entweder kommt eine Annäherung von selbst zustande, oder dann bleibt alles beim Nichts $u$. ist nur dafür zu sorgen, dass nicht eine Entfremdung eintritt. Noch vor der Abfahrt vom Klausen meinte Marieli, was es nur mit Abbühl anfangen müsse. Gewiss, es ist eine schwierige Frage, allein seine Schuld ist es, dass sie nun so gestellt ist. Denn ohne ihren Kummer u. ihre Bitte hätte ich nicht den Versuch mit seinem Secretariat gemacht, u. die schwere Enttäuschung wäre ihr u. mir erspart geblieben. Doch nichts mehr davon, solange es sich mit Schweigen verkleistern lässt! Und von Augusts hört man auch nichts mehr. Da habe ich auch aus dem Verhalten Marielis den schweren Schaden erlitten. Zwar ist es die Schuld von Augusts Söhnen, dass es so gekommen, aber dass es so kommen konnte, das fällt Marieli u. durch sie mir zur Last.

Du siehst, ich denke nach, ich grüble, wie ich es immer getan. Es muss aber doch auch aus diesen Situationen einen Ausweg geben. Ich muss ihn nur abwarten. Vielleicht lebe ich ja noch lange genug, um auch dies zu erleben. Überhaupt mit dem Erleben ist es eine eigene Sache. Was sich da von selbst abwickelt, das ist

kaum zu sagen. Man macht sich nicht das Schicksal, wenn man sich nicht das Spiel verdirbt, u. auch verdorbenes Spiel kann wieder eine gute Wendung bekommen.

Marieli ist um acht gut angekommen u. fröhlich. Siegwart betrachtete es als selbstverständlich, an den Bahnhof mitzukommen. Er ging noch in seine Wohnung, wir trafen uns auf dem Bahnsteig. Und nun gute Nacht, meine liebe, gute Seele! Ich bleibe immerdar

Dein getreuer

Eugen 
B. d. 31. Aug. / 1. Sept. 1912.

Mein liebstes Herz!

Es ist spät geworden. Wir kamen nach dem Nachtessen u. nach dem darauf folgenden Schach ins Plaudern. Ich erzählte aus der Zeit des Tonhallekrawalls u. so weiter. Marieli hat heute wieder ein etwas anderes Leben in das Haus gebracht. Erfüllt war es immer noch vom Veloplan. Es ging auch nach dem Café mit Siegwart in verschiedene Läden, um ein Velo zu kaufen. Aber sie fanden nichts Passendes u. ich hoffe, dass sich der «Glust» nun doch etwas abgekühlt hat. Schliesslich muss es doch selbst sehen, dass es hiefür in der Stadt keine rechte Gelegenheit u. neben seiner Arbeit keine Zeit hat. Aber ich befehle nicht, ich lasse ihm die Entscheidung, ich hoffe nur, dass es vernünftiger sei als so. Es scheint, dass auch in den Läden die Auskunft eher negativ gelautet hat.

Siegwart war heute sehr nett. Aber natürlich nur im allgemeinen. Zum Arbeiten kam er fast gar nicht. Ich habe auch nichts rechtes tun können. Nach Tisch kam Mülinen zu mir, der mir von den Traktanden der Sitzung erzählte, die ich am Mittwoch verpasst. Vorher erschien Gmür u. blieb noch, als Mülinen weggegangen. Er erzählte, welch nette Gesellschaft er auf Weissenstein gehabt, wie er gearbeitet, $u$. wie er sich habe durch den Würtembergischen Justizminister bewegen lassen, um mit seiner Frau an

dem österreichisch-deutschen Juristentag nach Wien zu reisen. Er war sehr angeregt. Morgen wollen sie verreisen.

Wie fliegt die Zeit! Jetzt ist auch dieser Ferienmonat vorüber. Und wie wird die nächste Woche vorübergehen? Was werde ich auf dieser Fahrt mit den zwei Obersten im Automobil erfahren? Warten wir ab. Das Wetter macht mir bange. 
Heute habe ich zum ersten Mal wieder einmal auf dem Aeolion gespielt. Ich weiss nicht, es macht mich das fast allemal traurig. Oder ich spiele darauf vorzugsweise, wenn ich in dieser Stimmung bin. Was soll ich so allein damit?

Heute habe ich auch die Abrechnung gemacht. Das Ergebnis ist nicht beängstigend. Bis jetzt habe ich mich in vernünftigen Schranken gehalten, u. ich hoffe, Marieli wird dazu helfen, dass es so bleibt. Anna scheint ihr möglichstes getan zu haben, um Ordnung zu halten.

Doch nun seis genug für heute. Es rückt gegen Mitternacht.

Den 1. Sept.

Heute, Sonntags, habe ich mich auf die morgige Fahrt gerüstet, Briefe geschrieben, mit Siegwart geplaudert, etwas gelesen, Schach gespielt, u. hatte den Besuch von Walter B., der von halb zwei bis drei bei mir war. Fast den ganzen Tag hatte ich Kopfschmerzen, u. nachher ein Wehmuts- oder Traurigkeitsgefühl, ich weiss nicht weshalb. Mir bangt vor der Fahrt mit Bühlmann u. Will, ich wollte, ich wäre schon wieder zu Hause. Vielleicht stört mich der Gedanke, dass nun fünf Wochen von den Ferien vorüber sind, ohne dass ich einen rechten Plan verfolgte, u. dass ich mich so gealtert fühle. Warum dies? Nicht wegen

der kleinen Beschwerden, die ich empfinde, wohl aber wegen der Nutzlosigkeit, mit der ich die Zeit sich zersplittern sehe. Und doch, wenn ich zurückdenke, hatte ich von jeher solche vorübergehenden Perioden, wo ich zu nichts fähig war. Was soll es mir heute etwas anderes bedeuten, als damals? Aber ich fürchte, es muss noch schlimmer kommen, bis es besser wird, $u$. ich werde es tragen müssen, $u$. wenn dann vor der Besserung das Ende kommt, auch gut, dann bin ich um so bälder bei Dir!

Marieli war heute viel mit Siegwart zusammen. Von dem Velokauf wurde glücklicherweise nicht mehr gesprochen. Es scheint, dass der gestrige Rundgang in den Veloläden, doch Marieli darüber die Augen geöffnet hat, dass das Velofahren unter den rechten Mädchen der Stadt nicht mehr im Schwange ist. Ich hoffe das, u. 
werde mich freuen, wenn es von selbst dieser Einsicht Folge leistet.

Heute nach dem Nachtessen haben wir mit Siegwart die

Familien- u. Freundesphotographien durchgesehen. Es war für mich ein Gang in allverschwundene Zeiten. Aber freilich nicht mit den Augen, die Du mir verliehen hättest. Wie viele sind schon gestorben. Wie geht das nun dem Ende zu! Wenn man diese Erinnerungen durch blättert, dann fühlt man den Schluss des Lebens.

Siegwart war sehr recht, wie immer. Er ist korrekt u. gescheit. Er wird wohl auch für die Familie Herz haben. Aber was in der Verschiedenheit der Traditionen zwischen ihm u. mir liegt, das lässt sich nicht durchmischen, das wird unter allen Umständen noch viele Bedenken erwecken. Und der Gesamteindruck bleibt mir, dass Siegwart selbst von diesen Bedenken beeinflusst wird, und dass er sich nicht dazu entschliessen wird können, seine

Zukunft unter deren Schatten zu stellen, u. es ist ja wohl auch besser so. Dann aber muss für Marieli Ziel u. Arbeit in ganz anderem Sinne geschaffen werden. Vielleicht ist es dann doch das beste, wenn es mein Secretär wird.

Und nun also, wieder ein Unterbruch im ruhigen Gang der Tage. Morgen, wenn ich überhaupt zum schreiben komme, grüsse ich Dich aus Frauenfeld. Wie anders, als damals, wo wir miteinander den lieben seligen Fehr u. seine Familie besuchten!

Nimm innigsten Gruss u. Kuss im Geiste, u. hilf Deinem immerdar treuen

Eugen 


\section{September 1912}

\section{2: September Nr. 183}

Frauenfeld, Bahnhofhotel, d. 2./3. Sept. 1912.

Mein liebstes Herz!

So sitze ich nun wieder, Abends zehn Uhr, im Hotelzimmer, u. zwar in Frauenfeld, an das wir eine so nette Erinnerung gemeinsam gepflegt haben, nachdem wir im Jahr 1903 die Fehrs hier besuchten. Früher schon einmal waren wir in hier, im Jahr 1888 von Halle aus in den Ferien, als wir nach Stammheim gefahren waren u. uns vom Badewirt Schmid im Einspänner hieher fahren liessen, um dann mit der Strassenbahn nach Wyl u. weiter nach Trogen zu gelangen. Morgen werde ich auch wieder den Weg nach Wyl machen, aber unter mir ganz andern Umständen! Ich bin in Gesellschaft von zwei Armeekorpskommandanten, im Automobil der Kraftwerke Berns, u. gehe an die Manöver.

Ich war heute beim Abschied etwas unwirsch zu Hause, da das Kleid, das ich für diesen Ausflug bestimmt hatte, nicht aufgefrischt worden war, u. da Marieli so gar keine Gedanken an die Sache beieinander hatte. Auch dass Siegwart mich durchaus zur Bahn begleiten wollte, während doch Marieli zum mitkommen bestimmt war, missfiel mir, trotzdem es von seiten Siegwarts in naiver Weise eine Freundlichkeit für mich sein sollte. Sie kamen also beide mit mir. Während wir am Bahnhof auf das Auto warteten, kam Sali vorbei, dem ich Siegwart vorstellte. Er war sehr gesprächig u. freundlich. Dann erschien Bühlmann, u. bald nachher im Automobil Will. Wir stiegen ein $u$. ich verabschiedete 
mich von Marieli u. Siegwart, bei letzterem mit dem deutlichen Hinweis darauf, dass ich ihn nicht mehr antreffen werde, wenn ich am Donnerstag von dieser Reise zurückkehre. Es schien mir das wirklich besser, da ich doch Marieli davor bewahren möchte, dass Siegwart zu lange bleibe u. dass dann es etwa ins Gerede kommen könnte. Wollen sehen, ob er es verstanden hat.

Und dann gings los, eine Fahrt, die mich anfangs fast ängstigte, nachher aber mir viel Freude machte. Wir fuhren zunächst im Wagen mit aufgestelltem Verdeck, nachher trotz gelegentlicher Regenspritzer offen, über Zollikofen, Kirchberg, Herzogenbuchsee, Langenthal, St. Urban, Zofingen. Hier aber geschah es, dass ein Reif platzte, wie mit einem Flintenschuss, u. wir mussten einen zweistündigen Halt machen, während dessen wir Rösti zu Mittag assen. Dann aber gings in gleicher Weise weiter, über Suhr, Lenzburg, Mellingen, Baden, Steinmaur, Embrach, Hettlingen, Wiesendangen u. $5^{1 / 4} \mathrm{Uhr}$ waren wir in Frauenfeld, die Fahrt von etwa $150 \mathrm{~km}$ hatte, den Halt abgerechnet fünf Stunden, von $10-12,2 \frac{1}{1} 4$ bis 5 11/4 gedauert. Es war sehr interessant, ich konnte es aber bei dem oft einsetzenden Sprühregen sehr wohl brauchen, dass ich vom Klausen her abgehärtet war. In hier lag der erwartete Bericht an Bühlmann vom Informationsbüreau nicht vor, u. schon hatte Bühlmann eine Depesche an Wille u. ich eine solche an Hoffmann aufgesetzt. Da kam das Couvert, das uns genügend für morgen orientiert hat. Ich bin auf diesen ersten Tag sehr gespannt. Am Mittwoch werden wir dann wohl den Kaiser sehn. Jetzt gute, gute Nacht!

Den 3. Sept.

Es war heute ein sehr interessanter Tag. Freilich Regen hat nicht gefehlt, u. am Morgen war es empfindlich kalt. Auch der Schmutz hat tüchtig angesetzt. Aber man hat alles gut ertragen. Wir fuhren um 7 1/2 Uhr von hier ab, waren um 8 1/4 in Wyl, mit guter Fahrt, nur an einer Stelle sprang uns eine Kuh ins Fahrzeug, glücklicher Weise ohne Schaden zu stiften oder zu nehmen. 
Von Wyl gings auf dem linken Thurufer auf- oder vielmehr abwärts. Wir begegneten dem Brigadier Scherrer mit seinen Mannschaften. Verschiedene Offiziere grüssten mich, ich kannte nicht alle. Von Gossau fuhren wir wieder nach Wyl zurück u. trafen unter andren Guhl. Das Mittagessen nahmen wir in Wyl, wo wieder verschiedene Bekannte, Müller vom «Bund» $\mathrm{u}$. andre anzutreffen waren. Wir besahen uns die Cavallerie-Brigade, wieder mit Bekannten, u. a. Wildbolz u. einen sympathischen Leutnant aus St. Gallen, der mir sehr vertraut die Hand drückte. Wer war es? Dann gings nach Kirchberg, wo wir einem Begegnungsgefecht, bei ziemlich starkem Regen, zuschauten. Auf der Rückfahrt auf Nebenwegen, stiessen wir auf Zürcher Bataillone, die trotz achtstündigem Marsch frisch die Höhen zu stürmen suchten. Wir verfolgten mit Interesse die Manöver, die jedenfalls der Leistungsfähigkeit der Mannschaften ein glänzendes Zeugnis gaben. Um 7.20 waren wir wieder in Wyl, u. vor acht in Frauenfeld.

Der Tag war sehr ausgefüllt $u$. ich komme mit Bühlmann $u$. Will gut aus. Morgen müssen wir vor 6 Uhr von hier weg. Das Wetter scheint besser werden zu wollen. Aber in dieser steten Anregung

verträgt man ja überhaupt alles. Hoffentlich gibt es mit dem Kaiser kein Unglück.

Nun aber zu Bett. Ich schlief gestern spät ein. Heut hoffe ich Besseres.

Denn morgen wird ein strenger Tag.

Gute, gute Nacht, mein liebstes Herz! Ich denke an dich in jeder Lage $u$. bleibe

Dein allzeit getreuer

Eugen 
Frauenfeld, den 4. Sept. 1912.

Meine liebe, gute Lina!

Es war heute Morgen recht kalt, als ich um halb fünf erwachte. Schon die Dämmerung liess aber einen hellen Tag erwarten. Um fünf wartete ich Bühlmann u. Will, vor halb sechs war ich am Frühstück. Die andern schlossen sich bald an u. 5 3/4 Uhr fuhren wir in den Morgennebel hinaus, in dem bald eine rote Sonne sichtbar wurden [sic!]. Wir fuhren in einer halben Stunde nach Wyl, wo Bühlmann die Informationen entgegennahm, u. dann weiter bis über Ober Bazenheid hinaus. Da begegneten wir dem Zürcher Bataillon 65, u. beschlossen auszusteigen $u$. den Marsch auf die Höhe von Kirchberg auf dem Fussweg zu machen, den das Bataillon bereits eingeschlagen hatte. Beim Aussteigen kam Wilhelm v. Wyss auf mich zu, der Leutnant in dem Bataillon ist. Sein Gruss freute mich herzlich. Wir stiegen mitten in der Truppe den Weg hinan. Die Leute, mit denen ich redete, waren sehr nette Zürcher aus Winterthur. Oben mussten wir noch über Schützengräben hinan u. kamen an die Stelle, wo wir schon gestern waren. Inzwischen war es acht Uhr geworden. Eine ungeheure Zuschauermenge, in der die Truppen fast verschwanden, sammelte sich, u. bald kündigte ein Strom nach einer Anhöhe, dass der Kaiser anrückte. Wir sahen die Automobile, zwölf, von Ferne, u. um den Platz, auf dem die Manöverleitung mit dem Kaiser sich befand, bildete sich ein dichter, fünf bis sechs gliedriger Ring von Zuschauern. Wir drei vermochten nicht hinüber zu sehen $u$. verharrten auf einem Ausblick, bis Bühlmann, 
nachdem die Menge sich etwas zu lichten begann, nochmals hinauf ging u. mit dem Bericht zurückkam, wir könnten jetzt näher treten. Der Kaiser war inzwischen in einem Automobil zu den verschiedenen Truppenstellungen weiter gefahren, es war lichter geworden in dem Menschknäuel, u. da rief ein Bekannter Bühlmann, Will in den Kreis u. ich durfte mit gehen. Bald traf auch ich Bekannte, wie die Obersten Weber, Isler, Iselin, dann von Bülow, Dirichart, A. Welti, Wildbolz. Es war eine ganz nette Unterhaltung. Wir sahen von ferne, wie der Kaiser (durchs Glas gut erkennbar) mit einer Gruppe von Soldaten sich unterhielt, in einen Jägergraben stieg u. s. w. Er soll, wie nachher erzählt wurde, gefragt haben, auf welche Distanz sie schiessen, gegen welches Ziel, wann sie den Graben ausgeworfen u. s. w. Nach einer Weile kehrte er in den Kreis zurück, den sofort wieder die grosse Menge umgab. Da sah ich dann bald auch Hoffmann, der sehr freundlich auf mich zukam. Forrer hatte ich vorher gesehen, er begrüsste mich gleichfalls ganz nett u. sagte: Der Unterschied sei der, dass ich nun in diesem Kreis zu sein, einer Erlaubnis bedürfe, er aber nicht. Auch Motta u. Wille grüssten mich. Motta war dann im Verlauf der langen Pause, die die Herrschaften da oben zu brachten, so freundlich mir zu sagen, wenn ich es wünsche, so wolle er mich dem Kaiser vorstellen. Aber nach einigem Schwanken lehnte ich ab. Mich bestimmte hiezu die Auffassung, dass es doch Sache Forrers oder Hoffmanns gewesen wäre, mir diese Ehrung zu verschaffen, u. diese hatten eben den Einfall nicht, oder wenn sie ihn hatten, so wiesen sie ihn mit Bewusstsein von sich. Umso weniger konnte ich Mottas Freundlichkeit acceptieren. Ich werde ihm aber dafür dankbar sein. 
Es wurde zwölf Uhr, bis der Kaiser mit allen hohen Herrschaften den Platz verliess, um in Ittingen das Frühstück einzunehmen. Um halb vier sahen wir ihn dann nochmals in Frauenfeld, als er von der Karthause zurück gelaufend den Zug nach Zürich bestieg. Über die Leutseligkeit des Kaisers war nur ein Lob. Nur Forrer meinte, er rede so gewandt, dass man es bei uns schnörren [?] hiesse. Man bräuche gar nichts zu sagen, er rede immer.

Wir fuhren dann, nachdem wir in all dem Publikum, in verschränkten Wegen, die die Herren Armeekorpskommandanten ausgeheckt, nach Bazenheid hinunter gelangt, u. dort im Wagen ein mitgenommenes Frühstück eingenommen, nach Wyl zurück, von Truppen umgeben, die nur ein langsames Fahren gestatteten. Von Wyl nach Frauenfeld gings wieder im richtigen Autotempo. Während des Frühstücks traf ich den Leutnant Huber aus Zürich, Doktor unserer Fakultät. Er trank ein Glas mit uns. Vor unserem Hotel stiessen wir auf Ulrich Meister. Ich trage nach, dass bei der Batterie, die auf dem Manöverplatz stand, zwei meiner jetzigen Studenten mich grüssten, Böcklin u. Hasenfratz.

Der Tag blieb sonnig, bis gegen Mittag, jetzt, da ich um fünf diese Zeilen schreibe, ist es wieder trübe, aber noch nicht regnerisch. Ich erwarte nun noch Hans Fehr, der mir in hier seinen Besuch angesagt, $u$. ich bin gespannt, zu hören, was er mir v. Halle u. Stammler zu sagen hat.

Der Kaiser trug die Uniform der Neuchateler Schützen, eine Aufmerksamkeit, wie er es auffasste. Der sehr schöne, ja grossartige Empfang in Zürich soll ihn sehr bewegt haben. Er habe bemerkt, er hätte das ja gar nicht verdient. Das Publikum hat sich scheints sehr würdig benommen. Auf dem 
Manöverfeld $u$. in hier wurde er von der Menge mit Hoch u. Bravos begrüsst.

Fehr ist richtig gekommen, freilich erst um $6 \mathrm{Uhr}$, blieb dann aber über das Nachtessen als guter, freundschaftlicher Gesellschafter. Er hat sich als treuer, verständiger, anhänglicher Mensch erwiesen.

Jetzt ist es aber Zeit zur Ruhe. Morgen ist 4 1/4 Uhr Frühstück. Gute, gute Nacht, meine liebe Seele!

Dein müder, aber treuer

Eugen

\section{2: September Nr. 185}

B. den 5. September 1912.

Mein liebstes Herz!

Ich bin heute um acht Uhr wieder zu Hause angelangt, von Marie u. von Siegwart bei meiner unangemeldeten Automobilankunft am Gartentor begrüsst. Froh wieder zu Hause zu sein, habe ich mich über das, was mich an dem Empfang des Einst vermissen liess, hinweg gesetzt. Und jetzt gehe ich gerne zu Bett, ich bin müde.

Diesen Morgen erwachte ich in meinem Hotelzimmer wie ich mir vorgenommen, um $33 / 4$ Uhr. Der Portier aber verschlief sich $u$. da ich die Herrn Bühlmann $u$. Will gestern zu früh geweckt hatte, wagte ich es nicht, sie nochmals zu stören, solange ich noch annehmen konnte, der Portier werde noch kommen. Aber er erschien wirklich nicht. Erst dann, nach vier Uhr, weckte ich die andern, $u$. Will sorgte gleich dafür, dass im Haus Alarm entstand. Immerhin wurde es dann 5 3/4 Uhr bis wir abfuhren, anstatt wie angesetzt 4 1/2 Uhr. Die Nacht hatte es in Strömen geregnet. Und der Regen dauerte, bald stärker bald 
schwächer an bis gegen Mittag. Wir fuhren also bei düsterer Beleuchtung nach Wyl, der Kaiser war aus Zürich vor uns dort. Wir stiegen auf den Ölberg u. hatten dort einen guten Überblick über die Manöver, die in dem vor uns liegenden Regengelände abgehalten wurden.

Ich traf wiederum eine Reihe von Bekannten, der Oberst Schulthess, Major Kissling, Gebhard Lutz von Thal, der nun mit Frau u. Kind im väterlichen Trüeterhof wohnt u. mich im Gespräch mit der Bemerkung überraschte, ich werde doch dem Kaiser vorgestellt worden sein, das sei doch selbstverständlich. Dann traf ich den Stud. Kaiser, den lieben Gustav Hürlimann u. s. w. - Hoffmann, der Kaiser u. andere waren auf einen Seitenvorsprung des «Hochbergs», über Öhlberg hinaus gelegen, gegangen, so dass wir sie nicht sahen. Sie kehrten erst auf den Gefechtsabbruch, neun Uhr, zum Frühstück des Kaisers im bereitstehenden Zelt zurück, u. die Herren B. u. W. schwankten, ob sie zuwarten $u$. dann auf eine Einladung $u$. auf Vorstellung beim Kaiser warten sollten. Schliesslich überwog bei ihnen die richtige Einsicht, dass es doch eigentlich unter ihrer Würde sie, sich vor dem Zelt aufzustellen, um sich eine Einladung zu ergattern, $u$. ich war froh, dass wir dann sofort mit dem Abblasen vom Öhlberg hinunterstiegen. Ich habe dann also niemand mehr gesehen. Wir stiegen um $10^{1 / 4}$ Uhr ins Automobil, fuhren bei geschlossenem Verdeck im Regen ab u. gelangten um 11 1/2 Uhr nach Zürich vor den «Gotthard», wo wir zu Mittag assen. Um 1 Uhr gings weiter, im offenen Wagen, bei Sonnenschein, wenn auch mit starkem Wind: Über Bremgarten, Münster, Sursee, Huttwil, Zollbrück nach Grosshöchstetten, wo wir einen fast anderthalbstündigen Halt machten. Bühlmanns gaben uns Gästen ein nettes Abendbrot. Nach sieben gings weiter, 
Will stieg an der Thunstrasse aus, $\mathrm{u}$. ich war, wie gesagt vor acht Uhr zu Hause. Siegwart meinte, was der Kaiser mache, u. ich erfuhr dann, dass das «Intelligenzblatt» die Nachricht gebracht habe, es seien dem Kaiser mehrere Zivilisten, namentlich ich als Schöpfer des ZGB. vorgestellt worden. Es lag also der Gedanke auch in Andrer Sinn, nicht nur in dem Mottas u.

Lutzs. Ich denke, dass Forrer daran Schuld ist, wenn nichts solches geschah, obgleich ich ja Hoffmann schon im Frühling eine Bemerkung gemacht. Auch schien mir Hoffmann, als er mich auf Kirchberg begrüsste, verlegen zu sein bei aller grossen $u$. herzlichen Freundlichkeit. Von Forrer nehme ich an, dass er jede solche «Ehrung» von sich gewiesen u. dazu Hand zu bieten sich geweigert hat. Nicht aus spezieller Renomme (obgleich auch diese mitgewirkt haben kann), sondern aus Kantigkeit, die er ja auch mit den Aussprüchen, von denen ich Dir gestern geschrieben, gezeigt hat. Wir fanden beim Mittagessen zusammen, dass es doch wirklich schade sei, dass gerade bei den Jahren mit besondrer Begegnung mit fremden Monarchen, 1906 mit dem König von Italien u. jetzt mit dem Deutschen Kaiser gerade Forrer Präsident sein musste, u. dazu noch gichtkrank! Nach den Aussprüchen Fehrs hat sich der Kaiser dann auch mit seinem Nachbar rechts fast ausschliesslich unterhalten $u$. den Nachbar rechts links quasi ignoriert. Jener war Hoffmann, dieser Forrer.

Auf dem Manöverfeld fiel es gestern u. heute auf, dass die französischen Offiziere den Deutschen Kaiser fast geflissentlich mieden u. immer theatralisch in einer Gruppe mit einem schönen

General als Schimmelreiter an der Spitze herumstreiften.

Es ist schon möglich, dass von dieser Seite aus gegen die Ovationen, deren Gegenstand der Kaiser war, noch Protest erhoben wird. Warten wir ab, wie die morgige Angelegenheit in Bern vorübergeht. In Frauenfeld sah ich nur ein klein wenig wie von Protest: Ein fliegender Händler verkaufte kleine tricolore Fähnchen, mit französischen Farben, ob aus Absicht oder aus 
Dummheit, weiss ich nicht. Am Abend aber ritten sechs Zivilisten aus dem Städtchen, deren Pferd solche Fähnchen trugen.

Auf der Automobilfahrt machte Will heute den Versuch, von Mosen direkt nach Sursee zu fahren. Der Weg war zu steil, u. wir mussten zurück, mit Verlust von mehr als einer halben Stunde. Der Chauffeur, Bucher, hat sich bei diesem Anlass, u. auch sonst, sehr nett benommen.

Das Automobilfahren ist übrigens nicht so erfreulich, wie man sichs vorstellt. Es ist zu offen, geht zu schnell, hat mit der Witterung, Sonne, Wind, Regen, viel zu viel Berührung. Wie weit angenehmer ist die Fahrt auf der Eisenbahn, oder gar ein Dampfschiff! Aufgefallen ist mir auch die durchwegs feindselige Haltung der Bevölkerung gegen das Auto. Nur die Kinder haben meist zugelacht.

Und nun müde zu Bett! Hilf mir zu tun, was zu tun ist! Ich bleibe in ewiger Treue

Dein

Eugen

\section{2: September Nr. 186}

[1]

B., den 6. / 7. Sept. 1912.

Mein liebstes Herz!

Also heute hat Bern den Kaiser empfangen. Es war kein grosser Enthusiasmus, aber viel Volk auf den Wegen, die er nahm, mit anständigem Hochgerufe. Elf Wagen, von denen er den zweiten besetzte, mit Forrer, der ihn fast zudeckte. Ich war mit Anna u. Marie u. den beiden Fräulein Reineck an einem der Westfenster der Bibliothek. Als ich mit Anna zurück wollte, konnten wir die Strassen nach Hause erst passieren, als der Zug vorüber war. Ich hatte den Eindruck, dass Bern für diesen Empfang im Volk keine Stimmung zeigte. Die Behörden nicht u. die Leute nicht. Die Mädchensecundarschule sollte Spalier bilden, der Direktor, Roten, lehnte ab. Die Kadetten sollten aufrücken, nur die Kadettenmusik 
war zur Stelle, oben an der Kornhausbrücke. An der Viktoriastrasse soll niemand hoch gerufen haben, erzählte Susanne. Ich kann mir gar wohl denken, wie es in den Gefühlen aussah, die Menschen sind so roh. Anna u. ich begegneten Frau Guhl, die weinend sagte, sie sei unter den Zuschauern schlecht behandelt worden. Forrer ist der Typ für diese Stimmung. Mir bangt davor, wenn ich denke, wie dieser Geist einmal durch die Geschichte seinen Lohn erhalten wird. Aber heute will ich froh sein, wenn es ohne Unglück vorbeigeht u. der Kaiser wieder wohlbehalten im Reich angekommen ist.

Als ich am Morgen in die Stadt ging, fand ich unter den Manöverkarten eine ausgestellt, auf der ich in der

Gruppe mit Bühlmann u. Will in der Nähe des Kaisers stehe, das hat mir Freude gemacht.

Auf der Bibliothek waren Anna u. ich am Fenster mit einem Pfarrer Ludwig u. seiner Frau, u. einem ältern, photographierenden Frl. v. Sinnes zusammen. Es waren merkwürdige Leute. Im Vorbeiweg wurde mir auch von v. Mülinen der bekannte Prof. Hess aus Kairo vorgestellt. Es ist eine ziemlich unansehnliche Erscheinung.

Siegwart ist um 10.50 abgereist. Ich habe ihn nicht aufgefordert noch über den Kaiserbesuch zu bleiben. Ich habe eine Art genug von ihm. Er war jetzt drei Wochen bei mir in Kost u. Logis, wovon sechs Tage mit Marieli zusammen, das hat mir auf die Nerven gegeben. Er war am Ende so unfassbar wie am Anfang. Immerhin will ich ihm alles Gute wünschen. Er wird seinen Weg schon machen, ohne dass ich ihm weiter helfe. An eine engere Verbindung mit ihm denke ich gar nicht mehr. Die Stimmung ist bei mir gewiss deshalb kühler geworden, weil er trotz Kenntnis meiner Abneigung Marieli nun doch geholfen hat, ein Velo sich anzuschaffen. Ich denke, Marieli wird es aus seinem Spargeld bezahlen müssen.

Und nun, was soll ich morgen tun? Ich bin bitter gestimmt, trotz der nun die sechste Woche beendigenden Ferien. Heute hatte ich noch aufzuräumen, u. nun soll der alte Trott wieder beginnen. Ich traf heute in der Stadt Walter B. u. s. 
Frau, die mir sagten, es sei heute ihr zehnter Hochzeitsfeiertag. Sie meinten, zehn Jahre seien eine lange Zeit, die doch so schnell

vorübergegangen. An unserm zehnten Hochzeitstag waren wir in Basel, d. h. Du in Blankenberghe. Ja, da war auch manches anders, als es später wurde.

Ich habe die gestrige Nacht den Schlaf noch nicht nachholen können, ich ging, obgleich ich mich von den Andern nach neun zurückzog, aus Missstimmung über das Velo u. seine beiden Käufer, nicht früh zu Bett u. stand zeitig auf. Ich will heute nun wenn möglich besser schlafen. Vielleicht wird es mir dann auch im Gemüt besser. Ich habe heute wieder einmal Liebe, hingebende Liebe Stunde für Stunde vermisst. Dazu war es kalt, nach der Rundfahrt des Kaisers regnete es. Es ist alles, alles unfreundlich geworden.

Den 7. Sept.

Es war heute ein recht frostiger Tag. Alles war kalt u. ich in erbärmlicher Stimmung. Es kam mir vor, alles sei mir missglückt. Und in der Tat, ich kann mit der Art, wie man mich behandelt, nicht zufrieden sein. Was ist jetzt aus den von Siegwarts Schwestern erbettelten, fast erzwungenen Annäherungen geworden? Marieli war zwei Wochen bei seinen Eltern zu Gast. Siegwart selbst drei Wochen bei uns in Kost u. Logis. Und das Resultat? Ein Velo hat sich gegen meinen Wunsch, den ich deutlich auch Siegwart aussprach, Marieli mit seiner Hülfe angeschafft. Und die Klavierspielerei, bei der nichts herauskommt, soll dazu fortgesetzt werden. Nicht ein einziges Mal vermag mich M. damit zu erfreuen oder andern eine Freude zu machen. Dann kam heute D. Lehmann aus Zürich zu mir, um mit mir über Wielands Kommentar zu sprechen. Er, Wieland, ist ein falscher Prophet, u. Leemann wird ihm auf eine Verteidigung hin auch entgegnen. Aber der penible Eindruck, mich mit solchen Leuten herumschlagen zu müssen, bleibt mir eben doch auf dem Herzen liegen. Es kam am Vormittag auch Elisabeth Hoffmann, um sich zu verabschieden. Sie geht für ein Jahr an das Conservatorium 
in München. Der Besuch freute mich u. Marieli, aber ich wurde des Unmutes doch nicht frei darüber, dass die Damen, die dem Kaiser Gruss u. Blumen boten, aus einer sonderbaren Aristokratie des Geldes u. des Judentums gewählt worden sind. Habeant sibi. Es waren vielleicht auch Freimaurer.

Ich las heute Arnolds 14. u. 15. Tagebuch. Immer der gleiche Eindruck:

Ein Mann mit grosser Energie, aber ganz u. gar unausgeglichen, oft cynisch, oft fanatisch. Ich begreife, wenn er schliesslich nur noch ein Ziel kennt, das Geldverdienen. Das ist dann noch die einzige Möglichkeit einer Konzentration. Ich bin gespannt auf seine Rückkehr, wenn er einmal zu mir kommen sollte.

Sonst erledigte ich heute Rückstände den ganzen Tag. Und das Lesen der Berichte über die Kaiserreise nahmen viel Zeit in Anspruch. Er ist nun glücklich wieder im Reich. Möge die Wirkung gut sein, ich bin dessen nicht sicher. Interessant war, wie Susanne Rossel gestern gelogen hat. Es seien am Viktoriaplatz fast keine Leute gewesen $u$. niemand habe Hoch gerufen. Und sie musste es erleben, dass ihr ein Bruder Müngerlis entgegnete, er habe sie dort gesehen, im Gedränge u. mitten unter den Hochrufenden. O diese Welschen!

Doch, ich bleibe heute verbittert. Kannst Du mir helfen? Ich würde so gerne anders sein, wenn ich auch nur ein bisschen Liebe um mich hätte!

Doch genug. Gute, gute Nacht. Ich bleibe bei Dir u. bitte um Deine Hülfe!

Immerdar Dein treuer

Eugen 
B. den 8. / 9. Sept. 1912.

Mein liebstes Herz!

Heute Abend fünf Uhr ist Freund Rümelin aus Genf hergekommen, um bis Donnerstag hier zu bleiben. Es ist also das erste Mal ein wirklicher Freundesbesuch im Hause, ohne dass Du ihn empfangen hast. Das tut weh, aber Wehmut mischt sich mit Freude darüber, dass ich doch an ihm eine wirkliche Freund schaft verspüre. Wir haben heute Abend schon über vieles gesprochen, was mir wohltat. Auch musiziert haben wir, u. ich sehe voraus, dass es ein recht netter Besuch werden wird, dem ich vielleicht auch eine Gemütserleichterung verdanken werde. Denn so schwer, wie es mir auch heute wieder war, darf es doch nicht bleiben. Den Vormittag fuhr ich fort mit Aufräumen u. war mit einigen Briefchen gerade fertig. Da kam Dürrenmatt, der sehr herzlich wieder einmal wissen wollte, wie es uns gehe. Er war noch da, so kam Walter B., u. als d. fortgegangen Mutzner, der sagte, dass er so herunter sei mit seinen Nerven wegen der überstandenen Ängsten um Frau u. Kind, dass er acht Tage Ferien machen müsse. Er geht nach Chur zu den Eltern. Seine Frau hat letzten Montag ein Söhnchen geboren, Raetus getauft. Es geht jetzt alles gut. Beide gingen dann, Walter B. u. Mutzner, miteinander fort, u. auf der Treppe sagte mir noch ersterer, Zürcher sei bei dem Nachtfest in Zürich auf dem Kaiserschiff gewesen (ob man mich nicht auch eingeladen habe), $u$. auf die Frage, er werde mit dem Kaiser, dem er vorgestellt wurde, über das Strafrecht gesprochen 
haben, habe er gesagt, nein, nur über den Vogelschutz. Ich hatte den Eindruck, Walter B. erzähle mir das absichtlich, mit einer Pointe, ich kenne ja vom letzten Winter her seine Schwäche mit Neid u. Schadenfreude. Und dazu musste ich mir sagen, es sei doch eigentlich ein starkes Stück von Forrer, dass er derart Zürcher mit dem Kaiser zusammen brachte, u. mich geflissentlich nicht. Freilich bin ich um so mehr froh, dass ich der Aufforderung Mottas auf Kirchberg nicht Folge geleistet habe. Mit welchen neidischen Bosheiten wäre mir das wieder eingetrieben worden! Dies alles ging mir durch den Kopf, u. ich war wieder recht unglücklich.

Am Nachmittag kam Marie in den Garten zu mir u. teilte mir allmählich mit, dass Siegwart mit ihr sehr vertraut gewesen, erzählte mir einige Aussprüche, wie dass er das Vertrauen, das ich in ihn setze, nicht missbrauchen wolle u. s. w. Ich meinte, es scheine mir, Siegwart wolle überhaupt nicht heiraten. Und Marie meinte, das scheine wirklich so, aber wenn er heiratete, würde er wohl keine andre als sie nehmen wollen. Er habe ihr auch eine Stelle aus einem Brief seiner Mutter vorgelesen, worin von dem lieben Eindruck die Rede sei, den M. in Altdorf hinterlassen, u. s. w. - diese Mitteilungen hätten mir von Marieli früher gemacht werden können. Sie sind vielleicht auch geeignet, meine Stimmung zu bessern.

Von Maries Schwester Anna empfing ich heute einen zweiten Brief, worin sie für ihre Aussteuer um 150 Fr. bittet, die sie später natürlich zurückzahlen wolle. Ich weiss noch nicht, was ich darauf antworten soll. Gib Du mir einen guten Gedanken. Marieli habe ich weder vom ersten, noch vom zweiten Brief Annelis Kenntnis gegeben. - Nun aber schliesse ich

den Tag u. geh zu Bett. Ich werde durch Rümelin die nächsten Tage wohl jeweils bis Abends spät in Anspruch genommen sein.

Nur noch eines: Rümelin hat in einer Zeitung gelesen, Forrer sei beim Essen, wohl in Wil - vom Kaiser aufgestanden u. weggelaufen. Darauf habe dann der Kaiser über den leeren Platz hin mit General Stau ein intensives Gespräch begonnen. Das wäre 
jedenfalls nicht die Absicht Forrers gewesen, war es denn die mir ja auch sonst wohlbekannte Kartigkeit?

Gute, gute Nacht! Es ist Zeit!

Den 9. Sept.

Heute bin ich mit Rümelin in das Bundeshaus gegangen, habe die vom Kaiser gespendete Porzellan Standuhr betrachtet u. BR. Müller besucht. Wir vernahmen einiges vom Kaiser durch ihn, aber nicht viel Neues. Er war mit Rümelin sehr nett. Ich habe mich natürlich nicht zu beklagen. Dann spazierten wir zum Bärengraben.

Am Nachmittag machte er Siesta u. ich konnte zwei kleinere Anfragen beantworten. Von vier Uhr an regnete es in Strömen. Um fünf kam Guhl, der allerlei vom Kriegsdienst zu berichten wusste $u$. auch über Juristisches sehr nett mit Rümelin sprach. Nach dem Nachtessen wurde ein Schach gespielt, das ich gewann. Wie wir dann so zusammen sassen, befragte ich Rümelin, wie die gemischte Ehe sich gestalte, u. er versicherte mich, dass er mit seiner Frau darüber nie einen Anstand gehabt habe. Als dann Marieli die Photographien aus Altdorf etc. zeigte, kam Rümelin, wie wir allein waren, auf die Frage, ob da etwas im Tun sei. Ich klärte ihn soweit auf, dass ich sagte, es sei schon eine gewisse Annäherung vorhanden, aber ich glaube nicht, dass jemals etwas daraus werden könnte. Denn es sei für Siegwart unmöglich eine Protestantin zu heiraten, u. überdies würde die Frage der Kindererziehung grosse

Schwierigkeiten darbieten. Doch wolle ich darüber mir keine Gedanken machen. Denn ich nehme bestimmt an, dass Siegwart nicht an diesen Plan denke. Immerhin weiss ich jetzt, dass Rümelin sehr grosse Bedenken hätte wegen der Kindererziehung u. auch sonst. Also habe ich den Aufschluss, den ich wünschte, u. kann mir die Situation um so mehr abklären lassen. 
Ich bin jetzt recht müde, es ist bald zwölf. Den Tag über hatte ich bis nach drei Kopfweh. Jetzt "Gäzuruh», wie Arnold Heim geschrieben hat.

Gute, gute Nacht! Ich bleibe immerdar Dein getreuer

\section{Eugen}

\section{2: September Nr. 188}

B. 10. / 11. Sept. 1912.

Mein liebstes Herz!

Heute hat mich Rümelin am Morgen mit der Mitteilung überrascht, dass er meine «soziale Gesinnung» in dem Correcturbogen gestern noch durch lesen habe u. den Aufsatz sehr gut finde. Er machte einige Detailbemerkungen, die aber für die Hauptsache ohne Bedeutung sind. So will ich nun diese Betrachtung, die so sehr aus meinem Innern stammt, von Stappel laufen lassen. Ich werde sie nach Rümelins Abreise nochmals durchnehmen, $u$. dann vogue la galère!

Über Siegwart haben wir weiter gesprochen. Er war heute viel weniger bestimmt gegen eine allfällige Verbindung, u. ich habe den Eindruck gehabt, er beurteile die Sache nicht viel anders als ich. Weiter sich Gedanken zu machen, hat jetzt keinen Sinn. Es muss nun alles abgewartet werden u. verläuft vielleicht glatt $u$. spurlos. Wie Marie sich dazu stellen würde, ist bei seinem verschlossenen Charakter nicht zu sagen. Es muss alles seinen Weg machen.

Ich war dann mit R. nach einem Geschäftsgang in die Stadt auf dem Fried hof. Er war recht lieb bei dem Anlass. Dann machten wir Besuch bei Walter B., den wir an der Arbeit u. nicht besonders gut gestimmt getroffen haben. Aber den Besuch konnten wir ihm abstatten.

Das viele Reden, Essen u. Trinken, das ein solcher Besuch mit sich bringt, hat eine aufregende Wirkung. Schlafen kann 
ich dabei nach dem Essen nicht, u. doch ist auch der Nachtschlaf bei dem spätern zur Ruhe gehen verkürzt. Ich fühle mich nicht im Gleichgewicht. Daneben klingt mir der Ärger über so Manches, was ich erlebt, nach, u. ich weiss nicht, wie

ich darüber weg komme. Am besten ist es, darüber nicht nachzudenken, sondern einfach weiter zu leben. Es wird sich die Sache auch wieder beruhigen.

Juristisches sprech ich mit Rümelin weniger als sonst, was ich daraus erkläre, dass er selber sich weniger mit solchem beschäftigt als früher, infolge seiner Kanzler-Beschäftigung. Aber wo wir etwas aufgreifen, zeigt er die alte Schärfe. In seiner Gesinnung hat er nicht gewechselt.

Von Gierke u. seiner Frau erhielt ich aus Wachau einen Kartengruss, der mich sehr freute. Unbehaglich war mir nur, dass Gmür u. seine Frau mitunterschrieben haben. Gmür hat dergestalt nun einen Umgang genossen, der mir gehört hätte. Aber ich wollte ja nicht, indem ich eben auf anderes mich zuspitzte, das nun freilich auch wieder ein anderes war, als ich erwartet hatte.

Dann erhielt ich auch eine Karte von Will, der mir damit zuvorgekommen ist, aber doch erfreut hat. Ich bin froh, wenn die Fahrt ihm wirklich in guter Erinnerung steht.

Nach dem Kaffee machten Rümelin u. ich noch einen Spaziergang nach Wabern u. durchs Dählhölzli zurück, indes Frl. Reineck bei Marieli war. Nach dem Nachtessen gabs ein Schach, das ich wieder gewonnen habe. Daneben viel freundschaftliche Diskussion u. gemütliches Plaudern, wie ich es lange nicht mehr genossen habe.

Die Hauptsache war mir heute neben dem Urteil über die «Soziale Gesinnung», dass Rümelin mir bemerkte, der Prof. Faber, der Mariechen hätte heiraten sollen, sei auch Katholik, u. zwar ein gläubiger. Das muss ich doch mitbedenken.

Nun aber ist es wieder halb zwölf. Also gute, gute Nacht für heute. Hilf immerdar Deinem 
den 11. Sept.

Heute Nachmittag habe ich mit Rümelin einen Spaziergang nach der Universität gemacht $u$. ihm die Nr. 31 gezeigt. Dann gingen wir über das «Bund» Haus, wo Kaiser Bilder ausgestellt waren, nach dem Grundbuchamt. Guhl war eben am Einräumen der frisch erhaltenen neuen Möbel, empfing uns aber sehr zuvorkommend u. hat Rümelin die Tabellen des Grundbuchs sehr nett erklärt. Die Diskussion über einen Rechtsfall, den er mir vorlegte, hielt uns dann bis gegen zwölf dort zurück.

Nach Tisch kam Walter B. sehr nett u. blieb bis über halb vier. Wir haben über rechtsphilosophische Fragen u. Völkerrecht diskutiert, Rümelin erzählte einige Schnurren von den Tübinger «Gangen». So ist die Zeit rasch verflossen.

Heute Morgen erhielt ich durch die Post die sechs rechtsphilosophischen Arbeiten zum Stammler-Preis. Das wird mir schon eine Woche zu tun geben, sie zu lesen. Auch entdeckte ich, dass ich falsch gerechnet, indem heute über sechs Wochen die Vorlesungen wieder begonnen haben werden. So schliesst sich der Ring immer enger $u$. ich sehe voraus, dass ich bald ganz wieder in dem Trubel der Berufsarbeit untergehen muss. Das Amüsement dieser freien Zeit ist dann doch noch beieinander gewesen. Das andauernde schlechte Wetter hat zu solcher Verkürzung beigetragen. Die Zurücksetzungen, die mir widerfahren, beginnen zu verblassen. Gefreut hat es mich, dass Walter B. mir heute sagte, mein Aufsatz werde im Jahrbuch als erster erscheinen. Und zwar scherzhaft mit dem Motiv, an das ich in umgekehrter Richtung ja auch gedacht, nämlich damit ich dadurch veranlasst werde, im nächsten Jahr wieder etwas ins Jahrbuch zu schreiben. Kann schon sein, dass ich mich dazu animieren lasse. Ein Aufsatz über «Recht u. Macht» wäre z. B. nicht 
unangebracht. Überhaupt könnte ich auf diese Weise eine Anzahl Kapitel der «Rechtsphilosophie» zur Veröffentlichung bringen, ohne mich von meiner Hauptaufgabe zu viel zu entfernen.

Um halb sieben kam Leo Merz zu mir zu einer Consultation i. S. der Fusion der B. L. B. mit der T. S. B., u. bei dem Anlass teilte er mir mit, dass er die Wahl ins Obergericht mit der bestimmten Zusicherung der Präsidentschaft des Handelsgerichts anzunehmen [entschlossen?] wäre, wenn nicht die Collegien Schwierigkeiten betr. die künftige Wiederwahl machen würden. Dennoch wird er sich zur Zusage entschliessen, das glaube ich. Über seinen Bruder wusste er neuerdings keine gute Nachricht zu geben. Mir gefiel der Ausdruck seines heutigen Ernstes wieder von ganzem Herzen, das ist ein Mann!

Mit Rümelin haben wir nach dem etwas verspäteten Nachtessen musiziert $u$. dann geplaudert bis nach zwölf, sodass ich diese Zeilen diesmal um halb eins abschliesse. Die Feder ist mir zum Schluss mit Tinte über das Papier gerollt, $\mathrm{Du}$ nimmst es nicht übel.

Gute, gute Nacht, meine liebe Seele! Ich vertraue in allen kommenden schweren Zeiten auf Deine gute Hilfe u. bin allezeit Dein getreuer

Eugen

\section{2: September Nr. 189}

[1]

B. d. 12./ 3. Sept. 1912.

Meine liebe, gute Seele!

Heute ist Rümelin um 10 1⁄2 Uhr abgereist. Er war noch sehr nett, bemerkte, es freue ihn, dass er mich so gut aufgehoben gefunden, Marieli habe ihm ausgezeichnet gefallen, er habe so etwas liebes im Gesichtsausdruck erhalten. Auch Anna sei viel weniger hinfällig, als seine gleichaltrige Tante Schmoller. Ich nahm diese Bemerkungen freundlich auf, sie treffen ja freilich 
nicht die Hauptsache. Aber ich muss ja froh sein, wenn Rümelin so denkt. Ich war daneben gerade heute Vormittag am wenigsten in der Stimmung, mich so trösten zu lassen. Sei es in Folge des zu kurzen Schlafes (da ich vor 7 Uhr wieder aufstand), oder aus irgend einem anderen Grund fühlte ich mich sehr gedrückt, bemerkte auch Rümelin, dass ich jetzt dann wieder gegen Depressionen zu kämpfen haben werde. Die Arbeit sollte mir jetzt aufhelfen $u$. ich sehe auch beide Hände voll auf Wochen hinaus vor mir. Aber es ist keine erfreuliche Arbeit: Dissertationen, Preisaufgaben, Gutachten u. s. w. Und doch geht ja alles ins Fach, u. das war mir Jahre lang genug, um eine Arbeit willkommen zu heissen. Warum sollte ich es nicht auch jetzt noch so halten? Also will ich mich dahinter machen u. sehen, wie weit ich komme. Wenn es nur nicht so kalt wäre u. bliebe, wie diese Tage, wo man ohne Frösteln u. Ungemütlichkeit nicht auf dem Zimmer sitzen kann.

Am Bahnhof traf ich Schatzmann an, der auch Rümelin noch schnell begrüsste. Er war recht vertraulich u. wir gingen noch miteinander bis zum Rathaus. Vom Kaiser wusste er nichts neues. Er ist ihm zwar auch vorgestellt worden, hat aber mit ihm nicht gesprochen.

Am Nachmittag kam Gmür zu mir, von seiner Wiener Reise zurück, indes Frau Gmür noch bei ihrer Mutter in Ragaz einen Halt gemacht hat. Gmür hat viele Leute gesehen, aber zu näheren Bekanntschaften war keine Gelegenheit. Die Karte von Gierke wurde auf einem Gesellschaftsausflug auf der Donau geschrieben. Brunner wohnte in derselben Pension wie Gmür, aber er sei unzufrieden gewesen, infolge der Ablehnung eines Artikels in einer Zeitung oder dgl. Auch habe er über seine Gesundheit geklagt $u$. sei fast ein Hypochonder geworden. Von Klein überbrachte mir Gmür die besten Grüsse.

Im übrigen habe ich den Tag benutzt, um mit den Dissertationen zunächst zu beginnen: Begutachtung von Martins Arbeit, die ich im Sommer gelesen. Darauf Arbeit an einer Anfrage Hofers u. anderes Kleineres. So ist wenigstens 
ein Anfang gemacht. Ich werde sehen, wie weit ich morgen komme. Heut will ich unter allen Umständen zeitig zu Bett. Ich habe nachzuholen. Ich spürte es daran, dass ich in Aufregung nach Tisch die Augen nicht zu schliessen vermochte. Es ist besser gesund zu bleiben.

Den 13. Sept.

Heute Vormittag habe ich einige amtliche Angelegenheiten erledigt u.war bei Kaiser auf dem Departement, wo ich zugleich mit Hofer verhandelte. In einer nicht unwichtigen Adoptionsfrage gelang es mir, eine unrichtige Auffassung zu beseitigen. Auch sonst war der Verkehr sehr freundlich. Nur in einer gelegentlichen Bemerkung Kaisers fand ich ein Anzeichen, dass dessen Missstimmung über den Verkehr mit Mutzner u. Guhl immer noch nachklingt. Er lobte nämlich den freundlichen Verkehr mit dem Interims-Assistenten Hugo Meyer im Gegensatz zu dem mit andern in andeutender Weise. Nach dem Esseen war Walter B. bei mir, um mit mir eine Wasserrechtsfrage zu bebesprechen [sic!]. Nachher kam Kocher, der mich ersuchte, ihm bei der definitiven Aufstellung der Urkunde über seine Jubiläums-Stiftung behülflich zu sein. Ich hatte einen prächtigen Eindruck von dem Manne u. freue mich, ihm behilflich sein zu können. Rechne ich dazu die Lektüre einer Sammlung von Dokumenten über die Wirksamkeit in Bogota, die mir Röthlisberger in Privatdruck zustellte, so wären das die Eindrücke dieses Tage, wo ich wieder einmal «allein» war.

Bis auf eines, nämlich den Gang zum Friedhof, den ich am Morgen mit Marieli machte. Marieli ist entschieden lieber geworden. Aber es brachte es doch auf dem Gange nicht über das Schweigen. Ich begann mit ihm darüber zu sprechen, ob es denn anginge, dass es mein Secretär würde. Und es sagte wohl, dass es das sehr gerne täte. Aber als ich die Mühe der Erlernung der Stenographie erwähnte, blieb es stumm. So wird das nun eben nach seinem Charakter immer der Fall sein: Es kann sich für nichts begeistern, es ist im wesentlichen Verstandesmensch. Das ist ja schon sehr viel, aber es ist eine Art, an die ich mich nie werde gewöhnen können, wenn ich auch bemüht sein will, sie anzuerkennen $u$. ihr gerecht zu werden. Mit der Secretärstelle ist also noch nichts entschieden. Es bleibt 
vorläufig alles im Schweben, u. mit jedem Tag häufen sich wieder mehr die Rückstände. Ich weiss nicht was ich machen soll.

Marieli war heute bei Frau Mutzner u. brachte ihr ein Kindbettgeschenkchen, es wurde herzlich empfangen. Dann hat es bei der Frau Tecklenburg Besuch gemacht, ohne bis dahin darüber weiter gesprochen zu haben.

Meine Arbeit war den Tag daneben das Dissertationenlesen, u. das wird mir jetzt noch weiter viele Zeit in Anspruch nehmen.

Wenn ich nur gesund bleibe! Auf heute u. mit heute war bestimmt eine Änderung des Wetters in Aussicht gestellt. Aber am Abend regnete es wieder. Ich habe den Gasofen, den wir s. Z. miteinander kauften u. einrichteten, angesteckt. Anna hat in Erinnerung an Deine liebe Fürsorge mich dazu gedrängt $u$. ich fühle mich besser dabei. Die Centralheizung können wir doch noch nicht spielen lassen. Mitte September! und Sophie geht morgen für etwa 12 Tage in die Ferien mit Karle. Es wird ihr gut tun. Sie hat sich übrigens während Rümelins Besuch recht brav gehalten.

Und nun lese ich noch einige Kapitel Dissertationen $u$. gehe dann zeitig zu Bett.

Ich spüre, dass ich mich wieder concentrieren muss. Die Zerfahrenheit wird mir zum Schmerz. Sie würde mich auch in einen Zustand versetzen, in dem ich den schweren Zeiten, denen ich vielleicht entgegen gehe, schwerlich gewachsen wäre. Die Concentration aber gibst Du mir, in Dir vereinigt sich alles, was mir das Leben bietet, weil ich mit Dir das Leben zu dem gestalten konnte, was es mir war.

Innigst bitte ich, hilf mir! Ich bleibe ewiglich Dein treuer

Eugen 
B. d. 14. Sept. 1912.

Mein liebstes Herz!

Ich habe heute wieder Dissertationen gelesen, die eine erledigt, die ich schon in der ersten Ausfertigung im Sommer gelesen (Zehnder), eine andere begonnen, nämlich die von Lauch, die mich bis jetzt sehr befriedigt. Dann las ich einen Aufsatz von Dr. Schmid in der Gewinn u. Geschr., der auf 1970 oder 2000 das Aufgehen der Schweiz im deutschen Reich prophezeit, u. zwar wegen der unaufhaltsam fortschreitenden Überflutung der Schweiz durch Fremde. Und dabei unterlässt er nicht darzulegen, dass diese Selbstauflösung sich friedlich bewerkstelligen werde $u$. dass sich die Einzelnen, namentlich in Zürich durch diese Entwicklung in wirtschaftlich bessere Verhältnisse versetzt fühlen dürften, als sie jetzt bestehen. Der Aufsatz plagte mich, weil er ja Gedanken Ausdruck gibt, denen ich auch schon nachgegangen bin, u. ich brachte ihn Walter B. damit er ihn auch lese $u$. wir darüber miteinander sprechen können. Ich denke dabei daran, dass er im nächsten Jahrbuch zu der Frage einen Artikel schreiben sollte, wenn seine trockene Art hiezu ausreicht. Wie oft habe ich gerade in diesem Zusammenhang an das Zivilrecht gedacht u. an den «Hannibal», den ich zufällig bei der Ehrenmitgliedschaft in der "Concordia» in Laupen in der Vereinsmütze erhielt! - Bei dem Besuch sah ich auch die vielbesprochene Kaisernummer der Leipziger [?] Zeitg., die aber lange nicht hält, was sie versprochen hat. Walter B.s Aufsatz konnte ich auch nicht lesen. Die Ztg. bringt auf einer Seite sechs neun Bilder von Schweizerischen 
Zeitgenossen, darunter neben Häusler, Kocher, v. Salis, Borel, A. Forel, Alb. Heim auch das meine. Es ist merkwürdig, wie sich diese Publikationen nun so arg zerstreuen $u$. nichts rechtes zu bieten vermögen, nichts Ganzes. Die Hast der Reproduktion verdirbt alles.

Am Nachmittag war ich bei Scheurer, der mich wegen einer Detailfrage herrief, die er ganz gut hätte von sich aus lösen können. Er ist eben bei aller Gescheitheit doch ein etwas beschränkter Geist, der alles furchtbar formal auffasst u. sich aus den Anwaltsgeleisen schwer zu befreien vermag. Mit ein paar Worten hatte ich ihm den Standpunkt klar gemacht. Aber ob er nicht gleich wieder in andere Schwierigkeiten hinein geraten wird? Jeden Fall behandelt er, als würde er unter einem besonderen Gesetze stehen $u$. vermag den Zusammenhang der Rechtssätze unter sich schwer zu fassen.

Sein Secretär Satzmann, ein fleissiger, eifriger, aber nicht sehr intelligenter Jurist, den ich wohl kenne, hat sich, wie ich schon von Guhl hörte, überarbeitet. Man sprach sogar von Gehirnblutungen, was nun aber wieder vom Arzt wegdiagnostiziert wird. Guhl meinte, er sei «ein Opfer Wielands", er habe sich an dem unverstandenen Wesen dieser Commentierung, die er zu ernst erfasst u. genommen, überstudiert. Kann schon sein. Seine Krankheit dauert jetzt schon zwei Monate, doch soll es ihm wieder besser gehen.

Ich sprach mit Scheurer auch über Leo Merz, er nimmt an, dass dieser die Wahl als Präsident des Handelsgerichts annehmen werde, u. auch wegen der späteren Wiederwahl werden die Oberrichter dem Druck der Grossräte u. der Handelswelt wohl nachgeben müssen. Wegen Viktor Merz, meint er, dass

die Wiederwahl durch die Bundesversammlung im Dezember, auch wenn die Krankheit andauern sollte, sicher sei. Nur im Frühjahr müsste er sich dann entscheiden. In der Art wie Scheurer von diesen Dingen sprach, lag eine eigentümliche souveräne Manier des «Schiebens» nach Willkür. Auch da fehlt nach meinem Eindruck 
das Herz des wirklichen Staatsmannes. Ich bin gespannt, wie sich die Karriere noch gestalten wird, wenn ich es erlebe. Ob Scheurer sich als Bundesrats Kandidat eignen würde? Ich meine es, aber die Dinge gehen manchmal gar zu merkwürdig.

Die Nachricht, dass Zürcher mit dem Kaiser über den Vogelschutz gesprochen, scheint sich nun darauf zurückzuführen, dass in der N.Z.Z. zu lesen war, auf dem Schiff seien die Vertreter der Behörden u. Nationalräte gewesen u. als Beispiel der Vielseitigkeit des Kaisers wurde angeführt, dass er mit Fabrikdirektoren über moderne Maschinen $u$. mit einem Rechtsprofessor über den Vogelschutz gesprochen. Frau Burckhardt hat das dann offenbar in freier Phantasie weiter ausgesponnen.

Ich bin mit meiner Gesundheit immer noch nicht zufrieden, u. leide unter Befürchtungen, die sich hoffentlich bald als grundlos herausstellen werden. Sonst bin ich ein armer Mann. Aber ich muss mich an das Beispiel halten, das Du gegeben: Geduldig tragen, was kommt. Ein Glück, dass ich jetzt bereits wieder in die Arbeit eingeschossen bin u. mit innerer Freude am Pult sitze. Dann wird auch Schlimmeres schliesslich gut vorüber gehen.

Sophie ist heute mit Karle nach Chaux-de-Fonds verreist $u$. will morgen nach Zweisimmen - Altensried. Sie darf, wenn nichts dazwischen kommt, bis zum 24. weg sein, u. inzwischen wird Marieli haushalten. Das hat heute eine nette Karte von Claire erhalten u. dann kam auch das berüchtigte Velo. Ich kann mich dazu nicht erheben, diese Anschaffung zu begrüssen, aber

ich denke, es wird in andrer Beziehung am Ende doch von guter Wirkung sein. Es ist so falsch, immer zu denken, die Sachen müssen nach meinem Kopfe gehen. Es kommt ja meistens auf solche Kleinigkeiten nicht an. Wenn nur das Ergebnis gut wird. Also werde ich mich fügen.

$\mathrm{Zu}$ Annelis Gesuch um eine Hochzeitsgabe habe ich immer noch keinen Beschluss gefasst. Wir müssen sehen, was das beste ist. Ich bin seit den unfreundlichen Erfahrungen vom letzten Frühjahr so zaudernd u. misstrauisch gegen mich selbst geworden. 
Das Wetter will immer noch nicht besser werden. Ich habe heute Abend wieder den Gasofen angesteckt.

Gute, gute Nacht! Dein immerdar treuer

Eugen

\section{2: September Nr. 191}

[1]

B. d. 15. Sept. 1912.

Mein liebstes Herz!

Ein stiller Sonntag, Nebel, Wolken, kühl, aber kein Regen. Marieli hat seinen Geburtstag gefeiert, wirklich innerlich vergnügt, auch durch liebe Gratulationen von vielen Seiten erfreut. Es hat gekocht, Besuche waren keine da, ausser einen kurzen Augenblick Susanne. Zu einem Gespräch mit ihm bin ich auch nicht gekommen, ich hätte das nicht vermocht, ohne über den Velo-Ankauf u. die Bitte Annelis mit ihm zu sprechen, u. für beides war mir der heutige Tag nicht geeignet, also habe ich, nur unterbrochen von einem Besuche Rossels, Lauchs Dissertation erst fertig gelesen $u$. eine tüchtige Arbeit bis an den Schluss darin gefunden, wenn auch einiges noch verändert u. ergänzt werden muss. Dann aber las ich einen Aufsatz von Maumann über Wundt in der d. Rundschau, zum 80. Geburtstag, wobei mir Wundts Arbeit gerade aus der Kritik, die Maumann ihr anfügt, ganz besonders klar $\mathrm{u}$. ansprechend entgegen getreten ist.

Marieli hat von Siegwart eine Gratulation erhalten, ohne jede Andeutung eines näheren Verhältnisses, also ohne jede Möglichkeit, ein Urteil zu gewinnen, aber mit freundlichem Humor. Ich habe bei mir diesen Brief mit dem Abbühls verglichen, den es auf dem Klausenpass erhalten. Darin ist doch ein ganz anderer Enthusiasmus, wenn der ächt ist. Aber ich darf es nicht wagen, hier nun einzuschreiten. Man kann auch die zwei Briefe, beide aus dem Militärdienst, nicht wohl miteinander vergleichen, schon wegen des verschiedenen Alters 
u. der verschiedenen Stellung der beiden. Wenn es wahr ist, dass in der Ehe immer eines liebt, u. das andere sich lieben lässt, so hätte ich den Eindruck, dass S. sich als der Begehrte geben möchte,

während A. ausgesprochen der Begehrende ist. Wie sich Marie zum einen oder anderen Vorgehen innerlich stellt, ist mich [sic!] noch nicht klar.

Und daneben bin ich heute in einer der Stimmungen, die Du in Herbsttagen oft an mir erfahren, nur dass sie heuer früher eintreten, weil die Natur der Jahreszeit vorausgeeilt ist. Ich fühle eine Sehnsucht, weit weg zu ziehen, u. das verbindet sich mit dem Gedanken an Dich. Die weite Reise, die ich jetzt vor mir sehe, ist die letzte Reise, die jeder macht. Denn schliesslich sehe ich ja, dass in den äussern Verbindungen u. Verhältnissen ich vom Leben nichts mehr erwarten darf. Ich muss froh sein, wenn es mich vor allzu schwerem Ungemach bewahrt. Heute werden es hundert achtundzwanzig Wochen, seit Du um diese Zeit zu mir ins Studierzimmer gekommen u. Abschied genommen hast. Und es ist mir zu Mute, wie immer, ich finde mich in die Einsamkeit, aber das Leben bietet mir nur noch ein Zuwarten, $u$. keine Ziele mehr. Das ist im Grunde auch recht gut, denn man schätzt die Lebenszeiten richtiger ein, als wenn man in dem Streben nach ihnen umfangen ist. - Ich bin nun schon in der Arbeit wieder recht ordentlich eingeschossen $u$. arbeite mit Freude, weil dies mein bester Trost ist. Ich sehe nun noch fünf Ferienwochen vor mir, ich weiss auch, wie ich sie zu verwenden habe. Etwa zwei Wochen werden noch den Dissertationen u. den Stammlerischen Preisaufgaben gewidmet werden müssen. Dann bleibt mir wohl noch Zeit für die Rechtsgeschichte. Rossel sprach mir heute einerseits von der angenehmen Tätigkeit im Bundesgericht $u$. anderseits von der Mühe des Packens seiner Bibliothek. Ich entgegnete, dass ich mich eigentlich nur durch die 
vielen Nebenarbeiten, Dissertationen u. Anfragen, belastet fühle, im übrigen aber den Gedanken an einen Wechsel auch nur in der Wohnung von mir weise. Es gibt für mich wirklich nichts anderes, als hier nun getreu auszuhalten, noch zu arbeiten, was ich kann, mich in die kleine, unsympathische Umgebung zu fügen $u$. treu zu sein bis in den Tod. Die Besprechung mit Scheurer von gestern, der Besuch bei Kaiser, bei Guhl, von letzter Woche konnten mir ja deutlich vor Augen führen, dass ich nur noch ein respektierter wohl, aber geduldeter Mann bin. In dem Aufsatz von Schmid, den ich gestern erwähnte, ist das auch berührt, wie sich bedeutendere Leute in den kleinen Aufgaben ohne die Möglichkeit voller Entfaltung verzehren. Aber denke ich dann wieder an die Mitteilungen Fehrs über seine Achtmann-Kollegien, so muss ich ja wohl mich hier wie ein König fühlen. Aber wäre ich in Halle geblieben? Das sind müssige Gedanken, die wir zusammen ja oft erwogen, um sie schliesslich von uns zu weisen. Was wir da als richtig erachteten, warum sollte ich es nicht jetzt, wo ich allein bin, auch als richtig empfinden?

Ich nehme mir mit aller Seelenkraft vor, nun noch so gut als nur möglich hier zu arbeiten. Es wird noch vieles zu tun geben, $u$. ich will auch mitarbeiten. Mag es mir auch oft schwer gemacht werden, die Hauptsache ist, seelenstark zu bleiben. Und wenn nicht eine übermächtige Krankheit kommt, so will ich das wohl mir als letztes Lebensziel festhalten!

Anna ist seit Rümelins Besuch recht zusammengefallen. Marieli dagegen zeigt ein Aufleben, von dem ich nur hoffen kann, dass es anhalte. Wenn ich mich auch einsam fühlen muss, so ist doch eine befriedigendere Gestaltung in meinem Hause nicht ohne Bedeutung für mich. Ich werde wohl auch gesundheitlich mich wohler fühlen, als wenn sogar in dieser engsten Beziehung, die mir 
noch geblieben, mein Gemüt immer nur auf Dinge stösst, die mir weh tun $u$. mich verbittern.

Doch ich verliere mich wieder! Gute, gute Nacht! Bleibe bei mir u. halte mich in Deinen Armen als Dein allzeit treuer Eugen

\section{2: September Nr. 192}

B. d. 16. Sept. 1912.

Mein liebstes, bestes Herz!

Heute habe ich die letzte Dissertation, die noch auf Lager war, erledigt u. dann ein wenig Ordnung geschaffen. Nachmittags war Walter B. ein Stündchen da. Nach her machte ich einen Spaziergang zum Grundbuch, traf aber Guhl nicht. Den Vormittag fühlte ich mich pessimistisch $u$. stellte mir alles mögliche von Peinlichem in Erwägungen u. in Befürchtungen vor Augen. Nachmittag fühlte ich mich leer, unlustig zu jeder Concentration $u$. doch nicht müde. Es wäre so die rechte Stimmung gewesen, um mit einander hinaus zu gehen. Da wäre das Gemüt zu seiner Befriedigung gekommen $u$. hätte die Seele ausgeruht u. sich gestärkt zu weiterer Arbeit. So flanierte ich über beide Brücken, traf viele Bekannte, die mich grüssten. Aber es war halt doch nicht eine innere Erholung, weil ich allein war. Marieli hatte der Agnes Vogel eine Lateinstunde gegeben u. die Schülerin blieb dann als Freundin bis nach sechs Uhr.

Walter B. brachte mir den Aufsatz von Schmid zurück, u. er bekannte sich zu demselben Eindruck, von dem ich ihm gesprochen. Er denkt nun daran Material zu sammeln u.im Jahrbuch 1913 einen Aufsatz mit gehöriger Beleuchtung der Frage der Entnationalisierung der Schweiz zu veröffentlichen. Das wird schon recht sein, wenn er es durchsetzt. Daneben sprachen wir 
von den Doktorarbeiten u. ich bekannte ihm meine Not, aber auch meine Bedenken, die Sache etwa in die Hand Guhls gleiten zu lassen. Ich habe nun gerade bei den Arbeiten

[2]

Lauchs u. Steiners gesehen, wie leicht die jungen Leute aus Missverstand etwas kritisieren, wofür ich dann doch vor der Welt die Verantwortlichkeit trüge, obgleich es gar nicht meiner Ansicht entspricht, umgekehrt gerade von meinem Standpunkt aus zurück zu weisen ist $u$. auch mit den besten Gründen zurückgewiesen werden kann. Es wird eben immer wieder darauf hinauslaufen, dass ich diese [?] auf mich nehmen muss, solange ich dabei bin u. erst sie von mir weisen darf, wenn ich auch die Professur verlasse. Auf dieses letzte verweisen mich ja immer wieder viele Gründe. Aber der einzige Gegengrund ist entscheidend, den ich schon oft genannt: Leben müsste man doch, also solange man leben kann, gilt es auch zu arbeiten. Und wo könnte ich nützlicher arbeiten als in diesem mir nun doch angepassten Gebiet? Vorwärts drum, ohne Bedenken, ja ohne Gedanken. Lieber einmal leichtsinnig sein, als mit schwerem Nachsinnen sich alles verderben.

Wenn ich die nächste Zeit so rasch vorwärts komme, die letzten Tage, so sollte ich in der Zeit bis zum Semesterbeginn noch recht ordentlich mich tummeln können u. am Ende dann doch noch mit den Ferien zufrieden sein müssen. Ob ich aber nicht doch noch ein paar Tage weggehe? Nach Monthey? Ich habe es eigentlich Pauline versprochen. Also da ich mehr als früher darauf halte, solche Versprechungen, die in momentanen, aber guten Impulsen gemacht worden, zu halten, unentwegt, so werde ich wohl die Fahrt machen müssen. Ich würde auch gerne nach Stammheim fahren, die Erinnerung an den letzten Besuch in dort ist gar freundlich. Zum Juristentag im Oktober werde ich wohl 
auch erwartet, u. es wäre aus verschiedenen Gründen angezeigt, hinzugehen. Wenn ich nur mehr Lust dazu hätte. Ich kann es nicht beschreiben, was mich von dieser Vereinsversammlung fern hält. Ich bin seit 1904 niemals mehr hingegangen, hatte jedes Jahr eine neue Entschuldigung, u. im Grunde war es eben eine Entfremdung gegenüber dem Geist, der hier sich festgesetzt, die Präponderanz des süffisanten Baslertums u. der inhaltsleeren kulischen Juristerei. Vielleicht würde ich wieder anders denken, wenn ich wieder einmal hinginge. Die unschöne Erinnerung an den Tag in Chaux de Fonds mit der süffisanten Rede Fareys als Präsidenten würde dann vielleicht ausgewischt. Wäre die Geschichte mit der Cantate Reichels nicht dazwischen gekommen, so würde ich wohl letztes Jahr nach Luzern gegangen sein. Im Jahr 1910 in Genf war es mir seelisch unmöglich, mich unter die Menge zu mischen. Im Jahr 1909 hatten wir Commissionssitzung in Heiden, als die Tagung in Aarau stattfand mit den Dementurenproduktionen. Im Jahr 1908 vertrieb mit Fick mit der unfeinen Art, in der er mir zum voraus die Ovationen schilderte, die ich empfangen sollte, $\mathrm{u}$. die dann auch so plump abgewickelt wurde, von der Zürcher Jeannette Dorée u. den Juden u. Meilifreunden, dass ich froh darüber war, mich versetzt zu haben u. in Heidelberg u. mit Dir in dem lieblichen Badenweiler geblieben zu sein. So könnte ich zurück gehen, immer war etwas von einem Hindernis, das objektiv gerechtfertigt doch auch meinem subjektiven Empfinden entsprochen u. mich von diesen Verhandlungen fern gehalten hat. Soll ich nun etwas anderes wieder beginnen? Soll ich diesmal gehen, wenn kein unerwartetes Hindernis mich abhält? Ich weiss es noch 
nicht. Du gibst mir inzwischen noch einen guten Rat. Übermässige Freude hast Du seit den Erlebnissen von 1890 in Zürich auch nicht daran gehabt.

Und nun genug für heute. Ich will noch ein klein wenig lesen u. dann wieder zeitig zu Bett. Bleibe bei mir, wie ich bei Dir als Dein allzeit getreuer

\section{Eugen}

\section{2: September Nr. 193}

B. d. 17. Sept. 1912.

Mein liebstes Herz!

Heute war ein wirklich schöner Herbsttag. Wenn die Ferien auch vorüber, so hat man ihn doch genossen. Ich sass vor Tisch mit Guhl ein Stündchen an der Sonne im Garten, nachmittags las ich auf der Terrasse, u. nach dem Nachtessen war es sehr angenehm im Garten sich zu ergehen.

Ich habe mich heute an die Preisaufgaben über das Rechtsgefühl gemacht $u$. emsig gelesen, nur ein Weilchen durch Guhl unterbrochen, die drei erstnumerierten sind nicht gross, aber es war interessant, die drei Typen kennen zu lernen, die sich da an die Aufgabe gemacht. Der erste ist ein populärer Stilist, der in sehr lebendiger Schreibart seine ganze Welt- $u$. Rechtsauffassung darlegt. Als Preislösung nicht genügend. Der zweite scheint fachphilosophisch zu sein. Er handelt ganz gescheit von dem Verhältnis der psychischen zur erkenntnistheoretischen Auffassung u. analysiert das Rechtsgefühl, bis dann gegen den Schluss sich alles unfertig aneinanderreiht. Der dritte tritt auf wie ein von sich eingenommener Referendar. Es ist gar nichts zu machen mit dem Dutzend Lehrsätzen, die er aufstellt, u. nur zu wundern, dass jemand glaubt, mit so was einen Preis gewinnen zu können. 
So weit bin ich gekommen, $u$. ich hätte gerne nun mit Musse diese Arbeiten der Reihe nach durchgenommen. Aber da erscheint heute Hugo Meyer $u$. bringt mir seine nun fertige Dissertation von über 300 Folioseiten. Das war mir ein wirklicher Schlag.

Kaum hatte ich geglaubt mit den Dissertationen unter Anspannung aller Kraft fertig geworden zu sein, sofort wieder eine, $u$. ich fürchte, so geht es jetzt wieder $u$. ich zersplittere mich in dieser Kleinarbeit.

Ich habe mir überlegt, wie es mir diesen Winter mit der Zeit gehen werde. Es wird sich nicht anders richten lassen, als dass ich eben fortfahre, alle Geselligkeit zu meiden. Dann kann ich vielleicht von den sechs Arbeitstagen, unter Abzug der sieben halben Tage, die mir die Collegien beanspruchen, in fünf Halbtagen etwas zusammenhängend arbeiten, am 1. Bande. Bis zum Semesterbeginn sind es nach dieser Woche noch vier. Die muss ich auf die eingelaufenen Arbeiten $u$. anderes was sicher noch kommt, verwenden. Vielleicht bleibt mir noch Zeit, mich etwas mit der Rechtsgeschichte zu beschäftigen. Ich bin ganz unglücklich, dass sich das alles so compliziert gestaltet, aber es ist, wie ich neulich schrieb, kein Entrinnen, sondern nur ein entweder - oder. Also bleiben wir dabei, solange es geht!

Gestern Abend gegen neun kam noch Haenny zu mir u. blieb bis gegen halb elf. Ich hatte Freude an ihm, wie er so von seinen Erlebnissen erzählte. Das neueste ist ihm bei der Ausstellung im Schweiz. Kunstsalon in Neuenburg begegnet. In der Aufnahme-Jury sitzt der Basler Graveur Frey, u. der berichtete Haenny, es sei alles, was er eingesandt, gut aufgenommen worden. Mit einem Vorbehalt. In einem Kästchen mit Broncen wurden zwei, die Haenny als die 
besten taxierte, zurückgewiesen u. Haenny vernahm erst welche, nachdem Frey bei ihm gewesen. Offenbar habe Frey diese zurückgewiesen, weil mit ihnen Haennys Ausstellung eindrucksvoller gewesen wäre, als die Freys selber. Und solches muss der Künstler erleben! Zurzeit concurriert Haenny auch um die CarnegieMedaille, wieder mit Frey. Was er mir von dem einen u. andern Entwurf gesagt, hat mich sehr für Haennys Vorlage eingenommen, gesehen habe ich ihn noch nicht. Aber die Preisrichter seien alle mit Frey befreundet $u$. kennen die Autoren.

Auch sonst erzählte er mir Vieles von Künstlers Erdenwelten, unter anderem auch von dem [L?] Niederhäuser, der durch ein Ehrenkreuz in Paris ausgezeichnet worden ist. Morgen will ich bei Haenny die Rechnung begleichen. Es ist keine wohlfeile Sache.

Heute ist nun auch die Kaiser-Nummer der ill. Leipziger erschienen. Der Artikel Walter Bs. ist recht, aber kühl, temperamentlos, wie es für diesen Anlass sich fast nicht schicken würde, wenn nicht die Nummer überhaupt viel ärmer wäre, als die Reclame versprochen. Amüsiert hat es mich, dass Häusler im Bild neben mir steht, u. dass ich zuerst besprochen u. er «auch» als ein hervorragender Jurist besprochen wird. Aber das gleicht sich dadurch aus, dass uns beiden voran der Baron von Salis-Marschlins aufrückt. Es ist eine amüsante Sache für den, der solche Journalistenpfade zu würdigen weiss. Die Bilder sind im übrigen nicht übel.

Und nun will ich heute bälder zu Bett als gestern. $\mathrm{Zu}$ lesen habe ich nichts mehr für diesen Abend. Ich fühle mich übrigens immer noch recht gedankenleer, weiss gar nicht was das ist. Ob mir die grössere Beweglichkeit gar nicht mehr

kommt? Oder ob es nur der Einfluss der sieben Wochen Regen mit Nichtstun ist, was derart die Gedankenwelt hat eintrocknen lassen? Das wird sich auch wieder zeigen. 
Gute Nacht, meine liebe, liebe Seele! Ich sollte halt mir Dir jetzt ein wenig plaudern können. Dann würde es rasch besser. Ach, solange ich es konnte, habe ich es zu wenig getan. Ich könnte manchmal auf meine getane Arbeit wütend werden, wenn ich daran denke, was ich darob auf immerdar verpasst habe!

Gute, gute Nacht von Deinem allzeit treuen

Eugen

\section{2: September Nr. 194}

[1]

B. d. 18. Sept. 1912.

Mein liebstes Herz!

Heute habe ich mit Mühe die Hälfte von Nr. 4 der Preisaufgaben gelesen $u$. viel dabei gelernt. Aber ich bin doch nicht zufrieden, weil ich mit der Zeit nicht zurecht komme u. mich wieder weniger wohl gefühlt habe. In der Nacht hatte ich stechenden Schmerz im rechten Auge. Er ging vorüber, am Morgen war nichts sichtbar. Es kommt vielleicht von dem andauernden gestrigen Lesen her. Und ich machte mir Gedanken, ob ich die stärkere Anspannung, an die ich gestern dachte, auch noch ertragen würde. Was soll ich dann anfangen? So tauchten mir in der Nacht wieder Rückzugsgedanken auf.

Nach dem Essen war Bühlmann mit seiner Frau bis halb vier Uhr bei uns, zum Kaffee u. einem Glase Wein. Er war sehr herzlich, seine Frau diesmal reservierter. Dabei kamen wir auf Guhl zu sprechen, mit dem Bühlmann diesen Morgen conferiert hat, u. er rühmt ihn sehr. Wie er das Buch, das er ihm zugesandt, so freundlich beurteilt, u. dass er es bis auf wenige Seiten schon gelesen habe. Und gestern sagte mir Guhl, er habe es noch nicht gelesen, erst wenige Seiten. Es ist das ein kleiner Zug, der mich aber wieder stutzig machen kann. Er gehört in das zu lieb reden, das ich schon an ihm mehrfach beobachtet, so in seinem Brief auf den Klausen u. gestern, da er meine Aufforderung, vor den Ferien nochmals zu mir 
zu kommen mit den Worten beantwortete «gern, wenn ich darf». Bühlmann ist voll seiner Arbeit, er geht jetzt noch dreimal auf die Jagd, zuerst nach [?], dann nochmals dorthin

[2]

u. nachher ins Elsass. Er brachte mir noch eine Kaiserphotographie, auf der ich en face ganz deutlich hinter den Offizieren stehe, während der Kaiser mit [?] v. Sprecher redet.

Vor dem Essen war ich bei Haenny. Er zeigte mir seine neuesten Sachen, namentlich den Entwurf einer Carnegie-Medaille. Der gefiel mir ausserordentlich. Ich hoffe, dass er vor dem Entwurf Freys den Vorzug erhalten werde. Aber Haenny hat bei der guten Freundschaft der Preisrichter mit diesem wenig Fidus. Ich brachte ihm zu den 200 Fr., die ich ihm im Winter gegeben, nochmals 200 für den Guss u. die andern Sachen, die er mir gemacht oder geschenkt. Er schaute die Inlage nicht an, dankte aber herzlich. Er wird wohl zufrieden sein, u. damit will ich nun die Beziehungen etwas lockern. Ich bin eben doch kein Mäzen, weder nach Mitteln noch nach der Gemütsanlage.

Weshalb war ich nun heute, namentlich bei Bühlmann Besuch, wieder so niedergeschlagen? Es muss sein, dass ich - wie auch zeitweise beim Besuche Rümelins - zu viel innerlich verglichen u. darob die Ruhe verloren habe. Es ist so schwer, wenn die Gedanken kommen, jetzt solltest Du da sein, darüber hinwegzukommen. Ich spüre bei solchen Anlässen dann jeweils meine Einsamkeit doppelt stark. Es war ja alles ganz recht, was Marie u. Anna rüsteten. Aber es ist halt doch nicht das Alte. Und wir waren so aneinander gewohnt. Ein Wink $u$. wir verstanden uns. Nun ja, das ist mir ein Fingerzeig, dass ich mit dem Gesellschaftlichen Leben nicht beginnen soll, wie ich es sonst etwa halb u. halb überlegt habe. Es ist ja auch sonst besser, wenn ich mein bisschen Kraft auf die Arbeit concentriere, solange es 
noch geht. Heiterer wird man dabei direkt nicht. Aber die Mühen werden sich doch allmählich überwinden lassen, u. vielleicht ist mir doch noch ein gemütsheiterer Abschnitt beschieden. Ich weiss nur nicht, ob ich die Kraft habe mir dies zu erringen!

Heute Abend habe ich nun auch von Anna Röthlisberger nähere Mitteilungen über ihre Verlobung erhalten $u$. werde ihr nun eine richtige Geldgabe zuwenden. Wäre es riskiert, ihr $500 \mathrm{Fr}$. zu senden? Ich bin moralisch schon etwas engagiert durch die Offerte, die ich ihr im März machte. Motiviert wäre also die Gabe. Aber könnte sie weitere unangenehme Folgen nach sich ziehen? Das soll kein Grund sein. Ich möchte Deinen Rat haben, ich weiss Du hast in solchen Dingen radikaler gedacht als ich, aber vielleicht würdest Du mir doch den Rat geben, diesmal eine offene Hand zu haben. Sie schickt mir heute die Photographie des Bräutigams, Jutzeler, die Hochzeit soll am 2. Nov. stattfinden. Von den Geschwistern hat sie in allen drei Briefen kein Wort mehr gesprochen.

Heute war ein sehr schöner Herbsttag u. männiglich äusserte die Hoffnung, dass es nun besseres Wetter geben werde. Ich war ganz dieser Ansicht. Aber auf den Abend ist es auffallend warm geworden, u. am Ende haben wir gleich wieder Regen. Für mich wäre es eine innere Freude, wenn noch etwas Sonne käme. Der stete Regen hat mir schliesslich nun doch genug gegeben. Ich schreibe meine Neigung zum Düstern zum Teil diesem Mangel an Sonne zu. Wenn ich nun bloss mit der Arbeit einiger massen vorwärts komme! Und nicht krank werde! Ich gehe ja mit Mut dem Semester entgegen, mag es mir auch mancherlei Enttäuschungen bringen. An Rümelin gefiel mir, wie er so offen davon sprach, dass der Besuch seiner Collegien sehr zurück gegangen sei.

Wie würde das anders auf dem Herzen liegen.

Bühlmann brachte mir einen Gruss von Stooss, der von Bergün noch nach Ragaz gegangen war $u$. nun in Wien sein wird. Scheints hatte er die Absicht alle Akten betr. die Art, wie er behandelt worden, zu publizieren. Doch Bühlmann hat es ihm ausgeredet. 
Und nun auch dieser Tag wieder vorüber! Bleib bei mir, liebe Seele! Ich habe Dich nötig, wenn ich allen drohenden Unbilden Stand halten soll!

Ewig Dein

\section{Eugen}

\section{2: September Nr. 195}

B. d. 19. / 20. Sept. 1912.

Mein liebstes, bestes Herz!

Ich lege seit einiger Zeit bei den kühlen Nächten $u$. dem ungeheizten Hause die Chaise-longue-Decke auf das Bett u. befinde mich so wohl dabei, dass ich mich doch wieder gefragt habe, ob nicht der Mangel an genügend warmer Bettdecke Dir in dem letzten Winter geschadet habe. Du äussertest Dich ja einige Male in dem Sinne, ob ich auch warm genug habe. Ich bejahte es, u. du selbst wolltest nichts anderes haben als ich. Aber hat das doch Deine Kräfte angegriffen. Als ich s. Z. Lüscher davon sprach, meinte er freundlich lächelnd, das sei ganz u. gar nicht anzunehmen, umgekehrt sei ein kühles Lager bei schwachem Herzen nur gesund. Aber er wusste nicht, wie Du von Jugend auf ein «Baumwoll-Kindli» gewesen. Kurz, der Gedanke ist mir wieder gekommen. Ich kann es halt nicht verwinden, dass es so habe kommen müssen. Es war so keine sichtbare Notwendigkeit, es muss ein Unglücksfall gewesen sein. Und daran trage ich nun vielleicht noch manches Jahr!

Heute las ich die vierte philosophische Arbeit fertig, angestrengt aber mit Freude u. Gewinn. Die 5te, ebenso umfangreich, ist dagegen ein Quatsch, was sich schon darin zeigt, dass ich in drei Stunden die Hälfte lesen konnte. Wie verschieden diese Leistungen! Es wird mir schwer werden, eine Auswahl für die Prämierung zu finden, oder Stammlers Vorschlägen zuzustimmen.

Um zwei kam Lauch zu mir, u. ich habe bis gegen halb vier mit ihm seine treffliche Dissertation besprochen. Zuerst wollte 
er, in aller Höflichkeit, sich gegen meine Bemerkungen auflehnen. Aber dann erkannte er mehr u. mehr ihre Begründetheit $u$. hat sich gut aus der Sache gezogen. Der junge Mann, mit dem roten Gesicht $u$. den roten Haaren, ist in Genf, wo er nun vier Monate war, mägerer geworden. Er gefiel mir sehr. Es ist aber doch eine eigentümliche Fügung, dass er jetzt die etwa acht Jahre ältere Frl. Reineck heiratet. Sie ist freilich auch so ein Naturkind, voll Enthusiasmus u. doch voll Rücksichtslosigkeit. Und so ist es möglich, dass eine Übereinstimmung besteht, die sie aufs trefflichste zusammen binden wird. Ich bemerkte schon früher einmal, dass die studierten Frauen scheints jüngere Männer an sich reissen. Und bei Paul war es etwas ähnliches. Hätte er nur die Bovet nicht von sich gewiesen. Wie viel Leid wäre da erspart geblieben!

Sonst ist der Tag in aller Stille verlaufen. Marieli wird durch die Haushaltung sehr angestrengt. Aber sonst geht es recht. Am Abend ging sie in die Stadt, um das Velo zu bezahlen, u. zwar aus ihrem Sparkassen Büchlein. Das konnte ich ihr nicht ersparen. Wie es auf sie wirkt, ob es sie richtig stimmt oder zum Trotze reizt, will ich abwarten. Sie spricht viel von Siegwart, wie von Abbühl. Ein eigenes Zusammentreffen ist es, dass diese beiden vorgestern ganz unerwartet im Manöver am Sustenpass gegeneinander fechten mussten. Vielleicht vernimmt man noch das eine oder andere darüber. Die Oberländer mussten vor den Urnern nach hartem Zusammenstoss weichen.

Heute sagte Frau Burckhardt zu Marieli, ich soll doch ihrem Mann zureden, dass er nicht nur zehn Tage Ferien mache. Er habe jetzt immer von Morgens sechs an gearbeitet $u$. sei sehr

[3]

ermüdet. Es trifft sich, dass ich ihm das schon gesagt habe. Aber er war nicht dafür zu haben. Es scheint mir überhaupt, dass er in eine wachsende schlechte Stimmung geraten ist. Kann auch sein, dass meine Ablehnung des Abendessens mit Rümelin ihn geärgert hat. Aber ich habe dir ja schon gesagt, weshalb ich nicht anders handeln konnte. 
Für heute schliesse ich. Ob wir morgen wieder Sonne haben? Heute war es zwar nicht kalt, aber den ganzen Tag bedeckt, auch nicht ein einziger Sonnenstrahl.

Den, 20. Sept.

Heute bin ich mit der 5ten u. der 6ten letzten Preisaufgabe fertig geworden, da sich im Verlauf zeigte, dass nur noch rezeptive historische Ausführungen zu lesen waren, die ich rasch überfliegen konnte. Mit Stammlers Würdigung gehe ich einig, bis auf zwei Punkte. Ich schätze Nr. 5 sehr gering ein u. Nr. 4 viel höher. Ich werde wohl beantragen Nr. 4 auch zum ersten Preis zuzulassen, dann meinetwegen mag Nr. 5 auch einen zweiten Preis erhalten. Es wird schwierig sein, Stammler darüber zu schreiben. Das will ich aber erst in einigen Tagen machen.

Der Tag ging mir vollständig auf in dieser Arbeit. Ein Stündchen war Walter B. nach dem Essen da, um Abschied zu nehmen. Ich sagte ihm, vielleicht besuche ich ihn in 14 Tagen. Er meinte, dann sei er nicht mehr in den Ferien, worauf ich ihm zureden konnte, wie seine Frau es gewünscht. Vielleicht bleibt er jetzt 14 Tage in Sitten, wohin er mit Frau u. Fredi zu reisen gedenkt.

Dann war ich vor dem Nachtessen bei Mutzner, der nun allein das Departement vertritt. Er scheint sehr munter zu sein. Bei dem Anlass vernahm ich, dass Werner Kaiser einen Strafrechtsentwurf ausgearbeitet u. der Redaktionskommission im August vorgelegt habe, aber die Kommission sei gar nicht darauf eingetreten. Ob es sich so verhält? Wer weiss es? Guhl habe darüber zu berichten gewusst. Ist es so, so tut es mir leid für Kaiser. Seine Arbeit war gewiss

sorgfältig entworfen. Aber bei dem Bestand der Red.Kommission konnte wohl vorausgesehen werden, dass man ihm ein «zu spät» entgegenhalten werde. Vermutlich wird das aber nur eine Verschiebung auf die parlamentarischen Beratungen bedeuten.

Ich bin wieder sehr matt u. gedankenarm. Es war wieder gar keine Sonne, fast den ganzen Tag. Ich brannte mein Gasöfelchen. Meine Augen brennen mich. In dem linken Oberschenkel brennt mich gleichsam der Knochen. Es wird rheumatisch sein. Ich fühle 
mich nicht recht bei Stimmung oder bei Gesundheit. Letzte Nacht träumte mir von Pferden u. von Hermine Abegg. Letzteres erinnerte mich an die Pflicht, wieder einmal ihr einen Gruss zu schicken. Ich sandte ihr eine «Kaiserkarte», mit der Papierbildfrage: Wo ist der Vetter?

Und nun sei der Tag geschlossen. Schlafe ich zu viel?

Nun ja, es wird wieder anders kommen.

Gute, gute Nacht, bleibe meine liebe teure Seele, wie ich festhange an Dir als Dein getreuer

Eugen

\section{2: September Nr. 196}

B. d. 21 / 2. Sept. 1912.

Meine liebe, gute Lina!

Über nichts geht doch die Zeit so rasch vorüber, als wenn man Tagelang über derselben Arbeit sitzt. Gestern Abend wurde ich mit den Praxisarbeiten fertig, in der Nacht legte ich mir zurecht, was ich an Natorz u. Stammler schreiben soll. Den Vormittag sass ich über den Korrekturen zur «Gesinnung» die ich um halb drei für die Druckerei zur Post geben konnte. Dann schrieb ich an Stammler u. Natorz u. verpackte die Arbeiten für Marburg. Und als ich nach dem Nachtessen im Garten, wie jetzt häufig, eine halbe Stunde auf u. ab ging, musste ich mich ernstlich fragen, was ich denn heute Vormittag getan. Vollends lag es mir wie ein Traum auf dem Gemüt, dass schon wieder Tag u. Nacht-Gleiche da u. wir mitten im Herbst stehen. Es ist nur zu wahr, man hat im Alter nicht mehr dieselben Eindrücke, wie früher, u. zwar geht es mit den Erlebnissen, die herankommen, auf Stufen abwärts. Ich sagte heute zu Marieli, ich hätte den Eindruck älter geworden zu sein in diesen Ferien, was es zwar lebhaft bestritt. Aber es ist doch richtig. Der ewige Regen, der Mangel an Sonne, das Gefühl der Zurücksetzung, das alles hat an mir den Einfluss geltend gemacht, dass ich älter geworden. Vielleicht wird es mit dem 
Beginn der Kollegien wieder besser, vielleicht auch umgekehrt. Das ist ja immer meine Sorge auf Beginn eines Semesters gewesen.

Heute wurde mir das fortgeschrittene Alter auch noch durch einen lieben Besuch vor Augen geführt: Alexander Schweizer aus Cairo kam her, der letzten Herbst mich auch besucht hatte. Er erwies sich wieder

als sehr anhänglich. Ich habe das um ihn u. um Hohnloher (Alexandrien), der mich ja auch bei jedem Aufenthalt in der Schweiz aufsucht, nicht besonders verdient. Aber es tut wohl, an solchen ehemaligen Schülern eine interesselose Anhänglichkeit wahrzunehmen u. zu geniessen. Es scheint übrigens Schweizer in Cairo recht gut zu gehen. Bank- u. Cementgeschäft florieren. Interessant war es, wie von ihm über die Engländer zu vernehmen, wie sie das Land mit den beherrschenden Stellen ausbeuten. Ohne jede Fachbildung u. ohne Verdienst werden da junge Männer aus englischen Familien versorgt. Die tun nichts, als andre für sich arbeiten zu lassen $u$. den gesellschaftlichen Vergnügen nachzustehen, bilden aber natürlich allzusammen eine Stütze der englischen Herrschaft. Seit Lord Kitschener regiere, sei es noch schlimmer geworden, als vorher. Ganz anders die Deutschen. Wo sie ankommen, senden sie gebildete Leute, die das Fach verstehen. So sei das mit einem Agrikultur-Institut in den letzten Jahren gewesen: Der [?ve] habe Deutsche hergerufen, zum Ärger der Engländer, die es dann auch durchgesetzt, dass der Direktor ein Engländer geworden. Aber die hiezu bestimmte Person, ein Elephantenjäger aus Indien, habe gar nichts verstanden $u$. habe über die Deutschen ein impertinentes Regiment führen wollen, bis der erste derselben einmal dem Engländer in aller Grobheit seine Untüchtigkeit vorgehalten habe. Seitdem behandle dieser die Deutschen besser. Wir mussten uns zusammen sagen, es werde überall in den englischen Verwaltungen so stehen $u$. schliesslich sei es gerade deshalb nicht so unmöglich, dass Deutschland die bessere Kriegsflotte besitze, weil die technisch gebildetere, $u$. dass es über Englands Übermacht am Ende doch siegen würde! 
Ich habe nun, soviel ich sehe, eine ruhigere Woche vor mir, wenn nicht Unerwartetes kommt. Darüber bin ich von Herzen froh!

\section{Den 22. Sept.}

Heute habe ich in der N. Z. Z. die Nachricht gelesen, dass Rietschel in Tübingen gestorben sei! Das hat mich ganz ergriffen $u$. in eine starke Gemütsbewegung versetzt. Er war so freundschaftlich auf dem Klausenpass. Ich hatte ein Gefühl von Wärme im Umgang mit ihm, wie selten mit jemandem. Es war mir, ich müsse mit diesem Mann näher bekannt werden. Und jetzt ist alles wieder zerstört. Man muss sich bald Gedanken darüber machen, alt zu werden, wenn man sieht, wie die Besten u. Treusten früh dahingerafft werden. Ja, es ist etwas daran: Nicht sich ausleben ist der wahre Lebenszweck, sondern sich aufopfern in einem nach Massgabe der Kräfte bestimmten Ziel! Ich schrieb an seine Frau, u. an Rümelin, der mir wohl bald näheres mitteilen wird. Es muss ihm u. seiner Frau der Verlust sehr nahe gehen, oder ich täusche mich am Gemüt meiner Freunde.

Ich denke nun daran, der Anna Röthlisberger ein Sparheft mit 500 Fr. zu senden. Das wäre zugleich eine kleine Entschädigung für die Enttäuschung, die sie durch mich erfahren hat. Ich ging heute Abend zu Rossel, um ihn über eine Bank zu fragen, in Tavannes. Aber er war nicht orientiert. Bei dem Anlass machte es mir den Eindruck, er warte noch einmal bei uns eingeladen zu sein. Soll ich es tun? Ich weiss es nicht, u. kann Dich nicht beraten. Würdest Du wohl dazu stimmen? Ich habe noch Zeit mich zu besinnen.

Heute habe ich lange am Kaminfeuer gesessen. Den Vormittag erledigte ich Pendenzen, las eine schöne Biographie Dahns von Herbert Meyer. Am Nachmittag schrieb ich den lange verschobenen Brief an Watherill in Philadelphia über die englische Übersetzung des ZGB. 
Sonst fühlte ich mich ruhiger. Es beginnt sich im Gemüt abzuklären. Ich sehe nun deutlicher, weshalb ich so gerne mit dem Kaiser ins Gespräch gekommen wäre, dass ich schon im Frühjahr Hoffmann über die Möglichkeit anfragte: Ich dachte mir, darin läge eine Anerkennung des Gesetzbuches in seiner Bedeutung auch für Deutschland. Ich würde so gerne eine Bedeutung für einen weiteren Kreis postuliert haben, um damit der Schweiz auch etwas mehr Perspektive zu geben. In dem gleichen Sinn dachte ich vor zwei Jahren an die Berufung nach Leipzig u. entschloss mich vor drei Jahren zur Zusage betr. die Haager Konferenzen. Allein dies alles ist mir vereitelt worden. Und zwar von einem Geist, der eben in dem Kleinleben befangen für diesen weitern Ausblick kein Verständnis hatte. Brenner sagte es mir ja einmal geradezu, ich soll doch zufrieden sein, ein geachteter Professor in Bern zu sein. Und Forrer hat natürlich den gleichen Gedanken gehabt in noch engerem Rahmen. Wie wenn es sich da überhaupt um ein Persönliches gehandelt hätte. Das ist die reinste, unmittelbarste Segnung des kleinstaatlichen Lebens. Andere haben das vor mir erfahren. Ich denke nur an Numa Droz. Aber ich bin, sobald ich das erkenne, persönlich darüber hinaus. Nur wird das immer noch mitklingen, dass dieser Geist der Umgebung mich verhindert hat, dem Lande Dienste zu leisten, die ich gekonnt hätte, u. die andere nicht können. Und damit soll die Sache abgetan sein. Kommt auch vielleicht weiteres dazu, so muss ich es nach demselben Massstab messen. Und nun schliesse ich wieder einen Sonntag ab. Gute, gute Nacht. Jeder Sonntag Abend zeigt mir das Bild Deines letzten Besuches. Ach Gott, Du versprachest, bald wieder zu kommen u. dann für länger. Geschieht es nun wirklich bald? Ich harre Deiner, mein Lieb, als Dein allzeit treuer

\section{Eugen}


B. d. 23. Sept. 1912.

Mein liebstes Herz!

Endlich ist mein «Dissertationentisch» leer (bis auf einige der bekannten Examensarbeiten). Hugo Meyer hat seine Diss. heute abgeholt, nachdem ich seine Verbesserungen $u$. Ergänzungen so weit nötig controliert hatte. Ich bin darüber sehr froh, indem ich jetzt früher an die Durchsicht der Rechtsgeschichte gehen kann, als ich befürchtet hatte. Freilich ist es ja sehr wahrscheinlich, dass gleich wieder eine neue Dissertation eingebracht werden wird. Damit muss ich mich dann wieder abfinden.

Ich war heute Vormittag noch aus einem andern Grund froh gestimmt, indem ich in der Nacht den Einfall gehabt hatte, meiner Bibliotheksraumnot durch Aufstellung eines grossen Regals, senkrecht zum Seitenfenster, abzuhelfen. Leider kam ich dann aber, als ich am Vormittag den Gedanken mit dem Ellstecken controllierte, in Conflict mit Teppich u. Möbeln, sodass ich der Ausführungsmöglichkeit nicht sicher bin. Aber etwas muss geschehen, u. helfen im Überlegen tut mir jetzt halt niemand. Anna kanns nicht, u. Marieli denkt an anderes.

Es war heute kalt, fast auf Null, u. wir können nicht heizen, weil Sophie noch ein paar Tage abwesend ist $u$. Ruef niemand schickt, trotz Telephon. Der Gasofen hilft noch, aber beim Stillsitzen ist es eben doch an Füssen $u$. Knien kalt. Nun ja, es geht ja rasch vorüber. Mit Marieli wollte ich heute über das kommende Semester sprechen, auf seinen Wunsch. Aber es kam dann 
dann [sic!] nicht wie verabredet, zu mir hinauf, wohl weil es seine eigenen Gedanken hat $\mathrm{u}$. die sprach es gestern Abend direkt aus, indem es sagte, das Kolleghören sei ihm mit jedem Semester mehr zuwider. Es möge nicht daran denken. Dafür spielte es auf die Klavierstunden an. Aber ich wies es darauf hin, dass ja auch in dieser Beziehung eine Fortsetzung u. energische Förderung nicht möglich sein werde, wegen der Schmerzen in der Achsel. Morgen hätte es eigentlich wieder die schon einmal verschobenen Stunden bei Reding aufnehmen sollen. Auf den morgigen Tag hat es nichts geübt. Ich sagte ihm auch, dass es ganz u. gar nicht mehr correct spiele, dass es früher doch einige Stücke beherrscht habe, jetzt aber kein einziges mehr. Es hörte das nicht gern, allein es ist so, $u$. ich habe ganz den Eindruck, dass darin das Fehlen einer wirklichen musicalischen Anlage deutlich zum Ausdruck komme. Es ist mir dann auch gar nicht mehr daran gelegen, dass Marieli die Stunden weiter nimmt, es kommt, wie sich nun deutlich heraus zu stellen scheint, gar nichts heraus, weder Kunst noch etwas für den Hausbedarf. Ich könnte auch nicht sagen, dass mir das eine schmerzliche Erfahrung sei. Am Ende ist es ja ganz gut, wenn Marieli sich mehr u. mehr dem Haus zu widmen beginnt. Solang ich lebe, hat sie dabei das Auskommen. Und wenn sie in der Sorge für eine andere Zukunft gar keine Neigung $u$. keinen Eifer bezeigt, so mag sie das schliesslich mit sich selbst ausmachen. Ich vermag da, bei ihrem selbständigen, unzugänglichen Wesen, nichts zu machen, als sie vor ökonomischen Folgen schlimmer Art zu schützen, u. das habe ich getan.

Ich hatte gestern Guhl erwartet, der heute in die Ferien zu reisen erklärt hatte. Da er nicht kam, hiess ich Marieli telephonisch Frau Guhl anfragen, ob sie wirklich heute verreisen. Da Guhl selbst ans Telephon kam, besorgte Marieli die Sache sehr tappig, $\mathrm{u}$. Folge davon war, dass Guhl heute vor Tisch noch sich zu verabschieden versprach. Nun wollte es der Zufall, dass etwas vor Guhl Frau Oberst Hebbel ankam, u. mit mir über ihre Steuergeschichten 
u. den Conflict mit ihrer Schwägerin sprechen wollte. Ich musste Guhl warten lassen, als er kam, was er sehr unfreundlich aufnahm, u. musste von Frau Hebbel mich früher, als unser Gespräch es verlangt hätte, verabschieden, was ihr sehr missfiel. So ist die Sache nach beiden Richtungen ungeschickt ausgefallen, freilich für den Charakter des einen u. der andern ganz typisch. Frau Oberst hat wieder grässlich geschimpft, es tut einem weh, einen solchen Mangel an Ausgleichung u. Überlegung bei einer Frau ihrer Bildung u. Lebenserfahrung wahrzunehmen.

Von Rümelin erhielt ich einen Brief mit näheren Nachrichten über Rietschels Tod. Er starb an derselben Krankheit wie Barth. Es scheint R. sehr nahe zu gehen, seine Frau hat ihren Aufenthalt in Freudenstadt abgebrochen $\mathrm{u}$. ist nach Hause geeilt, wo jetzt auch Busch scheint es als erkrankt zu Gaste weilt. So kommt die gute Frau Rümelin zu keiner rechten Erholung, nicht ohne seine Schuld.

Ich habe heute Nachmittag mit der Durchsicht der Rechtsgeschichte beginnen können. Vielleicht gelingt es mir, das Ganze so durchzusehen nach Roberts Stenogramm, dass eine Vorarbeit für späteren Druck vorliegt. Wir wollen sehen.

Gestern Abend schickte ich noch Marieli zu Rossels, zu fragen, ob sie Ende der Woche noch einmal bei uns essen wollten. Sie

waren aus. Susanne aber versprach, bei ihrer Rückkehr zu fragen u. heute zu berichten. Es ist aber kein Bericht gekommen.

Das sind nun wieder die Erlebnisse eines Tages. Will sehen, wie die Woche weiter geht.

Meine liebe, gute Seele - ich wollte so gerne, es würde mir leichter im Gemüt, ohne dass ich weniger eng mit Dir verbunden wäre. Das wird schon kommen. Es bedarf eben viel Zeit u. glückliche Umstände. Wird das eintreffen?

Gute, gute Nacht, von Deinem immerdar treuen Eugen 
B. d. 24. Sept. 1912.

Meine einzige Liebe!

Heute habe ich eine weitere Papierbeige, die wochenlang auf meinem Schreibtisch gelegen, entfernen können: Die letzten Korrekturen der «sozialen Gesinnung» sind erledigt. Es ist merkwürdig, wie der blosse Anblick solcher Bündel bedrücken kann, es war mir in letzter Zeit manchmal, ich werde zugedeckt von all den Sachen bis an den Hals hinauf, u. dann wusste ich fast nicht, wo anfangen, um damit fertig zu werden. Aber jetzt konnte ich schon freier atmen. Ausser ein paar nicht schwierige Gutachten ist jetzt nichts mehr pendent, als die Kollegarbeit u. das Obligationenrecht.

Die erstere begann ich gestern mit der Durchsicht der Stenogramme Roberts, über die Vorlesungen d. Rechtsgeschichte vom Sommer 1911. Und da erlebe ich nun freilich eine Enttäuschung. Das gibt viel mehr Arbeit, als ich gerechnet, ich müsste, um damit vor dem Kollegienbeginn fertig zu werden, die ganze noch übrige Ferienzeit darauf verwenden, u. da ist es mir doch fraglich, ob das angezeigt wäre. Ich komme also vielleicht dazu, jetzt nur davon zu erledigen, was ohne Mühe nebenbei gemacht werden kann, u. der grössere Teil der Durchsicht während des Semesters selbst zu besorgen. Das wollen wir uns ruhig überlegen. Ob ich dann auch noch mit dem Privatrecht mich abgeben kann, bleibt abzuwarten. Jedenfalls muss ich noch Praktikumsfälle vorbereiten, u. dies führt vielleicht zu weiterem. 
Ich habe den Tag über nichts anderes gearbeitet, als die Stenogramme gelesen. Aber freilich kam dabei nicht viel heraus. Um zwei Uhr kam Staatsanwalt Raaflaub zu mir u. blieb bis halb fünf. Ich habe den jungen Mann sehr gern. Ich ehre in ihm den trefflichen Charakter, den bescheidenen Sinn u. das hohe Billigkeitsgefühl. Das letztere hat er in seinem frei sprechenden Urteil über den Gesundbeter Rüetschi bekundet, ein Urteil, das dann von der Polizeikammer des Obergerichts umgestürzt worden ist. Aber das Bundesgericht hat seinerseits das Urteil der letztern aufgehoben $u$. so ist Raaflaub prächtig gerechtfertigt. Das war auch der Anlass, dass ich ihm geschrieben, worauf er nun mich besucht hat. Seine Gegner, namentlich der Mediziner Grandjean, der in Interlaken eine Nervenheilanstalt leitet, übrigens auch ein Alt Helveter, werden nun wohl ihre Polemik im «Bund» nicht mehr aufnehmen. Wir sprachen über allerlei, namentlich auch militärisches. Er denkt auch daran, noch eine Dissertation zu schrieben.

Wir litten heute wie gestern unter der Kälte, hätten gerne die Centralheizung angefeuert $u$. erhielten von Ruef trotz alles Telephonierens keinen Mann. Jetzt soll Sophie um halb neun zurückkehren. Wird sie kommen? Ich hoffe es, ich bin schon darüber nicht zufrieden, dass sie sich nicht von selbst gemeldet, wie es kalt wurde. Aber sie hat nicht dieselbe Sorgsamkeit u. nicht den gleichen Pflichteifer, wie Kathri, die s. Z. so pünktlich auf die Stunde aus den Ferien zurückkehrte, obgleich sie die drei Wochen kein Wort von sich hatte verlauten lassen. Wird

Sophie jetzt dann zur rechten Zeit kommen, so werde ich ihr das anrechnen u. mein Vertrauen in sie wird steigen. Kommt sie dagegen nicht, so bedeutet das in meinem Urteil über sie eine bedeutende Einbusse. Möge meine Befürchtung, dass das letztere wahrscheinlicher sei, sich nicht erwahren. 
Gestern Abend, ich hatte kaum meine Unterschrift unter den Brief an Dich gesetzt, kam noch der Sohn Teichmann ein Stündchen zu mir. Er brachte mir Grüsse seines Vaters u. Nachricht von dessen Befinden. Es scheint sich bei ihm um eine Blutvergiftung zu handeln, bei der seine Extremitäten anschwellen u. die Drüsen eitern, unter heftigen Schmerzen. Ein wahrer Hieb, es ist schwer zu sagen, was der Mann zu leiden hat. Der Junge ist ein gutes Kind, aber noch sehr unerfahren bei aller Gewandtheit im Sprechen. Er will nun doch bei Henn ein Jahr wenigstens aushalten. Wie er sich zu seiner Schwester stellt, ist mir nicht klar.

Heute habe ich nun doch Schreiner Rieser kommen lassen $\mathrm{u}$. ihm den Plan eines neuen Büchergestells, das im Schlafzimmer aufgestellt werden soll, vorgelegt. Natürlich hat er zugestimmt, u. darauf hin habe ich die Sache bestellt. Ich erhalte damit so viel Platz, dass dies mich nun für die Zeit, da ich noch Bücher anschaffe, aushalten sollte. Es beschlich mich ein merkwürdiges Gefühl, als ich diese Erweiterung der Bibliothek anordnete. Vor zwölf Jahren zog ich in das neue Studierzimmer ein, mit dem Gedanken, dass nun Platz für alle Zeiten geschaffen sei. Dann füllten sich rasch die Regale, u. nach einigen unbedeutenderen Erweiterungen muss ich jetzt wieder einen Hauptschnitt tun. Und niemand konnte mich dabei beraten. Ich fragte wohl Marieli, was es dazu meine, aber es bejahte schlechtweg den Plan, ohne nur die Bedenken zu bemerken, die dagegen sprachen. Du hättest mir wohl u. gut geraten. Aber wenn

Du noch bei mir wärst, würde überhaupt die Frage anders zu stellen gewesen sein.

Marieli erhielt eine Aufforderung durch Thilda, Ida zu besuchen, wenn Ida zur Empfangung von Gästen wohl genug sei. Es hätte gestern antworten sollen. Ich schrieb in der Nacht während einer wachen Stunde die Antwort in ablehnendem Sinn, u. Marieli konnte dann heute den Brief abschreiben $u$. abschicken. Bei Marieli waren heute zum Thee Gertrud, Susanne u. Helena Rossel. Am Samstag werden die Eltern bei uns zu Mittag essen. Heute sah ich auch Frau Mutzner wieder einmal mit der kleinen Lolette, einem prächtigen vierjährigen Mädchen. 
Sophie ist zur rechten Zeit angekommen, schlicht u. recht, u. ihr Karle war recht lieb! Wie bin ich froh darüber!

Gute Nacht, meine liebe teure Seele! Bleibe bei mir wie ich verbleibe Dein getreuer

Eugen

1912: September Nr. 199

[1]

B. d. 25./ 6. Sept. 1912.

Mein liebstes Herz!

Also Sophie ist gestern Abend mit Karle zur verabredeten Zeit ganz recht wieder heimgekommen. Ich bin darüber froh, es wäre peinlich gewesen, wenn sie nicht Wort gehalten. Sie hat auch heute die Arbeit willig wieder aufgenommen u. als ich ihr den Monatslohn (etwas früh) bezahlte, da ich eben am abrechnen war, bemerkte sie sogar dankend, aber das sei ja zu viel. Sie hat ja allen Anlass mit der Stellung bei uns zufrieden zu sein, aber nach ihrem früheren Wesen wäre ja ein anderes Benehmen nicht ausgeschlossen gewesen. Ihre «Ferien» verliefen übrigens günstig. Sie traf in Adlensried, ihre in Berlin verheiratete Schwester, Frau Moser, auf die sie einen so heftigen Hass geworfen hatte. Da scheint nun eine Art Annäherung oder Verzeihung stattgefunden zu haben. Frau Moser sei herzkrank $u$. bleibe den ganzen Winter oben.

Heute habe ich mich hinter das Gutachten für Schöpfer gemacht u. war Abends acht fertig. Zu etwas anderem kam ich nicht. Dann am Vormittag ging ich auf die Bank, wobei ich also für Anneli ein Sparheft [?], auf Tramelan, mit Einlage von $500 \mathrm{Fr}$. Will sehen, wie das aufgefasst wird. Marieli habe ich nichts gesagt. Auf der Bank traf ich Graf, u. beim Fortgehen hätte ich fast die 3000 erhobenen Franken liegen lassen, was mich vor dem Angestellten genierte. Am 
Nachmittag, wie ich eben wieder an die Arbeit wollte, kam Siegwart u. blieb bis vier Uhr. Er war sehr nett u. brachte allerseits Grüsse. Der Militärdienst hat ihm wieder nicht gefallen. Er war zu streng, für ihn noch besonders, weil er im Büreau arbeitete bis zum Ausmarsch, wo die fünf Kompanien von halb drei aus Andermatt mit Gewehr u. Tornister ohne längere Pause bis auf den Sustenpass marschieren mussten. Um 12 Uhr waren sie oben, richteten sich dann noch zur Verteidigung ein, der Feind kam erst am folgenden Morgen, allerdings noch in dunkler Nacht. Es sei oben bitter kalt gewesen. Siegwart ist von daher auch noch ziemlich verschnupft, aber sonst wohl an Leib u. Seele. Frau Dr. Jauch kommt morgen, sodass es sich also gut einrichtet, wenn er nicht bei uns schläft $u$. isst. Die Übersiedelung nach Freiburg soll in zwei Wochen stattfinden. Was Marieli noch mit ihm verhandelte, als es ihm das Velo zeigte (das ich noch nie gesehen), weiss ich nicht.

Marieli hat immer von «Aida» zu sprechen begonnen, sodass ich ihm heute die Erlaubnis gab, die Aufführung im Theater zu besuchen. Ich selber kann mich zum Theaterbesuch nicht entschliessen. Vielleicht leichter wäre es mir allein, als mit Marie. Es wird aber in allen Beziehungen besser sein, wenn ich die Lebensweise der letzten beiden Winter auch dieses Jahr beibehalte. Ich habe gar keinen Zug dazu, u. möchte das Stündchen abends mit Dir, wo ich so ganz ohne Überlegung schreibe, wie es mir gerade ist, um Deine Worte innerlich

zu vernehmen, niemals vermissen. Dagegen mag es ganz gut sein, wenn Marieli sich etwas enger an die Welt anschliesst. 
Den 26. Sept.

Heute nach dem Mittagessen hat mich Marieli mit der Nachricht überrascht, dass um halb zwei Siegwart kommen werde u. dass sie dann bis drei zusammen eine Velofahrt machen werden gegen Zollikofen. Siegwart miete ein Velo. Ich erschrak sehr, u. stellte Marieli dann vor, welches Risico es laufe, im Gerede der Leute. Siegwart sei doch kein Student mehr, dass er derart sich mit Marieli öffentlich zeigen dürfe, $u$. vollends mit dem Velo, auf dem vornehmere Damen in der Stadt gar nicht mehr herumfahren. Ein Wort gab das andere und ich wurde warm. Denn schliesslich habe ich doch ein wenig Verantwortung. Siegwart scheint ganz u. gar nicht ernste Absichten zu haben. Sein Benehmen sprach weder gestern noch heute in diesem Sinn u. die Briefe an Marieli auch nicht. Also wozu sich dann blossstellen? In der Leute Mäuler kommen? Für nichts u. wieder nichts? Glücklicherweise kam dann Siegwart gegen zwei Uhr mit dem Bericht, dass er kein Velo habe mieten können. Zwar sprach er dann davon, dass sie morgen die Fahrt machen wollten, aber darauf gab ich keine Antwort u. Marieli wartete $u$. wagte es auch nicht. Ich glaube, die Sache hat doch die gute Wirkung, dass Siegwart sich jetzt, wenn er wirklich nicht ernsthafte Absichten hat, zurückziehen wird. Das wäre mir auch recht. Ich weiss dann, woran ich bin. Dieses leidenschaftliche Berechnen u. Schwanken ist mir zuwider. Also!

Heute entdeckte Sophie einen grossen Vogel auf dem Tisch vor dem Esszimmerfenster. Sie rief Marieli u. dieses mich. Sie meinte, es sei eine Eule. Aber wie ich kam, erkannte ich darin einen Falk. Er flog dann auch, sobald ich im Garten um die Hausecke kam, Aren wärts davon. Man könnte in Aberglauben sich da etwas ausmalen.

Letzte Nacht sass ich im Traum in einer grossen Kapelle u. der Kaiser war unwirsch auf einer Estrade u. stellte den lauten Perpendikel einer Uhr. Dann trat plötzlich ein grosser, braun gekleideter Mann herein u. stürzte sich auf einen eleganten Uniformierten, der unter mir sass, warf ihn auf den Bauch 
u. prügelte ihn durch, dass es klatschte. Auch da könnte man sich etwas ausmalen in Traumdeutung.

Den ganzen Tag, ausser den Besuch Siegwarts u. einen halbstündigen Gang durch die Stadt, arbeitete ich an der Rechtsgeschichte, und bin noch nicht weit.

Heute konnte ich auch das Sparheft für Anna Röthlisberger aufgeben. Will sehen, was sie antwortet.

Ich bin nicht bei guter Stimmung, insofern als mich Marie wieder geängstigt hat. Hoffentlich, hoffentlich gibt's nicht noch ein Unglück!

Gute, gute Nacht - ich bin im Geist bei Dir auf Tod u. Leben!

Dein getreuer

\section{Eugen}

\section{2: September Nr. 200}

B. d. 27. / 8. Sept. 1912.

Mein liebstes Herz!

Heute habe ich wieder den ganzen Tag an der Rechtsgeschichte gearbeitet, nachdem ich noch die Correcturen für das Rechtswörterbuch (Quellenverzeichnis) in den eingelaufenen Bogen durchgesehen. Die Beschäftigung interessiert mich sehr u. ich habe mir wieder u. wieder überlegt, ob ich nicht doch den Schritt wagen u. die Geschichte über den Winter druckfertig machen soll. Wenn ich nur jemand hätte, der mir die Materialien aus Quellen $u$. Litteratur zu controlieren helfen würde! Aber so allein wäre es für mich eine heillose Arbeit, diese Drucklegung neben allem andern vorzubereiten.

Ich war sodann zweimal geschwind in der Stadt. Ich schrieb ferner an Rümelin eine Antwort auf die gestern von ihm aufgeworfene Kandidatenfrage, u. dabei entschloss ich mich, ihm Mutzner sehr, ja dringend zu empfehlen, wenn sie es mit einem Extraordinarius wagen wollten. 
Während ich diese Zeilen abschloss, kam ein neuer Brief Rümelins, worin er direkt frägt, ob ich nicht für Rechtsgeschichte, Deutsches Privatrecht u. Rechtsphilosophie nach Tübingen kommen würde. Die Anregung sei von Heck ausgegangen u. wurde von Rümelin nett $\mathrm{u}$. bescheiden weiter geleitet. Ich fügte daraufhin meinen Zeilen bei, dass ich herzlichst dankbar sei, aber dass ich nicht weg könne. Für mich gebe

es bei meinem Alter nur noch zwei Möglichkeiten, entweder auszuharren u. bis ans Ende in den Sichlen zu bleiben, oder mich ganz u. gar von jeder Amtspflicht zurückzuziehen. Was mir beschieden sei, hange von persönlichen Verhältnissen ab, über die ich nicht zu verfügen vermöge. Vielleicht gelangen sie nun auch an Egger. Und sollte dieser wider mein Erwarten gehen, so wäre dann eine Beförderung Guhls nach Zürich ziemlich sicher. Also kann man noch Überraschungen erleben.

Siegwart kam heute nach dem Nachtessen noch ein Stündchen zu mir, nachdem Frau Dr. Jauch schon am Nachmittag mit einem Neffen Amstad, der in Freiburg bei ihr wohnen u. das Gymnasium besuchen soll, fast zwei Stunden bei Marie u. Anna gewesen. Es war nun verabredet, dass Marie mit ihm zur Nachtzeit Velo fahren soll, heute nach sieben. Er kam aber, wie gestern, ohne Velo, indem er keines habe mieten können. Ich habe ihn im Verdacht, dass er gemerkt, wie wenig mir diese Velopläne gefallen $u$. dass er deshalb absichtlich ohne Velo gekommen. Ist mir auch recht. Aber Marieli ist schwer gekränkt darob, namentlich weil ich von seinem «Velofieber» gesprochen. Der Tadel, den es für seine Gelüster erfahren, wird ihm nur gut tun.

Heute traf ich Ernst Brenner in der Stadt, er kommt nächste Woche ins Examen. Ich fragte ihn nach Paul u. er erzählte mir, Paul sei diesen Sommer einmal in Bern u. ein Stündchen bei ihm gewesen, auf der Durchfahrt nach [?]. Mit der Verlobung scheine es ihm nicht mehr zu gefallen. Die 
Frl. Lehna Graf sei nicht so tief, wie er gemeint. Kurz, Ernst meinte, die Verlobung werde wieder ausgehen. Er liess dabei durchblicken, dass die Eltern das gerne sehen würden, aus ökonomischen Gründen. Auch sagte er, Paul beabsichtige seine Stellung in St. Gallen aufzugeben. Da haben wir ja die ganze Misere, wie ich sie für Marieli befürchtet hatte! Um so besser, dass es gegangen, wie es gegangen!

Den 28. Sept.

Mit der Durchsicht der Rechtsgeschichte habe ich heute wacker fortgefahren. Nach zehn kam Hugo Peter (Aarberg) wegen s. Dissertation zu mir u. blieb ein Stündchen. Zum Essen hatten wir Rossel u. Frau, ein Abschiedsdiner in kleiner Gestalt. Aber es ging alles recht, um drei gingen sie weg. Ich glaube nun doch richtiger gehandelt zu haben, dass ich sie noch einmal bei mir hatte.

Marieli hat letzte Nacht schlecht geschlafen. Die Sache mit dem Velo u. Siegwart hat es aufgeregt. Heute war es von Kopfweh geplagt $u$. wusste nicht recht, was anfangen vor innerem Groll. Wie ich Abends mit ihm gleichen Wegs zur Stadt ging, meinte es, am Ende könnte es den Winter über nach Jena, ich habe ja einmal davon gesprochen. Dann aber sah es doch selbst ein, dass dieser Plan nichts sei. Dazu kam, dass ein recht netter Brief von Ida eintraf, worin sie M. dringend ersucht, doch diesen Herbst noch für acht Tage zu ihr zu kommen. Auch das bewegte Marieli innerlich. Endlich trafen wir noch Abbühl, der uns nachlief, in Uniform, u. sehr zutraulich war. Ich glaube, Siegwart hat in Maries Augen sehr verloren. Es war eben doch so, dass er sich jetzt hätte entscheiden sollen, und dass er das nicht getan hat, das zeigt eben den Mangel, den

ich immer an ihm empfunden. Man weiss nicht woran man mit ihm mit dem Herzen ist. Doch ich will nichts sagen, die Dinge können sich so merkwürdig verschränken. Jedenfalls aber, das glaube ich sicher zu sehen, ist bei Marieli eine Umkehr eingetreten. Es war auch viel zu emsig dahinter her gewesen. Ich habe Dir ja das eine $u$. das andre darüber berichtet. 
Mit dem Klavier will es nun auch emsiger sein. Heut nach dem Nachtessen wollte es spielen $u$. ich sagte zum ersten mal zu ihm, es soll warten, bis ich die Zeitung gelesen $u$. hinauf gegangen sei. So wird man unter unsympathischen Dingen mit jedem Erlebnis liebloser.

Es ist mir manchmal, ich müsse noch eine recht schwere Zeit derart durchmachen. Hätte ich nicht besser getan, den Anruf aus Tübingen bejahend zu beantworten? Ich weiss es nicht, ich bin nicht mehr willenskräftig genug, um einfach eine Entscheidung für die richtige zu nehmen. Ich wäge $a b$, u. bleibe bei dem was ich habe.

So schliesse ich diese Woche! Noch drei u. die Ferien sind zu Ende. Gute, gute Nacht!

Innigst Dein allzeit treuer

Eugen

\section{2: September Nr. 201}

B. d. 29. Sept. 1912.

Mein einzig geliebtes Herz!

Es war heute ein stiller Sonntag, warm, föhnig. Ich schrieb einige Briefe, einen längern an Ida, da ich auf einen gestern eingelaufenen Brief zu antworten hatte. Erstlich betr. Kants Pflichtbegriff, in dem sie ähnliche Bedenken erhoben, wie sie Schiller in seinem Distichon «Gewissenscrupel» geschildert hat. Und sodann in Betreff den Besuch Marielis bei ihr, wobei ich ihr andeutete, dass es nach dem 15. noch für 8 Tage frei wäre. Sie mag nun machen was sie für gut findet.

Dann war Willy v. Wyss am Nachmittag hier, ein Freundschaftsbesuch, den er bis nach fünf Uhr ausdehnte. Er ist natürlicher geworden $u$. versieht seinen Posten mit Freude. Ich begleitete ihn zum Bahnhof u. da leitete er plötzlich das Gespräch auf Marieli, fragte, ob es jetzt den Haushalt besorge u. s. w. So habe ich den Ge- 
danken, der Besuch habe ihm gegolten. Das wird sich zeigen. Ein merkwürdiges Zusammentreffen wäre es, denn heute nach dem Essen kam ich mit Marieli auf Siegwart zu sprechen, u. es meinte, der werde nun die Annäherung bleiben lassen. Die Velo-Geschichte habe ihn abgeschreckt, er sei so empfindsam. Kann sein. Jedenfalls trifft mich aber an dem Scheitern dieser Pläne keine Schuld. Es gewinnt dann eher den Anschein, als habe er einen Anlass benutzt, um den Kopf aus einer Schlinge zu ziehen, die von der Freundlichkeit seiner

Schwestern ihm um den Hals gelegt ward. Nun, wenn ich vergleiche, was soll ich sagen! Bei Siegwart das Hemmnis mit dem Ultramontanismus u. der Abstammung von Siegwart-Müller. Ich musste voraus sehen, dass die Verbindung in dieser Richtung ganz allgemein von meinen Freunden u. Bekannten bös beurteilt worden wäre. Aber daneben ist Siegwart recht, wenn ihn die Jesuitenschule nicht verdorben hat, was ich nicht empfunden hätte. Arbeiten kann er, ist auch gleichmütig u. brav, aber ohne Enthusiasmus. Die Familie ist recht, aber in einer Leichtlebigkeit befangen, die man ja den Katholiken nachsagt - eine Folge der Ohrenbeichte - u. wie ich sie bis jetzt nicht kennen gelernt hatte. Bei Willy v. Wyss aber ein etwas sonderbarer Mensch, der sich Mühe gibt etwas rechtes zu werden. Sein Kampf um das Offiziersbrevet steht mir noch in Erinnerung. Wie anders dieser Geist, im Vergleich zu der Art wie Siegwart über seinen letzten Militärdienst gesprochen hat. Und dazu eine Verwandtschaft, die mir wohl täte in allen Beziehungen! Ich würde wohl nicht schwanken dem Willy vor dem Alfred den Vorzug zu geben. Wie Marie denkt, weiss ich nicht, aber wahrscheinlich ebenso.

So muss ich diese Dinge erleben, während eigentlich die Mutter hier dirigieren sollte, $u$. Marieli entbehrt ihrer. Es tut mir leid, unaussprechlich leid, denn ich kann die Lücke unmöglich ausfüllen $u$. Marieli hat darunter zu leiden. Anderseits darf es aber auch nicht kommen u. sagen, ich sei schuld, wenn Siegwart sich zurückziehe. Er hätte lange genug sich erklären können, wenn er gewollt. Das eben werfe ich 
ihm vor. Vielleicht war es ein Misstrauen gegen mich, oder den Protestanten in mir, vielleicht erwartete er, dass Marieli sich zum Katholizismuns convertieren liesse. Kurz er war ein Rätsel u. wird nun auch eines bleiben. Wenn nur nichts Schlimmeres!

Ich habe heute darüber nachdenken müssen, wie schön es doch für mir wäre, Professor für Rechtsgeschichte u. Rechtsphilosophie zu sein. Wie würde mir die Stelle in Tübingen gepasst haben! Aber ich komme damit nicht auf gegenüber der Pflicht zu meinem Land. Eine Entrüstung würde mich verfolgen, die ich nicht auf mich laden darf. So werde ich hier festgehalten. Die kurze Spanne Zeit, die mir noch zum Arbeiten gegeben ist, muss ich hier aushalten. In einer Umgebung von Personen, von denen auch nicht eine mir wohl will. Die ganze Kleinlichkeit der Verhältnisse verbittert mir einen Erfolg, den ich sonst so frei geniessen könnte, wie ich ihn geschaffen. Das alte Bild «Hannibal» steht wieder vor meinen Augen. Ich werde daran mich aufzehren u. dann vielleicht als Beispiel der Treue gelten, wenn es wahr ist, dass die Treue die Krone des Lebens ist.

Wäre ich nicht in diesen beängstigenden Verhältnissen, ich würde ja keinen Augenblick auch nur im geringsten daran denken, meinen Platz zu verlassen. Aber es ist so schwer, den Enthusiasmus unter Verhältnissen festzuhalten, wo alles diese Stimmung ablehnt $\mathrm{u}$. belächelt. Und doch, ist es je einem von dieser Stimmung anders ergangen? Keinem, auch nicht einem. Also Geduld u. Ausharren, das ist eben doch immer wieder das Einzige, auf das ich zurückkomme. Vorwärts also, solange es gehen mag!

Nun sind es 130 Wochen seit jenem letzten Abend, den wir zusammen erlebt. Und ich vermisse Dich mehr u.

tiefer denn je. Das bleibt nun mein Schicksal. Und ist es nicht dennoch schöner, als das der Vielen, die niemals solches Glück verloren haben?

Ich bin bei Dir, mein Lieb, u. will in deinem Geiste bleiben, dass wir zusammen halten! Dein ewig treuer

Eugen 
[1]

B. d. 30. Sept. 1912.

Mein liebstes Herz!

Heute ist Rossel definitiv verreist. Es ging mir doch nahe, ihn, mit dem ich so viel zusammen gearbeitet, nun als Nachbar zu verlieren. Ich stellte mir auch vor, dass seine Freunde ihm das Geleite geben werden, u. so verfügte ich mich zur rechten Zeit auf den Bahnsteig. Er kam mit Georges, der mit ihm verreiste, begleitet von André, sonst war niemand da. Wenn er auch erstaunt war über meine Anwesenheit, so hat sie ihn doch gefreut, u. wir scheiden als Freunde. Er wäre ja auch mein Freund, wenn er nicht so oft den Deutschenhass hervorgekehrt u. seine welsche Oberflächlichkeit promeniert hätte. Nun ja, das tritt jetzt in den Hintergrund. Es ist jetzt vorüber u. manche gute Stunde lebt nur noch in der Erinnerung in jenem Hause auf. Ich habe es nicht gern, dass es von Unbekannten bewohnt sein wird.

Um 5 1⁄2 Uhr kam Siegwart u. brachte Manuskripte zurück, die er abgeschrieben. Ich plauderte mit ihm, ohne dass etwas ernstes hervorgetreten wäre. Wir machten noch einen Spaziergang $u$. ich nahm ihn zum Nachtessen nach Hause, da seine Tante heute in Freiburg ist. Ich dachte nicht daran, dass Susanne auch hier ass. Es war dann aber ganz nett. Wir plauderten gemütlich, bis Siegwart auf die Rückkunft seiner Tante zurück musste. Ich habe an dem diesmaligen Besuch wieder gar keinen Eindruck gehabt, ist

Siegwart so oder anders gesinnt. Vielleicht konnte ihn Marieli besser beobachten. Aber vermutlich war es halt wieder die alte Geschichte: Verschlossen, unergründlich, wie immer. 
Sonst habe ich den Tag über Rechtsgeschichte gelesen, nichts anderes, als die alten Stenogramme corrigiert u. ergänzt. Eine Arbeit, die ermüdet, namentlich wenn es dazu wieder so föhnig warm geworden, wie das heute der Fall war. Ich überlegte mir daneben doch noch einmal, ob ich nicht besser getan hätte, die Anfrage aus Tübingen anzunehmen. Allein das Ergebnis des Nachdenkens musste ja schliesslich sein, dass ein solcher Schritt für mich ohne Schädigung des Rufes in der Schweiz nicht möglich gewesen wäre. Ich hätte eine offenbare Pflichtverletzung begangen, $u$. wenn ich sie auch persönlich vor mir mit meinen Anlagen $u$. Neigungen hätte rechtfertigen können, so wäre dies vor der Welt bei meinem Alter schwerlich mehr möglich gewesen. Also muss ich mich dabei beruhigen, wenn es mir auch schwer wird, in dieser Einsamkeit weiter zu leben. Es ist jämmerlich, wie es mir geht. Und dass da Marieli mir immer mehr statt zum Trost zum Kummer wird, ist auch keine erquickende Erfahrung. Gott bessere es! Heute erhielt ich von einer Zürcher Frau einen Brief um Hülfe. Aber sie sagt nicht, wofür. Sie wird an Verfolgungswahn leiden, aber ich kann ihr ja nicht helfen, weiss nicht was oder überhaupt ob ich ihr antworten soll. Ferner erhielt ich einen

in ganz gutem Mass gehaltenen Brief mit Dank von Anneli. Endlich bittet mich eine Karte Bühlmanns, ich soll ihm doch offen mein Urteil über sein Buch mitteilen. Der arme Mann macht also die Stimmungen des Autors durch, wie ein junger Schriftsteller. Jetzt werde ich ihm wohl ausführlicher darüber schreiben müssen.

Ich überlegte heute den Plan, nach Montreux-Sitten zu fahren u. Pauline in Monthey zu besuchen. Ich habe ihm für dieses Jahr den Besuch versprochen u. will Wort halten. Den Abend aber denke ich daran, die Fahrt doch eher zu verschieben, bis Guhl aus Clarens u. Walter B. aus Sitten zurück sind. Dann kann ich an einem Tag hin $u$. her zu Pauline, u. es ist auch 
sonst vielleicht besser, wenn ich erst in den letzten Tagen der Ferien noch mir diese Pause gönne.

An den Juristentag in Solothurn werde ich wohl auch nicht gehen.

Der heutige Tag hat mir wieder so deutlich gezeigt, wie sehr ich auf mich angewiesen bin. Würde ich in Solothurn Wieland, Häusler treffen, so hätte ich statt Erfrischung doch nur Kränkung zu gewärtigen, ohne Gewinn für irgend eine gute Sache. Ich bin nun einmal auf ein totes Geleise geführt worden. Die Umgebung drückt mich nieder, so schön sie an andern Orten war u. wieder hätte werden können. Ach, Du kennst ja diese Klage, wie fest Du darunter gelitten. Und doch war auch bei Dir schliesslich die Überzeugung vorhanden, es müsse das alles durch gekämpft werden, aus Pflicht. Es ist mir wieder so ganz im Gefühl, wie uns beiden so manchmal zusammen, als wohnen wir in fremder Welt unter Eingeborenen, mit einer wichtigen

Aufgabe, die erfüllt sein muss, ob man gerne dabei sei oder ungerne. Was Du ausgehalten hast, will ich auch aushalten. Also dulden wir alles weiter - arbeiten $u$. nicht verzweifeln.

Gute, gute Nacht, mein Lieb! Ach könnte ich Dir nur noch einmal zeigen, was Du mir bist, könnte ich nur in etwas das ausgleichen $u$. gut machen, was in früheren Zeiten von mir versäumt worden ist!

Dein allzeit getreuer

Eugen 


\section{Oktober 1912}

\section{2: Oktober Nr. 203}

B. d. 1. / 2. Okt. 1912.

Mein liebstes Herz!

Heute nach dem Morgenessen habe ich in fünf Exemplaren aus Boston die Übersicht über die Continentale Rechtsentwicklung erhalten, für die ich letztes Jahr den Abriss der Schw. Rg. geschrieben. Der Band ist stattlich u. die Schweiz sollte mit dem 47 Seiten starken Abriss so gut vertreten sein, als das mit andern kleinen Staaten, Niederlande, Skandinavien, der Fall ist. Sehr freundlich ist meiner gedacht, wenn auch nicht gerade so, wie ich es gerne habe. Wigmore hat mir Lob gespendet u. meine Arbeiten aufgezählt, auch der Glasscheiben des Juristenvereins gedacht. Nun ja, es ist alles recht.

Ich brachte eines der Exemplare Siegwart, der erfreut war, er hat doch bei Diktat u. Correctur mir damals geholfen. Er war sehr kleinlaut. Seine Tante schien meinen Besuch sehr zu freuen. Ich werde aber immer noch nicht daraus klug, ob er an eine Verbindung mit Marieli denkt, u. sich nun zurückgewiesen fühlt, oder ob er niemals ernsthaft daran gedacht hat u. nun den Anlass zum Rückzug benutzt. Das ist es ja eben, was den Katholiken unheimlich macht. Man weiss nicht, was sie denken. Es ist leichtes Blut in ihnen $\mathrm{u}$. doch eine so oft berechnende Art, wo in unserem Temperament ein Draufgehen vorliegt. 
Zum Essen war Frau Rossel bei uns. Sie war sehr im Sturm, aufgeregt, in Sorge, ob sie Platz haben mit ihren Möbeln u. s. w. Sie ging von uns zur Bahn nach Lausanne.

Susanne war über den ganzen Tag bei uns u. verreist morgen 7 Uhr. Sie ist eine fröhliche Bavarde, immer noch, $u$. hat erzählt, es gehe ihrem Bruder Georges wieder nicht so gut, er werde wohl den Winter über noch nicht die Arbeit wieder aufnehmen können.

Ich korrigierte heute an den R. gesch. Stenogrammen weiter, habe bald ein Viertel $\mathrm{u}$. im ganzen macht es mir Freude.

Es war heute ein Föhntag, Wind u. dabei $15^{\circ}$ R., u. hie u. da ein paar Regentropfen. Nachmittags sass ich auf der Verandah u. im Garten. Ich war erst wegen der Sendung aus Amerika in guter Stimmung. Nachher kamen wieder die Bedenken. Ich werde sie nicht los, ich bin dabei in steter Kümmernis.

Die Karte, die ich gestern von Bühlmann erhalten, der mich dringend bittet, ihm über sein Buch mein Urteil zu senden, habe ich heute Abend beantwortet. Es wurde ein ordentlicher Brief daraus, indem ich meine Anerkennung über die Leistung des Praktikers nicht zurückgehalten habe. Aber dazu konnte ich mich nicht entschliessen, worauf er vielleicht andeuten wollte, in eine Zeitung über das Buch etwas zu schreiben. Das liegt mir so ferne, dass ich es ganz meiner Natur zu wider laufend empfinden würde. Ich bin selber exponiert, um derart mich über die Leistung eines andern etwas publizieren zu können. Er wird meine Gründe, wenn er daran gedacht hat, meinen Ausführungen entnehmen können.

Es stürmt, wie im Februar. Das Barometer fällt, es wird Regen geben. Heute hörte man vom Längenberg her die Kanonen der 3. Division. Aber das morgige Manöver wird wohl verregnet. 
Mit diesem Wetterwechsel fällt nun auch mein Gedanke dahin, nächstens, vielleicht übermorgen, nach Monthey zu reisen. Ich kann das noch gegen Mitte Oktober machen.

Heute habe ich vor dem Nachtessen, d. h. schon um 6 1/4 Uhr im Studierzimmer die Lampe gebraucht. Es geht rasch in den Herbst hinein.

B. d. 2. Oktober.

Ich habe gestern noch wohl darüber nachgedacht, dass es zwölf Jahre war, seit wir in unser Haus eingezogen. Mit Frau Rossel sprach ich am Tisch darüber. Sie waren seit 1887 in dem Haus am Sonnenberg, also verlassen sie es nach 25 Jahren. Du hast das unsre nach zehn Jahren verlassen, wenn Du nicht im Geiste hier festgehalten wärest. - Was sind diese Räume? Erinnerungszeichen, die uns wohl oder weh tun. Man lebt, ob man da oder dort sei, u. doch habe ich jetzt weit mehr als früher das Gefühl, hier zu verbleiben sei meine Pflicht. Es würde ja kein anderer Raum mir wieder Deine Gegenwart verkürzen, wie dieser, den Du mir zum Heim gemacht hast!

Ich habe heute zuerst einige Briefe geschrieben, darunter ein Gutachten für Borlat. Wir standen früh auf, weil Susanne vor sieben auf der Bahn sein musste. Dann las ich wieder in den Stenogrammen. Am Nachmittag war Siegwart einen Augenblick da u. blieb zum Kaffee, er will auch heute nach acht Uhr noch ein Schach mit mir spielen. Er ist recht, aber meine Stimmung gegen ihn ist doch kritischer geworden. Es war ein ausgemachter Regentag heute. Als ich Siegwart unter die Haustüre begleitete, sah ich, dass eine der umgesetzten Tannen mit ihrer Spitze vom Telephondraht umgebogen wurde. 
Wir versuchten mit einer langen Stange zu helfen, Siegwart stieg auf die Stubenleiter, die hinausgestellt wurde. Dann sah ich, dass mit einer gewissen Bewegung die Sache wieder in Ordnung gebracht werden konnte, wie dann auch offenbar durch den Wind mit derselben Bewegung des Gipfels die Sache verhürschet worden war. Ich instruierte Siegwart, er begriff u. es ging.

Anna ist seit einiger Zeit furchtbar mürrisch, offenbar wegen Marie. Die alte Geschichte. Sie wird nur selbst dabei unzufrieden, uns kann sie nichts damit antun. Aber ich hätte eben doch nicht gedacht, dass ich noch derart im Alter mich in ihrer Gesellschaft über ihre Schwachheiten allein u. ohne Deine Hülfe zu ärgern brauchte. Ich sage das mit der Hülfe im Ernst. Wie oft hast Du mit Deiner Liebe die Sache gegenüber aller Renitenz in Ordnung gebracht, das war Deine strenge Liebe, oder liebe Strenge, die ich jetzt alle Augenblicke vermisse.

Die Berner Division hatte heute einen nassen Tag. Ich hörte das Schiessen, ward aber nicht verlockt. Gestern wurde der junge Jacob schwer verletzt, er verliert vielleicht einen Arm. Er ist gewiss derselbe, der Anfangs August am Scopi abgestürzt u. schon damals bedeutend blessiert worden ist.

Man liest heute von allerlei Kriegsgefahr. Das könnte eine schöne Bescherung werden für den Winter!

Ich arbeite jetzt gleichmütig weiter u. mir ist wohler dabei. Es ist merkwürdig, wie die kleine Anerkennung aus Boston mir wohl getan. Das ist nicht Eitelkeit, sondern Mangel an Selbstvertrauen, woran ich immer gelitten, was sich hierin spielgelt.

Gute, gute Nacht, meine gute, teure Seele! Ich bleibe allezeit Dein Eugen 
B. d. 2 3./ 4. Okt. 1912.

Mein liebstes Herz!

Auch heute habe ich wieder in den Stenogrammen drauflos gelesen, soviel ich konnte. Ich war aber geistig matter als die letzten Tage, ich war müde u. leer im Kopf. Ob das von der Folge der Arbeitstage kommt, oder weil das Wetter so warm ist, oder weil ich gestern bis gegen elf mit Siegwart Schach spielte? Mehrere Briefe habe ich heute gleich nach ihrem Eingang beantwortet. Da Dr. Max Studer mich für den Fall des Besuchs der Juristenversammlung zu sich eingeladen hat, musste ich mich heute entscheiden $u$. habe abgeschrieben. Zu den Hindernissen, die in meiner Stimmung u. in meiner Arbeitslast liegen, kam heute noch dass ich den Mittwoch wegen einer Konferenz verlieren werde, die der schw. Baumeisterverband von mir begehrt. Ich berief mich Studer gegenüber natürlich nur auf letzteres.

Überlege ich, weshalb ich seit der Zeit so schwer mich entschliessen, in gesellige Umgebung zu gehen, so ist da offenbar auch als Faktor mitsprechend, dass mir lästig ist mit der zitternden Hand zu essen u. zu trinken. Das hat sich seit Deinem Hinschied doch sehr vermehrt. Nun wenn auch nicht die Gemütsheiterkeit, so doch die Arbeit kann unter diesem Zustand nur gewinnen. So lang es noch sein muss, halte ich die Sache schon aus. Ich war übrigens heute auch wieder weniger wohl, was ich dem Föhnwetter - heute sogar mit

$[2]$

Gewitter bei fortdauernd geheiztem Haus zum Teil wenigstens zuschreiben muss.

Unter den Briefen, die eingegangen, befindet sich auch einer von Egger, der mir ausserordentlich freundlich geschrieben hat. Denkt er selbst an einen Ruf nach Tübingen? 
Ich schrieb ja darüber an Rümelin, indem ich ihm sagte, ich denke nicht, dass Egger von Zürich weggehen würde, er sei dort zu sehr verankert. Dringend empfehlen könne ich ihn überdies nicht, da sonst die Zürcher sagten, ich hätte einen Konkurrenten weg gelobt. Wie hoch ich ihn schätze, wisse er schon. Ich bin begierig, was Rümelin darauf antworten wird, namentlich auch in Betreff dessen, was ich ausführlich über Mutzner schrieb. Es ist aber wohl möglich, dass ich noch lange auf Rümelins Antwort warten kann. Er hält vielleicht gar keine Antwort mehr für nötig.

Heute von 5 bis sieben war Leo Merz bei mir in Rechtssachen. Dabei teilte er mir mit, wie sehr es ihn beschäftige, dass er die Wiederwahl ins Obergericht angenommen u. dafür nun so unartige Beurteilung seitens der Kollegen u. seitens der Konservativen erfahre. Die Aufgabe, das neue Handelsgericht einzuführen entschädige ihn gewiss, aber diejenigen, die ihn angetrieben hätten doch von ihm etwas verlangt, was sie eigentlich nicht hätten verlangen dürfen, u. was keiner von ihnen geopfert hätte. Merz nimmt an, er verliere per Jahr $12-15000$ Fr. Nun ja, dafür lebt er ruhiger. Immerhin schien er heute sehr niedergeschlagen. Ich weiss nicht, ob der Mann nicht wieder kränkelt. Jedenfalls ist er ein Idealist,

mit allem Schwung, aber auch aller Herbheit eines solchen. Ich verkehre gerne mit ihm.

Marieli wollte heute Frau Dr. Jauch besuchen. Ich riet ihm ab, es soll jetzt nicht wieder Entgegenkommens spielen. Den Abend war das überwunden, während es am Morgen darüber sehr unwirsch wurde. Launisch ist es nicht.

Den 4. Oktober.

Heute habe ich mit Gärtner Flückiger eine eigentümliche Geschichte erlebt. Ich erhielt gestern einen Brief von ihm mit der Mitteilung, in der jüngst bezahlten Rechnung sei ein Additionsfehler, es soll statt 245 $275 \mathrm{Fr}$. heissen. Ich hatte nicht controliert u. Anna u. Marie natürlich auch nicht. Beim Nachsehen fand ich die Bemerkung richtig, zugleich aber auch, 
dass für 53 Fr. Blumen doppelt aufgeschrieben waren! Ich liess ihn zu mir kommen, er gab es sofort zu, u. so musste er mir $23 \mathrm{Fr}$. herausbezahlen statt ich ihm 30 ! Bei dem Anlass sagte ich ihm energisch, dass ich unbedingt die Gärtnerrechnung vermindert haben wolle, das Blumenbett im Rasen müsse eingehen, die Flora vor dem Küchenfenster einfacher werden etc. Flückiger drückte sich kleinlaut. Meine Leute meinen, er sei nach dem Tode seines Vaters dem Geschäft nicht mehr gewachsen.

Heute habe ich zunächst ein Gutachten für Kuoni geschrieben. Dann auf elf ging ich mit Marieli in die Stadt. Wir warteten auf den Einmarsch der Berner. Wir trafen Staatsanwalt Raaflaub, dann BRichter Winkler, der die ganze Zeit bei uns blieb. Und sonst viele Bekannte. Winkler teilte mir mit, dass Hauser von Rivalta, der mir mit seiner Frau noch einen so freundlichen Besuch gemacht $u$. die Erfolge der Kocherschen Behandlung so gerühmt hatte, nun geistig umnachtet in Luzern liege, Folge von Sklerose. - Die Berner Truppen machten mir einen prächtigen Eindruck. Ich hatte noch die Ostschweizer vor Augen u. der Vergleich

bestätigte mir die früher oft gemachte Wahrnehmung, dass die Berner eben doch viel stattlichere Truppen stellen. Dagegen war mein Eindruck von den höheren Offizieren sehr sehr mässig. Geht es denn wirklich nach, dass solche Advokaten u. Politiker als militärische Fachmänner auftreten? Früher war ich ja auch der Ansicht, der politische Führer soll auch der Führer im Kriege sein. Ja, aber auch nur als politischer Führer. Wir müssen wieder Zeug- und SteuerHerren erhalten, die ganz dieser Aufgabe leben. Die mittelalterlichen Richter taten es auch bei uns vollständig.

Am Nachmittag brachte ich Walter B. das amerikanische Buch, traf ihn aber nicht. Sie sind gestern Abend zurückgekehrt.

Ich schreibe diese Zeilen vor dem Nachtessen, auf neun werde ich wohl mit Marieli zum Zapfenstreich der neun hier demobilisierenden Bataillone gehen.

Als ich gestern noch in der kleinen Schröderschen Rechtsgeschichte las, da kam es mir doch recht vermessen vor, meine Schweiz.-RG publizieren zu wollen, ohne die Kontrolle mit dem heutigen Stand der 
Deutschen RG gründlich vorgenommen zu haben, u. ich bin fast irre geworden an meiner jetzigen Arbeit. Heute habe ich dann aber doch weitergefahren.

Marieli hat von Ida einen (diktierten) Brief erhalten, worin es auf einige Tage zu Ida eingeladen wird, etwa vom 15. - 20. ds. Ich meine, sie soll gehen, was auch wohl geschehen wird.

Was heute noch etwa begegnet, will ich morgen nachtragen. Jetzt schliesse ich ab, mit einem einzigen Gruss in Liebe u. Treue!

\section{Immerdar Dein}

\section{Eugen}

\section{2: Oktober Nr. 205}

B. d. 5. / 6. Okt. 1912.

Mein liebstes Herz!

Ich war heute wieder in recht bedrückter Stimmung, bis ich am Abend, nachdem ich das Pensum der Rechtsgeschichte erledigt, das ich mir vorgenommen, noch allein auf den Friedhof ging. Bei der Rückkehr ging die Sonne als mächtig grosse Kugel hinter dem Rosengarten unter. Der Tag war recht tief Herbst. Eine kalte Bise strich über die in Laub raschelnden Alleen u. unter dem grauen Himmel hinweg. Ich sagte mir, so ist es bei dir jetzt auch Herbst, sei nur zufrieden.

Was mich beunruhigt hatte, war wieder das eigenmächtige, liebleere Wesen Marielis. Am Abend fasste ich das anders auf. Dass es nicht die Liebe ist, wie Du, was darf ich es ihm zürnen. Ich muss froh sein, wenn es vernünftig ist.

Den Vormittag schrieb ich das Dissertationsgutachten für Hugo Meyer, u. die Anschläge fürs Semester. Dann ordnete ich die Auszüge, die mir Abbühl gemacht. Ich wollte dann in Schröders kleiner Rechtsgeschichte lesen, aber Siegwart kam, u. ich benutzte den Anlass, um einige Stenogramme von seiner Hand auflösen zu lassen. Er war selbstbewusster als gewöhnlich wohl weil er mir diese Arbeit besorgte. Aber tüchtig ist er schon, daran darf ich nicht zweifeln. 
Am Nachmittag erhielt ich die 50 Abzüge der «sozialen Gesinnung». Ich bin mit der Ausstattung nicht zufrieden. Aber was schadets, besser als letztes Jahr ist es schon. Ich sandte sofort

ein Exemplar an Dr. Georg Müller in Chemnitz, zugleich mit «bewährte Lehre» u. «Erläuterungen» welch beide ich ihm versprochen hatte, u. eine Postkarte: So ist auch das erledigt.

Es ist merkwürdig, ich habe jetzt immer gerade so neben bei mit dem Erledigen der Einläufe eine angenehme Unterbrechung, u. bin glücklich, keine Rückstände zu haben. Ich ersehe daraus, wie wohl ich mich als Pensionär oder Rentner fühlen könnte. Das ist nun einmal meine Natur. Ich muss eine Aufgabe haben, die mich ganz erfüllt, oder dann nichts als Beschaulichkeit. Wäre ich in Winklers Stellung, ich würde niemals so herum krabeln in allem Offiziellen wie er.

Der alte Hauser auf Rivalta, der mich im Juli so freundlich besucht, ist gestorben, $u$. wie Winkler sich gestern im Hinblick auf diese Möglichkeit aussprach, einem schweren Siechtum entronnen. Welche Erinnerungen! So geht alles seinen Lauf.

Ich will Deine Gemütsruhe ergreifen $u$. festhalten. Es wird schon recht werden.

Von gestern Abend muss ich dir noch Mitteilung geben, dass Walter B.s kamen, aus den Ferien zurück, u. dass wir dann alle vier den Zapfenstreich besuchten. Prof. Schulthess, den ich traf, teilte mir mit, dass er schwer an Rheuma erkrankt sei. Und ich hab das früher durchgemacht.

Endlich noch, dass Marieli heute an Frau Hebbel telephonierte u. vernahm, Martha Gemperle sei acht Tage hier gewesen. Kein Gruss, keine Entschuldigung. Ich habe nun Marieli geraten, nicht beides zu machen, nach St. Gallen u. nach Stuttgart zu reisen, u. dass es aus Grund der letztern die erstere Gelegenheit absagen soll. Das könne es nach der erfahrenen Unfreundlichkeit sehr wohl tun. 
Was nun geschieht, will ich Dir später mitteilen. Ich fühle, dass mit Frau Hebbel nichts anzufangen ist, als Mitschlucken von Galle, u. dazu bin ich nicht bereit.

Den 6. Oktober.

Marieli hat gestern Abend mit sehr freundlichen Worten u. im Bezug auf die Stuttgarter Reise die Teilnahme an der Hochzeit Marthas abgesagt. Es wird so besser sein.

Heute fühlte ich mich eigentlich gottverlassen allein. Zwei Gründe erkenne ich dafür: Ich hatte von früh an Kopfschmerzen, die sich jetzt gegen Abend in einen Schnupfen auflösten, aber noch nicht vorbei sind, u. ich machte mir Vorwürfe, dass ich den Juristentag in Solothurn nicht doch heute zu besuchen gehe. Über [?] denke ich jetzt wieder ruhiger. Das ist nun einmal meine Art. Ich habe im Leben so wenig Feste mitgemacht, dass ich mir allemal ganz verloren vorkomme. Also, warum dann hingehen.

Den Vormittag schrieb ich kleinere Briefe u. las in Schröders RG. Nach dem Essen kam Walter B., herzlich, ich konnte ihm Grüsse für Solothurn aufgeben.

Später kam Siegwart, mit dem ich ein Schach spielte, das er verlor, bei Rückgabe des fatalen oder letalen Zuges aber Remis machte. Inzwischen erschien auch Frau Gmür wieder einmal bei mir. Sie wollte Marieli u. mich zum Essen einladen. Ich aber sagte ab. Ich kann nicht wieder beginnen, ich kann nicht. Mit Dir zusammen wäre es was anderes, aber so! Nein, u. abermals nein! Ich bin auch zudem wirklich zu alt, meine zitternde Hand passt nicht mehr an eine Tafel, also verzichten wir. Und im Gedanken an dich wird es so leicht, zu verzichten. Kommt dann u. wann die Einsamkeit dann über mich, sie mag mich wohl hie u. da falsch beraten u. 
ich mag mich in dem Groll, den sie leider in sich bergen kann, verpassen $u$. tun was mich reut, - im Ganzen bietet sie doch die bessere Luft, als die Geselligkeit, die ich hier hätte. Ja, wenn mich intime Freunde umgäben, aber davon ist ja hier leider, leider nicht die Rede. Der Neid führt den Reigen.

Nun also vorwärts, wieder ein Sonntag vorüber, $u$. in zwei Wochen ist Ferienschluss. Ich habe noch manches vorzubereiten, es ging alles so rasch vorüber. Das ist das Facit des Altwerdens!

Nun innige Umarmung von Deinem in aller Bitternis treuen u. dankbaren Kameraden, Deinem Eugen

1912: Oktober Nr. 206

B. d. 7. / 8. Okt. 1912.

Mein liebstes Herz!

Ich habe heute still für mich gearbeitet. Am Vormittag schrieb ich einige Betrachtungen nieder, zu denen mich die Hioblektüre veranlasste. Dann las ich in den zurückgelegten Brochüren, fertigte den Buchbinder ab, schrieb verschiedene kleine Briefe u. schon wieder ein Gutachtelchen, um das mich Borlat bat. Und nach dem Essen kommt Siegwart zu einer Partie Schach, wohl der letzten, denn morgen reist er an eine Hochzeit u. wenn er zurück ist, packt er u. siedelt nach Freiburg über. So schreibe ich dir vor dem Abendessen, es wird nachher, wenn ich zu Bette gehe, spät sein. Marieli besucht mit Leni Aren, Claire aus Altdorf, die heute ankommt u. einer Cousine Amstad ein [?]-Concert im Münster. 
Ich stand heute unter dem Eindruck, dass ich eigentlich in Solothurn sein sollte. Und es war etwas wie Gewissensbiss, was ich verspürte. Bis ich mir wieder klar machte, dass meine Entscheidung, hier zu bleiben, doch die richtige sei. Vollends als ich dann heute in dem Nachmittagsbund von der Anwesenheit des berühmten Andreas Häusler, u. verschiedener Belgier u. Ungarn las, da bekam ich wieder so recht den Eindruck, da hast du nicht hingehört. Bleibe bei dir, das bekommt dir u. Andern besser! Wie ich dann in Fuchs〉 Streitschrift las, da überkam mich das Gefühl, es wäre doch besser für mich, wenn ich ganz der Rechtsgeschichte u. der Rechtphilosophie lehren könnte, u. ich überlegte, ob ich nicht doch noch einmal betr. Tübingen mit Rümelin reden soll. Aber es war nur ein kurzer Augenblick. Ich sagte mir sofort wieder, dass

ich für einen solchen Wechsel um volle zehn Jahr zu alt sei. Ich muss mich mit dem begnügen, was ich getan habe, u. kann höchstens noch darauf rechnen, dies weiter auszugestalten. Also aushalten, Stille bleiben, etwas andres gibt es für mich nicht mehr. Freilich ist es ja wohl begründet, dass mein Verhältnis zum Schweiz. Juristenverein nicht ist, wie es sein sollte. Aber bin ich schuld daran? Wenn ich zurückblicke, war immer ein Haar in der Suppe, ohne meine Schuld. Ich habe einiges vor Kurzem schon angeführt. Hier sei es Dir noch in einigen Punkten ergänzt.

Im Jahr 1874 wurde die Herausgabe v. Schweiz. Rechtsquellen beschlossen u. mir fiel der Auftrag zu. Die Freiburger hintertrieben die Sache u. 1876 fiel sie unter den Tisch. Morel war auch dabei. Blumer war leider inzwischen gestorben. Im Jahr 1877 war ich in Trogen, nachher machte mir Geldnot es faktisch mehrfach unmöglich, die Tagungen zu besuchen. In St. Gallen wurde ich von Morel angeödet, aber in Lausanne unter dem Einfluss Ruchemonts dann doch zu Ehren gezogen. In Schaffhausen suchte mir Stooss, mit Weibel, das kaum begonnene Werk zu vereckeln. In Bellinzona wurde das Strafrecht dem Zivilrecht vorgezogen. In Solothurn fand ich für meine Rückkehr in die Schweiz im Festspiel eine mich lächerlich machende Würdigung. In Basel u. in Bern u. auf dem Rigi musste ich Vortrag halten. In Chur galts der Rechtseinheit, in St. Gallen hatte ich 
einen wunderbaren Triumph, dank der Anhänglichkeit früherer Schüler. Aber seitdem war wieder alles im Alten, die [?] in Zürich wäre ja, wenn ich mich dort befunden, geradezu peinlich für mich gewesen. In den Vorstand wurde ich nie portiert, also, lassen wir sie ihre Wege gehen. Überblicke ich alles, so war ich an der Versammlung: In Chur 1873, Schwyz 1874, Freiburg 1876,

Bern 1880, Zug 1881, St. Gallen 1883, Altdorf 1882, Schaffhausen 1886, Zürich 1890, Basel 1894, Bern 1895, Rigi Kulm 1896, Chur 1898, Freiburg 1899, St. Gallen 1900, Zug 1901, Sarnen 1902, Chaux de Fonds 1904, u.

seitdem, wegen der vielen Kommissionssitzungen, nicht wieder. Also in 40 Jahren $18 \mathrm{mal}$, das mag genügen!

Den 8. Oktober.

Heute habe ich Vorbereitung fürs Semester an die Hand genommen: Vorlesungsübersichten, Praktikumsfälle etc., war dann am späteren Nachmittag bei Bieri u. bei Dürrenmatt. Daneben kleinere Briefe u. Rechtgeschichtslektüre u. -correcturen. Der Tag war wieder gefüllt, u. ich litt fortgesetzt unter der Melancholie der Sachlage, dass ich eben fortgesetzt einsamer werde. Das Gefühl wurde etwas gemildert durch eine Karte von Werner Kaiser, der mir eine Zeitung schickte mit einem auch auf mich anspielenden Gedicht $u$. der mir schrieb, dass man allgemein bedauert habe, mich nicht begrüssen zu können. Also doch eine Stimme! Hätte Walter B. vielleicht ein Wörtchen gesagt, ich soll doch kommen, wer weiss, ich hätte mich anders besonnen u. wäre gegangen. Allein das Gegenteil war der Fall: Er war merklich froh, dass ich nicht mitging, natürlich, ein Basler.

Bei Dürrenmatts sprach ich in einem Moment vor, wo eben Frau Dürrenmatt mit Walter zur Victoria gefahren war. Walter ist gestern von einer Blinddarmentzündung befallen worden. Kellerhals, ihr Arzt, - für uns so unglückseligen Andenkens! - wartete bis heute, consultierte dann [?], der sofort Walter ins Spital überführen liess. Und eben teilte mich Vater Dürrenmatt telephonisch mit, dass die Operation bereits vollzogen $u$. gut verlaufen sei. Aber es sei hohe Zeit 
gewesen. Jetzt könne man hoffen, bis in zwei Wochen sei alles wieder geheilt!

Ich traf auch den Verwalter der Hypothekarkasse Wyss an, u. plauderte mit ihm über dies u. das. Es war mir recht, wahrnehmen zu können, dass seine Stimmung zum ZGB. wieder ganz recht, seine Niedergeschlagenheit wegen des Conflicts mit den Notaren doch wieder gehoben ist.

Bei Bieri traf ich den Rector Marti, der nun noch einem Begräbnis anwohnen muss: Tavel ist 53 jährig plötzlich an einem Schlaganfall gestorben.

Auch heute überlegte ich mir wieder, ob ich am Ende doch nicht nach Tübingen gehen soll. Aber das ist ja Unsinn, es geht schlechterdings nicht. Ich muss das Opfer bringen.

Walter B. telephonierte mir, es sei in Solothurn gut gegangen. Müller BRt habe einen guten Tag gehabt. Müller werde die Sache stramm an die Hand nehmen. Zu einem Besuch komme Walter erst in einigen Tagen wegen der morgen beginnenden Examina. Merkwürdig, wie auch das mir wieder zu dem latenten Misstrauen gegen ihn Anlass gibt. Doch ich weiss, es war immer so, auch schon als er noch Student war. Sonst hätte ich ihn nicht einmal, wie ich Dir damals sagte, in Verdacht gehabt, einen Brief von Hafner, den ich nirgends mehr finden konnte, eingesteckt zu haben. Die Vernunft sagt mir, dass er es recht meint, u. daran muss ich mich halten.

Mit Siegwart habe ich gestern noch ein Schach gespielt u. gewonnen. Heute war Frau Jauch, Claire u. eine jüngere Amstad zum Café da. Es geht jetzt dem Ende entgegen.

Gute, gute Nacht, liebe teure Seel! Dein treuer Camerad auf immerdar!

Eugen 
B. d. 9. Oktober 1912.

Meine liebste Lina!

Der Trubel kommt, das Semester naht. Heute hatte ich den Präsidenten des Schweiz. Baumeisterverbandes bei mir mit dem Centralsekretär Cagianut. Sie kamen wegen des Urteils von Hügli i. S. des Kündigungsrechts der Arbeit. Ich versprach ihnen weitere Nachfrage u. Bericht, womit wir hoffen wollen, eine andere Judicatur zu erreichen. Morgen kommt Egger. Übermorgen besuche ich Pauline in Monthey, Samstags bringt Rieser das neue Büchergestell, Sonntags will Viktor Schläpfer bei uns zu Mittag essen, u. ausserdem werden Freitags Claire u. das Frl. Amstad bei uns logieren u. alle vier Siegwarts zu Nacht essen, ich bin dann aber noch nicht zurück aus Monthey. Und für nächste Woche steht auch etwas in Aussicht: Am Montag Abend, vor Siegwarts Ankunft, war der junge Teichmann bei mir. Er sagte, im Haus zu Basel sollten die Öfen gestrichen werden etc. u. da sei der Vater Teichmann, namentlich jetzt in seinem kranken Zustand ganz verloren. Es wäre am besten, er könnte ein paar Tage fort u. so habe er, der Sohn gedacht, er könnte den Vater in sein Logis im Althof unterbringen, indes er, der Sohn in Basel ein paar Ferientage verbrächte. Ob ich dann mich des Vaters in hier etwas annehmen würde. Es war deutlich, dass er gerne gehabt hätte, ich würde ihn einladen. Allein daran kann ja bei dem kranken Mann, namentlich wenn Marieli nach Stuttgart verreist ist, keine Rede sein. Dagegen werde ich allerdings nicht darum herum kommen, ihm 
als alten Kollegen, der so dienstbedürftig ist, wie er stets dienstfertig war, viel Zeit zu widmen. Ich werde ihn auch etwa zum Essen haben müssen. Geht es mit den zwei Tagen, Montag u. Dienstag, ab, dann will ich mich erst nicht beklagen. Und nächste Woche also Ferienschluss. Es ist mir im Grunde recht, wenn die Kollegien wieder angehen. Es wird sich dann auch zeigen, wie das Semester ausfällt. Also vorwärts!

Heute habe ich neben der Consultation RG. corrigiert $u$. Schröders Büchlein fertig gelesen. Vor dem Nachtessen machte ich allein einen Spaziergang, war wiederum vergeblich bei Mutzner, der seinen Urlaub scheints immer noch nicht fortsetzen kann. Ich traf seine Frau u. dann auch die Hausgenossin Frau Robert. Wie schade, dass Rümelin nicht auf die Anregung betr. Mutzner eingegangen ist. Dass er es nicht ist, schliesse ich aus seinem Schweigen. Die Gedanken an Tübingen betr. mich selbst verfliegen doch allmählich. Zwar durchzuckt mich immer noch hin $u$. wieder der Gedanke, so ganz der Rechtsgeschichte u. der Rechtsphilosophie zu leben, wäre ein schöner Altenteil für mich. Aber das würde gar niemand begreifen, als solche, auf deren Urteil ich nicht einmal viel gäbe. Von Dürrenmatt erhielt ich gestern Abend noch Bericht, dass die Operation gut vorüber, $\mathrm{u}$. heute Abend, dass der Zustand recht befriedigend sei. Was wäre das für die altenden Leute, wenn es anders gekommen wäre.

Walter B. hat mir aus Solothurn mit Andern doch eine Karte geschickt, die ich heute erhalten. Sie klingt fast vorwurfsvoll, man vermisse mich. Aber bei seiner Abreise, da hatte er doch darüber kein Wort. Daraus eben werde ich nicht klug.

Und nun weiter! Ich will noch etwas lesen und dann zeitig

[3]

zu Bett. Ich weiss nicht, was das ist, ich bin wieder so durstig. Der Reisende Fehlmann hat mir Anfangs der Woche Besuch gemacht u. dabei zufällig erzählt, dass er eine Kur in Karlsbad gemacht, wegen Diabetes, u. erkannt hätte er diese Krankheit aus dem heftigen Durstgefühl, das ihn etwa befallen. 
Gestern Abend nach acht Uhr kam Walter B. doch zu mir u. gab mir ausführlich Bericht. Es war, als ob er sich eines bessern besonnen hätte. Er zeigte mir die Drucksachen, die erschienen u. verteilt worden, erzählte mir von seinen Begegnungen, brachte mir aber keine Grüsse. Das hat ja die gestern erwähnte Karte getan. Von Häusler u. Wieland wusste er gar nichts zu sagen, er habe kaum mit ihnen gesprochen. Leo Weber war nicht dort, wegen Müdigkeit, liess er sagen. Reichel war auch verhindert. Von Zürcher erzählte er, er sei ihm merkwürdig müde $u$. zerfallen vorgekommen, so dass es ihn nicht überraschen würde, wenn eine Krankheit einträte. Zürcher hat schon seit längerem ein wechselndes Aussehen. Es ist möglich, dass er in Solothurn keine guten Tage hatte. Dagegen meinte Burckhardt, Häusler sehe aus, als wolle er hundertjährig werden.

Heute Vormittag habe ich die Aktiengesellschaftsakten durchgesehen, über die ich dem Departement einen Bericht machen soll. Welche Schurkereien bewegen sich in diesem Kapitel, ich will sehen, was ich machen kann!

Gestern vor dem Einschlafen traten mir die alten Pläne, über die ich verflossenes Jahr noch so viel nachgedacht, wieder mit aller Deutlichkeit vor Augen. Ich war wieder in jener Stimmung der Lebensferne $u$. doch Lebenshebung, in die ich mich in jenen Zeiten befunden. Die kleinen Widerwertigkeiten des Tages traten wieder zurück u. gaben der Grundstimmung Raum. Möchte es doch den ganzen Winter über so bleiben. Es

ist für den Rest des Lebens eine so ganz andre Garantie, als wenn ich mich, wie die letzten Monate von den Sorgen $u$. Eifersüchteleien des Alltagslebens mitreissen lasse.

Heute um elf war Kebedegg bei mir, der mir vieles erzählte. Ich hatte den Eindruck, dass es wohl doch besser gewesen wäre, wenn ich nach Christiania gegangen statt nach dem Klausen. Nun ja, das letztere hatte auch sein gutes. Nur ist Marie eben nicht lieber geworden. 
Auf halb zwei holte ich Egger am Bahnhof ab. Ich verlebte einen sehr netten Nachmittag mit ihm u. hörte von manchem, was mich interessierte. Egger war sehr verletzt, dass ihn Forrer nicht auf dem Schiff in Zürich dem Kaiser vorgestellt. Mit Recht, Zürcher soll sehr stolz gewesen sein, dass ihn Forrer zusammen mit Usteri, Lutz u. Meister vorgestellt habe. Dabei soll die Bemerkung wegen des Vogelschutzes gefallen sein.

Und nun schliesse ich den Tag, an dem ich wieder einmal viel sprechen musste. Ich werde manches gelegentlich erwähnen, was Kebedegg oder Egger erzählten. Wenn ich z. B. heute noch anfüge, dass gestern Elise uns besucht hat, ich traf sie noch bei der Rückkehr aus der Stadt im Gang. Sie sieht gut aus. Morgen also mache ich den Besuch bei Pauline.

Gute, gute Nacht! Dein allzeit treuer

Eugen

\section{2: Oktober Nr. 208}

Monthey. d. 11. Oktb. 1912.

Mein liebstes Herz!

Ich schreibe auf einer Rebbergtreppe ein paar Wort an Dich. Nach unruhiger Nacht bin ich um 7 Uhr abgefahren. Ins halbe Coupé kam Herr Reber, der nach Pallanzo fuhr, so dass ich bis Aigle in seiner Gesellschaft war. Ich erfuhr allerlei von dem Betrieb der [?geschäfte], wäre aber sonst lieber allein gewesen. Die Strassenbahn führte mich nach Monthey hinüber, wo mich eine hagere ältere Dame ansprach. Es war Frau Martin, bei der Pauline wohnt, u. die mir mitteilte, dass Pauline krank sei. Sie führte mich zu ihr. Angekleidet lag sie zu Bett u. erzählte, dass sie seit sechs Wochen an Rheumatismen leide u. im Herz schwach sei. Ich sah bald, dass ich nicht lange bei ihr sein könne. Pauline erzählte mir, dass vor drei Wochen August bei ihr gewesen u. ihr von der Geschichte zwischen Paul u. Marie erzählt habe. Aber sie habe nichts verstanden u. wünsche von mir die Sache zu hören. Ich tat es, u. es wurde Mittag 
ohne dass wir vieles über andere Dinge hätten reden können. Dann wünschte Pauline allein zu sein $\mathrm{u}$. ich bin hinaus gegangen, angeblich um im Gasthof zu essen, in Wirklichkeit aber, damit ich sie nicht ermüde u. mir selbst den Eindruck klar mache, den ich von der Schwester hatte. Sie zeigte sich sehr gescheit, aber wieder wie früher nicht sehr vertraut. Immerhin weiss sie nun den Sachverhalt. Es wäre sogar vielleicht besser gewesen, wenn ich nicht soviel gesagt hätte. - Pauline ist krank, aber noch sehr geisteskräftig. Ich werde noch einiges mit ihr besprechen können. Dann fahre ich zeitig genug von hier weg, um schon halb neun in Bern zu sein. Das ist mir auch recht. Ich muss schon sagen, der Eindruck von heute Morgen ist gemischt. Allein das darf mich nicht überraschen, es war immer so. Am Ende muss ich froh sein, dass es nicht schlimmer ist. Und jedenfalls auch froh, die Schwester noch einmal gesehen zu haben. Denn es steht wirklich so, dass ich um Pauline besorgt

sein muss. Gegen zwei Uhr soll ich wieder bei ihr sein. Ich habe inzwischen diese kleine Anhöhe bestiegen u. diese Zeilen geschrieben. Ich fahre zu Hause fort, nachdem ich um halb neun wieder in Bern angekommen bin.

Nach halb zwei war ich verabredetermassen wieder bei Pauline: Dasselbe Bild resignierten, aber nicht unglücklichen Einsiedlertums, in dem sie sich durchschlägt innerlich u. äusserlich, ohne an Bedürfnisse gebunden zu sein. Sie wurde wieder bald müde. Um drei verabschiedete ich mich bei ihr, obgleich es noch nicht Zeit war für die Bahn, machte Frau Martin noch Besuch u. strich in dem Dorf herum, um vor vier abzufahren. Die Leute bei denen Pauline wohnte, sind wohlhabend, Weinhändler. Aber Pauline kann nichts mit ihnen anfangen.

Den Zustand Paulines erkläre ich mir als Herzschwäche. Sie glaubt, es komme aus dem Magen, der Arzt habe aber gesagt, man solle es sie nur glauben lassen. Ist es Herzschwäche, so kann natürlich jeder Tag das Ende bringen. Es ist dann dieselbe Schwäche, wie s. Z. bei Hilty u. wohl auch dasselbe Ende. Ich hatte Mitleid mit ihr, aber ich musste mir gestehen, dass diese Welt, die sie sich in der Einsamkeit geschaffen, nicht unsympathisch ist. Meine Teilnahme veranlasste mich, ihr den Vor- 
schlag zu machen, beim zweiten Besuch, zu Besuch zu uns zu kommen. Aber sie hat entschieden abgelehnt. Sie meinte, das sei nichts für sie, sie sei jetzt so an das Alleinsein gewöhnt, dass ihr der tägliche Umgang mit einem weiten Kreis ganz unmöglich scheine. Auch gegen den Eintritt in ein Asyl od. dgl. hatte sie sich mit Entschiedenheit ausgesprochen. Ich weiss sie hat das

schon früher getan $u$. ich habe nicht in sie gedrängt, wenn sie es vorzieht, allein zu sterben.

Anna berichtete bei meiner Rückkehr, es sei nichts passiert. $\mathrm{Zu}$ Recht war für mich wirklich nichts da. Marieli war mit beiden Siegwarts u. Frl. Amstad im Theater (Mignon). Die zwei Fräulein logieren im Zimmer oben, Siegwart u. Frau Dr. im Blauen Kreuz. So lässt sich die Sache ja gut richten. Morgen will Siegwart noch kommen u. mir Adieu sagen.

Der Tag war heute für die Reise recht nett. Vormittags allerdings Nebel, aber von Mittag an etwas Sonne, im Rhonetal u. scheints auch in Bern, sodass die gelben Blätter leuchteten. Von der Anhöhe ob Monthey, die ich angeführt, sah ich bei aufheiterndem Nebel nach Bex hinüber u. erinnerte mich der schönen Tage, die wir 1899 dort verbracht. Ich sah den Tour de Duin u. die Baumgruppen des Hotels. Auch nach der Dent de Morcles schaute ich hinüber u. suchte mir die militärischen Wege festzustellen, die ich im Herbst 1906 so fröhlich dort gewandelt. Wenn man so alles überblickt, so hat man ja manche Freude gehabt. Also, es muss ja, es musste ein Ende nehmen. Nur ziehe ich die Lehre aus dieser Erwägung, dass wenn Du Dich der Freude in diesem Sinn entziehen musstest, sie auch für mich nicht zu bestehen hat.

In summa bin ich froh, dass ich die Fahrt gemacht. Mag es nun gehen wie es will, ich habe doch das Wort eingelöst, das ich Pauline gegeben, $u$. kann mir ihren Zustand besser vorstellen. Ich habe manches dabei gelernt. Wäre ich einer solchen Einsamkeit 
fähig? Würde sie gut sein für mich? Das ist ja auch nicht eine Frage, sondern ein Schicksal.

Ich warte nicht ab, bis Marieli mit den zwei Fräulein aus dem Theater kommt, sondern gehe jetzt, zehn Uhr vorüber, gern zu Bett!

Gute, gute Nacht! Dass Gottes Güte - Dein Glück behüte! Gute Nacht!

Dein allzeit getreuer

Eugen

1912: Oktober Nr. 209

Bern, d. 12./ 3. Oktober 1912.

Mein liebstes Herz!

Heute sind Siegwarts nach Freiburg umgezogen. Der Möbelwagen wurde gestern gefüllt $u$. ist direkt per Achse nach dort geführt worden. Claire u. Frl. Amstad logierten bei uns, Frau Jauch mit Siegwart im Blauen Kreuz. Den Eindruck, den ich heute von den Leutchen hatte, kann ich ruhig als sehr gut bezeichnen. Zur Bahn begleitete ich sie nicht, sie gingen von uns weg erst in die Stadt zur Besorgung von Einkäufen. Marieli blieb auf mein Anraten ebenfalls da. Es musste mir helfen.

Dann um 10 Uhr kam Rieser mit dem Ungetüm von Bücherregal, das jetzt das Schlafzimmer verunstaltet. Ich werde mich daran gewöhnen. Sofort nach der Aufstellung habe ich mit Marielis Hülfe eingeräumt. Es wird jetzt schon gehen. Zunächst habe ich natürlich viel zu viel Platz, aber es füllt sich rasch. Immerhin habe ich die Beruhigung, dass dies das letzte Regal sein wird, das ich mir anschaffe. Egger bewunderte wieder meine Ordnung. Er erzählte, dass Marli die Bücher, die er erhalten, einfach auf einen Haufen gelegt u. schliesslich 
mit den Sendungen der Buchhändler einen solchen [?] erhalten habe, dass er sich durch Sendung einer Wagenladung an die Kantonsbibliothek habe Luft schaffen müssen. Ich hätte das von Marli nicht erwartet, ich hätte ihn in diesen Sachen für besser gehalten. Das steht ja auf dem Niveau des Lehrers Koch in Basel. Da ist Häusler ein anderer Sammler.

[2]

Ich habe heute nebenbei an der RGeschichte gearbeitet. Dann war Guhl ein Stündchen da, retour de Montreux. Er sieht sehr frisch aus, aber weshalb erinnert er mich jetzt so oft an Wettstein, den Redaktor? Was er mir mitteilte, war wieder sehr gescheidt. Aber ich will mich hüten, ihm allzu viel anzuvertrauen.

Heute tauchten vor meinen Augen immer wieder zwei Eindrücke aus den letzten Tagen auf: Egger, dem so sehr anzuspüren war, dass er in Zürich mit wachsenden Widerwärtigkeiten zu kämpfen hat. Das ist ja das Los eines jeden der tüchtiges leistet unter der Egide von Forrer, Usteri, Lutz, Zürcher, oder unter dem Charakter, den unser Volk nach dieser Richtung immer gezeigt hat. Die Nichtvorstellung auf dem Kaiserschiff hat diesen Gefühlen dann bei Egger Ausdruck verschafft. Aber auch die Art, wie er von der Fakultät sprach, wie man seine Ablehnung der Kassationspräsidentenstelle nicht begreife etc. u. die Neigung, die er offenbar hätte, dem Ruf nach Tübingen, wenn er kommt, anzunehmen, zeigen dieselbe Physiognomie. - Das zweite Bild ist Pauline, wie sie den langen Tag einsam auf ihrem Lager liegt u. sich nicht rührt, ja nicht einmal ein Bedürfnis nach Bewegung empfindet. Sie hat sich so in die Einsamkeit eingelebt, dass sie etwas anderes gar nicht mehr wünscht. Da passt das Solitudo dulcessit. Das Leben hat ihr furchtbar mitgespielt. Grosses Talent, aber Irreführung nach wichtigen Seiten, harte Kämpfe mit einem unbändigen Temperament, u. jetzt bei Lebzeiten ein Grab der Einsamkeit. Ich weiss, dass 
es mir noch zu den Zeiten meiner Universitätsstudien ganz ebenso hätte gehen können, $\mathrm{u}$. vielleicht gegangen wäre, wenn ich Dich nicht als Lebensgefährtin gehabt hätte. Es kommen mir da manchmal ganz eigene Gedanken, wenn ich an die Trogener Zeit denke. Und wie alles dann sich so wunderbar gewendet hat!

Den 13. Okt.

Auf heute Mittag hatte ich Victor Schläpfer erwartet. Eine Karte brachte aber die Absage $u$. Verschiebung des Besuchs auf später, wegen Verhinderung. Ich schrieb einige Briefe, ein kleines Gutachten, ordnete Bücher in dem neuen Büchergestell u. hatte am Vormittag Besuch von Walter B. u. am Nachmittag von Dürrenmatt. Walter B. war schärfer in verschiedenem Urteil als gewöhnlich, wie er dann seit einiger Zeit, nicht gegen mich, sondern im Allgemeinen, eine rauhere Seite zeigt. Ich weiss nicht, ist es Enttäuschung oder umgekehrt Erfolg, was diesen Wandel augenblicklich hervorgebracht. Der ja auch nur ganz vorübergehend sein kann. Auf $6^{1 / 4}$ ging ich zur Bahn, um Teichmann abzuholen. Ich brachte ihn zum «Althof» u. dann fuhren wir hieher. Das Abendessen war ganz nett. Wir konnten auf den 68sten Geburtstag Teichmanns anstossen. Am Essen war er sehr angeregt. Beim Gang zum «Althof» aber, nach neun Uhr fiel mein Gast sehr zusammen, klagte über Schmerzen u. hatte sehr viel zu klagen. Ich verabredete, ihn um $10 \mathrm{Uhr}$ morgens abzuholen. Aber was soll ich mit ihm anfangen? Ich finde es sehr sonderbar, dass die beiden Kinder ihren Vater aus einem doch recht windigen Grund - Herbstreine machen im Hause-

fortschicken, in seinem kranken Zustand. Wenn nur nichts schlimmes dahintersteckt! 
Und nun sei auch dieser Sonntag abgeschlossen. Ich bin müde u. in Sorgen. Wie froh will ich sein, wenn die nächsten Tage vorüber sind $u$. wir wieder im vollen Semester stehen!

Gute, gute Nacht! Hilf mir in aller Not, dann werde ich sie schon bestehen als

Dein allzeit getreuer

Eugen

\section{2: Oktober Nr. 210}

B. d. 14./ 5. Oktober 1912.

Meine gute Lina!

Heute schreibe ich noch einmal auf der Terrasse, vielleicht zum letzten mal in diesem Jahr. Ich habe hier von drei Uhr an gelesen, mit sonnigem Blick in die Ferne u. klaren Bergen. Jetzt wieder kühler, aber ich sitze noch hier u. schreibe an Dich.

Die letzte Ferienwoche! Es ist eine Geduldsprobe, dass der Besuch Teichmanns sie zu stören gekommen ist. Ich hatte mit ihm auf 10 Uhr zum «Althof» verabredet. Ein Gutachten, das ich für die Volksbank Zürich schon lange hätte schreiben sollen, hielt mich hin bis zur genannten Stunde ich durfte es nicht länger verschieben - $\mathrm{u}$. so kam ich eine Viertelstunde zu spät zum Rendez-Vous, was mich leid tat. Teichmann stand auf dem Trottoir, war aber nicht verletzt. Ich führte ihn ins Bahngesellschafts Museum, u. wir blieben dort eine Weile. Zusammenhängendes lässt sich mit ihm jetzt noch weniger besprechen als früher. Er wünschte dann Walter Burckhardt zu besuchen, $u$. ich ging mit ihm hin. Auch da war dasselbe Gespräch, mit vielen Complimenten für den Commentator der BVerf., aber ohne Inhalt. Ich begleitete alsdann T. zum Althof zurück, es war Mittag, u. verabredete auf zehn Uhr morgens ein neues Rednez-Vous in 
der Bahngesellschaft. Natürlich hatte T. erwartet, dass er Nachmittags mit mir wieder zusammen sein könne. Aber ich konnte die Zeit nicht wieder weg, es ist zu viel von allerlei Arbeit gerade in dieser Woche noch zu erledigen. Es kamen dann auch drei Studenten mit Dissertations- u.

andern Angelegenheiten, wie das zu Beginn des Semesters der Fall zu sein pflegt. Lauch, Sassler, Basler, u. dazu Mutzner, der jetzt seinen Urlaub wieder fortsetzt. Namentlich aber hatte ich noch mit Marieli zu sprechen, das noch vor seiner Abreise mit den Kollegarbeiten u. mit der Kata$\log$ Hülfe beginnen wollte. Morgen verreist es nach Stuttgart, u. es ist mir sehr lieb, wenn es mit einem gewissen innern Halt über seine Arbeitspläne zu Tante Ida kommt. Der Gesichtsausdruck spiegelt die grössere innere Befriedigung wieder. Möchte Deine Liebe es bewirken, dass das über all den Geschichten des Jahres der Fall sein konnte! Von Abbühl hat es einen Fächer geschenkt erhalten mit dem Helveter Cirkel. Was es darauf geantwortet hat, weiss ich nicht. Aber ich habe Vertrauen, dass es richtig geschrieben habe. Teichmann hat mir beim Weggehen eine kleine Bonbonière für Marieli auf die Reise mitgegeben, zugleich mit einigen Reclameschriften (eine Stuttgart betreffend) die er sich beim Verkehrsbüreau diesen Morgen geholt haben muss. Also immer der alte, verbindliche Teichmann! Und gewiss hatte ich Gewissensbisse, ihm nicht auf diesen Nachmittag eine Freundlichkeit erwiesen zu haben. Aber es geht nun einmal nicht, ich bin durch die vielerlei Geschäfte innerlich so in Anspruch genommen, ober vielmehr ich bin so sehr innerlich von anderem erfüllt, dass ich darüber nicht wegkomme u. ihm die Zeit nicht widmen kann, die er in so eigentümlicher Weise von mir erhofft. Es ist mir wieder ganz klar, wie Teichmanns Geschick sich gestaltet: Ein verwöhnter Junge, als Schüler mit seinem Gedächtnis glänzend, schien er eine grosse Zukunft zu haben. Aber es fehlte jede gestaltende Kraft, u. kam er in eine Stellung, der er nicht gewachsen war. Sein gutes Herz hat ihm dann 
die Correktur an die Hand gegeben für sein Bewusstsein. Seine feine gesellschaftliche Bildung verband sich mit dem Bedürfnis, den Andern immer wieder sich gefällig zu erweisen. Und so bestand sein Wirken in der Benutzung einer ungestalteten Gelehrsamkeit in Combination mit dem verbindlichsten Wesen, das ich je getroffen habe! Ich will sehen, dass ich ihm doch während seines Aufenthaltes noch einige Freundlichkeit erweisen kann.

Es wird neblich u. düster. Also schliesse ich diese Zeilen auf der Terrasse - es ist Herbst. Darüber kommt man nicht weg, auch wenn über Mittag noch die Sonne geschienen hat.

\section{Den 15. Okt.}

Heute also ist Marieli nach Stuttgart verreist, fröhlich, soweit es nicht sich infolge eines aus eigenem Antrieb eingenommenen Wagenimbisses nachher im Magen gedrückt fühlte. Möge es glücklich gereist sein! Der Tag war sehr schön. Ich erledigte einiges Amtliche, war auf dem Departement, - nur Käslin war anwesend, Kaiser ist mit Müller bei einer Kommission in Siders - $\mathrm{u}$. besprach einiges von den Strafrechtsberatungen. Vor $10 \mathrm{Uhr}$ kam ich mit Teichmann, zufällig auf der Strasse, zusammen u. wir machten dann gemeinsamen Besuch bei Oberst Frey. Von diesem, der uns liebenswürdigst empfing, vernahm ich, dass sein Sohn der Mediziner in Lyss seit zwei Wochen an beiden Beinen gelähmt sei, dass aber jetzt Sahli die Diagnose gestellt habe, es sei dies nicht vom Rückenmark her, sondern Folge einer Nervenentzündung. Er dulde fortwährend die heftigsten Schmerzen. Beruhigungsmittel werden nur sehr sparsam verabreicht - anders als leider Gottes bei Dir! - u. sie hoffen nun, dass er nach Wochen oder Monaten wieder geheilt sein werde. Helene pflege ihn mit rührender Aufmerksamkeit, seine Frau erwarte dieser Tage die Niederkunft, es ist die Amerikanerin, die s. Z. einmal mit Helene Frey bei uns zu Gast war. Ich ging dann von 
Teichmann weg, um Walter Dürrenmatt im Sanatorium zu besuchen, u. traf ihn munter. Es geht, wie es nicht besser gehen könnte. Morgen kann er nach Hause, also kam ich noch gerade zur rechten Zeit. Ich fand ihn übrigens sehr bleich u. hinfällig. Es wäre schrecklich, wenn er am Ende doch an einer schweren inneren Krankheit litte!

Um drei kam Teichmann zu mir u. wir plauderten bis sechs, wobei er mir wirklich näher gekommen ist. Was er mir erzählte, war viel sympathischer als ich es erwartet hatte. Dann konnte ich ihn auf halb sieben zu Walter B. begleiten, der den glücklichen Einfall gehabt hat, Teichmann zum Nachtessen einzuladen. Morgen werde ich wiederum den Nachmittag mit T. zusammen sein.

Ich las auch einige Rechtsgeschichte u. schrieb etwas auf über den «ungerechten Mammon». Sonst ist der Tag still verlaufen, ein schöner Herbsttag, still weil Marieli fehlte. Es ist doch sehr empfindlich, wenn es fehlt. Pauline hat recht gehabt, als sie sagte, Marieli sei ein Segen für mich. Und noch in einem andern Punkt hat sie recht gehabt: Als wir vom Bruch mit Paul sprachen, sagte sie, am Ende hätten sie Marieli später noch schlecht behandelt, weil es ein angenommenes Kind sei, $u$. das hätte der da wehgetan, u. dabei deutete sie mit Thränen auf das Bild, das über ihrem Bette hängt, Dein Bild! Ja, Pauline hat Herz u. Verstand, viel mehr als Anna u. August. Es war auch so rührend, als sie sagte, sie habe dem August den Bruch Pauls mit Leny Graf verwiesen, ob dann Paul nicht daran denke, dass das Mädchen jetzt weinen werde! - Der kurze Besuch hat mich Pauline viel näher gebracht. Ja ich bedaure, mich aus den früheren Erinnerungen heraus von ihr so ferne gehalten zu haben. Aber freilich, sie wollte, u. will es auch jetzt noch nicht anders.

Damit Gott befohlen! Ich bitte um Deine Hilfe u. bin Dein allzeit getreuer Eugen 
[1]

B. d. 16./ 7. Okt. 1912.

Mein liebstes Herz!

Heute verbrachte ich einige Stunden mit der Durchsicht $u$. Verpackung von 3690 Wörterbuchzetteln, die mir Gmür (einiges auch Mutzner) zugestellet hatten. Da ich alles allein machen musst, das Packen u. Schnüren etc., war es mir ausserordentlich lästig, u. ich war bei dem warmen Sonnenschein, den wir hatten, in den geheizten Zimmern schweisstriefend. Ich sagte immer vor mich hin, wenn ich Lina noch hätte, wäre mir wohler.

Die Post brachte mir dann einen lieben Brief von Rümelin, mit der ersten warmen Beurteilung meiner «sozialen Gesinnung». Das freute mich. Zugleich enthielt der Brief die Angabe, dass Mutzner vielleicht noch genannt werden könne. Diese Bemerkung veranlasste mich nun doch, mit Mutzner über die Sache zu sprechen. Ich liess ihn kommen u. erwog mit ihm die Möglichkeiten. Die Aussicht freute ihn sehr, aber er hatte doch Bedenken, was bei einem 31 jährigen Familienvater mit zwei Kindern u. einem guten Patrioten wohl begreiflich ist. Er will mir heute Abend noch oder dann morgen früh darüber Bericht machen, ob ich in seinem Einverständnis - ohne das könnte ich es doch nicht tun -, nochmals an Rümelin schreiben soll.

Teichmann kam nach drei zu mir. Ich fuhr mit ihm im Tram bis zum Brückfeld, spazierte über Karlsruhe nach der äussern Enge u. dort tranken wir eine Flasche Asti u. rauchten. Wir besprachen gar manches, Teichmann war in 
seinem Benehmen u. seinen Urteilen viel bestimmter $u$. zugänglicher, vernünftiger $u$. verständiger oder verständlicher, als ich es an ihm gewohnt war. Über den gestrigen Abend bei Burckhardts sprach er sehr nett, übrigens hatte auch Walter B. als wir heute uns antelephonierten, ein sympathisches Urteil.

Für morgen habe ich Teichmanns Besuch ausgeschaltet. Er geht Nachmittags zu Pfarrer Wyss in der Krone Muri, den er von einem Ferienaufenthalt her kennt, u. will Vormittags das Bundeshaus beschauen, wobei ich ihn nicht zu begleiten brauche, auch nicht begleiten möchte. Dagegen werde ich ihn dann Freitag Vormittags auf die Bibliothek führen müssen, $\mathrm{u}$. am Abend muss ich es doch wagen $u$. ihn nochmals zum Essen haben. So geht die Woche vorüber, hoffentlich bin ich Sonntags frei, oder noch besser schon Samstags.

Von Marieli ist eine Karte aus Karlsruh eingetroffen, bis wohin die Reise scheints gut verlaufen ist. Morgen wird wohl Bericht aus der Gänsheide eintreffen.

Mich beschäftigt die Angelegenheit Mutzner sehr. Habe ich da wieder zu viel Schicksal gespielt? Ich denke mir aber, in Mutzner würde die Wissenschaft eine hervorragende Kraft gewinnen, u. da darf ich doch mithelfen, oder was sagst Du dazu?

Den 17. Okt.

Mutzner kam gestern Abend noch vorbei, um mir zu sagen, dass seine Frau u. er gerne die Gelegenheit zur Habilitation in Tübingen ergreifen würden. Er war erregt u. voll Eifer. So habe ich nun Rümelin geschrieben mit dem Vorschlag, sie möchten

Mutzner zunächst als Privatdozenten aufnehmen mit dem Versprechen der Beförderung bei Erfolg. Wir wollen nun abwarten.

Heute habe ich Teichmann nicht gesehen, bin aber doch zu keiner Arbeit gekommen. Am Vormittag schrieb ich einige Briefe u. Gutachten u. las etwas RG. Dann machte ich Frau Oncken den längst schuldigen 
Gegenbesuch, traf sie aber nicht zu Hause. Am Nachmittag war wieder einmal Dr. Beck bei mir, der mich ersuchte, ein Manuskript von ihm zu lesen, das er mir demnächst bringen will. Ich konnte es ihm nicht abschlagen. Dann las ich einiges, Guhl kam mit wichtigen Angelegenheiten. Und so wurde es Abend. Ich schrieb endlich an Pauline, der ich den Vorschlag, zu uns zu kommen wiederholte. Heut Abend muss ich auch noch an Haring in Halle schreiben, der sich bei mir nach Pfarrer Hadorn erkundigte.

Sonst stand ich heute wieder so recht unter dem Eindruck der Führerlosigkeit. Die Vorfenster wurden eingehängt, u. es war niemand herum, eine tolle Sache, u. das war mir ein stiller Ärger. Ich muss mir immer wieder vorhalten, wie ist es nur gekommen, dass ich jetzt gerade den Haushalt führen muss, den ich mir für mich vorgestellt, den ich stets zurückgewiesen hätte. Geduld, Geduld, es geht ja nicht ewig.

Frau Oberst Hebbel fragte heute telephonisch, weshalb Marie nicht an Marthas Hochzeit gegangen sei. Sophie antwortete, es sei verreist. Nachher traf Anna Frau Oberst in einem Laden, natürlich Gespräch, wobei Frau Oberst sagt, Marie hätte Dr. Guggenheim als Cavalier gehabt, den Sohn eines Freundes von Hebbel (das hab ich nicht gewusst). Damit ist mir die Intrigue am Tag. Guggenheim ist Zofinger gewesen, war einer der besser mit Paul bekannten

Couleur Brüder. Es war also die Absicht, Marieli daran zu erinnern, was es mit Paul gehabt, $u$. vielleicht noch mehr, die Verleumdung schreitet ja flott weiter. Das arme Kind, in welche Geschichte hat es sich mit seiner Ungeschicklichkeit u. Unberatenheit gestürzt! Um so mehr werde ich ihm helfen, wenn es darauf ankommt. Das verspreche ich Dir! Aber ja nicht darüber sprechen. Skandal wäre jenen ganz recht, weil dann immer ein Teil der Leute zu einem hält. Im übrigen müssen wir der bösen Frau Oberst dafür dankbar sein, dass sie durch ihr Benehmen uns den Verdacht enthüllt. Wir hätten sonst keine Ahnung gehabt $u$. Marieli wäre blindlings in diese Sippschaft hineingeschossen.

Nun ja, vorwärts. Es geschehen so merkwürdige Dinge in der Welt. Etwas davon muss man doch auch miterleben. 
Damit genug für heute. Um zwei sass ich noch an der Sonne im Garten, Beck bei mir. Dann wurde es trübe u. um drei regnete es. Nun wird es auch wieder kühler werden, was mir recht ist.

Gute, gute Nacht! Ich bleibe auf immerdar

Dein getreuer

Eugen

1912: Oktober Nr. 212

[1]

B. d. 18. / 9. Okt. 1912.

Mein liebstes Herz!

Es ist merkwürdig, dass mir von fast nirgend her der Empfang der Brochüre «soziale Gesinnung» bestätigt wird. Es ist als würde das nur so wie ein Zeitungsartikel behandelt, von Freund u. Gegner. Ich muss an die Bemerkung Walter Bs. denken, der als ich ihm diesen zweiten Aufsatz für sein Jahrbuch in Aussicht stellte, zu mir ganz naiv bemerkte, ob es nicht schade sei, solche Abhandlungen da zu veröffentlichen. Nun ja, ich halte daran fest. Es muss etwas werden daraus, oder das ganze verfällt der Vergessenheit. Dass auch Georg Müller aus Chemnitz mir den Empfang meiner grossen Sendungen nicht bestätigt, ist ganz merkwürdig. Ist er krank?

Heute schrieb mir Teichmann für Vormittag ab, da er in Muri einen entlehnten Schirm zurück zu geben habe. Das war mir sehr lieb. Ich konnte einiges in der RG. lesen, u. namentlich den Brief Häuslers beantworten. Ich ging zunächst zu v. Mülinen u. habe von ihm das Nötige vernommen. Anderes telephonierte mir Guhl, sodass Häusler durch meine Antwort orientiert sein wird. Ich habe im Ton meines Schreibens es ihn schon merken lassen, dass ich von ihm nicht mehr denke, wie früher. Das Pamphlet v. Frischs hat mir die Augen geöffnet. - Ich brachte der Bibliothek m. Aufsatz «soz. Ges.» u. einer der fünf Bände, die ich von Chicago erhalten. Er war sehr erfreut. Im Lesesaal 
habe ich nachgeschaut, ob Burckhardts Besprechung des Pamphlets schon bei Berolzheimer abgedruckt sei. Es war aber nichts da.

Nach gestrigem Regen war es heute wieder heller, Sonne u. Wind wechseln, ich sass aber doch Nachmittags im Garten u. empfing dort zwei Studenten. Einer, Schmid, brachte mir einen Gruss seiner Grossmutter, was mich an die gehobene Stimmung in

der Zeit vom Frühjahr 1908 erinnerte. Wie viele Mächte haben damals dazu beigetragen, mir diese Stimmung zu trüben. Ich hätte zufrieden sein sollen, dass ich das noch mit Dir zusammen erlebte. Der 1. Januar 1912 traf mich allein!

Heute kam dann doch Teichmann um 4 Uhr zu mir u. blieb zum Nachtessen, bei welchem Anna bei nahe wieder eine Flasche umgestossen hätte. Ich wusste nicht, was ich mit dem bedauernswerten Mann anfangen soll. Etwas der Regel nach mit ihm besprechen hat man nie gekonnt. Etwas mitzuteilen verstand er nicht besser. Heute erzählte er mir in einer Weise, dass er mich verbarmete, von der Ungeschicklichkeit seiner Tochter im Haushalt, die vier Pfund Leber auf einmal kaufe, die keine Confitüre selbst mache, sondern sich Lenzburger anschaffe u. dann vier Töpfe mit einander öffne, um sie möglichst schnell zu leeren, damit sie nicht verderben etc. etc. Scheints haben die Kinder ihm geschrieben, er soll zu Hanna u. für den Sohn noch den Montag freibitten, u. das tut der alte Mann, während er sich im Althof jede Nacht um sein Lager grämt, das hier ihm so ganz u. gar nicht passe. So ist er eben doch auch etwas selbst Schuld an der Rücksichtslosigkeit seiner Kinder. Ich habe jetzt von dem Sohn einen andern Begriff als vor diesem Besuch. Nun, ich wusste also mit Teichmann nicht was zu reden, bis mir die Frage einfiel, ob er Musik liebe. Als er dies bejahte, spielte ich ihm einige Sachen vor u. nach dem Nachtessen auf dem Aeolion, u. damit war beiden geholfen. Für morgen habe ich mich, weil ich notwendig die Arbeit für die Baumeister machen muss, frei gebeten. Ob Teichmann am Sonntag noch zu mir kommt, wollen wir abwarten, jedenfalls habe ich ihn nicht mehr eingeladen, sondern werde etwa 
sehen, dass Werner Kaiser, sein ehemaliger Hörer, sich seiner annimmt.

Den 19. Okt.

Ich habe mich heute dahinter gemacht, die Antwort an die Herren Baumeister aufzusetzen $u$. brachte sie richtig fertig für die Nachmittagspost. Auf neun ging ich, um mich für diesen Bericht zu informieren, zu Müller, der mir sehr einlässlich von den Verhandlungen in Solothurn u. von denjenigen in Siders erzählte. Es scheint, dass er hier ein heftiges Rencontre mit Forrer hatte, er war noch ganz erbost auf ihn. Das merkwürdigste aber war, dass er dahinter ein Manöver witterte, womit Forrer das Justizdepartement zu erlangen versuchen würde. Das wäre interessant. Wäre auch merkwürdig, wenn dahinter ein Plan Zürchers stecken würde. Oder beider, sie sind ja so gut zusammen u. Müller hätte ein schönes Nachsehen. Denn von ihm erwarte ich keine Intrigue, wenn auch allerdings ebenfalls nicht mehr eine entscheidende Tat. In der Art, wie Müller heute zu mir sprach, hatte ich den Eindruck, dass er mir wieder wie früher gesinnt sei. Zugleich aber kam er mir auch geistig gealtert vor, von einer fröhlichen Gemütsverfassung, die am Umschlagen in Melancholie hart bei liegt, aber zunächst in vielen Worten sich äusserte, die bei Müller auch gescheite Worte sind.

Ich ging dann auch zu Werner Kaiser. Teichmann sagte mir gestern Abend, dass er heute zwischen 11 u. 12 zu Kaiser Teichmann gehen wolle. Und so bat ich diesen, der doch ehemaliger Schüler Teichmanns ist, sich für heute u. morgen Teichmanns etwas anzunehmen, da ich verhindert bin durch meine dringenden Arbeiten. Kaiser versprach ihn auf Sonntag zum Essen einzuladen,

telephonierte mir aber Abends, dass Teichmann gar nicht zu ihm gekommen sei. Was geschehen ist oder jetzt geschieht, weiss ich nicht. 
Heute Abend kam Walter Burckhardt noch einen Sprung zu mir, aus den Wasserrechts-Kommissionsverhandlungen, die er mitgemacht. Und er war sehr freundlich $u$. meinte, er verstehe erst jetzt, was ich zu tragen gehabt habe während der langen Jahre. Ja das weiss einer halt nicht, wenn er es nicht erfahren hat. Und ich weiss wohl, wie wenig Dank ich dafür ernte, u. wie das alles verkannt wird. Aber seis drum. Du hast es mir immer gesagt: Aushalten, u. ich sagte, die Pflicht tun, u. wir beide sagten: es ist gleichgültig, was die Welt dazu sagt!

Ich schrieb heute einige Gedanken nieder, die mich gestern in der Nacht verfolgten, über das Gerecht werden durch den Glauben. Ach, dass ich sie Dir nicht vorlegen kann!

Gute, gute Nacht, mein Lieb! Wie lange geht es noch? Ich bin Dein ewig treuer

\section{Eugen}

\section{2: Oktober Nr. 213}

B. d. 20. Oktober 1912.

Meine einzige Liebe!

Es war heute ein ausnehmend stiller Sonntag. Am Morgen liess ich durch Stadtauftrag Teichmann wissen, dass Werner Kaiser ihn heute erwarte. Ich denke er wird hingegangen sein, wenigstens kam er nicht zu mir. Dann las ich die Zeitungen, verweilte mich bei einer Schachaufgabe, die ich löste, schrieb einige kleine Briefe u. ging dann an die RG., von der ich eine ganze Serie Vor- $u$. Nachmittags durchgehen konnte, da niemand, gar niemand mich störte. Natürlich wars noch stiller, weil Marieli fehlte.

Ich benutzte die Stille um mir meine kommende Arbeit zu recht zu legen. Es kommt nun alles darauf an, ob mich das Kolleghalten stark ermüdet. Ich fühle mich jetzt seit einiger Zeit etwas marode, der kühle 
nasse Sommer mag daran schuld sein, u. natürlich vor allem das Alter, an das ich heute noch speziell dadurch gemahnt wurde, dass mir beim Frühstück ein Schneidezahn abbrach. Die Lücke ist grösser, aber für das Sprechen glaube ich macht die Sache nichts aus. Wir wollen sehen.

Zunächst muss ich nun nebenbei die Schw. RG. fertig durchlesen, etwa die Hälfte habe ich erledigt. Ich denke bis Weihnachten hiermit fertig zu werden, wenns

nicht zu viel Dissertationen oder andere Störungen gibt. Dann werde ich gleich zu Anfang des Semesters den Vortrag, den ich dem Bern. Juristenverein versprochen herrichten müssen. Es ist keine kleine, wie eine subtile u. verantwortungsschwere Arbeit. Ich werde wohl über die dinglichen u. persönlichen Rechte des ZGB. sprechen.

Rechne ich dazu, dass ich das Mskr. des ersten Bandes nebenbei mit den Vorlesungen etwas nachzunehmen beabsichtige, so werde ich mit alledem bis zu Weihnachten tüchtig beschäftigt sein.

In den Weihnachtsferien würde ich sodann gerne den ersten Entwurf des dritten Aufsatzes für Burckhardts Jahrbuch niederschreiben. Ich werde wieder etwa 50 Machinenseiten rechnen müssen, also zehn Tage hierfür zu reservieren haben. Wenn ich jetzt zwar sehe, wie mir die Zusendung der «soz. Ges.» fast von keiner Seite auch nur bestätigt wurde, so könnte ich an diesen meinen Wegen irre werden. Dass dies nicht der Fall ist, beweist mir, wie tief mich die Sachen beschäftigen. Es ist mir wirklich gleichviel wert, ob die Adressaten oder anderes Publikum darüber schreiben oder nicht. Wenn ich nur die Sache einmal gesagt, mein Bekenntnis abgelegt habe. Das andere überlasse ich der Zukunft. Der dritte Aufsatz solle von «Recht u. Gewalt» handeln. Ich glaube, dass sich 
darüber etwas entwickeln lässt, was ganz gut in den Rahmen des Jahrbuchs passt. Kann ich das schon um Neujahr entwerfen, so habe ich die Frühjahrsferien um so viel entlastet.

Im Januar u. Februar fahre ich fort, wie in der ersten Hälfte des Semesters. Es wird sich zeigen, was dabei herauskommt.

Über das ZGB. habe ich - Duplizität! - zwei Vorträge mit sehr sympathischem Tone zugeschickt erhalten. Der Staatsanwalt Tarlinden von Brüssel sandte mir die Rede, die mir Röthlisberger gestern mit sichtbarer Freude in einer Gerichtszeitung übergab. Und Karl Bürke hat seinen Vortrag über das Familienrecht eingesandt. Es ist also doch noch des guten Geistes vorhanden. Es gilt nur auszuharren.

Als Teichmann am Freitag bei uns zu Nacht ass, fand ich Gelegenheit, ihm doch einmal zu sagen, er soll mir nicht schreiben mit der Anrede «Gönner». Er verstand aber nicht recht, was ich meinte, indem er entgegnete, er dürfe mir doch nicht «Freund» schreiben. Ich hatte keine Veranlassung dieser letzteren Bemerkung zu widersprechen, bemerkte offen nur, es gebe so viele andere Titel, u. führte an, wie Soleilles in den verschiedenen Perioden meine Bekanntschaft mit ihm die Anreden gewechselt habe. Sonst wurde das Thema nicht weiter gesponnen. Ob nun Teichmann

morgen verreisen kann, oder ob er nochmals veranlasst wird, bei [He?] um die Ausdehnung der Ferien des Sohnes nachzusuchen? Mir täte es leid, wenn Teichmann wieder schwach wäre, u. im übrigen habe ich gegen die beiden Kinder ein grosses Misstrauen in mich aufgenommen.

Morgen Abend wird Marieli wieder hier sein, wenn nichts Unvorhergesehenes begegnet. Was wird es von Rümelins zu erzählen haben u. über Mutzners Plan wissen? 
So schliesse ich jetzt die letzte Ferienwoche. In letzter Nacht habe ich alles Erlebte nochmals rekapituliert. Es waren sonderbare Ferien.

Pauline, die ich wegen ihres kranken Zustandes, - sie leidet offenbar an Herzschwäche - zu uns eingeladen, ist in ihren alten Geist verfallen $u$. hat mir abgeschrieben. So muss jeder liegen, wie er sich bettet. Mir geht's auch so.

Gute, gute Nacht! Hilf mir, was auch kommen mag, die Schwere des Daseins zu tragen. Alte Tage sind schwerer als junge.

Immerdar Dein treuer Kamerad

Dein

\section{Eugen}

\section{2: Oktober Nr. 214}

[1]

B. d. 21. / 2. Okt. 1912.

Mein liebstes Herz!

Jetzt ist der letzte Tag vor dem Kolleglesen mit unheimlicher Schnelligkeit vorübergeflogen, ohne jede Möglichkeit von rechter Arbeit: Am Morgen Adressen zur Versendung der englischen Abzüge der Rechtsgeschichte, die nun unerwartet doch eingelaufen. Dann Wildbolz, u. dann Zahnarzt Wirth, weil mir gestern ein Schneidezahn abgebrochen ist. Das ging bis 12 1/2, mit Unterbrechung einer halben Stunde, die ich herumspazieren musste, da Wirth Bestellter hatte. Ich traf dabei auf Frau Dürrenmatt (es geht Walther recht gut) u. auf Nationalrat Wyss. Dann Nachm. wieder Wirth, darauf Ankunft Marielis, dann Guhl mit allerlei Berichten $u$. jetzt ist es acht Uhr.

Marieli ist sehr munter nach Hause gekehrt. Der Aufenthalt bei Rümelins scheint ihm gut getan zu haben. Was es von Ida sagt, ist auch recht. Aber der Plan mit Mutzners Habilitierung in Tübingen scheint nicht durchführbar zu sein, wegen der bereits dort vorhandenen Privatdozenten u. a. 
Marieli beachtet gut $\mathrm{u}$. konnte mir Rümelins Stellung ganz recht bezeichnen. Es tut mir leid für Mutzner, aber am Ende ist es so für uns besser.

Was Marieli von Gertrud u. Thilda sagt, ist köstlich. Thilda fast übermüthig, lustig, eine komische Figur. Dagegen Gertrud scheint am Rand ihrer Kräfte zu sein. Ihr Mann soll aber für sie grosse Sorge entwickeln.

Während ich bei Wirth war, kam Teichmann u. verabschiedete sich. Anna sprach mit ihm, er soll sehr unglücklich von der Rückkehr in die Basler Verhältnisse gesprochen haben. Dann wollte Oser mich besuchen, es tat mir leid, dass er mich nicht getroffen. Er soll sehr ruhig ausgesehen u. sich gar nicht verändert haben. Wegen des Jüngern soll er in Sorge sein. Den Haushalt führt ihm jetzt die Schwiegermutter.

Und nun morgen Kolleganfang! Wie wird das Semester? Guhl hat zuversichtlich gesprochen, aber er nimmt in neuester Zeit im allgemeinen einen Ton an, als dürfe er mir nur noch Angenehmes sagen. Das wird, hoffe ich, sich auch wieder verlieren.

Jetzt will ich mich noch auf morgen präparieren, um am Morgen nicht aussergewöhnlich früh aufstehen zu müssen. Ich planiere, das jeden Abend in diesem Winter so zu halten, so gut es geht.

Den 22. Okt.

Es war heute ein düsterer frostiger Regentag, auf dem Gurten Schnee. So bin ich mit Marieli gegen acht Uhr zur Universität hinaufgefahren. Es trug mir die 100 Übersichten, die ich vorsorglich mitnahm. Im Dozentenzimmer traf ich Schulthess $u$. Walter B., herzliche Begrüssung. Ich hatte als Auditorium Nr. 42. angezeigt, vorsorglich, um nur im Bedürfnisfall auf Nr. 31 greifen zu müssen. Ich betrat das Auditorium unter Beifall. Aber mehr als etwa 55 Hörer waren nicht da. In der zweiten Stunde dieselbe Zahl. Und Abends in der Rechtsgeschichte wenig mehr. Damit ist nun festgestellt, dass das 
Semester nicht gut werden wird. Es ist mir unerklärlich, wieso auf die über 100 des letzten Semesters dieser Abfall eingetreten. Dass das Kolleghalten nicht schuld daran ist, darf ich schon glauben. Denn die widerstrebenden Elemente, zu denen ich auch Guhl rechne, waren im letzten Semester sowohl vorhanden, wie jetzt. Es sind die kleinen Verhältnisse, die eine feste Grundlage nicht aufbauen lassen. Übrigens meinten Burckhardt $u$. Thormann, die Leute seien noch nicht da, es werden noch mehr kommen, u. das ist gewiss zu erwarten. Ebenso sicher aber ist es auch, dass dieser Zuwachs die Differenz nicht wird ausgleichen können. Wenn ich mit früheren vergleiche, so werde ich auf mehr als 70 Hörer nicht kommen, also nur auf etwas über die Hälfte vom letzten Sommer. Ein Gutes hat diese Situation: ich muss nicht in Nr. 31 lesen, mich also im ganzen weniger anstrengen, $u$. da ich mich so oft jetzt gar nicht wohl fühle, wird mir das wohl bekommen.

Sonst schrieb ich heute allerlei Kleines, musste unter anderem an Oberst Emil Frey eine eigentümliche Antwort senden. Er schrieb mir, er habe s. Z. bei der Sammlung für Teichmann nichts geliefert, u. doch habe ihm T. bei dem jüngsten Besuch mit mir gedankt, Dank für nichts wolle er nicht u. bitte mich daher, ihm die Adresse anzugeben, unter der er Teichmann 100 Fr. senden könne. Ich erwiderte, dass ich selbst niemals etwas gegeben, $\mathrm{u}$. dass T. gewiss nichts erwarte, auch nichts bedürfe u. dass der Dank eben nur eine der übergrossen Höflichkeiten Teichmanns gewesen sei. Was nun weiter geschieht, bleibt abzuwarten. Der Aufenthalt Ts. in hier war ja auch eine tolle Geschichte, bei der ich das Vertrauen in die zwei Kinder Ts. ganz eingebüsst habe.

Marieli hat heute noch viel von seiner Stuttgarter Reise erzählt. Die Übersiedlung nach Tübingen erfolgte wohl von seiner Seite aus dem Grund nicht ungern, weil es am Sonntag beim Essen in Gertruds Haus die Hedwig Gyr, Augusts Schwester, getroffen hätte. Davon weiss Ida wohl nichts, um so eher ist es möglich, dass sie die Abreise Marielis übel genommen hat. Bei Rümelins hat es Marieli weitaus besser gefallen als bei Ida. Von Thilda 
hat sie den Eindruck einer komischen Person, u. in Ida ist ihr eine Hysterie nicht entgangen, die sie kränker erscheinen lässt, als sie es sein müsste. Mit Gertrud hat sie Mitleid. Bei Rümelins scheinen der Vater u. die Mutter ganz ausnehmend freundlich gewesen zu sein. Auch die beiden Kleinen waren lieb. Mariechen hatte darunter zu leiden, dass der Vater sie jedesmal anfuhr, wenn sie etwas nicht gut gemacht, während er Marieli belobte, wenn sie etwas gut gemacht. Das sind Menschlichkeiten.

Ich gehe resigniert den kommenden Tagen entgegen. Wenn ein Semester nicht gut ist, hat man immer lange daran zu tragen. Doch seis darum, es wird vorübergehen.

Gute, gute Nacht! Marie u. Anna sind in das erste Abon. Konzert gegangen. Ich will mich nun noch auf morgen präparieren u. dann zeitig zu Bett.

Innigst bin ich bei Dir als Dein allzeit getreuer Eugen

\section{2: Oktober Nr. 215}

B. d. 23. / 4. Okt. 1912.

Mein liebstes Herz!

Heute war der Besuch der Collegien besser. Der Abstand zum Beginn des Sommersemesters ist aber doch da, u. vor allem ich selbst bin nicht so bestimmt dabei. Die Stunden fliegen mir wie im Traum vorüber $u$. ich weiss am Schluss nicht mehr alles, was ich gesagt, oder nicht mehr, was ich alles gesagt habe. Daran kann auch der Schnupfen Schuld sein, der heute zum Ausbruch gekommen ist, stärker als je, doch bis jetzt ohne Affektion des Halses.

Ich las heute neben der gewöhnlichen Arbeit des Tages, in Colleg, Correspondenz u. Zeitungen, die 100seitige Dissertation des Ernst Pfeiffer, leider trotz aller Gescheitheit, die daraus spricht, keine brauchbare Arbeit. Ich werde morgen Mühe haben, ihm das begreiflich zu machen. 
Eigentümlich berührte mich heute das Auftreten der beiden Collegen Thormann u. Blumenstein im Dekanatszimmer. Ja, ja, das sind Collegen! Aber ich kann ihnen nicht mehr entrinnen u. muss also herhalten. Walter Burkh. erzählte mir, dass er sich von Jakob Welti, der scheints seit Anfang Oktober wieder hier ist, malen lasse, u. zwar als Kniestück, gross. Es soll sehr hübsch werden.

Ganz eigentümlich hat mich berührt, dass Marie am Vormittag u. Sophie am Nachmittag Teichmann in der Strasse gesehen haben. Also ist er noch gar nicht verreist $u$. wagt es doch auch nicht mehr, mich zu besuchen, nachdem er am Montag bei Anna Abschied genommen, mit der Bemerkung,

er verreise um zwei Uhr. Was ist da begegnet? Was planen die beiden Kinder? Ich erkundige mich jetzt nicht danach, aber man muss da am Ende noch eine grosse Geschichte gewärtigen. Die Augen will ich schon offen halten. Endlich habe ich von Gierke eine sympathische Antwort auf meine Sendungen erhalten, nicht sehr freundlich, aber in Eile, wie das bei ihm der Fall ist. Anderes ist nicht erwähnenswert.

Marieli fühlt sich, trotzdem es ebenfalls von Schnupfen geplagt wird, seit der Rückkehr aus Tübingen recht munter. Die psychischen Faktoren sind bei ihm überaus wichtig.

Geht es nun das Semester über wieder ganz so mit der Arbeit wie heute? Dann komme ich wieder gar nicht zu grösserer wissenschaftlicher Arbeit. Ich konnte wohl vor dem Nachtessen noch etwas RGesch. Stenogramm durchnehmen. Aber was nützt so ein Stündchen? Und doch, wenn ich das festhalte, kommt vielleicht doch etwas dabei heraus. Ich muss nur munter bleiben. Ob dies bei dem steten $\mathrm{Ge}$ mütsdruck, unter dem ich seit Deinem Abschied stehe, sich machen lässt, wer weiss es! Bleibe ich körperlich gesund, so kann ich auch arbeiten, $u$. arbeite ich, so kommt etwas dabei heraus. Also vorwärts, so gut es geht! 
Heute habe ich im Dozentenzimmer Thormann eine Bemerkung gemacht, die mich jetzt reut, obgleich sie harmlos ist. Nachdem er gestern über die soziale Gesinnung einige schlotterige Worte fallen gelassen, sagte ich ihm heute, ich hätte an einer Stelle an ihn gedacht, wie ich sie geschrieben. Er wollte wissen,

wo sie stehe, ich nannte sie ihm aber nicht (wusste sie auch nicht recht zu nennen), worauf er meinte, er werde jetzt das ganze durchlesen u. sehen, ob er sie finde. Gerade das wollte ich ihm aber aufhalsen, nachdem er so obenhin von dem Aufsatz gesprochen. Hoffentlich gibt's keine Geschichte daraus.

Frey hat mir geschrieben, Teichmann setze offenbar voraus, er habe s. Z. für ihn auch beigesteuert, u. habe deshalb ihm gedankt. Meine Beruhigung hat nichts gefruchtet. Frey will jetzt etwas beisteuern u. ersucht mich um die Adresse, wohin sich wenden. Was ist das für eine dumme Geschichte! Ich will nichts davon wissen.

Heute habe ich sehr starken Schnupfen, den ich mir offenbar gestern oder vorgestern im überheizten Auditorium geholt. Ich konnte die Collegien halten, war aber recht abgeschlagen. Marieli ist noch schlimmer dran. Das Wetter ist düster, regnerisch, auf den nahen Höhen liegt Schnee, es geht Sturm. Da darf man sich über nichts wundern.

Peinlich war es, heute dem Ernst Pfeiffer seine Dissertation zurückzugeben. Er wollte die Mangelhaftigkeit gar nicht begreifen. Ich glaube ihm aber doch einen guten Ratschlag erteilt zu haben. Er ging mit Dank davon.

Auch Mutzner, dem ich vorläufig Marielis Bericht mitteilte, schreibt vernünftig. Ich hoffe von Rümelin einen Brief zu bekommen, den ich ihm zeigen kann.

Es trifft sich gut, dass ich morgen nur das Praktikum eröffnen muss. Am Samstag ist zwar Bern. Juristenversammlung, aber da kann ich, wenns sein muss, schwänzen u. Samstag wie Sonntag im Bett bleiben. Das wäre ein schöner Semesterbeginn.

Ich fühle mich sehr leer. Es kommt mir alles so schal vor, ob- 
gleich die Kollegien heute besser besucht waren, als gestern. Das Semester wird vielleicht doch nicht so schlimm. Wenigstens sind nette Leute unter den Neuen, an denen ich hoffentlich Freude erlebe.

Gute, gute Nacht! Meine fiebrige Hand kann nicht mehr schreiben, ich lese noch was, trinke meinen Mass u. geh zu Bett. Gute, gute Nacht, meine liebste, beste Seele.

Ich bin immerdar

Dein getreuer

Eugen

\section{2: Oktober Nr. 216}

[1]

B. d. 25. / 6.Okt. 1912 .

Mein liebstes Herz!

Die verwichene Nacht weckte mich der Schnupfen mit der verstockten Nase - Du kennst das - jede Stunde, ich stand vielmals auf, schlief aber nach her sofort wieder ein. Gegen Morgen war ich so niedergeschlagen, dass ich beschloss, heute $u$. morgen im Bett zu bleiben. Aber die Schwerfälligkeit bei der Herrichtung des Morgenkaffees im Schlafzimmer trieb mich doch aus dem Bett. Ich stand auf, las den Morgen Examensarbeiten u. einen Teil des Aufsatzes, den mir Dr. Gustav Beck gebracht, empfing auch den Candidaten Winleder aus Luzern, der mir einen recht lieben Eindruck machte. Zum Mittagessen war ich in der Stube. Nach zwei kam Prof. Balli u. dann der missglückte, Bruttel gewordene Spahn, der sich wegen des Abfalls von seiner Dissertation entschuldigen wollte. Ich fand dann auch, dass ich die Einleitung ins Praktikum sehr wohl abhalten könne, u. es hat mir dann auch nichts geschadet, sodass ich wohl morgen zum Berner Juristentag 
gehen u. die Antrittsrede Wegenmanns anhören kann, während ich freilich dem Essen - nicht ungern - ferne bleiben werde.

Die Mitteilungen Spahns haben mir wieder gezeigt, welch unheilvollen Einfluss BRat Forrer auf die jungen Leute ausübt. Er hat ihm das erste Dissertationsthema, das ich ihm gegeben, verleidet, während dasjenige, das Forrer empfohlen, erst recht nichts für Spahn war. Jetzt

[2]

meint Spahn aus eigenen Kräften eines gefunden zu haben, von dem ich ihm aber sagen musste, dass es in den Bereich W. Burckhardts falle, u. - glücklicher Weise - nicht in den meinigen. Ich hatte von dem jungen Mann einen schlechten Eindruck, wozu freilich die Mitteilungen beigetragen haben können, die mir Kronauer von seinem sittlichen Lebenswandel gemacht hat.

Das merkwürdigste war heute, dass Teichmann am Nachmittag, eben wie ich ins Kolleg gehen wollte, vorsprach. Sophie gab Bescheid, ich sei im Colleg, wie ich das ja im Momente des Aufbruchs sagen lassen muss, um nicht in vielen Fällen ungebührlich hingehalten zu werden. Aber um Gottes willen, was tut Teichmann noch hier? Läuft die Sache doch auf eine, - von mir ja gleich befürchtete - Teufelei seiner Kinder hinaus? Oder ist er selbst dabei? Ich werde mich nicht rühren. Das wird mir zu gering. Und doch ist er so erbarmenswürdig! Es wird sich zeigen, ob er wieder vorspricht.

Ich will heute zeitig zu Bett, $\mathrm{u}$. will alles tun, um auf den Montag wieder frisch zu sein. Jetzt fühle ich mich fiebrig, die Schrift der letzten Tage verrät es Dir. Gut, dass vom neuen Semester bereits eine Woche vorüber ist! 
Heute kam Teichmann richtig nochmals vorbei, sprach mit Anna, sagte ihr, dass er am Montag vor der Abreise eine Depesche erhalten, wonach er noch habe bleiben müssen, dass er jetzt aber heute Abend verreise. Ich sah ihn nicht mehr, auch bei

Kaiser u. bei Walter Burckhardt war er nicht mehr. Der arme Mann, Spielball seiner missratenen Kinder! Kaiser teilte mir mit, dass Horn mit dem Sohn gar nicht zufrieden sei, dass er ihn habe fortschicken wollen u. durch die «Bitten» der Schwester dazu bewogen worden sei, ihn noch einige Zeit zu behalten. Wie viel Schuld trifft den Vater, der seines eignen Lebens nicht Herr geworden ist!

Heute besuchte ich die Versammlung des Berner Juristenvereins, konnte aber nur bis gegen elf bleiben. Hätte ich gewusst, dass der Präsident in seinem Bericht das Scheibengeschenk erwähnen u. sagen würde, er hoffe, es seien alle damit einverstanden gewesen, so würde ich natürlich nicht hingegangen sein. Ich bin in dieser Hinsicht auch gar nicht vorsichtig.

Auf elf war ich in der Aula zur Antrittsvorlesung von Wegemann, die recht freundlich war. Will sehen, wie er sich weiter macht. Ich kam mit Frau Gmür u. mit Frau W. zusammen, denen sich Marieli zufällig angeschlossen hatte.

Am Nachmittag hatte ich BR. Müller zu consultieren, war auch bei Kaiser, traf BR. Ruchet, u. haben eben am späten Abend noch zwei Gutachten entworfen u. mit Maschine geschrieben. Ich bin jetzt recht müde. Aber gesundheitlich geht es mir seit heute Mittag entschieden besser. Die Gesichtsschmerzen sind fast ganz vorüber, das Fieber auch. Es wird mit dem Schnupfen auch erträglich werden.

Eines der Gutachten betraf die deutsche Übersetzung des Wechselrechts

von Haag, wo nun Wieland als Experte hingeht, was mir wieder die Misere im letzten Jahr unter Brenner vergegenwärtigt hat. Und noch dafür dieser feindselige Wieland! Ich konnte es nicht 
ganz vermeiden, bei Müller u. bei Kaiser mein Bedauern darüber auszusprechen, dass ein solcher nun die Schweiz in Berlin vertreten müsse. Kaiser war freundlich zustimmend, Müller hat gelacht. Und ich habe bedauert, etwas gesagt zu haben.

Ich bin müde, es sind strenge Tage, nicht kalt, aber voll Wind u. Regen, aber sie gehen ja vorüber. Es war mir nicht leicht, auf Kohlers Lobartikel zu antworten. Ich tat es, so wenig als möglich mich vergebend, ohne in Undank zu verfallen!

O bleibe bei mir, es wird ja mit jeder Woche schwerer um mich herum!

Gute, gute Nacht! Dein allzeit treuer Eugen

\section{2: Oktober Nr. 217}

B. d. 27. Okt. 1912.

Mein liebstes Herz!

Es ist heute ein sehr schöner Herbsttag, voll Sonne, mit wunderbar klarer Alpensicht. Ich könnte mich dessen freuen, wenn mich nicht äusserlich die Gesichtsschmerzen seit letzter Nacht wieder plagten, u. innerlich so manches traurig stimmen müsste. Ich hoffe, das erstere geht bald vorüber, das letztere aber könnte ich nur mit einer energischen Arbeit gegenüber aussen vertreiben, u. damit werde ich nicht fertig. Es rächt sich mir im Alter meine unbegrenzte Rücksicht u. mein Pflichteifer im Kleinen. Ich gehe in diesen Alltagsdingen auf u. bleibe dem Grossen nicht treu. Ich sollte mich mehr von jenen loszumachen vermögen, aber eben, da fehlt es. Hätte ich nicht diese Charaktereigenschaft von früh auf gehabt, so würde ich der von der Mutter ererbten Fabulierlust gefolgt u. nicht bei der ersten Collision mit den Berufspflichten 
ihr untreu geworden sein. Und ich wäre in dem grossen Kreis der deutschen Wissenschaft geblieben, zum mindesten jetzt wieder zu ihr zurückgekehrt, anstatt hier fest zu kleben. Und doch ich kann nicht anders, andere Entscheidungen hätten mich unglücklich gemacht. Und so sitze ich hier, mit dem deutlichen Empfinden, dass mich meine nächsten Berufsgenossen gerade noch dulden u. innerlich verwünschen. Das hohe Lob, das mir Josef Kohler in seiner neuesten Arbeit über das ZGB. gespendet hat, wird mich teuer zu stehen kommen. Einerseits werden die Gegner darüber spotten, dass «Deutschlands grösster Kohler» mein Lob singe, u. anderseits werden sie sich um so

mehr die giftigsten Angriffe auf mich erlauben. Das muss ich tragen, weil ich ihnen treu geblieben bin. Freilich sie haben ja diese Treue von mir gar nicht gewünscht, umgekehrt verwünschten sie mich, als ich sie hielt. Was waren das für Erlebnisse, die ich erfahren, mit Häusler, Hilty, Marti, Wieland, u. jetzt mit der grossen Masse der Berner Juristen. So sehe ich also meine innere Verbundenheit mit dem was ich gearbeitet, u. dem ich aus Pflichteifer meine liebsten Neigungen geopfert, u. das Zusammensein mit Dir eingeschränkt habe, angefressen von der Missgunst u. dem Mangel an wahrer Anerkennung. Das würde mir vielleicht weniger ausmachen, wenn ich jünger wäre, mich kräftiger fühlte. So wie es jetzt mit mir steht, kann ich mich nur mit Resignation darin schicken. - Freilich will ich versuchen, über alles das weg zu kommen. Es gelingt mir ja vielleicht doch, noch etwas zu schreiben, etwas zu leisten, was mich über diese schwermütigen Betrachtungen hinwegträgt. Es ist möglich, aber ob? Da spielt die Gesundheit mit, u. für diese wieder ist meine andauernde Grundstimmung keineswegs förderlich.

Ich hätte eigentlich aus diesem Trübsinn heute aufgerüttelt werden sollen. Denn ich hatte liebe Besuche. Zuerst kam Ernst Brenner, der das Fürsprecher-Examen bestanden, um mit mir über die Dissertation zu sprechen. Dann Jakob Matti mit seiner Frau. Er hat gealtert, gab sich aber in alter Herzlichkeit. 
Nach dem Essen kam Dr. Gustav Beck, der morgen nach Paris verreist für zehn Tage, eingeladen von einem Mediziner, mit dem er vor längerer Zeit eine Zeitschrift herausgegeben hat. Drauf war ich bei Prof. Steck, da Haring in Halle über Hadorn noch eine genauere Information haben wollte, die dann auch Steck in liebenswürdiger, feiner Art mir schon heute Abend schriftlich zugestellt hat. Ich war noch bei Steck, als ich nach Hause telephoniert wurde, da Rossel gekommen sei. Ich verbrachte mit diesem dann ein interessantes Plauderstündchen. Endlich nach dem Nachtessen kam Walter Burckhardt, mit dem ich über Gierkes Brief mich besprechen konnte u. dabei eine willkommene Aufklärung erfuhr. Dazu kam Hänny, der mir in seiner rührend unbeholfenen Gescheitheit einen prächtigen Eindruck machte. Und wie beide noch da waren, erschien der junge Teichmann! Er war, scheints, seit Dienstag hier, hat im Gotthard logiert, während Vater Teichmann im Althof blieb, u. so waren die beiden diese Woche beieinander. Der Vater habe am Montag nicht nach Hause kommen können, weil die Schwester mit Einräumen nicht fertig geworden sei. Das glaube, wer will! Ich gab dem Sohn zu verstehen, dass ich das Vorgehen der Kinder gegen den Vater herzlos finde, u. er verabschiedete sich schnell.

Rechne dazu, dass ich am Vormittag an der RG. arbeitete, u. am Nachmittag Kolleg vorzubereiten hatte, so erkennst Du, dass der heutige Tag recht angefüllt war, der dumpfe Schmerz,

der mich die ganze Zeit begleitete, liess mich zu einer beschaulichen Ruhe nicht kommen. Aber der Tag ist jetzt zu Ende. Ich geh zu Bett.

Gute, gute Nacht! Ich bleibe Dir ewig verbunden als Dein treuer

Eugen 
B. d. 28. / 9. Okt. 1912.

Mein liebstes Herz!

Auch heute war ein sonniger Tag, wenn auch nicht so hell u. mit so glänzender Bergaussicht wie gestern. Im Auditorium war es sehr warm, namentlich auch da es bis auf den letzten Platz sozusagen gefüllt war. Ich kam recht abgespannt nach Hause u. arbeitete den weitern Tag ungern. Guhl war da u. ich hatte ein paar wichtige Sachen mit ihm zu besprechen. Er war diesmal weniger augendienerisch. Überhaupt ists möglich, dass es ihm nur an festen Formen fehlt. Aber gerade da sind gescheidte Leute zu fühlen, indem sie nach Bedarf die naiven spielen. Mit den Zahnschmerzen u. der Neuralgie ists nicht vorüber, aber besser. Ich habe Rechtsgesch. corrigiert, Briefe geschrieben, Gutachten präpariert. Immer in Geschäften, aber nichts Rechtes. Ich muss mir jetzt doch überlegen, wie ich es mit der Rechtsgeschichte halten will, ob ich sie dem Schw. P. R. vorausgehen lassen soll.

Wenn ich denke, wie ich im Winter 8 / 9 u. 9 / 10 mich zu entlasten träumte, wie ich Abends nicht mehr arbeitete, sondern irgendetwas las u. häufig in Gesellschaft, im Theater, im Konzert war, da ist mein jetziger Zustand doch in grossem Gegensatz. Ich habe ja freilich nichts anderes mehr. Aber ich bin auch wirklich wieder strenger an der Arbeit, kann sein, dass ich damit mich ruiniere. Allein das macht mir keine Sorge. Ich will jetzt einfach noch arbeiten, was ich vermag.

Merkwürdig, dass Jakob Welti gestern fand, ich sei magerer geworden. Gewiss im Vergleich zu der Zeit, wo er mich malte. Aber das letzte Jahr doch nicht? Oder steckt doch etwas in mir, was ich hie u. da Nachts als Krankheitsgespenst zu empfinden glaube? Abwarten! 
Ich würde gerne die Rechtsgeschichte ausarbeiten. Soll ich die Frühjahrsferien dazu nehmen? Vielleicht. Ich würde gerne meine belletristischen Arbeiten fertig machen $u$. werde auch nur privatier drucken lassen. Soll ich die Abendstunden dazu nehmen? Den täglichen Verkehr mit Dir, in diesen Zeilen, darf ich nicht missen. Ist auch manches von mir dabei ungeschickt gesagt $u$., als Bekenntnis einer vorübergehenden Stimmung ungerechtfertigt zu Papier gebracht, so bist doch Du mir in diesen Momenten nahe u. füllst eine Lücke aus, die mir schwer zu tragen wäre. Also muss ich auf andere Weise mir helfen, oder ich lasse eben die Sachen an mich herankommen u. befolge nur eines: Arbeit.

Morgen werde ich mich entscheiden müssen, ob ich am Ende doch in Nr. 31 hinunter gehen soll. Ich würde es ungern tun, aber am Ende ist es doch besser, als in der dichtgefüllten niedren Bude. Der Pedell riet mir heute dazu. Wir wollen abwarten.

\section{Den 29. Oktober}

Ich habe mich heute entschlossen, in das grosse Auditorium hinunterzugehen. Es sassen Hörer in den Gängen u. die Luft war so schlecht, dass ich am Ende doch die grössere, viel grössere Anstrengung, die das Nr. 31 erfordert, als die kleinere Last

betrachten muss. Die Rechtsgeschichte werde ich aber wohl in Nr. 42 lesen müssen, weil Nr. 31 vermutlich um $4 \mathrm{Uhr}$ von Stocker belegt sein wird.

Marieli hat sich heute wieder über die Schmerzen in der Achsel beklagt $u$. die Vermutung ausgesprochen, das möchte mit der Lunge zusammenhangen, wie s. Z. Helene Frey. Ich wurde dadurch veranlasst, die Consultation von Sahli in Aussicht zu nehmen. Aber unmittelbar lässt sich Sahli schwer consultieren, sodass ich Dumont anfragte, ob diese Heranziehung nicht empfehlenswert wäre. Ich will nun sehen, wie sich Dumont hiezu verhält. Etwas habe ich den Eindruck, Marieli würde gern die Collegien u. alles 
Andere abhängen, um in die Sportwelt des winterlichen Kurorts zu kommen, ohne in einer Weise krank zu sein, die es an der Beteiligung am Sport wesentlich verhindern würde.

Es passt zu dem aufregenden Charakter des heutigen Tags, dass ich dann noch in der Eile meinen kleinen Füllfederhalter zerbrochen habe. Also!

$\mathrm{Zu}$ Arbeit bin ich neben alledem, was den Tag füllte, fast gar nicht gekommen. Es war warm, so dass ich am Nachmittag beim Gang zur Universität mehr geschwitzt habe als im Sommer. Die Stellung zu Marieli bedrückt mich. Es hat wieder weit mehr den feindseligen Ausdruck im Gesicht als letzte Woche, $u$. bei seiner Verschlossenheit weiss man ja nie, was hinter allem steckt.

Ich habe diese Zeilen während des ersten Examens in diesem Semester geschrieben. Fritz Scherrer, der Schwermütige, u. ein

ausländischer Jude kommen an die Reihe, ich hoffe Scherrer passiert, wenn auch rite. Ich schliesse aber diese Zeilen jetzt ab, da ich nach dem Nachtessen möglichst bald zu Bett gehen will u. nur noch die amtlichen Eingänge erledigen will.

Wenn ich doch nur einmal mit Marie Ruhe bekäme! Gute, gute Nacht! Hilf mir, dieses Schwere zu tragen, ich bin Dir dankbar in Ewigkeit!

Dein getreuer

Eugen

Scherrer ist richtig rite promoviert, war sehr befriedigt! Sein Compagnon ebenso. 
B. d. 30. / 1. Okt. 1912.

Mein liebstes Herz!

Heute Vormittag noch warmer Wind, Stimmung wie an einem Februartag, am Nachmittag dunkle Wolken u. dann Regen, Regen. Das Nachsömmerchen ist vorüber, $u$. ich bedaure das nicht, denn es war in den Winterkleidern u. im geheizten Haus u. gar in den Universitätsräumen lästig warm. Ich las also in Nr. 31, leider gerade mühsam mit heiserer Stimme, u. es war mir fast störend, anstatt der gedrängt vollen Bänke, die zerstreuten Häupter vor mir zu sehen. Doch es ging, u. die Hörsaal-Luft ist hier unzweifelhaft besser.

Ich erwartete heute Dr. Schläpfer, der sich wieder angekündigt, aus Anlass eines in Bern zu besprechenden Geschäftes. Aber er kam nicht. Ich hatte heute nur den Fürspr. Tenger zu einer Consultation bei mir, vernahm bei dem Anlass, dass sein Vater, erst 56 Jahre alt, an Sklerose $u$. Asthma leidet $u$. fast nicht mehr auf Heilung rechnen kann.

Heute war Marieli bei Dumont, der auf meine Anregung Sahli zu consultieren einging $u$. die Untersuchung ganz anders durchführte. Marieli musste heute schon die Temperatur messen, u. berichtete mir von $37^{\circ}$, was ich nicht controllieren kann. Es ist nun möglich, dass Sahli auf eine energische Kur drängt u.

dass dann M. den Winter über abwesend sein muss. Ich werde mich darauf zurecht machen müssen. Du würdest aber wohl nicht gedacht haben, dass ich mit der alten Anna dann einmal hauszuhalten hätte, so allein. Doch will ich für M. das beste hoffen. Freundlich ist es von Dumont nicht zurückgekehrt, sondern ziemlich garstig. Daran mag schuld sein, dass ich in meinem 
Bibliotheksregal, dem neuen, im Schlafzimmer eine andere Stelle anweisen wollte, u. eben bei der Rückkehr Sophie die nötigen Anweisungen gab. Marieli half dann mit. Das Zimmer sieht jetzt entschieden besser aus.

Vor dieser Umstellung hatte ich das Bedürfnis, etwas auszuspannen. Der Kopf wollte durchaus nicht an die Arbeit, u. ich spazierte auf der Terrasse im warmen Wind u. dem wirbelnden welken Laub der Glyzinie eine halbe Stunde auf u. ab. Ich machte mir Gedanken, wie doch Kummer u. Freude nach u. nach an Macht verlieren. Wenn ich jetzt so arbeite, so tu ich es aus dem blossen Drang, die Pflicht zu tun u. mich dabei aufrecht zu halten.

Am Vormittag, müde vom Kolleg, konnte ich etwas an der RGesch. arbeiten. Am Nachmittag ging ich aufs Departement zu Kaiser u. erhielt von ihm die Zusage, einen Aufsatz in d. Zsch. f. Schw. R. zu schreiben. Das gleiche versprachen mir gestern Walter B. u. Guhl. Ich teilte es heute Häusler mit. Ich war dann auch bei Müller wegen der Baumeister u. schrieb an diese noch eine Antwort.

So ist der Tag vorüber gegangen. Dies nefastus?

B. d. 31. Okt. 1912.

Ich muss dir noch berichten, dass ich am Dienstag in der Rechtsgesch. ganz genau alle Plätze in Nr. 42 besetzt hatte, also 80 . So kann ich mit dem Semester doch wohl zufrieden sein.

Marieli hatte gestern, als es nach Dumonts Anordnung das Fieber mass, $37.0 \mathrm{u}$. heute $8 \mathrm{Uhr} 36,9$, dagegen scheint es die Wallung wieder vorüber zu sein, denn heute Abend waren es nur $36,5^{\circ}$. Wollte Gott, dass die Sache sich nicht so schlimm gestalte, wie es jetzt doch eher den Anschein hat, dass man es hoffen darf. Marieli war heute auch wieder viel freundlicher.

Es waren heute viertelstundeweise heillose Sturm-Regen- $u$. Nieselschauer. Bei der Rückkehr vom Abendcolleg kam ich in einen solchen $u$. wurde nass, weil ich den Schirm nicht öffnen 
konnte. Der Sturm hatte ihn mir auf der Schanzenbrücke gekehrt u. obgleich ich ihn mir sofort wieder zurecht blasen lassen konnte, in den Gelenken beschädigt. Ich spüre heute Abend rheumatische Schmerzen, wohl vom Nasswerden.

Die Kollegien sind jetzt wieder recht besucht. In der Rechtsgeschichte hatte ich heute gegen 90 Leute. Aber das Auditorium war zu klein u. nicht beleuchtet. Die Schreibenden waren übel dran, wegen einer solchen Schlamperei des Personals der Verwaltung, es ist eine Schande, wie das in diesen Chargen bei uns zugeht.

Ich konnte heute etwas RG. korrigieren. Sonst aber war ich nicht zur Arbeit aufgelegt $u$. fühle mich auch heute Abend müde. Die Aussichten mit Marieli beschäftigen mich mehr als ich es mir gestehe. Wenn nur die Consultation bei Sahli nicht ein Unsinn ist! Aber ich glaube wohl, Du hättest bei den klagenden Worten

Marielis auch nicht anders gekonnt, als diesen Schritt zu versuchen. Warten wir ab, was daraus erfolgt. Ich selbst bin, wie gesagt, auch wieder nicht recht wohl. Wenn dann das letzte Nichtwohlwerden herankommen wird? Ich geh ihm mit Freuden entgegen, die Menschen, die ich hier als Arbeitsgespanne habe, halten mich jedenfalls nicht fest. Gestern zitierte Marieli Hebels Sonntag Morgen u. meinte, die Worte liessen sich wohl sagen auf unsern Fall - «und winkt ein Guhl, verrat mi nit!»

Ach, wozu wieder klagen! Die Hauptsache ist, dass jetzt das Wintersemester sich wieder gut anlässt. Ich bin ja in der guten Lage, dass ich mir nichts vergebe, wenn ich gar nichts anderes mehr arbeite, als Kolleg lesen. Solange ich das kann, ist es ja eine schöne Genugtuung. Also vorwärts, fällt daneben noch etwas ab, um so besser. Im ganzen bin ich ja gerne bei der Arbeit, so dass vielleicht doch noch etwas herauskommt. Nur heute Abend, nach den drei Kollegstunden, bin ich müde. 
Heute von halb sechs bis sechs war Frl. Helena Burckhardt bei mir. Sie verreist übermorgen wieder nach Pagli. Dann erhielt ich einen Brief von Marie Heim. Sie ist im Sanatorium bei Piotta als Lungenkrank. Es soll aber besser gehen.

Und jetzt Schluss. Ich bin wie gelähmt im Denken u. die Glieder sind schmerzhaft ungelenk. Bis morgen wird es schon wieder besser werden.

Beschütze mich, liebe, gute Seele, ich bin ja Dein alter guter Kamerad

\section{Dein treuer}

Eugen 


\section{November 1912}

1912: November Nr. 220

B. d. 1. / 2. Nov. 1912.

Meine einzige Liebe!

Es hat zu dem heutigen Tag ganz gut gepasst, dass ich daran gemahnt wurde, wie schnell eine Wendung zum Schlimmen da ist. Ich stand regelrecht auf, hatte sofort ein kleines Gutachten zu erledigen $u$. ärgerte mich über einen Brief Dumonts, worin er sich wegen der Beiziehung Sahlis verletzt zeigt. Dann ging ich zu Jakob Welti u. besah mir das Bild Walter Bs. es ist gut, namentlich kommt der Spötterzug zum Ausdruck, wie ich es mir bishin nicht bewusst wurde. Dann war ich bei v. Mülinen, auf der Bank, aber nach der Rückkehr überfiel mich eine so rapide Kälte im ganzen Empfinden, dass ich statt des Mittagessens mit heissem Café reichen liess. Ich konnte dann etwas schlafen. Um zwei war Abbühl da, der nun also sich ganz der Matura widmen will. Nachher entschloss ich mich, doch ins Praktikum zu fahren, u. habe es schlecht u. recht abgehalten. Als ich nach Hause gekommen, hatte Marie 36.9 u. ich $38.1^{\circ}$ Temperatur. Vielleicht ists morgen besser. Wie gesagt, es passt die Erinnerung heute zur Mahnung an das Ende. Wie mich dieser Schlotter gepackt hat, kann auch etwas anderes einmal plötzlich eintreten.

Trotz meiner Gliederschmerzen $u$. Fieber habe ich am Praktikum Freude gehabt. Dagegen fühlte ich mich ausserstande, 
einen Brief zu schreiben. Also auf morgen!

Anna hat einen Kranz auf den Friedhof getragen. Schon das

dritte mal der Aller Seelen-Tag!

Den 2. November.

Heute habe ich, nachdem ein Gutachten für Borlet, den unermüdlichen, geschrieben, die grosse Freude gehabt, eine sehr schöne Antrittsrede von Hoffmann zu hören. Es war ein Genuss, diesen klaren, tiefsinnigen Entwicklungen über die Aufklärungstheologie zu folgen. Am Nachmittag entschloss ich mich, Siegwart den versprochenen Besuch zu machen. Es war ein sonniger, kühler Tag. Ich traf Siegwart allein zu Hause u. hatte ein ruhiges Plauderstündchen mit ihm. Dann kam ein Professor Turmann, Lothringer, Nationalökonom, um Siegwart den Besuch zu erwidern u. wir hatten eine recht nette französische Unterhaltung. Nach dessen Fortgang begrüsste ich Frau Dr. Jauch, die von einem Ausgang zurückgekehrt war. Bei ihr ist immer noch die Martha Amstad, die bei uns übernachtete. Ich trank den Kaffee dort, wobei auch der Neffe Amstad, der Gymnasiast, anwesend war. Im Augenblick wurde es sechs Uhr u. Siegwart kam dann mit mir zu einem Spaziergang, der dann zum Bahnhof führte, u. um acht war ich wieder in Bern.

Siegwarts Wohnung hat mir sehr gefallen. Sein Wesen ist enger geworden, da er nun so ganz auf sich selbst angewiesen, denn er pflegt wenig Umgang. Von einer besonderen Erinnerung an Marieli habe ich nichts gemerkt, es wäre aber auch schwer bei Siegwart etwas zu merken. Eher hatte ich den Eindruck, dass er mit der Cousine sehr zufrieden sei.

Ich bin froh den Besuch gemacht zu haben, hatte ich ihn doch versprochen. Allein ob ein engeres Zusammenarbeiten mit Siegwart möglich sein wird, bezweifle ich. Es ist wahrscheinlicher, dass die Wege uns weiter auseinander führen. 
Wie ich die geistlichen Gewänder auf den Strassen Freiburgs sah, hatte ich auch ein Gefühl, es sei doch nicht meine u. Marielis Bestimmung, hier festzuliegen. Jedenfalls ist zur Zeit die Sache im Schlaf, u. wenn ein Erwachen stattfindet, zeigt sich vielleicht eine ganz veränderte Situation. Hoffnung, Zweifel, alles soll zurücktreten vor dem Ungewissen.

Ich bin heute etwas wohler als gestern, aber immer noch sehr fiebrig im Gefühl, u. namentlich mit dem Magen unsicher. Ich glaubte, die Fahrt nach Freiburg werde mir wohl tun, allein seit der Rückkehr ist mir weniger wohl. Der morgige Tag muss das ausgleichen.

Gestern fragte mich v. Mülinen, ob ich Präsident der Bibliothekskommission werden wolle, anstelle des zurücktretenden Wäber. Aber dann müsste ich in den Burgerrat eintreten $u$. davon ist ja keine Rede. Ich glaube kaum, dass v. Mülinen ernsthaft hieran gedacht hat. Nun wird Philipp Thormann die erste Chance haben. Was ich dann machen werde, ist nicht sicher. Es sind dann zwei Juristen in der Kommission u. kein Vertreter der philosophischen Fakultät erste Sektion. Das darf auf die Dauer nicht sein, also muss dann wohl Abhülfe geschaffen werden.

Ob ich wohl auf die nächste Woche wieder ordentlich wohl sein werde? Es wäre mir lieb. Die Geschichte mit Sahli muss sich abwickeln u. der Zahnarzt steht in Sicht. Aber sowieso,

die Zeit geht ja vorüber, ob freundlich oder unfreundlich. Freude u. Kummer, fühl ich, zerrann!

Gute, gute Nacht, meine liebe, liebe Seele. In sehnsuchtsvoller Erinnerung Dein allzeit getreuer

Eugen 
B. d. 3. Nov. 1912.

Mein liebstes Herz!

Letzte Nacht habe ich wieder einmal bei allem guten Schlaf jenes Durcheinander von Plänen im Kopfe gehabt, die mich zwischen den Schlafzeiten zwei-, dreimal ganz occupiert u. bis zu Entschlüssen getrieben haben, die dann freilich beim angebrochenen Tage nicht mehr stand gehalten haben. Die erste Serie betraf unser Testament. Ich redigierte ein neues, ganz im innern Einverständnis mit Dir, strich den Zusatz, den wir 1908 miteinander machten, u. modifizierte die Grundlage von 1902 nach den veränderten Umständen. Der Zusatz war ja wesentlich der Rücksicht auf Deine Stellung entsprungen, die nun Gott seis geklagt dahingefallen ist, im Ganzen aber war eine Besserstellung Marielis damit verbunden. Was ich diesfalls diesen Sommer aufgeschrieben, baute ich näher aus u. sorgte für eine reinliche Scheidung von den Söhnen Augusts. In diesem Sinne werde ich wohl manches, was ich die Nacht mir zurecht legte, brauchen können, wenn ich an die Neuredaktion gehe, die ich Dir u. mir u. Marieli u. den mir am Herzen liegenden wissenschaftlichen Plänen schuldig bin. - Die zweite Serie betraf meinen Haushalt. Ich stellte mir vor, dass es doch weit besser wäre, namentlich falls Marieli einen längeren Aufenthalt in einem Sanatorium von Sahli diktiert erhielte, wenn ich in einem Gasthof lebte: An das PalaceHotel Bellevue würde ich schreiben, mir Vorschläge erbittend für die Miete von vier Zimmern u. s. w. Aber wenn das auch billiger zu stehen käme, müsste ich mir doch sagen, dass der 
Wechsel für mich u. die meinen eine zu schmerzliche Sache bedeutete. Die Ersparnis kommt ja für mich nicht in Betracht, ich würde am Ende damit in eine Atmosphäre versetzt, die das Einzige, was ich noch habe von Dir, gefährden könnte. Und dies um keinen Preis. Oder soll ich mir ein Leben schaffen, wie Kronauer oder wie Langhans es haben. Nein, das tue ich nicht, mag ich mich auch noch so oft über die Unvollkommenheiten $u$. das Schmerzliche meines jetzigen Haushaltes ärgern. Es ist ja auch möglich, dass Marieli auf die Dauer bei mir bleibt. Die Heiratsgedanken drängen sich ja wieder ganz in den Hintergrund. Der gestrige Besuch liess mir die Gedanken, die Marieli sicher gehegt hat, ganz in nebelhafte Ferne verschwinden. Ich hatte ja gar nicht an eine Verbindung mit Siegwart gedacht. Frau Schmid-Siegwart muss es gewesen sein, die die Pläne aufgebracht $u$. mit Eifer verfolgt hat. Nun freilich, Marieli ist etwas weit gegangen, $u$. ich selbst war auch nicht vorsichtig genug. Der Aufenthalt auf dem Klausen war von mir so gedacht, dass sich alles natürlich vorbereiten könnte, wenn man wollte, schliesslich ist er fast compromittierlich geworden, freilich nicht aus meiner Schuld, sondern wegen des Verhaltens der andern, nicht zum mindesten Marielis selbst. Siegwart ist ein braver Kerl, aber er bleibt eben doch das, was ich in ihm in den vielen Monaten erkannt habe, $\mathrm{u}$. ich glaube nicht, dass darüber noch etwas anderes sich entwickeln kann. Von dem stockkatholischen Wesen, das seine Umgebung (mit Ausnahme der Marie Schmid) an sich trägt, u. das an ihm selber in Freiburg wie ich deutlich wahrnehmen konnte, sich bedeutend verschärfen wird,

gar nicht zu sprechen. Bleibt Abbühl, aber von dessen geistiger Potenz hatte ich bei seinem Besuch am Freitag wieder einen auch gar zu bescheidenen Eindruck bekommen. Vielleicht macht seine Energie noch etwas rechtes aus ihm. In seinem Enthusiasmus steht er mir ja viel näher, als der andere, oder ein anderer. 
Am Vormittag habe ich Correspondenzen erledigt. Dann war Dr. Im Hof bei mir u. überraschte mich mit der Mitteilung, dass er das St. Gallische Anwaltsexamen bereits bestanden habe. Der junge Mann war immer noch etwas scheu, sprach von der Depression, unter der er vor der Dissertation gestanden, $u$. hofft, diese jetzt ganz überwunden zu haben. Er gefiel mir besser denn je. Zu gleicher Zeit kam dann endlich Martha, die junge Frau Zollikofer, mit ihrem Mann, um sich für unser Hochzeitsgeschenk zu bedanken. Ich bin für Marieli froh, dass dies jetzt soweit wieder im Reinen wäre, obgleich der Gedanke in mir haften bleibt, dass da etwas Unlauteres, in Verbindung mit Paul vorgefallen ist.

Am Nachmittag konnte ich ein Stündchen im Garten an der Sonne sitzen. Dann präparierte ich mich für die morgigen Vorlesungen u. dabei überkam mich eine peinliche Stimmung, ein Verdruss darüber, dass ich so viele Unannehmlichkeiten erdulden muss, ein Schmerz, der durch die Lobsprüche Kohlers, wenn andere schweigen, ja nur gesteigert wird! Ich machte mich dann hinter den Aufsatz Gustav Becks, über Rumpfs «Strafrichter» u. las ihn fertig, damit ich ihm die Sache, wenn er Ende der Woche vorspricht, mein Urteil sagen kann. Es wird anerkennend lauten. Und nun habe ich noch vor dem Nachtessen die Zeilen geschrieben,

die ich dann vor Schlafengehen noch abschliessen will.

Ich habe nach dem Nachtessen noch ein Dutzend Seiten im neuen Heft der Deutschen Rundschau - die Dir so oft Freude gemacht - gelesen, auch die Füllfedern in Ordnung gebracht $u$. den «Tintenkuli», den mir Hemmeler der Buchbinder aufgeschwatzt repariert, zum dritten Mal, diesmal hoffentlich in dauerhafter Weise, denn ich konnte gestern, als mir Siegwart denjenigen seiner Cousine Martha Amstad zeigte, etwas besser erkennen, was an dem meinen fehlte. Und dabei ist es mir sehr weh ums Herz geworden. Aus der Beschaulichkeit, die ich anfangs fühlte, wurde Einsamkeit u. aus der Einsamkeit tauchte die Traurigkeit auf über alles, was im Leben anders gegangen, als es hätte sein sollen. Solche Traurigkeit lehrt mich, mit dem mich zu begnügen, was ich habe, die Erinnerung an Dich, 
meine einzig gute Seele, $\mathrm{u}$. die noch bestehende Fähigkeit zur Arbeit. Also mutig vorwärts, Tag für Tag, es muss

doch endlich zu einem guten Ende kommen!

Gute, gute Nacht! In Deiner Liebe weiss ich mich sicher, mag da kommen, was will!

Immerdar Dein treuer Kamerad

Dein

Eugen

1912: November Nr. 222

B. d. 4. November 1912.

Mein liebstes Herz!

Was soll ich sagen? Heute schwebt mir den ganzen Tag der Montag als 4ter vor, wie sich Monats- $u$. Wochentag mit dem Tag Deines Hinschiedes verknüpft. Jetzt sind es schon 31 Monate, seitdem du mich verlassen hattest! Und der Tag ist besonders geeignet, mir das in Erinnerung zu rufen.

Nach einer Schlafnacht, bei der ich die beruhigende Wirkung meiner gestrigen Betrachtungen über die notwendige Resignation verspürte, erwachte ich mit einer belegten Stimme, die mir während den zwei Stunden Morgenvorlesung recht Mühe machte. Ich glaubte dann einem beschaulichen Tag entgegenzugehen. Vor Tisch machte ich noch einige RGesch. Korrekturen. Nach Tisch begann ich in dem Büchlein von Holtzendorff zu lesen, das mir Teichmann geschickt, über den englischen Landsquire. Dann brachte mir Jost seine neu redigierte Dissertation als erste Überraschung. Sie wird mir voraussichtlich wieder viel Arbeit verursachen. Als ich dann weiter in der RG korrigierte, kam Marthaler, der mir persönlich für die Zusendung der «sozialen Gesinnung» dankte, u. mit dem ich über Paulus u. anderes ein anregendes Gespräch führen konnte. Und jetzt erwarte ich dann noch gegen sieben Uhr Sahli, zur Untersuchung Marielis, mit Dumont, u. nachher Guhl, nach acht, in wichtigen Amtsgeschäften. 
Was wird Sahli berichten? Ich will nicht zum voraus darüber schreiben. Hoffentlich bleibt mir dann noch bis zur Ankunft Guhls Zeit genug einiges anzufügen. Ich werde froh sein, wenn die Unruhe, in der ich $u$. auch Marieli leben, gehoben werden

kann. Marieli nannte gestern Dumont ganz richtig einen Optimisten. Möge der Pessimist Sahli sich zu ihm in das richtige Gleichgewicht stellen!

Sahli hat also um sieben Uhr den Besuch mit Dumont gemacht $u$. bei genauer Untersuchung die Lunge nicht angegriffen gefunden! Dagegen war er nicht zufrieden mit der schwachen Circulation, der Appetitlosigkeit u. dem Mangel an Schlaf. Er verschrieb hiegegen Mittel. So haben wir also die alte Geschichte aufs Neue bestätigt. Die Überreizung im ganzen Wesen ist Quelle der ganzen Krankheit. Und lässt sich dagegen nun etwas machen? Ich fürchte, es wird den alten Trott gehen, aber wenigstens ist nun die Sorge mit der Lunge verringert, $\mathrm{u}$. das ist auch etwas wert. Ich fühle mich darüber in der Verantwortlichkeit wesentlich erleichtert, u. will tun was ich kann, um die Sache zum guten zu führen. Dumont ist in der Sache eher rehabilitiert. Wenn ich auch seinem Urteil deshalb nicht mehr zutraue als vordem.

Jetzt kommt noch Guhl, sodass ich morgen weiter schreiben werde $u$. hier abbreche.

Den 5. Nov.

Ich habe heute eine Enttäuschung erlebt. Du weisst, dass ich für Burckhardt - Hiltys Jahrb. einen zweiten Aufsatz geschrieben, u. dass B. mit Wyss verabredet, er soll an erster Linie stehen, damit ich fortfahre. Und ich hatte mir schon zurecht gelegt, ich könnte so in entsprechenden Aufsätzen was mir von meiner Rechtsphilosophie u. Gesetzgebungspolitik am Herzen liegt, veröffentlichen, dem 
Jahrbuch damit, wenigstens was an mir liegt, den Charakter einer schweizerischen Orientierung in den wichtigsten $u$. tiefsten Fragen verschaffen. Und nun seh` ich, dass ich mit dem Gedanken keinen Anklang finde. Walter B. teilt mir mit, dass der Verleger eigenmächtig einen Aufsatz von Oechsli an erste Stelle gesetzt habe. B. selber ist darüber erzürnt, soweit das bei ihm sein kann. Es war vielleicht eine dumme Idee, dass ich glaubte, es liesse sich da so nebenbei etwas von den Idealen einer "prophetischen" Anleitung des Volkes, in greifbarer wissenschaftlicher Art, als das Hilty vermochte, durchführen. Es war auch dumm von mir, dies auf Hilty besinnen zu wollen. Item ich habe noch gestern mir die Sachen zurecht gelegt. Trotz der Anzeichen, die ich ja aus dem Mangel an Antworten auf meine Separatabdrucksendungen hätte entnehmen können, wollte ich den Plan an die Hand nehmen u. durchführen. Jetzt bin ich ernüchtert. Es ist bei uns in der Schweiz so etwas nicht zu wollen u. nicht zu machen. Also fertig. Ich muss meine «Rechtsphilosophie» auf andere Weise publizieren.

Gestern hatte ich noch mit Guhl bis $10 \mathrm{Uhr}$ zu verhandeln, er war recht, aber das Misstrauen ist mir natürlich nicht weggeblasen, dass seine Veröffentlichung in «Recht $u$. Wirtschaft» über die Mobiliarhypothek geschaffen hat. Er hat mir ja auch den Aufsatz bis jetzt immer noch verheimlicht.

Heute fiel mir die Zwinge vom Stock, als ich sie reparieren wollte, vom Stock, den wir - es war wohl 1898 - in Zürich miteinander gekauft haben. Der Stock ist abgebraucht, aber ich leg ihn doch nicht weg, ich will das Andenken weiter in der Hand führen.

Ich erhielt heute einen Besuch von Lipschitz, der gern das Dozentenhonorar hätte-immer Bettelei. 
Dann war ich den Vormittag nach dem Kolleg beim Zahnarzt u. muss noch zweimal gehen.

So bin ich zu keiner weitern Arbeit gekommen u. bin doch todmüde. Es ist der fressende Kummer. Ich sollte jetzt ja froh sein, dass Marieli nicht krank ist. Aber es war heute wieder unfreundlich. Der Hochmut macht es so. Aber soviel hat es sich doch gestern belehren lassen, dass es heute wieder einmal mehr gegessen hat. Wirds anhalten?

Pfarrer Marthaler sagte gestern, als er bewundernd von den Schlachten der Bulgaren sprach, so würden es auch die unsern machen. Ich lasse u. liess ihn bei diesem Glauben. Ich leider habe ihn nicht mehr. Möge ich mich täuschen! Ich kann mir einen «mutigen» Guhl, oder Scheurer etc. gar nicht denken, u. so sind sie bis eine kleine Ausnahme alle zusammen, nur Interesse.

Doch ich habe mir vorgenommen heiter zu bleiben $u$. gehe jetzt bald zu Bett. Marie ist mit Lena Arn ins AbonnementsKonzert.

Gute, gute Nacht! Dein allzeit treuer

Eugen

1912: November Nr. 223

B. d. 6. / 7. Nov. 1912.

Mein liebstes Herz!

Die letzte Nacht schlief ich lange, ich ging bald zu Bett, Marieli kam erst gegen elf aus dem Konzert. Weder Anna noch ich hörten seine Rückkehr. Ich war aber doch in der Nacht einige Zeit wach u. überlegte, was denn mit Marieli wieder los sei. Wir hatten im Herbst verabredet, sie mache die Helveter-Anlässe diesen Winter nicht mehr mit, namentlich um den Zudringlichkeiten Abbühls zu entgehen, das war Marielis dringender Wunsch u. ich stimmte bei, so wie ich das sah. Nun kam die Einladung 
u. Marie schwankte wieder. Abbühl hatte inzwischen sich ihr wieder genähert, ein Geschenk gemacht u. s. w. Über dem Schwanken vergingen einige Tage. Da teilte Abbühl Marieli mit, dass er aus der Helvetia mit zwei andern dimittiert sei wegen einer an den Corpsbruder Schwab gerichteten unseriösen Karte, für drei Monate. Also konnte er jetzt nicht mehr zudringlich sein u. so entschloss sich M. zur Zusage. Inzwischen waren aber die Einladungen schon ergangen u. es blieb für Marie nur ein Fuchs Bäriswil, der nachträglich sie einlud. Darüber war sie so gekränkt, dass sie absagen wollte. Und das kam mir nun unsäglich arm u. hochnäsig vor. Am Morgen, als sie mich zum Tor begleitete, sagte ich ihr das. Sie war bestürzt, mir aber ging ein Stich durchs Herz, dass ich mit denen, die mir am nächsten stehen, so ruchlos verfahren muss. Am Mittag hatte Marieli wieder Erbrechen, u. essen will sie auch nicht recht, der alte Jammer!

Heute Nachmittag waren die beiden Fräulein Reineck zum Thee bei Marie. Ich begrüsste sie. Lauch wird nun doch bald heiraten können, wenn er den Posten als Handelsgerichtsschreiber erhält, u. die Aussichten sind für ihn besser geworden, weil der nächststehende Candidat Giorgio eine Bundesstelle angemommen hat.

Ich konnte heute mit der Diss. Jost beginnen, die immer noch nicht prima ist, u. korrigierte Beträchtliches in der RG. Das Scheitern des Planes mit den jährlichen rechtsphilosophischen Arbeiten im Polit. Jahrbuch hat mich veranlasst, dem alten Plan wieder näher zu treten $u$. die philosophischen u. politischen Betrachtungen über die Gesetzgebung hervorzunehmen, ob sie publizierbar wären? Ich glaube ja. Es würde im Format des Jahrb. etwa 450 Seiten, u. in der Ausstattung von Rümelins Richtigem Recht etwa 550 Seiten werden, also ein stattlicher Band. Das muss ich nun ernsthaft überlegen u. dann mich entschliessen.

Es ist wieder wärmer geworden $u$. ich fühle mich wieder weniger wohl. Die Müdigkeit habe ich zwar mit dem langen Schlaf von gestern auf heute ziemlich überwunden. Aber es ist merkwürdig, wie mich die zwei Stunden Vorlesung am 
Morgen jeweils herunter bringen. Oder bin ich einfach bequemer geworden? Ich weiss es nicht. Schlafbedürfnis habe ich nachher allemal freilich nicht, aber ich müsste mich zwingen, wenn ich gleich wieder etwas anderes ernsthaft betreiben sollte. Und während langen Jahren habe ich dies doch so gehalten.

Von Häusler erhielt ich eine freundlichere Karte. Von anderen Seiten, wo ich glaubte, ganz nebenaus gekommen zu sein, freundliche Grüsse. Darüber bin ich schon meiner Arbeit wegen froh! Morgen Zahnarzt!

Marieli will mir helfen mit dem Katalog, aber er kommt nicht dazu.

Noch eines: Die Nacht kam mir im Traum Dr. Widemann in Konstantinopel vor, ganz bleich, u. sagte mir, er sei ermordet worden. Das würde man, wenns einträfe, «Kündigen» nennen.

Den 7. Nov.

Es war heute ein heller Tag mit scharfer Bise. Ich war guten Muts unter Nachwirkung meiner gestrigen Betrachtungen über die Publikation der Gesetzgebungspolitik. In der Nacht, wie ich eine Weile wach lag, dachte ich schon über das Vorwort nach, so bin ich. Der Tag wurde in Anspruch genommen durch die drei Stunden Colleg u. den Zahnarzt. Kaum konnte ich zwischendurch an den RG-Korrekturen etwas vorwärts machen. Ein Depotschein der Kreditanstalt, der einlief, veranlasste mich auch diesen Abend eine Zusammenstellung unserer Titel zu machen. Ich erreiche in diesem Jahr die 300 000, nicht mitgerechnet das Haus, das doch mindestens 110000 gerechnet werden kann. Dass Du diesen Segen nicht noch miterlebt, tut mir unsäglich weh - aber es ist ja eine falsche Betrachtung. Die letzten Tage sehe ich Dich so oft vor mir. Ganz lebhaft, wenn ich aus dem Kolleg komme, meine ich, Du müsstest unter die Türe kommen, um mich zu begrüssen. Und ich habe Dir so selten mit Worten dafür gedankt! Jetzt müsse ich es, ja, jetzt weiss ich, was ich gehabt habe. Marieli war übrigens heute lieb. Es scheint, dass die Erlebnisse ihm 
schliesslich doch gut getan haben. O wie wäre ich glücklich, wenn es etwas von Deiner Liebe empfangen würde.

Heute war Mutzner da, grad vor dem Kolleg. Ich konnte ihn nicht recht sprechen, er will aber am Samstag Nachmittag wiederkommen.

Mit der Arbeit bin ich jetzt, unberufen, weniger gehetzt. Es ist gut, denn die Sache greift mich an. Sobald ich es ruhiger habe, vermindert sich auch meine Depression. Dabei kann ich jetzt freilich nicht sagen, dass ich ganz wohl bin. Wenns nicht besser wird, glaube ich bald, es steckt ein Leiden in mir. Schmerzen habe ich nicht.

Doch genug, genug! Noch ein kleiner Plauder unten u. dann zu Bett. Gute, gute Nacht!

Dein ewig getreuer

Eugen

1912: November Nr. 224

[1]

B. d. 8. / 9. Nov. 1912.

Mein liebstes Herz!

Wenn es mir constant so besser ginge in meiner Stimmung, wie heute, so könnte ich am Ende doch noch hoffen, meiner Schwermut Herr zu werden. Ich schlief die letzte Nacht wieder einmal acht Stunden mit einem ganz kurzen Unterbruch, wo ich zwei Uhr - Deine Todesstunde - schlagen hörte. Am Vormittag erledigte ich zwei Gutachten für das Departement, war zu einer freundlichen Besprechung bei Kaiser, u. dann bei Mülinen, auf der Bibliothek, wo ich für das Wörterbuch einiges zu erledigen hatte. Sonst las ich etwas in Josts Dissertation, präparierte mich auf das Praktikum, erledigte das kleine Büchlein von Holtzendorff, das mir Teichmann gesandt, u. schickte es 
mit einem Briefchen an ihn zurück. Das Praktikum war recht besucht, die Begegnung mit Walter B. im

Dekanatszimmer gemütlich. Jetzt habe ich einige mathematische Probleme ganz zufällig an die Hand genommen, die Zeitungen, mit den gruseligen Berichten über die Niederlagen der Türken gelesen, $u$. schreibe nunmehr noch diese Zeilen, indes Marieli allein zu Hofmanns Erzählungen in die Oper gegangen ist.

Ich bin ruhig, mache mir auch über mein fortdauerndes Unwohlsein keine Gedanken, überlege zwischendurch, wie ich es mit der Arbeit halten wolle, freue mich an

dem Plan, das eine $u$. andere abzuschliessen. Gewiss ist die grössere innere Ruhe eine Folge der sich befestigenden Pläne. Zugleich aber auch das Anzeichen meines älter Werdens. Denn was mir begegnet $u$. alle die Unvollkommenheiten beschäftigen mich im Grunde doch viel weniger als früher. Mag da kommen was will, der leise «Schlummer», der über mir liegt, deutet mir an, wie es allmählich Abend geworden ist. Ich arbeite rüstig weiter, ich arbeite auch gerne, u. das Fehlen jeder gesellschaftlichen Zerstreuung empfinde ich als eine sich mehrende Wohltat. Wenn nur dabei noch etwas rechtes, Positives herauskommt! Ich will es hoffen, um mich in dieser besseren Stimmung zu erhalten.

Von Forrer erzählte mir Burckhardt wieder ein sonderbares Exempel. Er rief ihn eilends auf sein Büreau, wegen der Begutachtung des Gotthardvertrages in einem bestimmten Punkt, sprach dann aber wesentlich mit ihm über die Dissertation, die Spahn nun, nachdem er bei mir "abgefault», bei Burckhardt machen soll. Und dabei drehte sich die Besprechung um eine Frage, mit der sich Forrer bei dem Candidaten in seiner früher schon bezeichneten Art verhängnisvoll für den Candidaten eingemischt hat. Ich bleibe dabei, es ist ein Landesunglück, dass wir diesen fast pathologisch sprunghaften «Löwen» im Bundesrat 
haben. Er wird uns noch manches zu schaffen geben, wenn uns der Himmel nicht bald von ihm erlöst! Weshalb hat er die Fragen nicht früher studiert, um deren willen er jetzt die ganze Gotthardfrage wieder hat verschieben lassen? Doch, auch diese politischen Schwierigkeiten stehen mir nur in einem traumhaften Ausblick vor Augen!

Der heutige Morgen war noch kalt, mit Bise, vor Mittag änderte sich der Wind u. es gab Regen. Beim Heimweg aus dem Praktikum regnete es kalt u. in Strömen. Ich besinne mich fast nicht auf das, was ich im Praktikum sagte. Habe ich mich verirrt? Ich weiss es nicht, das ist das Traumhafte, das mich heute umringt. Und doch glaube ich dabei ganz bei scharfer Besinnung zu sein. Morgen schreibe ich vielleicht klarer darüber.

Den 9. Nov.

Heute hatte ich einen so ruhigen Tag, dass ich wirklich zur Besinnung gekommen bin. In der Dissertation Jost bin ich bis zur Mitte gekommen, es geht an, u. in der RG. habe ich heute das VIII. Couvert fertig gemacht, es rückt also auch vorwärts. Mutzner war von 4-6 Uhr bei mir, wegen seines Commentars zum Intertemporalen Recht, sehr gescheit u. bescheiden. Guhl will morgen kommen, wie er telephoniert, auch Dr. Beck erwarte ich morgen. Dann las ich die Einleitung zu m. Ges.politik mit dem Gedanken an die geplante Publikation, u. ich glaube, es sollte gehen. - Marieli hat gestern in Hofmanns Erzählungen Freude gehabt, es war munter. Kleinigkeiten sind wieder passiert, aber sie sollen mich nicht anfechten. Der Zustand, von dem ich Dir

gestern schrieb, ist doch offenbar Ermüdung, oder tritt wenigstens nur ein, wenn ich ermüdet bin. Sonst würde ich nach der Ruhe, die ich jetzt 24 Stunden genossen, nicht wieder fest im Sattel sitzen. Also getrost vorwärts. 
Briefe von auswärts bekomme ich gerade diese Tage nicht viele. Ich vermisse einige Antworten, namentlich die von Rümelin. Aber das plagt mich nicht, es dient ja auch nur zur Befestigung der Ruhe. Ob ich gesundheitlich schwereren Störungen entgegen gehe? Wer weiss es, es ist möglich, dass die Resten des alten Rheuma sich jetzt intern geltend machen, denn äusserlich spüre ich trotz aller schlechten Witterung nichts davon. Nun, dann wird es auch intern vorüberfliessen!

Heute habe ich den versprochenen Brief von Siegwart erhalten mit guten Nachrichten über seinen Kollegienbeginn. Der Ton ist ganz nett, aber durchaus nicht herzlich, wie ich es erwarten dürfte. Allein S. ist nun einmal die rückhaltende Natur, seine Schrift zeigt ja auch so wenig Männlichkeit. Aber er wird, wenn er Fleiss entwickelt, seinen Weg schon machen.

Und jetzt lese ich noch die Zeitungen, rauche eine Zigarre, treibe etwas Beschaulichkeit u. gehe dann zu Bett. Schon die dritte Semesterwoche vorüber!

Gute, gute Nacht! Bleib immer bei mir, meine gute, teure Seele, wie ich bei Dir als

Dein getreuer

Eugen

1912: November Nr. 225

[1] B. d. 10. Nov. 1912.

Meine liebe, gute Lina!

Heute schwebte den ganzen Tag Dein liebes Gesicht vor meinen Augen u. ich vermochte mich Deiner Güte zu erinnern, ohne ob dem Gegensatz in Seelenangst zu verfallen. Ich dachte an das Schöne u. Freundliche, was ich durch Dich gewonnen u. lange Jahre genossen habe, u. fügte mich in den heutigen Tag ohne Schmerz. Es war auch ein recht beschaulicher Tag. In der Nacht hatte ich mir ein Vorwort zur "Gesetzgebung» ausge- 
dacht u. es dann am Vormittag niedergeschrieben, nur eine Seite, die mir jetzt passend zu sein scheint, wenngleich ich sie vielleicht nach einem halben Jahr verwerfe. Dann setzte ich mich ein wenig an die RG. Nachher kam Dr. Langhard, um mich in der Frage der Ordnung des Erbrechts seiner Kinder oder Nichten zu befragen. Guhl erschien verabredeter Weise, erzählte mir von seinen Conferenzen im Tessin u. wollte in ein paar schwierigen Fragen meine Ansicht wissen. Nach dem Essen kam Dr. Beck, mit dem ich fast zwei Stunden über die Kritik sprach, die er über ein Buch von Rumpf entworfen u. mir zu lesen gegeben hat. Merkwürdig, wie frisch er mit seinen achtzig Jahren noch ist. Er machte die letzten Wochen einen zehntägigen Besuch in Paris u. wusste von seinen Fahrten u. Erlebnissen gar gemütlich zu erzählen. Endlich kamen noch Tecklenburg u. seine Frau, natürlich auch wieder nur, damit er sich mir wegen einer für ihn zu schaffenden

Professur für Genossenschaftsrecht empfehle, obgleich ich ja in der Sache niemals für ihn etwas tun kann. Es wundert mich immer u. einzig, wie so nur jemand derart herumgehen u. betteln kann. Würde er doch erst einmal etwas tüchtiges leisten! Von seinen Kollegien hat er scheints diesen Winter nur eines, eine Stunde über Gesandtschaftswesen, zustande gebracht.

Zwischen den zwei Besuchen am Nachmittag konnte ich gerade noch die Kollegien für morgen präparieren. Das geht jetzt doch viel leichter, als nur noch letztes Jahr. Man liest sich in die Gedankengänge hinein, dass gleichsam Schienen daraus werden, auf denen das Vehikel leicht dahinrollt. Ich stelle mir vor, dass dies mit jedem Jahr leichter wird, wenn auch allerdings die sich ansammelnde Praxis neue Schwierigkeiten bereiten wird. Allein das kommt erst später, u. wie ich mich dann wieder einrichten werde, wollen wir erst zu gegebener Zeit bedenken $u$. entscheiden.

Nach Tisch fuhr ich fort in der gestern begonnenen Lektüre des von Siegwart letzten Winter nachgeschriebenen Kollegs über die Gesetzgebungspolitik. Ich hoffe, wenn ich nun 
derart täglich etwas nachlese, so komme ich so ganz allmählich u. wie von selbst zur gedanklichen Beherrschung des Stoffes, den ich in dem geplanten Buch gerne behandeln würde. Vielleicht fällt sogar einiges für die Form ab u. kann ich ohne viel besondere Concentration ein Manuskript für den Druck herstellen. Schliesslich sind dies doch alles Dinge, die ich schon gar oft

überlegt habe, sodass es nur darum sich handelt, ihnen eine endgültige Form für den Druck zu geben. Lese ich so jeden Tag etwa 50 Seiten, so würde ich in den Weihnachtsferien daran gehen können, das Manuskript fertig zu machen. Freilich, wie viel Störung kann dazwischen kommen. Nicht nur Dissertationen u. amtliche Arbeit, sondern auch Krankheit u. Kummer u. Unlust. Doch hoffe ich, diese letztern drei endlich doch aus dem Kreise meiner Gemütsoccupation verbannen zu können. O wie wäre ich Dir dankbar, wenn Du mir dabei hülfest! Du hast diese Lebensweisheit u. Herzensgüte besessen, die hiefür nötig ist. Von Dir fiel auf mich ein Strahl der Sonne des frohen Gemüts, die Dir geschienen hat, ja Du warst meine Sonne. Ich will sie mir festhalten mit aller Kraft. So verbittert, wie ich gar oft in den letzten Jahren gewesen, darf ich nicht bleiben. Und es ist auch kein Grund dazu, es geht ja alles nur so weit, als es in der Welt gehen kann, u. wer den richtigen Herzensgrund hat, der wird sich in allen Lagen $u$. Erlebnissen mit dem bessern Teil seines Bewusstseins zum Guten halten!

Letzten Sonntag kam Walter B. nicht zu mir. Er sagte mir am Dienstag, er sei verhindert worden. Heute ist er auch nicht gekommen, es wäre denn dass er jetzt noch erscheinen würde, ich schreibe diese Zeilen am früheren Abend. Ich muss ja sagen, seine regelmässigen Sonntagsbesuche waren mir lieb, jetzt mögen sie vielleicht in die Brüche gehen, ohne einen Grund, einfach nur deshalb, weil man doch so etwas nicht sein 
Leben lang fortsetzen kann, oder aus einer Verstimmung, deren Grund ich nicht kannte, u. die mir um Walters willen leid tun würde. Ich werdes noch hinsetzen, wenn er vor der Nachtruhe doch zu mir gekommen ist.

Jetzt schliesse ich ab. Gute, gute Nacht! Sei mein Glück u. mein Stern - ich bleibe mit Dir verbunden!

Dein getreuer Eugen

1912: November Nr. 226

B. d. 11./ 2. Nov. 1912.

Meine liebste Lina!

Ich kann es mir nicht denken, wie alles gekommen u. gegangen ist seit heute vor 41 Jahren, da ich Dir in dem unglaublich naiven Brief meine Hülfe anbot. Wie war da mein Schicksal schon mit dem Deinen verknüpft! Und es ist eben doch wahr, dass der Himmel die Ehen schliesst, eine jede für jedes nach seiner ganzen Natur u. Anlage. Es war so bestimmt, dass wir zusammen gekommen, u. alles Sträuben Deinerseits u. alle Überlegung meinerseits, u. alle Geduld u. Ungeduld hat nur immer enger uns verbunden. Gelt, es war dann doch recht, sehr bald sehr recht? Du hättest mir sonst ja nicht immer von neuem Deine Dankbarkeit gezeigt!

Der heutige Tag war stürmisch draussen, $u$. es fiel mit Regen ein kleiner erster Schnee. Drinnen war es sehr ruhig, ich hielt mein Kolleg, las zu Hause etwas in der Dissertation Jost, corrigierte $\mathrm{RG}$ u. redigierte an der Gesetzgebung, stille, beschauliche Arbeit, an der mich gar niemand störte. Jetzt muss ich mich dann noch auf morgen präparieren, u. dann ist auch dieser Tag wieder vorüber. 
Marieli zeigte heute sehr guten Willen. Es ist als ob die gestrige, ganz ruhige $u$. ganz kurze Aussprache ihr gut getan habe. Sie bemerkte nämlich, der dümmste Streich, den sie je begangen, sei doch, dass sie nicht nach Halle gewollt habe, u. fügte an, ihr Leben komme ihr so verfehlt vor. Ich sagte ihr einzig, dass sie das alles ja so gewollt, u. dass sie eben ein verwöhntes Kind sei. Das hörte sie staunend, aber es hat gewirkt. Sie

wird jetzt dann doch einige Zucht sich aneignen, ich meine innere Zucht. Sie sollte ja niemals sagen, oder auch nur den Eindruck verfehlter Jahre haben, wenn sie zu Hause das sein kann, was sie freilich sein sollte!

Die Arbeit an der "Gesetzgebung» macht mir Freude, aber freilich, es ist eine grosse Arbeit, die ich jetzt an die Hand nehmen will, das heisst eben doch wieder viel Arbeit, ich habe es heute bereits gespürt. Nun ja, machen wir, was wir können. Die Ruhe, die ich jetzt in mir empfinde, will ich festhalten, so gut als nur möglich $u$. sie mir namentlich nicht durch zu viel Arbeit wieder stören lassen. Denn meine schweren Gedanken waren doch nur Ermüdungssymptome, das sehe ich immer deutlicher ein.

Eben telephoniert Dr. Langhard, ob er mich noch sprechen könne. Ich habe zugesagt, muss deshalb jetzt hier abbrechen. Fast hätte mich die Anfrage in Unruhe versetzt. Ich will das aber nicht, ich will an dem Errungenen festhalten.

Den 12. Nov.

Es war heute ein miserabler Tag, Wind, Schnee, nasse Wege u. allerhand Unruhe. Das zweistündige Morgenkolleg hatte mich schon ziemlich ermüdet. Der Zahnarzt, der dann folgte, $u$. bei dem ich leider noch nicht fertig wurde, diente nicht zur Erfrischung. Zu Hause fand ich wieder einmal ein Stöckchen Briefe, die mir zum Teil zu denken gaben. Nach Tisch suchte ich mich zu beruhigen, indem ich einen Abschnitt der "Gesetzgebungspolitik», wie ich es jetzt angefangen, gelesen habe, erreichte aber wenig damit. Ich präparierte mich dann auf das Abendkolleg 
u. fand, wie ich fertig war, es sei jetzt gerade noch Zeit zu Hans Weber zu gehen, der mich wegen der Besetzung seines internat. Schiedsgerichtes mit einem welschen Juristen anfragte. Ich nannte ihm vorzugsweise Gentet. Bei Webers ging es mir übrigens sonderbar. Frau Weber hatte mich telephonisch ins Büreau gewiesen, dort sagte man mir, der Direktor sei noch in seiner Wohnung. Oben begrüsste mich Frau Weber u. sagte dann, ihr Mann sei auf dem Büreau. Schliesslich kam er durch eine Seitentür herein, wahrscheinlich vom Mittagsschlaf (halb vier), aber beide waren recht herzlich. - Ich musste dann vor dem Kolleg noch mit Bieri sprechen. Einmal um von ihm ein Verzeichnis der Vorlesungen Kebedeggs zu erbitten, wegen dessen Berufung an Meilis Stelle mir dieser geschrieben. Meili fügte bei dem Anlass bei, dass es ihm zwar ordentlich gehe, dass er aber auf den «Mahner» hin sich doch fast sicher entschlossen habe, von der Professur zurückzutreten, u. einen Nachfolger suche. Ich hatte ihm, [?] Egger K. genannt. Sodann sollte ich auf Rossels Bitte die Circulation von Jeans Dissertation beschleunigen u. sprach auch darüber mit Bieri. Endlich kam ich zum Abendkolleg, das schlecht $u$. recht verlief. Zu Hause hatte ich neue Einläufe zu lesen, u. Marieli drängte zu raschem Abendessen, da heute das erste Helveterkränzchen stattfindet zu dem es eben jetzt dann von dem Stud. Bäriswil, den ich nicht kenne, abgeholt wird.

Was mich aber seit Mittag besonders innerlich beschäftigt, ist etwas anderes. Die Post brachte, wie gesagt, einen Brief Rossels, worin er schreibt, die Rolle gefalle ihm so sehr, er habe so nette Beziehungen in seiner Abteilung $\mathrm{u}$. er gedenke, sich in Lausanne sein neues Haus baldmöglichst zu bauen. Und in dem gleichzeitig

eingelaufenen Brief Webers war gesagt, Dr. Fick habe von Reichel, Schurter, Kirchhofer u. a. Bundesrichtern über Rossel das einstimmige Urteil gehört, Rossel versage in seinem neuen Amt vollständig! Ich kann mir schon denken, was sie an ihm auszusetzen haben. Ist mir selber diese Seite Rossels oft genug über u. über gewesen. Allein dieser Gegensatz, diese Selbsttäuschung! Wenn Rossel dieses Urteils seiner Kollegen einmal 
bewusst wird, so wird er tief unglücklich werden! Ja, ja, die kluge Mache ist nicht alles.

Langhard war gestern Abend nur ein Moment da, um mich über den Erbverzicht seiner beiden Adoptiv töchterchen zu beraten. Er war recht, teilte mir auch mit, dass er letzten Sommer Vaters Kreuz auf dem Kirchhof in Stammheim habe reparieren lassen.

Soeben hat der $2^{t}$ semestrige Jurist Bäriswyl, ein feiner Junge, M. abgeholt. Und ich will nun noch auf morgen präparieren u. dann zu Bett. Ich bin müde.

Innigst gut Nacht!

Dein allzeit getreuer

Eugen

1912: November Nr. 227

B. d. 13. / 4. Nov. 1912.

Mein liebstes Herz!

Das zweistündige Kolleg hat mich heute Morgen mehr als gewöhnlich ermüdet. Das mag daher kommen, dass ich in der Nacht längere Zeit wach über eine Anfrage Kaisers nachdachte u. dann gegen Morgen, als ich eingeschlafen von der bösen Sophie geweckt wurde, die wieder einmal um halb sechs zu rumoren begann, ohne jeden Grund als ihre Laune. Ich habe es durch Anna den Standpunkt klar machen lassen, aber die Störung war da. Vor Tisch musste ich mit Guhl conferieren $u$. vernahm dabei, dass er heute 32 Jahre alt geworden ist.* Den Nachmittag glaubte ich, wieder wie am Montag für mich arbeiten zu können. Ich kam aber nicht in Stimmung. Ich las Josts Dissertation fertig, sie geht an. Dann arbeitete ich etwas an der RG. u. zuletzt an der Gesetzgebung, für die ich die Einleitung präpariert habe. Zwischendurch waren Jakob Welti u. Frau hier, sie brachten Walter Bs Bild, das bis zu Weihnachten in unserem Besuchszimmer stehen wird. 
Ferner brachte mich in Unruhe, dass während des Kaffees jemand kam $u$. mich heraus verlangte, d. h. zuerst Marieli, das dann mich rief. Man fragte einer Emma Röthlisberger geb. im Sept. 1892 nach, ich konnte auch keine Auskunft geben u. verwies den Mann, ein Polizist im Civil mit schönem Polizei*Er hat also den schönen 13. Nov. 1898 Geburtstag gehabt!

hund - an Bösigers. So treten immer wieder Momente auf, die unangenehm sind.

Freude machte mir, dass Lüdemann im Sprechzimmer auf meine soziale Gesinnung zu sprechen kam $u$. mit grosser Anerkennung darüber mir dankte. Er sei mit der philosophischen Grundlage ganz u. gar einverstanden etc. etc.

Es war heute kalt, trüb, Eis, aber weder Schnee noch Wind. Insofern ein guter Wintertag, aber früher Winter. Immerhin haben wir heute in sieben Wochen schon Neujahrstag.

Marieli kam vom Helveterkränzchen um halb fünf nach Hause. Ganz vergnügt. Die Helveter haben heute bei mir im Colleg gefehlt. Das kommt jetzt wieder so bei den Studenten, es ist kein sympathischer Geist. Sophies Zorn, nach der Zurechtweisung, richtete sich in meiner Abwesenheit offenbar zuerst gegen Marieli. Sie polterte im Badezimmer scheints ganz pöbelhaft an der Türe zu Maries Zimmer herum, das sich noch etwas zur Ruhe gelegt hatte.

Ja, die Müdigkeit! Ich spüre eben doch allemal von Mittwoch an eine andere Ermüdung als nach dem Sonntag. Also ists eben doch für mich reichlich, oder zu viel Anstrengung geworden. Nun ich will sehen, wie lange ich es noch aushalte. Und bis dahin - vorwärts! Jeder Tag bringt mich dem Ziele näher. Das sage ich mir, zugleich mit dem Rezept: es ist Dein Spruch: jeden Tag dankbar, dass es nicht schlimmer ist, u. jeden Tag Liebe zu den Andern! 
Heute ist es mir begegnet, dass ich zum ersten Kolleg das Heft für das zweite aufs Katheder nach [sic!]. Schulthess hatte so viel im Sprechzimmer erzählt, dass ich im letzten Augenblick mich vergriff. Ich schwankte einen Augenblick, dann aber blieb ich u. hielt meine Vorlesung, auswendig. Es ging, nur in der Reihenfolge habe ich unwillentlich Veränderungen angebracht $\mathrm{u}$. die Citate waren spärlicher. Aber immer wäre es nicht gegangen. Die Stunde verflog mir in rasanter Eile. Nach dem zweiten Kolleg war ich bei Merz, den ich durch eine unachtsame Bewegung der Oberlippe erzürnte. Sonst war er recht. Dann habe ich mit Werner Kaiser über den Fall gesprochen, den er mir mitteilte zur Begutachtung. Und um 12 Uhr hatten wir wegen der Stundungsgesuche Facultätssitzung. Blumenstein suchte dabei den Antrag durchzusetzen, dass an Farben tragende Studenten keine Stundung mehr zu gewähren sei. Ich bekämpfte das u. erreichte Verschiebung. Ein grässlicher Pedant. So oft ich mit ihm zusammenkomme habe ich das gleiche Bedauern, mit diesem Collegen zusammensein zu müssen. Und dabei ist dann doch wieder so vieles an ihm der Anerkennung wert. Er sollte aber nur nicht das sein, was er ist. Das Nachmittagskolleg war recht. Ich war am Abend weniger müde, als Mittags.

Walter B. scheint von Jakob Weltis Bild sehr befriedigt zu sein. Es freue ihn, dass er einen gewissen Zug herausgefühlt u. dargestellt habe. Und gerade dieser Zug - das Lästermaul ist mir nicht sympathisch an dem Porträt. Marieli hat freilich immer gesagt, Walter B. sei so einer, $u$. ich habe es ja auch erfahren. Nur wird es bei ihm gemildert durch Bräve, was nicht bei allen Baslern der Fall ist. 
Marieli u. Anna sind in das Konzert eines jungen

Musikers Fischer gegangen, eines Freundes von Ernst Brenner, für den Annie Brenner geworben hat.

Es war mir gestern $u$. heute Mittag fast Angst geworden wegen meiner

Müdigkeit, dass sie jetzt vorüber ist, zeigt mir ihren Ursprung. Es ist die kalte Witterung u. nicht eine allgemeine Ermüdung. Ich kann aushalten, ich rechne sicher darauf.

Jetzt will ich noch einige Antworten schreiben. Oscar Honegger hat mir auf meine Sendung der «sozialen Gesinnung» einen eigentümlichen Brief geschickt. Darauf muss ich nicht antworten. Aber auf anderes, z. B. die Anfrage Meilis.

Also breche ich hier ab. Hoffentlich halte ich aus den Winter über, nicht wahr, Du hilfst mir ja!

Innigst Dein allzeit getreuer

Eugen

1912: November Nr. 228

[1]

B. d. 15. / 6. November 1912.

Meine liebe, gute Lina!

Wenn ich denke, dass heute 39 Jahre verflossen sind, dass ich Abends, in trüber, früher Winterdämmerung auf den Bahnhof in Bern eilte, um es an ein Ende zu bringen, was mich so unablässig in Ungewissheit quälte, dass ich nach Zürich fuhr, um mit Dir zu reden, - da kommt mir das Leben lange, lange vor. Denn zwischen heute u. damals liegt es wie eine unendliche Reihe von glücklichen u. schweren Tagen, die mein Leben gebildet haben, so wie es sich aus meinem Wesen heraus mit allen 
Schwachheiten, Irrwegen, glücklichen Impulsen, unerhörten Anstrengungen $u$. innern wie äussern Stürmen allmählich summiert hat. Und ich überspringe doch mit Einem Gedanken, was mir das Alles gewesen ist, sodass es mir wieder als Ganzes wie ein kurzer Traum vorkommt! Wenn ich damals nicht dem Drange gefolgt, wenn ich, vielleicht wegen einer äussern Abhaltung den Sprung nicht getan hätte! Alles wäre für Dich u. mich anders geworden. Aber dass es nicht anders hat sein können, es nicht anders geworden, das steht ja deutlich vor meinen Augen. Du hast Dein Leben lang an meiner Seite nicht anders gedacht. Aber hätte ich nicht einen andern Schluss verdient? Weshalb muss ich nun, nachdem ich jahrelang Deine Liebe genossen, in einer liebelosen Umgebung noch weiter leben? Denn liebelos ist sie, das spüre ich ja jeden Tag. Anna ist, was sie immer war, so sehr sie sich anstrengt, die innere Unzufriedenheit, der gemütslose Ausdruck, mit dem sie alle Erlebnisse begleitet, der Mangel an innerer Teilnahme, die geheime Freude an jedem ungehörigen Ereignis - wie Du es an ihr ja immer erkannt hast, darüber komme ich nicht weg, u. doch muss ich jetzt zusammen leben

und dabei Busse tun für alles Unrecht, das früher geschehen. Und die Kollegen, u. die Welt wie sie mich umgibt! Ich sehe alles nur unter dem Vergleich, wie es war, wie es sein könnte u. sollte, u. wie es jetzt ist! Jedoch, will ich gerecht urteilen, so darf ich ja nicht übersehen, dass es schlimmer sein könnte. Wie nahe war ich ein paar mal einem schimpflichen Zusammenbruch des ganzen Lebens. Und wie viele günstige Umstände haben mir immer wieder geholfen. Und dass Du mein warst, das wiegt ja alles Ungemach auf, weit auf, das ich jetzt erfahre u. noch erfahren mag. Also hervor mit Deiner Weisheit, die Dich so stark gemacht hat: Liebe u. Dankbarkeit, jeden, jeden Tag, auch heute! Ich will nicht in die schwere Düsterkeit versinken, die mich so oft jetzt zu umfangen droht. Das wird auch der einzige Weg sein, Dich mir festzuhalten u. treu zu bleiben bis in den Tod! 
Wenn ich mich gestern Abend mehr ausgeruht fühlte, als die vorhergehenden Tage, so hat mir dieses Gefühl dann auch eine bessere Nacht, eine Schlafnacht, wie wir es allemal nannten, verschafft. Zwar musste ich nach dem ersten Einschlafen nach halb elf noch einmal aufstehen, weil aus Versehen die Corridortüre geschlossen worden war u. Anna u. Marieli bei ihrer Rückkehr aus dem Concert anklingelten. Nachher aber schlief ich bis vier u. dann gleich weiter bis halb sieben. Heute Vormittag habe ich dann in aller Ruhe etwas an der Gesetzgebung gearbeitet u. dann Praktikumsfälle ausgearbeitet, bis in den Januar hinein genügend, die Marieli Nachmittags - ungern - zu Frau Schrämmli trug. Das Praktikum ist mir immer noch lieb, aber ich weiss nicht, was das ist, es liegt mir nicht mehr soviel Persönliches drin, wie als Du noch die Bogen vervielfältigt hast $u$. über die Fälle Deine Gedanken äussertest. Jetzt nimmt niemand mehr recht Anteil daran. Auch da bin ich einsam geworden.

Heute habe ich eine Karte von Häusler erhalten, worin er mir nun doch nachträglich für die Übersendung der sozialen Gesinnung u. des Abrisses der RG. dankt, mit Entschuldigung, dass er verspätet sei. Das hat mich gefreut. Es ist viel von ihm. Und es tut mir

[3]

doch wohler, hier mich wieder in besserer Stimmung zu wissen, als das nach dem Pamphlet v. Frischs bei mir mit Recht der Fall war.

Ich wollte heute Abend noch ausführlicher schreiben. Nun aber hat sich der junge Teichmann telephonisch angekündigt, er kann jeden Augenblick kommen, u. ich breche daher ab.

Mut, Mut, sage ich mir jede Stunde. Hilf mir dabei! Ich bin ja doch nur noch in Dir glücklich.

Den 16. Nov.

Heute habe ich den Tag, an dem Du mir jeweils in so rührender Tiefe Deine Liebe u. Dankbarkeit erzeigt hast, damit gefeiert, dass ich dem Departement ein Gutachten ausfertigte, das ich vor Tisch noch Kaiser überbringen konnte. Ich hatte die Nacht darüber nachgedacht, konnte es infolge dessen rasch conzipieren $u$. die Maschinenabschrift hat mich auch nicht zu lange aufgehalten. Ich konnte hierbei daran 
denken, wie Du mir das schnell abgeschrieben hattest. Jetzt habe ich dafür niemand. Marieli hat weder Lust noch Zeit, ein Secretär ist nicht mehr da, wofür ich übrigens dankbar bin, denn angenehm war es zumeist nicht, durch den jungen Mann in eine Art Büreauatmosphäre versetzt zu sein. Am Nachmittag machte ich einen Abschnitt in der RG. u. in der Ges.gebg fertig. Gegen Abend entwarf ich noch ein zweites Gutachten für das Departement, das ich aber erst nächste Woche mit Gelegenheit ausfertigen werde.

Kaiser gab mir heute seine Redaktion des Strafr. Entw., die von der Redaktionskommission abgelehnt worden ist. Ich finde sie viel besser als die offizielle. Er folgt meinem Vorbild, da muss ich das ja besser finden. Er war übrigens heute wieder wie früher, herzlich.

Marieli war heute wieder bei Dumont, u. da sprach er davon, dass jetzt die Rabbenthalstrasse fertig gebaut werden soll. Das wäre für uns persönlich eine grosse Störung, aber doch nur vorübergehend.

Im Resultat würde ich es begrüssen, an eine öffentliche Strasse zu kommen. Wir haben s. Z. für diesen Fall eine ebene Terrasse in Aussicht genommen. Was meinst Du dazu? Ich glaube Du wärst damit einverstanden.

Der junge Teichmann war gestern sehr gesprächig. Aber, ich weiss nicht, es fehlt mir etwas an ihm, was ich nicht leicht aus dem Gefühl loskriegen werde.

Und jetzt gut Nacht - ich will dran denken vor dem Einschlafen $u$. in nachtwachender Zeit, damit ichs festhalte, auch heute, welch Glück mir schwand, u. welches mir geblieben!

Dein ewig getreuer

Eugen 
[1]

B. d. 17. Nov. 1912.

Meine liebste Lina!

Gestern Abend zog ich beim Plaudern nach dem Nachtessen meinen Trauring vom Finger, um zu zeigen, dass ich doch etwas weniger fest sei als vor Jahren, u. reichte ihn Marieli, die die Inschrift las u. das Datum von gestern eingegraben fand. Die Bewegung war sichtlich, sie hat Anteil genommen. Ich betrachte die «Erleichterung» als ein Zeichen gefestigter Gesundheit, fühle mich auch wirklich seit einiger Zeit gesunder als die Zeit vorher. Die regelmässige Arbeit, die stille, arbeitsame Zurückgezogenheit bekommt mir je länger je besser, u. ich hoffe wieder auf die Möglichkeit, dass ich alles das, war mir noch auf dem Herzen liegt, werde aussprechen u. hinterlassen können. Es ist so vieles, u. die Furcht, dass das alles begraben $u$. nutzlos verlorene Mühe gewesen sein möchte, weicht wieder einer vertrauensvolleren Stimmung.

Heute war Walter B. wieder - nach zweimaligem Ausbleiben - zum Sonntagsbesuch bei mir. Wir haben über den Vortrag, den er im Juristenverein halten, u. die Abhandlung, die daraus für die Zeitschrift werden soll, geplaudert $u$. zum Schluss noch Weltis Bild miteinander betrachtet. Der Ausdruck kam mir heute milder vor. Es ist ein schönes u. gutes Bild, was nicht stimmt, ist malerisch erlaubte Ausgestaltung. Nur kam mir heute die Gestalt gegenüber dem Kopf als zu fest vor. Die schlanke Postur ist in ein grösseres Format verwandelt. Würde der Walter im Bild aufstehen, so müsste er den Walter in Natur erheblich überragen. Doch 
kann die Perspektive da etwas irreführen. Welti hat eben auf Grund einer von ihm aufgenommenen Photographie gearbeitet.

Ich habe dann eine Reihe von Briefen geschrieben, unter anderem eine längere Karte an Marie Heim, die mir die Rückkehr Arnolds, die gestern Morgen erfolgt ist, angezeigt hatte. Und dann war ich bei dem Nachbar Arm. Er war noch gar nicht orientiert über die Pläne die betr. die Anlegung der neuen Rabbenthalstrasse zur Ausführung gelangen sollen. Er nahm an, das Projekt werde an dem Widerstand des «Salem» scheitern, u. war ganz bestürzt, als ich ihm mitteilte, dass nach den gestrigen Aussagen Dumonts die Möglichkeit bestehe, Salem werde sich in Unterhandlungen einlassen $u$. wahrscheinlich zuschlagen. Bei näherer Überlegung stelle ich mich auf den Standpunkt, dass für mich die Sache nicht gefährlich wird. Voraussichtlich wird unser Heim ebensoviel gewinnen, als es verliert, oder noch mehr. Die Terrasse, an die Du selbst immer gedacht hast, würde uns entschieden nur erfreuen können. Und die Lage an einer öffentlichen Strasse wäre auch zu begrüssen. Bei Arm ist es anders. Sein Zugang würde voraussichtlich sehr beeinträchtigt. Warten wir das weitere ab. Arm will sich erkundigen, $u$. ich werde noch mit Beguin sprechen.

Was mich nun aber heute namentlich beschäftigt hat, war etwas anderes. Gestern teilte mir Dr. Kaiser mit, dass die Erläuterungen vergriffen seien $u$. dass von verschiedener Seite eine neue Auflage gewünscht werde, die er sehr angezeigt erachte. Ich ersuchte ihn, mir nähere Angaben zu machen, u. er meinte von sich aus, dass man die Auflage durch Verweisungen auf das Gesetz noch brauchbarer machen könnte, was ja ganz meinem früheren Plan entspricht, also meine Zustimmung fand. So werde ich also 
vermutlich demnächst eine Anfrage vom Departement in der Sache erhalten. Und was soll ich dann machen? Gegenüber den Plänen betr. das mehrbändige Schweiz. Privatrecht habe ich keine Bedenken, umgekehrt wäre es mir ganz recht, aus dem Anlass eine Verschiebung eintreten zu lassen. Ich mag nicht an diese Publikation heran, wegen der feindseligen Stimmung, die mir aus Basel in der Sache entgegengeklungen $u$. wegen der Antipathie gegen den Verleger, die ich seit den Geschichten mit der Publikation meiner Rechtseinheits Aufsätze u. mit der Herausgabe meiner Berner Vorträge gegen ihn empfinde u. immer noch nicht völlig zu überwinden vermag. Also soll die Sache warten. Sie wird ja auch mit dem Warten immer mehr vertieft, weil ich meine Vorlesungen darüber auch stets verbessern kann. Aber die «Gesetzgebung»! Die müsste dann noch ein ganzes Jahr warten. Denn der Druck der neuen Auflage der Erläuterungen mit den geplanten Ergänzungen würde mindestens so lange dauern. Andrerseits würde durch die neue Publikation das mühsame Werk der Erläuterungen so aufgeheizt, dass er erst recht zur Geltung käme, u. daran muss mir doch auch viel liegen.

So werde ich also vermutlich doch dazu kommen, die erwartete Anfrage zusagend zu beantworten. Ich muss dann sehen, wie ich es mit der Arbeit machen kann. Bleibe ich gesund, so wird es schon zu machen sein.

Während ich diese Zeilen schrieb, erhielt ich von dem Rechtsbüreau Fischer aus Zürich eine telegraphische Anfrage, die ich mit Rückantwort erledigen musste. Nun hatte ich gestern Abend noch ein Gutachten für das Departement entworfen, wie ich Dir gestern geschrieben. Und siehe, die Anfrage betraf gerade diesen Gegenstand. So war ich in der Lage, kurz, in 22 Worten, präzis die Antwort zu erteilen, was mich gefreut hat.

Ich will nun, - es ist acht Uhr - noch den Versuch machen, mit 
Beguin über den Strassenplan zu sprechen. Ich wollte nach dem

Besuch bei Arm zu ihm gehen, allein es gingen eben Besuche in sein Haus. Ich möchte nichts versäumt haben.

Und nun kann die Woche wieder beginnen. Die zwei

Stunden am Vormittag versetzen mich immer - in dem grossen

Auditorium - in eine Aufregung, die mich von Anfang der

Woche bis zum Donnerstag Abend nicht mehr recht zur Besinnung

kommen lassen. Du siehst es allemal meiner Schrift an. So

fliegt Woche um Woche pfeilschnell vorüber - ewig still steht die Vergangenheit.

Gute, gute Nacht! Bleibe bei mir - an den Sonntag

Abenden sage ich es mit eigener Erinnerung - wie ich verbleibe

Dein allzeit getreuer

Eugen

\section{2: November Nr. 230}

B. d. 18. / 9. Nov. 1912.

Meine liebste Lina!

Düster, feucht, windig, am Abend mit nassem Schnee, das war der heutige Tag, an dem ich wieder mit Mühe einer Aufregung erwehrte, die ich die letzte Zeit überwunden hatte. Wenn ich die zwei Morgenstunden in Nr. 31 gelesen, bin ich offenbar aus dem seelischen Gleichgewicht. Früher freute mich die «Bewusstlosigkeit», in der ich nach blos einer Collegstunde an Jakob Burckhardt oder an Hans Weber vorübergehen konnte, ohne sie zu sehen. Jetzt ist mir nach den zwei Stunden ein ähnlicher Zustand peinlich. Aber es muss durchgekämpft werden, es gibt ja für mich nichts anderes mehr. 
Ich hatte mich gestern gefreut, die telegraphische Begutachtung nach Zürich zu geben, heute wie ich nach Hause kam, lag eine Depesche da mit der Bitte, die Antwort zu wiederholen, sie sei verstümmelt $u$. daher unleserlich $u$. unverständlich angekommen. Ich habe das gestrige wiederholt. Hoffentlich verstehen sie es jetzt.

Dann hatte ich am Nachmittag Dr. Surbeck u. Ingenieur Herzog bei mir wegen des Lory-Testaments. Die Verhandlungen hatten für mich keinen Zweck. Ich weiss nicht, zu welchem Zweck die Herren kamen. Einen mir zugedachten Besuch von Dr. Volland, St. Gallen, musste ich deswegen absagen.

Um 6 Uhr war Guhl bei mir in wichtigen Sachen. Auch das ging vorüber, im Sturm.

Dazwischen präparierte ich Kolleg, las in der "Gesetzgebg», u. corrigierte Rechtsgeschichte. Das letztere hatte ich, trotz fortdauernden Aergers mit dem von Hemweler erstandenen Tintenkuli gemacht. Heute Nachmittag erhielt ich endlich genug von dem undankbaren Werkzeug u. schmiss es zum Fenster hinaus.

Es kann sein, dass auch der Schnee, wie immer, wenn er naht, ein wenig angriff. Hauptsorge ist mir, dass ich am Ende doch die Doppelstunden nicht mehr vertragen könnte. Morgen muss ich zum Zahnarzt nach zehn Uhr, u. nach dem AbendKolleg habe ich eine Fakultätssitzung, die wohl bis gegen acht Uhr dauern wird. Sonst ist meine Arbeit auf dem Tisch ziemlich aufgeräumt. Einiges will ich noch diesen Abend erledigen.

Marieli hat mir heute wieder etwas in der Bibliothek geholfen. Wenn es doch so weiter ginge!

Genug für heute. Ich schreibe Dir morgen wohl aus der Fakultätssitzung. 
Den 19. Nov.

Heute habe ich wieder in einem Taumel gestanden, vom Schluss der zwei Morgenvorlesungen bis zu diesem Moment. Es mag sein, dass ein neuer Schnupfen, auf den mich Collegen im Sprechzimmer aufmerksam machten, hiezu beigetragen hat. Aber ganz erklärt ist die Sache damit doch nicht. Nun ich werde ja sehen, was daraus wird. - Zahnarzt Wirz hat mich heute

entlassen. Dies also wäre vorüber, u. zwar war er sehr nett zu mir, hat mir auch mitgeteilt, dass er das Haus Hallwilstrasseobere Dufourstrasse-Ecke gekauft habe u. im Frühling Wohnung u. Atelier dorthin verlegen werde. Er meint, ich sollte nun mit den Zähnen einige Zeit Ruhe haben, wenn sie auch nicht besonders mehr solid seien. Ich bin froh genug, wenn ich so nun noch die gänzliche Ersetzung hinaus zögern kann. Vielleicht wird das dann ja gar nicht mehr nötig.

Nach Tisch war ein Student bei mir, Brunner aus Oprund, um mich wegen einer Dissertation zu konsultieren, die in Blumensteins Gebiet fällt. Ich sagte ihm das u. wies ihn an diesen. Er aber ersuchte mich treuherzig, ihm doch etwas an die Hand zu gehen, er könne mit Blumenstein nicht reden. Ich werde nun sehen, was ich mit allem Takt dem Candidaten gegenüber machen kann.

Ich schreibe eben jetzt im Dekanatszimmer u. bin durch das Eintreten von Wegemann, Folletête, Röthlisberger u. Blumenstein gestört worden. Es war eine lebhafte Unterhaltung. Inzwischen sitzt der Candidat Hugo Meyer zitternd im Seminarzimmer am grünen Tisch. Seine bisherigen Leistungen haben mich sehr enttäuscht, er schneidet gar nicht gut ab, wenns nicht noch besser kommt.

Was soll ich sagen von dem Tag, als dass ich nebenbei Kolleg präpariert habe u. mir vorstellte, es könnte so vieles besser sein. Aber dies darf nicht weiter aufkommen. Ich will bei Deinem Rezept verharren mit aller Kraft: Dankbarkeit u. Liebe! 
Beguin, mit dem ich am Sonntag über die Strasse durchs Rabbenthal gesprochen, teilte mir heute, als ich ihn antraf, mit, dass auf dem Bauamt von einer Förderung der Projekte nichts bekannt sei. Also abwarten. Ich habe Dir vorgestern geschrieben, wie wenig mich eigentlich die Sache berührt.

Nun will ich zum Examen zurücku. zu Hause noch einige Worte über die Sitzung beifügen.

Gute, gute Nacht, mein Lieb! Dein allzeit treuer Eugen

Hugo Meier war im Examen entsetzlich stumm, z. Tl. aus Aufregung, grösseren Teil aber offenbar aus Mangel an Präparation. Er wurde rite promoviert. Mit Recht, aber er tut mir leid. Ohne die Dissertation wäre er durchgefallen.

Noch muss ich Dir sagen, dass Marieli neulich sagte, Bankiers Vogels verkaufen ihr Haus. Ich dachte halb daran, es wäre für das künftige Fakultätszimmer eine gute Gelegenheit. Aber die Sache ist nichts. Frl. Vogel sagte Marieli, die Mutter erwarte 200 Mille, u. es sei nicht sicher, dass sie den Sitz verkaufen würde. Es waren von mir so spazierende Gedanken. Weg damit. Unser Heim bleibt unser Heim!

Nochmals gute, gute Nacht! 
B. d. 20. Nov. 1912.

Meine liebe, gute Lina!

Die letzten Tage habe ich wiederholt mir vergegenwärtigt, wie ganz anders es war, wenn ich früher aus dem Kolleg nach Hause kam. In den Jahren, da wir am Rabbenthal wohnten, war so oft als nur möglich die Haustüre schon geöffnet $u$. Du standest dabei, oder eiltest beim ersten Geräusch meiner Schritte herbei, um mir Stock u. Hut u. Mantel abzunehmen. Und ich zeigte Dir dafür nicht einmal besondere Dankbarkeit, meinte sogar gelegentlich, das solltest Du nicht tun. Und jetzt? Ich komme ins Haus, im Corridor, niemand ist da, ich fühle keine Liebe die mir entgegenschlägt. Wohl zur Strafe dafür, dass ich nicht dankbarer war, lässt mich das Schicksal jetzt einsam. Und doch arbeitet Anna im Haushalt, so gut sie es versteht, auch Sophie ist dabei, soviel es ihr rücksichtsloses Temperament zulässt, u. Marie ist ja so viel geschäftig, wie die Jugend es sein kann u. hat gewiss für mich so viel Gedanken, als es einem Mädchen ihres Alters möglich ist. Aber es ist ein Unterschied sollte er nicht naturnotwendig sein? Ja, Deine grenzenlose Liebe $u$. Hingebung war eben eine Ausnahme, eine seltene Ausnahme, u. ich muss dankbar dafür sein, dass ich viele glückliche Jahre unter dieser Ausnahme leben durfte.

Heute habe ich nach dem Morgenkolleg in der Bibliothek die Kaufsachen mir angesehen, die für das Ochsstipendium ausgestellt waren. Am Nachmittag hatten wir Kommissionssitzung, die nichts erwähnenswertes geboten hat. Nach dem 
Essen war der Luzerner Jost bei mir u. holte vergnügt seine nun annehmbare Dissertation. Nachher erschien der junge Doktor Hugo Meyer u. verabschiedete sich dankend, wenn er auch wegen des schlimmen Ausfalls seines mündlichen Examens gedrückt zu sein schien. Er erkannte nun, dass er unter dem Einfluss des Wunsches, den Winter noch in Berlin zuzubringen, auf die Vorbereitung zu wenig Zeit verwendet habe. Dann war Dr. Werner Kaiser längere Zeit bei mir, consultierte mich über verschiedene Fragen, Commanditenbeteiligung, Übersetzung des internationalen Wechselrechts, wobei scheints Wieland sich mit übergrossem Eifer gegen die Annahme des Ausdrucks «blank» ([?essement]) anstatt «blanco» ausgesprochen hatte u. nun Unterstützung von Seiten des Departementes verlangte, die ich nicht empfehlen konnte. Namentlich aber brachte er mir die Liste der noch vorrätigen Exemplare der Erläuterungen, aus der deutlich hervorgeht, dass ein Neudruck notwendig ist, wenn man die Sache nicht veralten lassen will. So wird nun also die Frage wegen dieser neuen, grossen Arbeit, von der ich Dir letzthin geschrieben, wirklich an mich herantreten. Was soll ich tun? Ich weiss es noch nicht.

Bei diesen Umständen, $\mathrm{u}$. da ich heute ganz zum wehmutigen Staunen aufgelegt war, kam ich zu keiner weitern Arbeit. Es geht ja auch auf Donnerstag u. da empfinde ich die Mühe der Woche, die innere Müdigkeit am allerstärksten. Immerhin habe ich doch Kolleg präpariert u. ein Kapitel in

der Gesetzgebung gelesen. Die Zeitungen mit den vielen aufregenden Kriegsberichten sind jetzt auch mehr als gewöhnlich zeitraubend.

Marieli sagte heute, Frau Isenschmid, die voriges Jahr so aufdringlich freundlich mit ihr gewesen, grüsse sie kaum mehr, sehe sogar zur Seite. Das zeige deutlich, dass sie damals nur 
freundlich gewesen sei, um vor dem Examen ihres Sohnes gutes Wetter zu machen. Als sie damals jene Freundlichkeit erzeigte, äusserte ich selbst gelegentlich eine solche Vermutung. Die Umkehr kann nun aber auch von Zürich her bewirkt worden sein, denn der junge Isenschmid ist dort, $u$. ist mit August Gyr u. mit Paul bekannt oder befreundet. Dass eine wilde Verleumdung u. ein rücksichtsloser Hass von dort ausgeht, bezweifle ich gar nicht, u. ich werde mich gewiss darnach richten.

Marie war heute zum Thee bei Frau Georges, musste dann aber, da ein Besuch zu ihr kam, mit Susanne u. André vorlieb nehmen. Diese scheinen ihr Herz geflissentlich geleert zu haben. Und wenn ihre Mitteilungen richtig sind, so versteht allerdings Madame Georges die Ausbeutung, wie sie in der welschen Schweiz ja Mode ist, aufs beste. Jedes der Rossel-Kinder zahlt nämlich für eine Dachkammer, bei nur einmal Fleisch $u$. bei blossem Brot mit Cacao, im Monat 110 Fr. u. die Beleuchtung wird teuer verrechnet, ebenso die überdies ungenügende Heizung. Und Susanne muss neben den Stunden bei Frau Georges für die Benutzung des Pianos monatlich 5 Fr. bezahlen. Und dies nennt man die Unterbringung bei einer befreundeten Familie. Es scheint, dass Rossels die Offerte der Frau Georges

seinerzeit angenommen hatten, ohne zugleich den Preis abzu machen. Es scheint aber vielleicht auch, dass Georges sehr wenig verdient. Die lächelnde Frau Georges hat mich übrigens immer etwas an die pfiffige Sophie in Zürich erinnert.

Jetzt will ich noch einiges nachlesen $u$. dann wieder zur Ruhe. Jeder Tag ist mir willkommen, wenn er vorüber ist. Es geht mir damit fast wie jenem Mann, von dem ich heute las, die neuen Schuhe seien so eng, dass er nicht hineinschlüpfen könne, bevor er sie ein paar mal getragen. Das Künftige nehme ich voraus in Gedanken u. springe über die Vergangenheit weg, als wäre sie die Zukunft. Was ist Zukunft: «Die Fremden haben in Zukunft sofort nach ihrer Ankunft über ihre Herkunft u. Abkunft Auskunft zu geben, wenn sie Unterkunft finden wollen.» So las ich neulich, u. solche Spässe machen mir wieder mehr Freude als früher, so dass Du 
an meinem Gemüt für die Zukunft doch nicht zu verzweifeln brauchst. Hilf mir nur dabei!

In innigster Liebe, meine gute Seele,

Dein immerdar getreuer

Eugen

1912: November Nr. 232

[1]

B. d.21./ 2. Nov. 1912.

Mein liebstes Herz!

Wieder Donnerstag Abend u. ich spüre es auch, wenngleich mich die zehn Stunden Kolleg diese Woche weniger ermüdet haben, als die letzten, so dass ich das Dutzend morgen ganz gern voll mache. Ich habe eben die letzten Tage besser geschlafen $u$. auch die Wiederangewöhnung wird etwas ausmachen.

Was mich heute beschäftigte, sodass ich neben den Collegien gar nichts anderes tun konnte, war die Nachricht, die in der Morgenzeitung stand, dass Dr. Friedrich Schreiber gestorben ist. Ich verspürte recht, wie ich ihm innerlich nahe gestanden, wenn ich ihn auch die letzten Jahre selten mehr gesehen hatte. Das freundliche Zusammentreffen auf dem Schiff von Luzern nach Vitznau im letzten Frühling sollte also die letzte Begegnung sein. Er kam mir da im Ausdruck der Augen etwas erloschen vor, namentlich weil ich sein Feuer in Erinnerung hatte. Auch war er im Gespräch viel friedlicher $u$. nachgiebiger, während er sonst die Diskussion liebte. Aber lebhaft war er doch, sodass ich an das nahe Ende nicht gedacht hätte. Mit seinen Söhnen, werde ich wohl das freundschaftliche Verhältnis nicht fortsetzen können, sie sind von anderem Schlag. Hätte ich die Möglichkeit bedacht, so würde ich wohl vom Klausen her doch im Sommer über den Rigi heimgefahren sein. Ich schrieb Frau Schreiber einen Brief, worin ich eine Würdigung seiner Leistungen als 
Jurist in seinen jüngern Jahren niederlegte. Er war mir ein lieber Mann u. treuer Gefährte, von der Zeit an, da wir in Zürich zusammen studierten u. er uns bei Deinem ersten Besuch in Bern auf dem Schänzli begrüsste. Er war auch immer zu Dir so gut u. correct. Ich habe ihm das immer hoch angerechnet.

Daneben dachte ich auch über die Anregung nach, die Marieli gemacht, dass ich Lauch als Secretär nehmen würde, wenn er die Stelle als Obergerichtsschreiber nicht erhalten sollte. Dagegen sprachen mir zwei Gefühle mehr als Erwägungen. Ich empfinde es nach den Diensten, die mir Siegwart u. Abbühl geleistet, so angenehm wieder allein zu sein. Und ich fürchte mich etwas vor dem selbstbewussten Wesen Lauchs. Er war im Praktikum doch immer ein schwieriger Charakter, aber Frl. Reineck versicherte Marieli, dass er mir grenzenlos ergeben wäre. Würde das bei täglichem Zusammenarbeiten aushalten? Ich bezweifle es, besage wenigstens ein anderes. Daher die Bedenken. Am Ende ist es doch besser, auf das Buch zu verzichten, oder in absehbarer Zeit mich vom Kolleg frei zu machen. Doch was mache ich mir Gedanken darüber. Erinnert mich doch Schreiber wieder eindringlich daran, an welchem Ende wir stehen. Ich will heute Abend nicht mehr arbeiten, ich will mir einige Beschaulichkeit aneignen, um die Kräfte richtig zu sparen. Heute klagte Walter B. über starke Müdigkeit. Kommt der Gegenschlag gegenüber der Steigerung im Empfinden, in die ihn die

Walkampagne mit Jakob Welti sichtlich versetzt hatte? Kann sein, er würde mich dauern, aber so geht es im Leben! 
Den 22. Nov. 1912.

Heute habe ich das Gutachten über den Eigentumsvorbehalt zur Eingabe Winkler expediert u. Kaiser gebracht. Dann war Frau Rossel da, machte einen freundlichen Besuch u. schien sehr glücklich. Weiter präparierte ich Praktikum u. dachte über die neue Ausgabe der Erläuterungen nach. Sonst aber war ich zufrieden, mein Praktikum zu halten u. trieb nebenbei nur noch etwas Mathematik, ohne zu rechter Arbeit aufgelegt zu sein. Ich war mehr träge als müde. Es war ein milder Wintertag.

Ich dachte heute wieder lebhaft an die Hülfe, die Du mir in meinen Praktikumssachen so lange Jahre geleistet. Mit welchem Eifer! Wie hast Du einmal Dich beeilt, mir den vergessenen Bogen ins Hochschulgebäude zu bringen. In Pantoffeln im Tram bist Du gekommen, u. warst Du glücklich, noch zur Zeit anzukommen! Wer würde das Dir gleichtun? Und das alles ist jetzt verloren, $u$. die die Erinnerung an Dich pflegen $u$. heilig halten sollten, vergessen oder gar verleumden Dich, weil ihre Interessen ihnen unter Deiner Liebe zu mir nicht gefördert worden sind. Da muss man doch auf einen Ausgleich sich richten, sonst wäre es erbärmlich, so weiter leben zu müssen!

Anna war heute unwohl, die Migräne tritt jetzt meist nur noch stossweise auf, sodass man ihren Charakter fast nicht mehr

erkennt. Marieli will lieb sein $u$. ist entschieden in der Gesundheit besser dran als seit langem. Das macht wohl zumeist das Rezulin, das sie entgegen Dumonts Ansicht nach Rombergs bei Rümelins erteiltem Rat nimmt. Die Dummheit will missachtet sein, dann gehts gut.

Marieli erzählte neulich viel von Frl. Reineck u. ihrer Feindschaft zu Frl. Tumarkin u. Frl. Hoff. Das ist eine nette Geschichte. Zwei Jüdinnen mit einer Germanin in ächtem Rasseconflict, der begann, sobald die Germanin nicht mehr im seichten Wasser der andern schwimmen wollte, sondern etwas Enthusiasmus angenommen hat. Ich bin begierig, wies weiter geht. 
Nun Gute Nacht, ich will schlafen, es ist mir Bedürfnis. Sei innigst umarmt von Deinem allzeit getreuen

Eugen

1912: November Nr. 233

[1]

B. d. 23. Nov. 1912.

Mein liebstes Herz!

Heute war wieder ein heller kalter Wintertag $\mathrm{u}$. ich gab meiner Neigung nach, war bequem $u$. habe ausser ein paar Briefchen u. einer Besprechung mit Guhl gar nichts gearbeitet. Mathematische $u$. Schachaufgaben reizten mich u. ich habe in der Freude darüber, dass nichts Pressantes vorlag, nachgegeben $u$. Allotria getrieben. Dabei habe ich immer an Dich gedacht, ich stellte mir vor, ich geniesse die paar freien Stunden mit Dir. Ich ging am Vormittag auf den Friedhof, hing meinen Gedanken u. Erinnerungen nach, dachte an all die Erlebnisse, die mir in den Grabmälern aus unserer Berner Zeit entgegen schauten. Aber ich könnte nicht einmal sagen, dass die Gedanken mir in die Tiefe gegangen wären. Ich empfand auch da, ein Bedürfnis der Ruhe, des Ausruhens. Vielleicht war es begründet, vielleicht auch nur ein gewisser Überdruss am Alltäglichen, der sich, wenn es so ist, durch ein unbefriedigtes Gefühl rasch genug rächen wird. Es ist etwas Sonderbares. Früher konnte ich oft Tagelang nichts tun, ohne diese Selbstanklage zu verspüren. Jetzt bin ich dessen nicht mehr fähig. Auch wenn nichts dabei herauskommt u. ich nur an den Korrekturen der Stenogramme meiner Rechtsgeschichte oder Gesetzgebungspolitik sitze, worin ich besser getan zu haben, als wenn 
planlos die Gedanken spazieren führe wie heute.

Die Anzeige der Kollegiengelder ist gekommen. Ich habe ein besseres Semester als letzten Winter, aber lange nicht so gut wie letzten Sommer. Ich schreibe das hier in der Erinnerung daran, wie Du allemal teilgenommen hast an allen Schwankungen $u$. freudigen oder entmutigenden Überraschungen. Marieli holte das Geld bei Jenny u. es erzählte nachher, mit welchen Professoren es im Büreau zusammen gekommen. Jenny habe mit Prof. Bürgi ein Gespräch geführt, indem er ihn tröstete, es werde andere Semester auch wieder mehr geben als nur $600 \mathrm{Fr}$., worauf Bürgi geantwortet, nein, nein, das ist vorüber. Ich musste mir dabei denken, wie sehr ich doch wirklich dafür dankbar sein könne, einen so anhaltenden Erfolg zu haben. So lange er anhält. Nachher, wenn es abnimmt, wird man auch wieder sehen müssen, wie man sich darein findet. Denke ich daran, wie z. B. Thering in seinen letzten zehn Jahren sich mit etwa 15 Hörern begnügen musste, nach den vollen Sälen seiner bessern Zeit, so kann ich mir vergegenwärtigen, was meiner vielleicht noch erwartet. Aber ich würde dann doch gewiss mich zurückziehen, lieber als in solcher Qual verweilen. Freilich vielleicht hat Thering in seiner guten Zeit auch so gedacht $u$. nachher war er dessen nicht mehr fähig den Rank zu finden. Zum Glück habe ich genug erspart, um einen Rücktritt unabhängig wagen zu

können, wenn etwa nicht der Krieg mir meine Stellung wieder erschüttert. Auch das ist eine Möglichkeit, die gerade jetzt recht drohend scheint. Die Banken halten das Geld zurück. Hemmeler sagte mir heute auch, als er Bücher brachte u. gleich Bezahlung wünschte, die Leute halten mit den Zahlungen merkwürdig zurück. Man wird sich, wenn er kommt, auch durchschlagen müssen. Es können gar vielerlei Leiden über das Land hereinbrechen $u$. man 
wird dann sehen, ob unser Volk der Ordnung fähig sein wird, derer es bedarf um ihrer Herr zu werden. Ich bin nicht davon überzeugt, aber ich hoffe doch $\mathrm{u}$. will gewiss, wenn es kommt, mithelfen.

Heute begegnete ich Frau Prof. Burckhardt. Sie machte ein furchtbar düsteres Gesicht, wie Marieli in den letzten Tagen dasselbe beobachtet $u$. berichtet hat. War die Teilnahme an der Hochzeit in Basel für sie eine Entmutigung? War deshalb vielleicht Walter B. nach seiner Rückkehr so apathisch u. in den Gedanken gehemmt? Das würde mir leid tun. So wenig mir die Frau sympathisch ist, wenn ihr eine Demütigung zugefügt wurde, so geschah es aus Gründen, die mir verhasst sind. Vielleicht wird mir Walter, wenn er morgen kommt, darüber noch Aufschluss verschaffen.

Mit der Neuausgabe der Erläuterungen komme ich jetzt ins Klare. Die Aufgabe ist so schön, u. für mich speziell erfreulich, dass ich sie nicht von mir weisen darf. Am Ende ist dieser Weg dann doch einer von denen, die eingermassen die Zurücksetzung meiner andern Publikationswünsche betreffend

meine Rechtseinheitsarbeiten gut machen kann.

Interessant war mir heute, dass wie Guhl mir sagte, Lotmar einen Secretär für die Dekanatsarbeit haben möchte, u. zwar Guhl selbst, der aber unmöglich Zeit hat. Da sieht man, wie er sich verrechnet hat, da er es durchsetzte, gegenüber Reichesberg das Amt zu erhalten. Es geht ihm wie Hilty, der auch lachend meinte, das Dekanat sei ja keine Arbeit, u. dann gleich einem Secretär rief.

Und nun schliesse ich wieder eine Woche, die heiterere Gemütsverfassung hat angehalten, wenn auch das Wehmütige u. die Selbstanklagen zwischendurch sich nur um so beklemmender gelten machen. Ich will es so fortsetzen u. bin auch überzeugt, dass ich es kann, wenn die Arbeit mich nicht überwältigt. 
Gute, gute Nacht! Bleib bei mir, liebe Seele, hilf

uns allen!

Dein ewig treuer

Eugen

1912: November Nr. 234

[1]

B. d.24. Nov. 1912.

Mein liebstes Herz!

Ich habe heute im gestrigen Ton fortgefahren: Unlust zu Arbeit, Trägheit geradezu, wobei ich als Anlass zum Nichtstun eine schwere Schachaufgabe benutzte, die ich natürlich auch nicht lösen konnte. Daneben fühlte ich mich unruhig, wie es die Schrift ausweist, u. mache mir Gedanken, wie das herauskommen möge, wenn ich an alle vor mir stehende Arbeit denke. Ich hätte heute gerne einen guten Freund bei mir gehabt. Am Morgen war Walter B. bei mir, aber wir konnten nicht viel miteinander sprechen, indem der Volkswirtschaftler Prof. Steiger zu mir kam, diesmal ohne ein bestimmtes Begehren, abgesehen davon, dass er von mir erklärt haben wollte, dass im Kolleg im Sommer, das er auf meine Stunden z. Thl. verlegt, keine Kollision bedeute. Dann telephonierte Pfarrer Marthaler, ob wir mit ihnen einen Spaziergang im Bremgartenwald machen wollten, wie das Frau Pfarrer schon vor einiger Zeit Mariel in Aussicht stellte. Ich dachte mir, heute komme ganz gewiss Bundesrat Müller zu mir, oder vielleicht Siegwart, u. so lehnte ich ab, worüber Marieli sehr froh war. Zum Dank oder zur Strafe meiner Ablehnung ist dann Niemand zu uns gekommen. Und es ist mir ja auch recht, ich habe eigentlich nur noch die Einsamkeit gerne. Also will daraus auch die Consequenzen ziehen. 
Ich sagte heute, dass mir das Unwohlsein bei Walter B. eher als eine psychische Depression erschienen, $u$. ich sprach ihn darauf direkt an. Er gab zu in der letzten Zeit, in Basel allerlei erlebt zu haben - wahrscheinlich im Verhältnis der Frau Sophie zu seinen Verwandten - was ihn beschäftigt habe. Doch sei er wirklich unwohl gewesen, indem er beim Hochzeitsessen

in der Nähe eines offenen Fensters gesessen. Ich aber weiss, was ich von alledem zu halten habe.

Ich präparierte für morgen die Kollegien, eine Arbeit, die mir in diesem Winter schon bedeutend weniger Mühe verursacht, als voriges Jahr. Und ich sollte nun von dieser Aufgabe mich zurückziehen, da sie mir immer leichter wird? Und sie den Jüngern überlassen, die die Finger darnach schlecken? Das mute ich mir selber nicht mehr zu, nachdem ich - ja seiner Zeit eigentlich gegen Deinen Rat - mit Guhl meine Experimente gemacht. Doch waren meine Entschlüsse damals wohl erklärlich. Ich war von der jahrelangen Entwurfsarbeit müde, übermüde u. sehnte mich nach Entlastung. Besser wäre es gewesen, wenn ich damals einen längern Urlaub genommen hätte. Aber die Dazwischenschiebung des Oblig.rechts verhinderte mich ja daran. So habe ich mich durchgerungen $u$. bin nach $u$. nach zu der Erholung gekommen, die mir jetzt eine gleichmässige, wenn auch strenge Arbeit verhältnismässig gut tragen lässt. Ja ich denke gar nicht mehr so häufig an längere Urlaubszeit. Ich bin gewissermassen zu alt dafür. Ich vermöchte ja doch die Freiheit nicht mehr so zu geniessen, wie es früher der Fall gewesen wäre, weil keine weiteren Perspektiven sich damit verknüpfen würden. Jetzt muss ich mich an das Regelmässige halten, das ist des Alters Teil, u. so nur kann man noch etwas leisten. Das andere würde sich zu leicht als eitel Täuschung erweisen.

Im Grunde bin ich ja auch wieder froh, den Sonntag Nachmittag für mich gehabt zu haben. Wenn nicht böse Gedanken u. Unmut quälen, ist diese Einsamkeit die beste Erholung. Für gar manche $u$. in gar vielen Verhältnissen bedeutet das gesellschaftliche Leben nichts als eine Betäubung. Dass mir 
in Bern eine rechte Freundschaft versagt war - wesentlich wegen des Neides - ist ja schlimm. Aber ich habe ja immer noch die schönen Erinnerungen.

Heute erhielt ich von dem Säufer, Hans aus Lenzburg, dessen Dissertation mir letztes Jahr soviel Mühe u. Ärger bereitete, einen flehentlichen Brief erhalten, worin er mich ersucht, eine Bewerbung um eine Kanzlistenstelle bei der Bundesanwaltschaft zu unterstützen. Er habe mich als Referenz angegeben. Ich antwortete ihm, dass ich ihm als Referenz dienen wolle, aber seine Concurrenten nicht kenne. Kaum war diese Antwort abgegeben, so fragte mich Kronauer telephonisch an, ob ich einen Otto Häberli für eben jene Stelle empfehlen könnte. Das ist jener Unglückliche, der sich durch den Abschluss einer guten Dissertation von seiner Schwermut zum Teil befreit hat. Und ich teilte Kronauer das mit u. fügte bei, dass gerade ein solcher Posten für den bedauernswerten tüchtigen Mann, der Besseres verdient hätte, unter obwaltenden Umständen das allerbeste sein könnte. Es scheint mir, dass Kronauer ihn vorzuschlagen beabsichtigt.

Marieli hat sich heute so geäussert, als ob Frl. Reineck es dringend wünschte, dass Georg Lauch bei mir Secretär würde. Aber ich kann mich nicht entschliessen. Ich würde neben seinem unbändigen Temperament, fürchte ich, meine Freiheit viel zu sehr verlieren $u$. einer fortgesetzten Kritik mich ausgesetzt fühlen. Das geht nicht. Übrigens wird in diesen Tagen die Wahl stattfinden u. dann mag es sich ja glücklich wenden, dass er als Obergerichtsschreiber seine Hörnchen etwas abstösst. Besser als in meinem Arbeitskabinett. Natürlich war es eine Dummheit, dass er die Mitarbeiterschaft auf dem Büreau

Brand nicht sofort mit beiden Händen ergriffen hat. Da haben wir eben eine Äusserung seines Charakters. Daneben ist er sehr tüchtig u. wird, wenn er durchdringt, hervorragendes leisten. Seine kräftigen Sympathien u. Antipathien werden ihm noch manchen Streich spielen. Aber sie sind ja ein treffliches Zeichen 
für die Willensstärke. Hoffentlich vollzieht sich jetzt seine Promotion noch glatt u. macht nicht etwa Lotmar, den er nicht liebt, ihm Schwierigkeiten. Wir werden das erleben.

Was soll ich noch anfügen? Heute vor 138 Wochen bist Du zum letzten Mal an meinem Schreibtisch gestanden, mit den lieben Worten, heute sei's nur ein kurzes Bsüchli, das nächste Mal werdest Du länger bleiben. Ach Gott, Du konntest das Wort nicht einlösen, u. ich habe nichts getan, Dich mir zu retten. Ich war wie blind, wie in allen schwersten Momenten meines Lebens, bald zum Glück, bald zum Unglück, u. dieses Mal war es zum schwersten Geschick, das mich treffen konnte!

Gute, gute Nacht, ich beginne die Woche mit weniger Zuversicht, als ich es gestern noch gehofft hatte. Bleibe bei mir!

Dein allzeit getreuer

Eugen

\section{2: November Nr. 235}

B. d. 25./ 6. Nov. 1912.

Mein liebstes Herz!

Den Unmut, den mir das «Handbuch der Politik» gestern Abend wegen seines Inhaltes (Fleischmanns Artikel u. a.) u. wegen des schlechten Einbandes von Hemmeler bereitet, habe ich rasch überwunden. Ich schlief zwar schlecht - aus andern Gründen -, aber am Morgen war ich frisch $\mathrm{u}$. habe auch bereits Hemmeler den Band zurückgegeben, der ihn richtig zu machen versprach.

Ich kam heute wieder nur zu einiger weniger Arbeit am Stenogramm der RG. Aber das Kolleg hat mir Freude gemacht. Auch dass Lauch, wie ich der Zeitung entnehme, zum Handelsgerichtschreiber gewählt worden ist, freut mich sehr, nebenbei entbindet es mich auch der Notwendigkeit, mir 
nochmals zu überlegen, ob ich ihn auf die Bitte seiner Braut, Frl. Reineck, doch als Secretär anstellen sollte. Er hat mir ein Dankesbillet geschickt, auch dies bei aller Herzlichkeit in einem Ton gehalten, der mir deutlich zeigt, dass ich an ihm einen schwierigen Gehülfen, jedenfalls keinen «ergebenen» erhalten hätte, bei aller Sympathie, die er mir offenbar aufrichtig entgegenbringt.

Heute gelangte auch Prof. Kocher an mich, mit der früher in Aussicht gestellten Bitte, ihm seine Schenkung juristisch glatt zu streichen. Ich habe ihm sofort zwei Seiten Berner Kunzen geschickt, u. nächsten Mittwoch will er nachmittags zu mir

kommen, um das weitere zu besprechen. Es freut mich, ihm behülflich sein zu können.

Von Tuor erhielt ich eine Anfrage, die ich diesen Abend gleich noch beantworten konnte.

So, das wäre wieder ein Tag. Das Wetter ist schön, frisch, bald auch staubig, aber voll Sonnenschein, soweit das nur an einem Novembertag der Fall sein kann.

Heute vernahm ich auf der Hochschule eine eigentümliche Geschichte. Letzten Donnerstag fiel ein Schuss vom HodlerHügel u. die Kugel flog neben Gmür, der auf dem Katheder in Nr. 45 stand, vorbei an die Decke, prallte ab u. flog in die Wand ein. Gmür machte merkwürdigerweise nichts daraus, wohl aber erweckte sie Unruhe, als sie andere Professoren, Wegemann, Herberts, Dürr bekannt wurde, die Drohbriefe erhalten haben sollen. Mir sprach Marti von der Sache. Dachte wohl Gmür an den Hass, der ihn immer noch in gewissen Kreisen verfolgt? Wer weiss es! Jedenfalls hat sich die Polizei nachträglich der Sache angenommen, für deren Untersuchung es aber jetzt wohl zu spät ist.

Natürlich habe ich mich bei dem Anlass an die Kugel des alten Vogel erinnert, die glatt auf mein Pult fiel. Wie hat Dich das s. Z. erschreckt! Aber da war die Sache ja anders. Da lag ganz sicher nichts anderes vor, als eine bodenlose Nachlässigkeit. 
Jetzt muss ich mich noch auf morgen präparieren. Vielleicht überlege ich auch die immer noch nicht gelöste Schachaufgabe ein wenig, u. dann zu Bett. Froh war ich, heute auch über die Dissertation Josts mein annehmendes Gutachten aus-

arbeiten zu können. Er ist doch ein guter Charakter, das hat er mit seiner Einsicht in die alten Fehler u. die Energie der Umarbeitung bewiesen. Bei Hans Hauser war ja das ganz anders!

Den 26. Nov.

Ich bin heute Abend merkwürdig müde. Das Abendkolleg ging, als hätte ich Harz im Kopf. Und auch sonst muss ich mich der Depression erwehren, obgleich keinen Grund für eine solche anzugeben wüsste. Die Schachaufgabe habe ich durch einen glücklichen Zufall nach dem Essen auf dem Divan gelöst, u. ich bin heute in den Stenogrammen der RG. etwas weiter gekommen. Aber vielleicht drückt mich gerade das wieder, dass ich dabei sehe, wie nichts recht fertig ist. Ich muss wirklich mich damit bescheiden, Kolleg zu lesen, $u$. das ist mir eine bittere Entsagung. Mit der Gesundheit bin ich auch wieder weniger zufrieden. Kurz, alles läuft auf den alternden Mann hinaus, der sich von dem Verlust seiner Lebensgefährtin nicht mehr erholen kann. Und doch soll ich, nach Hiltys Ausspruch, ja die achtzig Jahre erreichen! Wie kann das nur werden?

Liebe Briefe erhalte ich seit langem keine mehr, von keiner Seite. Marieli hat heute von Frau Dr. Jauch einen sehr netten Brief erhalten. Aber ich merke es ihm schon an, es denkt nicht mehr an eine Verbindung mit Siegwart, u. ich eigentlich auch nicht. Schade nur, dass es so weit gegangen u. sich an dieses Altdorf fast weggeschmissen hat. Ich selbst musste ja dazu überredet werden, gab es schliesslich zu, ohne innere Überzeugung, u. das wird sich nun wohl rächen.

Auch die Geschichte mit Paul, steht mir seit einigen Tagen wieder zu vorderst. Ja, man hat in der Welt viel Angst $u$. Plage. 
Heute begegnete ich Prof. Dumont, u. fragte ihn, wie die SalemKommission letzte Woche wegen der Strasse entschieden habe? Da stellte es sich heraus, dass er zu Marieli nur hatte freundlich reden wollen, um zu zeigen, dass er mein Interesse freundschaftlich wahrnehmen werde. Beguin u. Arm sind richtig informiert, es wird von dem Bau der uns interessierenden Strasse zur Zeit gar nicht gesprochen. Nun, es hat doch gut getan, dass ich mit den Nachbarn in der Sache verhandelt habe!

Jetzt noch Kolleg präparieren, Zeitung u. dann zu Bett. Warum bin ich denn heute Abend schon körperlich so müde? Es ist mir in diesem Zustand oft, wie wenn rein äusserlich alles über mir zusammenbrechen wollte. Ich schaue auf zur Decke, ob sie nicht niederfalle. Das ist Müdigkeit.

Gute, gute Nacht, u. hab mich lieb, gute Seele, wie ich verbleibe immerdar

Dein getreuer

Eugen

1912: November Nr. 236

[1]

B. d. 27./ 8. Nov. 1912.

Meine liebste Lina!

Nach sonnigem kalten Morgen am Nachmittag

Sturm u. Regen. Ich war mit dem Kolleg nicht unzufrieden, habe ich etwas RG durchlesen u. Gesetzgebg. Dann aber war heute Kocher bei mir, um über die Stiftung zu beraten. Wir waren bald einig, er schien mir sehr befriedigt $u$. war herzlich. Es ist ein merkwürdiger Mann, ich glaube eng, aber ein hoher Geist u. sehr stark in der Persönlichkeit. Nachher war Gmür da. Er hat einen heillosen Aufwand mit den 
Farbenstudenten $\mathrm{u}$. wollte mir sein Leid klagen.

Sie haben ihm erklärt, sie kommen, wenn er nicht nachgebe, nicht an den Dies. Das ist wieder so eine Berner Büblitat. Aber seis drum. Er tat mir leid, als er sagte, dass das ganze Rektorat ihm damit verärgert worden sei. An die Kommerse der Farbenstudenten geht er natürlich nun auch nicht. So hat sich sein Triumph nun schnell gewendet. Hoffen wir, es kommt doch noch besser. Es ist nur so merkwürdig, dass Gmür überall seine Anstände hat. Es müssen ihn doch viele zu Hass angenommen haben. Mit mir stand er seit Jahresfrist wieder besser.

Und nun den übrigen Nachmittag habe ich zu einem Geschäft benutzt, das ich lange vor hatte: Ich habe unsere letzt-

willige Verfügung nun aufgesetzt $u$. eingerichtet. Ich schrieb ein eigenhändiges Testament, zweimal, eines kommt zu von Dach, das andere behalte ich. Ich habe unsere Verfügungen nur in zwei Punkten, den gegenwärtigen Verhältnissen entsprechend, modifiziert: Unser Haus soll nicht Wohnung eines Bundesrates, sondern Seminargebäude werden, u. August u. seine Söhne sollen nichts erhalten. Es ist wirklich nicht nötig u. er hat sich ja s. Z. damit einverstanden erklärt. Nun, wer weiss, wer länger lebt. Die acht Jahre Differenz werden ja mit jedem Jahr kleiner.

Und nun will ich noch die Zeitungen lesen $u$. die Kollegien präparieren. Bei dem Sturm der draussen geht eine heimelige Arbeit!

Gute, gute Nacht, morgen ein weiteres!

Den 28. Nov.

Der heutige Tag war nass u. trübe. Ich habe aber meine Stimmung aufrecht erhalten. Im Morgenkolleg passierte mir die Verwechslung, dass ich das acht Uhr Kolleg mit den Einleitungsworten zum neun Uhr Kolleg begann. Ich merkte aber an den erstaunten Gesichtern sofort meinen Irrtum $u$. sattelte rasch 
um zur Heiterkeit der Hörer. Schuld daran war Schulthess, der mich bis zur Türe begleitete $u$. solche spassige Geschichten wusste, dass ich ganz abgelenkt war.

Ich habe heute den ganzen Tag immer wieder an Rektor Gmürs Krach mit dem Farben convent gedacht. Er hat ganz

gewiss nicht den rechten Ton gefunden, soll er doch auch sonst die Studenten als Rektor schroff behandeln, wie das beispielweise Jean Rossel erzählte nach eigenem Erlebnis. Wenn ich denke, ich wäre nun Rektor gewesen u. mir wäre so was begegnet, ich glaube, ich hätte meine Entlassung genommen. Aber gerade solche Befürchtungen haben mich ja mitbestimmt, schon vor Jahren, das Rektorat von Bern abzulehnen. Für Gmür ist die Freude am Rektorat jedenfalls jetzt auf lange hinaus vermindert. Er kann nun nicht an die Kommerse, ist in seiner Stellung zu den Studenten gehemmt, kurz es ist eine fatale Sache, die um der Universität willen sehr zu bedauern ist. Allein auf Gmür fällt wohl sicher die Hälfte der Schuld, wenn nicht mehr.

Heute konnte ich etwas an der RG. arbeiten. Sonst war es Donnerstag. Ich bin müde u. habe mich etwas in Beschaulichkeit gehen lassen. Um sechs Uhr war Fürsprech Moser bei mir, zum Glück betraf es aber die Sache Schweizerhof v. Ernst, in der mich vor einigen Wochen der junge Tenger schon beraten hatte. So konnte ich längere Verhandlungen vermeiden $u$. die Sache zurückweisen. Dann kam Walter B. zu mir, um das Büchlein von Sieber über die Expropriation zu holen. Er blieb einige Zeit. Es geht ihm wieder besser, aber er schlafe nicht gut, klagte er. Ich vernahm durch ihn, dass Guhl heute auf der Strasse gefallen $u$. sich eine Hüfte gequetscht habe. Hoffentlich ists nichts ernsthafteres! Bei allen solchen Erlebnissen muss ich immer wieder sagen, wie soll man zufrieden sein, wenn sich alles ruhig abwickelt. Ich will mir dies jeden Tag, jede Stunde sagen $u$. ruhig meinem Amte leben. Es ist ja schon ein gutes Stück Arbeit, wenn man, so wie ich jetzt im Falle bin, Tag für Tag seine Collegien halten kann. Wenn ich auch heute wieder einen Augenblick, als ich ungern das Bett verliess, daran dachte, mein Pensum zu reduzieren, 
eine ruhige Überlegung lässt mich immer wieder hieran zurückkommen. Ich muss ausharren, es geht nicht anders. Also!

Ich bin heute weniger müde, als sonst am Donnerstag. Vielleicht kommts morgen. Dann aber kann ich ja wieder Pause machen $u$. in drei Wochen ist Weihnachtsferien.

Gute, gute Nacht! Bleibe bei mir!

Dein allzeit treuer

Eugen

Heute waren Susanne u. André Rossel zum Mittagessen bei uns. Sie waren recht liebe Gäste.

\section{2: November Nr. 237}

[1]

B. d. 29. / 30. Nov. 1912.

Mein liebstes Herz!

Heute kalt u. ein leichter Schnee, schönes Winterwetter. Das Praktikum war aber gleichwohl gut besucht, u. wie ich glaube interessant. Nach einer unruhigen Nacht, bei der ich zweimal aufgestanden bin, habe ich am Vormittag das Gutachten für das Departement betr. die AG Eintragungen in Genf im Entwurf fast fertig gebracht (vielleicht kann ich es jetzt dann noch vor Schlafengehen, wenn ich nicht zu müde bin, fertig kriegen. Sonst musste ich einigen Studenten Rede stehen $u$. hatte den Besuch des Deutsch-Engländers Schröder, der vor zwölf Jahren hier Kollegien besuchte. Er war seither in Zürich, in England, dann in Aegypten u. war der alte freundliche Plauderer, nur dass ich mit ihm nichts anzufangen weiss. Er sucht hier eine Stelle oder Stellung, ob er sie findet? Ich kann ihm nicht helfen. Sonst plagte mich heute etwas Kopfweh u. ich fühlte mich recht matt. Die Übungen haben mich dann etwas aufgerüttelt, aber ich war doch so müde, dass ich das Nachtessen in der Hauptsache verschmähte. Früher machte ich Dir dann u. wann einen Vorwurf daraus, 
dass Du mir besondere Plättchen für den Abend rüstetest, wie Du etwa meine Liebhabereien kanntest, denn es tat mir weh, dass Du etwas anderes essen solltest als ich. Jetzt komme ich schwerlich noch in den Fall, solchen Vorwurf zu erheben. Weder Anna noch Marie noch Sophie denken so wie Du gedacht hast. Aber das ist ja nur eine Kleinigkeit. Als ich heute mit innerer Befriedigung aus dem Kolleg nach Hause ging, war es mir, ich sei in der alten Zeit im

Gemüt. Wie ich dann aber den Garten betrat, da war alles anders. Es gab mir einen Stich ins Herz.

Heute Morgen ist Prof. Niehans gestorben, sanft entschlafen, wie mir Frau Niehans telephonieren liess. Er ist 64 Jahr alt geworden. Ich werde heute noch eine Condolenzkarte schreiben u. morgen einen Kranz schicken.

Dann kam eine Verlobungsanzeige: Der Ingenieur Hans Schatzmann hat sich mit der Tochter meines Studienfreundes Natrat Fehr in Frauenfeld verlobt. Wir haben sie bei einem Besuch in dort $u$. bei einem Besuch, den sie mit ihrem Vater in hier bei uns machte, u. ihn auf Griesalp kennen gelernt. Die Sache freut mich.

Walter B. sagte mir, dass er mit dem Helveter Waldkirch wegen der Demonstration gegen Gmür gesprochen habe. Es sei jetzt aber wohl nichts mehr zu machen. Gmür hat heute das Kolleg ausgesetzt, wie Reichesberg sagte, mit der Motivierung, dass er sich noch auf morgen präparieren müsse. Oder hat ihn der Ärger krank gemacht? Ich mag nicht fragen.

Sonst ist der Tag schlecht $\mathrm{u}$. recht abgelaufen. Man schickt sich ja in alles. Liebe Briefe sind keine gekommen. Mit Marieli ist es die alte Geschichte, wieder mehr als die letzte Zeit. Heute meinte sie, sie könne nicht recht telephonieren, wenn ich hinter ihr stehe. Und ich stand oben im Gang, damit ich, wenn etwas für mich sei, ihr gleich Bescheid geben könne. Ich werde das künftig bleiben lassen. Ich konnte ja die ganze Woche wieder meine Kollegien mit Erfolg abhalten. Was will ich mehr in meiner Einsamkeit? 
Den 30. Nov.

Heute Vormittag war also die Hochschulfeier. Die Farbenstudenten sind richtig nicht erschienen, ganze Stuhlreihen waren leer. Der Studentengesangverein hat nicht gesungen, was ich an sich nicht vermisse, denn die Wahl der Lieder hat doch in der Regel gar zu wenig zu dem Anlass gepasst. Aber es war die Feier natürlich um so nüchterner. Die Rede des Rektors war im letzten Drittel interessant. Schade, dass er diesen Teil nicht zum einzigen Gegenstand seiner Ausführungen gemacht. Er bezeichnete als Zielpunkte der Entwicklung des Privat- u. Handelsrechts drei Momente: die Sozialisierung in besonderer Bedeutung, die Ausbildung der Wirtschaft zum Machtelement, ähnlich den grundherrlichen Höfen des Mittelalters, mit den «Grafen» als Grosskapitalisten u. den «Ministerialen» als Bank u. Fabrikdirektoren, u. die internationale Unifikation. Das Zivilrecht kam gut weg. Gmür schien übrigens sehr verärgert, hat sich aber zusammen genommen. Am Nachmittag war Dr. Baumberger, der Eisenbahnbeamte wegen des Druckes seiner Dissertation bei mir, u. nachher habe ich das Gutachten für das Departement mit der Maschine abgeschrieben, 9 Seiten, was mich bis Abends in Anspruch nahm. Ich dachte dabei an Deine Hülfe. War ich Dir dafür immer genug dankbar? Jetzt vermisse ich sie an solchen Tagen doppelt schmerzlich. Ersatz habe ich nicht, will ich auch eigentlich nicht. Ich muss mich darein finden, Dir im Geiste den Dank nachzuholen, ach, so lieb, $u$. jetzt für mich so schwer. Zur Beerdigung von Prof. Niehans ist Anna gegangen. 
Mich hat Frau Niehans von sich aus entschuldigt, am

Telephon, weil ich ja durch den Dies in Anspruch genommen sei, u. mir war dieser Wink auch recht.

Nun muss ich zum akademischen Essen. Nachher vielleicht noch ein paar Worte. Es ist höchste Zeit!

Ich komme soeben 12 3/4 Uhr aus dem «Bären» nach Hause, in die einsamen Räume. Ich sass zwischen W. Burckhardt $u$. Thormann, an einer Ecke der Tafel, Folletête ziemlich vis à vis. In Entfernung als Gäste Reichel u. Rossel, mit denen ich wenig sprechen konnte. Ich war nicht schlecht gestimmt, u. der Abend hat sich auch bei gutem Besuch recht hübsch gestaltet. Gmür sprach gut. Auch Lotmar hat eine gute spitze Rede gehalten, während sein Sohn Privatdozent nachher ab- oder vielmehr mit einer sonderbaren Rede auffiel. Franke, der Ehrendoktor geworden, sprach von seiner Überraschung u., was mich freute für ihn, von seiner Frau. Schulthess machte Spässe (vom Thurgauer Gesangverein. Geiser war zutunlich. Thormann der Oberrichter zeigte sich sehr erfreut von dem Ehrendoktor, den wir ihm verliehen. Und so wäre noch manches zu sagen. Freilich, ich bekam dann bald ein drückendes Gefühl, als gehöre ich eigentlich nicht in den Kreis. Ich hatte Dich vor Augen $u$. brachte den Gedanken nicht mehr los, der mir neben allem Getümmel zur Seite ging. Bei der Rückkehr verstärkte sich dieses Empfinden. Nun ja, dies ist jetzt mein Teil.

Gute, gute Nacht, halte fest zu mir, ich will allzeit bei Dir sein!

Dein getreuer

Eugen 


\section{Dezember 1912}

\section{2: Dezember Nr. 238}

B. d. 1. Dezember 1912.

Mein liebstes Herz!

Nach unruhiger Nacht, wobei mich wieder einmal ein Gepolter von oben aus dem endlich gefundenen Morgenschlaf um fünf Uhr aufweckte - der Wecker der bösen Sophie war auf den Boden gefallen $u$. rasselte getreulich die Feder ab-, stand ich wie gewohnt auf, las die Zeitungen $u$. erhielt den versprochenen Besuch von Rossel. Was ich von ihm erfuhr ist nicht viel anderes, als dass es ihm fortgesetzt gut gefällt in Lausanne, sowohl mit der Arbeit als mit den Kollegen. Viel zu tun habe er nicht, er sieht auch sehr ausgeruht aus. Seine Hauspläne haben sich zu der Bestimmtheit verdichtet, dass er sich bereits von einem Architekten eine Skizze ausarbeiten liess, die er mir im Grundriss vorzeichnete. Es verspricht ein nettes Ding zu werden. Der Bauplatz an der Avenue Beaumont misst 1260 Q. M., für die er 10 F. p. M. gezahlt. Das Haus mit Berner Giebel würde in der Front 14 1/2 u. in der Tiefe 8 1/2 m messen. Zwischen Esszimmer ( $61 / 2 \mathrm{~m})$ u. Salon, die die ganze Parterre-Front einnehmen, ist ein Hall gedacht, ganz hübsch. Der Garten ist ein kleiner Hügel, zu dessen Seiten eine Tanne u. ein Kastanienbaum hochgewachsen bei dem Bau erhalten bleiben können. Rossel hat nun mit Reichel, Kirchhofer u. Schurter einen SkatAbend eingerichtet im Restaurant Kugel. Also auch da schon wieder ganz eingeheimelt. - Wie ich dann zur Wahlurne ging, begegnete mir Georges, von dessen Anwesenheit 
mir der Vater Rossel nichts gesagt hatte, am Sonnenberg. Er sieht gut aus. Er war mir von der Kornhausbrücke entgegengeeilt, als er mich heraufkommen sah u. war sehr herzlich.

Abgestimmt wurde über das Steuergesetz, ich weiss aber nicht wie es gegangen. Die Agitation von hüben u. drüben war ziemlich verlogen. Mir scheint, das alte Gesetz würde noch ganz genügen, wenn nur die Bauern u. Gewerbsleute besser versteuerten. Ich bin auf das Ergebnis gespannt.

Als ich von der Urne heimwärts ging, begegnete mir Walter B. auf demselben Gang. Wir kamen auf Gmür zu sprechen, u. dabei äusserte sich Walter, dass er jetzt den Eindruck gewonnen habe, Gmür sei nicht aus Ungeschicklichkeit so, wie er sei, sondern in ihm stecke eine gewalttätige, rücksichtslose Natur. Er beurteile ihn jetzt anders. Sonst war Walter wieder ziemlich niedergedrückt, hatte auch wenig geschlafen, wie ich. Aber er ist jünger $u$. verträgt das alles noch besser.

Anna hatte heute wiedereinmal Migräne. Ich war beim Abendessen mit Marieli allein, u. da erzählte es, dass letzten Freitag vor acht Tagen Abbühl zur Universität gekommen sei, um drei, u. dann um vier wieder da gestanden. Susanne habe dann aber Marie nach Hause begleitet, u. als es Abbühl bemerkt, auffällig gelacht $u$. Marie gestossen $u$. aufihn gezeigt. Abbühl sei mit rotem Kopf davon geeilt. Er werde nun sehr darüber erzürnt sein. Der Umgang mit Susanne bringe Marieli überhaupt bei Vielem in eine ganz falsche Beurteilung. Und ich muss sagen, dass es mir in diesem Falle

recht ist, wenn es so gegangen. Denn dieses Zusammenkommen mit Abbühl ist mir in der Seele zuwider.

Ich habe heute Nachmittag den Plan mit der zweiten Auflage der Erläuterungen näher überlegt. Wenn ich die durch die Verweisungen auf das ZGB auf etwa 5 Bogen zu berechnenden, notwendig werdenden Anmerkungen in Anschlag bringe, so würde durch die Hinzufügung von 3 Zeilen pro Seite die Zahl der Bogen die gleiche bleiben. Das Ganze würde etwas höher u. in 
Folge der Anfügung des Entwurfes um etwa 10 Bogen stärker. Ich glaube aber, das würde schon gehen $u$. bin jetzt ziemlich entschlossen, mit Büchler darüber Rücksprache zu nehmen u. dann dem Departement einen solchen Vorschlag zu unterbreiten. Der Gedanke an diese Arbeit tut mir wohl. Ich sagte schon früher einmal, es ist etwas darin, was die peinliche Verurteilung meines Planes betr. meiner Rechtseinheitsschriften ein klein wenig corrigiert.

Sonst habe ich heute nichts gearbeitet, etwas Militaria (York von Wartenburg) gelesen u. gestaunt. Nicht dass ich mich müde gefühlt hätte. Aber es war doch das Gefühl der Schlafenskürzung, was ich in den Gliedern fühlte. Ich muss einen 7 Stunden Schlaf haben. Komme ich spät zu Bett, so kann ich es am Morgen bekanntlich nicht nachholen, sondern erst in der folgenden Nacht. So muss ich jetzt heute schon auf neun im Bett sein, damit ich zu 9 Stunden komme. Ziehe ich dann zwei ab, um sie den gestrigen blossen fünf anzufügen, so komme ich auf meine Rechnung. Freilich

so mechanisch geht es in Wirklichkeit doch nicht. Aber im Grossen u. Ganzen bewährt sich mir diese Maxime.

So will ich jetzt schliessen. In drei Wochen sind schon die Weihnachtsferien begonnen. Die Zeit wird rasch genug verfliessen.

Gute, gute Nacht! Vor 139 Wochen wars Dein letzter Gruss! Ich litt heute unter dem Gedanken weniger als gestern. Aber wenn es wie gestern andauerte, würde es kaum zu ertragen sein.

Nochmals, meine liebe Seele, gute Nacht!

Dein allzeit getreuer

Eugen 
[1]

B. d. 2. Dezember 1912.

Meine liebe, gute Lina!

Ich schreibe Dir heute vor dem Nachtessen, weil ich auf halbacht in den ersten Diskussionsabend des Bern. Juristenvereins gehen muss u. nach der Rückkehr aus demselben wohl gerne gleich zu Bett gehe, um für das Morgenkolleg wieder frisch zu sein. $\mathrm{Zu}$ berichten ist eigentlich nichts. Die Vorlesungen sind normal abgewickelt worden. Briefe sind keine angekommen, es ist merkwürdig, wie wenig liebe Nachrichten, oder Nachrichten von Lieben ich seit einiger Zeit erhalte, es ist gleich als ob ich in Vergessenheit geraten wäre. Den Vor- $u$. Nachmittag habe ich etwas an den Stenogrammen der RG gearbeitet $u$. in der Gesetzgebung gelesen, dort wenig befriedigt, hier besser.

Es hat geschneit den Nachmittag. Wäre ich noch in der Bundesvers., so müsste ich heute wieder antreten, u. die kleinen Kämpfe mit den vielen Personen, denen ich so wenig Vertrauen entgegenbringen kann, mitzumachen. Solange ich etwas dabei zu tun hatte, war's ja etwas ganz anderes. Auch wäre es schon möglich gewesen, dass ich wieder mehr Vertrauen gewonnen hätte, wenn Leute wie Welti, Ruhonnet an die Spitze getreten wären. Aber Forrer ist eben immer noch da, u. leider haben sie Hoffmann im Militärdepartement für das Allgemeine gleichsam kalt gestellt. Möglicherweise taucht er daraus wieder hervor, wenn - eigentlich gegen meine Auffassung ein Departement des Äussern geschaffen u. ihm übertragen wird. Sonst kommt in der Bundesversammlung 
in dieser Session gar nichts vor, was mich speziell beschäftigt hätte, u. es ist auch auf lange hinaus für künftig nichts solches vorauszusehen. Wie gerne will ich da meine Zeit auf die Kollegien concentrieren u. dafür sorgen, dass diese wohl geraten, anstatt mich als Politiker zu zersplittern. Auch gesundheitlich würde es mir gewiss nicht so wohl bekommen, in diesem Getriebe zu stecken, anstatt mich meinem Fache zu widmen. Ich kenne ja den Rummel nun, nach Jahren des Mitmachens, genügend, um es mir vorstellen zu können.

Heute früh las ich in der Zeitung gerne zwei Nachrichten: Das Steuergesetz ist mit 46 gegen 21 Tausend verworfen $u$. der Anarchist, Frick, für den die Dr. Faass falsches Zeugnis abgelegt hat, ist zu einem Jahr Gefängnis verurteilt worden. Das Bundesstrafgericht hatte den Mut, dieses Urteil zu fällen, nachdem vor wenigen Monaten das Schwurgericht in Pfäffikon in der Beurteilung desselben Tatbestandes nach anderer Seite noch der Frau Faas Glauben geschenkt u. Frick freigesprochen hatte. Beim Steuergesetz lag die Sache für mich so, dass ich eben trotz aller Fehler des geltenden Steuerrechtes eben zu dem Elaborat von Kunz, Scheurer u. Blumenstein kein rechtes Vertrauen gewinnen konnte. Kunz ist ein kapitalistischer Streber böserer Nummer, Scheurer macht sich als wenig umsichtiger Parteimann immer verdächtiger, obgleich ich ihm eine gute Absicht wohl zutraue. Blumenstein kennen wir als formalistischen $u$. sehr egoistischen Kleinarbeiter, der nur von denen geschützt werden kann, die in der Jurisprudenz nichts als dialektischen Formenkram

erblicken. Das hat man auch dem verworfenen Steuergesetz, das er entworfen haben soll, angemerkt. Es wimmelte von Widersprüchen, die der opportunistischen Ausgestaltung nach den Wünschen der einen $u$. der andern Interessenten aufgenommen worden waren. Darum kam kein Zug hinein, trotz mancher guten Bestimmung. Es ist merkwürdig, wie Scheurer diesem Juristen so sein volles Vertrauen schenken konnte. Aber wir leben eben in einem kleinen Staat. 
Heute Abend wird Walter B. in der erwähnten Versammlung einen Vortrag halten. Ich bin gespannt darauf, u. es wundert mich auch, ob der Besuch gut sein wird. Morgen darüber einige Worte.

Gmür war heute im Sprechzimmer. Die Anerkennung seitens der nicht Farbenstudenten u. der Kollegen in seinem Stock mit dem Farbenkonvent macht, dass er sich nun wieder wohler fühlt. Er war heute ganz munter. Jedenfalls haben die Corporationen einen grossen Fehler begangen, als sie ihm trotz seiner schroffen Art nicht höflich behandelten $u$. ihm einen groben Brief schrieben. Das kann jetzt das Semester über u. bis zum Ende des Rektorates noch nette Zwischenfälle geben.

Guhl will vor sieben Uhr in dringender Sache noch zu mir kommen, er telephonierte mir, dass er gestern zu Bett gelegen $u$. dass es ihm heute viel besser gehe. Gelegentlich muss ich mit ihm doch über seinen Artikel in des Zürcher Reichels Zeitschrift «Wirtschaft u. Recht» interpellieren. Er hat ja dort eine kleine Bosheit niedergelegt, u. namentlich Hoffmann BR zu caplieren versucht, drum auch den Artikel mir quasi verheimlicht. Aber ich will es ganz gelegentlich anbringen, nur damit er weiss, ich bin orientiert. Er ist ja jetzt ein ganz guter Mitarbeiter. Ich freue mich seiner. Wenn er seinen Eifer behält, so wird er gewiss noch grosse Erfolge davon

tragen. Wie froh muss ich sein, ihn mir zur Seite zu haben. Da darf man schon einiges am Charakter übersehen, das sich auch, wie ich bestimmt hoffe, ausgleichen wird. Im Grunde hat er das Herz auf dem rechten Fleck.

So, jetzt ist es Zeit, ich schliesse! Bleib immer bei mir u. lass Dich meine Klagen nicht verdriessen. Ich kann ja damit zu niemand anderem kommen als zu Dir!

Dein allzeit getreuer

Eugen 
B. d. 3. / 4. Dez. 1912.

Mein liebstes Herz!

Gestern Abend, als Guhl bei mir war, kam unangemeldet Albert Heim. Er traf es nicht gut, denn obgleich ich Guhl sofort verabschiedete, konnte ich wegen des Vortrags von Walter B. nur kurze Zeit mit Albert zusammen sein. Er ass mit uns zu Nacht $u$. blieb bis acht Uhr, um dann zur Bahn zu gehen, indess ich um 7 1/2 Uhr in Pfistern sein musste. Was er mir mitteilte, war inhaltlich sehr beruhigend. Marie leide zwar an Tuberkeln, aber Huguenin habe eine sichere Heilung versprochen, wenn sie ein halbes Jahr im Sanatorium zu Piotta bleibe, u. es gehe auch schon viel besser. Helena sei jetzt zu Hause, leide zwar wieder sehr an Migräne, sei aber sonst sehr munter u. gesund. Die kleine Haudhausen würde gerne in Zürich verbleiben, aber der Vater zwinge sie nach Hause zu kommen. Endlich Arnold sei sehr munter, bleibe nun doch bei der Geologie, um in Petrolwerken etc. seine Carriere zu machen. Es sei merkwürdig, dass er nun so sehr auf das Reichwerden erpicht sei, aber die Hauptsache sei doch, dass er der Geologie nicht untreu werde. Bei solchen $u$. andern Mitteilungen war Albert aber bald merkwürdig aufgeregt, zeigte wechselnde Gesichtszüge, bemerkte, er fürchte sich so vor der Ansteckung der Tuberkulose. Kurz ich fand, er sei nicht ganz der Alte, er leide an einer körperlichen Depression, u. ich würde mich nicht verwundern, wenn er krank würde. Doch ich sah ihn ja zu wenig, um ein Urteil haben zu können. Bei längerem Zusammensein, bei weitern Gesprächen wäre mir das alles anders vorgekommen. Nach meinem, nach unserm Empfinden erkundigte er sich gar nicht, was ja auch immer bei ihm ein Zeichen hochgradiger Selbstbetrachtung ist, die freilich zeitweise immer bei Heims die Regel gebildet hat.

Der Vortrag von Walter B. von gestern war sehr nett. 
In freiem Vortrag mit wenig Notizen vor sich sprach er stehend über eine Stunde u. brachte einige hübsche Entwicklungen. Ich war sehr erfreut über seine klare sachliche Art.

Als ich am Morgen ins Colleg ging, traf ich Zürcher beim Sanatorium mit Frl. Meister. Wir begrüssten uns, er wird nächstens, wie er sagte, zu mir kommen.

Heute habe ich wieder etwas mehr an der RG. arbeiten können. Es war Meitschi-Märit, also kein Nachmittags-Kolleg-Ganz hat auch am Vormittag nicht gelesen - u. so konnte ich dann die Meiergerichtsurteile, die Stutz herausgegeben hat, mir näher ansehen. Die deutsche Juristenzeitung hat mich um deren kurze Besprechung ersucht. Ich versuchte dann Nachmittags etwas entsprechendes aufzusetzen. Es liegt schon vor, u. wenn es mir nach ein paar Tagen noch gefällt, so sende ich es ab. Ich hätte mich ungern Stutz versagt, das Buch ist auch wirklich eine prächtige Sammlung.

Guhl kam heute nochmals, weil wir gestern wegen Alberts Ankunft das Nötige nicht besprechen konnten. Es geht ihm besser. Von dem gestrigen Vortrag muss ich leider noch anfügen, dass der Besuch schlecht war. Alles in allem waren wir 23 Mann. Ich muss auch damit rechnen, den schlechten Besuch zu haben, wenn ich im Januar an die Reihe komme. Dafür hatten unser ein paar von 9 bis $10 \mathrm{Uhr}$ noch ein gemütliches Plauderstündchen.

Regen $u$. Schnee wechselten gestern Abend $u$. heute den ganzen Tag miteinander. Aber sonst ist es nicht ungemütlich zu Hause zu sein. Ich planiere, sinne, arbeite, lese, schreibe was zu erledigen ist, $u$. in vier Wochen haben wir schon Sylvester!

\section{Den 4. Dez.}

Heute hatten wir wieder einen herrlichen Wintertag. Ich verzichtete auf den Tramm u. ging zeitig fort, um vor acht Uhr noch ein wenig auf der grossen Schanz mich ergehen zu können. 
Im Kolleg hatte ich unter dem Einfluss des schönen Morgens anfangs fast Mühe mich zu concentrieren. Aber es ging, u. die zwei Stunden verflogen mir in einem Augenblick, wie eigentlich jeder Tag. Das ist nun doch das eigentlich Erfreuliche, was mir im Leben geblieben ist. Ich mag nicht daran denken, dass ich jetzt in der Bundesversammlung sitzen müsste, wenn ich nicht den Mut gehabt hätte, auszureissen. Stundenlang da sitzen $u$. Reden anhören zu müssen, nein, ich bin froh, den andern Teil gewählt zu haben. Ich verdanke es noch Deinem Widerstreben, dass ich nicht 1908 einen Teil der Professur aufgegeben. Jetzt habe u. halte ich noch das Ganze u. will es auch behalten, solange ich kann u. vermag. Ob ich die Ferien dann jeweils Bücher schreiben oder mich im Ausland oder irgendsonstwo ergehen werde? Das weiss ich nicht. Zeitweise meine ich, es wäre gescheiter zu Hause zu bleiben. Zeitweise reisst es mich fast mit Naturgewalt fort u. ich stelle mir vor, wie schön es wäre, einen Monat lang im Frühjahr beispielsweise auf Anacapri zu sitzen. Das Schöne ist es ja gerade, dass ich frei bin zu tun, was mir gefällt, u. dabei beruhige ich mich. Ich kam heute in den Fall zwei Bekannten gegenüber die Gründe für mein Ausscheiden aus der Bundesversammlung kurz darzulegen. Ich traf am Morgen bei der Post Nationalrat Jenny, der mich fragte, ob ich nicht etwa Sehnsucht habe nach dem Ratssaal, worauf ich das verneinte u. einiges anfügte. Heute Nachmittag kam dann Dr. Langhard wieder wegen seinen Adoptionssachen zu mir u. wir kamen auf dasselbe Thema zu sprechen. Ich glaube, sie merken, dass es mir Ernst ist. In seiner Rede vom letzten Samstag äusserte sich der alte Kummer über Kocher, ohne ihn zu nennen, indem er es rühmte, wie er zu allem Zeit fände $u$. wenn die Arbeit

sich vermehre, einfach später ins Bett gehe u. früher aufstehe. Das sei noch einer von den Rechten. Ich spürte etwas wie ein Vorwurf heraus, weil ich eine andere Taktik befolge $u$. alles Beiwerk abstreife. Aber ich weiss ja wohl, dass gerade solche Leute, wie der alte Kummer (ähnlich gewiss auch B'rat Müller) für mein Naturell einfach kein Verständnis haben. Sich auf eine Aufgabe 
konzentrieren war nie ihre Sache. Die Stellung, das Amt scheint ihnen das einzig mögliche u. sie sehen dabei nicht, wie selbstgefällig sie sich einschätzen, ohne etwas rechtes je leisten zu können. Aber das macht mich alles nicht irre. Ich bleibe bei meiner innern Stimme. Kann sein, dass ich in jüngeren Jahren auch in dieses Fahrwasser hätte geraten können. Gutes u. Böses hat mich davon abgehalten: Mein lahmer Arm, meine Dichterhoffnungen, meine Kränklichkeit, meine Verbindung mit Dir. So bin ich jetzt, was ich bin, u. glaube dafür dankbar sein zu müssen, dass es so u. nicht anders gekommen ist.

Am Nachmittag schrieb ich ein kleines Gutachten für Dr. Meyer in Aarau. Vor Tisch corrigierte ich etwas Rechtsgeschichte. Und jetzt will ich dann vor Schlafengehen noch etwas in York von Wartenburg lesen, den Du mir s. Z. geschenkt u. seine Angaben über 1912 mit einem Aufsatz vergleichen, der in der Deutschen Rundschau steht.

Gute Nacht, liebe Seele! Bleibe bei mir, wie ich immerdar verbleibe

Dein getreuer

Eugen

1912: Dezember Nr. 241

B. d. 5./ 6. Dezember 1912.

Mein liebstes Herz!

Nachdem ich einige Zeit ziemlich Ruhe hatte, werde ich in den letzten Tagen wieder um vielerlei Auskunft ersucht $u$. muss mich zusammennehmen, dass ich nicht unruhig werde. Es ist eine schlimme Sache, ich komme nur nicht dazu, an etwas grösserem zu arbeiten. Habe ich keine Anfragen, so fühle ich mich so abgespannt, dass ich lieber einen Tag ruhe, u. kommen die Petenten, so bin ich im Gedränge. Nun ja, heute ist halt auch wieder Donnerstag Abend, wo die Summe der Wochenarbeit 
für mich bereits vorliegt. Da darf ich etwas müde sein.

Die drei Tage bis Montag werden mich schon wieder auf den Damm bringen.

Gestern Abend spät telephonierte mir noch der junge Teichmann. Sein Vater sei wieder im Spital, er leide an einer allgemeinen Drüsenkrankheit u. sei von Schmerzen geplagt. Ja, das ist ein armer Mann. Und war er in der Jugend ein verwöhntes Kind, so erfährt er im Alter eine schwere schwere Busse. Ich will mich zusammennehmen, dass es mir nicht auch so geht. Jetzt bin ich wieder eher mutlos. Freilich von Verwöhnung kann ich bei meiner Jugend nicht sprechen, wohl aber von einer Verwilderung.

Ich las heute in der N. Z. Z., wonach das Justizdepartement der Notariatskommission im Aargau eine Antwort in Betreff von Zugehör erteilt haben soll, die, wenn sie erfolgt wäre, falsch sein würde. Ich habe Guhl sofort telephoniert. Er will morgen mit Isler sprechen u. mir dann Bericht erstatten.

Heute habe ich wenig anders als die Anfragen beantworten können. In den Vorlesungen war ich etwas erregt, aber knapp, wenn auch die Neigung zum Versprechen, mir deutlich gezeigt hat, dass die Pause mir gut tun wird. Im Hause war es etwas meisterlos. Ja, natürlich, wenn Niemand straff die Zügel führt. Mit Sophie ist nie ein voller Verlass.

Es ist jetzt bald zehn Uhr u. ich will abbrechen, um noch eine Viertelstunde in der Stube zu sein u. dann zur Ruhe. Sie wird mir gut tun. Letzte Nacht träumte ich wieder einmal von Dir, aber etwas ganz Unbedeutendes u. Bedeutungsloses. - Von Rümelin erhielt ich heute die Kanzlerrede, aber immer noch keinen Brief. Doch ich schliesse für heute! 
Den 6. Dezember.

Heute war ein kalter Wintertag, $5^{\circ} \mathrm{mit}$ Wind $\mathrm{u}$. Nebel, an den Bäumen prächtiger Rauhreif. Am Morgen las ich in der Gesetzgebgspol. u. legte mir einiges zurecht. Dann ging ich zu Mülinen auf die Bibliothek, u. nachher kam Guhl, mit dem

wegen seiner etwas saloppen Beantwortung der Anfrage aus Aargau ernster als gewöhnlich sprechen musste. Sie stammt aus Ende Juli, aus der Zeit, wo er den sonderbaren, mir verheimlichten Artikel über die Fahrnisverschreibung für den Zürcher Reichel, u. anderes nicht ganz gutes schrieb. Er muss damals in einer sonderbaren Verfassung mir gegenüber gewesen sein, sonst hätte er in der wichtigen Sache gewiss mit mir vor seiner Antwort gesprochen. Er war heute wieder blitzartig bald bei dieser, bald bei jener Auffassung, so dass mir die Schwäche seines Intellektes besonders deutlich entgegentrat. Die Gewandtheit ist das wesentliche daran.

Als Guhl weg gegangen, hatte ich gerade noch Zeit, Frau Prof. Niehans die schuldige Leidvisite zu machen. Ich fand sie ruhig, ruhiger als s. Z. Frau Prof. Barth. Es ist aber auch ein anderer Fall. Das letzte Jahr muss ihr Mann, nach dem was sie heute mir andeutete, fast verblödet gewesen sein. Gesprochen habe er im letzten Jahr kein Wort mehr, obgleich er sonst sich noch ordentlich bewegen, aufstehen u. umhergehen konnte. Fast zwei Jahre war Frau Niehans mit gar nichts anderm beschäftigt, als mit seiner Pflege, ging nie aus dem Hause, empfing auch so zu sagen niemand. Sie habe, sagte sie mir, das Bild ihres Mannes seinen Freunden u. Collegen aus der früheren Zeit erhalten u. nicht durch Eindrücke aus diesen Tagen stören wollen. Sie meinte, sie u. ich hätten eben mit «Elitenseelen» gelebt, u. da gebe es keinen Trost, nur die Erinnerung u. Dankbarkeit. Sie sagte auch, wie lieb Du ihr gewesen $u$. wie Du ihr auch gesagt habest, dass Du sie so sehr lieb habest, das wusste ich ja. Ich habe nie dieselbe 
intime Fühlung mit den beiden trefflichen Menschen gewinnen können. Die Wege gingen allzu sehr auseinander. Du standest ihr als Frau zu Frau von vorneherein anders. Ich blieb etwa eine halbe Stunde.

Am Nachmittag las ich etwas in der neuesten Kanzlerrede, die ich heute von Rümelin erhalten habe. Er verteidigt mich gegen Rabel, nicht ganz geschickt. Aber ich muss ja dafür dankbar sein. Dann hielt ich mein Praktikum, es war weniger dankbar als das letzte Mal.

Nach dem Nachtessen corrigierte ich noch eine Partie RG. u. jetzt ist es Zeit, den Tag abzuschliessen. Ich fühlte mich gestern müder als heute. Aber ich gehe jetzt gerne zur Ruhe.

Gute, gute Nacht! Dir innigst verbunden verbleibe ich immerdar

\section{Dein getreuer}

Eugen

1912: Dezember Nr. 242

[1]

B. d. 7. / 8. Dez. 1912.

Meine liebste Seele!

Heute war ich recht in persönliche Arbeit vertieft $u$. las in der Gesetzgebungspolitik, corrigierte RG. Ich ging am Vormittag nur geschwind mit Marie zum Uhrenladen Hagenbach u. kaufte für Frau Montani eine Reiseuhr, nicht so kostbar wie die unsere, aber ausreichend für das Geschenk, das ich dort noch wegen Marielis langem Aufenthalt schuldete. Ich musste doch etwa Fr 200. rechnen für die zwei Monate u. alle Anlässe, die M. nie bezahlen durfte. Jetzt ist dann die Schuld getilgt, mit guter Erinnerung. 
Ich dachte wieder sehr über die Gesetzgbg. nach u. bekomme bei der Durchsicht der Blätter den Eindruck, ich dürfe die Publikation wagen. Mit dem Titel schwanke ich immer noch. Heute meinte ich «Theorie der Gesetzgebung» wäre am richtigsten. Aber ich weiss nicht, bleibe ich dabei.

Am Nachmittag kam gleich wieder Unruhe u. störte mich in den getrübten Gedanken Kammern. Dr. Alfred Huber aus Zell war da u. am Abend Winkler, der mich wegen der Erbschaft von Hauser-Döpfner beraten hat. Dazu zwei Anfragen, die ich glücklicherweise rasch $\mathrm{u}$. sicher erledigen konnte.

Die Hauser sind doch sehr reich. Der Willy Hauser vom Schweizerhof hinterlässt gegen $2 \frac{1}{2} 2$ Millionen. Ja nun!

Als ich mit Marieli aus der Stadt zurückkehrte, begann es von selbst davon zu sprechen, dass wenn es an den Brief von August Gyr denke, es immer noch ein wahrer

Schauer überfliege. Mir geht es auch so, u. ich komme nicht darüber weg, dass August mein Bruder oder besser noch Konrad sich hätte entschuldigen sollen. Solange das nicht geschehen ist, bleibt meine Gesinnung befestigt, ich lehne diese Verwandten ab, wie wir zusammen Deine Basler Schwester abgelehnt haben, mit Schmerz, aber notgedrungen.

Marieli hat an Susanne Rossel ein recht betrübendes Stücklein erlebt. Infolge einer Zahnoperation trug die gemeinsame Freundin Münger eine Arterienverletzung davon $u$. war wegen Verblutung am Grabesrand. Das war vor acht Tagen. Susanne wusste von Anfang an davon u. erhielt von Frl. Münger sogar Auftrag, Marieli zu grüssen, u. Susanne richtete nicht nur den Gruss nicht aus, sondern teilte M. gar nichts von dem Vorfall mit, obgleich es mehrfach da war u. mit M. sogar über Frl. Münger gesprochen hat. Ist das nicht ein hübsches Müsterchen von Eifersucht? Mehr als dies!

Aber ich habe mir ja vorgenommen, mich über die hiesigen Charaktere nicht mehr zu ärgern. Also, munter vorwärts, dankbar, wenn man selbst nicht in diesem Spital krank ist. 
Ein ungemein stiller Sonntag ist wieder vorüber. Es war kalt am Morgen, $6^{\circ}$, aber bald kam wenigstens zeitweise die Sonne u. beleuchtete die mit Rauhreif bedeckte Tanne. Gar niemand kam zu uns. Nur der junge Niehans, der jetzt Assistent bei Guggisberg ist, war fünf Minuten da, um mir

im Namen seiner Mutter für meine Condolenz zu danken. Er war sehr ruhig, wie man in seinem Alter es sein kann, wenn ein elend gewordener Vater endlich stirbt. Er meinte auch, das Unglück sei nicht mit dem Tod eingetreten, sondern mit dem Schlaganfall vom Frühjahr 1909. Sein Ziel hat jetzt der Junge erreicht, zunächst. Es steht auf seiner Visitenkarte, Licencié en théologie, V. Dr. M. u. Praktischer Arzt.

Walter Burckhardt hatte heute Besuch. Anna hat ihn, als sie gegen unsern Rat Vormittags in die Stadt ging, angetroffen. Übrigens war Anna, wie heute vor acht Tagen, gar nicht wohl. Am Nachmittag klagte sie über starke Rücken- u. Seitenschmerzen, u. ich war im Begriff, Dumont kommen zu lassen. Es ist dann aber vorüber gegangen. Wir bewogen sie ins Bett zu gehen u. sie schlief ein, so fest, dass sie, als sie nach einer Stunde, als Marieli zu ihr ins Zimmer trat, meinte, es sei schon Morgen u. sie müsse zum Frühstück aufstehen. Nach dem Nachtessen, das für sie in Thee bestand, glaubte sie, die Schmerzen seien ganz vorüber.

Ich schreib am Morgen an Rümelin, las etwas, corrigierte an der RG. Am Nachmittag war ich mit der Ges.politik u. mit einer Schachaufgabe beschäftigt, die ich mit Mühe löste. Sonst blätterte ich in dem u. diesem. Ich gönne mir doch nicht ungern etwa solche Ausspannungen. Da ich ja gar nicht mehr gesellschaftlich verkehre, so besteht dann eben darin meine Abwechslung. Vielleicht bleibt es ja nicht immer so.

Und nun schliesse ich den Tag. Ich will noch etwas lesen, bevor ich ins Bett gehe. Aber ich geh bald. Es ist merkwürdig, wie ich nach solchem Ruhetag eine Müdigkeit verspüre, die sich ganz anders fühlt als gewöhnlich. Sie gestaltet sich zur Trägheit. 
Auch zur geistigen Trägheit. Wenn man dann ausgeschlafen hat, dann kommen die angeregten Geister wieder. Aber ich würde mich selbst bedauern, wenn ich nicht hie u. da solche Stunden oder Tage hätte. Sie waren mir schon vor Jahren eine Wohltat.

Und jetzt gute, gute Nacht. Ich war u. bin immer bei Dir, ich setze mich nicht zu Tisch, ich stehe nicht davon auf ohne einen Blick auf Dein Bild. Und im Bett, bevor ich liegend die Lampe lösche, sage ich es laut für mich hin, nach rechts zum Oelbild, nach links zur Bronce: Gut Nacht, gut Nacht, liebe Seele!

Dein immer treuer

Eugen

1912: Dezember Nr. 243

[1]

B. d.9. / 10. Dezember 1912.

Mein liebstes Herz!

Ich musste mich heute zusammen nehmen, um nicht unruhig zu werden. Die Post brachte eine Anfrage, die ich erledigte. Abends war Guhl bei mir u. wir sprachen über verschiedene schwierige Fragen, bei denen namentlich das oft ganz kopflose Vorgehen der Bernischen Justizdirektion uns viel zu denken u. zu reden gab. Der Beamte, der die Sache für Scheurer vorbereitet, Salzmann, ist offenbar seiner Aufgabe nicht gewachsen. Er hat guten Willen, aber er ist, wie das bei mittelmässig begabten so häufig vorkommt, steckköpfig u. schwer belehrbar, sodass dann eben, nur zu leicht, eine Verärgerung eintritt, die dem Verkehr schadet. Überdies hat er sich, infolge seiner Anlage bei der Einführung des Ges., mit den vielen Rekursen überarbeitet, war einige Zeit nervenkrank, so dass er jetzt geschont werden muss, was natürlich dem Verkehr auch nicht förderlich ist. Dann brachte 
die N. Z. Z. wieder einmal, wie schon in zwei Fällen letzten Sommer (worauf ich BRichter Honegger geschrieben, der mich aber keiner Antwort gewürdigt hat) eine hämische Bemerkung, als ob ein Beschluss des Nationalrates bei der Beratung unter den Tisch gefallen wäre. Ich hatte den Eindruck, mir das nicht gefallen lassen zu müssen, u. schrieb diesmal an Bissegger, indem ich die Sache richtig stellte. Es wird zwar nichts nützen, umgekehrt, wenn der Correspondent ein frecher Zeitungsschreiber ist, wird es eben gehen, wie bei uns $u$. anderswo immer erlebt wird, der Mensch wird nur um so aufsässiger. Doch kann man dann wieder sehen, was gemacht werden muss, ich bin gespannt, ob mir Bissegger

antworten wird. Glücklicherweise habe ich den Anflug von Ärger rasch überwunden. Ich corrigierte den Nachmittag eine Partie der RG. u. las in der Ges.politik weiter. Betr. letztere komme ich immer fester in den Entschluss hinein, die «Theorie der Gesetzgebung» wirklich mit Eifer druckfertig gestalten zu wollen. Das wird ein gutes Stück Arbeit sein. Allein wenn ich die Neujahrsferien u. die Frühjahrsferien, bei aller Musse, darauf verwende, wird es schon gehen, weil ich Freude daran habe. Daneben freilich müssten dann auch die Erläuterungen mit den Anmerkungen versehen werden, die ich für deren zweite Auflage im Plan habe.

Anna ist es heute etwas besser, aber doch nicht gut gegangen, u. ich beginne mehr u. mehr zu befürchten, dass eine schwerere Erkrankung im Anrücken ist. Damit würde ja auch ihre in der letzten Zeit sich rasch steigernde Hinfälligkeit übereinstimmen. Wenns nicht bald besser wird, rufe ich Dumont. Ich weiss keinen andern Arzt.

Morgen haben wir ein Dreier-Examen, sodass ich Dir vermutlich nur kurz schreiben kann. Wenn die Post nichts besondres bringt, u. Annas Zustand nicht ängstlicher wird, so sollte sonst der Tag ruhig werden. Die drei Collegstunden machen mir ja immer nur Freude. Und ich denke dabei immer daran, wie ich im Grunde Dir es verdanke, dass ich sie festgehalten habe. 
Es ist fortgesetzt festes Winterwetter. Auf den Höhen Sonne, bei uns Nebel u. Rauhreif, wenngleich auch hier die Sonne stundenweise durchbricht. Wenn nur die Gesundheit so stand hält wie es mir bis jetzt beschieden war.

Gestern hat Marieli an Frau Dr. Jauch geschrieben $u$. heute hat es von Claire einen lieben Brief erhalten. Wird die Sache am Ende doch noch an ein gutes Ziel führen?

Ich schreibe Dir heute noch einige Zeilen, bevor ich in Nachmittagskolleg $u$. in die sich anschliessende Fakultätssitzung gehe. Denn während der Sitzung vermöchte ich diesmal nicht, wie sonst, zu schreiben, weil ich dreimal je zwanzig Minuten zu prüfen habe, voraussichtlich. Es ist heute ein gefüllter Tag. Das Kolleg ging gut vorüber. $\mathrm{Zu}$ Hause fand ich ein Schreiben des Fürsprechers F. Zeerleder, worin er mich um ein Gutachten in einer Baugläubigersache ersuchte. Ich hatte zu der Hauptfrage bereits bei den Beratungen so deutlich Stellung genommen, dass ich ihn hierauf verweisen konnte. Zudem darf ich mich auf Prozessgutachten nicht mehr einlassen, u. überdies fühle ich mich Zeerleder, nachdem er sich mir gegenüber mit der Übersendung meines Bildes s. Z. so ablehnend verhalten hatte, wirklich nicht verpflichtet. Es ist zwar bald ein Jahr seither, aber es war doch ein Symptom, das ich für die Zukunft nicht ausser Acht lassen dürfte. Dann war Guhl bei mir, in wichtigen Sachen. Und eben jetzt habe ich noch die Kollegien auf heute Abend u. morgen Vormittag präpariert. Nach Tisch las ich wieder ein Stück in der Gesetzgebungspolitik. Und jetzt vorwärts zum Amt.

Bei dem andauernden guten Winterwetter ist im ganzen um mich eine fröhliche Stimmung. Sie zeigt sich im Sprechzimmer unter den Professoren sogar. Walter B. ist wieder bei ganzem Selbstbewusstsein in seiner bescheidenen Art. Schulthess macht seine Spässe wie je. Hofmann ist freundlich. Zu Hause geht es auch wieder besser. Anna hat die Schmerzen nicht mehr. Marieli sieht auch besser drein, wenn es ihm auch gesundheitlich wieder weniger gut geht. Heute meinte es, wenn es dann eine alte Jungfer sei, etc., aber es corrigierte sich schnell, - eine alte Frau. 
Ich will Dir von der Sitzung schreiben, wenn ich zurück bin. Ich fühle die Belastung doch im ganzen weniger, als letzten Winter,

wohl wesentlich deshalb, weil mir das Colleg schon weniger Mühe macht als damals.

Ich war schon um $8 \mathrm{Uhr}$ aus der Sitzung zurück. Infolge eines merkwürdigen Ungeschicks sollte an Steiners Stelle ein v. Arx treten, u. dann sagte dieser auch ab. So hatten wir nur zwei Kandidaten, Brunner (m. c. l.) u. Basler (rite). Dazu kam der Berner Fürsprech Leu ohne mündl. Examen (m. c. l.).

Reichesberg war heute wieder munterer. Er meinte doch vor acht Tagen, ich hätte an die Uhr geschaut, ob er, in der Pause, nicht bald gehen werde. Das zeigt, wie sehr ihn die Concurrenz mit Weyermann plagt, der übrigens immer allgemeiner als intriganter Streber beurteilt wird. Man kann dazu nur das sagen, dass damit dem Reichesberg etwas vergolten wird, was er selbst an Oncken s. Z. sündigte. So gehts den Strebern. Wir waren heute in der Sitzung alle fröhlich gestimmt, wie ich Dir geschrieben habe, eine Wirkung des festen Winterwetters. Marieli ist im Concert mit Gertrud Lüdemann.

Jetzt gehe ich zu Bett. Gute, gute Nacht! Ich bin müde u. eigentlich schläfrig. Das bisschen Herzklopfen, das ich empfinde, rührt wohl von der Gänseleber her, die man mir zum Nachtessen vorgesetzt hat.

Jetzt aber gewiss gute Nacht, liebe, liebe Seele! Immerdar Dein getreuer Eugen

Beim Nachhause gehen sprang mir an der Zeughausgasse Gabuzzi aus Bellinzona nach $\mathrm{u}$. begrüsste mir herzlichst. Er sitzt bekanntlich im Ständerat, die Begegnung freute mich. 
[1]

B. d. 11./ 2. Dez. 1912.

Mein liebstes Herz!

Trotz der Unruhe, von der ich Dir gestern geschrieben, habe ich die letzte Nacht einen herrlichen Schlaf gehabt, ja mich beinahe am Morgen verschlafen. Als ich nach dem Colleg nach Hause kam, hat es mich dann etwas beunruhigt, in der N. Z.Z. den Brief zu lesen, den ich an Bissegger geschrieben, mit einem Zusatz, den er selbst angefügt. So war mein Schreiben nicht gemeint. Er hätte mich zum mindesten fragen können, denn ich schrieb ihm ausdrücklich, dass ich eine Veröffentlichung nicht für nötig erachte. Am Nachmittag kam dann Guhl (Mutzner) zu mir u. wir kamen auf die Sache zu sprechen. Dabei machte er mich aufmerksam auf etwas ähnliches, was in der Praxis des BGer. gestanden. Und richtig, es zeigte sich, dass jener hämische Angriff in dem Urteil des BG. stand, allerdings gegen Hoffmann als Berichterstatter im Ständerat direkt gerichtet, u. in der Fassung correct. Daraus kann ich nun ersehen, dass meine Besorgnis, ein Correspondent in Lausanne trete systematisch, von einem böswilligen Mitglied des Bundesgerichts unterstützt, gegen das ZGB. auf, nur zum Teil begründet war. Es handelt sich im Wesentlichen um eine Dumheit. Hätte ich das früher gemerkt, so würde ich wohl geschwiegen haben. Doch kann es jetzt um so direkter wirken, u. am Ende löchert mich die Sache. Ich kann mir daraus nur den so oft bestätigten Grundsatz bestärken lassen, dass man was in den Zeitungen steht, gar nie ernst nehmen darf. Wenn man reklamiert, wird es ja doch immer ärger. Man bekommt 
nie Recht, u. ich muss auch da noch eine verdrehte Antwort gewärtigen. Ich will sie abwarten u. dazu schweigen.

Im Grunde genommen muss ich schon sagen, dass mich diese einfältige Geschichte traurig gemacht hat, aber es ist eine resignierte Traurigkeit. Sie kam mir erst ins Bewusstsein, als ich mit Mutzner bei seinem Weggehen darauf zu sprechen kam, wie schnell die Zeit vergehe, $u$. als ich anfügte, das ist ja das beste was einem begegnen kann; ich sah ihm an, dass er davon betroffen war u. stutzte.

Mutzner ist übrigens mit seiner Habilitationsarbeit nicht fertig geworden, trotz Urlaub. Er will nun, während er die Büreauarbeit wieder aufgenommen hat, nebenbei fertig machen. Mit der Habilitation vor dem Druck des Sommer-Vorlesungsverzeichnisses ist es jetzt natürlich nichts. Mutzner muss froh sein, wenn er in diesem Winter überhaupt mi der Habilitation fertig wird u. im Sommer, ohne Ankündigung im Katalog, lesen kann. Ich befürchte, dass er sogar erst auf nächsten Winter fertig wird. Er ist gründlich, aber bündnerisch langsam.

Von August erhielt ich einen Brief. Heute Abend, aus Anlass des fünfzigsten Todestages unseres Vaters, der am 13. Dez. 1862 gestorben ist. Ich weiss noch nicht, was ich darauf antworten soll. Der Brief enthielt nichts, was mich aufgeklärt über unsere Störung der guten Beziehungen. Dagegen teilte mir Lüdemann heute im Sprechzimmer mit, dass er im Oktober aus Bayern einen Brief von August Gyr erhalten habe. Daraus oder aus anderer Quelle hat Lüdemann erfahren, dass August in Leipzig mit einer Dissertation abgewiesen worden, weil sie zu kurz sei, aber das Thema, das ihm Sohm gegeben, sei zu kurz gewesen, zu wenig elastisch. Das stimmt mit dem, was Ernst Brenner, glaub ich schon im Sommer, mir mitteilte, dass August mit Sohm Krach gehabt habe, wobei dieser ihm gesagt habe, er sei unverschämt

u. werde unter ihm niemals das Examen bestehen. Deutet das auf die pathologische Geistesverfassung Augusts, so ist es eben doch nicht geeignet, das gut zu machen, was wir durch ihn an Leid erfahren. Sein «Studieren» wird jetzt freilich erledigt sein. Aber die furchtbare 
Geschichte mit seiner Verleumdung bleibt ungesühnt. Doch ich mag nicht weiter daran denken.

Ich habe heute Ges.politik u. ein gut Stück RG. gelesen. Wir wollen sehen, wie ich darin weiter komme.

\section{Den 12. Dez.}

Heute ist von Morgen auf Abend wärmer geworden u. es regnet! Der Witterungsumschlag mag mich etwas beeinflusst haben. Ich war nicht in gesammelter Stimmung. Zudem kam vor dem Abendkolleg zuerst der junge Dr. Boivin zu mir u. wollte von mir in langer Rede wissen, ob er sich bei uns oder besser in Freiburg als Privatdozent für Verwaltungsrecht habilitieren würde. Es ist der Sohn jenes Direktor Boivin, der im August 1897 bei uns einmal auf dem Gryphenhübeli zu Nacht gegessen hat u. uns die Wohnung bei Gremiers empfahl. Natürlich konnte ich ihm keine Auskunft geben. Dann kam kurz vor halb vier Zürcher, der mich bis zur Universität begleitete. Darauf erzählte mir in der Pause Walter B. von einer Kritik, die Ostertag an einem Gutachten, das ich der Solothurner Kantonalbank erstattet habe, bei der letzten Comitésitzung geübt. Und endlich, wie ich auf dem Katheder den Zwicker aufsetzen wollte, verwickelte sich die Schnur so bedenklich, dass ich die längste Zeit sie nicht losbringen konnte $u$. es nur meiner Routine verdankte, wenn ich ohne Pause die Vorlesung gleichwohl

störungsfrei fortführen konnte. Sonst habe ich heute etwas RG. u. Ges.pol. gelesen. Erfreut hat mich ein lieber Brief Idas u. «Die Geschichte Stammheims», die mir Pfarrer Farner auf Langhards Veranlassung zugesandt.

Die Geschichte mit Ostertag könnte ich übel nehmen, wenn ich nicht schon recht stumpf geworden wäre gegen solche Erfahrungen. Offenbar ist Ostertag das «böse Element» im Bundesgericht, für das ich schon lange Witterung habe. Nun ja, er wird sich selbst damit richten. Anfechten darfs mich nicht. Erklären kann ich mirs, weil er zu jung ins hohe 
Amt kam, um noch etwas rechtes aus sich zu machen, $u$. weil er ein Schüler Häuslers u. Wielands, u. selbst ein Basler ist.

Und nun schliesse ich auch diesen Tag mit einem innigen gute Nacht. Vergelt Dir's Gott, was Du mir bist u. sei innigst umarmt von

Deinem allzeit getreuen Eugen

\section{2: Dezember Nr. 245}

B. d. 13. / 4. Dez. 1912.

Mein liebstes Herz!

Heute habe ich wieder einmal einem Einfall Gehör geschenkt, der mir in der Nacht gekommen ist, ohne morgendliches Besinnen, wie ich es schon hie u. da gemacht habe $u$. wie es mich mehrfach in Situationen gebracht hat, aus denen ich mich schwer wieder herauswinden musste. Ob es diesmal auch so kommen wird? Ich mache mich gefasst darauf. Ich schrieb nämlich an Ostertag, um ihm direkt zu sagen, dass das was er zu Walter B. über mich gesagt, unrichtig sei. Ich fasste mich in freundliche Worte, drückte mich aber bestimmt aus. Nun wird es sich ja zeigen, was er tut. Macht er es wie Bundesrichter Honegger, so antwortet er mir gar nicht. Vielleicht auch wird er umgekehrt redeselig, aber unartig. Das wird mir beides gleich bleiben. Ich habe jetzt begonnen, mich gegen dieses schleichende Gift zu wehren, $u$. werde fortfahren, wo es mir nur rätlich erscheint, die Dreckseelen müssen dann doch gezeichnet werden. Übrigens war ich in der Beziehung froh, selbst geschrieben zu haben: Walter B. versprach mir gestern, gleich an Ostertag die nötige aufklärende Anfrage zu richten. Ich traute der Sache nicht $u$. fragte ihn heute Nachmittag, ob er es getan habe. Auf seine etwas kleinlaute Verneinung konnte ich ihm entgegnen, dass ich es selbst getan. Er wurde nicht böse darüber. 
Heute habe ich die Besprechung der neuesten Publikation von Stutz an die deutsche Juristenzeitung abgehen lassen.

Ferner las ich die Gesetzgebungspolitik fertig, zu Ende. Dann arbeitete ich ein Gutächtchen für einen Förster Knüsel in Eschenbach aus u. expedierte es gleich. Weiter las ich in Arnold Heims Tagebüchern, mit dem alten Eindruck.

Im Praktikum ging es diesmal besser als vor acht Tagen. Aber nach Ablauf einer Stunde wurde ich mit einemmal müde u. musste mich sehr zusammennehmen, um nicht abzufallen. Auch jetzt noch bin ich sehr müde. Es ist wieder Wochenschluss.

So will dich denn auch heute nicht weiter schreiben. Es wird morgen gescheiteres herauskommen. Nur eines muss ich noch anfügen: Es schwebte mir heute immer jener trübe nasse Dezembertag vor Augen, da unser Vater am Sterben lag. Seitdem sind fünfzig Jahre verflossen. Ach, es lässt sich ja gar nicht überdenken, so viel ist dazwischen vorübergegangen, $u$. eine Rechtfertigung zum Dasein sehe ich schwer. Waren sie früher nicht glücklicher, dass sie früher starben? Ich sollte es meinen, denn sie hatten mehr Wärme, mehr Enthusiasmus, mehr Gemüt, weniger Berechnung, weniger Neid u. Eifersucht. Aber jedes Zeitalter muss für das Gute danken, das es birgt. Und ich danke meinem lieben Vater für das was ich geworden bin. Sagte er mir nicht beim Abschied: Werde was Du willst, aber was Du wirst, werde es mit ganzer Seele u. ganzer Kraft! Wie sehr hatte ich gerade diesen Zuspruch nötig! Wie arg hat es mich herumgetrieben! Jetzt Gute Nacht! 
Den 14. Dez. 1912.

Heute hat Folletête seine Antrittsvorlesung gehalten. Er gab eine vergleichende Zusammenstellung des Jurassischen Rechts u. d. ZGB. u. kam bis zum Vormundschaftrecht. Dann klingelte es 12 Uhr, u. er übersprang ruhig alles weitere, las die Schlusssätze ab u. war fertig. Das war geschickt, das übrige etwas langweilig. Merkwürdig war die formlose Art der Gelegenheit. So wurde diesmal, als wäre es nur ein Privatdozent, der reden soll, der Vortrag in Nr. 31 verlegt u. nicht wie bei Weyermann u. Hofmann, in die Aula. Dann veranstaltete der Dekan keine Sammlung der Mitglieder der Fakultät, so dass wir durcheinander auf den vordersten Studentenbänken sassen. Auch beim Schluss nichts irgend die Anteilnahme verratendes, nur Geklatsch, von den zunächst Stehenden dem Redner die Hand gedrückt, u. fort war man. Gmür sagte, als ich ihm beim Nachhausegehen die Hand drückte, Tobler habe Nr. 31 angeordnet. Aber er ist Rektor.

Sonst bin ich heute Vor- u. Nachmittag an der RG. gesessen, es naht endlich dem Ende. Ich hatte um 3 Uhr einen netten Studenten, Friedrich aus Winterthur, der mir schon im Praktikum aufgefallen. Er will hier doktorieren, war bis jetzt vier Semester in Zürich, wusste von Egger nicht viel zu rühmen, wohl aber von Hitzig. Dann kam Dr. Langhard nochmals wegen der Erbverzichtssache zu mir. Der Notar in Stammheim ist immer noch bockbeinig. Endlich hatte ich Guhl bei mir, mit hübschen Fragen, in deren Beantwortung wir einig gingen.

Die Gärtner waren die Tage da. Sie fuhren mit ihrem Handwagen in den Garten u. beschädigten die Ränder einiger der Winterbretter, dass es nicht schön aussieht. Aber es hat es niemand gemerkt, bis ich heute Morgen reklamierte. Ich muss am Ende doch noch Flückiger abdanken. Sophie war mit dem Essen heute ungeschickt. Es hat es niemand gemerkt, bis ich reklamierte,

dann wurde sie erst taub, nachher erwachte scheinbar ihr Eifer. Sonst war Lärm im Haus durch Frau Schory. Es soll das nächste Mal besser werden. 
Ich kann ja nicht verlangen, dass die Sachen gut gehen, wie es unter Deiner lieben Hand der Fall war. Allein dass Anna nun das Haus führen muss, daran hätten weder Du noch ich je gedacht. Und sie erfährt so riesige Schätzung, Du weisst, wie Frau BR. Brenner darüber einmal sprach, es war fast eine Kränkung für Dich. Und fast dasselbe sagte mir Frau Prof. Niehans, als ich ihr letzte Woche Besuch machte.

Prof. Weyermann fragte mich heute, ich soll über die Neujahrsferien einmal zu ihm kommen, wenn Diehl aus Freiburg da sei. Ich habe abgelehnt. - Auf der Universität traf ich Fritz v. Wyss, er will wieder einmal zu mir kommen. Der Tag kommt mir fast wie verloren vor, weil ich mich so zornig fühlte, über alles was begegnete. Morgen sollen Dr. Fick u. dann Dr. Schläpfer mich besuchen. Wird es mir darüber besser?

Es hat mir wohl getan, an Dich zu schreiben. Mögen sie mich verunglimpfen. Mir ist wohl bange, aber ich verzage nicht.

Gute, gute Nacht! Oh Du liebe Seele - was bin ich denn noch ohne Dich!

Dein ewig treuer

\section{Eugen}

Arnold Heims Tagebücher $15 \mathrm{u}$. 16 habe ich gestern fertig gelesen u. zurück gesandt, mit einer kurzen Karte, wie er sie mir zugestellt. 
B. den 15. Dez. 1912.

Mein liebstes Herz!

Ich kann nun wieder einmal wahrnehmen, wie der Ärger u. Zorn an den Kräften zehrt. Wie war ich hellauf die letzten Wochen. Da ist der perfide Angriff auf das ZGB. in der N. Z. Z. gekommen u. meine Antwort, u. dann die Mitteilung Burckhardts über die noch perfidere Verunglimpfung durch Ostertag u. mein Brief an ihn. Wie es bei mir der Fall zu sein pflegt, nahm ich das Anfangs ruhig, noch am Freitag glitt ich darüber weg, aber gestern, mit den andern Dingen zusammen, machte mich die Sache ganz unglücklich, so dass ich mir allerlei Dummes überlegte. Und obgleich ich gleichwohl gestern wie vorgestern gut schlief, bin ich heute gar müde gewesen, ganz abgeschlagen, wie wenn ich die grösste Arbeit verrichtet hätte. Ich darf mich nun mit der Sache nicht weiter beschäftigen, mag Ostertag mir antworten oder nicht. Es ist genug, dass ich mich gewehrt habe. Heute telephonierte mir Frau Prof. Burckhardt, ihr Mann sei so unglücklich, dass er nicht gleich an Ostertag geschrieben. Er habe es wirklich vergessen, wegen einer sehr dummen Familiengeschichte, u. nicht etwa absichtlich, aus Abneigung gegen den Schritt nicht getan. Er habe heute früh darüber geklagt $u$. sei ganz aufgeregt gewesen. Ich soll ihm doch, wenn er zu mir komme, keine Vorwürfe machen. Er kam dann wirklich, ohne von dieser Vorausmeldung etwas zu wissen, $u$. ich habe mit ihm von dem

Fall kaum gesprochen. Das richtige wäre natürlich gewesen, er hätte vor zwei Wochen mich gleich in der Sache befragt. Ich hätte ihm dann geantwortet, Ostertags Aussage sei falsch $u$. das hätte er diesem gemeldet. Jetzt bleibt natürlich auch auf ihm etwas hängen. Es sieht so aus, als haben 
die beiden miteinander über mich belustigt $u$. nachträglich habe Burckhardt den Complicen preisgegeben. Mag nun Ostertag antworten oder nicht, ich habe getan, was ich meinem Renomée schuldig war. Und es gehört ihnen auf die Nase, wenn sie sich als Lastermäuler entpuppt oder entlarvt fühlen müssen. Greif niemals in ein Wespennest, doch wenn Du greifst, so greife fest. In der Stimmung von gestern $u$. vorgestern hätte ich einen brennenden Angriff auf das ganze Bundesgericht nicht gescheut. Indem ich das schreibe, spüre ich, dass ich auch jetzt noch dazu kommen könnte. Aber wenn es nur nicht so schade wäre für die Zeit, die damit verloren geht. Hoffen wir, dass ich nicht zu solchen Zeitopfern genötigt werde!

Heute habe ich ein gut Stück RG. gelesen u. vorkorrigiert. Ich bin bald fertig. Nach zehn Uhr kam Dr. Fick, sehr nett, sehr recht. Er erzählte mir unter Anderem, wie Häusler ein alter Mann geworden, der auf zwei Wochen vergesse, was er einem gesagt habe. Wenn es so fortgehe, müsse er einmal energisch u. rücksichtslos gegen ihn auftreten. Auch vom Bundesgericht erzählte er viel, wie die Richter in ihren Voten so spitzfindig $u$. rationierend votieren $u$. gar nicht auf die

Hauptsache aufmerksam seien. Er erzählte dafür einige Beispiele. Inzwischen kam Walter B., mit dem ich nach Ficks Fortgang das Weltische Porträt beschaute. Diesmal fand ich die Augen wie retouchiert, also auch hier Photographie statt Bild. Aber nett ist das ganze. Während diesen Besuchen war Walter Dürrenmatt da, den ich nicht gesehen, der sich mit Marie u. Anna aber gut unterhalten haben soll.

Viktor Schläpfer hatte Vormittags hier sein wollen. Er sandte aber eine Depesche, dass er den Zug verfehlt habe, u. langte erst etwas nach ein Uhr an. Sein Besuch war sehr nett. Während das letzte Mal ich selbst gewissermassen das Unterhaltungsobjekt war, vermochte ich diesmal es anders zu richten. Ich vernahm viel von ihm. Er sah immer noch schlecht aus. Aber in Basel geht es ihm gut. Er hat jetzt den Plan, sich dort oder in Zürich oder in Bern als Privatdozent aufzutun. Ich redete ihm zu, hiefür Basel 
den Vorzug zu geben, namentlich auch deshalb, weil, wie er sagte, das dortige milde Klima ihm so gut bekomme. Er verliess uns halb fünf Uhr. Vorher aber hatte ich noch einen Besuch: Bundesrat Hoffmann u. Frau kamen u. blieben ein halbes Stündchen. Es geht ihr jetzt wieder besser, aber sie hätten bis jetzt gar nichts gesellschaftliches mitmachen können. Er sah gut aus. Er war aber viel ernster gestimmt als sonst, u. meinte, ein grosser Krieg sei wahrscheinlich. Was dann mit uns? Die Rede Forrers betr. Tessin u. Italien hat er lächelnd verurteilt, es seien eben nicht alle Politiker Diplomaten. Wie man nur habe annehmen können, eine solche Erklärung sei vom Gesamtbundesrat geprüft u. genehmigt worden. Frau

Hoffmann fragte mich, ob ich nicht demnächst wieder einmal zu ihnen komme. Ich lehnte ab, ich kann nicht mehr.

So war dieser Sonntag wieder einmal bewegter als die letzten. Schade, dass manches wieder unter dem Zusammentreffen gelitten hat. Und dass ich gerade heute so müde war. Kann sein, dass diese Müdigkeit auch etwas mit dem Wetter zusammen gehangen hat. Es war heute ausserordentlich mild, feucht $u$. sonnenhell. Die Berge waren prachtvoll.

Ich will heute bald zu Bett. Es wird mir gut tun. Ich habe die Ruhe nötig. Bleibe bei mir, liebe Seele - ich denke wieder, wie die 141 Wochen vorüber gegangen, seit Du mir zum letzten mal gut Nacht gesagt. Es geht lange, bis ich Dir folgen darf!

$$
\begin{array}{r}
\text { Ewig Dein getreuer } \\
\text { Eugen }
\end{array}
$$


[1]

B. d. 16. / 7. Dez. 1912.

Meine liebe, gute Lina!

Heute ist mit der Morgenpost die nicht bestimmt erwartete Antwort Ostertags nun doch eingetroffen. Aber sie ist sehr patzig. Er entschuldigt seinen Irrtum u. sagt, er habe meine «Berichtigung» dem mitgeteilt, von dem er die Nachricht erhalten. Damit übergeht er oder verdeckt er sein eigentliches Unrecht. Freilich, was wollte er anders sagen, wenn er sich nicht entschliessen konnte, sein Unrecht zu bekennen. Der Ton bestätigt mir, dass in ihm ein Hauptfaktor der verdrehten Richtung, die im Bundesgericht auftritt, gefunden werden muss. Mein freundliches, sogar herzliches Schreiben hat nun statt zur Ausgleichung beizutragen, den Gegensatz nur vermehrt. Es ist aber auch möglich, dass er doch etwas gemildert wird, wenn nämlich tatsächlich infolge meiner Reklamationen der Ton von dorther etwas besser wird. Honegger hat mir s. Z. auf meine Reklamation gar nicht geantwortet. Das war bei ihm, wegen der geringen Beweglichkeit seines Geistes, entschuldbar. Ostertag ist gewandter. Aber seine paar Sätze beweisen, dass Fick wohl recht hat, wenn er gestern sagte, Ostertag sei hie u. da sehr oberflächlich.

Heute Abend hat mir Bundespräsident Forrer telephoniert $u$. mich auf morgen oder übermorgen (ich habe nicht genau acht gegeben) zu einem Abendessen bei sich eingeladen, bei dem «Klassiker» der Bundesversammlung u. einige Professoren (Schulthess, Füsler) anwesend seien. Ich habe morgen Fakultätssitzung u. übermorgen Bibliothekskommission, u. so bot sich mir rasch der Ausweg, zu antworten, dass ich durch eine Sitzung verhindert werde. Ich hätte ja wohl gehen können, aber erst gestern 
habe ich Frau Bundesrat Hoffmann abgewinkt, u. nun soll ich aus meiner immer süsser werdenden Einsamkeit des Forrers wegen heraustreten, den ich so wenig achte? Aber ich musste mir sagen, wenn er so über mich dächte, wie ich über ihn, so würde er mich nicht eingeladen haben. Und dieser Gegensatz tut mir leid, ja weh. Doch ich kann es nicht ändern.

Heute war auch Dr. Langhard wieder bei mir wegen des Erbverzichts der adoptierten Kinder. Es stellt sich jetzt heraus, dass der Stammheimer Notar die Vormundschaftsbehörden eingreifen lassen will, weil eine Gefährdung der Interessen derselben vorliege. Das ist richtig, wenn man die vorausgegangene Adoption nicht berücksichtigt. Überdies klingt es wie eine Beleidigung gegen Langhard. So kommen die alten Auffassungen über die Controle betr. die Eltern wieder durch ein Hintertürchen auf den Plan. Es gibt aber andere Auswege für Langhard. Ich habe ihm solche genannt u. bin nun begierig, was geschehen wird.

Heute habe ich an der RG weiter gearbeitet, es fehlt nur noch wenig, so bin ich fertig. Zugleich habe ich mit den Bemerkungen zur zweiten Auflage der Erläuterungen einen ersten kleinen Anfang gemacht. Ich muss mich jetzt dann entscheiden. Dann kam ein Brief von Stammler mit der Nachricht, dass er sich entschlossen habe, eine Zeitschrift für Rechtsphilosophie herauszugeben, $u$. mit der Bitte um meine Mitarbeiterschaft. Ich kann diese nicht verweigern. Aber es hätte mich mehr gefreut, wenn er mich schon beim Plan consultiert u. mich derart enger mit der Sache verbunden hätte. Er glaubt zwei tüchtige Gehülfen gefunden zu haben, die ihm das Unternehmen möglich machen, Helldeck in Leipzig u. Jörges in Halle. Er selber

[3]

eignet sich, wie er selbst bekennt, gar nicht für solche Arbeit. Wir wollen sehen, wie sich der Plan weiter gestaltet. 
Anna ist wieder unwohl. Alles drängt mich, nichts will ganz recht werden. Von Arnold Heim erhielt ich das letzte Tagebuch. Übrigens mit einer Ablehnung seines Vaters schliessend, die mir für den Jungen leid tut.

Den 17. Dez.

Heute habe ich nun auch von Rümelin den lange erwarteten Brief erhalten. Er berichtet mir, dass der Plan, für Mutzner in Tübingen etwas zu tun gescheitert ist. Mir ist es auch recht, wenn M. dableibt, aber es besteht die Gefahr, dass er nun überhaupt für die Wissenschaft verloren gehen wird, $u$. das tut mir leid.

Ich hatte heute keinen angenehmen Tag. Ich zeigte Walter B. den Brief Ostertags. Er fand ihn nichtssagend u. gegen mich wenig respektvoll. Das Gefühl hatte ich auch, allein ich schrieb die Beobachtung auf Rechnung des mir ja wohl bekannten Basler Tons. Sie sind eben nur zu oft Knoten, die feinen Herren. Sie sind u. bleiben die verwöhnten Reichen, die man sich am besten zehn Schritt vom Leibe hält. Walter B.s Urteil bestätigt mir nun aber, dass in Ostertag noch etwas anderes steckt, eine oberflächliche Renomé. Ich werde mir das nun ein für allemal merken u. dem Herrn Bundesrichter aus dem Weg gehen.

Um zwei Uhr kam Bühlmann ein Stündchen zu mir. Er sieht gut aus u. war munter. Eigentlich Neues habe ich nicht von ihm erfahren. Auch Nationalrat Balmer wollte zu mir kommen, telephonierte dann aber ab auf morgen.

Weiter erhielt ich eine Biographie Soleilles, die ich mit grösstem Interesse lesen werde. Von einem Freundschaftsverhältnis zu ihm scheint dem Verfasser nichts bekannt gewesen zu sein. Um fünf, nach meinem RG-Kolleg hatten wir die Probevorlesung von Seggessers, nicht übel. Nachher aber gab es einen widerwärtigen

Disput zwischen Reichenberg u. Weyermann, da letzterer in der Correktur eine Vorlesungsankündigung, wie sie zwischen beiden von der Fakultät verabredet worden war, einseitig änderte.

Es wäre sehr peinlich, wenn jetzt solche Dinge sich unserer Fakultät wieder einnisten würden. 
Es gibt sonst so viel unangenehmes. Die Verhältnisse in Bern werden zu leicht gar unergründlich, weil keine Formen beachtet werden. Marieli hat jetzt auch wieder Geschichten, ich weiss nicht wie bekommen, mit Frl. Reineck. Ich denke, hier hat diese Unrecht. Aber machen kann man nichts.

Zum Arbeiten bin ich heute gar nicht gekommen. Es war am Vormittag ein finsterer, kalter Regentag, die schlechteste Acht UhrStunde in diesem Semester. Sonst schleppe ich mich weiter. Es sind ja nur noch ein paar Tage. Die letzten Nächte habe ich unruhig geschlafen u. angstvolle Träume gehabt.

Noch muss ich von Dr. Schläpfer nachtragen, dass er mir sagte, die Teichmann gelte als eine Schneppe u. der Sohn als eine Art Zuhälter. Ich hatte schon einige Male solchen Verdacht. Weiss Gott, was sie getrieben, solange der Vater in Bern war!

Jetzt muss ich der Müdigkeit nachgeben u. gehe zeitig zu Bett. Kann sein, dass das wärmere Wetter mir etwas zusetzt, mit all dem versteckten Ärger zusammen.

Gute, gute Nacht, liebe Seele! Im Traum denk ich Dein u. bleibe immerdar Dein guter Kamerad!

Dein

\section{Eugen}

Gestern Abend vor Schlafengehen habe ich, eigentlich gegen jede Zeitökonomie, noch etwas Mathematik getrieben u. ein paar hübsche Aufgaben gelöst.

Du weisst, wie mir das immer Freude gemacht hat! Gute Nacht! 
[1]

B. d. 18./ 9. Dez. 1912.

Mein liebstes Herz!

Ich bin heute Abend auffallend müde $u$. fiebrig $u$. weiss keinen rechten Grund dafür. Allerdings war es ein unruhiger Tag, auch hat das nochmalige Umschlagen des Wetters - es war vom Morgen an wieder hell u. kalt, u. gegen Abend setzte ein heftiger Ostwind ein - wohl auf mich gewirkt. Aber daneben sind es psychische Dinge, die mich niederschlagen, das Gefühl einer Lieblosigkeit, die mich nicht loskommen lässt, u. die ich nicht überwältigen kann. Es liebt mich niemand mehr. Überall stellen sich mir nur der krasse Eigennutz anderer u. der Neid wieder Anderer entgegen. Doch will ich auch das mit Deiner Hülfe zu überwinden suchen. Ich hoffte heute Nachmittag in einer ruhigen Stunde an Ida schreiben zu können. Aber auch das war nicht möglich. Also muss man halt in dem Strome mitschwimmen u. nehmen, was man nicht ändern kann.

Nach dem Morgenkolleg schrieb ich einige Briefe. Nach der kurzen Mittagspause wollte ich etwas in der RG. corrigieren, nahm dann aber wieder für eine Viertelstunde Mathematik zur Hand. Dann kam der Student Caflisch mit Dissertationsplänen, darauf der Candidat Stocker von Luzern, der mir seine fertige Dissertation brachte. Darauf ein Gschwend von Frauenfeld, der sich für die Unter Bibliothekarstelle angemeldet hat. Während dieser fortging, erschien Nationalrat Balmer, der mich über die Verantwortlichkeit der Verwaltungsräte der verkrachten Luzerna consultierte. Mein Bericht lautete nicht günstig, bei dem Anlass erfuhr ich, dass BRat Schobinger sein ganzes Vermögen, 400000 Fr. in dem Unternehmen verloren 
hat. Und kaum war Balmer da, erschien Siegwart. Er musste über eine Stunde warten, bis ich die Besprechung mit Balmer erledigt hatte. Nachher war ich, $4 \frac{1 / 4}{4}$ bis $4 \frac{3}{4}$ mit Siegwart zusammen. Er erschien mir, als wie aus einer andern Welt hergekommen, u. noch nie hatte ich so bestimmt den Eindruck wie heute, dass, wenn die Verhältnisse so bleiben, wie sie sind, von einer noch näheren Verbindung nicht die Rede sein könne. Es war gut, dass es bis jetzt so gegangen, wie es gegangen ist. Siegwart begleitete mich alsdann zur Bibliothek, wo wir in der Kommission drei wichtigere Geschäfte zu erledigen hatten: die Ankenlauben-Verträge, die Entlassung Reinhards aus der Kellermiete u. die Wahl des Unterbibliothekars an Stelle des demissionierenden Bänzigers. Gewählt wurde ein von Bibliothekar Diesbach angelegentlichst empfohlener Wilhelm Meier von Zug.

Nach dem Abendessen habe ich die Zeitungen gelesen u. muss mich noch auf das letzte Kolleg dieses Jahres vorbereiten. Dann ist der Tag zu Ende.

Liebe, gute Lina, wenn ich nur nicht wieder in die düstre Stimmung verfalle. Ich muss mich aufrecht erhalten. Ich habe noch so vieles zu arbeiten, bevor die Zeit völliger Leistungsunfähigkeit über mich kommen wird. Von Arnold habe ich endlich eine freundliche Karte bekommen. Es ist wenigstens etwas. Aber Du siehst an dieser Kleinigkeit, wie mir etwas mehr Liebe so furchtbar Not täte. Ja, ich muss es mir jeden Tag sagen, es ist doch ganz klar, dass die Liebe, seit Du mir entrissen bist, für mich verloren gegangen. Es wäre ja nicht recht, stünde es anders. Allein doch, es ist doch schwer zu tragen. Immerdar aber will ich jetzt mir vor Augen halten, dass ich wenigstens in der Dankbarkeit verharre, gegen Dich, gegen das was gewesen. Sonst, umfange mich, Einsamkeit! Ich will auch Dir dankbar sein! 
Den 19. Dez.

Heute habe ich die zwei Vorlesungen über das ZGB. u. die über Rechtsg. für die erste Semesterhälfte geschlossen. Der Besuch war am Morgen noch ordentlich, am Abend sehr flau. Das ist jetzt eine regelmässige Erscheinung, eine Folge der Weihnachtskneipen u. sich anschliessenden

Katerbummels. Die Leute halten das für wichtiger als die Vorlesungen. Wir sind eben arme Dinger, wir Dozenten. Es könnte Einem manchmal die Lust vergehen, den Karren weiter zu ziehen. Aber dass die andern Dozenten dasselbe in noch stärkerem Masse erfahren, muss mich darüber trösten. Walter B. erhielt heute im Dekanatszimmer von einem Studenten in meiner Gegenwart die Mitteilung, dass sich am Samstag in seinen Übungen nach Frage des Berichterstatters nur noch 3 bis 4 Hörer einfinden werden. Offenbar wurde Walter B. nur durch mein Zuhören veranlasst, zu erklären, er werde also doch lesen, - wenn nicht noch ungünstigerer Bericht komme.

Ich bin heute weniger müde als gestern, obgleich die Unruhe wieder sehr gross war. Nationalrat Balmer kam nochmals vorbei, aber weder er noch ich wussten Neues zu sagen. Es wird eben bei meiner nicht günstigen Antwort sein Bewenden haben. Dann kamen noch drei Studenten wegen Dissertationen etc. Einer, Rohr, machte mir Freude durch seine bestimmte Entschliessung für ein günstiges Thema, das er selbst gefunden (Notariat im Aargau). Dann war vor Tisch Dr. Brunner aus Winterthur bei mir. Er war ein Jahr in Paris u. kommt nun als Auditor nach Horgen, zu Fischer u. Willy v. Wyss. Er machte mir einen recht guten Eindruck.

Am Nachmittag war Frau Guhl bei Marieli u. wollte einen Wunsch wissen, was mir die Schweiz. Notare im Wert bis $200 \mathrm{Fr}$. schenken könnten. Die Sache liegt mir nicht recht. Ich habe dann aber den Abend doch nachgeschlagen, etwa wegen eines Buches, aber nichts gefunden, was ich den Herren vorschlagen dürfte. Sie sollten mir doch das Geld geben. Aber sie sind etwas naiv. Sie wollen ein Andenken schenken, u. es fällt mir so schwer, etwas zu nennen. Du weisst ja, wie ich darüber keine Wünsche habe, es wurde mir ja sogar Dir gegenüber 
jeweils schwer, etwas zu nennen. Ich bin eben eine Natur, die keine solch äussere Bedürfnisse empfindet $\mathrm{u}$. der das Aufstellen neuer Gegenstände fast bange macht. Das ist ein nicht ganz guter Charakterzug von

mir. Es fehlt mir die unmittelbare Freude an den Sachen, wenngleich ich gewohnte Gegenstände ja sehr lieb, oft launenhaft lieb haben kann. Am besten werde ich mich ausschweigen u. die Sache ihnen überlassen.

Es ist mir, ich werde auf Ende des Jahres noch einen rechten Ärger erleben, weiss nicht warum. Und eine compensierende Freude, wie letztes Jahr auf den 1. Januar, wird kaum eintreten. So geht die Zeit zu Ende. Heute habe ich die letzten Blätter der RG. corrigiert. Was ich nun an die Hand nehmen werde, wer weiss es, ich nicht. Aber etwas muss schon getan werden, sonst verliere ich mich wieder in Stimmungen, die nicht günstig wirken. Man fühlt darin am sichersten, wie man alt geworden ist. Aber wem geht es besser? Denen die sich früh verabschieden. Das Überleben ist eine schlimme Sache, wenn man es richtig überlegt.

Und jetzt, morgen noch das Praktikum u. dann Ferien. Ich sagte heute zu den Studenten, die eigentlich «ungesorgeten» Ferien. Wenn sie mir nur nicht neue Sorgen bringen.

Gute, gute Nacht, liebe Seele! Mir wird immer so wohl, wenn ich an Dich schreibe! Dann vergesse ich die Gegenwart, u. betrachte die Zukunft als das, was sie ist, ein Warten.

Immerdar in alter Liebe $\mathrm{u}$. Treue

Dein

Eugen 
[1]

B. d. 20. / 1. Dez. 1912.

Mein liebstes Herz!

Heute war das Praktikum nur mehr halb besucht, doch hatte ich Freude an der Aufmerksamkeit der Teilnehmer. Namentlich die beiden Zürcher Friedrich u. Gisler kommen mir mit ihrer intelligenten Diskussionsfreude immer näher. Am Vormittag war wieder Dr. Langhard bei mir, der nun doch den Erbvertrag hier in Bern abschliessen wird. Die Stammheimer machen ihm immer grössere Schwierigkeiten, u. deren Quelle ist - Neid. Der Bruder Langhards wird mit der Hülfe aus Bern immer wohlhabender, mit dem Erbverzicht der adoptierten Geschwister wächst für dessen Sohn das Vermögen, u. das soll verunmöglicht oder doch vereckelt werden. Es ist eine recht schweizerische Geschichte, die sich im Kleinen hier wieder einmal abspielt. Da zeigt sich das Hauptlaster des Volkes, der Neid, in kleinlichster Weise. Aber mit dem neuen Recht kann nun geholfen werden.

Dann war ich bei v. Mülinen - die Wahlangelegenheit mit dem Dr. Wilhelm Meyer ist jetzt in Ordnung.

Sonst habe ich etwas an den Erläuterungen geschrieben. Ein Anfang von Kopfweh ging glücklicherweise rasch vorüber.

Nach zwei Uhr kam, wie sie es mir vorgestern angekündigt, Frau Fees zu mir, jetzt geschieden Handegger. Sie trat in höchst deprimierter Art auf, weinte, jammerte, bat mich dann, doch Ständerat Usteri mitzuteilen, dass sie in der Zeugnissache nicht weiter verfolgt werden möge. Sie wolle sich zu diesem Zwecke an ihn wenden. Es sei ganz genügend, 
wenn ich Usteri nur schreibe, sie sei meine Hörerin gewesen. Ich hatte ein Grauen vor dieser fanatischen Person, sagte ihr auch offen, ich halte sie für schuldig. Ich könne bei Usteri nichts für sie tun, u. Usteri nichts für sie. Schliesslich bat sie mich, doch nur Usteri zu bezeugen, dass sie bei mir gehört habe, u. das konnte ich ihr nicht verweigern. Ich schrieb ihm nach ihrem Weggang gleich eine Karte mit den Worten: Soeben war Frau Hardegger, geschiedene Fees, die verdächtige Zeugin im Prozess Frick, bei mir u. bat mich, Ihnen zu sagen, dass sie als «Studentin» an der jur. Facultät eingeschrieben sei u. bei mir Vorlesungen u. Praktikum gehört habe. Ich komme hiermit diesem Gesuche nach, ohne zu wissen, was sie Ihnen zu sagen hat. Ich kenne sie gar nicht näher, sie hat nur im Praktikum vom Sommer 1911 sehr tätig sich beteiligt. Ich schreibe Ihnen dies nur in dem Sinne, wie ich jedem Studenten diese Teilnahme bezeugen müsste. Weiter weiss ich gar nichts zu sagen. Fast wörtlich so habe ich Usteri geschrieben. Ich sprach dann mit Walter B. darüber, in der Besorgnis, eine Dummheit gemacht zu haben, er hat aber geantwortet, er würde das auch getan haben. Der Frau Hardegger gab ich das Collegiengeld, das sie für dieses Semester einbezahlt, 10 Fr. für die Übungen zurück. Sie hat zwei Kinder von 8 u. 9 Jahren. Sie machte mir einen schrecklichen Eindruck. Welch ein Elend, u. dabei wohl doch nur die Hälfte Schlechtigkeit. Fees, der jetzt Heldentenor in Erfurt sein soll, hat ein gross Teil Schuld daran.

Marieli musste die Tage wieder herumspringen wegen der Weihnachtssachen. Ich dachte daran, wie wir vor Jahren jeweils miteinander gegangen sind. Dann kam die Zeit der Bundes-

versammlungen, wo ich jeweils so sehr bedauerte, nicht mehr Zeit zu haben, mit Dir zu gehen. Jetzt bin ich der Bundesversammlung ledig. Dafür aber ist mir jenes Zusammengehen nicht wieder geworden. So wechseln die Zeiten u. wenn man glaubt, ein lästiges abgelegt zu haben, kommt ein Unglück $u$. vereitelt doch u. bleibend das frühere Glück! 
Walter B. hat von Ostertag eine Antwort erhalten, die die Sache wieder anders gedeutet $u$. verdreht hat. Allein ich habe genug von der Sache. Der Ostertag ist für mich abgetan. Er trägt seinen Namen zu Unrecht.

\section{Den 21. Dez.}

Heute als am ersten Ferientag bin ich früh aufgestanden u. habe ein Gutächtelchen vor dem Café aufgesetzt für einen Aargauer Gemeindeammann. Dann nach Café u. Zeitungen folgten noch zwei zurückgelegte Gutachten für Borlet u. den Grundbuchbeamten von Rheinfelden. Weiter schrieb ich das Gesuch um Subvention für das R.wörterbuch. Nachmittags aber war ich bei Müller, der wider Erwarten sehr nett mit mir war. Er ist mit der Subvention zufrieden $u$. hat auch meinem Plan u. meiner Auffassung betr. die zweite Auflage der Erläuterungen zugestimmt. Bei dem Anlass war ich auch bei Mutzner, dem ich die negative Antwort Rümelins mitteilen musste. Er war so geknickt davon, dass ich gesehen, wie sehr er sich immer noch Hoffnung gemacht. Aber ich konnte ja nichts weiter für ihn tun. Er muss das einsehen. Sonst sah ich im Bundeshaus niemand, Kaiser war abwesend.

Um fünf traf Hedi Rümelin ein, es bleibt bis morgen, um die Weihnachtsfahrt nach Tübingen etwas zu coupieren.

Es ist noch immer ein sehr stummes Mädchen, wie mir aber scheint, mehr aus Geniertheit als aus Suffisonen. Mit der Genfer Familie, in der es untergebracht ist, kommt es sehr gut aus, das ist doch ein günstiges Zeichen.

Ich muss nun doch mich noch etwas dem kleinen Besuche widmen $u$. schliesse daher für heute mit einem innigen Gute Nacht! Wie habe ich Deine liebe Hand wieder an dem Nachtessen mit dem jungen Gast vermisst! Es war alles steif $u$. stumm. Meine Versuche es zu ändern glitten glatt ab. Kannst Du Dir Anna dabei vorstellen?

Doch gute, gute Nacht! Ich bleibe immerdar Dein getreuer 
Mein liebstes Herz!

Heute habe ich mir die Abwechslung gegönnt $u$. habe statt in meinen Arbeitsbüchern im J. Gotthelf gelesen u. zwar Kurt von Koppigen. Merkwürdig, trotz manch Schönem hat mir das Ganze weniger gefallen, namentlich weniger Eindruck gemacht, als ich erwartet hatte. Ich begreife jetzt Leists Urteil besser, dem ich $1889 \mathrm{zu}$ Weihnachten ein Bändchen, das mit den kleinen Erzählungen mitgab u. der es mir dankend aber mit der Bemerkung zurückbrachte, seine Eltern hätten es nicht lesen können, weil es zu wenig fein $u$. ausgeglichen sei. So kam mir der Stil heut auch vor, riesige Übertreibung in den Bildern. Aber freilich die Charakterzeichnung bleibt ungemein fesselnd. Ich hatte dann heute wieder den jungen Dürrenmatt bei mir, der mich vor acht Tagen, weil Fick da war, nicht sprechen konnte. Er teilte mir von ihren Plänen mit, dass sie die Werksääle vergrössern sollten, $u$. namentlich auch, dass Schobert sich gerne mit ihm associeren würde. Es sei jetzt Zeit, dass er sich einrichte, da er bald 33 Jahre alt werde. Ich fühlte heraus, dass er an Marieli denken. Aber bei aller Sympathie, die ich mit ihm haben muss, denke ich doch nicht an diese Verbindung. Die Differenz in der Lebensart ist zu gross. Seit ich an jenem Abend die Mutter an den [Schweins?] schnetzeln sah u. neben sie gesetzt wurde, habe ich ein anderes inneres Gefühl gegen die Leute u. kann es nicht überwinden. Ich werde also jedenfalls Marieli nicht ermutigen, überhaupt nichts in der Sache tun, sondern zusehen, wie es kommt. Gibt es denn etwas daraus, so will ich nicht dagegen sein. 
Dann war Walter B. bei mir u. ich konnte endlich mit ihm über den Fall Ostertag einlässlicher reden, sodass er jetzt wenn er mit Ostertag zusammenkommt, orientiert sein sollte. Er ist heute zutraulicher gewesen als die letzten Male.

Endlich hatten wir Besuch von Bundesrat Müller u. Frau. Marieli wartete Thee auf u. eine Flache Dezolay. Beide waren sehr herzlich. Neues vernahm ich nicht, als dass Müller findet, Forrer habe in letzter Zeit geistig abgegeben, er sei hie u. da so einfach in seiner geistigen Teilnahme. Natürlich, er wird nun auch 68 Jahre alt. Über den Kaiserbesuch sprach er sich erfreut aus. Frau BR. Müller war ganz bei der Vorstellung der jungen Damen u. sprach sehr freundlich über Elisabeth Hoffmann. Zum Schlusse forderte mich Müller, als wir auf die Gelegenheit zu sprechen kamen, auf, jeweils am Donnerstag nach 7 Uhr zu der Zusammenkunft der Bundesräte mich einzufinden. Das freut mich, allein ob ich es tun darf?

Ich habe seit gestern Abend wieder etwas Gesichtsschmerzen u. will heute bald zu Bett. Sie rühren gewiss von den kranken Zähnen her. Ich hatte aber gehofft, dass Wirth mich davon befreit hätte. Vielleicht bringe ich die Sache durch einige Bettruhe vorüber $\mathrm{u}$. weg. Ich will also heute bald zu Bett. Gestern wurde es wegen Hedis Besuch doch wieder später $\mathrm{u}$. am Morgen kann ich ja nicht liegen bleiben. Hedi war übrigens heute Morgen noch recht nett, wenn auch stumm. Es verreiste mit dem halbelf Uhr Zug u. wird in diesem Moment in Horb sein. Marieli ging mit an den Bahnhof.

So war heute ein gefüllter Sonntag bei aller Ruhe. Es war schon etwas Feierstimmung da u. die tut wohl. 
Den 23. Dez.

Von Mr. Collier habe ich gestern, aus London, einen recht lieben Brief erhalten. Es ist nett, dass wir dieses Verhältnis derart fortsetzen können. An Marieli sandte er eine Illustrierte Zeitung mit den Meddings-Berichten u. Bildern von Pegg u. ihrem Bräutigam.

Kurt von Koppigen hat mich an einer Stelle an ein Amüsantes vom letzten Freitag Abend erinnert, das ich Dir mitteile. Ich ging unter den Bogen der Aarberger Gasse, vor mir eine junge Frau mit einem widerstrebenden Kleinen in der Hand. Ich hörte, wie sie zu dem Kinde sagte, es soll vorwärts machen $u$. nicht trotzen, sonst komme ein Mann mit einem Stock. In dem Moment schritt ich an ihnen vorbei. Gsehsch jetzt! sagte die Mutter, das Kleine schrack zusammen u. tat einen Ruck, ich wandte mich u. schaute dem lächelnden Mütterchen ins Gesicht, dem das Kleine nun willig folgte. So war ich mit einem Mal zum Böhlimann geworden!

Heute habe ich am Morgen einen längeren Brief an Ida geschrieben (über Kant u. a.). Dann aber kamen die Notare Ramseyer u. Roth zu mir u. überbrachten mir im Auftrag der Bernischen Notare einen Café-Sevice u. ein Silberplateau, als Dank für die verschiedene Beihülfe, die ich ihnen geleistet. Guhl soll, von ihm gewünscht, einen Bücherschrank erhalten. Da Marieli von der Überraschung orientiert worden war, hatte es Chery bereit $u$. so blieben die zwei Herren von elf bis halb zwölf bei einem gemütlichen Plauder. - Am Nachmittag war Winkler bei mir, in Betr. des Schweizerhofs, aber diesmal wegen der Liquidation der Collectivgesellschaft. Ich konnte ihm wieder einen guten Rat erteilen. Den Nachmittag verbrachte Frau Guhl bei Marieli mit Minna u. Yvonne, u. um fünf kam Guhl selbst, als s. Frau wegging, u. hatte mit mir allerlei bis halb sieben zu besprechen. Dazwischen las ich in Houssayes 1875 I, mit Freude. Ausgegangen bin ich nicht. 
Es kommt wieder, wie allemal in diesen Ferien, man zersplittert sich. Aber man soll auch seine Erholung haben. Anna ist merkwürdig schwach geworden. Nach Weihnachten will sie zum Arzt. Ich weiss nicht, was es ist. Und Marieli ist im Eifer, aber ohne sichtbare Freude.

Doch jetzt gute Nacht, ich will bald zu Bett, schon der Andern wegen, die es nötig haben. Marieli hat ein paar hübsche Weihnachtsarbeiten gemacht, für Frau Montani u. für Frau Rümelin.

Gute, gute Nacht! Innigst verbleibe ich auf immerdar Dein getreuer

Eugen

1912: Dezember Nr. 251

B. d. 24. Dezember 1912.

Mein liebstes Herz!

Nach meinen innersten Wünschen sollen die Heiligen Abend nicht mehr so gefeiert werden, wie zu Deiner gesegneten Zeit. Es wäre ja doch nur ein schwacher, unwürdiger Abglanz im Vergleich zu dem, wie Du die festliche Stunde zu gestalten verstandest. Wie steht mir das in Erinnerung, welche Fülle von Liebe u. Freude hast Du aufgewendet, um jedem eine Freude zu machen. Und ich habe das ja auch getreulich mitgeholfen, bis in die letzten Jahre, wo mich die Bundesversammlung neben den Kollegien bis zum letzten Moment vor der Bescherung derart in Anspruch nahmen, dass ich jede Teilnahme an den Vorbereitungen aufgeben musste u. als müder Mann zugegen war. Wie hatten Marie u. Anna unter Deiner Liebe einen Segen -, aber dass sie das jetzt wenig vermissen, ist eines der vielen Anzeichen, dass es eben jetzt eine andere Zeit ist als damals. 
So ist auch der heutige Abend vorbeigegangen. Sie haben der Sophie auf dem Küchentisch alles ausgebreitet, was Sophie selbst u. Karle erhalten sollten. Ich habe ihr Geld gegeben. Ihre Freude war nicht gross. Und Karle hat sich sofort auf die «Eisenbahn" gestürzt, die ihm Marieli gekauft hatte u. raisonniert, dass kein Stationshaus dabei sei. Er hat die Maschine dann auch in der ersten Viertelstunde kaput gemacht. - Von Marieli erhielt ich ein hübsches Aquarel

von Gertrud Münger, u. dazu Kalender etc., das gewöhnliche. Von Anna eine Mappe auf den Schlafzimmertisch zu legen - wenig dienlich u. einige andere Kleinigkeiten. Ich gab M. ein Buch von Widmann u. Geld, Anna auch Geld, mit dem ihr abgenommenen Versprechen, sich daraus etwas zu kaufen. - Von August hat Anna heute das obligate Semestergeld erhalten. Geschenke haben wir die Jahr nach Zürich keine geschickt. Wer will denn heucheln? Wo jede Freundlichkeit nur wieder vom Versuch, sie auszunutzen, gefolgt wäre.

Heute um 9 Uhr hat Walter B. sein Bild geholt. Sophie hat es hinunter ins Häuschen getragen. Er traf mich beim Ordnen an Manuskripten, gewiss kurz angebunden. Nachher war ich bei Werner Kaiser u. hatte einen guten Eindruck. Ich begreife Mutzner je länger je weniger, dass er diesem Manne alles so übel nimmt. Kaiser sagte mir auch, dass Ostertag die Arbeit Siegmunds über das Grundbuch, die dem Departement als Privatarbeit eingereicht und Ostertag auf seine Bitte mitgeteilt wurde, ohne jede Erwähnung u. Verweisung in unfeiner Weise ausgeschrieben habe. Das sieht ihm gleich, wie ich ihn nun auch kennen gelernt.

Mit der Morgenpost erhielt ich eine lakonische Karte von Siegwart: er werde um elf d. Litteraturverzeichnis bei mir abholen u. die Sängerin Marietta Amstad werde mitkommen u. sich freuen, Proben ihres Könnens bei uns abzulegen. So mussten wir schnell für drei Personen einen 
Mittagstisch rüsten u. es kamen dann sogar vier, nämlich neben Frau Dr. Jauch noch der Gymnasiast Werner Amstad. Die Marietta hat dann aber wirklich hübsch gesungen, Mozart, Bellini, Dvorschak, Thomas, Brahms, ein reiches Repertoire, ohne Pause. Sie hat seit vorigem Jahr mehr dramatische Art in sich aufgenommen u. die Stimme gestärkt. In Lausanne soll sie recht schönen Erfolg gehabt haben. Gegen Mitte Januar verreist sie nach Italien, wo sie schon letzten Winter war, Mailand, Florenz, Rom u. zuletzt, im März San Remo. Sie wusste über Tisch dann sehr hübsch zu erzählen von ihren dortigen Begegnungen, mit der Regina Margerita, mit der Prinzessin Laetitia u. a. m. Es war eine recht belebte Unterhaltung, die wir untereinander führten.

Siegwart schien Marieli einige Aufmerksamkeit zu widmen, aber er ist ein Schalk. Aber auch Marieli ist nicht Simplex. Sie erhielt heute eine offene Karte von Abbühl u. zu gleicher Zeit einen verschlossenen Brief von demselben aus Fiesch. Den letzteren hat sie mir noch nicht gezeigt, u. wird ihn auch nach den gemachten Erfahrungen, wenn ich es nicht verlange, nicht zeigen. Und verlangen werd > ich es nicht.

Rechne dazu, dass ich an Pauline geschrieben, u. zwischendurch etwas Houssaye gelesen, so hast Du den ganzen Tag beieinander, ohne eigentliche Arbeit. Doch war dies ja in diesen Tagen jedes Jahr so gewesen.

Gestern habe ich im Bett Deine Andachtsbücher wieder einmal durchblättert, von zehn bis elf, in der Hoffnung vielleicht

noch ein Zeichen von Dir zu finden, das mir bis jetzt entgangen. Aber ich fand nichts. Nur ist mir diesmal aufgefallen, dass Du in Hofackers Predigten diejenige über die Liebe an verschiedenen Stellen angekreuzelt hast. Das war, wie ja nicht anders möglich, Deine Lieblingsandacht. Dass wir sie nicht zusammen gehalten haben, jetzt, wo ich zu dieser Erkenntnis gekommen, nicht mehr zusammen halten können! Das bleibt ein Unglück. 
Doch nun - an den Menschen ein Wohlgefallen! Gute, gute Nacht, bleib bei mir, wie ich immerdar bleibe

Dein getreuer

Eugen

1912: Dezember Nr. 252

[1]

B. d. 25./ 6. Dez. 1912.

Mein liebstes Herz!

Die Zeit, da ich Dir heute ausführlicher schreiben wollte, als am Weihnachtstag, ist verloren gegangen. Ich hatte die Musse nach dem Nachtessen in Aussicht genommen. Da erschien Frau Burckhardt mit ihrem Mann, ganz unerwartet, u. von halbacht bis halbzehn mussten Marieli u. ich ihr unglaublich grobes Geschwätz anhören. Schliesslich wurde sie doch wegen des fortgesetzten Schweigens stutzig $u$. brach, nach drei vergeblichen Ansätzen, beim vierten auf. Es war wieder einer der Momente in ihrem Benehmen, wie sie ihr den Charakter von Rohheit u. Gemeinheit verleihen, wie Du es ja hie u. da erlebt u. schliesslich zu dem ablehnenden Gesamturteil vereinigt hast. Nur ein Beispiel: «I ka ietz säge, gester $z$ abe häd sich ei Ma ufgehänkt ä un lache derzä»-so gings weiter. Das ist unser Berner Umgang. Marieli weinte nachher geradezu.

Ich war umso weniger in der Stimmung zu solcher Ödigkeit, weil es Weihnacht war, bei der gesteigerten Erinnerung an Dich, u. weil Anna zu Bett gegangen u. wir wegen ihrer andauernden Beschwerden Dumont auf morgen Vormittag erwarten. Nun ja, sei es drum. Der Empfang, den sie erfahren, wird sie nicht ermutigen, sobald wieder zu kommen, wenn sie überhaupt etwas merkt in ihrem Hochmut. 
Den heutigen Tag verbrachte ich in aller Stille mit Briefeschreiben u. mit Houssaye. Es war draussen wolkig, regnerisch, gar nicht Weihnachtsstimmung. Dagegen war mir wohl dabei, bis diese unglaubliche Rohheit dazwischen bengelte. Jetzt, da ich an Dich geschrieben, bin ich auch wieder ruhiger. Man muss es halt hinnehmen. Was habe ich nicht schon von anderer Seite erlebt!

Und nun, entgegen meinem Plan, schliesse ich mit diesen wenigen Zeilen für heute. Nur eines will ich noch beifügen: Ich las heute wieder einmal den Nekrolog Vaters von Wyss. Es hat mir wohlgetan. Und die letzten Nächte habe ich lebhaft von Dir geträumt. Merkwürdigerweise warst Du aber für mein Empfinden zugleich identisch mit meiner Mutter. Habe ich nicht früher diese Übereinstimmung auch schon im Gemüt gehabt, u. sie Dir gegenüber geäussert? Ich glaube wohl, jetzt aber kommt mir das im Traum vor.

\section{Den 26. Dez.}

Heute um zehn Uhr kam Dumont wegen Anna. Er entdeckte einen starken, schon brandig schwarzen Leistenabszess, der operiert werden müsse. Was die Ursache sei, werde sich zeigen. An sich sei die Sache nicht gefährlich, aber es könnten maligne Wucherungen unterliegen $u$. dies wäre bei Annas Alter fatal. Anna nahm die Sache sehr ruhig auf. Sie meinte zu mir, Du habest zu ihr einmal gesagt, sie soll froh sein, nicht solche Krankheiten durchmachen zu müssen, wie Du zweimal, u. jetzt komme es doch an sie. Um drei Uhr fuhr Marieli mit ihr ins Salem, wo sie ein gutes Stübchen erhalten, mit einer sympathischen Schwester. Marie war um 6 Uhr nochmals

oben. Die Operation, die nur kurze Zeit dauern soll, ist auf morgen 9 Uhr angesetzt. Ich habe mir schon die Nacht in wachen Momenten Gedanken darüber gemacht, wie das mit mir kommen würde, wenn ich sie verlöre. Sie war ja stets mangelhaft in ihren 
Leistungen u. der Verkehr mit ihr kein lieblicher, weil sie so rasch verglichen $u$. sich zurückgesetzt gefühlt, u. doch alles, was sie besorgen wollte, nur lückenhaft geleistet hat. Aber das habe ich immer anerkannt, dass sie seit Deinem Hinschied nach ihren Kräften bemüht war, die Dienste recht zu leisten, die sie übernahm. Wie so manches hat mich dabei geärgert, aber ich musste doch immer sagen, wenn ich nicht ihre Hülfe hätte, wäre ich mit Leuten fremden Interesses wahrscheinlich schlimmer dran. Und dann waren so viele gemeinsame Interessen u. Erinnerungen zur Stelle. Gerade in der letzten Zeit haben wir über Tisch u. Abends sehr viel aus alten Tagen aufgefrischt. Nur war auch da ihr Gedächtnis mehr u. mehr ins Wanken gekommen. Jetzt gilt es abzuwarten, was weiter uns beschieden ist. Auch wenn sie wiederkehrt, wird wohl ihre Stellung eine andere sein müssen, als bishin. Aber hoffen wir, dass sich das freundlich realisieren lässt. - Marieli war heute dienstfertig u. tüchtig bei der Hand. Auch Sophie zeigte Mitgefühl, hat der sich verabschiedenden Anna die Hand geküsst. Ach, es wird mir doch schliesslich nicht alles drunter u. drüber gehen!

Heute hatte ich Consultation von Notar Tomi mit seinem Sohn Tomi Bohny, recte Tomi-Schwagemann, wegen Namensänderung. Ich konnte einen guten Rat geben. Dann besuchte mich R. Reding von Biberegg mit seinem Sohn, der bei Feigenwinter in Basel praktiziert. Um sechs war noch Mutzner ein Stündchen da, dem ich ein Gutachten vermittelt habe. Die andere Zeit schrieb ich einige kleine Briefe u. las in Houssaye, wo ich an der Rückkehr

Napoleons aus Elba stehe, ein ganz ausserordentlich spannend entwickeltes Kapitel. - Nur vor Dumonts Besuch arbeitete ich etwas an der neuen Ausgabe der Erläuterungen.

Und nun, die Gedanken wenden sich immer zu Anna. Ich erinnere mich der Gefühle, die mich bedrückten, als vor 15 Jahren davon gesprochen wurde, Du sollest ins Salem gebracht werden. Ich glaubte nicht daran $u$. hatte recht. Und wir erlebten noch ein Dutzend schöne Jahre, ja darüber, miteinander. Jetzt ist die Sache anders. Anna stellt mir nur einen trümmerhaften Rest des früheren häuslichen Glückes dar. Fällt auch der weg, so werde 
ich umso mehr an den Verlust erinnert. Wird sie wieder gesund, so will ich ihr meine Dankbarkeit beweisen.

Damit genug, ich kann nicht weiter schreiben. Es liegt mir ein Druck auf der Brust. Ich werde vielleicht morgen freier sein. Gute, gute Nacht! Bleibe bei mir, Du einzige, treue, liebe Seele! Ich will in treuen sein auf immerdar

Dein Eugen

\section{2: Dezember Nr. 253}

Bern, den 27. / 8. Dez. 1912.

Mein liebstes Herz!

Heute um neun Uhr wurde Anna der Leistenabszess aufgeschnitten, bei leichter Narkose, u. vor halbzehn telephonierte Dumont bereits, dass alles gut gegangen, dass er aber die Diagnose betr. tiefere Erkrankung noch nicht stellen könne. Immerhin sehe jetzt die Sache befriedigend aus. Marieli war Vormittags $u$. Nachmittags dort. Die Verpflegung u. Fürsorge sei ausgezeichnet. Jedenfalls ist sie besser, als wie Du es haben musstest in Deiner letzten Krankheit. Es schneidet mir in die Seele, wenn ich daran denke. Ja, Anna hat es jetzt besser, u. sie war damals Deine «Pflegerin». Aber - lassen wir die Sachen. Es ist gut, dass sie bald wieder hergestellt sein wird. Von August habe ich noch keine Antwort auf die Anzeige von Annas Krankheit erhalten. Ich weiss nicht, was das mit den Leuten ist. Kleiners antworten auch nicht mehr.

Dann hatte ich wieder einmal nicht weniger als drei Antworten zu geben, ich wollte sie nicht anstehen lassen. Darunter die nochmalige Consultation betr. Kochers Stiftung u. Schreibers Teilungsfall (Rigikulm). Zudem war Oberrichter Trüssel da als neuer Präsident 
des Hochschulvereins. Er wollte, dass ich bei der ersten der nun projektierten Generalversammlungen auf dem Lande einen Vortrag übernehme, u. ich habe zugesagt, sintemal es erst auf Anfang des Sommersemesters gemeint ist. Immerhin äufnen sich die Verpflichtungen: Vortrag im Jur. Verein Ende Januar, Aufsatz für Stammlers Zeitschrift auf Ostern, u. nun das dritte. Und daneben soll ich an meinen andern Aufgaben weiter arbeiten. Heute war ich mehrere Stunden an den Erläuterungen. Sonst las ich in Houssaye, den Abfall Nays. Weder Napoleon noch Nay sind dabei sympathisch. Das ist beiderseits weit entfernt von «sozialer Gesinnung»! Nebenbei war Frau Burckhardt da. Ihr Mann ist nach Lausanne gegangen. Sie erkundigte sich nach Anna, in besserer Manier als vorgestern, u. brachte die Nachricht, dass Maja, die jüngste Schwester Burckhardts, sich mit Pfarrer Schärrer in Bolligen verlobt habe, dem Witwer der Tochter Marthalers. Darob grosse Freude, ich denke auch bei Marthalers.

Die Nacht hatten wir schrecklichen Sturm. Ich bin heute sehr müde $\mathrm{u}$. abgeschlagen geworden, wohl wirklich wegen der anhaltenden Arbeit, ohne Abwechslung, u. ohne Freude an der Umgebung. Aber die Depressionen sind ja nur momentan. Der Gedanke an das Schöne der Arbeit rappelt mich sofort wieder auf. Aber ich bin müde, müde.

Den 28. Dez.

Heute war Vormittags ich eine Stunde bei Anna u. Nachmittags Marie. Die Operation des Abszesses ist gut überwunden, auch das Fieber hat nachgelassen. Dagegen leidet Anna an grosser Schwäche. Sie wird jedenfalls, auch wenn's gut geht, längere Zeit oben bleiben müssen. Von Pauline u. Frau Moser sind teilnehmende 
Anfragen eingelaufen, von August kein Wort. Ist er abwesend? Ist er krank? Hat man ihm die Karte unterschlagen? Nun, es wird sich zeigen. Hoffentlich klärt es sich beruhigend auf.

Heute habe ich meine Anträge betr. die Erläuterungen an das Departement aufgesetzt $u$. abgesandt. Dann war ich im Salem, nachher war Burckhardt da u. Abends wieder Mutzner. Am Nachmittag von halb vier bis halb sechs machte ich mit Burckhardt einen Spaziergang zur Elfenau um den Bau Lüdemanns einmal zu sehen. Es war zuerst helle Sonne mit Bergaussicht, nachher dichter Nebel. Das Haus hat mir nicht übel gefallen, aber es ist niedrig u. klein. An sich würde ich lieber eine Mietwohnung wie die jetzige Lüdemanns mit den grossen Räumen haben, als diese Schächtelchen, in die das Parterrehäuschen eingeteilt ist. - Der Spaziergang mit Burckhardt war interessant, weil B. mir auseinandersetzte, wie es mit Fleiner nichts sei, u. wie die Probleme ganz anders angepackt werden müssen. Jedes Thema werde interessant $u$. könne zu neuen Behauptungen Anlass geben, wenn man sich recht vertiefe. Es gehe ihm immer so: er fange irgend an einer Frage zu arbeiten an u. dann ergebe sich das neue von selbst. Ich entgegnete ihm, dass er sich deshalb so gut für die Praxis geeignet habe, wo es auch ganz zufällig sei, welche Themata man zu bearbeiten habe. Wie

ich Walter B. abholte zum Spaziergang, traf ich Maja Burckhardt u. den Pfarrer Schärrer, der von auffallender Hässlichkeit ist. Ich gratulierte beiden.

Sonst habe ich diesen Tag gelesen u. geruht. Ich habe die Ruhe nötig. Ich bin wieder recht müde.

Ich schliesse mit innigstem Gut Nacht-Gruss u. bin aufimmerdar

Dein getreuer

Eugen 
Ich vergass Dir noch zu sagen, dass gestern Hans König, der Subdirektor der Rentenanstalt, wieder einmal bei mir war, um sich nach den verschiedenen Candidaten für die Secretärstelle, die er bishin bekleidete, zu erkundigen. Er sagte, in seiner Familie stehe es jetzt gut, er selbst aber machte mir den Eindruck eines merkwürdig gealterten jungen Mannes. Er zehrt sich auf in der grossen, einseitigen Arbeit, die auf ihm lastet. Er war sehr herzlich. Von Rölli erzählte er, dass er mit seiner zweiten Frau es sehr glücklich getroffen habe. Sie mildere seine Eigenheiten, seinen Verfolgungswahn, u. erhalte ihn der Arbeit. Schon als Student hatte er jene fatalen Eigenschaften. Wie machte er mir in Basel eine Szene, als ich harmlos seinen Praktikumsvortrag aus didaktischen Gründen verlegte. Und später im hiesigen Juristenverein wars dasselbe. Aber er hat Ausdauer u. versteht zu grübeln. - Heute erzählte mir Mutzner von dem ehemaligen Schüler Bärlocher, der so ganz ultramontan sei. Hat der mir s. Z. etwas vorgeschwindelt von seinem «Freisinn", weil er eine Stelle im Bundeshaus wollte? Das wäre doch sehr sonderbar! Gute, gute Nacht, meine liebe treue Seele!

\section{2: Dezember Nr. 254}

Bern, d. 29. / 30. Dez. 1912.

Mein liebstes Herz!

Heute hat mir gegen Abend der junge Teichmann telephoniert, dass sein Vater in der letzten Nacht gestorben sei. Welch eine Tragödie ist hier zu Ende! Ein Mann, der in äusserlich glänzenden Verhältnissen aufgewachsen $u$. die allerbesten Fachstudien absolviert hat. Ausgerüstet mit ausserordentlichem Gedächtnis, von emsigstem Fleiss. Zuvorkommend in des Wortes extremster Bedeutung, anhänglich, pflichteifrig. Und doch im Leben gescheitert. Warum? Weil er zunächst von sich eingenommen sein überlegenes Wissen den Andern ent- 
gegen setzte, $u$. dann dazu nicht befähigt war, irgendetwas in längerem Zusammenhang zu gestalten. Daneben hatte er ein feines soziales Gefühl u. stand in dessen Banne bis zur Selbstverleugnung. Seine kollektivistische Gesinnung war der individualistischen weit überlegen. Das war es, was mich immer zu ihm hingezogen hat. Was er als Individuum darstellte, war daneben gar oft nicht mehr als eine komische Figur. Wie hat er hierunter leiden müssen! Er ist nicht in die Stellung gekommen, wo das gleichgültig gewesen wäre. Basel war bei der freisinnigen Gesinnung, die ihn erfüllte, der Ort, wo die Fehler übertrieben empfunden $u$. das Gleichgewicht um so mehr für ihn verloren gehen musste. So ging es ihm schlechter mit jedem Jahr. Als er gar die Dirne heiratete, die ihm zwölf Jahre früher ein Kind geboren, u. als die zwei am Leben gebliebenen Kinder sich schlimm entwickelten, so dass nämlich Dr. Schläpfer sogar sagen konnte, die Tochter sei eine H. u. der Sohn

ihr Zuhälter, da war es um ihn vollends geschehen. Welch bemühenden Eindruck hatte ich von ihm, als er letzten Herbst die zehn Tage in Bern zugebracht. Jetzt hat er Ruhe. Es war ein schweres Leben. Oder hat er es selbst vielleicht, in seinem Unvermögen sich nach andern zu beurteilen, gar nicht so tief empfunden? Ans Begräbnis gehe ich nicht. Ich kann jetzt bei Annas Erkrankung nicht von hier weggehen.

Anna traf ich den VorNachmittag ordentlich. Ob eine tiefere Erkrankung den Abszess herbeigeführt hat, ist noch nicht festgestellt, wie Dumont mir sagte. Marie war auch bei Anna, Nachmittags auch Sophie. Sie hatten beide denselben Eindruck wie ich.

Sonst war heute noch Werner Kaiser mit seiner Frau bei mir zu Besuch, als Neujahrsvisite. Sie waren herzlich. Am Nachmittag kam Frl. Henzi, die ich aber nicht gesehen, u. nachher Frau Julie Weber, die erzählte, dass Frieda in Lugano an Rheumatismen leide u. daher nicht nach Hause kommen könne. Dafür werden Fick u. Alma sie über Neujahr in dort besuchen.

Sonst habe ich den Tag über ein paar Briefe geschrieben $u$. in Houssaye gelesen, so ist der letzte Sonntag des Jahres vorüber gegangen. Draussen war Nebel, es war feucht u. kühl, wenn 
auch nicht gefroren. Und der Tag war so still. Wie manches Jahresende erlebe ich noch? Es ist das dritte ohne Dich, u. die 143ste Woche seit Deinem Hinschied. Nun ja, ich werde weiter aushalten, komme was wolle! August hat endlich geschrieben $u$. seinen Besuch etwa auf Freitag vorausgesagt. $\mathrm{Ob}$ ich dann mit ihm über die traurigen Geschichten mit seinen Söhnen zu sprechen kommen werde? Vielleicht besser nicht.

Den 30. Dez.

Ich habe heute drei Jahrgänge meiner so unsinnig vollständig aufbewahrten Correspondenz in alter Weise geordnet, 1905 / 7, u. kam dabei in eine unangenehme Aufregung. Platz u. Zeit bereiteten Schwierigkeiten. Man hat zu lange gelebt, sagte ich mir, mit solchem Balast. Ich verspürte eigentlich Herzklopfen, so griff mich das an. Dazu kam, dass ich die Absicht hatte, Anna am Nachmittag zu besuchen, worauf Marieli sagte, es gehe hin u. werde der Anna etwas aus dem neuen Büchlein von Zöpf vorlesen, das Marieli von Mariechen in Tübingen erhalten. Und dann ging es nach dem Essen zu Frau Sophie Burckhardt hinunter u. brachte den Bericht, dass es mit dieser zu Anna gehen werde. Richtig wurde das ausgeführt u. die Folge war, dass sich Anna über eine Stunde von der groben Frau anrednern lassen musste, sodass Marieli selbst ganz entrüstet erzählte, Anna sei sehr müde u. ungehalten gewesen, als sie fortgegangen. Zum Vorlesen kam es nicht mehr.

Ich war am Vormittag in der Stadt, unter anderem bei Werner Kaiser. Am späteren Nachmittag machte A. Welti mir einen Besuch. Guhl kam auch u. musste lange warten, bis wir das Geschäftliche erledigen konnten. Dabei teilte mir Guhl mit, dass Kaiser u. Kronauer sich überworfen haben. Auf einem Aktenstück habe er selbst Kaisers Bemerkung gegen Kronauer gefunden «ich bin nicht Ihr Schreiber, machen Sie das gefälligst selber.» Also auch da die widerwärtige Art der Anekelung. Ich halte je länger je mehr dafür, dass Kaiser in diesen Streitigkeiten nicht im Unrecht ist. 
Zu irgend einer Arbeit bin ich nicht gekommen. Ich habe ein kleines Gutachten gemacht, einige kleine Briefe geschrieben u. dann eben die Correspendenzen geordnet. Ich erhielt ein paar liebe Briefe, wie von Fitting. Auch von den Eltern

[4]

Siegwarts eine herzliche Gratulation, die ich ebenso erwiderte. Werde ich morgen noch einen ruhigen Tag haben? Ich weiss es nicht. Wenn mein Herz ruhig bleibt, will ich darauf hoffen.

Und nun gute Nacht, mein Lieb! Ich bin in dem Wirrwarr der Dinge, wie da alles auf mich einstürmt, dass ich mich wirklich nach Ruhe sehne. Aber kommt diese, so bist Du nicht da. Das sind meine Schicksale.

Heute hat auch ein Student die zweite Auflage seiner Dissertation gebracht. Also auch da wieder Arbeit, die mich von dem abhält, was ich tun sollte u. möchte.

Aber ich betrachte die Sache schon ruhiger, wenn ich nur an Dich darüber schreibe. Wenn es nur mit Marieli nicht schlimmer kommt. Gute, gute Nacht!

Immerdar in Schmerz u. Freude

Dein getreuer

Eugen

\section{2: Dezember Nr. 255}

Sylvester 1912.

Meine liebe, gute Lina!

Ich schreibe diese ersten Zeilen des letzten Briefes aus diesem Jahr am Morgen bevor ich hinunter gehe. Es ist noch Nacht, ein dichter Nebel drängt den Tag noch mehr zurück. Ich habe diese Nacht viel geträumt, u. a. auch dass mir Conrad nachgesprungen sei u. um Verzeihung gebeten habe, die ich ihm gerne gewährte. Dann wieder hatte ich einen schönen schwarzen Stock mit Silbergriff stehen lassen, u. er wurde mir 
auf eine sonderbare Weise wieder zugebracht. Daneben dachte ich über mein Leben, über meine Gespanne $u$. anderes nach, $u$. verschaffte mir eine heitere Betrachtung der Dinge, mit der ich gerne heute das alte Jahr schliessen möchte. Hoffentlich kommt keine Störung dazwischen.

Marieli erklärte gestern, dass es die Kollegien aufgeben wolle, aus dem Anlass, wo es jetzt für Anna eintreten könne. Das wäre mir schon recht, wenn später nicht Vorwürfe kommen. Ich muss es nun abwarten. Zureden zu einem solchen Entschluss will ich ihm in keiner Weise. Wenn er aus ihm selbst erfolgt, so würde ich das als eine ganz gute Lösung betrachten. Ich würde mich wohl dabei zurechtfinden können. Eine fremde Hülfe brauchten wir dann jetzt wenigstens nicht.

Sophie gibt sich viel mehr Mühe u. auch mehr Ansehen, seit Anna im Spital ist. Ob das anhält? Ob die moralischen Kräfte stark genug sind, um auf die Dauer die Schwachheiten zurückzudrängen u. die «Müssigkeit» zu corrigieren? Ich glaube fest, das annehmen zu dürfen, u. ist dem so, so wäre diese Lösung für mich auch wieder die beste. Sophie hat die letztmaligen Tadel ganz anders angenommen als früher. Daraus wäre die Hoffnung abzuleiten, dass sie sich auch anders zusammen nehmen wird, u. dann wird sie schon mehr leisten $u$. werden können, als bisher. Auch das will ich hoffen.

Den Tag über hatte ich viele Glückwünsche zu beantworten, las den Houssaye-Band ganz zu Ende, u. war eine Stunde bei Anna, der es fortgesetzt recht gut geht. Was mich in der Sache am meisten betroffen, ist, dass jetzt mit einem Mal Klarheit in die mysteriöse Erkrankung zu kommen scheint. Ich begegnete nämlich auf dem Rückweg Dr. Dick, machte ihm von dem Abszess Mitteilung, u. da sagte er gleich, ob Anna am Fuss, an einer Zehe, eine Verletzung gehabt habe. Das sei eine der häufigeren Ursachen dieser Lympfgefäss- $u$. Drüsenentzündungen. Ich wusste nichts davon. Aber wie Marieli heute Nachmittag Anna das mitteilte, soll sie aufgefahren sein u. gerufen haben, darum habe ihr ja die grosse Zehe schon lange so furchtbar weh getan. Da hätten wir also die Zusammenhänge: Der Nagel wird nicht geschnitten, er wächst ins Fleisch, es entsteht eine Entzündung, die wird vernachlässigt, es schwellen die Drüsen an, das wird 
auch vernachlässigt, $u$. schliesslich kommt die ganze Geschichte zum [?]. Wie froh wollen wir sein, wenn es wirk-

lich nichts anderes ist. Dumont hat hierüber gar nicht[s] gesagt.

Und nun kann ich fortfahren, wo ich am Morgen begonnen.

Ich verkehre mit wenig Kollegen u. ehemaligen Schülern, die jetzt meine Streitgenossen sind. Aber wie verschieden sind sie zu mir. Fast so wie Lionardo es erlebt hat.

Walter Burckhardt ist wohl der bedeutendste unter ihnen, auch der älteste. Gmür ist ihm gleich alt. Von Gmür kann ich aber nichts mehr sagen, weil er durch seine ganze Richtung mir fremd geworden. Ich konnte nie mit ihm ein Gespräch führen, u. so ist es geblieben. Ich habe mich von ihm zurückgezogen, um nicht alle Augenblicke durch ihn in Unannehmlichkeiten zu geraten, denn er ist rauflustig u. nicht diskret. Nun aber Walter Burckhardt. So wie ich bei näherer Kenntnis erfahren, hat

er neben seinem klaren Kopf sehr viel Ehrgeiz u. Eifersucht in sich. Zudem scheut er sich bei aller Bescheidenheit u. Behutsamkeit im Auftreten, wenn er überrascht wird oder bei sich ist, recht scharfe Urteile zu fällen, die von jenen Eigenschaften getränkt sind. Doch wiegt die gerechte Stimmung vor. Sein Mangel an jedem Enthusiasmus bringt es mit sich, dass er für lebhaftere Naturen, wie z. B. Kleiner, wenn sie nicht besonders tüchtig sind, gar nichts übrig hat. Ich glaube nicht, dass man viel Unterstützung in einem geistigen Kampf von ihm haben würde. Das beste ist, diese Probe nicht zu machen, sondern einfach ihn als selbständig Intressierten mitzunehmen, wo es angeht. Er hat mir manches verdorben, anderes geholfen. Ich muss es ja anerkennen, dass er mich nicht offen angreift, obgleich er manchmal genug auf mich eifersüchtig sein wird. Ich habe ihm ausserordentlich viel geholfen.

Guhl ist viel beweglicher, ist auch ein guter Dozent, u. ein eifriger Militär. Allein, wie Burckhardt neulich von ihm sagte, er ist bald zufrieden. Seine Kenntnisse sind nicht gross. Was er als Jurist leistet verdankt er seiner Dialektik. Rechtsgeschichte u. Rechtsphilosophie sind ihm durchaus fremd. Bei Burckhardt ist wenigstens für letztere grosses Interesse vorhanden. Guhl ist ehrgeizig, aber nicht eifersüchtig. Was ihm fehlt, ist die Konstanz der Anschliessung. Er kann ohne dass er es weiss, sehr unvertraut sein. Manchmal weiss er 
das auch. Wo es gilt, durch Einstehen etwas zu erreichen, würde ich Guhl mehr vertrauen. Dagegen fehlt seine Zuverlässigkeit, sobald er kein eigenes Interesse hat, oder gar ein entgegengesetztes. Er wird jetzt vielfach als mein Alter ego betrachtet. Das kann ich aber nur in dem kleinen Rahmen der Schweizerischen Zivilistik etwa gelten lassen, u. auch da muss ich ihn vor mancher Übereilung bewahren. Arbeiten kann er wie wenige.

Ziehe ich Mutzner noch heran, so hat er mit Burckhardt mehr Ähnlichkeit als mit Guhl. Er interessiert sich aber für Rechtsphilosophie

noch gar nicht, wohl aber sehr für Rechtsgeschichte. Seine Schärfe zeigt sich weit mehr im gewöhnlichen Verkehr als bei Burckhardt. Ich erwarte noch viel von ihm.

Ich habe mir diese Zeichnungen - um andere liegen zu lassenan diesem Jahresschluss gern entworfen, damit es mir klar wird, welch tüchtige Kräfte ich mir doch im Ganzen herangebildet habe, u. wie treu sie im Ganzen doch zu mir stehen. Wie will ich dankbar sein, wenn sie mir treu bleiben. Einen Anspruch darauf habe ich ja eigentlich nicht, trotz allem was ich für die drei getan. Sie sind sich selbst, also wenn sie zu mir stehen, ist das ein Geschenk des Schicksals, u. für Geschenke muss man immer danken.

Und nun soll das Jahr zu Ende gehen. Wie die letzten zwei Jahre erwarten wir auch diesmal das Läuten nicht mehr, jetzt, wo Marieli u. ich allein sind, auch gar nicht. Und dann hinüber. Dein Bild ist mir so frisch vor Augen, wie Du jeweils beim Läuten sagtest: Weisst, lieber Eugen, wir wissen nie, ob es nicht das letzte Mal ist. Ich weiss nicht, ob es nicht für mich auch das letzte Mal ist, das Mal, wo ich mit Dir wieder vereinigt sein werde. In einer Weise, die wir nicht kennen.

Hab Dank für das ganze Jahr, da Du so treu mich begleitet hast. Bleib bei mir auch das kommende Jahr! Ich halte Dich fest in Dankbarkeit u. Liebe, ich bleibe in alle Zeit

Dein getreuer

Eugen 
Gegen 9 Uhr kommen noch Herr u. Frau

Walter u. Sophie Burckhard-Wütrich. Ich muss

fertig machen die Sylvestersachen. Nachher gehe ich

hinunter. Die Frau bringt mich um alle Beschaulichkeit

des Abends. Sie ist unsagbar grob, auch heute wieder.

Doch nein, ich behalte die Stimmung. Wär das ein Grund sich irre werden zu lassen? Nimmermehr. 